NATURAL HISTORY 


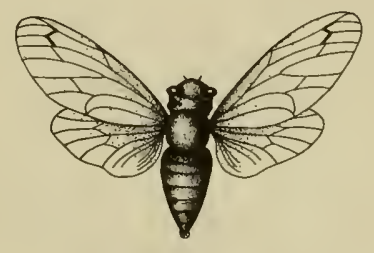

\section{LIBRARY OF}

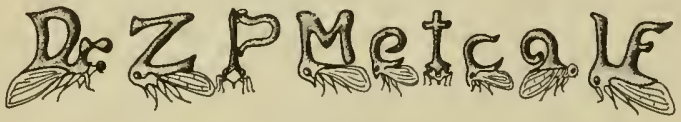

$$
\text { 1885_1956 }
$$






\section{Knowledge Library}

NATURAL HISTORY

Edited by Alfred H. Miles 




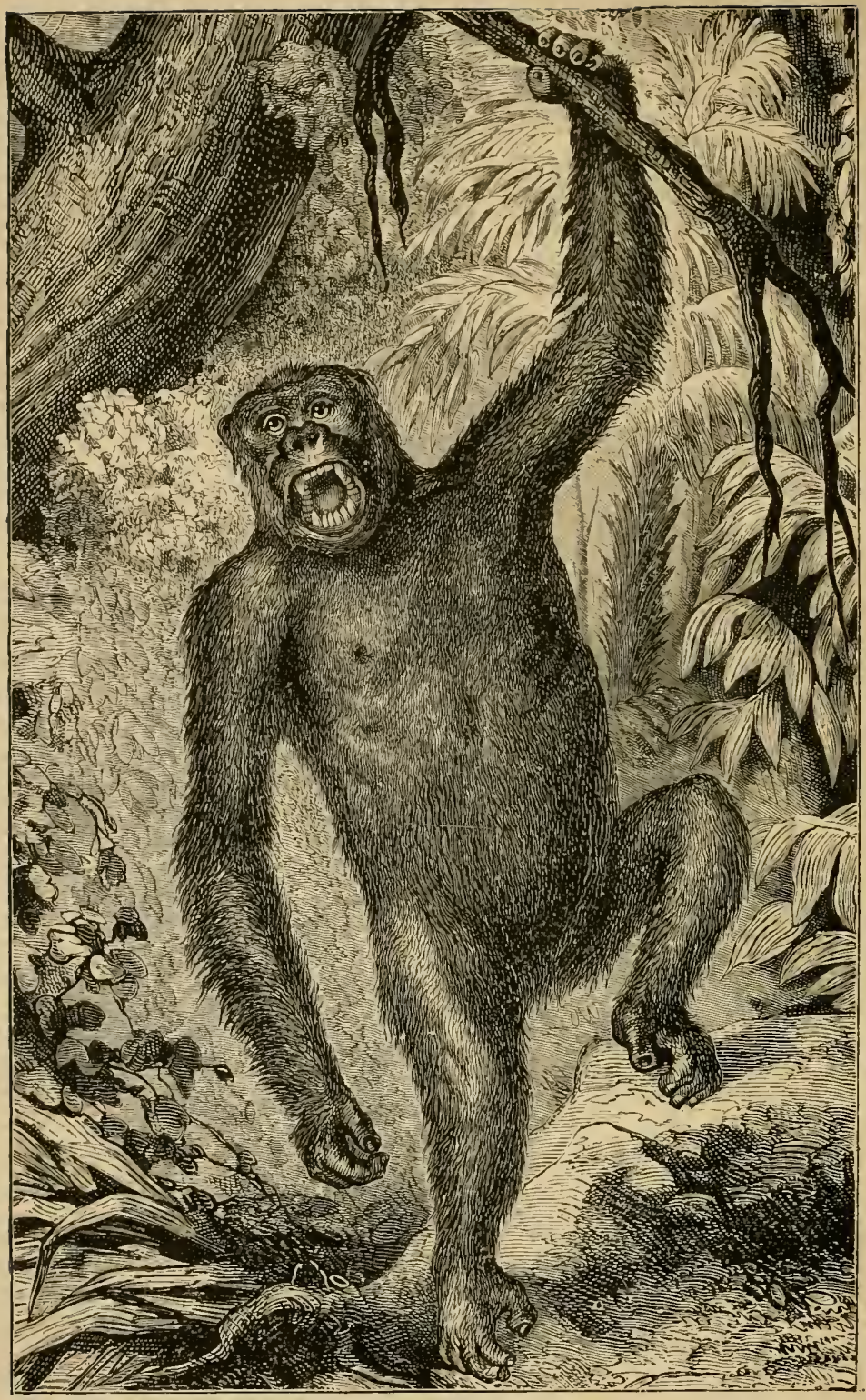

The Gorilla. 


\section{The}

\section{Concise Knowledge}

\section{Natural History}

R. LYDEKKER, B.A., F.R.S., V.P.G.S.; R. BOWDLER SHARPE, LL.D.; W. F. KIRBY, F.L.S., F.E.S. ; W. GARSTANG, M.A., F.Z.S.;

B. 13. WOODIVARD, F.L.S., F.G.S.; F. A. BATHER, M.A., F.G.S.;

R. KIRKPATRICK; R. I. POCOCK; AND

H. M. BERNARD, M.A., F.L.S.

With 530 Original Illustrations by

J. KEULEMANS, F. H. MICHAEL, ERNALD W. MILES,

FRANK C. ALDWORTH, AND OTHER ARTISTS

LONDON

\section{Hutchinson \& Co.}

34 Paternoster Row, E.C.

I 897 



\section{PREFACE}

THis work aims to be a concise and popular Natural History, at once accurate in statement, handy in form, and ready of reference.

The several departments of Zoological science are treated by specialists, all of whom are distinguished as authorities and as original investigators; and the text is illustrated by upwards of five hundred original drawings made and reproduced expressly for the work.

A concise systematic index precedes the work, and a full alphabetical index which contains about ten thousand references is given at the end. Great pains have been taken to render these both accurate and complete.

As a whole the volume contains nearly eight hundred pages and is issued at a price which makes it phenomenal. In the result it is hoped that much time may be saved to busy people and much help afforded to students. 


\section{CORRIGENDA-MAMMALS.}

Page 56, Fig. 32, for Felidce, read Felis.

" I02, line 45, for Trilophomys, read Lophiomys.

," I12, line 23, for Trianlacodus, read Thrynomys. 


\section{THE ANIMAL KINGDOM. \\ SUB-KINGDOM I.-VERTEBRATA.}

\section{CLASS I.-MAMMALIA.}

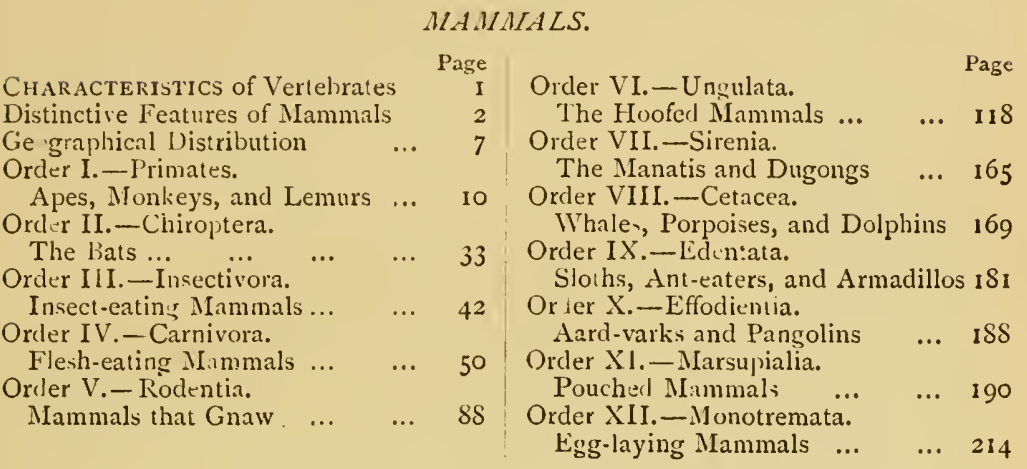

CLASS II.-AVES.

BIRDS.

Bird Structure and Developinent

Sub-Ciass Saurure.

Order Archæopteryges.

The Archaupteryx

... ..

220

Sub-Ci.ass Ratite.

Order Rheiformes.

The Rhtas $\quad \ldots \quad \ldots \quad \ldots 221$

Order Struthioniformes.

The Ostıiches ...

Order Casuariiformes.

The Emus and Cassowaries

Order Linornithiformes, Etc.

The Extinct Moas

Urder Apterygiformes.

The Apteryges
$2 \mathrm{IS}$

Order Tinamiformes.

The Tinamous $\ldots \quad \ldots \quad \ldots \quad \ldots \quad 225$

Order Gall formes.

The Game-lirds .. $\quad \ldots \quad \quad \ldots \quad 226$

Order Pterocletes.

The Sand-grouse $\quad \ldots \quad \ldots 24$ I

Order Columbiformes.

Pigreons ... $\quad \ldots \quad \ldots . \quad \ldots \quad 242$

Sub-order Didi.

The Dodo, Etc. ... $\quad \ldots \quad \quad \ldots \quad 245$

Order Opisthocomiformes.

$\begin{array}{lllll}\text { The HLatzini } & \ldots & \ldots & \ldots & 247\end{array}$

Order Ralliformes.

$\begin{array}{lllll}\text { The Rails } \quad \ldots & \ldots & \ldots & 248\end{array}$

Order Podicipedidiformes. ix

The Grebes $\quad \ldots \quad \ldots \quad \ldots 253$ 


\section{BIRDS-continued.}

Order Colymbiformes.

The Divers

Order Sphenisciformes.

The Penguins

Order Procellariiformes.

The Petrels

Order Alciformes.

The Auks

Order Lariformes.

The Gulls

Order Charadriiformes.

The Plovers and Bustards $\quad \ldots \quad 264$

Sub-order Attagides.

The Seesl-snipes ...

Sub-order Charadrii.

The Plovers

Sub-order Glareola.

The Pratincoles.

Sub-order Cursorii.

The Coursers

Sub-order Edicnemi.

The Stone-plovers

Sub-order Otides.

The Bustards

Order Gruiformes.

The Cranes

Sub-order Grues.

The True Cranes

Sub-order Arami.

The Limpkins

Sub-orcler Rhinochetides.

The Kagus

Sub-order Mesitides.

The Madagascar Kagus

Sub-order Eurypygæ.

The Sun-bitterns

Sub-order Psophize.

The Trumpeters ..

Sul)-order Dicholophi.

The Seriamas

Order Stereornithes.

The Extinct Birds of Patagonia

Order Ardeiformes.

The Heron:, Etc.

Sub-order Ciconii.

The Storks

Sub-order Scopi.

Hammer-headecl Storks

Sub-order Balrenicipitides.

Shoe-billed Storks

sub-order IIerodiones.

The Herons

Sub-order Platalex.

The Spoon-bills, Etc.
Page

Order Phcenicopteriformes.

The Flamingoes ...

Sub-order Palamedea.

The Screamers ...

Order Anseriformes.

Geese, Etc.

Sub-order Anseres.

Ducks, Etc.

Order Pelecaniformes.

The l'elicans, Etc.

Sub-order Sulie.

The Gannets

Sub-order Phalacrocoraces.

The Cormorants...

Sub-order l'elecani.

'The Pelicans

Sub-order Fregati.

The Frigate Birds

Order Catharticliformes.

The Turkey Vultures

Orcler Accipitriformes.

Birds of Prey

Sub-order Serpentarii.

The Secretary Birds

Sub-order Accipitres.

The True Birds of Prey...

Sub-order Pandiones.

The Ospreys

Sub-order Striges.

The Owls

Order Psittaciformes.

The Parrots

Order Coraciiformes.

'I he Picarian Birds

Sub-orcler steatornithes.

The Oil-birds

Sub-order Podargi.

The Frog-mouths

Suh-order Leptosomati.

The Kiroumios ...

Sub-order Coraciz.

The Rollers

Sub-order Halcyones.

The King-fishers

Sub-order Bucerotes.

The Hornbills

Sub-order Upupa.

'I he Hoopoes

Sub-order Meropes.

The Bee-eaters

Sub-order Momoti.

The Motmots

Sub-order Todi.

The Todies
Page

288

290

290

292

298

299

299

301

303

jo4

304

305

305

320

320

325

332

332

333

335

335

336

339

340

340

$34^{1}$

$3+2$ 
Sub-order Caprimulgi.

Page

The Nightjars

Sub-order Cypseli.

The Swifts

Sub-order Trochili.

The Humming-birds $\quad$.. $\quad$.. 347

Sub-order Colii.

The Colies

Order Trogones.

The Trogons

Order Coccyges.

Cuckoo-like Bird:

Sub-order Cuculi.

The Cuckoos

Sub-order Musophagi.

The Touracoes

Order Scansores.

The Climbing Birds

$\begin{array}{lll}\ldots & \ldots & 342 \\ \ldots & \ldots & 345 \\ \ldots & \ldots & 347 \\ \ldots & \ldots & 348 \\ \ldots & \ldots & 349 \\ \ldots & \ldots & 349 \\ \ldots & \ldots & 349 \\ \ldots & \ldots & 35 \text { I } \\ \ldots & \ldots & 352\end{array}$

Page

Sub-order Rhamphastides.

The Toucans ... ... .. 352

Sub-order Capitones.

The Barhets

Sub-order Indicatores.

The Honey-guides $\quad \ldots \quad \ldots \quad 353$

Order Piciformes.

Woodpecker-like Birds ... _.. 353

Sub-order Pici.

The Woodpeckers $\quad \ldots \quad \ldots 353$

Sub-order Buccones.

The Puff-birls $\quad \ldots \quad \quad \ldots \quad$... 355

Order Eurylemi.

The Broad-bills ... $\quad \ldots \quad$... 356

Order Passeriformes.

The l'erching Birds $\quad \ldots \quad \ldots 357$

\section{CLASS III.-REPTILIA.}

\section{REPTILES.}

Characteristics of Reptiles

Classification of Reptiles .. $\quad \ldots \quad 377$

Order I. - Crocodilia.

Crocodiles, Alligators, Garials ... 378

Order II.-Chelonia.

Tortoises and Turtles $\quad \ldots \quad \ldots \quad \ldots 3_{3}$

Sub-order i.-Cryptodira.

Land Tortoises, Etc. $\quad \ldots \quad \ldots \quad 385$

Sub-order ii._-Plewrodira.

Fresh-water Tortoises $\quad \ldots \quad \quad \ldots 392$

Sub-order iii. - Trionychoidea.

The Soft Tortoises

.... $\mathbf{3 9 4}$
Order III.-Squamata.

Scaled Reptiles ...

Sub-order i. - Lacertilia.

The Lizards

Sub-or(ler ii._Rhiptoglossa.

The Chamaleons

Sub-order iii. - Ophidia.

The Snakes

Order IV.-Rhynchocephalia.

The Tuatera
… 395

... 396

... 4 II

CLASS IV.-AMPHIBIA.

AMPHIBIANS.

Characteristics of Amphibians $\quad \ldots \quad 431$

Order I. -Ecaudata.

Frogs and Toads

Sub-order i. - Firmisternia.

Typical Frogs, Etc.

Sub-order ii.--Arcifera.

The Toads, Eic...

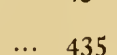

‥ 435

... 436

... 440
Sub-order iii.-Aglossa.

The Surinam Water-toad, Etc.

Order II. - Caudata.

Newts and Salamanders

Order III.-Apoda.

The Crecilians 
CLASS Y.-PISCES.

\section{FISHES.}

Characteristics of Fishes ... Page

The Clasification of Fishes $\quad \ldots \quad 45^{8}$ Sub-Class I. - DipNOI.

Lung-fishes ... $\quad \ldots \quad \ldots \quad$... 459

Sub-Class II. - Holocephali.

The Chimæroids ... $\quad . . \quad \ldots \quad 46 \mathrm{I}$

SUB-Class III.-TELeOSTOMI.

Bony Fishes and Ganoids ... $\quad \ldots \quad 462$

Order I.-Actinopterygii.

The Fan-finned Teleostomes .. $46_{3}$

Sub-order i.-Acanthopterygii.

The Spiny-finned Fishes, Etc. ... 463

Section Perciformes.

The Common Perch, Etc. $\quad \ldots \quad 463$

Section Scorpæniformes.

The Micropus, Eic.

Section Berychiformes.

The Sline-lieads

Section Curtiformes.

The Indian Curtis, Elc.

Section Polynemiformes.

'I he Polynemus, Etc.

Section Scizeniformes.

The Meagre, Etc.

Section Xiphiiformes.

The Sword-fish

Section Trichiuriformes.

The Scablard Fish, Etc.

Section Cotlo-Scomluriformes,

The Surgeons, Etc.

Section Gobiiformes.

The Lump-suckers, Etc.

Section Blenniiformes.

Maıine Band-fishes, Etc.

Section Mugiliformes.

The Burracuda-pikes, Etc.

Section Scombresociformes.

The Flying-fish, Etc.

Section Gastrusteiformes.

The Sticklebacks, Etc. ...

Section Centrisciformes.

The Bellow's-fish, Etc.

Section Golioesociformes.

The Sucker-fishes, Etc....

Section Channiformes.

The Serpent-beads, Etc.
Section Labyrinthici.

The Climbing-perch, Etc. $\quad \ldots \quad 483$

Section Lophotiformes.

The Unicorn-fish $\quad \ldots \quad \ldots 4_{4}^{84}$

Section Treniiformes.

The Riband-fishes $\quad \ldots \quad \quad \ldots \quad{ }_{4} \mathrm{~S}_{4}$

Section Notacanthiformes.

The Thorn-backs

Section Pharyngognathi.

The Coral-fishes, Etc.

Sub-order ii.-Lophobranchii.

The Pipe-fishes, Etc. $\quad \ldots \quad \quad \ldots \quad 4 \delta_{7}$

Sub-order iii.-Plectognathi.

The Spine-clad Globe-fishcs $\quad \ldots \quad 488$

Sub-orcler iv. - Anacanthini.

The Common Cod, Etc.

Sub-order v. - Physostomi.

Seciion A.-Apodes.

The Eel-tribe

Section B.-Nematognathi.

The Cat-fishes ... ...

Section C.-Plectispondyli.

The Common Carp, Etc.

Section D.-Haplopomi.

The Common Pike, Etc.

Section E.-Scyphophori.

The Gymnarchus, Etc. ... ‥ 503

Seciion F.-Isospondyli.

The Salmon, Etc. $\quad$... $\quad \ldots \quad 503$

Sub-order vi. - Etheospondyli.

The Bony Pikes, Etc. ...

Sub-oriter vii. - I'rotospondyli.

The Bow-fin $\ldots$... ... 510

Sub-order viii. - Chondrostei.

The Sturgeens $\quad . . \quad \ldots \quad \ldots 510$

Order II.-Crossopterygii.

Fringe-finned Ganoids ... $\quad \ldots \quad 512$

Sub-Class IV.-ElasiobranchiI.

Sharks and Rays ... $\quad \ldots \quad \ldots \quad 513$

Order Selachii.

Sharks, Dog-fishes, Etc. _... 515

Sul-order i.-Asterospondyli.

The Blue Shark, Etc. ... ... 515

Sub-order ii. - Tectospondyli.

The Saw-fish $\quad \ldots \quad \ldots \quad$... 519 
CLASS VI.-CYCLOSTOMA.

I.AMPREYS AND HAG-FISHES.

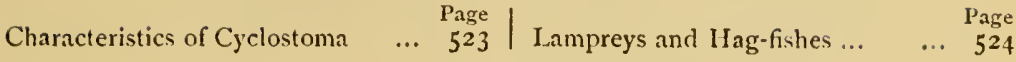

\title{
CLASS VII.-PROTOCIIORDA.
}

Sub-Ci.ass I.-Cerihalochorda.

SUb-Ci.ASS II. - UROCHORdA

The Lancelet $\quad . . \quad \ldots \quad \ldots \quad 526$ The Common Sea-squirt, Etc. ...

\section{CLASS VIII.-HEMICHORDA.}

Hemichorda or Enteropneusta $\ldots \quad 528$ | The Balanoglossus ... $\quad \ldots \quad \ldots \quad 528$

\section{SUB-KINGDOM II._ARTHROPODA.}

\author{
CRUSTACEA, INSECTA, \&.
}

\section{CLASS I.-CRUSTACEA.}

Characteristics of Arthropoda $\quad \ldots \quad 529$

Edible Arthropoda, Etc. ... ... 530 Sub-Ci.ass I.-Entomostraca.

The Smaller Crustacea $\quad \ldots \quad \ldots \quad$ 53 I

Order I. - Phyllopoda.

The Water-flea, Etc. $\quad \ldots \quad \ldots \quad 53$ I

Orier II. - Ostracoda.

$\begin{array}{lllll}\text { The Ostracoda } & \ldots & \ldots & \ldots & 532\end{array}$

Order III. - Copepoda.

The Cyclops, Carp-lice, Etc. $\quad \ldots \quad 532$

Order IV.-Cirripedia.

Barnacles, Etc. $\ldots . \quad \ldots \quad \ldots \quad 533$

Sub-Class II.-MIalacostraca.

$\begin{array}{llll}\text { The Higher Crustacea } & \ldots & \ldots & 5.33\end{array}$

Order I.-Arthrostraca.

Sub-order i. - Isopoda.

Woorl-lice, Etc. ... $\quad \ldots \quad \ldots \quad 534$

Sub-order ii._Amphipoda.

The whale-iouse, Etc.
Order II. - Thoracostraca.

Sub-order i. - Cumacea.

Marine Parasites, Etc. ... $\quad$.. 535

Sub-order ii.-Stomatopoda.

Squilla Mantis, Etc.

Suh-order iii.-Schizopoda.

Shrimp-like Crustacea $\ldots . \quad \ldots \quad 536$

Order III. - Decapoda.

Sub-order i.-Macrura.

Shrimps, Lobsters, Crayfish, Etc. 536

Sub-oriler ii.-Anomura.

Robber Crabs, Hermit Crabs, Etc. 537

Sub-order iii.-Brachyura.

The Spider Crab, Etc. ... ... 537

Sub-Cllass III. - Gigantostraca.

Order Xiphosura.

The King-crabs .. $\quad \ldots \quad \ldots \quad 538$

Sub-Class IV.- PyCNOgonida.

Order Pycnogonida

CLASS II.-ARACHNIDA.

SPIDERS, SCORPIONS, AND MITES.

Order I.-Scorpionidea.

The Scorpions, Etc.
Order II. --Solpugiclea.

.. 540 Galeodes Arabs, Etc. 
AracilnIDA-continued. Page

Page

Order III.-Pseudoscorpioniclea.

Bonk-scorpions ... $\quad \ldots \quad \ldots 54$ I

Orcler IV. - Pedipalpi.

False Scorpions ... $\quad . . \quad \ldots 5$ 54I

Order V.-Phalangiida.

Harvest-men. Etc.

Order VI.-Araneida.

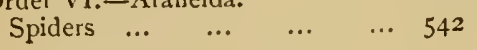

Order VII.-Acarina.

Mites and Ticks ... ... … 545

Order VIII. - Tardigrada.

Moss Mites, Etc. … ‥ 547

Order IX.-Linguatulida.

Worm-like Parasites

... 548

CLASS III.-MYRIOPODA.

CENTIPEDES AND NILLEPEDES.

Order Chilopoda.

Centipedes

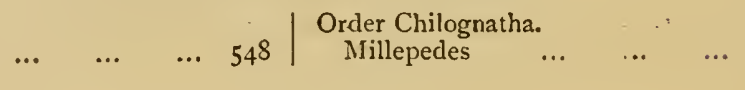

\section{CLASS IV.-PROTRACIIEATA.}

$\begin{array}{llllllllll}\text { Order Peripatidæe } & \ldots & \ldots & \ldots & 550 & \ldots & \text { Peripatus Iuliformis } & \ldots & \ldots & 551\end{array}$

CLASS V.-INSECTA.

Classification of Insects $\quad \ldots \quad \ldots \quad 55$ I $\quad$ Order Lepidoptera.

\begin{tabular}{llll|lllll} 
Order Coleoptera. & $\cdots$ & $\cdots$ & 55 & Butterflies and Moths & $\ldots$ & & $\ldots$ & $58 \mathrm{I}$
\end{tabular}

Peetles … … … ‥ 553

Order Hemiptera.

Bugs and Frog-hoppers... … 594

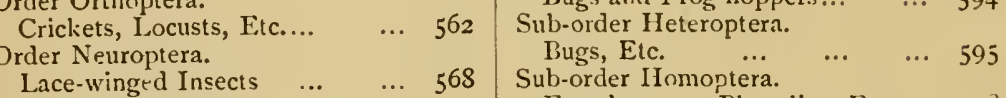

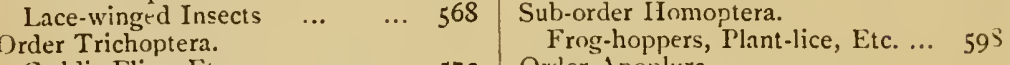

Caddis Flies, Etc. $\quad \ldots \quad \ldots \quad 572$

Order Hymenoptera.

Bees, Wasps, Ants, Etc. $\quad$... 573

Orler Anoplura.

The True Lice $\ldots \quad \ldots \quad \ldots 602$

Order Diptera.

$\begin{array}{lllll}\text { The Flies... } & \ldots & \ldots & \ldots & 602\end{array}$

\section{SUB-KINGDOM III.-MOLLUSCA.}

WHELKS, OYSTERS, SNAILS, \&..

CLASS I. -AMPIHINEURA.

Characteristics of Mollusca

Classification of Mollusca

Order I. - Polyplacophora.

Chitons, Etc. $\quad \ldots \quad \quad \ldots \quad \quad \ldots \quad 615$
Order II.-Aplacophora.

(Worm-like Mollusca) ... ... 616

Sub-order i. -Neomeniina.

Nenmenians $\quad . . . \quad \ldots \quad \ldots 6$ 6 6 


\section{CLASS 11.-PELECYPODA (BIVALVES).}

Page

Characteristics of the Pelecypoda... 616

Order I.-Pıololıranchiata.

Nut-hells, Eic.

... 620

Order II. - Fililıranchiata.

Sub-order i.-Anomiacex.

The Saldle Oyster, Etc.

Suts-order ii. - Arcacea.

Noah's Ark Shellis, Etc.

Sub-orler iii. - Trigoniacea.

The Trigonia

Suh-r)r(er iv.-Mytilacea.

The Marine Mussel, Etc.

Order III. - Pseudolamellibranchiata.

The Oyster, Etc. $\quad \therefore \quad \quad \ldots \quad 622$

Sub-order i. - Aviculacea.

Swallow Shells, Etc. $\quad \ldots \quad \ldots 622$

Sub-orcler ii._Ostreacea.

Oysters $\ldots \quad \ldots \quad \ldots \quad \ldots 622$

Sub-order iii.-Pectinacea.

Page

Scallnps, Etc. ... $\quad \ldots \quad \ldots 622$

Order IV.--Eulamellibranchiata.

Sub-order i, -Submytilacea.

Fresh-water Mussels _.. $\quad \ldots \quad 623$

Sub-order ii.-Tellinacea.

Sunset Shells, Etc. $\quad$... $\quad \ldots .624$

Sub-order iii. - Veneracea.

The Venus Shells, Etc. ... .. 625

Sub-order iv. --Cardiacea.

The Cockles, Etc. $\quad \ldots \quad \quad \ldots \quad 625$

Sub-order v, -Myacea.

The Mya or (iaper, Etc. $\quad$... 626

Sub-order vi. - Pholadacea.

The Piddock and Ship-worm, Etc. 627

Sub-order vii. - Anatinacea.

Pandora, Etc. $\quad \ldots \quad \ldots . \quad \ldots 627$

Order V.-Septibranchiata.

Poromyidze, Etc.

... 628

CLASS III. -SCAPHOPODA.

Scaphopoda or Solenoconcha ... 628 | The Elephant's-tooth Shells $\ldots 628$

CLASS IV.-GASTROPODA.

Sub-Class A.-Streptoneura.

Order I.-Scutibranchiata.

The Limpets, Etc. $\quad \ldots \quad \quad \ldots \quad 63 \mathrm{I}$

Sub-order i.-Docoglossa.

The Common Limpet, Etc. ... 63 I

Sub-order ii. - Rhipidoglossa.

The Keyhole Limpet, Etc.

Order II.-Pectinibranchiata.

(The Marine Gastropods)

Sub-orrler i. - Gymnoglossa.

(Parasitic Mollusca) ...

Sub-order ii. - Ptenorrlossa.

The Purple Sex-snails, Etc.

Suli-orier iii.-Taniuglossa.

The Cowries, Etc. ...

Sub-order iv, - Rachiglossa.

The Dug-periwinkle, Etc.
Suh-order v. - Toxoglossa.

The Cone Shells, Etc. ... $\quad \ldots \quad 638$

Sub-Class B.-Euthyneura.

Order I.-Opisthobranchiata.

Sub-order i. - Tectibranchiata.

Group A. - Bulloidea.

The Bulla, Etc. ... ... .. 640

Group B.-Aplysioidea.

The Sea-hares, Etc. $\quad . . \quad$.. 640

Group C. - Pleurolranchoidea.

Sub-or!er ii. - \udibranchiata.

The Se $x$-slugs $\quad . \quad \ldots 6 \quad \ldots 640$

... 633 Order II. - Pulmonata.

Land Mrollusca ... $\quad \ldots \quad \ldots 66_{4}$ I

.. 633 Sut)-order i.-Basommatophora.

Pond-snails, Etc. $\quad . . \quad \ldots 6$ 64I

.. 637 Sub-order ii._Stylommatoplora.

Jancl-snails, Etc.

... 642

\section{CLASS V.-CEPIIALUPODA.}

Order I.-Tetrabranchiata.

The Nautilus $\ldots . \quad \ldots . \quad \ldots \quad 645$

Order II.-Dibranchiata.

Sub-order i. - Decapnda.

The Cuttle-fish, Etc. $\ldots . \quad \ldots \quad 646$

Sub-order ii.-Octopoda.

The Argonaut, Etc.

\section{SUB-KINGDOM IV.-BRACHIOPODA.}

LAMPSHELLS, \& $c$. 


\section{SUB-KINGDOM V.-ECHINODERMA.}

$$
\text { STAR-FISH, SEA-URCHINS, \& } \%
$$

\begin{tabular}{lll|l} 
Characteristics of Echinoderma & $\ldots$ & $\begin{array}{c}\text { Page } \\
63\end{array}$ & Class Echinoidea.
\end{tabular}

Class Asteroidea.

Star-fish ... $\quad . . \quad \ldots \quad$.. 656

Class Ophiuroidea.

Brittle-stars, Etc.

... $\quad . .658$

Class Holothuroidea. Sea-cucumbers ... $\quad \ldots \quad$... 660

Class Crinoidea.

Sea-lilies ... 662

\section{SUB-KINGDOM VI.-BRYOZOA [POLYZOA]. MIOSS ANIMALS.}
Sub-Class I. - Infundibulata.
Order Ctenostomata. Order Chilostomata.
Lip-mouthed Bryozoa ...
Comb-mouthed Bryozoz
Order Cyclostomata.
Circular-mouthed Bryozoa
... 665
... 668
SUB-Class II. - LOPHOPODA.
Fresh-water Bryozoa, Etc.

... 668

668

\section{SUB-KINGDOM VII.-VERMES. \\ THE WORNIS.}

Characteristics of Worms ...

Class Annelicla.

The Ringed Worms, Etc.

Sub-class Chrtopoda.

Bristle-footed Worms ...

Order Polychata.

Marine WTorms ... $\quad \ldots \quad$... 671

Sub-order Sedentaria.

Tube-making IVorms $\quad \ldots \quad \ldots 672$

Sub-order Errantia.

The Predacious Sea-worma, Etc. 672 Order Oligochreta.

The Earth-worms, Etc. ... .. 674 Sub-class Hirudinea.

$\begin{array}{lllll}\text { The Leeches } \quad . . & \text {.. } & \text {.. } & 675\end{array}$
Class Gephyrea.

The Gephyrean IVorms... ... 677

Class Nenatohelminthes.

The Thread-worms $\quad \ldots \quad \ldots 678$

Class Rotifera.

The Wheel-animalcules ... $\quad \ldots \quad 682$

Class Nemertınea.

Nemertine Vorms $\quad \ldots \quad \ldots 6 \delta_{3}$

Class Platyhelminthes.

The Flat-worms ... $\quad \ldots \quad \ldots 685$

Sub-class Turbeliaria.

The Plmarian Vorms $\ldots . \quad \ldots \quad 68_{5}$

Sub-class Cestorla.

The Tape-worms $\quad \ldots \quad \ldots 686$

Sub-class Tremaioda.

The Fluke-worms

\section{SUB-KINGDOM VIII_-COELENTERA.}

SPONGES, CORALS, E्C.

Characterisics of Coelentera

Group I.-Porifera.

The Sponges

Group II. - The Cnidaria.

The Stinging Coelenterates
.. 690/ Section i. - The Hydrozoa.

\begin{tabular}{l|lll} 
The Zonphytes, Etc. & .. & .. & 694
\end{tabular}

.. 690 Seciion ii.-The Scyphnzoa:

Sea-anemones and Corals _.. 700

... 694 Section iii.-Citenophora.

The Comb-bearers

\section{SUB-KINGDOM IX.-PROTOZOA.}

ANIMALCULAE.

Characteristics of Protozoa

Group I. - The Monera ...

Group II. - The Rhizopoda

Section i.-The Amoba ...

Section ii. - The Foraminifera
... 713

... 713

... 714

‥ 714

... 715
Section iii.- The IIeliozoa

Section iv. - The Rndiolaria

Group III. - The Flagellata

Group IV. - The Gregarinx

Group V.-The Infusoria
... 716

… 716

... 718

... 720

... 720 


\title{
THE ANIMAL KINGDOM.
}

SUB-KINGDOM I._VERTEBRATA.

\section{CLASS I.-MAIIIALIA.}

\author{
By R. Lydekker, B.A., F.R.S., V.P.G.S., \&c.
}

IT is a somewhat curious deficiency in the English language that it has no word of its own that will iuclucle all the animals forming the class known to zoologists as the Mammalia. It is true that the term Beasts properly belongs to the great majority of the menbers of the class, but it has also acquired another meaning, and expressly excludes man. Even more objectionable is the term Quadrupeds, since not only does this exclude man and the higher apes, but etymologically includes crocodiles, lizards, and turtles. Accordingly, as neither of these two words are suitable to designate the class as a whole, naturalists have long been in the habit of using an Anglicised version of its scientific designation, and at the present day the term "Mammals" has come so wiclely into use that no apology for its employment here is called for. Mammals, then, are the highest of the Vertebrata, and thus of all animals, and take their name from the general presence of prominent udders, furnished with teats, in the female, for the secretion of the nilk, by which the young are invariably fed during the earlier stages of their existence, such udders being situated in the higher types on the breast, although in many of the lower forms they are abdominal in position. In the very lowest members of the class there are, howcver, no distinct teats, the milk-glands discharging by means of a number of small apertures in the skin of the lower surface of the body. It is thus the presence of these milk-glands, and the suckling of the more or less helpless young, that are the prime essential features of the class.

Before glancing at certain others of their distinctive features, a few words may be said in regard to the Vertebrata, which form a sub-kingdom, including the five classes of Mammals (Mammalia), Birds (Ares), Reptiles (Reptilia), Amphibians (Amphibia), and Fishes (Pisces). And here it may be noticed that certain low forms, such as

Characteristics of Vertebrates. the lampreys and lancelet (Amphioxus), commonly classed among Fishes, are now regarded as forming a portion of a lower group known as the Protochordata. Vertebrates take their name from the general presence of the structure termed the vertebral column, or backbone, although in some of the lower forms this is represented merely by a cartilaginous rod. Whether this struc- 
ture be merely such a rod, or whether it be divided into the numerous bony segments known as vertebre, it is invariably situated on the dorsal aspect of the borly, or that from which the limbs are turned away. On that side of the primitive backbone lying nearest to the back, there runs a tube or canal, formed by arches of bone or cartilage arising from the bodics of the vertebrie, and containing the great nervous cort commonly spoken of as the spinal marrow or cord. This cord in the adult state of the higher forms being thus included within what are called the arches of the vertebre. On the side of the primitive backbone opposite to that occupied by the spinal marrow is a much larger chamber, containing the heart and digestive organs; so that, in cross-section, the body of a Vertebrate consists of a smaller nerve-tube lying above the primitive backbone, and of a much larger tube, containing the heart and digestive organs below the latter. Throughout the Vertebrates the limbs never exceed two pairs, and are always turned away from that aspect of the body containing the nerve-tube; and the two jaws are upper and lower, and work against onc another in a vertical plane.

In addition to the presence of milk-glands, and the suckling by the young of the fluid they secrete, the following structural features may be noticed as

Distinctive distinctive of the Mammalian class. A highly important

Features of feature is the mode of articulation of the lower jaw to the Mammals. skull proper, or cranium ; this being effected by means of a prominence, or condyle, at the higher portion of the hinder extremity of the lower jaw, articulating with a special cavity - the glenoid cavity-. in the cranium. On the other hand, in the lower Vertebrates this articulation is effected by means of a special separate bone-the quadrate-articulating above with the cranium, and below with the lower jaw; this quadrate, as such, being absent in the Mammalia. Another peculiarity connected with the lower jaw is that it consists of a right and left branch-connected at the chin by a bony or cartilaginous union-cach of which is formed of but a single bone; whereas in the inferior Vertebrates several distinct bones enter into the composition of the two branches. Externally, Mammals are further characterised by the possession of hair on the skin, although this may be represented merely by a few bristles in the neighboumhood of the mouth during the earlier stages of existence. Internally, that portion of the great body-cavity containing the heart and lungs is completely shut off from the chamber in which are placed the digrestive organs by means of a trausverse partition, known as the midriff or diaphragm. Existing Mammals, at any rate, have also a higher type of brain than the inferior classes, an especial feature being the prescnce of a transverse band of tissue on its lower surface, connecting together the main lateral halves or hemispheres.

Such are some of the leading characters by which the Mammalia may bo distinguished from the whole of the other Vertebrates. From both Birds and Reptiles the class differs by the circumstance that the skull is movably articulated to the first vertebra of the neck by means of two knobs, or condyles, situatcd one on each sicle of the lower part of the aperture, or foramen, through which the spinal cord passes into the skull to join the brain. Two condyles are, however, present in the Amphibians (frogs and salamanders), which differ from Mammals in their cold blood. A second distinction from Birds and Reptiles is to be found in the structure of the ankle joint; the movable joint in Mammals being situated above the ankle, whereas in the other groups it is placed in the middle of the same. In common with Birds, Mammals differ from the three lower classes of the Tertcbrata in having 
warm blood, driven by a four-chambered heart through a double circalatory system ; one portion of the blood being propelled through the lungs for the purpose of re-oxygenation, while a second portion is sent through the body by means of the general circulation. IWhereas, however, in Mammals, the aorta, or great vessel, by which the blood passes from the heart to the body, crosses the left branch of the windpipe, in Birds it crosses the right. At no stage of their existence do Mammals ever breathe by means of gills : lungs, even in the aquatic forms, being the sole respiratory agents. Neither do they ever pass through any kind of metamorplosis, such as takes place in the Amphibia. As a general rule, the young are born in a living, and frequently in a more or less helpless condition; but in the very lowest members of the class the female lays eggs.

With but very few exceptions, Mammals have seven vertebre in the meek, and thereby present a remarkable contrast to Birds and Reptiles, in which the number is exceedingly variable. In all the terrestrial forms the two pairs of limbs are fully developed; but in the marine Cetaceans and Sirenians the front pair are modified into paddles, and all external traces of the hinder ones completely lost, while the body has assumed a fish-like form. In the Bats alone are the fore limbs structurally modified to subserve the purpose of true flight, like that of Birds.

As in the following pages reference is often made to various bones of the skeleton, this part of the subject cannot be passed over without brief mention. The fully developed skeleton, as shown by the accompanying diagram, comprises a skull (1), a jointed breast-bone, or

\section{Skeleton.} sternum $(b)$, a still more numerously jointed backbone, the ribs (2), the limbbones, and the girdles by which they are suspended to the backbone and its neighbourhood, and a pair of collar-bones, or clavicles (c). As already mentioned, the skull proper, or the skull without the lower jaw, is termed the cranium ; this consisting of a number of (mostly pairecl) bones, articulated immovably together at their edges. The hinder portion of the cranium encloses the brain ; while the front part, or facial region, contains the mouth and organs of smell. Of especial importauce are the bones forming the upper jaw, which comprise in front a pair of premaxillie, containing the front or incisor teeth ; behind which are the maxillæ, containing the tusks and cheek-teeth. 'The lower jaw has been already mentioned sufficiently. In the backbone the cervical, or neck-vertebrae are recognised by having no ribs attached to them ; behind these follow the dorsal vertebræ, each carrying a pair of movable ribs, of which the more anterior are comnected with the breast-bone; and these in turn are succeeded by the lumbar, or loin-vertebire, to which no movable ribs are articulated. Behind the lumbars comes the solid rnass of several united vertebrie, known as the sacrum, to which are firmly articulated the haunch-bones, or ilia ( $a$ ), forming the upper part of the pelvis (3). Behind the pelvis are the bones of the tail, or caudal vertebre, which may be either very few or very numerous. In the higher Mammals the shoulder-girdle proper is formed only by the two blade-bones, or scapulæ, which overlie the anterior ribs without any attachment to the backbone, and have at their lower end a shallow cavity for the reception of the head of the uppermost bone of the arm or fore-limb. When fully developed, the collar-bones are articulated by one extremity to the blade-bones, and by the other to the upper segment of the breast-bone. Certain other bones entering into the composition of the shoulder-girdle of the lowest representatives of the class, will be noticed under that group. In the skeleton of the fore-limb, or arm, we have the upper 


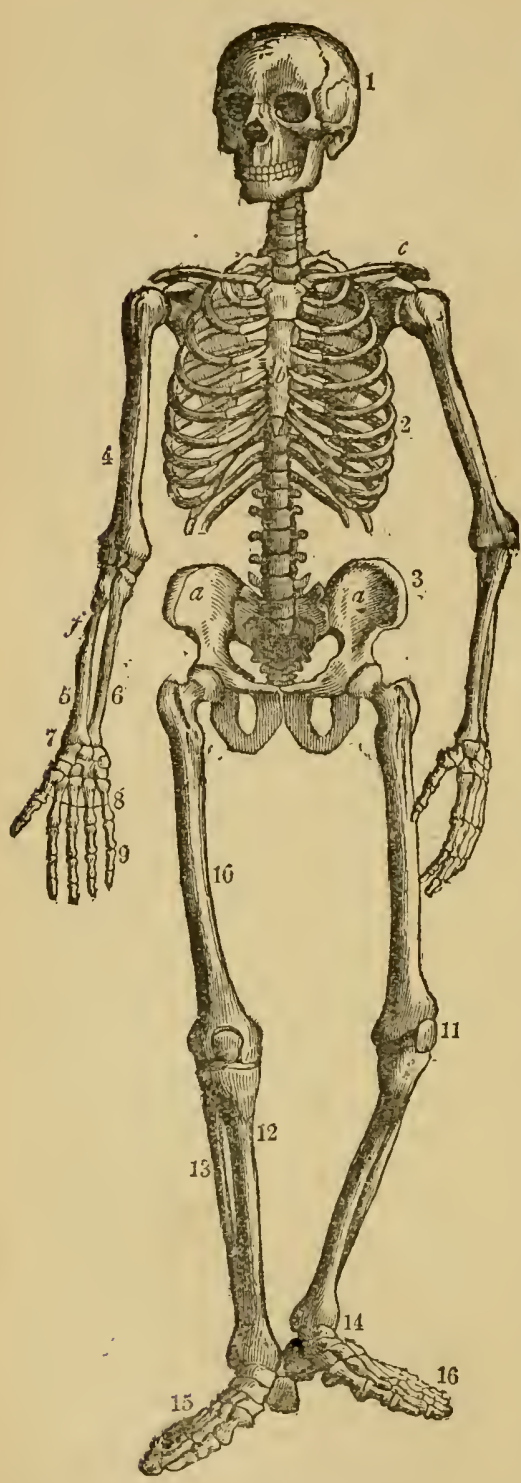

Fig. 1.-Humax Seletos. arm-bone, or Inumerus (4), articu. lating to the blade-bone. The forearm $(f)$ comprises two bones, the ridius ( $\tilde{)}$ anteriorly, and ulua $(b)$ posteriorly, both articulating with the lower end of the liumerus, and the upper end of the latter forming the prominence of the elbow. At the lower end of the radius and ulna comes the rrist-joint, or carpus (7), consisting of an upper and lower row of small massive bones, frequently having a central bone between thern. To the upper row of bones, counting from the side of the thumb to the little finger, the names of scaphoid, lunar, and cuneiform are applied. When these three bones directly overlie the bones of the lower row, the carpms is said io be of the linear type; but when they overlap, it is said to be an alternating carpus. The wrist is followed by the metacarpal bones (S), which never exceed tive in number, and these again by the phalanges, or bones of the digits; such cligits (9) being likewise nover more thain five in number. Whereas in the first dirit, or thumb, there are but two plialanges, in the other digits there are normally three. The pelvic-girdle (3), or that by which the lind-limb is supported, differs essentially from the shoulder-girdle, in that it is immovably fixed to the backbone at the sacrum. The pelvis, as the whole structure is called, is divided into a right and left innominate bone. In the higher Mammals, each imominate consists of a single bone, although it primarily consists of three distinct elements. The uppermost of these, and the one by means of which the attachment to the sacrum is made, is cilled the haunch-bone, or ilimm (it), and corresponds to the scipula in the fore-limb. Inferiorly there are two elements, of which the first is the pubis, and 
the second the ischium. Each innominate bone on its onter side contains a cup-shaped cavity (into the composition of which enter alike the ilim, pubis, and ischium) known as the acetabulum; and with this articulates the femur, or thigh-bone (10), representing the humerus of the fore-limb. Toward the middle of the hinder surface of its shaft this bone frequently bears a bold projecting crest termed the third trochanter. As the humerus articulates with the two bones of the fore-nrm, so the thigh-bone articulates with the two bones of the lower leg, of which the larger is lnown as the tibia (12), and the smaller as the fibula (13). Following these comes the ankle-joint, or tarsus (14), which, like the carpus, is formed of an upper and a lower row of small massive bones; the two uppermost bones being respectively known as the huckle-bone, or astragalus ; and the heel-bone, or calcaneun. Inferiorly the tarsus is succeeded by the metatarsal bones (15), corresponding to the metacurpals in the fore-limb, these being followed by the phalanges of the toes (16), which are similar to those of the front limb. To the first toe of the lind foot the name hallux is often applierl. It may be added that when (as in the ruminants) there are only two metacarpals, or metatarsals, which are completely joined together so as to form a single bone, or when (as in the horses) there is originally bat a single metacarpal or metatarsal, such bone, whether of dual origin or primarily single, is called a cannon-bone. The knee-cap, or patellit (11), is a bone in the tendon of the great muscle of the thigh.

With regard to the teeth, it has been already stated that in the upper jaw
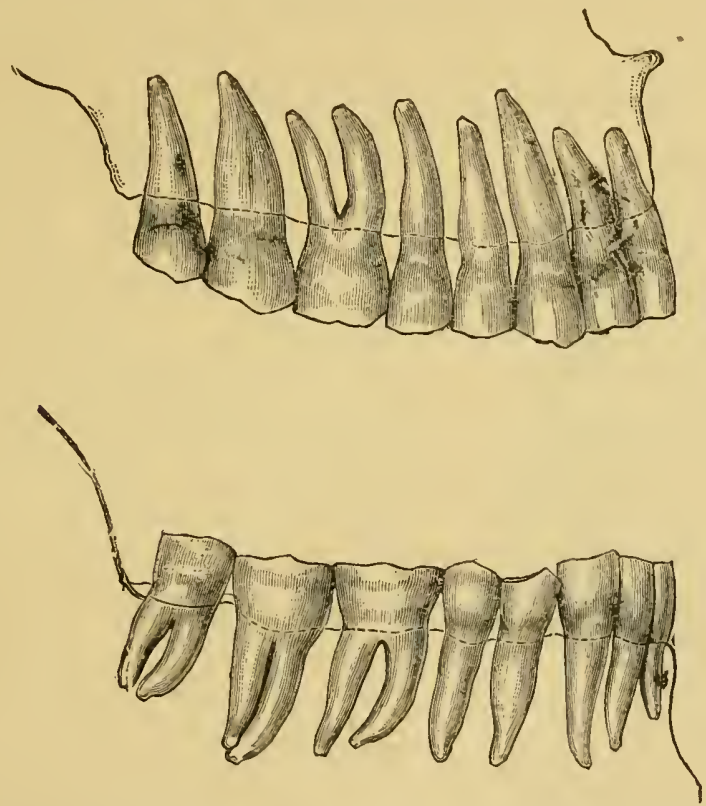

Fig. 2. - Side View of Upper and Lower Human Dentition, with the sides of the jaw removed to show the rests of the teeth. The three lower teeth with branched roots are the molars; in front of these are the two premolars, then comes the canine, and, finally, the pair of incisors. 
the teeth implanted in the premaxillary bones, which are always of a comparatively simple type, with single roots, are termed incisors. In the great

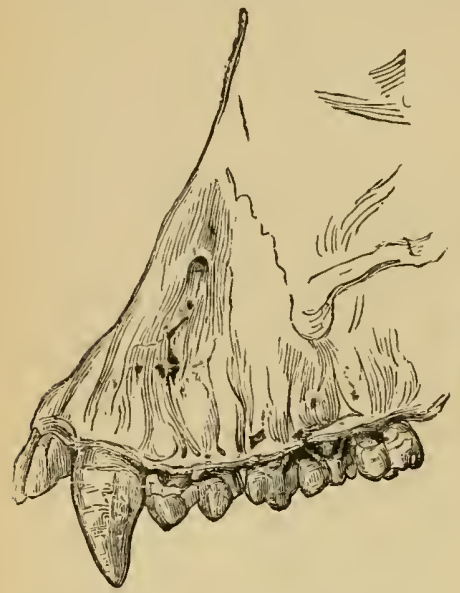

Fig. 3.-Upper JAW of the Gotrlla.

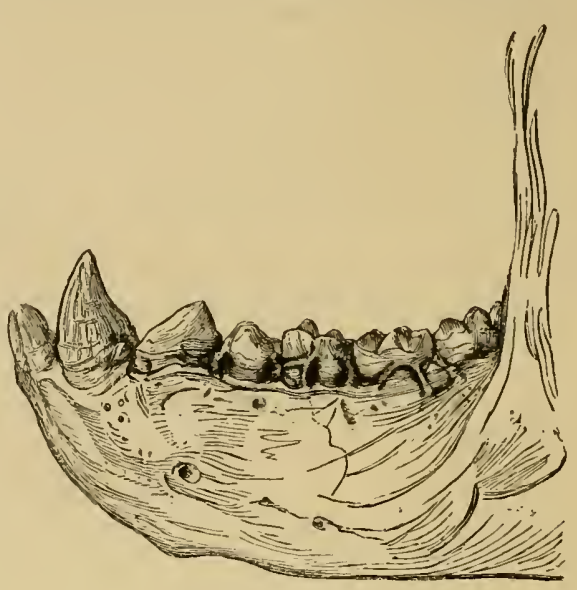

Fig. 4.-LOWER JAW OF THE Gorilla.

majority of Mammals, there are not more than three pairs of these teeth, although there may be four or five pairs in the Pouched Mammals. The first tooth in the upper jaw, which is implanted in the maxillary bone, and is very generally long and tusl--like, is termed the canine : this tooth heing also of simple type, and generally with a single undivided root. Behind this come a series of, at most, four pairs of cheek-teeth, which have generally, exeept the first, two roots each, and, in ordinary Placental Mammals, are preceded (as are the incisors and canine) by milk-teeth in the young. To these teeth, which may be reduced to a single pair, is applied the term, premolars. Behind these come the true molars, which have generally broad eomplex crowns and branching roots, and are not preceded by milk-teeth. In Placental Mammals there are but seldom more than three pairs of molars, but in Marsupials the ordinary number is four. In the lower jaw the tooth biting in front of the upper canine is the lower eanine, in front of which are the incisors. In the Placental Mammals these do not exceed three pairs, and are 
generally numerically the same as the upper incisors; but in the Marsupials, where there may be four pairs, they are generally less numerous than the upper. Behind the lower canine come the premolars, which are followed by the molars, the latter being distinguished from the last premolar by having no deciduous predecessors.

A very important subject comnected with the study of Mammals is their geographical distribution on the surface of the globe, but to understand this thoroughly, it is essential to have a knowledge of the extinct forms, and to be acquainted with the changes in the form of the continents and islands which have taken place during

Geographical Distribution. earlier epochs of the earth's history. Every traveller is aware that the Mammals of different regions of the globe differ more or less markedly, but this difference is by no means co-extensive with the distance of the rarious regions from one another. Thus, whereas the Mammals of Japan are very similar to those of Europe, while there is a marked resemblance between the former and those of Nortl America, when we pass from the Malayan Islands to Australia, there is a very sudden and remarkable change.

As a whole, Mammals are a comparatively modern group, which have only attained their present great development during the Tertiary, or latest epoch, of the earth's history. It is true that they existed during the preceding Secondary Epoch, or the one in which the chalk, oolites, lias, etc., were deposited ; but all the forms were then small, and occupied a subordinate position in the fam of the world, the continents being then peopled by various strange, and frequently gigantic, kinds of Reptiles, while, in the oceans, the place of the modern whales, porpoises, and Sirenians was taken by the Reptilian Ichthyosaurs and Plesiosaurs, It is in consequence of this comparatively late development that the geographical distribution of Mammals differs widely from that of Reptiles and Amphibians, although it coincides to a certain degree with that of Birds, which are likewise a relatively modem group.

From the evidence of Mammals alone, the globe may be divided into three main zoo-geographical realms, two of which may be further sub-clivided into regions. These three primary divisions are respectively named the Notogreic, Neogæic, and Arctogreic realms, or Notogæa, Neogæa, and Arctogæa. The tirst of these includes Australia, New Guimea, Now Zealand, and the islands as far east as New Ireland and New Caledonia, together with Celebes, Lombok, and the islands between these and Australia. From Borneo and Java, Celebes and Lombok are separated by a deep chamel, and whereas all the islands to the west of this channel, which is known as Wallace's line, have their Mammalian fauna of an Oriental or Indian type, and are without any Marsupials, those on the west of the same show a mole or less marked Australian type, Marsupials making their first appearance in Celebes, and becoming more numerous as we approach Australia and Papua, where that group is the dominant one.

The Austro-Malayan islands, as Celebes and the adjacent islands may be called, form, incleed, a transition, so far as Mammals are concerned, between the regions to the west and Australia and New Guinea, although it is on the whole most convenient to include them in the Notogæic realm. The typical part of that realm, as represented by Australia, New Guinea, and the acijacent islands, is characterised by the great preponderance of Pouched Mammals, or Marsupials, while it is here only that the Erg-Laying Mammals, or Monotremes, are inet with. In Australia itself, in addition to Bats, which 
here and elsewhere need not clain our attention, the only Mammals except Marsupials and Monotremes are a certain number of Rodents belonging to the family Muride, and the Australian wild dog, or dingo. New Guinea, on the other land, possesses a pig, which may possibly, however, have been introduced.

When Celebes and the other Austro-Malayan islancls are reached, Monotremes are absent, and Marsupials form only a small moiety in the fauma. This realm is the sole lomme, not only of the Monotremes, but likewise of the typical Diprotodont Marsupials, ${ }^{1}$ while the only other part of the world where Marsupials are now found is America, where they are represented among other forms by the opossums, which are quite unknown in Australia. As Marsupials of extinct types inhabiled the Northern Hemisphere during earlier epochs, it is evident that the Notogaic realm received its Marsupial and MIonotremes fauna at a date when such creatures were the dominant forms in South-Eastern Asia, which was then populated by but few other types of Mamnalian life. When these ancestral Marsupials and Monotremes had effected an entrance into Australia and New Guinea, with the adjacent islands, they became more or less completely cut off from the rest of the world, and were enabled to devclop apart from the competition of the higher forms of life. It is noteworthy that some of the Australian Rodents present a marked similarity to these of the Philippines, showing that the immigration has been from the northward. Notogea may be divided into several regions. One of these is the New Zealand region, characterised by the absence of all terrestrial Mammals, and the abundance of flightless birds, nearly all of which are now extinct. Under the title of the Australian region may he included Australia, Tasmania, New Guinea, the Aru Islands, New Caledonia, New Britain, etc. ; this region being characterised by the preponderance of Marsupials and the presence of Monotremes. The Austro-Malayan region, which includes the islands mentioned above, has, on the other hand, only a small number of Marsupials among a preponderance of Placentals, so that this region forms a transition between Notogra and Arctogrea.

Nearly as distinct from the rest of the world as the last, is the Neogreic realm, comprising South and Central America, together with the West Indian Islands. Now, however, the distinction of this realm, as a primary region, is much obseured by the union of South with North America, which has allowed many essentially Northern types to migrate into South America, while a ccrtain number of Southern forms have penetrated into the Northern half of the continent. There is evidence that during the Cretaceous Period, or latest division of the Secondary Epoch. what is now Mexico was a sea, while in the Middle, or Miocene division of the Tertiary Epoch, the same was the case with Central Ameriea. It is thus evident that at two distinct periods, North and South America were disconnected; although it is quite possible that during some other part of the Tertiary Period antecedent to the Miocene, there may have been a temporary connection either by way of the Isthmus of Darien, or by Florida and the IVest Indies. At the present day the Neogreic realm is practically the sole home of the Edentates, ${ }^{2}$ of the New World monkeys (Cebidee) and marmosets (Hapclidce), as well as of many peculiar types of Hystricomorphous Rodents, such as the viscacha (Lagostomus), coypu (Myopotamus), carpincho (Hydrocherus), cavies (Cavia), agutis (Daryprocta),

1 This and other terms are fully explained in the sequel.

A few of these and other grouns range into Texas. 
pacas (Cologenys), etc, etc., several of them belonging to fimilies which are confined to this realm. Here also the Marsupial opossums (Didelplingida) attain their maximum development, only a couple of species ranging into North America; while the camel-like llamas ( L ( $m$ ma) are restricted to this realum. Thepeccaries (Dicotyles), again, are minly South and Contral American while among the Carnivori the coatis (Nasua) are exclusively so. In addition to the llimas and pecenries, the only other Ungulates are deer, mostly belonging to the American genus Cariacus. True deer (Cervus) are totally wanting, as are all Insectivora.

Here, it must be mentioned, that during the Pleistocene Period, or latest division of the Tertiary Epoch, South America was populated ly a much more wonderful fauma. Among these were horses and mastodons (allies of the elephants), together with a giant Ungulate (Toxodon) typifying a distinct sub-order (Toxodontia) by itself, together with a second, linown as the Macranchenia, which is likewise the type of a sub-order (Litopterna.) Here also flourished the gigantic Glyptodonts, which are cxtinct allies of the armadillos of the present day. Deer, llamas, peccaries, coatis, and various cats were also present at the period in question. When, however, we go back to a still earlier era-the Lower Miocene-horses, peccaries, deer, llamas, coatis, and cats were entirely absent; and the fauna consisted solely of monkeys, marmosets, various peculiar extinct groups of Ungulates, and Hystricomorphous Rodents, together with certain peculiar extinct Marsupials, and some other groups which need not be mentioned. Whicu this fauna flourished, Neogrea must have been quite isolated from the rest of the world. It is, however, clear that (although the Edentates may have originated there) the Ungulates and Hystricomorphous Rodents must have entered from other regions, although how they got there is at present a mystery, seeing that none of the latter occur in the earlier Tertiary strata of North America. At the close of the Miocene Period, Suth America became connected with North America, from whence it received its extinct horses, together with its existing deer, llamas, peccaries, mice, coatis, cats, doggs, etc.; while, at the same time, a certain number of essentially Neogeic types obtained a footing in North America.

Although fuller details would be necessary to make this very complicated subject clear, it is thus evident that previous to its latest and existing union with North America, Notogrea possessed a very peculiar and characteristic fauna which entitles it to form a primary rcalm by itself; but that this original clistinction has been greatly obscured by later emigrations and immigrations. Of this primitive fauna the Edentates, monkeys, marmosets, Hystricomorplous Rodents, and certain Marsupials, are now remmants; while the coatis and llamas, which are at the present day confined to the realm, do not properly belong to it at all.

Arctogiea includes the whole of the rest of the world, and may be characterised by the absence of Monotremes, Diprotodont Marsupials, and Edentates, ${ }^{1}$ and the presence of Insectivora; Marsupials occurring only in North America. This rast tract may be divided into a number of regions. First and most distinct comes the Malagnsy region, including Madagascar and the Comoro Islands, which is specially characterised by the abundance of its lemurs, civet-like Carnivores, and Insectivora, coupled with the absence of

I The pangolins and aard-varks are here separated as a distinct order (Effodientia). The few Edentates straggling into North America may be disregarded. 
all Ungulates except an African type of pig, and the paucity of Rodents, which are represented only by the rat tribe (Muride). Next in importance is the Ethiopian region, comprising Africa south of the Tropic of Cancer and Southern Arabia. Here one of the most distinctive features are the number of large Ungulates, among which the zebras, a host of antelopes, hippopotami, wart-hogs, and the giraffe are now peculiar; while deer are absent, and sheep and goats very scarce, and only represented in the northern portion of the region. Gorillas and chimpanzees are now solely Ethiopian, as are practically the dog-headed baboons ( $P_{\text {tipio) }}$, while certain other genera of monkeys are confined to the region. Elephants and rhinoceroses also occur, although these are markedly distinct from their Oriental cousins. Aard-yarks are now solely Ethiopian; while pangolins are common to this and the Oriental regions. Bears are practically wanting.

Although in many ways mearly related to the Ethiopian, the Oriental region, which comprises India, Southern China and the Malayan countries as far as Wallace's line, is markedly distinct, having no hippopotami, giraffes, or wart-logs, while its antelopes are far less numerous, and also generically distinct from those of Africa south of the Tropic. Instead of chimpanzees and gorillas, there are orangs and gibbons ; log-faced baboons are wanting, and there are several peculiar genera of monkeys, while the lemurs are quite distinct from those of Africa. True pigs, as distinct from bush-pigs, are abundant, as are also bears and deer, the latter mostly of a peculiar subgeneric type. There are no aard-varks, although pangolins are common: and the rhinoceroses and elephant are widely different from those of Africa. The region may be sub-divided into several sub-regions, which need not be mentioned here.

With the exception of Southern North America, the whole of the remainder of the Arctogieic realm may be inclucled in the Holarctic region, which is characterised by the absence of man-like apes, lemurs, elephants, and rhinoceroses, the paucity of monkeys, the abundance of goats and sheep, and the presence of the two species of bison ; marmots and beavers being also characteristic of this region, while pangolins are practically wanting. Finally, we have the Sonoran region, including Southern Nortli America, to about as far north as latitude 45 deg., and especially characterised by being the home of the prong-buck (Antilocapr'a) and the family of pocket-gophers (Geomyidce.)

MAMMALIA.

ORDER I.-PRIMATES。

Ape;, Monkeys, and Lemurs.

The first ordinal group of Mammals is the one named by the great Swedish naturalist Limneus, Primates, and includes not only apes, monkeys, baboons, and marmosets, but likewise man himself, as well as the infinitely lower creatures commonly designated lemurs, which differ from all the others in 
their expressionless, fox-like faces. Were the latter animals (as they not unfrequently are) separated as a distinct ordinal group, the Primates would be much easier of definition than is the case when they are included ; but as there is little doubt that the latter arrangement is the proper one, it is essential that it should be followed.

In the great majority of the members of the order, the hand, which is always a grasping organ, is furnished with five fingers, generally provided with more or less flattened nails, but in certain cases the thumb is wanting. The thumb itself in the higher forms is completely opposable to the other digits, but in certain of the lower representatives of the order its power of opposition is but very limited. In the five-toed hind-foot, cxcept in man, the great-toe is similarly opposable to the other digits. With the exception of the second, or index finger of the lemurs, the terminal joints of the fingers and toes are expanded to form a support for the broad and flattened nails. In both the fore and hind-limbs all the component bones are separate from one another ; and perfect collar-bones or cavicles are invariably present. All the Primates are further characterised by the sockets, or orbits, of the eyes being surrounded by a complete bony rim. As regards the teeth, the molars have broad, flattened crowns, surmounted either by tubercles or a pair of transverse ridges, and are thus admirably adapted for the mastication of the fruits, leaves, or other vegetable substances on which the majority of these animals subsist. In number, the molar teeth form three pairs in each jaw, save only in the marmosets; these teeth being always more complex and larger than the premolars.

The latter are reduced to two pairs in cach jaw in all the higher forms, with the exception of one family of American monkeys ; and even among the lemurs no existing species has more than three pairs of these teeth. Moreover, in all the apes and monkeys the incisor teeth, which in many other' animals form three pairs, are reduced to two pairs in both jaws; but among the lemurs the number of these tecth is subject to a considerable amount of rariation. Save in the abcrrant lenur known as the aye-aye, there are at least two teats on the breast of the females.

As a rule, the members of the order are forest-dwelling animals, inhabiting tropieal and sub-tropieal countries, although a few range into regions where in winter the boughs of the trees are enveloped in snow; but it is only in the hottest and dampest tropical forests that the largest members of the or'cler are met with. Although many apes and monkeys are able to assume the upright position, it is very few that liabitually use it; and even when they do, the aid of the arms is necessary to maintain the balance in walking.

The Primates may be divided into two grent subordinal groups; the first (Anthropoider) including man, apes, baboons, monkeys, and marmosets, whilst the second (Lemuroider.) embraces only the lemurs.

The first and highest group of the Primates includes the so-called man-like apes, such as the gorilla, chimpanzee, orang, and gibbons, collectively constituting the family Simiidce. That these apes are our nearest cousins is well known; but the degree and extent of this relationship, as well as the characters by which it is displayed, are probably less familiar. In the first place, it will be noticed that we speak of this relationship as one of Man-like Apes.-Family Simiide. cousinship, and not of ancestry; and it is well that the reader should free himself from any idea tlat there is any vestige of direst ancestral kinship) between these, for the most part, hideous creatures and humself. Such 
relationship as does exist is of a comparatively distant klnd; and the common ancestor must have lived ages before the mammoth roamed ove1 England, since at that date man was as distinctly differentiated from the apes as he is in the present century. Whether this "missing link" will ever be found, or in what country it is most likely to have lived, are questions inpossible to answer; but from the extreme rarity with which fossil remains of man-like apes are found in countries where they are known to have existed for-long ages, and from the probability that the distributional area of the aforesaid "link" was extremely limited, there is not much hope that the researches of paleeontologists will ever be rewarded by such a cliscovery.

From their large bodily size, compled with that hideous caricature of the human face and form characterising the more typical representatires of the man-like apes, no one would have any difticulty in clistinguishing these creatures from their lower relatives. There inight, however, be some hesitation with regard to the long-armed gibbons, and it is, therefore, essential to point out how the members of the man-like group may be distinguished as a whole from other monkeys.

Among the sub-order Anthropoidea there is an important distinction between the Old and New World forms. The whole of the Old World representatives of this division of the order are characterised by having teeth agreeing both in number and arrangement with those of man. Thus in all cases in each jaw there are two pairs of incisors, a single pair of tusks, or canines, and five pairs of cheek-teeth, of which the last, or "wisclom-tnoth," is frequently very late in making its appearance (see fig. 5). Of these five cheekteeth the first two on each side are simpler than the three hinder ones, and are preceded in the infant by milk-teeth, whereas the latter have 110 such predecessors. It is accordingly the custom to call the two simpler teeth premolars or bicuspicls, and the three more complex ones molars. If, now, we examine an ordinary American monkey, we shall find six check teeth on each side of both the upper and lower jaws, of which half are premolar's and half molars; while in the marmosets, which constitute a second American family, although the total number of cheek-teeth is the same as in the Old World forms, yet the proportion is different, there being chree premolars and two molars. It may, therefore, be stated that all American monkeys differ from their Old World cousins in having three instead of two pairs of premolar teeth, whence it may be inferred that they belong to a lower and more generalized type, there being a universal tendency thronghout the higher Vertebrates to a diminution, or clisappearance of the teeth with the advance of specialisation. In the marmosets the loss of the last molar is unique in the higher division of the order, and is, indeed, a somewhat remarkable peculiarity to occur in a herbivorous Mammal, among which the reduction is usually confined to the front and premolar teeth.

As the teeth serve most readily to differentiate the Old World monkeys from their American allies, so the man-like apes are sharply distinguished from their relatives by the conformation of the same organs. Thus the molar teeth of the man-like apes closely resemble those of man, having the angles of their crowns rounded off, and carrying on their grinding-surfaces four very blunt tubercles, placed alternately to one another, as well as a somewhat smaller tubercle at the hinder end. On the other hand, in the lower monkeys the molar teeth are oblong in form, ancl carry four very prominent tubercles arranged in pairs at the two extremities of each tooth, and each pair being connected so as to form a couple of more or less well- 
defined transverse ridges extending right across the crown. 'ihen, again, whereas in the man-like apes the last molar, or "wisdom-tooth," in the lower jaw is similar in form to the two teeth in front of it, in the great majority of the Old World monkeys this tooth has a large projecting heel at its linder end. These lental chiracters afford very important evidence of the close kinship of the man-like apes to man himself, and undoubtedly outweigh the difference in the form of the whole dental series now to be noticed, which is largely due to adaptation. In both the upper and lower jaws of man the teeth are arranged in a regular horse-shoe series, with scarcely any interruption to the continuity by the tusks, which are but little taller than the other members of the series. On the other hand, in the adults (and especially the males of the larger species) of the man-like apes the cheek-teeth are arranged in a nearly straiglit line, and form a more or less angulated junetion with the line of the incisors ; the large canines, or tusks, occmpying the angle between the two series, and thus forming a marked break in continuity. In these respects the manl like apes resemble their inferior kindred. If, however, a young individual of the larger man-like apes, and especially the chimpanzee, be examined, it will be found that the teeth, owing partly to the imperfect protrusion of the tusks, form a less interrupted and more regularly curved series. Indeed, with the exception that the whole jaw is longer and narrower, and the partially-protruded tusks are proportionately larger, the characters of such specimens make a marked approximation to the liuman type; and the jaw of a chimpanzee at this stage may be regarded as almost intermediate in structure between that of man and that of an adult male gorilla. Moreover, in this jurenile state the bony union of the two branches of the lower jaw partakes of the short and rounded form characterizing that of man ; whereas in the adult it becomes longer and more deeply channelled, like that of the lower monkeys. In many respects the teeth and jaws of the gibbons, or smallest representatives of the present group, conform to the intermediate type. Not only are the human characteristics most developed in the teeth and jaws of the young of the lirger man-like apes and the gihbons at all ages, but the same is true with regard to the skull of the former. The skull of the young gorilla, for instance, lacks the beetling crests over the eyes and the prominent ridge down the middle of the crown, which give such a forbidding and repulsive aspect to the cranium of tho full-grown male. This loss of human resemblances is due to specialisation taking two difficulty lines in man on the one hand, and in the larger man-like anes on the other; the development in the one case tending to increased size of brain, conpled witl no marked increase in the size of the tusks, while in the other the brain grows at a less rapid rate, and the skull and tusks (more especially in the male) assume characters approximating them to those of the inferior animals. Both in men and apes the young condition may accordingly be regarded as the most generalised.

Among the other features in which the man-like apes differ from the lower monkeys and resemble man, are the absence of dilatable pouches in the cheeks for the storage of food, and the total loss of the tail, as woll as the flattened, instead of laterally compressed, form of the breast-bone; the gribbons alone retaining the naked patches on the buttocks so characteristic of the monkeys, but only in a much reduced condition. The gorilla and chimpanzees further cliffer from the other members of the group, and thereby resemble man alone, in the loss of the so-called central bone of the wrist-a bone occupying a nearly central position between the upper and lower rows 
of small bones of which that joint is composed. What may be the object of the disappearance of this bone, it is not easy to say; but the fact that it is wanting in the two genera of apes just mentioned is very significant of their close structural affinity with man. In one respect the man-like apes stand apart both from the human and the monkey type, namely, in the great relative length of the arms as compared with the legs, the disproportion being most strongly marked in the gibbons, which are actually able to walk in the upright posture with their bent knuckles touching the ground.

So far, indeed, as their bodily structure is concerned, the man-like apcs seem undoubtedly more nearly related to man than they are to the lower monkeys ; and they constitute a family (Simiide) by themselves, which may be regarded as intermediate between the one (Ccrcopithecidce) including the lower monkeys, and that represented by man himself. While at present the "missing link" between man and the apes is wanting, extinct forms tend to connect the latter very closely with the monkeys. For instance, a fossil ape (Dryopithecus) from the Miocene Tertiary strata of France has the bony union between the two branches of the lower jaw much longer than in any existing man-like ape, although it is approached in this respect by the gorilla; while from the corresponding beds of Italy another extinct form (Oreopithecus) appears to be in great part intermediate between the man-like apes and the lower monkeys.

The present distribution of the anthropoid apes clearly points to the existing species being the last survivors of a group which was once widely spread over the Old World, when warner climatic conditions prevailed over what we now call the temperate regions. The gorilla, for instance, is confined to Western Equatorial Africa; where it is accompanied by the two specics of chimpanzee, one of which ranges eastwards across the continent as far as Uganda. The orangs, of which there are probably two species, on the other hand, are confined to the great islands of Sumatra and Borneo; while the numerous species of gibbons have a wide range in South-Eastern Asia, attaining their maximum derelopment in the Malayan Archipelago and the adjacent regions. This distribution is remarkably discontinuous, but the little known of the past history of the group tends somewhat to consolidate the present scattered distributional areas. For instance, a chimpanzee once inhabited Northern India ; while it is most probable that an orang also was a contemporaneous dweller in the same country. This suggests that India may have been the original home of the larger man-like apes, from whence the chimpanzees and gorillas migrated south-westwards to Equatorial Africa, while the orangs travelled in an easterly direction to find a last home in the tropical islands to which they are now confined.

Of the four existing genera of the man-like apes, the chimpanzees (Anthropopithecus) are those which come nearest to man, this being especially shown by the shortness of the bony union between the two branches

Chimpanzees of the lower jaw, the form and mode of arrangement of the teeth (Authropopithe- (especially in the young), the relatively small development of cus). the tusks of the male, the absence of the enormous bony crests on the skull so characteristic of the gorilla, and the slight difference in the size of the two rexes. The chimpanzees and the gorilla alone resemble man in having seventeen vertebre between the neck and the sacrum, and likewise in the absence of the central bone in the wrist, although they differ in the comparatively unimportant feature of possessing an additional pair of ribs. It will be unnecessary to give a full description of 
these animals, and it will suffice to say that the common species ( $A$. troglodytes), which ranges across Tropical Africa from the Gabun to Uganda, has the face, ears, hands, and feet, dark reddish flesh-colour, or more rarely blackish brown, while the general colour of the hair is wholly black, except on the lips, where it is short and white, and on the buttocks, where it has a dash of reddish brown. There has been some difference of opinion as to whether the so-called bald chimpanzee (A. caltus) of the West Coast of Africa is entitled to rank as a distinct species, but recont researches tend to show that it has no such claim. In size chimpanzees are much smaller animals than the gorilla. In walking, the palm of the hand can be applied to the ground, and the same is the case with the sole of the foot; but although chimpanzees can stand or walk erect on the soles of their feet, they much prefer to progress in a stooping posture, supporting themselves on their bent knuckles.

In some districts living to a great extent on the ground, chimpanzees are more arboreal in their general habits than the gorilla, although much less so than the orang. They feed on wikl or even cultivated fruits, and generally

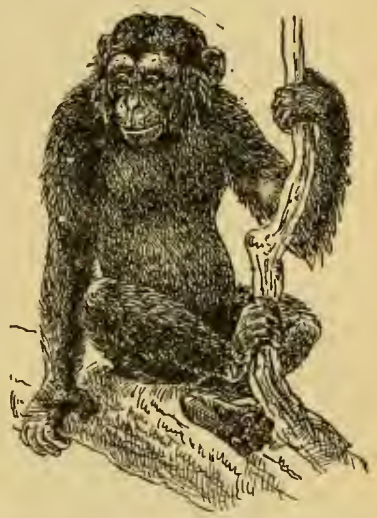

Fig. 6.--Common ChIMPANZE (Anthropopithecus troglodytes). associate either in family parties or in small communities, although the

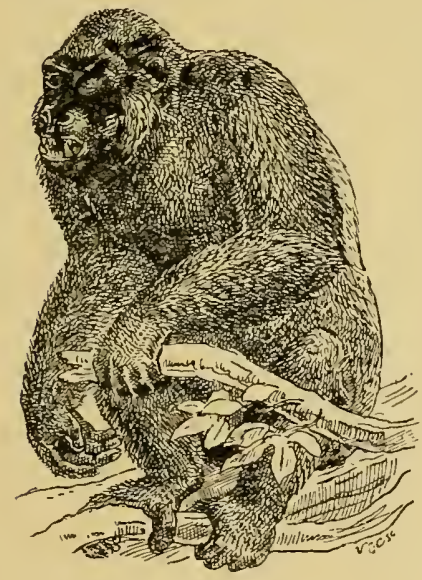
males and females pair for life. For the protection of the female and young a kind of nest or resting-place is built in some tree, where they pass the night, the male remaining on ground below. "In the early morning and evening, and less commonly during the night, chimpanzees give vent to a serics of unearthly shrieks and howls; Dr. Pechuel-Lösche observing that "since they are really accomplished in the art of bringing forth these unpleasant sounds, which may be heard at a groat distance, and are reproduced by the echoes, it is impossible to estimate the number of individuals who take part in the dreary noise, but often we seemed to hear more than a hundred."

The hideous creature forming the sole representative of the genus Gorilla differs from the chimpanzees in

Fig. 7,-Tнe GoRiLlA (Gorilla savagei). the great development of the tusks of the male as

\section{Gorilla.}

well as in the large size of the bony crests on the skull above the eyes, and likewise by the male being very much larger than the female. There are also certain differences in the conformation of the cheek-teeth, and the brain has a more 
oval contour, thereby approximating to the human type. In height the male gorilla $(G$. suragei) may exceed six feet, although the female does not measure more than four and a half feet. The general colour of the animal is black or blickish, the whole shin of the face being glossy black, scattered over with a few hairs. The geographical range of this gigmintic ape is exceedingly limited, being confined to that part of the West Coast of Equatorial Africa lying between the Camerun mountains and the Congo River. Like chimpanzees, gorillas live in family parties, although these do not combine to form communities ; and they are likewiso stated to construct arboreal resting-places for the female and young. They walk in a shuffing manner somewhat similar to that

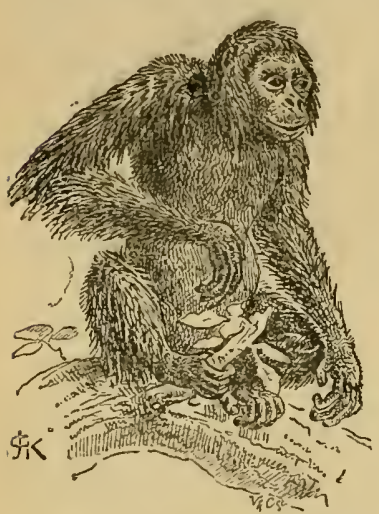

Fig. 8.-THE ORANG-UTAN (Simia sutyrus).

adopted by chimpanzes, but as their arms are longer they are not compelled to stoop so much, and the open hand, in place of the bent knuckle, is stated to be put on the giound in this mode of progression. The yell of the male gorilla is described as a terrific sound; and these animals appear to be not only ferocious, but likewise extremely courageous, always advancing boldly to meet a foe, and never running away like a chimpanzee. As in all the min-like apes, the female produces but a single young at a birth, which is nurtured with tender solicitude, and defendecl to the last extremity. When at rest, the gorilla generally assumes a squatting posture, witl the arms folded across the breast; and in sleep lies stretched out at full length either on the back or on one side, with an arm under the head. Extremely delicate in constitution when removed from its native haunts, this ape rarely survives captivity long even in Africa, while the climate of Europe soon puts an end to its existence.

The first skeletun of the gorilla which reached England was presented to th 3 Royal College of Surgeons ly Cartain Harris in 1851. This was followed in 18.58 by an entire gorilla preserved in spirits, which was sent from the Gabun to the British Museum. Of the few live specimens which have reached Europe, none seem to have survived more than fifteen or eighteen montlis. The earliest to reach England appears to have been onc which, in $18 j 0$, was the property of an itinerant showman, who mistook it for a chimpanzee, and did not discover his mistake until after the animal's deatl. Fifteen years later a young male gorilla was procured from the natives liy the German Loango Expedition, and taken to Berlin. This animal was fed on fruits ancl goat's milk, and under kindly treatment became so tractable that he was allowed t. wander about the ship with little or no restraint. He showed some cumning and a tendency to mischief, but no evil propensities. He would pay surreptitious visits to the store-room on occasion, and slyly lielp himself to the clainties he affected, making off with nmmistakable signs of guilty consciousness when clisturbed or canght in the act. Arrived at Be:lin, he was placed in the Aquarium, where for fifteen months he was the object of much attention. He died of consumptim, as did his successor, who arrived at Berlin in 1883, and died the following year. A young gorilla which reached the Zoological Gardens, London, a few years age, livel but a few montlis. 
The reduction of the number vertebri between the neck and the sacrum to sixteen, together with the retention of the central bone in the wrist, the great length of the arms, which in the upright posture reach to the ankies, and the peculiar upward prolongation of the vertex of the skull, serve at once to show that the orang (Simice) stancis on a lower evolutionary platform

Orang-Utan

(Simia.) than either of the preceding representatives of the family. Externally it is further distinguished by the rudimentary condition of the great-toc, the peculiarly flattened form of the almost dish-like leaden-hued face of the adult, and the red tinge of the long and shaggy hair, the latter being in marked contrast to the black hue of the gorilla and chimpanzees. Although in possessing only a dozen pairs of ribs the orang differs from both the latter and resembles man, yet this resemblance is greatly outweighed by the cliffer. ence in the number of the vertebrie.

It is now generally admitted that there is but a single species of orang. utan (Simia satyrns), which is confined to the great islands of Sumatra and Borneo, and is known to the Dyak inhabitants of the latter by the name of Mias. A peculiar characteristic of the adult male is the presence of a large, smooth, soft, tumour-like, flexible expansion of the skin of the sides of the face, giving the remarkable breadth and flatness so characteristic of the whole countenance. In size, orangs are subject to considerable variation, large males reaching from four feet two inches to four feet six inches; the females being much smaller.

The orang is a much more truly arboreal animal than either of the other large apes, and is likewise a solitary creature, the sexes only coming together at the pairing season. Females are gencrally to be seen accompanied by their young, sometimes only a single one, but in other instances with those of two births. The young cling with remarkable tenacity to the body of the mother as she climbs from tree to tree. Although most excellent climbers, orangs are exccelingly slow and deliberate in their movements, and are thus quite unlike the gibbons.

Mr. Brooke of Sarawak says, "The orangs, so far as I have been able to observe them, are as dull and as slothful as can well be conceived, and on no occasion, when pursuing them, did they more so fast as to preclude my keeping pace with them ensily through a moderately clear forest ; and even when obstructions below (such as wading up to the neck) allowed them to get away some distance, they were sure to stop and allow us to come up. I never observed the slightest attempt at defence; and the wood, which sometimes rattled about our ears, was broken by their weight, and not thrown, as some persons represent. If pushed to extremity, however, the pappan could not be otherwise than formidable; and one unfortunate man, who with a party was trying to catch one alive, lost two of his fingers, besides being severely bitten on the face, whilst the animal finally beat off his pursuers and escaped. When hunters wish to catch an adult, they cut down a circle of trees round the one on which he is seated, and then fell that also, and close before he can recover himself, and endeavour to bind him. The rude hut which they are stated to build in the trees would be more properly called a seat, or nest, for it has no roof or cover of any sort. 'The facility with which they form this seat is curious; and I had an opportunity of sceing a wounded female weave the brauches together, and seat herself in a minute. She afterwards received our fire without moving, and expired in her lofty abode, whence it cust us much trouble to dislodge licr. The adult male 1 killed was seated 
lazily on a tree; and when approached, only took the trouble to interpose the trunk between us, peeping at me and dodging as I dodged. I lit lim on the wrist, and he was afterwards despatched."

The list nembers of the family are the gibbons (Hylobates) which are restricted to the warmer parts of South-Eastern Asia, and are especially abundant in the Malay Peninsula and islands. They are

Gibbons (IIylo. the lowest and smallest representatives of the man-like apes, bates). and although agreeing with those above described in the absence of a tail and cheek-pouches, and by the circumstance that their grinding-teetl are constructed on precisely the same plan as those of ourselves, they approximate to the lower monkeys in posscssing small naked callosities on the buttocks. In liabitually walking in the upright position, frequently with the assistance of their enormously clongated arms, they are peculiar in the ape world. This peculiarity, coupled with their apparently human-like skulls, might lead the uninitiated to suppose that these creatures were the most man-like of all apes. A moment's reflection would, however, show that in such highly-organised animals, a small species, in order to be able to carry on the functions necessary to its existence, must have a proportionately larger brain than its bigger relatives; and a large brain implies, of course, a large skull. Moreorer, in small and purely arboreal aninals like the gibbons, there is no reason why the skull should be strengthened by the enormous frontal ridges which give such a repulsive aspect to the physiognony of the male gorilla. Accordingly, we see that the somewhat hunan-like form of the skulls of the gibbons does not in any way indicate that they are more nearly related to ourselves than their larger lindred; while the callosities on their buttocks, and several features in their anatomical structure, show that they are decidedly less so.

Although in the confined space of a cage in the "Zoo" the gibbons have but little opportunity of displaying the marvellous activity by which they

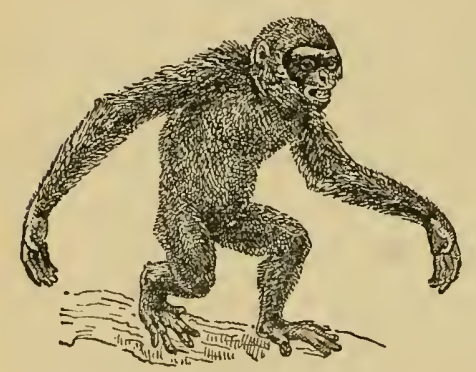

Fig 9-A (imbeon (IIylobates). are characterised in their native woods, yet even there their engaging manners cammot fail to attract attention; and many show the gentleness and docility so distinctive of these apes in a most marked manner. In the more congenial climate of Calcutta, which admits of gibbons being placed in the open air, their movements are, howerer, far more like those of the wild state; and one of these creatures in the local "Zoo"showed its lightning-like activity by actually catching birds while on the wing. Not only is this bold activity characteristic of the gibbons, but they likewise exhibit a wonderful delicacy of touch. For instance, many gibbons display a marked penchent for spiders, which are captured with the long slender finger's ; but before devouring their prizes these animals will not unfrequently play with them for hours, allowing them to descend by spinning a thread from one of their captor's fingers, and then suidenly jerking them upwards into their hands. Not less noteworthy than their active movements are the loud, unearthly cries of the gibbons, in imitation of which the luulock (II. hulock) of Assam, Burma, etc., derives 
its name. These wailing eries, which are uttered hour after hour in the morning, and again, although less continuously, in the evening, may be heard for miles when a whole drove me shouting in concert; and even those of a solitary individual in the Calcutta Gardens male themselves audible at least a mile off.

Out of a totil of eight species of the genus, the siamang ( $H$. syindactylus) of Sumatra is the largest, measuring more than a yard in length; and it differs from all the rest by having the second and thirrt toes of the hind foot mited by a web as far as their terminal joints. In colour, the siamang is miformly black throughout, and in this respect it agrees with the Hainan gibbon (H. hainames); whereas, in all the other species there is a white band across the forehead. Aniong these litter, one of the best known is the lulock ( $H$. hulock) from Assam and the countries immelliately to the east. Writing of the cries of another species (II. lenciscus), Mr. H. O. Forbes observes that it "makes its presence known to the trareller in Java, when he reaches its uplind forest-districts. In the evening just about smolown, and more especially in the early morning, commencing before sunrise and finally ceasing when the sun is abore the tops of the trees, lie will be surprised by a sudden outbreak of what appears to be now the plaintive wailings of a crowd of women, now the united howling of a band of castigated children."

The whole of the remaining monkeys and baboons of the old World form a second family, which, while agreeing with the man-like apes in the number of their teeth, differ by the crowns of the molars being surmounted by a pair of transverse ridges, eaeh formed by the

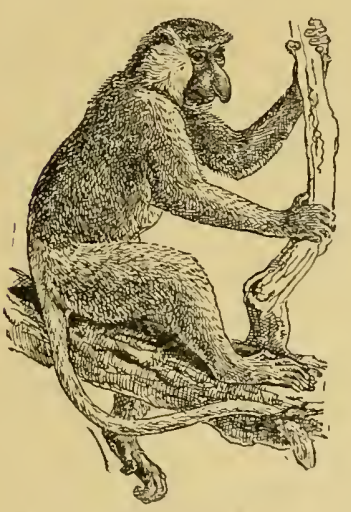

Fig. 10,-Proboscis-Minkey (Nasalis lurvatuts). coalescenee of two sub-conical tubereles. All the members of the family have naked callosities on the buttocks, and cheek-ponches are very gener-

\section{Old Worid}

Monkeys.-

Family

Cercopithecida. ally present. The breist-bone differs from that of the man-like apes in being laterally compressecl and narrow, instead of broad and flattened from back to front. The tail, which may le either wanting, short, or very long, is never endowed with the power of prehension ; and the partition between the two nostrils is narrow. Eight existing genera are included in the family, some of which are Oriental, while others are contined to Africa south of the Sahara. None are known from Madilgasear, New Cruinea, or Australia, the eastern limits of the group being formed by Celebes and the Philippine lslands.

The most Indicrous in appearance of all the tribe is the well-known proboscis-monkey (Nascll is larutus) of Borneo, easily distinguished from all its kin by the extraordinary length of its nose. This monkey, togrether with the two following genera, constitutes a sub-family characterised by the absence of chcekpouches for storing food, the complex and sacculated

ProboscisNionkey (Tasalis). structure of the stomach, the great length of the tail, and also by the front limbs being shorter than the hinder pair. All these monlieys feed lingely or 
chiefly on young shoots or lenves; and it is in adaptation to this diet that their stomach is specially modified and cheek-ponches are wanting. The constitution of all the tribe is very delicate, so that these monkeys are illadisted to stand captivity.

The peculiar structure of the nose is sufticient to differentiate the proboscismonkcy from all its allies; but to this may be adiled the circumstance that the tail is shorter than the head and body.

The numerous species of langurs, which are nearly thirty in number, are confined to the Oriental countries, where one species ranges as far north as Kiashmir, while a second is peculiar to the highlands of

Langurs Eastern Tibet. All these monkeys have thin and slender (Semnopithecus). bodies, elongated limbs, and a very long and whip-like tail; the head being rounded, and the muzzle short and thick. The thumb is rather short, but the great-toe well developed; and the callosities on the buttocks are relatively small. The hair is abundant, and generally long, soft, and frequently glossy ; while there is usually a fringe of long, stiff hair's projecting over the eyes. Grey is the predominant hue in the pellage; but the face, hands, and feet are perfectly black.

The best known of all the group is the Hanuman, or sacred langur (Semnopithecus cutellus) of India, which ranges from the Deccan northwards to the south bank of the Ganges, and is held sacred by the Hindus. Of this monkey a writer in the Graphic gives the following interesting account:

"Anong the thousand or more temples and shrines with which the holy Hindu city of Benares is endowed, visitors generally find the great temple dedicated to the worship of the goddess Durrga one of the most interesting. It is known to Europeans as the monkey-temple, because in and around its precincts many hundreds of sicred monkeys roam about withont interference. The temple was erected during the last century by the Rani Bhawani of Natre in honour of Shiva's wife, the goddess who is supposed to delight in death and slaughter, and of whom the believers in the various attributes of the deities, comprising the Hindu Pantheon, stand in the greatest dread. The Dûrga Kund is conspicuous in this city of tomples for the grace and simplicity of its architecture. It adjoins a tank which is the finest in Benares, and occupies the central portion of a quadrangle, the walls being stained red with ochre. The sacred portion of the temple consists of twelve fincly-carved pillars standing on a marble platform, and supporting a heavy ronf. This platform is about $4 \mathrm{ft}$. from the ground, and is ascended by a flight of low steps on each side of the square. The temple is" well provided with the necessary instruments for creating the frightful moises which emanate from these abodes of idolatry all over India. Drums of huge dimcusions, gongs, bells, and tom-toms are all at the service of the priests in performing the rites required of them. But the anties of the monkeys which make this temple their home are, next to its architecture, the most attractive feature of the place. The goat's blood with which the walls are sprinkled, and the sicrifices that are known to take place here to appease the wrath of Shiva and his terrifying spouse, are rather revolting to a Christian ; but the grotesque play of the nonkeys, their importunate begging, the pranks they enact on one another, and the graceful agility they are constantly displaying, supply a perpetual source of amusement which one is apt to think unst prove rather districting to the devont Hindus who come here to worship. A few years ago, as no one dared molest these inimals, they not only increased rapidly in numbers, but, growing to be extrnordinarily bold, developed alarming thiev- 
ing propensities. The ammoyance they eansed amounted to a public nuisance, for no lionse in the place was safe from their depreclations. At last the trouble grew so serious that some recluetion in the number of these arlept thieves became a neeessity, although the prejudices of the people were against nny such steps being taken. In the end the Gorerument was requested to interfere, and, waving aside all sther considerations but that of public polity, the authorities had many lumblyeds-report says thousands-eaptured and sent away. Nevertheless there are plenty of them left, and they certainly constitute one of the sights of a eity that is probably in many lespects the most interesting in the world."

In Afriea south of the Sahara the plaee of the langurs is taken by the guerezas, of which there are nime species, easily distinguished by the total absence of the thumb. In the true guereza (Colobus grevesin), ranging from Somalilind to the Nimm-Niam country and Mnunt Kilima-Njaro, the hair of the back is developed into a beautiful, long silky mantle langing down on the sides of the

Guerezas

(Colobus). body, and likewise by the extremely bushy tail; the mantle and tail, as well as i ring round the face, being pure white, while the rest of the fur is jetty black. The pellage of this species is extensively used by the matives of Africa; while that of all the long-haired linds is largely imported into Europe for manufacture into muff's and other articles of clress.

The gruenons, or typical representatives of the family, which include considerably orer thirty species, are likerise exelusively confined to Africa south of the Sahara desert. In common with the remaining members of the family, they constitute a sub-family distinguished from the last by the presence of cheek-pouches (Ccrcopithecus). and the simple structure of the stomach. Their food is more varied than that of the langurs and their allies, and conscquently these monkeys are much better adapted for captivity than are the latter. The guenons are spceially characterised by the relative slenderness of their build, the more or less shortened muzzle, the moderate size of the callosities on the buttocks, and the long tail. From the two following genera they may be readily distinguished by the ciremmstance that the last molar tooth in the lower jaw has no projecting heel at its hinder end, but consists simply of two transverse ridges, like the teeth immediately in advance of it. Among the better known species may be mentioned the green monkey (Cercopithecus callitrichus), the Diana monkey (C. diunct), so named from the white fillet above the eyes, and the mona monkey ( $C$. monu); all these being from West Africe.

Differing from the guenons solely in the presenee of the aforesaid heel to the last lower molar, the mangabeys, or white-eyelid monkeys, likewise form a genus eonfined to Africa, where they are represented by only half-a-dozen species. They form a gromp

Mangabeys

(C'ercocebus). intermediate between the preceding and the following one.

In the Oriental comntries this group of monkeys is represented by the macaques, of which there are rather less than a score of species. The macaques resemble the mangabeys in the structure of the last molar tooth, but are readily distinguished by the considerable production of the muzzle, in which the

Macaques

(1Itcacus).

nostrils are not terninal. While the cheek-pouches and the callosities on the buttocks are always well dereloped, the tail may be either long, short, or absent. Although these monkeys are mainly Oriental, one species, the 
Barbary ape (Macacus imues), is found in North Africa and on the rock of Gibraltar; and one of the Asiatic species ranges as far north as Eastern Tibet, while a third is fomd in Japan. In the Barbary ape the tail is wanting, in the common Bengal monkey ( $M$. thesus) it is about half the length of the heal and body, and in the crab-eating macaque $(M$. cynomolgnes) it is considerably longer. The well-known Indian lion-tailed monkey (M. silemus) takes its name from the presence of a large terminal tuft to the tail ; the head and neck being also furnished with a mane. Many of these monkeys are of eomparatively large size, and are ver'y sarage in disposition, biting tiercely when amnoyed.

The black ape ('ynopithecus niger') of the island of Celebes is the sole representative of a genus forming a comnecting link between

Black Ape (Cyropithecus).

the preceding and the following, the muzzle beins more produced than in the macaques, and the fore part of the skull bearing longitudinal ridges, as in sume of the dog-faced babons. This monkey, which takes its name from the diurk colour of the hair, his the tail reduced to a mere fleshy tubercle concealed among the fur. It is also found in the island of Batchian, in the Molueca group, where it has probably been introduced by the Malays.

Two species of baboons, the one (Theropithecus getudu) from Southern Abyssinia, and the other ('T. rbscurus) from North-Eastern Gelada Baboons Africa-constitute a genus differing from the next by having (Theropithecus). the nostrils placed on the sides of the long muzzle, as in the macaques, instead of being terminal and opening on its trumcated extremity. The true gelada is a most extriordinary-looking creature, having a long crest of clark brown hair above the eyes, and a mantle-like mane of the same descending from the neck and shoulders to the loins, and also reaching on the arms as far as the elbows; the chin, and a patch on the throat, as well as another on the chest, being bare, and, as are all the other naked parts, black in colour. In size this baboon measures 29 inches to the root of the tail; the latter appendage, inclu. sive of the tuft at the tip, being upwards of 32 inches.

The remaining members of the family Cercopithecidre are all in$\begin{array}{cl}\text { Dog-faced } & \text { cluded in the genus } \\ \text { Baboons (Papio) } & \text { monly known an an } \\ \text { dog-faced baboons }\end{array}$ on iccount of the great elongation of the muzzlo, in the truncated ter-

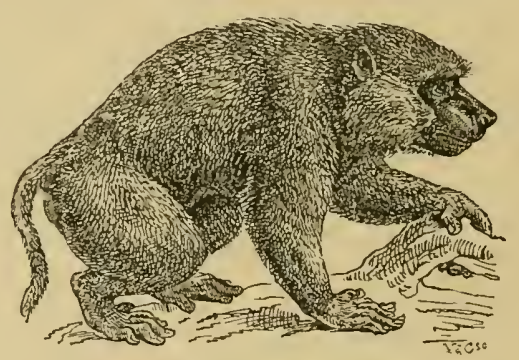

Fig. 11.-A Dog-Faced Paroon (l'apio).

mination of which are pierced the nostrils in the same manner as in a dog. The callosities on the buttocks are very large and frequently brilliantly coloured; the muzzle is greatly swollen and often marked by longitudinal flutings; and the tail is more or less shortened. The dugr-faced baboons, of which there are eleven different species, include the largest and most repulsive-looking members of the entire family; and are now confined to Africa south of the Saliara and Southern Arabia, although during the later geological periods they were represented in India. 
The largest and most hideous of the tribe is the mandril (Papio maimon) of the forests of Western Equatorial Africa, remarkallo for its robust build, stump-like tail, highly swollen and fluted muzale, and the brilliant tints of blue and scarlet with which the naked portions of the face and buttocks of the adult males are decorated. In South Africa the genus is represented by the chacmin ( $P$. poicurius), which is a more soberly-colomred species, with a tail equal in length to half the boly; while the yellow baboon ( $P$. babuin) of West Africa may be taken as an example of species in which the tail is still longer. Although found in the uplund forests of Momt Kilima-Njaro, the dog-faced baboons are more generally inhabitints of open, rocky districts, where they go about in large parties, inflicting serere damage on the proclucts of the cultivated lands, and fiercely attacking all intruders on their domains. In their diet they are well-nigh onmivorous, feeding not only upon fruits and cereals, but likewise devouring large numbers of lizards and insects, in search of which they turn over stones with their fingers. The late Sir R. Burton wrote that in the jungles of Usulimm these baboons " are the terror" of the neighbouring districts; women never dare to approach their haunts; they set the leopard at defiance, and, when in a large body, they do not, it is said, fear the lion."

As illready stated on page 12, the monkeys of the New World differ from their Old World cousins in having three in place of two pairs of premolar teeth in each jaw; the number of molars New World Mon. being the same in both. In consequence of these and other keys. - Family differences, the New ITorld monkeys, which do not range to Cebielce. the north of tropical America, are referred to a separate family group, under the name of Cebidce. These monkeys are further characterised by the absence both of cheek-ponches and of naked callosities on the buttocks, while the tail, when long, is frequently, although by no means invariably, prehensile. The thumb is quite incapable of being opposed to the other digits, but all the finger's and toes have flattened nails. In the nose the partition between the two nostrils is very broad, so that the nostrils themselves are widely separated, and frequently direrge to a great extent frum each other. The upper molar teeth have very short crowns, with the four tubercles arranged obliquely, and the external surfaces of the outer pair flattened and fluted, while the imner ones are distinctly crescent-shaped.

So different, incleed, are the American monkeys-which attain their maximum development in the tropical forests of Brazil - from the Old World forms, that it is quite possible they may trace their origin to a totally independent source. They may be clivided into ten genera, some of which comprise a very large number of specific representatives.

The half-dozen species commonly called, from their lond nocturnal cries, howlers constitute a genus characterised by the massive, unwieldy body, the pyramidal head, long and somewhat dog-liko muzzle, the massiveness of the angle, or hinder part of the lower jaw, and a remarkable thickening of the throat due to

\section{The Howlers}

(Aloualla).

the enlargement of the so-called hyoid bones into a thin bony capsule of large size. It is owing to the development of this capsule that the howlers are enabled to utter the discordant yells with which they make night hideous to all travellers in the forests of Tropical America. All the species have a large beard and whiskers, but the colour of the hair is subject to great specitic variation. In the red howler (A. seniculus), for instance, the head, neck, linbs, and tail are dark chestnut-brown, and the back and sides of the 
body golden yellow; whereas in the black howler (A. nigra) the whole of the long hair is cleep black.

All the howlers are surly in disposition, and feed chiefly on fruits and leaves. When howling, two or three take up their position on the topmost branches of the forest trees, and commence their chorus. Mr. O. Salvin writes that their wonderful cry is certainly most striking, "and I have sometimes endeavoured to ascertain how far this cry may be heard. It has taken me an hour or more to thread the forest undergrowth from the time the cry first struck my ear to when, guided by the cry alune, I stood under the tree where the animals were. It would certainly not be over-estimating the distance to say two miles. When the suund came over the Lake of Yzabal unhindered by the trees, a leaguo would be more like the distance at which the cry may be heard."

Agreeing with the howlers (which form a sub-family by themselvos) in having the lower incisor teeth placed vertically, the capuchins,

Capuchins together with several allied genera, differ by the absence of (Cebus). "any inflation of the hyoid bone. In all the group the tail is long and prehensile; although in some species, when its tip is haired, instead of bare and sensitive, the grasping power of this organ is much less well marked than in the rest. The thumb may be either present or wanting.

The capuchins, or typical representatives of the entire fumily, are somewhat stoutly-built monkeys, with the limbs of moderate length, the fur not woolly, the thumb fully developed, and the lower surface of the extremity of the tail covered with hair. Although the various species of capuchins are extremely difficult to distinguish, about eighteen different kinds are now recognised by naturalists ; their range extending from Mexico to Paraguay. In constitution these monkeys are exceedingly hardy, and as they are easy to train, and gentle in disposition, they are more commonly carried about in England and other European countries by peripatetic organ-grinders than any other of their kindred. From its completely haired tip, the tail of the capuchins does not act so thoroughly as a fifth hand as it does in the spider-monkeys. The white-throated capuchin (Cebus hypoleucus) is a well-known representative of the genus.

Nearly allied to the eapuchins, the two species of woolly monkeys take thêir name

$\begin{array}{cl}\text { Woolly } & \text { from the peculiar texture of } \\ \text { Monkeys } & \text { their fur, which forms the } \\ \text { (Lagothrix). most characteristic feature of } & \text { the genus to which they be- }\end{array}$

long. In addition to this character, these

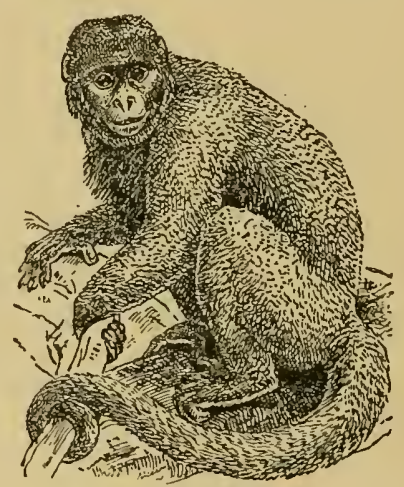

Fig. 12,-A Wooldy MoNkey (Lagothrix). monkeys are distinguished by the clumsy build of the body, the rounded head, the much flattened muzzle-in which the nostrils are circular, but not approximated-and by the naked lower surface of the tip of the tail. The two species are both inlubitants of the forests of Amazonia, the best known being Humboldt's woolly monkey (Lagothrix humboldti). 'The barrigudus, as these monkeys are called by the Brazilians, live exclusively on fruits, and are 
of larger size and less active habits than the capuchins. They suffer consicterably from the cold, and even at Bahia I have seen them on a wet day fall into a torpid endition, when they were relentlessly thrown into the sea by their captors. MIr. Wallace remarked that from their gentle clisposition they are "most frequently seen in confinement, and are great favuurites from their grave countenances, which resemble the human face more than those of any other monkeys, their quiet manners, and the great affection and docility they exhibit."

'The woolly spider-monkey (Brachyteles arachooides), which is now eunsidered to be the sole representative of its genus, is in many respects intermediate between the woolly monkeys and the true spidermonkeys, having the dense woolly pellage of the former, coupled with the long and slender limbs of the latter. The thumb is rudimental, and the nails of the other digits are compressed and pointed. These monkeys, which are con-

Woolly SpiderMonkey

(Brachyteles). fined to the dense forests of South-Eastern Brazil, from Cape san Roque to Rio Grande do Sul, appear to be very rare, and little is eonsequently linown of their habits.'

6. The last genus of this sub-family inclndes the half-seore species of true spider-monkeys, " constituting a genus distinguished from the preceling by the fur not being of a woolly nature, spider-rionkeys the complete absence of the thumb, and the slight compression of the nails. Both the tail and limbs are greatly clongated. These monkeys have a wide range, extending from Nexico to Paraguay; the variegated spicler-monkey (Atcles rariegulus) being one of the most familiar. ' In it the prehensile tail reaches its perfection. It is a remarkably sensitive organ, answering the purpose of a "fifth hand," being capable of use "for any purpose to which the hand could be applied," and for hooking out objects from places "where a hand eould not be inserted.". They wrap their tails about them to protect themselves from cold, to which they are very sensitive, and hold on by them to the branches of trees with such tenacity that they remain suspended after death. The prehensile part of the tail is naked and of extreme sensibility. The tail is also used to preserve balanee when walking erect, for which purpose it is thrown up and curled over. The appearance of these monkeys, as they leap from branch to branch in their native woods, swinging by their tails, and often lianging on to those of each other, mitil a living bridge is formed from tree to tree, is exceedingly picturesque. Although they lick the extreme agility of the Oriental gibbons,

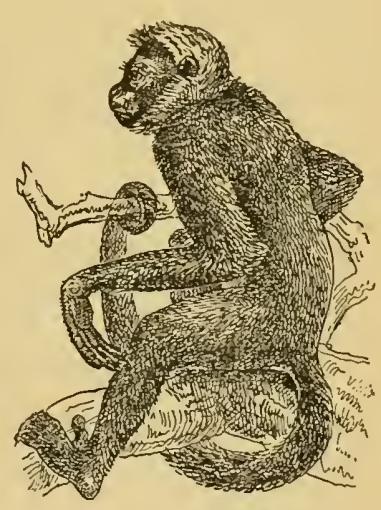

Fij. 13.-A SPIDER-MoNkEy (Lteles). the spider-monkeys are by far the most actire members of the family to which they belong. Mr. Belt writes that he has often seen two or threo togrether on the lower branches of the forest trees, "holding on to each other, and to the branch with their fore-feet and long tail, whilst their hindfeet hang down, all the time making threatening gestures and eries. Sume- 
times a female would be seen carrying a young one on its back, to which it clung with legs and tail, the mother making its way among the branches, and leaping from tree to tree, apparently but little encumbered by its baby."

The beautiful little squirrel-monkeys are the first representatives of a third sub-family of the Cebide, which, while agreeing with the last in the rertical position of the incisor teeth, and the normal conforma-

Squirrel-

Monkeys (Chrysothrix). tion of the hyoid bone, are distinguished by the tail, which is long, having no power of prehension. In all the thumb is well developerl. From the allied forms the squirrelmonkeys, or saimiris, are specially distinguished by the soft, close, and erect fur, and the backward production of the head ; the face being relatively small, the eyes very large and set close together, the partition between the nostrils very wide, and the rather long tail covered with comparatively short hair. There are four species of the genus, of which the common squirrel-monkey (Chrysothix scinreus) is the type. These monkeys are some of the commonest of their tribe in America, where they range from Costa Rica to Brizil and Bolivia. In habits they are diumal, feeding chiefly upon insects, although they will also lill and eat the smaller birds.

The eleven representatives of this genus form a group which is to a considerable extent intermediate between the squirrel-monkeys and the under-mentioned douroucoulis. From the former the small Titis head is distinguished by not being produced backwards, and (Callithrix). the small size of the eyes; but the nostrils are similar in the width of the partition by which they are separated, and the fur has the same close and soft texture. The tail is, however, bushy, and the canine teeth are relatively small, while the angle, or hinder extremity, of the lower jaw is expanded somewhat after the sane fashion as in tho howlers, although to a smaller degree. The titis range from Pauna to the southern limits of the great forests; a well-lnown species being the whitecollared titi (Callithrix torquatu). In habits, they are very similar to the squirrel-monkeys; insects, eggs, and small birds constituting their chief nutriment.

From both the preceding genera the small monkeys commonly known as douroucoulis are distinguished by their nocturnal habits and the great size of the eyes, which are only scparated from each other by a very

Douroucoulis narrow partition. The head is rounded, and the nostrils (Nyctipithecus). are placed closer together thin in either of the allied genera; the moderately long tail boing bushy, and the fur soft and close. In colour the eyes are yellowish, and they have a peculiar stare, communicating, in conjunction with their large size, a somewhat owl-like expression to the whole face. There are five species of the grenus, several of which, like the three-striped clouroucouli (Nyctipithecus trivirgatus), have three more or' less distinctly defined longitudinal dark stripes running down the forehead. The range of the douroucoulis extends from Nicaragua to the Amazon and Eastern Pern. During the daytime, these somewhat lemur-like monkeys remain snugly coiled away in the holes or among the branches of trees, and only issue forth at night in search of prey. When on the prowl, they give vent to loud howls or cat-like cries ; and their food includes insects, birds, and fruits. In constitution they are extremely delicate, only surviving cıpture for a brief period 
The last group of the family is formed by the uakari and sali monkeys, which constitute a sub-family distinguished from all the foregoing by the lower incisor teeth being inclined obliquely forward, somewhat after the manner of those of the lemurs, and separated by an interval from the cumines. The tail, which may be

Uakaris

(Uacaria). either long or short, is never prehensile, and the thumb is well developed. Usuilly the nostrils are widely separated, and the ears are large.

The liakaris, of which there are three species, each with a very small distributional area, are readily distinguished from all other Aneriean monkeys by the extreme shortness of the tail. The bald uakari (Uucuriec caleu) from the Ris Negro, and the reel uakiri (U. rubirumel, from the Upper Amazom, have a brilliant scarlet face, contrasting strongly with the long silky whito hair of the boily, whereas the black-faced species ( $U$. melunocephlutur) hias in dink countenanee. All are timid, gentle ereatures, of so clelicate a constitution that it is almost impossible to keep them in confinement.

The sakis, of which there are five species, are readily distinguished from the last by the long bushy tail and the thick beard adorning the chin. In the lower jaw the angle is expanded in a manner approaching that of the howlers. A funiliar type is the black saki (Pithccic satanus) of the Lower Amazonl;

Sakis (Pithecia).

and while in some species, like the hairy saki (P. monachus), long hair clothes the heid, body, and tail, in others this is confined to the region of the head. In habits these monkeys appear to be very similar to the vakaris.

The beautiful and delicate little creatures from Tropical America, commonly known as marmosets, form a family agreeing in many respects with the last, but distinguished by having only two pairs of molar teeth in each jaw, and also by the fingers and toes, with the exception of the shortened great-toe, terminating in carved compressed claws, instead of flattened nails. The long thumb lies parallel to the other digits, to which it is incapable of

The Marmosets.

-Family

Hapalide. being opposed, so that the forc-limb terminates in a paw rather than a hand. The skin of the face is naked, the ears are large and frequently surmounterl by a fringe of long hairs, and the long and bushy tail has no prehensile power. The family, which is represented by a large number of speeies, mostly inhabitants of the forests of Equatorial South Ameriea, has been divided into two generia according to the length of the lower canine teeth. Those forms in which these teeth are not longer than the incisor's are known as true marmosets (Hapule), whereas those in which the former considerably exceed the latter have been termed tamarins (Midas). Marmosets vary considerably in colour, some having the fur mottled with grey, brown, and black, whereas in others it has a more or less uniformly golden or silvery tint. MIarmosets are essentially forest animals, feeding chiefly on insects and

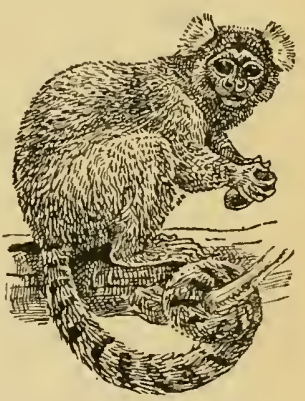

Fig. 14. A Mardoset (Hapale). fruit, and are so delicate that it is difficu't to keep them alive out of the tropics. They are exceedingly gentle in disposition, and soon become tame and affectionate. In their organisation they are the lowest of the monkey tribe. 
The typieal lemurs, which attain their maximum development in the islind of Madagasear, and are now found elsewhere only in Africa and the Oriental countries, are the first of three existing old World families,

The Typical

Lemurs. Family

Lemuricle, collectively forming the second great division of the Primates, technically known as the Lemuroidea. From the first subordinnl division, or Anthropoidea, the Lemuroids are distinguished by the following features. In the first place, their faces, instead of being more or less mobile and rounded, are long, fox-like, and quite devoid of expression ; but in this respect they are not very different from the marmosets. More important are certain differenees in the structure of the skull and the soft internal organs, but as these require a certain amount of anatomical knowledge on the part of the reader for their proper comprehension, they may be passed without further notice. A distinctive character of the group is to be found in the circumstance that the second toe in the hind-foot always terminates in a long curved elaw. The thumb and great-toe are invariably present, but the second or index finger of the fore-paw may be wanting. With the exception of the aberrint aye-aye and tarsiers, which respectively form a family by themselves, the middle pair of upper front or incisor teeth are separated from one another by an interval or gap, whereas in all the monkeys they are in contact.

In appearance the various kinds of lemurs differ remarkably from one another, some looking not unlike monkeys, while others are eharacterised by their very long and slender limbs, enormous eyes, and somewhat ghostly form. Whereas some are furnished with long tails, others are devoid of these appendages ; and the ring-tailed lemur of Miadagasear differs from the rest in its tail being ringed with black and white. This species is, moreover, an exception in that it lives among rocks, whereas all the others are arboreal in their habits. None of the living lemurs are of large size, the length of the head and body in the largest being only about two feet, and many are not larger than a rat. All are exeellent climbers, and the majority spend the day in sleep, either in the hole of a tree, in a nest, or rolled up in a ball and hanging to a bough. Their food comprises leaves, fruits, birds and their eggs, reptiles and insects, and, in one case, sugar-cane; and the majority rarely descend to the ground. Some of the larger Malagasy linds are, however, an exception in this respect, as well as in their diurnal habits, and they may at times be seen jumping across the open spaces separating one wood fron another in search of fresh feeding-places. The strueture of their brains shews that lemurs are creatures of low organisation, and the existing forms are probably not very remotely related to the ancestral stock which gave rise both to monkeys and lemurs. Geologically the group is an ancient one; and the living forms attain their maximum development where they liave been free from the competition of the liurger and more highly organised Mammals.

In the typical lemurs constituting the family under consideration there are two pairs of upper incisor teeth separated from one another by at gap in the middle line; while there are three pairs of lower incisor's inclined almost horizontally forwards. There are three pairs of molars in each jaw, but the premolars may be either two or three on each side, and in the lower jaw the first of these teeth assumes a tusk-like form, and thus plings the part of a canine. The family may be sub-divided into four sub-families, most of which contain a considerable number of genera.

The first and highest sub-family, which is restricted to MIadiagascar and 
contains the largest existing representatives of the group, is characterised by possessing thirty teeth in the arluli, by the length of the hind-limbs, the normal structure of the ankle-joint, the large size of the opposable great-toe, and the union of the other toes by a web which extends as far as the end of their first

Endrina

(Inctris). joints. In the female two teats are on the breast.

The endrina (Iulris brexicumlata), which is the sole representative of its genus, is the largest of the living lemurs, measuring about two feet in length. It may be easily recognised by its rudimental tail, large ears, and moderately elongated muzzle ; its coloration being usually black with whitish spots and patches; but in some cases almost or entirely white. Like the sifakas, this lemur is diumal in its habits.

Nearly allied to the last are the three species of sifakas, easily recognised by the long tail, the ratier short muzzle, and the partial concealument of the ears by the fur. The species are extremely variable in coloration, and while some inhabit the dense forests on the eastern sile of Madagascar, others frequent

Sifakas

(Propithecus). the sparsely wooded, mid tracks on the west. Writing of the habits of the sifilias, Mr. Foster observes that "they live in companies of six or eight, and are very gentle and inoffensive animals, wearing always a most melanchuly expression, and, as a rule, being morose, inactive, and more silent than other lemurs. They rarely live long in captivity. In their native state they are most alert in the morning and evening, as during the heat of the day tiney conceal themselves amid the foliage of the trees. When asleep or in repose, the liead is dropped on the ehest and buried beneath the arms, the tail rolled up on itself and disposed between the hind-legs. The sifakas live exclusively on vegetable substances-leaves, fruits, and flowers-their diet not beingr varied, as in the sther groups, by small birds, eggs, or insects. Their life is almost entirely arboreal, for which the muscles of their hands and feet, as well as the parachute-like fold of skin between their arms and bodies, and their peculiarly look-like fingers are most fitted. The young one is carried about by its mother on her back, its hands grasping her arm-pits tightly. The sifakas are held in great veneration or fear by the natives of Madagiscar, and are never intentionally killed by them."

The third and last generic representation of the sub-family is the woolly avahi (Arahis lanigera), distinguished from the last by the greater length of the tail, the short muzzle, and the total concealment of the ear's by the fur, which is of a soft,

Avahi woolly nature.

The second sub-family of the Lemuride, which is likewise confined to Maclagascar and the Comoro Islands, is typically represented by the true lemms. It is distinguished from the last by the presence of 36 teeth in the adult, the shorter relative length of the hind-limbs, and the free lind-toes; all the former having long tails. As a genus the true lemurs are characterised by the

True Lemurs

(Lemur). elongated muzzle, the conspicnous, tufted ears, and the separation of the upper incisor teeth both from one amother and from the canines; the two teats of the female being situated on the breast. The genus contains eight species, among which the ring-tailed lemur (Lemur cattu) is peculiar on account of the charneter from which it takes its name, and likewise from its dwelling among rocks instead of in trees. Strictly noc- 
turnal in habits, these lemurs feed on a mixed diet; and the females carry their offspring singly transversely across the lower part of their bodies.

The two species of gentle lemurs are separated from the last on account of their short, truncated muzzle, small and hairy ears, the small size of the t:jper incisur teeth, which

Gentle Lemur are in contact with one (Hapalemur). another, and with the canine on each side, and likewise by the presence of four teats on the breast of the female.

A third seneric group, with several species, is separated on account of the small size or absence of the upper incisor Sportive Lemur teetl, the bald ears, and the (Lepidolemur). more elongated muzzle; the females having four teeth. One species (Lepidolemur caniccps) is by some referred to a genus apart, under the name of Mixocebus.

The galagos, which are confined to the forests of the wamer parts of Africa, are the typical representatives

Galagos

(Galago). of a third sub-family, readily distinguished from the fore-

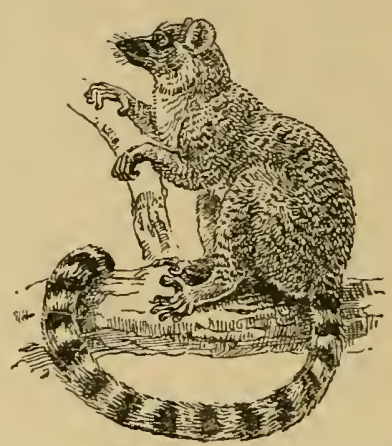

Fig. 15.-Th: Risc-Tatled LeMur (Lemur cutla.) going by the great elongation of two of the bones of the ankle-joint. The galagos themselves are characterised by the large naked ears being capable of folding at the will of their owner; the long tail being generally bushy, and the females having two teats on the breast and two on the abclomen.

Galagos vary in size from that of a rat to that of a small cat. In habits they are nocturnal and omnirorous; and when they descend to the ground, their progression is by hops, for which the structure of their hind-limbs is specially adapted. T'Te Senegal galago (Galago senegralensis), which goes about the forest either singly or in pairs, makes a nest in the fork of a tree, and in the daytime either retires to that resort, or reposes on a branch, with its tail folded across its body and round its neck; always being unwilling to move, and staring with its great cyes at passing travellers.

The mouse-lemurs, which by nany writers are divided into the genera Chirogate, Microcebus, and Opolemur, although here all included under the former name, are the Malagasy representatives of the Mouse-Lemurs galagos, and include a large number of small-sized species. (Chirogale). From the galagos they may be distinguished by the large ears being liairy at the base, and incapable of folding. None of these lemurs exceed a rat in size, and several of the species pass the dry season in a state of torpor, which they are enabled to endure by previously accumulating a large store of fat at the root of the tail. Such sleeps usually take place in hollow trees, where the little animals carefully build a comfortable nest of grass and fallen leaves.

The remaining members of the Lemuride form a fourth sub-family, agreeing with the typical one in the number of the teeth, but distinguished by the second or index finger of the fore-paws being either very short or rucli- 
mental. While tho fore and hind-limbsare of nearly equal length, the anklejoint is not specially elongated, the thumb and great-toe diverge widely from tho other digits, and the tail is sloort or ruclimental. In the female there are only two teats, which are situited on the breist. So sreat is the divergence of the

Lorisis

(Nyclicebus

and Loris). great-toe that it is communly direeted backwards. None of these lemurs are found in Mradagatseir.

The lorisis, or slow lemurs, which are confined to the Oriental countries, and lave no externil tiil, but a perfect, although small, index finger, are divided into the two genera Nycticebus and Loris; the former being eharacterised by the inner pair of upper incisor teeth being consicleribly larger than the outer, and the comparitive stuntness of the limbs; whereis in the latter both pairs of iucisors are very small and of cqual length, and the limbs are very long and slender. The slow lorises, as the members of the dirst genus are called, range over tlie Malayan countries to Cochin-China, while the slender loris is confined to Southem India and Ceylon. Both types are small creatures, with very large eyes, slow in their movements, ommivorous in their diet, and purely noeturual.

In West Afica the lorisis are represented by two nearly allied animals lnown as pottos, in which the index finger is reduced to a mere tuberele without a nail ; the tail being sharp or rudimental. The larger of these is the true potto (Perodicticus potto), the awantibo ( $P$. colubrirensis) of Olel Calabar being a rather smaller and more delicately made animal, with the index finger and tail more rudimental than in the former. In their morements the pottos are even slower than the lurises.

The second family of the Lemuroids is constituted by the two or three species of tarsier, all of which are included in the single genus Tarsius, and lange from the Malayan countries to Celebes and the Philippines. Rather smaller than an ordinary squirrel, the tarsiers may be reeognised by their enomous eyes and ears, long, thin, and tufted tail, and long, slender limbs, in which the ankle-joint is greatly lengthened. They have 34 teeth; and their dentition differs from that of the typical lemurs in that the first pair of upper incisor teetl are in contrist with one another in the middle line, and that the anterior lower premolar is not tusk-like. Tarsiers live on insects and lizarcls, in seareh of which they may be seen on moonlight nights hopping on the boughs of trees in a curiously frog-like manner.

The last of the existing lemurs is the remarkable aye-aye (Chiromys madurnscriensis) of Madagascar, which likewise constitutes a family by itself. It is about the size of a cat, and is dis-Aye-Aye.-Family tinguished from all the rest of its tribe by the structure of its

Tarsiers. Family

Tarsiide. teeth, which are singularly like those of the Rodents; each jaw liaving a single pair of ehisel-like incisors in front, followed after an interval by the blunt clieek-teeth. The fore-paws are very large, with all the fingers long and slender, but the middle, or third one, much more attenuated 
than the rest; and in the hind-foot all the digits except the great-too have curved elaws. The ears and eyes are large, the tail is bushy, and the two teats of the female are abdominal. The aye-aye feeds both upon sugar-cane

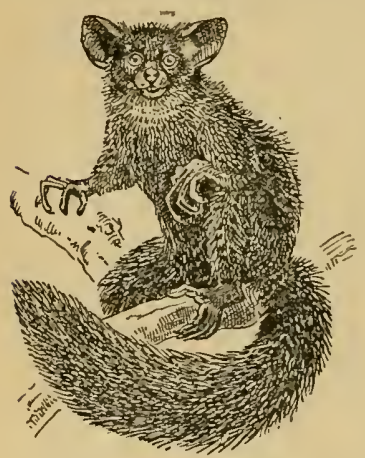

Fig. 17. -THF, AYE-AyE (Chiromys madagascariensis). and large wood-boring caterpillars; both its teeth and the slender third finger being cmployed to extraet the latter.

At the present day, the lemurs of Madagasear may be compared in point of size to small or medium-sized monkeys, the largest of them-the short-tailed encirina-not measuring much more than two fect in length. The investigation recently carried on by various explorers in the island have, however, revealed the fact that up to a very late period Madagascar was the home of a lemnr vastly exeeeding in size any of the existing representatives of the group, and which in this respeet may be compared to the great West African baboon known as the mandril. This giant lemur(Megaladapis, as it is called) is known by the somewhat imperfect skull and lower jaw, which are about three times the dimensions of those of the endrina. The interest of this animal is, however, by no means confined to its comparatively gigantic proportions, since while its skull and teeth eonform in their general structural features to those of the existing members of the group, they are specially modified in a mammer altogrether peculiar. The most strikGiant Extinct ing peculiarity connected with the skull is the extreme Lemur slenderness of the linder portion containing the brain in (Megaladapis). comparison with the great elongation of the face; the latter seeming out of all proportion to the former. In this respect, indeed, the skull presents a curious resemblance to the dog-faced baboons of Africa; as it also does in the strongly-marked ridges it bears for the attachment of powerful muscles. Such resemblanees, however, it is almost needless to observe, are merely superfieial, and must by no means be taken as inclicative of any genetic relationship between the two groups; and if a young skull were forthcoming, it is probable that we should find this much less unlike ordinary lemurs. Another pecnliarity of the giant lemur is to be found in the more lateral position and wider separation of the sockets of the eyes, which are also relatively smaller than in existing forms, thus indicating that the habits of the animal were less empletely nocturnal than those of the latter. The molar teeth of the upper jaw are eharacterised by the presence of only three tubercles on the crown, owing to the fusion of the two inner ones of the four-columned molars of ordinary lemurs ; a few of the smaller existing species having, however, teeth of a nearly similar type. Although in the type skull the front teeth are wanting, the form of their sockets shows that they must have been very similar in general form to those of living lemurs. In many respects the skull shows a marked resemblance to that of the European Tertiary lemur known as Adapis, a feature of especial interest in regard to the origin of the Mialagasy fauna from that of the Eocene Period in Europe.

The remains of the giant lemur were diseovered in the great marsh of Ambolisatra, and their slightly mineralised condition indieates their eom- 
paratively recent age. Indeel, there is but little doubt that the creature has been killed off within the human period, and in his history of Madagascar, published in 1658 , De Flacourt writes in the following terms of an animal then inhabiting the island, which, if not actually the giant lemur, would appear to have been a closely allied form. He writes that "the T'rétrétrétré or Tratratrutra, is an animal of the size of a two-year-old cali, with a rounded head and human-like face; both fore and hind feet being like those of a monkey. It has the hair wavy, the tail short, and ears like those of a man. It resembled the Tunuche described by Ambroise Paré. It was seen by the tank of Lipomini, in the neighbourhoud of which was its abode. It is a solitary creature, held in great terrur by the natives, who flee whenever it comes in sight." With the exception of the rounded head and the size (which is doubtless exaggerated), this description accords remarkably with the giant lemur, and when the head was covered with fur, it is probable that it would appear much less elungated than does the bare skull.

\section{ORDER II.-CHIROPTERA.}

\section{The Bats.}

THE second ordinal division of the Mammalia is that of the bats, or Chiroptera, which is the one most easily defined of all, seeing that in no other members of the class are the limbs similarly modified for the purposes of flight, while it is in these animals alone among the class that the power of true flight is found. By true flight is meant the capacity of sustaining the body in the air for an indefinite period by the shortness of the wings ; this being markedly different from the spurious thight of such ereatures as flying-foxes, whose progress through the air is due merely to a leap from a height aided by parachute-like expansions of the skin of the limbs and the sides of the body.

In the fore-limb or wing of a bat, the humerus or upper-arm bone is only moderately elongated, but in the fore-arm the single bone corresponding to the human radius has become greatly leugthened; and this lengthening is much more strongly marked in the case of the bones of the fingers, exclusive of the thumb, all of which assume the form of very long and slender rodis. The thumb, which terminates in a hooked claw used for climbing and suspension, remains free; but the other four fingers are comnected together by the delicate, naked, leathery membrane of the wing, and mostly have neither claws nor nails at the tip ; the longest of the whole five digits being the third or middle finger. The membrane of the wing, or, as it is often called, patagium, is continued up the arm and along the sides of the body to the hindlegs, down which it extends; while the two hind-legs are also connected by nnother extension, which may embrace a considerable portion of the tail. The membrane of the hind-legs is usually supported by a peculiar spur projecting from the foot; but the toes, which are of normal proportions, remain perfectly free from one another. Owing to the connection of the hind-limbs with the membrane of the wings, the knee-joint is directed backwards insteacl of forwards in the manner characteristic of all other terrestrial Mrmmals, and this structure renders the movements of these animals on the ground so awkward and shuftling. Bats always have very large and roomy chests, with 
well-dereloper collar-bones; but the hind-rquarters are feeble and weak. In many bats the delicate sense of tonch, by which they are enabled to avoid coming into collision with objeets when flying in the dark, appears to be mainly situated in the wing-membranes and in the delieate skin of the frequently large ears, the latter often having an inner earlet, or tragus. In a large number of species there are, howerer, expansions of the skin in the region of the nose ; these nose-leaves sometimes merely taking the form of a triangular single or double plate standing up abore the muzzle, whereas in other cases they assume a marked appearance, corering a greater portion of the face. These organs appear to be entirely sensory in function ; and it is quite possible that bats may possess some special sense of which we have no cognizance.

Ordinary bats have teeth very similar to those of the order Insectirora (the next in the scries), and there is no doubt that these animals are clerived from some early members of the latter gronp whieh have gradually become adapted for true flight; the transition having probably been effected by the derelopment of a parachute-like expansion of the skin of the sicles of the body and limbs. In habits all bats are noeturnal, and the majority are insectivorous, although a few have taken to blood-sucking. There is, however, one important group - the fruit-bats - which are entirely frngivorons, and in these the teeth have quite lost the cusped structure distinetive of orlinary bats, and have assumed an altogether peculiar eonformation. All the fruitbats are of comparatively large dimensions; and in this group are includecl the largest representatives of the entire order. A certain number of bits have acquired the habit of licking out the honey from the corollie of flowers, and for this purpose their tongues have become modified into elongated protrusile organs, frequently terminating in a bush-like expansion of delieate tilaments.

Although one lrat, at least, extends as far north as the Arctic circle, the members of the order obtain their maximum development in tropical and subtropical countries; and it is to such regions of the old World that the fruit-bats are confined, that group being entirely mknown in America.

The number of bats known to science is between four and fire lumdred, which are arranged in rather more than eighty genera, distributed under six family-groups. As bats are Aammals with which the ordinary student has but little to do, this large assemblage will be treated.much more briefly than most of the other orders; such genera as are mentioned not having separate paragraphs to themselves.

Popularly known by the highly inappropriate title of flying-foxes, the fruit-bats form not only a family by themselves, but likewise a subordinal group differing from a second one, in which are contained all Fruit-Bats. - the members of the order. From other bats this group of Family Ptero- Megachiroptera, as it is called, is ehiefly distinguished by the porlide. characters of the molar teeth, which have low, rounded crowns, elongated in the antern-posterior direction, and divided by a distinct longitudinal ridge; such teeth being far better adapted for frnit-eating than are the eusped molars of ordinary bats. From other bats, fruit-bats are also distinguished by the structure of the wing, in which there are three joints in the second or index finger, whereas in the other memhers of the order the number of such joints is reduced to two, or even one. Another peculiarity of the group is to be found in the complete cirele formed by the base of the conch of the ear; while the tail, if present, is 
short, and situated below the membrane hetween the hind-legs, with which it may have no connection. In all cases the ears are small, and unprovided with an innes tragus. Fruit-lats are confined to the warmer parts of the Old World.

The common fruit-bats, or fox-bats (Pteromes), forming the typical representatives of the family, are characterised by their long and fox-like faces, the presence of 34 teeth, the absence of a tail, and the thick coat of woolly fur on the neck; all being of large size. These bats inhabit the Oriental countries, Madagascar, New Guinea, and Australia, but are unknown in Africa. The long lines in which they wend their way to their feeding-grounds at evening are well known to all resiclenters in tropical conntries. From this genus the tailed fruit-bats (Xinthorpyint) may be distinguished by the presence of a short tail, which is connected with the membrane between the legs, as well as by their smaller size, duller colours, and the absence of any difference between the fur of the neck and that of the body. These bats are common to the Oriental countries, Syria, Africa, and Marlagiscar. In Africa south of the Sahara the place of the common fruit-bats is taken by the epauletted fruit-bats (Epomophorus), so called from

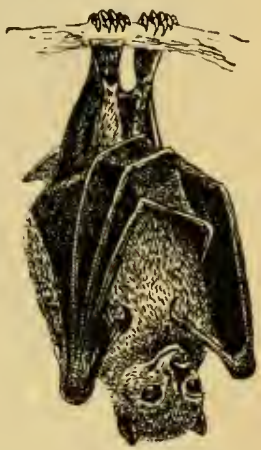

Fiy. is.-Fruit-Bat ('teropus). the tufts of long hair on the shoulders of the males. Their large and elongated heads have a bluntly conical or truncated muzzle, large, flabby, and cxtensive lips, and a tuft of white hair on the margin of each ear. While some are tailless, others have a short tail, unconnected with the leg-nembrane. The tufts of hair on the shoulders of the males arise from long pouches on the sides of the neck. These bats are most abuulant on the West Coast, where the single species of the allied genus Scotonycteris is also found.

Another genus is formed by the short-nosed fruit-bats (Cynopterus), ranging from India to the Philippine Islands, and distinguished by the short and rounded murgle, marked by a vertical groove, the reduction of the teeth to 32 or 30 , and their small size. Most of them have a short tail comnected with the membrane between the legs. Very curious are the two species of tube-nosed fruit-bats (Harpria), inhabiting the islands of Celebes, New Guinea, Nortly Australia, and New Ireland, and taking their name from the production of the nostrils into a pair of tubes reaching a short distance in advance of the blunt inuzzle. Even more interesting is the cusptoothed fruit-bat (Ptcrulopex) of the Solomon Islands, since the cusps in its molar teeth serve to indicate that all the fruit-bats liave been derived from insectivorous members of the order. Another group of the family, comprising seven genera, among which Corponycteris may be selected as an example, is distinguished by the great length of the extensile tongue, which terminates in a number of papills, and is probably employed for licking ont the soft contents of tropical fruits. Sare that one species is found in West Africa, these bats are confined to the Oriental and A ustralasian countries. They are all of comparatively small size, and have long and pointed faces, and the narrow molar teeth scarcely projecting above the surface of the gums.

This exclusively Old World family is the first group of the ordinary bats, or Microchiroptera, in which the molar teeth are usually surmounted by a number of sharip cusps, and the food generally consists of insects. The other leading 
characteristics by which the sub-order is distinguislied from the fruit-bats have been already noticed under the heading of the latter. As a family, the Rhinolophide are characterised by the presence of a wellHorse-shoe and developed nose-leaf surrounding the nostrils, which are Leaf-nosed Bats. plaeed in a hollow on the muzzle, as well as by the large size -Family of the ears, in which an inner tragus is wanting, and which Rhinolophide. are generally quite separate from one another at the base. The greater horse-shoe bat (Rhinolophus ferrum-equinum) is a familiar British representative of a very widely-spread genus, in which there are 32 teeth, and the nose-leaf consists of two portions, namely a horse-shoe-like moiety immediately over the nose, and a pointed one behind.

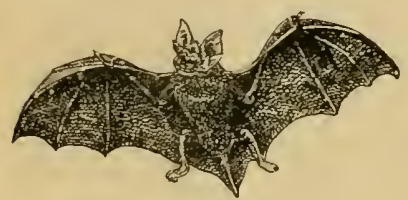

Fig. 19.-IORSE-SHOE BAT

(Rhinolophus ferrum-equinum).

In the leaf-nosed bats (Hiprosiderus), which have, likewise, a wide range, and are represented by a large number of speeies, the hincler portion of the nose-leaf is not pointed, and there is no median portion concealing the uostrils; while the teeth are reduced to 30 or 28 in number. There are 110 Europeall representatives of these bats, which range over Africa, Asia, and Australia. The most eurious member of the whole family is the flower-nosed bat (Authops ornatus) of the Solomon Islands, in which the whole front of the face, save the eyes and lips, is covered with a complex and ornate membrane, forming a complete mask to the comitenance.

The so-called false vampire bats (Megaderma) form one of two genera constituting a family distinguished from the last by the presence of a large inner tragus in the very long ears. In this genus, which is

False Vampire common to the Oriental countries and Africa, the muzzle is Bats.-Family surmounted by a rather tall nose-leaf; whereas in the allied Nycteride. genus $N$ ycteris this appendage is almost wanting, and the ears are not joined together to nearly such an extent as is the case in the former, where their union extends nearly half their height. With the exception of one Javan and Malayan species, and a second from Egypt, all the members of the second genus are confined to Africa south of the Sahara.

The typical bats form an extensive family, with a large number of genera and species, ranging over both the Eastern and Western Hemispheres; and it is to this family that all the British bats, with the exception Typical Bats. - of the two species of the genus Rhinolophus, and likewise Family Texper the majority of those inlabiting Europe generally, belong. tilionida. In this family the nose-leaf is wanting, so that the nostrils for'm simple crescentic or cireular apertures at the end of the muzzle; the comparatively long tail is inclucled in the membiane joining the hind-legs, and extends to its free edge, and the ear has a distinct inner tragus. In the upper jaw the ineisor teeth, of which there may be either one (1) two pairs, are of small size, and separated by a gap in the middle line; but, with one exception, there are three pairs of the correspondling lower teeth. Over one hundred and fifty speeies are known. The long-eared bats (Plecotus), of which there is one species from the northern portion of the Old World, and a second from North America, constitute a genus characterised by the great length of the delicate ears, which are united 
for a short distance above the forehead, and the presence of grooves, representing an incipient nose-leaf on the muzzle just behind the nostrils. When at rest, the long ear's ire folded lack, leaving the tragus alone standing upricht. In the allied genus (Symotus), of which the barbastelle is the British representative, there are also only two species, (me of which is European and the other. Asiatic. They may be easily distinguished from the loner-eared bats by the shortmess of the ears, which are united for some distance basilly, and likewise by the reduction in the number of the teeth from 36 to 34 .

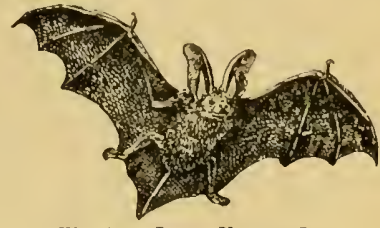

Fig. 20.-LON(H.EAREI Bat (Plecotus uuritus).

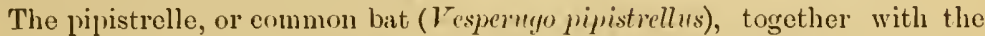
much larger noctule ( $V$.noctulu) and serotine ( $V$. serotinus), are British representatives of a third grenus, differing in several particulars from the two preceding. There are, for instance, no traces of grooves or foldings in the skin of the nose, and the small ears are completely separate from each other. The genus, which apparently contains a greater number of species than any other in the order, has an almost cosmopolitan distribution, but is one somewhat difficult to define, as some of its representatives approximate more or less to other genera; the number of teeth being either 30,34 , or 36 . The nore typical kinds may be reengnised by the relatively stout body, the broad, flattened head and blunt muzzle, and the broad, short, and triangular ears, in which the tragus is generally thickened and somewhat inelined outwards. As a rule, the hind-legs are short, and the membrane connecting them with the tail noarly always has an additional portion on the outer side of the spur on the heel. Omitting uotice of the genera Nycticejus and Chalinolobus, mention must be made of the Ameriean genus Atalitha, of which the hoary bat ( $A$. cinerea) of the United States is a familiar representative. All members of this genus have but a single pair of upper incisor teeth, and are further characterised by the membrane lietween the hind-legs being more or less hairy. Like other bats living in cold elimates, the hoary bat libernates during winter ; this species selecting cares, to which it resorts in large number's for the period of torpor. Many European bats prefer, however, church-towers and roofs, or outbuildings, while some select hollow trees, and it is a curious fact that in the case of certain species the males and females associate in separate colonies. An umusually warm day, even in mid-winter, will generally cause a certain number of bats to awake from slumber and issue forth, after which they again fall into the same torpor as before.

Among the numerous genera of this family, the tube-nosed bats (Harpyiocephulus), from hilly districts in the Oriental countries, Tibet and Japan, deserve special mention, on account of the romarkable similarity between the structure of their nostrils and those of the tube-nosed fruitbats. In the present genus the tubes into which the nostrils are prolonged are, however, shorter and much more divergent than in the lastnamed group.

Of the typical genus (Vespertilio), which is only second in point of numbers, there are four British representatives, among which Daubenton's bat ( $V$. dawbentoni) is one of the best known. Those bats differ from the members of the family already noticed in having upwards of 38 teeth, there being two pairs of incisors in the upper jaw ; and they are specially distinguished by the circum. 
stance that these latter are so fixed in the jaw as to diverge from one another, as well as by the cheek-teeth (that is to say premolars, and molars together) forming three pairs in each jaw. $A$ further distinctive feature is to be found in the minute size of the second upper premolar tooth, while the ear has a characteristic elongated oval form, and its inner tragus is remarkably narrow. The genus has a wide geographical distribution, being spread over the temperate and tropical regions of hoth hemispheres. A bat belonging to this genus ( $V$. welwitschi) from West Africa, closely allied to the British Bechstein's bat ( $\boldsymbol{V}$. bechsteini), is remarkable for the circumstance that the wing-memloranes arc coloured orange and black; the Indian $V$. hodysomi also having a very similar type of coloration. Another Indian bat with black and orange wings belongs to the genus Ceviroula, distinguished from Vespertilio by the upper incisor teeth being vertical instead of divergent. A fourth peculiarly coloured species is the West African Nycticejus albofuseus, belonging to a genus closely allied to Vespertyo, and having the outer portions of the wing-membranes dazzling white. In these abnormally coloured bats it appears that those in which black and orange obtain are in the habit of reposing anong the fruit and leaves of various tropical trees, in which an orange ground is frequently reliered by black spots.

Schreibar's' bat (Miniopterus schreibersi), rauging from Germany to Japan anct Australia, is the only member of a genus differing from all thuse hithertu noticed by the great elevation of the crown of the head above the face: the sime feature also characterises the South American and West Indiun bats forming the genus Natulus. Two very curious bats belonging to this family, and each forming a genus by itself, are remarkable for having the fect furnished with adhesive dises, by which they are enabled to climb smooth, polished surfaces. One of these is the tricolor bat (Thyroptere tricolor) of Brazil, in which the suckers form eircular dises on the lower surface of the thumb and the sole of the hind-foot; the second being the golden bat (Myxopola arvita) of Madagasear, in which the sucker on the thumb is in the form of a horse-shoe, while those on the feet are of smaller size. Both these bats are distinguished from all the other members of the fanily by having three joints to the third or middle finger of the wing, thereby resembling the undermentioned family Phyllostomatide.

In the preceding families of the Microchiroptera the tail is enclosed in the membrane comnecting the two hind-legs, but in the two families of this group still remaining for consideration, this appendage, when pre-

Free-tailed Bats. sent, generally either perforates the membrane in such a -Family manner that its free extremity appears on the upper extrem. Emballonuridu. ity of the latter, or is produced considerably beyond the free hinder margin of the same. Another feiture is that the inner, and frequently the only, pair of upper incisor teeth, are of large sizc and placed close together in the middle line; and a third cliaracteristic is to be found in the circumstance that when the wing is at rest, the first joint of the third finger is folded back upon the supporting metacarpal bone instead of being extended forwards in the same line. In two species, each representing a genus by itself, the last-mamed characteristic is, however, wanting. Only a single species of these two families is met with in Europe, the second fanily being exclusively American. In the members of the family $E$ mballonumbe there are but two joints in the third finger of the wing, and there is no distinct nose-leaf; but, as a rule, the ear is furnished with a small inner tragus, and there is but a single pair of upper incisor teeth, 
whieh are inclined towards one inother. An oblique truncation of the extremity of the snout causes the nostrils to project more or less in advance of the extremity of the lower jaw. These bats are nost abundant in the zone lying thirty degrees on each sicle of the Eyuator ; and among them are the only two indigenous Mammals foumd in New Koaland. Both in this and the next family only a small moportion of the more interesting types out of a very linge number of genera will he noticed in this place.

The typical representatives of the family are the sheath-tailed bats (Embullomma), ranging from the Malayan countries to the Philippine Islands, and also found from Madagascar to the Navigator group. They belong to in group of several genera in which the free extremity of the slender tail perforates the membrane between the legs, while the legs are relatively long, and the upper incisor teeth are weak ; two pairs of these teeth being present in this particular genus. Further distinctive characteristics of Emballonure are that there are 34 teeth, that the muzzle is more or less distinctly produced, the top of the head flat, the ears completely separate from each other, and their tragus somewhat oblong and expanded above. Tropical America is the home of the allied pouch-winged bats (Succopteryx), all of which are small-sizerl creatures, with only a single pair of upper incisor teetl, and a peculiar glindular pouch on the under side of the wing in the neighbourhood of the elbow-joint. 'These pouches, which are rudimental in the fenales, appear to have a sexual function, and in one species a white frill of skin protrudes from the aperture of each.

The tomb-bats (Taphozons) form another large genus, with representatives in Africa, the Oriental countries, and Australia, and differ from other nembers of the gromp in liaving only two pairs of lower incisor teeth, and also in the shedding of the single upper pair in the adult condition. The males, and in some cases also the females, of many species have glandular pouches beneath the chin; and some forms whieh hibernate for a long period accumulate large deposits of fat about the root of the tail before retiring for their torpor. The typical representative of the genus is found in large numbers in the ancient tombs of Esypt.

The two species of white bats (Diclidurus) from Tropical America are worthy of notice, on account of the yellowish or creany-white colour of the tips of the fur. Closely allied to the tomb-bats, they differ in having three pairs of lower incisor teeth, while they are distinguished from all other bats by the presence of a pouch on the under surface of the membrane between the hind-legs. Two other bats from the same region, known as the hare-lipped bats (Noctilio), take their name from the curious resemblance of their folded upper lips to those of the Rodents, while one species is remarkable on account of its diet, which consists mainly, if not exclusively, of small fish. Another peculiar' nember of the sime sub-family is the long-tailed bat (Rhinopoma microphyllum), ranging from North-Eastern Africa through India to Burma, and is easily recognised by the very long, whip-like tail, which projects far beyond the hinder margin of the extremely short membrane joining the hind-legs.

The mastiff-bats (Molossus), so named on account of their rery broad and wide-mouthed muzzles, are the first representatives of a second sub-family of the Emballonuride characterised by the thickness of the tail, which, save in one species, is produced a considerable distance beyond the free margin of the membrane joining the legs. All have short, strong legs, very broad feet, and callosities at the base of the thumbs, while there is only a single pair of incisor tecth in the upper jaw. The hind-feet have no attachment to the wings, the 
membranes of which can be folded away between the arms and legs, while the membrane joining the hind-legs can be drawn upwards along the tail ; and it appears that all the nembers of the sub-family are better adapted for crawling than are any other bats. The mastiff-bats are confined to Tropical and SubTropical America, and generally have 26 or 28 teeth, with two pairs of lower incisors. The large ears, in which there is generally a small tragus, are united at their bases; the lips, in common with those of two allied genera, are very large, and often thrown into pouches; while the wings are remarkably long and narrow.

The large Malayan naked bat (Chiromeles torquatu) takes its name from the thick and puckered skin being almost entirely naked; and is further peculiar in that the large first hind-toe can be opposed to the other digits. But the most curious feature about the animal is the presence of a large pouch on the under surface of the body below the armpits, in which the young are carried during the period of suckling. The object of this special development is sufticiently apparent, since, owing to the absence of fur, the young would be quite unable to cling to the body of the parent in the usual bat fashion. The muzzle of this curious bat is remarkably long and pig-like; and the rather large ears are widely separated from one another. Although most abundant in Africa south of the Sahara, the wrinkled-lipped bats, constituting the genus Nyctinomus, are the most widely spread, and, at the same time, the most numerously represented group of the present sub-family, being found in India and Burma, China, Australia, New Guinen, Tropical America, and Madagascar; while a single species $(N$. cestoni) is found in Southern and Central Europe, where it is the sole representative of the entire family. Closely allied to the mastiff-bats, the members of the present genus may be distinguished by the gap dividing the upper incisor teeth in the middle line, and likewise by the greater development of the wrinkles on the full, fleshy lips.

The last member of the family that will be mentioned is the New Zealand bat (Mystacops triberculatus), distinguished by having three joints to the third finger of the wing, the first of which, when at rest, is folded back beneath the metacarpal bone, instead of above it, as in the other members of the family. Owing to a peculiarity in the structure of the wings, this species is better suited for crawling than any other bat. The other species of bat inhabiting New Zealand (Chalinolobus tuberculatus) belongs to a genus nearly allied to Vcsperngo, and is also found in Australin.

The great family of vampire-bats is exclusively confined to Tropical America and the West Indies, and bears nearly the same relation to the preceding family as is presented by the horse-shoe bats Vampire-Bats. - to the typical bats. In addition to the features common to Family Phyllo- the Emballonurida, all have three joints to the middle stomatida. or third finger of the wing, while there is eitlier a welldeveloped nose-leaf, or folds and warts are present on the chin. A distinct tragus in the moderately-sized ears will always serve to distinguish the numerous representatives of this family which have in noseleaf from the horse-shoe bats, without the necessity of comting the number of joints in the middle finger of the wing. Vanpire-bats are exceedingly numerous, both as regards genera and species, so that only a few of the former can be referred to here. All are strong flyers; but the various groups present great differences in the nature of their food, some devouring insects and fruits alike, while others are wholly frugivorous, and others again have taken to a blood sucking habit. 
In two small genera of the family (Chilonycteris and Mormops) the nuseleaf is wanting, and its place supplied by two or more lippets of skin hanging from beneath the skin. One of these chin-leafod bats ( $M$. bluinvillei) is remarkable for its bright orange fur, and likewise for the extremely fragile structure of bise whole head and hody. The harmless rampires (Trmpritus) belong to a group of grenera in which the tail, when present, perforates the membrane between the legs, while the nose-leaf is spearshaped. The largest is the great rampire ( $V$. spectrum), from Brazil, in which the expanse of wing is upwards of 28 inches ; the tail being wanting. Appinently these bats feed exclusively on fruits. Nearly allied are the three species of javelin-hats

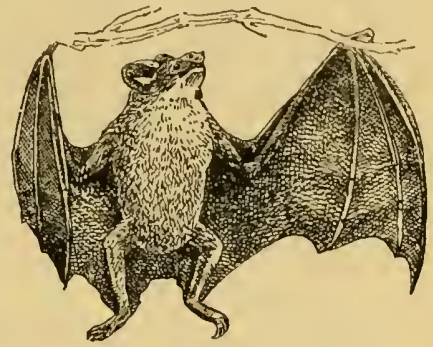

Fig. 21.-VAMpine-Bat (Desmodus rufus). (I'h!llostoma), which may be distinguished from the harmuless vampires by the shorter and broader form of the muzzle, as well as by the recluction in the number of the lower premular teeth from three to two pairs. There is some degree of doubt whether any of the javelin-bats are addicted to blood-sucking propensities.

More remarkable than any of the family are the long-tongued vampires, which are referred to sevoral genera, such as Glossophaga, Churmucteris, Phyllonycteris, etc., easily recognised by the narrow muzzle and the long, slender, extensile tongue, tipped at the extremity with sensile papillie, and capable of being protruded a long distance in advance of the tongue. Like the javelin-bats, these rampires have a sinall spear-shaped nose-leaf rising rertically from the muzzle immediately between the nostrils. The tongue appear's to be used both to scoop out the soft interior of fruits, and likewise to extract small insects from tubular flowers.

Another well-marked assemblage is formed by the short-nosed vampires, of which there are no less than nine genera, and among which Artibens and Stenoderma may be mentioned by name. All these bats, which are for the most part frugivorous in their diet, are distinguished by the extreme shortness of their muzzles, which are gencrally very wide, and are provided with a short nose-leaf ; the fore-part of the latter being in the form of a horse-shoe, and the hinder moiety spear-shaped. One of these species (Avtibens perspicillutus) is very common in the plantations of Jamaica, where it feeds on mangoes, bread-fruit, etc.

The last representatives of this extensive family are the blood-sucking rampires, of which one species alone constitutes the genus losmodus, while the latter represents another genus named Diphinlla. Both these bats are characterised by the short and conical form of the muzzle, which carries a small nosc-leaf, the shortness of the membrane between the hind-legrs, the absence of a tail, and the small number and peculiar structure of the tecth. In the first-named genus the total number of teeth is 20 , molars being wanting; but in the second it is 22 , owing to the presence of a pair of rudimentary molars in the upper jaw. Botl have a single pair of broad chisel-like incisor teeth in the upper jaw, which fill up the whole space between the tusks; and the two pairs of upper, and thrce pairs of lower premolars have sharl' eutting edges. In 
correlation with the nature of their diet, the stomach of these bats is narrowed and elongated into a tube-like organ. The common vampire (Desmodus rufus), ranging fiom Central America to the south of Brazil, measures about three inches in length, and has redclish-brown fur on the upper parts. The second species (Diphyllu ecuruluta) is rather smaller, and confined to Brazil. These bats attack animals by shaving away the upper layer of the skin from some bare part with their incisor teeth, and then suck up the blood as it oozes from the capillary vessels.

\section{ORDER IIT.-- INSECTIVUURA.}

\section{Ixsect-Eativit MLAmals.}

THE third order of Mammals comprises a large number of mostly small-sized insectivorous species, structurally nearly allied to the bats, but with the forelimbs of normal structure. With the exception of the tree-shrews and a few aquatic species, they are all more or less completely nocturnal in their habits; but the group as a whole is one by no means easy of detinition. As a rule, they have five toes to each foot, all of which are furnished with claws, and neither the thumb nor the $g$.eat toe is capable of being opposed to the other digits. In walking the whule sole of the foot is applied to the gromud, in what is terned the plantigrade manner. The crowns of their short uyper molar teeth are surmounted by a number of minute, sharp cusps, which may be arranged either in the form of a $\mathrm{W}$ or a $\mathrm{V}$; and the incisor teetl, of which there are not less than two pairs in the lower jaw, are never chisel-like, but the tirst pair is often larger than the others. The camines, or tusks, are very generally not distinctly larger than the other teeth; and there is never it pair of scissor-like cheek-teeth like those characterising the terrestrial Camivorn. Except in one or two species, perfect collar-bones are developed ; and the lobes of the brain are nearly smooth, thus indicating very low mental powers. Externally, Insectivores very generally have long slender and narrow snuuts, with the muzzle projecting consiclerably beyond the extremity of the lower jaw; and while many of them are coated with fur, which nay be liarsh and rough, others have a covering of spines, or spines mingled with fur.

As regards their geographical distribution, these Mammals present some very curious features. In the first place, they are totally wanting in South America, where their place is taken by the Marsupial opossums ; but they are represented by a peculiar family, with one genus, in the West Indian Islands. A more or less closely allied family occurs in Madagasear, where there are also other peculiar types; and the order is distributed over North America and all the great continents of the Old World, although absent from Australia and Papua. From geological evidence, compled with its abunclance in Madagascar, the order is evidently an ancient one; and its existing members have probably been enabled to survive either by their small size and nocturna] habits, their protective armour of spines, or from dwelling in countries where the larger Carnivora are either absent or but few in number, or by liaving taken to a subterranem mode of life. Whereas the majority of the Insectivorit are terrestrial, the fiying-lemurs are arboreal, and able to take flying leaps 
from tree to tree; the tree-shrews are also arboreal ; the moles and some of the shruws, on the other hand, are burrowers; and the desmans, certain shrews, and the Africin $t$ tamogale are ayuatic in their habits.

From all other members of the order the so-called flying-lemurs, or cobegos, are at once distinguished loy the presence of an expansion of the skin of the sides of the body connecting the fore and hinl-limbs, and also by the tres of both feet being webbed right up to the sharp and curved claws. The hind-legs are likewise connected together in a similar numner; the comecting skin involving the whole of the long tail. Another remarkable

The

Flying-Lemurs. - Family Galecpithecille. feature is to be fomd in the conformation of the incisor teeth, which in both jaws are thattened from bak to front, the upper ones being eusped, while the lower ones differ from those of all other Mammals in being of a comb-like strueture.

The cobegus, of which there are two species belonging to the single genus Goleopithecus, range from Tenasserim though the Malayan Peninsula and Islands to the Philippines and Siam. Unlike the ordinary nembers of the oreler to which they are assigned, they subsist mainly on leaves and fruits. During the day. time they hang head-downwarels in a bat-like manner from the boughs or stems of trees; but at dusk and during the night pass from tree to tree in long flying leaps, supported by the parachute, such leaps being at times as much as serenty yards in length. In size, the conmon Malayan species may be compared to an ordinary cat. Owing to their great structural differences from the other

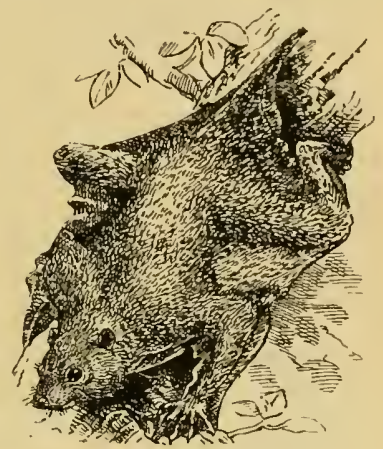

Fiy. 22.-THE FLYIXG-LeIUR (Guleopithecums volans). members of the urder, the cobegos are regarded as forning a sub-order by themselves, under the name of Dermoptera; all the other forms constituting in second subordinal group known as the Insectivoria Vera.

The tree-shrews, or tupaias, of the Oriental countries, are the first of a group of tive families characterised by having broad upper molin teeth, upon

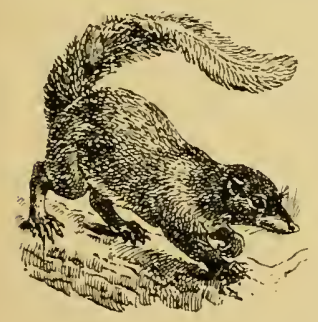

Fig. 23. -TREE-SHREW (Tupecia $\tan a$ ). the summits of which the numervus small cusps are arranged more or less in the shape of the letter W. In appearance the tree-

Tree-Shrews.Family Tupaiider. shrews, except as regards their long, pointed muzzles, are so like small squirrels, that they might easily be mistaken for those animals; and this resemblance, together with their arboreal labits, is one of the features by which they are most easily recognised. From the next family they may be distinguished by the socket of the eye being completely surromded by bone in the skull, and likewise lyy the metatirsus, or upper portion of the hind-foot, being of normal proportions. They are all animals of small size, with thick fur, short ears, and the long tail either bushy throughout or with a pen-like expansion near the end. Tree-shrews subsist on both insects and fruit, taking the latter in 
their fore-paws and sitting up to derour it in a squirrel-like manner. Although chiefly arboreal, they at times seek their food on the gromnd.

The typical tree-shrews (Tupaia), which range from Inclia to the Plilippines, and are represented by a large number of species, have the long tail bushy throughout, although the longer hairs are arranged on the upper and lateril surfaces, the uncler side being short-haired. Two species, of which one is from Borneo and the other from Siam, have been separated as Dendroygle, although this scarcely seems necessary. Very distinct is, however, the beautiful little pen-tailed shrew (Ptilucercus lovi) of Borneo and some of the adjacent islands, in which the exceeding long tail is evenly short-haired for the greater portion of its length, although towards its extremity it bears a double row of long hairs, arranged like the vanes of a feather. This little creature measures between five and six inches to the root of the tail, which is considerably longer than the head and body.

In Africa sonth of the Sahara the place of the tree-shrews is taken by the terrestrial jumping-shrews, one species of the typical genus ranging into Northern Africil. From the tree-shrews these Jumping-Shrews. animals differ not only by their terrestrial habits, but also -Family by the elongation of the metatirsal segment of the lind-foot, Macroscticlicke. which enables them to take the leaps from which they derive their name; and likewise by the bony rim of the socket of the eye being inccuplete behind. The tail also is not bushy. In the typical genus the snout is elongated so as to form a short proboscis, on which

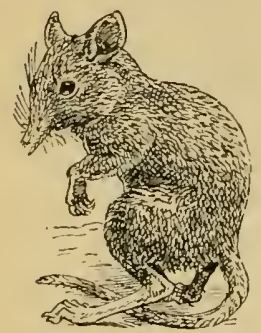

Fig. 24,-A Jumpino. Fig. 24, - A JuMpin(s:
SHREW (Macroscelides) account the name of elephant-shrew is applied to these creatures.

In the typical jumping-shrews (Macrosceides) the number of teeth is usually 42 , and there are five toes on the for -foot and generally the same number on the hind-foot; while the ears are large, and the tail is naked and rat-like. In me species (M. tetradactylus), from the Mozambique Coast, there are, however, but 40 teeth, while the number of toes on the hind-foot is reduced to four ; and on this account the animal is generically separated by some as Petrodomm.s. A very distinct genus is formed by the long-nosed jumping-shrews (Rhynchocyon) from the East Coast of Africa, in which there are only 36 teeth, and but four toes to both the front and hindfeet. The hind-legs are also relatively shorter. Unlike the tree-shrews, the members of this family are nocturnal in their habits.

In the three remaining families of the group with the cusps on the upper molars arranged in the form of the letter W, the brain-carity is relatively smaller than in the two preceding families, and

Hedgehog Tribe. the union of the front portion of the lower part of the -Family pelvis in the mildle line of the body either shorter or Erinaceider. altogether wanting, while not only has the socket of the eye no complete bony ring, but even the postorbital process found in the jumping-shrews is totally absent. Although the hedgehogs themselves are ensily distinguished from the other nembers of the group by their spiny covering, this is not the case with their more rat-like allies the gymmuras ; and accordingly other characters have to be songht in order to define the family Erinaceide. In all save one species the teet are five-toed and furnished with claws adapted for dirgoing; while the 
first and second upper molar teeth have firo distinct cusps, the central one of which is minute and commected witl the two imner ones by oblique ridges. The family is confined to the Old World.

The hedgehogs (Brinaceus) are sufticiently distinguished by the coat of spines covering the upper surface and sicles of the body, and their power of rolling themselves up into a ball as a defence against attack, and are likewise such familiar animals, that but little in the way of description is necessary. The tail is extremely short; and the total number of teeth is 36 . Hedgeloogs are distributed over the creater part of Europe and portions of Africin and Asia, although unknown in the countries lying east of the Bay of Bengal, and likewise in Madagascar. The European species (E. exropreus) differs from all the others by the coarser nature of the fur between the spines, and by the upper canine tooth being inserted by one instead of two roots. In habits, all hedgehogs are nocturnal and omnivorous, their diet comprising insects, molluses, eggs, voles, fruits, and roots. In cold countries they libernate in a nest made of leares and grass, and well concealed among bushes.

The slirew-hedgehogs, which may be compared to lirge, coarsely-haired shrews, replace the hedgehogs in Burma and the Mality comntries. They differ from the latter by being covered with coarse hair insteack of spines, as well as in having 44 teeth. There are two species, of which Rattles's shrew-hedgehog (Gymmura rufflesi) is by far the commoner, and consiclerably the larger, measuring 12 or 14 inches to the root of the tail, which is long and rat-like. The smaller shrew-liedgehog (Hylomys suillus), on the other hand, measures less than 5 inches, with a tail of only an inch in length, and has the third upper premolar tooth much smaller than in the first species. The range of both is nearly co-extensive.

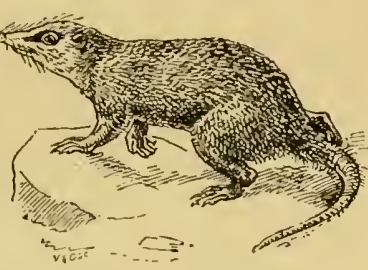

Fig. 25.-SHREW-HEDGEHOr: (Gymmuru rafllesi).

The numerous representatives of this extensive family are mouse-like or rat-like creatures, with soft, short fur, long and pointed suouts, rounded ears, closely pressed to the sides of the head, and a very peculiar type of dentition. From ordinary rats and mice they may be distinguished by their typically inseetivorous snouts; but it is remarkable that a peculiar rat recently discovered in the Philippines is curiously like a shrew in this respect, although it retains the characteristic rodent incisor teeth, which are, however, reduced to an exceedingly small size. As regards their dentition, shrews are specially characterised by the first pair of upper incisor teeth being long and generally sickle-shaped, with a more or less distinct projecting basal cusp on the hinder border, while those of the lower jaw are long, and prujecting forwards, in some cases with an upward curve at the tip. With the exception of ole African species, there are only six pairs of lower teeth. A peeuliarity of the skull of the shrews is the absence of the bony zygomatic arch ruming beneath the socket of the eye, although the same deficiency is found in one species of hedgehog. The upper molars of the shrews lack the fifth cusp found in the first two of these teeth in the hedgehogs.

The shrews are not only more numerous in genera and species than any other family of the order to which they belong, but have likewise a mucil wider geographical distribution, being found over the greater part of Europe. 
as well as in the temperate and tropical portions of Asia and North Ameriea, and also in Africa, although they are represented in Madagascar only by a single species, which is not improbably introduced. Although the majority of the shrews are terrestrial and nocturnal in their habits, a few lave taken to an aquatic mode of, life. They are all very shy and retiring, which is probably their ehief protection ; and their food is entirely composed of inseets, worms, molluses, and such like. Many shrews exhale a strong, musky oclour; and at certain times of the year many of these animals are found lying dead in the open, the cause of this mortality not being at present clearly asecrtained. Although it may seem a trivial eharacter, the eircumstance of the teeth being stained reddish-brown, or simply white, serves to divide the shrews into two groups.

The typical shrews, or those forming the grenus Sorex, belnng to the group with reclchish teeth, anci are specially eharacterised by having 32 teeth, the ear well-developed, and the long tail covererl with hairs of equal or nearly equal length. The range of the genus ineludes North America, Europe, and Asia north of the Himalaya; its British representatives being the eommon slurew (S. avanens) and the lesser shrew ( $S$. pygmuns). Although shrews hibernate, specimens have been occasionally seen rumning over the snow in micl-winter. The Oriental shrews (Soriculus), which are the only representatives of the red-toothed group in that region, are nearly allied ; but they have gencrally only 30 teeth, and the first upper inciscir lias an inner eusp. Nearly allied are two Mexican species constituting the genus Notiosorex, and elaracterised by having only 28 teeth and no inner eusp to the first upper incisor, the tail being also shorter. A larger Ameriean genus is Blarinc, which is mainly confined to the northern part of that eontinent, although a few forms clescend into Central America. Here the number of teeth varies from 30 to 32, while the ear is truncated above and the tail short, the other characters being the same as in Soriculus. The water-shrews (Cinssopus), which are the last representatives of the red-toothed seetion, have 30 teeth, small, non-truncated ears, the long tail fringed on its lower surface with elongated hairs, and the feet also fringed. The single species ( $C$ : foliens) is thoroughly aquatic, and ranges from England to the Altai Mountains.

Certain shrews from Africa enustituting the genus Mynsorex are the first representatives of the white-toothed section, and are specially characterised hy having well-developed cars, a long tail elothed with nearly or quite equal luairs, and either 30 or $: 2$ teeth, one minute species being unique in having seren pairs of lower teeth. More numerous are the well-known musk-shrews (Crociblure), differing from the last in having 28 or 30 teeth, and the long tail covered with a mixture of long and short hairs. These shrews lange from South and Central Europe to Africa and A sia, reaching as far east as Amurland, and being represented by nue species in Madagascar. Ont of some 80 species one of the best known is the Indian musk-shrew (r'. comlea), commonly known as the musk-lat, of which the odour is so strong that every article of fond is rendered nneatable by the mere passage orer it of the animal. The Kirghiz sluew (Jiplomesorlon pulchellus) alone represents a genus iffering from the last by the shorter tail, the hairy soles of the feet, and the presence of only 26 teeth. The two mole-shrews (Ammosorex), of which one is from Assam and the other from Tibet and China, are peculiar in being of fossorial habits, and may be distinguished by the alosence of the external ennch of the ear, the short tail, the naked soles of the scale-covered feet, and the velvety fur. The two remaining genera are arquatic, and thus occupy in this 
section a position similar to that held by the water-shrew in the red-toothed division of the family. Of these, the swimming shrews (Chimarrogale) are represented by one species from the Himalaya, the hills north of Burma, and the mountains of North Borneo, and by a second from Japan. 'They have 28 teeth, the long tail with a fringe of elongated hair hencath, small ears, and the toes free. On the other hand, the web-footed shrew (Ncctoyule elcranss) of 'Tibet, while agreeing with the last in the number of its teeth, differs in the absence of extermal ear-eonches, its webbed toes, and in the clevelopment of the pads on the soles of the hind-feet into adhesive suckers, the tail being longer than the body. Probably this shrew is more completely aquatic than any other member of the family. Its eyes are very minute, and the dark velvety fur of the upper parts displays a beautiful irideseent lustre.

Although the common mole is suttieiently distinet from a shrew, other forms so elosely comect the 'Talpide with the Soricide that internal eharaeters have to be relied on to distinguish the two families. The present family may, however, be differentiated from the last The Desmansand by the presence of a bony zygomatic arch in the skull, and Noles.-Family lilisewise by the development of a distinct auditory bullia in Talpidu. the same, as well as by the conformation of the teeth. The eyes are always small, and may be covered by the skin; the short ears are buried in the dense fur ; the fore-limbs are generally modified either for digging or swimming; there is no median union of the pubic portion of the pelvis on the under surface of the body; in the lower leg the tibia and fibula are welded into a single bone; and the first pair of incisor teeth in each jaw are of simple structure, and the lower pair do not project forwards. The range of the family includes the temperate portions of Europe, Asia, and North America, two moles only occurring south of the Himalaya. A few species are cursorial, and the desmans are aquatic, but the majority of the family are fossorial in their habits.

The two species of desmau (Myogale) are the typical representatives of a section of the family in whieh the collar.bones and humerus or upper aru bone, are moderately elongated, and the front paws have no additional sickle-shaped bone. As a genus, the desmans are speeially distinguished by the possession of 44 teeth, their webbed feet, the long, trunk-like snout, which projects far in advance of the upper lip, and the long scaly tail. The Russian desman (M. Moschita), which measures about 16 inches in length, has a compressed tail ; whereas in the much smaller Pyrenean species ( $M$ pyrenaica) the tail is eylindrical, and the snout relatively longer. Both inhabit the banks of rivers and lakes, are excellent swimmers, and live on water-insects and snails.

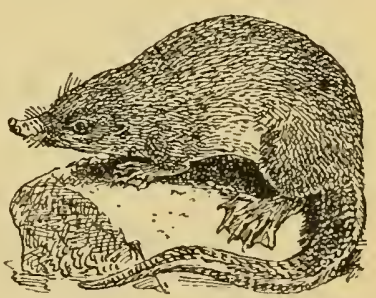

Fig. 26.-Russian Dessati (Myogale moschata).

The shrew-moles, of which there are two genera, form a commecting link between the moles and shrews. In Urotrichus, of whieh there is onc Japanese and one North American species (the latter being separated liy some as Neurotrichus), there are 36 teeth, and the broad fore-paws are adapted for digging; whereas in the single Tibetan species of Uropsilus there are 34 teeth, the fore-paws are narrow, and the tail is naked and scaly.

The North American web-fcoted moles (Scalops) bolong to the second 
division of the family, in which the collar-bones and humerus are rery short. and wide, and the fore-paws are furnished with an additional sickle-like bone next the thmmb. In this genus the tip of the snout is simple, the hind-foot webbed, the tail short and nearly naked, and the first upper incisor tooth longer than the second. Curiously enough, in spite of their webbed hindfeet, these animals are not aquatic, but subterranean in their habits, burrowing after the manner of the ordinary mole. The two North American hairytailed moles (Scapcemes) differ in having $4 t$ teeth, and the tail hairy. Having the sane number of teeth as the last, the star-nosed mole (Condyluracristutu) of North America is sufticiently distinguished by the curious star-like ring of appendages surrounding the extremity of the muzzle. The tail is nearly equal in length to the body ; and the front-paws are less powerful than in the true moles, and have no cleft in the bones of their terminal joints.

From all the American representations of the section the true moles (Tulpec) of the Old Workd may be at once clistinguished by the first pair of upper incisor teeth scarcely exceeding the second in size. As a rule, there are 44 teeth, and the fore-paws are characterised by their extraordinary width and power; the tail being very short, and in a Nepalese species ( 1 . micrurel) concealed by the fur. With the exception of the common mole (T. curopecu), the eyes are covered by a membrane; and in all they are functionally useless. The appearance and habits of the moles are too well knuwn to need description. The common species, although unknown in Ireland, ranges from England to Japan, and a second European species (T. ceca) is found to the south of the Alps. The other seven species are exclusively Asiatic, two only occurring to the south of the Himalaya, one of which inhabits Nepal and Assam. By some the Tibet:m musk-mole (T. moschat $r$ ) is generically separated as Scaptochirus. The only other member of the family is the yellow-tailed mole (Sccuptonyx fuscicaudatus) of Eastern Tibet, which differ's from the true moles in having only two pairs of lower incisor teeth, and also in the narrower fore-feet, thus approximating to the shrew-moles.

Two very remarkable Insectivores, the one from Western Africa, and the other from Madagascar, clifter from all the preceding, and agree with the following families in having narrow upper teeth, with their Family Pola- cusps arranged in the form of the letter $\mathrm{V}$; this section mogalicke. being apparently less specialised than the one in which they form a W. In the skull the zygomatic arch is wanting, and the auditory bulla is represented by a simple ring; collar-bones are wanting: and the pubic portion of the pelvis is united inferiorly only by ligament.

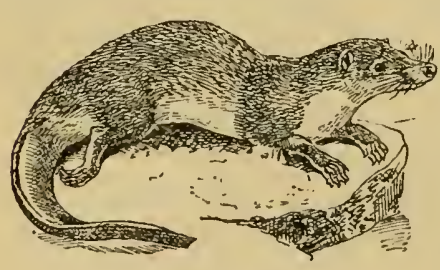

Fig. 27.-Potamogale vclox.

The African Potemogale is a thoroughly aquatic creature, measuring about two feet in length, with 40 teeth, a long cylindrical body, loug and compressed tail, short legs, unwebbed feet, and the nostrils with protecting valves. In colour it is dark brown above, with violet reflexions, and whitish below. Very different is the small mouse-like Gieogale of Madigascar, which has only 34 teeth, and also cliffers in having the lower encls of the tibia and fibula in the leg separate, although it is not known whether collar-bones are present. 
Two curions Insectirores, one inhabiting Cuba and the other Hayti, form the genus Nolenodon, which alone represents a family agreeing in the general characters of the teeth and skull with the last, but diftering in thit there is a short bony union between the pubic portion of the pelris; and also in thist the teats are situated on

Family solen. odontilu. the buttocks. These animals have a very long cylindrical snout, with the nostrils opening on its sides, a long naked tail, feet adapted for walking, and the fur long and coarse. They resemble Potamogale in liaving the second pair of lower ineisor teeth much larger than the first, but are peculiar in that the crowns of the former are deeply excavated. 'These animals prubably feed on thesh as well as on insects.

The tenrecs of Madagascar and the Comoro Islands, of which thero are fire genera and a considerahle number of species, constitute another closely allied family, mainly distinguished from the last by the teats being situated on the breast and abdomen. The true tenrec (Contetes ecrudutus), which is the largest member of the order and the sole member of its genus, is characterised by

The Tenrecs。

-Family

Centetide. the absence of a tail, and the possession of 40 teeth, among which there are four pairs of upper molars - the latter feature being almost unique among Mammals other than the Marsupials. The adult males differ from most Insectivores in possessing large tusks in both jaws; and while the young have long rows of white spines along the back, these disappear in the adult. The total length of a full-grown specimen varies from 12 to 16 inches. The number of young produced at a birth is very great, upwards of twenty-one having been recorded in one instance. Nearly allied are the two species of streaked tenrecs Fig. 28. -Texrec (Centetes ecaudatus). (Hemicentetes), distinguished by having three in place of two pairs of upper incisor teeth, and probably only three of upper molars, as well as by the smaller dimensions of the eanines, which scarcely exceel the incisors in size. In these animals, which may be compared in size to a mole, the rows of spines on the back are permanently retained. The small animals known as hedgehog-tenrees (Ericulus) take their title from their resemblance to miniature hedgehogs, although it is probable that they are incapable of rolling themselves into such a complete ball-like form as are the latter. The whole of the back and sides are protected by a coat of parti-coloured short spines ; and these animals are further distinguished by the possession of a short tail. While in one species ( $E$. setosus) the number of teeth is 36 , in the second ( $E$. telfuiri) it is reduced to 34 . By some the latter is made the type of a distinct genus, under the name of Echinops. The two mouselike long-tailed tenrecs, forming the genus Microgale, differ from all the foregoing in the absence of spines in the fur at all acyes, and likewise by the extraordinary length of the tail, which in one of the two is double that of the head and body. The number of teeth is 40 . Lastly, the two molelike rice-temrecs (Ory orictes), while agreeing with the preceding genus in the absence of spines among the fur, differ by the shortness of the tail and their burowing habits. Whereas in one species ( 0 . hora) the fore-foot has the usual five toes, in the other ( $O$. tetradactylus) the number is reduced to four, of which the three imner ones are armed with strong digging elaws. These animals do much harm to the rice crops in Mada- 
gascar by burrowing beneath the roots of the plants in search of insects and grubs.

The last family of the Insectivora is represented by the golden or Cape moles (Chrysochloris), which take their name from the iridescent golden,

Golden Moles. wreen, and purple metallic tints adorning the fur; and all of

-Family preceling families of the present section of the ordem the Chrysochloridce. golden moles are distinguished by the possession of a the golden moles are distinguished by the possession of a bony
zygomatic arch and auditory bulla in the skull; and their triangular molar teeth are remarkable for the height of their crowns. In form, these animals are shorter and thicker than ordinary moles, with the head deeper, and the muzzle much more blunt. The eyes are covered with

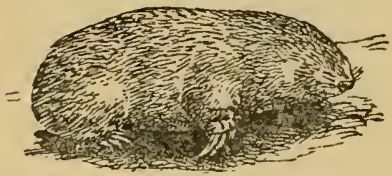

Fig. 29.-CAPE Golden Mole skin, and the ears completely buried in the fur. The fore-fect are modified into special digging instruments, and have but four toes, of which the middle pair are provicled with large and powerful triangular claws. Usually there are 40 teeth, although in some species the number is reduced to 36 , owing to the loss of the anterior premolars in each jaw. The golden moles burrow in much the same manmer as the European mole, but their runs are made so little below the surface that the earth is raised as a continuous ridge, and no hillocks are thrown up. Like the common mole, they feed almost exclusively on earthworms.

\section{ORDER IV.-CARNIVORA.}

\section{Flesh-Eating Mamiats.}

THIs great and important order of Mammals includes all the terrestrial beasts of prey, together with the aquatic seals and walruses. Although their carnivorous propensities form one of the most distinctive features of the majority of the members of the order, it must not be assumed that by any means all the Carnivora are exchsively flesh-eaters, many of the bears feeding largely on fruits and roots, while some of the smaller forms subsist largely on insects. Whether the typical Carnivora are more highly organised animals than the Primates, is a matter regarding which different views may be entertained; but it is certain that for their particular mode of life these animals have attained the highest development of which the Mammalian type is capable, and the beauty of form and coloration of the larger cats, as well as their extreme agility, cannot but draw forth the admiration of all. A striking feature of Carnivola in general is the wide geographical range of families, genera and species, and the large number of specitie types by which the former are represented; the order presenting in this respect a most marked contrast to the Insectivora, in which, as shown above, most of the families and genera have an exceedingly limited distribution, while the number of species contained in a genus is usually very small. The reason of this is obvious. Carnivora are enabled to obtain suitable prey in every 
part of tho globe, and there is, in consequence, practically no limit to tho range over which a spccies may extend itself; while being dominant forms, the number of species in a genus has niaturally multiplied to a great extent. As might be expected in such a case, the different species of many large genera display a maked tendency to variation, so that there is frequently much dithiculty in deciding as to what constitutes a species, and what a mere variety; this being remarkably exemplified among the great gromps of the cats and foxes.

Although certain extinct forms, of which no further mention will be made in this volume, tend to connect them with the Insectivora, the modern Carnivora form a tolerably well-clefined group, which would, however, be ensier of definition were the seals and walruses referred to a separate order. Throughout the group the number of toes is rery generally tive, and never falls below four on each foot; and in all eases these toes are armed with claws, which are usuilly curved and sliarp, and bear no resemblance to nails. Neither the equivilent of the thumb or the great toe of the Primates can be in any way opposed to the other digits. Very frecuently collar-bones are wanting, and in 110 instance are they complete; that is to say, they never comnect the blate-bone, or scapuli, with the bu'east-bone, as they do in the Primates and Inscetivora (except the Potamogalida). The teeth, which are divisible into the ordinary four series, are generally well-dereloped; the number of incisor's being usually three on each side of both jaws, and the outer pair, especially in the upuer jaw, is consiclerably longer than either of the other two. The canines almost invariably form large tusks; and the more anterior, or the whole of the cheek-teeth have compressed and pointed erowns, frequently consisting of one large central cone, supported by a smaller cusp in front and behincl. In the terrestrial Carnivora the last premolar in the upper, and the first molar in the lower jaw, are specially modified to bite against one mother with a scissor-like action, ind are accordingly spoken of as the carnassial, or sectorial teeth. These teeth attain their maximum specialisation and perfeotion among the cats: whereas in the bears and some of the raccoon family their sectorial character is much less marked, although it is still noticeable. On the other hind, in the seals and walruses all the chcek-teeth are nearly alike, and are generally cusped and sharp-pointed throughout the series, although blunt in the latter family. The modification of the limbs into flippers affords, however, an easy method of distinguishing the whole of the seal group from other Mammals. As a jule, when the number of cheek-teeth is reduced below the normal, the reduction takes place at the hinder, or molar end of the series, whereas in most other Mammals it is the anterior premolars that tend to disappear.

In the skull of all Carmivores the lower jaw is articulated by a transverselyextended sub-cylindrical condyle, clasped in front and behind by two overlapping processes from the shull itsclf, which are sometimes so prominent as (in the baclger) to prevent the dislocation of the lower jaw without fracturing the bone. Very generally, the socket of the eye is freely open behind, although in certinin cats and the mungooses it is surrounded by a complete bony ring. The zysomatic areh, so frequently absent in the Insectivora, is almost invariably well dereloped in the present order. A peculiarity in the wristjoint of all the Carnirora is that the two bones known as the scaphoid and lunar, forming the inner and upper elements of the upper row of this part of the skeleton in other MLammals, are here fused together to form but a 
single bone. Moreover, the central hone of the wrist, which is mresent in all the Primates, save man and some of the man-like apes in the Carnivora, is invariably lacking. From the Insectivora the Carnivora are further distinguished by the numerous convolutions on the surface of the large hemispheres of the brain.

In common with the three following fanilies of the terrestrial Carnivora, the cats are distingnished from the other members of the order by certain very important structural features connected with the hinder part of The Cat Tribe.- the base of the skull. In all these families that chamber of Family Felidre. the inner ear known as the auditory bulla forms a thin bladder-like expansion, divided (except in the hyrenas) into two compartments by a vertical bony partition; while the bony auditory meatus, or tube, leading into this bulla, is remarkable for its shortness. From their allies, existing cats are distinguished by the strong development of the canine teeth, by the molar teeth never exceeding one pair in both the upper and lower jaws, and also by the three pairs of incisors occupying the same transverse line, instead of the middle pair being pushed up above the level of the other two. The single upper molar is a flat functionless tooth, with its crown considerably wider than long, and placed on the immer side of the upper carnassial, which consists of three distinct lobes. The lower molar, or carnassial, is a highly specialised tooth, usually consisting solely of a two-lobed cutting blade, alchongh in a few species a sniall ledge on its hinder surface represents the large lieel characterising the same tooth in most other members of the order. There are three upper and two lower premolars; the last in the upper jaw being the carnassial, and the first small and functionless. The skull, in conformity with the shape of the head. is claracterised by the shortness of its facial portion and the great width of the zygomatic arches. The general form of the eats is too well known to need description; but it may be mentioned that the fur is generally thick and close, and that its markings usually talie the for'm either of dark transverse stripes, spots, rosettes, or dark-margined cloudings on a lighter ground. As a rule, the tail is long, cylindrical, and tapering; while it is very frequently marked with dark and light rings. In the extreme elongation of the body, a few cats, like the Sonth American eyra, approximate to the civet-tribe; but, in most cases, the body is of moderate length, and the limbs by no means remarkably short. All cats have five front and four hind toes, the first front toe being raised above the others. They walk on the tips of their toes, in the digitigrade mamner ; and in the great majority the claws are capable of complete retraction within hollow horny sheaths, by specially arranged muscles, and are thus always kept sharp and fit for nse. In the hunting-leopard this, however, is not the case, and that animal is accordingly referred to a genus apart from the one containing the whole of the other species. The tongne of cats is remarkable for the rough rasping papillie with which its upper surface is coated; and in the eye the pmpil, when contracted, frequently assumes the form of a vertical slit.

With the exception of New Guinea, Australia and New Zealand, cats have a. world-wide distribution, and inhabit all climates and stations, save the extreme north.

The typical cats (Felis), which include about forty-six different species, and have a distribution co-extensive with that of the family, are characterised by the claws being capable of withdrawal into the aforesaid protecting sheaths, and likewise by the presence of a distinct tubercle on the inner side of the upper carmassial tooth. Th: largest and most powerf ul members of the genus 


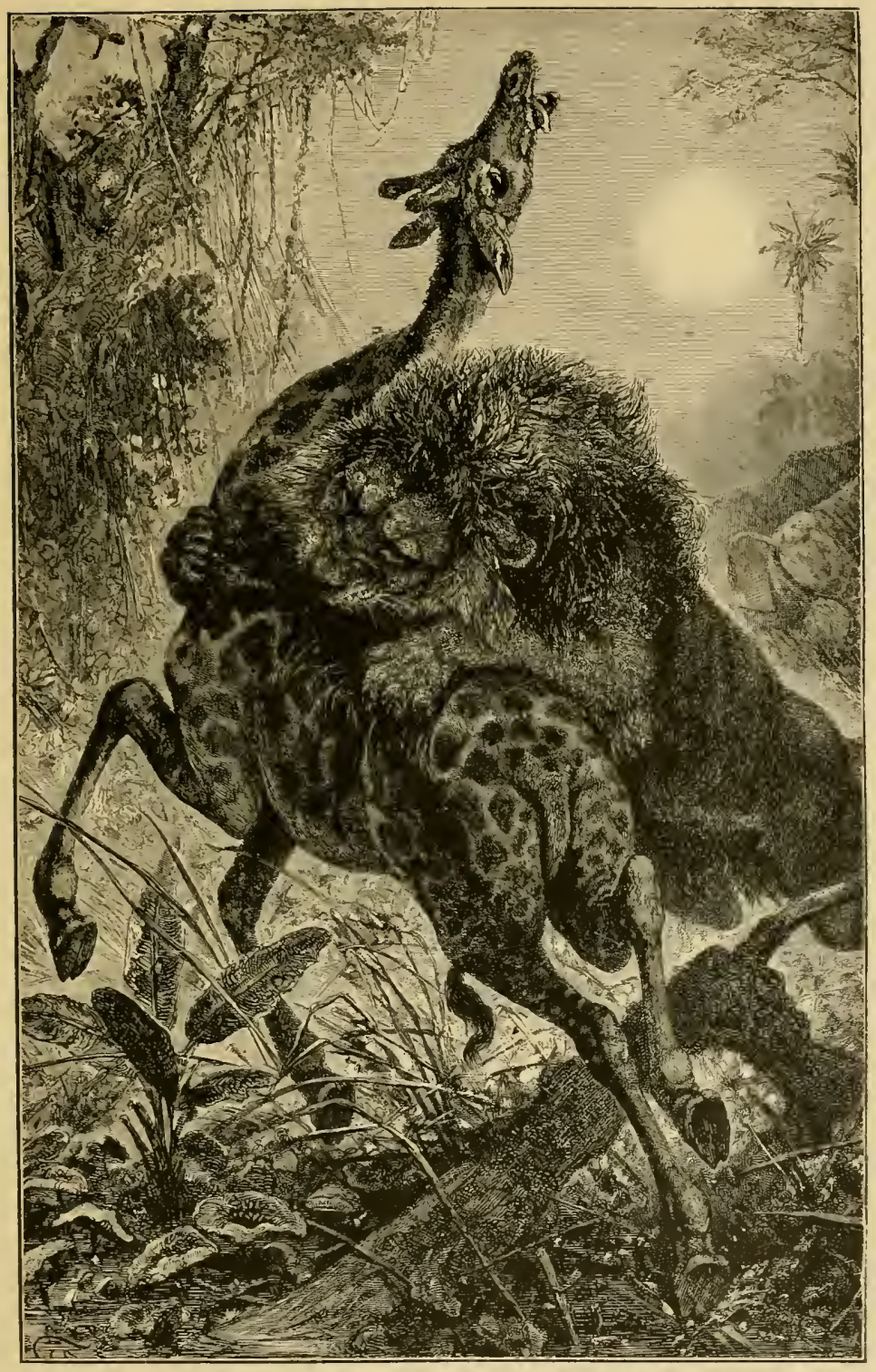



are the lion $(F$. leo), comnon to Africa, Persia, and India, althongh rapidly disalpearing from the latter country; the tiger ( $F$. tigris), ranging from India to Chinia and Siberia, although unknown in Ceylon; the leopand or panther ( $F$. pardus), also common to Asia and Africa ; the smow-leopard, or vunce ( $F$. rancia) of Central Asia; the jagruar ( $F$. oncu) of South and Central Amerjea ; and the puma ( $F$. (oncoulor), which has the widest range in latitude of any animal, extending from the sonth of Patagonia to the Gireat Slave Lake. Of these, the liom and puma are uniformly tawny colomed species, although showing traces of spots in the young state and sometimes in certain lights even in the adult; the male liom being distinguished from all other nembers of the genus by the lange mane (which may be dark coloured), covering the lead, neck, and shoulders, and the tuft at the tip of the tail, in which is a small horny elaw of unknown function. The tiger has dumble transverse black stripes on an orange or tawny gromul; while all the other species named are marked ly dark ruscttes or rings on a light gromd. In both the leopard and jaguar the central portion of the rusette is clarker than the general ground eolour of the fur; but whereas in the former the rosettes form simple lings, in the latter there is one or more solid black spots in the centre. On the head and limls the spots are solid, and the tail is ornamented with rings. In the ommee the fur is much longer than that of the ordinary leopard, and the Siberian variety of the tiger differs in the same manner from Indian examples. Nlthough the lion is a much noisier animal than the tiger, in power, size, and habits, the two are very similar. It would be sut of place to enter into any detailed discussion as to the dimensions of either lions or tigers, as this has been fully investigated in other works. In regard to tiger's, it may, however, be mentioned, that it is now grenerally adnitter that males do oeeasionally reach, or even slightly exceed 1: feet in total length, measured along the curves of the bodv in what is termed sportsman's style; one shot by Colonel Boileau in 1861 being slightly over 12 feet, while General Sir C. Reid's tiger, exhibited in Londion stuffed in 1862 , is recurded to have measured 12 feet 2 inches as it lay on the ground. Further information is required as to the maximum weights attained by male tiger's. Sandersur gives the weight of a well-grown male shot by hinself as 350 pounds; while Elliot has recorcied examples

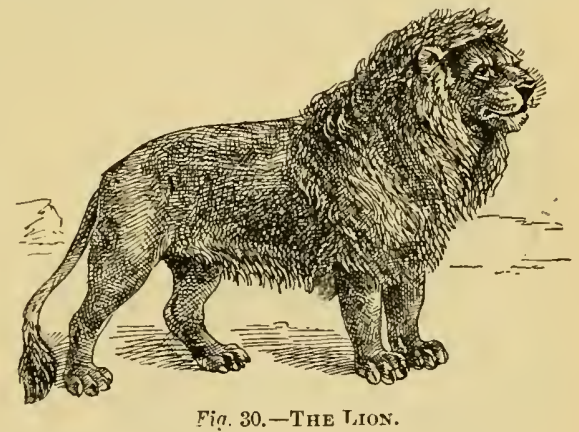
respectively weighing 362 and 380 pounds. The late Captain J. Fursyth has, however, estimated the weights of tiger's killed by himself at from 450 to 500 pounds, and these large weights have been confirmed of late years by Mr. Hornaday, who, in his work, "Two Years in the Jungle," records a tiger of 9 feet $11 \frac{1}{2}$ inches in length, which weighed upwards of 495 pounds ; while the Maharajal of Cuch Behar has given weights varying from 540 to 481 pounds, and a tiger killed by Mr. F. A. Shillingford, measuring 9 feet 10 inches, weighed 528 pounds. One killed by Sir Samuel Baker weighed 437 
pouncls after losing about a gallon of blood, so that its whole weight was probably about 447 pounds. Of course, much depends upon how fat the animal is at the time of its death. Sir S. Baker estimating that, while a very fine tiger in average condition will weigh some 440 pounds, the same animal, when unusually fat, will scale 500 pounds. If, however, a tiger just mnder 10) feet in length will weigh about 500 pounds, it may be safely assumed that an 11 or 12 feet example in similar condition will considerably exceed this weight, and it is, therefore, probable that the maximum weight attinined by the tiger has yet to be recorded. It is accordingly carnestly to be clesired that sportsmen will not only measure, but will likewise weigh any unusually liarge tigers they may liave the good fortune to kill.

Those who have the opportunity of seeing an attack by a tiger on large animals like buffalo or gamr, which he is unable to overtirow, will do good service if they can throw any light on the mode of attack in those instances where the prey is hamstrung. Mr. Blanford considers that in this occasional mode of attack the lianstringing is probably effected by a blow from the claws, and states that he has known two instunces where buffaloes were left hamstrung by tigers. This mole of attack being apparently very rare, will of coursc be seldo:n scen by European eyes, so that should it come under notice a record will be of extreme value.

As a rule, however, it is believed that a tiger seizes large animals by the fore-quarter's, throwing one paw over the shoulder, and attacking the throat with the jaws; a sudden upward wrench, during which the destroyer often springs to the opposite side of his victim, serving to dislocate the neck. On the other hand, some writers are of ppinion that the tiger first seizes the animal by the back of the neck. Thus Sir S. Baker writes that "the attack of a large tiger is terrific, and the effect may well be intagined of an amimal of such vast muscular proportions, weighing between 400 and 500 pounds, springing with great veloeity and exerting its momentum at the instant that it seizes a bullock by the meck. It is supposed by the natives that the tiger,

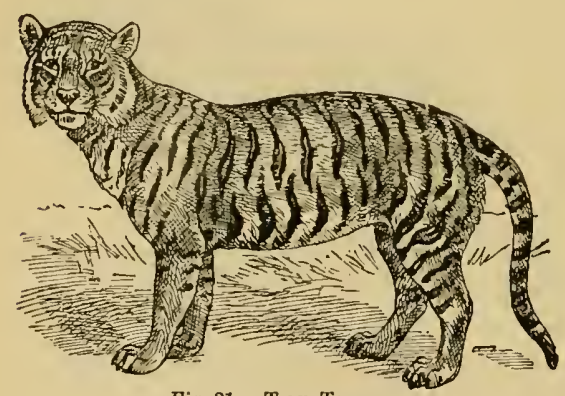

Fig. 31.-THE TIGEr. when well fastened upon the crest, by fixing its teeth in the back of the neck at the first. onset, continues its spring, so as to pass over the animal attacked. This wrenches the neck suddenly round, and as the animal struggles, the dislocation is easily effected ; the tiger then clianges the hold to underneatl the throat, and drags the body to some convenient retreat, where tlie meal may be commenced in security. With very few exceptions, the tiger breaks the neel of every animal it lislls."

Another observer, Mr. Mervyn Smith, who had the good fortune to see two buffaloes killed by a tiger, writes as follows :- "The animals, when first seen by me, were about a hundred yards off, and a little to my left front. There was a clistance of perhaps ten yalds between thom. I noticed the farthest buffalo suddenly stumble and fall, as $I$ thought, but it did nct rise again ; its 
mate looked up and gazed in the direction of its companion, and then turned its head as if to flee, but before it could do so a dark object rose out of the ground, as it were, and seized it by the throat, and flung it on its side. My horse hat also caught sight of the dark object, and instinct told him at once what it wis, for he galloped like mad, and never stopped till he got to the bungalow. It was fully an hour before I could assemble the villagers and return to the spot, where we found both buflaloes stone dead. In both cases the bite was on the uncler part of the throat, so as to close the windpipe and prevent the animal making any cry. The necks also appeared to hive been hroken by a sulden wrench of the head to one side, by the tremendously powerful fore-arm of the tiger. There appeared to liave been rery little strugrcle, and deatl must hare been almost instantaneous. Now, what I wonli particularly like to draw attention to, is the stealthy method of attack. There wis absolutely no noise-no roar, scarcely a rustling of the bushes when the second animal was struck down-and very little of the tiger to be seen. Had not my eyes been on the buffaloes at the time, I hardly think I should have been disturbed at all. In fact, I should not have known that the buffiloes had been killed by a tiger within a few yards of me. I scarcely saw the tiger at all-only his head, which appearer to rise up out of the ground and seize the second buffilo by the throat." A tiger almost invariably commences his meal on the hind-quarters; and neither this animal nor the lion are by any means averse to carrion. Both have a very similar roar, although that of the tiger is but rarely uttered; and both differ from the nujority of cats in their inability to climb trees. In common with cats in general, lions and tigers go about either singly, in pairs, or in small family parties, and although a few may, it is said, combine to drive their prey to one another, they never liunt in packs after the manner of dogs. The stealthy manner in which cats stalk, with their body elongated to its utmost extent and almost touching the ground, and the rigid tail occisionally twisting nervously, is well known to all.

Among the sinaller species of the genus, the clouded leopard ( $F$. ncbulosa) and the marbled cat ( $F$. marmorcta), of the Oriental countries, may be cited as excellent examples of the clouded type of coloration. The Bornean Bay cat $(F$. badic $)$ is one of the few uniformly-coloured species; a second being the South American eyra $(F$. ey/r $t)$, which is more remarkable on account of its elongated and weasel-like form. One of the most variable of all is the Oriental leopard-cat ( $F$. bengilensis). The African serval ( $F$. serval) is a longlegged and short-tailed species, in which the dark spots are solid; while the caffer cat ( $F$. coffin $(1)$ of the same country is generally regarded as the ancestral stock of the dlomestic cats of Europe, although there has probably been a considerable amount of erossing with the wild cat ( $F$. catus), which has led to the prevalence of the tabby type of coloration. In South America the very variable ocelot ( $F . p$ rordalis) exhibits a modification of the clouded type of coloration, while the tiger-cat $(F$. tigrina) is more distinctly spotted; the pampas cat slowing a striped pattern. The jumgle-cat ( $F$. chans), which is common to India and Afriea, together with certain allied Asiatic species, forms a transition from the more typical cats to the lynxes, the latter being characterised by the Fong pencils of hain's terminating the ears and the moderately long or short tail. In the caracal ( $F$. caracal), which is a uniformly. coloured species common to Iudia and Africa, and connecting the jungle-cat with the true lynxes, the tail is of considerable length; but in the latter group, all the members of which are confined to the Northern Hemisphere, it is very short, and the pellage is always spotted, at least during somo 
portion of the year. Whether the Canactian lynx (F. cancedensis) is distinct from the common lynx $(F$. lyikr) of Europe and Northern Asia is a moot point ; but the Spranish lynx ( $F$. premlinct) is a well-marked form.

The slender-bodied and long-limbed eat, known as the liunting-leopard (Cymalurus jubutus), is referred to in genus apart from the other members of

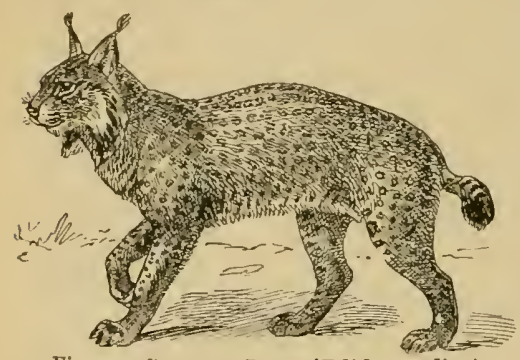

Fig. 32 -SPaxish Lxxx (Felidec pardina). the family on account of the elaws being only partially retractile, although their extremities are protected by sheaths; while a further point of distinction is to be found in the rudimental condition of the tuberele on the inner side of the upper carnassial tooth. The hunting-leopard, which is found both in India and $A$ frica, has the fur marked with solid black spots. In habits it differs somewhat from the true eats - two individuals huntiug together, and making a simultaneous sudden rush when their prey comes within striking distance. These animals are liept for liunting in India.

The nearest allies of the ents are the great tribe of eivets, palm-civets, mungooses, ete., all of which differ from the Felide in that the auditory bulla of the skull is marked by a transverse external con-

Civet Tribe. Family

Vicerride. striction, indicating the position of the internal bony septum, while the middle pair of lower teeth are raised above the leve] of the other two, as in all other land Carnirora. From the living Felicte the Tivervide are further distinguished by the more numerous series of teeth, the number of premolars varying from three to four on each side of the jaws; while there are generally two pairs of molars in each jaw, although occasionally these may be reduced to a single pair in the upper, and very rarely also in the lower jaw. The toes, which may be either digitigrade or plantigrade, are generally five in number on each foot, although they may be reduced to four in either the front or hind pair, or even in both. Considerable difference obtains in regard to the retractibility of the claws, and likewise as to the extent to which the sole of the hind-foot is elothed with hair. From ordinary cats eivets differ externally in the more elongated form of the body, the longer head and sharper muzzle, and the shorter legs ; although in these respects they are approached by the eyra. In eoloration they are generally striped, spotted, or blotehed; some of them having distinct longitudinal stripes, which are never seen in the eats. The family is strictly contined to the Old World, exelusive of Australia and Papua, and attains its miximum derelopment in Africa and the Oriental countries-Europe having only a comple of speeies in its southern districts. Madagascar is the home of several peculiar genera. Upwards of twenty-three distinct generic types are now recognised.

The most aberrant of all is the fossa (Cryptoprocte ferox) of Madagascar, which in the number and structure of its tecth approaches the eats, and is regarded by many authorities as entitled to constitute a

Fossa (Crypto. family by itself. In the form of the auditory bulla of the proctc). skivll this animal is somewlat intermediate between the civets and the mungooses; and each foot has five toes, with completely retractile elaws. There are four pairs of premolar teeth, of 
which the first is shed at an early period, and a single pan of molars, which are eat-like in form, the lower one laving only a small pusterior ledge, as in the lynxes, and no inmer eusp. The nose and npper lip) have a median grove ; and the feet are sub-plantigracle, the tarsus and metatarsus being naked. The fossa measures about five feet in total length, and is nearly miform sandy brown in colvur.

Torether with several allied genera, the true civets (Virera) are characterised by the eonical form of the auditory bulla of the skull, in which the hinder border is broal, trumcated, and not everted, while in front it is narrow and compressed, with the anterior chamber

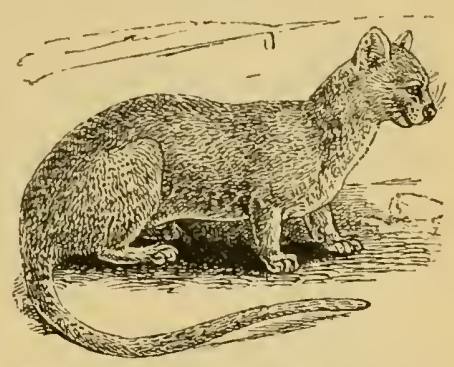

Fig 33. -The Fossa (Cryptoprocta ferox). small. Usually there are highly odoriferous glands in front of the serotum ; and the curved claws are generally more or less retractile. In form and number the teeth come very close to those of the dogs, there being always four pairs of premolars in eacle jaw. The blade of the upper carnassial tooth differs from that of the cats in consisting of only two lobes, and there is a well-developed tubercle on the innex side of the sime tuoth; while the lower carnassial is composed of an anterior cutting blade, and a long posterior tuberculated heel. In sliape, the upper molars are triangular; the first of the two being placed behind the carnassial tootl, and not on its inner side.

From the allied grenera the true civets are distinguished by the following cliaracters. A vertical groove divides the middle of the upper lip : the rather long tail is ringed dark and light; the feet are completely digitigrade, with the tarsus and metatarsus fully haired; and there are no tufts of hair on the ears. The upper molar teeth are two in number on each side; a black gorget ornaments the throat ; an elongated erest of erectile hairs usually rums down the back; and the whole hair is loose and long. The rather short and blunt claws can be only partially retracted; and the pupil of the eye contracts to a circular form. There are five species of eiret, one of which (Viverra circtta) is African, while the other four are Oriental. Four are of nearly equal size, and may be compared in this respeet to a large eat ; but the rasse ( $V$ iverru malaccensis), which differs somewhat in the structure of the skull from the four uthers, and is referred by many writers to a distinct genus, under the name of firericule, is a much smaller animal. An inhabitant of India, China, and the Malayan countries, it has been introduced into Madagascinr. All civets have comparatively short, stout, and rather compressed bodies, with the limbs proportionately longer than in the allied genera. Their coloration takes the form of black or blackish-brown streaks and blotehes on a greyish ground. Must of them are non-arboreal; and all are strongsmelling creatures, one of their secretions being used in perfumery. For the purpose of collecting the perfume, tame civets are kept in cages by the ILalays, and their secretion periodically seraped from the pouch with a wooden sproon. Daubenton's civet (Fusse dueubentemi) of Madagascar closely resembles the above-mentioned rasse in general characters, but differs from all the species of Viverre in the lresence of two small bare spots on the 
under surface of the metatarsus ; and the scent-poucin is apparently wanting The limbs are slender; and there is neither a dark line down the back, nol' a black gorget on the throat. Nearly allied to the civets are the six species of genets (Genettr), five of which are exclusively African, while the ordinary genet is common to Northern Africa, Southern Etrope, and Syria. From both Virerra and Fossa they may be distinguished by the presence of a bare, longitudinal strip along the lower surface of the metatarsus; a hairy space dividing this naked strip from the foot-pads. The absence of a scent-ponch forms a further distinction from Virerra, while the presence of a dark stripe down the back constitutes another difference from Fossa. All the genets are comparatively small animals, which live chiefly on the ground, where they prey upon small rodents, b.rds, and eggs. None have a black gorget on the throat, although there may be a short crest of erectile hairs down the back.

The benutifully-coloured Oriental viverroids known as linsangs (Linsanga) have the under surface of the tarsus and metatarsus as fully clothed with hair as in the true civets, but differ in possessing only a single pair of upper molar teeth. All the three species are very long-bodied and short-limbed animals, with the claws of the five-toed feet almost as retractile as in the cats; and the fur remarkably short, close, and erect, resembling, in fact, velvetpile. There are no scent-glands corresponding to those which yield the perfume in the civets. Upon a white or greyish-white ground-colour the fur is beautifully marked with black or dark brown patches, such patches form. ing either a small number of large, dark areas extending transversely across the body, or being broken up into smaller quadrangle spots. Dark longitudinal streaks, some of which may break up into spots, traverse the neek and shoulders, while there are smaller ones on the head; and the long cylindrical is marked with alternate clark and light rings of considerable length. When contracted, the pupil of the eye is circular. The skull and teeth are very similar to those of the genets, but the heel of the lower carnassial tooth is relatively smaller. In West Africa the linsangs are represented by the closely allied torcun poënsis, distinguished by liaving a naked strip on the under surface of the metatarsus, as in the genets. Linsangs are good climbers, feeding chiefly on small birds. They produce two litters in a year, griving birth to a pair of young at a time.

The two Malayan species of Hemigale differ from all the preceding menbers of the group except Fosse in the absence of distinct rings on the tail, except, at most, near the root; while they are further distinguished by the front of the auditory bulla of the skull being pointed instead of blunt. The carnassials are also relatively smaller and of a less trenchant type. A distinctive feature of the genus is the concentration of the pads of the hind-foot to form a naked space on the metatarsus, ending in a sharp point behind; the tarsus being fully haired. The hair on the back of the neck is peculiar in being directed forwards; and when there are any dark markings on the back they take the form of uninterrupted transverse bands. The claws on the five-toed feet are strongly curved; and the nose and upper lip, as in all the preceding genera, are grooved. Nunerically, the teeth are the same as in Viverra. Hard wicke's hemigale' $(H . h a r d w i c k e i)$, from the Malay Peninsula, Sumatra, and Borneo, measures about $15_{\frac{2}{2}}$ inches to the root of the tail, and has clark transverse bands on the back; whereas $H$. hosei, from the mountains of North Borneo, is uniformly dusky.

The palm-civets form three nearly allied genera, one of which is African, 
while the other two are Oriental. The two species of Africin palm-cirets (Namlinia), one of which is from the west, and the other from the east side of the continent, agree with Hemigule in the form of the naked area on the metatarsus, but differ in the incomplete ossifieation of the auditory bulla of the skull. Otherwise the genus is very similar to the true paim-eivets, the marking taking the form of spots, and the tail being ringed. 'The two species of small-touthed prim-civets (Arctogale), from Burma and the Malayan comntries, differ from the preceding gentis in the uniformly-eoloured tail; and are further distinguished by the relatively small size of the teeth, the narrow palate, which is produced far behind the last molar, and the ossification of the bulla of the skull. The alark markings take the form of longitudinal rows of stripes or spots on the back. Represented by ten species, the true palm-civets (Priadoxums) range throughout the Oriental countries from India to the Philippines and Celebes, and are distinguished from the last by their larger teeth, the less prolongation of the palate backwards, and the presence of it naked glandular area in front of the scrotum of the males, and in a similar position in the females. Like Arctoyrcle, they have the whole of the metiatarsus and a considerable portion of the tarsus bare, the hair extending in an evenly curved line across the hinder part of the lieel. The claws

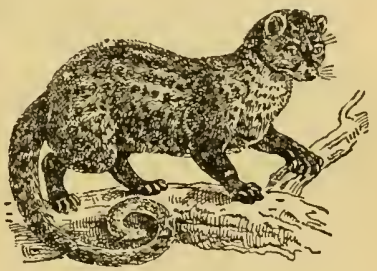

Fig. 24.-PALM-CIVET (Paradoxurus). of the five-tood feet are as curved and retractile as in the genets; the tail is loug and generally not ringed; the markings are usually in the form of elongated streaks, although more rarely spots, but some species are miformly coloured; and the pupil of the eye contracts to a rertical slit. The teeth are numerically the same as in Virerra, but the carnassials relatively shorter and less trenchant. In size these imimils may be compared to an ordinary cat. Palm-civets are essentially

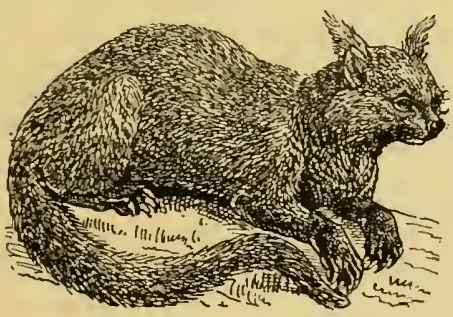

Fig. 35.-The Bintufong (Arctictis binturoug). nocturnal and arboreal creatures, feeding upon small birds, mammals, eggs, and lizards, and frequently taking up their abole among the leaves of paluntrees, From their habit of drinking the palm-juice, or toddy, from the vessels suspended from the trees for its reception, they are termed toddy-eats.

From all other members of the family, the binturong (Arctict is binturong), ranging from the Eastern Himalaya to the Malayan countries and Sian, differs by its prehensile tail and tufted ears, as well as by the tarsus and metatarsus of the plantigrade hind-feet being completely naked. The ears are short, the short claws only partially retractile, the liair very long, coarse, and loose, and the long tail very bushy; the general colour being black. The binturong, which may be compared in size to a cat, is a thoroughly nocturnal and arboreal creature. 
The last member of the sub-family is the peeuliar Bennett's eivet (Cynogale bennetti) from the Malay Peninsula, Sumatra, and Borneo, which is a grizzled srey animal, readily distinguished from all the foregoing by the absence of a groove on the nose and upper lip, the short tail, the partially webbed feet, and by the under surface of the metatarsus and tarsus being somewhat less naked. In size it may be compared to the larger civets, the length of the head and body being about 32 inches. Its habits are believed to be partially aquatic.

With the exception of the fossa, which forms a sub-family by itself, the whole of the foregoing member's of the family constitute the sub-family Viverine, elamaterised by the features noticed above.

The Mungoose The 11 ungooses, or ichmeumons, are the first representatives Group. of a second sub-family (Herpestince) presenting the following distinctive charaeters. The auditory bulla of the skull is pear-shaped, and its hinder margin distinctly averted, with the so-ealled paroceipital process not projecting beyond, but spread over it, and in the adult becoming merged in its hinder surface. The claws are loug and nonretractile : and there are no glauds in front of the scrotum. As a grenus, the mungooses may be c.istinguished from their allies by the presence of five toes to each foot, a vertical groove on the nose, and usually four pairs of premolar teeth; the molars being, as usual, two in each jaw. The muzzle is sharply pointed, the body long and weasel-like, the legs very short, the ears short and romded; and the tail generally long and tapering, with loose, elongated hair. 'The feet are plantigrade; rut there is much variation in the extent of the bare portion of the soles of the hind ones; in some species this area extending back to the heel, while in others the Jower surface of the tarsus is hairy. The coarse and loose fur has a peculiar speckled appearance, owing to the presence of dark and light rings on the hairs, and the tail is never ringed. The sharp eusps of the elieek-teetl are in marked contrast to the bluntly-cusped ones of the palm-cirets; and the still is remarkable for a sharp constriction behind the soekets of the eyes, and likewise for the cireumstance that the latter generally have a complete bony ring. Mungouses range over Africa and the Oriental comtries as far as the Plitippines, the Egyptian species ( $H$. ichneumon) entering Southern Europe. All these animals are terrestrial, and very active in their habits, generaliy living in holes. They are deadly enemies to rats and other Rodents, is they are to smakes. The most venomous serpents are attacked without hesitation, the immunity of the mungose from liarm in sueh encounters being apparently due to its extreme activity and watchfulness. From the majority of species of Herpestes, the Afriean small mungoose (Helogale parre) differs in having only three pairs of premolar teeth in each jaw ; the first of these heing approximated to the canine, and thus distinguishing the genus from the few species of Herpestes with a similar number of teeth, in all of which there is a gap between the eanine and the first tooth of the premolar series.

Africa is the home of several peculiar generic types of mungooses. First. there are the three species of four-toed mungooses (Bdeogale), distinguished hy having but four toes to each foot; the soles of the hind-feet being hairy. The South African pencilled mungoose (cymictis penicillutu) is the sole member of another genus with five front and four hind toes; but more easily defined by the presence of a hole in the centre of the peculiarly-shaped auditory bulla of the skull, the soles of the hind-feet being hairy. A third 
genus is represented by the large red Meller's mungoose (Thynchogale melleri)), easily distinguished from all the preceding members of the subfamily by the absence of a vertical groove on the nose and upper lip. Each foot is furnished with five toes, there are four pairs of premolar teeth in each jaw, and the under surface of the tarsus and metatarsus is hairy. The fourth African genus (Crosscirhus) contains the five species of cusimanses, which while resembling the last in the absence of a groove on the muzzle, differ by having only three pairs of premolar teeth in each jaw, the flat bony palate of the skull, and the unked soles of the hinder portion of the hind-feet. Several of the species, such as $C$. fusciotus, have a number of dark transverse bands across the bach. Lastly, the pretty little meerkat (S'mrircito tetradactylu) of South Africa differs from all the other smootl-nosed mumgooses in having only four toes io eacl foot: and is further characterised by possessing three pairs of upper, and four of lower premolars, as well as by the naked under surface of the whole of the tarsus and metatarsus. The muzzle is sharp, the front claws are very long, and the profile of the face is convex. 'The general colour of the fur is light grizzled grey, witl black bands

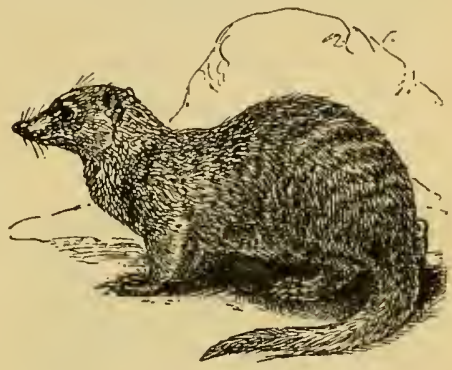

Fig. 36.-BAnIET Mtivgoose ('rossurchus fitsiciatus). across the hinder part of the back, and a black ring round cach eye. Meerkats measure from 14 to 15 inches to the root of the tail; and are vivacious little animals, living in holes in colonies, and eoming out to air themselves in the smu, when they survey passers-by with a peculiarly inquisitive expression.

The Island of Madagascar is inhabited by four peculiar genera of mungooses, three of which are more or less closely related to the Herpestince, while the fourth certainly forms a sub-fanily by itself. From all other members of the Fiveride, the two species of striped mungoose are distinguished by the numerous con-

Madagascar Mungooses. tinuous dark stripes rumning down the whole length of the

back and sides. They have but three pairs of premolar teeth in each jaw, the first of which is placed close to the canine; and the canines themselves are of large size. The five-toerl feet have longer elaws than in the typical mungooses; the muzzle is grooved inferiorly; the tail is covered with elongated hairs; and the muder surface of the tarsus is bare. From the last, the elegant mungonse (Galidia elegrons) may be distinguished by the smaller size of the Iower canine teeth, the presence of short sparse hairs on the lower surface of the tarsus and inetatarsus, the uniform coloration of the body, and the risged tail. The two species of brown-tailed mungrose (Temigulidia) differ from the preceding by the presence of four pairs of premolar's in each jaw, the larger size of the second upper molar, the uniformly-coloured tail, the more pointed form of the muzale, and the smaller degrce of curvature of the claws.

Finally, there is the small-toothed mungoose (Eupleres gondoti), distingnished from all other mungooses by the non-eversion of the hinder border of the auditory bulla of the skull, ancl from the rest of the family by its very 
remarkable dentition. The eanines are minute, and like the first three premolars, whiel are widely separated from one another, and the molars :re but little different from the premolars. Indeed, the whole dentition is strikingly like that of an Insectivore, and there ean be little cloubt that this highly moditied mungoose subsists entirely or ehiefly on inseets.

A peculiar hyæena-like animal from Africa, known to the Duteh as the aardwolf, and scientifically as Proteles cristatus, is regarded as representing a family by itself, distinguished by having the auditory bulla The Aard-Wolf. of the skull divided by a septum into two chambers, and by -Family the small and degraded charaeters of the cheek-teeth, among

Proteleide. which there is but a single pair of molars in each jaw. In the fore-foet there are five toes, but in the hinder pair the number is reduserl to four; their elaws being strong, blunt, and non-

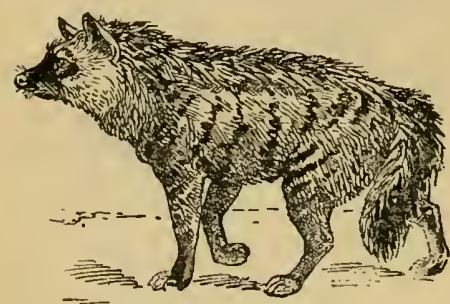

Fig. 37.-AARD.WOLF (Proteles cristatus). retractile. In a ppearance, the aardwolf is curiousiy like a small striped hyæena, with a more pointed muzzle, longer ears, and a thiek mane of elongated ereetile hair along the neck and back. Common in South Africa, this animal has also been recorded from Angola and Somaliland. It feeds on carrion, grubs, and white ants.

From the two preeeding families the hyænas, of which all the three existing species may be ineluded in the single genus $H$ ycune, differ by the absence of my internal partition in the auditory bulla of the skull. In the living species there is only one pair of molar teeth in each jaw, The Hyænas.- the upper one being small, and placed on the inmer side of the Family earnassial. The latter tooth resembles the upper carnassial IIycenidice. of the ents in having three distinct lobes to the blade ; and the lower carnassial has a bi-lobed blade and a very small posterior heel. All the teeth are very strong and powerful; the antericr premolars being in the form of blunt cones; and the skull, in which the sockets of the eyes are freely open behind, is remarkable for the great height of the erest on the middle of the upper part. The limbs are somewhat elongated, especially the front pair ; the tail is relatively short; and the fur is loose and long.

In appearance, hyæenas are the most ungainly of all Carnivora, and thereby present a marked contrast to the cats. They are noeturnal, gregarious, and cowardly, feeding ehiefly on earrion and carcases; and being generally unable or indisposed to kill the larger animals for themselves, feast on the remmants of earcases left by lions and tigers. For eracking the bones of such derelicts their powerful teeth and strong jaw-museles are most admirably adapted.

The striped hyæna (H. striata) of India, South-West Asia, and North and Eist Africa, is ensily reeognised by its transversely strijed pellage, long fur, which forms a mane on the shoulders and baek, and large pointed ears. The teeth are eharacterised by the relatively large size of the upper molar and by the lower carnassial having a heel of eonsiderable size, and a cusp on the inner side of the blade. The brown hyrena (H. Lrumneu) of South 
Africa, although nearly allicd, has some points of resemblanco to the third species. Tho largest and most powerful of all is the spotted hysena (H. crocuta), now confined to South Africa, and characterised by the spotted coluration of the body, smaller proportionate length of the forelimbs, largo head, with moderatesized and rounded ears, the presence of a mane on the neck and back, and the smoother and shorter tail. The last upper molar tooth is very small, or even wanting, and the lower carnassial has no inner cusp and a very small posterior heel, thus closely approaching the corresponding tootl of the cats.

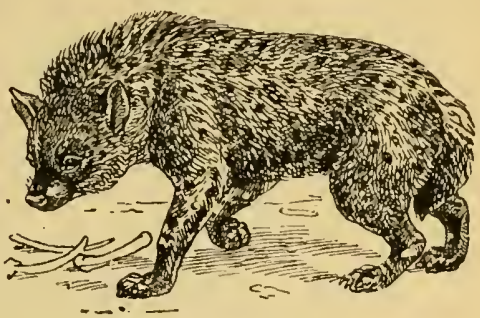

Fig. 38.-SPOTTED HYANA (Hyena crocuta).

As regards the auditory bulla and adjacent regions of the skull, the Dog Tribe are in many respects intermediate between the preceding group of families and those which follow. The bulla itself is inflated and bladder-

like, but has no interual partition ; and the paroccipital The Dog Tribe.process, although in contact with the bulla, is prominent, Family Canidee. and not applied to it, as it is in the cats and civets. Another distinctive feature of the group is the presence of a long and coiled coecum, or blind appendage, at the junction of the large and small intestine; that appendage being either very small or absent in the preceding families. 'The crowns of the upper molar teeth are triangular in shape; and these teeth, which are nearly always two in number, are situated behind the carnassial. The latter tooth, as in the civets, has two lobes to the blade; and the lower carnassial generally has a large tubercular heel behind the blacle, and in welldeveloped cusp on its inner side. In most cases there are threo lower molars (of which the carnassial is the first), whereas in the civets there are never more than two of these teeth; and there are always four pairs of premolar teetl in each jaw. Dogs, under which title may be included wolves, jackals, and foxes, have a cosmopolitan distribution, and differ markedly in their liabits from the cats. Although a few will run up the stems of sloping trees, none are climbers; and many consort in packs to hunt their prey by scent. Many form burrows in the ground ; and while they are more or less carnivorous, some will supplement a flesh diet with fruits, insects, or garbage. All walk on the tips of their toes, and are thus digitigrade; and the claws are short, blunt, slightly curved, and non-retractile.

By far the great majority of the members of the family may be included in the genus Canis, which has a geographical clistribution equal in extent to that of the former. It is characterised by the general presenee of 42 teeth, and there are five front and four hind toes. The Typical Genus. tail is of muderate length or long, ind generally more or less bushy; and the pupil of the eye may contract either to a vertical slit or a circle. The general form is too well known to require description. The genus may be divided, from the characters of the skull, into two primary series, the first typified by the wolves, and the second by the foxes.

This series includes the wolves. jackals, and wild dogs, together with the domesticated breeds, and is best characterised by the circumstance that 
the postorbital proeess of the frontal bone, that is to say the one forming the hinder boundary of the socket of the eye, lias its superior surface smooth and convex, and its free extremity bent downwarls. Wolf-like series. In this group the wolves are the largest wild representatives; the common wolf ( $C$. lupms) ranging over the northern portions of both the Old and. New Worlds. There are no wolves either in Africa or South America, although it is curious that the so-called Antaretic wolf ( $C$. antaicticus) of the Falkland Islands appears to belong to the group. In Asia there are several wolves, althongh none are found in the countries to the east and south-east of the Bay of Bengal, and there is some difference of "pininn as to their relationship to the common wolf. With regard to the

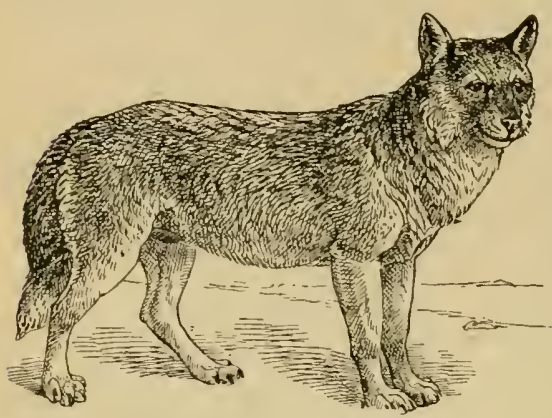

Fig. 39.-Cosson WoLk. wolf inliabiting the plains of India, most persons not specially versed in the mysteries of zoology would probably be unable to distinguislı it from its European cousin, 1mless specimens were placed side by side, and even then would find some difticulty. It appears, however, that there are certain differences in the habits of the two amimals, which suggest tine probability of their specitic distinctness from one another. For instance, the Inclian wolf is remarkable for its silence, only very rarely, if ever, uttering the wellknown howl of the common species ; although it is stated that it will occasionally bark, after the manner of a pariah dogr. Then, again, Indian wolves, although sometimes found in small family parties of half-a-dozen or so, are never known to collect in the enormous packs which make the European species so dreaded in winter. It is probable that these differences in habits would not by themselves alone be regarcled as sufficient to establish the right of the Indian wolf to rank as a distinct species. When, however, it is found that there are in addition certain points by which the two animals can be distinguished from one another, these differences in habits become of importance in adrling to their distinctness. The Indian wolf is, indeed, a somewhat smaller and slighter animal than the Emopean speeies, the average difference in the length of the two animals being about six inches. Then, also, the hair is rather shorter, and there is little or no under-fur; while the colour is generally rather more inclined to brown than in the eommon wolf. The absence of under-fur in the Indian wolf might, we think, be well explained by the hotter climate in which it dwells; but, in spite of this, naturalists are probably right in regarding it as a distinct species, under the name of ('anis pallipes.

The Indian wolf does not range into the Himalaya, neither is it found to the westward of the Indus, or in Ceylon. That island seems, indeed, to enjoy a lappy immunity from the presence of several of the larger Indian Carnivorn, as it lias neither wolves, wild dogs, hyrenas nor tigers. In the ease of the tiger it has been attempted to account for this absence by the suggestion that this animal is but a comparatively recent immigrant into India from 
the north, and had not reached that country at the time Ceylon was united with the mainland. If this were so, it would seem, however, that the same explanation ought to hold good for hyanas and wolves; but as both the latter are known to liave been well represented in India in the later geological epochs, some other reason must apparently be sought, at least, in their cases.

It is difticult to leave the Iudian wolf without referring to the subject of wolf-nurtured children. Many of the stories relating to these have been brought together by Professor $\mathrm{V}$. Ball, in his "Jungle Life in India," where it is related that in all tho recorded instances the cliildren were boys, and that the greater number of cases have occurred in Onde. Many persons refuse to attach any eredence to such stories, but Mr. Ball strongly urges a suspension of judgment until further evidence be attained. If such stories be really based on fact, we can only look to Europeans who are stationed or travelling in the wilder parts of India to bring to light decisive evidence in support of any new cases that

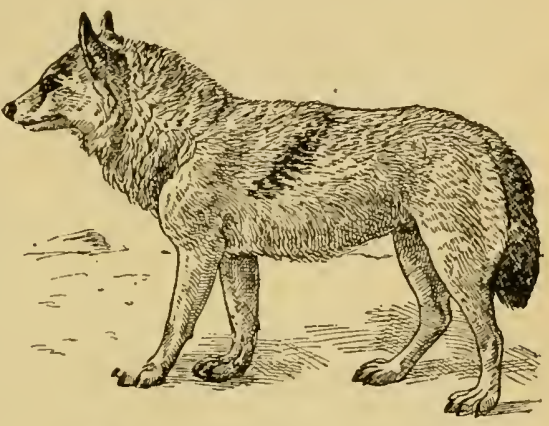

Fig. 40.-INDIAN WoLF (Canis pallipes). may oceur.

It has been already mentioned that the Indian wolf does not extend west. ward of the Indus ; and in Sind, Baluchistan, and Gilgit its place is taken by the European wolf, which not improbably may also range into the northern part of the Punjab. Large wolves, distinguished by their long soft hair and pale colour, are common on the farther side of the snowy range in Ladak and Tibet, where they are known to the natives by the name of Changu. These Tibetan wolves liave been generally regarded as a distinct specics, described as Canis laniger or chanco, and considered to be more nearly allied to the Indian than to the European wolf. It seems, however, that this view is incorrect, and that the Tibetan wolf is nothing more than a pale-coloured and woolly-haired variety of the common wolf. Occasionally long-haired black wolves are met with in Tibet, which have been regarded as indicating yet anotlier species $(C$. niger). There is, however, no doubt but that these are merely varieties of the ordinary Tibetan wolf, similar to the dark variety of the short-haired wolf of Europe. It is to a considerable extent for the purposes of protecting their flocks against the ravages of wolves that Tibetan villages and encampments are guarded by the luge mastiffs, which not unfrequently make themselves so extremely unpleasant to the European visitor.

The following interesting account of the habits of wolves in Norway, where these animals are still abundant, is given by a writer in the Asian newspaper of August 19th, 1893 :-

"The pairing-season occurs in February, and in nine weeks the female brings forth her young. When the time of birth approaches, the mother retires to the most remote and unfrequented parts of the forest, where in some cleft or cave in the rocks, surrounded by close undergrowth, she conceals her offspring. These remain blind for ten or eleven days, and for six 
or eight weeks are nourished by the mother, but when only a month old they leave the den for short distances, and play about with one another like puppies. The she-wolf is a good mother, and as long as her young are small she never goes any great distance from them, and they remain with her till the pairing-season comes round again, when they themselves are capable of procreation. At first they are dark coloured, the end of the tail being black, but after they have got to be about a couple of feet in length they are of a yellowsh-grey, of a darker shape on the back, and have a black muzzle.

"During the summer months wolves are partial to extensive woodland solitudes, especially those interspersed with mossy tarns and streams. In winter, on the other hand, especially during severe cold and rough weather, they tend towards the more inhabited and open districts. Wolves always make their excursions at night, and between sunset and sunrise they frequently cover great distances; while during the clay they rest in close covert. When pressed by liunger, in extreme cold, when they leave or are returning to their young, or when they have been deprived of these, they send forth long-drawn and melancholy howls. In woods, and generally speaking, in narrow surroundings, wolves are cowardly and cunning; while on extensive plains or tracts of ice, where they can see about them, they are much more courageous, especially when in company ; but even under such circumstances they rarely assume the offensive towards man. In districts frequented by these animals they have certain paths which they almost invariably follow, and so closely do they keep in one another's tracks it is difficult to say that more than one has passed. In going to and from the place where the young are concealed they invariably follow the same route, and so a regular beaten track is formed. Ouly when in droves will they attack the larger animals, such as the elk; at first they steal as near their victim as possible, and endeavour to seize it by making long bounds; failing in this, they set about running it down, two or three following the hunted beast closely, the rest trying to cut it off, or by lying in wait and springing at its throat. If captured when quite young, wolves remain comparatively tame for some time, but their savage nature generally breaks out ere long, and they cannot be depended on."

Of other species, the North American coyote (C. latrans) is a smaller form, with very long hair, which appears to connect the true wolves with the jackals. The latter animals are really lothing more than small wolves, and usually have the bushy tail equal to about one-third the length of the head and body. The common jackal (C. aureus) extends from Burma andi India through South-Western Asia to South-Eastern Europe and North Africa ; but is replaced in Africa south of the Sahara by several allied forms, such as the side-striped jackal ( $C$. adustus) and the handsome black-backed jackal (C. mesomelas). The dingo ( $C$. dingo) of Australia is generally reckoned as a domesticated species, but there is considerable evidence that it existed in Australia previous to the advent of men.

Most sportsmen who have shot in India, whether in the plains or in the hills, are probably more or less familiar with those animals commonly known as wild dogs. Although they are not often seen actually hunting their prey, yet they may not unfrequently be met with when shooting in or near forests ; while in the liills the frightened and disturbed condition of ibex and other large game will often indicate their presence in a district where it would otherwise be unsuspected. Like many of the colloquial names applied to animals, the term wild dogs by which these creatures are generally knowa is 
an exceedingly inappropriate one, because it is just this particular group of dogr-like animals which differs more from ordinary dogs than do most others of the larger Canide. It would indeed be far better if wolves and jackals were spoken of as "wild dogs," since it is those members of the family which come closest to our domestic dogs, of some of which they are probably tho parent stock. In such cases, howevor, it is utterly hopeless for the naturalist to attenpt to fight against popular usage, and we must accordingly be content to accept the ordinary names for the animals under consideration.

All who have ever seen an Indian wild dog, whether in the flesh or stuffed, will not be likely to mistake it for any other member of the canine family. In size it is somewhat larger than a jackal of arerage dimensions, and is characterised by the gemerally ruldy colour of the hair, and especially by the black tip of the moderately long and bushy tail. Noreover, the muzzle and legs are relatively rather short in comparison with the size of the head and body; while the profile of the face differs from that of other canine animals by being slightly convex instead of concave or straight.

The reader may ask whether such characteristics as the above offer any justification for the objection to the term wild dog as applied to these animals; and if it were these alone on which naturalists rely, he would be perfectly justitied in so doing. To obtain, however, any true ideas as to the relationships of an animal, we are compelled not only to study its colonr and proportions, but likewise to take into consideration its skelcton and other parts of its organisation. Now, if we take the skull of a wild dog and compare the number of teeth in the lower jaw with those of a wolf, jackal, or* fox, we shall find an important point of difference. In the lower jaws of all the three animals last mentioned, and also in those of domestic dogs, we shall find that there are 11 teeth on each side; the eleventh being the smallest of all those situated behind the tusk. If, on the other hand, we examine the lower jaw of any wild dog, we shall find that the small eleventh tooth is wanting, so that there are only 10 lower teeth. A wild dog has, indeed, only 10 teeth on each side of both the upper and lower jaws, whereas in dogs, wolves, jackals, and foxes there are 10 upper and 11 lower teeth. We have here, therefore, an easily recognised point of distinction between a wild $\log$ and most other members of the family. 'There are, however, two African and one South American representatives of the family, which, while differing from the ordinary type as regards the number of their tecth, have no intimate connection with the wild dogs. A difference of one tonth mole or less in the lower jaws of different members of the family may not appear a very important one-and to a certain extent it is not so. But it at any rate serves to show that wild dogs cannot possibly be the parents of any of our domestic breeds of $\operatorname{dogs}$, since it is a well ascertained fact that when once a tooth has been lost in any group of animals it never reappear's (unless it may be as an occasional abnormality) in their descendants. Another point of distinction between wild dogs and other members of the family is that there are either 12 or 14 teats in place of the usual 10.

Relying on the two points of difference last noticerl, many naturalists have considered that wild dogs ought not to be included in the same genus as wolves and jackals, and the former have accordingly been described under a separate generic title, as Cuon, or more correctly Cyon, from the Greek name for a dog. Such a distinction appears, however, umnecessary, ard it is preferable to include wolves, jackals, foxes, and wild dogs under the common title of Canis. 
As regards their distribution, wild dogs are found in India, Burma, Siam, and the Malayan Peninsula and islands; while in Central Asia they extend as far northwards as the Altai Mountains, which divide Mongolia from Siberia, and as far westwards as Amurland, and the Isle of Saghalien in the Sea of Okhotsk. It is, however, somewhat curious that, so far as our information goes, these animals are quite unknown both in Northern China and Japan. Wild dogs are, therefore, at the present day exclusively confined to Asia, where they do not appear to extend eastwarcls of the longitude of the Ural Mountains. This distribution will, lowever, only hold good for the present epoch, since there liave been found in the caves of various parts of Europe lower jaws of camine animals agreeing with those of living wild dogs in having 10 instead of 11 teeth; and we shall, therefore, be justified in considering at or about the time when the mammoth Hourished that wild dogs hunted over Europe as they do at the present day in Asia. The circumstances of the occurrence at a former epoch in Europe of a group of animals, now confined to Asia is by no means an isolated one, since there is eridence that at still earlier periods of the earth's history deer, like the muntjac and spotted deer of India, and long-snouted crocodiles akin to the garials of the Ganges and Borneo, flourished in various parts of Europe. All these facts in distribution seem, indeed, to point to the conclusion that Asia has served as a kind of refuge for groups of a nimals which, for some reason or another, were unade to exist any longer in Europe.

Naturalists have longr been exercised as to whether the wild dog of the Himalaya was identica! with that of the plains of India, and also whether one or both of these conid be distinguished from the wild dog of Burma and the Malayan islands. In many works the wild dog of India and the Himalaya will be found alluded to by the name of Cyon rutilans-a name properly belonging to the Malayan form. These writers probably derived their information from the late Dr. Jerclon, who in his "Indian Mammals" included the Malayan, Indian, and Himalayan forms under this single name. Colonel Sykes had, lowever, long before separated the Indian wild dog under the name of $C$. duhhunensis, while for the Himalayan torm Hodgson proposed the name of C.primcevus. Mr. Blanford, who states that !he can find no difference between the wild dog of he Himalnya and that of the plains of India, considers that these are probably listinct from the kind found in Burma and the Malayan region. The difference between the two is, however, very slight ; but the Himalayan and Indian species (C. deccunensis) is a rather larger and stouter animal, with longer hair, and a woolly under-fur, and the general colour varying from a ferruginous red to tawny; while the Burmese and Malayan species (C.rutılans) is smaller and slighter, with shorter hair, no underfur, and a brighter colour. The Indian species extends to the nortli-west as far as Gilgit and Hunza, from whence it ranges eastwards through Ladak into Tibet. Curiously enough, it is found that this wild dog is quite distinct from the species inhabiting the Altai ( $C$. alpinns) which has much larger upper molar teeth. This, as Mr. Blanford well observes, is a most remarkable feature in distribution, for whereas most of the animals of the Himalaya, like the ibex and the great Tibetan sheep, are either identical with or closely related to those of the Altai and adjacent regions, here we have a case where the Himalayan form is identical with one inhabiting the plains of India, and perfectly distinct from the one found in the Altai. This may, however, be explained by the greater facility with which the Carnivora can adapt themselves to different surroundings, owing to the circumstance that wherever 
they go they are sure to neet with herbivorous animals, on which they can prey. Herbivorous aninils, on the other hand, are generally more or less completely dependent on one or nure particular kinds of plants for sustenance, and are consequently unable to exist in regions where such plants do not grow.

lil the same series with the wolves and jackals are included a number of South American species, commonly spoken of as foxes, which they much resemble in external aspect, although having wolf-like skulls. Among these are Azarit's dog $(C$. arvice) and the crab-eating dog ( $C$. cancricores). A much larger Sonth Anerican form is the so-called maned wolf (C. jubutus)-a large reddish-coloured animal. The so-called racenou-dog ( $C$. procyonides), which has been generically separated as $N$ ycter $\epsilon u t e s$, is distingnished by its long loose fur, short ears, and abbreviated bushy tail, its general colour being dusky.

Probably every Englishmin thinks he knows a fox when he sees it; and it is zot unlikely that he would be disposed to resent the suggestion that he could not distinguish between foxes and certain other nembers of the cinine fanily, or that there could be any Fox-like Series. hesitation in deciding whether any foxes he might be shown were or were not specifically identical with the common English kind. Nevertheless, it is by no means easy to determime from external characters alone whether a given canine animal is or is not a fox ; while the difficulty of deciding whether many of the larger foxes of Asia and America should be regarded merely as varieties of the common $\mathrm{f}(\mathrm{x}$, or as distinct species, has long exercised the minds of naturalists. Indeed, the latter question lias only recent?y been decided by the leading zoologists of England in favour of the former view; and we are by no means sure that their opinions are accepted iy all American zoologists.

Prubably most people would say that a fox is sufficiently characterised by his slight build, elongated body, short limbs, long ears, sharp muzzle, and long bushy tail, of which the length always considerably exceeds half that of the head and body. So far, indeed, as they go, these characteristics are excellent, and they will serve to distinguish a fox from a wolf or jackial. The whule of them are, however, not applicable to all foxes, the Aretic fox having comparatively short ear's, while they will not serve to distinguish foxes from the above-mentioned South American representatives of the family, such as the so-called Azara's dog. The latter animals have, indeed, the general build and appearance of foxes, their muzzles being sharp, their ears long, and their tails of great length and thickly haired. The naturalist says cmphatically, however, that they are not true foxes, and it is, therefore, eviclent that he has certain characteristies to rely on which are not included among those just mentioned.

A more careful examination of a fox will show that the pupil of the eye forms merely a narrow vertical ellipse when seen in a strong light, whereas that of wolves, jackals, and dogs is circular. Unfortunately, however, even this character will not serve to distinguish foxes from the above-mentioned South American species. Of more importance is the circumstance that vixen foxes have but 6 teats, whereas the females of wolves, jackils, and dogs generally lave 10 , but occasionally only 8 teats, while in the Indian wild dogs the number is increased to 12 or 14. As usual, however, when he wants to find a feature which shall be absolutely characteristic, the naturalist has recourse to the skull in order to definitely separate foxes frou all uther members of the family. If, indeed, ve cximine 
the skull of any kind of domestic or wild dog, of a wolf, or a jackal, we shall not fail to observe, as noticed above, that the triangular boiny projection from the middle of the skull which forms the hinder border of the upper part of the socket of the eye-hence known as the postorbital process-is highly convex, and curves from above downwards. On the other hand, in the skull of any species of fox, the same process has a very distinct hollow on its upper surface, and it does not curve downwards in the smallest degree. A further examination will also show that in a clog, jackal, or wolf the middle portion of the skull is considerably elevated above the level of the extremities of these two processes; whereas in a fox the whole surface of this part of the skull lics nearly in a horizontal plane. If we were to make a vertical section of the two skulls, we should find that in the skulls of the dog, jackal, and wolf the bone forming the roof was honeycombed by a number of cells, whereas in the fox it is solid; and it is the presence, or absence, of these cells which causes the great difference in the contour of the skulls of a dog and a fox.

The above feature absolutely distinguishes the skulls of all species of foxes from those of all other members of the family, and we are accordingly now able to give a much more satisfactory definition of a fox, which will be somewhat is follows, riw: A long-bodied, short-limbed member of the canine family, with a long and bushy tail exceeding half the length of the head and body, generally long ears, a sharp muzzle, elliptical pupils to the eyes, 6 teats, and the forehead of the skull not honeycombed by cells, and with the postorbital processes hollowed above. From these important differences some writers are inclined to separate the foxes from the genus Canis under the name of Vulpes.

There has been much discussion as to whether foxes and dogs will breed together. Thus, Mr. Bartlett, the superintendent of the Zoological Society's Gardens, whose wide experience entitles him to rank as a high authority on the point, writing in 1890 , says that, "So far as my experience goes. I have never met with a well-authenticated instance of a hybrid between a fox and a dog, notwithstanding numerous specimens of supposed hybrids of this sort which from time to time have been brought to my notice." Since that date. several writers in Land and Water have, however, asserted the existence of such hybrids, but further evidence is still desirable on the subject. And if such a hybrid be proved to exist, it would be very desirable that the form of the pupils of its eyes, and the number of its teats, should be carefully recorded during life, while after death an examination of its skull by a qualified observer would be of the highest interest.

Turning to the numerous varieties of the common fox and their distribution, it is almost needless to observe that in England the fox is of a bright reddish-brown colour on the upper-parts, with the under-parts and the tip of the brush white, and the back of the ears and the lower portions of the limbs black. There are, however, some local or individual variations even in this country, which have given rise to the names of greyhound, mountain, and bush foxes ; but all these are, at the most, of trivial import. Occasionally English foxes are killed with the tip of the brush grey or black, and there is one instance on record of a white English fox. Of far more in.portance is the circumstance that ome time previous to 1864 an immature fox was killed in Warwickshire with all the under-parts of a greyish black hue. Now, as a general rule, the foxes of Northern and Central Europe are similar in colour to the ordinary English form, but in Southern 
Europe they are all palcr above, with the under-parts dnsky. There can, however, be no question but that these are all of one spccies, and it is therefore very interesting to find one instance of the occurrence of the Southern variety-assuming that the Warwickshire specinen was not an imported animal-in this country.

Proceeding eastwards into Asia, we find two large foxes differing very markedly from the ordinary English form. The first of these is the ycllow fox of Central Asia, formerly regarded as a distinct species under the name of C. flavescens, and characterised by its general pale and yellowish colour, and the large size of its magnificent brush. It has, however, still the dark ears and white brush-tip of the English fox, and there can be no doubt that molem writers are right in regarding it merely as a pale variety of the latter. This variety inhabits open country, and lives in burrows, or among rocks or bushes.

The handsome animal known as the mountain-fox (the so-called $C$. montanus) of the Himalaya, although nearly allied to the last, is frequently so strikingly different, when in its winter dress, from the ordinary English fox, that most sportsmen would regard it as a distinct spccies. The fur of the back varies in colour from chestnut to iron-grey, and the shoulders are often marked by a conspicuous dark transverse stripe, while the under-parts, and especially the throat, are more or less dusky. The black outer surfaces of the ear's and the white tip to the brush proclaim, however, the aftinity of this fox to the southern variety of the European fox ; and it appear's to be merely another variety of the latter. This Himalayan fox differs from the Central Asian variety in that it does not excavate burrows, but lives in thickets or on cultivated land. When we add that the so-called Nile fox (C.niloticus) is but another variety of the same species, it will be evident that if he can but obtain a pack of lounds and suitable ground, the sportsman may hunt one and the same species of fox, whether lie be in England, in the South of Europe, on the banks of the Nile, in the deserts of Central Asia, or in the vale of Kashmir.

This is, however, by no means all, for if the fox-hunter cares to cross the Atlantic he may again hunt the common fox in Virginia and other parts of North America. It is true, incleed, that these large North American foxes have been considered distinctspecies, underthe names of the red fox (C. fulvus) and the cross-fox (C.pennsylianicus). The cross-fox is, however, obviously but a variety of the red fox, distinguished by the presence of a more or less distinct dark stripe across the shoulders ; and since both forms have the black ear's and white tail-tip of the

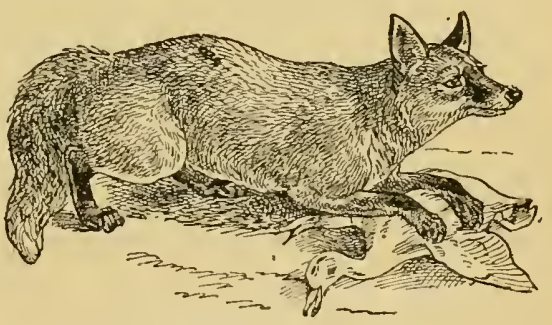

Fig. 41.-The Common Fox. European species, there can be little hesitation, in spite of their variation in colour, in regarding them merely as local races of the same widely-spread form.

Again the so-called silver or black fox ( $C$. argentatus) from California and the Western United States, so valued on account of its beautiful fur, is only a melanistic (dark) variety of the red fox, and is therefore merely another race of Cunis vulpes. The silver fox, we may ubserve in passing, is a comparatively rare animal, of which perfectly black skins, with only the characteristic white 
tip of the tail, are so scarce that they fetch from $£ 50$ to $£ 70$ in the market. It thus appears that an animal may vary in colour from foxy-red above, with white under-parts and tail-tip and black limbs and ears, to one in which the whole of the fur is black save the tip of the tail, and yet belong to one and the same species.

No account of the distribution of the common fox would be complete without some reference to the fact that it is one of the very oldest of our British Mammals, its fossilised remains having been dug up in the topmost beds of the so. called red crag of the Suffolk coast. These deposits far ante-date the river gravels and cavern-mud in which occur the remains of the mammotl and other gigantic extinct Mammals; and it will thus be evident that this extreme antiquity of the British fox will readily account for its present unusually wide geographical distribution.

Before taking leave of the common fox and its numerous varieties we may refer to the circumstance that there has been much discussion as to whether badgers are hurtful to young foxes. As the result of these it appears that the charge against the badger has been effectually disproved, more than one writer recounting instances where fox and badger-cubs have been brought up in amity as inhabitants of the same earth. In spite, however, of this, it appears that there is still, at least in some districts, war waged by sportsmen against the unfortunate badger.

With regard to North American foxes, it may be observed that in addition to the red and cross-fox, the so-called grey fox or Virginian fox (C. virginiamus) is largely hunted with hounds in some parts of the States. This fox is much smaller than the European species, the length of its head and body being only about 19 inches, in place of some 24 inches. It is further distinguished by its relatively shorter muzzle, and also by the presence of a ridge of long stiff hairs ruming along the middle of the upper part of the tail. The general colour of this fox, as its common name implies, is some shade of grey ; but there is considerable individual variation in this respect, and some specimens show a more or less marked reddish tinge. If an English huntsman were to see his quarry suddenly rush straight up the trunk of a tree in the midst of a rum, his astonishment would certainly be great, yet we are assured by American writers that tree-climbing is a frequent habit of the grey fox. Thus Dr. Ellzey writes in Shields' "Big Game of North America," that " whether the greys ever climb trees in pursuit of prey I am uncertain; but they take to a tree as readily as a cat, when hard run by hounds. I think it nearly certain that they climb for persimmons, grapes, and berries. Red foxes never climb trees under any circumstances; when hard run they go to earth." If the above explanation of this curious habit is the trus one, it would seem that grapes are not sour to the grey fox. Grey foxes afford but a poor run in comparison with the common species, their course only holding for a short distance, and that accompanied by many doublings ; while the rum usually terminates either by the capture of a fox within an hour, or by the animal either climbing a tree or taking refuge in a hole of the same. On the other hand, the American red fox rums as strongly as his European relative; his course, it is said, generally taking the form of a large parallelogram. The cubs of the grey fox have been compared to small black puppies, and are thus very different in appearance from those of our own species. A second North American species is the kit-fox $(C \cdot v e l o x)$, which is still smaller than the grey, its brush being only abont 11 inches in length, against 16 inches in the latter. Above, this fox is light grey, with an admixture of long white 
hairs, while the flanks are yellowish and the under-parts white, the brush having no white tip. This species lives in burrows, and takes its name from its extreme speed. Whether it is commonly hunted with hounds I am unaware. More distinct than either of the above is the long-eared fox ( $C$. macrotis), of Califormia, in which the ears are nearly as large as in the undermentioned fennecs. Its general colour above is grizzled grey. South America has no true foxes.

In India the place of the common fox is taken by two small species-the Indian desert-fox (C. levcopus) and the Bengal fox ( $C$. bengulensis). The former, which is somewhat the linger of the two, agrees with the common species in the white tip to the brush, and also in the dark brown or black outsides to the ears; while the latter has a black tip to the brush and greyish ears. The desert-fox, as its nane implies, inhabits sandy wastes, and has a considerable turn of speed; Jerdon stating that it "gives a capital run sometimes, even with English dogs."

The Bengal fox, which only measures about 20 inches from the tip of the snout to the root of the tail, is found in more or less open country over the greater part of India, and may not unfrequently be seen by residents in Calcutta playing about the Maidan near Fort-Wiiliam. Jerdon writes that "this fox is much coursed with greyhounds in many parts of India, and with Arab or country dogs, or half-bred English dogs it gives a most excellent course, doubling in a most dexterous manner, and if it is within a short distance of its earth, racing the dogs. Its numerous earths prevent in general mueh sport being had in hunting it with foxhounds, and its scent is poor." Another small Asiatic species, with a dark tip to the brush, is the Corsic fox (C. corsac), whose habitat extends from the shores of the Caspian through the Russian steppes to Mongolia. The skin of this species is an article of considerable commereial importance, an average of about 50,000 coming annually into the market. There are several other allied species of foxes inhabiting Asia, such as the Japanese fox (C. japonicus) and the Tibetan fox (C. ferrilatus), but as they are mostly but little known in Europe, it is unnecessary to make further allusion to them on this oceasion. Mention must, however, be made of the Arctie fox (C. lagopus), characteriserl by its short ear's, extremely bushy brush, and the long hair clothing the soles of the feet. As a rule, this fox is bluish-grey in summer (when it is known as the blue fox), but changes to pure white in winter'; although in some cases, more especially in Iceland, the dark tint is retained throughout the year. This specics is practically circumpolar, and on an average from 25,000 to 60,000 skins annually find their way into the market. The Aretic fox, in order to provide a supply of food for the long and dreary winter of its native habitat, is in the habit of laying up stores of lemmings and other small animals concealed in holes and fissures of the rocks.

South and Central Africa is the home of an entirely different group of small foxes, known as fennees (C. zerle, C. fomelicus, and C. comca), and characterised by the enormous length of their ears. 'These femnecs are more or less sandy-coloured animals, with a dark tip to the tail, and differ from the European fox in their social habits, dwelling together in small companies. A skin of an apparently allied species has been obtained from Afghanistan.

The Cape hunting-dog (Lyccom pictus) is the sole living representative of a genus differing from Canis in having but four toes to each foot. Its shull approximates to that of the wolves, but is somewhat shorter and broaler, and there is a slight difference in the form of the teetl. This animal is of large 
size, and marked with mnsymmetrical blutches of white, yellow, and black, the distribution of which shows considerable individual variation. Number's combine in packs to hunt their prey. A second well-marked other Genera. genus of the Canidee is formed by the bush-dog (Icticyon renaticus) of British Guiana and Brazil, which is a darkcoloured animal not larger than a fux, with a short, sparsely-haired tail, short limbs, very small ears, close hair, and a very aberrant dentition. In th:e first place, the number of molars is reduced to one pair in the upper and

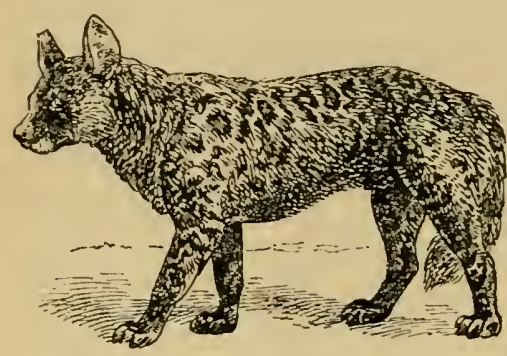

Fig. 42.-CAPE Hextisg.Dog (Lycaon pictus). two in the lower jaw, while the lower carnassial has no cusp on the inner side of the blade, and its posterior heel is secant instead of tubercular, so that practically the entire tooth is reduced to a cutting blade. The last member of the dog family is Lalande's femnec (Otocyor mequlutis) of South Africa, which, while agreeing in many respects with the true femecs, has very much larger ears, but is specially distinguished by having four pairs of lower molar teeth, and either three or four pairs of the same in the upper jaw, the total number of

teeth thus being either 46 or 48 . Its habits are like those of the femnecs.

In the three remaining families of the terrestrial Carnivora the auditory bulla of the skull possesses a simple undivided septum, and its bony external tube, or meatus, leading to the outer ear, has its lower The Bear Tribe. margin considerably produced, while the triangular paroc- Family cipital process stands quitc apart from the bulla. In the inUrsidu. testine the blind appendage or coecum is entirely absent. The bears themselves are specially characterised by the broad, flat, tuberculated crowns of the molar teeth, of which there are two upper and three lower pairs; and likewise by the rudimentary development of the first three pairs of premolars in each jaw, which arc in many cases entirely lost. The upper carnassial is very short and triangular, and both this tooth and the lower carnassial have but little resemblance to the true sectorial type, as shown in the cats and dogs. In the skull the auclitory bulla is very flat, and scarcely at all inflated. The large feet are furnished with five toes each, and arc completely plantigrade; while their long and slightly compressed claws are non-retractile. The body is

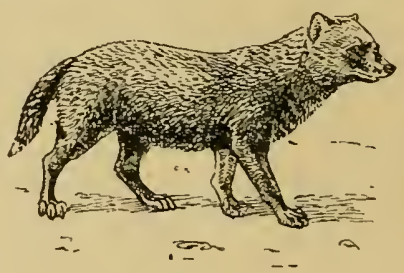

Fig. 43.-Busir-Dog (Icticyon venaticus).

very stout, the tail short, the ears moderate, the hair generally long and loose, and the gait clumsy and shambling. Bears go about either in pairs or in small family-parties, and are all excellent climbers. Most of them eat roots, fruits, and other vegetable substances, although they will also consume the flesh of deacl animals and carrion; and in cold 
countries all libernate during the inclement season, their liding-places being frequently caverns, the clefts of rocks, or hollow trees. The typical genus Ursus, in which there are 42 teeth, and some of the premolars are deciduous, includes all the existing members of the family except two. Of these the polar bear ( $U$. muritimus) of the Arctic regiums stands apart from the rest on account of its relatively smaller head, small and nar'row molars, more liairy soles, and creamy white colour. Its food consists mainly of flesh. 'The brown bear' ( $U$. arctus) is a very widely-spread species, ranging all over Europe and Northern Asia, and represented in Syria by one variety ( $U$. syriacus), in the Himalaya by the pale isabelline bear ( $U$. isabellimus), and in North America by the grizzly bear ( $U$. homibilis) and the American blick bear ( $U$. amerieamus), both of which are now considered merely as varieties of the European species. The Himalayan black bear ( $U$. torquctus), with shagrsy black fur and a white gorget, is a very distinct species; as is also the small Malayan bear ( $U$. malayauus), ranging from North-Eastern India to the Malayan countries, and distinguished by its long extensile tongue and short black fur, with a light gorget on the throat. Another well-marked form is the spectacled bear ( $U$. omatus) of the Chilian Andes. With the exception of $U$. crouther, of the Atlas range, which may be only a variety of the common species, Africa has no bear. The Indian sloth bear (Meluersus ursinus) differs in having only two pairs of upper incisor teeth, small molars,

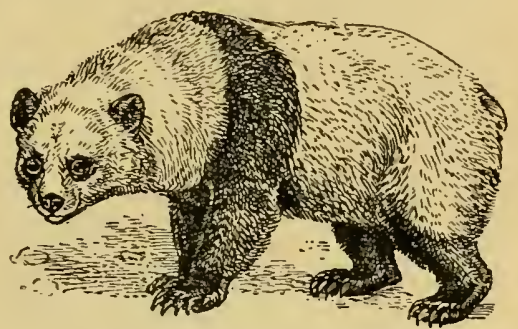

Fig. 44.-PArti-colovred Bear (Eluropus melanoleucus).

large extensile lips, and a deeply hollowed palate; the black fur being very long, loose, and harsh, and the throat marked by the usual light gorget. It feeds chiefly on ants, other insects, fruit, flowers and honey. More different than all is the parti-coloured bear (Eluropus melanolenens) of Tibet, with a total of 40 teeth, the premolars large and, except the first, two-rooted, and the first upper molar broader than long, instead of longer than broad, as in other bears. In colour it is black and white, with black rings round the eyes.

Mainly American, the raccoon tribe includes small carnivores with two pairs of molar's in each jaw, which may be either many-cusped or tuberculated, a short and broad upper carnassial tootl, plantigrade feet, and the tail ringed. The single Old World form Raccoon Tribe. is the panda or cat-bear (Alurus fulyens) of the Easterm Family ProHimalaya, which is a reddish-coloured animal, of the size of eyonidie. a cat, with a long, ringed tail. It has a total of 38 teeth, very broad many-cusped upper molars, and a curiously rounded and vaulted skull. The face is cat-like, the ear's are moderate and rounded, and the limbs stout, with large partially retractile claws. The panda is a good climber, and feeds chiefly upon vergetable substances. The American raccoons (Procyon) have 40 teeth, broad and tuberculated molars, and three lobes to the blade of the upper carmassial. The boly is stout, the head broad, with a sharp muzzle, the whole sole of the foot not applied to the ground in walking, and the toes capable of being widely spread, with sharp non-retractile claws. The tail is rather short and ringed, and the fur thick and soft. 
Raccoons are almost omnirorous animals, obtaining mucl of their food along the banks of lakes and streans, and swimming well. Much of their time is, however, spent in trees, in hollows of which the young are brought forth ; and in North America they hibernate dur-

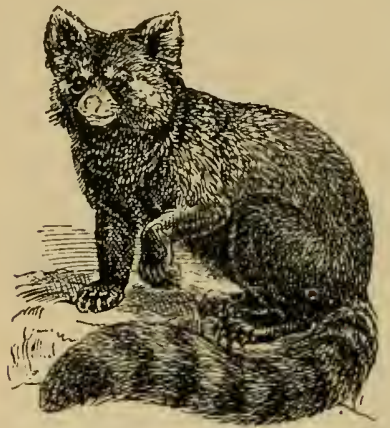

Fig. 45.-The PANda (Elurus fulyens). ing the cold season. 'The cacomistles (Bassuriscus), represented by one species from the Southern Lnited States and Mexico and another from Central America, form a elosely allied genus, distinguished by the more slender build, sharper nose, longer tail, and less completely plantigrade feet. Another genus is Bussuric!nen, of Central America, which has raccom-like teeth, but an external form very like that of the kinkajou. The cratis (Nresue ), which range from Central America to Paraynay, are easily recognised by the prolongation of the muzzle into a long and somewhat upturned mobile suout; the long and tapering tail being ringed. The dentition is similar to that of the raccoons, with the exception that the upper canines are longer and more pointed, and the molars smaller. Coatis are arboreal animals, going about the forest in small parties, and feeding chiefly on birds, eggs, insects, lizards, and fruits. Lastly, the kinkajou (Cercoleptes caudicolvulus) differs from all the rest in its long and taper tail being prehensile; the number of teeth being 36 . It is a pale yellowish-brown animal, of the size of a cat, entirely nocturnal, and arboreal in its laabits.

The last family of the land Carnivora is the large and widely-spread one of the weasels, which includes the otters, badgers, shunks, etc. Except in the ratels (where there is

Weasel Tribe.- but a single pair in each

Family lfuste- jaw), the member's of lide. this family may be distinguislied from the two preceding ones by having one pair of upper, and two of lower molars, and by the inmer portion of the upper molars being longer from back to front than the vuter blade. The auditory bulla of the skull is but little inflated.

The otters (Lutro) form an aquatic group cinaracterised by the short and rounied feet, the webb-

otters. ed toes, the small, curved, and blunt claws,

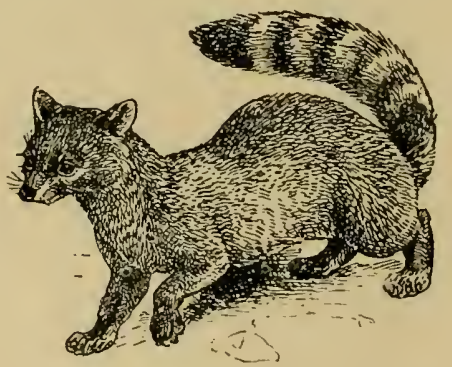

Fig. 46.-Caconistre (Basstriscus astutus). and the bruad and flittened head. The jaws are short, with large, closely packed teeth ; the upper molir being especially large, quadrangular in form, and its inner tubercular portion much expanded from back to front; and all the cheek teeth sharply cusped. The body is very elongated, the ears are slort and rounded, the limbs short, the tail long, thick, and tapering rapidly, and the fur very short and close. In certain species the claws 


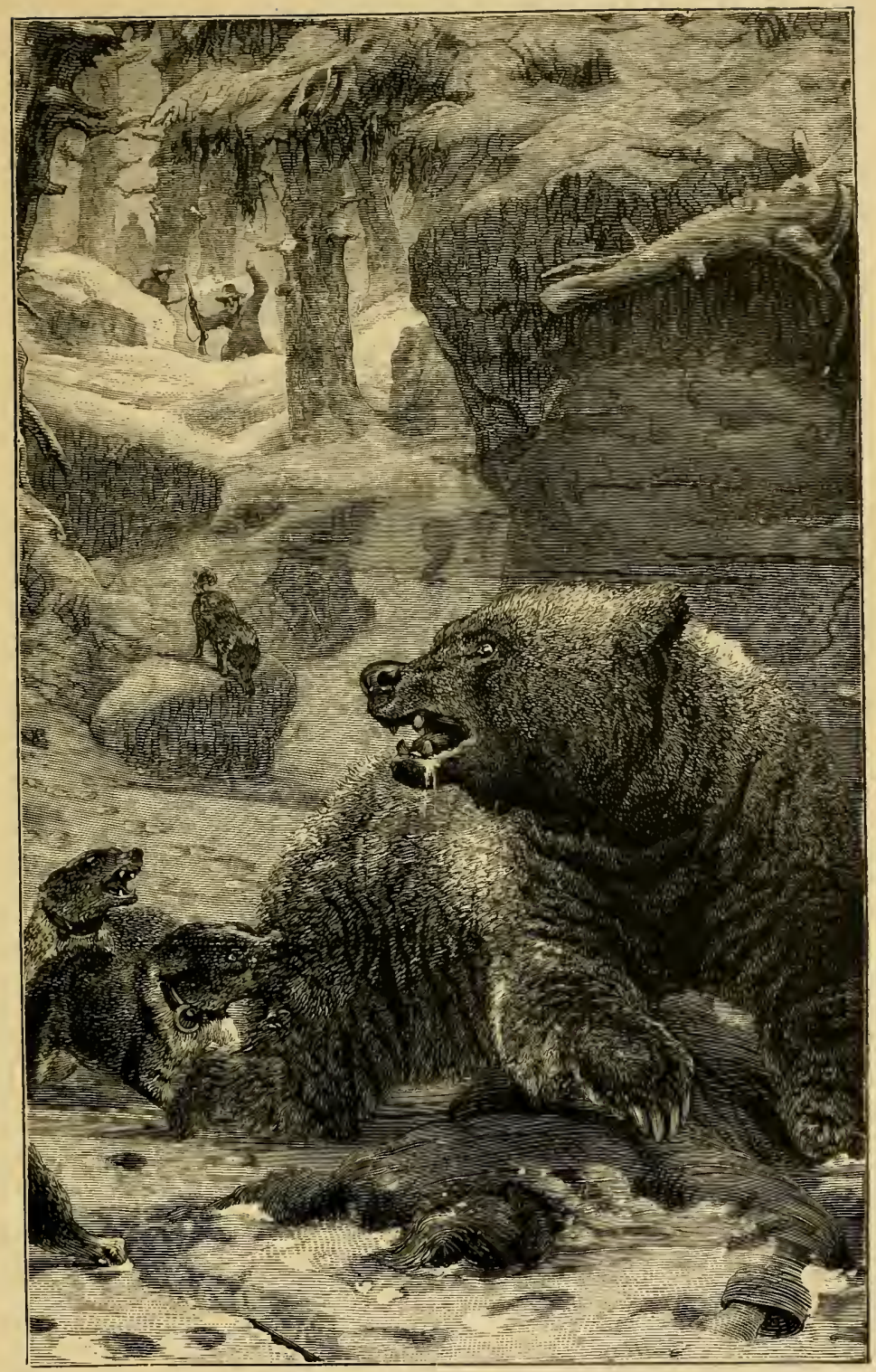

The Grizzly BeAR 

may be rudimental or wanting. With the exception of Australia and New Guinea, otter's are cosmopolitan in their distribution, the largest species being the Brazilian otter. They are expert diver's and swimmers, feeding entirely on fisll, for the capture and retention of which their powerful and sliarply-cusped teeth are admirably suited. The total number of teeth is 36. Nearly allied to the otters is the sea-otter (Latu. lutris), distinguished by having only 32 teeth, among which the lower incisors are reduced to two pairs, the blunt and rounded tubercles of the molar's, and the flipper-like hind-feet, in which the toes are flattened, as in the seals, and the fifth toe is the longest and stuutest. The head is rounded, the ear's very small, the tail short and bushy, and the pellage with a beautiful

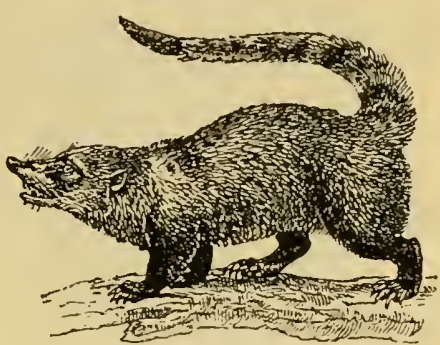

Fig. 47.-Cost I (Nasua rufu). under-fur. The total length of the aninal is about four feet. Naturalists have hitherto believed that the sea-otter when on land has the hind-toes turmed forwards, but Mr. Snow, of Yokoliama, states that this is incorrect, and that they are really cloubled backwards, beneath the soles. The southern range of the sea-otter extends as far as Southern California and Mexico. On the Asiatic side, it occurs at the Kumandorski Islands, Kamschatka, and the Kurile Islands. As a rule, only one is produced at birth, but occasionally two. Mr. Snow has seen two small pups with their mother, and has taken two from the insicle of an otter he killed. It is not absolutely known at what age the otter arrives at maturity. Mr. Snow believes that it does so in the third year. Crabs and sea-urchins are the usual contents of the stomach, but occasionally small fish and spawn are also found. The crabs are crushed by the strong molar teeth, it being impossible that the crushing is produced by the striking of two shells together, as the form of the fore-feet will not allow of anything being grasped. The otter dives for its food, and returns to the surface with the prey held between its two forepaws, in which it continues to hold it while eating it. On many occasions Mr. Snow has seen schools of from 10 to 50 or more otters together some 10 or 15 miles from any land, but not of late years. The mode of capture adopted by Europeans is to "lun" the sea-otter with three boats, each manned by four or five men, a hunter being in the bow armed with a rifle. When an otter is "raised" (as it is called), the boats proceed to surround it, lying some 500 to $600 \mathrm{y}$ ards apart in the form of a triangle. The boats are so manceurred that the otter is kept between them. Every time the animal makes its appearance above the water, it is shot at, until it is secured. When the sea-otter is netted, it becomes entangled in the meshes and drowned. The long white hairs of the fur are its chief beauty. They are not removed when it is prepared for use. A skin has sold for upwards of $£ 225$.

The skunks of America are the first representatives of a second sub-family in which the feec are elongated, with straight toes, and non-retractile, slightly curved, somewhat compressed, and blunt claws, which are of very large size in the hind-foot; the form of the upper molar being variable. The typical skunks (Mephitis), which

skunks. are confined to North and Central America, are easily recognised by their 
black fur, relieved on the back with broad longitudinal stripes of white, and the bushy black and white tail, which is generally carried over the back. They have 34 toetl, and are provided with

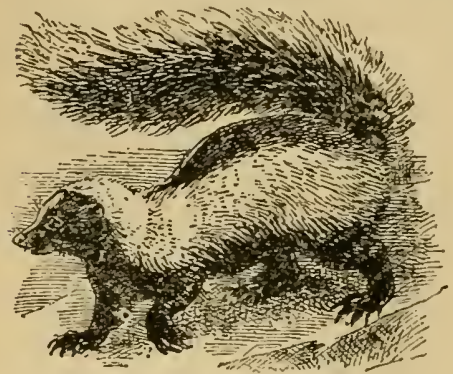

Fig. 48. - Commox SkLxk (Mephitis mephitica). special glands for the secretion of the noisome fluid to which they owe their name. The little skunk (Spilogale putorius) of the Southern United States and Contral America is a muchsmalleranimal, and the only member of thegroup thatcan climb. The South American skunk (Concpatus mapurito), ranging from Texas to Patagonia, differs in having only 32 teeth, and also in its heavier build, and by the nostrils openingdownwards and forwards, instead of on the sides of the muzzle. Mr. Aplin, writing of this species, obserres that "the scent-rgland cannot be opened unless the tail is at a right angle, or something near it, with the line of the body; and that therefore when held by the tail the weight of the skunk's body keeps the tail more or less in a line with it, and the skunk is unable to discharge its rile secretion. To perform this operation it is of course necessary to catch the skunk asleep, or otherwise deeply occupied (digging roots, for instance), and to run the risk of its waking up or turning round and seeing you. I be. lieve I could have easily clone it myself, as I have more than once seen a skunk lying curled up asleep in the daytime. Indeed, while looking for a parrot I had shot among some bushes, I very nearly stepped upon one which was curled up on the ground; and there it remained until I put a revolver bullet through its body. However, I never cared to risk the loss of useful garments, it having been proved, I believe, that clothes once well dosed at close quarters may as well be burnt. The skunk passes the daytime in sleep, when undisturbed. In Soriano I used to find them laid up in holes and under clefts in the granite boulder rocks, in cleserted ant-nests, among paja grass, or in the crown of a big hassock of this, and in one or two cases on the ground among bushes. In the latter case it lies on its side curled round. When roused in a hole by a dog, it presents a rather diabolical appearance as it pops its little vicious head out. Notwithstancling demonstrations of this kind, I have only once seen a skunk use its teeth. In this case one fastened on to Jim's flanks, and the old dog walked about with it hanging on for half a minute, looking round at it in much astonishment at this unusual and unseemly behaviour-the fact being that he could not get hold of his enemy, which turned with him. The sliunk seems to be an omnirorous feeder. Its long strong claws are well adapted for digging, and places where they have been scratching are to be seen all about the camp. They probably feed on small mammals, reptiles, and insects, as well as roots, and are always credited with robbing hen-roosts. With regard to the distance at which you can smell a skunk, I camnot give an opinion; but you often smell them when you cannot sce them, and just about sundown the smell is a usual and familiar one about the camp ; at night, too, a strong whiff of it as you sit or stroll in the patio is a very common occurrence. At a hundred yards to leeward, with the slightest breeze the smell of a discharge 
would be very pungent. The smell is said to be a good remedio for the headache." Although skunks aro essentially nocturnal animals, they may occisionally be seen walking about on the open Argentine pampas in broal daylight.

The next group of the sub-family includes the badgers, of which there are likewise several genera, none of which are found in Suuth America. Of these the sand-baclgers (Artonyx), of the Oriental countries, form a genus characterised by having 38 teeth, of which the lower incisors project forwards, the anteriur premolars are

Badgers.

often rudimental or wanting, and the upper molar is much larger than the carnassial, and longer than broad. The naked mobile snout is pig-like, the ears are minute and rounded, the eyes small, the feet digitigrade when walking, the tail moderately long and tapering, and the fur bristly, with a soft underfur. The Indian species is rather larger than the ordinary badger. Nearly allied is the Malayan badger (Mydcus meliceps), from Java, Sumatra, and Borneo, which is a small burrowing animal, distinguished from the last by the nostrils being inferior, instead of terminal in position, and by the extreme shortness of the tail, which is clothed with rather long bushy hair. In the true badgers (Meles) the number of the teeth is also 38 , but the first premolar in each jaw is minute, and often shed at an early age, while the very large upper molar is quadrangular, as broad as long, and much surpassing the carmassial in size. Moreover, the lower jaw is so firmly articulated to the skull that it camnot be separated without fracture. The skull differs from that of the sand-badgers, and thereby resembles the Malayan badger, in that its bony palate is only produced a comparatively short distance behind the last pair of teeth. The muzzle is pointer, the body stout and broad, the ears and tail very short, and the limbs short and strong, with partially plantigrade feet. The coloration of the common badger is tou well known to need description. The genus includes only a few species, which are confined to Europe and Asia north of the Himalaya, one kind inhabiting Persia and another Japan. Badgers are nocturnal, omnivorous, and burrowing animals, producing three or four blind young at a birtl. In North America the group is represented by the Americau badgers (Taxidect), in which the first upper premolar appears to be always wanting, and the upper carnassial is nearly as large as the molar, and the tubercular heel of the lower carmassial relatively smaller than in the Old World badgers. The stout body is depressed, and the tail very short. Nearly allied to the badgers are the ratels (Mellivora) of India and Africa south of the Sahara, which differ from all other members of the family in having but a single pair of lower molars, and are fur. ther distinguished by the limbs and under surface of the body being black, while the upper-parts

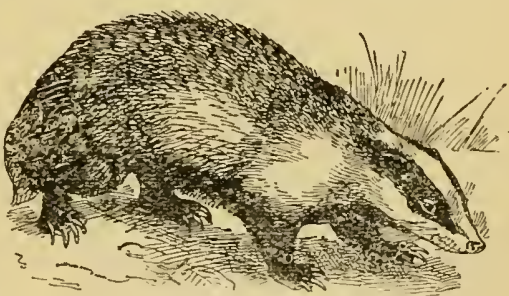

Fig. 49.-Common BuDGer.

are greyish. In this genus the upper carnassial is a large tooth, with its inner tubercle at the front end, as in the remaining genera of the sub-family; the upper molar being short from back to front, with its inner portion much expanded. In the lower carnassial the posterior heel is very minute. Ex. 
ternally, the ratels liave a stout body, a flattened head, rather pointed nose, rudimental ears, stout and short limbs, and a very short tail. They subsist chiefly on honey-comb, which they dig out with their powerful claws. The so-called ferret-badgers (Helictis), from the Oriental countries, some of which are remarkable for their brilliant coloration, form a very distinet genus. They have 38 teeth, a long head, with a sharp naked muzzle, obliquely truncated at the tip, small ears, elongated body, short limbs, and a rather short or moclerate bushy tail. All are small aninals, climbing well, and subsisting on a mixed diet. The last genus of the sub-family is typified by the Cape polecat (Ictonyx zorill (c) ; another species occurring in Egypt, and, it is said, Asia Minor. These animals lave a dentition and bodily form very similar $t$ " those of the true polecats, from which they may at once be distinguished by their coloration, which is very similar to that of the skunks.

The last sub-family of the Mrstelilce comprises the true weasels and their allies, and is characterised by the toes being short and partially webbed, the claws also short, sharp, compressed, curved, and frequently

weasels, etc. partially retractile; while the upper molar is of moderate size, and wide transversely. The first genus is Galictis, of which there are two well-defined South American species, loeally known as the grison and the tayra. Both these have 34 teeth, among which the molars are small but stout, while the upper carnassial has

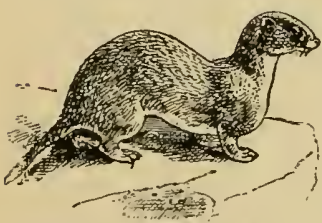

Fig. 50,-THE COMMON its inner tubercle near the middle of its length, and the lower carnassial has a minute posterior heel, and either a very small or no inner cusp. The head is broad and flattened, the body elongate, the limbs short, with plantigrade feet, in which the claws are non-retractile and the soles naked, while the tail is long or moderate. Both species are found as far south as the Argentine pampas, and are noted for their savage disposition. In the typical genus Mrestela may be included not only the martens, but likewise the smaller polecats and weasels. In the two latter the dentition is numerically the same as in Galictis, but in the former the number of teeth is increased to 38 , owing to the presence of the first pair of premolar's in each jaw, on which account these animals are frequently referred to a genus by themselves, under the name of Putorius. From Galictis they are all readily distinguished by the inner tuberele of the upper carnassial tooth being situated close to its front edge, instead of in the middle. All these animals have the characteristic long and slender weasel-body, short, digitigrade limbs, rounded feet, short toes, with sharp, compressed, and partially retractile claws, and the long or moderate tail more or less bushy. The larger forms, or martens, are restricted to the Northern Hemispliere, one species occurring as far south as Sumatra. They are all mainly carnivorous and arboreal, and generally produce from four to six young at a birth. The best-known species are the pine-marten (Mustela martes), ranging from Britain across Northern Europe and Asia ; the beech-marten ( $M$. foinc), extending from Central and Southern Europe to the Himalaya and Turkestan; the sable ( $M$. zibellina) of Siberia and Kamschatka; the closely-allied North American marten ( $M$. americana); the very distinct Indian or yellowthroated marten (M. flavigula), ranging from India to Sumatra, China, and Amurland: and the large Pennant's marten ( $M$. pennanti) of North America. 
Of the forms with only three pairs of premolars and no immer eusp to the lower carnassial tooth, the largest are the nertz ( $M$. lutrcolu) of Eastern Europe, and the nearly related North American mink (M. rison). Next come the tivo species of polecat, as typified by the common European polecat ( $M$. putorius); while the smaller forms include the true weasels and storts. Of these, tho stoat or ermine (M. ermince) and the weasel (M. velyaris) are common to Europe, North and Central Asia, and North America, while the assogue (M. hibernica), which is intermediate in size and coloration between the other two, is restrieted to Ireland, being the only Mammal peculiar to the British Islands. The South African Pecilogale albinuchu, which has a eoloration similar to that of the Cape polecat (Ictmyx), has been referred to a listinet genus, on account of there being only two pairs of premolar teeth in each, and by the lower molars being generally reduced to a single pair. The name Lyncodon has been proposerl for a Patagonian weasel, in which the dentition is numerically the same as in the preceding.

The lnst genus of the mustelines is represented solely by the wolverene or gylutton (Giulo luscus) of the northern districts of both hemispheres. In this comparatively large animal, which is an inhabitant of forests, there are 38 teeth, all of which are very stout and strong; the upper molar being much smaller than the carnassial, the lower carnassial large, with no inner cusp, and a small posterior touth, and the third upper ineisor so large as to resemble a second tusk. The form is more like that of a bear than a weasel, the body and limbs being stout, the latter long, with large, partially plantigrade feet, the small ears almost buried in the loose, coarse fur, the eyes, the tail short, thick, and bushy, and the soles of the feet covered with bristly hairs. The dark fur has a light saddle-shaped mark on the back. The wolverene is a good elimber, and lives on large birds and mammals, killing animals even as large as the reindeer. It has a curious habit of carrying off' and eollecting articles for which it can have no possible use.

The fur-seals, or eared-seals, are the first of three families of the aquatic Carnirora, all the members of which are modified for an aquatic life, and collectively constitute the sub-order Pinnipedia. In all these animals the upper-arm and fore-arm, and the corresponding Eared-seals.segments of the hind-limb, are abnormally shortened, and to Family Otariidle. a great extent enclosed in the skin of the body, whereas the feet, and more especially the hinder pair, are elongated and expanded into large flippers, with the toes widely separated and completely united by webs. Five toes are present, of which the first and fifth in the hind-limb are stouter and usually longer than the three middle ones. The incisor teeth are always reduced below the typical number of three pairs in one or both jaws; and the cheek teeth, which usually consist of four pairs of premolars and a single pair of molars, are nearly alike, and lack the specially modified car-

nassials characteristic of the land Carnivora. The body is of a tapering:

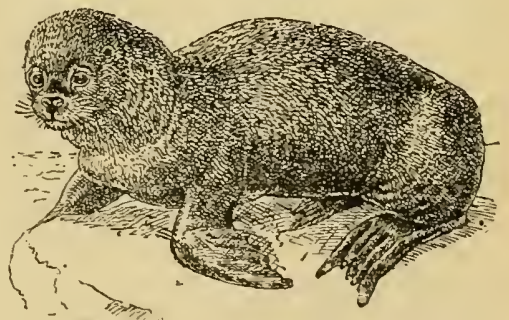

Iig. ö1.-SEa-LION. 
pyriform shape, admirably adapted for progression through the water, passing almost imperceptibly into the tail, which is always short. On land seals are awkward animals, progressing with a series of ungainly jumps, and most of them spend the greater part of their time in the water, although all come ashore for the purpose of breeding. The great majority are marine, although a fow inhabit inland seas and lakes. Most feed on fish, crustaceans, and other marine animals.

The e:rred-seals, all of which may be included in the single genus Otaria, are distinguished as a family by the circumstance that when on land the lindflippers are turned forwards beneatl the body, and likewise by the presence of small external ears; the under surfaces of both flippers being naked. They have either 36 or 34 teeth, aceording to the presence or absence of the second pair of upper molars ; and there are three pairs of upper, and two of lower incisors. The cheek teeth are sharp and compressed, consisting of one large central cusp, flanked by two much smaller ones. The head is separated from the body by a distinct neck, and the claws, especially those of the first and fifth toes, are small or rudimental. Many species have a very dense under-fur, constituting the "sealskin" of commerce, and these are known as fur-seals ; while others, in which there is no under-fur, are termed hair-seals. Although absent from the shores of the North Atlantic, the eared-seals have a wide geographical distribution. Among the better-known forms may be mentioned the southern sea-lion $(O$. jubata) of the Falkland Islands and Patagonia, which differs remarkably from all the rest in the structure of its skull; the large northern sea-lion (O. stelleri) of the North Pacific, which may attain as much as 10 feet in length; Gillespie's sea-lion (O. gillespii) from California and Japan; the sea-bear $(O$. u'sina $)$ from the Pribyloff Islands and other parts of the North Pacific; O. pusilla of South Africa ; and O. fosteri from Australia and New Zealand. All the eared-seals are peculiar for their habit of spending a long period on land during the breeding-season, where they form the well-known "rookeries." Here the males arrive first, and proceed to take up fixed stations, where they collect as many females as they are able to capture ; and it is not a little remarkable that during their whole sojourn on shore, which may extend to a period of three months, they undergo a complete fast.

The following account of seals and sealing in Japanese waters is from the consular report on the trade of Hakodate, as given in the Times of May, 1895. The writer states that in the island of Yezo the "eonditions, as regards space and time, are very similar on both sides of the ocean. The Russian rookeries of the Commander Islands are the exact counterpart (though smaller) of the American rookeries of the Pribyloff Islands ; the two face each other, in about the same latitude, from the opposite sides of Pehring Sea. From these centres the seals, after their four or five months: summer sojourn, start southwards for their immense swims in the Pacific, extending on the American side as far down as San Francisco, and on the Asiatic side as far down as Sendai Bay, and even the entrance of Yedo Bay. But there is one noteworthy difference between the two cases. While, on the American side, owing to the long sweep and turns of the coast-line, the range of the swim is quite 3,200 miles, on the Asiatic side it is a nearly straight run of less than half that distance. Hence the seal-herd, though larger, is more dispersed on the American side; and it is probablo that hunters choosing the Asiatic side gain more through the concentration of the herd than they lose through its inferiority in numbers. Indeed, the effective 
hunting range - at all events, for the first stige of tho hunting season-is not much more than 800 miles long, extending from Sendai Bay to Nemuro, the most easterly point of Yezo Island. On reaching Nemuro the seals suddenly disappear about the end of June, and no sealing craft as yet lias followed them up, kecping them in sight, between this point and the rookeries on Behring and Copper Islands, or the still smaller rookery of Robben Island in the Okhotsk Sea. 'The explanation of this sudden acceleration of the seal's pace may be, as the hunters think, merely the quickening of the natmal instincts, on the eve of the breeding-time. But it may also be due to a falling off in the food supply along the line of the Kurile archipelago. The fact, howerer, is uncloubted that, beyond Nemuro, the schooners lose sight of the seals about the end of $\mathbf{J u m e}$, and this check of their pursuit serves as a mark to divide the hunting season into two distinct stages.

"The schooners, as a rule, leave Victoria or Sau Francisco at the end of December or early in January, and, aftel' a two montlis' voyage across the Pacific, strike the Japanese coast about the latitude of Yokohama, where some of them put in to victual and refit. They begin hunting about the middle $\mathrm{Or}^{\circ}$ end of March, first mecting large clusters of seals in about latitude 38 deg. N. ott' Sendai Bay, from about 30 to 250 miles off the shore. The seals are then proceeding northwards at a leisurely pace, travelling during the night and feeding and sleeping in the daytime, especially in bright, sunshiny weather. 'Sleepers,' as the lumters call them, ure the easiest to shoot; 'travellers' are more difticult. A schooner with six or seven boats can take, on the average, close on 1,000 skins in the four months, March to Jume. That closes the first stage of the season, and they then either tranship their catches at sea into a collecting ship from Victoria and San Francisco, or clse put into Hakodate and prepare their skins for shipment to Londom or America. This done, after a slort stay and revictualling in port, they start northwards for the second stage of the liming on the westeru side of Belning Sea and in the Okhotsk Sea. This part of the hunting season, lasting from the end of July till the end of October, yields a very much smaller catch than the first stage, and, with a protective zone established round the rookeries, the scalers will probably find it hardly worth while to continue it. At the rate at which the pelagic sealing schooners are increasing, and in the absence of more effective measures for the protection of the herd on the rookeries, no less than at sea, the industry camnot last long. The Canadian sealing flect engaged in lumting on the western side of the Pacific has increased even more rapidly than on the American side. In 1891 only one schooner, in 189211 or 12 , and in 1893 at least 30 hunted in Asiatic waters. In the first place, the advantage, as compared with the Americau side, of the shorter range and greater concentration of the herd, is now well known to the sealers. Secondly, the close season, and the linits prescribed by the award of the Behring Sea arbitrators, are sure to drive many to the western side. And, lastly, the fact that there is a considerable saving in freight and cliarges when the slins are packed in Japan and shipped vice the Snez Canal to London, as compared with the charges and freight from the American side, will tell in the same direction."

Of the Alaskan seal-herd, Mr. H. W. Elliott writes, that " the fighting between the old males for the cows is mostly-or, rather, entirely-done with the mouth. The opponents seize one another with their teeth, and then, clenching their jaws, nothing but the sheer strength of the onc, and the other tugging to escape, can shake them loose, and that effort invariably 
leaves an ngly wound, the sharp canines tearing ont deep gutters in the skin and furrows in the blubber, or shredding the llippers into ribbon-strips. The bulls generally approach each other with comically averted heads, just as though they were ashimed of the rumpus which they are determined to precipitate. When they get near enough to reach one another, they enter upon the repetition of many feints or passes before either the one or the other talies the initiative by gripping. The heads are dirted out and back as quick as a flash ; their hoarse roaring and shrill piping whistle nerer censes, while their fat bodies writhe and swell with exertion and liage; furious lights gleam in their eyes; their hair flies off into the air, and their blood streams down. All this combined makes a picture so fierce and so strange that, from its uncexpected position and its novelty, this is ome of the most extraordinary brutal contests man can witness."

The walrus or morse (Trichichnes rosmamus) of the polar scas, although differing remarkably in its dentition from both, presents in unany respects a comecting link between the preceding and following fimilies.

The Walrus.- It agrees, for instance, with the Oturide in having the hindFamily flippers turned forwards beneath the body when on lind,

Trichcchide. but resembles the Phocide in having lost all external traces of cars. As rearals the dentition, the upper canines are developed into enomous tusks, projecting far below the lower jaw, but the whole of the other teeth are small, simple, and single-rooted, the molars

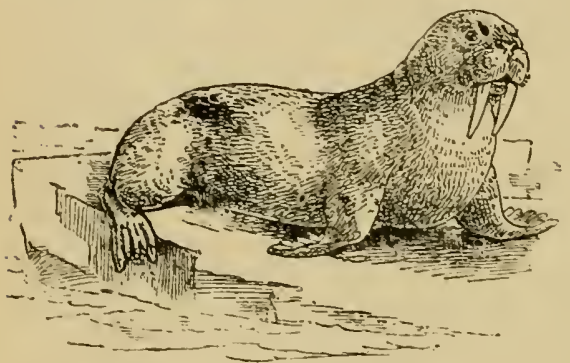

Fig. 52.-Walnus (Trichechus rosmarus.) having rounded, flattened crowns. The walrus is one of the heaviest and most bulky of all seals, old males not unfrequently measuring from 10 to 11 feet in length, while much lamerer examples are on record. In form the head is round, with rather small eyes, and the short, broad muzzle furnished with a tuft of stiff bristles on each side. The hair of the rest of the body is short and closely pressed to the skin, its general colour being yellowish. The tail is rudimental; in the front-flippers the toes are nearly equal in length, and furnished with small, tlat nails, but in the hindp:iir the nails of the three middle digits are lirge, and those of the two marginal ones minute. There is some diflerence of opinion as to whether the walruses of the Atlantic and North Pacific Oceans belong to the same or to distinct species, but, in any case, the difference between them is extremely slight. Walruses are social animals, collecting on the ice-fields in herds of considerable size, and being (fften found on detacheel ice-floes. The females produce one, or occasionally two calies in the spring or early summer, for which they display the most marked affection. Their food consists almost entircly of two species of bivalve molluses, which are raked ont of the mud with the insks, and easily crushed by the flat molar teeth. Whether the tusks arc also employed to drag the animals out of the water by being l:itched $(m$ to the ice, is a disputed point. The cry of the walrus is a loud ruan, which, when many are together, ean be heard for a long distancs. 
The true or earless seals eonstitute the last family of the fin-fouted Carnivori, and are those best adapted for a thoroughly aytuatic life, the hindthippers being permanently directed backwards alongsicle of the tail, and external ear's totally winting. A further difference from the eared-seals is to be fomd in the eircunstance that the under True Seals... surface of the feet is hairy; and in no case is there any under- Family Phocide. fur, the ordinary fur being short and closely pressed to the

skin. All the species have five pairs of cheek teeth in each jaw, but the number of incisors is viniable. On lind, most of the true seals advance by a jumping movement, produced by the museles of the body, assisted only by the front-tlippers.

The eommon grey seill (II alicharns ar!mus), of the coasts of the whole North Atlantie, is the type of the sub-fimily I'horilre, charucterised by liaving three pairs of upper, and two of lower ineisor teeth, well-developed claws on all the toes, and the hind-toes of nearly equal length, with the webs not reaching beyond their extremities. In the gricy seal the cheekteeth, except the last one or two in the upper, and the last in the lower jaw, are single-rooted, and consist generally of a single compressed cusp, ilthough additional cusps may be present in the two hinder pitrs in the lower jaw. The typical seals (Plower), all of which are confined to the Northern Hemisphere, differ from the last in

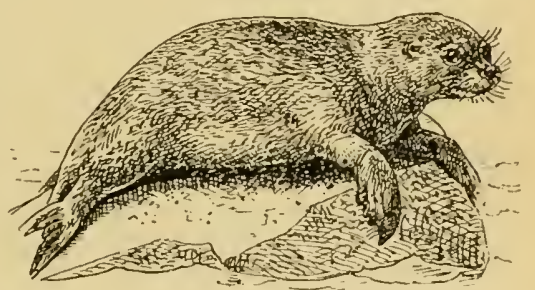

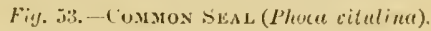
that all the cheok teeth are of smaller size, and, with the exception of the first pair in each jaw, are inserted by double roots, and hare iceessory eusps to their crowns. As examples of this genus may be cited the bearded-seal ( $P$. burbata), Greenland senl ( $P^{\prime}$. groulaudier), common seal ( $I^{\prime}$. vituliure), the Caspian seal ( $P$. cuspice) from the Caspian and Sea of Aral, and $P$. sibirice of Lake Baikal. Like other members of their tribe, these seals resort to the coast to bring forth their young, which may be either one or two in number ; and not the least remarkalole fact in their life-history is the circumstance that the offspring have to be taught by their parents to enter the water. They usually congregate in large herds, and are especially fond of lying basking in the sun like so many pigs. Seals are regularly hunted for the sake of their hides and blubber, the latter yielding a raluable oil.

A second sub-family of the Jhocide is typified by the monk-senl of the Mediterranean and adjacent portions of the Atlantic, which, with the nearly extinct West Indian seal, constitutes the genus Monachus. In this sub-family there are but two pairs of incisor teeth in each jaw, the cheek teeth, with the exception of the first pair, are inserted by two roots, and the first and fifth toes of the hind-flippers much exceed the three middle ones in length, and have their claws rudimental or wanting. The monk-seal is characterised by the possession of 32 teeth, and by the erowns of the clieek teeth being hollowed on the inner side-where there is a strongly marked basal ledge -and their front and back accessory cusps rery small. The first cleek tooth in both jaws, as well as the last in the upper, are considerably sualler than the rest; and all the claws are rudimental. The four other generic 
representatives of the sub-family Monachince are restricted to the southern seas : each genus including only a single species. First among these comes the beatifully spotted leopard-seal (Ogmorhinus leptonyx), in which all the cheek teeth have three large cusps; tho central one being the largest, with its apex curved backwards, while the tips of the others incline towards the middle one. Writing of the seals of this and other species seen during a voyage undertaken in $1892-93, \mathrm{Mr}$. IV. S. Bruce observes that from December to February they "are to be found on the pack-ice, where, during the day, they bask in the sum, digesting the meal of the previous night. Their food consists of fish or shrimp-like crustaceans, and sometimes of penguins. Stones, which were probably first swallowed by the penguins, may also be found in their' stomachs. 'They become so lazy with sleep that a man may dig them in the ribs with the muzzle of his gum, and wondering what it is disturbing their slumbers, they raise their head, which quickly falls piercerl with a bullet. There may only be one seal on a piece of icc, which is usually the case with the leopard-seals, but the smaller kinds lie in half-clozens and tens, and as many as forty-seven were seen on one piece diring the recent cruise. On one occasion several seals were found upon a tilted ber's ; so high was the lowest edge above the surface of the water that the boat's crew with difticulty clambered up and secured their prey. Fet the seals must hare made a leap from the water on to this their last resting-place. December seens to be their mating-season : about that time they are in rery poor condition, and very much scarred. The females appear to be as frecly scarred as the males. It was also noted that the seals were most numerous where the water was bluest and clearest-this in all probability meaning that they were more numerous on the outside of the pack, since the muddy olivc-brown colour of the water, due to diatoms, seen so frequently in the south polar seas, seems to indicate proximity to the main pack. The males appear to be as uumerous as the females, and, in the case of the leopard-seal and Weddell's seal at least, the males are perhaps rather smaller than the females. They move swiftly through the water, and can throw themselves eiglit or nine feet abore the surface, covering distances of fully 20 feet. Their moaning in the gloming of a calm grey day comes as a weird sound through the liaze, and makes the icy solitude more lonely, adding awe to a scene alrearly full of fascination. They seem to wonder at man, and not recognising him as an cnemy they allow him to approach, only to be laicl low witl club or bullet. It is a matter of great regret that they should be so indiscriminately massacred ; there is no regard for sex or age, and even females heavy with young lo not escape. If fleets of sealers continue to visit the south, there should be some law of protection, otherwise there is no doubt that, like the southern fur-seals at the beginning of the century, these Antaretic seals will be exterminated."

The second genus is represented by the still more beautiful Antarctic white seal (Lobodon carcinophaga), distinguished from the last by the much compressed and elongated cheek teeth having one chief recurved cusp, with one anterior, and from one to three much smaller but distinct posterior cusps. Of this lorely seal Mr. Bruce writes that "its coat is of a beautiful creamy white, resemblung that of tho polar bear, but short-haired, the colour becoming somewhat more intense along the back. Looking at the animal face to face, its coat appear's silvery, and the dorsal stripe almost vanishes; but when looked at from behind it assumes a deeper cream colour, and the broad stripe along the back becomes quite prominent. 'The full-grown animal may 
attain a length of about seven fect. The sea-leopard is a very striking animal, and, with the exception of the elephant-seal, is the largest of true seals. In the recent Antaretic expedition (1892-3) some were met with that measured over 13 feet in length. Their coat is a dark brown-grey and mottled, becoming paler grey below, and in some cises almost black on the back. A rather striking and not altogether inappropriate name was given to these scals by the sailors in the recent cruise ; they called them 'serpents,' and they do really often look very serpent-like with their long necks and green eyes." Less common is Weddell's seal (Leptonychotes wetdelli), in which the cheek. teeth are small, with simple, somewhat compressed, conicil crowns, carrying a broad basal ledge, but no distinct fore-and-aft cusps. These scals are nearly as large as the leopard-seal, but of less graceful make, having a thicker crat of blubber, and the fur more wonlly, and dark brownish-grey in colour. The last member of the sub-fimily is the rare Ross's seal (Ommutophoca rossi), characterised by the small size of all the teeth, the small posterior, and still smaller anterior cusps of those of the cheek series, and the very large size of the sockets of the eyes, as well as by the small size of the claws on the frontflippers, and their absence in the hinder pair. It is described as a beautiful animal, with large, affectionate-looking eyes, and resembling the white seal in form and size, but with a mottled grey pellage, darker above than below.

The third and last sub-family is represented solely by the hooded or bladder-seal (Cystophore cristat 1 ) of the Arctic Seas, and the gigantic elephantseal (Mucrorlinus tconimus) of the Southern Ocean and the coast of California. In this group the incisor teeth form two pairs in the upper, and one pair in the lower jaw, the total number of teeth thus being 30 , in place of the 32 characterising the preceding sub-family; and as a rule the cheek-teeth are implanted by single roots. In the males the nose is surmounted by an appendage capable of being inflated at will; and the first and fifth toes of the hind-flippers are much longer than the others; all these toes having the claws rudimental or absent, and webs projecting beyond their tips. The hooded-seal takes its name from the large loose sac of skin over the nostrils of the fullurown males, which, when inflated with air, looks somewhat like a hood. Rudimental nails are present on the hind-feet; and the last molar in each jaw is generally implanted by two roots. In the elephant-seal, on the other hand, the old males have a kind of trunk-like prolongation of the nose, which, although ordinarily limp, can be distended under the stimulus of excitement. All the teeth are relatively small, those of the cheek series being all simple and single-rooted, and nails are totally wanting on the hind-flippers. The elephant-seal is the largest of all seals, the males attaining the enormous length of 20 feet, and the females about one-third less. Mr. Bruce writes that "the males are said to come ashore on the South Shetlands about the end of August and beginning of September, and in the first part of October are followed by the females. The males are very fat when they first arrive, but get lean towards the end of Decenber, when they leave the islands. Another herd was said to visit the islands about the middle of January - when they renew their hair-and still another in March; by the end of April all returning to the sea. They are very difficult to kill, but, like the other species, allow themselves to be approached even with a club. This seal used to be highly valued for its blubber; in 1821 and 1822 alone as much as 940 tous of sea-elephant oil was taken from the South Shetlands; and it may here be mentioned that during these same two years at least 320,000 fur-seals were also taken from these islands." 


\section{ORDER V.-RODENTIA.}

\section{Mamals that Graw.}

Next to the Bats, the order of Mammals most ensily defined is the one including the Rodents or Gnawing Nammals, all of which have a very similar and pecuhar type of dentition specially adapted for rasping and gnawing liard vegetable substances. The order comprises a large number of familics and genera, many of which are exceedingly numerous in species, so that the total number of its members is greater than that of any ordinal group in the whole class. As common and well-known examples of the Rodent order may be cited squirrels, dormice, marmots, beavers, rats, voles, porcupines, and hares and rabbits, all of which are characterised by possessing a pair of chisel-shaped teeth in the front of each jaw, which are worn by use into a sharp, cutting, transverse edge, and grow continuously throughout the life of their owners. It is with these chisel-like front or incisor teeth that the Rodents perform that gnawing action (so markedly developed in the bearers and porcupines) from which they derive their name; and it is owing to the circumstance that the front of each tooth is faced with a plate of hard enamel, while the remainder consists of soft ivory, that these beautiful instruments maintain their cutting-edges. These two pairs of front teeth are absolutely characteristic of all Rodents; and in by far the greater majority of the order there are no other teeth in this region of the jaw. As if, however, for the purpose of hinting how these animals were originally related to Mammals provided with a fuller set of teeth, the hares and rabbits, together with their near allies the picas or tailless hares, have a minute pair of somewhat similar teeth placed immediately behind the large pair in the upper jaw. Being perfectly useless to their owners, this second pair of upper front teeth evidently comes under the category of rudimental or vestigiary structures. Behind the front teeth of all Rodents comes a long gap in each jaw, after which is the series of grinding or cheek teeth, which are never more than six in number, and are frequently reduced to four, or even three. Consequently, no member of the order ever has canine teeth. Were it not that there are two groups of animals with a dentition of a similar type, these peculiarities in the teeth would absolutely distinguish Rodents from all other members of the Mammalian class. Of the groups in question, the one contains the wombats of Australia, which are broadly distinguished by the presence of a pouch for the young, while the second group is represented solely by the curions aye-aye of Madagascar, which agrees in its internal anatomy with the lemurs, and is accordingly assigned to that group. Witl these exceptions the clentition is absolutely characteristic of the Rodent order; and as the student is not likely to confound with them either of the creatures named, he may rely on the nature of the teeth in identifying the members of the order. A curious feature in the anatomy of Rodents is that the mouth is divided into two chambers communicating by a narrow orifiee ; the first containing the incisors, and the second the cheek teeth, and the hair being continued inwards behind the formes. The object of this arrangement is evidently to prevent the intrusion of foreign objects into the 
mouth. As a rule collar-bones are well developed, although they may be wanting. There are generally five toes to the fore-feet, but in the hind-feet the number may be reduced to four, or even three; the claws being usually sharp and curved. A single species of Spermophilus las a ringed tail.

The orcler has a cosmopolitan distribution, being fairly well represented eren in Australia, New Gumen, and Marlagascar ; but it is in South America that it attains its maximum development, the number of family types peculiar to that region being very large. In size, Rodents riny from that of a rather small pig to that of the smallest slirew, the liarvest-mouse being one of the most minute of Mammals. The carpincho (Iycliveharus cepreare) of sonth America is the largest of the Rodents. As regards habits, all feed almost exclusively upon vegetable substances (except perhaps one rat from the Philippines, and a second from South America), but in other respects they present great diversity. The flyingsquirrels, for instance, are flying, arboreal, and nocturnal, whereas the ground-squirrels are terrestrial. Others agrain, such as the marmots, form large colonies, the members of which live in burrows, and are to a great extent dimmal; while otliers, like the beaver and coypu, have taken to an aquatic life. In structure, Rodents are so molh alike that

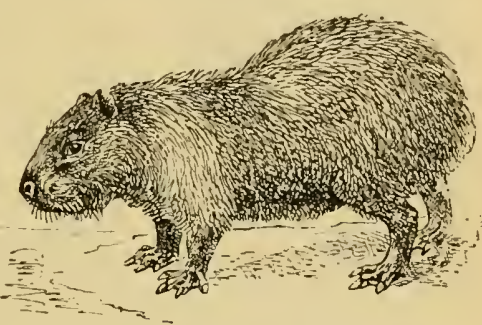

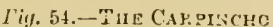

(Hydrocherus capivaru). somewhat obscure osteological characters have to be relied upon in oreler to divide them into groups.

Agreeing with the great bulk of the order in the possession of only a single pair of upper incisor teeth, the members of this and the three following families constitute a group (Sciuromorpha) chiefly cliaracterised by certain peculiarities in the structure of the skull. In this portion of the sliull the cheek or zygomatic arch (that is to say the long slender bar of bone rumming along the lower border of the socket of the eye) is chiefly formed

\section{African Flying- Squirrels.-} Family Anomalurider. by the bone known as the jugal, which is not supported by a backwarlly-directed process from the upper jiwbone, or maxilla; postorbital processes arising from the frontals to define the hinder margin of the sockets of the eyes may or may not be developed; and in the lower jaw the hinder, or angular portion arises from the socket of the lower incisor tooth.

Although flying-squirrels are abundant in the Oriental countries, in Africa south of the Sahara their place is taken by a separate family, comprising two distinct genera. These African flying-squirrels differ from their Asiatic cousins in that the parachute, by means of which they take their long flying leaps, is supported in front by a rod of cartilage projecting from the elbow, instead of from the wrist ; and an additional peculiarity is the presence of a row of overlapping horny scales on the under surface of the tail, which are believed to be of use in climbing. The typical representatives of the family are the short-tailed flying-squirrels (Anomalums), most of the species inhabiting West Africa, altlough one is found in Equatoria, and a second near 
Zanzibar. The smallest is the equatorial flying-squirrel (A. pusillus), in which the length of the head and body is 11 inches, and that of the tail just over five inches. The second genus (Idiurus) is represented only by a single species from the Cameruns district, which is not larger than a small house-mouse, the length of the head and body being only just over two and a half inches, and that of the tail four inches. Agreeing with the ordinary African Hying-squirrels in the general form and mode of support of the para-

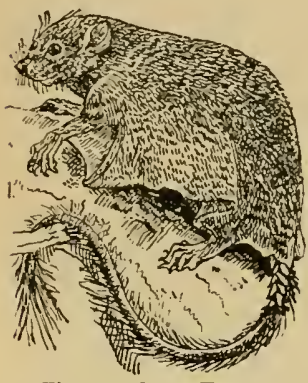

Fig. 55.--LONG.TAILED

A FiICAN FLYING-SQUiRREL (Idiurus). chute, as well as in the presence of rows of scales on the uncler surface of the tail, this species is at orice distinguished by the short, knob-like nose, and the thinly-haired tail ; the latter terminating in a pencil of hairs, and being nearly double the length of the head and body, instead of shorter. In place of being uniformly and thickly covered with fur, the tail is short-haired on its upper surface, with three longitudinal rows of elongated sparse hairs, while beneath it is naked, with three rows of scales near the base. An important clifference is also to be found in the structure of the fore-foot, in which the thumb is reduced to a mere knob-like radiment, while in the hind-foot the first toe is much smaller than the other four, which are of approximately equal length. There are likewise structural differences in the skull, into the consideration of which it will be unnecessary to enter on this oceasion. In colour, the fur of the back and upper surface of the parachute is pale whitisll-brown, the hairs being blackish-grey at the base; while on the under surface the general hue is a mixture of yellowish and dark grey, with a tinge of silver-grey on the parachute.

Writing of the habits of Pel's Hying-squirrel (Anomalums peli) of West Africa, Mr. W. H. Adams observes that "these squirrels come out of their holes in the trees some hours after sumset, returning long before daybreak. They are only to be seen on bright moonlight nights, and, in fact, the natives say they do not come out at all in sturmy weather or on very dark nights. They live on berries and fruits, being specially fond of the palm oil-nut, which they take to their nests to peel and eat. They pass from tree to tree with great rapidity, usually choosing to jump from a higher branch to a lower one, and then climbing up the tree to make a fresh start. The temperature on the hills varies considerably. During the time I was there-the rainy season, from the middle of April to the middle of June-it was never very hot, one night the thermometer going down to 44 deg. on the ground. Of course, in the dry season it is much hotter, but the natives say these animals are much more plentiful in the rains, and that the rainier the season the more they see. They litter twice a year, once about September, the young remaining in the nest for about nine weeks, during which they are fed by the old ones on such food as shoots and kernels; they do not attempt to jump till the end of that period, extending the length of their jumps with their growth. I do not know the other time of breeding, or whether they have a regular season. The hunters told me that two or three were usually born at one birth, and never more than four."

This extensive family includes not only ordinary squirrels, but likewise 
the typical, or northern flying-squirrels, together with marmots, ehipmunks, etc. The family is clistinguished from the last by the absence of seales on the bushy tail, and the presence of postorbital processes defining the linder border of the socket of the eye; while if a squirrel Tribe.parachute is developed, it is stipported by a cartilaginous rod arising from the wrist. The palate is broad, and there Family are usually two pairs of upper and one of lower premolar Sciuriele. teeth, although the first pair in the upjer jaw, which are always small, may be shed at an carly age, or even wanting. The eheek tecth are rooted, and in the young always bear tubereles on their crowns, although in the adult these may be converted into deep plates separated by clefts extending partially across the crown. With the exception of Madigascar and Australisia, the family has a cosmopolitan range.

The first genus is represented only by the large groove-toothed squirrel (Kihithrosciurus) of Borneo, easily recognised by the numerous vertical grooves on the upper incisor teeth. Next come the Ethiopian spiny squirrels (Yerus), typically characterised by the coarse spiny fur, the small size or absence of external ears, and the comparatively straight and long elaws; while they are further distinguished by certain features of the skull and teeth. This group ranges all over Africa from A byssinia southwards. The numerous species of true squirrels (Scimves) differ from the last by the shrortness of the skull, in which the postorbital processes are more elongated. The tail is rery long and bushy ; the ears are generally large, and in some instances tufted; there are only four functional toes to the fore-feet; the claws are long, curved, and sharp; and the females have citler four or six teats. The cheek teeth have low tuberculated crowns. The genus has a very wicle distriluntion, but attains its maximum development in the Malayan countries. Whereas, with the exception of the muzzle and chest, the common squirrel ( $S$. vulyuris) is nearly uniform brownish-red, the little Indian palm-squirel (S. pulmarum) is marked with longitudinal dark and light stripes on the back, and many species have two or three conspicuous bright-coloured and white bands on the flanks, while one American form is peculiar among Mammals in assuming a special brilliant breeding-clress. All the squirrels are arboreal, but their habits are too well known to need special mention. From the true squirrels the ground-squirrels, or chipmunks (Tamias), of the northern portions of both hemispleres, ditfer by having pouches inside the cheeks for the storage of food; and are also characterised by the presence of distinct white or greyish-white longitudinal stripes bordered by black bands on the sides, or sicles and back. Chipmunks, which are among the most common of North. American Rodents, are terrestrial in their habits, and chicfly remarkable for the accumulations of food which they collect for winter use; such supplies being carried to the place of storage in the capacions cheek pouches.

The susliks, or grophers (Spermophilus ${ }^{1}$ ), which have a geographical distribution nearly similar to that of the chipmunks, althongh most of them are found in desert regions where the latter never go, are readily characterised by their somewhat slender and squirrel-like form, the presence of cheek pouches, and the rudimental first toe of the fore-foot, which may, however, be provided with a nail. In the skull the first upper premolar is larger than in the true squirrels, and the two series of clieek teeth are nearly parallel. The ears may be either minute, or relatively large and tufted ; and the tail 
may be either of medium length, (r) reriuced to a stump. The coloration, which is never like that of the chipmunks, may be either uniform or striped. In liabits, the susliks are social and burrowing animals, selecting dry sandy soil for their underground habitations; and in the colder portion of theil range hibernating during the inclement montlss of the year. The common American species is the striped gopher (s. tridecemlineatus). Susliks agree with the tion following genera in that the incisor tectl lack the compressed form chanacterising those of the squirels and their immediate allies, and also in the simple structure of their molars. The prairie-marmots, or prairiedogs (Cynomys) of North America form in some respects a conmecting link between the susliks and the true marmots, being intermediate in size between the two, and having stouter bodies than the former. Their ears are small, and the tail is generally short, while their cheek pouches are less capacious than those of the susliks, and the first toe of the fore-feet is well developed, and carries a large claw. The massive skull has the large postorbital processes directed nearly outwards, and the stout molar teeth, which form two series converging behind, differ from those of both the susliks and marmots in liaving three, in place of two grooves, on their crowns. In habits the prairiemarmots very closely resemble the true marmots, but the mounds of earth they throw up from their burrows have a very distinct crater-like for'm.

From the prairie-marmots the true marmots (Aretomys) may be distinsuished by their stouter form, the absence of cheek pouches, the rudimental first toe of the fore-foot, which carries only a

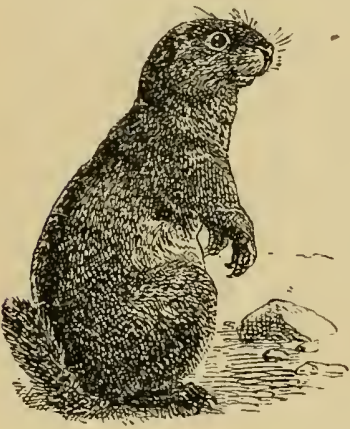

Fig. 56.-Соммох MАRмот (Aretomys mamotta). small flat mail, and the above-mentioned differences in the form and direction of the upper molar teeth. Marmots are common to the northern half of both the Old and New World, ranging as far south as the Pyrences, Alps, and Himalaya. They are among the larger members of the order; the common Alpine marmot measuring more than 20 inches in length, exclusive of the tail. In appearance they are stoutly built, with short legs, powerful claws, a broad and short head, small and roundedears, and a bushy tail, usually less than half the length of the body. Their' fur is moderately long, and somewhat stiff; while their colour exhibits various tints of golden or reddish-brown, shading, more or less markedly into black along the back and tail, the tip of the latter being always blackish. As regards their habits, marmots live in extensive societies, their large and deep burrows forming warrens, and communicating with one another underground. All the regions they inliabit experience a very severe winter climate, during which the marmots hibernate securely in the depths of their burrows, only waking from their long sleep at the melting of the snows. Those that dwell in the mountains of Europe and Asia generally select open valleys or uplands, where the soil is more or less sandy, for the construction of their burrows, the neighbourhood of water being essential. In Russia and Siberia they inhabit the open and barren steppes. Extreme wariness, especially where they dwell on frequented routes, is characteristic 
of all marmots. During the daytime they may be scen playing around their burrows, at the mouths of which they sit upright when the least alarmed. In this situation, the moment they catch sight of a suspicious object, they throw themselves down their burrows, which are often situated at the root of a rhubarb plant, with the well-known shrill scream, at the sound of which any other animal that may be in the vicinity immediately takes alarm. It is almost superfluous to observe that, in order to secure them when thus sitting, it is necessary to shont marmots cleat ; for, even with the slightest kick left in them, they will often manage to tumble into their holes before they can be seized. When disturbed for the first time, they will usually rappear after a short interval; but after a second fright they generally sulk, and selclom show agrain. Wishing to secure a number of skins for rugs, the writer and his party, after much toil, once succeeded in turning a small livulet into a narmot warren on one of the platenus of Little Tibet, but, to their dismay, were uniable to "bolt" a single marmot - the whole colony preferring to perish miserably by drowning in their burrows rather than face their foes in the open.

In Europe there occur two species of marmot-namely, the Alpine marmot (A. mamotta) and the somewhat smailer bobac (A. bobuc). The former is an exclusively European form, only found in the three disconnected mountain chains of the Pyrenees, Alps, and Carpathians, at elevations varying between 5,000 and 1,000 feet, where it meets with a climate suitable to its existence. The second species, in which the head and body measure about 15 inches in length, has its western limit on the German frontier, and thence langes tastward through Galicia and Poland, right across the steppes of Southern Russia, and thence to Amur, Kamschatka, and Siberia-the climate of these regions being sufticiently rigorous to admit of the existence of these animals at ordinary elevitions. It is noteworthy that marmots do not extend to the north-westward either into Lapland or the Scandinavian peninsula, where the country does not present the character of the Russinn steppes, which in summer are scorclied by a burning heat, and in winter form a trackless expanse of snow. The southern limits of the bubac do not appear to be yet definitely known. When, however, we reach the mountains of Yarkand and other parts of Turkestan, and thence proceed southwards to the northern districts of Ladak in Wester'n Tibet, we meet with a very similar, although somewhat larger, short-tailed species known as the Himalayan marmot (A. himalaycures), the range of which appears to extend eastward into Tibet proper, where this species has been described under other names. The Iimalayan marmot is another species which, at all events in the southern portion of its range, can only find a suitable climate at great elevations, the height at which it is usually found in Ladak and 'Turkestan varying between 12,000 feet and something over 17,000 feet. Another species is also met with in the neighbourhood of Yarkand and the Pimir, at elevations of about 13,000 feet, known as the golden marmot (A. arrers), and is distinguished from the last by its more golden colour, and shorter and thicker tail. Examples of this species were also obtained in Turkestan during Przewalski's expeditions. To the south-west the writer, when crossing the elevated plateau of Deosai, or "Devil's Plains," situated between the town of Skardo on the Indus in Western Tibet and the mountains north of Kashmir, the elevation of which is between 12,500 feet and 13,000 feet, found marmots exceedingly abundant, although he was unable to cletermine to which of the two preceding species they belonged, or whether they were nore nearly 
allied to the Cabul species to be immediately mentioned. The Deosai plateau, it may be mentioned, is one of the most desolate and dreary regions that can well be imagined, consisting of rolling hills and dunes of sand and gravel, with a sparse coating of vegetation, where almost the only living things to be seen are marmots and mosquitoes. The climate is most rigorous; the sun's rays beating down with terrific power through the dry and rarified atmosphere during the day in the summer months, but the temperature rapidly falling, and often sinking below the freezing point after sunset. In winter this region is absolutely impassible; so that its climate may be regarded as an intensification of that of the steppes.

The Cabul marmot (A. dichrous), which is also met with in Turkestan, is a smaller species than the golden marmot, from which it is further distinguished by its duller coloration, and the absence of any black on the back. The regions whence it is obtained have a climate of the general character mentioned above. The last spccies to be mentioned is known as the red or longtailed marmot (A. cardatus). This appears to be the largest of all those found in the Old World, attaining a length of neirly two feet, exclusive of the tail, which measures about one foot. It is readily recognised, not only by its size and long, bushy tail, but also by the full rufous tinge of the hair, and the large extent of black found on the back of many individuals, the skins being handsomer than those of any of the other kinds.

The distribution of this Himalaym marnot is extremely interesting as showing that these animals can only exist in an aricl climate more or less nearly approaching that of the steppes or of Tibet. To understand this, it must be mentioned that the immense mountain-barrier lying to the nortiward of the valley of Kashmir, the lowest gap in which lias an elevation of 11,500 feet, cuts off almost completely the clouds coming up from the plains of India from the more or less arid regions to the northward. Now, whereas marmots are totally unknown on the great range of mountains south of the Kashmir valley, where the rainfall is excessive, directly the traveller reaches the summits of the passes of the northern range, and thence far down on the northern side, the shrill cry of the red marmot strikes his ear. This is very noticeable in travelling on the Central Asian high road up the Sind Valley, when le crosses the Zogi Pass into the Tibetan area. This marmot may likewise be met with on crossing the passes leading to our distant frontier station of Gilgit; and it also appears to range into many parts of Ladak, although its exact limits are not yet accurately defined. It is thus evident that marmots now exist only at such elevations or in such regions as possess an extreme continental climate-that is to say, one where the summers are hot and the winters excessively cold. It has been shown that in Emope the Alpine marmot inhabits three distinct and isolated ringes, separated from one mother by low-lying areas possessing a climate entirely different from the type above referred to ; and it is thus clear that it could not have crossed these unsuitable low areas while the climate of Europe was the same as at the present day. 'That there must have been at some time or other a direct communication between these isulated marmot areas is, therefore, selfevident.

The next section of the Sciwide is formed by the true, or northern flying squirrels, of which there are three well-marked generic groups. In all these animals the parachute is supported by a rod of cartilage projecting like a yard-arm from the outer side of the wrist, and there is another expansion of skin connecting the fore-limbs with the neck, while there nay be a third 
between the hind-legs and the root of the tail. The whole of these flyingsquirrels are characterised by the complex structure of their molar teeth; and as their skulls differ considerably from those of other members of the family, they must be regarded as constituting a sub-family group by themselves.

Flying-squirrels of this group have existed since a comparatively early epoch in the Tertiary period, and it is consequently impossible to affiliate them with any of the genera of ordiniry squirrels ; so that it is quite likely that they have originated from a totally extinct genus or genera. Hence, it is impossible to say whether the three genera into which they are divided have all taken origin from one non-volant form, or whether the power of flight lias been separately evolved in each of the three generic groups. Of the three genera, the one known as Sciuroptems inchuces the lesser flying-squirrels, all of which have the erowns of their molar teeth comparatively low, and the parachute of moderate wilth, and not including any portion of the tail. Having one representative in North Amerien, and a second in North. Eastern Europe and Siberia, the lesser flying-squirrels are mainly eharacteristic of India and the Malayan countries. While some of the larger kinds measure as much as 12 inches from the nose to the root of the tail, in the pigmy flying-squirrel of Cochin-China and Arakan the length of the head and body searcely exceeds five inches. These squirrels collect in numbers in hollow trees, where they remain in slumber during the daytime, to issue forth at night for the purpose of feeding. Climbing to a coign of vantage on some tree, they take their flying leaps to the bough or trunk of another at a lower level, not unfrequently covering a distance of some 30 or 40 yards. The length of the leap is, however, still greater among the members of the next genus, reaching from 60 to nearly 80 yards. The larger flyingsquirrels (Pteromys) form an exclusively Asiatic group, represented by some ten species, and extending from the Malayan countries as far nortl as Eastern Tibet. In addition to their superior dimensions, these flying-squirrels are distinguished from the preceding group by the greater width of the parachute along the sides of the body, and the enclosure of the base of the tail in the portion connecting the two hind-legs. The tail itself is, moreover, completely cylindrical, instead of slightly compressed; and the molar teetl have rather taller and more eomplex erowns than in the lesser flying-squirrels. In some of the larger speeies the head and body may measure as much as 18 inches in length, while the tail may reach to 24 or 25 inches. The last member of the sub-family is the woolly flying-squirrel (Eupetaurus) - a large species from the neighbourhood of Gilgit, distinguished by the very tall molir teetl, which have flat, instead of ridged, mastieating surfaces.

Finally, the five speeies of pigmy squirrels (Nannosciums), of which one is West African, a second from the Philippines, while the other three are Bornean, eonstitute another sub-family, elaracterised by eertain peculiarities in the skull and the eomplex strueture of the molar teeth.

An unimportant family is constituted by two North American Rodents known as sewellels (Haploden ), which differ from the Sciuridce by the absence of postorbital processes in the skull and the rootless molars. According to Dr. Merriam, they are aquatic in their habits.

The Sewellels.Family

Haplodontidar.

The last family of the squirrel-like group of the order is represented only 
by the beaver's ('́cstor), easily distinguished by the broad, flattened, and scaly tiil. The skull is massively made and devoid of postorbital processes, with the angle of the lower jaw rounded; the cheek teeth The Beavers. - clo not derelop roots, and have their crowns marked with Family re-entering folds of enamel ; the premolars are limited to a Castorinle. single pair in each jaw ; and the hind-feet are webbed. Beavers, which are the lirgest Rodents in the Northern Hemisphere, and are thoroughly aquatic in their habits, are confined to certain parts of that hemisphere, being found only in Europe, Northern Asia, and North America. The actual extent of their range in the Old World is nut so clearly defined as could be wished. Thers is, howerer, ample

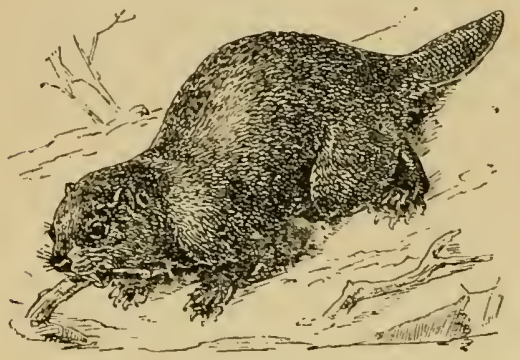

Fig. 5i.-De.tvere (Castor jilier). evidence that this range originally extended from the British Islands in the west, to France, and perhaps Italy, Spain, and Creece, in the south, thence eastward to Asia Minor, and possibly Persia, and to the north-eastward as far as the Yenesei and Lena in Siberia, and thence to Amur, Scandinavia, and Russia ; but there does not appear to be any good evidence as to the eastern limits of beavers in the direction of Northern China, although it may not be improbable that in this region these animals only inhabited the rivers flowing northwards into the Caspian Sea and the Arctic Ocean. On the Continent, beavers were finally exterminated in Holland in 1825. In France a number of names, sucl as Bievre, Beurron, and Beuvray, or Beury, as well as the ancient Bibrax and Bibracte, point to the originally wide distribution of benvers. Fossil remains of these animals occur in many places, such as Abberille, in the valley of the Somme, the neighbourhoods of Paris and Clermont, and the cavern of Lunel-Viel, in Hérault. The Rhone and its tributaries, especially the Gardon and the Cése, appear to have been the great stronghold of these creatures within the historic period. Even, howerer, in the last century they had become exceedingly rare, owing to the incessint persecution to which they had been subjected. Still, they have been met with at intervals even up to the present day. Thus Gervais records the capture of a specimen in 1846 , close to the port of Arignon, and mentions having seen two other's near Arles. The floods of 1840 doubtless led to the destruction of a considerable number, so that after this date they were much more rare than formerly. The circumstance that the monks of a monastery on the right bank of the Rhone at Villeneuve-les-Avignon included bearers among their plats muigres, indicates that in earlier days they were probably abundant. MI. St. Hilaire, in the Bulletin de la Societé r'Acclimatation for 1888 , records the capture of three specimens during that year in the Rhone, and a recent witer concludes that from 25 to 30 bearers are still ammually killed in that river and its tributaries. There does not appear to be evilence that these animals linger in any other of the French rivers.

It is mentioned in some of the old writers that beavers occur ravely in Italy, Spain, and Greece, but it is difticult to find on what evidence these 
statements rest ; but since remains of the existing species are found in the superfieial beds in the neighbourhood of Rome, there is a eonsiderable likelihood that its alleged occurrence in Italy within the historie period may be based on fact. The lake-cities or "phalbauten" of Switzerland afford evidence of the abundance of beavers in that country during the pre-historie period, and in the last eentury a few were still to be found in the Aar, Limmat, Reuss, and other tributaries of the Rhine. That some lingered on into the present century is proved by a specimen from the Rhine exhibited in the Jardin des Plantes in 1829 ; and there is evidence of their presence in the early part of this century both in the Rhine and the Rhone basins.

In Germany fossil remains of beavers are found in several of the great caves, more especially in that of Gailenreuth in Franeonit. As late as the elosing decades of the last and the early ones of the present century, colonies of these animals were abundant on many of the Gemnan rivers, remnants of which still exist here and there up to the present time. In North-Western Germany the Moselle and the Maas were formerly noted habitats of these animals, although we have no record of the date of their disappearanee, even if this has yet taken plaee. The Lippe, which, like the Moselle, is a tributary of the Rhine, was likewise a well-known haunt. Thus at Ketlinghausen, and still higher up the river at Padderbun, beavers were abundant, and formed regular colonies, like their Canadian cousins, at the beginning of the present century, and it is probable that some few still exist. Proceeding north ward to the basin of the Elbe, the account by Meyernick, published in 1829 , of a colony on one of the tributaries of this river near Magdeburg, is too well knuwn to need repetition. Lower down the river at Wittenberg, and also at Kähmert, they were also comparatively abundant in 1801; and at the former lucality there is evidence of their occurrence in 1848, and again as late as 1878 , when no less than eight individuals were observed in an old river ehannel. Again in Bohemia, the valley of the Moldau, with its numerous afluents, which forms the upper reaches of the extensive basin drained by the Elbe, abounded in beavers up to the year 1848, since whiel date, in spite of strict precaution, they have probably been greatly reduced in numbers. The basin of the Danube, in South-Eastern Germany, is, however, probably the greatest stronghold of German beavers at the present time. In 1837 the small river Amper, a tributary of the Isar, situated some distance to the north of Munieh, was oecupied by several colonies, which were preserved as a valuable eommereial property. There is also good evidence of the existence of the last-named colonies, as well as of others on the Isar, Iller, and Salzach - tributaries of the Danube-up to 1846, since which date I have been unable to eome across any records of them.

There is a dearth of information with regard to the presence of beavers lower down the Danube valley in Austria-Hungary and Turkey; but it is certain that they did, or do still, exist in the former regions; and they have also been recorded from the Lower Danube on well-authenticated evidenee. That beavers may have existed, or still exist, in other parts of European Turkey, is suggested by the fact of their appearance in Asia Minor. They have been recorded in the upper Euphrates valley by Helfer in a book published in 1879; while Eichwald long since mentioned their occurrenee in the rivers of the Caucasus; and Smarda included them in his list of the Mammals of MIesopotamia. MIessis. Danford and Alston observe that trustworthy authorities at Kaisariyeh (a town in Rumelia, on the Kizil river, flowing into the Black Sea) stated "that in the marshes between that place 
and Sudjesu there existed an animal like an otter, but which had a broad, hairless tail." And there can be no reasonable doubt that these authors are right in identifying this creature with the beaver. The possible eastward extension of the beaver into Persia is suggested by Mr. Blanford.

From the Caucasus the range of the beaver may be traced through Russia, Poland, and Livonia, to Lapland, and thence to the Scandinavian Peninsula. Immediately to the north of the Caucasus, Oken recorded their abundance in the valley of the Tereck in 1842. In Central Russia there is no definite evidence of their occurrence, but in the Baltic provinces of Livonia the record is again ample. Many places in this district take, incleed, their name from beavers, and about the middle of the last century these animals appear to have had populous colonies on most of the streams of the country. In 1724 , so common were they, that their dams were a serious inconvenience to the clistrict, owing to the Hoods caused by them. It appears, however, from the researches of Loewis, that bearers are now completely exterminated from Livonia, the last specimen haring been shot in 1841 . In 1889 the existence of a few beavers in the river Svislotch, Government of Mink, and also in the Dnieper, was recorded. In North Russia the rivers Dwina and Petchora, flowing respectively into the Whice Sea and the Arctic Ocean, were the resorts of beavers as late as 1842 , but it is probable that they are now completely extinct. Passing eastward into Silesia, there is evidence of the former wide distribution of these animals, it being stated that they extended as far as Amur. In the basin of the Obi, in Western Siberia, they appear to be extinct in the valley of the Irtsh, where they were formerly abundant; but at least up to 1876 they continued to be found in the small afluent of the Obi known as the Pelyin. Beavers have long since completely disappeared from the Yenesei, in Eastern Siberia, but information is still required with regard to the more easterly valley of the Lena. In Poland and Lithuania beavers may still linger on ; but, as already observed, there is a want of evidence as to the limits of their original range in the region lying eastward of a line comnecting the Baltic with the Black Sea. Reverting to the neighbourhood of the White Sea, and pursuing a course towards the north-east, it appears that Lapland lost its beavers early in the present century. The skull of the last specimen known to have been killed in these regions was obtained about 1830 .

In Scandinavia, although beavers were widely distributed in the last and early part of the present century, it appears that they have now totally disappeared from Sweden but still exist in at least three remote spots in Norway. The number of specimens living in the latter country in 1880 was estimated at not more than 60 ; but Collett placed their number at about 100 , and, as they were strictly preserved, he did not consider that they were decreasing. Completing this survey of the range of the Eurupean beaver with Denmark, evidence of its former existence is found in the shape of skulls and bones from the mosses and turbaries, while it is also known to have lived there within the historic period. As to the precise date of its extermination, there appears no definite record.

With regard to the range of the American beaver, few words will suffice. It may be observed, in the first place, that, although some writers are indisposed to regard this beaver as specifically distinct from the European one; yet, from the constant difference in the form of the bones of the nasal region of the skull, it seems to be a valid species, the proper name of which is Castor canadensis. The earliest epoch of its occurrence is in the Pleistocene 
deposits of South Carolinn, New Jersey, Tennessee, and other localities, as well as in the cavern-deposits of Virginia and Pennsylvania. Within the historic period its range extended from Alaska and the Hudson Bay territories in the north, along the Atlantic seaboard as far south as Georgia and Northern Florida, and thence along the Gulf of Mexico as far as the Riv Grande in Texis, and for some distance into Mexico itself, while on tlie Pacific Coast it is known to have extended as far south as California and Arizona. In the intcrior of the continent beavers were naturally contined to the neighbourhood of the great lakes and river villeys. W'riting in 1877 of the American beaver, Dr. Allen observes that "its present range, however, is much less extended, very few being found east of the Mississippi River south of the great lakes, and it is everywhere less numerons than formerly. Some still remain in Northern Maine and in tho Adirondack region of New York, and probably some still survive thence southward in the sparsely settled districts to Alabama and Mississippi. A recent article states that they are still abundant in portions of Virginia. Their existence in grent abuudance throughout the Atlintic States, and thence westward to the Pacific, is thoruughly attested. They having been less persistently hunted during recent years than formerly, they are reported to be slowly on the increase in most lucalities where they still remain."

The dormice are the first representatives of the second section of the Rodents, or Myomorpha, whicl presents the following characteristics. In the skull the zygomatic arch is slender, and usually lias the jugal bone extending but little forwards, being supported by a long backwirdly directed process of the upper jaw-bone, or maxilla. There are 110 posturbital processes defining the hinder borter of the socket of the eye ; and, except in one

The Dormouse

Tribe.-Family Myoxislue. sub-family of the syctucide, the angle of the lower jaw takes origin from the inferior surface of the sheath of the lower incisor. All the members of the section differ from the Sciuromorpha in that the tibia and fibula, or bones of the lower leg, are welded trigether.

Resembling the true squirrels in shape and habits, the dormice form an Old World family of small arboreal Rodents characterised by their long hairy tail, the large size of the ears and eyes, and the shortness of the fore-limbs. There is but one pair of premolar's in each jaw, and the molars are rootecl with transverse re-entering foldings of enamel on their crowns. The dormice may be divided into two main groups, according to the structure of the stomach. In Myoxus, as typified by $M$. glis of continental Europe, the stomach is simple, but the different species, which have been arranged under several generic heads, differ considerably in other respects. In the typical snecies the bushy tail has the hairs arranged in a row on cach side, while the nolars are large, with flat crowis and complex enamel-foldings. In a second group (Eliomy's), typified by the European $M$. nitella, and extending over Europe, Asia, and Africa, the tail has the hairs arranged in two rows, but is tufted at the end, while the molars are small, with concave crowns, and the folds of enmel indistinct. The third group of the genus (Grophiurus) is solely African, and is distinguished by the tail being short, cylindrical, and tufted, while the enamel-foldings on the small molars are almost wanting. A West African form (Claviglis) differs by the shorter and more distinctly tufted tail. On the other hand, the common dormouse of England and the rest of Europe (Museardinus arellanarins) differs from all the foregoing in the thickened glandular walls of the anterior portion of the stomach; the 
molars having flat crowns, with complicated foldings of cnamel, and the somewhat bushy tail being cylindrical. The more northern representatives of the family take their name from the long winter torpor they undergo.

From the Myoxidce the very extensive and cosmopolitan family of the Murida, which includes rats, mice, and voles, may be distinguished by the total absence of premolar teeth in both jaws. The group is,

The Mouse Tribe. however, better characterised by the structure of the skull, -Family Muri- in which the frontal bones are markedly constricted, while dee. in the zygomatic arch the short and slender jugal bone is in most cases reduced to a small splint connecting a backwardly-directed process from the upper jaw-bone, or maxilla, with a forward projection from the squamosal bone at the hinder end of the skull. Still more characteristic is the expansion of the lower part of the first-named process into a large, flattened descending plate; and in most cases the large aperture in the skull for the passage of nerves situated beneath the anterior root of the zygomatic arch is elevated, and much wider above than below. The first toe of the fore-foot is rudimental, and in most cases naked and scaly. This family, which includes nure than a third of the members of the entire order, is the only one annong the Rodents represented either in Madagascar or in Australia. Although a few species are aquatic, and some arboreal, the great majority of the Muridce are terrestrial, a considerable number of them living in burrows. Some fifty gencra have been described.

The first sub-family is confined to Australia, New Guinea, and the island of Luzon, in the Philippines, where it is represented by three genera. In this group the molars, which are frequently reduced to two

The Australasian pairs in each jaw, develop rocits, and have their crowns Group. - divided into alternating oblique lobes, partially splitting up

Sub-Family into tubercles. In the typical genus Hydromys, of Australia Hydromyince. and New Guinea, the molars are two in number, and the external form is moditied for the needs of an aquatic existence, the feet being webbed, the tip of the muzzle thickly clothed with hairs, by means of which the nostrils can be clothed; while the skull differs from that of other members of the family in that the aperture beneath the socket of the eye is nearly circular, instead of pear-shaped, and the descending vertical plate at the front of the zygomatic arch is absent. In habits the two species of this genus resemble water-voles. The genus Chrotomys, of which there is one species from Luzon, differs from the other two in having three pairs of molars; its skull being intermediate between that of the first and third gentis, and its external form mouse-like, the toes being devoid of webs. In Xeromys, which occurs typically in Australia, but is taken to include a rat from Luzon, the molar's resenible those of Hydromys in structure and number, but the skull and external form are nearly similar to those of an ordinary mouse. In size this species is not larger than the common mouse, whereas the other members of the group are much bigger.

The second sub-family is represented only by the beautiful little Malabar spiny mouse (Plutacanthomys lasinris) of Sonthern India,

Malabar spiny Mouse (Platacanthomyince). which is an arboreal form easily distinguished by the long bushy tail, which exceeds the head and body in length, and also by the presence of flattened spines mingled with the hairs. The rooted molars have their crowns divided into complete transverse laminze. 
The beautiful little large-eyed murines, known as gerbils, typify a third sub-fimily, characterised by the narrowness of the incisors, the sub-division of the crowns of the molars into transverse lamine, tho grenerally large size of the auditory bulla of the skull, and the elongation of the hind-limbs. From the other genera, the gerbils (ferbillus), which range over Southern Europe, Asia, and Africa, are distinguished by the deeply grooved

The Gerbil Group

(Crerbillince). upper incisors, and the circumstance that the first molar has one, the second two, and the third three transrerse lamine; the long tail being tufted at the tip Gerbils are inlabitants of desert districts, where they burrow in the sandy soil. Some writers separate certain species as Meriomes. The short and club-like form of the fleshy tail, as well as the very large size of the auditory bulla of the skull, serve to distinguish the African genus Pachyuromys, in which the narrow incisors are faintly grooved. Three other small genera from Africa, namely, Mystromys, Otomys, and Dasymys, differ from the gerbils and from one another in the structure of the molars; they are all typically South Afican, but the second has also been recorded from East Africa and the Congo. A fifth genus (Malacomys), represented by a single species from the Gabun, commects the gerbils with the rats, having the teeth and limbs of the former, but the long scaly tail of the latter.

Two genera of very large long-haired rats from the Philippine islands represent a sub-family in which the incisors are very broad, the molars divided into transverse laminse, and the claws large. In Phlocomys, of which there is but a single well-defined species, the ears are small and hairy, the tail moderate and sparsely haired, and the auditory bulla very small; the first molir having three, and the others two lamine. The sccond genus

The Philippine Rats (Phlocomyin $(e)$. (Crateromys) includes one very large greyish species from Luzon, which may be compared in size to a small marmot, and has a totally different type of molars.

This group, which is confined to Africa south of the Sahara, is typified by the two species of Dendromys, and is characterised by the convexity of the incisors, the rooted and tuberculated molars, hairy ears, and long claws. The members of the typical genus have the habits of dormice, a slender build, grooved incisors, and a long, scaly, thinly-haired tail. Steatomys also has grooved

The Tree-Mice (Dendromyinæ) incisors, but of stouter form, and a ratler short, thickly-haired tail ; while Loplutromys differs by its smooth incisors, and the fine flattened bristles which replace the hair. The fourth genus is Limacomys.

The large, generalised, and almost cosmopolitan group of the cricetine Muride is characterised by the rooted upper molars carrying two longitudinal rows of tubercles. It is typified by the hamsters (Cricetis) of the Old World, which are confined to Europe and Asia, and are characterised by having six tubercles on the first upper molar, large cheek pouches, and a very short tail.

Cricetine Group

(Cricetince). The true hamster ( $C$. frumenta;ins) is a burrowing species, well known on the Continent from the large amount of food it accumulates in its subterranean dwelling. The white-footed mice (S'itomys) of the New World form a very large, closely allied group, in which cheek pouches may be present or absent. They are divided into a number of sub-genera, according to habits, bodily form, dentition, etc., which have been named Rhipidomys, Oryzomys, Calomys, Vesperimus, Onychomys, Scapteromys, Phyllotis, Acodon, and Oxymycterns. S. hydrobates is peculiar on account of its fringed feet and aquatic habits; 
while another species has spines mingled with the fur. The Brazilian genus Holochilus, which includes the largest American rats, differs by the relatively larger last upper molar and the stouter skull. Another allied type are the fisheating rats (Iclithyomys) of South America, characterised by the webbed and fringed hind-feet, and their aquatic and probably fish-eating habits, while Nectomys is another allied Peruvian form. The rice-rat (Sigmodon hispidns), ranging from the United States to Ecuador, differs markedly from Sitomys in the pattern of the tubercles on the molar teeth. Writing of these rats, Mr. G. Lincecum, in the Americun Nuturalist for 1872 , states that they dwell together on the prairies of Texas in families in much the same mamner as the pr:airie-marnot. "They prefer light sandy soil on the prairie, where the shivered limy sandstone crops out; but where the prairie is enclosed and cultivated they take possession of the fencing, and burrowing under the bottom rail, exeavate sufficient colls, and construct their copious giassy becls there. Out on the prairie, in the wild state, they make one principal burrow, in front of which they pile up the earth that comes from all their subterranean galleries. They rarely extend their main burrow more than eight or nine inches in depth, while their underground passages are seldom more than four or fire inches below the surfice. They also construct several secret outlets, opening 10 or 12 inches from the main hole, which opening they very ingeniously conceal by strewing a few grass blades over it; and so, when the rat-hunter attacks the citadel, the inmates escape through some of the concealed passages. Eight or nine inches deep, and turned a little to one side in the main hole, is a carity, seven or eight inches in diameter, filled with fine, soft grass hlades, which must be quite warm and plensant, serving the family for winter-quarters. During the hot months they construct nice grass beds in a basin-like cavity, which they dig out under the sides of tufts of grass, or heaps of bush." From all the abore the South American genus Rhithrodon, with five rat-like species, and the North American lihithrodontomys, containing three species of the size of large nice, differ in their grooved upper incisors. Another well-marked type of the group is presented by the North American wood-rats ( $N$ cotoma), in which the molars simulate the prismatie pattern charaeteristic of the roles. Certain species in which the tail is very bushy have been separated generically as Tconoma; while $N$. alleni has been referred to a distinct genus under the name of Hodomys. The next five genern of cricetines are confined to the island of Madagascar, where they are the sole representativos of the Rodent order. Of these, Hypogeomys is a large fawn-culuured rat, with large ears and feet and a long tail; Nesomys include; two long-haired rufous species; Brachytarsomy/s contains a single rat with velvety fawn-colourer fur, short feet, and a long tail ; the single species of Hallomys differs from Nesomys by the much longer hind fect; while the two dormouse-like representatives of Eliurus are easily recognised by the short and nearly naked ears, and hy the long tail being bushy, except on its basal thircl, where it is scaly. The last representative of the subfamily is the crested rat (Tritophomys imhansi) of North-Fastern Africa, so named on account of the crest of long hair rumning along the back. This very large rat, which is arboreal in its habits, differs from all other members of the family in the first toe of the fore-foot being opposable, the rudimental collarbones, and by the bony roof covering the muscles of the hinder part of the skull. All the hair is long, the long tail bushy; and the colour black and white. The animal has quite unnecessarily been made the type of a distinct family. 
Closely allier to the cricetines, of which they may be regarder as a specialised branch, the large group of voles are distinguished by their generally rootless, or imperfectly rooted molars being composed of two longitudinal rows of alternating triangular prisms, The vole Group Externally they differ in most cases flom the typical rats and mice by their heavier and less elegant form, less active

(Microtinue). movements, smiller eyes, blunter muzzle, smaller ears, and shorter limbs and tiil. They are restricted to Europe, Asia north of the Himalaya, and North America. An annectant form between the cricetines and typical voles is the North American genus Phenacomys, in which the molars develop roots. The typical genus Microtus, which includes nearly half a hmodred species ranging over Europe, Northern Asia, and North America, is sufticiently characterised by its rootless molirs and the naked soles of the feet; the British forms being the water-vole (M. amphibins), the field-vole (M. agrestis), and the red, or bank-vole ( $M$, glarcolus), Each of these is the representative of a distinct sub-generic group, severally characterised by the number of prisms in tho molar teetl, and to which the names Paludicola, Agricola, and Evotomys have respectively been applied, The extraordinary hordes in which some species of land voles make their appearance at certain seasons, and the damage they then inflict on agricultural produce, are matters of common knowledge. Tho round-tailed musk-rat of Florida, which has boen rogarded as constituting a gemus ( $\mathrm{N}$ cofiber) by itself, is considered by Dr. Merriam to be not more than a sub-genus of Mierotis, Nearly allied is the true musk-rat, or musquash (Fiber zibethicus), of North America, which is the largest member of the group, and measures nearly a foot in length to the root of the tail. Heavily built, it is characterised by its broad head--which joins the body without any well-defined neck, - short limbs, small eyes, ears nearly concealed in the thick, beaver-like fur, and the rudimental first toe of the fore-foot; the long tail being laterally compressed, scaly, and sparsely haired, The general colour is dark brown, tending to black on the back, and grey on the under-parts. Both sexes have a gland sccreting the musky substance from which the animal derives its name. Although its toes are not webbed, the musk-rat is an aquatic creature, feeding on a mixed vegetable and animal diet, Its fur is of considerable value; and the skull is very similar to that of Microt?s. Another distinct generic type is presented by the groove-toothed vole (Symaptomys) of the United States, in which the upper incisors are grooved, while the external form resembles that of the true voles, and the molars are like those of the lemmings. The latter Rodents (Myodes), of which there is one Old World and one North American species, differ from the voles by their heavier build, the blunt convex head, very short tail and ears, the hairy soles of the small feet, the bevelled upper incisors, and the pattern of the molar teeth.

The common lemming ( $M$. lemmus), which measures about five inches in length, and has yellowish-brown fur with darker spots, is remarkable for the periodical migrations undertaken by its countless swarms ; these hordes pass. ing over every obstacle in their conrse till they finally reach the sea, in which they perish. Nearly allied to the last genus, the circumpolar bancled lemming (Cnniculus torquatus) may be easily distinguished by the absence of external ears, the shortness of the feet, which are thickly haired beneath, the rudimental first toe of the fore-foot, and the great length of the claws of the third and fourth toes of the same. The molars apploximate to those of the voles, but the first in the upper jaw differs 
from that of all the other members of the sub-family in having seven prisms.

Although frequently regarded as representing a sub-family by themselves, the mole-voles, of which there are two genera, may be considered merely as voles specially adapted for a subterranean existence; the limbs and tail being very short, and the body somewhat mole-like, while the eyes are small. In the genus Ellobius, with one species from Russia, and a second from Afghanistan, the claws are short, whereas in Siphneus, of which there are several representatives from Central and Northern Asia, those of the fore-feet are enormously powerful.

In the typical rats and mice and their allies, forming the murine group of the family, the molars are rooted and tuberculated, with three rows of tubercles on at least the anterior ridge of the first one in the Typical Group upper jaw. Indeed, with one exception, there are three longi(MLurinue). tudinal rows of tubercles on all the upper molars; while, save in one genus, there are two such rows in the corresponding lower teeth. The whole group is restricted to the old World, being represented in Australia and New Guinea, but unknown in Madagascar. The great majority of forms are very similar in external appearance, their build being light, their eyes large and bright, their tails long and scaly, their movements active, their coloration sombre, and their habits generally burrowing and nocturnal.

The least specialised member of the family is a small mouse from the Congo Valley, known as Deomys, which differs from all the others in that only the first ridge of the anterior upper molar has three rows of tubercles, the other two ridges of this tooth and all those of the other molars having but two such rows, as in the cricetines. On the other hand, Berdmore's rat (Hapalomys berdmorei), from Burma, appears to be the most specialised of all, the lower as well as the upper molars having three longitudinal rows of tubercles. Another peculiar genus (V andelevirii) is represented by a species extending from India to Yumnan, and characterised by laving flat nails on the first and fiftl digits of both feet, as well as by the great length of the tail. North-Eastern India and some of the countries to the east of the Bay of Bengal are the lome of the peneil-tailed tree-mouse (Chiropodomys), distinguished by having flat nails on the first cligit of both feet, whereas all other members of the family, except one species of $M \Gamma u s$, have a flat nail only

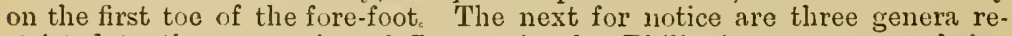
stricted to the mountains of Juzon, in the Philippine group, two being represented only by a single species. By far the most remarkable of these is the shrew-rat (Rhynchom!s), distinguished by the shrew-like prolongation of the muzzle, the short and feeble incisors, and the reduction of the molars, which are very small, to two pairs in each jaw. Not improbably this species, which is of the size of the black rat, and of a uniform olive-grey coloration, subsists on insects or larve, as the incisors appear too weak for gnawing. The second genus, Carpomys, is represented by two somewhat dormouse-like rats, with thick, woolly fur, and the long tail well haired; while the single species of Batomys differs by the hind-feet being wider and shorter, and the fore-feet more elongated.

The true rats and mice constitute a genus (Mus) having a distribution coextensive with that of the sub-family, and including nearly 150 species. In these Rodents the incisors are narrow and smooth, the molars of the typical murine structure, the formina at the anterior end of the bony palate 
elongated, both the eyes and ears large, the extremity of the muzzle naked, the fur soft, occasionally mixed with spines, a flat nail on the first toe of the fore-foot, the long and nearly naked tail covered with overlapping rings of scales, and cheek pouches absent. The species found in Britain are the common rat $(M$. decumcuns), which appears to have been originally a native of Western China, but has now been introduced into all parts of the liabitable globe ; the smaller and sharper-nosed black rat ( $M$. vattus), which is likewise an Eastern form ; the conmon house-mouse ( $M$. musculus), also hailing from the East; the wood-mouse $(M$. syluaticus), together with a larger variety known as $M$. fluvicollis; and the tiny harvest-mouse ( $M$. mimutus). The latter, it is well known, builds small globular nests between several cornstalks, and is itself able to ascend a single one of such stalks, aided in climbing by its partially prehensile tail. It will be unnecessary here to refer to the habits of mice in general, but some reference may be made to the socalled "singing" and "waltzing mice." Singing mice are ordinary housemice, which, owing to some disease of the vocal organs, are enabled to produce musical notes. Waltzing mice are a Japanese product, of which the following account is given by Mr. E. R. Waite:- "At first," he writes, "a visitor probably regards the mice as mere colour varieties of the common white race. A moment's observation reveals the peculiarities of the breed, and attention is riveted by their strange performances. Early in life they exhibit the tendency which has earned for them the name above employed. When a nursling leaves the nest its gait consists of an evident attempt to proceed in a straight line ; this is frustrated by a tremulous movement of the head, which is nerrously shaken from side to side. Shortly, a tendency is exhibited to turn; this develops into a rotatory motion, performed with extraordinary rapidity, which constitutes the peculiarity of the waltzing mouse. The ordinary rontine of daily life is constantly interrupted by this mad disposition to whirl, frequently indulged in for several minutes, and, with an occasional stoppage of a few seconds, continued for hours. The floor of one cage being somewhat rough, the mice actually reduced their feet to stumps before it was noticed. Like ordinary mice, they sleep during the day, but apparently waltz the wlole night long. If, however, they are disturbed during daylight, they leave their bed and work off some supcrfluous energy. The rotation is so rapid that all individuality of head and tail is lost to the eye, only a confused ball of black and white being recognised. Very often they spin in couples, revolving head to tail at sucl a speed that an unbroken ring only is perceived. . . An individual generally spins in one direction only, and the majority turn to the left." Althongh probably due in the first instance to brain-diseasc, the peculiarity, like the "tumbling " of tumbler-pigeons, is now hereditary in the breed.

The longitudinally-striped Barbary mouse ( $M$. barbanus), together with certain other more or less variegated African species, are frequently separated from MIus as a distinct genus, under the name of Avicanthis. Nearly allied are the numerous species of bandicoot-rats (Nesocia), ranging in Southern Asia from Palcstine to Formosa, and from Ceylon to Kashmir, but also extending into Turkestan and the Lob-nor district of Central Asia. They differ from the typical genus by the wider incisors and molars; the tubercles on the latter being partially comnected by transverse ridges so as to produce a semilaminated type of structure. The two species of groove-toothed mice (Go? $G$ nda), one of which is Indian and the other African, are easily distinguished by having a groove down each of the front incisors. In addition 
to having a species of Mits, Australasia is the home of four peculiar genera of the sub-family. Of these, the mosaic-tailed mice (Uromys), ranging from the Aru Islands to Queensland, may be distinguished from MIus by the seales on the tail being united by their edges so as to form a mosaic-like parement, instead of overlapping. The prehensile-tailed mouse (Chimuromys), of which there is but a single species inhabiting the mountains of New Guinen, is characterised by the naked tip of the tail being endowed with prehensile power; the scales of the rest of the tail being arranged in diagonal rows. The upper molars hare their tubercles very numerous, and arranged in a complex manmer; while there are several peculiarities eonnected with the structure of the skull. The numerous Australian species of jerboa-rats (Conilunts) are easily recognised by their elongated hind-limbs, and long cars and tail. They are inhabitants of desert clistricts, where they loop after the mannel of jerboas. The fifth genus (Mrastecomys) is known only by a single Tasmanian species, and differs from Mins by the great wilth of the molars, and the reduction of the number of teats to four ; the fur being noticeable for its length and softness. Differing remarkably as regards the latter feature, the spiny-mice (Acomys), of which there are about seven small-sized species, take their name from the fur being almost entirely replaced by flattened spines. The skull and dentition are very similar to those of the type genus, but the ascending process of each branch of the lower jaw is much smaller. These mice range from Syria tlurough East Africa as far south as Mosambique, generally frequenting cleserts, whero some, at least, feed on bulbs. The longnosed rat (Echinothrix) of Celebes takes its name from the elongation of the face, and is further characterised by the faint grooving of the incisors, and the thick admixture of spines among the fur. The small blind-mouse (Typhlomys) of China is sufficiently characterised by the minute size of the eyes, which are almost eoncealed by the long lashes. Except that it has smaller ears, it is otherwise very similar in appearance to a house-mouse. The Afrien pouched rats (Cricetmmys and Saccostomus) differ from all the other members of the sub-family in being provided with cheek pouches, the single West African species of the former having grooved upper incisors, while in the two representatives of the latter these teeth are plain. The last member of the family is a mouse from Sumatra and Java, described as Pithechinus, and presenting a considerable external resemblance to Chiropodomys.

The mole-rats constitute a small family eonfined to the old World and characterised by their generally mole-like build, eylindrieal bodies, short limbs, furnished with large claws, small or rudimental eyes The Mole-Rats, and ears, usually short or rudimentary tail, large incisors, -Family and rooted molars with re-entering enamel-folds on their Spalacidce. erowns. Premolars, varying in number, are present in some forms but wanting in others; the palate is narrow; and the anterior part of the zygomatic arch of the skull lacks the clescending vertical plate so characteristic of the Muride. The great mole-rat (Spalcax typhlus) of South-Eastern Europe, South-Western Asia, and North-Eastern Afrien, which is the sole member of its genus, is the type of a sub-family characterised by the anyular portion of the lower jaw arising from the lower part of the sheath of the incisor in the manner characteristic of the Myomorpha generally; and also by the absence of premo'ars. It is a subterranean animal, clriving tunnels in the earth in search of the bulbs which form its food, and has the eyes eompletely eovered by skin, and rudimental ears and tail. In the nearly allied bamboo-rats (Phizomys), of whieh there 
are severul species from the Oriental comutries, Tibet, and Abyssinia, the minute eyes are open; there are small naked external ears, and the short tail is partially covered with liair. The other four genera, all of which are confined to Africis south of the Sahara, cliffer from other Myomorpha, and thereby resemble the undermentioned Hystrieomorpha, in that the angle of the lower juw arises from the side of the sheath of the incisor. Of these, the great sand-mole (Buthyergus maritimus) of the Cape, which attains a length of 10 inches, has grooved upper ineisors, a single pair of premolar teeth in each jaw, no external cars,

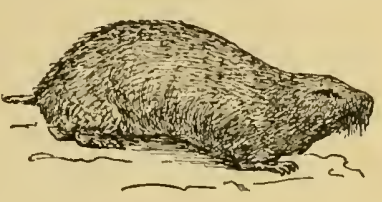

Fug. 58.-BAMBOo-RAT

(Rlizomys badius). and extremely powerful claws. In the allied Georychws and Myosectops the incisors are smooth; the members of the former genus usually have a single pair of premulars, and the single species of the latter thrce pairs of these teeth in both jaws, while the second toe of the hind-foot is the longest. In both, the first pair of premolars may be absent. The curions little naked sand-rats (Heterocephalns), of which the two species are confined to Somaliland, are degracled forms, with 110 premolars, either two or three pairs of molars, an almost completely bare skin, small eyes, no external ears, a tail of moderate proportions, and a pair of large pads on the powerful forefeet. These tiny little animals make shallow tumnels in the hot sand of the descrt, throwing up at intervals small heaps resembling miniature volcanic craters.

This comparatively small family is exclusively confined to North and Central America, where it ranges from the plains of the Saskatchewim, in Canada, southwards to Custa Rica, although attaining its maximum development in the Western United States and Mexico, and being unknown in the region east of the Mississippi, save the Gulf States. The essential claracteristic of these Rodents is the possession of large pouches open-

The Pocket-

Gophers.Family Geomyidle. ing externally on the checks at the sicles of the mouth. In addition to three pairs of molars, they have a single pair of premolar teeth in each jaw ; all the cheek teeth in the more typical forms being rootless, and consisting of simple prisms, without any unfolding of the enamel. The premolars consist of a clouble prism, but all the molars, with the exception of the last pair in the upper jaw of some species, comprise but a single prism, whose summit presents an oval dise of ivory bordered by a ring of enanel.

"All the members of the family," writes Dr. Merriam, "spend their entire lives underground, and their whole organisation is modified in accordance with the needs of a subterranean existence. The species, though numerous, are rery much alike externally They are slıort-legged, thick-set animals, without any appreciable neck, without noticeable external ears, and with rery small eyes. The feet are largely developed for digging. The fore-paws in particular are very strong, and armerl with long curved claws, and the sides of the toes are lined with rows of bristles that evidently scrve in prerenting the dirt from passing between the fingers, thus completing a more iffectire arrangement for keeping the tunnels clean, and for pushing the earth out of the openings of the burrows. The tail, which is of moderate length, is thick, fleshy, and usually devoid of hair, and is endowed with tactile sensibility. 
"The pocket-gophers in working their way through the earth in the construction of their tunnels, use the powerful upper incisors as a pick to loosen the ground. At the same time the fore-feet are kept in active operation, both in diggring and in pressing the earth back under the body, and the hind-feet are also used in noving it still further backwards. When a sufficient quantity has accumulated belind the animal, he immediately turns in the burrow, and by bringing the wrists together under the chin with the palms of the hands lield vertically, forces limself along by the hind-feet, pushing the earth out in front. When an opening in the tunnel is reached, the earth is discharged through it, forming a little hillock that resembles in a general way the hills thrown up by moles. In many species there is a naked callosity over the front half of the nose, which must be of great assistance in the construction of the tunnels. When this callosity is largely developed, the nasal bones underneath are lighlly arched or inflated."

The same writer then goes on to obseive that he was much surprised to see a captive example of one of the species run as rapidly backwards as forwards. "This method of progression was particularly noticeable when the animal was in his own quarters, where he could follow a runway or an accustomed route. When carrying food to one of his store-houses he rarely turned round, but usually ran back wards to the place of deposit, returning for more, and repeating the opcration again and again, the to-and-fro movement suggesting a shuttle on its track."

The cheek pouches, which are clothed internally with fur, according to the same author, " are used exclusively in carrying food, and not in carting dirt, as often erroneously supposed. They reach hack as far as t'le shoulder, ard are so attaclied that they cannot be completely averted without rupture of their connections." Writing of a tame specimen, Dr. Merriam observes that " the manner of eating was peculiar and interesting, and showed an ability to use the liuge fore-feet and claws in a way previously unsuspected. After satisfying the immediate demands of liunger, it was his practice to fill one or both cheek pouches. His motions were so swift that it was exceedingly difficult to follow them with sufficient exactness to see just how the operation was performed. If a potato was given him, or a piece too large to go into the pouch, he invariably grasped it between the fore-paws, and proceeded to pry off a small piece with the large lower incisors. He would then raise liimself slightly on his hind-legs and hold the fragment between his forepaws while eating, for he usually ate a certain quantity before putting any into the pouches. If small pieces were given him he took them promptly, and passed them quickly into the pouches. Some pieces were thus disposed of at once; others were just trimmed by biting off projecting angles. As a rule, one pouch was filled at a time, though not always, and the hand of the same side was used to push the food in. The usual course is as follows :-A piece of potato, root, or other food is seized between the incisor teeth, and immediately transferred to the fore-paws, which are held in a horizontal position, the tips of the claws curving toward one another. If the food requires reduction in size, the trimming is done while held in this position. The piece is then passed rapidly across the side of the face with a sort of wiping motion which forces it into the open mouth of the pouch. Sometimes a single rapid stroke with one hand is sufficient; at other times both hands are used, particularly if the piece is large. In such cases the long claws of one hand are used to draw down the lower side of the opening, 
while the food is poked in with the other. It is obviously impossible for the animal to pass food from tho mouth to the pouches without tho aid of its fore-claws. 'The most remarkable thing connected with the use of the pouches is the way they aro emptied. The forc-feet are brought back simultaneously along the sides of the head until they reach a point opposito the hinder end of the pouches; they are then pressed firmly against the head and carried rapidly forward. In this way the contents of the pouches are promptly deposited in front of the animal. Sometimes several strokes are necessary, I am not prepared to say that the animal cannot empty the pouches by means of the delicate investiug muscles; but I lave never seen them emptied in any other way than that here described."

According to American writers, the typical members of the family may be divided into no less than nine genera; but by English zoologists they have hitherto been included in only two. Of these, (reomyss, as typitied by the common pocket-gopher $(G$. burserius $)$, is characterised by having either one or two grooves on the upper incisors. In the typical species there are two of these grooves, and the same is the case with another form which has been separated as $Z$ ygogeomys; the latter being peculiar in that the jugal, or cheekbone, does not enter into the formation of the upper border of the zygomatic arch. In all the other forms, which have received the

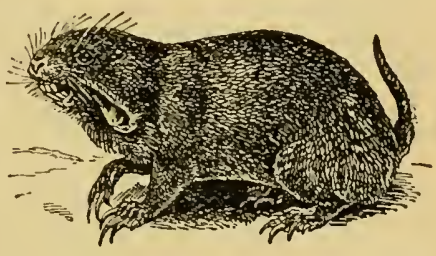

Fig. 59.-Pocket-GopHeR (Geomys bursarius). names of Puppogeomys, Orthogeomys, Cratogeomys, Platygeomys, Heterogeomys, and Macroyeomys, there is but a single groove on each incisor; the groups being distinguished by the conformation of the skull, and the extent to which the cheek teeth are covered with enamel. From the above the species of Thomomys are distinguished by the upper incisors being either perfectly smooth, or marked only by a single fine streak on the inner side.

The kangaroo-rats (Dipodomys), together with the two following genera, aré referred by American writer's to a different family, and are distinguished by their narrow incisors, moderate or large ears and cyes, and the elongated hind-limbs and tail. In the kangarou-rats the molar teeth are rootless; the typical forms having four toes, whereas others, which it has been proposed to separate as Perodipus, possess five. These sinall Rodents iuhabit open sandy districts, and have habits very similar to those of jerboas. From the foregoing, the genern Perognathus and Heteromys differ by their rooted molars; the latter being distinguished by the admixture of thattened spines in the fur, and having species ranging into South America. All the forms are small and mouse-like ; the common $D$. phillipsi being from South Mexico.

The jerboas and their allies form a small, widely-distributed fanily, by ino means easy of definition. Usually there is a pair of upper premolars, the incisors are narrow, the molars are divided by transverse folds of enamel into lamine, the vacuity in the skull below the anterior root of the zygomatic arch is large and rounded, and the hinder part of the auditory bulla is very large. The rit-like Rodents of the genus Sminthus, which range over

Jerboa Tribe. -Family

Dipodide. Eastern and Northern Europe, Central Asia, Kashmir, and Kansu, differ 
from the other members of the family in the equality of the length of the fore and hind-limbs ; the upper jaw having a single pair of premolars, while there are none in the lower. The North American jumping-mice (Zapus) are distinguished by the elongation of the hind-limbs, and the presence of a pair of premolars in both jaws; the hind-feet being furnished with five toes, and the metatarsal bones separate from one another. The common species ranges from Hudson Bay to Colorado. Agreeing with the last in their elongated

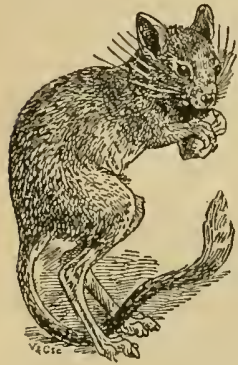

Irig. 60.-A JEREOA (Dipus). hind-limbs, the next four genera differ in having only three functional hind-toes, and by the union of the metatarsal bones of the hind-foot. Of these four genera Dipus has only three hind-toes, while Euchoretes, Alactaga, and Platycercomys have five, of which the first and fifth do not touch the ground. The first three of these have a long, cylindrical and tufted tiril; Dipus being distinguished from the other two by its grooved incisors, and the frequent absence of premolars. Euchoretes is represented only by the Yarkand jerboa, characterised by its elongated muzzle and large ears: while Platycercomys, of which there are several species, ranging frum Siberia to Nubia, differs by its flattened and lancet-shaped tail, and the invariable absence of premolins, the incisors being smooth. The true jerboas (Dipus), of which there are several species, extend from Algeria through Egypt and North Arabia to Eastern Persia and Central Asia. Aluctege is best known by the Kirghiz jerboa ( $A$. decumance) of the Kirghiz steppes. All the jerboas are essentially desert-haunting animals, living in the open, and progressing by long leaps. The last and largest member of the family is the so-called Cape jumping-hare (Pedetes craffer), ranging from the Cape to Angola and Mozambique, and differing from all the other genera in having rootless molars. The hind-limbs are elongated, the metatarsil bones separate, and the hind-feet furnished with four toes; while the ears are long and narrow, and the very long tail is clothed with elongated hair.

With the exception of the lares and picas, which form a group by themselves, the whole of the remaining members of the orler are included in a section known as the Hystrico-

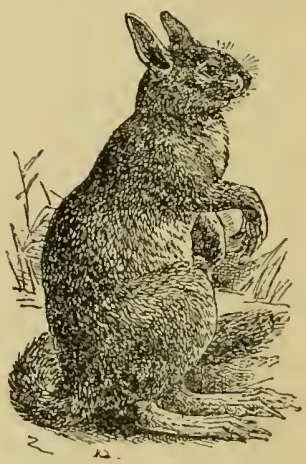

Fig. 61.-CAPE JUMPING. HaRe (Pedetcs caffer). morpha, which embraces six families. As a whole, this section is charicterised by the stoutness of the zygomatic arch of the skull, in which the jugal bone forms the whole of the central portion without Octodont Tribe. any support from a process of the maxilla, while the angla -Family Octo- of the lower jaw arises from the outer side of the bony clontide.

sheath of the socket of the incisor. The cullar-bones may be cither crmplete or imperfect; in the lower part of the hind-leg the fibula is distinct from the tibia; and there is almost always a single pair of premolar teeth in each jaw. The members of this section are particularly characteristic of Central and South Aınerica 
(including the West Indies), the whole of the six families being represented there, while four are confined to these countries, and one is net with elsewhere only in Africa.

By far the largest of these families is that of the Octodontidoe, which has some representatives in Africa, although the majority of the forms are confined to South and Central America and the West Indies. All have complete collar-bones; the vacuities in the front of the bony palate of the skull are greatly elongated; the crowns of the molar teeth are marked by infoldings of enamel on both sides; there are generally five toes to each foot; and the teats are placed ligh up on the sides of the body. In form, these Rodents are usually more or less rat-like, and most are terrestrial in their habits.

The first group of the family is African, and is represented by two genera, both easily distinguished by having the two inner toes of the hind-foot furnished with a lorny comb and bristles for the purpose of cleansing the fur. Each genus has but a single species. The gundi, Ctenodactylus, is in inhabitant of North Africa, near. Tripoli, and is peculiar anong the family in having no premolars, the tail being reduced to a stump ; whereas in Pectinator, of Somaliland, premolars are present, and the tail is moderately long and busliy. Both are about the size of a water-vole.

The second group comprises six genera, five of which are South American, and the other African. They have partially rooted or rootless molars, with simple enamel-folds and soft fur. The typieal form is the degu (Octodon) of Chili and Peru, which is a rat-like animal, with a rather long brush-tipped tail, medium-sized ears, and the upper and lower molir's alike. "Other speeies of the same genus inhabit Bolivial, which is also the liome of the two species of Hebrocomu, characterised by the lower nulars being more complex than the upper, the large ears, and the extreme softness of the fur. Nearly related are the burrowing tuco-tuens (Ctenomys) of South America, deriving their popular name from the bell-like cry uttered underground. They have broad incisors, kidney-shaped crowns to the rootless molirs, small eyes, moderate ears, long claws, and bristles on the hind-feet. The one species of the genus Aconamys, from the Southern Andes, differs from the last by its larger ears and shorter claws, and is further characterised by the enamelfolds of the upper molars meeting in the middle.

From Ctenomys, the two Chilian species of Spalacopus differ by their rudimental ears ; they are noticeable on account of their laying up a winter store of food. The very similin. African genus Petromys 1 may be distinguished from the last by its harsher fur, the shortness of the first toe of the forefoot, and more thickly-haired tail.

The coypu, or nutria (Hyopotamus), of South America, which is the only member of its genus, is the typical representative of the last sub-family, which has one African and ten American genera. In this group the molars, which may be rootless or partially rooted, have deep and curved folds of enamel, more or less harsh fur, which may be mingled with spines, and the tail generally long. As a genus, the coypu, which attains a length of about two feet, has very large red incisors, two inner and two outer enamel-folds in the upper molars, and three inner and one outer in the lower ones, moderate-sized ears, a rather lung, scaly, and sparsely haired tail, and webbed lind-feet. Mr. Aplin writes that in Uruguay " it inhabits the larger permanent lagunas. I have heard it stated that if a laguna is inhabited by

1 Some writers place this genus in the first sub-family. 
nutrias it is a sign that it never dries up in a drought. But during the drought which prevailed during the time I was in the country, some places

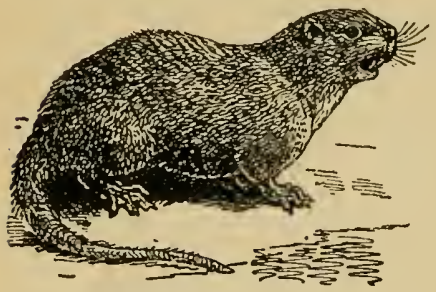

Fig. 62.-COYPu (Myopotamus coypu). inhabited by nutrias did clry up, but it was probably many years since they had done so previously. In the steep banks of the lagunas the nutrias make drives, the mouths of the tunnels being half in and half out of the water when it is at its normal height. The nutria is not a very shy animal. Some of them inhabited a little water-course by the side of which the sheep-dipping place was situated; they were probably attracted by the head of water kept up by a small dam. The nutria swims with hardly a ripple, and disappears noiselessly in the dive at the water-line. The body is clull brown, muzzle greyish, and there is a little warm brown on the side of the head. It swims with the nose, the top of the head, and a narrow line of the back out of water, all on a dead level, or almost so ; the nostrils being very high up in the line of the skull, they are kept out of the water without the nose being poked up towards the sky. A half-grown one brought to me alive ate green maize readily."

In the West Indies the family is represented by the large arboreal Rodents known as hutias, most of which are included in the genus Cupromys, altinough, on account of the more complex structure of its molars, one species from Hayti and Jamaica is separated as Playiodon. They may be compared to gigantic rats, one of them measuring 22 inches to the root of the tail. Their incisors are narrower than those of the coypu, the first genus having one imner and two outer folds of enamel in the upper molars. From both the above the two species of cane-rat (Triunlacodus) ${ }^{1}$ from Southern Africa are at once distinguished by the presence of three deep grooves in each of the upper incisors. The small American forms consti-

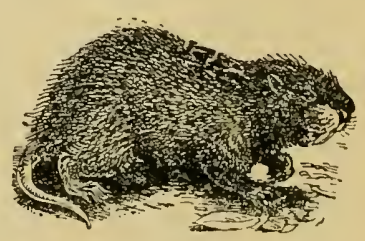

Fig. 63.-Hutra (Capromys). tuting the genera Echinomys and Loncheres are sufficiently characterised by generally having flat, lance-shaped spines intermingled with the fur; most of the species being inhabitants of Brazil and Guiana, although one of the second genus is found in Central America. The South American Mesomys cliffer's from Loncheres in having a short, curved claw on the first toe of the fore-foot, as well as in the absence of spines. The single and rare species of the Brazilian genus Dactylomys is characterised by its short ears, long scaly tail, the rudimental first toe of the fore-foot, the very long third and fourth toes of the same, which are furnished with short, convex nails, the flat incisors, and the division of the molars into two complete lobes, each of which has a single enamel-fold, forming a fork-shaped grinding surface; as well as by the two series of upper cheek teeth converging so much as to meet in front. A smaller Brazilian form known as Cumnebateomys differs by the union of the two lobes of the molars by means of a bridge of enimel, and the slight convergence of the teeth. Another South

1 To replace the preoccupied name Aulacolus. 
American genus is Carterodon, which includes small rat-like animals differing from all the other member's of the family inhabiting the same country in its broad and grooved upper incisors; the upper molars having one inner and two outer enamel-folds, and the lower ones the reverse of this arrangement. Lastly, the South American Cercomys differs from the foregoing by its pointed muzzle and smooth incisors.

The number of long, sharp spines with which the skin of "the fretful porcupine" and its allies are protected sufticiently distinguish the Hystricidce from all other Rodents. These animals are of stout build with the fore and hind-limbs of nearly equal length, the front portion of the skull very short and broad, and the molars, which may be either completely or partially rooted, with folds of enamel on both sides. The family may be

Porcupine Tribe, - Family

Hystricidee. divided into two groups, one of which is confined to the New World, and the other to the Old. In the American porcupines the molars are fully rooted, the collar-bones complete, the upper-lip undivided, the soles of the hind? f zet covered with rough tubercles, the first digit of the fore-foot wanting, and numerous long hairs mixed with the spines; while the females have only four teats. The numereus species of trec-porcupine (Synetheres) are confined to the forest districts of trepical America, and are specially characterised by their long, prehensile tails, short, many-coloured spines, light build, and the presence of only four toes to the hind-feet; these toes grasping against a fleslyy pad on the inner side of the foot. In habits these porcupines are thoronghly arbereal, and also less nocturnal than their Old World allies. A Brazilian species (Chatomys) is generically distinguished on account of the different conformation of its skull and more complex pattern of its molar teeth. The Canadian porcupine (Erethizon) forms a kind of connecting link between the New and Old World members of the family, the build being heavy, and the tail stumpy and non-prehensile. The spines are almost buried in the long hairs, and there are four toes in front and five behind.

In the three Old World genera of the family, the molars are only partially rooted, the collar-bones incomplete, and the soles of the hind-feet smooth, while there is a rudimental first toe to the fore-foot, and the female has six teats. In no case is the tail prehensile. The true porcupines (Hystrix), which are spread over the warmer parts of Europe and A sia, as well as Africa, are best characterised by their large size, highly inflated and convex skull, and the short tail, terminating in a number of hollow quills, which produce a rattling noise when the creatures move. These porcupines are burrowing and nocturnal in their habits. The brush-tailed porcupines (Athernira), of which one species is Malayan and the other two West African, differ by their inferiur size and long tails, the latter sumounted with a tuft of flattened spines. A third genus (Trichys) is represented by a single Bornean species, differing from the last in the structure of the skull; the spines being also shorter, and the bristles on the tail narrower and parallel-sided.

This and the following families of the group are exclusirely confined to South and Central America and the West Indies. In the present family the hind-limbs are elongated, the tail is bushy, the fur extremely short, the collar-bones complete, the bony palate of the skull Chinchilla Tribe. narrowed in front and deeply excavated behind, the incisors short, and the molars separated into isolated transverse -Family lamine by continuous folds of cnamel. This family is typically represented by the beautiful little chinchillas (Eriomys) of the 
Andes, so much esteemed on account of the marvellous softness of the pearly. grey fur, and characterised by liaving five toes in front and four behind, as well as by the bushy tail. The larger Cuvier's chinchilla (Lagidium), which is likewise an inhabitant of the Andes, has only four toes both in front and behind; whereas in the viscacha (Lagostomus), of the Argentine pampas, there are but three toes to the lind-feet; the fore-feet having the same number as in the last genus.

As regards its external appearance, the viscacha may be not inaptly compared in point of form and size to a marmot, although its hind-limbs are proportionately longer, and the head is inordinately large. The tail, which is bushy throughout, is about one-third the length of the head and body, whicl varies from about 19 inches to 23 inches; and the short ears are clistinetly notched behind. Alnıst as soft as that of the chinchilla, the fur (which is unfortunately useless for commercial purposes) is of a greyish hue above, with some dusky mottlings and black markings on the upper-parts, while beneath it is white, or white tinged with yellow, the tail being blackishbrown. The head has some very characteristic markings, which render the animal so conspicuous from a distance. Thus a blackish stripe extends across each cheek from the muzzle, while above this is a broad white stripe, ending in front of each eye, this being followed by a third band of a dark colour across the lower part of the forehead. Essentially burrowing and nocturnal in their habits, and seldom issuing from their hiding-places before dusk, viscachas live in companies numbering from about 20 to 30 head. The viscacheria forms a dome-shaped elevated mound on the pampas, perforated here and there by the numerous apertures of the burrows. The burrows themselves are excavated for a great depth in the soft black mould of the pampas ; and as they frequently diverge near their extremities, or open out into a large common chamber, it may be easily imagined that the task of digging out a warren in ordinary circumstances is an almost impossible one. Carefully cleared of all vegetation, the mound of the viseacheria is kept scrupulously clean; but the viscachas have the curious habit of collecting on this spot not only the débris of their food, but likewise any objects they may come across in their wanderings. Consequently the summit of the mound is littered over with bones of cattle and ostriches, thistle-stalks, maize-colss, clods of earth, and masses of the hard calcareous rock, locally known as tosea. Moreover, if a passer-by happen to lose any of his smaller belongings, such as a knife or a wateh, he will be pretty sure to come acruss it by searching all the viscacherias in the neighbourhood. The olject of this remarkable habit it is almost impossible to conjecture, although it is probably analogous to that of the Australian bower-birds. For some distance round the viscacheria the grass of the camp, through continual nibbling, is much finer than that of the pampas in its original condition ; and before the introduction of sheep, and the consequent refining of the turf, the viseachas were undoubtedly in this respect of service to the farmer. W'hen about to issue from their loles, or when driven in by the intrusion of a visitor after they have come forth, viscachas make a most unearthly growling and snarling deep down in their holes-the sound, which may be best compared to the booming of a bear in its lair, giving the impression to the uninitiated that the dwelling is tenanted by animals of much larger size and fiercer disposition than is really the case. In spite of the refining of the herbage already alluded to, viscachas are an unmitigated pest to the farmer, not only on account of the large area covered by their burrows, but likewise by the enormous quantity of fodder consumed 
by the animals themselves, which in former days absolutely swarmed on the pampas. Consequently for years the estincieros have waged incessant war ingainst these Roclents, with the result that in the parts of Argentina which lave been longest under cultivation one may ride for miles without coming icross a warrell.

The two genera of this South and Central American and West Indian family include a small number of relatively large, terrestrial Rodents, characterised by the fore and hind-limbs being of nearly equal length, and having their toes furnished with hoof-like claws, by the short or rudimental tail, the very imperfect collar-bones, the broad palate, long incisors, and the partially routed nolars, in which the foldings of enamel form notches on the two sides of the crowns. The ingutis (Dasyprocta) are rather delicately built animals, with long limbs and three hind-toes, ranging from the confines of Mexico to Paraguay, and represented by a single outlying species in the West Indies. On the other hand, the pacas (Ckelogenys), which are found from Ecrador to Brazil and Paraguay, are larger and more heavily-built inimals, with five toes to the hind-feet, and further characterised by the longitudinal rows of light-coloured spots on the fur, and the enormots hollow, bony capsules formed by the expanded bones of the clieeks. Branick's pacil (Dinomys), of which only a single specinen from Peru las hitherto

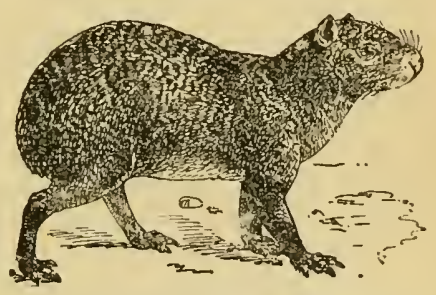

Fig. 64.-Aavti (Dasyprocta). been obtined, is clistinguished from the Dusyproctidce by the cleft upper-lip, somewhat long and bushy tail, the presence of four toes to each foot, and the complete collar-bones; and is accordingly regarded as the representative of a separate family.

The next of these South American families is that of the cavies, and includes large or small heavily-built Rocients, with four front and three hind-toes, rudimental or short tails, and the cheek teeth divided by transverse folds of enamel into a number of thin plates The Cavies.lying parallel to one another. The typical representatives Family Cariide. of the family are the true cavies (ciriil), of which the guinen-pig is a domesticated descendant, having assumed a coloration quite different from the miform olive-brown tint characteristic of its wild ancestors. Quizos, as these animals are cilled in the Argentine, may be found not only among aquatic plants in mirshy districts, and skulling in the tufts of coirse griss on the pampas, but also in the neighbourhood of human habitations, where they will not unfrequently take up their residence under the floors of outbuildings, whence they issue forth to feed at night. All the true cavies are small and short-legred creatures, with no tail, and short eas; but the Patagonian cavy, representing the genus Inolichotis, is a much linger and taller animal, neasuring nearly a yiud in length, and standing over a foot at the shoulder, with tall cars and a short tail. An inhabitant of the open districts of Patagonia and Argentinal, the mara, as it is called by the natives, much resembles a hare in its morements. Unfortunately, the spread of cultiration has well-nigh exterminated this handsome Rodent from most parts of the Argentine. Largest, not only anong South American Rodents, but 
in the order, is the aquatic carpincho or capivara (IIylrochorus), figured on p. 89 , and attaining a length of four feet. The most remarkablo peculiarity of this animal is the large size and complex structure of the list molar tooth, which in the upper jaw may have as many as twelve plates, and is comparable in structure to the corresponding touth of the Indian elephant. The carpincho is an inhabitant of the moro tropical districts, not extending southwards of Uruguay. Writing of the habits of the carpincho, Mr. Aplin observes that "a favourite locality is a broad laguna in the river, furnished with open water, and also beds of 'camelotes,'-a sloping, open, grassy bank on one side, where the carpinchos can lie in the daytime in the cooler weather, sleeping and basking in the sunshine; on the other a low, shelving bank, clothed with 'sarandi' scrub growing out into the black, reeking mud and shallow water beyond. The stems of the sarandi in the festering mud have a gloomy appearance, sometimes brightened in spring by the large, pink flower of a convolvulus climbing up the stems. In one or two places of this description, I could almost al ways make sure of seeing some carpinchos-sometimes a herd of a dozen or fifteen together, for they are sociable. You might meet with them at any part of the river's where there was plenty of water, or in the montè on the banks, and I have put one up in thick dry grass fifty yards or more from a river. At night they are said to wander for some distance to visit maizefields. When alarmed, they snort violently, and rush impetuously into the river with a great splash and noise. It is said that a frightened carpincho making for the river will not turn out of its way for anything, and that if you are between them and the river they will knock you over. The paces of the carpincho are a walk and a hurried gallop, reminding one of that of a pig, but most likely differing little in character from that of a guinea-pig, which the earpincho resembles in shape and make. Probably their habit of rushing impetuously into the rivers is the reason why some horses are so frightened at these animals; the horses may have been scared when they went down to clrink, or perhaps even charged by two or three lumbering brutes. Sometimes carpinchos are much more tame than at others. If they are on the opposite side of a small river, they often take no notice at all; and I have watched them in the autumn sitting up on their haunches like dogs, sunning themselves, or lying asleep on their bellies, with their fore-paws stretched out in front of them, and their heads in some cases laid on their paws, a little on one side. I have also on more than one occrsion walked up within half a dozen yards of them. Sometimes when you approach a little herd of them, they sound their alarm and merely wateh you, walling slowly down to the water as you get nearer. At other times they rush impetuously into the water at the first sign of danger. They are said to be mucl wilder on the larger rivers, the Rio Negro for instance, probably because they are less aceustomed to seeing any people except those who hunt them. No doubt the protection they were afforded in the Santa Eleni camp contributed largely to their tameness there, but I always noticed they were less tame on the Arroyo Grande than on its tributary the Sitúce. When disturbed and rising to their feet, carpinchos get upon their fore-legs first. The hair of the carpincho is seanty, not much more plentiful than some pigs' bristles, which it greatly resembles. Their colour varies from dull brown to bright chestnut, and this irrespective of age, or size, or season either, for I have noticed all colours from spring to late autumn; smaller aninials are, however, generally of the dull brown colour, and vice rersî. Their skins tan into splendidly thick, soft leather, which is used for belts, slippers, saddle-corers, etc. Like other 
thick-skimed animals, they like to wallow in mud. They work out hollows in the ground, in which they wallow ; these are known as carpinchobaths. The carpincho does not go to ground, but lives on the banks of the rivers in such cover as it can find. It is capable of remaining under water and of proceeding for some distance under the surface; but when a herd has been disturbed at a laguna, the members probably lie low by putting just their noses above water under the shelter of a bed of camelotes or other water-plants. I am puzzled to say how many young they have at a birth. On the 8th May I saw two females, each with a young one, about 18 inches long, at her side. I hare nerer seen more than one young one with a female, but this I have often seen ; the young one keeps close to its mother's side, and they plunge into the water together. I am aware that the supposition that the carpincho has only one young one at a birth is contrary to what has been written about this animal ; but I merely give my own obscrvations for what they are worth."

The two last fanilies of the order, coustituting the group Lagomorpha, differ from the rest in having a small second pair of upper incisors behind the large ones of the upper jaw; the latter being also peculiar in that the coating of enamel, instead of being confined to the front surface, extends round to the back. Young animals hare three pairs of upper incisors. The

Picas. - Family Layomyidce. small Rodents known as picas, or tailless hares, all of which are included in the single genus Lagomys, are characterised by the equality in the length of the limbs, the absence of a tail, the short ears, complete collar-bones, and rootless molars, divided into transverse lamine by complete folds of enamel. The living species have two pairs of premolar teeth in each jaw, and the skull has no postorbital processes. Rcpresented by about a dozen species, the picas are chiefly inhabitants of the Himalaya and the highlands of Central and Northern Asia, although one outlying form inhabits South - Eastern Europe, and a second the Rocky Moun-

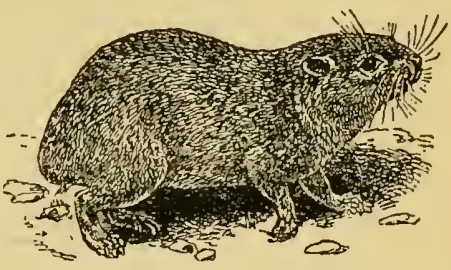

Fig. 65.-A Pica (Lrg, mys). tains. These little creatures dwell in the chinks and crevices of rocks, from which they clart out with remarkable celerity, uttering at the same time their peculiarly shrill cry.

From the picas, the linres and rabbits (Lepus) are at once distinguished by their elongated lind-limbs, long ears, short, upwardly-bent tail, and imperfect collar-bones ; while the skull differs in possessing large postorbital processes, and there are three pairs of premolar teeth in the upper jaw and two in the lower. Whereas there are five toes to the fore-limbs, the lind pair has but four, and the soles of all four are as fully haired as the rest

Hares and

Rabbits. Family

Leporida. of the limbs; the inside of the cheeks being also hairy.

There are rather more than a score of species belonging to the genus, which lhas an almost cosmopolitan distribution, although more numerous in the northern hemisphere than elsewhere, being absent from Madagascar and Australasia, and represented only hy a single species in South America. All are very much alikc in external appearance. Of the European species, the 
common hare (L. curoperts), distinguished by the very long ears and hindlegs, inluabits the whole of Europe with the exception of Northern Russia, Scindinavia, and Ireland. In the latter countries its place is taken by the mountain hare (L.timidus), which ranges eastwards to. Japan, and is found on several of the mountain ranges of Southern Europe, namely the Pyrenees, Alps, and Caucasus. Smaller than the common hare, it has shorter ears and hind-legs ; and in the colder portions of its habitat changes to pure white in winter, with the exception of the black tips to its ears. The rabbit (L. cuniculus) is a smaller and shorter-limbed form, with the black tips to the car's much reduced in size, or absent; it was originally a native of the countries bordering the western half of the Mediterranean, but has been introduced into Northern Europe and many other parts of the world. It differs from the hares in its burrowing habits.

\section{ORDER VI.-TNGULATA.}

\section{The Hoofen Mamals.}

This extensive orcler, which includes hyrinces, elephants, hor'ses, rhinoceroses, oxcn, antelopes, pigs, etc., is one by no means easy of definition, although its cxisting member's are characterised by having the toes enclosed either in loofs, or furnished with broad, flattened nails. The number of toes varies from five (in the elephants) to one (in the horses); in the fore-arm the radius and ulna may be united ; in the wrist the senphoid and lunar bones (united in the Carnivora) are always separate; collar-bones are wanting in all the existing forms ; and the condyle, or knob, by which the lower jaw articulates with the skull, is always more or less elongated transversely, and never from before backwards in the manner characteristic of the Rodents. The cheek teeth have broad and flattened crowns-often interpenetrated by deep foldings of the enamel from the summits and sides-adapted for grinding; and when these teeth are reduced below the typical number of seven, the reduction always takes place from the anterinr portion of the series, or, in other words, in the premolars, so that there are constantly three pairs of molars in each jaw. The limbs are always adapted for terrestrial progression, so that there is no power of supining the fore-foot; and when the first toe is present it has no power of opposition to the others.

Although a few are omnivorous, the great majority of the Ungulates subsist entirely on a regetable diet; and, with the exception of these sufliciently protected by their great bodily size, most depend upon their swiftness of foot to eseape their enemies. While a small number are not larger than hares, the great majority of the members of the order are animals of large size, and they include among them the most gigantic of all existing terrestrial creatures. The living Ungulates may be divided into four wellmarked subordinal groups, white there are others which are now extinct.

The Probosciden or first subordinal group of the Hoofed Mammals, is now represented solely by the two existing species of elephants, both of which are included in the genus Flephes. In addition to their liuge bodily size, clephants differ externally from all other animals by the production of the nose into a long, flexible proboscis, or trunk, and likewise by the large tusks 
normally present in the males, and often in both sexes. Their huge and massive limbs are less enveloped superiorly in the skin of the body than is the case with the great majority of Ungulates; and their component longbones are remarkable in being placed almost vertically one above the other, so as to form straight columns for the support of the body. From all other living members of the order elephants differ in liaving five perfect toes to each foot; while they are further distinguished from all, except the little

\section{The Elephants.}

-.-Family

Elephantidce. liyraces, by the arrangement of the bones of the wrist-joint in the fore-foot. In this joint the two horizontal series of quadrangular bones are placed almost directly over one another, and likewise above the supporting metacarpal bones, in such a manner that the whole foot could be completely cleft in twain between the third and fourth toes. The rounded feet are supported on large, flat cushions, on the front edse of which the position of the toes is indicated by large, broad nails. As regards the teeth, the upper tusks correspond to one of the three pairs of incisors characterising more typical Mammals; but there are no other incisors, nor any traces of canines. The tusks always remain open at the base, and grow continuously throughout the life of their owners. The cheek teeth, of which there are six pairs in each jaw, are peculiar in that they are not all in use at the same time, the small anteriol ones coming into use first, and being in turn shed as they aro worn out and replaced by the larger hinder ones, which make their appearance in the jaws in an arc of a circle, so that very old individuals aro left with only a single huge molar on each side of each jaw. Equally peculiar are these teeth in structure. They consist of a great number of tall, parallel, thin, transverse plates growing from a common base, and consisting of a core of comparatively soft ivory, covered with a thin layer of flint-like enamel; the interspaces, or valleys, left between the plates being filled ul' with a still softer sulsstance known as cement. When such a tooth is worn by grinding against its fellow in the opposite jaw, the summits of the enamelcovered plates are cut through so as to expose elongated ellipses of ivory ; and the roughenerl, flat surface thus prodnced is made of vertical transverso layers of three substances, arranged in the order of cement, enamel, ivory, enamel, cement. Since each of these constituents differs in hardness, it will be suficiently apparent that the millstone-like apparatus formed by the teeth is admirably adapted for triturating vegetable substances of all kinds to a pulp.

Of the two existing species, the Indian elephant ( $E$. indicus) is best dis: tinguished by the structure of the molar teeth, in which the constituent plates are very numerous and very thin, with their investing enamel, which is also thin, thrown into a number of fine crimpings. Tusks are usually present in the male sex only, and may even be wanting in that. The ears are relatively small; and the finger-like process on the upper margin of the tip of the trunk is much more developed than the one on the lower edge. As a rule, there are four nails on the hind-foot, and five on the front. The Indian clepliant is an inhabitant not only of the country from which it takes its name, but likewise of Ceylon, Burma, the Malay Peninsula, Cochin-China, Sumatra, and Borneo, although it may have been introduced into the island list named. Associating in herds of variable size, it is fond of cool, shady forests in the neighbourhood of water, avoiding as much as possible the full grlare of the sun, and fecding chiefly upon leaves, fruits, and small branches. So much has been written on the subject of the habits of this species that this 
may be passed orer here; but as much misapprehension obtains as to the height attained by the animal, a somewhat full notice may be given.

With all his large experience of Indian elephants, the late Mr. Sinderson, in his "Thirteen Years among the Wild Beasts of India," stated that the largest male he had at that time ever seen measured 9 feet 10 inches at the shoulder; while two others with which he was acquainted tonclied 9 feet 8 inches. He adds, "There is little doubt that there is not an elephant 10 feet at the shoulder in India." Next comes Sir Samuel Baker, who, after mentioning in "IVild Beasts and their Ways" that the well-known African elephant "Jumbo" measured 11 feet at the shoulder, and weighed $6 \frac{1}{2}$ tons,

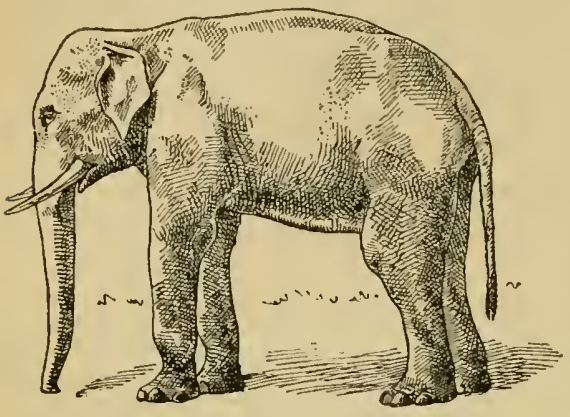

Fig. 66.-Indian Elephant. declared that no Indian elephant approaches these dimensions. It is further set down in the same book that " 9 feet at the highest portion of the back is a good height for an Indian male, and 8 feet for the female, although occasionally they are considerably larger. There are hardly any elephants that measure 10 feet in a direct perpendicular." Later on Mr. Sanderson was forced to admit that his statement as to there being no elephants of 10 feet in lieight in India required modification, for he himself subsequently measured a male

standing 10 feet $7 \frac{1}{2}$ inches. Those dimensions are, however, reported by Colonel D. Hamilton to have been exceeded in a male killed in 1863 by the late Sir Victor Brooke, of which the lieight is given as 11 feet, or the same as that of "Jumbo." Moriom Kelaart, wliose observations are generally most trustworthy, records having seen an elephant in Ceylon of upwards of 12 feet in height. That such a stature may occasionally be reached by a few giants of the tribe seems to be supported by an enormous skeleton of a tusker mounted in the Indian Museum, Caleutta, which, as now articulated, stands 11 feet 3 inches at the shoulder, thus indicating a height of about 12 feet when in the flesh. This skeleton is believed to have belonged to the tusker of a small herd that haunted the clistrict to the north of the Raniganj Coal Field from Soory and the southern spurs of the Rajmehal Hills to Jamtara. In our opinion this skeleton is correctly mounted, so that its height would appear to be truly 12 feet, although it has been stated that the thigh bone is not perceptibly larger than one belonging to an elephant known to liave been less than 10 feet in height. The elephant of 10 feet $7 \frac{1}{2}$ inches measured by Mr. Sanderson is, however, still the tallest actually known with absolute certainty; although we by no means venture to assert that Colonel Hamilton's estimate of the height of the one shot by Sir Victor Brooke may not be perfectly accurate. Be this as it may, it is eertain that the Indian elephant is, on the average, a considerably smaller nnimal than its African cousin ; and individuals attaining a height of even $\mathbf{1 0}$ feet are so rare that eacl ease is deserving of record. That elephants vastly exceeding 10 feet in height formerly lived in India is proved by tlic occurrence 
in the gravels of the Narbada Valley of limb bones besicle which those of the skeleton last mentioned appear almost puny, many of these fossil bones being exhibited in the geological galleries of the Calcutta Museum. These elephants belonged, however, to an extinct species.

From the height of the Indian elephant we turn naturally to the largest dimensions and weight of its tusks. Mr. Sanderson states that the largest tusks he ever obtained measured 5 feet along the curve, with a circumference of 16 inclies at their junction with the gum; while the weight of the pair was $74 \frac{1}{2}$ pounds. The single perfect tusk of the elephint shot by Sir V. Brooke, to which allusion lias been made, measured 8 feet, with a maximum girth of 16.9 inches, and weighed 90 pounds. Mr. Blanford mentions, however, that a somewhat sliorter tusk weighed upwards of 100 pounds; and two pairs from the Garo Hills, mentioned in The Asian newspaper in October, 1888, are stated to have been respectively of 155 and 157 pounds weight. The tusks of the large skeleton in the Calcutta Museum have unfortunately been removed, but the size of their sockets indicates that they must have been immense. All these dimensions are, however, comparatively small when set against those of unusually large African elephants; Sir Samuel Baker referring to single tusks of that species, which weighed respectively 149, 172, and 188 pounds; while Sir E. G. Loder lias a tusk of 184 pounds in weight. Huge as are tho tusks indicated by such weights, they must, however, have been small by the side of those of an extinct Indian elephant from the Siwalik lills, of which the skull is preserved in the Jritish Musem. The tusks of this monster have a total length of about 12 feet 9 inches, with a girth of 26 inches near the base ; and the weight of each in the living state may be safely estimated at considerably over 200 pounds. While on the subject of elephants' tusks, we may take the opportunity of mentioning that, as we learn from Mr. Sanderson's book, there appears to be a widespread belief that clephants have no milk or deciduous tusks. Nevertheless, such tusks are developed in all young elephants, and may be seen in place in skulls of suitable age. They may be at once distinguished from the permanent tusks by the circumstance that their lower extremities are completely closed, whereas those of the latter always remain open. These milk-tusks are, however, so small, and are slied at such an early age, that their fall is not likely to be noticed by the mahonits, even when they have under their charge animals sufficiently young for this change to take place.

In India, elephimts, as a rule, do not breed in captivity, but in Burma they not unfrequently do so; and a writer in The Asian newspaper of April, 1895 , states that in the Chindwin division, there were kept a male end "five female elephants ; four out of the five female elephants have calved since last September, and these calves will go and suck any elephant they like without the elephant objectiug. I liave seen two calves go and suck one elephant at the same time, then go off to amother and suck her. Elephants, without a calf, will allow another's calf to suck them. 'This I noticed down in Pyiumana, where one of the elephants culved ; the calf used to go round and suck three of the females. Again, with the elephants up here, one calved in Sejtember, another in October, a third in February, and the fourth in March. The calf that was born in September used to regularly suck the elephant that calved in October, and this before lier calf was born ; in fact, it used to follow the one that had not calved more than it did its own mother, and the female seemed to be as fond of the calf as if it har been her own. When No. 2 calved in Octuber it did not make any difference, both the calves sucked either 
No. 1 or No. 2 just as they liked, and they invariably sucked the same elephant at the same time; then they used to go off and suck the other two that had not calved then. These six elephants have now been in the Forest Department for at least six years to my knowledge, and how long they were in it before I don't know. It shows how absurd it is people in India saying elephants will not breed in enptivity; here, in Burma, our elephants are always fettered and turned out into the forest to graze, and elephants in better condition it would be hard to find ; our elephants get no flour, paddy, or any other kind of rations, and no tree-fodder. After the dlay's work is done, they are hobbled and turned out to feed themselves; when they are not wanterl, they remain ont in the jungle, the mahout going and seeing them once or twice a day. In this way they can eat just what they like." The teats of the female elephant are placed between the hind legs; and the young calf sueks with its month, and not with its trunk.

There are many methods by which elephants are eaptured, among which the following, as detailed in The A sion newspaper, may be selected for notice: - "Elephant-capturing operations by the pit-fall systens were set in working order in the locality of the forest station at Mount Stuart on the Anaimalai Hills in the season of 1890. For the past five years, during each of the working seasons which commence in June and end in December, elephantcaptures have been attempted. Places were selected in the known runs of the elephants, and the pits were dug in groups of three. To eommence with, about 21 pits were dug in different parts, all, however, being within a two-1nile radius of the Mount Stuart forest station. Since 1890, some 20 pits more have been dug out. The dimensions of the original pits were 12 feet by 9 feet, with a depth of 10 feet. These are too large, and a pit 10 feet by 10 feet by 10 feet is aniply big enough. The sides of the pits were made vertical and not sloping downwards, as are the pits in Malabar; and some 2 or 3 feet of brushwood was placerl in the bottom of each to act as hedding to break the fall of the animal. The pits were then covered by means of bamboos placed across them, and on these were spread grass, leaves, etc. The pits are visited every morning by a forest-guard or watcher deputed for the purpose, and these report to their superior officers whenever a fall takes place. During the first year, one animal, to which the name of Juno was given, was captured. This subsequently died. In the second year, 1891, four animals were captured, two of which subsequently died, and two of which are now living. In the third year, 1892, two extraordinary falls took place by which seven animals were captured in five pits. Out of these seven animals, fuur are still living. During $189: 3$ two animals were eaptured, and cluring the present year, 1894, four animals have been caught, all of which are living. Ont of a total of 17 eaptures, 12 are now living. It may be remarked, moreover, that the easualties took place amongst the first three years' captures, when the attendants, who are local hillmen, ealled MIuleers, were entirely inexperienced eoncerning elephants. During the last two years the bed of brushwood has been inereased eonsiclerably so as to reach to within 4 feet of the top of the pit. The results speak for themselves: not a single animal has sinee been injured in the fall, although two of the latest eaptures are the largest animals eaught sinee operations were commeneed. The removal of a eapture to the kraals, which are within two or three miles from the pits, is a very simple matter, provided everything is in readiness beforehand. The size of the animal's neek is estimated, and a peg is put in the rope so as to prevent the noose going smaller than the neck-sizo as 
estimated. This noose is then thrown over the elephant's neck and pulled tight to the peg, the end of the rope being bound round a neighbouring tree ; next, one of the elephant's hind-legs is noosed, and the end of this rope, for the time being, bound round a neighbouring tree. The neck-rope at the peg theu has to be tied with twine or fibre to prevent the noose being loosened by the elephant. This operation is, taking it all round, the most risky one comnected with the capture. But if proper care is taken there is nothing to fear. The pit is then filled up by means of billets of wood being thrown in, and as the animal rises nearer the surface of the ground, the two ropes fasten. ing him are pulled tighter around the trees. Eventually lie gets out of the pit somewhat fatigued; the ropes which secure him are then fastened to two tame elephants, and the animals are marched in single file (the captured one being of course in the middle) to the kraal, and all the ropes are removed. $\mathrm{He}$ is watered three times a day, and soon made tame by kindness, given sugarcane, etc. Somewhat large animals are generally in the kraal three months before they can be taken out; the little ones of 4 feet or $5 \frac{1}{2}$ feet high are, however, removed within three weeks of capture. The work of capturing elephants is an exceedingly interesting one, and only needs care and constant supervision to render it successful; and certainly the more ono has to do with these animals the more one is bound to recognise what intelligent, useful beasts they are."

The African elephant (E. africamus), which, as already stated, is a larger animal than the Indian, has large tusks in both sexes, and is broadly distinguished by the structure of the molar teeth, in which the plates are fewer and lower, with the ivory-spaces wider and morelozenge-shaped, and the enamel thicker and only slightly crimped. The tinger-like processes on the upper and lower edges of the tip of the trunk are more nearly equal in size; the ears are enormous, forming large flaps extending over the shoulders, and there are only three nails on the hind-foot. As in the Indian species, the rugged, naked skin bears only a few sparse hairs, but there are a number of stout bristles on the edges of the end of the tail. Until decimated or exter. minated in many districts by human greed, this species ranged over the whole of Africa south of the Sahara, and frequently occurred in enormous herds. It s less impatient of the sun than its Inclian cousin, and subsists largely on the soft roots of trees, which are dug up by the tusks; one tusk being generally employed in this service, and thus more rapidly worn away than its fellow.

The second sub-order of the Ungulates - the Hyracoidea-is formed by the small Rodent-like animals known as hyraces, all of which are confined to Africa and Syria, and may be comprised in the single gents Procavia. In the structure of the wrist-joint of the forefoot these animals resemble the elephants, from which they differ in having only three toes on the hind-foot, and but

The Hyraces - Family

Proccuviido. four functional ones in the fore-foot, where the first is rudimental, as well as in the characters of the dentition. As regards their front teeth, the hyraces make a curious approximation to the Rodents, the upper jaw having a single pair of curvea incisors, which grow throughout life, and are separated by a long gap, without the intervention of a canine, from the cheek-teeth. In the lower juw there are, however, two pairs of the former teeth, in place of the single pair characterising the Rodents, while the upper incisors differ from those of the latter in being sharp-pointed instead of chisel-shaped, and also in their triangular section, two of their surfaces 
being coated with enamel. The cheek teeth, which include four pairs of premolars and four of molars in each jaw, are singularly like those of the rhinoceroses, and thus quite different from those of the Rodents. With the

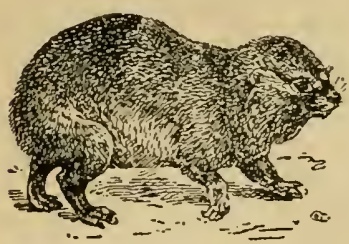

Fig. 6\%.-A Hrax (Procavia). exception of the second toe of the hind-foot, the toes are protected by short. broad nails; and the tail is remarkable for its extreme shortness. In general appearance, hyraces (which are the conies of Scripture) are very like large cavies. While the majority live in colonies among the cracks and crannies of rocks, sume of the African species are arboleal in their habits, climbing the stems and larger branches of trees, and sleeping in their holes; in this respect they are unique among the Ungulate order.

The primitive and ancient group of animals commonly known as tapirs are the first representatires of the third sub-ordinal section of the Ungulates, technically termed the Perissodactyle section. The essential

The Tapirs. - feature of the members of this section is to be found in the Family

Tapiricle. structure of the feet, in which the toe corresponding to tho third or middle digit of the human hand or foot is always larger than the one on each side of it, and symmetrical in itself ; the total number of toes on the hind-foot never exceeding three, and on the front-foot four. It is in consequence of this special derelopment of the third toe that the group is spoken of as the Odd-toed or Perissodactyle Ungulates. In addition to this essential feature, the Perissodactyla differ from the two preceding sub-orders in the structure of the wrist-joint of the fore-foot, in which the two horizontal rows of small bones not only interlock with one another, but are likewise not disposed in vertical lines immediately above the supporting metacarpals. Hence in these animals it would be impossible to cleave the foot between any two of the toes without cutting through solid bone. A further difference from the elephants is to be found in the

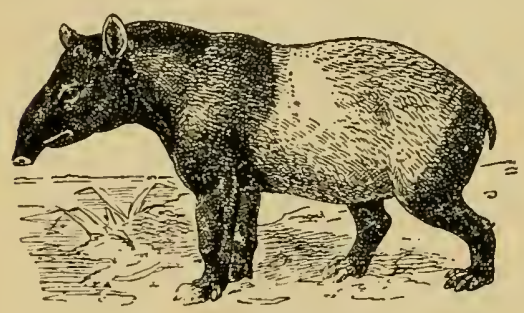

Fig. 68.--Malayan T_pin (Tapirus indicus). circumstance that the huckle-bone, or astragalus, of the ankle-joint of the Perissodactyles is a vertically elongated bone terminating above in a deeply grooved, pulley-like surface for articulation with the larger bone of the leg, instead of being shallow, with a flat upper surface. All these animals walk in the digitigrade fashion on the summits of their toes, which are more elongated thin in the elephants. At the present day the Perissodactyla are represented by only three families, each containing a comparatively small number of species ; but in former epochs of the earth's history they were much more numerous.

From the other members of the sub-order, tapirs, which are somewhat pig-like and antediluvian-looking animals, are readily distinguished by the production of the muzzle into a short, mobile snout, and the presence of four toes on the 
front-feet, the hind pair having three. 'T'hey have low-erowned eheek-teeth ; the upper molats liaving an outer wall formed by the mion of two conical tubereles, from the inner side of which a jair of transverse erests run obliquely across the grinding surface of the crown. In the lower molars there is simply a pair of transrerse ridges to each ; the total number of teeth being 42 . The skin of all the tapirs is sparsely haired; and in size these animals may be compared to a large donkey.

The whole of the five living species of tapirs may be included in the single genus Tupirus, to which special interest attaches on account of its remarkable geographical distribution. Thus, whereas one of the five species is found in the Malayan countries, the whole of the other four are restricted to the forestregion of 'Tropical America, some of the latter ranging ligh into the Andes. This, however, is by no means all, since the Malayan species is much more nearly related to two of the American species than are the latter to their compatriots. Had we the existing forms alone to deal with, this discontinuous distribution would be very difficult to explain ; but we learn from geology that these animals were formerly widely spread over the Northern Hemisphere, whence they have migrated southwards to their present isolated labitats.

The Malayin species ( $T$, indicus), which is the largest of the five, differs from all the others in liaving the middle of the body white; the remainder of the skin being uniformly black, as is the whole of that of the American species. In all the five kinds the skin of the young is, however, striped and spotted with white. As regards their mode of life, tapirs are essentially shy, hamless, and nocturnal forest animals, always frequenting the neighbourliood of water, in whiel they often swim.

The rhinoceroses, which include by far the largest representatives of the Perissodactyle sub-order, may be best distinguished from the tapirs by the form and number of their teeth. These are always numerically less than 42 in the living species; and the uppermolars liffer from those of the tapir's in that their outer surface forms a continuous wall, undivided into lobes, while the grinding surface, although consisting primarily of two oblique trans-

\section{The \\ Rhinoceroses.-} Family

Rhinocerotidu. verse ridges, presents a much more complicated pattern. In the lower molars, the ridges, instead of being simply transverse, are curved into crescents. Another point of distinction, so far as the existing kinds are concerned, is the presence of only three toes on both the front and hind-feet. Rhinoceroses derive their name from the presence of either one or two horns arising from the middle line of the fore-part and middle of the liead ; these liorns consisting entirely of an agglutinated mass of liair-like substances, having no commection with the bones of the skull.

In appearance, rhinoceroses are huge, ungainly brutes, witl an enormous head, much elevated and expanded posteriorly, shoit, massive limbs, large, tubular, upright ears, often fringed with laairs, a moderately long, tapering tail, and very thick slin, which is generally but sparsely covered with hair, and may be thrown into a number of massive folds. They have always the full number of seven pairs of cheek teeth; but canines are wanting, and the incisors, if present at all, are reduced below the typical number of three pairs.

Rhinoceroses are restricted to the Oriental countries and Africa; but there is some difference of opinion whether they slould be divided into several genera, or all included under the single reneric tern Rhinoceros. Adopting 
the latter alternative, the five existing species may be arranged in two divisions, of which one includes the three Oriental forms, and the other the two African. The Oriental rhinoceroses are characterised by possessing

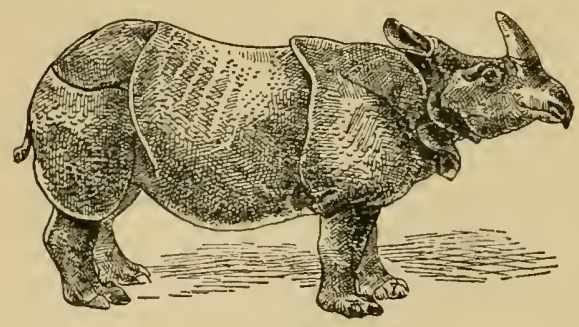

Fig, 69.-Indian Rminoceros (lihinoceros unicornis). incisor teeth in both jaws, one (or the only) pair in the lower jaw forming sharp, triangular, projecting tusks, eapable of inflicting terrifie gashes when their owner's charge. By f:r the largest of these is the great Indian rhinoceros $(R$. unicomis), whiel is confined to the great grass-jungles of North-Eastern India, and is characterised by its massive but short, single horm, the large bosses on the deeply. folded skin, the numerous pleats round the neck, and the complicated structure of the upper molar teeth. The Javan rhinoceros (R. sondaicus), which is a much smaller animal, ranging from Eastern Bengal and the Sandarbans to Burma, the Malay Peninsula, and the islands of Sumatra, Borneo, and Java, differs in the arrangement of the folds of the skin, which lacks the great bosses of the larger species, and likewise by the lower and simpler crowns of the upper molar teeth. The third representative of the Oriental group of the genus is the Sumatran rhinoceros (R. simatrensis), which ranges from Assam, Chittagong, and Burma, to the Malay Peninsula, Sian, Sumatra, and Borneo, and is the smallest of the three. Having upper molar teeth of the same type as those of the Jaran species, it differs from buth that and the Indian rhinoceros in having two horns on the luead, the foremost of which is often much larger than the single one of either of the other Asiatic species.

The two species of African rhinoceroses differ in that the incisors of the adults are rudimental or wanting in both jaws, and likewise in the absence of foldings in the skin, which covers the body uniformly; both having two horns. The largest of these is the square-nouthed, or Burchell's rhinocerus ( $l i$. simns), frequently inappropriately spoken of as the white rhinoceros. This animal, which was formerly met with in enormous numbers to the north of the Orange River, but is now well-nigh exterminated, if, incleed, it be not actually extinct, takes its name from its square and truncated upper-lip. In addition to this, it is characterised by the tall and complex crowns of the upper molar teeth, which present a pattern rery similar to that obtaining in the Indian species, as well as by the great length of the front horn, which is frequently found with its tip obliquely abraded, on account of laving becn pushed along the ground as its owner walked. The goneral coluur of the skin is slaty-grey. On the other hand, the common African, or so-called black rhinoceros ( $R$. bicomis), has the prehensile lip characteristic of the other members of the genus, while its front horn dnes not attain the enormous length reached in $R$. simus, and the npper molars are of simpler structure. This rhinoceros ranges from Abyssinia to the Cape, and differs considerably in liabits from the other African species. Possibly a third species may cxist in North-Eastern Africa.

The third and last family of the Odd-toed Ungulates is that of the horses, 
under which title aro included not only horses proper, but also zebrus and asses, all of which may be comprised in tho single genus Liques. From all other living Mammals the members of this genus cliffer by the reduetion of the number of toes to a single one in cach foot; but as there are certain cxtinct

The Horse Tribe. -Family Equicle. horses provided with three perfeet toes on each foot, we learn that this essential peculiarity of the existing forms is a feature of comparatively late acquisition. Indeed, evidence of this descent from a threetoed ancestor is attorded by the so-called splint-bones which are found in the horse, lying on each side of the upper half of each camon-bone, and enrespond to the metacarpals and metatarsals of the second and fourth digits of the typical five-toed foot, the cammon-bone representing the thircl or middle one. In the case of such well-kmown animals as the horses, it would be quite superfluous in a work of the present nature to describe them in any detail, and it will accordingly suffice to point out a few of the features which indicate that they form a family by themselves. More important than the single digit of the feet is the peculiar structure of the molar and premolar tceth, which form tall quadrangular prisms, in which the enamel is thrown into a number of deep foldings and plieations, the intervening depressions and flutings being eompletely filled with cement. Although the resemblance is at first not very easy to make out, a careful study of the pattern on the crowns of the upper molar teeth of a horse will show that it is really essentially the same as in the rhinoceroses, of which it maly be regarded as a specialised modification. The upper premolar teeth, which are generally three in number, although occasionally a small anterior oue is present, are as complex as the molars, and are peeuliar in being larger than the latter; similar features oecurring in the lower jaw. There are thus normally six pairs of check tecth in each jaw ; the total number of teeth in the adult male being 40 , although in the female it may be redueed to 36 , as the canines, 0$)^{\circ}$ tusks, which are always rudimental in that sex, are in some eases altogether wanting. The canines vecupy the centre of a long gap between the premolars and the ineisors; the three pairs of the latter forming a semi-eirele at the extremities of the jaws. The incisors of the horses are peculiar in liaving the summits of their crowns deeply infolded, like the finger of a glove with the tip pushed in; and it is according as to low muel of this infold, or "mark," remains in the teeth of a horse that its age is approximately cletermined. The skull of a horse, which is of an exceedingly elonsated form, differs from that of either a tapir or a rhinoeeros in liaving the soeket of the eye completely surrounded by a ring of bone; and in the limbs the bones known as the ulna in the front pair, and the fibula in the hind, are incomplete, and respectively united with the radius and the tibia. A special feature of the horses is the great elongation of the camnon-bone (metacarpal and metatarsal) in each foot, which gives them their clraracteristic length and slenderness of limb, and enables the upper parts of both the fore and hindlegs to be enelosed in the skin of the body. It is almost superfluous to observe that the so-ealled knee of a horse represents the human wrist, and the hock the ankle; the whole of the limbs situated below these joints corresponding to the middle finger or toe of the human hand or foot, with the supporting metacarpal or metatarsal bone. The toe of each foot is enveloped in a solid hoof, which is broader in the front than in the hind-limb; and the imer sicles of the fore-limb always has a maked wart-like callosity above the wrist-joint, whils there may be a similar pair of callosities on the hind-limb. 
The ears are elongated; the long and tapering tail may be cither long-haired throughout its length, or only at the tip; and the neck is ornamented with an upright or flowing mane. Horses are now restricted to the Old World, although they formerly existed both in the northern and southern halves of the New World.

The common or true horse (Equus caballus) is now best known in a domes. ticated or half-wild condition, although it is probable that the wild horses, or tarpans, of the Russian steppes, are the direct descendants of the original primitive stock, and have never been domesticated. From the other species of the genus the horse is distinguished by the tail being covered with abundant long hair from root to tip, by the presence of a warty callosity on each hind-leg, just below the inner side of the ankle-joint, the longer and pendant mane, shorter ears, more elongated limbs, smaller head, and wider hoofs. Some doubt exists whether the horse from Central Asia described as $E$. preaerclskii is a valid species; but if it be, it appears to be intermediate between the horse and the asses, having callosities on both limbs, an erect mane, no forelock, small ears, and the upper part of the tail short-haired.

The zebras of Africa south of the Sahara form a group closely allied to the asses, but distinguished by their more or less completely striped colora-

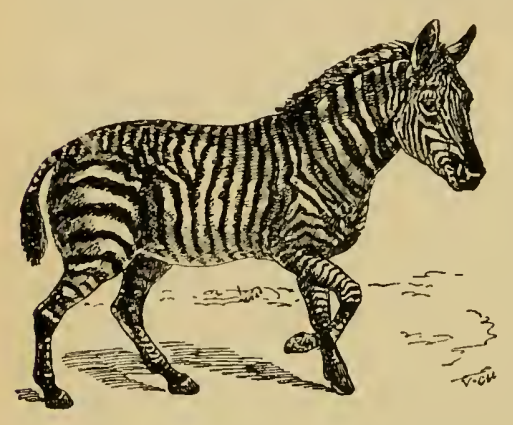

Fig. 70.-BURCHeLL's Zebra (Equus Uurehelli). tion. Of these the true, or mountain zebra $(E$. zebra) formerly inlabited the mountains of the Cape Colony in large herds, but is now greatly reduced in numbers. It is a rather small species, standing about four feet at the withers, with rather long ears, the lower part of the tail somewhat thinly clothed with long hairs, and a short mane : the ground colour being white, with broad, black, transverse stripes, extending over the whole skin, except that of the under-parts and the inner surface of the thighs, and the lower part of the face chestnut brown. On the hincl-quarters short transverse stripes extend from the longitudinal one running down the spine towards or to the oblique ones of the haunches. Grevy's zebra (E. grevili), of the Galla comtry, differs by the much narrower and more numerous stripes, especially those of the head, the spine-stripe being disconnected from the others. More distinct is the larger Burchell's zebra ( $E$. burchelli), from the open plains to the north of the Orange River, characterised by the pale yellowish-brown ground-colour of the hair, and the broad brown or black stripes; a dark stripe, to which the lateral stripes may be united, traversing the middle line of the under-surface of the body, and the spinal stripe being isolated from the uppermost haunch-stripe parallel to it. Very generally faint stripes occupy the middle of the broad intervals between the dark stripes of the haunches; and the limbs and tail may be either fully or partially striped, or uniform. Upon such variations several nominal species have been established, but it appears preferable to look upon all these in the light of mere varieties of a single variable species. Many attempts have been made, with more or less marked success, to break this zebra to harness. 
According to a newspaper report, recent experiments in the Transvaal have been "successful, in so far as the training is concerned, but the trials with these animals have wofully disappointed those who faneied they might be advantageously utilised for draught purposes. Most people in South Africa, in districts where zebras abound, have hitherto regarded these animals as impervious to that human control that would be necessary to render them reliable between the shafts or in traces, and it is only lately that efforts havo been directed towards their domestication. Teans of then, comprising ten or more, have been broken in and 'inspanned ' to conches and other vehicles, by way of testing their amenability to the bit and the whip, and their behaviour in harness has been in some respects most satisfactory and promising, though their peculiarities sometimes rather out-mule the mule, their shyness being partieularly pronounced, and their disinclination to start gentiy another characteristie, resulting often in jumps out of harness, or other antics, such as those practised by a jibbing or highly-nervous horse. These faults, however, eure themselves in time, simply by the punitive lessons they teach the zebras; but the stamina of the animals is not of a nature to stand the strain of either the lessons so acquired, or the burden of the draught for any length of time, and looking at the conformation of the zebra one is hardly surprised. Resembling the mule in many points, he yet lacks that essential inherited by the latter from both his progenitors-toughness of bone and musele, prescribed by generations of usage as a beast of burden. It is adnitted by all who have seen zebras in harness that, from a speetacular point of view, they are worth the trouble spent upon their training, and as nounts for ehildren they are certainly more respectable-looking and dignified than the donkey, and in chaises, too, they would probably be found equal to very light work. As draught animals, in the ordinary sense of the term, however, they are not successes. Whether a breed could be manufactured from the zebra, in the same way as the mule has been, and whether with similar suecess, are questions that an intermingling of blood at the present time might satisfactorily answer in the future."

The fourth species is the quagga $(E$. quergga) of South Africa, which forms a connecting link between the others and the asses, having the head, neek, shoulders, and the middle of the body striped, but the hind-quarters, tail, and limbs uniformly coloured. This animal always had a very restrieted distribution, and is now nearly, if not quite, exterminated.

The leading characters by which the uniformly-eoloured asses differ from the horse have been already pointed out. The Asiatic wild ass ( $H$. hemionus) is a variable species, of an isabelline rufous tint, with a dark, longitudinal stripe down the spine, but none across the withers, and comparatively small ear's. Its three leading varieties are the Syrian wild ass, the onager of Persia, Baluchistan, the Punjab, Sind, and Kach, and the kiang of Mongolia and the Tibetan highlands, which is the largest and most horselike of the three. All these wild asses inhabit more or less completely desert districts, and are exceedingly fleet of foot, passing over the roughest ground at a gallop. The Afriean wild ass ( $E$. asinns), from Abyssinia, Nubia, and Somaliland, differs from the preceding by its greyer coloration, much longer ears, and the general presence of a dark stripe across the withers. It is evidently the ancestor of the domestic breed, but its speed and endurance must not be judged by those of the latter. The late Sir Samuel Baker wrote that "those who have seen donkeys only in their eivilised state can have no conception of the beauty of the wild $n r$ original animal. It is the perfection of aetivity and courage." It 
lias a high-breù tone in his deportment, a high-actioned step when it trots freely over the rocks and sand, with the speed of a liorse when it gallops over the boundless desert. The specimens now in the Zoologieal Gardens will enable any one to perceive the character of the animal as it was before being altered by generations of captivity." The bray of the Abyssinian is identieal with that of our eommon ass, and Darwin notes the marked aversion to walking across a bronk, which characterises the domestic donkey, as indicating its derivation from a desert-haunting animal; as also does its pleasure in rolling in the dust. The Somali ass differs from the ordinary African form in its more greyish colour, the absence of the cross-stripe over the shoulders, the very slight indication of the spinal stripe, and more especially in the numerous black markings on both front and hind-legs. It his, likiwise, emaller ears and a longer mane. It may be a matter of doubt whether these differences are of specific value, but they probably only indicate a variety. Of this form Mr. Lort Phillips writes that " on March 22, 1884, when about 20 miles to the west of Berbera, we fell in with a small herd of wild asses. After a long and tedious stalk I succeeded in bagrging one, which turned out to be of quite a new species to me, having no mark whatever on the boly, which was of a beautiful French grey colour. On its legs, however, it had black stripes running diagonally. I lave, unfortunately, lost the book in which I put its measurements, but it was a superb creature, and stood quite 14 hands at the shoulder; our Berbera hor'ses looked quite small in comparison."

The two species of hippopotamus, both of which are now confined to Africa. and may be referred to the genus Hippopotamus, bring us to the fourth and last sub-ordinal division of the Hoofed Mammals, which far The Hippopot- outnumbers the whole of the other three put together, both ami.-Family as regards families, genera, and species. From the fact that IIippopotamicle the two toes corresponding to the third and fourth digits of: the human hand and foot are of equal size, and symmetrical to a vertical line drawn between them, this group has been appropriately named the Artiodactyla, or Even-tued Ungulates. Whereas, however, in some species, such as the giraffe, only these twodigits are present; in others, like the hippopotami, there are four functional digits; while in yet others, as the oxen, the middle pair alone are functional, and the lateral ones much reduced in size, and of no functional importance. In the pecearies the hindfoot is unique among the sub-order in having only three toes. Although the structure of the feet forms the prime distinction between the Artiodactyla and Perissodactyla, there are many other points of difference between the two groups, a few of which may be mentioned. As regards the teeth, the premolars of the Artiodactyla are almust invariably of simpler structure than the molars; while the last lower molar is nearly always composed of three transverse lobes, whereas in all the living representatives of the Perissodactyla it is two-lobed. The femur or thigh-bone of the latter sroup is alivays provided with a large projecting process in the upper lialf of the shaft known as the third trochanter, which is in variably absent in the one under consideration. Again, in the ankle-joint the liuckle-bone, or astralagus, of the Artiodactyla has its lower articular surface divided into two nearly equal facets, whereas in the Perissodactyla such surface is single. There are many other minor points of difference, but those griven are amply sufficient to distinguish between the two sub-orders.

The hippopotami are the most primitive and least specialised of the existing 
members of the Artiodactyli, and are characterised as a family by the followin: features. Hiving a very bulky, clumsily-built body, and short limbs, these animals possess a rery broad and obtuse muzzle; the feet are short and broad, each having four toes of neirly equal size, invested in rounded hoofs, and all applied to the sround in walking; the incisor teeth, which grow throughout life, are curved downwarls in the upper jaw, and project straight forwards in the lower ; and the eanines, which also grow eontimuonsly, are very large and curved, those of the upper jaw being directed downwards. The molair teeth are tuberculated, and have four columns, the summits of which show trefoil-shaped surfaces of irory, bordered by a broad rim of enimel, when worn by use. In the head, the grent elongation of the face causes the small eyes and still more minute ear's to be situated rery far back-

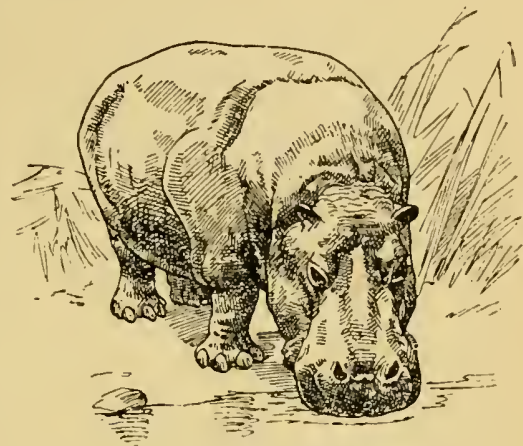

Fig. 71.-Common Hippopotants

(Hipponotemus amplibius). wards; the legs are so short that the lower surfice of the body is seareely raised above the gromend in the standing posture ; and the round tail is likewise extremely short. The thick skin is almost entirely naked. The common hippopotamus ( $H$. umphibius) is an animal too well-known, both as regards form and habits, to require any detailed description; its most distinctive feature being the possession of two pairs of incisor teeth in each jaw. On the West Coast of Africa there exists, howerer, in Liberia, a second species of the genus, known as the pigmy hippopotamus (1I. liberiensis), differing not only in size, but likewise in habits, from the one with which all are familiar. In p'ace of attaining a total length of about 11 feet, neasured in a straight line, and weighing probably some three or four tons, the pigmy hippopotamus is not larger than a grood-sized wild boar, although it has the short and stout limbs of its gigantic cousin, with which it also agrees to a certain extent in the relatively large size of its head. As regarcls its mode of life, this species differs, how. ever, in toto from the common one. Instead of passing at least as much of its time in the water as on the land, and never livinu away from rivers or lakes, the pigmy hippopotamus is an inhabitant of the dense tropical forests of that part of Westem Africa which is its home, where it apparently learls a life very similar to that of wild pigs, wallowing in swamps after the mamer of those animals, but appisently not habitually frequenting rivers, though it is doubt. less, like almost all Mammils, able to swim well when the necessity arises. Moreover, in place of associating in large herds after the mamer of the common species, and never moving far from one particular locality, the Liberian hippopotamus is a comparatively solitary creature, going about at most only in pairs, and wandering long distances through the woods. It differs essentially from the common species in usually having only a single pair of lower incisors, on which account it has been generically separated by some under the name of Chworosis. Specimens are, however, occasionally 
met with liaving two pairs of these teeth on one side of the jaw. If fossil species be taken into consideration, other variations will be found in the number of these teeth ; but before proceeding farther, it is necessary to remark tliat, since in ordinary Mammals the typical or full complement of incisor teeth consists of three pairs, it is natural to suppose that one pair has been lost in the common species. 'That such is the case is clemonstrited by the extinct Siwalik hippopotamus ( $H$. siculensis) of the Himalaya, in which, between the two large tusks, there are three pairs of incisors, differing from those of the common species in being all of nearly equal size; and if we were to examine the upper jaw, we should find the same number of teeth. In the mesence of these three pairs of incisors the Siwalik hippopotanus resembles the pis, from which it departs less widely than does the common species, in that these teeth are relatively smaller, and also of nearly equal size. 'The Siwalik hippopotamus must nccordingly be regarded as a less specialised species than either of its living cousins; and since, together witl an allied species from Burma ( $H$. iracuticus), it is the oldest representative of the genus, its generulised features are precisely what evolutionary considerations would have led us to expect. There is, however, yet ancther point in con. nection with these teeth demanding notice. From the evidence of the common species, it is impossible to determine which of the three pairs of lower incisors found in the Siwalik hippopotamus have dissippeared in the former ; but in the gravels of the Narbada Valley in Central India, there are found two extinet members of the genus, $I T$. numalicus and $H$. prelcindicus, in the former of which the lower incisors are similar in size and number to those of the Siwalik species; but in the latter, while the inner and outer pairs are very liure, there occurs on each side between them a minute and ruclimentiry tootl, squeezed out from the general line to the upper margin of the jaw, and eviclently about to disappeir altogether. There is thus evidence that the missing pair of lower incisor teeth in the common lippopotamus is the second ; and a complete transition ean be traced, as regalls the number of these teeth, from the Siwalik species through the common one to the Liberian hippopotamus. While it is quite possible that the African hippopotamus may have been derived from the Siwalik species, it is clear that the pigmy hippopotamus is not the descendant of its giart existing cousin.

With regard to the geographical distribution of the genus, while there is no evilence that the pigmy species ever ranged beyond its present habitat of Liberia, the case is very different with regard to the range of the common species. At the present day this animal is found from the Cappe Coluny northwards to the cataricts of the Nile, and it extends westwards to Senegal; but while for several centuries it has been very seldom net with on the Nile below the entrance of the Atbara and Blue Nile, there is abunctant evidence that in the time of the Pharahs it was common in Egypt, where in the temple of Edfu, as well as several other buildings, there are frescoes representing the mode in which it was hunted and speared. That the hippopotamus is the animal indicated in the book of Jub under the name of behemotl is minloubted, but there is no evidence that the Jews vere acquainted with it otherwise than during their sojourn in Egypt. It is true it lias been suggested that its lange may liare extended castwarls as far as Palestine, but this is conjecture, and, had the creature ever lived there, some of its remains should have been found. In the superficial deposits of Southern and Central Eume there oceur, however, numerous remains of a hippopotamus which cannot be specifically distinguished from the existing African 
form, although it was generally of rather larger size. This difference in sizo was once thought to indicate that the fossil form was a distinct species, but the discovery of a half-fossilised jaw in the alluvium of the Nile near. Kalabshi, in Nubia, showed that in former times the African hippopotamus attained dimensions as largo as the Europen form. In England the hippopotamus ranged at least as far north as Leeds, and it is a remarkiable cireumstance that in many places its remains have been found in association with those of the reindecr. In Algeria, where the grenus is now umepresented, a small species ( $H$. hipponensis) flourished duming the I'leistocene period; this being distinguished by having three pairs of lower incisor teetl, which diftered from those of other members of the grenus in laving their enamel smooth and their extremities somewhat expanded, thus approximating to the corresponding teetl of the pigs. Equally noteworthy is the ncenrence of another species ( 11 . lemerlei) in Madagascar, where its remains are common in the great marsh of Ambulisatra. Somewhat intermediate between the common and the Siwalik species, this rather small hippopotamus had sometimes three and sometimes two pairs of incisors in the lower jaw. One or two small species, which may have been partially terrestrial in their habits, dwelt in Italy, Malta, and some of the other Mediterranean islands in past times.

From the hippopotami the nembers of the great pig tribe, all of which are contined to the Old World, are at once distinguished, not only by their lighter build and longer limbs, but likewise by the peculiar form of the snout, which always terminates in an oval, fleshy The Pig Tribe. disc, in which are perforated the nostrils. The feet, al- - Family Suidr. though severally furnished with four toes, are also different

in that they are much narrower, and that the middle pair, which are alone functional when the animals are walking on firm ground, are much larger than the lateral ones, and have that adjacent surfaces, so as to form a si-called divided hoof. In the teeth, the incisurs, wlich are somewhat variable in number, are routed, and thus only grow for a brief period, while the cimines are rootless, and distinernished by the upper pair heing directed mol'e or less markedly outwards or upwards. The molir teeth, which are tulberculated, do not wear into the distinct trefoils characterising the corresponding teeth of the hippopotami.

The true pios (Sus) differ from all the other members of the family in laving the typical number of 44 teeth, although in certain African representatives of the genus the anterior premolars are irequently shed in the aduit. The canines of the upper jaw are curver outwards and upwards, and in the males are very large, and jroject far beyond the lips; thcy are worn on their onter convex suifaces to a sliarp edgre by the attrition of the longer and more slender lower tusks. In the upper incisors, which are directed downwards, the first is considerably larger than the second, which, in turn, suceeds the third in size; and the three pairs of lower incisors are directed almost horizontally forwards. The skull is characterised by tha great elevation of its hinder or necipital portion. The external form of tho pigs is too well known to need anything in the way of description; but it may be remarked that whereas in many of the domesticated breeds the skin is nearly naked, " $n$ the wild boar it is covered with a thick coat of bristly hair. Whereas the adults of all the species are more or less uniformly coloured, the young of the wild breeds are longitudinally striped and spotted with yellow or white. The typical representative of the genus is the wild buar ( $S$. scrofa) of Europe, 
Nortl Africn, Asia Mrinor, and Central Asia, replaced in India by the closely allied s. cristutus. India is the home of the smallest species, the pigmy horg (N). salvanius) of the Bhutan terai, which scarcely execerls al lare in size. Numerous species inlanit the Malayan combtries and islands as far east as Celebes aurl the Philippines, while one, which may, however, hive been introduced, is found in Now (ininea. Afriea sonth of the Sahima has but one of the more typical representatives of the genus, which inhabits the Senhar

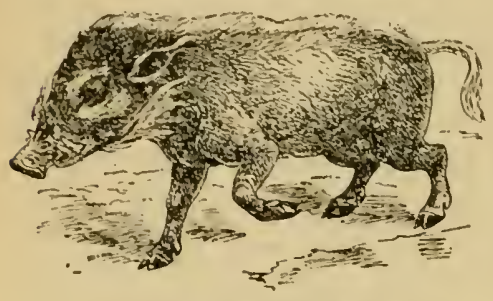

Fij. i2.-Bush-Pre (Sus africanus). listricts. Elsewhere in that continent, is well its in the adjacent islinel of Mradagnisear, the plince of the typieal swine is talien by the bush-pigs, which are frequently regatrded as representing i distinct genus, uncler the name of Potum\%. chernes. The bush-pigs Jave long, peneilled ears, and tend to lose tho interior premolar teeth in botl jaws, while their molars are of simpler structure thin those of the other members of the genus. Of the two Afriean species, S. afrieruns, ranging from South to Central Africa, has grey hatir, whereas in the West African s. porcus the colour is red, and the pencilled ears are of great length.

The other wo genera of swine lifier from the foregoing in laving miformly coloured young, both being remarkable for the extraordinary develomment of the tusks of the males. This fenture attains its maximmm in the bathirusa (Bubivuse alfurms) of the island of Celebes, in the males of whiels the upper tusks pierce the skin of the face, and eurve backwarls over the eyes in a manner recalling the horns of the chamois. The lower tusks, which are equally long and slender, eurve backwards in a somewhat similar mamer, but do not wear against the uperer pair. There are but two pairs of upper incisers, and only two pritis of premolars in ench jaw. In appearance, the bahirnsa is a mather short-bodied and long.limbed pis, with small enrs, a very wrinkled skin, and the upper edge of the extremity of the sucut crerhanging the lower. By far the most hideous and repulsive-looking members of the family are the two Africin sprecies of wart-liogs (Phetcolion-

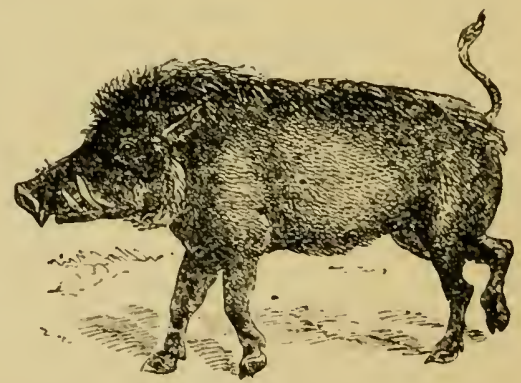

Fig. 73.-Wart.Hou (Phacucherus athiopiers). ris), characterised liy lirge conical warty growths projecting from the sicles of the face. The whole head is much Hattened and expanded, and the muzzle rery broal. The huge tusks, whien are nearly as large in the sows as in the boirs, curvo upwards, outwards, and forwards; the upher ones, which are tipped with enamel only at the apex, being of great thickness, and almated on their convex surfaces ly the more slender lower piir. In the arlult there is but a single pair of upper ixcisor teeth, 
although, as in all the pigs, the norrnal three pairs of these teeth aro retained in the lower jaw. The premolars aro reduced to three pairs in the upper, and two in tho lower jaw ; but in aged animals not only all these teeth, but likewise the first two pairs of inolars, aro gencrally shed, so that there is orly the list pair of molars left in each jaw behind the tusks. These last molars are of great size and very peculiar structure, beins composed of a number of narrow cylindrical columns arising from it common base, and closely packed together, so as to form a long, narow, tall crown. Different as such a tooth looks at first sight from the eorresponding molar of an ordinary pig, a closer inspection will show that it is nothing but a highly specialised moditication of the same general type.

All pigs are more or less nocturnal in their habits, associating in clroves, or "somulers," of variable size, and inflicting much damage on erops by their liabit of grovelling in the soil in search of roots with their snouts. In diet they may be said to bo omnivorous, scarcely anything edible coming amiss to them. The females produce a largo number of young at a birth, and thereby clifter very remarkably from the ruminants, in which the number very seldom excecds two, and is more generally one. Boars attack with their lower tusks, and tho wounds inflicted by these formidablo weapons are territic, a horse being not unfrequently ripped open by one sweep from tho tusk of a charging boar.

Although nearly allied to the pigs of the Old World, with which they appear to be still more intimately connected by means of certain extinct types, the small American swine known as pecearies (Dicotyles) are generally regarded as indicating a family group by themselves. They are specially distinguished by the circumstance thint the canine teeth of the upper jaw have their points directed downwards in the ordinary manner, witl their hinder edges sharpened to a cutting edge ; and likewise by the toes on the hind-feet being reduced to three. In the skeleton the third and fourth metacarpal and metatarsal bones are united at their upper ends. Another peculiarity is to be found in the circumstance that the last premolar in the upper jaw is as complex as the first molar, its crown carrying four distinct tubercles. The stomach also is of a more complicated construction than that of the true pigs; and the back is provided with a peculiar gland, from which these animals derive their scientific title. The total number of teeth is 38 , there being only two pairs of incisors in tho upper jaw, and three pairs of premolars in each. Peccaries, which rango from the Iied River of Arkansas to the Rio Negro of Patagonia, mueh resemble small blackish pigs in general appearance. They are forest-haunting animals; and although of small size individually, the larere droves in which they colleet render them foes by no means to be despised by the lonely traveller in the Brazilian or Paraguayan forests.

The three preceding families of the sub-order Artiodactyla constitute a sectional group known as the Suina, and are collectively characterised by the tuberculate molar teeth and tlo circumstance that the third

Camel Tribe. - and fourth metacarpal and metatarsal bones of the feet (that Family is to say those corresponding to the third and fourth digits Cameliler. of the luman hand and foot) are never completely united together, and are in most cases entirely separate. The ro. mainime members of the sub-orcler are divided into three otler sections, ail 
of which differ from the Suina, and arree with one another in that the molar teeth, instead of being simply tubercular, have the columns on their crowns bent into the form of crescents, of which there are four in those of the upper jaw. Technically, this type of tooth is known as the sclenorlont; and all the animals possessing it are characterised by their power of ruminating, or chewing the cud. Moreover, in all cases the third and fourth metatarsal bones of the hind-feet are completely fused together to form a cannon-bowe, terminating inferiorly in two pulley-like surfaces, or trochlere, which carry the two middle toes; the same condition also obtaining in the corresponding metacarpal bones of the fore-foot, except in one species of cherrotain. All these animals are thus more specialised than the Suina; the tubercular type of molar, and the separate metacarpal and metatarsal bones of the foot, being evidently the more primitive type.

The first section of these selenodont Artiodactyles is known as the Tylopoda, or cushion-footed group, and includes only the single family of the Camclide, now represented by the camels of the Old World and the llamas of South America. Having selenodont molars and complete cannon-bones in both feet, the camel tribe are specially distinguished by retaining incisor teeth in the upper jaw, and by the lower canines being tusk-like and separated from the incisors, which always form three pairs. The limbs are long, with the thigh of the hinder pair less enclosed in the skin of the body than is the case in the following families; while the feet have but two toes, which are cmbedded in a large pad-like cushion, and have only small nails on the upper surface of their extremities. In the cannon-bones the two trochlete of the lower extremity are widely divergent, and lack the median longitudinal ridge found in all other members of the sub-or'der. The neck of these animals is long and flexible, and its component vertebre present a peculi. arity unknown in any other living Mammals. As regards their soft internal parts, the camels have a less complex stomach than the true Ruminants; two of its chambers having special honeycomb-like cells for the retention of water.

From their allies the llamas, the two species of camel (Cumelus) are readily distinguished not only by their much larger bodily size, but likewise by the presence of one or two fatty humps on the back, which diminish or increase in size according to the plysical condition of the animal. The head is large, with relatively short and rounded ears; the broad feet have the toes very slightly separated; the moderately long tail terminates in a tuft; and the nearly straight hair is not woolly. Adult camels have a total of 34 teeth, with but one pair of upper incisors, although in the young there are three pairs of the latter. The camels are among the few animals of which there are now no wild representatives; the so-called wild Bactrian camels of 'I'urkestan being now pretty conclusively proved to be the descendants of a domestic race which escaped long ago from captivity. Of the two species, the Arabian camel ( $C$. dromedarins), which is found in a domesticated state from Africa to India, is characterised by the single hump; while in the stouterbuilt and moro shaggily-haired Bactrian camel ( $C$. buctionus) there are two of these excrescences. The latter species is kept as a benst of burden from the Crimea to Turkestan and Pekin, From the large loads they are capable of carrying, as well as their power of encluring deprivation from water for a considerable period, camels are invaluable as a means of transport in dry ccuntries, where the roals are not too rocky. They are, however, best suited for traversing sandy deserts; but where the ground is wet, 
especially on inclined roads, they are almost nseless. The Bactrian eamel, which is doubtless a native of Asia, is much better suited for traversing high mountains and enduring cold than the Arabian species. Regarding the twohumped camels of the neighbourhood of Yarkand, it has long been a cisjuted point whother these arc really wild, or whether they are the descendants of an originally domesticated race. Something towards clearing up this question has been done by Major C. S. Cumberland, who liad the good fortune to shoot one of these animals. Its skin and skull were submitted to MIr. Blanford, who reports that they belonged to a two-humped camel, in which the humps were represented by large tufts of hair. The skull

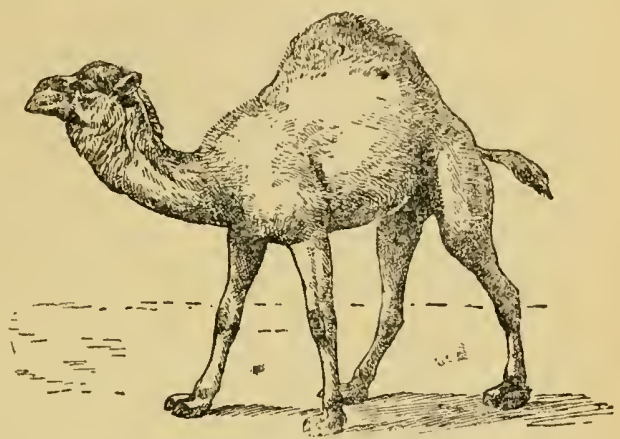

Fig. 74.-The arabiax Canel. agreed fairly well with that of a domestie Bactrian camel (C. Lactrianus), and differed from that of the single-humped Arabian camel (C. dromedarius). Whether, however, sucir differences, as presented by the former, were indicative of the existence of a distinct race, the materials at hand were insufficient to determine. In regard to these camels in their native home, Major Cumberland writes as follows:-_"The habitat of the wild camel is the Gobi steppe from lihotan to Lob-Nor. Hxcept when snow lies on the ground, these animals

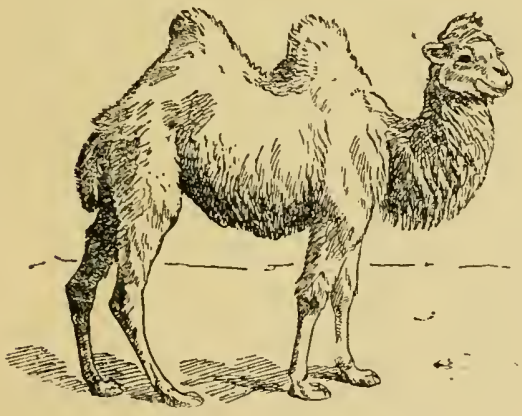

Fig. 75.-The Bactrian CaMet. may be met with here and there along the old bed of the Yarkand and Tarim Rivers, which they frequent for the pools of brackish water that are to be found here and there. But as soon as the snow fills they move off into the desert, as if then independent of the water-supply. They prefer the sllow, I imagine, as being less salt than the water, although it also is impregnated to a certain extent soon after it falls. The camel is very shy in its habits, and, so far as I could ascertain, has never been caught or domesticated. The natives told me that no horse in the country could catch the camels in the deep sand of the region they frequent. They appear to me to be distinct from the Bactrian camel; they are less stumpy in build, the hair is finer, closer, and shorter. They rary in colour, like the domestic species, from dark brown to lightish dun. 'Their origin has yet to be traced. I take it that they have sprung 
from camels when the district known as Takla Makan was buried in a great sandstorm some centuries aro. Tradition relates that no human beings survired, but it is likely enough that some of the canmels and horses did so, and that this was the origin of the wild cancls and ponies that are found in this clistrict."

Camels have been successfully introduced into North America; and for some y'ears, according to a writer in The Asiun newspaper, have been largely employed as a meaus of transport in South Australia and Qucensland, while recently the Swan River colonists have followed the example there set them; a large number of superior Rajputana camels, which had been marched down from Bikanir to Calcutta, having been shipped to Western Australia to bo used in carrying supplies from Perth to the newly discovered gold fields at Coolgarlic. The utility of the camel being thoroughly recognised in the Antipodes, the fact that an agitation against the animal is being raised in Qucensland is rather a surprise. "Such, however, is the case, as a petition was recently presenter by the resiclents of the Charleville district to the Gurernor of Queensland, praying that something should be done to prevent the introduction of camels into the colony. In it the petitioners pointed out the urgent need that some constitutional means should be adopted to prevent an imminent and clangerous invasion of Western Queensland by camels, as their employment would tend to deprive the present carriers of their means of livelihood. It was stated that the rates of carriage were low, the teams plentiful, and that the carriers were willing to travel on all roads, while the low standard of living among the camel-drivers must result in loss of tracle to the district. It was further said that many of the Western carriers were settlers on the land, and the colony wonld suffer if such a class of men were forced to emigrate; that the value of the W'estern lands would be depreciated, and the welfare of the community injuriously affected. In reply the Premier, to whom the petition was forwarded by the Governor, expressed the opinion that the agitation against the camels was rather hasty. The cause of their presence in the colony was the drought in the SouthWestern districts. It was impossible for teams to travel at all times, and as the Warrego Rabbit Board could not get their netting bronght by the ordinary methods, an officer was sent to South Australia, and the required quantity of netting carried to its destination by cimels. Then a squatter in the district, whose wool could not be taken away by the earriers in consequence of the want of water on the ronte to be travelled, had had it forwarled by the camels to Charleville. The forty camels carried aitogether cighty bales of wool-two bales to each animal-or just about the quantity that is sometimes taken by one tean of bullocks."

Although the name llama properly belongs only to the domesticated forms, it is commonly applied to all the South American representatives of the family, which differ from the camels by their greatly inferior size and lighter build, the want of any hump, the longer and more pointed ears, the short and bushy tail, the narrower feet, with more distinctly separated toes, and the long and woolly hair. They have two teeth less than the camels, owing to the upper premolars in the adult being reduced from three to two pairs. Of the two wild species, the ricuna (Lamce vicuna) is the smaller and more lightly-built animal of the two, and is restricted to tho high Andes of Peru, Ecuador, and part of Boloria, where it associates in large herds in the coldest and most inhospitable districts. On the other hand, the guanaco ( $T_{\text {. }}$ gucenreves $)$ raneses from the Perurian Ancles through the open pampas of Argentina to Pata. 
gonia and Tierm del Fuego; although it has now been exterminated from most parts of the pampas. In size it may be compared to a red-deer; and its fur is of beantiful, light fawn-brown colour. The llama and alpaca are domesticated varieties of the guanaco, kept by the inhabitants of tho l'eruvian highlands; the former and larger of the two being emiloyed as a beast of hurren, while the litter is bred for the sake of its viluable wool. Ail these animals have a peeuliar. cry, with some resemblance to the neigh of a horse; and in the domesticated state they are disagrecab!e associates, on account of their umpleasant habit of spitting, apparently as a means of defence. Extinet members of the family are common in the Tertiary rocks of North America, while fossil carnels occur in Northern India; and it is by these lost types

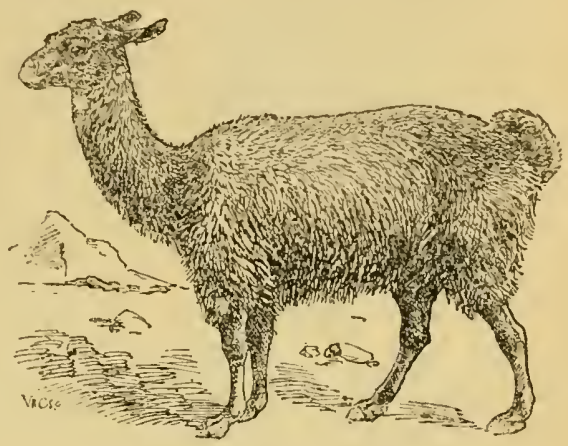

Fig. 76.-Guanaco (Lama guanacu).

that we are enabled to account for the present anomalons gecmraphical ais. tribution of the group, which is cvidently of northern origin.

Among the smallest of all Ungulates are the graceful little Oriental animals commonly known as cherrotains, or mouse-deer, which in coloration, form, and habits, more nearly resemble the Rodent agutis than ordinary Hoofed Mammals. Together with a ne:rily- Tue chovrotains. allied African genus, these nnimals constitute a third section of the selenodont Artioriactyles, known as the Tragulina. From the camel tribe they differ in the total absence of - Family incisor teeth in the upper jaw, and also by the circumstance that in the lower jaw the canines are approximated to the incisors, which they resemble in form, as well as in the structure of the fect. From the true Ruminants they may be distinguished by the stomach liaving only three in place of four distinct compartments, as well as by the fibula, or outer and smaller bone of the lower lialf of the hind-leg, being complete and quite distinet fiom the larger bone, or tibia. Another point of distinction is to be found in the form of the so-called odontoicl process projecting from the lower part of the front surface of the second vertebra of tho neck, which in the present group is conical, whereas it is spout-like in the true Ruminants. A resemblance to the latter group, and at the same time a clistinetion from the camel tribe, is to be found in that the two bones of the ankle-joint, respectively known as the cuboid and the navicular, are welded together to form a single bone. As in the truo Ruminants, the tocs are enclosed in solid hoofs; four completo toes being leveloped in each foot.

The smallest representatives of the family are the truo or Oricntal ehevrotains (i'ragulus), of which there are four or five specios, ranging from India and Ceylon through the Malayan countries, as far east as the island of Palawan in the Philippine group. They havo a total of 34 teeth, and aro mostly uniform in coloration. Tho somewhat lareer West African cherrotaia (Dorcatherivim) differs by the shorter and stouter feet, and the separation 
of the third and fourth metacarpal bones ; the latter feature distinguishing it from all other selenodont Artiodnetyles, In colour, it is deep brown, with

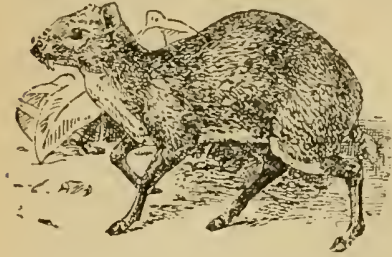

Fig. $\because$ - A Chevrotain (Trayulus). longitudinal white stripes on the flanks, spots of the same on the back, and a white chest and throat. Both in this animal and the true cherrotains the upper canines of the males form tuisks projecting below the lip. In appearance they are very like minute deer, having muderate-sized ears and a short tail, but the head has no bony or horny appendages.

The cleer tribe is the first of four families constituting the true Ruminants, or Pecora, andincluding the whole of the remining mem-

bers of the order. They derive their name of Ruminants from their power of chewing the cud-a feature which they possess in common with the camel tribe and cheviotains; and they agree with the latter group in The Deer Trive. lacking upper incisors, and in having the lower canine ap-Family proximated to and rescmbling the lower incisor's as well as Cervide. $\quad$ in the union of the cuboid and navicular bones in the anklejoint, and in the covering of the toes taking the form of horny hoofs. From the chevrotains they may be distinguished by the stomach being divided into four distinct compartments, by the anterior, or odontoid process of the second vertebra of the neck assuming the form of a spout, or half-cylinder, and by the fibula of the hind-leg being reduced to a mere nodule representing the lower extremity of the complete bone, and articulated to the tibia. Another point of distinction is that the lateral metacarpal and metitarsil bones of the feet are never complete, but are represented only by their upper or lower ends. Tery generally the skull is providerl with a pair of laterally placed appendages, which may he either unbanched, corered with horn, and permanent, or blanched, bony, and deciduons. When such appemlages are present, the upper canines are generally small or wanting; but when the former are absent, the latter are frequently large. As a source of food, the true Ruminants are by far the most important of all animals to the human race. Unknown in Australia and New Guinea, they attain their maximum development in the continents of the Old World proper; in North America, except the Cericle, theyare poorly represented, while in the southern half of the New World the only members of the group are deer.

As a fimily, the deer tribe are generally distinguished by the heads of the males being ornamentel with the branching deciduous appenclinges properly known as antlers, although often wrongly termed horus; these when fully developed consisting simply of lifeless bone, and being nearly always shed ammally, to be reproduced in a somewhat nore complex form the following season. Both sexes usually have well-rleveloped upper canines, which may attain very large dimensions in the males, especially in the few jnstances where antlers are wanting. The face is always provided with the so-called larmiers, or tear-pits, below the eyes; and the underlying region of the skull always has a very large unossified vacuity. As a general rule, both fore and hind-feet carry four toes; and very often the lower ends of the lateral metacarpal and metatarsal bones persist. With the single exception of the musk-tleer, the liver is provided with a gall-bladder.

It would require too much space to describe the mode in which antlers are 
formed and subsequently shed, but it may be mentioned that the annual formation of such an cnormous amount of bone as is contained in the antlers of the wapiti, for instance, is one of the most extraordinary phenomena to be met with in the whole animal kinglom. As regards their distribution, it is remarkable that deer are totally absent from Africa south of tho Sahara, as they are from Madigascar. Although the more northern deer inhabiting the New World are either grenerically or specitically identical with Old World forms, the majority of the American forms, and all those inhabiting Soutl Anerica, are jerfectly distinct from those of other regions.

The nost aberrant members of the fimily are the well-known musk-rleer (Moschus) of Asia, which constitute a sub-family by themselves, and aro represented by one species ( $\boldsymbol{M}$. moschiferus) ranging from the Himalaya and Cochin-China to Siberia, and by is second (M. sifunieus) from Kansu, in North-Western China. One of the peculiar features of these deel--the fresence of a gall-bladder in the liverhas been already referred to; a second, although less peculiar character, is the absence of antlers in both sexes. To compensate for this deficiency, the upper jaw of the male is provided with a pair of long scimitar-like tusks, which may project as much as three inclies below the mal'gin of the lips. 'The

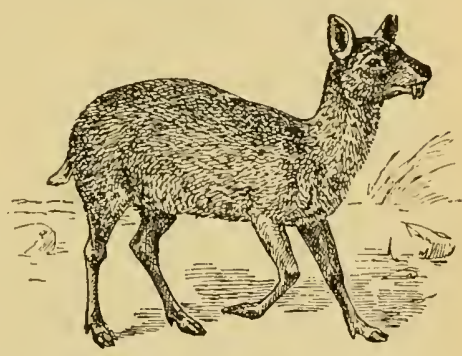

Fig. 73.-Musk-DeEn (Moschus moschiferus). musk-deer has moderately long and somewhat pointed ears, a short tail, very large lateral hoofs to the feet, and the fur of a peculiarly coarse and brittle nature, its general colour being a speckled brownish-grey. The most peculiar. feature about the animal is, however, the presence on the abdomen of the male of a large gland, discharging by a small orifice, and secreting the lighly odoriferous substance known as musk, which is much used in perfumery, and commands a high price in the market. For the sake of obtaining this precious product, musk-deer are regularly hunted by the natives of the countries they inhabit; one plan being to drive them against nets. In the Himalaya they are met with either singly or in pairs ; and during the early spring may be seen traversing the snow-clad birch and pine forests.

Of the more typical deer, the first group is that of the Oriental muntjacs (Cervilus), all of which are comparatively small species characterised by the short antlers arising from long bony pedicles on the skull, which rapidly converge as they descend the face. From this peculiarity these animals are often called rib-faced deer. The males have large tusks; and the antlers consist of a beam, or shaft, with a small tine at the base. In the lateral toes all trinces of the bones have disappeared. There appear to be three well-marked species of inuntjacs, the range of the genus extencling from Inciiz to Eastern Tibet and China. In common with most of the deer of the Old World, the muntjacs are characterised by the retention of the upper extremities of the lateral metacarpal and metatarsal bones of the feet. Nearly allied to the muntjacs are two small deer from China and Eastern Tibet, constituting the genus Eluphorlus, and commonly known, from the presence of a tuft of lnair between the antlews, as tufted deer. They differ from the muntiacs in that the pedicles of the antlers converge, instead of diverging, as 
they ascend on the face; while the very small and simple antlers have no basal knobs representing a brow-tine. The males lave large upper canines, and the hairs are coarse and almost quill-like.

By far the grenter number of the deer of the Eastern Hemisphere belong to the typical genus Cercus, of which the most familiar examples are the red-

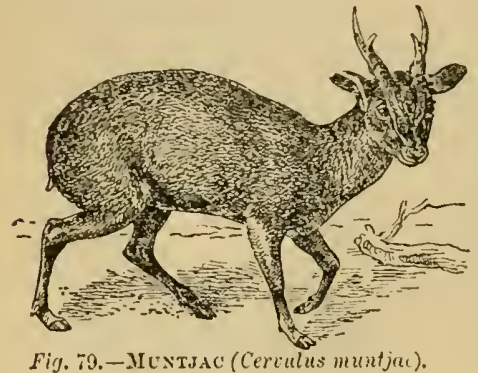
cleer and the fallow-deer. From the muntjacs and their allies all these cleer are easily distinguished by the alosence of the bony ridges which form the bases of the long pedicles of the antlers of the former. As a rule, the antler's, which, as in most members of the family, are contined to the male sex, are of large size, considerably exceeding the whole skull in length, and they do not branch in the regular forked manner characteristic of the American deer. While, in the majority of the species, the antlers are rounded, or slightly flattened, in a fow they are flattened, or palmated. Unlike those of the munt jacs, the upper canine teeth are of comparatively small size, and in the lateral digits of the feet the bones are present. Although the grenus is mainly cunfined to the Old World, it is represented in North America by the magnificent wapiti. In the main, deer are forest-haunting animals, the old bucks going about with several does during the breeding season, which they have obtained by driving away younger competitors, or by vanquishing rivals of their own age. Generally but a single ofispring is produced by the hinds at a birth. and these, as is the case with almost all Ungulates, are able to run by the side of their dam in the course of a few clays. Whereas the adults may be either miform!y coloured, or spotted witl white for a portion or the whole of the year, the young are very generally spotted, although those of the Indian sambar are usually an exception in this respect. Many of the uniformly coloured species of the genus display a conspicuous white blaze on the buttucks, and in all the muzzle is naked and narow, while the antlers of the males arise at a sharp angle to the micldle line of the fice. The European species are very regular in their times of feeding and repose; and, like other members of the family, the males cluring the breeding season utter a peculiar "belling" cry, which is buth a challenge to rivals of iheir own sex, and likewise a call to the female. 'The genus may be divided into several more or less well defined groups according to the form of the antlers, and otler structural features.

Of these the first for consicleration is the Iiusine group, which is exclusively confined to the Oriental countries, ranging as far eastwards as the Philip jime Islands. In this group the antlers are rounded and frequently' marked by strong vertical grooves, while they lack the so-called bez-tine (the one arising immediatcly above the first, or brow-tine), and the upright and slightly curved beam terminates in a simple forl;, so that the number of points to each antler is only three. The brow, or basal-tine, rises close to the thickened rugose ring forming the base, and known as the burr, and makes an acute angle with the beam, or main shaft. In the more typical forms, the colour is uniformly brown, the tiril is of medium length in all, and the neck is generally maned. The largest and best. linown representative of this 
gloup is the sambar (C. micolor), which stands nearly five feet in height, and, with its numerous varieties, langes from India and L'uma, through the Malay Peninsulin, Borneo, and Samatra to China. As a rule, the young are not spotted. In Formosa there is the nearly allied C'. swinhoei, while C'. philippinns and $C$. alfredi are smaller forms inhilbiting the Plilippine Islands, the last being elistinguished by its spotted evit. Still smaller is the Indian luer-cleer (C. porciures), easily distinguished by the alusence of a ciistinct mane on the neck, and the comparatively simple antlers, the young being spotted till they attain an age of about six months. A secomel Oriental assemblage is the Rucervine group, typieally represented by tho Indian swamp-decr (C! drecenceli), and the elosely allied 4 . schomburgli of Siam. In these the beam of the antlers is rither flattened and nore eurved than in the first group, while the large brow-tine arises at an obtuse angle from the beam, with an upward curvatme. To the same group belongs tise remarlable Eld's deer, or tameng ( $C^{\prime}$ e eldi) of Buma, Cambodia, and the Island of Hainan, in which the who!e antler forms a eontinuous curve from its extreme summit to the tip of the brow-tine. In all the three species the tail is sharp, and the neck provided with a mane, the young being spotted. David's deer (C: daridaums) of Northern China may be regarded as rejresenting a third group by itself, the antlers rising straight from the brow, and then griving off a long back-time. Each antler is forked at the smmmit, but the prongs of the fork may again divide. 'The brilliantly coloured axis, or spotted deer' (C. axis) of Inclia, in which the coat is permanently spotted with white, likewise forms a group by itself. It lias antlers of the same general type as those of the Rusine group, the brow-tine usually arising at an acute or right angle from the beam, but it difters in the absence of a mane on the neek, and the greater length of the tail. The molar teeth are characteriser by the great height of their crowns. The pretty little Japanese deer (C' sica), which has been successfully introduced into several English parks, is the typical representative of a small assemblage of species, chiefly from North-Lastern Asial, which constitute the Pseudixine group. When fully developed, the antlens have a brow and trez-tine (the second, or bez-tine, being absent), and terminate in a fork, of which the linder-tine is the smaller, so that the total number of points on each is four. In summer the coat is spotted, but it becomes uniformly coloured in winter; the tail is of medium length, and the weck slightly maned.

The typical or elaphine group, which includes the red-deer ( $C$. elrophus) of Europe, and the North Auneriean wapiti (C. canadensis), is characterised by the presence of a second, or bez-tine, to the antlers, when these attain their maximum development; the beam of each antler being rounded, and near its stummit splitting $u$ p into a larger or smaller number of points, which in some species form a cup. 'The tail is short, and included within a large lightcoloured patch on the buttocks ; the remainder of the bouly being uniformly brown. The red-deer, which ranges over Europe, Western Asia, and North Africa, has the antlers, when fully levelojed, as in a " Joyal liart, "forming a distinct eup at the summits. The deer of Northern Asia, from the Caucasus to Siberia, and thence to North China, has been separated as C. xanthopygus; but its right to specific distinetion seems rather duubtful. Other members of this group are the Persian maral (C. maral); the Kashmir stag or hangul ( $C$. castmirianus), represented by a rariety in Yarkand; the shou (C. affinis) of Tibet; Thorold's deer ( $C$, thoroldi), which is also a Tibetan form, casily distinguished by its white muzzle; the great Thian Shan stag (6! custeplucuus); 
and tho closely-allied wapiti ( $C$. camalensis) of North America. In all these species, which inclucle the largest members of the genus, the antlers do not f(rm a distinct eup at the summit. The Barbary variety of the reel-eleer does not clevelop the hez-tine.

The common fallow-deer ( $C$. cluma), whoso nativo home appears to be tho Mediterranean comtries, mul the Persian fallow-deer (C. mesopotamicus), aro the sole existing members of the last, or Damine, gromp of the gemus, characterised by the palmation of the antlers, and by the fur being generally spotted, il though there is a unifurmly brown rariety of the common species. 'These deer have no upper eanine teeth, and the tail is of molerate length. 'To this group may be referred two very fine species, which have only become extinct comparatively recently. Since the year 169\%, when certain of its remains wero clescribed hy a Dr. Molyneux in the Philosuphical Transactions of the Royal Society of London, the gigantic extinct deer of tho Irish peatbogs land been known to seience; while the magnificent proportions at tained by its antlers have given it a notoriety not shared by most other animals of a past epoch. Although founcl more abuneluntly, and generally in a better state of preservation, in the hogs of Ireland than elsewhere, the Irish deer is by no means contined to the island from which it takes its mame. On the contraly, its remaius have heen obtimed from many of the eaverns and superticial deposits of both England and the Cuntinent, and its continental range extencled from Italy in the south to Russia in the north. In penular linguage, this deer is generally spoken of as the Irish elk; but, as is the case witl a number of popular terms, this is a misnomer, the anmal really heing a true deer, referable to the genus (ervis. It is true, indeed, that its broad, palmated antlers present a superticial resemblince to those of the elli; but this $n 0$ moro inclicates any elose aftinity with that animal than to the somewhat similarly palmated antlers of the fallow-cleer. Like many other animals, both living and extinct, the Irish deer rejoices in a number of scientific naumes ; but its proper ticle is Coms qugantens. It is almost superfluons to mention that the antlers of this magnitieent deer are litger than thuse of any other known species, having a spin in some eases of orer 11 feet from tip to tip. In form, the antlers have a short, and nearly cylinclical beam, given ofl in a nearly horizontal plane at right angles to the axis of the skull. Near their orion from the skull, there arises a descending brow-tine, which is thattoned, and generally forked. As soon as the beam expands, it gives off from the front, or lower edge, a trez-tine, nearly opposite to which is a thirel, or posterior tine on the hinder or lipper margin, both these tines being seen fully from the front. Beyond these tines, the antlers expand to their fullest widh, and usually terminate in tive or six snags, of which the tommost are direeted nearly upwarls. The sccond of the extinct species is Ruth"s decr (C. mini), hitherto only found in Ciermany. In place of the ontwark horizontal extension characteristic of the Irish deer, the antlers of Rutl's deer are lirected unwards and outwards, nearly after the faslion of a f.llow-deer, so that their imermost terminal smags are separated only by a comparatively small interval: That this deer is closely allied to tho Irish deer, and has no such close kinship with the fallow-deer, is, lowerer, prowed by the flistiened and expanded form of the brow-tine. A further ditlerence from the ordinary - Irish deer is exhibited by the different position of the plane of the expanded portion of the antlers. Thus, whereas in the former the whole of their imer surface and the entire trez and posterior tines are visible from the front, in Rutl's deer we see, instead of the inner surface, the front edge and a pirt of 
the outer surface, while only the tijes of the posterior tines are visible, and the trez-tine (which is much longer than in the normal form) is foreshortened. The position of the plane of the expanded portion of the antlers is another point in which Rutt's deer approxinates to the fallow-rleer.

The reindeer (lawnifir), tugether witls all the remaining members of the f:mily, differ from the foregoing in that the lateral metacirpal bones of tho fore-feet and the corresponding metatalsals in the hind-limbs are represented by their lower, instead of their upper, extremities. From all other deer, the reindeer are at once ristinguished by havi:g antlers in both sexes ; these being very large, with the cylindrical beam suddenly bent forwards near the midclle of its length, and having a brow-tine which is generally branched and palmated on one side, and simple on the other. Above the brow-tine eomes a large bez-tine. In form, reindeer are heavily-built animals, with short limbs, in which the main

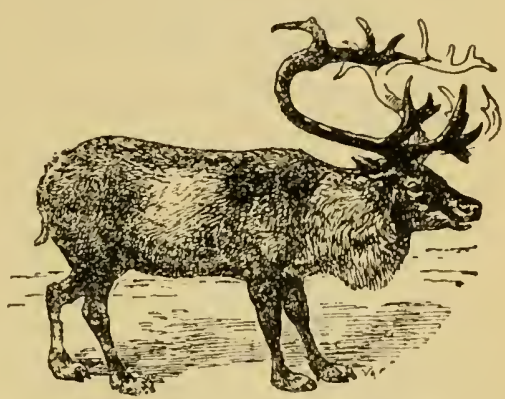

Fij. 80.-PEINDEER (Rangifirtarandus). hoofs are widely separible, and the lateral pair unusually large, the muzzle being broad and hairy. The young, like their parents, are uniformly coloured. The ordinary reindeer $(R$. turundus) ranges from Norway and Sweden over the northern regions of the Old IVorld; and it is probable that the North American variefy known as the caribou is not specifically distinct. The uses to which reindeer are put by the Lapps and the imhabitants of other northern countries are too well known to require mention.

The largest of all living deer is the elk or moose (Alces machlis), which is the only livin's member of its genus, and has a circumpolar distribution,

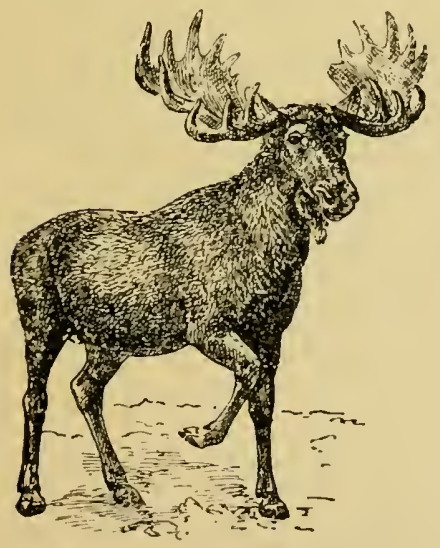

Fig. 81. Fi. K (Alers marhlix). ranging in the Old Worlel as far sonth as Prussia and the Cumeasus. It is a longlegged, ungainly-looking animal, with the large, overhanging, broad muzzle eovered with short hairs, exeept a small, naked triangular spot below the nostrils. The tail is rudimental, and the hair of the young uniformly coloured. In the males the enormons antlers arise from a cylindrical beam directed at right angles to the mildle line of the skull, and then expand into a huge basin-shaped mass, consisting primarily of an upper and lower moiety, and having the free edge bordered by a number of irregular suags. Elk feed cliefly upon the leaves and twigs of trees; and during the winter collect in small parties, keeping open a small pateh of ground by continually trampling down the snow. Frequently the hind gives birth to a pair of fawns. The ant. 
lers may weigh as much as sixty pounds. The two romaining genera of Old liorld deer are represented by small furms. Of these, the roe-deer (Capreo'us) have comparatively sliort eylindrieal antlers with three tines each ; the front tine rising from the front of the upper lialf of the bean and inelining upwards. There are no upper eanines, the naked portion of the muzzle is sumall, and does not extend below the nostrils, the tail is very short, and the fur of the young spotted. In addition to the common roe (C. caprea) of Europe and Western Asia, a second species (C. pugurgu(s) inhabits Turkestan and the momtains dividing Russia from China, while a smaller variety is found in Manchuria. Roe-deer usually inhabit more or less open country, and go about in pairs. From all other members of the family except the musk-deer, which it resembles in the long tusks of the males, the small Chinese water-deer ( $H$ yelropotes inermis) differs in the absence of antlers from both sexes. The muzzle has a rather large nalied portion, and the young are spotted. As in the roes, there are large glands in the hind-feet, and small ones in the front pair. In form, these deer have long bodies and shurt limbs, and they are remarkable for producing from three to six fawns at a birth.

Agreeing with the genera just deseribed in the structure of the metacarpal and metatarsal bones, the American deer, exclusive of the wapiti, reindeer, and elk, are, with two exceptions, included in a genus (Curiucus) elaracterised by the antlers, when fully developed, dividing in a more or less regularly fork-like manner. Whereas, however, in some species the antlers are large and branching, in eertain of the smaller forms they form simple spikes. The muzzle resenibles that of Cervus, the tail is of variable length, and the fur of the adults is uniformly coloured. 'The genus ranges over almost the whole of the American Continent, but attains its maximum development in the south. The brockets, of which the red brocket (C. rufues) is a well-known example, are a southern group, easily recognised by their unbranched, spilielike antler's. They have a tail of moderate length, and the fawns are spotted. The Costa Riea deer (C. clacatus) of Central Amerien differ's from the bruekets in liaving the hair of the face directed upwards, instead of ridiating from two points. The Andes is the home of two species (C. chilensis and $C$. rutisiensis) known as guemels, and eharacterised by their simply forked antlers, of which the front prong is the longer. There are tusks in the upper jaw, and the young are uniformly coloured. The pampas-deer (C. campestris) is the typical representative of another South Aneriean group of the genus, in which the antlers are regularly forked, with the hinder prong, and occisionally also the front one, again forking. There are no upper canines, the tail is very short, and the eoloration of the fawns is uniform. The last group of the genus is typified by the Virginian deer ( $C$. virginianus), and cumprises not only the largest speeies, but likewise all those inhabiting North America. In this group the antlers are very large and complex, and distinguished by the presence of a larger or smaller basil snag near the base of the front surface. Upper tuslis are absent, and the fawns are spotted. Wherens in the Virginian deer the basal snag is very large, and directed upwards, in the large-eared mule-deer ( 1 . macrotis) of North America it is mueh smaller. Of the former Mr. Parker Gilmore writes, that "this splendid animal has still a very wicle habitat. Its boundaries, however, originally were from the Atlantic Ocean to the Roekies, and from the Gulf of Mexico tu about $47^{\circ}$ N. latitude, and although eagerly sought by everyone deeming himself a hunter, it can be found in greater or less numbers near the oldest settlements. As an article of food tlee meat of this deer is unsurnassed, especi- 
ally when the animal has fattened upon Indian corn. Forgrace and contour of outline they are incomparable. Their horns have a most peculiar and graceful outline, receding at first backwards from the burr, then coming forward with a bold sweep It is extremely timorous and wary, but if wounded and unable to escape it will fight gallantly for its life. In such encounters its horns are not, in my experience, so much to be dreaded as its fore-feet." Finally, the two pudu-deer (Puluri) of the Chilian Andes and Ecuador, although nearly related to the brockets, differ sufficiently to form a genns by themselves. In size they scarcely exceed a hare; and they have a pair of very ninute simple antlers rising from the middle of the forehead, while they exhibit certain pecularities in the structure of the skull and ankle-joint,

The African girafte (Giraffic camelopardalis), which is the sole existing representative of its genus and family, enjoys the prond distinction of being the tallest of all Mammals, and is easily recognised by its extremely elongated neek and limbs, as well as by its dappled coloration. In many respects intermediate between the deer and the liollow-liorned Ruminants, although more nearly allied to the former than to the latter, it is chiefly entitler

The Giraffe.-

Family

Giraficla. to form a family by itself on account of the peculiar strueture of the appendages on the skull, which, properly speaking, come under the designation neither of antlers nor horns. Between the linge ear's are a pair of short lowns, as they may be called, which are completely covered with skin, and are forned of bones, which in the young state can be easily detached from the skull. Lower down on the forehead is a single median dome-like bone, which is likewise detachable in the young. In general conformation the skull of the giraffe is very like that of the deer; but the eheek teeth have very short crowns, and a peculiarly rugose enamel. There are no upper tusks; the lateral hoofs are totally wanting in both limbs; the tail is long and tufted at the end; and there is generally no gall-bladder to the liver. In colour, the South African giraffe differs from the North African variety by the darker tint and larger size of the cliestnut blotehes, and the narrower buff lines by which they are divided. The giratfe, however, has attained its towering stature without any important departure from the general structure characterising its nearest allies. and thus prescrves all the essential features of an ordinary quadruped. It owes its leight mainly to the enormous elomgation of two of the bones of the leus. coupled with a corresponding lengthening of the vertebre of the reck. As in all its kin. dred, the lower segment of each leg of this animal forms a cannon-bone, the nature of

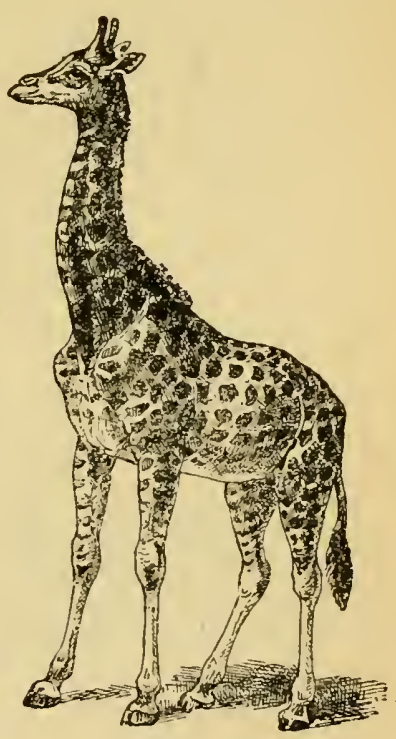

Fig. S2.-- The GirafFe. which has been explained above, and in the fore-limb it is the bone below the wrist (commonly termed the knee), and the radius above the latter, which have undergone an elongation so extraordinary as to male 
them quite unlike, as regards proportion, the corresponding elements in the skeleton of an ordinary Ruminant, although retaining precisely the same structure. Similarly, in the hinder-limb, it is the eamnon-bone below the ankle-joint, or hock, and the tibia above, which have been thins elongated. To one unaequainted with anatomy, it might appear that a giraffe and a hippopotamns would differ greatly in regard to the number of vertebre in the neck; but, nevertheless, both conform in this respect to the ordinary Mammalian type, possessing only seven of such segments.

Other noticeable features in the organisation of the girafte are the large size and prominence of the liquid eyes, and the great length of the extensile tongue ; the former being designed to give the creature the greatest possible range of vision, while the extensibility of the latter enhances the eapability of reaching the folinge of tall trees afforded by the lengthened limbs and neck. In comparison with the slenderness of the neck, the head of the giraffe appears of relatively large size; but this bulk, whieh is probably necessarly to the proper working of the long tongue, is compensated by the extreme lightness and porous structure of the bones of the skull. Somewhat stiff and ungainly in its motions - the small number of vertebre not admitting of the graceful arching of the neek--the giraffe in all its organisation is admirably alapted to a life on open plains dotted over with tall trees, upon which it can browse withont fear of competition by iny other living creature. Its wide range of vision affords it timely warning of the approach of foes ; from the effect of sand-storms it is proteeted by the power of automatically closing its mostrils; while its capacity of existing for months at a time without drinking renders it suited to inhabit waterless districts like the northern part of the great Kalahari desert. Although calrable of withstanding the want of water for a long period during the summer, the giraffe, when opportunity offers, will drink long and freeruently; but it is certain that for more than half the year, in many parts of Southem Africa at least, it never takes water at all. In certain districts, as in the Northern Kalahari, this abstinence is, from the nature of the comtry, involuntary ; but accorling to Mrr. Bryden. the giraffes living in the neighbourhood of the Botletli River-their only source of water-never drink therefrom throughout the spring and winter months. When a giraffe dloes drink, unless it wades into the stream, it is compelled to straddle its fore-legs far apart in order to bring down its lips to the required level, and the same ungainly attitude is perforce assumed on the rare oceasions when it grazes.

Absent from the countries to the north of the Sahara, as well as in the great forest regions of the west, which are unsuitable tn its habits, the girafte at the present day ranges from the North Kalahari and Northern Bechuanaland in the south, throngh such portions of Eastern and Central Africa as aro suited to its mode of life, to the Sonthem Sulan in the north. Culhappily, however, it is almost daily diminishing in numbers throughout a large area of Southern and Eastern Africa, and its distributional area as steadily slninking. Whether it was ever found to the suth of the Orange River and in the Cape Colony may be doubtful, although there are traditions that it once occurred there. Apart from this, it is definitely known that about the year 1813 these animals were met with only a little to the north of the lastnamed river ; while as late as 1836 they were still common throughout the Transwaal, and more especially near the junction of the Marico with the Limpopo River. Now their last refuge in these districts is the extreme eastern borter of the Transval (where only a few remain), and the district 
lying to the nortl of Bechuanaland and linown as Khama's eomntry, $\mathrm{Cr}$ Bawingwato, together with the Northern Kalahini. Even here, lowever, their existence is threatened, as there is a proposal to put down tube-wells in the Kalahari, which, if successfully accomplished, will open up the one great stronghold of the animal to the hunter. Unless, therefore, efticient and prompt measures are taken for its protection, there is much reason to fear that the giratie will ere long be practically exterminated from this part of Africa, although it will doubtless long survive in the remote districts of the Sudin and Kirdofan.

Although clusely allied to the typical hollow-homed Ruminants, the prongbuck, or prong-horned antelope (Antilocupre americana) is regarded as representing a distinct family, on account of the circumstance that not only are the sheaths of the horns branched, but The Prongbuck. that they are ammually shed, and their place taken by new sheaths, which have been growing up beneath the old ones. Antilocapride. In size, the promgbuck may be compared to a fallow-deer, although its form is lighter and more elegant. It has no lateral hoofs; the horns are present usually only in the males; the ears are rather long anel puinted; and the tail is short. There is a thick mane of long hair on the neck, and the general colour is chestnut; but there is a white patch on the rump, and white bars on the throat, while the lower portion of the Hanks, tugether with the under-parts, are likewise white; the eompressed and scimitar-like horns being black. Prongbucks are inliabitants of the open plains of Eastern-Central North America, where they associate in lierds, which may frequently be of large size.

The last, and at the same time by far the largest firmily group of the Ungulates, is that of the hollow-horned Ruminants, or Boridce; under which title are comprised antelopes, goats, sheep, oxen, etc. Almost the whole of the members of this great assemblage Hollow-horned are inhabitants of the Old World, the only Ameriean forms Ruminants.being the Rocky Mountain goat, the bighorn sheep, musk- Family Bovider. ox, and American butralo, and all these contined to the

northern lialf of that continent. Indeed, there is little duubt that the ancestors of at least three of these were immigrants from the Eastern Henisphere; and there is no evidence that South America was ever the home of any nember of the group. The essential feature of the hollow-horned Ruminants is the presence, in one sex at least of all the existing forms, of a pair of unbranched horns on the upper part of the head, composed of an underlying core of bome, covered with a lollow, horny sheath, which is never shed. None of these animals ever have upper canine tecth ; and the lateral metacarpal and metatarsal bones of the feet are

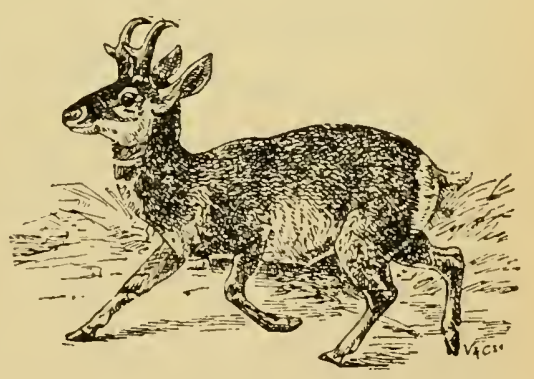

Fig. 83,-Pronesuck (Antilocapra anericana). invariably absent, although lateral hoofs are not unfrequently present. In many cases the tear-pits, or larmiers, so characteristic of the deer, are 
absent from the face; and in such cises the underlying region of the skull is fully ossified, while, whon those glands are developed, the nnossitied space in the strull below each eye is grenerally of less extent than in the Cervidce.

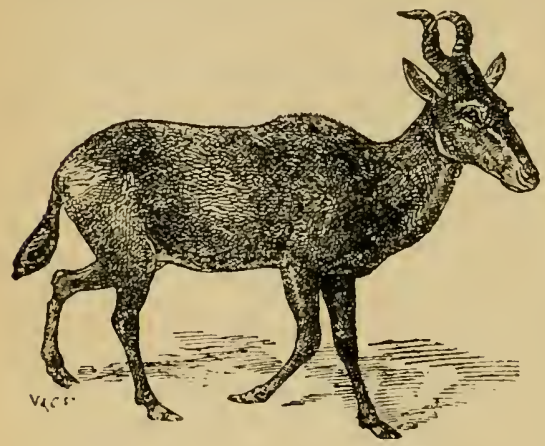

Fij. 84 -Bubalixe Axtelope (Bubalis)

The first and least specialised group of the family includes the animals commonly known as intelopes, which are arranged, under a very large number of genera, and pass imperceptibly into the goats. Although no definition ean be given of an antelope, as a rule these animals lave comparatively long necks, and are of more or less light and graceful build, while theiv bony horn-cores are generally solid throughout. By far the great majority of antelopes inlabit the open plains of Africa south of the Sahara, but there are none in Madagasear, while Burua and the Malayan comntries only possess a few forms, which may be regarded as intermediate between the true antelopes and the goats. The well-known hartebeests (Bubalis), so remarkable on account of their long, sulemn-looking faces, are the typical representatives of a section comprising two genera, all of which, with the exception of one species of hartebeest, which is Syrian, are confined to Africa, and mostly to the regions lying south of the Sahara desert. All are of comparatively large dimensions, and generally have the withers considerably taller than the rump. Horns of moderate length are present in both sexes, and are either lyre-shaped or recurved. with their bases more or less closely approximated; the muzzle is naked; there is a small, tufted gland below each eye; and the tail is comparatively long. In the skull there are 1!o large pits in the forehead, nor any unossified spaces below the eye-sockets; and the upper molar teeth have very tall and narrow crowus. The typical hartebeests, of which there are several species, ranging from Syria and Algeria to the Cape, are characterised by the great height of the wither's, the great length of the head, which has the horns placed on a kind of crest at its summit, and the suclden backward flexure of the extremities of the horns. The horns themselves are compressed and ringed at the base; the muzzle is narrow, and the tail hairy. In certain other species the aborementioned features aro less strongly developed; and in the blesbok (B. albifions) and bontebok (B. pygargus) the horns are lyrite, the crest on the top of the head much less strongly marked, and the withers lower. In consequence of these differences many writers separate the latter animais uncler the name of Dumaliscus. The strange-looking wildebeests, or gnus (Comochotes), differ from the hartebeests by their shorter liead and broad and bristly muzzle, as well as by the heavily-maned neek, and in the conformation of the horns. The latter, which are situated on the vertex of the skuil and approximated at their bases, are nearly sinooth and cylindrical, and curvo cutwards, or outwards and downwards, with their tips bent upwards. The hoofs are remarkable for their extreme narrowness, and the elongated sweeping tail is elothed with a mass of long liairs. Whereas the females of 
the hartebeests resemble sheep in liaving but two tents, those of the wilclebeests agree with cows in possessing four. The two spceies of wildebeests are chietly remarkable for the strange ganbles and anties in which they indulge, especially when the herd is approached by travellers. They are frequently found in company with zebras.

The African duikerboks (Cephelophus), most of which are exceedingly diminutivo and graceful little creatures, although two species from the west coast are of much larger dimensions, form the typical representatives of the second section. In all these the horns are short and simple, withont ridges, and are dereloped only in the males. 'There is a moro or less elongated gland beneath each eye; the muzzle is large and naked; the tail is short; and the tents of the females are always four in number. The upper nolar teeth have broal, squale crowns; and in the skull there are no pits on the forehead, and no tissure beneath the socket of the eye, although there is a deep clepression in the bones of this region. The duikerboks are characterised by having a tuft of long hairs between the small horns, which are situated far back on the forehead, the gland below the eye taking the form of a narrow slit or a row of pores, and the tail being very short. The nearly allied fourhorned intelope (Tetraceros qualviconis) of Peninsular India is sufticiently distinguished by the males generally carrying two pairs of horns, of which the front ones are very minute.

More numerously represented is the C'ercicumine group of antelopes, which comprises sereral genera, with species of large or medium size, confined to Africa south of the Sahara. In these the horns are confined to the males; the gland below the eye may be either large, rudimental, or wanting ; the muzzle is either hairy or naked ; the tail is short; and the upper molars are narrow. There is usually a linge unossified space in the skull below the eyo, and also distinct pits on the forehead.

According to the recent classification of Messrs. Sclater and Thomas. a number of small African antelopes generally included in the Cercicuprince are entitled to form a section by themselves (Nenotragina). Of these the six species of the genus Mudoque-among which the Abyssinian Salt's antelope (1I. seltiana) lias been longest known-are very small antelopes characterised by the production of the hairy muzzle into a more or less marked proboscis, and the presence of a tuft of hair on the crown of the head. In three of the species, among which is the one named, the last lower molar has no third lobe at its hinder end, and the proboscis is relatively short. Nearly allied is the royal antelope (Nanotiagus pygmenus) of Guinea, the smallest member of the entire family, sufliciently distinguished by the smooth crown of the head, the presence of a small naked area on the muzzle, and the minute horns. Another genus, which includes the Zanzibar steinbols (Nesotragnes moschatus) and $N$. liringstonianus, difiers from the last hy the larger horns. The true steinbok (Raphiceros campestris) agrees with the two last geneva in the absence of lateral hoofs and of tufts of liair on the knees, but differs by other characters which are regarded as entitling it to form a genus apart. Nore distinct is the Sonth African oribi (Oribice scoparia), which has both lateral hoofs and tufts of hair at the linees. From all these the well-known klipspringer (Oieotrayus saltrtor), which ranges along the east coast fron the Cape to Abyssinia, and has the habits of a chamnis, differs in the form of the skull, the thick, brittle hair, resembling that of the muskdeer, and the clunsy hoofs. In the skull of both senera there is a deep pit below the eye. Among the typical Cerricaprines, the rehboli ( $I^{\prime}$ cla capicola) 
of South Africa is a linger mifomly-colomed amimal, with small, compressed, upright, and scircely diserging horns placed wer the eyes, a large bare part to the nuzzle, and no depression in the skull below the latter. It is an inhabitunt of open, sandy districts, and may be compared in size to a fallowdeer. Still larger is the handsome water-buck and its allies, ennstituting the genus Cobus, characterised by the long sub-lyrate horns of the males, which are ringed nearly throughout their length, the large portion of the muzzle that is deroid of hair, the deep hollow in the forehead of the skull and the absence of a depression below the eye, the gland being rudimental. The tail is long, ridged with hair above, and tufted at the end ; and the colour of the fur uniform. In most species the hair is lung and conrse ; and all frequent the neighbourhood of water. The three representatives of the allied genus Cervicupro may be distinguished by the short and bushy tail; and also hy the circunstance that the premaxillary bones, which from the extremity of the muzle, do not extend upwards to join the nasils. The best known of these is the South Africun reitbok (C. arumdinemm), which stands nearly a yarl at the withers, and is of grizzled ochre colour.

The typical, or Antilopine, section is also a large one, and includes the grazelles and certain allied forms which are mostly inhabitants of sandy or desert districts. The horns, which are usually restricted to the males, are generally either compressed and lyate or recurved, or eylindrical and spiral, with well-marked rings on their lower portion. The muzzle is covered with short hairs ; the short or moderate tril is compressed and hairy on its upper surface; and the upper molars are narrow, and resemble those of the sheep. In the skull there are generally large pits in the forehead, and a depression below the eye. Perhajs the handsomest member of the group is the Indian blackbuck (Antilope cervicapru), which is the sole representative of its genus, and easily recognised by the deep blackish hue of the back and head of the adult males, and the benutiful spirally-twisted and ringed holns ; the gland below the eye being very large. The pala (Elpresos) and its other Afriean allies have the homs compressed, widely divergent, and ringed only at the lase ; and differ from the black buck lyy the absence of a gland on the face, and of lateral hoofs to the feet. A clumsily-built and somewhat sheep-like antelupe from the Asiatic steppes, known as the saiga (Suigu tatarica), is one of two genera characterised by the large and putly muzzle, this feature being most dereloped in the present form, in which the nostrils open downwarls. There is a small gland on the face, lateral hoofs are present, and the female has four teats. In the males the horns are short, lyrate, ringed, and yellow in colour. The Tibetan chiru (Pantholops hodgsoni) differs from the last in the nostrils opening anteriorly, and in the form of the homs; the latter being very long, erect, compressed, sublyrate, and ringed in front for twothirds in length, while their colour is deep black. There is no gland on the face, and the female has only two teats. These benutiful antelopes are found in herds on some of the most elevated regions in the world. The largest grenus of the group (Gazella) is represented by the beautiful gazelles, which are mainly contined to the desert regions of Africa and Asia, although the aberrant springbok is found on the plains of the Cape Colony and adjacent clistricts. All the gazelles are noticeable for their elegant build, and their more or less sandy coloration, while the majority differ from the foregoing members of the section in that horns are developed by both sexes. Nearly all the species are characterised by having a whitc streak, borclered by a dark line, running down the face from each horn to the nostril, so as to isolate a 
dark central patch on the inuzzle. The gland below the eye is small and concealed by hair, and the knees generally carry tufts of long hair. The springbok (G. euchore), remarkable on account of its habit of taking leaps in the air, and also from the enormous herds in which it was formerly found, differs from all the rest of the gazelles in having an erectile crest of long, stiff, white hair running down the back. Clarke's gazelle ( 1 mmodorcus clurkei), from Northern Somaliland, is distinguished by tho regular upwards and forwards curvature of the horns of the males, which are ringed in part at the base; the females being hornless. The skull is intermediate between that of the preceding and following genus. Waller's gazelle (Lithocrowius walleri), which is an East African form ranging from the Kilimanjaro district to Somaliland, represents another genus by itself. The females are hornless, but in the males the horns are erect and curved forwards in a hook-like manner; while both are characterised by the extraordinary neck, which gives to the animal almost the appearance of a small girafte. The genus is, lowever, best characterised by the solid structure of the skull. The small Somali Dorcatragus seems to be another aberrant gazelle.

The next group of antelopes, which are common to Africa and Arabia, are best characterised by the upper molar teeth being structurally similar to those of the oxen. In these teeth the crowns are very tall and broad, so as to form an almost square section, while, on their inner side, they have a narrow additimial column superadded to the four large normal crescentic ones. All these antelopes are of very large size, and both sexes are provided with long holns, which are placed immediately over or behind the eyes, and are recurved, straight, or subspiral in form. The muzzle is hairy, there is no gland below the eye, and the long, cylindrical tail is tufted at the extremity. In the skull there are no distinct pits on the forehead, there is no depression below the eye, and only a very small unossified slit in the same region. The handsome recurved horns, rising vertically from a crest above the eyes and sweeping backwards in a scimitarlike sweep at an obtuse angle to the profile of the face, serve at a glance to distinguish the sable-antelope (Mippotragus niger) of South Africa and its near ally the roan antelope ( $I I$. equinus). In both these large and splendid animals, as well as in a kindred species from the Sudan, the horns are ringed nearly to their tips, the sable-antelope being one of the few members of the tribe which have the whole upper-parts, sive some white streaks on the face, a deep, full black. In all these antelopes the neck is furnished with an erect or curving mane, and the tip of the tail is strongly tufted. 'The gemsbok of South Africa is the type of an allied genus $(O r y x)$, ranging not only over the whole of Africa south of the Sahara, but also found in Syria and on the shores of the

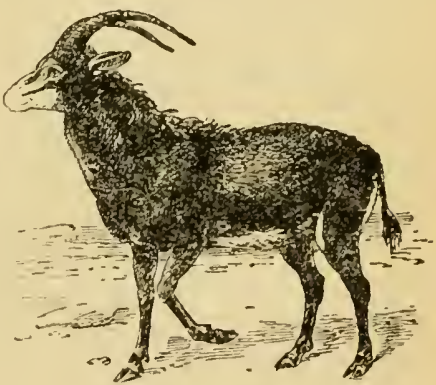

Fig. 85. -SARLP.A ATtPIOPP

(IIippotragus nuyer). Persian Gulf. Here the horns are long, slender, and ringed at the base, but may be either straight or somewhat curved backwards, although in all the specics they arise behind the eyes with their direction at first in the plane of 
the face. The mane on the neck is shorter and the tail longer and more hairy than in the last gentis. 'The general bue of the hair in the oryx is grey or tawny, with black markings on the ficc and legs; and, although somewhat ungainly in build, they are all decidedly handsome animals, the typical species standing about $4 \mathrm{ft}$. at the withers, and its horns often exceediug a yard in length. Oryxes are inhabitants of open sandy plains, where they associate in small herds. 'I'he third genus of the group is the addax (Addux ns somcuculatus) of the deserts of North Africa and Arabia, which differs from the last by the horns being subspiral and lyrate, and also by the heary inane of long hair on the neck and throat, and the presence of a tuft of hair on the throat, the general colour of the hair being whitish.

The last, or Treyclayhine, section of the true antelopes comprises several genera of large-sized forms, all of which, save one, are inhabitants of Afıica south of the Sahara. The horns, which are usually confined to the male sex, cre not ringed, but have a ridge at least on the basal portion of the front surface, and are generally twisted in a spiral, with the front ridge curving uutwards from the base. The muzzle is naked, and there is a small gland below each eye. The skull has a small unossitied fissure, but no depression below the eye, and thure is very generally a puir of pits on the forehead. The upper nolar teeth are broad, but may have either tall or short crowns. A very characteristic, although by no means universal, feature of the group is the marking of the body by vertical white stripes. In India the group is represented solely by the well-known nilgai (Boselaphus tragacomeins), chardcterised by having the hind limbs much shorter this the front pair, the short horns-which are placed behind the cyes-ridged and triangular at the base, and nearly straight, the naked portion of the muzzle large, the ears small, and the upper molars tall, with an additional column on their inner sides; the body being uniformly coloured. Nilgai, which may be fuund either in jungle or open country, generally associate in small herds, although the bulls are often found singly. In all the other members of the group the fore and hind limbs are of approximately equal length; the horns are long, ridged throughout, and twisted into a spiral; while the naked portion of the muzzle is of small extent, and the size of the ears large. ' $\mathrm{C}$ ho molar teeth are short-crowned, and the body is generally striped. Pcrhaps the handsomest of all are the two African species of kudu, constituting the genus Strepsiceros, in which the horns of the males are situated behind the line of the eyes, rising in the form of an open spiral, with their front ridge very strong'y marked, at an obtuse angle to the plane of the face. The neck is fringt with a mane, the tail relatively short, the body marked with vertical white streaks descending from a spinal stripe of the same colour, and the hoofs short. In the skull there is a deep hollow, with pits, on the forehead, and a large unossified space below each eyc. Oi the two species, the true kudu ( $s$. kudu.) ranges from South Africi to Abyssinia, while the much smaller, lesser kudu (S. imberbis) is confiued to Sumaliland and the Kilimanjaro district. Of the former splendid animal, Mr. Bryddon, in the Asirn newspaper of November, 1894, writes as follows :- "The kudu bull stands $5 \mathrm{ft}$. or a little more at the withers. Its general colour varies from rufous grey to almost blue, and especially in the older animals this bluish colouring will be found predominating. Along the spine runs a white streak, and fron this thin white stripes extend transversely across the body towards the belly. Just under the eye on either sicle is a clear white band which meets on the front of the face; while upon the cheeks two or three circular white spots are to be found. The 
head is neat, game-like, and altogether beautiful, and is surmounted hy tall spreading spiral lurus of great weiglit and size, which diminish in corkscrewlike formation to sharp points. The greatest recurdcd length of a kudu's horns appear to be $3 \mathrm{ft}$. $9: \mathrm{in}$. in a straight line; over the curve $5 \mathrm{ft} .5 \mathrm{in}$. The greatest length of the horns of a lesser kudu in a straight line is $2 \mathrm{ft} .1 \frac{\mathrm{l}}{4} \mathrm{in}$; over the curve $2 \mathrm{ft} .7 \frac{1}{2} \mathrm{in}$. Thero are often greis and striking differences in the spread of kudu horns. Fine specimens will sometimes spread between the tips as much as nearly $3 \mathrm{ft} .9 \mathrm{in}$. Otlier and equally fin.s horns will only spread a little over $2 \mathrm{ft}$. But whether widespread or closer in growth, the effect of these magnificent spiral horns is equally grand. The eyes are large and very beautiful. 'The ears are of a light brown colour, and rery large and spreading. The hearing of this antelnpe is marvellously acute, and the great, yet delicate, ears are manifestly exactly fitted for the arrest of the slightest vibration of sound. The senses of smell and sight are also excessively fine, and, united to its preternaturally sharp hearing and general suspiciousness, render the kudu usually a very diflicult animal to approach or surprise. The neck of the male is strong, shapely, and well fitted to support the weight of the immense horns. The chin is white. From the throat to the dewlap extends a long and handsome fringe of white and blackish-brown hair, which adds not a little to the handsome appearance of the antelope. The neck also is slightly manod. The legs are strong yet slender, elean, and beautifully formed, terninating in shapely fect, which give a dainty spoor, shaped like the ace of hearts. The kudu spoor is, indeed, one of the nost perfect imprints of all African beasts of chise. In length this animal extends some $9 \mathrm{ft}$. The withers, as in so many other examples of African game, are high ; the bocly is stoutly formed, and in general contour not unlike that of a Higlland stag. The hair is, however, much closer and finer than the red deer's. The tail is about $2 \mathrm{ft}$. long, terminating in a point. The general port and demeanour of this antelope is exceedingly noble; and the magnificent carriage of the head, surmounted as it is by the great spiral horns, is one of the finest things in nature. The female, lacking as she is in horns, cuts a much poorer figure than her lord ; and her ears, unrelieved by the fine spiral horns, appear far more prominent and remarkable. The calves are beautiful little creatures, of a bright rufous colour, strongly lined with white. Tho cows have only one calf at a time, usually between September and November-the farourite calving period with most South African antelopes. The kudu feeds more upon the young leafage and sprouting greenery of bushes, shrubs, and trees, than upon grass. Its favourite browsing-ground is bush and woodland, the stony slopes of hills, and well-bushed mountain-sides. In these haunts this antelope is difficult of approach, and offers very excellent stalking. In cumntries not much shot over, however, the kudu may be occasionally surprised at quite close quarters. In woodland and bushy countrg the pace of the kudu, considering the weight and size of its horns, and the difliculties and obstacles of covert, is surprising. In hill country it is wonderfully active and will jump magnificently; upon open ground, however, where it occasionally strays, it may be ridden down without much trouble, and upon the flat its gait is laboured and somewhat slow. This antelope is gregarious, and runs usually in parties of from five to eight; occasionally, however, larger troops, numbering as many as twenty individuals, are encountered. In the dense forest south of the Botletli river, while hunting giraffe, I startled a troop of fifteen upon one oscasion. The hide of the kudu is one of the most valuable of all South 
African antelopes; it commands a high price and is mush sought after. From it are manufactured velschoens (shoes), leather thongs, whip-lashes, and even harness. The hide is thinnish, but excessively tough. I have seen a complete set of Cape cart harness made of kudu hide, which was smart-looking, serviceable, and of everlasting wear. The thesh is excellent and well-tasted, and the marrow bones are esteemed a very great dainty by lunters and natives in the interior. The kudu is widely distributed. Its range extends beyond the Zambesi into Central Africa, and it is found as far north as Somaliland and even Abyssinia. It has a variety of native names even in South Africa. The Bechuanas call it tolo; the Matabele, e-balabala; the Makalakas, e-zilarwa ; the Makobag, unzwa ; the Masarwa bush. men, dwar; the Mashunas, noro. In North-east Africa the Sonali name is godir ; while upon the Lower Zambesi it is goma."

Nearly allied to the kudus are the numerous Africau species of harnessed antelopes (Tragelaphus), most of which are distinguished by the smaller number

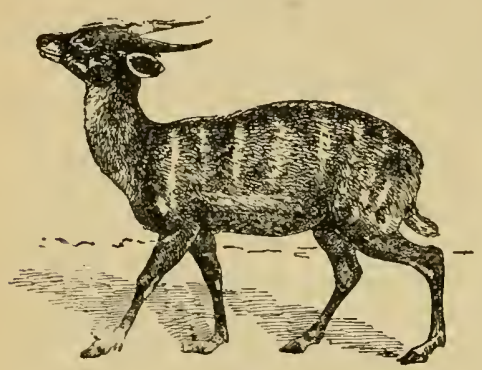

Fiy. S6.-IIARNESKED-AxTELOPE (Trayelaphus angasi). of spiral turns in the horns, although one species comes so cluse in this respect to the kudus, that it may be a question whether all shonld not be included in a single genus. The harnessed-antelopes take their name from the white stripes or rows of syots with which the bodies of nearly all are adomed, some of them being remarkable for the extreme brilliaucy of their coloration. Whereas the splendid $T$. euryceros of West Africa, conspicuous for the brilliant ehestmut ground colour of its coat, is only second in size to the kudu, the guib ( $T$. scriptus) does not exceed a goat in height. Two of the syecies, one of which is the well.known sitatunga or nakung ( $T$. spekei) of South Central Africa, have their hoofs remarkably elongated, and spend their time in marshy situations, where they will conceal themselves by submerging the whole body except the tip of the muzzle. The largest of all antelopes are the two African species of eland (Orias), which differ from the other members of the present section by having horns in both sexes, while they are further distinguished by the close, corkscrew-like spiral of these appendages. Although in one rariety of the common species they are fairly well marked, as a rule the white stripes on the body are indistinct or absent. There are few handsomer antelopes than a large eland bull, with its fine dewlap, full tuft of dark brown hair on the forehead, slight mane, and generally pale tawny hair.

The well-known chamois, gemze, or izard (Rupicapra traqus), which inhabits all the higher mountain ranges of Europe, and is locally known by the above-mentioned names, is the typical representative of a section of the hollow-horned ruminants, in many respects intermediate between the true antelopes and the goats. Accordingly, they are often spoken of as the saprine, or goat-like antelopes. As a rule, the horns, which are nearly equally developed in both sexes, and rise behind the line of the eyes, are short and wrinkled at their bases, and conical or somewhat compressed in form, with a 
more or less divided backward curvature. Although it may be much reduced in size, there is generally a gland beneath each of the eyes; the short and tapering tnil is well-hatired above, the hoofs are relatively large, and the whole build is heavy and clumsy. In form the molar teeth resemble those of the goats; and the skull generally has a depression, but no fissure, below each eye. From its allies, the chanois is readily distinguished by the peculiar hooked form of the horns, which rise close together almost vertically from the forehead, and then curve suddenly back in the well-known hook. The muzale is hairy, and the gland beneath the eye small. In height, a chamois does not stand more than a couple of feet at the withers. Chamois are inhabitants of the high Alpine regiors immediately below the snow-line; and although they were formerly met with in large herds, in most of their habitats their numbers have been greatly reduced by constant persecution, while from some districts they have completely disappeared. 'Their marvellous powers of leaping are familiar to all. In the Himalaya, Malay countries, frarts of Chima, and Japan, the place of the chamois is taken by the allied but larger and more clumsily-built animals known as serows (Nemorholus), of which there are several species. From the former they are readily distinguished by the finely-wrinkled and sharply-tapering black horns having no distinct houk at the extremities. The ears are large, the fur is coarse and long, and the gland below the eye small. The Himalayan species is found in thick bush at moderate elevations, and is a marvellous adept at getting orer the roughest ground at a rapid pace. Nearly allied are the smaller animals known as goral (Cemas), of which the typical representative is met with in the outer ranges of the Himalaya, while other forms occur in Eastern Tibet, Northern China, and Amurland. They differ from the serows in lacking a gland beneath the eye, and also in the conformation of the skull. One of the most remarkable members of the group is the takin (Budorats taxicolor) of the Mishmi Hills in Assam, and Eastern Tibet, which may be compared to a very large, rough-haired, and reddishcoloured serow, with greatly developed smooth horns, whose size and curvature strongly recalls those of the gnus. Scarcely anything is known of these animals in a wild state, although they are probably sufficiently common in their native haunts. Another nearly allied form is the so-called Rocky Mountain goat (Haploceros montamus) of North America, which is one of the very few American representa tives of the hollow-horned ruminants. It is likewise one of the few animals which are permanently white at all seasons of the year, its coat being very long and shargy, and forming a most striking contrast to the jet-black horns and hoofs. The horns, which are set close together and curve somewhat backwards, are distinctly compressed at their bases ; the ears are smail, and there is no gland below the eyes. The

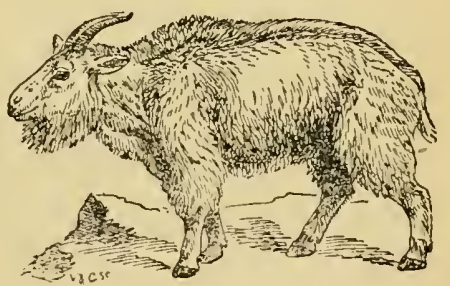

Fig. 8\%.-ROCKY JIOT:SAIN GOAT

(Huploceros inontanus). most remarkable structural peculiarity about the animal is, however, the extrene shortness of the cannon-bones in both the fore and hind feet, which in this respect are quite unlike those of any other ruminants.

The next group of the Bovide is formed by the goats and sheep, which are 
so nearly allied that it is very difficult to distinguish betwcen them. In this C'aprine section both sexes are provided with liorns, but those of the feinales are much inferior in size to those of the males. They are usually compressed, triangular in cross section, and marked with bold, transverse ridges or wrinkles, while they may either curve backwards or outwards, or may be spirally twisted. The muzzle is usually completely covered with hair; the gland below the eye is either very small or totally absent; the tail is generally short and flattened; and glands are often present between the hoofs. With the exception of one species of goat, the females have but a single pair of teats. The molar teeth are characterised by the great height of their crowns, those of the upper jaw having only four crescentic columns. In the skull a depression below each eye may or may not be developed. In the true goats, constituting the genus Capra, the long horns are laterally compressed, and either curvo backwards in a bold sweep, with an outward inclination at the tips, or are spirally twisted. There is neither a gland beneath the eye nor a depression of the skull in the same region; the chin is more or less distinctly bearded; the males emit a powerful and characteristic odour; and, if glands are developed between the hoofs, these are confined to the fore feet. The true goats are nainly confiner to the mountains of Europe and Asia, although sparingly represented in Abyssinia, Egypt, and Palestine. In Europe there are two species, viz., the ibex $(C$. ibex) and the Spanish ibex (C. pyrencica), of which the former was confined to the Alps, but is now extinct in its pure form, although a half-breed between this and the domestic goat exists in certain districts. The ibex is easily recrynised by the bold transwerse ridges or knobs or the front of its scinitar-lihe horns, whereas in the Spanish ibex these are much less developed, and the curvature tends to become spiral. Mr. A. Chapman writes that this goat survives in some of the secluded valleys on the Spunish side of the Pyrenees, and finds a congenial home in the elevated cordilleras of Central Spain, especially in the Sierra de Gredos-the apex of the long range which forms the watershed between tho Tagus and the Douro, and continues to Portugal as the Sierra de. Estrelha. In the south of Spain the ibex occurs in the Sierra Morena, and especially in the Sierra Nevada, as well as the Sierra Bermeja, which runs parallel with the Mediterranean; but examples from these localities differ somewhat from those of the northern and central ranges, and Sehimper distinguished the southern race as Caprr hisparica. In the Gredos and Nevada ranges the ibex leave the vicinity of the snow, or, at least, the most rugged and inaccessible ground, after sunset only, when they descend to feed; and under no circumstances are they found, even in winter, amongst forest or covert of any kind; but in the lower ranges of the Bermeja and Palmitera, which do not cxceed 4800 feet in height, and where the scrub and even pine trees attain the summit, they are found comparatively low down, and may be hunted over ground that looks far more suitable for roe-deer. But wherever found, the races have one habit in common: they take refuge on the narrowest ledges, where it seems hardly possible that their bodies can pass, and still further avail themselves of crevices and recesses in the wall of rock. In the Caucasus there are at least two species of goats, one known as C. cylindricomis, in which the horns in curvature, smoothness, and colour are so like those of certain wild sheep as to render it almost impossible to draw any valid distinction between the two groups. Of wild goats firc well-defined species are recognised from India, four of 
which are not found southwards of the Himalaya. Three out of these are included in the genus Capra; while the other two have much shorter horns, and are referred to a second genus. The pasang or l'elsian wild goat (C. agagrus) is a western form only extending into India on its western side, where it is met with in Baluchistan and Sind. It is easily recognised by the sharp edge of its scimitar-like horns; and is eonsidered to be the ancestral stock from which the domesticated breeds of guat have been derised. The Himalayan ibex is generally regarded as identical with the ibex of Siberia and the Thian Shan (C. sulirica), although it has been thought that it may be ristinct. It differs from the pasang by the front of the horns of the bucks being thattened and marked by buld knots. Further information is required about in dark coloured ibex from Baltistan, which has been considered to lee merely the common species in its winter dress, but this is not yot ascertained witl. eertaiuty. There is also much uncertainty about an ibex of which three specimens have been obtained-probably from the upper Kishanganga Talley in Kashmir territory-characterised by the marked outward curvature of the horns, and the absence of knobs except near their tips. The markhor (C. falconeri) is easily recognised by its spirally-twisted horns; and zuologists are now satisfied that, in spite of the great difference in the form of the spiral of their horns, all the varieties belong to a single species. The two remaining Indian wild goats are the Himalayan tahr (Hemitrugus jemlaicus) and the so-called Nilgiri ibex (Hemitragus hylocrins). Both differ from the true goats by their comparatively short horns; and they are further distinguished by having a small naked area at the end of the muzzle. The Nilgiri wild goat differs from the tahr by having the outer side of its horns convex, and not pussing into a sharp

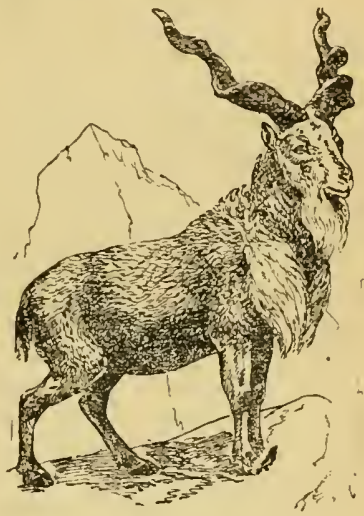

Fig. S:- THR Markior

(Capratalconeri). ridge in front; while the latter is distinguished from all other goats and sheep by the presence of four teats in the females. A third species of the same genus inhabits the Muscat district of Southern Arabia. The sheep (1/vis) are connected with the sheep-like goats. such as Capia cylindricomis of the Caucasus, by means of the bharal of Tibet and the North African arui, or Barbary sheep, both of which differ from the more typical representatives of their genus by the absence of a gland helow the eye, anil their sinooth, olive. coloured horns; although they resenble other sheep in having glands between the hoofs of both the fure and lind feet. As a group, sheep are characterised by the massive horns of the rams curving backwards and duwnwards in a bold sweep, with the tips generally turned inwards, while they are usually marked with more or less prominent transverse ridges. Except in the two species named, their colsur is brownish, and there is a sm.tll gland on the face below the eye, with a corresponding shallow clepression in the skull. All the feet have glands between their hoof 3 ; the chin is devoid of a beard, although there may he a ruff of long hair on the throst; and the rams have not the umpleas int odour characteristic of the males of the goats. 
Sheep are mainly inhabitants of Central and North-Eastern Asia, one species just entering the Punjab. In Europe two or three kinds are found in the Mediterranean regions, and there is one in the north of Africa, but no other throughout the whole extent of that continent; while a single species inhabits Nurth America. The largest and finest of the group are

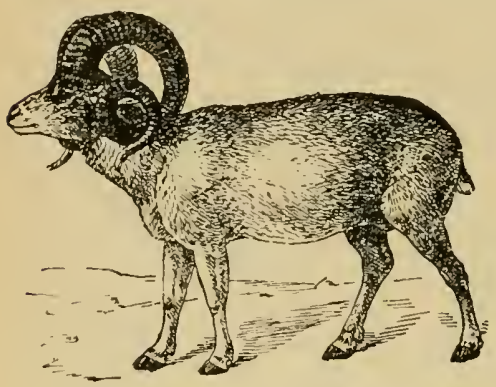

Fig. 89,-Pamir-Sileep (Oris poli). the argalis of Central Asia, and amongst these the most magnificent is the Pamir-sheep ( $O$. poli $)$, whose horns are characterised by their double twist and outward direction. In the true argali (O. ammon) of the Altai, and the clusely-allied $O$. hodgsoni of Tibet, the horns, although more massive, are shorter, and form but a single curve. In these species the wrinkles on the horns are strongly marked, but in the bighorns, of which one species (O. cruadensis) inhabits the highlands of western North America, while the second (O. nivicola) is found on the opposite side of Pehring Straits in the Kamschatkan Peninsula, these wrinkles are much less develuped, and the depression below the eye in the skull is less deep. Another group, in which the horns, although well wrinkled, are smaller than in the argalis, is represented by the sha ( $O$. vignei) of the inner Himalaya, Persia, and certain ranges of the Punjab (where it is known as the urial), as well as by the Armenian sheep (O. gmelini) of Asia Minor and Persia, the smaller but closely allied $O$. ophion of the island of Cyprus, and the mouflon (O. musimon) of Sardinia and Corsica, easily distinguished by the saddleshaped mark on the back; the three last-named kinds being further characterised by the absence of horns in the ewes. The two remaining suecies, as already said, differ from all the foregoing in their comparatively smooth and olive-coloured horns, and the absence of a gland below the eye and $a$ depression in the skull for its reception. Of these the bharal ( $($ ). nahur(a) is a Tibetan form, with short, bluish-grey fur ornamented with black markings; while the arui ( $O$. trogelaphus) of the mountains of Northern Africa differs from all the others in possessing a fringe of long hair on the fore-quarters, and likewise by the greater length of the tail. It is a remarkable fact that nearly all the wild shcep are short-tailed animals, and have fur instead of wool ; but, although it is difticult to explain the origin of the long tail of the domesticated breeds, it is noteworthy that certain African races have the fleece partaking more of the nature of fur than of wool. In habits sheep much resemble goats, the young males and females associating in large flocks, from which the old males often disassociate themselves, except during the breeding-season. Both groups are exceedingly wary aninials, and both are inhabitants of mountain regions; but whereas goats always restrict themselves to rocky and more or less precipitous districts, wild slieep may be often found on open, undulating, grassy ground like the Pamirs.

Nearly allied to the sheep is the somewhat larger ruminant commonly known as the musk-ox (Oribss moschatus), which may be compared roughly 
in point of size to Highland cattle, although its coat is still more shaggy. The musk-ox is now restricted to Arctic America and the north of Greenland, although in a past epoch it ranged over northern Asia and Europe as far south as Britain. With tho sheep this ruminant agrees in its hairy muzzle and the general structure of the molar teeth; but the horns are quite peculiar, those of the adult males being greatly flattened and expanded at their bases, where they almost meet in the middle line of the furelead, after which they bend downwards by the sides of the face, and then curve shajply upwards. While they are whitish and fibrous at the base, at the tips they are smooth

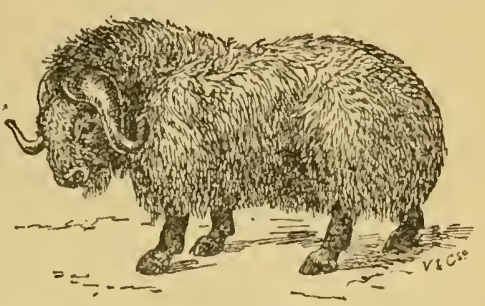

Fig. 90-Ditsk-0x (Oribos moschatus). and black, with a nearly circular section. The small and pointed ears are almost buried in the long hair; the general colour is brown, and the short and sheeplike tail is completely lost among the hair. In winter a woolly under-fur is ningled with the long hair to form an efficient protection against the intense cold of the regions inhabited by this animal. A peculiar feature of the feet of the musk-ox is that the two hoofs of each are not symmetrieal; these being partially covered with hair on the lower surface. In general habits musk: oxen mueh resemble sheep, collecting in floeks of considerable size, among which the proportion of old rams is eomparatively small. The musky odour from which the animal derives its name does not appear to be due to the secretion of any special scent-gland.

The last, or bovine section of the family, is represented by the buffaloes, bison, and oxen, all of which nay be included in the single genus Bus. All are animals of very massive build, with a short neek, and the head earried nearly in the line of the back, the largest members of the whole family being included anrong them. From the sheep, the oxen, as the group may be collectively termed, are markedly distinguished by the conformation of the tall crowns of the molar teeth. In the upper jaw these have a nearly square cross section, with a well-defined additional fifth column on the inner side, and the whole of the valleys and elefts completely filled up with cement. The horns, which are massive, and nearly as large in the females as in the males, are placed on the summit of the skull with their bases far apart, and may be cylindrical or triangular in section, their direction being at first more or less outwards, after which they turn upwards at and near the tips. They always laek the transverse knobs of the goats and the wrinkles of those of the sheep, so that the surface is comparatively smooth, the colour being dark. Internally the bony cores of the horns, like those of the goats and sheep, are much honeycombed. In all eases the broad muzzle, in which the nostrils are placed wide apart, is more or less completely naked and moist; there is no gland beneath the eye, and consequently no depression in this region of the skull; the bulls usually have an ample dewlap beneath the throat, the long and tapering tail is generally tipped with a large bunch of long hair, and there are no glands between the hoofs of either foot. The udders of the cows are provided with four teats. As in the sheep and goats, small lateral hoofs are retained. The majority of the oxen are eonfined to the continents of Europe, Asia, and Africa, but one species of biscn 
inhabits North America, and a small aberrant form is found in the Island of Celebes.

The latter species, which is known as the anoa (B. depressicornis), is the smallest and most antelope-like member of the whole group, having the short angulated horns directed nearly upwards from the forehead, and the colour black, with a few white spots on the hind quarters. Another smill but more buffilo-like form ( $B$. mindorensis) inhabits the Philippine Islands, where it is locally known as the tamarao, but it is not certain whether this may not prove to be a hybrid between the anoa and the Indian buffislo. The true buffaloes are characterised by their more or less angulated horns and convex forehead. Of these, the Indian buffilo (B. bubalus) has its home in the Criental countries, but has been introduced as a domesticated animal into Egypt and the South of Europe. It is a huge, ungainly brute, with the long horns flattened and angulated throughout their length; those of the bulls being very thick and curving upwards in a crescentic form, while those of the cows are slender and directed more immediately outwards. In their habits these buffaloes are essentially marsh-haunting animals, loving to wallow in the soft, warm mud of such situations. The skin of old animals is almost devoid of hair. The Cape buffalo $(B$. caffer) is a very differentlooking animal, with a shorter

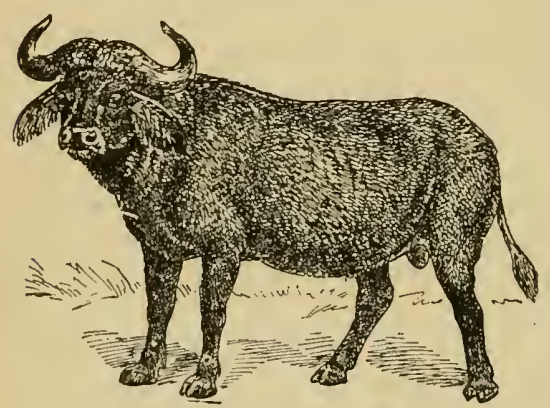

Fig. 91.-CAPE Bufalo (Bos cafier). skull and horns than the Indian species; the bases of the horns growing together in a kind of helmet-like mass on the forehead, where they nearly meet in the middle line; these appendages curving downwards at their origin from the skull, and then taking an inward direction, while their tips are almost cylindrical. The black skin is nearly naked, but the ears are margined with a fringe of elongated hairs. In certain forms from Central Africa the hairs on the skin are reddish in colour, and the horns smaller and less expanded and approximative on the forehesd. This form grades almost imperceptibly into a smaller variety or species known as $B$. pumilus, in which the small horns are very widely separated from one another at their bases.

The bisons differ from the buffaloes by their cylindrical horns, which are placed rather low down on the forehead; the latter being very wide and convex, and the whole skull comparatively short and wide. In the skeleton the number of pairs of ribs may be either fourteen or fifteen. In place of the nearly-naked or sparsely-haired hide of the buffaloes, the bisons have an abundant coat of short, thick, crisp, curly brown hair over the greater part of the body, while the hexd, neck, shoulders, and fore limbs are clothed with a massive mane of longer and darker hair, almost hiding the ears, and concealing the bases of the horns, as well as shading the eycs. The great elevation of the withers, as compared with the hind quarters, gives the appearance of a large hump behind the neck. Of the two species, the Europaan bison (B. bison) is now confined to the Caucasus, Lithuania, and 
some of the adjacent districts, running completely wild in the former area, but artificially protected in the latter. It appears to be essentially a foresthaunting animal. The American bison ( $B$. americames), locally known as the buffalo, is very closely allied, but is of rather smaller dimensions, with lower and weaker hind-quarters, but a stronger and more massive shoulder, a greater abundance of long hair on the fore-quarters, and a rather shorter tail. The range of this splendid animal extended from a short distance north of the Gulf of Mexico to beyond the Saskatchewan in Canada, and probably reached almost from the Atlantic to the Pacific sea-board. Fur serenty years, at least, the Mississippi nay, however, be regarded as its extreme eastern boundary. The countless millions in which bison formerly roamed over the open prairies are known to all; but incessant pursuit and the opening up of the country by railroads, slowly, but too surely, tended to its complete extermination from the open country. According, however, to Mrr. Theodore Rooseveldt, there are still, and always have been, small numbers of bison inhabiting the Rocky Mountains northwards from Colorado, and the depths of the great forests in the sub-Arctic regions beyond the Saskatchewan River, and these, though locally called mountain-buffalo or wood-bison, are only a variety of the bison of the plains. For some years there have been reports of a small herd of bison inhabiting the remote corner of Val Verde county, Texas, near the Rio Grande border ; and some time ago a shepherd came upon the herd and counted it to comprise fifty individuals. Commenting on this, a writer in the Asian newspatper of June 15 th, 1895, observes that, "when we consider the enormous area of the country and the sparse population in the more mountainous and wooded districts, we find no difficulty in believing that the animal survives in small numbers, as a denizen of the forest, varying, in accordance with his new conditions of life, from the bison which roamed the prairies in tens of thousands a quarter of a century ago. And when we consider the physical peculiarities of the animal, thero is reason to think that in the woods the species may hold its own against min and other enemies with better success than it did on the plains. His eyesight is not keen-a defect gravely against him in the open, but for obvious reasons of much less consequence in the forest. His acute hearing, of little service on the plains, is invaluable in the woods; and his excellent nose is equally serviceable in either cxse. It would seem as though the bison had been primarily designed for a sylvan existence. Mr. Rocseveldt observes that the so-called muuntain-buffalo or wood-bison is rather heavier in body and shurter of limb than his brother of the prairie; but in regard to this we have to remember what a recent writer has said of the jrairie-bison in his latter days. Living in a state of perpetual flight from mounted hunters he became specialised with wonderful rapidity. His heavy body became lighter, his legs developed in length, and his whule appearance aequired a certain 'ranginess,' indicative of the effort of nature to adapt herself to changed conditions; flight was the refuge of the bison in the last days of his existence as a beast of the plains, and his formation in a few generations underwent the change compelled by the struggle for life. It is possible that MIr. Rooseveldt, when comparing the bison of the Rockies with that of the plains, may have had in mind this latterly specialised animal ; but, nevertheless, we can well believe that forest existence, more sedentary than prairie life even in its past peaceful days, is calculated to develop greater weight of body and brevity of limb. There is no good reason for believing that the bison now dwelling in the Rockies, sub-Arctic regions, Texas, and, 
we venturo to hope, elsewhere, in inaccessible corners of the continent, varies very markedly from the prairie form. There always have been woodland-dwelling members of the species. Bison were indigenous to the tract of country known as the Yellowstone Park, when it avas proclaimed a national reserve. Tho park is admirably adapted for a sanctuary. Embracing an area of some 3300 square miles, and forming, roughly speaking, an oblong of about 70 miles by 50 , not less than 84 per cent. of the whole is forest-clad mountain, valley, and plateau. The central psrtion forms a plateau varying from 7000 to 8500 feet in elevation, and averaging 8000 feet. Here tho indigenous bison finds comparative security, and is steadily increasing in numbers. In 1884 the bison population of the Yellowstone Park was estimated at 200 ; in the winter of $1891-92$ a snow-shoe party, exploring for the purpose, found various small herds, which by actual count gave nearly 300 animals, exch herd containing a proportion of well-grown calves."

Somewhat intermediate between the bison and the true oxen is the Tibetan yak (B. grunniens), so invaluable to the inhabitants of the highlands of the inner Himalaya as a means of transport across those arid and inhospitable regions. While the horns are not unlike those of the bison in form and position, and the general conformation of the skull is also similar in the two groups, the yak has the long hair disposed as a fringe from the fore legs along the flanks to the hind limbs, the tail being also invested with similar elongated hairs from root to tip. The ribs are fourteen in number ; and the colour of the wild race is uniformly blackish-brown, although many of the hybrid domestic breeds are more or less variegated with white. The male lacks the distinct dewlap characteristic of almost all the other oxen. Another peculiarity of the yak is to be found in the strange grunting cry from which its scientific name is taken.

Three species of oxen confined to the Oriental countries constitute what is termed the Bibovine group. These are characterised, like the true oxen, by possessing only thirteen pairs of ribs, but are peculiar in having ${ }^{\circ}$ more or less wcll-marked ridge running down the anterior half of the back, produced by the unusual height of the spines of the vertebre in that region. The horns, which occupy the highest portion of the skull, are somewhat flattened, more especially at the base, and after inclining outwards for some distance are then directed upwards. The tail is relatively short, not reaching below the hocks; the lower portions of the legs are white, and the general colour of the males is blackish, and those of the females either amber or blackishbrown. The largest and handsomest of the three species is the well-known gaur (B. gaurus) - the bison of Indian sportsmen-which inhabits hilly forests throughout India, and is also found in the Malay peninsula. The most characteristic feature of this splendid animal, which attains a height of fully six feet at the withers, is the largc, convex, and forwardly-curving crest between the bases of the horns, communicating a concave profile to the forehead. The ridge on the back is very strongly clevcloped, and stops very sharply with a sudden step-like descent; and the colour of the female is nearly similar to that of the male. As in the other members of the group, the thick coat of hair is short, fine, and remarkably sleck. From this species the gayal, or mithan ( $B$. frontulis), differs by the straight line formed by the ridge of the skull between the widely-sundercd horns, and the consequently straight profile of the forehend. The horns differ from those of the gaur in being shorter, rounder, and less curved, their tips having no distinct inward curvature, while their colour is uniformly black, instead of being 
of a greenish tinge at the base. In the males also the dewlap is more developed, while in both sexes the lim's are relatively shorter and the colour is blacker. Gayals are kept in a semi-domesticated state in Assam, Chittagong, and other parts of north-eastern India, but occur wild in the interior of the Tenasserim provinces of Burma. From both the above, the smaller aniinal from Burma, Java, Balli, and Lombok known as the bunteng ( $B$. banting), differs by the more rounded horns, the slight development of the ridge on the back, the white patch on the rump of both sexes, and the reddish-brown colour of the body of the cows.

Lastly, the true, or Taurine oxen are represented by the common ox (B. taurus) and the Indian humped cattle (B. imlicus), both of which are now known only in the domesticated state, although it is possible that the halfwild cattle of certain British parks may be the more or less modified direct descendants of the old English aurochs, as the wild ox was originally called. In this group the spinal ridge characterising the gaur and its allies is absent; the horns are cylindrical, with their tips inclined backwards, and are placed at the very extremity of the highest ridge of the skull; while the forehead is flat, and the whole skull much elongated. The tail also is larger, reaching below the hocks; and the hoofs are large and roundcd, instead of being narrow and pointed. Probably the original colour of the aurochs was reddish.

\section{ORDER VII.-SIRENIA.}

\section{Tire Maratis axd Dugorgs.}

Trrs and the sfollowing order of mammals differ from all those hitherto described in that all their members are adapted for a permanently aquatic life-that is to say, they never voluntarily leave the water, as do the seals during the breeding-season. Accordingly, their bodies have assumed a more or less completely fish-like form, with little or no traces of a distinct neck ; while the fore-limbs are modified into paddle-like flippers, the lind-limbs are completely wanting externally, and the tail forms a flattened paddle lying horizontally in the water. Structural evidences clearly show that both groups are descended from terrestrial mammals; and as these creatures have to come to the surface periodically for the purpose of breathing, the horizontallyexpanded form of the tail-fin is sufficiently obvious; such an organ being admirably adapted, by means of a few powerful strokes, to bring its owner rapidly to the surface. In fishes, on the other hand, which breathe the atmospheric air contained in water by means of their gills, there is no necessity for such periodical visits to the surface, and the tail-fin is accordingly expanded in the rertical direction, thus forming a most efficient propeller for progression in a horizontal plane.

The manatis and dugongs, forming the present order, constitute a very small group of mammals, all of which may be included in the single family Manatidce. IIaving the general fish-like bodily conformation alluded to above, the sirenians, as members of the present group are collectively termed, differ in many important respects from the whales and porpoises. One marked point of distinction is to be found in the circumstance that the body, 
instead of being laterally compressed, is flattened from above downwards. The head, again, is of an ordinary type, being relatively small in comparison to the body, with the nostrils placed at the extremity of the muzzle, and the summit rounded. To meet the exigencies of an aquatic life, external ears are, however, wanting, and the nostrils are capable of being closed at will by means of tightly-fitting valves, so as to prevent the ingress of water. In no case is the back furnished with a fin; and the fore Hippers may retain traces of nails, although the whole of their toes are enveloped in a common skin, while the skeleton of these parts contains no more than the normal complement of bones to the toes-that is to say, each toe, except the first (where there are but two), has three joints. The backbone, or spinal column, differs from that of land mammals, in that none of the vertebre in the region of the haunches are welded together to form a sacrum, such a structure being unnecessaly in an animal devoid of hind limbs, while its presence would hinder the supple movements of the body so essential in purely alyuatic creatures. From those of whales and porpoises, the vertebrre of existing sirenians differ by the absence of thin bony plates at the extremity of each end of the body, or lower portion of the same; although these were well developed in certain extinct members of the order. The manati is remarkable for the circumstance that the seven vertebrre of the neck, which are so remarkably constant in the class, are reduced to six. Neither of the genera have collar-bones, or clavicles, but in all the members of the group the bones of the skeleton are remarkable for the extreme solidity and denseness of their structure. Great variability is displayed in regard to the dentition; the recently extinct species from Behring Strait having no teeth at all; whereas in the manatis there is a very full series of masticating organs, which present a certain resemblance to the molars of the hippopotamus. In no case do the teeth resemble those of the toothed cetaceans; and although in the recent forms milk-teeth are not developed, rudiments of these have been detected, and in certain extinct kinds such teeth were functional. Similarly, nasal bones, or those roofing the cavity of the nose in ordinary mammals, have disappeared in the existing representatives of the group, although they were well developed in the earlier forms. From these peculiarities it is evident that the existing sirenians are specialised creatures evidently derived from land manmals of a more ordinary type. To fit them for long periods of submergence, both manatis and dugongs have the lungs much elongated, and extending almost the whole length of the back; while the blood-vessels are expanded in certain parts of the body into net-like structures, known as retia mirabilia, in which pure blood can be held back for a considerable time, instead of immediately passing onwards to the heart.

As regards their mode of life, the sirenians are inhabitants of large rivers, estuaries, sheltered bays, and shallow seas generally; never ploughing through the water of the open ocean in the manner so characteristic of the whalcs and porpoises; and seldom, indeed, wandering out of sight of shore. Moreover, instead of having the carnivorous habits so characteristic of the cetaceans, all the sirenians are exclusively vegetable feeders; tearing up the sea-weed and tangle when in the ocean, and other aquatic plants when they frequent fresh-waters, and masticating them after the manner of a pig either by means of their powerful molar teeth, or, when these are wanting, with the aid of horny plates which then invest the surface of the mouth. Both manatis and dugongs produce but a single offspring at a birth, which is tended with great care and affection by the mother. When suckling, the 
young is lield between the flippers of the female parent and pressed close to her breast, upon which are situated the single pair of teats; and as both parent and oftspring hold their rouncled and somewhat human-shaped heads above water, there is no reasonable doubt that it is these animals that havo given rise to the old legends of mermaids and mermen. The representatives of both the existing genera are usually found associating in small herds, their range including the coasts of the warmer portions of the Atlantic Ocean, the Red Sea, Inclian Ocean, parts of the Bay of Bengal, and the seas of Australia. The northern sea.cow was, however, an inhabitant of colder regions, being only found in Behring Strait.

The manatis (Manatus), of which there appear to be three well-defined species from the tropical coasts of the Atlantic, are chiefly fluviatile creatures, seldom venturing into the ocean, but ascending long distances up tho larger rivers, and being especially abundant in the

Aniazon. They grow to a length of about twelve feet, and

Manatis.

aro heavy, ungainly-looking creatures, with the thick and almost bark-like skin traversed by a number of fine wrinkles. Although in old age the skin may be nearly naked, in early life it is sparsely covered with soft hairs. Externally these animals are specially distinguished by the position of the nostrils at the extremity of the muzzle, the rounded form of the rudder-like tail, and the usual retention of three rudimental nails on each of the flippers. In the front of the jaws no incisor teeth are visible, although in the young state rudiments exist beneath the horny plates investing this region; but the cheek-teeth, of which eleven pairs are developed in each jaw, are fully developed and appreximate in structure to those of the hippopotamus. As a rule, however, only six pairs of the latter teeth are in use at any one time, the anterior ones falling out before those at the hinder end of the series have cut the gums. In the skeleton the extremity of the skull and lower jaw are comparatively short and but slightly bent downwards, while, as already mentioned, there are only six vertebre in the neck.

The triangular muzzle of the manati is remarkable for the circumstance that the extremities of the upper lip are developed into a pair of large fleshy flaps, which can be either brought into apposition with one another or widely separated, so that the animal can, when they are in the former position, seize and retain a leaf between them. Commercially, manatis are valued for their thick hides and the abundant supply of oil yielded by their fat; and they have in consequence of late years been greatly reduced in numbers.

The dugeng (Halicore dugong), which ranges from the Red Sea along the Indian and Malayan coasts to Australia, may bo distinguished externally from the manatis by the nostrils being situated on the superior aspect of the muzzle, the concave hinder border of the tail, and the total disappearance of all traces of nails

Dugong.

from the flippers. In the skull the front extremity of both of the upper and lower jaws are extremely massive and deep, with a very marked and sudden downward flexure, while the dentition is of a totally different type from that of the manatis. None of the teeth develop roots, and consequently grow throughout the life of their owner; the number in the adult condition including a pair of upper incisors and five pairs of cheek-teeth in each jaw. In the males the upper incisors take the form of large downwardly-directed tusks, partially invested with enamel; but in the female these teeth never pierce the gums. The cheek-teeth, which are quite devoid of enamel, and 
equally developed in both sexes, form simple cylinders, increasing in size from the first to the last, the latter being more complex than those in advance, and consisting of two cylinders united by a narrow bridge. Although usually

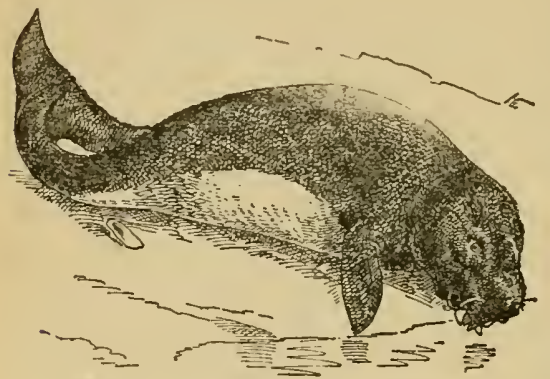

Fig. 02.-Dugosit (llaticore dugong). measuring from 5 to 7 feet in length, dugong grow to as inuch as from 8 to 9 feet. In colour they are generally bluish-grey throughout, but in some examples the under-parts are more or less decidedly lighter. The essential difference between the dugong and manatis in the matter of luabits is that the former is essentially a marine animal which never attempts to ascend rivers, and its food consequently consists entirely of seaweed of various kinds. In former days dugong were met with in herds comprising hundreds of individuals, which were remarkable for their extraordinary tameness and fearlessness of man. Human greed lias, however, done the usual work, and now their haunts are tenanted only by solitary individuals nr pairs, which are shy and difficult of approach. Dugong oil is valued for its extremely limpid character; and in Timor-Laut these animals are hunted by the natives for the sake of their tusks, from which ear-rings and other ornaments are manufactured.

To their comparatively wide geograplical distribution may be attributed the escape of the manatis and dugong from complete extermination; but the rhytina, or northern sea-cow (Khytina gigas), which, at the

Northern time of its discovery in 1741, existed in numbers on the Sea-Cow. shores of the Commander group of islands in Behring Strait, soon fell a victim to the persecution of man. Indeed, it appears that within less than thirty years from the date when its haunts were first invaded by Behring's porty, the rhytina had ceased to exist ; and it is now known to us only by certain descriptions and a number of more or less well-preserved skeletons which have been disinterred from its former haunts. In size the northern sea-cow vastly exceeded all its allies, being stated to attain a length of between 20 and 30 feet, with a weight in some cases of upwards of eight thousand pounds. It was evidently the most specialised member of the group, teeth being entirely wanting, and their function discharged by horny plates on the surfaces of the mouth, while the extremities of the flippers were blunted, and the bones of the digits apparently wanting. The head was small in proportion to the size of the body, and the tail was more deeply forked than in the clugong. So rough and ragged was the thick epidermis of the naked skin, that it has been compared to the bark of an oak tree, and could only be cut by an axe. While one account states that the colour of the skin was generally uniform brown, although occasionally flecked with white, a drawing taken from life shows alternate dark and light transverse bandings. 


\section{ORDER VIII.-CETACEA.}

\section{Winles, I'orpoises, and Dolphins.}

BEFORE the doctrine of the aciaptation of animals to their natural surrounding had become understood, no creatures were a greater puzzle to naturalists than the cetaceans, under which title are included whales, sperm-whales, porpoises, and dolphins. Their fish-like form and marine habits seemed indicative of their fish-like aftinities; whereas their internal structure, breathing, and mode of reproduction proclaimed their mammalian kinship. The latter features ought to have shown at onee what their real position in the zoological seale really was; but, nevertheless, they long occupied a place among the fishes. We read, for instance, in an abridged English edition of Buffon's "Natural History," published in the year 1821, that all these creatures "resemble quadrupeds in their internal structure, and in some of their appetites and affections. Like quadrupeds, they have lungs, a midriff, a stomach, intestines, liver, spleen, bladder, and parts of generation ; their heart also resembles that of quadrupeds, with its partitions closed up as in them, and driving red and warm blood in circulation through the body ; and to keep these parts warm, the whole kind are also covered between the skin and muscles with a thick coat of fat or blubber. As these animals breathe the air, it is obvious that they cannot bear to be any long time under water. They are constrained, therefore, every two or three minutes, to come up to the surface to take breath, as well as to spont out through their nostril-for they have but one-that water which they sucked in while gaping for their prey. But it is in the circumstances in which they eontinue their kind that these animals show an eminent superiority. Other fish deposit their spawn, and leave the success to accident; these never produce above one young, or two at the most, and this the female suckles entirely in the manner of quadrupeds, her breasts being placed, as in the human kind, above the navel. Their tails also are different from those of all other fish; they are placed so as to lie flat on the surface of the water; while the other linds have them, as we every day see, upright or edgeways. This flat position of the tail enables them to foree themselves suddenly to the surface of the water to breathe, which they are continually constrained to do."

With such a generally admirable account of the leading features of their organisation, it is marvellous how naturalists could have failed to recognise the true aftinities of the eetaceans, and continued to class them among fishes, instead of transferring them to mammals. Indeed, almost the only error in the foregoing account is the portion relating to the "spouting" of cetaceans; this error being by no means extinct among non-zoological persons even at the present day. Instead of the water thrown up in the air when a whale "spouts" having been taken in at the mouth and expelled through the nostrils, it is mainly the eondensed vapour from the ereature's breath, although when a whale commenees to spout or blow before it has quite reached the surface, a certain quantity of the superincumbent water is thrown up with the breath.

Cetaceans, then, are neither more nor less than highly speeialised mammals which have assumed a fish-like form in eorrelation with the needs of a purely aquatic mode of existence. Although a few are found in large rivers, the 
majority are thoroughly pelagic in their habits, never coming to shore even for the purpose of breeding, and, in consequence, their fish-like characters are even more pronounced than is the case with the sirenians. The tail, or "flukes," which is always more or less distinctly forked, is, however, as we have seen, expanded in a horizontal, instead of in a vertical, plane, and in place of the two paired fins of most fishes, cetaceans have only a single pair of flippers, corresponding to the fore limbs of ordinary mammals. Although these flippers are completely invested in a continuous skin without any nails or external traces of digits, internally they contain the same skeletal elements-albeit, highly modified-as their terrestrixl kindred. There is, however, the important exception that the bones of the digits are greatly more numerous than in other mammals, although the number of digits themselves never exceeds the nornal fire; this peculiarity offering an important distinction between cetaceans and sirenians. Jike fishes, many nembers of the present order have a back-fin; although this differs from that of the former group in lacking an internal skeleton. Unlike most fishes, cetaceans have, howerer, a perfectly naked skin ; although the greneral presence of a few scattcred bristles, especially in the young state, around the mouth, proclaims their origin from fully haired mammals. And here may be mentioned tho rery remarkab?e circumstance that certain extinct members of the order were fumished with a bony armour, somewhat comparable to that of crocodiles; although this does not permit of our saying that all cetaceans are descended from armoured ancestors. In coloration, whales and porpoises resemble most fishes inhabiting the surface of the sea, such as mackerel and herrings, in that the upper eurface of the body is dark, and the lower light-this being obviously a protective resemblance, as the clark upper surface, when viewed by reflected light, harmonises with the dark waves; while the light under surface, when viewed from below by transmitted light, must be scarcely distinguishable from the bright sky above. As in the sirenians, the external conchs of the ears are totally wanting, and the aperture of the ear itself is extremely minute. The eyes also are relatively small, and placed far back on the sides of the head, which is always large in proportion to the size of the body. An important difference from the sirenians is to be found in the position of the nostrils, which may open externally by either a double or a single aperture; these being invariably situated on the very summit of the head, and thus enabling the creatures to commence breathing the very monent they reach the surface, without altering their normal horizontal position. To prevent the ingress of water while beneath the surface, the nostrils can be completely closed by a valve or valves. Reference has already been made to the essential difference between the skeleton of the flipper of a cetacean and a sirenian; and it may be added that the vertebra of the former have the terminal plates, or epiphyses, which are practically or entirely wanting in the existing members of the latter group, very strongly developed. The coat of fat, or blubber, lying beneath the skin, so characteristic of all cetaceans, has been already alluded to; but it must be also mentioned that these animals have net-works-retia mirabilia-of bloodvesscls for the retention of oxygenated blood during their descent, which can be used gradually, and thus enable them to stay below for a longer period than would otherwise be the case. The two teats of the female differ from those of the sirenians in being placed far back on the abdomen.

Although none of the porpoises and dolphins attain very large dimensions, 
and some of them are comparatirely small creatures, the cetacean order includes not only tho largest of all mammals, but likewiso of all living animals. 'That they trace their origin back to terrestrial mammals may be considered beyond all doubt, although from what particular group they are descended cannot at present bo determined. As a rule, the various pelagic representatives of the order enjoy a very wide geographical range, althongh certain species, such as the Greenland-whale of the Arctic Ocean, and the pigmy-whale of the Southern Seas, are confined to a relatively small area. Almost all cetaceans are carnivorous.

Cetaceaus are divisible into two great divisions, or sub-orders, known as the whalebone-whales (Mystricocet $i)$, and the toothed whales (Udontocet $i)$; the former group comprising only the single family (Bulcuidec), whereas the latter is dirided into three families. As their nanies imply, the most obvious distinction between these two groups relates to the absence or presence of functional teeth;

WhaleboneWhales. the absence of teeth in the first group being compensated by the development of the peculiar substance known as whalebone, or baleen. In the young of the whalebone-whales, rudiments of true teeth are, however, developed beneath the roots of the incipient whalebone, although these sub. sequently wither without having ever cut the gum. As the nature and structure of whalebone is a matter of some interest and importance, a small space must be devoted to its consideration before entering upon the leading characteristics of the Mystacoceti. Whalebone, then, is a horny substance attached to the roof of the mouth, from which it hangs by a broxd, transversely-arched base, in the form of a series of parallel, narrow, elongated triangular plates, placed transiersely to the long axis of the mouth, with their external edges firm and straight, but the inner ones frayed out into a kind of fringe. The longest plates of whalebone are situated near the middle of the jaw, from which point the length gradualy diminishes towards the two extremities, where they become very short. Whereas, however, in the Greenland-whale the length of the longest plates varies from some 10 to $12 \mathrm{ft}$, and the total number of plates in the series is about 330 , in the great rorquals or fin-whales, the length is only a few incles, while the number of plates is considerably less. To accommodate the enormons whalebone-plates of the Greenlandwhale, the bones of the upper jaw are greatly arched upwards, and the slender lower jaw is bowed outwards, thus leaving a large space-both in the vertical and horizontal directions - the transverse diameter of which is much wider below than above. When the mouth is closed, the plates of whalebone are folded obliquely backwards, with the front ones lying beneath those behind them; but directly the jaws are opened, the elastic nature of this substance causes it to spring at once into a vertical position, and thus form a sieve-like wall on both sides of the mouth, the thin ends of the plates being prevented from pushing outwards by the stiff lower lip which overlaps them. By elerating its enormous fleshy tongue within the cavity thus formed, the whale causes the enclosed water to rush out between the plates, leaving such small creatures as it contained lying dry on the surface of the tongue ready for swallowing. In structure, whalebone, which, although black in the Greenland. whale, is white in some of the other species, is of a horny nature, and grows from transverse ridges on the mucous membrane of the roof of the mouth; being, in fact, nothing moro than an extremo development of the ridges on the palate of a cow, hardened and lengthened by an excessire growth of a horny superficial or epithelial layer. The whole of this vast 
horny growth takes place, however, after birth, young whales having smooth palates, with no trace of the horny plates.

Apart from the presence of the distinctive and characteristic whalebone, the inembers of the present group have the following characteristic features in common. In the first place, the nostrils open externally by two distinct longitudinal slits, or "blow-holes;" while the internal region of the nose retains traces of an organ of smell-this, by the way, being another proof that cetaceans are descended from terrestrial mammals. Distinct, although small, nasal bones partially roof over the nose-cavity of the skull; and the whole region of this part of the skull retains the normal symmetry. In order to accommodate the whalebone, the two branches of the lower jaw aro curved outwards in a bow-like form; while at their front extremities they are only loosely connected together by ligament. The breast-bone, or sternum, consists of only a single piece, to which but one pair of ribs articulate; and all the ribs have but a slight connection with the vertebre, articulating only with the horizontal transverse processes, and not touching the bodies of the vertebre. Although the whalebone-whales are represented by a comparatively small number of species, all these are of large bodily dimensions, the sniallest of them-the pigmy-whale-attaining a length of some $20 \mathrm{ft}$.

The most specialised representatives of the sub-order and family are the true, or right-whales, constituting the genus Balcenc, of which there appear to be two well-defined species. Externally, the right-whales are easily recognised by the enormous relative size of the head, the perfectly smooth throat, the absence of a back-fin, and the moderate length of the flippers. Their whalebone, which is black in colour, is proportionately longer and more elastic than that of any other species, with the exception of the pigmy-whale; and for its accommodation the palate of the skull is much narrower and more highly arched than in other whales, while the branches of the lower jaw are more bowed outwards. The skeleton of the flippers contains five fullyformed divits; the vertebre of the neck, which are reduced to the condition of thin plates, are completely welded together into a solid, immovable mass, and the tympanic bone of the internal ear is squared. In conformity with the arched form of the skull, the margin of the lower lip runs high up on the sides of the head and is highly convex; while the size of the opened month is enormous. In spite, huwerer, of the huge dimensions of this cavity, the calibre of the throat is so small that it is a common saying among sailors that a herring is sufficient to choke a whale. Of the two existing species, the Greenland-whale (B. mysticetus) of the Arctic seas is the more specialised, the head being larger and the whalebone longer than in its southern cousin. The latter (B. antralis) is commonly known as the southern right-whale, and although formerly abundant in the Atlantic, is nowadays a rare creature. From the right-whales the single species of pigmy-whale (Neobclcenct), from the South American and Australasian seas, differs in having a small, hooked back-fin, as it does in its white whalebone. Whereas the Greenland species grows to a length of from 45 to $50 \mathrm{ft}$., the pigmy-whale does not appear to exceed 20. A connecting link between tho right-whales and the under-mentioned rorquals is afforded ky the great Pacific grey-whale (Rhachianectes), in which the throat has a single fold, and the back is devoid of a fin, while the whalebone is even shorter and more coarse than in the rorquals, the palate showing but a slight degree of raulting, and the head being relatively small, and the body elongated. The rertebrio of 
the neck are thicker than in the right-whales, and mostly free from one another. In length the female varics from 40 to $44 \mathrm{ft}$., but the male is rather smaller.

The other members of the family are the humpback (Megaptere) and the rorquals or finners (Balenopter(s), in both of which the skin of the throat is marked by a number of longitudinal flutings or grooves, while the back carries a fin ; the whalebone being short and conrse, and usually of a yellow ish colour. The vertebrio of the neck are of considerable thickness, and totally separate

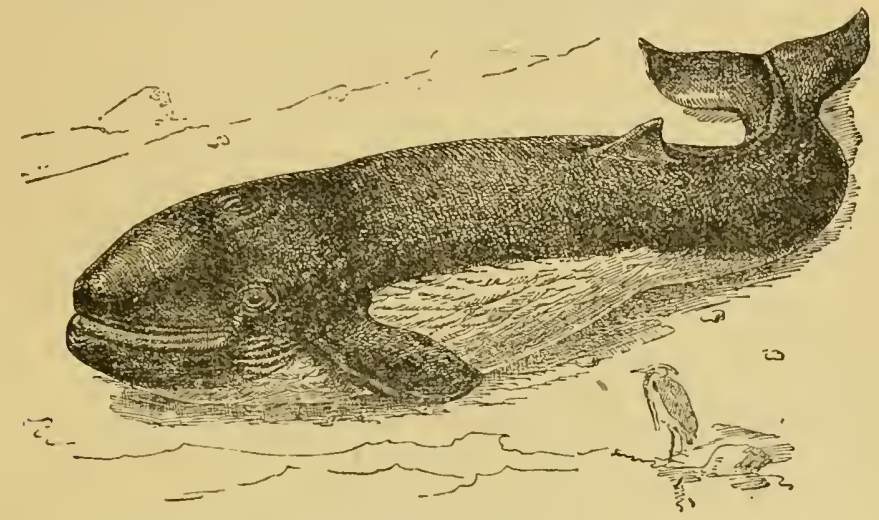

Fig. 93.- A Fix Whale (Balcenoptera).

from one another; and the tympanic bone of the internal ear is much more rounded and globular than in the right-whales, its shape somewhat recalling that of a large cowri shell. In the skeleton of the flippers the number of digits is reduced to four ; and the head is comparatively small in proportion to the body, with the palate but slightly arched, and the branches of the lower jaw little bowed outwards. Another character of the group, as compared with the right-whales, is the smaller degree of expansion of the tail-fin or flukes. From the finners, the single species of humpback (Megapterc boops) is distinguished by the relative shortness and depth of the body, which rises above the level of the back-fin behind the shoulders, and likewise by the extraordinary length of the flippers, which is nearly one-fourth that of the entire animal. In length the female is about the same as the Greenland-whale. As a rule humplacks have the flippers of a pure glistening white; and when one of these animals is gambolling, as they often do, it will frequently lie on its side just below the surface of the water, so that the whole body is concealed. In this position one white flipper will be seen sticking straight up some 9 or $10 \mathrm{ft}$. above the water, and when first viewed from the deck of a passing ressel appears a most extraordinary object, which may well puzzle the beholder.

The rorquals, or finners, on the other hand, are characterised by the elongation and slenderness of the body and the comparative shortness of the flippers, which are pointed at their extremities. The largest member of the group, as indeed it is of all whales, is the blue, or Sibbald's rorqual (Balonoptera sibbaldi), commonly known to the American whalers by the 
name of "sulphur-bottom," which reaches the enormous length of from 80 to $84 \mathrm{ft}$. The common rorqual ( $B$. musculus), frequently stranded on the British coasts, is also a huge animal, frequently measuring from 65 to $70 \mathrm{ft}$.; but the other two species are of inferior dimensions, the smallest being the lesser finwhale (B. rostrata), of which the length does not exceed from 30 to $35 \mathrm{ft}$. While some of the species feed largely on cod, other's subsist chiefly on cuttlefish.

On account of the length and elasticity of the whalebone, and the abundance of oil yielded by their blubber, from a commercial point of view, the rightwhales are of far greater value thin the humpback and finners; while their inferior speed, as compared with the latter, renclers them far more easy to overtake and capture. The southern right-whale was, however, long ago practically exterminated from the Atlantic by the old Basque whalers; and incessant persecution has so climinished the numbers of the Greenland-whalo that comparatively few are now to be met with on the old whaling-grounds. Consequently, whalers have been compelled to turn their attention to the less valuablo finners and humpback; and the use of steam vesscls and explosive harpoons fired from guns has rendered their capture far less difticult than in the days of rowing-boats and harpoons and lances thrown by hand. Till recently the "fishing" has been mainly carried on in the northern and sub-tropical seas, but a few years ago four ships were fitted out for whaling in the Antarctic ; and the following account of what was observed is condensed from a newspaper report. It is there stated that the rightwhales always come north to the gromnds eastward of New Zealand early in October, and remain till near the end of December. Then they collect in "schools," and stirt on a south-east course with a speed of about five knots an hour night and day. Several ships have followed them in this course until they met with the ice-drift in lat. $50 \mathrm{deg}$. south and $10 n g .160 \mathrm{deg}$. west, where the chase was abandoned. The whales always arrive on the ground in schools of ten or fifteen, and then separate and pair off-or at most one bull and two cows. It is not thought that the whales, with the exception of the humpbacks, come north to calve, as they are never seen with any young. Of late years right-whales have been seen north of $3 \check{\mathrm{deg} .} 30 \mathrm{~min}$. south lat. Finners and humpbacks are always to be found on the "ground," apparently travelling in a south-easterly direction. The humpbacks come up from the southward along both the east and west sides of Australia and New Zealancl about the end of $\mathrm{MI}$ y, and continue their course northerly to about lat. 18 deg. south, when they disperse. About the first weck of Out ber they begin to work their way back south until lost amidst the ice. Experienced whalingmasters are of the opinion that there must be some place to the souchward, as yet unknown, where the whales assemble in large numbers. A vessel fitted with an auxiliary screw, it is stated, could follow the whales to their destination without danger of being blocked by the ice. The right-whale, according to men who are engaged in the trade at the present time, must be very numerous in the Antarctic Ocean, as the fishery has never been carried on there with any constancy and vigour; whereas in the Arctic Occan the whales are looked upon as almost extinct. The southern-whale is not so large as the Greenland, only yielding from $800 \mathrm{lbs}$. to $1200 \mathrm{lbs}$. of boncthe length of which varies from $S \mathrm{ft}$. to $15 \mathrm{ft}$. - valued at $£ 1600$ to $£ 1800 \mathrm{a}$ ton, while the oil, averaging from 8 to 14 tons, brings 228 per ton. The humpbacks are very numerous off Norfolk Island of late. These whales measure from 60 to $70 \mathrm{ft}$. in length and yield from 50 to 70 barrels of oil. 
The Australians interested in the success of the trade are confident that a large industry in whale and seal-fishing could be developed in the Antarctic seas by auxiliary screw-whalers, which could be fitted out at the comparatively small cost of $\AA^{6} 6000$ each.

The essential characteristic of the toothed-whalcs, or Odontoceti, is a negative one, and consists in the entire absence of whalebone. Very gencrally, indeed, teeth are developed, at least in the lower jaw, but these may be reduced to a single pair, or even in the male narwhal to a solitary tooth, while in the female of the latter species there-are none of any functional importance. Another rery wellmarked point of distinction is the single external aperture of the nostrils, which very frequently takes the form of a transverse crescentic slit, closed by a flap-like valve. Then, again, the skull is always more or less unsymmetrical in the region of the nostrils, and in the existing members of the sub-order the nasal bones are reduced to mere rounded nodules, taking no share in roofing the nasal cavity. In certain extinct forms, however, these bones are of more normal character, and partially corer the chamber of the nose. No trace of an organ of smell is retained by any of the toothed-whales. In the skeleten the breast-bone, or sternum, is usually composed of several distinct portions, to which the extremities of several of the ribs are articulated by the intervention of cartilages; and a certain number of the anterior ribs are articulated at their upper ends to the bodies of the vertebre, as well as to the transverse processes of the same. The lower jaw of a toothed-whale may always be distinguished from that of a whalebone-whale by the two branches being nearly straight, of great depth at the hinder extremity, and in front uniting with one another by a bony union of larger or smaller extent. In all the members of the group the skeleton of the flippers exhibits five complete digits. Throughout the sub-order the teeth are always of a simple structure, having conical or compressed crowns and undivided roots; and only a single series is ever developed, the roplacement of the anterior teeth, so common among mammals, being wanting. In number the teeth of many species greatly exceed the ordinary mammalian series. Observations on foetal cetaceans have indeed shown that rudiments of a second series of teeth are developed in the gums, which serve to show that the functional teeth correspond in the main to the milk-series of ordinary mammals.

Although in the development of whalebone and the loose articulation of the ribs to the backbone the whalebone-whales are clearly more specialised than the toothed-whales, yet as regards the single nostril and the structure of the nasal bones the latter group is decidedly more aberrant than the former. Hence it may be inferrecl that neither of the two sub-orders is derived from the other, but that both have grown up side by side quite independently. It has generally been considered that they are divergent branches from a conmon ancestral stock; but it is possible that they have no sort of genetic aftinity with each other, and have respectively originated from two totally distinct mammalian groups. More decisive evidence than any yet adduced is, how over, required before the latter view can be definitely accepted.

The largest of all the toothed-whales is the gigantic sperm-whale (Physeter macrocephalus), the sole member of its genus, and the typical representative of a fanily (Physeteridce) characterised by the absence of teeth in the upper jaw of the adult, and the variability, both as regards size and number, of those of the lower jaw. In all the members of the family the hinder portion of the sikull is much elevated, so as to form either a semi-circular wall, or a pair of 
crests behind the nasal aperture. All these cetaceans are entirely pelagic in their habits, and feed exclusively or chietly on cuttles and squids. In the sperm-whale the number of teeth in the lower jaw varies from twenty to twenty-five pairs; the teeth themselves being of large size, with pointed and somewhat curved crowns, upon which there is no trace of enamel. The head is of enormous dimensions, measuring about one-fourth the tutal length

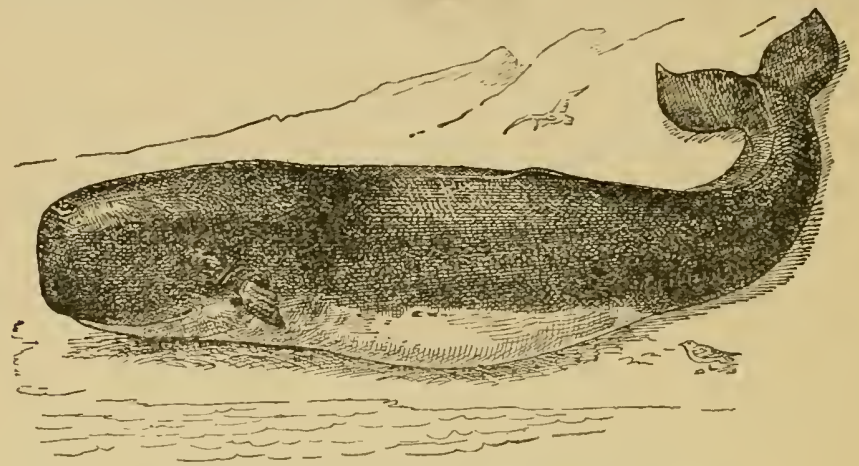

Fig. 94.-THe SPERM-Wuale (Physcter macrocephalus).

of the animal, and characterised by the abrupt truncation of the enormous muzzle, the S-like form of the blow-hole, which is situated somewhat to the left of the middle line, and the long mouth opening below, and somewhat behind, the extremity of the muzzle. The skull behind the nostrils has an enormous cavity, bounded belind by a semi-circular wall of bone of several feet in height, and containing during life the oily substance which yields, when refined, the valuable spermaceti. An even more precious product of this cetacean is ambergris, which, although generally found floating on tho surface of the ocean, is really a concretion formed in the intestines of the sperm-whale. It is an amber-coloured substance, generally containing a number of the horny beaks of the squils on which sperm-whales feed. Although the female is a much smaller animal, the male cachalot, as the sperm-whale is often called, grows to a length of between 50 and $60 \mathrm{ft}$. In the sperm-whale the two branches of the lower jaw are united in front for about half their length, but in the much snaller and somewhat porpoise-like animal known as the lesser sperm-whale (Cogia brericeps) the union between the two branches of the lower jaw is less than half the total length of the jaw, and the number of lower teeth is reduced to from nine to twelve pairs. This whale attains a length of about $10 \mathrm{ft}$., and difiers from the cachalot in carrying a large back-fin. The flippers, moreover, which in the spermwhale are remarkably small in propurtion to the size of the body, are here relatively longer. It is interesting to notice that fossil sperm-whales (Physocton) have been discovered possessing a full serics of enamel-capped tceth in both the upper and lower jaw.

Nearly allied to the preceding are the bottled-nosed and beaked-whales, belonging to a group distinguished by the reduction of the lower functional teeth to a single pair, the others being rudimentary and concealed in the gum. None attain a large size, and all are pclagic, subsisting almost 
exclusively on squids and cuttle-fish. The bottle-noses, as typified by the common Hyperoüdon rostralus, so frequently stranded on the British coasts, take their name from the extreme convexity of the crown of the head in the adult male, which rises abruptly above the base of the short beak. They have but a single pair of teeth in front of the lower jaw, but even these are invisible in the living state; and the back, like that of the beaked-whales, bears a fin. Although the common bottle-nose, which has a very wide geographical distribution, does not exceed about $30 \mathrm{ft}$. in lengtl, it is valued not only on account of its oil, but likewise for the spermaceti contained in the head. In addition to the large overhanging and unsymmetrical crests above the nostrils, the skulls of old males have another pair of longitudinal crests on the sides of the base of the beak, which come almost into contact, and have their front surfaces broad, flat, and rugose. Cuvier's whale (Chone iphius* cuvieri) differs from the bottle-nose in possessing a pair of large forwardly and upwardly directed teeth at the extremity of the lower jaw. From both the preceding the beaked-whales (Mesoplodon) are readily distinguished by the production of the anterior portion of the skull into a long cylindrical beak, composed of massive, ivory-like bone; while they are further characterised by the pair of lower teeth being generally situated near the middle of the jaw. These teeth are generally of large size, and more or less compressed latterly. In one species (MI. layurdi) they are enormously developed, and of a strap-like form, curving over the beak to such an extent as in some cases actually to prevent the mouth from being fully opened. The beaked-whales appear to be solitary creatures, avoiding the neighbourhood of the coasts, and thus but seldom stranded. During the P'liocene epoch they nuust, however, have been abundant in the English seas, as their solid fossilised beaks are of common occurrence in the so-called crag deposits of the East Coast. Arnux's whale (Berardius ammexi), from the seas of New 'Lealand, which is the last member of the family, differs from the true beaked-whales in possessing two pairs of lower teeth. Whereas the beaked whales usually measure about 15 or $16 \mathrm{ft}$. in length, this species reaches as much as $30 \mathrm{ft}$.

A small family of the Odontoceti known as the Platcristicle is represented solely by three small species, two of which are exclusively freshwater, while the third is an estuarine form. While resembling the members of the next family in the possession of a numerous series of teeth in both the upper and lower jaw, they are distinguished by the length of the bony union between the

FreshwaterDolphius. two branches of the latter, and likewise by the mode of articulation of the ribs with the backbone. None of the vertebrre of the neck are welded together. The typical member of the group is the well-known susu, or Gangetic dolphin (Platanisla gengetica), which may often be seen sporting in the Ganges, Indus, or Bramaputra. This species usually attains a length of 7 or $8 \mathrm{ft}$., and is characterised by the long and compressed beak, in which are crowded a very numerous series of sharply-pointed teeth, the rudimental back-fin, the fan-shaped flippers, the slit-like form of the blow* hole, and the minute size of the eye, which is perfectly useless as an organ of vision. The skull may be recognised by the enormous curving longitudinal crests arising from the base of the beak, and almost meeting above it. The food of the susu appears to consist almost exclusirely of prawns and bottom-

* This name-originally applied to an allied fossil form-is used by Cope to replace Ziplizus, on account of the pre-occupation of the latter. 
haunting fish, which are raked up from the mud by the long beak. The other two existing members of the family are South American. One of these is the inia or Amazonian dolphin (Inic geoffroyensis), inhabiting the upper

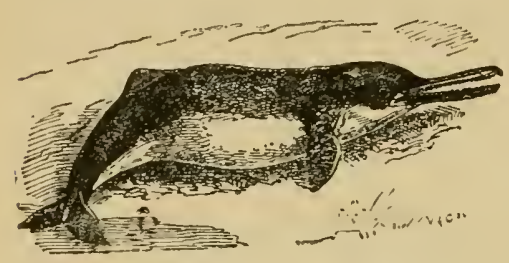

Fij. 95.-Gaxa etic DourhiN

(Plutarisia ganjetica).

portions of the river-system from which it derives its name, and being more porpoise-like in form than the last. The long cylindrical beak has a number of sparse bristly hairs; and its numerous teeth have a tubercle at the base. Unlike the susu, the eye is fairly large, and the flippers are not fan-shaped. Seven feet is the maximum length of the male inia; and the general colour is blackish above and reddish beneath. From both the preceding the small La Plata dolphin (Stenodelphis blainvillei), from the estuary of the Rio de La Plata, may be at once distinguished by its uniformly buff coloration, which is admirably suited to harmonize with the colour of the stained water of the Plate river, and at once proclaims that the species is not of pelagie liabits. In size, this dolphin seldom, if ever, exceeds $5 \mathrm{ft}$., and is often considerably less. Unlike both the other species, it has a well-developed back-fin, and the beak is of great length, and furnished on each side with from fifty to sixty teeth; the number in the other genera being about thirty. Another distinctive feature is to be found in the form of the blow hole, which forms a transverse crescent, instead of a longitudinal slit. At certain seasons of the year enormous numbers of these elegant little cetaceans are captured in the Bay of Monte Video by the fishermen, who detest them on account of the large quantities of fish they consume.

The whole of the remaining menbers of the order are included in the single family Delphmidie. The majority of the species are of comparatively small size; and while most are found in the neighbourhood

Porpoises, of coasts where they frequently ascend tidal rivers, a few are Dolphine, etc. of exclusively fluviatile habits. Many of the genera are very closely allied, and distinguished mainly by the structure of the skull, so that in a popular work it is by no means easy to indicate their distinctive peculiarities. While the majority resemble the Plutanistidce in possessing a numerous series of teeth in each jaw, in two species this is not the ease. From that family they may be distinguished by the shorter union bet ween the two branches of the lower jaw, and also by a difference in the mode of articulation of the ribs to the backbone. In all cases the blow hole is in the form of a transverse crescent, with the two horns pointine furwards; and very generally from two to four of the anterior vertebre of the neck are welded together into a solid mass. One of the most aberrant, and at the same time one of the most beautiful, members of the family is the spottednarwhal, or sea-unicorn (Monodon monoceros), the males of which carry the well-known spirally-twisted "horn," or tusk, from which several of the names of the species are derived. Exclusirely contined to the Arctic seas, where it associates in small "schools," the narwhal belongs to a group of dolplins characterised by the blunt and rounded form of the head and the total absence of a beak. There is no back-fin; the wide and rounded llippers are short; and the colour is dusky, with dark-grey mottlings. The 
single tusk of the males is always the left one, the right remaining, as a rule, undeveloped in the gum; but occasionally specimens are found with two tusks. Besides these tusks there are no other functional teeth in the males, and the females aro toothless. The length of the head and body varies from 12 to $16 \mathrm{ft}$. and that of the tusk between 7 and $8 \mathrm{ft}$. Allied to the narwhal is the beautiful white-whale or beluga (Delphincupterus leucus), which is likewiso a northern form, and also the sole representative of its genus. It may be recognised by its pure glistening white skin, the absence of a tusk, and the presence of numerous teeth in the front of the jaws. The beluga, which congregates in troops of considerable size, is regularly hunted for the sake of its hide, blubber, and flesh ; the latter being dried and caten by the Greenlanders and Eskimos, as well as by the sledge-dogs of the latter.

In ordinary language the term porpoise is applied to nany of the members of the present family, but in a scientific sense it is confined to the members of the sniall genus Phocana, all of which are comparatively small-sized cetaceans, characterised by possessing from sixteen to twenty-six pairs of small, short, somewhat spade-shaped teeth. In the common porpoise ( $P$. communis) of the European seas the back is furnished with a well-developed fin ; but in the Indian species ( $P$. phocanoides) this appendage is wanting. Porpoises are the most common and familiar of all cetaceans, their rolling gambols being well known not only to all those who have made a voyarre, but likewise to visitors to the sea-side. The allied genus Cephalorhmohns is typified by Heaviside's dolphin (C. heverisidei), and includes four species from the Southern seas. They have a conical head, without any distinct beak, and from twentyfive to thirty-one pairs of small and sharp teeth. The back-fin is triangular or ovate ; and in three out of the four species the flippers have a characteristic elliptical shape. Externally their most distinctive feature is the coloration, the upper-parts being black, and the under surface of the body white, with the white area terminating on the uncler side of the tail in a trident, the lateral prongs of which run obliquely upwards on the flanks a little behind the back-fin. The Irawadi dolphin (Oreella fluminalis), of which a variety, or perhaps an allied species, occurs in the Bay of Bengal and some of the neighbouring seas, represents a genus distinguished by the globose, beakless head, and the small size and number of the teeth, the latter vccupying nearly the entire length of the jaws, and including from thirteen to seventeen pairs in the upper, and from twelve to fifteen in the lower jaw. Thev are set close together, and are conical and pointed in shape, those in the front of the jaws of the adult males being inclined outwards. The moderate-sized flippers are broad at the base, and of a subcrate contour ; while the back-fin is small and hooked. From 7 to $7 \frac{1}{2} \mathrm{ft}$. is the usual length of these dolphins, which are either blackish or slaty in colour.

From all the preceding the large and strikingly-coloured cetaceans known as killers, or grampuses (O,cre), differ by the large size of their powerful conical teeth, which are crowded together, and usually form twelve pairs in each jaw. And they are further characterised by the great vertical height of the back-fin. As regaris colour, the upper-parts and Hippers are black and the lower surface whitish; the white area ending on the under side of the tail in a trident, very nearly the same as in the above-mentioned genus Cephalorhynchus. Above and behind the eye is a white streak, and there is a purplish band across the back behind the fin. Killers, of which there is but a single well-defined species, grow to a length of at least $20 \mathrm{ft}$., and enjoy an almost cosmopolitan distribution. They derive their popular 
name from their rapacious habits, and are the only cetaceans which prey on other menbers of their own order. One killer has been known to swallow several entire seals one after the other; and not unfrequently several individuals combine forces to

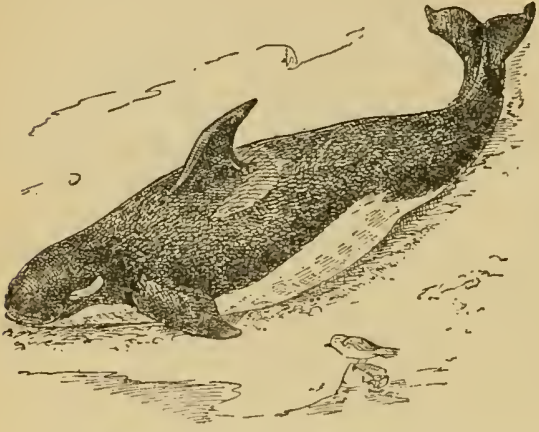

Fig. 93.- Killer (Oicx gladiator). attack and kill one of the larger whales, hunting with the perseverance of a pack of hounds. When swimming near the surfice of the water, killers may be easily recognised by the great size of the nearly vertical backfin. The lesser killer (Pseudorca crassidens), which is also cosmopolitan, and attains a length of about $14 \mathrm{ft}$., differs from its larger relative by the sinaller size of the back-fin, the pointed flippers, and the cylindrical (instead of angulated) roots of the teeth, as well as by the uniformly black colour of the skin. There are generally eight pairs of upper and ten of lower teeth.

Although the name of black-fish would apply equally well to the foregoing, it is given to the cetacean known scientifically as Globiocephalus melus. The black-fish is characterised by the extremely short and rounded head, the almost uniformly black colour of the skin, and the presence of from eight to twelve pairs of small conical teeth in the front portion of the jaws. The back-fin is long, low, and thick, and the flippers are relatively long and narrow. Generally there is a lance-shaped white patch on the throat. In length, the black-fish, or, as it is often called, pilot-whale, grows to a length of $20 \mathrm{ft}$. Whether there is more than one species is somewhat uncertain ; but, at anyrate, a form inhabiting the Bay of Bengal is distinguishable by the reduction in the number of the teeth. As regards habits, this cetacean is the most sociable of its order, and since all the members of a herd always blindly follow their leader, enormous numbers are frequently slaughtered at a time. 'The last of the beakless group of the family is the rare Risso's dolphin (Grompusgriseus), which diflers from all the other Delphinide, save the female of the narwhal, by the absence of upper teeth, while the lower jaw carries only from three to seven small teeth towards its anterior end. In general appearance this species is very similar to the black-fish, although the head is less decidedly glubular, and the flippers are rather shorter. It is easily recognised by the peeuliar grey striping and mottling of the skin ; scarcely any two individuals being quite alike in this respect. This species is almost cosmopolitan, specimens being stranded from time to time on the British coasts.

Intermediate, between the bcakless and beaked members of the family, is a genus known as Letyenorlyndhus, which includes the various species of shurt-weaked dolphins. Noticeable on account of their strongly-contrasted black and white coloration, the short-beaked dolphins are characterised as a whole by the short, ill-defined and somewhat ploughshare-like beak of the skull, the moderate size of the back-fin and flippers, and the distinct ridges on the tail. The teeth vary considerably both in size and in number; but, 
as in the black-fish, the bony union between the two branches of the lower jaw is short. The sides of the budy are always marked by two light-coloured areas, between which is a band, or a series of streaks of black.

The second group of the family includes the true dolphins and their allies, in all of which there is a clistinctly defincd beak, generally exeeeding the brain-cavity in length, and marked off from the hinder portion of the head by a $\mathrm{V}$-shaped groove. By sailors dulphins are indifferently spoken of either as porpoises or bottle-noses, which frecuently leads to a confusion between them and either true porpoises or the buttle-nosed whales. They are divided into numerous genera, according to the number of the teeth, the relative length of the beak, and the conformation of the bones of the palate. They are all consaritively small animals, but few exceeding a length of about $10 \mathrm{ft}$; and while most of them are marine, some ascend the larger rivers temporarily, and others are permanent inhabitants of fresh-waters. Fish of various kinds constitute the usuil prey of dolphins, but it is believed that one species of the genus Sotalic from the Canerums district subsists on sea-weed. In the true dolphins (Delphinus), of which there are sereral species, the beak is of considerable length; the flippers and back-fin are long and slightly hooked; there are from about forty to sixty-five plirs of sharp teeth in each jaw, which have an oval section at the base; and the union between the two branches of the lower jaw is short. In the bottle-nosed dolphins (Tursiops) the beak is shorter and more tapering, and the number of teeth less, there being generally from twenty-two to twenty-six pairs. A third genus is typified by the rough-toothed dolphin (Steno frontilus), from the Atlantic and Indian Oceans. Here the beak is greatly elongated, and the bony union between the two branches of the lower jaw very long; the rather large teeth varying from twenty to twenty-five pairs, and being often mirked by rough groovings. Nearly allied are the long-beaked river-dolphins forming the genus Sotalia, which may be distinguished by their fluviatile or estuarine habits, and the smaller number of vertebre in the backbone; the teeth being always smooth, and the base of the flippers very wide. Several of the species inhabit the Amazon-system, while one is found in some of the Chinese rivers, and another in the estuaries and rivers of the Cameruns district.

\section{ORDER IX. - EDENTATA.}

\section{Stoths, Ant-Eaters, AND Armadillos.}

The three families of mammals named above, all of which are practically confined to South and Central America, although one or two wander as far north as Texas, are the representatives of an order in which all the existing forms are devoid of front teeth, while the cheek-teeth have no external coating of enamel, but consist solely of ivory, or of ivory with a layer of cement. In consequence of this poor development of the teeth, the group is known by the name of Edentata. To the same group have been commonly referred the pangolins of the warmer parts of the Old World and the aardvarks of Africa, but it is nearly certain that these cannot rightly be included in the same order, and they are accordingly referred here to a group by themselves. It is rather difficult to give many other characters in addition 
to the absence of front teetl common to all members of the order, but it may be stated that the cheek-teeth grow throughout life and thus never develop roots; while it is but very rarely that milk-teeth are present, and in only a single instance do these cut the gum. With the exception of the sloths, in which they have probably been lost, the hinder vertebra of the trunk have additional articular surfaces. In tleir whole organisation the edentates displat a low type, as is exemplified by the generally small size of their brains, in which there are usually but few convolutions on the surface.

The sloths, or Bradypodide, form a small family of edentates specially characterised by their adaptation to an arboreal life, and differing from nearly

all other mammals by their habit of hanging back-downwards

Sloths. from the branches of the trees on wlich they dwell. They are comparatively small, slenderly-built animals, with a peculiarly rough, shaggy coat, a short, rounded, and almost sperical head, and inordinately long and slender limbs-especially the front pairterminating in huge, hook-like claws. The small ears are completely buried among the long fur covering the head; and the tail is rudimental. The cheek-teeth, which comprise five pairs in the upper and four in the lower jaw, form short cylinders, of which the external layer is harder than the central core, so that by use their grinding surfaces become slightly cupped. 11 liereas, however, in the three-toed sloths the whole of the teeth are of this simple type, in the two-toed species the first pair in each jaw are taller than the rest and assume a somewhat tusk-like form, with their summits obliquely bevelled by mutual wear. In the limbs the narrow and curred feet are reduced to the condition of little more than hooks; the three-toed forms having three claws on each foot, whereas in the other group the number of claws in the fore feet is reduced to two. Although admirably adapted for suspending the animal back downwards from a brancli, the feet of the sloth are but poor instruments for progression on the ground, and when walking, a sloth advances awkwardly and slowly, with the soles turned inwards. Externally the fur of the sloth is of a dull brownish or ashy colour, the individual hairs having a fluted outer surface. The most extraordinary feature about the fur is, however, the growth of a vegetable substance on the surface of the hairs, thus increasing the resemblance of the animal, when hanging at rest from a bough, to a rough lichen-clad knot. Beneath the outer coat of long grey hairs is a finer under-fur marked by longitudinal stripes of chocolate-brown and orange; a patch of this under-fur being frequently exposed in the middle of the back by the habit these creatures have of rubbing or resting this part of their bodies against the trees. In conformity with the shape of the skull, the soft tongue is very short. The female has the single pair of teats situated on the breast. Internally sloths are specially characterised by the complexity of their stomachs, and a peculiar folding of the windpipe. Sloths are divided into two distinct generic groups. Of these, the three-toed sloths (Bradupus) are characterised by having three toes to each foot, and all the teeth short and cupped, whereas in the two-toed sloths (Cholcepus), there are only two toes on the fore feet, and the front pair of teeth in each jaw are taller than the others and obliquely bevelled at the summits. Tery exceptional among mammals are the sloths in regard to the number of vertebrie in the neck. Thus, whereas in one of the two-toed kinds there are the normal seven, in a second the number is reduced to six; while in the three-toed group there are invariably nine of these segments. 
Iy the natives of the tropical forest-regions of South and Central America, where sloths are alone found, the three-toed kinds are spoken of as aï, while the name of unat is applied to the members of the two-toed group. Mainly nocturual in their habits, sloths appear to bu sliggish creatures, passing the daylight hours curled up with the head siffely tucked between the forc-limbs, and at night wandering about slowly in search of food, which consists solely of leares and other regetable substinces. Caution is a great charicteristic of their movements, a fresh branch being firmly seized before hold is relaxed of the one they are about to leave. They are usually found either singly or in small family parties; and

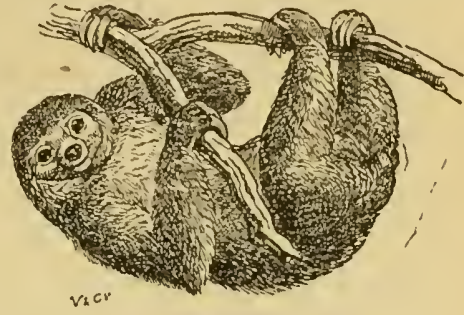

Fij. $\{7$--THREe-Toed Slotir

(Bradypus tridactylus). the females produce but a single offspring at a birth, which is fully developed, except in the matter of size, when it makes its appearance in the world.

The second family of the edentates is formed by the South American or true ant-eaters (Myrmecophagide), of which there are threo species, referable to as many genera; one of these being strictly terrestrial, while the other two are more or less arboreal in their habits. Ant-Eaters. So unlike are these creatures, botll as regards external character and the structure of their skeleton, to the sloths, that it is at first sight difficult to believe that there is any very intimate relationship between the two groups. And, indeed, were it not that in the superficial deposits of Soutl Anerica thero occur remains of certiin extinet edentates known as ground-sloths (of which the gig intic Megalotherium is a familiar example in our museums), forming to a great extent a group intermediate between the sloths and the ant-eaters, it would be difficult even for zoologists to fully realise how intimate this relationship really is. Taking the existence of these extinct connecting links for granted, it may be noticed that in place of the short and rounded head of the sloths, the ant-eaters have the head and skull more or less elongated and narrow, while the slender jaws are entirely toothless, and the tongue is lonr, cylindrical, and capable of being protruded far in advance of the lips. The degree of elongation of the skull is, however, by no means the sime in all the members of the group, the maximum derelopment in this respect being exhibited in the case of the great anteater. Still more striking is the difference in the structure of the feet in the two groups. In the great ant-eater, for instance, the forc-foot is furnished with tive complete toes, the middle one of which is much larger and more powerful than the rest; and all but the fifth, or outermost, are furnished with strong claws. In this genus there are also five toes to the hind-feet; but in the third representative of the family there are only four claws to each foot. When the great ant-eater is walking, only the extreme outer side and part of the upper surface of the fore-foot is applied to the ground; but in the hind-foot, which has the fourth toe the largest, and claws to all five, the whole of the short and wide sole touches the ground in the ordinary manner. An important point of distinction from the sloths is that the bones of the terminil joints of the fore-feet have a longi- 
tudinal slit in the middle of the upper surface; and in all cases the limbs are relatively short and stout. Unlike the sloths, tho ant-eaters have a very long and powerful tail, which in two of the species is endowed with the power of prehension, as indeed is the case with so many of the animals inhabiting the dense forest-regions of tropical Anerica. In correlation with their insectivorous habits, the stomach of the ant-eaters is perfectly simple in structure, and the brain is more convoluted than in the sloths. Two out of the three species have the fur of the body marked by dark and light longitudinal bands or patches, and it is noteworthy that this type of coloration approxinuates to that obtaining in the under-fur of the sloths. In order to procure their insect-food, which mostly comprises ants and termites, the long worm-like tongue, which can be protruded with great rapidity from the tubular mouth, is provided with a viscid secretion.

The largest and most specialised member of the family is the great anteater, or tamahoa (Myrmecoplacega jubata), which is terrestrial in its habits, and is easily recognised by the

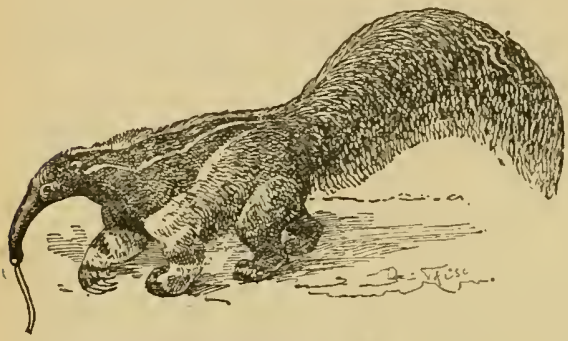

Fig. 98,-Great Ant-Eater (Myrmecophaga jubata). exceedingly long and slender liead, passing almost imperceptibly into the neck, the minute ears, the fringe of long hair clothing the fore-limbs and flunks, and the huge nuss of still more elongated hairs covering the tail. This ant-eater, which attains a length of about $4 \mathrm{ft}$. to the root of the tail, is distributed over the whole of the tropical districts of South and Central America, frequenting either damp swampy forests or the margins of

rivers. Like the other species, it is strictly nocturnal in its habits, and but a single offspring, which is carried for some time on the back of its parent, is produced at a birth. Next in point of size is the lesser ant-eater, or tamandua (Tamandua tetradactyla), which scarcely attains half the dimensions of its larger cousin, and is distinguished by the uniformly short fur, shorter head, the much longer ears, and the cylindrical prehensile tail, which is naked both at the tip and along the whole of the lower aspect. In the fore-feet the claw of the fifth digit is rudimental and concealed beneath the skin, while that of the third is nuch larger than either of the others, the hind-foot being generally similar to that of the larger species. The tamandua has approximately the same geographical distribution as the latter, from which it differs in being mainly arboreal in its habits. The most sloth-like, and at the same time the most diminutive member of the group is the two-clawed ant-eater (Cycloturus didactylus), which does not exceed a rat in size, and has the sloth-like habit of hanging back downwards from the boughs of trees, to which it clings by its long, hook-like claws. In the shortness of the head this species likewise presents a decided approximation to the sloths. While the front paws have four toes, only the first and second of these-that is to say, those corresponding to the index and middle fingers of the human hand-are furnished with claws; but the four toes of the hind-foot are all clawed, and as they are 
placed close together and the claws are of nearly equal length, they collectively form a hook-like organ not unlike the foot of a sloth. From the other ant-eaters this species diflers in the uniformly foxy-red lue of the short silky fur. In its skeleton it differs from the other two members of the group in possessing collar-bones, in which respect this species once again approximates to the sloths. In other ant-eaters the ribs are unusually broad, but in the present species this character is so exaggerated that they almost come into contact with one another, and thus nearly enclose the body in a solid bony casque. Thoroughly arboreal in its mode of life, and furnished with a highly prehensile tail, the two-clawed ant-eater is restricted to the hottest regions of America, ranging from Northern Brazil through Peru and the Guimas to Central America.

The development of a bony shield composed of isolated plates welded together by their edges, or overlapping like tiles on a rouf over more or less of the upper surface of the body, serves to differentiate the armadillos and their tiny relative the pichiago not only from all other existing edentates, but likewise from other

Armadillcs. mammals. All these animals collectively constitute the family Dasypodida, which is sufficiently distinguished by the aforesaid bony armour. In ordinary armadillos the armour is divided into two solid shields, one of which protects the shoulders, and the other the haunches, while between these are a variable number of movable transverse bands, permitting the animal to bend its back to a smaller or greater extent, and in one case even allowing the assumption of a completely ball-like form. Both in the front and hind shield the constituent plates are polygonal in form, and articulate with one another immovably by their edges; but in the movable bands they are tilelike and overlapping. The fixed shields and movable bands collectively constitute the carapace. The component plates are marked by a characteristic sculpture, which varies much in the different genera, and may consist either of raised pustules or minute punctures; and each plate is overlaid by a thin horny shield. MIore or less abundant hairs grow from the skin at the junction of the plates of the carapace; and occasionally these are so abundant and luxuriant as practically to conceal the latter from view. A small shield of polygonal bony plates, with their edges in apposition, serves to protect the upper surface of the head; while the tail is usually defended by a similar type of armour, which may either take the form of oblique rows of plates or tubercles, or of a series of rings of gradually decreasing diameter, severally cumposed of the same plates. Irregular bony plates likewise protect the short and powerful limbs, of which the front pair are provided with strong claws adapted for digging. In the fore-limbs the claws may vary in number from three to five, whereas the much smaller and weaker ones of the hind-foot are always the latter number. Armadillos have moderately long and more or less depressed heads, sharply pointed in front, and armed with a rather small number of simple peg-like teeth. They have long tails, fully dereloped collar-bones; and the bones of the arm and fore-arm are specially expanded and modified for the purpose of digging. Their tongues, although relatively long, have not the extreme elongation characterising the ant-eaters. Armadillos have a much more extensive geographical range than either of the preceding families of edentates, ranging from Patagonia to Central America, and one species at least reaching as far northwards as Texas. Although different species or genera are confined to different localities and situations, nembers of the group are to be met with 
alike on the grassy pampaz of Buenos Aires, the sandy plains of Mendoz and the tropical forests of Brazil. While a few are diurnal, the majority are nocturnal in their habits, and a!l are burrowers. In many districts the Argentine pampas is perfectly honeycombed witi the long burrows of various kinds of armadillos. Armadillos live chiefly upon insects, worms, and molluscs, but one species at least feeds largely upon carrion, although this is probably an acquired habit, due to the large number of carcases of liorsez and cattle which nowadays strew the pampas. In their movements they are extremely swift, starting off with a tremendous rush when disturbed while feeding at night, and requiring a good dog to keep pace with them. Whereas some species run on the tips of their claws, with the body raised high above the ground, other s carry the carapace lower. The rapidity with which an armadillo will bury itself in the soft ground of the Argentine pampss must be witnessed to be credited. Most of the true armadillos have niedium-sized or rather large ears, placed far apart from one another; the first and sccond claws of the fore-foot are, if present at all, slender; and the breast of the female bears a single pair of teats.

The first genus (Dasypuss) includes the typical armadillos, of which the sixbanded species (D. sexinctus) of Brazil, and the Argentine peludo, or hairy

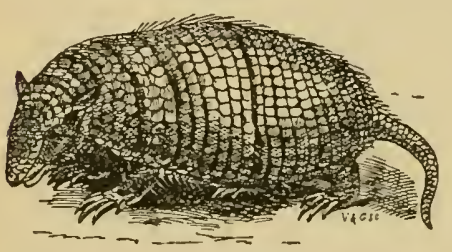

Fig. 99.-II villosus). armadillo (D. rillosus), are well-known examples. These animals have from six to eight movable bands in the carapace, which is more or less depressed with strongly serrated margins. The ears are small or moderate, and the head is very broad and much depressed, with the muzzle comparatively blunt. The tail, which is shorter than the head and body, is plated with distinct rings near the root. In the fure-foot the first toe is the slenderest of all, and the second the longest. The teeth, which are relatively large, are generally nine above and ten below, the first upper pair being usually implinted in the prenaxillary or anterior jaw. bones. Some of the species are of considerable size, the head and body in the typical one measuring as much as 16 inches. In the Argentine the peludo is now mainly nocturmal, and feeds largely upon the carcases of cattle, beneath which its burrows are frequently formed. The much snialler pichi (D. minutus) of the same districts is, however, chiefly a diurnal animal. In spite of having but $t w o$ teats, the female produces from two to four young, which are born blind, with the armour already developed, but in a soft and flexible condition. The second genus, of which the broad armadillo or tatouay (Lysiumes unicinctus) of Brazil, Paraguay, and Surinam is the typical representative, differs from the last by the greater number of movable bands in the carapace, which are either twelve or thirteen. The teeth, of which there are either eight or nine pairs in each jaw, are relatively smaller than in the first genus, and in the upper jaw do not extend so far backwards on the sides of the palate. The tail, also, is almost devoid of bony plates, of which it has only a fer on the under side and near the tip. The chief characteristic of the fore-foot is the great size of the curved claw borne by the third toe; the fourth and fifth toes having similar but smaller claws, while those of the first and second are long and slender. In the hind-foot 
the cliws take the form of short and blunt nails. The plates of the carapaco are ornamented by an indistinct granular sculpture. In size the tatouay is intermediate between the six-binded armadillo and the next species. The great number of the teeth-of which there are from twenty to twenty-five pairs - at once serves to distinguish the giant armadillo (Priodon giques) of Brazil and Surinam from all its relatives. It is also the largest liring member of the family, the head and body measuring about $3 \mathrm{ft}$. in length. The number of moviable bands in the carapace is thirteen; and in the anterior and posterior shields of the carapace the plates are arranged in rows very similar to those of the movable bands which they resemble in sculpture. Structurally the feet are very similar to those of Lysineres, but the claw of the third toe in the front foot is relatively larger, while that of the fifth is very small. The tail, which is nearly equal in length to the carapace, is, however, of a totally different type, being completely invested with large plates arranged in spiral rows. Very different are the three small species of three-banded armudillos (Tolypentes), in which the fore and aft shields of the carapace are very greatly developed and the movable bands reduced to three. The plates on the carapace are small and tuberculated, the shield on the head is very large and flat, and the extremely short tail is covered with prominent tubercles. As the borders of the carapace, which are smooth, are much produced on either side of the fore and hind limbs, these animals are enabled to roll themselves up into a complete although somewhat flattened ball; the shield of the head, by one side of which lies the tail, almost completely filling up the front and hinder notches in the carapace. The head is long and narrow, with the rather large ovate ears placed somewhat low down; while the jaws carry eight or nine pairs of upper and nine of lower teeth, which are of relatively small size and reach backwards to the hinder end of the palate. In the fore-foot the third claw is more developed than in any other species, the claws of the first and fifth toes being either rudimental or absent. The common species grows to a length of about fitteen inches, and is found in the pampas of Argentina, where, however, it now seems extremely rare. Trusting to their impassive power of defence, all the armadillos of this genus are diurnal and non. burrowing animals, generally lurking in the large tussocks of pampas-grass. When running they go on the extreme tips of their claws, and scuttle along at a great pace. The last genus of the true armadillos is represented on the Argentine pampas by the mulita (Tatusia hybrida), and there are other species in different parts of the continent, one of which ranges into Texas, while another from Peru is remarkable for the thick coat of fur which entirely conceals the carapace. These pretty little armadillos differ from the whole of the foregoing by the close approximation of the long mule-like ears (whence the name of mulita for the Argentine species), as well as by the presence of an additional pair of teats on the abdomen of the females, and also by the development of a set of milk-teeth. The seven or eight pairs of permanent teeth are very minute, and do not make their appearance till comparatively late in life. The long and narrow head is produced into a cylindrical and obliquely-truncated, somewhat pig-like snout. Extreme elongation and compression is the leading characteristic of the carapace, which has from seven to nine movable bands; the plates of the latter being marked by a V-shaped line of punctures, while the smaller ones of the solid shields have an elevated oval central area surrounded by an incomplete ring of small tubercles. The tail is surrounded by a series of bony rings, 
decreasing in size from root to tip, and thus reculls a partially opened telescope. In the fore-feet there are four long claws, of which the innermost are the largest; while in the five-clawed hind-feet the third is the longest and the fuurth and fifth the shortest. About $11 \mathrm{in}$ is the average length of the head and body of the mulita, but another species is somewhat larger. The mulita may be often found skulking among the tussocks of pampas-grass during the daytime, when, with the aid of a dog, it can generally be captured before it las time to make good its escape into its burrow. Not unfrequently when a Gaucho captures a mulita he crops its ears and turns it loose, such crop-eared specimens being at first rather a puzzle to the naturalist. In spite of the circumstance that carrion forms a considerable portion of the diet of these animals, roasted mulita is a favourite dish in the Argentine.

Quite different from the true armadillos are the beautiful little pichiciagos, or fairy pink armadillos, of which one species (Chlumydophorus truncutus) is locally distributed over the sandy districts of Western Argentina, while the second (C. retusa) is from the Bolivian highlands. From the armadillos these tiny little creatures differ by having the upper surface of the head and body covered by a continuous mantle, formed of quadrangular horny shields underlain by thin bony plates, and gradually widening from the front of the head to the hinder end of the body, where it is abruptly truncated. In the Argentine species this mantle is attached to the body only along the line of the backbone, its under surface being hairy; but in the Bolivian form (which is referred by some writers to a separate genus, under the name of $B u r$ meisteria) it is joined to the skin tliroughout its whole extent. The truncated hinder end of the body is protected by a solid bony shield with overlying horny scales; the short tail protruding through a notch in its lower border. The whole of the rest of the body is covered with long silky hair, which in the Argentine species is pure glistening white, while the mantle is pinkish. The minute ears are completely concealed by this fur; and both fore and hind feet have five claws, the front toes being comnected to the base of the latter, while those of the hinder pair are free. In length the Argentine species measures only about 5 in., but the Bolivian form is somewhat larger. Pichiciagos inhabit sandy districts, where they excavate burrows with marvellous rapidity; and it is believed that the hinder shield is used as a rammer to close the burrow when tenanted, the creatures apparently making their exit by digging a fresh passage.

\section{ORDER X.-EFFODIENTIA.}

\section{Aard-Varks and Pangoliss.}

Althovgh, as stated above, the animals known as aard-rarks and pangolins are generally included among the Edentata, they have little in common with the typical representatives of that order. Hence they are assigned to a distinct ordinal group termed the Effodientia. That group is typified by the aardvarks, and is only provisionally regarded as comprising the pangolins, which are perhaps entitled to constitute an order by themselves. The Effodientia resemble the Edentata in never having front teeth; but differ 
from all the latter in the absence of additional articular facets to the hinder trunk-vertebre. More definitely they my be distinguished from the edentates as follows. When teeth are present these aro of a totally different type to those of the latter, and when tecth are absent the hinder trunkrertebre lack the aforesaid additional articulations which aro present in the toothless edentates.

The aard-rarks, or ant-bears (Orycteropodidce), forming the typieal members of the order, are now represented by two closely allied species of the genus Ony teropus, buth of which are confined to the kithiopian region. There is, however, evidence that during the Aard-Varks. Tertiary period aard-rarks existed in the south of Europo.

The existing forms are uncoutl and strange-looking animals of large size, with the skin nearly naked, or sparsely covered with bristly hairs. The long and narrow head is furnished with greatly elongated, slender, and pointed ears, and torminates in a some what pig-like snout, in which are perforated the circular nostrils, while the mouth is tubular. The neck is short, the fore-quarters are comparatively short, the back is much arched, and the tail, which is nearly as long as the body, is thick, cylindrical, and tapering. In the short but powerful fore-limbs, the four

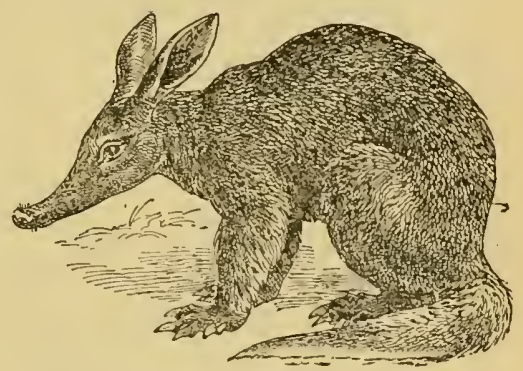

Fij.100-Aard.Vark (Orycteropus capensis). toes are furnished with medium-sized strong nails; while the hind-feet have five nearly equal toes, each bearing a nail. When walking, the entire soles are applied to the ground. Adult aard-varks usually have five pairs of cheek-teeth in each $\mathrm{j} i \mathrm{w}$, althougl from eight to ten pairs of upper teeth, and eiglit of lower ones are developed. Of these all but the last three have milkpredecessors, which nerer cut the gum. These teeth have no enamel, and are composed of a number of adherent polygonal denticules, traversed by a scries of radiating tubes; such a structure being quite unparalleled in the mammalian class. The tongue is cylindrical and extensile. In total length these animals may measure as much as $5 \mathrm{ft}$. In habits, aard-varks aro nocturnal, burrowing, and insectivorous, feeding chiefly on ants and termites. Their powers of digging are very great, and in Suuth Africa their burrows are generally constructed in the neighbourhood of termite hills.

Very different both in external appearance and internal structure are the pangolins, or scaly ant-eaters, of the warner parts of the Old World, constituting the family $M$ (cnide, and all included in thesingle genus $M$ anis. The most peeuliar and striking feature of the animals is the investiture of the head, body, tail, and limbs in a complete Pangolins. coat of overlapping horny scales, so that the general appearance is much like the cone of a spruce-fir. Teeth aro wanting; and the skull is long, conical, and devoid of a zygomatic or cheek-arch, with a very slender lower jaw. 'l'he eyes are minute, and the external conchs of the ears rudimental. A few bristly hairs often occur between the seales, and the latter do not extend on to the under surface of the body, or the immer sides of the limbs. The long and worm-like tongue can be protruded a great distance in front 
of the tubular mouth. Eich of the limbs is furnished with five toes, terminating in long powerful claws, of which the supporting bones are longitudinaliy split at their extrenities; the front claws being much larger than the hinder ones, and the third toe in each foot superior in size to the rest. In walking, the front claws are bent beneath the soles, so that the weight of the body is mainly borne on the upper and outer sides of the third and fourth digits; but in the hind-limbs

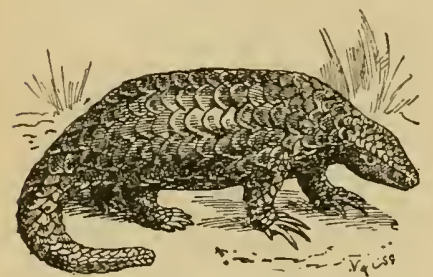

Fig. 101.-A. Paxajhix (Manis). the whole sole of the fuot is applied to the ground in the ordinary manner. The tail may be either long or medium. Collar-bones are wanting in the skeleton. Pangoling are confined to south-eastem Asia, and Africa south of the Sahara; the largest species, which measures upwards of $6 \mathrm{ft}$. in total length, being an inhabitant of West Africa. They resemble the axrd-rarks in feeding on ants and termites, which are licked up by the extensile tongue, after their hillocks have

been laid open by the powerful claws of these animals. They are likewise nocturnal, and have the power of rolling themselves up into a ball, when they are completely secure from most enemies. Some of the African forms are more or less arboreal, but all the rest are purely terrestrial. Apparently only a single young is produced at a birth, for the nourishment of which the breast of the female carries a pair of teats.

\section{ORDER XI.-MARSUPIALIA。}

\section{Pouched Mammals.}

THE whole of the ten mammalian orders treated of above are collectively cliaracterised by the circunsstance that, during intra-uterine Iife, the bloodvessels of the foetus are connected with those of the parent by means of a vascular organ known as the placenta. And it is due to this communication between the foetal and maternal circulations that the young are born in the more or less highly-developed state characteristio of the whole assemblage. Collectively, the whole ten orders form a sub-class, known indifferently as the Eutheria or Placentalia. On the other hand, in the mammals forming the subject of the present section, a placenta is never developed, and there is consequently no direct connection between the circulatory systems of the parent and offspring, so that the young are produced in an exceedingly imperfect state of derelopment. To this group, which forms a second subclass, the name of Metatheria, or Implacentalia, is applied, while it is sometimes known as the Didelphia, on account of the completely double uterus or womb, and thereby contrasts with the Eutheria, in which the uterus is either single, or its two branches are united at their outlet. Hence the name Monodelphia is not unfrequentiy given to the first of the two sub-classes.

Whereas the Placentals, as already indicated, are split up into the ten 
orders described above, no such dirision seems practicable in the case of the Implacentals. Cunsequently the whole of them may bo included in the single order Marsupialia, which may bo popularly known either as Marsupials or Pouched Mammals.

Both the technical and popular names of the group aro derived from the rery general presence of a more or less fully-developed pouch ou the abdominal surface of the body of the female, into which the imperfectlydeveloped young are transferred at birth, and whero they remain until sufficiently advanced to take care of themselves. This pouch is, lowever, by no means universally present in the orcler, and cannot, therefore, bo taken as its distinctive cliaracter. The imperfect state of development of the young at birth is, however, absolutely distinctive of all Marsupials; and when born the fotuses resemble helpless and nearly motionless sacs of flesh, which are extremely sinall in proportion to the size of the parent, those of the large kangaroos being no larger than a man's thumb. These helpless little abortions are transferred by their parent immediately after birth to her teats, which are always situated vithin the pouch whenever that appendage is developed. Of course such ill-developed creatures can do nothing in the way of sucking by themselves, and Nature has accordingly provided a special arrangement by means of which their wants can be supplied. This arrangement takes the form of special muscles surrounding the milk glands of the female, which by a spontaneous contraction compress the glands, and thus force the nourishing Huid down the throats of the immovable, naked young. In order to prevent the helpless young from being choked as they liang to the teats of the mother; the upper part of the larynx, or superior extremity of the windpipe, is so elongated as to project through the fauces, or hinder apertures of the mouth, and thus reach the internal nostrils. In consequence of this arrangement a closed passage is formed from the nostrils to the lungs, so that the foetus can breathe while the milk flows down its throat. The young Marsupials thus nourished hang on to the nipples of the mother until their bodies and limbs are sufficiently developed to enable them to more about by themselves; but, as in the case of the kangaroos, they frequently resort to the pouch as a haven of refuge from danger for a long time after they have made their appearance in the outer world, and it is by no means uncommon for the pouch to be tenanted by helpless foetuses and half-grown young. Except in the thylacine, where they are reduced to a rudimental condition, the pouch is supported by a pair of marsupial or epipubic bones attached to the front edge of the lower part of the pelvis; these bones being also present in the male.

In all the Pouched Mammals the brain is characterised by its proportionately small size, and the slight development of the convolutions on its surface. As already mentioned, the womb or uterus is double throughout its entire length; and in most cases the lower border of the angle, or hinder extremity of the inferior margin of each branch of the lower jaw is more or less strongly bent inwards. Although there is great variation, both numerically and structurally, in the dentition, yet there is one feature in regard to the teeth characteristic of the order generally. This relates to the mode of succession and replacenent of the teeth. Whereas in the great majority of terrestrial Placentals the whole or the greater number of the teeth in advance of the true molars (which in that group are typically three in number on each side of each jaw) are preceded by milk or baby-teeth, in the Pouched Mammals only one tooth on each side of the jaws has such deciduous predecessor, and even this is not invariably cleveloped. Regarding the 
dental succession in the order, the writer may quote the following passage from a work he has devoted to the group:- "The tooth thus replaced hias been hitherto generally regarded as corresponding to the last or fourth milkmolir of the higher mammals, while the apparently replacing tooth has consequently been identified with the last or fourth pre-molar of the sime. Recent researches have, however, tended to show that this is not a case of true replacement at all, and that the tooth, which makes its appearance late in life, is really a retarded pre-molar, which will consequently be the fourth of the full series, while the apparently replaced tooth is really the fifth. Be this as it may, the mode of succession is peculiar and unicque ; and it nay be still convenient to speak of the replacing tooth as the fourth pre-molar, and the one it replaces as the fourth milk-mular." It should be added that some authorities consider the whole of the teeth of a Marsujial in advanco of the molars as corresponding to the milk-series of the l'lacentals ; and also that, when the full series is developed, there are four pairs of molars in each jiw in the present order.

That the Pouched Mammals are inferior in their organisation to the Placentals, is admitted by all; and they are also, as shown by their history in past times, among the oldest, if not actually the oldest, representatives of the entire class. There is, however, some difference of opinion among zoologists as to whether this group includes the ancestors from which the higher mammals have originated.

In regard to their geographical distribution, the Marsupials present some very curious features. At this present day their head-quarters are the Notogivic realm, comprising Australia, Papua, Celeles, and the other islands lying to the eastward of Wallace's line. And it is here that they attain their maximum development. Whereas, however, they form the great bulk of the mammalian population of Australia and Papua, in Celebes and the adjacent islands they constitute only a small minority of the fauna. Elsewhere, Pouched Mammals are found only in America, where they are represented by the opossums and selvas; and liere they are chiefly restricted to South and Central America, constituting the Neogreic realm, only a single species, which is evidently an immigrant from the south, inhabiting the northern half of the continent. During the Secondary epoch of geological history, Marsupials of extinct generic types were abundant in the northern hemispliere, while in the succeeding Tertiary epoch opossums flourished in Europe and North America. It is thus evident that the ancestral Marsupials were driven from the northern hemisphere by the incoming of the higher forms of mammalian life to find a secure refuge in southern islands. And it further appears that while in South America they have had to compete with numerous types of Eutherians, in Australasia they have had the land pretty much to themselves, and hare there been enabled to attain the wonderful development so especially characteristic of that region.

The kangaroos and their immediate allies form a large family (Macropodiche) belonging to the first of the two great subordinal divisions of the Pouched Mammals, technically known as the

Kangaroo Diprotodontia. This division, which is mainly confined Tribe. to the Notogric realm, is specially characterised by the number of the front or incisor teeth, of which there are never more than three pairs; the usual complement being three pairs in the upper jaw and one in the lower. The innermost, which are in some cases the only pair of incisors in both jaws, are always large, with sharp, cutting 
edges, while generally the upper canines, if present at all, ate small, and the lower ones are absent. Among the cheek-teeth, the four pairs of molar-teeth have broad, quadrangular crowns, generally surmounted either by a pilir of transverse ridges or by four blunt and rounded tubercles. Such a type of dentition is adapted for a regretable diet, which is charac. teristic of the diprotodonts generally.

From the allied families the kangaroo tribe are specially distinguished by possessing rooted teeth, among which are three pairs of upper and one of lower incisors, the upper incisors being nearly vertical, while the large lower pair project nearly horizontally forwards, and in some cases are capable of working against one another like the blades of a pair of scissors. A small upper canine may or may not be present. The five-toed fore-limbs are in general much shorter and weaker than the hinder pair, while the latter are generally four-toed, and have the digit corresponding to the fourth of the typical series of five greatly developed at the expense of the other three, and forming the sole axis of support for the limb. Of the smaller toes, the second and third, or those on the inuer side of the enlarged digit, are enclosed in a common skin, from which feature the hind-foot of this fanily is termed syndactylous. The great relative size and strength of the hind-limbs of the more typical members of the family is correlated with the upright position of the body, and the mode of progression is by enormous leaps. In repose the body is swung on a kind of pivot supported by the thigh-bones, the feet resting on the ground, and the large and thick tail serving to form the third leg of a tripod. Among the smaller forms the tail may be prehensile; and there are a few arboreal types in which the disproportion between the fore and hind limbs is very much less strongly marked than is the case with tlie typical kangaroos. All feed entirely on grass or leaves; and the stomach, as is so frequently the case with vegetable feeders, is of a somewhat complex type. In the females the opening of the pouch is forwards, so that when it contains young, these are in an upright position. The members of the family are confined to Australia, Tasmania, and New Guinea, with some of the neighbouring islands, such as the Aru group; the true kangaroos, which generally associate in large herd, or "mobs," and frequent either open grassy plains or timbered districts, being the largest existing members of the order.

The true kangaroos and wallabies, constituting the genus $M$ (acropus, are the typical representatives of a sub-family (Mucropodine) characterised by the sub-equality of the claws of the fore-feet, whicl are never very large, and the generally elongated and pointed ears. In the dentition the last upper pre-molar is placed either imnediately in the line of the molars, or is at most but slightly everted; and the molars, which increase regularly in size from the first to the fourth, are transversely ridged. As a rule, the upper canime is either very small or wanting, and the central pair of upper incisors are but slightly larger than the other two. From the other members of the sub-family the numerous species contained in the genus MIcropus have the nose naked, the ears large, and the fur on the nape of the neck nearly always directed downwards. The clisproportion between the length of the fore and hind limbs is very strongly marked; and the large claw of the hind-foot is always larger than the naked terminal pad on the sole of the same. The tail is thick, tapering, and evenly haired throughout; and there are four teats in the pouch of the females. There are upwards of trenty-tinree species included in the genus, which may be arranged under 
the heading of kangaroos proper, and larger and lesser wallabies. Whilo the great g'ey kangaruo (.1\%. gigunteus) lias the stature of a man, some of the smaller wallabies are no bigger than a rabbit. The great majority of the species are confined to Australia and Tas-

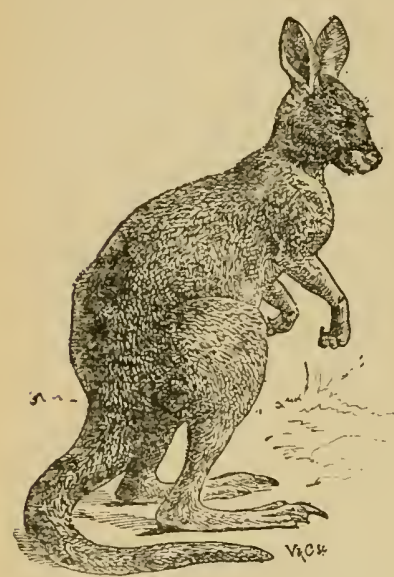

Fig. 102.-BENNET'S WALLABY (Iacropus ualabalus). mania, but the agile wallaby $(M$. agilis $)$ is common to Australia and New Guinea, while the Aru Island wallaby (M. brunii) is restricted to the Aru and Kei Islands, and the sombre wallaby ( $M$. browni) is conmon to New Guinea and the New Britain group. From the true kangaroos the larger wallabies differ by their more brilliant coloration, and the presence of a longitudinal external bridge connecting the anterior ledge of the molars with the first of the two transverse ridges, coupled with the absence of a median longitudinal bridge between the same ledge and ridge. The habits of kangaroos and wallabies have been so often described as to render a repetition unnecessary.

From the preceding genus the six species of rock-wallabies (Petrogale) are distinguished by the shortness of the large claw of the hind-foot, which only slightly exceeds the naked pads on the sole in leugth, and by the long cylindrical tail being thinner, more thickly haired, and tufted at the tip. These wallabies are restricted to the Australian mainland, and differ from the true wallabies by inhabiting rocky districts instead of open plains. Their climbing and leaping powers are highly developed; but the tail is employed solely as a balincing organ, and never as a support to the body. The presence of a horny spur or nail of unknown function at the tip of the long, tapering, and short-haired tail is a sufficiently distinctive feature of the three nail-tailed wallabies constituting the genus Onychogale. In addition to this, these animals have the nose hairy (with the exception in some cases of the base of the partition between the two nostrils); while the large claw of the hind-foot is long, narrow, compressed, and sharply pointed. There is also a difference in the form of the upper incisor teeth. Like the rockwallabies, the members of this genus are restricted to continental Australia. The same is the case with the three species of hare-wallabies (Lagorchestes), in which the nose is entirely or partially covered with hair, the large claw of the hind-foot is long, stout, and not concealed by hair, while the rather short tail is evenly haired throughout its length. In some respects forming a connecting link between the genus Macropus and the under-mentioned sreekangaroos, the three species of dorca kingaroos (Dorcopsis) are confined to New Guinea, and present the following distinctive features. The excess in the lengih of the hind over the fore-limbs is much less strongly marked than in the true kangaroo and wallabies; there is a large and broad portion of the nose completely naked; the head is long and narrow, with small ears; the fur on the nape of the neck is entirely or partially reversed, so as to be directed forwards towards the head. In both jaws the fourth pre-molar is a compressed cutting tooth, greatly elongated, from before backwards, and 
having its surfaces marked by upright grooves, and a distinct ledge on the base of the inner side. The direction of the two series of cheek-teeth is nearly parallel. Although it is known that they are not arboresl, nothing definite has been ascertained in regard to the habits of these rather small kangaroos.

More remarkable than all are the tree-kangaroos (Dendrolagus), of which three species are known from New Guinea, and two from Queensland. In general build these animals are of fairly normal proportions, and quite unlike ordinary kangaroos, the fore-limbs being strong, stout, and nearly equal in length to the hinder pair. The naked portion of the nose is broad and covered with sparse hairs; and the fur on the nape of the neck is reversed, as is sometimes also that of the back. In the broad hind-foot the two united inner toes are not very markedly smaller than the other two; while the stout and strong claws of the latter are nearly as curved as those of the fore-foot. The elongated tail is thickly and evenly haired. One of the species measures 26 in. to the root of the tail. Regarding the habits of one of the Queensland species, Mr. E. R. Waite, writing in the "Proceedings of the Linneean Society of New South Wales," observes that "the native name is mapi, and the aninials are difficult to procure, as the blacks esteem them as a delicacy, and only surrender their captures when compelled. When a mapi is

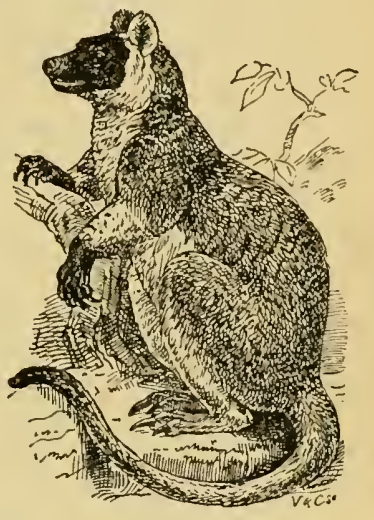

Fig. 103. -Trea Kangaroo (Dendrolagus). discovered, a fence 5 or $6 \mathrm{ft}$. in height and several feet in diameter is built of rattan and bushes round the tree. Some of the blacks enter the enclosure, ascend the tree, and drive the animal down. It usually jumps to the ground, often from a height of $20 \mathrm{ft}$. Should it elect to descend the trunk, it does so tail-foremost. On reaching the ground the animal is eventually caught by the men surrounding the enclosure, generally by the tail, which menber is dragged through the fence, the unfortunate mapi being despatched with blows from a nulla-nulla. The blacks will not venture within the fence on account of the dread in which they hold the powerful claws of the animal. The natives who hunted for Dr. Lumholtz the discoverer of the first example of this species made known to science] called the animal bungary, and adopted a somewhat different method of capture." Regarding the second Queensland species of the genus ( $D$. bennettianus), a correspondent wrote to Mr. Waite as follows:-"The native name of the climbing kangaroo is charibeena. The blacks hunt them with dogs and are very fond of the flesh. I had often heard the blacks talking about them, but though I have been here nearly ten years it was only about three years ago that I succeeded in obtaining one. In the daytime they are found among the top branches of the trees and come down in the evening to feed upon creepers, ferns, and fruit. I have found several down on the flat land, but as a rule they seem to be most numerous on or near the top of the hill ridges here, which are about 1500 to $2500 \mathrm{ft}$. high. When found in the daytime, the animals generally sleep with the heads 
hanging on the breasts between the fore-limbs, and the tail is used as a balancing pole. At first I could not induce the blacks to catch any of the charibeenas, as they said that a full-grown one would show fight, but when I went with then and caught the first one myself with a lasso they saw how easy it was, and have since always caught them in this manner, except when out of reach ; in this case they make the animal jump; as soon as it reaches the ground one boy holds its head down with a furked stick while another passes a bag over its hind-quarters and slips it over its head. The best time to hunt them is early in the morning while the scent is fresh. A dingo, or mongrel-the former preferred-is used, and follows the scent to the foot of the tree which the kangaroo has climbed to camp for the day. If the tree be a low one, it is tolerably easy to find the animal, but it often happens that they go from one tree to another before they find a suitable 'camp,' and then it becomes necessary for a native to ascend a high tree in the vicinity so as to be able to look down on the surrounding trees, as the kangaroo sits right out in the sun and is more easily seen from above than from below. If one approaches quietly, it is quite easy to catch the animal by the tail and slip it into a bag while up the tree; but the least noise rouses them, and it is surprising how quickly they can travel, jumping sometimes 20 to $30 \mathrm{ft}$. fronl one tree to another, and I have seen one jump fully $60 \mathrm{ft}$, from a high tree to the ground and not hurt itself at all. When jumping it seems always to land on its fore-feet, and though I have repeatedly shaken them down from great heights, I have never seen one injured, as they always, like a cat, fall on their feet. The tail is never used to hang by, only to balance with, though I have often seen one bend its tail over a branch while it reached down below the branch upon which it was sitting to secure some berries. These kangaroos can stiffen the tail so that it stands straight out like a rod. When caught and kept in captivity they soon become quiet and take readily to eating bread, sweet potatoes, apples, oranges, mangoes, and the rinds of sweet potatoes and yams; also the leaves of several of the eucalypti, white cedar, and many other trees, the names of which I do not know. In the scrub they seem to have a partiality for the bird's-nest fern, the moustera, and a small climber like the pepper-plant, and eat almost any of the wild fruits which are so plentiful here. The males are very pugnacious, and if two of them be put into an enclosure together will often fight until one is killed. They spar with the fore-paws in quite a scientific manner, uttering grunts all the time, till one sees an opportunity of closing with the other, when he makes straight for the back of the neck, and if he succeeds in getting a grip with his teeth, he shakes the other like a dog does a rat. Some of the old males have quite a harem, and keep their wives from straying apart, and do not let any other males go near them. I liare fuund several of these families numbering from three to five females and cue male. The young males, and also the very old ones, are generally found by themselves, or two or three of them together without any females. I think they breed twice a year, and have only one young one at birth. The kangaroos are most plentiful among rocky hills, where the scrub is thick and stunted, and though they feed both on the ground and in the trees and among rocks, I fancy that they feed mostly in the two latter places." With the single species of banded-wallaby (Lagostrophus fasciatus) from Western Australia, we again come to a genus in which the general build is the same as in Macropus; the nose being naked, the hind-feet covered with long bristly hairs by which the claws are completely hidden, and the back marked 
by dark cross-bands. The banded-wallaby is a comparatively small species, measuring only about $18 \mathrm{in}$. to the root of the tail.

Still smaller are the rat-kangaroos, of Australia and Tasmania, of which there are several distinct generic types, collectively constituting the subfamily Potoroince. Of this group the distinctive characteristics are as follows:-In size all the forms are small, and may be compared to hares or rabbits, the ears being usually snall and rouuded. In the fore-feet the claws are greatly elongated, those of the three middle toes being disproportionately larger than those of the other two; as in the Mucropodinu, there are only four toes to the hind-foot; and the long tail is hairy. In the dentition the upper canines are invariably present and generally welldeveloped ; the central pair of upper incisors have taller crowns than either of the other two ; the fourth pre-nolar, which is a compressed and trenchant tooth of great antero-posterior length, may either be set in the same line as the molars, or somewhat bent outwards in front; and the molars, which decrease in size from the first to the fourth, have tuberculated crowns. The three species of typical rat-kangaroos forming the genus Potorons vary somewhat in size, and have the nose naked, the ears very short and rounded, the front claws long and somewhat slender, the hind-limbs not very much larger than the front ones, the hind-feet very short, with naked and coarselygranulated soles, and the tapering hairy tail devoid of a crest. In the dentition the fourth pre-molar has from two to four vertical grooves. These rat-kangaroos, which generally inlabit scrub-jungle, have their leaping powers much less strongly developed than in the allied genera. In running, both fore and hind limbs are brought into action. Nearly allied in external character is the South Australian plain rat-kangaroo (Caloprymmus campestris), which is an animal of comparatively large size, with the nose and ears as in the typical genus, the front claws long and strong, the hind-feet relatively long, with coarsely-granular soles, and the tail thin, cylindrical, and covered evenly with short hair. While the last pre-molar is similar to that of the preceding genus, the skull is generally like that of the next. The four species of prehensile-tailed rat-kangaroos (Bettongia) are sufficiently distinguished by the feature from which they take their popular name. The hair on the tail is long, and forms a more or less distinct crest; the last pre-molar is much elongated, with from seven to fifteen distinctly-marked, oblique grooves on the sides; and the squared molars, of which the fourth is much the smallest, carry four tubercles. These little animals are completely terrestrial and nocturnal, using their prehensile tails solely for the purpose of carrying bundles of grass and twigs to their nest; sucl bundles being held by the tail being bent down over and round them. Three of the species are Australian, and the fourth Tasmanian. The last member of the sub-family is the rufous rat-kangaroo (Epyprymnus rufescens) of New South Wales, in which the nose is partially hairy, the ears are somew hat elongated, the hindfeet long, with narrow, granulated soles, and the tail evenly-haired. The long and narrow last pre-nolar has from seven to eight vertical grooves, but no inner ledge; and the molars are oblong, with the tubercles less distinct and tending more to form ridges than in the other genera, while the decrease in size from the first to the last is less marked. Like the other members of the group, this animal is nocturnal, but it is remarkable for its speed and the great length of its leaps when disturbed.

Of especial interest is the tiny musk-kangaroo (Hypsiprymnodon moschatus) of Northern Queensland, since it forms a connecting link between the 
kangaroo tribe on the one hand, and the phalangers on the other. Indeed, it is chiefly owing to the presence of a pocket-like pit on the outer side of the hinder part of the bone of the lower jaw that it is referred to the present rather than to the following family. It is regarded as representing a distinct sub-family (Hypsiprymnodontince) of the Macropodidee, characterised by the small, weak, and nearly equal-sized claws, the presence of five toes in the hind foot (the first of which can be opposed to the rest), the naked and scaly tail, and the oblique position of the short last pre-molar tooth. In size this creature is very small, with a rat-like bodily form, a completely bare nose, large, thin, and naked ears, the hind and fore limbs of nearly equal length, and adapted for walking, the first toe of the hind-foot elongated and without a claw, the fourth toe of the same not abnormally large, and the tail cylindric a and tapering, with some hair at the root. The musk-kangaroo is a partially arboreal animal, which is mainly diurnal, and frequents scrubs on the banks of rivers and in the coast-range. Either one or two young are produced at a birtl ; and the characteristic musky odour is more pronounced in the female than in her partner.

Owing to the intermediate characters presented by the musk-kangaron, the differentiation of the phalanger tribe (Phalangeride) from the Macropodidee is by no means so easy as would be the case were that

Phalanger creature non-existent. There are, however, two leading Tribe. features which may be regarded as absolutely distinctive of the former group. In the first place, each branch of the lower jaw-bone lacks the deep pocket-like pit on the outer side of its hinder extremity so characteristic of the kangaroo tribe; and, secondly, the aperture of the pouch of the female is directed backwards instead of forwards. Among other more or less distinctive features, the following may be enumerated :-Five toes are present in both the hind and fore feet, those of the latter being usually of nearly equal size ; while in those of the former the second and third are syndactylous, the fourth is the largest, the fifth but little smaller, and the first large, opposable to the rest, and terminating in a broad, clawless pad. With the exception of the koala, the tail is long and generally prehensile; and the stomach is simple. The dentition is extremely variable, owing to the frequent presence of a number of small functionless teeth in the front portion of the jaws. It may be said, however, that, as a general rule, there are three pairs of upper, and one of functional lower incisors, and that the latter never have the scissor-like action characteristic of the kangaroos. The last of the two or three pre-molars usually present is generally furnished with a rather sharp-cutting edge, and is placed obliquely to the line of the molars, with its front eoge everted; and the molars, of which there are usually four pairs, have either blunt tubercles, or sharpcutting crests. The family includes not only the animals properly known as cuscuses and phalangers (the mis-called opossums of the Australian colonists), but likewise the flying-phalangers, the kuala or native bear, and the longsnouted pouched mouse. The geographical range of this extensive family includes not only Australia, Tasmania, and Papua, but likewise Celebes, and some of the other Austro-Malayan islands. The koala and long-snouted pouched mouse are, however, exclusively Australian. All are essentially arboreal and nocturnal in their mode of life, most using their prehensile tails to assist in climbing, while a few are enabled to take (like the flying squirrels) long fiying leaps by the aid of parachute-like expansions of skin from the sides of the body. The great majority of the phalanger tribe are vegetable 
feeders, subsisting nainly on fruits and leaves; but a few consume insects, which form either the whole or a portion of their diet, and some aro carnivorous.

The peculiar animal known as the koala (Phascolaretus cincreus), which presents some external resemblance to a small bear, is the sulo reprosentative of a sub-family (Phescularctince) characterised by the following distinctive features:-The tail is absent, the muzzlo short and broad, the tongue non-extensile, the cheeks furnished with pouches for the storage of food, the intestine provided with a crecum, or blind appendage, the teeth relatively large, and only a single pair of pre-molars in the upper jaw. In size the koala is a rather large animal, measuring about $32 \mathrm{in}$. in length. Its build is stout and clumsy, and the thick woolly fur is generally greyish above and whitish below. The large ears are thickly haired and ragged at the edges; the front toes are sub-equal in length, the fourth being the longest and the first the shortest, while both the first and second can be opposed to the other two. The strong claws are thick and sharp, and in both the fure and hind limbs the soles of the feet are simply granulated, and have no striated pads. The female has a single pair of teats. In the skeleton there are eleven pairs of ribs, and the

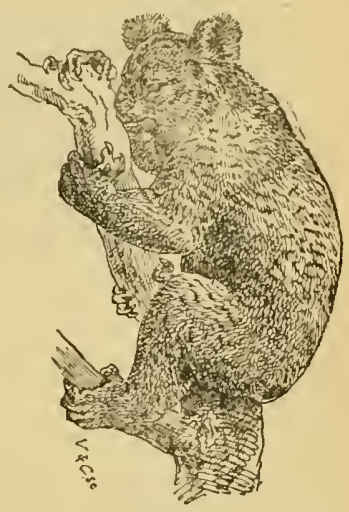

Fig. 104.-Koatd (Thascolarctus cincreus! upper molar teeth have short, broad, and squared crowns, bearing curved longitudinal crests, of which the convexity is directed outwards. The koala, which is confined to Eastern Australia, is a dull, sluggish creature, addicted to crawling on the stems and branches of gum-trees in a deliberate lazy manner, and feeding mainly on leaves and flowers. During the daytime it generally lies asleep in the hollow of some forest giant, but at night prowls among the topmost branches in search of food, the females carrying their offspring securely perched on their backs, where the woolly fur affords them a secure foothold. Only a single young one is produced at a birth, and the adults seem to be more or less completely solitary animals.

The second sub-family (Phalangerinoe), which includes all the other members of the family save one, may be defined as follows:-The tail, which is always well-developed, is generally prehensile, the muzzle is short and broad, the tongue is incapahle of extension, there are no chetk-pouches, the intestine has a cecum, the stomach is simple, and the teeth are cumparatively large. The first and ts pical genus (Phalanger) is represented hy the cuscuses, of which there are five species, ranging from Celebes and the M'luccas to Australia and New Guinea. They are rather large, or medium-sized, somewhat cat-like animals, of stout build, with thick and woolly fur, which may be either coarse and wiry, or fine and silky, and moderate-sized or small ears. In the fore-feet the toes are nearly equal in length, their relative lengths being in the order $4,3,5,2,1$. The long claws of all the feet are stout and curved, and the naked soles are striated, with large and ill-defined cushion-like pads. The prehensile tail is stout and strong, with its terminal portion naked, and either smootl or granulated. Two pairs of 
teats are borne by the female. Cuscuses are slow and sleepy animals, completely arboreal and mainly herbivorous in their habits, passing the day curled up asleep among the densest foliage of forest trees, and only be-

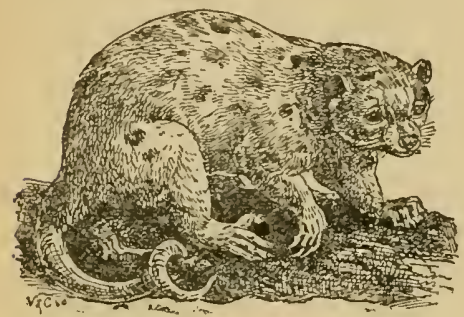

Fig. 105,-Spotted Cuscers (I'halanger maculatus). coming active as the shades of evening approach. A great amount of variation obtains in the coloration of the different sexes and individuals of the same species, while there is frequently some difference in the tecth. II hereas in the black cuscus of Celebes $(P$. ursiuns) both sexes are of a uniformly dark blackish brown colour; in the widely distributed spotted cuscus ( $P$. maculatus) the sexes are generally different, and the coloration takes the form of various combinations of white, rufous, and black, the females being generally grey and black, while the

smaller males are usually spotted, although occasionally they resemble an ordinary grey female, save for a few indistinct whitish spots on the flanks and back. Nearly allied to the cuscuses are the true phalangers (Trichosurus) the opossums of the colonists-of which the two species are restricted to the Australian mainland and Tasmania. These also are large, stoutly-built catlike animals, with thick, woolly fur, and short or medium ears. The front toes may be distinguished from those of the cuscuses in that relative lengths follow the order $4,3,2,5,1$; the claws being large and strong, and the soles of the hind-feet densely haired beneath the heel, but elsewhere naked, and furnished with low, rounded, ill-defined pads. In the powerful prehensile tail the terminal third or half is bare inferiorly, and the extreme tip devoid of hair all round. A peculiar gland is situated in the centre of the chest. Among the teeth, the nolars have four cusps, tending to unite into a pair of transverse ridges; and the last pre-molar, which closely approximates to the corresponding tooth of Hypsiprymnodon, is large, placed obliquely, and marked by vertical groovings. The common phalanger ( $T$. vulpinus) takes up its habitation in the branches of the tallest red and blue gum-trees of the Australian and Tasmanian forests, passing the day in slumber, and wandering forth at night to brouse on their leaves, bulbs, and seeds. In climbing, they are much aided by their highly prehensile tails ; and on the rare occasions when they descend to the ground, it is probably for the purpose of drinking. In the breeding season, and less commonly at other times, phalangers utter a loud cry; and, as a rule, but one offspring is produced at a birth, although there

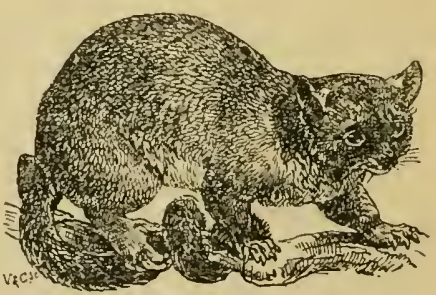

Fig. 106,-Commox Phalanger (Trichosurus vulpinus).

may occasionally be a pair. More numerous, and at the same time more widely distributed than the preceding, are the ring-tailecl-phalangers (Pserdochimus), of which there are eleven specific representatives, whose 
geographical range includes New Guinea, as well as Australia and Tasmania. While some are as large as the true phalangers, others are considerably smaller; but all possess short and rather woolly fur, and stout and medium sized ears, which are well haired on the hind aspect. The relative lengths of tho toes of the fore-foot hold the samo order as in the cuscuses; but the first and second toes resemble those of the koala in being markedly opposable to the ather three. In both feet the claws are of moderate length, and the bare soles are provided with large striated pads. The long and tapering tail has the lower surface of the extremity devoid of hair for a variable distance, and is highly prehensile. Four teats are present in the female. The upper molars are larere and oblong, with the tubercles modified into sharp cusps, from which proceed crescentic ridges ; the corresponding low er teeth having i nearly similar structure. In habits the common ring-tailed-phalanger differs from the true plalangers in that it prefers the so-called tea-scrub to the gum-trees; and also in that it generally associates in small colonies. These animals construct small nests, not unlike the drey of a squirrel; and whereas usually but a single young one is produced at a birth, occasionally as many as three may be found in the pouch. Nearly allied in the structure of its skull and teeth to the preceding genus is the taguan flying-phalanger (Petauroides volans), which is the first of three genera provided with a para. chute for the purpose of taking flying leaps from tree to tree. This species is of comparatively large size, measuring about $17 \mathrm{in.} \mathrm{to} \mathrm{the} \mathrm{root} \mathrm{of} \mathrm{the} \mathrm{tail,}$ while the latter is about $20 \mathrm{in.}$ in length. The fur of the body is remarkable for its long, soft, and silky character; the unusually large ears are oval in form, and bare internally, but hairy on the outside; and the skin of the flanks is expanded to form a parachute. The long claws are much curved and sharply pointed; and the tail is long, cylindrical, and evenly covered with bushy hair, its extreme tip being prehensile and destitute of hair on the lower surface. The habits of this and the other flying-phalangers are very similar to those of the flying-squirrels; and in Australia these animals are commonly known by the latter name. The present species is confined to Eastern Australia.

Two species of rather small phalangers, ranging from Northern Australia to New Guinea and the Aru Islands, constitutea genus (Dactylopsila) distinguished by the great elongation of the fourth digit of the front paws, and the conspicuous black and white longitudinal striping of the fur of the body. In these stripedphalangers, which are devoid of a parachute, the oval ears have nearly naked tips. In the front paws the length of the digits follows the order 4, 3, 5, 2, 1, the inequality in their lengths, as in the hind-feet-where the fourth and fifth are much elongated-being very marked. A prominent, soft pad is situated on the wrist; and the claws are long. The long and cylindrical tail is evenly bushy throughout, except the under surface of the tip, which is bare. The oblong molars bear four simple tubercles. Some degree of doubt exists as to the reason for the elongation of the fourth digit of the fore-paws. The suggestion has, indeed, been made that the elongation is for the purpose of extracting insects and grubs from beneath the bark and from crevices in trees, and consequently that these phalangers are largely, if not exclusively insectivorcus ; but other writers consider that they subsist on leaves. From the striped-phalangers the little Leadbeater's-phalanger (Gymnobelideus leadbeateri) of Victoria, which measures only $5 \frac{1}{2} \mathrm{in.}$ to the root of the long tail, differs by the normal proportions of the toes; the length of those of the fore-feet following the order $4,3,5,2,1$. The claws are rather short; the 
large ears entirely naked and untufted; and the tail, which exceeds the head and body in length by about an inch, is cylindrical and bushy. With the exception of the last, which is triangular, the upper molars are square, with rounded corners, and carry four tubercles.

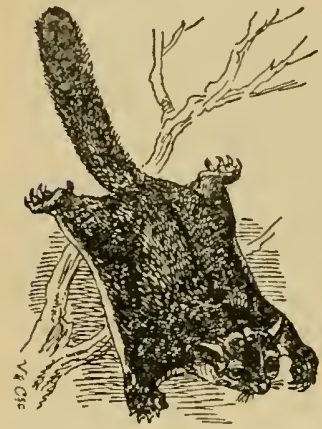

Fig. 16.7.-FLtiva-PHalanger (Petaurus breviceps). Several peculiarities characterise the skull. From their similarity in cranial and dental characters to the last, it is believed that the three species of flying-phalangers forning the genus Petaums have been erolved either from an ancestral form of Gymnobelideus, or some nearly allied type. These animals, which are of small or medium size, have a soft and silky fur, rather large, oral, and almost naked ears, and a broad parachute-like expansion of the skin of the flanks. In the fore-foot the toes gradually increase in length from the first, the fifth attaining the maximum elongation in the largest species, and the fourth in the two smaller ones. The claws, which are longer than in the preceding genus, are strong, sharp, and highly curved; and the long tail is evenly bushy throughout. Both the chest and the crown of the head bear a gland. The range of the genus includes New Guinea and part of Australia, extending from Victoria to the islands of the Halmahera gruup. All the three species are inhabitants of Australia; a variety of one ( $P$. breviceps) being peculiar to New Guinea, New Britain, the Halmahera group, and certain other islands. Writing of one of the species, Bennett observes that " it retires either between the forked branches or in the hollow cavities of the trees during the day to sleep, and at night passes from one to another by flying leaps, aided by its parachute-like membrane, descending to the ground only from unavoidable necessity; such as when the trees are so far apart as to render it impossible to traverse the space by leaping."

With the pretty little dormouse-phalangers (Dromicia), of which there are four species, ranging over New Guinea, Western Australia, and Australia, we revert to a genus unprovided with a parachute. In addition to this feature and their small dimensions, the dormouse-phalangers are characterised by their large, thin, and almost naked ears ; the normal proportions of the toes, which in the fore-limb follow the order $3,4,2,5,1$, as regards relative length; and the short and rudimental fore-claws. The cylindrical tail is well furred only near the root, being elsewhere scaly and sparsely covered with short hairs, except at the extremity, where it is roughened and completely naked bene:th, and endowed with the power of prehension. With the excejtion of the last, which may be wanting, the molars have regularly rounded crowns, carrying four tubercles each. These little animals, one of which is rather smaller than the British dormouse, are purely nocturnal creatures, living on fruits, honey, and insects, and hiding during the daytime in the hollows, or beneath the dead strips of bark which hang down from the stems of gum-trees. One species undergoes a partial hibernation during the colder months of the year. A curious resemblance is presented by the pretty little pen-tailed-phalanger of New Guinea (Distochurnes pennatus) to the pen-tailed tree-shrew (Ptilocercus) among the Insectivora described on page 44, in that 
both have the long hairs of the elongated tail arranged in two opposite lateral rows like the vaues of a feather. Whereas, however, in the shrew these vanes accupy only the terminal portion of the tail, in the phalanger they extend uninterruptedly throughout its length. In addition to this very important feature and the absence of a parachute, tho pen-tailed-phalanger is characterised by its rather short and thinly-haired ears, which have several tufts near the base, the normal length of the toes, and the sharp and curved claws. The molars, of which there are invariably but three pairs, aro small and rounded, with smooth, unridged cusps, and the last pre-molar is very small $i n$ the upper $j a w$, and wanting in the lower. Only a single pair of teats is present in the female. The third genus in which a parachute is developed is Acrobates, comprising the two species of pigmy-flying-phalangers, one of which is Australian and the other Papuan. And since these beautiful little animals, although considerably smaller, resemble the pen-tailed-phalanger, not only in the structure of their skulls and teeth, but likewise in their vaned tails, it is pretty evident that they are derived from the same ancestral stock. The pigmy-phalangers have moderate-sized ears, a narrow parachute-like expansion of skin along the flanks, and the toes-which are of normal proportions-terminating in a broad striated pad. In the fore-foot the length of the digits follows the general order of $4,3,5,2,1$, and tho claws, although not very prominent, are sharp and well developed. Additional differences from Distochurus are to be found in the larger size of the upper pre-molar, and the presence of the corresponding tooth in the lower jaw, and likewise in the existence of two pairs of teats in the pnuch of the fenale. The Australian species, which measures $3 \mathrm{in}$. to the root of the tail, is a far less brilliantly-coloured animal than its Papuan ally. It is commonly known as the flying-mouse, and was formerly abundant about Port-Jackson, but nothing very definite has been ascertained in regard to its mode of life.

The last sub-family (Tarsipedina) of the tribe under consideration is repre. sented only by the elegant little long-snouted-phalanger (Tarsipes rostratus) of Western Australia. The sub-family is characterised by the elongation of the tail, the long and slender muzzle, the extensile tongue, the absence of a crecum, or blind appendage to the intestine, and the minute size and rudimental character of the cheek-teeth. As a genus, the animal, which measures about 3 in. to the root of the tail, may be characterised as follows:-The size is small and the form light and graceful ; while the long and narrow head is furnished with ears of moderate size, which are but thinly covered with hair : and the soles of the fect are naked and granulated. With the exception of thrise of the united second and third toes of the hind-foot, the claws are rudimental; and the tail, which exceeds the head and body in length by about an inch, is thinly haired and prehensile. Four teats are present in the pouch of the female. Althugh the upper canine and the lower incisor teeth are fairly well der, loped, there are at nost but three pairs of molars, and the pre-molars are reduced to a single pair in the upper jaw. A remarkable feature is the absence of any inflection of the angle of the rery slender lower jaw. The long-snouted-phalanger appears to be an exceedingly raro animal, inhabiting fliwering shrubs, from the blossoms of which it extracts honey by the insertion of its highly extensile tongue.

The three species of wombat, all of which are confined to Tasmania and Australia south of the tropics, and are included in the single genus Phascolomys, are the sole representatives of the third and last family of 
Australian diprotodont marsupials (Phascolomyidec). They are clumsily-built animals, differing from all the members of the group hitherto mentioned by their burrowing habits; and they may be regarded as

Wombats. occupying among the Australian fauna the position held in other regions by the burrowing rodents. Curiously enough, they also approximate to the latter order in the nature of their dentition, the incisors being reduced to a single cutting pair in each jaw, behind which comes a long gap, without any canines, till the cheek-teeth are reached. Stout and clumsy in form, the wombats have a short and broad nuzzle; thick, short, and strong limbs of nearly equal length in front and behind; the fore-feet with five nearly sub-equal and powerfully-clawed toes; the first hind-toe short and clawless, the remaining toes of the same foot having strong and curved claws, and the second and third imperfectly united by a common skin; and the tail rudimental. Internally, the stomach is simple, and the intestine is furnished with a crecum. The teeth are rootless throughout life; the large, curved, and chisel-like incisors having enamel only on the front and sides; and the five pairs of cheek-teeth are strongly curved, the molars consisting of two lobes, but the pre-molars with only one. As regards their habits, it will suffice to say that wombats are harmless, inoffensive animals, burrowing deeply in the ground, and subsisting on the roots which they thus disinter. They are entirely nocturnal, never issuing from their holes till evening, and returning to them with the first rays of morning.

A distinct family (Epanorthidec) is now represented solely by two small ratlike South American animals, which, from the estate where the second example was obtained, may be known as the selvas. One was Selvas. originally described and referred to the present order under the name of Hyracodon fuliginosus, in the year 1863, upon the evidence of a specimen obtained in Ecuador ; but the description was so insufficient that naturalists had no clue to its affinities. In the autumn of 1895 a second example was obtained from Colombia, which showed that it indicated a type of marsupial hitherto known only from fossil forms occurring in the Tertiary rocks of Patagonia, which have been described under the names of Epanorthus, Abderites, etc. As the name Hyracolon had been previously employed for an extinct genus of mammals, the selvas were at the same time re-christened Canolestes.

The selvas have an elongated skull somewhat like that of the Australianbandicoots, with four pairs of upper incisor teeth and a large pair of canines, and thus resemble the Polyprotodont type. In the lower jaw there is, however, a single pair of horizontally projecting lower incisors, not unlike those of the kangaroo, behind which are several pairs of small functionless teeth representing the other incisors, canine, and earlier pre-molars. Iu both jaws the four pairs of molars are oblong teeth, with four blunt cusps, and thus totally unlike the corresponding teeth of the opossums and other members of the Polyprotodont sub-order. The feet are of normal type, with five toes each, of which the first appears to be opposable in a limited degree to the others; and the rat-like tail is partially prehensile towards the extremity. Externally, the selvas look very like small, blackish rats, with a sharp nose.

In all probability, these animals and their extinct allies are descendants from a group of Polyprotodont Marsupials whose remains are found in the Tertiary deposits of Patagonia, and whose ancestors reached South America by means of a land connection-perhaps by way of the Antarctic continent-with 
Australia. Unlike the opossums, which are comparatively recent immigrants from the North, the selvas, like the edentates, belong to the original primitive fauna of South America, which was first developed when that country was completely cut off from North America by a sea occupying the site of the Isthmus of Panama and Mexico.

The bandicoots (Peramelide $e$ ) are the first representatives of the second great subordinal division of the pouched mammals, technically known as the Polyprotodontia. This name is assigned from the circumstance that these animals differ from the preceding group by the larger number of incisor teeth, of which there are never less than three pairs in each jaw, while more generally

Bandicoot Tribe. there are four or five pairs of these teeth in the upper, and three or four in the lower jaw. These incisors are always relatively small and of subequal size, and they are flanked by large, tusk-like canines, close behind which are the anterior cheek-teeth. Nearly always the cusps of the molars are numerous and sharp; and the whole dentition is of a markedly carnivorous type. In all their characters, the Polyprotodonts are a less specialised group than the Diprotodonts; and they have at the present day a wide geographical distribution, being represented not only in the Notogreic realm, but likewise in South America, and, more sparingly, in North America. They were also living in various parts of the world during the Tertiary and Secondary epochs. In Australasia, and to a certain extent in South America, the members of the present group-all of which are either flesh or insect eaters-take the place of the Carnivora and Insectivora of other parts of the world.

From the other three families included in the sub-order the bandicoots are broadly distinguished by the circumstance that the second and third toes of the hind-foot are reduced in size, and enclosed in a common skin in the same manner as among the Diprotodonts. In addition to this rery striking and characteristic feature, the members of the present family have the hind-limbs markedly longer than the front pair; in the fore-limbs the three middle toes, or occasionally only two, are long and furnished with claws, the others being rudimental or wanting; and the hind-foot has either four or five toes of very unequal lengths, the first toe being rudimental or absent, the second and third small and united, and the fourth the stoutest. As in the phalangers, the opening of the pouch of the female is directed backwards. Internally, there is a citcum to the intestine; and in the skeleton collarbones are lacking. In the upper jaw there may be either four or five pairs of incisor teeth, whereas in the lower jaw there are invariably three. The tail, which is always relatively long, is never prehensile. Bandicoots are restrictea to Australia, Tasınania, New Guinea, and certain of the adjacent islands, such as the Aru, Kei, and Duke of York group. In habits they are mainly fossorial and insectivorous, although \& few are nore or less completely omnivorous. Among the more aberrant forms are the rabbit-bandicoots (Perctgale), of which there appear to be two species, both restricted to the A ustralian mainland. Their most distinctive feature, and the one from which they derive their name, is the great length of the ears. In form these animals are light and delicate, with 2 long and narrow muzzle. The three middle toes of the fore-foot are long and furnished with stout, curved claws, and in the hind-foot all trace of the first toe is wanting externally. The hind-limbs greatly exceed the front ones in length ; the soles of the hind-feet are hairy ; and there is a distinct crest of hair on the upper surface of the terminal half of the tail. The upper jaw carries five pairs of incisor teeth; and the 
molars have a quadrangular or rounded section. In size and habits, these bandicoots, which are omnivorous, may be compared to a rabbit, which they resemble in their habit of constructing burrows in places where the soil is suitable. The true bandicoots (Perameles), of which

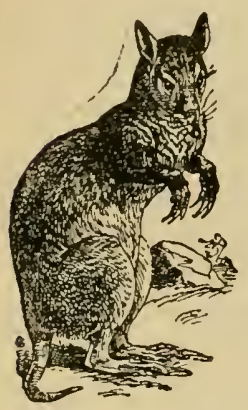

Fij. 108.-A Bandicoor (Perameles). there are about a dozen different species, are com. paratively small animals, ranging over Australia, Tasmania, Papua, and some of the neighbouring islands. While some are heavy and ungainly, and others light and elegant in bodily form, all have long and pig-like snouts, but the length of the ears is variable. The three middle toes of the fore-foot are nearly equal in length, and furnished with strong, curved claws; while in the hind-foot there is a clawless first toe, the second and third digits having flat twisted nails, the fourth exceeding all the rest in length, and carrying a stout pointed claw, and the fifth being similar but smaller. The tapering tail may be either clothed with short hair or almost hare; and there are three pairs of teats in the pouch of the female. In the dentition there aro usually five pairs of upper incisors; and the upper molars, which may lie either squared or triangular in form, carry sharp cusps. They are exclusively terrestrial and nocturnal in their habits; and apparently feed chiefly on earth-worms, although they also consume insects, grubs, bulbs. roots, and fallen berries and fruit. Bandicoots make sleeping-nests of clried grass, leaves, and sticks ; and, in spite of ridding them of worms and insects, do much harm to gardens and corn-fields. The third and last genus of the family is represented only by the pig-footed bandicoot (Choeropus castanotii:) of Australia, which, although allied to Gunn's bandicoot (Perameles gunni), is clearly distinguished by the very peculiar structure of the feet. In the fore-foot, the first and fifth toes are absent, the fourth is rudimental, while the second and third are alone fully developed and furnished with long, slender claws. Considerably different is the structure of the hind-foot, in which the first toe is wanting, and the fifth rudimental, the fourth being very large. Of a grizzled grey colour, and measuring about ten inches to the root of the tail, the pig-footed bandicoot is an animal of light and slender build, with a short and narrow muzzle, long and slender ears, and a short, cylindrical tail, slightly crested on its upper surface. There are five pairs of upper incisors; and the pouch of the females contains eight teats. In its habits this animal closely resembles the other members of the family, burrowing holes in the ground, and being omnivorous in diet, although feeding chiefly upon insec's. In spite of the number of its teats, the female only produces two young ones at a birth.

The second of the four families of the Polyprotodonts is characterised by having a simpler type of foot-structure than obtains in the Peramelide, the second and third digits of the hind-foot being completely

Dasyure Tribe. separate. Hence, it is probable that the Dasynuidce (as the present family is termed) constitute the original stock from which the Percumelide have branched off. In addition to this primary feature in the structure of the limbs, it may be noticed that there are five toes to the fore-foot, and that in the hind-foot the first toe is either small or wanting, while the other four are pretty equally developed. The long and 
hairy tail is never prehensile; and the pouch, when developed, opens forwards and downwards. Intermally, the stomach is simple, and the intestine devoid of a blind appendage. There are four pairs of incisor teeth in the upper jaw, and three in the lower; the entire dentition being of an essentially carnivorous type, the upper molars having more or less distinctly triangular crowns bearing a number of sliarp cusps. Indeed, although a few of the smal!er kincls are more or less completely insectivorous, the present family includes all the truly flesheating Australian Marsupials, as it does the largest members of the entire sub-order. Geographically, the range of the group embraces Australia, Tasmania, and New Guinea, together with many of the adjacent islands, exclusive of the Austro-Malayan group.

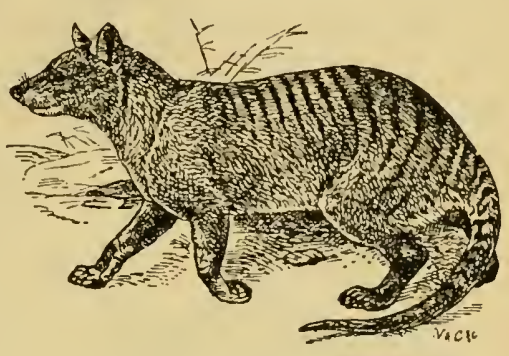

Fig. 109. -TASMANIAN-WOLF (Thylacinus cynocefhalus).

Its large size, generally wolf-like form, and striped body are sufficient to distinguish at a glance the thylacine or Tasmanian-wulf (Thylacinus cynocephalus) from all its kindred. This animal, which measures about 44 in. to the root of the tail, has a large wolf-like head, with moderate-sized ears, a long and slender muzzle, and the elongated jaws armed with very powerful teeth. The long tail is covered with close, short hair. All the feet are markedly digitigrade, the five toes of the front pair being armed with short, thick, conical claws, while the hind-feet have but four toes each. The back is marked with transverse black bands on a tawny ground. Unly four teats are present in the pouch of the female, and the marsupial bones are rudimental. The full marsupial number of three pairs of pre-molar teeth are present. Although this ferocious animal appears to be now restricted to Tasmania, the genus was

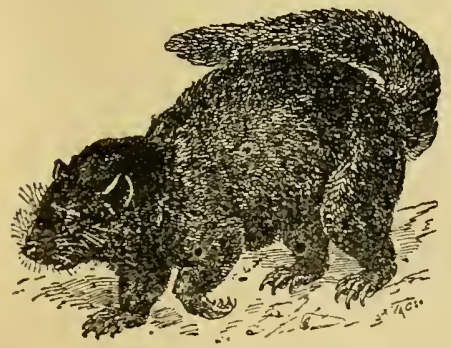

Fig. 110.-TAEMavian-Detil

(Sarcophilus ursinus). represented at a comparatively recent epoch on the Australian mainland. It is a nocturnal creature, inhabiting caves and hollows among rocky fastnesses; and, if seen abroad by daylight, is dull and sluggish. It never hunts in pack, and its sole cry appears to be a dull guttural growl. At the present day sheep are the chief prey of the thylacine, as these are both more numerous and easier to capture than the diprotodont marsupials upon which it formerly lived. Four is the number of young produced in a litter. Although but little more than half its size, the Tasmanian devil (Sarcophilus ursinus) is an even more sanguinary and destructive creature, killing sheep and fowls, apparently for the mere pleasure of slaughter, long after its appetite is satiated. In form this animal is very stout and powerful, having 
a short and broad muzzle, wide and rounded ears, an evenly-haired tail of medium length, and plantigrade feet, in the front pair of which the toes are armed with strong, curved claws; while in the hind pair the first digit is absent, and the naked soles lack well-defined pads. In colour the body is blackish, flecked with white. As regards the dentition, this differs from that of the thylacine in that there are only two pairs of pre-molars in each jaw; while the upper molars, with the exception of the fourth pair, aro strong, triangular, and much shorter and wider. The distribution of the 'Tasnanian devil, both now and in the past, is precisely similar to that of its cousin the thylacine.

Under the common title of native cats are included, in Australia, a number of considerably smaller predaceous marsupials, usually showing a slender,

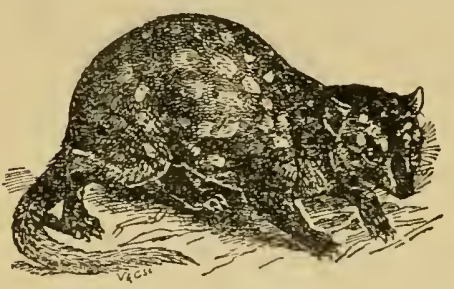

Fig. 111-SpotTed-Dasture

(Dasyurus viverrinus). weasel-like form of body, although a few are more stoutly built. These constitute the genus Dasyurus of zoologists, of which the leading characteristics are as follows:-The ears are elongated and narrow; the bare nose is marked by a deep, vertical groovo running down to the upper lip; the long tail is uniformly and thickly haired throughout its length; the feet are plantigrade, with sharp, curved claws, the first toe in the hinder pair being either rudinental or absent, and the partially or wholly naked soles of the hind-fect are granulated. In all cases the body is marked with spots. The pouch, which opens vertically down wards, contains either six or eight teats. The teeth are numerically the same as in Sarcophilus, but much less strongly developed. Dasyures are found alike in Australia, Tasmania, New Guinea, and some of the neighbouring islands. They differ from the two preceding genera, in that the majurity are more or less completely arboreal in their habits; and they feed not only on flesh, but likewise on insects, being especially destructive to birds and their eggs. The largest among the six species is the spotted-tailed dasyure ( $D$. maculatus), from east and south-east Australia, and Tasmania, which may be compared roughly in size to a cat, and differs from the rest by having the tail, as well as the body, spotted. It is further characterised by having well-defined, transversely striated pads on the soles of the feet, from which it may be inferred that its habits are largely arboreal. The pouched-nice (Phascologate), of which no less than thirteen species are recognised, are smaller animals, differing from the dasyures in the absence of spots on the fur, and the practical want of the pouch in the female. In all, the form is slender and graceful; the ears are rounded; the tail is long, but may be either bushy, crested, or nearly bare, and the broad and short feet terminate in sub-equal toes furnished witl sharp, curred claws. In the hind-foot the first toe is, however, short and clawless, and the soles of the feet are naked and smootl, with five transversely striated pads, the first toe frequently having its pad divided. Except in one species, where the first lower pair are wanting, there are three pairs of pre-molars in each jaw. The pouchedmice, which range over Australia, Tasmania, New Guinea, the Aru Islands, ctc., are thoroughly arboreal animals, feeding exclusively on insects, and 
thus taking the place of the tree-shreiss of tho Oriental region. Whereas the larges: is not bigger than an ordinary rat, the others are considerably smaller. In all the Australian species the fur of the back is uniformly coloured, and the same is the case with a few of the forms inhabiting Papua, although the majority from that area are longitudinally striped. Four nearly allied animals, which may be known as the narrow-footed pouchedmice, and constitute the genus Sminthopsis, are easily distinguished from the foregoing by the narrow feet which are either partially haired or naked, with the bare portion granulated, and with or without pads, the latter, when present, being either smooth or but faintly striated. These pouched-mice are restricted to Australia and Tasmania, and differ from the members of the preceding genus in being strictly terrestrial, so that in this respect they are comparable to ordinary shrews. More markedly distinct is the long-legced pouched-mouse (Anteshinomys laniyer), from the interior of New South Wales and southern Queensland, which is a mouselike, leaping animal specially characterised by the great elongation of the hind-limbs and the loss of the first toe in the hind-foot. The fur is uniformly coluured, the tail is long and tufted, and the ears are of large size. These little creatures, which subsist exclusively on insects, inhabit open sandy districts. As the members of the two preceding genera respectively represent the tree-shrews and ordinary shrews, so the present form may be likened to the African jumping-shrews.

One of the most remarkable of all the pouched mammals is the banded ant-eater (Myrmecobins fusciatus) of south and west Australia, which presents a curious approximation in the sumber and structure of its teeth to some of the extinct Secondary marsupials of Europe. By many writers it is regarded as the representative of a distinct family by itself, and it certainly constitutes a subfamily (Myrmecobiince) of the Dasyuride, which may be distinguished from the whole of the foregoing genera (Dasyvrince) by the following features:- In place of being of normal proportions, the tongue is long, cylindrical, and extensile; the nose is naked and grooved below;

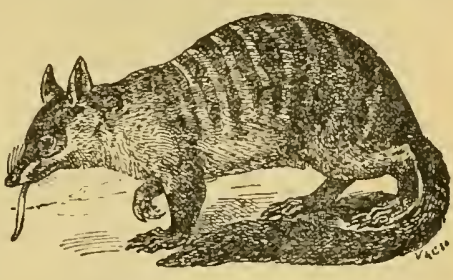

Fig. 112.-BANDSD ANT-EATER (Myrmecobius fasciatus). the pointed lower lip projects in advance of the teeth; and there is a gland on the chest opening on the exterior by means of several apertures. The cheek-teeth are small and delicate, the molars forming nore than four pairs, and being separated from one another by intervals, while those of the lower jaw have their inner cusps larger than the outer ones. In general appearance the banded ant-eater is a graceful squirrel-like animal, with the hinder part of the back marked by a series of narrow white stripes on a bright rufous ground. The ears are rather long and narrow, and the tail is elongated and bushy. All external trace of the first toe of the hind-foot is wantiug, and all the functional toes are armed with claws adapted for digging; the soles of the fore-feet being partially naked, while those of the hinder pair are completely so, their pads being small and granulated. The pouch is obsolete, and the number of teats appears to be four. The cheek-teeth usually comprise three pairs of pre-nolars and five of molars in each jaw, but occasionally there is a sixth pair of lower molars. As a rare abnormality, 
four pairs of lower incisors may be developed. The banded ant-eater feeds mainly on ants, which are licked up by the tongue, but it will also consume insec:s of other kinds. It proceeds in a series of hols, with the tail uplifted: and when pursued, or for sleeping, retires to a hullow log or tree. It is stated to produce from seren to nine young at a birth, although it is difficult to reconcile this with the alleged presence of only four teats. After birth, the young are protected solely by the long hair on the abdomen of the mother.

A separate family (Notoryctide) of polyprotodont marsupials is representcd solely by the curious marsupial mole (Notoryctes typhlops), from the sundy deserts of central South Australia. Among the Marsupial essential characteristics of the family the following are the Mole. most important:- There are only three pairs of incisor teeth in each jaw, and there are neither ear.conchs or eyes visible externally. The limbs, which are sub-equal in length, are stout, strong, and each furnished with five toes; the hind-foot having a clawed first toe, not opposable to the other digits which are of unequal size. Collar-bones

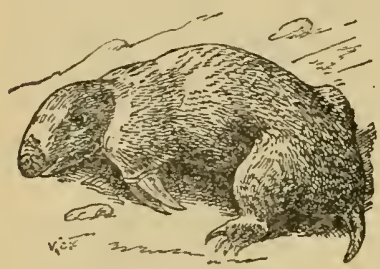

Fig. 113. Marsupial HoLE (Notoryctes typhlops). are present ; and the under surface of the skeleton of the tail carries the so-called chevron-bones so commonly present in reptiles. The upper molar teeth have tringular crowns bearing three cusps only. Externally, the marsupial mole is a somewhat peculiar-looking animal, of a pale golden-red colour, and measuring about 5 in. to the root of the stumpy tail. A hard, horny shield, divided into two parts by a transverse ridge, serves to protect the upper surface of the blunt muzzle ; and the apertures of the ears are well-nigh hidden by the fur. In both feet the four inner toes are clawed, but the fifth carries a short, broad nail ; the claws of the third and fourth front toes are very liarge and powerful, while those of the corresponding hind toes curve outwards and backwards, the toes of these feet decreasing in size from the second to the fifth. In both pairs of limbs the soles of the feet are naked and covered with a tough leathery skin. The short, stumpy tail is also hard and leathery, decreasing rapidly in diameter from the base, and terminating in a blunt, knob-like extremity. The pouch opens backwards, and contains only two teats. The creature spends most of its time burrowing in the sand of the Australian deserts in search of its insect-food, occasionally making its appearance on the surface. Its enormously-powerful front claws enable it to bury itself in the sand with extraordinary rapidity.

The last family of the marsupials is an American one, and is represented solely by the opossuins (Didelphyidce). In spite of the remoteness of their habitat, these animals are very closely allied to the

Opossums. Dasyuridce, from which they may be distinguished by having four (instead of three) pairs of lower incisors, and by the first hind toe being oppos sble to the other digits. There is no claw to the first hind toe; and the number of pairs of upper incisor teeth is five, or the same as in the Dasyuridce. As a rule, the tail is long, scaly, naked, and prehensile, although rarely it may be short, and more or less covered with hair. Internally, the stomach is simple, and the intestine has a blind appendage. 
In most species the pouch is wanting, although it may be represented by two lateral folds of skin, while more rarely it is complete. There are three pairs of pre-molar teeth in each jaw. The females have from five to twenty-five teats. Opossums, which vary in size from that of a cat to that of a mouse, include more than a score of species, all but two of which are restricted to the Neogeic realm, whence the northern forms are probably comparatively recent wanderers. With the exception of the water-opossum, the members of the fanily are mainly arboreal animals, although some of the smaller kinds are more or less terrestrial. Arboreal species have, however, extended their range to the open Argentine pampas. Whereas the larger kinds are very destructive to poultry, the smaller species subsist exclusively on insects. In those opossums in which the female has no pouch, the young are borne on the back of their parent, generally curling their own tails round that of the latter, which is purposely bent forwards orer the back and head. Nearly all the species may be included in the typical genus Didelphys, which may, however, be split up into several sub-generic groups. The first of these is represented solely by the common opossum (D. marsupialis), with its numerous varieties, which is four to five times the dimensions of any other kind, and may be compared, in this respect, to a cat. Its range extends from the United States to Chili, South Brazil, Uruguay, and Argentina, and it is the only species entering North America above Mexico. As the representative of a sub.genus, it may be characterised as follows :The very long tail is naked, scaly, and

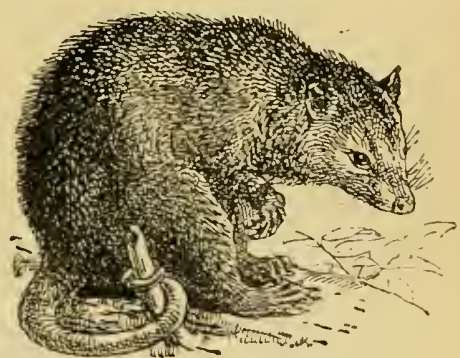

Fig. 114.-Commox Opositai (Didelphys marsupialis).

highly prehensile; elongated bristle-like hairs are mingled with the fur; and the fifth hind toe is much shorter than the fourth, which is of nearly the same length as the first and second. The female has a well-developed pouch for the reception of the young, which at birth are extremely minute. They develop, however, very rapidly, and soon become as large as mice, when they leave the pouch, although returning for the purpose of sucking, or in order to escape from impending danger. Of the habits of this species Mr. C. Lincecum, in the American Naturalist for 1872, writes as follows:"They dwell in hollow logs, stumps, and in holes at the roots of the trees. They do not burrow or prepare dens for themselves, but find such as are ready-made. I have seen them carrying into their holes, at the approach of cold weather, considerable bundles of dry leaves rolled up in their tail; they understand the signs of the coming spells of bad weather, and they prepare for it by making for themselves good confortable beds. They do not hibernate, but are found out hunting in frosty weather. They possess but little caution. Hence they are often found in the poultry-houses, chickencoops, smoke-houses, and even in our dining-rooms, rustling about for something to eat. I hare often seen their tracks in the roads and paths where they had travelled three or four miles to a farmyard, to which they had no doubt been attracted hy the crowing of the rooster's. They will catch a grown hen and carry her off squalling at the top 
of her voice, and will not abandon her till the dogs, which have been aroused by the uproar, have overtaken them and commenced cracking their bones. They will eat bacon, dry beef, carrion, any kind of fowl, rabbits, any sort of small game, almost all the insects, and fruits of every variety. They voraciously devour the musk-melon, and several species of mushrooms; in short, they are nearly omnivorous. The only case in which the opossum manifests any respectable degree of cautiousness is when it is lounted at night in the forest; on hearing the din and noise of the hunters it with some difficulty makes shift to climb a small tree or sapling, where, wrapping the naked, rasp-like tail round some convenient linı, it quietly awaits the approaching dogs and hunters. By many people the flesh is considered delicious. Its flarour resembles that of the flesh of a young hog, but is sweeter, less gross, and is, no doubt, a more healthy food fur man. A dog will starve sooner than eat the flesh of an opossum; negroes and many other persons are exceedingly fond of it. During their breeding season, the males are very rampant and belligerent. Numbers will collect round a femnle and fight like dugs. Twenty or thirty years aro I witnessed a fight myself in the furests of Mississippi. The female was present; there were three males; two of them were fighting, while the third one was sitting a little distance off, looking as though he felt he had seen enough. They were fighting hard, and had been, from the signs in the wallowed-down grass, for three or four days, kicking over the female, who immediately went into a spasm when I examined the pouch. Opossums are exceedingly tenacious of life. I have many times seen the dogs catch them and chew and crack, seemingly, all the bones in their skin, leaving them to all appearance entirely lifeless; and, going out the next morning for the purpose of removing the deac thing, would find that, it had left its death-bed, and putting the dogs on its track, trail him a mile or more before overtaking him. He would, to be sure, be found in a bad fix, but at the same time he lacked two or three more bone-crackings of being dead. They cannot, like the raccoon, be so far donesticated as to form any attachment for persons or their houses, though I have two or three times found them under the floors of dwelling-houses, where they had been for some time, and had evidently taken up winterquarters, but they did not remain there long." Of the South American variety known as Azara's opossum, Mr. Aplin, in the "Proceedings of the Zoological Society for 1894," observes that in Uruguay, "where it is known by the name of Comadreja, this opossum lives in a nearly treeless country, the river monté in Soutl Soriano being the only natural wood (composed of low thorny trees and big willows), and the Conadréja preferring to live on the higher camp, where it lies up in clefts and holes among the granite boulder-rocks; among these a few low thorny bushes are found in some cases. I have never seen a Comadréja in the monté or up any native tree, but have no doubt they often climbed the trees at the estuncius, which they are all well able to do. Yet this animal has a very prehensile tail, naked and scaly. Having hauled one out of a cleft by the tail, I found that it twined the latter tightly round ny fingers, the muscular power being considerable. They run up the boulder-rocks with great agility. At bay, whether in rocky holt or old ants'-nest, laid up in a soft bed of dead grass, or drawn and facing a dog with arched back and grinning teeth, they make a snarling, grunting growl and a hiss. It is necessary to kill those tiking up their quarters near houses, but they are often very difficult to kill. I have hammered one with a stick and thrown its heavy body against a rock time 
after time, and then, after carrying it by the tail for some distance, discovered that it was still alive. Much of the difliculty arises from their habit of shamming. Once I smoked out a female and two one-third grown young ones. A young ono came first and was apparently laid out with a blow from my stick; I had to run round the rock after the next, and when I came back (in less than half a minute) the first had come to life again and departed. An old buck, worried by a dog and finished off with a shot in the head from a collecting-gun and left for dead, was found an hour or so after partly recovered. A femalo was brought in with ten young, naked, pink, and blind ; head and body 2 in., tail $1 \frac{1}{2}$ in. long. Inside the mother's pouch were nine teats only."

As a representative of the second sub-genus (Metchimus) may be mentioned the quica-opossum ( $D$. opossum), ranging from MIexico to the Argentine. The three representatives of this sub-genus are medium-sized species, with the relative lengths of the hind-toes the same as in the eommon-opossum-that is to say, the three middle toes are sub-equal in this respect, and considerably exceed the outermost. The fur is short and straight, without any admixture of bristles; and the pouch may be either well developed or rudimental. Of the thick-tailed-opossum (D. crassiccudatu) from Guiana, South Brazil, Uruguay, and Argentina, which is another member of the same sub-genus, Mr. Aplin writes as follows:- "The Comadréja-colorada, as this species is called, is rare in the part of Soriana where I was living, only one having been killed there during my stay so far as I know. It is said by the residents to be excessively savage for so small an animal. Responding to a suggestion, I inquired whether the female had a pouch capable of carrying her young, and one rather sharp and observant puestero's boy declared that it had. Although the adults are so savage, a lady of my acquaintance had a young one, taken from the body of its dead mother in the camp south of the Rio Negro in February, which was perfectly tame. It unfortunately shared the fate of so many ladies' pets and was slain by a large cat belonging to a house at which she was staying on her way to the coast, a day or two before I went over there. The fur of this animal is very beautiful. It is of a warm, light chestnut, paler and yellower on the sides and lower parts. The upper-parts have a flush on then of what can only be described as crimson." As a matter of fact, this species has no pouch, which in a fully developed condition is present only in the common and quica-opossums. The third sub-genus (Philander) is represented by two South American species of nedium size, in which the fourth hind-toe is the longest, while the third and fifth are about equal and next in size, and the second is somewhat the shortest of the four. In both the pouch is rudimental, while externally these species are characterised by their woolly fur and the presence of a dark longitudinal stripe down the middle of the face. A considerable number of small-sized opossums from Central and South America constitute the subgenus Micourens, in which the form is slender, the fur generally straight, although occasionally slightly woolly, and there is no dark face-stripe. The relative lengths of the hind-toes are generally the same as in the last group, but in some cases the fifth digit is not longer than the second. A pouch is always wanting, and the tail is generally longer than the body, and highly prehensile. In the velvety-opossum ( $D$. velutina) the tail is, however, much shorter, and thereby serves to connect this group with the following one. In the last group (Peramys), which is likewise confined to South and Central America, and contains about eight very small species, the tail is generally 
only about half the length of the head and body, and more or less covered with short, fine hairs, while it has but little or no prehensile power. In the hind-foot the fifth toe is considerably shorter than the second, and the third and fourth digits are equal, and but little longer than the latter. From the absence

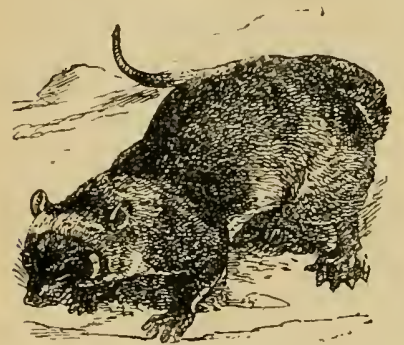

Fig. 115.-YAPOCK (Chironectes minimus). of prehensile power in the tail, it has been inferred that these tiny little opossums are mainly terrestrial in their habits. A small opossum recently described from Chiloe Island, off the coast of Central Chili, is regarded as representing a separate genus under the name of Dromiciops. A third genus contains only the water-opossum, or yapock (Chironectes minimus), ranging from Guatemala to the south of Brazil, and distinguished by its parti-coloured fur and aquatic habits. Structurally it is characterised by the presence of a projecting tubercle on the inner side of the fore-foot, giving the appearance of a sixth digit; and likewise by the webbing of the hind-toes as far as their terminal pads, whereby the first digit is much less opposable than in other opossums. In size the yapock may be compared to the common-opossum.

\section{ORDER XII. - MONOTREMATA.}

\section{Egg-Laying Mammals.}

THE third and last sub-class of mammals - variously known as the Proto. theria, or Ornithodelphia, and containing only the single order Monotrenata - differs much more widely from the otlier two than do the latter from one another, and thereby approximates to the lower vertebrates. These strange manmals, which are confined to the Notogaic realm, are especially characterised by laying eggs, after the manner of birds and reptiles; although the young subsequently developed from such eggs are nourished by milk from the mammary glands of the female parent. Instead, however, of opening into teats, these milk-glands discharge their secretion upon the porous skin of the inside of a more or less developed temporary pouch by means of numerous small apertures. After hatching, the head of the young, which derclops a special suctorial mouth, is thrust into the pouch, and the milk forced into its mouth by the contraction of special muscles. Structurally, the milk-glands of the Monotremes correspond to the ordinary sweat-glands of other mammals, and not to their milk-glands. From the other two subclasses of nammals, Monotremes differ in that the hinder extremity of the body possesses but a single orifice, from which are discharged both the waste-products and the reproductivo elements; the two egg-passages, or oviducts, opening into the extremity of this cloaca, as the single excretory passage is termed. In these respects the egg-laying manimals resemble birds and reptiles. Similar. resemblances are presented by the portion of 
the skeleton known as the shoulder-girdle, or that serving for the support and articulation of the bones of the fore-limb. In all the higher mammals, with the exception of some of the Edentates (where the coracuids may be distinct), the shoulder-girdle comprises, at most, only a pair of collar-bones (cluvicles) and two shoulder-blades (scapulce), of which tho latter bear a so-called coraeoid process at the lower extremity. On the other hand, in the egg-laying mammals, as in lizards, an unpaired additional T-shaped bone known as the interclavicle overlies the collar-bones and breast-bone (stermum); while the coracoid processes are represented by a pair of separate coracoid bones situated on the lower surface of the chest, and connected with the blade-bones to form the articular cavity for the head of the upper arm-bone, or humerus. Behind these, on the same aspect of the body, are a second pair of bones known as the meta-coracoids, and representing the bones commonly called coracoids in birds, which are articulated inferiorly to the breast-bone. The brain is also of a lower and simpler type than in the higher mammals; the same being also the case with the small bones of the internal ear. Anrther feature (which at present appears to have been verified only in the first of the two families) indicative of inferior organisation is the low temperature of the blood as compared with that of other mammals.

In both the families of Monotremes the males are furnished on the inner surface of the heel with a perforated horny spur, connected with a gland behind the thigh; and it is not improbable that during the breeding season this gland may secrete a poisonous fluid which flows into any wound inflicted by the spur. As in the Pouched Mammals, the NIonotremes have a pair of marsupial bones afhixed to the front edge of the lower part of the pelvis. Both families have the skull produced into a beak, which may be either cylindrical or flattened; and in the adult state at least, teeth are wanting. There are no traces of external ear-conchs; the two pairs of limbs, which are of nearly equal length, are modified for burrowing or digging; and the tail is either rudimental or short and wide. As in the case of the Edentates, there is no clue to the origin of the Monotremes, but there can be no doubt that the existing forms are highly modified and specialised descendants from some extremely ancient stock.

The strange Australian creature, known as the duck-bill or duck-mole (Orithorhynchus anatimus), is the sole representative of the first family (Ornitho. rhynchid(e) of the Monotremes. As distinctive of the fanily,

the following features appear the most important:-In the Duck-bill. head the nuzzle is produced and expanded to form a broad, depressed beak, covered with a delicate sensitive skin, which, in the dried state, assumes the appearance of horn. The tongue is of normal proportions, and non-extensile. In the fur there is no mixture of spines; the tail, although short, is broad and flattened; and the feet are large and wide, with the toes webbed, and the soles bare and without pads. In the young and adolescent condition, each jaw bears three pairs of many-cusped molars, of which the first is the smallest in the upper jaw, and the last in the lower; but in the adult these teeth are shed, and their functions discharged by horny plates growing up around and beneath them. In the male the horny spur on the hind-foot is very large; while in the female the puuch is rudimental. The brain has smooth hemispheres. The duck-bill has a somewhat elongated and depressed body, covered with dark-coloured fur of two kinds. In both limbs the five-toed feet have long claws to all the digits, although those on the fore-feet are broad and blunt, while those behind are compressed and 
pointed. The beak is smooth, short, and evenly-rounded in front, with a flap of skin marking its junction with the head; and the cheeks lave pouches for the storage of food. In length the adult male measures about 18 in. to the root of the tail, which is one-

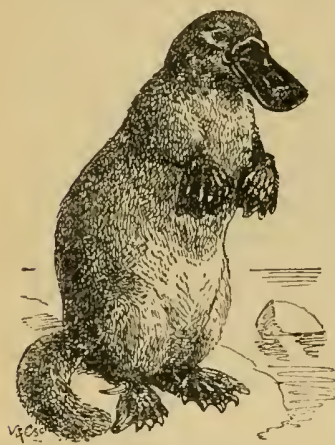

Fig. 116.-Duch-BILt

(Ornithorhynchus anatinus). third the length of the head and body; but the female is considerably smaller. The duck-bill is confined to the fresh-waters of Tasmania and Australia, where it especially frequents still and deep pools in rivers with banks suitable for the construction of its long and tortuous burrows; these burrows generally having two entrances, the one situated above, and the other below the level of the surface of the water. In length a burrow may be as much as $20 \mathrm{ft}$., and at its extremity it expands into a capacious chamber, which is lined at the breeding season for the reception of the white eggs-usually two in number. Here in due course they are hatched, the female sitting upon them in the same manner as a bird, since the pouch is not sufficiently large for their reception. When first hatched, the young are completely naked and helpless, and are fed

with milk in the manner indicated above. As soon as they are able to feed, they are supplied with fresh-water snails and insects such as form the chief nutriment of their parents. Duck-bills are mainly nocturnal animals, passing the day rolled up asleep in their burrows.

Very different, both in appearance and their mode of life, to duck-bills are the echidnas, or spiny ant-eaters, constituting the family Echidnide. In place of being aquatic, these Monotrenies are terrestrial and Echidnas. nocturnal in their habits, while the sexes lack that discrepancy in size which forms such a marked feature in the preceding group. In place of the duck-like beak of the Ornithorhynchus, the muzzle of the echidnas forms a long, slender beak, which is completely devoid of teeth at all ages, and is suited to the long, extensile, worm-like tongue characteristic of all ant-eating nammals. The fur is so thickly intermingled with short and stout spines, not unlike those of the hedgehogs, that sometimes little more than the latter are visible. The tail is quite rudimental; the short, sub-equal limbs have unwebbed toes, furnished with broad, powerful, nail-like claws, and, although the soles of the feet are provided with soft, fleshy cushions, there are no pads. A peculiar feature connected with the mouth is the presence of spines on both the palate and the tongue. During the breeding season the pouch of the female is much more developed than in the duck-bill; and the hemispheres of the brain differ from those of the latter in being well convoluted. The smooth surface and bird-like form of the skull is very characteristic of the family, and the lower jaw is remarkable for its extreme slenderness. These animals subsist exclusively on ants, which are dug out by the powerful claws and licked up by the extensile tongue. The large size of the pouch enables the female to carry about with her the two eggs, which in due course are hatched by the heat of her body. The echidnas have a wider geographical distribution than the duck-bill, and are represented by two genera, one of which ranges from 
south-eastern New Guinea to Australia and Tasmania, while the second is exclusively Papuan. All the echiduas have stout and depressed bodies, which when the creatures are in repose rest flat on the ground, although in walking the legs raiso the body some distance above the surface. In the typical genus, of which there appears to be only one very variable specitic representative (Echidnre aculeatri), the whole of the five digits of each foot are furnished with claws, which in the fore-feet are broad, slightly curved, and directed forwards, while in the hinder pair they are more slender, and curved outwards, the second, or the second and third, considerably exceeding the fourth and fifth in length, and that of the first toe being short,

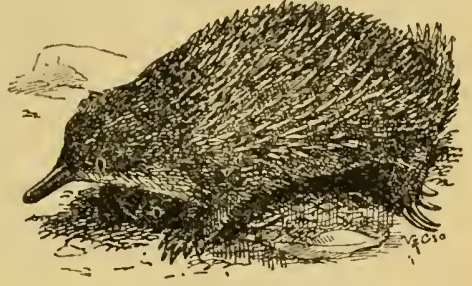

Fig. 117.-Five-Toed Ecridxa

(Echidna aculeata).

blunt, and rounded. The beak, which is of about the same length as the rest of the head, may be either straight or slightly curved upwards ; and the tongue taper's at the tip, and has the spines confined to its basal portion. Of this spucies there are three well-marked local races or varieties. The ordinary or typical form, which is confined to the Australian mainland, is of medium size, measuring about $17 \mathrm{in.}$ to the root of the tail. Next comes the variety from south-eastern New Guinea, measuring only about 14 in. in length, and with the spines of the back shorter. The largest and most distinct of all is the Tasmanian form, which grows to $20 \mathrm{in.}$, and has the fur so long as almost to conceal the spines, while the claw of the third toe of the hind-foot is almost as much elongated as that of the second. In Australia the common echidna is generally met with in sandy or rocky districts and is especially abundant in the mountains. When on level ground, it proceeds with an unsteady, shuffling gait, the short and broad front feet being turned outwards, and the claws of the hind-feet bent outwards and backwards in such a mamner as to cause the inuer border of the sole to rest on the ground. These animals do not venture abroad till evening, but during the night they are very active, burrowing with great activity in search of their favourite ants. When suddenly attacked or surprised, echidnas roll themselves up into a ball-like form, but if time be allowed, they invariably endeavour to make their escape by burrowing.

The second genus of the family (Proëchidna ${ }^{1}$ ) is distinguished by the feet usually carrying only three claws each, although the first and fifth toes are represented by two or more joints, and riay occasionally be clawed. The length of the claws of the hind-foot diminishes regularly from the second to the fourth toe; and the beak, which is markedly curved downwards, is much longer than in the typical echidna, being nearly as long as twice tho length of the remainder of the head. In the Arfak mountaius of northwestern New Guinea the genus is rer,resented by Bruijn's cchidna ( $P$. bruijni), which measures about 19 to $20 \mathrm{in}$. in length, and has dense woolly fur, with but few spines. In western New Guinea it is replaced by a larger form with stouter limbs, shorter claws, and longer, more sparsely distributed, and more hairy fur, but whether it is anything more than a local variety may be doubtful.

'It has recently been proposed to substitute the name Zaglossus, which is stated to be earlier. 


\title{
SUB-KINGDOM I.-VERTEBRATA.
}

\section{CLASS II.-AVES.}

\author{
By R. Bowdeer Sharpe, LL.D., F.L.S., \&.
}

StrRucturaluy the skeleton of a bird differs very remarkably from that of an ordiuary mammal, although it is considerably less unlike that of the egg-laying mammals. In all the features in which the bird's bony framework departs from the mammalian type, it approximates to the reptilian conformation in general features. Still, it must not be supposed that in this respect birds are exactly like any living reptiles. Although in their general structural plan their skeletons are similar, that of the bird has become modified and specialised from the original type, which renders it markedly different from that of either a crocodile or a lizard. One of the chief points in which the skeleton of a bird resembles that of a lizard, and thereby departs from the mammalian type, is the mode in which the skull is articulated to the first joint of the backbone. Whereas in a mammal the articulation takes place by means of a pair of knobs on the hinder part of the skull, which are received into corresponding cups in the first joint of the backbone, in the bird and reptile there is but a single knob, or condyle, fitting into a cup in the first vertebra. Then, again, while in the mammal the lower jaw articulates directly with the solid wall of the true skull, or cranium, in the bird and reptile there is on each side an intervening separate bone, known as the quadrate. A third feature in which the skulls of birds and reptiles resemble one another, and differ from those of mammals, is the complex structure of each branch of the lower jaw-each branch consisting in the two former groups of several distinct bones, whereas in the latter it is formed of a single bone.

In order to give strength to the back in flying, the vertebre of the hinder part of the backbone are fused together into a solid mass, forming the socalled sacrum, which is much more extensive than in mammals. To either side of this sacrum are firmly attached the bones of the pelvis, all of which are very unlike the corresponding bones of mammals, and of which the upper elements, or ilia, are by far the largest. In all living birds the bones of the tilil are aborted, and terminate in a triangular piece known as the "ploughshare bone." In all birds the ribs are few in number, and in most cases these differ from the mammalian type by the presence of an oblique process on the hinder border. These uncinate processes, as they are called, are met witl in some reptiles.

Perhaps the most extraordinary feature in the skeleton of an ordinary flying bircl is the excessive development of the bones of the breast, which in soine cases cover almost the whole of the under surface of the body. By far the largest of these elements is the breast-bone, or sternum, corresponding with the element similarly named in mammals. Whercas in flying birds this sternum is strongly keeled, in order to afford a firm basis of origin for the pectoral muscles, in the ostrich and its kindred it is flattened. At the sides the sternum is attached to the true ribs by the intervention of so-called sternal ribs. Superiorly it bears a pair of bones commonly known as cora. 
coids, but more properly termed metacoracoids. Superiorly these metacoracoids join the scimitar-like scapulæ, or sloulder-bones, and at their junction form the cavity for the reception of the head of the upper wing-bone, or humerus. Joining the upper ends of the metacolacoids, and extending downwards towards the sternum, is the well-known merry-thought, or furcula; although in this modification peculiar to birds, the furcula really represents the united collar-bones, or clavicles, of man. In ordinary manimals there are no separate representatives of the metacoracoids; but such occur in the egg-laying manmals, although differing widely from those of bircls. Before leaving this region of a bird's skeleton, it is important to mention that in the backbone-at least in the neck-the indiviclual joints, or vertebre, are articulated together by saddle-shaped surfaces, such a mode of articulation being unknown in any other class of vertebrate inimals.

As regards the structure of the bones of the wing, very few words will suftice. The two upper segments of this pirt of the skeleton are essentially similar to the same part in mammals. The bones of the wrist, or carpus, are, however, reduced to two in number; while those of the metacarpus and fingers are flattened and otherwise modified, the number of digits never exceeding three. The three digits respectively represent the thumb, index, ind middle fingers of the liuman hand. Of these, the thumb has either one or two joints, the index two, and the third digit one. The metacarpals of the index and third tingers are united together by a thin plate of bone, which may be perforated.

In a bird's leg the general plan of structure is a specialised modification of that obtaining in reptiles. The grand distinction between the leg of a reptile and that of a mammal, lies in the fact that, whereas in the latter the ankle-joint occurs at the top of the two rows forming the ankle, or tarsus, in the former the joint is situated between the two rows. A bird's leg is formed on the latter plan, but has undergone the further modification that the two rows of tarsal bones are respectively welded to the bones above and below them. We have first of all the thigh-bone, or femur; next comes the tibia (with the aborted fibula at its upper end), to the lower extremity of which are attached the upper row of tarsal bones, thus forming a tibio-tarsus. Below this comes a compound bone, formed by the lower row of tarsal bones and the three middle metatarsal bones of the typical five-toed foot, this compound bone being termed the tarso-metatarsus. Usually this bone terminates below in three pulley-like surfaces, to which are attached the bones of the toes; but in the ostrich there are only two of these pulleys, and likewise only two toes. When the first toe, or halhex, is present, it is attached to the hinder surface of the lower end of the tarso-metatarsus. No trace of the fifth toe ever remains. Whereas in mammals each of the toes, save the thumb, has three joints, in a bird (as also in a rejtile) the number of these joints increase from the second to the fourth toe.

The chief character which distinguishes the class Aves from the other classes of vertebrate animals is the possession of feather's. The production of the young from an egg is not confined to the bircls, but is shared by some mammals and reptiles; nor is the power of fliglit a sole prerocative of the birds, but their feathery covering is a really distinctive characteristic.

That birds existed on the earth in very remote times is undoubted, and that they were very different in form and structure from those which we have around us now, is equally certain. As the special character of the class 
Ares is the possession of feathers, the earliest creature which can be determined to have possessed this special prerogative of the birds is the Archcopteryx. The remains of this curious animal were first discorered in the sand-stone formation of Solenlofen in Bavaria, whence comes the bulk of the stone used for lithograplic purposes in the present day. The original slab containing these priceless remains is now in the British Museum, and with it we commence the study of the class Ares. The head is, unfortunately, missing in this specimen, but the imprint of the tail is clear enough, and shows a structure quite different from that which is to be seen in any birl of modern times. It is longer than the body of the bird itself, and, instead of the feathers being placed side by side, and capable of being spread like a fan, we find in the Archcoptery $x$ the tail consisting of a scries of vertebra, upon which the feathers were disposed laterally, while there must evidently have been quills upon the wings. The digits of the latter terminated in little claws or horks, a condition which exists in some of our present-day birds, though the exact structure is modified. A second specimen of an Archeopteryx was afterwards rliscovered in the sane formation at Solenhofen, and has passed into the possession of the Berlin Museum. In this individual the head has been preserved, and shows us a reptilianlooking skull with actual teeth. Thus we know that Archoopteryx possessed tecth and feathers, but of a kind unlike those of any bird of modern times. It introluces the filst sub.class of birds, viz., the Saurure.

Among the numerous other members of the class Aves, which we shall have to pass in review, will also occur several birds with teeth; but these will all be found to belong to a much earlier age than our own, so that we may safely say that at the present day no really toothed bird exists.

At the same time, there are found on the earth to-day many types of birds which must be considered to be the survivors of very ancient bird-life ; and if these do not belong exclusively to one type, or to any single order or family of existing lirds, we shall yethave little difficulty in assigning to most of them their proper position in the natural system. The idea that all toothed birds must belong to one group is now held to be erroneous, and the notion that the diving Hesperornis of the New World was allied to the Archcoptery $x$ of the Old World, simply because they both possessed teeth, is not admitted at the present day.

Granting, however, that our Passerine birds are the highest development of the Avian form at present existing, it naturally follows that we must look to a totally different type if we desire to connect the bird-Jife of the present day with that of the past ; and the flightless birds, the ostriches, and their kin, are admitted by all ornithologists to be the modern survivors of ancient forms. Like the liuge mammals and reptiles, which were the fore-runners of the modern representatives of these classes, the birds of the Struthious order of Madagascar (Apyornis) and the Moas of New Zealand were enormous. A singular interest attaches to the ancient Struthiones, which were immensely larger than their descendants of our own epoch. Thus the moas of New Zealand attained a huge size, and, as far as recent researches carry us, they must have been alive on the earth not so very long ago. The moas live in the traditional history of the Maories; specimens have been unearthed with the skin still attached to the bones; moa-feathers have been found in some number; and much controversy has been excited as to whether they have become extinct within the last hundred, or five hundred, yeurs. That they were living within historic times is certain. Of the Epyornis of Madagascar 
we know less, but thougl its bones are not so often discorered as those of the moa, its eggs, unearthed from the tombs of buried chiefs, are not unfrequently found

The Ratite Bircls, as these great flightless creatures of the ostrich tribe are usually called, derive their nime from the fact that they have a "ratite" or" " raft"-like breast-bone. On the latter there is no keel, to which a pectoral muscle may be attached for the purposes of flight, and they have now no mechanism by which they can propel their huge bodies through the air like ordinary birds. That ostriches and their allies will erer fly is simply impossible, as their numbers are being annually decreased, and the necessary ages requisite for them to develop the means of flight as an escape from their enemies will never be allowed to them, as man, with his sprearling civilisation and his deaclly ritle, gradually encircles the poor birds in their last liwvens of rest. The probability is, judging from the well-developed wings of the early Archeopteryx, that ancient birds could fly, and that the ostriches and moas are the descendants of birds perfectly capable of flight, but which from the lack of natural enemies in ancient times, have gradually lost their power of flying, and ultimately dereloped into the flightless birds of the present clay, wherein safety is secured by their excellent power of running, or by their nocturmal habits, where concealment and swiftuess of foot play the most important part in their preservation.

The Struthious or Ratite Bircls (Sub-class Ratita) may, therefore, be divided into six Orders, rim. the Rheas (Rheiformes), the Ostriches (Struthioniformes),

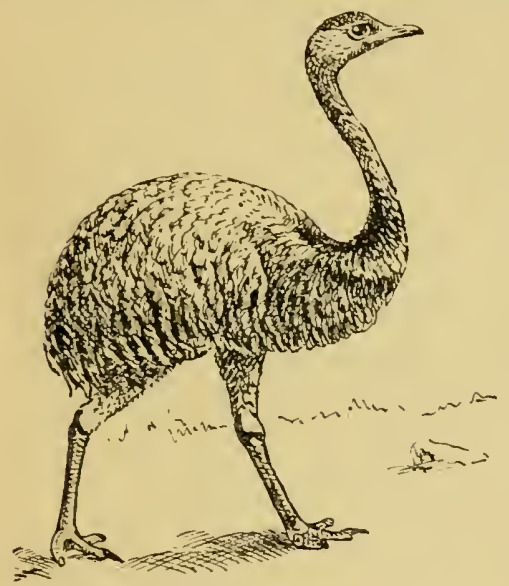

Fig. 1.-THE Comsox RHEd

(Rhen uwericana). the Emus and Cassowaries (Casuariiformes), the extinct

Sub-class Ratite.

formes and Epyornithiformes), and the Apteryges (Apterygiformes). Of these the moas are extinct, but members of the other orders still survive.

The ostriches may be distinguished by having only two toes instead of three. The moas had three toes, and, therefore, they belonged to the great group of three-toed Struthious Birds, of which so many have perished. Of those that survive, the rheas (Rheiformes) are distinguished by the following characters: the absence of any keel to the breastbone, no hind-toe, and three toes in front. They are to all intents and purposes ostriches, and generally go by the name of the "South American Ostrich," as they are entirely confined to the South American Continent. Of the rheas, four species are recosnised. One of these may be considered an unknown species as yet, as Thicu nanu (Lydekker) has only been characterised from its egg, which is remarkably small, and on this evidence, which is cert:inly self-evident, Mr. Lyilekker has separated the small Patagonian speeies as distinct. The common rhea (liheu americana) is the best-known species, 
and the most widely distributed, being found from Southern Erazil and Paraguay to the province of Matagrosso, westwards to Bolivia, south to the Rio Negro in Patagonia, and even beyond. In the provinees of Bahia and Peruambuco it is replaced by the great-billed rhen ( $R$. macrorhyncha), and in Chili and Patagonia by Darwin's rhea ( $R$. darwini), which is said to range north of the Rio Negro, where it may be coterminous with the range of $\mathcal{R}$. americana.

The nandu, as the rhea is called in Argentina, is, according to Mr. W. H. Hudson, doomed to speedy extinetion, the republican governments of South Ameriea apparently being too much occupied in other business to trouble their heads about bird protection, which appears to be only an outcome of extreme civilisation. Mr. Hudson, the recorder of. so much that is interesting in the habits of the birds of Argentina, has given the results of lis acquaintance with the rhea, and we regret that space forbids us to quote inore than a brief extract. It seems that the male takes upon himself the duties of incubation, and Mr. Hudson's story is as follows :- "In the month of July the love season begins, and it is then that the eurious ventriloquial bellowing, booming, and weird-like sounds are cmitted by the male. The young nales in the flock are attacked and driven off by the old cock-bird; and when there are two old males, they fight for hens. Their battles are conducted in a curious manner, the combatants twisting their long necks together like a couple of serpents, and then viciously biting at each others' heads with their beaks; meanwhile, they turn round and round in a circle, pounding the earth with their feet, so that where the soil is wet or soft, they make a circular trench where they tread. The females of a flock all lay together in a natural depression of the ground, with nothing to shelter it from sight, each hen laying a dozen, or more, eggs. It is common to find from thirty to sixty eggs in a nest, but sometimes a larger number, and $I$ have heard of a nest being found containirg one hundred and twenty eggs. If the females are many, the cock usually becomes broody before they finish laying, and he then drives them away with great fury, and begins to incubate. The hens then drop their eggs about the plains; and from the large number of wasted eggs found, it seems probable that more are dropped out of, than in, the nest. The egg when fresh is of a fine golden yellow, but this colour grows paler from day to day, and finally fades to a parchment-white.

"After hatehing, the young are assiduously tended and watched over by the sock, and it is then dangerous to approach the rhea on horseback, as the bird, with neck outstretched and outspread wings, charges suddenly, making so huge and grotesque a figure that the tamest horse beeomes ungovernable through terror. Eagles and the large caracara are the cnemies which the rhea most fears when the young are still small ; and at the sight of one flying overhead, he crouches down and utters a loud, snorting cry, whereupon the scattered young birds run in the greatest terror to shelter themselves under his wings."

Although at present only to be found in Africa and Arabia, there is no doubt that in former times the range of the ostrich was much more extensive. It is now practically extinct in Mesopotamia and in Syria, but, The 0strich. according to Mr. Lydekker, fossil remains of an ostrieh have been found in North Western India, while an egg, supposed to belong to one of these birds, has been described from Southern Russia.

Three species of ostrich are recognised in Africa, of which the common one 
Struthio camelus, and the South African form, S. australis, liave flesh-coloured thighs, whereas the Somali-land ostrich, S. molybdophane", has black thighs. It is not a little vexatious that no one has yet determined how many species of ostrich really exist at the present day. Their plumes are classified by dealers, and those of the Barbary form are supposed to be different from those of the South African form, but at present no museum contains a series which illustrates the life listory, or the number of species existing of these welllinown birds.

The ostriches have only two toes, the first and second being absent. The quills and tail-feathers are well-dereloped for this class of bird, but no after-shaft is present. The male is larger than the female, and he undertakes the carc of bringing up the family after he has hatched out the eggs. He especially looks after the nest at night, and broods.over the eggs, though in many tropical countries the latter aro covered over with sand, and left to the lieat of the sun during the day. The cock-bird has more than one wife, generally three or four, who make common cause in the laying of the eggs, and deposit them in the same nest, sometimes as many as twenty eggs being found together.

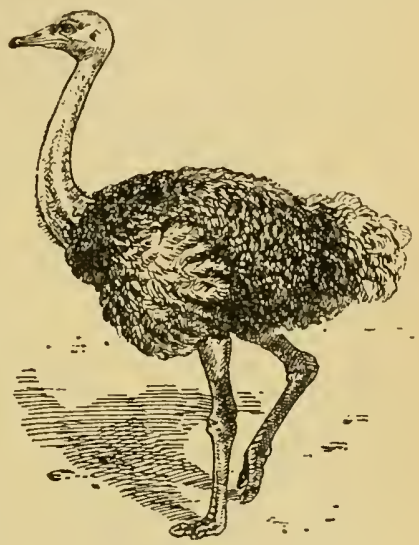

Fig. 2.-The Ostrich (Stmuthio camelus).

These birds comprise the order Casuariformes, with two sub-orders, Dromeo (Emus) and Casuarii (Cassownies). Buth are inhabitants of the Australian region, the cassowaries being confined to the Papuan sub-region of the latter. Of the emus, three species are known, and it is quite possible that a fourth existed

The Emus. within recent times, as the Tasmanian emu was apparently distinct from the Australian form, but is now quite extinct. The small black emu of Kangaroo Island is known only from two specimens in the Paris Museum, and is also extinct. Thus we have but the common emu (D. nove hollandice) and the spotted emu (D. irroratus), the former inhabiting Eastern and the latter Western Australia. The birds of this sub-order all have three toes, and are further distinguished from the ostriches by their rudimentary wings and apparent absence of a tail, while the body feathers have an after-shaft, which is as long as the actual plume itself, so that the latter appears as if it were a double feather.

The habits of the emu can now be studied in parks and public menageries in this country, where they not unfrequently nest. The bird is said by travellers to be good eating. As with the other Struthious Birds, constant persecution is making it rarer year by year, and it has now entirely disappeared from haunts where it once was quite numerous. The female is smaller than tlie male, and on the latter devolves the principal part of the duties of incubation. It lias a curious note, which Gould has described as follows :"The note of the emu is a low booming or pumping noise, which we know to be produced in the female by means of the expansion and contraction of a large membranous bag, surrounding an oblong opening tlirough the rings of 
the trachea." The nestlings are beautifully striped little creatures. The egg is of a rich dark green, but this colour fades in course of time, and gives place to a dull black.

These are curious birds, which commence their life in a mottled plumage, with no visible casque on the skull, and grow to an adult black plumage with an elevated casque of varying shape and The Cassowaries. generally some highly coloured wattles on the throat and neck. Eleren species are known, all of them met with in the Papuan group of islands, with the exception of one species, the Australian cassowary, which occurs in the Cape York Peninsula and extends as far south as Rockingham Bay. Most of our information regarding these curious flightless members of the class Aves is derived from the study of specincons sent alive to Europe, and many of us are familiar with the great turkey-like lieads and black bodies of the cassowaries, with their five spiny quills in lieu of wings, their helmets and ornamental throat-wattles. Like the emus, the long after-shaft to the body-feathers gives these the appearance of being a double plume. Some of the New Guinea species apparently inhabit the same districts of that great island, while others are poculiar to Ceram, the Arn Islands, and New Britain respectively. The colour of the eggs of the cassowaries is dark green, and the young are brown, when full-grown, and have no casque. As in the case of the other Struthions Birds, the duties of incubation fall upon the male, who looks after the young ones when they are hatched.

Extinct forms, allied to the emus and cassowaries, have been found in Australia (Dromomis), in India (Hypselornis); while the moas of New Zealand (Dinomithidee) and Madagascar (APyomis) belong to the same group.

Although the kiwis are recognised as belonging to the Struthious Birds, they are decidedly aberrant members of the sub-class, and are very like gigantic rails in their ways, being ex-

The Kiwis. cellent rumners and chiefly nocturnal in their habits. Like the emus and their kindred, they are great hands at kicking, and at a meeting of the British Ornithologists' Club, when the Hon. Walter Rothschild exhibited living specimens of every known species of kiwi, the birds made known their resentment by vigorous and lightning-like kicks on the walls of their cages, some assaulting the wires front-ways, and some kicking backwards.

These curious birds will, doubtless, become extinct within a short period. There are only five species of kiwi now to be met with in New Zealand, thuugh there is no doubt that the genus Apteryx was more widely distributed over the southern lands in past times. The kiwis have four' toes, but there is no visible wing, and the nostrils are placed near the tip of the long bill. There is

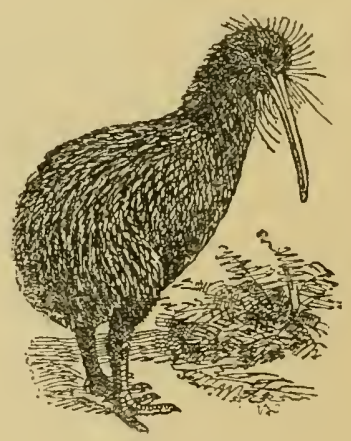

Fï. 3.-THE APTERYX (-12,teryx austrulis). no tail visible, and the long after-shaft of the emus and cassowaries is absent. In the kiwis the hind toe, or hallux, is present, so that all four toes are represented. The egg is white, and may be considered enormous for the size of the bird which lays it. There is no marked difference in the size of the sexes, but the female appears to be slightly larger thin the male. The 
observations on the ways of the kiwis in a state of nature are singularly deficient, and it is to be feared that the members of the grenus Aptery will disappear from the face of the globe without their life-history being thoroughly recorded. The eggs, judging from those laid in captivity, never appear to exceed two in number, and they are incubated in true Struthious manner by the male. Those which have been kept in our zoological gardens in this country have been seldom seen in daylight, as they go to sleep all the day and conceal themselves in the straw of their dens. When taken out, they run round in a dazed manner, and quickly return to thair eoncealment. It is even said that when poked with sticks they will not rouse themselves, and quickly go to sleep again. An extinct form of Apteryx has been discovered in New Zealand (Psendapteryx, Lydekker).

All the rest of the birds belong to the order Carinatce, or birds with a keeled stemum. Thus they ought to be all capable of flight, but as a matter of fact there are many exceptions, and there are not a few which have lost this

Carinate Birds. power. The vast majority, however, have a deep keel or ridge to the breast-bone, which distinguishes them from the Ratitu, of which we have just spoken. The nearest allies to the Apteryges, in a natural series, would be, in our opinion, the rails (licllide), but we are bound to take notice of the curious partridges of South America, the tinamous, because they possess a remarkable palate, the bones of which are very like those of the Struthious Birds, and hence we commence our study of the Aves Carinate with the order Tinami. formes. In general appearance they resemble partridges, and they have much the liabits of the latter birds, excepting the fact, that many of them are inhabitants of the forests, whereas the partridges are, essentially, birds of the open country.

The Tinamous.Order

Tinamiformes. Sixty-tive species of tinamous are enumerated by Count Salvadori in his recent treatise on the order, and they are all inhabitants of the neo-tropical region, i.e. Central America, south of Mexico, and South America generally. Some of them are of large size, as big as an orclinary hen, but with the feathering much closer set, and with very little of the tail visible. The most remarkable feature of the tinamous is, perhaps, the colour of their eggs, which varies from a purplish brown or red to a bluish green, but whatever the colour may be, the eggs are always remarkable for their gloss. As Count Salvadori observes, they are "curiously unlike those of other birls, and the shell looks like lighly burnished metal, or glized porcelain, presenting also varions colours, which seem to be constant in the particular speeies, varying from pale primrose to sage green, or light indigo, or from chocolate brown to pinkish orauge."

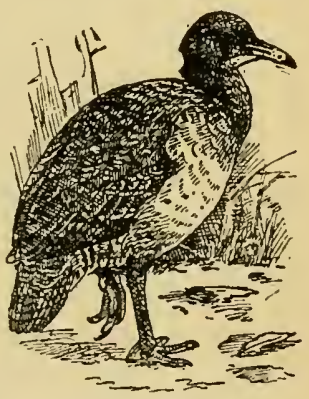

Fig. 4.-ThE Great Tinamot (Rhynchotus rufesecns).

The species of timamou vary very much in size, some being no larger than an ordinary quail, while others are as big as a good-sized fowl. The plumage of many of them is mottled and barred, and none exhibit any decorative ornament beyond the occasional presence of a chestnut breast. While some of them inhabit the open pampas, others are strictly forest birds, and the conclusion forced upon us is that tinamous are struthious partridges, 
Game-Birds of the partridge type, which have retained some of the osteological characters of their struthious ancestors. Of the great tinamou (Rhynchotus rufescens) of Argentina, Mr. W. H. Hudson writes :- "This spccies is solitary in its habits, conceals itself very closely in the grass, and flics with the greatest reluctance. I doubt if there is anywhere a bird with such a sounding flight as a tinamou; the whirr of its wings can only be compared to the rattling of a vehicle driven at great speed over a stony road. From the moment it rises until it alights again, there is no cessation in the rapid vibration of the wings; but, like a ball thrown from the hand, the bird flies straight away with extraordinary violence until the impelling force is spent, when it slopes gradually to the earth, the distance it is able to accomplish at a flight being from 800 to 1,500 yards. This flight it can repeat when driven un again. as many as three timcs, after which the bird can rise no more."

This is a very large order of birds, and may be divided into four big suoorders, viz. the Megapodii, or mound-builders; the Craces, or curassows; the Phasicmi, consisting of the grouse, pheasants, partridges, The Game-Birds. guinea-fowls, and turkeys ; and, lastly, the bustard-quails, or -order Galli- hemipodes (Hemipodii). Everyone is familiar with the apformes. pearance of an ordinary Game-Bird, such as the common fowl, or the turkey, the pheasant, the partridge, or the grouse. The mound-builder, the curassow, and the bustard-quail are less known, because in Great Britain we have no representative of these sub-orders, though occasionally examples of each of them may be seen in captivity. The palate in the Game-Birds is cleft, or, as it is usually called, "schizognathous," and another peculiar character is the perforation of the episternal process of the breast-bone, or sternum, so that the fect of the coracoid-bones meet through the opening thus afforded.

These curious birds have a somewhat remarkable distribution, as they extend from Australia throughout the Malayan Archipelago to the Island of Labuan and the Philippine Archipelago. They are not

The found in Java or Sumatra, but have recently been discovered Mound-Builders, in the Kangean group of islands; and a species is also known - sub-Order from the Nicobar Islands in the Bay of Bengal. Thus it will Megapodii. be seen that the distribution of the megapodes is restricted to the south-east of Asia and Australia.

Professor Huxley separated the megapodes of the Austro-Malayan subregion and the curassows of the neo-tropical region into a sub-order, Peristeropodes, in contrast to the Alectoropodes, or true Game-Birds, because they have i smaller inner notch of the sternum, this inner notch being less than half the length of the entire sternum, whereas in the ordinary Game-Birds the inner notch of the sternum is more than half the length of the entire sternum. Again, in the megapodes and curassows, the hallux, or hind-toe, is on the same level as the other toes, whereas in the Alectoropodes the hallux is raised above the level of the other toes. Of the mound-builders thero are seven genera, of which the most striking types are the true moundbuilders (Megapodius), the brush-turkeys (Talegallus), and the maleo-bird (Megacephalum).

The maleo is confined to the Island of Celebes, and is the only one of this dull-coloured group of Game-Pirds which shows any pretension to colour. It has a breast of a delicate pink, and an ornamental bare knob on the crown, but is otherwise of a dusky colour like the rest of the group. Dr. A. R. 
Wallace, during his celebrated expedition to the Malay Archipelago, found the maleo practising all the usual nesting devices of the mound-builders. The female lays eggs at interrals, and he says that the size of the latter precludes the female bird from having more than one fully-developed egg at the same time. The egrgs are, therefore, laid at an intervening period of ten or twelve days, and are deposited in a mound of loose, loot, black sand. "In the montlis of August and September," he writes, "they come down in pairs to the nesting-place, and scratch holes three or four fect deep, just above high-water mark, where the female deposits a single large egg, which she covers over with about a foot of sind, and then returins to the forest." Eacl female is supposed to lay six or eight eggs during the season, the male assisting her in making the hole, coming down and returning with her. Many birds, according to Dr. Wallace, lay in the same hole, as a dozen eggs are often found together.

Some of these birds gain their name of brush-"turkeys" from the wattle which is seen on the base of the neck in the genera Catheturns and Expypulius. Though devoid of these fleshy wattles, which are turkey-like, the remaining genus, Talegallus, is of large size, and, in a country which possesses no real Game-Bird of the kind, Brush-Turkeys. night pass for a near approach to a turkey in size and general appearance. Of the habits of the Australian brush-turkey (Catheturus lathami), Gould gives the following account:- "At the commencement of spring, this species scratches together an immense heap of decaying vegetable inatter as a clepository for its eggs, and trusts to the heat engenclered ly the process of fermentation for the development of its young. The heap employed for this purpose is collected by the bir ds during screral weeks previous to the period of laying; it raries in size from that of two to that of many cart-loads, and in most instances is of a pyramidal form. The construction of the mound is either the work of one pair of birds, or, as some suppose, the united labours of several ; the same site appears to be resorted to for several years in succession, the birds adding a fresh supply of materials each succeeding season. The material composing these mounds is accumulated by the bird's grasping a quantity of carth in its foot and throwing it backwards to one common centre, the surface of the ground being so completely scratched over, that scarcely a leaf or a blade of grass is left. The mound being completed, and time allowed for a sufficient heat to be engendered, the eggs are deposited in a circle at the clistance of nine or twelve inches from each other, and buried more than an arm's depth, with the large end upwards; they are covered up as they are laid, and allowed to remain until they are hatched. I have been credibly informed, both by natives and by settlers living near their haunts, that it is not an unusual event to obtain half a bushel of eggs at one time from a single mound. Some of the natives state that the females are constantly in the neighbourhood of the mound about the time when the young ones are liable to be hatched, and that they frequently uncover and cover 
them up again, apparently for the purpose of assisting those that may have appeared; while others have informed me that the eggs are merely deposited, and the young allowed to force their way out unassisted. One point, however, has been clearly ascertained, riz. that the young, from the hour they are liatched, are clothed with feathers, and have their wings sufficiently developed to enable them to fly on to the branches of trees, should they need to do so to escape from danger; they are equally nimble on their legs. In fact, as a moth emerges from its ehrysalis, clries its wings, and tlies away, so the youthful brush-turkey, when it leaves the eggr, is sufticiently perfect to be able to act independently and procure its own food."

Of the habits of the Papuan and Moluccan genera, Talegullus and Epypodius, Iittle is known; but the ways of the species of Lipoe and Megerporlius have been more carefully studied. Eutipou from the Moluccas has but one species, $E$. vallecii, with a more rounded wing than in the ordinary megapodes, and further remarkal,le for its brighter colours. Of the ocellated megapode (Lipon vellutu) Sir George Grey sent to Mr. Gould a most interesting account of the labits, from which it appears that the birds dirst scratch a hole in the sand, fill it up with dead leaves and griss, and then build a momel of dried grass, etc., over it. The hole is then opened and an ergo deposited in the sand, and as many as eight are placed at intervals, an ergg being deposited every day, or at least every few days; and the male bird lielps the female to uncover the hole. The eggs are placed upright, and several mounds are fomd within a short distance of each other, each being the property of a single pair of birds. All the megapodes are very shy birds, and escape to the trees when pursued, roosting in these during the heat of the day, and being then apparently stupid birds, they can be shot down in suceession without attempting to fly, so that the whole party is soon cleared off.

The true megapodes (Meyupodurs) are the most widely distributed of any of the group, but are best known from the studies which have been made of the habits of the Australian species, M. tumulus. Gilbert found many nests of this bird in the Cobourg Peninsula, and dug ont a young bird, which he kept alive for a few days. It was, however, very wild and intractable, and malde its escape; but it is interesting to learn that this little ehick employed its time in continually scratching up sand, for which purpose it only used one foot Egys were taken by Gillbert from a depth of six feet in the mound, but ins the holes ran down obliquely from the centre, towards the onter slope of the hillock, the eggs might be six feet deep from the summit but only two or three feet from the side of the momul. One mound that Gilbert found in Knocker's Bay in a thicket was fifty feet in height and sixty feet in circumferenee: and the late Mr. Davison met with a mound of the Nicubar megapode (M. nicoldriensis) which was eight feet in height and " puite sixty feet in circumferenec. Mr. John Whitehead, in the conrse of his famous explorations in the Mality Archipelago, visited the Island of Palawan, and there made the aeruaintanee of Cuming's megapode (Meyryorlins cumingi), which he found nesting from June to August. The note of this species is a most. duleful "mew," exactly like that of a cat in clistress, and is heard many times towards evening, adding to the melancholy of the forest. The nest he describes as a most wonderful structure, and no doubt the result of the labonr of several pairs of birds. The eggs were placed so deep that it was impossible to reach them, and he says that he dug out a young bird so far grown that it louked like the adult of another species, and yet, although 
fully feathered and able to fly well, he was convinced that it had never seen diayılght.

l'he curassows form the second sub-order of Professor Huxley's Peristeropodes, and like the megapodes have the hind-tue not elevated, but on the same level as the uther tues. Iney have aloo a tufted oil-gland, and then whole appearance is more like that of the pheasants and true Game-birus, and quite different trom that of the megapodes. 'The wind-pipe is long and convoluted. They like-

\section{The Curassows.} - Sub-Order Oraces. wise nest in trees and lay two white eggs, and the nestlings have a patterned downy stage, like that of true Game-Birds. Mr. Ogilvie-Grant, who has mince a special study of all the (iallinaceous Birds, recognises eleven genera of curissuws, and he clivides them into two sections, the true curassows with a very deep bill, and the guans with it more elongated and widened bill, the upper mandible bemg broader than it is high. Very little has been recorded of the habits of the curassows in their wild state, but they are often to be seen in menageries, where they walk about like great turkeys, or sit on the branches of the trees providerl for them.

One of the most curious of the curassows is Lord Derby's guan (Ureophasis derbiunus), or the Derbyan momntain-pheasint, as it is also called. It has the top of the head almost bare, and an elevated kind of cylindrical casque on the crown, situated between the eyes. This remarkable bird is found only in Guatemala, where it is apparently restricted to the forests on the Volcan de Fuego. Here Mr. Usbert Salvin found it feeding on fruits in

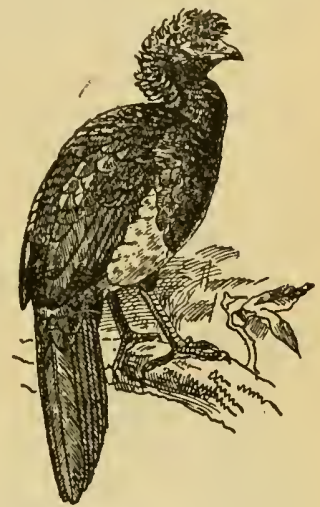

Fiy 6. -The Crested Curas. sow (Crax alector). the higher branches of the forest-trees in the early morning, and descending to the unclerwood as day advances, remaining there all the day time, basking or seratching among the leaves. 'I'his, says Mr. Salvin, is pretty much what the curassows and guans of the lowlands do. The Indian name for the mountainguan is "khannanay," and it is apparently very rare even on the mountain which is its sole habitat.

All the rest of the Game-Birds, comprising by far the greater number of known species, belong to the sub-order Alectoropodes, and have the hind-toe elevated, and raised above the level of the other toes. Mr. Ogilvie-Grant recognises two large families, the Tetreonide or grouse, and the Phasicande or pheasants and partridges. In the grouse the nostrils are hidden by feathers. the toes are mostly feathered, and there are never any spurs on the legs.

Eleven genera are recognised as constituting the family Tetraonidee, and among them are the genera Layopus, Lyiorus, and T'eirao, which are represented in Great Britain by our red grouse and ptarmigan, the black grouse, and the capercailzie.

The willow-grouse or "Ripa" of Scandinavia (Lagopus lagopus) is the most wide-spread of all the group, for it inhabits the northern regions of both hemispheres, varying slightly in different localities, so that many races are recugnised by modern ornithologists. These forms, however, all belong to one type, and they are characterised by a common character, the as- 
sumption of three different styles of plumages, in summer, autumn, and winter respectively, their plumage thus varying in accord with the colour of the country which they inhabit. Thus, in summer, when

The True their surroundings are darkest, the plumage is of a dak Grouse. colour; in autumu, when the tint of the country is grey, they become grey ; and, lastly, when the land becomes white from its envering of snow, the willow-grouse again changes its plumage into snowy white. In our red grouse (Lagopus scoticus), which is an insular form of the * "Ripa," the changes of plumage are quite different, and the bird always remains dark-coloured throughout the year, the necessity for change on the ground of protective resemblance to its surroundings having becone removed in our island elimate. It is to be noticed as a curious fact that the willow-grouse, throughout its changes, never loses its white wings. The nest of the red grouse is al ways

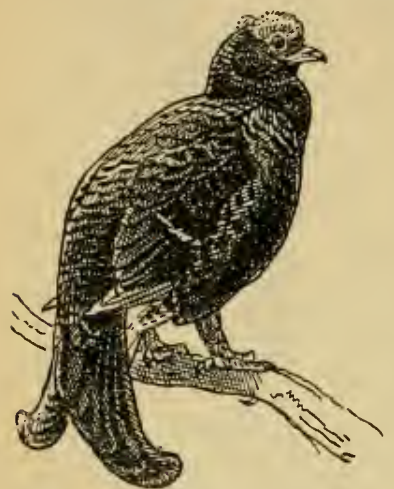

Fig. 7.-The Black Grouse (Lyrurus tetrix). upon the ground, and the birds are subject to the attacks of many enemies, of which the carrion and hooded crows are perhaps the most active. Unlike some of the other grouse, nur British species has but one mate, and is monngamous, the nesting season being in April and May, though sometimes lasting into the early days of June, as grouse are mucl affected by the mildness or inclemency of the season, and when the latter is wet, the number of eggs laid is much smaller than in favourable summers. The red grouse is essentially a bird of the moors, and its place on the higher mountains is taken by the ptarmigan (Lagopus mutus), which also inhabits the higher mountains of Scotland and Europe generally as far east as the Urals.

The black grouse (Lynums) are represented by two species only, one of which, L. tetrix, is our British species, and extends in suitable localities across Europe and Northern Asia to Eastern Siberia, being represented in the Caucasus by a second species, the Georgian black grouse (Lymunus mlokinsievic $\approx i$ ).

These wondland grouse are the largest representatives of the family, and rank, indeed, among the largest of Gime-Birds. They are peculiar to the Old World, where they inhabit the pine-forests of Europe

The and Asia. Four species are known, our British capercailzie Cajercailzies. (Tetroo virugallus) inhabiting certain parts of Scotland and extending its range through the pine-covered mountains of Cunope and Asia as far as Lake Baikal. In the Ural Mountains it is replaced by 'T' uralensis, and again in Eastern Siberia by T. purvirostris, which is represented in Kamtchatka by T. kamtchaticus. They are woodland birds, and vur own species feeds on the tender shoots of lareh and spruce, as well as on various ground-fruits, in pursuit of which it sometimes quits its favourite fir-woods for the more open country. Like the black grouse, the capercailzie has several wives, and desperate fights take place amongst the males, who, at the commencement of the nesting season, are often shot by the hunter, as they are engaged in "laking," as it is called. The male resorts to some particular spot to utter his love-song, and becomes so 
absorbed in his "spell" as to be utterly oblivious to anything going on around linin.

In America several peculiar forms of grouse are found, the dusky capercailzies (Dendragajus) having a naked air-sac on the sides of the neck, which they are able to inflate at will. Mr. Gale describes the nesting habits of D. obscumes in Colorido, and says that the male, during the nesting season, performs some curious evolutions. "If," he says, "you are allywhere near" the haunts of a pair, you will surely hear the male, and most likely seo lin. He may interview you on foot, strutting along before you, in short, hurried tacks, alternating from right to left, with wide-spread tail tipped forward, head drawn in and back, and wings dragging along the ground, much in tho style of a turkey-gobbler. At other times you may hear his mimie thunder overhead again and again in his flight from tree to tree. As you walk along, lie leads, and this reconnoitring on his part, if you are not familiar with it, may cause you to suppose that the trees are alive with grouse. He then takes his stand upon a rock, stump, or log, and distends the lower part of his neck, opens his frill of white, edged with the darker feather tips, showing in the centre a pink narrow line, describing somewhat the centre of a circle; then with very little apparent motion he performs his growling or groaning, I don't know which to call it, which has the strange peculiarity of seeming quite distant when quite near, and near when distant; in fact, appearing to come from every direction but the true one." The pinnated grouse (Tympannchus) have an elongated tuft of feathers on each side of the neck, as well as an air-sac. These and the ruffed grouse (Bonasa) are also North American, being replaced in Europe and Northern Asia by the liazel-hens (Tetrastes), which inhabit hilly and wooded districts.

In the family Phasianidce, which includes all the partridges, quails, and pheasants, we meet with the most typical of the Game-Birds. Mr. OgilvieGrant proposes to divide them into three sub-familiespartridges (Perdicina), pheasants (Phasianince), and Odontophorince, or American tooth-billed partridges. The latter may be at once distinguished by liaving the cutting edge of

The

Partridges. the lower mandible serrated or toothed. The partridges may be recognised by their short and stumpy tails, which never exceed the length of the wing, and there are other minor differences, which the above-mentioned author has pointed out. Unfortunately for the elassification of the Game-Pirds, many forms are intermediate, while the characters assigned to the partridges loold good only to a certain extent, the character which should separato partridges from pheasants, viz. the proportion of the primaries and the secondaries, breaks down, as Mr. Ogilvie-Grant has pointed out, in the important genus Phasicuus, which has the wing of a partridge, but the long tail of a plieasant. Thus the two groups, the partridges and the pheasants, to outward appearance so different, appear to be inseparably connected, and it is difficult to find any line of demarcation between them. Pheasant-like partridges and partridge-like pheasants fill the gap between the true partridges and the true pheasants.

The snow-partridges of the Himalayas are represented by the genus Lever, which has the upper half of the tarsus covered with feathers, indicating an inhabitant of high elevations. Thus we find the genus Lerwa only in the upper ranges of the Himalayan system, from Koteghur to Sikkim, and again in Moupin and the mountains of Szechuen in Western China. It is found near

The SnowPartridges.Genus Itruve 
the snow-line in summer, and is somewhat local in its distribution, inhabiting rocky situations, where its plumage blends with its surroundings, and makes the bird difficult to identify. It nests in the Himalayas at an elevation of from 12,000 to 15,000 feet, and is very tame, probably on account of its habitat being only reached by a most adventurous sportsman, whose visits are few and far between.

These large and handsome birds are readily distinguished by their larg? size and by the number of their tail-feathers, which are 20 or 22 in The number. The snow-cocks, or snow-pheasants as they are

Snow-Cocks. Genus

Tetraogjallus. called (Tetroogallus), are the largest of the partridge-group. and are only found in high ranges, from the nountains of Asia Minor, the Caucasus, and Persia, to the Himalayas, Turkestan, the Altai, and the higher hills of Moupin and North-Western China. In the Himalayas, the snow-pheasant (T.himclicyensis) is an inhabitant of the snowy ranges, from which it only migrates to somewhat lower altitudes on the approach of the winter snow. These birds are generally found in packs of from five to ten, but sometimes twenty or thirty are in a single flock; and even during the nesting-season a good many are found in company. Snow-pheasants are birds of the open, rocky hill-country, frequenting grass-lands, and never entering the forest or perching on trees. They are, therefore, evidently gigantic partridges in their ways, and it is a mistake to call them snow- "pheasants," as is so often done.

The red-legged partridges differ from the true partridges in having only 14 feathers in the tail. 'They are also easily recognisable by the beautiful

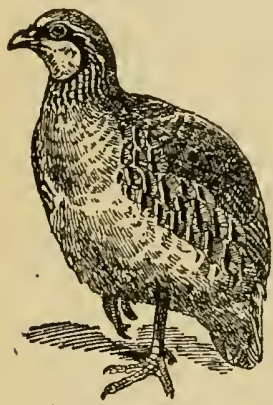

Fig. 8-THE RED.

Ligiged Partinue (Caccabis rufa). barring of red, grey, and black of the sides of the body. The most familiar of all the group is the redlegged partridge of England (Caccalis mifo), which is contined to South-Western and Western Europe. In North-West Africn, Sardinia, and Southern Spain it has a near ally in the Barbary red-legged partridge (C. petrosi $)$, while the rock red-legged partridge $(C$. surcetil is) takes its place in the mountains of Southern Europe, from the Pyrenees to the Balkans. A paler form, known as the Chukar or Greek partridge (C. chutiar), extends from Greece through Central Asia to China, and is a well-known bird in the Himalayas. In Tibet and Kokonoor a large species, Prjevalski's red-legged partridge (Caccabis magna), is met with ; but the largest of all is the black-headed red-legged partridge (C. melanocephalu), which lives in Southern Arabia, and is a very fine bird, approaching even some members of the genus Tetruogallus in size. The distribution of these species of Caccrbis is most interesting, and there is no doubt that climate exercises considerable influence on their plumage, those which inhabit dry and sandy localities being paler than those of the more cultivated country. This is especially true of the chukars; but considerable variation in tint is also seen in the common red-leg from different areas. The chukars inhabit dry and stony situations, and never go into the forests, pre. ferring in the Lower Himalayas the grassy hill-sides to the cultivated fields. In summer they are met with in pairs, or in small parties; but in winter they assemble in loose, scattered flocks, sometimes to the number of forty or fifty, or even a hundred. 
In the bare portion of the countries between North-Western India, Persia, and North-Eastern Africa, is the home of the see-see partridges (Ammonerdir), of which two species, 1 . bonhum $i$ and $A$. heyi, are known; and then we leare the true partriclges for the francolins, which are a rery large group, principally African. They may be divided into two genera, Funcolinus and Pternistes. Both these genera lave 14 tail-feathers; but the former has it feathered throat, while in Pteruistes the throat is bare. More than forty species of francolin are known, of which all but four are peculiar to Africa. They inhabit all kincls of country : some the open grass-lands, some bare and desert situations, while others are found in forest-lands.

This interesting species ( $F$. franeolimus) has now been prictically exterminated in its former ham in Sicily and other parts of Southern Europe, but is still found in Cyprus, Palestine, and Asia Minor, whence it extends castwards to the Indian Peninsula, as far as Assam and Manipur. It is familiarly known as the black partridge, hy Indian sportsmen, and is a favourite Game-Bird in the north-west provinces of India, though it is much less

The Common

Francolin.-

F. francolinus. common in many places than it was formerly. This is partly owing to the persecution it receives, while from the accounts published by Mr. Allan Hume and his friends, the frincolin is not a prolific breeder, and the young birds suffer from the clepredations of stoats, jackals, etc. It is, like most of its kind, a ground birl, but Mr. Greig says that the cock will at times get on to a stump or ant-hill, when calling, and he has even seen them high up in fir-trees. The natives are very fond of keeping the francolin as a pet, and numbers are netted by them. Some of the African species are quite small, scarcely larger than a quail, whilst others are of large size and heavy build, and they aro sometimes so disinclined to fly, that after being flushed a second time, they will allow themselves to be taken with the hand rather than rise agrain.

These birds have all the appearance of francolins, but differ from them in having the throat naked. Nine species are known, and they are all peculiar to the Ethiopian region. Pternistes sucrinson $i$ is one of the best-known species, and is the "pheasant" of Matabeleland. Mr. T. E. Buckley says that the coveys are extremely difticult to flush, aud they prefer to escape by ruming. In the day-time they come out into the open, and frequent the Genus Pternistes. neighbourhood of small streams; they pass the night in the

brushwood, and roost on trees. They feed on bulbs, seeds, berries, and insects. The egrgs of Swainson's bare-throated francolin are six or more in number; they are rounded in shape, of a pinkish cleam-colour, finely speckled with chalky-white.

In the Malayan Archipelago the francolins of Africa and India are represented by the genus Rhimothera, distinguished by its long bill. The typical species, the long-billed francolin ( $R$. longirostris), is an inhalbitant of the southern portion of the Malay Peninsula, Sumatra, and the lowlands of Borneo. In the highlands of the latter island, on Mount Dulit, at an elevation of 4,000 feet, it is replaced by Hose's long-billed francolin (Rhizotheru dulitensis).

Of these birds our common partridge $(P$. perdix $)$ is the type, and the bestknown species. In illustration of the curiosities of bird-life, especially in species the most familiar to us, I may mention that Mr. Ogilvie-Grant, who has made the game-birds his special study, has recently discovered differences in the coloration of the sexes of the partridge hitherto unrecorded. 
The malc, as might be believed, has a large horse-shoe shaped mark of chestnut on the breast. This is either feebly developed or entirely absent in the adult female, which can always be recog-

The True Fartridges.Genus Perdix. nised by the barred wing-coverts, of which the ground colour is black, with widely set buff cross-bars. Young hirls of buth sexes can be told by the pointed, not rounded, end to the first primary, while the yellowish horncolour of the feet is also a distinguishing character. Then comes the curious fact that the young female has a horse-shoe mark on the breast, which is not seen in the immature male. Many ornithologists recognise certain races of the common partridge in Europe, and a small form, supposed to inhabit the ligher ground in summer and to desccnd to the lower ground in winter, is known as Perdix damascenc. A still more curious hill race from the mountains of Lorraine, which crops up occasionally in certain parts of England, is the mountain partridge (Perdix montana), a bird almost entirely rufous, with a creamy buff head. It cannot be considered more than a variety of the ordinary partridge, but at first sight would seem to be a perfectly distinct species.

In Eastern Siberia our common partridgc is represented by the bearded partridge ( $P$. dumica), which has tufts of feathors on the throat, forming a kind of "beard." In Tibet and Kansu two species of true partridge are encountered, $P$. hodgsonice and $P$. sifanica, both of which have sixteen tail feathers, instead of eighteen, as in our common species.

Passing by several small genera of bush quails (Margaroperdix of Madagascar, Perdiculu and Microperdix of India), we come to the tree partridges (Arboricola) which inhabit the hill ranges of the Himalayas,

The Tree Partridges.Genus

Arboricola. Assam, and the Burmese provinces, and those of Sumatra, Java, Borneo, Hainan, and Formosa. This distribution is interesting as showing the Himalayan element in the mountain fauna of the last-named islands. In the lower hills of Burna, Malacca, Sumatra, and Borneo occurs the allied genus Tropicoperdix, which contains a couple of species very like those of Arboricola, but distinguished by the absence of the supra-orbital chain of bones, which is one of the features of Arboricola. Closely allied to these tree-partridges are the genera Hicmatortyx of Mount Kina Balu, in North-Western Borneo, remarkable for its three-spurred leg and crimson head, and Caloperdix, the latter genus containing three species, inhabiting respectively the mountains of Tenasserim and the Malay Peninsula, Sumatra and Java, and North-Western Borneo. The crested wood-partridges (Rollnlus), which have a tuft of long liair-like bristles on the middle of the forehead, are represented by a single species ( $R$. soulon $l$ ), which is found in the Indo-Malayan sub-region from Southern Tenasserim and the Malay Peninsula to the Sunda Islands. It is accompanied in the greater part of its range by the black wood-partridge (Melanoperdix nigra).

These little birds are only found in the Old World, the common or migra. tory quail (Cotumix cotnmix) being found in Europe and Nortlern Asia in summer, and migrating in vast hosts. The numbers which The Quails. - appear in the winter quarters of the species, in Northern Genus Coturnix. Africa, in Egypt, and, above all, in North-Western India, are sometimes incredible. Colonel Tickell, in one of his shooting experiences, speaks of them as like locusts in nuniber. In Soutl Africa our European quail is replaced by the Cape quail (Cotumix capensis), 
which extends northwards to the Azores, and the Canary Islinds; and in Japan, Mongolia, and China, C.juponicu replaces $C$. coturmix. 'The female of $C . j u p o n i c a$ is bearded, which is a curious fact, when one remembers that a bearded partridge of Siberia replaces our own western partridge ( $P$. perdix). In Indial, Africa, and Australia are peeuliar species of the genus Cotumix, and New Zealand formerly possessed a species of its own (C. noze zeclumdice). The New Kealand quail is now extinet, and specimens are valued at nearly $£ 100$, and yet tifty years ago it was so common that twenty brace in a day's shooting wis not considered a lange bag! If the sportsmen of those days hatd known of the impending extinction of the species, and had preserved the skins of the birds they shot for the table, a small fortune might have been their lot.

These small birds are peculiar to the Australian region, inhabiting Australia, New Guinea, and the islands of Timor and Flores. They closely resemible the true quails, and only differ in their short grey

axillaries. The eggs, however, are not so boldly marked as The swamp and in those of the quails, and are of a pale bluish white, with a Painted Quails. number of light brown spots. The painted quails (Excalfactorice are birds of small size, but of many colours. They inhabit India, the Indo-Chinese countries, and the entire Malayan Archipelago to Australia, while one species, $E$. adansoni, is found in Africa.

Under this sub-family are also included the turkeys and the guinea-fow-s, and it contains the most widely distributed and the most highly decorated of the Game-Birds. The bamboo-plieasants and the spur-fowl of the Indian region have rather the aspect of partridges than true pheasants. Another intermediate form between the two sub-families is seen in the blood-pheasants (Ithagenes) of the Himalayas and the allied chains of mountains in Nortl-

The Pheasants.

- Sub-Family

Phasianinu. Western China. They are forest birds, living at a great altitude near the snows, affecting the clumps of mountain-bamboo, and feeding at some seasons on the tops of pine and juniper, when their flesh is somewhat rank to eat, and at others on seeds and small fruits, when their flesli is quite palatable.

"These splendid birds, generally called "Argus" pheasants by Indian sportsmen, on accomnt of their white-spotted plumage, are found in the Himalayas and the hills of Assam and South-Eastern China. They are remarkable for the adornments of the males, which have fleshy horns and a bare gular lappet of bright colours. The latter is displayed during the breeding-season, but is Genus Tragopan. scarcely distinguishable in the winter, when the birds are most easily observed, as they descend to the lower grounds and are often snared by the natives. In summer they frequent the forests near the snow-line.

The monnals or impeyan pheasants are some of the handsomest of all known birds, their plumage being metallic, and of divers colours of green, purple, and blue, and they carry a crest of light spade-shaped

plumes or curled feathers. They inhabit the higher ranges The Moonals.of the Himalayas and the mountains of Assam and Western China, descending to lower elevations as the winter comes Genus on. Mr. Hume, speaking of the common moonal, says:-

Lophophorus.

"There are few sights more striking, where birds are concerned, than that of in grand old cock shooting out horizontally from the hillside just below one, glittering and flashing in the golden sunlight, a gigantic rambow. 
tinted gem, and then dropping stome-like, with elosed wings, into the abyss below."

The fire-backed pheasants (Acomus and $L$ (nphwor) are inhabitants of the momntains of the Judo-Chinese provinees and the Mialayan Peninsula and Islands. On the high mountains of North-Western Borneo, on the Lawas River and the region of Mount Dulit oceurs one of the most remarkable of all game

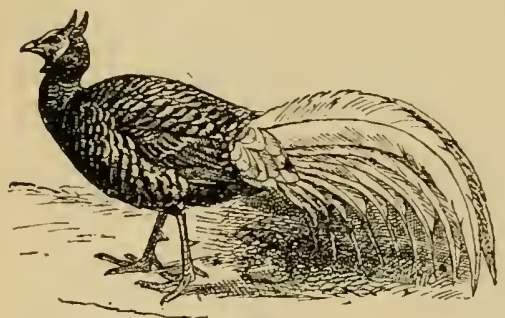

Fig. 9.-Lobed Pheasaxt (Lobioplasis bulweri). bircls, the lobed pheasant (Lobioplirsis), which has no less than thirtytwo feathers in the t:il, which, as Mr. Ogilvie-Grant says, is "by far the largest number of tail-feathers in the Phasicuider. One of the eared phensants (Crossoptilum ruritum.) has twenty-four, and the smallest number occur's in the painted quails (Excolfuctoric), which have only eight!" The female of the lobed pheasant, howerer, has twentyeight feathers only. The horns and wattles on the head show some sort of likeness to the naked ornaments found in the tragopans, but the style of plumage is in other respects entirely different. Like the tragopans, the lobed pheasant inhabits the mountains, but does not extend beyond 2,000 feet, and, aceording to Mr. C. Hose, it lives in the forest, and has the ways of a jungle-fowl.

In these birds, which are remarkable for the long white tufts on the side of the head, whence the name of "eared" pheasants, the sexes are alike in colour. They are large birds, inhabiting the high mountains

The Eared

Pheasants. Genus

Crossoptilum. of Tibet, Western China, and Manchuril. They live in the woods at high elevations, and assemble in large flocks.

The best-known species of fremurns is the silver pheasant, so often seen in aviaries. The kalijes inhabit the Himalayas and the lills of Assam and Burmah. In the Himalayas they are found at different elevations, from 1,000 up to 9,000 feet. They are easily rearod in eaptivity, and large number's are snared by the natives. The black-backed kalij is described by $\mathrm{Mr}$.

The Kalij

Pheasants. Genus Giemurus
Gammie, a well-known Himalayan naturalist, as being very tame when it is found away from its mative forests, which it does not often quit. He says :- " In fine weather, the male often makes a sharp, drumming noise by beating his wings against his sides, somewhat after the style of the wing-flapping of a domestic cock, preparatory to crowing from some elevated place; but instead of the cock's few leisurely flaps, the kalij strikes oftener and sinarter, producing a sound more like drumning than flapping. This noise is heard at all seasons of the year, but most frequently before the setting in of the rainy season; at other times just before a fall of rain. Hence the natives look on tho drumming of the kalij as a sure sign of approaching rain." The Himalayan kalijes, even in a wild state, interbreed, while in the species from the Burmese provinces, intermediate forms also occur, which render it diftienlt to draw the line between the different species.

The koklass or pucras pheasants (Pucrasice) are found in the Himalayan chain from Afghanistan eastwards to Tibet, and the mountain ranges of 


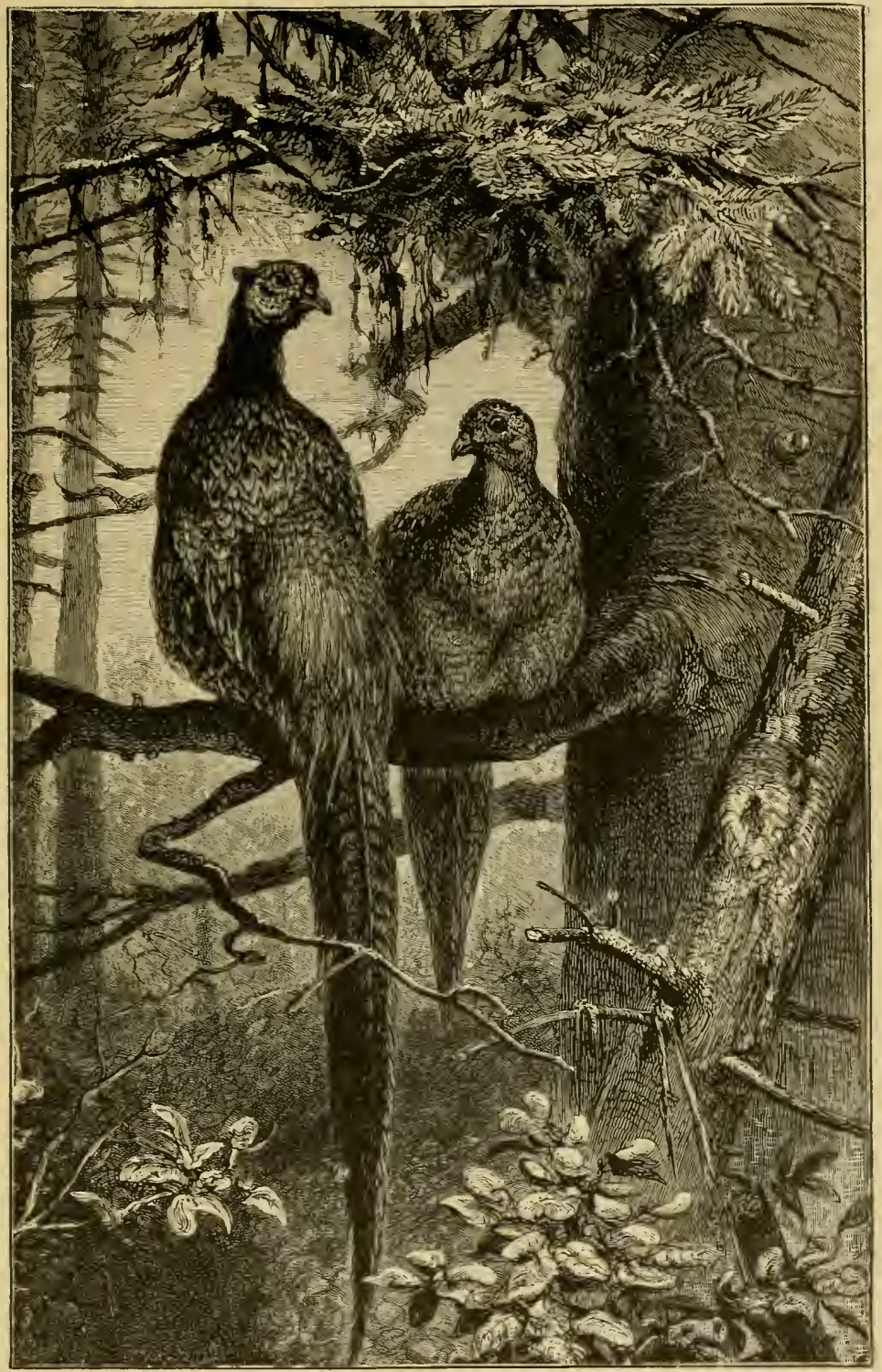

Commos PheAsaxts. 

Sunthern China to Fukien and Manchuria. They are birds of the forests like the kalijes, and of a somewhat retired and solitary disposition, according tu Mr. F. IIilson, who wites of $P$. macrolopha:- "In the remote forests of the interior of the Himalayas, on the report of a gun, all the koklass pheasants within half a mile or so will often erow after' such a report. They will also crow after' a elap Genus l'ucrasia. of thmoler or any loud or sudden noise, and this peeuliarity

seems to be confined tu those which live in the dark shady wouds of the interior, as I never noticed them acting thus in the lower hills. The food of the koklass pheasants is varied, like that of the kalijes, and consists, according to Mr. irilsum, of leaves and buds, roots, grubs, acorns, seeds, ber'ries, moss, and flowers. The nest of $P$. macrolopha is deseribed as a liole seraped in the ground, and sheltered by a tuft of grass, or a bush, or rock. The species is found nesting at an elevation of from 5,000 to 11,000 feet in the Himalayas."

To the grenus Phusiumus belong the birds which we all know familiarly as pheasimts, and it is interesting as representing one of the few types peculiar to the l'alianctic region. There are a great many species of the gemus Phusiunus scattered througl Europe, Central Asia, and China, must of them being of the form and general coloration of our common pheasant ( $P$. colchicus), which is supposed not to be a native of ITestern Europe, but to have

The Common Pheasant. Phasiuntes colchicus. leen imported from the Caucasus or from Asia Minol.

Recent discoveries of fossil lemains, however, tend to prove that pheasants of some lind were ancient inhabitants of the western Paliearetic region, and it is quite possible that the phensant of om own day is a descendant of these ald forms, and that the story of its introduction into England by the Romans is a myth. At the present time it is very dificult to find a purebred pheasant in the British Islands as by far the greater number those birds lilled in the autumn have white rings romd their necks, uwing to the introcluetion of the Chinese ringr-neeked plieasants, with which our native birds have freely erossecl. The genus Phosiums is one of the few typieal forms of bircls peculia to the Paliearetie region, for in the Hinalayas it is represented by the cheer pheasant

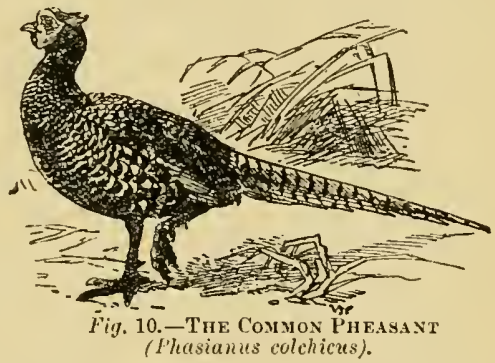
(c'ulreus vullichii). Thus the true pheasants are found in temperate Europe, where $P$. colchicus is the only representative species of the genus, to Central Asia and China, where the species are many, though in these countries the pheasants have either white rings on their necks or white patehes on the upper part of their wings. Of $P$. colchicus there are several representative rices, as for instance $P$. talischensis, from Talisch, on the south-western border of the Caspian Sea; $P$. persicus, from the south-eastern shores of the Caspian; and $P$. principalis, from North-IVestern Afyhanistan. Thence in the Uxus Valley, Zarafshan, and other localities in Central Asia, om common pheasant is represented by various speeies and races, for a description of which students must search the writings of Mr. Ogilvie-Grant and others. The ring-necked pheasants are found from Turestan to Kuldja, Eastern Siberia, 
China, and the island of Formosa. In Japan a splendid species is resident, $P$. versicolar, remarkable for its dark green breast, and in the same country are found the copper pheasants ( $P$. scommeringi and $P$. scintillans), birds of a different type altogether from our ordinary pheasant. The finest of all, however, is Reeves' pheasant (Phasianus reevesi), which lives in China, and is remarkable for its white crown and the length of its tail, which, in fully adult birds, attains to the dimensions of five feet!

The barred-backed pheasants (Callophasis) are represented by two species only, C. eilioti, from the mountains of South-Eastern China, and C. humiee, from the Shan States and the Lushai Hills and those of Manipur.

The best-known species of the genus Chrysolophus is the golden pheasant (C. pictus), and the name is commonly used to designate the genus, and is

The Caped

Pheasants.

-Genus

Chrysolophes perfectly appropriate to the golden pheasant, but is a misnomer for the Lady Amhersts' pheasant, which has no golden colour on its neck, but carries a "cape" of white, barred with steel-blue. The golden pheasant inhabits Southern and Western China to Kokonoor, and C. Amherstice replaces it in the mountains of Western China and Eastern Tibet.

These birds have a special interest, as it is from them that all our breeds of poultry have been derived, although it is difticult to believe that a cochinchina, a dorking, or it Spanish fowl can have originated in

The Jungle-

Fowl.-Genus Gullus. these spangled, many-coloured denizens of the forests of the East. The nearest approach to the wild stock that domestic variation produces is found in the "Game" fowl, and a very interesting group is to be seen in the Natural History Museum of some birds shot wild in the Fiji Islands by Mr. E. L. Layard, C.M.G. In the early voyages in the Pacific by Captain Cook and other navigators, fowls were turned loose on some of the islands, to provide food for any unfortunate sea-faring folk who might be shipwrecked on them. At the present day these birds have taken to their original habits as jungle-fowl, and have to be hunted and shot. They have, moreover, reverted to the plumage of true junglc-fowl, and though the cocks still show traces of a domestic strain, the hens, as well as some of the cock-birds, have assumed once more the coloration of the wild stock from which they were originally derived. The true jungle-fowl are found at the present day in the Indian Peninsula and Ceylon, the Indo-Malayan region to Cochin-China and the island of Hainan, south to the Philippines, Java, Sumatra, Borneo, Celebes, and other islands of the North Moluccas.

These are birds of grey coloration, but remarkable for the metallic green, purple, or blue spots or "eyes" which adorn their plumage. Five species

\section{The Peacock}

Pheasants. Genus

Polypectrum. are known, inhabiting the Himalayan system of mountains from Sikkim to Tenasserim and Cochin-China, and thence throngh the Malayan Peninsula to Sumatra, Burneo, and the islind of Palawan in the south of the Philippine Arehipelago. They are found from the lowlands up to 6,000 feet in Tenasserim. They seem to affect forest country, feeding on fruit, insects, worms, and small land-shells. The call of $P$. chinquis, the Ifimalayin species, is said by Mr. Clark to be something like a laugh-" ha-hu-ha-ha. Mr. John Whitehead says that in Palawan he found the species of the island, $P$. napoleonis, very local, and his specimens were all collected in one district of the forest. It is not known for certain whether the peacock pheasants are polygamous, and Mr. Whitehead inclines to the idea that they are not; but 
Mr. Clark once came aeross a party of four, consisting of one male and three female birds. In Palawan Mr. Whitehead found that Napoleon's peacoek pheasant had a "showing-off" ground, like that of the argus pheasants, a bare space cleared in the forest, kept scrupulously clean, "with a small hump of earth in the middle, where, no doubt, the male birds show ofl their splendid plumage, and perhaps do battle." He adds that the fights, if they have any, must be very short and decisive, as the double spurs of the cocks would be sufficient to cut his adversary into bits. In the Himalayan speeies, $P$. chinquis, which ranges into Cachar and Tenasserim, as nany as four spurs are sometimes found on the legs of the male.

Of these extraordinary pheasants, three species are known: the common argus (A. argns) of the Malay Peninsula, Gray's argus (A. grayji) of Borneo, and $A$. bipunctatus, the habitat of which is at present unknown. In Tonquin the erested argus (Rheinhardins ocellatus) oceurs. The argus pheasants are remarkable for "the hundred metallic eyes" on the wings, the feathers of which are prolonged in an extraordinary manner, while the tail-feathers exeeed in length the

\section{The Argus \\ Pheasants. - Genus \\ Aryusianus.} dimensions of any of the Game-Birds. Like the giraffe, which most people would think to be incapable of threading its way through jungle, the apparently clumsy argus makes its escape by darting into the thicket, and it is one of the most difficult of birds to foree into flight. So siys the greatest of modern collectors of birds, the late $\mathbf{M r}_{\mathrm{r}}$. W. $\mathrm{R}$. Davison, who spent years in the jumgles of Tenasserim and the Malayan Peninsula, engaged in forming that wonderful collection of Oriental birds presented to the nation in 1885 by Mr. Allen Hume, C.B. In Tenasserim he paid great attention to the habits of the argus, and is perhaps the only white man who has seen the bird in its native haunts. He found them extremely shy and difficult of observation, never rising, but seeking safety in running a way through the thick jungle. The males themselves do not seem to engage in combat, though they will answer each other's call. The note is "how-how," repeated ten or a dozen times, though the report of a gun in the neighbourhood, or the passing of a troop of monkeys, will set every male calling. The cry of the female is different, "how-o-woo," repeated ten times or more. The males clear an open space in the forest, which Mr. Davison believed to be a "dancing-ground," though he never caught a bird in flagrante delicto. Not a leaf is allowed to soil the hallowed spot, though occasionally a male of the fire-back pheasant will intrude, and take a savage delight in driving the argus from his carefully-prepared "arena."

Two kinds of pea-fuwl are known, the common Paro cristatus of India and Ceylon, and P. mutiens of Indo-China and the Malayan Peninsula. These birds do not ascend the mountains, as a rule, but are plentiful in the plains of North-Western India, and in The Pea-Fow1. Rajputana they are held sacred by the natives. Near JeyGenus Paro. pur, for instance, the number of pea-fowl is very large, and they can be observed from the windows of the passing train, walking atout in the grass near the sides of the line, or perching on the fences. They are rery well-known birds in confinement, and the "train" of eyed plumes, formed by the elongated upper tail-coverts of the male bird, is one of the most extraordinary clevelopments of plumage in the Class $A$ res.

Two very aberrant forms of guinea-fowl, Phusidus and Agetustes, inhabit West Africit, from Liberia to the Congo; but the true guinea fowls (Numida) 
are found over nearly the whole of Africa, to which continent and Madagascar they are peculiar. Seren species are recognised, each with a kind of horn or helmet on the head, and they are all birds of the

The Guinea- open country, in contradistinction to the crested guineaFowls.- fowls, which are forest-haunting birds. The true guireaGenus fowls (Numidu) go in tlocks, and frequent the scrubby Numida. bush on the borders of streams. They escape by running, but when hotly pursued by a dog, they take to the trees, and are so occupied with taking stock of their canine pursuer, that they can be shot down, one after the other. That they can be easily tamed is proved by the way in which they are domesticated in nearly every country. In Damara Land, the late Mr. C. J. Andel'sson says that he has seen a thousand together. When the birds assemble in search of water, and when a pool is discovered, the first-comers act in a most civilised manner, approaching and drinking their fill, and retiring in an opposite direction, that the next in order may have room to file in and slake their thirst.

Of the crested guinea-fowls (Guttera) four species are known, all inhabitants of the bush-comntry and forests. One of them is peculiar to West Africa (G. cristata), one to South-East Africa ( $G$. edouarcli), and one to East Africa (6. pucher(ni). Like the ordinary guinea-fowls, when hunted with a dog; they take to the trees, and are easily shot. One of the most beautiful of the group is the vulturine guinea-fowl (Acryllium vulturiuum), with a bare head like a vulture, whence its name, and remarkable for the bright cobalt-blue colour on the wings and flanks. The bare portions of the head and neck are also cobalt-bhue. It is an inhabitant of Eastern Africa, from the Pangani River to Somali Land.

The common turkey of our farmyards is descended from the Mexican turkey (Meleagris gallopavo). Many races of wild turkeys are known in the Southern

The Turkeys.Genus Meleagris. United States and Florida, each of which has a seprrate and clefinite range; but the most beautiful species of all is the Honduras turkey ( $\boldsymbol{M}$. ocelluta). Though they feed on different kinds of seeds during the day, the turkeys betake themselves at night to the trees to roost. They even ascend the momntains to a height of 8,000 to 10,000 feet, descending to the lower valleys in autumu, when they congregate in great flocks. They are polygamous, and the male

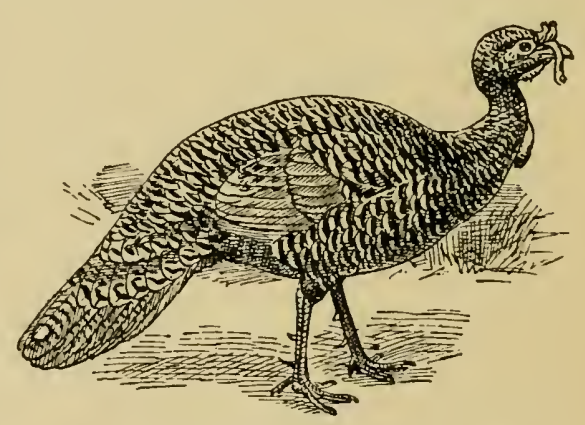

Fig. 11. -THE TURKeY (Meleayris gallopuro).

leaves to the female the entire duty of rearing the young.

These are all birds of the New World, and are remarkable for having the

The Toothed Partridges. -

Sub-family Odontophorhinx. edge of the lower mandible serrated and toothed. They are a somewhat large group, and include all the colins and tufted and painted partridges. Two of the best known species are the Californian quail (Lophortyx ealiformiana) and the Virginian quail (O,tyx rirginianus). 
At the end of the series of Game-Bircts are found some tiny birds, which look like dwarf partridges. These aro the bustard-quails or hemijodes, which were formerly associated with the true quails (Coturnix). The differences between the hemipoiles and the The Hemipodes. Game-Birds are chiefly osteological, and need not be detailed -Genus T'urnix. here; but the absence of the hind-twe distinguishes the genus Turnix at a glance, though the Australian genus Pedionomus has four toes like an ordinary Game-Bird. One of the most curious facts connected with the hemipodes is the superior size and colour of the female. In some cases she is nearly twice the size of her mate, and on the latter devolves the duty of hatching the eggrs out and taking care of the youmg. It is curious that these little birds should have such an ostrich-like peculiarity, but there is otherwise nothing struthious about them, for the hemipodes have the bones of the palate more like those of Passerine-Birds than those of Game-Birds. They frequent the open julains and grass-country, but are also found in some places on the outskirts of cultivation. Hemipodes are entirely birds of the Old World, and are distributed over Africa, Madagascar, India, and China, and extend throughout the Malayan Archipelago to Australia.

The sand-grouse are peculiar birds, half Pigeons, half Game-Birds, of which the English people are not ignorant. Although the sand-grouse are birds of the desert, and are found throughout Africa, Central Asia, India, and the Tibetan and Mongolian plateaux, there is one species, Pallas' sand-grouse (Syirhoptes paradoxus), which makes regular irruptions from its Eastern home in the

\section{The Sand- Grouse-Order Pterocletes.} Kirghis deserts inte Western Europe, and at times visits England in swarms. Doubtless these immigrations have occurred for ages at regular intervals, but in the Middle Ages our ancestors were too much vccupied in fighting and cutting each others' throats to notice a swift-flying bird like the sand-grouse, which their weapons would liave been powerless to capture. And thus it happens that our first great record of the occur'ence of Pallas' sand-grouse in England took place in 1863, and then again in 1888 another great irruption took place, when not only a large number were seen in Western Europe, but they actually stayed and even nested in Great Britain. In some places the Hocks were protected by intelligent land-owners; but they ultimately clisappeared, having apparently migrited back to their Eastern liome.

The sand-crouse are certainly desert bircls, their very plumage

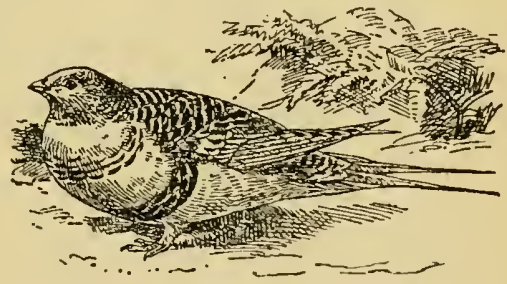

Fiy. 12.-The Pix-taled Saxi-Grouse. I'terochures ulchate

being of a sandy colour, and assimilating to their surroundings. In many of their osteological characters they resemble the pigeons, but in the digestive organs they resemble Game-Birds, so that their natural position is as a distinct order between these two well-marked groups. They have feathered legs, but never carry a spur like Game-Birds, and they have either three toes, or, if the fourth toe is present, it is only rudimentary. The egg is, howerer, peculiar, being neither white like that of the pigeons, nor uniform like that of the pheasants and partridges, nor richly mottled like that of the grouse, but double-spotted, with brown spots mostly in evidence, and under- 
lying spots of pale purple. The eggs are, moreover, oval in shape, but equally rounded at each end.

Although the sand-grouse are not often observed during the day-time, they are to be obtained in the mornings and evenings, when they assemble at the water-pools to drink. Of Pallas' sand-grouse the late General Prjevalski writes :- "At the drinking-places, as well as at the feeding-places, these birds never settle on the ground without first describing a circle, in order to assure themselves that there is no danger. On alighting, they hastily drink and rise again; and, in cases where the flocks are large, the birds in front get up before those at the back have time to alight. They know their drinkingplaces very well, and very often go to them from distances of tens of miles, especially in the mornings between nine and ten o'clock, but after twelve at noon they seldom visit these spots." Sometimes the sand-grouse are driven south by an unexpected fall of snow, and by elearing the snow from a patch of ground, Swinhoe tells us that the natives sometimes manage to net an entire flock of birds. It may be such a sudden snow-storm that forces the sand-grouse of Central Asia to make the unexpected invasion into Western Europe to which we have referred.

The Pigeons are a large order of birds, and are divisible into two suborders, viz, the Columbce or True Pigeons, and the Dodos (Didi). Pigeons have a swelling of the bill near the tip, similar to the bill of The Pigeons.- the plovers, which we shall discuss presently. At the base of Order Columbiformes. in some of the fruit-pigeons, and is generally of a bright colour. The osteological and anatomical characters which seprate them from the Game-Birds (which some of the ground pigeons greatly resemble) are numerous, the chief one, perhaps, being that the fore-part of the sternum or breast-bone is never perforated to receive the feet of the coracoids, as is the case in the Game-Birds. The nest which pigeons build is one of the simplest structures known among birds, for it consists of a slight eradle of sticks, and is generally placed in a tree. The eggs are white, and two in number, though there are many species which lay but a single egc, and in this order of birds we meet with the great exception to the rule in the Class Aves, viz. that birds which lay white eggs usually nest in holes or burrows, so that the eggs are concealed from view. Not only, however, are the eggs of the pigeons white, but the frail platform on which they are placed renders them easily visible from above, and often from below. The young are hatched naked, but after a little while become clothed with hairy down; they remain helpless in the nest for a long time after they are hatched, and are fed by the old birds.

The True Pigeons, of which our ring-dove or wood-pigeon, and the ordinary dove-cote pigeons may be taken as representatives, constitute the order Columbce, and they are divided by Count Salvadori, the latest monographer of the order, into five families.

The first family of the pigeons consist of the fruit-pigeons (Treronide $)^{\text {) with }}$ three sub-families, Treronince, or green fruit-pigeons, painted fruit-pigeons (P'tilopodince), and true fruit-pigeons (Carpophagince). The The Fruit- green fruit-pigeons are found in Africa, India, and the IndoPigeons.-Family Chinese sub-region, through the Malayan sub-region to the Treronida. Molucea Islandis. All the members of the sub-family Trcronince have the tarsus short, exceeded in length by the middle toe, and the tail feathers vary from 12 in number to 16 , while the 
chief peculiarity is the broadening of the toes beneath, and having the skin expanded on the soles, as Count Salvadori has pointed out. The green fruitpigeons are accustomed to assemble in flocks of comparatively large size, and feed, as a rule, on small fruit.

The Ptilopoline include some of the most beautiful birds of the workl among their number. Although they are mostly birds of small size, the exquisite blending of their bright coloration renders their combination of plumage extremely beautiful, and there is $n 0$ more wonderful bird in the world thin the golden fruitpigeon of the Fiji Islands (Chrysenas victor).

The true painted pigeons (Ptilomes) are nearly all highlycoloured birds, and have generally the first primary narrowed to a slender point. They are among the smallest of all the pigeons, many of them scarcely exceeding the bulk of a thrush, but they are ornamenterl, as a rule, with a patch of bright colour on the fore part of the crown, which may be rose-colour, pink, or even pale lavender. Very little has been written about their habits, but of the allied genus, Megaloprepia, which las not the attenuated ending to the first primary-quill, and has a somewhat longer and more rounded tail than Ptilopms, we learn from Gould that the magnificent fruit-pigeon (Megaloprepia magnifica) is found in the bushes of the interior of South-Eastern Australia, where it feeds on wild figs and the nut-like fruit of the large pahns. It is a shy bird, and is not easily discovered, unless it betrays its presence by the hoarse, loud, and monotonous note, which is frequently uttered by the male during the pairing season. The note is so extraordinary, and so unlike that of any other bird, that it causes the utmost surprise and wonderment as to what it can proceed from, in the minds of persons who hear it for the first time. Five species of Megaloprepia arc known, ranging from the Northern Moluccas to New Guinen and to South-East Australia; whereas no less than 75 of the painted pigeons (Ptilopus) are known. They are distributed over the Malayan Archipelago, from the Malay Peninsula to Australia, and even to the Pacific Islands. In Madagascar and the neighbouring islands they are represented by the species of wattled fruit-pigeons (Alectrences), of which four kinds only are known, that from Mauritins, $A$. nitill issima, being now extinct.

In this sub-fanily are found some of the largest of all the existing pigenns, and many of them are beantifully ornamented with bright patches of colonr. Even where ornamental plumage does not obtain, the tones of rufous and grey and bronzy-green render them very lovely birds. Some have a fleshy knob at the base of the bill, as in the grenus Globicera; others carry a conspicuous crest, as in Lopholaimus. They are found from India and the IndoChinese countries throughout the entire Malayan Archipelago to Australia. One of these great fruit-pigeons, Curpophaga rence, is a very well-known-bird in certain parts of India and Burma. In the lastnamed province Mr. Eugene Oates says that the imperial green fruit-pigeon, as he calls (\% cener, is generally distributed throughout the forests and wellwooded parts of the country, wherever, in faet, there are trees which yield edible fiuits. It is entirely arboreal, going about in parties, and occasionally in couples, and feeding on fruits. It makes its nest in thickets and bamboo bushes, and lays but one egg, though in India two young birds have been found in a nest.

In the true pigeons, of which our wood-pigeon and rock-pigeon may bo 
considered the types, the tail is always composed of twelve feathers. The soles of the feet are not so broad as in the fruit-pigeons, and, according to Count Salvadori, only the hind-toe has any expansion on the

The True

Pigeons. -

Family

Columbielee. sides. Only foul senera of columbide are achitted by the above-liamed author, riz. (rymnophops, represented by it single species from South-Eastern New Guinea, G'. albertisi, named after the famous Italian naturalist, D'Albertis, who discovered it ; Columbu, with fifty-eight species and a cosmupolitan range; Nescenas, from Mauritius, with its single species, N. mayeri; and 'Tutmena, peculiar to Africa, with five species.

It is not necessary to dilate on the characteristics of the ordinary pigeons, In the woods, the wood-pigeon or ring-dove is, in many parts of its range, the mildest and shyest of birds, but in confinement it makes the tamest of pets, and can be fed by children in the gardens of Paris, and is now so civilised that it is one of the features of St. James' Park in London. 'The stockdove (C." crencs) is a more retiring bird, and nests in holes of trees or of old buildings, while the rock-dove ( $C$. licire) frequents caves on the sea-coast. From the latter are believed to have sprung all our numerous forms of domestic pigeon. All the species of the African genus Tutwruma are somewhat rarc, and little is known of their lubits.

All these are Finstein birds, with a rery long tail, exceeding the wing in length. Only fons genera are known: T'urucum, of Celebes and Timor ; Mucromygia, the dominant form, with about thirty speeies, The Long-Tailed mostly of a rufous colonation, with many bands ; Rein-

Pigeons.- -

Sub-family Marropyyiine. curdtenas, with its three species, inhabiting the Holuceas froin Culebes, south to the Bismarck Archipelagro; and lastly, Coryphurues of the Solomon Islands. Both the latter grenera have short and somewhat hooked bills.

The Mueropygice are commonly called cuckoo-doves, on account of their barred plumage. They are forest-lirds, feeding on fruits, and building a slicht nest, in which two egrs are litid.

This sub-family is peculiar to North America, and only onc species $(E$. migrutoria) is known. It has occasionally visited Groat Britain. In its uative country it is remarkable for the enormous flocks which pass

The Passenger- on migration, and occupy a breeding aren of great extent.

Pigeons.- -

Sub-family

íetopistince. One observer states that he saw a Hight of these piroms five miles long and a mile in breadth, while their nests were found in ncarly every tree for a distance of twenty-eight miles. As with the Cinolina pirrot, huwever, eunstint persecution is rapidly diminishing the numbers of this interesting birel, and its nesting-arrit is no longer so widely extended as in former times.

'This family of pigeons has rather a longer leg than those we have been jreviously discussing, the length of the tarsus being equal to, or exceeding, that of the middle toe. The tail-feathers vary in number

The Ground- from 12 to 20 , according to the different gener:m. The

Pigeons. -

Family

Perinturide. Zenaidine arc exclusively American, the Peristerine are American and African; the Geopeliime are American, Anstralian, and Indo-Malaym; while the Phubine, Geotrygonine, and Colenduline are Malayan and Australian. There is nothing very peculiar about the habits of these ground-rloves, but the remaining sub-fimily 'Turturince, or turtle-doves, is one of the lar-sest in the whole family of pigeons, ant contains abut thirty species, of which our British turte-dort, 
(T. turtur), and the erean-eoloured turtle-dore ( $T$. risorins) so often liept in cares, are the best-known eximuples. The sub-fimily chlonediure is represented hy the single genus (ílumer, the Nicobar pigeons, as they are called, remialiable for their netallic pluniage and the lomg latekles on the neek, like those of a fowl. The clowned pigeons (fomra) which are only found in the T'apuan Islands, are remarliable for their beantiful crests of diffused plumes. Six species are known, all of them inhabiting different areas of the great island of Now Guinea, or the islands immediately aljaent to it.

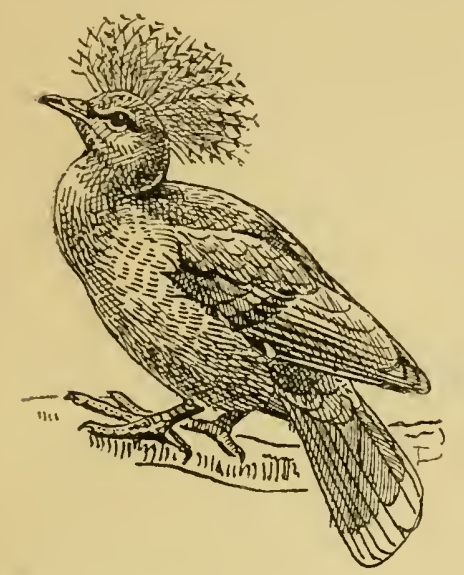

Fig. 13.-The Crowsed Pigeon (Goura coronate)

'This interesting for'm of pigeon, jepresented by a single genus only, Didunculus, is an inlabitant of Simusa or the Navigator's Islands. It hiss Billed Pigeons.it large luooked bill, Family which has also some Inirluneutiden. motches or toothed serrations near the tip of the lower mindible. It is remarkable for the similarity of its form to that of the dodo, thougl, of eourse, it is on it much smaller scile. Hence the name Didunculus, (1) little dods, of which the single species, 1). strifirostris, was, a sloort time ago, threatened with the same extine. tim as that which has overtaken its lar'ser relative. The dodo, not having wings capable of flight, was umable to save itself when dinger threatened; but the Didunculus, though a ground-bird, and formerly nesting on the ground, so that it was fast diminishing in ummbers, owing to the attacks of wild cats, appears suddenly to liave resumed its arboreal liabits, and now both roosts and nests in trees, so that of late years its numbers liave greatly increased.

The sub-order, Dilli, consists of two genera, Pesophaps and Didus, both now extinct, but living on the earth less than three hundred years ago. The solitaine (Pesophops soliturims) inhabited the island of Rodriguez, and was abont the size of a turkey. The old traveller, Leguat, has given a description of the bird as follows:- "They never fly; their wings are too little to support the reight of the bodies: they serve only to beat themselves aud flutter when they call one another. They will whill about for twenty or thirty times together on the same side during the space of four or five minutes. The motion of their wings makes a moise rery like that of a rattle, and one may hear it two humbed paces ofl. The bone of their wing grows greater towards the extremity, and forms a little round mass under the feathers as big as a musket ball. That and its beak are the chief defence of this bircl. Sone of the males weigh forty-five pounds. The females are wonclerfully beatiful, some fair, sme brown; I call them fair, hecause they are of the eolour of fair hair. They have a sort of peak, like a wiriow's, upon their breasts (leyp beaks), which is of dum coloum. To ome feather is stragglins from the other all orel their borlies, they being very careful to atdjust themselves, and make them all even with their bealis. The feathers 
on their thighs are round like shells at the end, and bein's there rery thich, have an agreeable effect They have two risings on their craws, and the feathers are whiter th:m the rest, which lively represents the fine neck of a beatiful woman. They walk with so much stateliness and good grace, that one camnot help admiring and loving them; by which means their fine mien often saves their lives. We find in the gizzards of both male and female a brown stone, of the bigness of a hen's egg ; 'tis somewhat rough, flat on one side, and round on the other, heavy and liard. We believe that this stone was there when they were liatehed, for let them never be so young, you meet with it always. They have never but one of 'em, and besides, the passage from the craw to the gizzard is so narrow, that a like mass of half the bigness could not pass. It served to whet our knives better than any other stone, whatsoever."

The dodo lived in Mauritius, and more is known of its appearance than of the solitaire, as several drawings of it were made from life, and now exist in

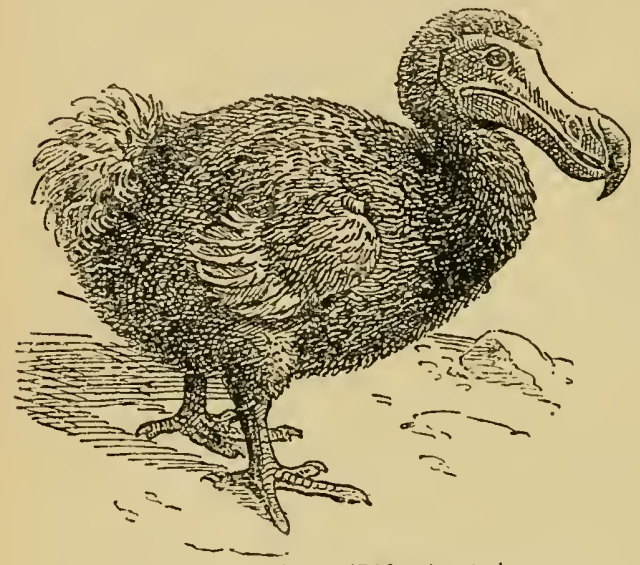

Fig. 14.-Tие DODo (Didus ineptus). various libraries. A foot of the bird is in the British Museum, and another is in the Ashmolean Museum at Oxford, along with a head, these being the last relies of an embalned specimen which was destroyed by the autlorities at Oxford in 1855. Anotlier head of the dodo is in the Museum at Copenhagen, but the actual remains of the body of this wonderful bird are very few, and the species is principally known from the skeletons which have been unearthed during the last few years. The lieavy body of the dodo, with its fenthery tail, and wings represented by a few plumes only, have led some anthorities to consider it as a kind of struthious bird, from the similarity of its wings to those of an ostrich, but recent reisearches liare shown that the dorlo was a gigantic pigeon.

We have now followed the Class Aies from the Ratitie, through the Timamous to the Game-Birds, and thence through the Sand-Grouse to the Pigeons. We now come to a sudden stop in the emtinuity of the series of orders of birds, and take up the thread of comection a little further back, it being absolutely impossible to follow a direct linear arrangement in a scheme of classification.

The hoatzin lias the appearance of a Game-Bird, and especially of a guan. Like the latter birds, it is an inhabitant of Sonth America, whore it is found on the Amazon and the rivers of Guiana, Venezuela, Colombia, Ecuador, Peru, and Bolivia. For all its guan-like appearance, the bird is more of a rail than a Game-Bird, and its curious nest. suspended in the branches overhanging the water, is like that of a rail, while its egrs greatly resemble those 
of the Rillicle. Many of its anatomical characters, its osteology, and the peculiarities of the young birds, show that the genus Opisthocomus is an isolated form, probably the survival of some ancient stock of birds, of which it is the only survivor. Fossilized remains of a bird like the hoatzin have been found in France, so that the type may have been far more widely spread in ancient times, and have been distributed over certain portions of the Old IVorld.

One curious featmre about the hoatzin is the size of its crop, which is situated in a deep cavity in the upper half of the pectoral muscles. It occupies the upper part of the chest, and is so enormous as to distort the furcula and sternum. The nestling is hatched naked, and has a well-developed claw on the pollex and index fingers of the wings, so that it is able to crawl about by their means. Mr. J. J. Quelch, the Director of the Museum at Georgetown in British Guiana, has written a most interesting account of the hoatzin, from which we have extracted the following notes:"Soon after the liatching of the eggs, the nest. lings begin to crawl about by means of their wings and legs, the well-developed claws on the pollex and index being constantly in use for holding and hooking on to the surrounding ubjects. If the birds are drawn from their nest by means of their legs, they hold on firmly to the twigs both with bill and wings; and if the nest be upset by means of a rod pushed up from below, they hold on to all objects with which they come in contact by means of bill, fect, and wings, mak.

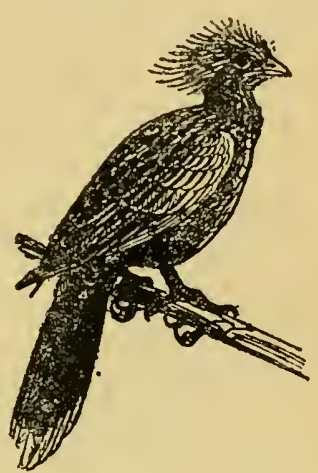

Fig. 15.-THE HoAtzIN (Opisthocomus cristatus). ing considerable use of the bill, not only to reach objects above them, but also with the help of the clawed wings to raise themselves to a higher level. One curious feature noticed with a nestling which had been upset in the river, was its power of rapid swimming and diving when pursued. As soon as the hand was placed close to it, it rapidly dived into the dark water, in which it was impossible to see it, and would rise at distances of more than a yard away. Owing to this power, the little creature managed to evade all my attempts to seize it, taking refuge eventually under the bushy growth, where it was impossible to pursue it. The prolonged immersion which a nestling will thus instinctively and voluntarily undergo, or which an adult bird will bear in an attempt to drown it, seems to me to be quite remarkable.

"The nestlings, when resting on the bare sticks of the nest, are observed to rest the weight of the body, as in the adult birds, on the bare and thickened integument of the carina stemi, the toes being spread out and the wings generally drawn up to the side."

The food of the adult hoatzin consists of leaves or fruit, and the birds after death have a very unpleasant odour, which prevents them being eaten as food. They are incapable of sustained flight, and in this fact we see another rail-like characteristic. Mr. Quelch observes :- "Whether from the fact of their occupying situations where they are but seldom disturbed, or" but little likely to be pursued, or from a natural weakness of wing, the birds are but scldom seen in flight; and when they take to the wing during disturbance, they do so for but a very short distance-a very exceptional flight 
being once observed of a length of about 40 yards, with the wind, across at creek, from a high growth on one bank to a lower level on the other. Usually they rise almost with a jump from the branch, seldom in a straight line, but with a marked convex curve to the point where they alight. The flight of the birds, in spite of their great expanse of wings, in relation to the weight of the body, is thus extremely awkward, and the body presents a peculiarly humped appearance. During their longer courses, the wings are rapidly and violently flapped. The apparent awkwardness in placing themselves when they alight, is chiefly due, I. believe, to the smallness of the branches on which they usually settle, and which they are unable firmly to grasp with their long toes, balancing themselres mean while by the expanded wings and tail ; but it is also attributable, I think, though to a much less degree, to a certain weakness in their legs-even thongh they are thick and apparently strong-looking-since when they alight on a thick limb, a certain amount of instability is still manifest.

"This weakness of limbs seems to be still more evidenced by the method of perehing characteristic of the birds. At any time during the heat of the day they will be found resting on the branches, two or nore together, the body directly applied to the wood, and supported on the bare, thickened, and hardened pateh of skin which covers the Hattened and broadened surface of the posterior determination of the carina stemi."

From the game-like rail, or rail-like Game-Bird Opisthocomus, we now pass to the true rails. Only one family can be admitted, which bears the name of Rellide. At first sight it would seem more natural to

The Rails. - divide the rails into three families-true rails (Rollide), Order water-hens (Gullimulide), and coots (Fulicidu); but after a

Ralliformes. prolonged study of the family, we have come to the conclusion that there is no separation to be drawn between these apparently natural groups, and the must that can be done is to recognise two subfamilies, rails and water-hens (Rullince), and coots (Fulicince), the latter having lobate webs on the toes like the grebes.

That the rails are birds of an ancient origin is undoubted. Their feeble powers of flight are compensated for by their swiftness of foot and power of concealment, and at the present day there are many flightless rails, descendants of an ancient stock. At the same time there are species, like our corn-crake (Crex crex), which are capable of long migrations, as are also others of the crakes; but, as a rule, the rails are stay-at-home birds, and do not care for long journeys across the seas. With the exception of the blue waterhens (Forphyrio), they are birds of rather sombre coloration.

Numerous fossil species of rails have been described from the Miocene and Eocene formations, and in America extinct forms (Telmatorris) have been found in the Cretaceous.

Fifty-three genera of rails have been admitted by me in the twenty-third volume of the "Catalogue of Birds," and the following are the most remarkable, and call for special notice. The Rallide may be divided into three great groups-true rails (Kalline), crakes (Crecince), and coots (Fulicince). As before mentioned, on account of their lobed toes, the coots may be even further separated from the rails and crakes.

In the rails the bill is long and slender, so as to exceed in length the middle toe and claw. The crakes hive a shorter and stouter bill. Thic true rails may be divided into two groups, water-rails and wood-rails. Of the former four genera aro reconnised, and un English water-mil is the 
type of this section. The water dril is certainly not a bird to be observed every day. It is the impersonification of shyness and retiring habits. A coot or a moor-hen is often seen in the open, and may be observed from the windows of a railway train, swimming about on lakes or pools of water, the coot easily discernible by its waxy-white shield on the forehead, the moor-hen by

The Rails,-

Sub-Family lialline. its red frontal shield and the bright red ganter above the lock, which is easily in evidence as it swims. The water-rail, on the contrary, is never seen, nol can its roice be heard, like that of the noisy corncrake. It is a bird of the reed-beds and the min'shes, and is so disinclined for Hight, that even when pursted by a dog, it will double and turn and twist, rather than fly, and is often caught by the dogs before it can bring itself to use its wings. The eggs are numerous, from seven to eleven in number, of a creamy white, double-spotted, with reddish-brown overlying spots and ashy-grey underlying ones. The nest is well concealed imomg cuarse herbage, of which it is composed, and the young are covered with black down, and can take care of themselves soon after they are hatched, swinming and diving, and managing to conceal themselves from danger in a marvellous manner.

The water-rails are found all orer the New World, and also in the Old World, except in the Indo-Malayan sub-region and the whole of the Australian region, where their place is taken by the barred rails (H!jpotenidiu). In the tropical regions of South America, Limnopardalus replaces the genus Rifllus, and in the islands of the Australian region, the dusky rails (Cabalus) are one of the most curious forms of bircl-life. In the Chatham Islands is, or rather was, found $C$.

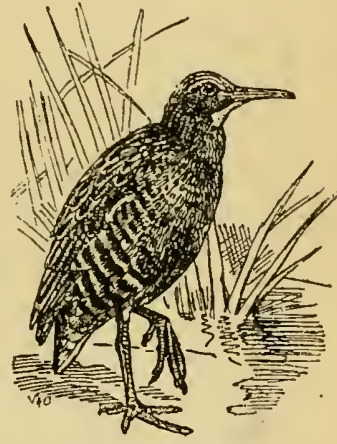

Fig. 16 -W ATER-RAIL (Rallus aquaticus).

dieffenbachii, now believed to be extinct, and in these islands also occurs $C$. modestus, a dusky-brown species, which cannot fly, and is also on the verge of extinction, while a third species, C. sylcestris, is peculiar to Lorrl Howe Island.

These are birds of the bush and forest, though sluowing considerable likeness to the water-hens. They are found in both hemispheres, and one genus at least, Mequerex, from Southern New Guinea, is incapable of flight. The black wood-rail (Habroptila vallacii) was dis- The Wood-Rails. covered by Dr. A. R. Wallace in the island of Halmahéra

in the Moluceas, and when sent home by him, the species was described and figured in the "Proceedings of the Zoological Society," as an ordinary rail standing in the water. Consequently, when the Dutch travellers received instruetions from Professor Schlegel to be sure and find IIalmoptila, they searched for the bird in the marshes, but ultimately discovered it in the bush. It is altogether a curious form, black like a water-hen, and having in small frontal shield.

Perhaps one of the most interesting genera of this group of rails are the wood-rails of the neo-tropical region (Amemides), which have a somewhat irnamental plumage of rufous and wrey, with a bright ycllow bill and resl leggs. Of late yaan's they hare been seen in the aviaries and zoological girlens of Europe, and have eren been known to nest in captivity. 
Oi the ypecaha wood-rail of Argentina (Aramides mpereha) Mr. Hudson, the biographer of Argentine birds, has given many anusing details, and he crcolits the species with considerable intelligence, repudiating the idca that this wood-rail is to be considered an ideal member of what has been called a "stupjid family" of birds. He writes :- "On spying an intruder: it inmediately utters a jowerful cry, in strength and intonation not unlike that of the pea-fowl. 'I'lis note of alarm is answered by other birls at a ristance as they liastily advance to the spot whence tlie waruing was sounded. The cry is repeated at irregular intervals, first on one side, then on the other, as the birds change their position to rog the intruder's steps and inspect him from the reeds. I have surprised parties of them in an open space, and shot one or more; but no socmer had the survivor's gained their refuge, than they turned about to watch and follow me, sounding their powerful alarm the whole time. I have frequently been followed half a mile through the rushes by them, and by lying close and mimicking their cries, have always succeded in drawing them about me. But the ypeealia's loudest notes of alarm are weak compared with the eries he utters at other times: when, untroubled wish a strange presence, he pours out his soul in sereams and shrieks that amaze the listener with their unparalleled power. These screams, in all their changes and modulations, have a resemblance to the human voice, but of the liuman voice exerted to its utmost pitch, ar.d expressive of acrony, frenzy, and despair. A long piercing shriek, astonishing for its strength and rehemence, is succecded by a lower note, as if in the first one the creature had well-nigh exhausted itself. The double scream is repeated several times; then follow other sounds, resembling, as they rise and fall, half-suppressed cries of pain and moans of ar.guish. Suddenly the unearthly shricks are renewed in all their power. This is kept up for some time, several birds screaming in concert ; it is renewed at intervals throughout the day, and again at set of sun, when the woods and marshes resound with the extravagant uproar. I have said that severnl birds unite in screaming; this is invariably the case. I have enjoyed the rare pleasure of witnessing the birds at such times, and the screams then scem a fit accompaniment to their disordered gestures and motions. A dozen or twenty birds have their place of reunion on a sniall area of smooth, clean ground s:ulmounded by reeds; and by lying well concealed and exercising some patience, one is enabled to watch their proceedings. First one lird is heard to utter a loud metallic-sounding note, three times repeated, and somewhat like the call of the guinea-fowl. It issues from the reeds, and is a note of invitation quickly responded to by other birds on every hand as they all hurriedly repair to the customary spot. In a few moments, and almost simultaneously, the birds appear, emerging from the reeds and running into the open spice, where they all immediately whirl about and begin the exhibition. Whilst screaming, they rush from side to side as if possessed with frenzy, the wings spread and agitated, the beak wide open and raised vertically. I never obsorved them fight or manifest anger towards each other during these performances; and, knowing the pugnacious spirit of the ypecahas, and how ready they are to seek a quarrel with birds of other species, this at first surprised me, for I was then under the mistaken impression that these gatherings were in some way related to the sexual instinct. Whilst watching them I also remarked another circumstance. When concoaling myself amongst the rushes I have been compelled to place myself so disadrantageously, owing to the wet ground, that any single bird straying 
aceidentally into the "yen space would have discoverch my presence immediately; yet the lirds have entered and finished their performance without seeing me, so carried away are they by the emotion that possesscs them cluring these moments. But no sooner las the wild chorus ended than, aware of my presence, they liave fled precipitately into the reeds."

These are rails with a stout bill, the culmen being shorter than the middle toe and claw. They may be diviled into two sections, distinguished by the fresence or absence of $n$ bare frontal shield. Those which possess the latter characters are the moor-hons.

Anong the largest of the crikes are the weka rails of New /caland (Ocyliomus), of whieh there are three speeies. These birds are remarkable for their pugnacious disposition, and

The Crakes.Sub-Family

Crecina. also for the tameness with whieh they will wander from their homes in the bush, even entering camps and houses. They are heavy-bodied birds, with fceble wings, which are insuftieient to carry them through the air, and they "re consequently incapable of flight. Like their distant relative, the Apteryx, they serve themselves by runuing only, and are also protected by their crepuscular hibits, being more lively at night thin in the day, and calling throughout the dark hours. These birds evince a curious antipathy to anything of a red colour, and this is the more interesting as remains of extinct forms of weka rails have been found in the Masearene Islands, one of whieh is known as Erythromachne, "the fighter of red." The former distribution of forms of flightless rails in New Zealand and the Chatham Islands, almost, if not absolutely, identical with each other, lias given rise to some very interesting speculations as to whether there was an ancient continuation of lind area between these two portions of the globe. Certainly the discovery of the remains of an extinct genus, Aphancipteryx, in Mauritius and in the Chatham Islinds, is very remarkable.

Of these, the most typical form is our corm-crake or land-rail (Crex crex), whose harsh voice is heard in the hay-fields during the summer, often far into the night. Like all of its kind, the corn-crake loves seclu. sion, and is seldom seen on the wing, except during the shooting season, when the birds are driven up by the dogs.

The smaller Crakes. Even then they only take short flirhts, and drop into cover again. Everything points to the wing-power of the corn-crake being of the feeblest description, and yet we know that it nust be a bird capable of covering considerable distanees, as it reaches South Africa on its winter migration. The little crake (Zapornia parve), the spotted crake (Porzana porwana), and Baillon's crake (Porzmıa intermedia), are all species which visit England, and the genus Porouk may be said to be cosmopolitan in its range. In the Sandwich Islands were found two curious flightless crakes of small size, Penmula ecculute and $P$. sanduichensis, and in the island of Inshai also lived till recently a small black crake (Aphunolimmas moncisa). All these interesting little birds are now believed to be extinct, and as they could not fly, they were doubtless exterminated by cats and rats. In the island of Laysan in the Pacific, however, there still exists one of these curious little crakes, Porzanula palmeri.

Numerous genera of small crakes aro known, of which space does not permit us to give a detailed description; but the distribution of the whitewinged crakes (Orty!yos) is deserving of special mention. There are four speeies, each of which is peeuliar fur having some white quills, which aro very conspicuuus when the bird thes. The distribution of tilu four species is 
very iuteresting. One, $O$. noveborecensis, is only found in Forth America ; i second, $O$. exquisita, in Eastern Siberia and China ; a third, $O$. notate, in Uruguay; and a fourth, 0 . ayresi, in South-Eastern Africa.

Passing from the crakes to the water-hens, we find many varied forms, some of them flightless, as Pareudiastes pucificus, the black water-hen of Samoa, and the isolated water-hens of 'Tristan d'Acunha (Porphyriornis nesiotis) and of Gough Island (P.comeri). All rails, isolated on any island, appear to become rapidly incapable of flight. They secm to be birds whicli are always averse to taking wing, and doubtless for this reason the power of flight soon disappears; but they are, as a rule, perfectly able to tike care of themselves by runuing, or by concealing themselves in the grass.

The water-hens are found all over the world, and are all very similar to our own species, the "moor-hen," as it is frequently called (Gallinulu chloropus). They sre birds of black plumage, and liave a bare red slield The Water-Hens. on the forehead. The most brilliant of all the rails are -Genus the blue water-liens (Poiphyrio), which are found all over Gallinula. the Old World, from the Mediterranean over Africa, and from India and China to Australia, They are very handsome birds, with bright red bills and red legs, contrasting with their blue and green plumage, and in niany places they are kept in confinement as oruamental fowl; they are, however, somewhat destructire and mischievous. The largest of the blue water-hens is the famous Notornis of New Zealand, which is a giant form, incapable of fliglit, and believed to have become extinct during recent year's. A fossil form of rail, Aptornis, also from New. Zealand, was at first believed to be a small kind of moa, which will give some idea of its large size.

These birds are remarkable for their stout bodies, bare frontal shield of ivory-white or yellow, and, above all, for their curiously lobed toes. They are found in nearly every

The Coots. - part of the globe, and several

sub-family species are met with in Soutl

Fulicince. America. One of the most curious of the amcient forms was the extinct Leguctia gigantea of Mauritius.

These curious birds are intermediate between the rails and the grebes, and are chiefly remarkable for their lobed The Finfeet - toes, which in the South

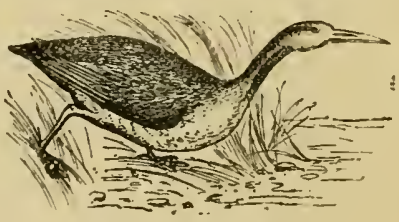

Fig. 17.-THE Fisfout. (Heliornis fulice).

\section{Family}

Heliornithida. American finfoot (Heliornis fulicu) are banded with black and yellow. Whereas all the rails, as well as the water-hens and coots, have the nestlings clothed in black down, the young finfoot is said to be hatched naked. At present very little is known about these birds and their habits, and the above statement may turn out to be incorrect. It certainly seems to be very unlikely that birds so obviously connected with the rails and grebes should have anything but downy young. There are three genera of the Heliornithida-Podica from Africa, Heliopctis from Burma and Malacca, and Helionis from South America. All the species are very shy and difficult of observation. The Senegal finfoot (Podica senegalensis) was found by Mr. Biittikofer in Liberia, and his is apparently tlee vily record of the habits of the bircls. They swim about in pairs, and do not scek to escape by diving, like the rails or grebes, but simply by concealing 
themselves in the foliage on the banks. When Hying, which they seldom do, they go heavily, striking the water with their bill and feet.

These birds are familiarly known on aceount of the use made of their beautiful white breasts for' muft's (11 the trimming of dresses, but in at wilk state they are not easy to observe, as they are annong the shiest of birds. Although the species are not very numerous, there is seareely a portion of the globe which grebes do not inhabit. The feet are lobed, and there is never any visible tail, the broal rectrices of other birds being represented

The Grebes.Order

Podicipedidi. formes. in the grebes by it tuft of downy plumes.

The Sclavonian Grebe is one of the most beautiful of the order, and is an inhabitant of the northern portions of both hemispheres. It is not an unfreunent visitor to Great Britain in winter. The great-crested grebe (Pudicipes cristutus) is almost cosmopolitan in its range, ind is the lapes of the Butish on some of the Norfolk broads and inland lakes of England, buileling, like all grebes, a nest of the clampest deseription, composed of weeds and rushes. The egrgs are at first white, but become stained in it rery short time, as the bird generally covers then "1, with weeds on leaving the nest. All the grebes are splendid divers, and even the little nestlings take to the witer som after they are hatched, and eseape either by diving or by hiding themselves in the weeds and rushes. The nestlings are very pretty little creatures, ecrered with soft down of a zebril-like pattern in streaks of white and bitck or brown.

There are not many genera of the grebes, most of the species belonging to the genus Podicipes, but in America the thick-hilled grebe belongs to a distinct senus, Podilymulus, while on Lake Titicacn, in Bolivia, is found a large form, Centropetme, which lias such small wings that it is alpparently ineapable of flight.

The dabehick of our English waters (Tachybaptes flurintilis) is one of the smallest grebes, and is dis-

The Sclevonian Grebe (Podicipts unritus). tributed urer the greater part of the Palearctic region, but is replaced by an allied speeies in Africa (T. capensis), and in india by 'T'. albipenuis.

In the summer the dabchick frequents rivers, lakes, and eren ponds and small sleets of water, where it builds in nest of weeds, which are always in anoist condition, and the nest always resembles a small heap of refuse more than anything else. A dabchick is is pretty object to wateh, but it is so shy a bird that a near approach is impossible, and it is only at a distance that they ean be seen swimming alout on the water. On the first sign of danger, it disanpenrs like magic, and comes to the surfine again for a second, only to dive agtin out of sight on the instant. If one of them be surinised in the open, it will dive immediately, and if there be $a$ bed of reeds or riner shelter, it makes for them under the water, and one never knows at what distance its head will reappear. Twenty and thirty yards is loy no means an uncommon dive for a dabchick to make, and it uses its lobed feet as propellers and steerers, not making much use of its wings. which are lield elose to the body, the stumpy and soft tail being of no sort of use to it as a steering apparatus, 
The downy nestlings are striped, and in the first plumage the dabchicks are brown above. In the autumn they are to a certain extent migratory, and are shot in our tidal harbours; but in mild winters they do not desert their native homes. In summer, both sexes don a nuptial plunage, with a yellow patch on the bill and a black breast, against which the rufous colour of the face and neck forms a striking contrast. In all the grebes, the brighter colours and the ornamental tippets and crests are dropped during the winter season.

The clivers are birds of the Northern Hemi. sphere, few in number and aretic in habitat. Four species are known, all of The Divers.- which are found in Great BriOrder - tain, two of them nesting within Colymbiformes. our limits. The red-throated diver (Colymbus septentrionalis) is one of them, and the black-throated diver ( $C$. arcticus $)$ is the second. The great northern diver ( $C$. glacialis) is a more or less frequent visitor in winter, and the white-billed diver (C. adamsi) has occurred a few times.

This is chiefly known as an inhabitant of North America and Icelind, as the great northeru diver which breeds in the Tho Great Old World will probably be Northern Diver found to be $C$. adrimsi. The

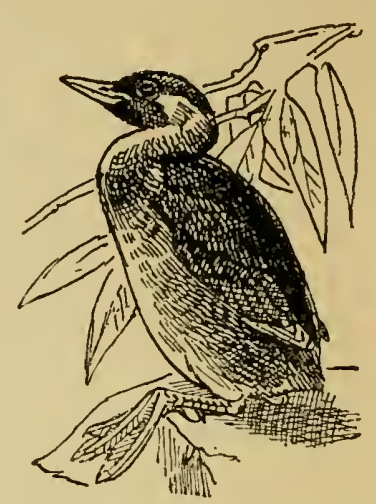

Fig. 19. -The Little Grebe or

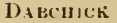

(Tachyl.aptes Auxiatilis),

(Colymbus habits of all the divers are mueh the same. On the water glacialis). they are at home, swimming about and diving with the greatest of ease; but on land they are very awkward, and the backward position of their legs seems to make it impossible for the birds ever to stand upright. In fact, they seem to shuftle along the ground with in snake-like motion, and never walk. They excel all the grebes in their power

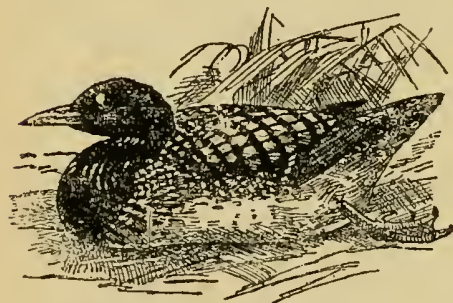

Fig. 20.-The Great Northern Diver (Colymbus glacialis). of flight, though, as a rule, they trust to their swimning and diving powers to eseape from danger, and are uften to be seen swimming in the seil firr away from land; and they are a!so able to submerge their bodies, so that only the head and neck is exporsed, and they can remain under water for an astunishing time, the great northern diver having been known to remain below the surface for eight minutes. The nesting-place is on some intind loch or secluded like, and the nest is a poorly eonstrueted affair. 'The egrgs are? two in number, of a russet-brown or olive-brown colour, with black spots and fainter black underlying markings.

The divers differ from the grebes in having webbed feet and a well-developed tail. The young birds are covered with down, and are able to dive and shift for themselves shortly after they are hatehed. The sexes are alike in plumage, and they have a distinct summer and winter dress, as with the grebes. 
The penguins are birds of the Southern Hemisphere, the most northerly ranging species occurring in the Galapagos Islands, off the coast of South Americi. They are chiefly remarkable for their close-set plumage, unlike that of any other birds, and the flipper-like The Penguins.character of their wings. The feithers, which are liarsh and scaly, and gencrally devoid of barbs, are distributed over Sphenisciformes. the whole body, so that there are no bare spaces between the featlier-tracts, as in most birds. Penguins are found in astonishing numbers in the Soutliern Seas, especially at their breedingplaces, which are selected on rocky islands, such as Kerguclen, Tristan d'Acunha, the islets round New Zcaland, and the Falklands. As they camnot fly, great havoc is worked among them on their island homes during the nesting season, when thousands are killed for the sake of their oil.

The penguins vary very much in size, from the diminutive Eudyptile minor to the gigantic emperor and king penguins (Apteno. dytcs patachonica) of the Antarctic Seas. They always walk or hop in an erect position, and they are assisted in the support of their lieavy bodies by the unusual strength of their tarsi, the metatarsal bone being very short and wide. The scapular bone is also of unusual widtl for a bird. The nestlings are covered with dense down, which is retained for a consiclerable period, until, in fact, the birds are nearly full-grown.

The haljits of all the penguins are very similar, and the following account of the "Johnnie" (Pyynscelis teniutu), by the Rer. A. E. Eaton, who ohserved the species on Kerguelen Island, during the "Transit of Venus Expedition," is very characteristic of the order, and we therefore give the following extracts :-

"It builds in communities, some of only a dozen, others from 50 to 150 families. A more pupulous colony was visited by six ofticers from the ships, who estimated the number of nests in it to amount to 2,000 or more. These larger conmunities are approached from the sea by regular paths, conspicuous at a distance, like well-worn sheep tracks, which lend straight up the hill from the water. Their formation is due to the penguins being very particular about where they land and enter the sea. A small party of the birds occupied a position upon the neck of a low promontory within an hour's walk of Observatory Bay. Their nests were nearest to the further side of the istlunus ; but when they were approached, the male birds used to run to the water, not by the shortest route where it was deep close to the rocks, but by the longest to a place where the shore was shelving. It was amusing to see them start off in a troop as fast as their legs could carry them, holding out their wings and tumbling headlong over stones in their way, because as they ran they would kcep looking baek instead of before them, and to hear their ontcries. Panic and consternation scemed to possess them all ; but the females (possibly because they could not keep up with their mates) seldom went far from their nests, and, if the intruder stood still, soon 
returned and settled down again upon their eggs. Not many weeks hacl passed before a change was effected in their conduct. The young wero hatched, and now the mother's anxionsly endeavoured to persuade them to follow the example of their fathers, and run away to sea. But the nestlings preferred to stay in their nests ; they did not mind if the stranger dicl stroke them, although their anxious mothers ran at him with open mouths whenever he dared to do so. Only a few of the older chicks could be prevailed upon to stir, and they after waddling a few yards, became satistied with their perfurmance, and turned to go home again. The mothers, who had straggled to a greater distance, began to return too. It was now that the more tardy youngsters began to experience the ills of life. Every penguin that had reached its place before them aimed blows at them as they passed by towards their own abodes. One of the littlo birds certainly did seem to deserve correction. It saw its neighbour's nest empty, and sat down in it. The old female Johnnie, the rightful occupier, presently returned in company with her own chick, to whon, having put her heal well into his mouth, she began to administer refreshment after his run. Seeing them so pleasantly engaged, the small vagrant, thoughtlessly presuming upon her generosity, went nearer and presented himself to be fed also, as if he had a right to her attention and care. She looked at him while he stood gaping before her with drooping wings, unable for the moment to credit what she saw. But suddenly the truth flashed upon her, and, provoked by his consummate audacity, she gave vent to her indignation, pecked his tongue as hard as she could, chased him out of the nest, darting bluws at his back, and croaked ominously after him as he fled precipitately beyond the range of her beak, leaving trophies of down upon the scene of his unfurtunate adventure. The whole of this community of penguins was subsequently boiled down into 'hare soup' for' the ofticers of H.M.S. Voluge, and very nice they found it. The nests were composed of dried leaf-stalks and seed-stems of pringlea, together with such other suitable material as happened to be at hand. There were two eggs in every nest, and one of them was invariably larger than the other. Most likely the birds hatched from the larger eggs are of the opposite sex to those which are produced from the smaller. Whether the big or the little egg is the first to be laid was not ascertained.

"As is the case with many other kinds of birds, Johmmies are very regular in their habits. Every afternoon at nearly tho same time they repair to the shore when they have done fishing, lancling in small parties at their aceustomed places at the heads of shallow inlets. On issuing from the water they dispose themselves to rest, seldom proceeding beyond the verge of the shore. Those which are inclined to sleep put their heads behind their Hippers; the other's stand amongst them with their neck shortened so as to loring the head down close to the body, with the beak slanting upwards and forwards, somewhat in the mamner of a very young thrush during repose. Their eyes present a rather tearful appearance, and resemble bits of clull black glass set in their heals,--perhaps the nictititing membrane may be kept drawn over them. At frequent intervals a kind of watery thuid is ejected from their mouth by a shake of the head."

The Petrels. - The petrels are also often called the T'ubinares, on account order Pro- of their tubular nostrils. They are generally associated with cellariiformes. the gulls, but there is really little in common between the two groups, beyond the fact that they are both marine orders of birds. The petrels differ from the gulls in many important anatomical 
and osteologieal cliaraeters, but we need go no further here than to specializo their peculiar nostril and bill, the eovering of the latter consisting of several hormy pieces separated by deep grooves.

The albatroses are the limgest of the petrels, and, indeed, possess a wider spread of wing than any known bird. On the other hand, some of the storm-petrels are hardly larger than a swallow. All of them have a peculiar odour, a sort of musky smell, which clings to the person after handling a number of these bircls. The egrgs, too, are impregnated with this smell, which adheres to them for years after they liave been in a eabinet.

The petrels lay but one egg, and this is generally concealed under a rock or boulder, the nest being of the flimsiest deseription, thongh the albatroses make a rough nest in the open. 'The young are eovered with down, and remain helpless for some time in the nest; the down is generally of a sooty colour, but is white in the ease of some of the larger albatruses. Mr. Osbert Salvin, in his recent work on the group, recognises four families- $H^{\prime} r$ eclluriche or storm-petrels, Puffuide or shearwaters, Pelecunoide or divingpetrels, and Jiomedeide or albatroses.

There are two sub-fanilies of the Procellariide, the short-legged petrels (Procellariune), and the long-legged petrels (Oceanitiuce). In the former we find the storm-petrel of the British coast (Procellarie pelagica), which is the typical form of the group. It inhabits the North Atlantic Oeean as far south as West Africa, and enters the Meditermean Sea. At the nesting tine it visits the islands and western coasts of Great Britain, but has not been found breeding on the east coasts of England or Seotland. Another well-known member of the storm-petrels is the forl-tailed or Leach's petrel, which is found throughout the North Atlantic, and also oceurs in the Japanese Islands. It is a larger bird than the storm-petrel, and is easily known by its forked tail. It breeds on some of the Outer Hebrides and also on the islands off the coast of Kerry. A curious instance of

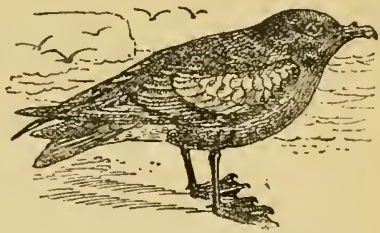

Fig. 22.-Fonk-Tatled Petrex. (Oceanodroma leucorrhoa). the way in which petrels are distributed over the ocean, and how very little we really know of their range, has lately been noted in England, where in December, 1895 , a specimen of the Canarian fork-tailed petrel was obtained for the first time, at Littlestone in Kent. It is only fourteen years ago that this species was deseribed by Mr. Ridgrway from the Sandwich Islands in the Pacifie, to which it was believed to be confined. In $1895 \mathrm{Mr}$. OgilvieGrant discovered it on the Salvage Islands in the Atlantic, and now the British Museum contains specimens from Madeira and the Desertas group, as well as from St. Helena. It has also been recently discovered as an inlabitant of the Galapagos Islands off South America. Another remarkable case occurred a few years ago, when a petrel from the Fiji Islands and the New Hebrides, Estrelate breripes, one of the rarest of all petrels, turned up unexpectedly in Wales. It had never been heard of before away from the Pacific Ocean.

This family is numerously represented in all the great oceans of the world, with the exception of the Indian Oeean, where there are not so many species. The British Islands are visited by several species of Puffinus, and one, tho 
manx shearwater, is resident and brecis un St. Killa, as well as in other places in the west of Europe. Like all other members of their family, the shearwaters are birds of rapid tlight, and may be seen in

The Shearwaters flocks far out at sea, apparently revelling in the rough and Fulmars.- weather.

Family

Puffinide.

The fulmar-petrels (sub-family Fulmorinct) are also very wiclely distributed over all the oceans, and some of them are as larre as gulls, one speeies, Ossifraga gigantea, from the Southem Seas, being as linge as some of the albatroses. The common fuhmar-petrel (Fulmarus glacialis) is a well-known inhabitant of the seas of Arctic Europe, and nests on St. Kilda and the Shetland Islands.

The diving-petrels (Peleconoidide) are curious little birds from the Southern Seas, which have much the appearance of the little auk (Mirgulies alle) of the Northern Hemisphere. Mr. Eaton says that, like that species, the divingpetrels have a hurried flight, and dive into the sea without any interruption of the action of their wings; both also emerge from beneath the surface flying, and they both swim with their tails lather deep in the water. This resemblanee, he silys, dres not extend to other partieulars of their habits. The little ark, when breeding, usually flies and fishes in small flocks of six or a dozen birds, and nests in communities of considerable size, which are exceedingly noisy. Diving-petrels, on the other liand, are more domestic in their mode of living, fishiug and flying for the most part in pairs or alone, and nest sporadically. Their burows are about as small in diameter as the holes of bink martins or kingfishers. They are made in dry banks and slopes where the ground is easily penetrable, and terminate in an enlarged chamber, on the flour of which the egg is deposited. There is no specially comstructed nest. Some of the burrows are branched, but the branches are without terminal enlargements, and do not appear to be put to any use by the birds.

The family of albatroses or Diomedeide contains three genera, Diomedea with nine speeies of truealbatroses, Thalussogeron, or cubminated albatroses, witl

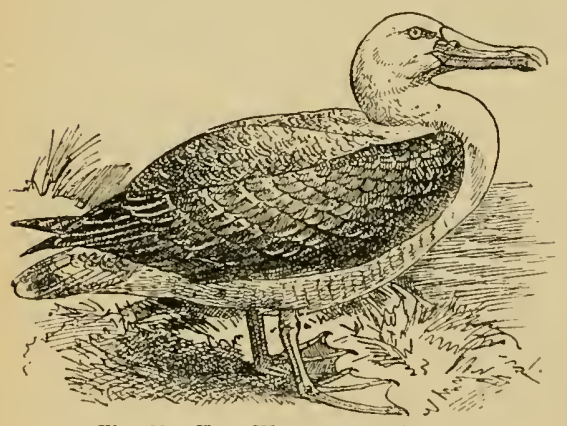

Fig. 23.-ThF WANDERING AlBatros (Diomerlea exulans). five species, and Plicubtria, or suoty albatroses, with a single species. Most of the members of this family are lirids of wide range, whence the common speeies gets its name of "wandering." They are lemarkable for their wide extent of wing and their graeeful and sustained flight. At certain periods of the year they resort to the islands in the Southern oceans to breed, and the gatherings which take place are sometimes incredible. Thus on the island of Laysan, in the Paeitie. thousands upon thousands of eggs of the white albatros

(Diomedec rmmutabilis) are colleeted. Mr. Pahier, who visited this island on behalf of the Hon. Walter Rothsehild, says that the birds literally eovered 
the surface of Laysan, the young in some places being as thick as they could stand. He writes:-" "It is very curious to watch the love-making anties of the birds. First they stand face to face, then they begin nodding and bowing vigorously, and then rub their bills together with a whistling cry ; after this they begin shaking their heads and snapping their bills with marvellous rapidity, occasionally lifting one wing, strightening themselves out, and blowing out their breasts ; then they put their bill under their wings or toss it in the air, with a groaning seream, and walk round each other, often for fifteen minutes at a time. They are quite fearless, and do not move out of the way. When Mr. Freetly was going to the guano-field on his tramway-line, he had to send a boy ahead to clear the tracks of the young albatroses."

Mr. D. le Souef gives a very interesting account of a visit to Albatros Island in Bass' Straits, Australia:- "The mests of the eautious albatros (Thulassogeron cuntus) are situated at varying distances one from the other, from a foot upwards, some on the ground, and others again on the uneven side or top of a point of rock. Some of the birds liad come on shore to rest only, while a few of them had their heads turned back and partially under their wings, and were asleep. When one wished to fly it had to walk to the edge of the cliff, and go off with a downward sweep; but when the wind was blowing very strong the birl eould then rise, facing it, from a point of rock. One bird I found in a depression about 60 feet across and 30 feet deep, with steep sides, and as it could neither climb or tly out I caught it and climbed up the bank with the bird under my arm, and took it back to the "rookery." On approaching very elose to the birds, they would partly stand up on their nest, leaning backwards and apparently resting the tail on the edge of the nest, and then facing the intruder. When one was within two feet of them, they would utter a loud cackling noise, shaking their heads up and down, and opening and shutting their beaks rapidly. A considerable noise was made by the mandibles coming together, and at the same time a strongsmelling oily secretion was thrown up. In order to secure an egg, the beak of the bird was caught hold of with one hand and the egg taken up with the other, and on stepping back the beak was let go again. The bird would then sit or stand on its nest for some time afterwards. The birds often had difficulty in alighting on a particular spot, when the wind was blowing strongly on to their breeding-ground from the sea, as they always flew against the wind when desiring to alight, and I have watched them sometimes try seven or eight times before they could successfully accomplish their object. They came up with considerable force, holding their heads well back, and stretehing out their expanded feet at the same time, and the fict of having their wings half-closed gave them a very ungainly appearance when alighting."

The auks are birds of the Northern Seas. They form a peculiar group, and are usually associated with the gulls, from which birds, however, they differ in many important characters, though in their osteology the two orders have many points in common. Externally, however, the differences are apparent at a glance. The gulls are splendid flyers, but are no great divers, while diving is one

The Auks.Order Alcce. of the chief features of an auk's economy. Again, the gulls make a nest of some sort, the auks seldom or never, for the latter birds select a bare ledge or eleft of a cliff, or the broken rocks, on which to lay their egg, the colour and markings of which are entirely different from those of any gull or tern. 
One of the most interesting of all the Alce is the great auk, which was a kind of gigantic razorbill, but possessing such diminutive wings that the power of flight was denied to it. It has become extinct during the first half of the present century, and specimens of the bird and the egrg feteh large prices whenever they eome into the market. The great auk, as Professor Newton has pointed out, owes its extinction entirely to the agency of man, who hunted the bird to its destruction. It secms to liave had a compara. tively limited range, laving been abundint in Newfoundland and the adjacent shores of North

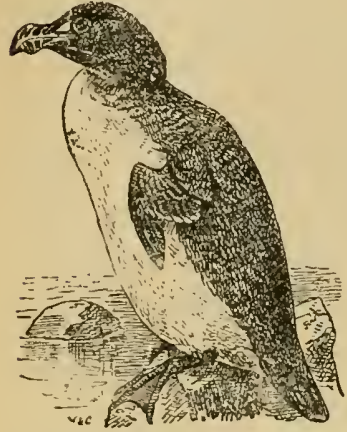

Fig 24.-The CrReat AUK (Plautus impennis). America and Iceland, ranging in smaller num. bers to the Hebrides and the shores of Northern Britain.

The razorbill (Alea tord $\iota$ ) and the guillemot (Uric troile) are well-known British birds, which breed in vast numbers on our coasts, the best-known nesting colonies being on the eliffs of Flamborough and on the Farne Islands, Here large numbers of the eggs are taken every year, those of the guillemot presenting an endless variety of colour and marking. 'The black guillemot (Uria grylle) nests in the Arctic regions, and in the north of Scotland and Irelind, and the rotche or little auk (Mergulus (alle) is a winter visitor to Great Britain, being often driven far inland by stress of weather. The breeding-places of the little auk have been described as tenanted by countless thousands, Admiral Beechey having stated tliat lie saw a column of these birds on the wing at one time which he estimated at four millions !

Our Englisl puffin, or sea-parrot, is a representative of the group of the auks which are most numerous in the North Pacific Ocean, where several erested species are found. They are remarkable for the coloration of the bill, which is grooved in a curious fashion, and exhibits bright colours, while there is also a blue excrescence above the eye. These ormamental features of the bird's bill are a sign of the breeding-season, and are slied as by a moult in the winter, to be resumed in the following spring. The bircls of the year have quite a small bill, without any of the grooving or coloured ornamentation which characterises the adults. Puffins differ from the other aulis in their nesting habits, the egg, which is white, with occasionally a

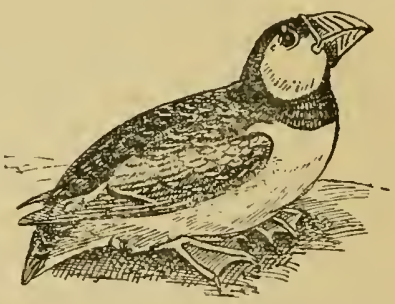

Fig. 25.-The Puffin (Fratercula arctica). few indistinct markings, being placed in a rabbit burrow, or in a hole tumnclled by the birds themselves.

The gulls are divided into two families, the true gulls, or Lavidoe, and the skuas, or Stercoraride. The general appearance of gulls is too well known to detain us long with the characters which define the order, whieh is admitted to be closely related to the order Charadriformes, the great group of plovers 
and snipes, with which the Gulls possess many anatomical characters in common, though they differ from the plovers and their allies in having webberl feet. The Laride, or true gulls, differ from the skuas in having no "cere" on the bill, which is a feature in the latter family. The cere is a wax-like bare space at the base of the bill, a common characteristic of Hawks and

The GullsOrder

Lariformes. Parrots, but rare in every other srcler of birds, and it is decidedly interesting that it should reappear in a famly of gulls, especially as it is combined with a decicledly rapacious disposition in the skuas.

The family Laridre is dirided by Mr. Howard Saunders into three sub. families: the terns, or sea-swallows (Sterninee); the skimners (Rhynchopiner); and the gulls (Larince).

The sea-swallows are found all over the world, from the high north to the extreme south. They are mostly marine, but many of them are birds of the marshes, especially during the nesting season, while others frequent rivers and inland lakes. It is, however, on the sea that these graceful birds are generally seen to the greatest advantage, as they hover over the water, or glide along abure its surface, occastonally dropping down to capture some small tish or other prey. They often follow shoals of small fry, and we remenber seeing a flock of large terns in the Red Sea, evidently engaged in decimating a shoal of fish on the surface of the water,

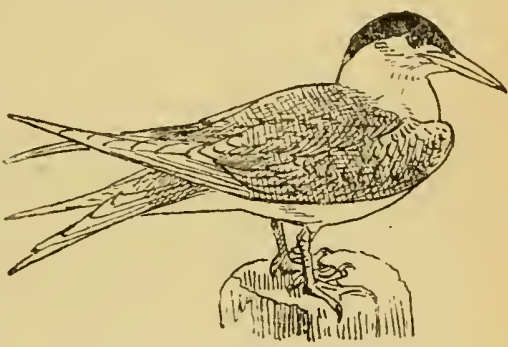

Fig. 26.-Arctic Terx (Sterna macrena), and keeping up such a cackling all the time that they could be heard at least a nile off.

In the British Islands we have thirteen different kinds of terns, fire of which breed with us, the best known being the common tern (Stevna furvintilis), the arctic tern ( 5. macruma), and the lesser tern (S. minuta). 'Tho sandwich tern (S. cantiaca) now only nests in a few localities; and a few pairs of the beautiful roseate tern ( $S$. dongalli) are believed to still breed in one or two places off our coasts. Among the visitors to the British Islands are the three species of marsh ter'n. helonging to the genus Hydrochelidon, which have only moderately forkcd tiils, the outer feather or "streamer" not being prolonged, as in most of the terns. The black tem ( $H$. nigra) is the commonest of the three species which visit England, the white-winged black tern and the whiskered tern beino of very rare occurrence. These marsh terns nest in swamps and marshes throughout temperate Europe, Asia, and North America, and they are plentiful in the marismas of Southerm Spain and the Danube. The nests are made of weeds, and are placed on tussocks, or on floating vegetation.

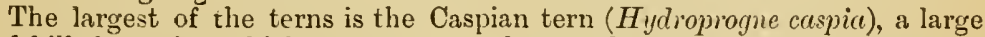
red-billed species, which measures nearly two feet in length, and is found over the greater part of the globe. The common and Arctic terns are species which breed in colonies on many parts of the British coasts, laying their eggs on the shingle, and making scarcely any attempt at a nest. The eggs have a great resemblance to those of some of the plovers, and, like the latter 
are difficult to distinguish on the ground. This is especially the case with the eggrs of the lesser tern (Sterna minuta).

One of the rarest visitors to Britain is the sooty tern (Sterna fuliginosa). This is the species which breeds in such enormous numbers on certain islands, such as Laysan in the Pacific, and Ascension Island in the Atlantic. In the latter the assemblage of these birds is known as "Wideawake Fair." On Ascension, according to Mr. Howard Sausiders, the sooty terns lay but one egg, and this was also found to be the case by Mr. Palmer on Laysan, the birds being perfectly fearless, and not moving off their nest, but pecking and biting at anyone that approached them. As many as two hunclred dozens of eggs have been coilected on Ascension Islaud in the course of a morning, and this will give some idea of the numbers frequenting that spot.

In the tropical islands of the southern oce:uns is found a curious form of tern, snowy-white in plumage, with a pointed black bill. This is the snowy tern (Gyyis alba), which possesses a very wide range over the islinds of the Pacific and South Atlantic. It lays but a single egg, which is placed carelessly among the rocks or scrub, but is also often found in a cavity of a branch or on the fork of a tree.

These curious river terns are called scissor-bills, on account of the remarkable disparity in the length of the two mandibles of the bill and their extreme sharpness of the ridges, which is compressed like the

The Skimmers. - blacle of a pair of scissors. The name given to the American sub-family species by one of the old writers in 1731 is "cut-water," Rhynehopince. a very good title for the bird, as these scissor-bills fly along the top of the water, cutting the latter with their blade-like under mandible, which is considerably longer than the upper one. The skimmers frequent rivers in the tropical countries of the Old and New Worlds, being found nesting as far north as Virginia in North Amcrica, and Egypt in the Old World. The eggs, which resemble those of the true terns, are laid on sand-banks in the rivers frequented by the birds. Five species are known, each with a separate range, lihynchops nigre being found in the Southern United States to Central America, $R$. intercedens in Brazil, and $R$. melanura in the northern part of South America. $R$. flarirostris is an inhabitant of Africa, and $R$. relbicollis of India.

Thcir heavy build and square tails, as a rule, distinguish gulls from terns, but it must be remembered that some of the gulls are small, and many are not so big as the Caspian tern, for instanco. The forked tail

The Gulls. - of the terns is seen in one genus of gulls, Xema, which conSub-family tains two species, Sabine's gull ( $X$. scibinii), and the large Larina. fork-tailed gull (X. furcata). The former is an inhabitant of the Arctic Sens, but sometimes straggles as far as the coasts of Britain, while $X$. furcata is only known from the Galapagos and the coasts of Western America. Ross's gull (Rhodostethia rosea) is another Arctic species, which on rare occasions visits Europe, but is one of the rarest of all the gulls, and is remarkable for its wedge-shaped tail and the beautiful rosy blush on its white breast, which is like that seen in the roseate tern.

Of the true gulls ( $L(1)^{\prime}(s)$ ), of which the common gull ( $L$. canns) may be considered the type, there are more than forty species known, and these are distributed, like the terns, throughout the greater part of the globe, from the Aretic regions in the north to the extreme soutls. The gulls may be divided into two groups, those with a hood and those without. The hooded gulls comprise such species as our black-headed gull (Iarus ridibundus) and its 
allies, another British species heing the little gull (L. mimutus). The other gulls with which we are familiar in this comtry, such as the greater blackbacker gull (L. murinus), the lesser black-backed gull ( $L$. fuscus), the herring gull (L. uryentatus), have white heads and whito tails. The hibits of gulls are mueh the sime all the world over. They feed mostly on fish ; but some of the larger kinds are not only great robbers, but will eat almost anything, and will derour young birds and cren sickly mammals." The little black-liended gull, on the other liand, is a most useful bird, as it frequents and breeds in inland distriets, where it often follows the plough, and devours large numbers of grubs and insects. The other gulls breed on the rocky coasts, mostly in the north, sometimes in vast numbers together. This is especially the case with the kittiwake (Rissa tridactyla), which is separated

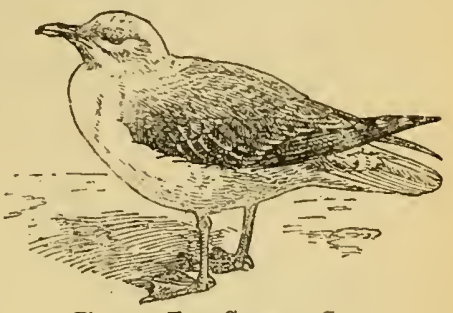

Fig. 27.-Tne Common Gule (Larus canus). from the true gulls on aceount of the absenee of a hind toe.

The skuas are often called the parasitic gulls, from their habit of robbing the smaller gulls of their food, instead of catching it for themselves. They differ from the true onlls in hilving a cere, or bare wax-like base, to the bill. The latter is very strongly hooked at the tip, and in the posterior portion of the sternum, or breastbone, there is only a single notch, instead of two, as in the

The Skuas. Family

Stercorariicle. gulls.

Four species of the great skuas are known, of which one, $M$. cuturhactes, is an inluabitant of the North Atlantic, where it breeds in a few scattered localities, such

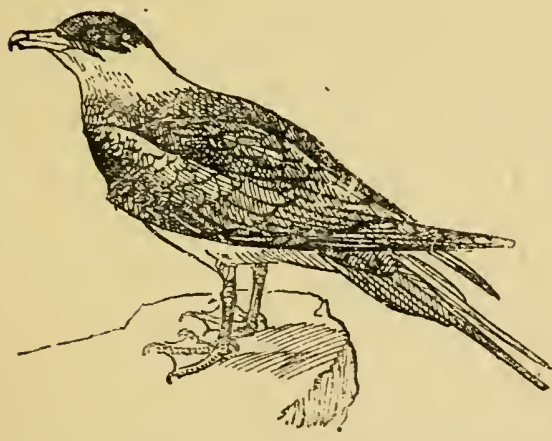

Fig. 23.-BuFrox's SRUA (S*crorarius parasiticus) as Ieeland, the The Great Skuas. Faeroes, and Norway, and a -Genus few pairs still Megalestris. nest in the Shetland Tsles, where great pains are now taken to preserve them, as they had become nearly extinct there. They not only feed on fish and carrion, but rob other gulls of their prey, and even kill and eat some of the smaller speeies. The egros are two in number, and the birds become very bold in defence of their nests. A second species of great skua (M. chilensis) inhabits both the Atlantic and Pacific coasts of South America, from Peru on the west, to Sonthern Brazil on the east. From the New Zealand seas to Kerguelen, and thence to the Falkland Islands, oceurs $I$. centarctica, while in Vietoria Land and the frozen countries of the Antarctic Continent is found a peeuliar pale form of great sliua, $M$. mac. 
cormicki. The long-tailed skuas (Stercorarius) differ from the members of the preceding genus in having more or less elongated central tail-feathers, these being developed in some of the species to a great length. The members of the genus Stercorarins are three in number, all of them breeding in the high nortl, and visiting more southern localities in winter. With the exception of the Pacific coast of South America, where only the pomatorhine skua ( $S$. pomatorhinus) has been known to occur, the whole of the other Southern oceans appear to bevisited by these skuas. They all nest on the tundra of the Arctic regions, and the pomatorhine skua and Buffon's skua are only winter visitors to the British Islands, but Richardson's skua (S. crepidatus) nests in the Orkneys and Shetland Isles, as well as in some of the Hebrides and on the north-west of Scotland. Like their larger relatives, these smaller skuas live principally by robbing the terus and smaller gulls of the fish they capture. They will also devour young birds and eggs, as well as lemmings and small rodents, crustacea, etc., while the young of Buffor's skuas are said to be fed on crowberries in the summer.

As has already been mentioned, there are many characters which the Charadriiformes, or Limicoline birds, as they are often called, share with the gulls, the principal one being the cleft, or schizognathous The Plovers palate. The nostrils are almost entirely schizorhinal, or in and Bustards. - the form of a slit, though there are exceptions to this in the Order Chara- seed-snipes, the bustards, and the thick-knees. The eggs of driiformes. most of the Charadriiformes are peculiar to the group, being generally pear-shaped, four in number, and double spotted, having the overlying markings black, arranged in lines, blotches, or spots, and the underlying spots grey. The young are covered with down, and can take care of themselves very shortly after their birth, running with great swiftness, and being able to escape capture by their protective coloration, which effectually conceals them in the midst of their natural surroundings.

There is but a single species to represent this sub-order, and it is one of the most peculiar of birds. While possessing anatomical characters which show that it is an aberrant kind of plover (though many observers liave

The Crab. Plovers.Sub-order Dromades. considered it to be rather an aberrant kind of tern), it differs from all gulls and plovers in laying a pure white egg. Its nesting liabits are in fact altogether peculiar. Not only does it lay a white egg, but only one, and that is placed in a tunnel hollowed out in the sand, as described below. The crab-plover is a handsome black and white bird, the mantle being black, and having the plumes elongated, so as to form a swallow-tailed patch when the bird is flying. It is long-legged, like a thick-knee or stone-plover, and inhabits the coast-land of Eastern Africa and Arabia, the Persian Gulf, and the eastern shores of the Indian Ocean, as far as Ceylon, reappearing in the Andamans and the Nicobar Islands in the Bay of Bengal. It probably breeds in most of the above localities, but the headquarters of the species seem to be in the Persian Gulf, and the coasts of Arabia and Mekran. Mr. Nash, who risited one of the islands off Bushire, found that the birds bur. rowed into the sand-hills to the distance of about four feet, and in the shape of a bow, the passage being about a foot below the surface of the ground, and the entrance usually near or under tussocks of grass or low shrubs, the single egg being laid on the bare soil at the end of the hole, without any sign of a nest. The birds nest in colonies, and the young, which are covered with 
greyish down, remain in the holes during the day, like young petrels, and they are apparently night-feeders.

Like Dromas, the sheathbills are very aberrant members of the Limicoline group, and are only found on the islands of the Atlintic, such as the Crozettes, Kerguelen, Marion Island, and the Falklands.

The species of the liatter islands is Chionis alba, the yellow- The Sheathbills. billed sheathbill, which is also found in Southern Patagonia, and extends to the island of South Georgia and the land of the Antaretic Continent. The species inhabiting Kergnelen

- Sub-order

Chionides. and Marion Islands is Chionarchus minor, which has a black bill, and does not exhibit the wattles on the face found in Chionis alba. The form of the sheath is also somewhat different, though both show a tube-like opening on the base of the bill, something like that of a petrel. In the bird from the Crozettes (Chionarchus crowcttensis) this petrel-like opening to the sheath is alosent, and the bird is smaller than $C$. minor, and has darker legs.

The Rev. A. E. Eaton gives an amusing account of the habits of the sheathbills in Ferguelen Islaud during the visit of the "Transit of Venus Expedition" to that place. They were common where the

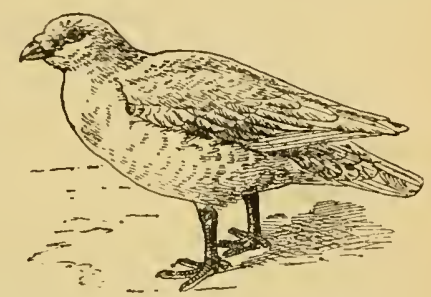

Fig. 29.-THE YeLLOW.BHLED SHEATHLILL (Chionis alba). coast was rocky and sheltered, and were seen in flocks of as many as thirty, but during the breeding season they were met with only in pairs. They were very tame and inquisitive, and suffered eonsiderably in consequence during the stay of the expedition, as they could often be knoeked on the head with a stick. Mr. Eaton writes.- "They were also very assiduous in their attendance on the colonies of shags and erested penguins, whose eggs they greedily devoured. The sitting birds stretched out their necks and eroaked at the sheathbills sauntering past their nests; but the marauders, keeping just out of reach of their bills, paid sittle regard to them, and proeeeded in a business-like manner to eat up the first eggs they ehanced to find unguarded. It occasionally happened that while an old shag was gestieulating violently at a Chionis in front of her, his friend peeked from behind at the eggs, which, in the excitement of the moment, were not completely covered by her. When she found out what was taking place she drove him away with a croak, and, true to her sex, affected to liave won her point in the affray. Reseating herself upon the nest with great dignity of deportment, and gently replaeing with her bill the broken eggs under her feathers, she resigned herself to the task of trying to liatch them. Some time after the sheathbills have gone away the broken eggs are inspected, and if there is only a small hole pecked in each of them they are kept in the nest. Their appearance and manner of earessing one another led the blue-jackets to call sheathbils 'white pigeons.' In their gait and flight they closely resemble ptarmigan; and like these they utter their cry when starting on the wing, as well as cluring flight. After they have attained a fair rate of speed, they sail along from time to time with outstretehed wings. On alighting at their destination they often greet one another with a gentle chuckle, nodding their heads the while."

Tho eggs of the sheathbills are plentifully marked, and resemble those of 
oyster-catchers among the plovers. The nest is a rough affair, placed in in hole behind or between rocks, sometimes an old burlow of a petrel being uscd and enlarged by the sheathbill. Enough has been said to show that the sheatnvill is a very remarkable form of bird. Its inquisitiveness and tameness reminds us of the weka rails, while its habit of derouring egss is also one of the bad propensities of the larger rails. In some other respects, as Mr. Eaton remarks, it resembles a ptarmigan, and that it is a bird of considerable power of flight is proved by a specimen in the British Museum, which was shot whilst flying round a ship 200 miles from land.

These birds are only found on the Andes and in the southern portion of South America, frọ̣ Argentina to Tierra del Fnego and the Falkland 1slands on the east, and from Chili to Ecuator on the west. There

The Seed Snipes. are but two genera, Attagis and Thinocoms, the former birds - Sub-order being as large as grouse, the latter of the size of a quail. Attagides. Despite their game-like plumage, they are ailied to the plovers; though they differ from these in having a palate much like that of a passerine bird, while the nostrils are holorhinal, not schizorhinal. The nest is a mere depression in the ground, sometimes lined with a few blades of grass, and the eggs are pale stone-colour, very thickly speckleil with light and dark brown.

This is a vory large group, and contains all the plovers, snipes, and sandpipers. The palate throughout is cleft or schizognathous, the nostrils split or schizorhinal, basipterygoid processes are present, The Plovers.- and the spinal feather tract is forked on the upper back. Sub-order The eggs are nearly always pear-shaped, four in number, Charadrii. and are deposited point to point. The plovers and snipes form one large family, Charadriidce, but there are no less than ten sub-families.

These are small Arctic birds, which exhibit certain grebe-like characters, for they have the toes lobed, swim well, and have also i serrated edge to the hinder margin of the planti trisi, the hind portion of the

The exposed leg being exactly as in the grebes. The phalaropes are Phalaropes. - likewise remarkable for their bright coloration, in which the Sub-family female excels the male, and is the handsomer bird of the

Phalaropine. two; she is also larger than the male, and does alI the courting. There are three genera of phalaropes, each containing a single species-Crymophilus, with the grey phalarope ( $C$. fulicarius); Phalaropus, with the red-necked phalarope (P. hyperboreus); and Steganopus, with Wilson's phalarope ( $\$$. tivicolor), as the representatives of the three respective genera. The two former breed in the Arctic regions of botl liemisplıeres, but Wilson's phalarope inhabits temperate Nortl America. All of them migrate far soutl in winter, and are found off the coasts of Soutl America as well as in the Indian and Australian seas.

Some of the details of the nesting habits of phalaropes, as observed by $M$ r. E. W. Nelson in Alaska, are very amusing. Speaking of the red-necked phalarope ( $P$. hyperborens), he remarks :- "As the season comes on, when the tlames of love mount high, the slull-coloured males move about the pool, apparently heedless of the surrounding fair ones. Such stoical indifference usually appears too much for the feelings of some of the latter to bear. A female coyly glides close to him and bows her head in pretty submissiveness, but lie turns away, picks at a bit of food, and moves off; she fullows, and he quickens his speed, but in vain; he is her choice, and she proudly 
arehes her neck; and, in mazy circles, passes and repasses elose before the harassed bachelor. He turns his breast first to one side, then to the other, but there is his gentle woner ever pressing her suit before him. Frequently he takes flight to another part of the pool, all to no purpose. If, with aflected indifferenee, he tries to feed, she swims along side by side, almost touching him, and at intervals rises on wing above him, anc, poised a toot or two above his body, makes a half-clozen quick, short wing-strokes, produc. ing a series of sliarp whistling noises in rapid suceession. In the course of time, it is said, water will wear away the hordest rock, but it is certain that time and importunity have their full effect upon the male phalarope, and soon all are comfortably married, while muterfumilias no longrer needs to use her seductive ways and chaming blandishments to draw his notice. About the first of June the dry rounded sirle of a little knoll, near some small pond, has four dark heavily-1narked eggs, laid in a slight hollow or whatever lining the spot affords, or, more rarely, upon a few dry straws and grass-blades, brought and loosely laid together by the birds. Here the captive male is introducerl to new duties, and spends half his time on the eggs, while the female keeps about the pool close by."

Snipes and sandpipers differ from plovers in having a long bill, with no "dertrum." The latter name is applied to the swelling of the end of the bill, which makes this portion ligher than the middle or the bisal part. Similar swellings are seen in pigeons. The bill in many of the snipes is wiclened at the tip and is pitted, but it is not cleeper at the end than at any other part of its length. The nasal groove or clepression in which the mostrils

The Snipes. Sub-family Scolopaeince. are plaeed is continued through nearly the whole line of the bill. The snipes and sandpipers, moreover, differ from the Totanine or Tatlers in having their long toes cleft to the bases, without any connecting web between the basal joints.

The sub-family Scolopacince may be divided into two main groups, the snipes and woodecicks, which have the eye placed far back in the head, almost on the ear-opening, while the sandpipers have the eye placed as in other ordinary wading biris. One of the most eurious genera belonging to this sub-family is that of the painted snipes (Rostratula), which contains three species, one, R. semicollaris, being confined to South America, while $R$. crupensis is found in Afriea and India as far north as Japan,

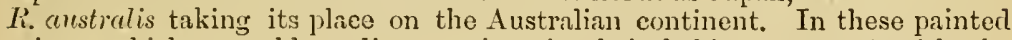
snipes, which resemble ordinary snipes in their habits, we meet with the same peculiarity as in the phalaropes, viv. that the female is handsomer in plumage than the male. The latter is a grey bird, with romded spots of golden buff on the wing-eoverts and quills, while the fentals is not only larger, but has chestnut on the hind neck, and in the hen of $R$. capensis on the throat also. The South American $R$. semicollaris, however, does not ditfer in the plumage of the sexes. In Chili and Peru occurs the curious Phegonis mitchclli, which has a chestnut neek like Rhynchoe, but has no lind toe.

The true woodcocks ( $S c o l o p(a x)$ are only two in number, our own well-known species, and a dark form resident in the mountains of Java and New Guinea, called S. saturata. In North America, however, there is a small form called Philohela minor, which is distinguished by its attenuated outer primaries; and in the island of Bouron, in the Malay Archipelago, occurs a peculiar woodcock 
Neoscolopax rochusseni. All the woodcocks differ from the snipes in having successive broad bars of black and buff on the hinder head and neck, whereas the snipes always have a buff land down the centre of the crown. They are

likewise birds of the woods and forests rather than the

The Woodcocks. Open marshes, which the snipes love to frequent. The -Genus jack snipe (Limnoeryptes gallinula) differs from the true Scolopax. snipes in having four notehes in the linder margin of the sternum instead of two.

The true snipes (Gallinago), of which our common snipe ( $G$. gallinago) is the type, differ from the woodeocks in lhaving much more pointed wings, the long inner secondaries equalling the primaries in length, while the markings on the head are longitudinal, not crosswise. They are lovers or the marshes, as a rule, but some of them occur only on the high lands, and appear to have the habits of woodencks. Such are the wood-snipe ( $G$. nemoricola) of the Himalayas, and the imperial snipe (G. imperialis) of the Andes of Colombia, and Jameson's snipe (G. jamesoni) from the Andes of Ecuador in South America. In the Auckland and Chatham Islands are found peculiar tawny-coloured species (G. ancklandica and G. pusilla), which run like rails, and do not take to flight, unless very hard pressed. With the

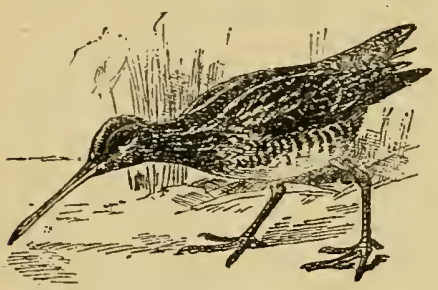

Fig. 30.-THE Conmon SNIPE (Gallinago gallinago). exception of these few resident species, snipes are migratory birds, nesting in the temperate and sub-Arctic regions of the north, and going to the far south in winter. Thus Lathan's snipe (G. australis) nests in Japan and winters in Australia, and the North American Wilson's snipe wanders south to British Guiana and Brazil, and the great snipe (G. major), which breeds in the morth of Europe, winters in South Africi. Snipes vary very much in the number of the tail-feathers, our own snipe having only 14, though sometimes it is found with 16 , but in the wire-tailed snipes, $G$. stemere and $G$. megala, as many as 26 and 20 are found. These two species nest in Eastern Siberia, and visit India and China in great numbers on migration. The outer tailfeathers in $G$. stenurc are reduced to wire-like plumes, the eight feathers on the outside measuring less than 0.2 inch in widtl. The largest of the snipes are G. gigunter from Southern Brazil, and G. undulute of British Guiana, which are from 15 to 20 inches in length.

A curious habit of the common snipe during the nesting season is known as " "drumming." "The male may then be seen," says Mr. Seebohm, "in broad daylight, high in the air, wheeling round and round in enormous circles, and flying diagonally upwards with rapid beats of the wings, then swooping down an imaginary inclined plane with half-expanded and visibly-vibrating wings, but with outspread tail-feathers, uttering a sound which is technically called "drumming." "The sound is heard only when the bird is descending, but some observers assert that they have heard it proceeding from a snipe on the ground or perched on a dead branch. It has been likened to the bleating of a goat, and bears some resemblance to the suppressed gobble sometimes heard from a turkey. Many naturalists believe that the sound is produced by the vibration of the wings or the action of the air on the outspread tail; but others, 
Mr. Seebohm among the number, believe that it is effected by the rocul organs.

The sandpiper's differ from the snipes in having the position of the eye normal, and not renching to the ear-opening, as in the snipes and woodeocks. In this group of the sub-fanily Scolopreince we find some of the most interesting of the waders, the purple sandpipers (Arruatella), the dunlins (Pelidna), the knots (Tringu), the curlew simdpiper's (Aneylochilus), the stints (Limonites), and the sunderlings (Culidris). They are mostly birds which breed in the Arctic regions, and go to the southern continents of the globe to pass the winter. Ổ tho curlew sandpiper no egg has yet been found; of the knot no leally authentic egrg is known; and of the sanderling but very few. In this group of sandpipers occurs the spoon-billed sandpiper Eurymorhynchus pygmens), a little stint with a spoon-shaped bill, which nests in the arctic regions of Eastern Siberia, where Nordenskjold met with it during the voyage of the Tegu, and passes along the coasts of Japan and China to winter on the shores of Bumma.

These birds are very elosely allied to the foregoing, but are distinguished by having the outer toes comnected with the middle one by a web at the base. In the Totomince are included all the curlews and whimbrels (Numenins), the godwits (Limosu), the tatlers (Totunus), the green sandpipers (Helodromas), the summer snipes (Tringoides), the wood sandpipers (Thyncophilus), and the ruff's (Ptoroncella). They are mostly birls which build

The Tatlers. - Sub-family

Totunince. in northern climes and in the temperate portions of the Palcearctic and Nearctic regions. The nest is usually placed in a marsh, the eggs being pearshaped and four in number, laid with the pointed ends directed towards each other; the green sanclpiper (Helodromas ochropus), however, nests in trees, utilising the old nest of a thrush or some other bird in which to deposit its eggs. The tatlers frequent the sea-shores on their journey south, and their musical notes enliven the dreary expanse of mud-flats on many parts of the British coasts during the autumn. In the breeding seasum many of the stints have a musical trill or song, which they utter as they mount into the air above their nests.

One of the most remarkable of the tatler group is the ruff, no two males of which are alike in plumage. The female, called the reeve, is smaller than the male, and of a plainer brown plumage. In winter both sexes don a plain-coloured clress, much like that of any other tatler, and the male can only be distinguished from the hen by his larger size. On arriving at their breedingplaces in Europe and Siberia, the males have a large ruff or shield on the neck, and a tuft of occipital plumes on each side of the liead. These rufi's are sometimes plain without bars, and may be white, rufous, or black, while every kind of variation is seen in the colour of the ruffs and occipital ornaments. Some-

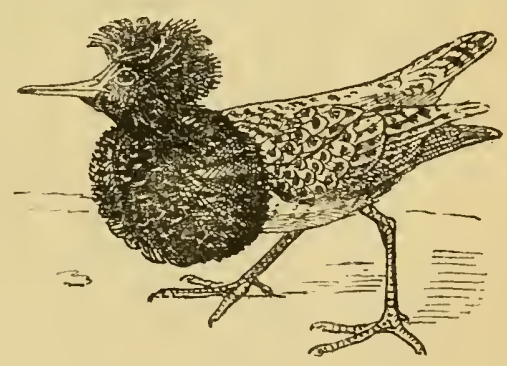

Fig. 31. -Tre Ruff (Paroncella pugnax). times they are white barred with black, or rufous with black bar3; in fact, 
the variation is endless. They are pugnacious birds, and fight for the females, before whom they dance and pirouette, always ending by placing the bill on the ground, so as to display the beauty of the ruff to the chosen lady.

Close to the true curlews comes the pearl-grey curlew (Ibidorhynchus struthersi), which is found on the inland streams of the mountains of China, Central Asia, and the Himalayas. It is the sole representation of the subfamily Ibidorhynchince, and has a curlew-like bill, but differs in having the metatarsus reticulated both in front and behind. In outward appearance it much resembles the small ibises, but an examination of the skull shows that it is really an aberrant Limicoline bird.

These birds are remarkable for their long legs and for the shape of their bills. In the stilts (Himuntopus) the bill is slender and straight, and the legs are extremely long, and when the birds are flying these

The stilts and are carried out behind them, and from their bright red Avocets. - colour are very conspicuous. The stilts are mostly black

Sub-family and white birds, distributed through the marshes of the Himantopodince. temperate and tropical portions of both hemispheres, only in New Zealancl.

while a completely black species ( $H$. melas) is found

The avocets have the bill upturned, and the lower edge of the under mandible is broad and flattened, the bird using it to scoop aside the sand in search of food. The range of the avocets is very similar to that of the stilts, and thongh they pass southwards in winter, they nest in Africa and India in places suitable to their marsh-loring habits. One species, Recurvirostra andina, is only known from the Andes of Chili, and in Australia the chestnutbreasted avocet is found (Cladorhynchus leucocephalus), a bird with webbed toes and devoid of a hind toe like the arocets, but with a very slightly upcurved bill, and with longer and more stilt-like legs.

The sub-family Peltohyatince is represented by a single genus, Peltohyos, which again has but one species, $P$. australis. This bird has usually been considered to be a kind of dotterel, and it has a dertral swelling towards the end of the bill, as in these birds, kut the tarsus has transverse scutes both in front and behind, and the species is more like a courser in appearance. I fully expect that an examination of its osteology and general anatomy will prove that it is allied rather to the latter birds than to the plovers.

In this sub-family we find the majority of the plovers, which are distinguished by having both aspects of the tarsus covered with hexagonal scales. They may be divided into two groups, the lapwings and the

The True clotterels, the former with broad and rounded wings, mostly Plovers.- resident in the countries they inhabit; the latter with sharp sub-family and pointed wings, with the seconclaries nearly as long as Choradriina. the primaries, and accustomed to long nigrations. Some of them are known, like the American golden plover (Charctdrius dominicus), to be capable of immense flights, such as from Labrador to the Bermudas, without touching land.

Two genera have longer bills than any of the rest, Thimomis and Anarhynchus of New Zealand. The latter is known as the wry-billed plover, and has its bill twisted to the right. Then comes the long array of dotterels, such as Egialitis, of which our common ring-dotterel is the type. The members of the genus Agialitis are found nearly over the whole world, and perform long mirgrations to the South in the winter. Their four pear-shaped eggs are laid in a little depression in the sand or shingle, and the nestlings 
are difficult to capture, on account of their resemblance to the surromndings in which they are hatched; the same may be said of the eggs, which closely rescmble the adjacent shingle. Some of the other dotterels, such as the members of the genus Ochthorlomme, are handsome birds, with a chestnut collar across the chest. 'The true dotterels (Eudromires) are mountain-breeding bircls, and our English species, $E$. morinellus, is the only one of the group with any black on the belly. This, howerer, is not assumed as a brecdingdress, as is the ease with the grey and golden plovers.

The latter birds have a spangled plumage, and don a black breast in summer, passing into a white-breasted livery in winter. The grey plover (Siputarolu helretica) differs from the golden plover (Charadrius pluvialis) in having a hind toe. It nests on the tundra or barren grounds in the Palaaretic and Nearetic regions beyond the limit of forest growth, and until reeently its eggs were amongst the rarest in eollections. Mr. Seebohm and Mr. Harvie Brown, however, have obtained them on tho Lower Petehora River, and Mr. Trevor-Battye and Mr. H. J. Pearson on Kíolguev Island.

Alsother group of the broad-winged lapwings is represented by our common pewit ( $V$ anellus vanellus), which lias no wattle on the face or spur on the wing, like many of the other genera of the Charadriiuce, such as the spur-winged plovers of Afrier (Hoplopterus), which have a formidable spur on the bend of the wing, with which they fight. $H$. spinosus is said to be the species which attends on the croeodile, and enters its mouth to clean the teeth of the monster. Some of the other grenera of this group of plovers have a facial wattle, but no spur on the wing, while in the genus Xiphidiopterus we have two species, one Javan, and the other West African, which have a large wingspur and a conspicuous facial lappet as well.

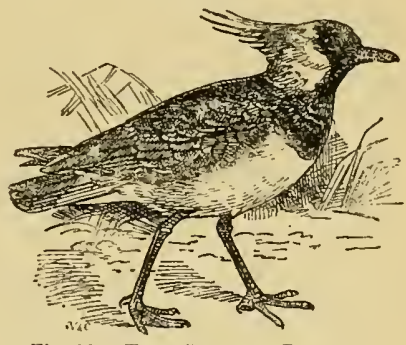

Fig. 32.-The Common Lapwing (Tanellus vanellus).

All the wattled plovers (sub-family Lobivanellina) have the metatirsus trans versely sealed in front, but reticulated behind. They are nearly all broadwinged birds like the pewits or lapwings, and most of them have spurs on the wings, and wattles or lappets on the face.

We now. come to a group of the Charadriina, where there is no swelling at the end of the bill, and in this section of the plovers are the oystereatchers (Humrtopodince) and the turnstones (Arenariince).

All the oyster-eatehers have the metatarsus reticulated both in front and behind, and the angle of the lower mandible is placed very far back, the end of the bill being compressed, and having a somewhat sharp ridge. Twelve speeies of oyster-catchers are known, most of them being black orblack and whitein plumage. They are found in all parts of the glube, but do not extend very far north. They breed on the shores and on the sindy beds of rivers,

The Oystercatchers. Sub-family Hamatopodina. and the nest is a little depression in the sand or moss. The eggs are not unlike those of the stone-plovers or thick-knees, being of a claybrown with blackish spots or seribblings.

- Only one genus, Arenaria, represents this sub-family of ployers, which is a 
very distinct one. There is no dertral swelling to the end of the bill, and the metatarsus is transversely sealed in frout, but reticulated

The Turn-stones. behind, while there is no connecting web between the toes, - Sub-family as in the oyster-catchers. Two species of turn-stone are Arenariince. kuown.

The common turn-stone (A. interpres) is one of the most cosmopolitan of birds, nesting in the Arctic regions of both hemispheres, and ranging south almost as far as land extends. The male is a very handsome bird in the nesting plumage, though the females and young birds are not so brightly coloured. It gains its name of "turn-stone" from its labit of turning over stones, often of considerable size, in order to reach the insects underneath. A second species is found in Western North America, the black turn-stone (A. melanocephala).

These are curious birds, peculiar to the Old World, where they are found from South.

The Pratincoles, ern Europe and Sub-order Central Asia to Glareolce. China, south to India and Aus-

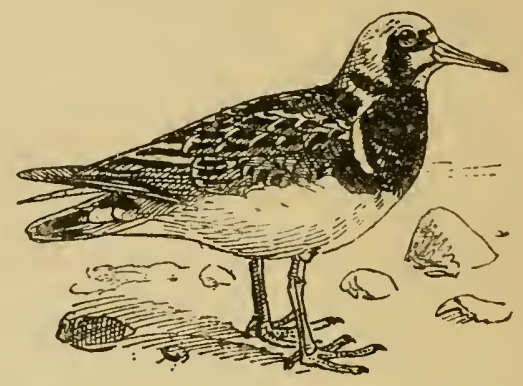

Fig. 33,-The Common Turn-Stone (Arenaria interpres).

tralia. They have all long wings and a swallow-like flight, and they nest in companies, laying eggs which are unlike those of plover's or snipes, being so thickly scribbled over that the ground-colour is almost invisible. One of them, the common pratincole (Glareola pratincola), has occurred in England on a few occasions. The pratincoles have the claw of the middle toe pectinated, as in the coursers, from which they are distinguished by their long wings.

Although allied to the plovers and pratincoles, and, like these birds, possessing slit or schizorhinal nostrils, the coursers differ from them in having $n$ basipterygoid pro-

The Coursers. - cesses, and they may - Sub-order be differentiated from Cursorii. the former by their pectinated middle claw. They have both aspects of the metatarsus transversely scaled. Of true coursers (Cursorius) there are five species, the best-known of which is the creamcoloured courser (C. gallicus), which has occasionally wandered to England, though its natural habitat is the desert

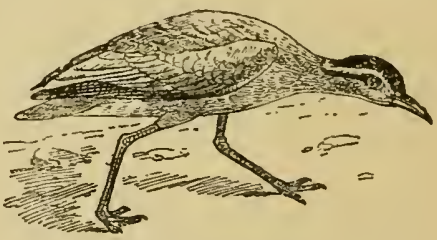

Fig. 34.-The Cream-coloured Courser (Cursorius gallicus). country to the south of the Mediterranean, where it is found from the Azores and the Canary Islands eastwards to North-Western India. On the island of Fuerteventura it breeds in large numbers, and the eggs, till lately very rare, are now in the collection of every oologist. Two eggs only are laicl, on the bare ground, without any attempt at a nest; they are stonecoloured, with numerous dots and scribblings of brown, and are scarcely distinguishable from the surrounding soil. Three species are found in 
Ifrica, and one, the coromandel courser (C. coromandelicus), is plentiful in the Indian Peninsula. Of the allied genus Rhinoptilus, eight species are known, all Ethiopian, scepting one, $R$. bitorquatus, which is a bushfrequenting species in a restricted area of Central India.

These birds, with their great yellow eyes and stout legs, form the connecting group between the plovers and the bustards. They have holorhinal nostrils like the latter, and in many anatomical characters are more like the latter sub-order than the Charadrii. 'They are found throughout the temperate and tropical portions of the Old World, and re-occur in Central and South America.

The common stone-curlew, thick-knee, or Norfolk plover,

The Stone.

Plovers. -

Sub-order

U'idicnemi. is found on barren wolds and shingly portions of the coast in many parts of England. It occur's in similar situations throughout Central and Southern Europe, as far east as India. It is a particularly shy bird, and on the approach of danger, it sinks its body on the ground, and lies quite flat, with its neck stretched out. The little nestlings, which are clothed with greyishbuft' down, also endeavour to conceal themselves in like minner. The eggs, two in number, are laid on the bare ground, without any attempt at a nest, and are stone-coloured, with brown and grey markings, and so closely resemble stones that they are very difficult to find. Of the seven other species of stone-curlew known, four are African and three American. In Australiz the long-legged thick-knee (Burhinus grallurins), and in India and the Malay Archipeligo two gigantic species, Esrecus recurvircstris, and Orthorhemphes inayinrostris, occur.

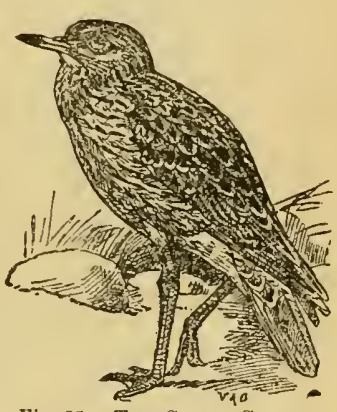

Fily. 35. -THE Stone-CURLEW (Édicnemus adicnemus).

Like the stone-curlew, the bustarcls have holorhinal nostrils, as well as a split or schizognathous palate. The breast-bone has two notches on its posterior margin, there is no oil-gland, and the feathers have a distinct after-shaft. In the males of some of the The Bustards.species there is a gular pouch, and the throat is capable of sub-orderOtides. being inflated to an enormous extent.

The bustards differ very much in size, some of them being scarcely larger than stone-curlews, though they are always heavier in build. The male of the great bustard measures more than three feet and a half in length, and the great kori bustard of Africa is over four feet in length, while some of the small forms, such as the crested bustards of Africa (Lophotis), only measure a foot and a half in length.

They are all birds of the deserts and open wolds, and are strictly confined to the Old World, the larger number being found in Africa, which is the home of six genera out of the twelve which are known. India has two genera of florikins, Houbaropsis and Sypheotis, while the genus Otis, of which the great bustard is the type, and Tetrax, containing the lesser bustard ( $T$. tetrax), are found only in Europe and Northern Asia.

The great bustard (Otis tarda) is now extinct as a British species, but was one of our indigenous birds in the early part of the present century, inhabiting Salisbury Plain and other open wolds in England from the borders of Scotland to Dorset. It now occurs only as a rare visitor, and it is not known 
whether the native British bustards oceurred in former times as migrants or were resident in this country. The former supposition is probally correct, as the species is known to be migratory to most of the European countries in which it still breeds. In the nesting season it retires to the fields of tall grass and corm, where it is able to conceal its great bulk, and it is said that at this season of the year the birds moult their quills, and are mable to fly.

The male of the great bustard is much larger than the feniale, and has, besides his brighter coloration, more conspicuous whiskers. His method of showing off, when courting the female, is one of the most curious sights in the whole of nature. He commences by shivering his wings and lowering his quills, and his next action is to turn up his tail and lay it flat on his back, so that the snow-white under tail-coverts form a sort of frill. Across the flattened tail he disposes lis primary quills so that the ends of these cross each other, and keep the tail ont of sight, the whole proceeding being hidden by ruffling up the scapular feathers till nothing can be seen of the tail or the primary quills. The act of crossing the latter across the back naturally brings the fure-part of the wing into an extended position, and the inner secondaries, which are pure white, are thrown up as a frill on tach side of the back, while all the wing-coverts are more or less inverted, at if the bird were trying to turn himself inside out, the long parapteral wing-coverts beins thrown back, so as to secure an uninterrupted view of the white frill caused by the eleration of the inner secondaries and the halo of the under tail-coverts. 'The bird then lays its head deep down between the shoulders, so that the whiskers stand up on each side, and then proceeds to inflate his throat and chest, which become distended to an enomous degree. He then shows limself to his lady-love, and paces slowly in front of her, now and then springing round to exhibit the white under tail-eoverts. This curious performance was witnessed in the Zoological Gardens by Mr. Pickhardt, who Ias mounted the group of bustards for the grallery in the Natural History Museum.

The eggs of the bustards are two or three in number, of an olive-brown colour, spotted or blotched with brown, the underlying spots being grey, the egrs being never very strongly marked. No nest is made.

In this assemblage we have birds of very varied form and the Cranes were considered in former times to be allied to the lierons. The difference in the structure of the palate, lowever, shows that The Cranes. - they are not really related, as the herons have a bridged Order or desmognathous palate, whereas in the cranes and their Gruiformes. allies the maxillo-palatine bones do not coalesce with each other or with the vomer. The young, likewise, are latched covered with down, and can take care of themselves soon after leaving the egg, while the nestlings of herons have to remain for a long time helpless, and are fed by the parent birds in the nest. There are also many other anatomical and osteological characters which separate the cranes.

They are stately birds, with long legs and generally some bright ornamental colour on the head, while the inner secondaries are dereloped into handsome drooping plumes. WVith the exception of South

The True Cranes. America, cranes are found in every part of the world, and

-Sub-order Africa possesses three out of the nime known genera. The Grues. sarus cranes (Antigone) are found in India and Buma, and one species, the well-known "native companion" ( $A$. australasiana), in Australia. This is a peculiar and interesting distribution, 
as there is a large Indian bustard (Eupodutis educurdsi), which has its nearest ally ( $E$. australis) in Australia. As a rule, however, the cranes are Northern birds, five species nesting in the Palrearctic region. In many of them the trachea is convoluted, and enters a cavity in the fore-part of the sternum.

The common crane (Grus grus) is now only an occasional visitor to Great Britain, but there is no doubt that it formerly bred in England, before the drainage of the meres deprived it of its favourite breeding lraunts, and the discovery of fossil remains in Ireland slows that it was once still more widely distributed in the Britisl Islands. The nesting-hume of the crane is at present in the forest morasses of Torth and Central Europe, and in the marshes of Southern Spain. It is a summer visitor to Europe, and sometines liarge numbers of clanes are observed on migration, flying in a V or $\mathrm{Y}$ formation, and trumpeting loudly. Colonel Irby recoris that he must un one oceasion have seen, at least, four thousand pass overhead near Gibraltar. The foul of the erane consists of corn and seeds of all kinds, as well as lizards and frogs, and in India the cranes, which arrive from the North to winter, do great lamage to the water-melons. The eggs are two in number, brown, with a few spots or smudges of larker brown and underlying spots of grey. The nest is often a large structure, as much as five feet across, and is built among sedge and rushes,

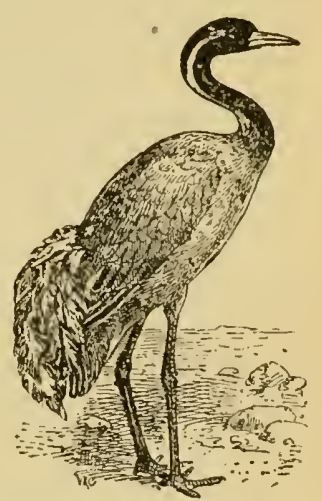

Fig. 36,-The Commox Crane (Grus gints). sufficiently short to enable the bird when standing up to catch sight of any intruder.

The limpkins are long-billed birds, having the appearance of large rails, of a brown colour, spotted with white. In ostcological characters, however, they most resemble the cranes, and, like the latter birds, they liave no notches in the hinder margin of the sternum. The The Limpkins.wings are rounded, and the secondaries are as long as the primaries, the first of the latter quills being sickle-shaped, Sub-order narrowed and incised for the basal two-thirds, with the tip spatulite. Two species of the genus Aramus are known, the Florida limpkin (A. pictus) extending from Southern Florida to Central America and the West Indian Islands, while the South American limpkin (A. scolopaceus) is found from Paraguay to Guiana and Venezuela. Mr. IV. H. Hudson, the chronicler of bird-Jife in Argentina, says that the limplins, or caraus, as they are called in that country, are more nocturnal than the rails, and take wing more readily, as they have greater powers of flight. In their gestures and motions on the ground they resemble rails, but differ strikingly from all Ralline birds in their habit of flying, when clisturbed, to some open place, where they walk about conspicuously, watching the intruder. "By day," writes Mr. Hudson, "the carau is a dull bird, concealing itself in dense reedleeds in streams and marshes. When driven up he rises laboriously, the legs clangling down, and mounts vertically to a considerable height. He flies high, the wings curved upwards and violently flapped at irregular intervals ; descending, he drops suddenly to the earth, the wings motionless, pointed up, and the body swaying from side to side, so that the bird presents the 
appearance of a falling parachute. On smooth ground he walks faster than a man, striking out his feet in a stately manner, and jerking the tail, and runs rapidly for ten or twelve yards before rising. At the approach of night lie becomes active, uttering long, clear, piercing cries, many times repeated, and hend distinctly two miles away. These cries are most melancholy, and together with its mourning plumage and reeluse habits, have won for the courlans several pretty vernacular names. It is called the "lannenting bird" and the "crazy widow," but is more familiarly known as the carau. As the breeding season draws near they become exceedingly clamoroms, maliing the marshes resound day and night with their long wailing cries. The nest is built among the rushes, and contains ten or twelve eggs as large as turkeys', slightly elliptical, sparsely marked with blotehes of pale brown and purple on a dull white ground, the whole egg having a powdery or floury apperiance."

In New Caledonia is found the singular bird known as the kagu (1hlimnchetus jubatus), the only representative of the sub-order Rhinochetides. It is all elecrantly coloured grey bird, with a lirge crest, and is

The Kagus. -

Sub-order Rhinochetides. nocturnal in its habits. In internal structure, it has much that is crane-like; but it differs from the latter group of birds by possessing powder-clown patches on each side of the rump. When in captivity, the kagu exhibits considerable dancing powers, in which feature he also resembles t!he cranes.

This sub-order is represented by a single species, Mesites variegata, a bird peculiar to the eastern slope of the mountain-chain which traverses the island of Madagascar. Its plumage is of a reddish-browir, The Madagascar and it looks like an aberrant kind of rail. Like the kagu, it Kagus.-

Sub-order Mesitides. possesses jowder-down patches, but instead of two, there are five: two on the side of the back, one on the sides of the body, and two on the belly. It is said to build its nest on the ground, but little is known of its habits.

These remarkable birds are confined to South and Central America. They are also very rail-like in appearance, and resemble the lingus in having powder-down patches. Two species

The are known, the Soutl American

Sun-Bitterns. sun-bittern (Exrypyga helics), inSub-order

Eurypyge. luabiting Amazonia, Brizil, and Guiana, and the large sun-bittern (E. major) being found in Central America and Colombia.

The plumage of the sum-bittern is curiously variegated; the wings are beautifully spotted, and the bird is fond of sitting with its wings outspread, as if sunning itself. The nest is placed in a tree, and the bird has another heron-like character in having to feed the young birds in the nest for some time, though the nestlings are covered with dowu, as in true cranes. The eggs are said to resemble those of a woodeock.

The members of this sub-order are five in num-

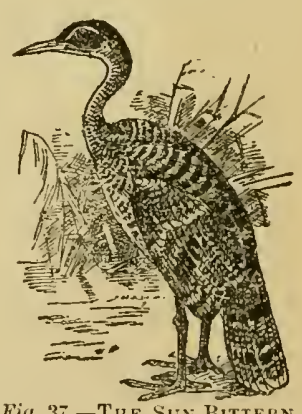

Fig. 37.-TuE SUN-BitTerN (Eurypyga helias). ber, all confined to South America. They possess many crane-like features, but differ from all the aberrant gruiformes which we have been considering, in their clomesticity, as they are often tamed by the natives of Brazil. 
The nest is o: the ground, the eggs being white, a peculiar colour for it Crano-liko bird, and the nestling is covered with down, and is able to provide for itself soon after it is hatched. The birds gain their name "Trumpeter" from their peculiar trumpet-like

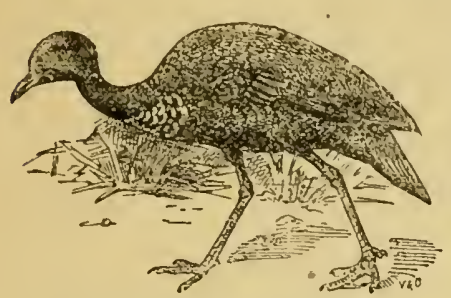

Fig. 38.-THE Comm Trumpeter (Psophia re ile is). note, and no doubt the modification of

The Trumpeters. - Sub-order Phosphice. the trachea has something to do with this, as the windpipe is enormously long, and is continued under the skin of the abdomen nearly. to the anus. The Trumpeters differ from the Cranes in haring oval or holorhinal nostrils, and their plumage, instead of being firm and harsh, is particularly soft. They are residents in the parts of South America they inhabit, and have not any great powers of flight. They. live at large in the forests, and often assemble in fiocks of considerable size.

In asinciating the Serianas with the Cranes, we are following the most recent conclusions of anatomists; but it must be conceded that they are very aberrant members of the Gruiformes. In some respects they resemble the bustards, and, like them, have holorhinal nostrils, but in the possession of four toes, and in other characters, they differ so

The Seriamas, Sub-order Dicholophi. much from those birds that in our opinion there is really no real affinity between them. Like the Cranes and the other allied forms we have just been considering, the Seriamas have a cleft or schizognathous palate, and their mode of life presents some features in common with the Secretary-Bird (Serpentarins secretorins) of Africa. Recognising this fact, some ornithnlogists, myself among the number, have considered the Seriama to be an aberran: accipitrine bird. The common Seriama is an inhabitant of South-Eastern Brazil; and in Argentina another species occurs, Burmeister's Seriama (Chunga bumeisteri). Theso two represent the ouly known species of the sub. order. The resemblance in appearance to the secretary-bird is remarkable, aud in its mod., of walk, its crested head, and its long legs, there is much that reminds us of the latte: bird, which has a curious method of pounding its food. If the latter be a rat, it springs into the air, and brings down both feet with all its force, till it has reduced its prey to a pulp. This is also done by the Seriama. Mr. Hudson says that these birds live on the

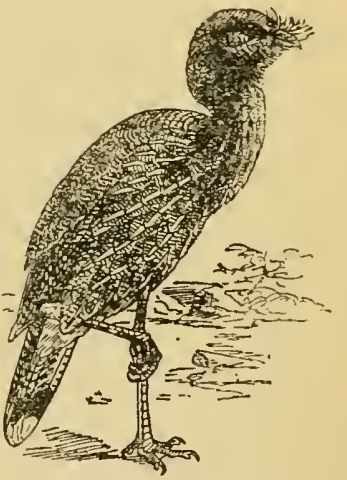

Fig. 39.-TIr SFrialia (Cariama cristata). grouud among the high grasses of the Campos, where the traveller frequently liears their loud screaming cry as he rides along the tracks. Their ford consists principally of insects and caterpiliars, but they also devour berries 
and reptiles. They nest in low bushes, the eggs being two in number, rounded and spotted, resembling those of Cranes ant Rails.

Somewhere in the neighbourhood of the Seriamas and the Cranes and Rails must apparently be placed some extraordinary forms of bird-life which have been discovered in the Miocene deposits of Patagonia,

The Extinct Birds of Patagonia

(Stercornithes).

and described by Dr. Ameghino under the order Stereornithes. These peculiar creatures are only known from their fossil remains, and they were at first supposed to be Struthious Birds, and akin to the Rheas. Further information is required concerning them, but at the present time, my colleague, Mr. Andrews, considers that they are totally different from any ostrich-like birds, and were probably gigantic fore-runners of the Seriama and the Crane-like birds of modern times.

All the members of this order have a bridged or desmognathous palate, and the nestlings are hatched helpless, and are fed in the

The Heron.Order

-Arderformes.

nest by the parent birds for a considerable period. Thus they differ from the Cranes, with which they were associated in the older classifications. The Heron-like birds may be divicled into three great groups, viz., the Storks (Ciconiid(e), the Spoonbills and Ibises, and the Herons.

Although in outward appearance Storks and Herons look very much alike, there are several characters which render them easily separable. For instance, no Stork has the claw of the third or middle

The Storks, Family "icturivar. toe pectinated; that is, furnished with a comb-like process, as is the case with all Herons. Again, the hinrl toe is not on a level with the other toes, but is elevated above it ; and the farcula, or "merry-thought," bone shows no median projection in the angle, as is seen in the true Herons. There are other anatomical and osteological characters which can be adduced for the separation of the Storks from the Herons which it is not necessary to enumerate in detail.

In this Order are included the true Strorks (Ciconiide), the Marabous, or Adjutants (Leptoptilus), the Open-bills (Anrestomus), and the Wood-Storks or Wood-Ibises (Tantalus), the latter being

The Storks.Sub-order Ciconii. generally admitted as a distinct sub-family, Tantalince. All these birds have no "powder-down" patches on the sides of the rump, thus differing from the true Herons and the Hammerheads (Scopi) and the Shoe-billed Storks (Balcenicipitido).

The best-known representative of the Ciconii is the White Stork (Ciconia ciconia) of Europe, a bird which occasionally visits England, but is to be more easily studied on

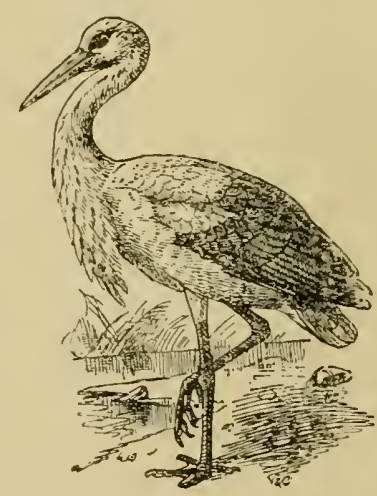

Fig. 40.-THF WIITE STORK (Ciconia ciconia). the olpposite shores of the Continent. It is always interesting to take a country walk in Holland in the spring and see the Storks' 1.csis, which are plentifully distributed in the Dutch gardens, where the birds are encouraged 
to nest by the erection of cradles or other accommodation (often an old cart wheel) erected for their bcnefit. In most places frequented by the Storks it is considered lucky to have a nest on the premises, and the latter increases in bulk year by year as the birds return to their nesting-places, which are often on the tops of houses. They have a curious habit of sitting motionless for hours together, often on one leg, as if absorbed in contemplation, uttering occasionally their single exclamation, which is produced by the snapping of the mandibles, for they apparently have no true note or call.

Before migrating to spend the winter months in Africa the Storks often assemble in large flocks, returning to Europe in January and February, and their first halting-place to nest secms to be in the Mediterranean countries, especially in Morocen, where they are strictly protected. Colonel Irby states that ho was told by a Frenchman that "in the City of Morocco, as well as at Fє\% and some other large towns in the Moorish Empire, there are regular Storks' hospitals, and that should one be injured, or fall from the nest, it is sent to this institution, or rather enclosure, which is kept up by subscription from realthy MInors, who consider the Stork a sacred bird." The late M. Favier, who lived for some years in Morocco, writes the following note, which gives a very good idea of the migrations of the Stork and its habits in this favoured country. He says:- "The Stork is seen on migration in rast numbers around Tangier passing to Europe during January and February, some of tho birds terminating their journey by remaining to breed in Morocco. These are the first to depart south, returning again year after year to the same places, and apparently by the same route as that taken in their gradual cleparture.

"Some large flights pass on without stopping; those which migrate in August rest awhile on their way south; so during the autumnal migration (which lasts, like the spring, for about a month-the latter half of August and the first part of September) this species is extremely numerous, and is scen round the environs of Tangier in all directions; they are very tame, and often follow close behind the plough.

"The superstition which shelters this bird from molestation by the natives is the belief that the Storks were inspired by Allah to protect the harvest and the country from noxious insects and reptiles, and that the birds themselves (knowing the benefits they confer on man) ask in return protection for their offspring by building their nests on the walls of towns and houses, and that, therefore, anyone who kills them must be a Kaffir, i.e., not a true believer of the Prophet, especially as the birds would only be killed for mischief, and not for food. It may be added that some of the Arabs believe that the Storks originate from a wicked Kadi and his family, who, as a punishment for their great cruelty, were all changed into these birds, and that these miserables humble themselves to appease Allah, and in the hope of some day regaining their human form, pray without ceasing day and night, and, whenever they rest, prostrate themselves and clean their bills."

The White Stork of Europe has a red bill, and is represented in Eastern Siberia and Japan by the Black-billed White Stork (Ciconia boyciana), and in America by the Maguari Stork (Enxemure magueri), which has a greenish bill. The Black Stork (Ciconia nigra) is another European bird which has occasionally visited England. It winters in Africa and in the Indian Peninsula, and, like its white relative, only visits Europe in the summer, when it is also found over Northern Asia. It differ's from the White Stork in being a forest bird, but in labits and food it resembles that species. Indeed, in these respects all Storks are very similar. 
In India and Africa a curious species occurs, viz, the lihite necked Stork (Dissurc episcopus), which, on examinacion, would seem to have a double tail, whence its Latin name. The white under tail-coverts are longer than the black tail-feathers, and are stiffened so as to appeai like rectrices rather than coverts. The same curious formation occurs in one of the American Storks (Euxenura maguari).

The Jabirus are the largest of the Storks, standing higher on their legs than even the Adjutants. There are two species of Jabiru besides the American one mentioned above, viz., Mycteria senegralensis of Africa and MI. anstralis of Australia. They have a very peculiar bill, which is slightly upturned at the end, and of a black and red colour.

Of a more ungainly form, and with a bare and scabious head, are the Adjutants (Leptoptilus). They are very large birds, and as fossil reniains have been found in the Miocene deposits in France, we may conclude that they were at one tine much more widely distributed than they are now. At present one species of Leptoptilus is African, another Indian, and a third Javan. They all possess the beautiful soft under tail-coverts known as "Marabou" feathers, and on the neck they have a bare pendulous pouch which they are able to inflate; and from the way in which this is done by the birds in confinement, it would appear as if it was considered an ornamental appendage, though $\mathrm{fr}$, its livid colour the protrusion of this naked bag is anything but ornamental. In India the Adjutants are protected on account of their usefulness as scavengers, as they will devour almost anything, and they may often be scen in the streets of the towns. In aviaries they often stand on one leg for hours motionless, or, with their legs stretched forward under them, they will go to sleep with their heavy heads resting on their crops. Mr. Fugene Uates says that he noticed enormous numbers of Adjutants in Pegu. " Along with the Pelicans," he says, "breeding in the same trees, were innumerable Adjutants. One can liardly realise the number of these birds that visit Pegu in October, unless, as I liave done, one has seen the vast armies which settle on the plains on their first arrival. I have stood on a bund where I could see for about two miles around me, and the whole area was literally covered with them. Some fifty birds stand luddled together, then there is a bare spare of about $100 \mathrm{ft}$., and then another group of birds. Their numbers are incredible. They all arrive suddenly in the Pegu plain on the same day, and after resting for about two days, they betake themselves to the forest, where I had the pleasure of visiting then. Certainly almost all the Indian Adjutants must come to Pegu to breed. These birds utter only one sound, and it resembles the lowing of a cow when separated from her calf. It was the only sound heard in these gloomy forests." Colonel Bingliam found the nests of the Indian Adjutant on the Nedong Hills in Tenasserim, and only succeeded in reaching the rocks on which they were built after a stiff and difficult climb.

These birds are generally known as the "Shell-Ibises," though they have no connection with the true Ibises, but are Storks of a peculiar type; Mr. Leydecker calls them "Shell-Storks," which is a much

The Open-billed

Stork3.-Genus Anestomes.

more appropriate name for them, as their food consists principally of molluscs, for the breaking of which the bird's "nut-cracker"-like bill is distinctly well adapted. The peculiar gap in the bill is not seen in the young birds, but seems to develop as the birds get older.

These birds have also generally been called "Wood Ibises," and they scem 
to be a hind of connecting link between the Storks and the Ibises, though in structure they resemble the former. Three species are known-the American IVood-Sturk (Tantalus loculator), the Afriean Pserdotantalus ivis, and the Indian species, $P$. lencocephalus. Of the nesting of the latter bird Lieut.

The WoodStorks.-Family l'entalude. Burgess has given the following account:- "In a village about ten miles from the Godavery river, where there are a great number of large banian trees both outside and inside the walls, I found a community of these birds, which had built their nests on them, probably to the number of fifty. The trees inside the walls were as thickly covered with nests as those outside, and the birds, which appeared docile and tame, did not mind the noise of the people passing beneath them. When I visited the village, the young birds were all well fledged and most of them able to fly. The villagers informed me that the old birds move off to the river in the very early dawn, and having caught a sufficient supply for their young, return at about eight or nine o'clock; a second expedition is made in the afternoon. Some idea of the quantity of fish caught by these birds may be gathered from what the people told me, that numbers of fine fish were dropped by the old birds when feeding their young and were eaten by them. A young bird of this species, which I shot in Sind, disgorged a large quantity of small eels. The nest is composed of small sticks, and is placed at the top of the trees, and if there are many on the same tree, they are placed pretty close together."

In many of its characters the African genus sropms, which represents this sub-order, is intermediate between the Storks and the Herons. In the form of the furcula, without any median projection, it resembles the former, and it also wants the pectinated claw of the Herons, while the absence of powder-down patches likewise allies it to the Storks. In some points of its anatomy scopus is Heron-like, but in external appearance it is unlike any member of the above-mentioned sub-orders. The colour of the plumage is a sombre brown, hut the bird has a fine crest and a curiously-compressed bill, with a strong dertral hook at the end. Both the inner and the onter toe are connected together hy a distinct basal web.

But it is in its nesting habits that the Hammerhead is so peculiar. The nest is the work of a pair of birds, and is placed either on rocks or trees, sometimes six or eight being found within a short distance of each other. Sir John Kirk found one on the Zambesi, $6 \mathrm{ft}$. in diameter, with small openings on one side. The nest is a mass of sticks, and the bird has been said to make three distinct chambers; but in South Africa the nests are described as being for the most part a solid mass of sticks, sometimes to the extent of a cart load, the nest being often decorated with bones, bits of erockery, or other rubbish, or any bright thing which the bird can eollect, after the manner of a Bower Bird (Ptilonorhynchus).

The Hammerheaded Storks.Sub-order scopi.

These extraordinary birds are represented, as in the preceding instance, by a single genus Balconiceps, which, like Scopus, is confined to the Ethionian 
region, but instead of being widely distributed like the Hammer-hear, the Slioe-bill is confined to the districts of the Upper Nile. The shape of the bill, with its dertral hook,

The Shoe-billed is sufticient to distinguish Storks.-Sub.order Balceniceps at a glance. The linlenicipitides. genus further possesses two powder-down patches like the Herons, but differs from the latter birds in the absence of any pectination on the middle claw, and in its Stork-like furcula. Taking all points of its anatomy into consideration, the balance of evidence seems to be in favour of the alliance of Brelceniceps with the Storks.

Von Heuglin considered the "Abu-maskup" or Shoe-bill to be a kind of Marabou, and an inhabitant of the Upper Nile regions, such as the Saraf River, the Lower Kir district, and the Gazelle River, and the countries lying hetweell. It is everywhere a shy bird and decidedly scarce, its habits being Stork-like, standing on one leg and feeding on fish. Its only note seems to be a snapping of the bill like that of a Stork.

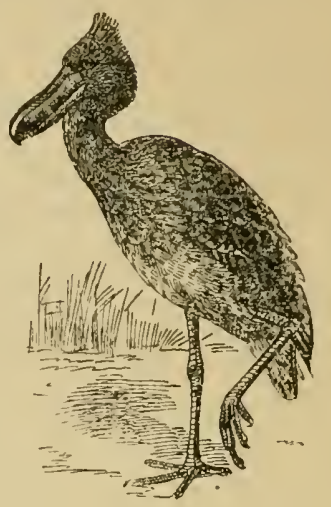

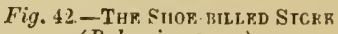
(Balrenicepss rex).

One of the chief differences between the Herons and the Storks is the pectinated claw on the third or middle toe, and another difference is the position of the hind toe, which, in

The Herons.Sub-order Ile rorliones. the Storks, is elevated above the level of the other toes, and in the Herons is on the same level as the latter. The median process on the furcula has been already alluded to. The Heroliones may be divided roughly into the Herons and the Bitterns. The former have tuclve tail-feathers, and the latter ten.

The true Herons comprise a large number of genera, all more of less closely connected together, but differing in certain constant peculiarities, which warrant their being separated as genera, or, at least, as sub-genera. Thus the Purple Heron of Europe is remarkable for its long middle toe, which is as long as the tarsus, and hence it is known as Phoyx purpurea.

The genus Ardea, on the other hand, has the proportions of the toes different, the middle toe being shorter, and the tarsus longer than the

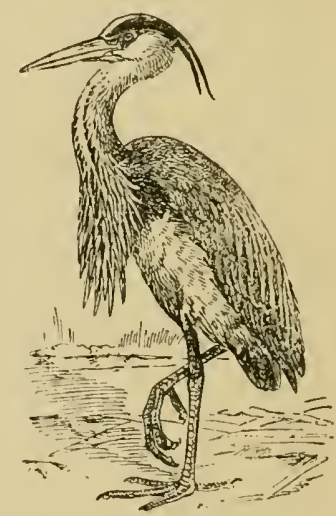

Fig. 43.-Tirs Commos Hzrow (Ardea cinereri). middle toe and claw. Besides the pectinate or comb-like claw on the middle tne, our Common Heron (A. cinerea) has the tip of the bill serrated or furnished with saw-like notches along the cutting edge at the end of the upper mandible.

The Common Heron is now to be found nesting in England nnly in certain heronries where the bird is protected. The havoc which the bird 
plays anoung the fish in preserved waters is suflicient excusc for its slaughter, and many are killed on account of the damage they do. Nevertheless, the Heron is an extremely handsome ornament to our waters, and it is always a beautiful sight to see one of these birds standing motionless by a pool of water, or flying with its heavy wings and outstretched legs high above us in the air. The nests of the Common Heron are bulky structures. and, as a rule, are built on trees, though occasionally, where trees aro absent, they will be built on bushes or even on the ground. "The eggs are of a beautiful greenish-blue colour.

When in full nesting plumage, our own Arder cinerea dons some long erest feathers and some elongated feathers on the back, but in these features it is entirely eclipsed by some of the Egrets, such as tho species of Herodias and Grereltu, which have beautiful ornamental plumes on the breast and lower back during the breeding season. The long dorsal train of the Little Egrets (Gurvette gar ofta) forms the material with which the English ladies of the present day decorate their bonnets and hats. Every one of these plumes, sold as "osprey" feathers by the dealers, has been taken from the body of a bird killed while bringing food to its nestlings, which are in consequence left to starve. It is scarcely possible that, in the present day, when so much publicity has been given to the fact that the wearers of these plunes are responsible for the slaughter of numberless beautiful Egrets, and the death of the young ones by starvation, any Englishwoman can plear immunity from complicity in the crime of consenting to the murder of these pretty birds; and one is forced reluctantly, seeing that the plumes are whtained solely for the English market, to believe that our people love to have it so, and that they would rather that thousands of Egrets wero killed than that their bonnets should be without an "osprey" plume.

Passing from the true Herons and the Egrets to the Night-Herons, we find several intermediate forms, such as the lovely Agami Heron of (Buiana (Agumir agami), and the Reef-Herons (Demiegrettr).

In tho latter birds we meet with a curious fact, viz., that they have two forns, a white and a grey one, and, as far as one can say at present, the white form goes through all

The Night-Herons. Genus Tyrterorax. the changes of the grey one, assuming the ornamental plumes of the breeding season; and yet, when the two forms cross, as they often seem to do, the result is seen in any amount of pied birds. The same phenomenon is exhibited in an American Heron (Dichromanassa rufa), where one form of the species is white and the other rufous. The two forms breed together, and sone of the lestlings will be white and others rufous.

The Night-Herons are found nearly everywhere on the globe, and the European species, $N$ yctieorax nyctieorax, occurs in the temperate and tropical portions of the Old and the New Worlds. These birds breed in colonies, and build a nest of a framework of sticks, in which the eggs lie in a sort of cradle. One may travel for miles through a marsh without suspecting the presence of the Night-Herons, and suddenly come upon the breeding place, when the air becomes full of the noisy cries of the birds, as they hover over their nests, and evince the greatest concern at the invasion of their retreat.

One of the most curious of the Night-Herons is the American Boat-bill (Canchroma). At first sight the remarkably wide and shoe-shaped bill would suggest an affinity with the Shoe-billed Stork (Balceniceps rex), but the sharacters of the bird are absolutely Heron-like, and there is no doubt that 
the bird is an exaggerated form of Night-Herun, its plumage also suggesting the propriety of this allianee. The genus stands, in fact, between the true

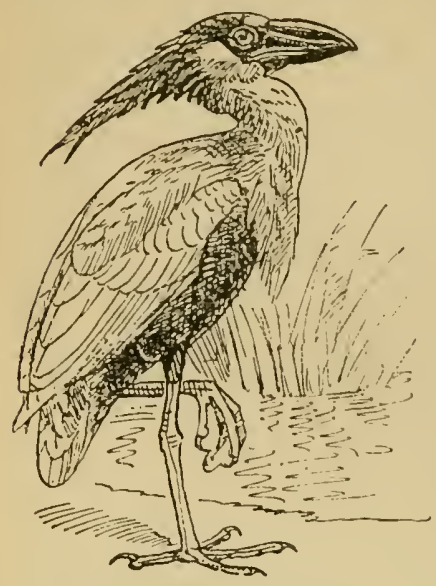

Fig. 41 - TIF Boat BILLR? HRFoN (Canchrume eochlcaria). Night-Herons (Nyctieorax) and the Mottled Night-Herons (Gorsachius) of the Indian Region.

Two species of Boat-billed Herons are known-the South American species C. cochlearia, which is found from Brazil to Guiana, Colombia, and Ecuador, and the Central American species, C. zeledoni, which takes its jiace from Panama to Mexico, and has it tawny-coloured breast instead of a white one. They are nocturnal birds, and Mr. Richmond says that in Costa Riea he found $C$. zclerdoni in colonies, and the note of the species was a "squawk," something like that of the Night-Heron.

The Bitterns have ten tail-fenthers and the end of the bill serrated. In this group are contained the Little Bitterns (Ardetta), the Drarf Tiger Bitterns of South America (Zebrilus), and the Asiatie Bitterns (Ardeirallus and Dupetor), as well as the True Bitterns (Botaurus). Of the Little Bitterns ten species are known, and the distribution of the genus is almost cosmopolitan. The most tyoical species is the Little Bittern of Eurove (Ardetta mmetr), a bird which still occasionally finds its way to Eugland, and doubtless formerly bred in the British Islands. One of the most remarkable of the Little Bitterns is, however, the Argentine species (Ardettn involucris), coneerning which Mr. W. H. Hudson tells a remarkable story, one of the most interesting of all histories of bird-life. Most of the Bitterns have the curious faculty of concealing themselves from ubservation by their faculty of "reedsimulating," and many of our readers must have noticed some of these birds in the Zoolugieal Gardens standing stoekstill, and evidently imagining that by so doing they were invisible to the intruder. The Common Bittern (Botaurus stellaris) will not only do this, but will gradually and slowly turn his breast to any observer if the latter only walks slowly away from

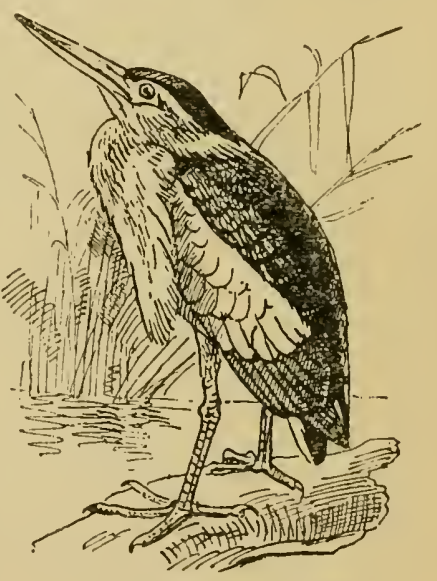

Fij. 45 - Thi Little BittrerN (Ardetta minuta) him, under the evident impression that by so doing he renders himseli invisible, as, indeed, the bird would be if he were in his natire reed-bed; 
but, as he has a background of green bushes or wood-work, his effurts at concealment are vaill.

The notiun of concealment in relation to natural surroundings is, however, thoroughly explained by Mr. Hudson's experiences. He writes :- "One day in November, 1870, when out shooting, I noticed a Variegated Bittern stealing off quickly through a bed of rushes thirty or forty yards from me. He was a foot or so above the ground, and went so rapidly that he appeared to glide through the rushes without touching them. I tired, but afterwards ascertained that in my hurry I missed my aim. The bird, however, disappeared at the report, and, thinking I had killed him, I went to the spot.

"It was a small isolated bed of rushes I had seen hin in; the mud below, and for some distance round, was quite bare and hard, so that it would have been impossible for the bird to escape without being perceived; and yet, dead or alive, he was not to be found. After vainly searching and re-searching through the rushes for a quarter of an hour, I gave over the quest in great disgust and bewilderment, and, after reloading, was just turning to go, when, behold! there stood my Heron on a reed, 110 more than eight inches from, and on a level with, my knees. He was perched, the body erect, and the point of the tail touching the reed grasped by its feet, the long, slender, tapering neck was held stiff, straight, and vertically; and the head and beak, instead of being carried obliquely, were also pointing up. There was not, from his feet to the tip of his beak, a perceptible curve or inequality, but the whole was the figure (lle exact counterpart) of a straight, tapering l'ush ; the loose plumage arranged to fill inequalities, and the wings pressed into the hollow sides, made it impossible to see where the body ended and the neck began, or to distinguish head from neck or beak from head. This was, of course, a front view; and the entire under-surface of the bird was thus displayed all of a uniform dull yellow, like that of a faded rush. I regarded the bird wonderingly for some time, but not the least motion did it make. I thought it was wounded or paralysed with fear, and, placing my hand on the point of its beak, forced the head down till it touched the back; when I withdrew my hand, up flew the head, like a steel spring, to its first position. I repeated the experiment many times with the sanie result, the very eyes of the bird appearing all the time rigid and unwinking, like those of a creature in a fit. What wonder that it is so difficult-almost in possible-to discover the bird in such an attitude. But how happened it that, while repeatedly walking round the bird through the rushes, I had not caught sight of the striped back and the broad, dark-coloured siaes? I asked nyyself this question, and stepped round to get a side view, when, mirctile dictu, I could still see nothing but the rush-like front of the bird. His motions on the perch as he turned slowly or quickly round, still keeping the edge of the blade-like body before me, corresponded so exactly witn my own that I almost doubted that I had moved at all. No sooner had I seen the finishing part of this marvellous instinct of self-preservation (this last act making the whole complete), than such a degree of delight and admiration pussessed me as I have never before experienced during my researches, much as I have conversed with wild animals in the wilderness, and many and perfect as are the instances of adaptation I have witnessed. I could not finish adniring, and thought that never had anything so beautiful fallen in my way before, for even the sublime cloud-seeking instinct of the White Egret and the typical Herons seemed less admirable than this, and for some time I continued experimenting, pressing down the bird's head and trying to bend him by nain force into 
some other position; but the strange rigidity remained unrelaxed, the fixed attitude unchanged. I also found, as I walked round him, that as soon as I got to the opposite side, and he could no longer twist himself on his perch, lie whirled his body with great rapidity the other way, instantly presenting the same front as before.

"Finally I plucked him forcibly from the rush and perched him on my hand, upon which he flew away; but he flew only fifty or sixty yards off, and dropped into the dry grass. Here he again put in practice the-same instinct so ably, that I groped about for ten or twelve minutes before refinding him, and was astonished that a creature, to all appearance so weak and frail, should have strength and endurance sufficient to keep its body rigid and in one attitude for so long a time."

This habit of concealing themselves among surroundings to which their plumage assimilates in colour seens to be a characteristic of all the Bitterns, as I have seen our Common Bittern (Butaurns stellaris) attempting to perform this feat in an aviary, and the 'Tiger Bitterns (Tigrisoma) also remain in a rigid position for hours together.

It should be mentioned that nearly all the Herons lay eggs of a beautiful greenish-blue colour, while those of many of the Bitterns are white, and that of the Common Bittern is yellowish brown.

Although agreeing with the Storks in the form of the furcula, the members of this sub-order differ from them and from the Herons in several important osteological characters, the prineipal one being the

The Spoon-bills and "oises.-Suborder llitulece. by their thattened and spoon-shajed bill. They are found in nearly every part of the globe, but do not extend very far north, and six species are

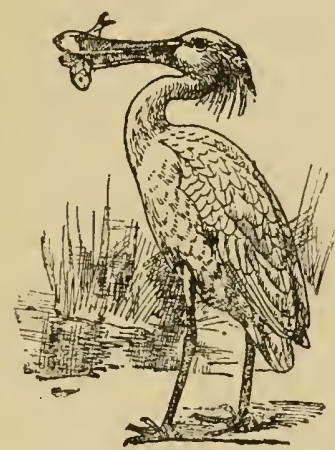

Fig. 46.-Thr Cosimon Spoon-Biul (Platalece lencerodea). klown, viz., four species of Plutalew, one of Plutilis, confined to Australia, and one of Ajaju, viz, the Rosy Spoon-bill of the New World (Ajaja ajaju).

The Common Spoon-bill used to breed in the marshes of our eastern counties, but has not been known to do so for the last three hundred years. Now the species is only an accidental visitor, but it still nests on the Horster Meer. in Holland, where its breeding places are strictly protected. The nests are made of dead reuds lined with dry grass, and are placed on the tussocks of grass with a few sticks as a foundation; a few nests being built low down in the alder trees. On the Danube the Spoon-bills nest in company with Egrets and other Herons, and the following interesting account of a visit to one of these breeding-places is given in Mr. Barkley's work, "Bulgaria Before the War." He found a colony on an island a few miles below Rustchuk, and he describes the scene as follows:- "Pushing our small boat into a nariow creek, we took off our shnes and stockings, and, turning up our trousers, picked our way through the tangled boughs in the direction of the sound, which evidently 
proceeled from the centre of the island, and I shall not easily forget the sight we beheld when we reached it.

"There, on the pressed-down boughs of the willows, only a few feet above the water, were hundreds of great flat nests of the various kinds of Herons, Spoon-bills, Ergrets, Bitterns, etc., all huddled together in one confused mass, and the entire colony reeking with the must indeseribably tiithy sinell.

"It was rather late for eggs, as most of them were hatched off; but was just the time to observe the duings of the children of these sedite, quiet, peaceful-looking birds, and I must say that I never yet beheld such a collection of little fiends, nor a more lideous set.

"Their bodies were of the smallest proportions, while every other part of them-their wings, legrs, necks, and beaks-were of the longest. Most of them had no feathors, and all seemed possessed with one idea, and that was cither to limb a small brother or swallow him whole, and all kept up either a shriek of fear or pain or a yell of rage. Floating on the top of the putrid water were masses of dead birds, some with legs torn off, others without heads or wings. Most of them were dead, but others were dragging their maimed carcases about in a ghastly manner. So intent were they on their fiendish pastime that they took little notice of us, and dragged and clawed themselves about after their weaker brethren at our very feet, whilst the o.d parent bird sit looking on from the topmost twigs as if fratricide were the proper moral pastime of the young. A big Spoon-bill would chase a small Egret from bough to bough till at last he tired it out, and then seizing it with one claw, would take loold of its leg or wing and tear it from the poor victim, or else, getting its head in its mouth, would try to swallow it whole, and grulp and gulp till so much of the little one was down its throat that it was itself ehoked, and would turn over on its back, kieking and struggling, to be in turn seized by a brother and torn limb from limb.

"All uttered up some hideous scream, and all kept clambering and dragging themselves about from bough to bough, either hunting or being hunted, and from what we saw I am sure that nine-tenths of all hatched in that colony came to an untimely end before they could fly. We did not stay long to warch them, hut quickly securing some eggs from the few nests that were not liatched off we beat a retreat, with our opinions of the beautiful, gentle-looking birds greatly changed."

The Ibises are easily distinguished from the Spoon-bills by the shape of their bills, which are long and curred, and have the nasal groove extending nearly the whole length of the bill, which is soft, excepting at the extreme tip. The bill in some of the Ibises is indeed very like that of a Curlew (Numenins), and one yenus of the Charadriiformes, Ibidorhymchns, is so like an

The Ibises.Family lbididee. Ibis, that extermally jis characters would ally it to the latter group of birds rather than to the Waders, to which, as its internal structure shows, it actually belongs.

The most interesting of all the Ibises is undoubtedly the Sacred Ibis of the Egyptians. As the ancient paintings show, the bird was a great feature in Fgyptian life, and the mumnies of these birds which are found in the temples show that it was regarder with great veneration by the ancient Egyptians. The species still inhabits the Upper Nile regions, and many writers state that it $\mathrm{i}$ never found in Egypt at the present day. This, however, is not the case, as the British Museum has several specimeis 
procured in Egypt, one of them having been shot near Damietta about twelve yeas ago. We know also that the species extends to the Persian Gulf, its winter home being in Eastern and Southern Africa.

There are no less than twenty different genera of Ibises, and many of them are remarkable for highly dereloped erests and ornamental ylumes, while in the Sacred Ibis and its allies the head and neek are bare. The Glossy Ibises (Plegudis) are among the commonest and best known of the whole family, as one of them, $P$. fulcinellus, ha visited England on many occasions. This species breeds in numbers on the marshes of the lower Dinube, as well as in similar places in Africa and India, and the egg is one of the most beautiful of any of the Heron-like birds, being of a deep greenish-blue, darker and richer in tint than the ergss of any species of Herons.

We now approach the great group of swimming birds, such as the Ducks, the Pelieans, and their allies; but, before arriving at the consideration

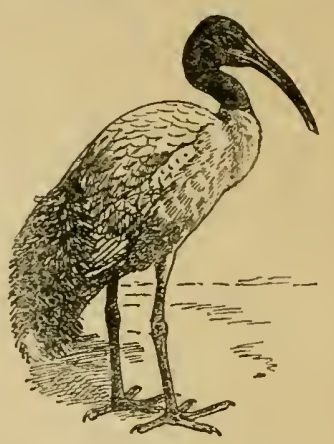

Fiig. 47.-TIR SACZED I UIS (Ibis cethiopica). of these well-narked orders, there intervenes a remarkable The Flamingoes.- form of bird, the Flamingo. In i's long legs and long Order

Plianicupteriforme neck it might well be taken for a kind of Heron or Stork; and, indeed, until recent years, the position of the Flamingoes was considered to be in close proximity to the last-named birds. 'They are, however, more nearly allied to the Ducks and Geese, having a desinngnathous ol "lridged" palate; while the young are hatched covered with down, and are able to run about in a few hours and obtain food for themselves. These features they possess in commun with the Ducks and Geese and the Screamers, and these three groups were united by Huxley into one natural order, Chenomorphe.

The Flamingoes resemble the Ducks and Geese in having the sides of the bill laminated, an arrangement which enables them to sift their food in the way which every one of our readers must have seen tame Ducks do in a farmyard or on a lake. Besides many osteological characters, the Flamingoes present an external appearance unique amoug birds. The legs are abnormally long, the metatarsus being three times as long as the femur, and the anterior toes fully webbed. The neck is also extremely long, the cervical vertebre being eighteen or nincteen iu number. The bill is decurved in a remarkable manner; but in the nestling, which is covered with greyish-white down, the bill is straight,

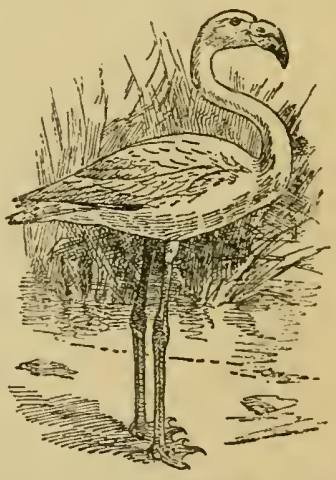

Fig. 45. - Thв CกmMon Fuamingo (Phonicopterus roseus). as in any other Duck-like bird.

The most curious feature in the economy of the Flamingo is its nest, which is built of mud. For a lung time it was suppused that the birds sat upon 
their single egg, with the legs straddled on each side of them. This idea was, however, dissipated by Mr. Abel Chapman in 1883, when he visited the Marismas of the Guadalquivir, in Spain, and found out the nesting habits of the Flamingo. He writes:- "Ono cannot go far into the Marisina without seeing that extraordinary fowl the Flamingo, certainly the most characteristic bird of the wilderness. In herds of 300 to 500 , several of which are often in sight at once, they stand feeding in the open water, all their heads under, greedily tearing up the grasses and water-plants from the bottom. On approaching them, which can only be done by extreme caution, their silenco is tirst broken by the sentries, who commence walking away with low croaks, then the whole five hundred necks rise at once to the full extent, every bird gaggling his loudest as they walk obliquely away, looking back over their shoulders as though to take stock of the extent of the danger. Pushing a few yards forward, up they all rise, and a nore beautiful sight cannot be imagined than the simultaneous spreading of their thousand crimson wings, Hashing against the sky like a gleam of rosy light. Then one descends to the practical, and a volley of slugs cuts a lane through their phalanx.

"In many respects these birds bear" a strong resemblance to Geese. Like them Flamingoes feed by day, and great quantities of grass, etc., are always floating about the muddy water where a herd has been feeding. Their cry is almost indistinguishable from the gaggling of Geese, and they tly in tho same catenanan formations. In size Flamingoes vary greatly. The largest 1 have measured was fully $(i \mathrm{ft}$. 5 in., whilst others (old red birds) barely reached $5 \mathrm{ft}$." He thus describes the finding of the nests:-"On reaching the spot we found a perfect mass of nests; the low mud plateau was crowded with them as thickly as the space permitted. These nests had little or no height; some were raised 2 or 3 in., a few might be 5 or 6 in.; but the majority were merely circular bulwarks of mud, with the impression of the bird's legs distinctly marked on it. The general aspect of the plateau was not unlike a large table covered with plates. In the centre was a deep hole full of muddy water, which, from the 'gouged' appearance of its sides, appeared to be used as a reservoir for nest-making materials. Scattered all round this main colony were numerous single nests rising out of the water, and evidently built up from the bottom. Here and there two or three or more of these were joined together-'semi-detached,' so to speak. These separate nests rose 6 or 8 in. above the water level, and were about 15 in. across. The water was about 12 or $1 \tilde{\mathrm{in}}$. deep. None of these nests as yet contained eggs, and though I returned to the 'pajarera' on the latest day I was in its neighbourhood (11th May), they still remained empty. On both occasions many hundreds of Flamingoes were sitting on the nests, and on the 11 th we had a good view of them at close quarters. Linked arm in arm with Felipe, and crouching low in the water, to look as little human as possible, we approached within some $70 \mathrm{yds}$. before their sentries showed signs of alarm, and, at that distance, we observed the sitting birds as distinctly as one need wish. Their long red legs doubled uncler their bodies, the knees projecting as far as, or beyond, the tail, and their graceful necks neatly curled away among their back fenthers, like a sitting swan, with their heads resting on their breasts-all these points were unmistakable. Indeed, it is hardly necessary to point out that in the great majority of cases (the nest being hardly raised above the level of the flat mud) no other position was possible."

Of Flamingoes six species are known, and they are found in the temperato 
and tropical portions of both the Old and New Worlds. Three species belong to the genus Phonicopterns-Phceniconaias has one species, $P$. minor, found in Africa and North-Western India ; and Phonicoparmes inhabits the Andes of Chili and Peru and has two species, $P$. andinus and $P$. jamesi.

In Miocene times several forms of birds allied to the Flamingoes existed in Europe, and have been classed by Mr. Lydekker under the extinct genus Palcolodus. He states that they were smaller than the Flamingces of the present day, and had shorter and stouter legs, while it is probable also that their bill was not deflected.

Although agreeing in many characters with the Ducks and the Geese, the Screamers have one peculiarity which separates them from all chenomorphine birds, in that they hare no uncinate processes to the ribs, The screamers. - and no lamine on the sides of the bill. The toes are long Sub-order Pultemedere. and almost devoid of web, and the general appearance of the birds is gallinaceous. 'T'wo genera are known, Palameder and Chauna. The genus Prtementec is recognised by the long horn which it carrics on its forehead. Beyond this it has no erest on the head, and has fourteen tail-feathers. Only une species, $P$. cornuta, is known, and this is an inhabitant of Guiana, Amazonia, Venezuela, Ecuador, and Bolivia. The general plumage is black, with a white belly, and the wing carries two spurs, the anterior one of which is much the longer. Very little has been recorded of the habits of the Horned Screamer, but Mr. Edward Bartlett noticed the species about the lakes in the Upper Amazons, and the habits are prubably very similar to those of the next species.

The genus Channce differs from Palamedea in having a crested head, naked lores, no horn on the forehead, and in

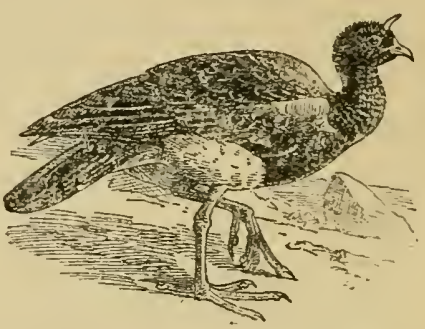

Fig. 49. - TIIR HORNFD SCREAMER (Palamedea cu. inuta).

possessing twelve tail-feathers instead of fourteen. Two

The Crested

Screamer

(Chatina cristata). species of Chunnce are known-the Crested Screamer (C. cristata) and the Derbian Screamer (C. chavaria). The latter is found in Venezuela and Colombia, while the Crested Screamer inhabits Argentina and the neighbouring provinces of Southern Brazil. In Mr. Hudson's well-known work on Argentine ornithology we find the following notes on the species :-

"The Crested Screamer, like most of the larger Birds and Nammals in every part of the globe to which European emigration is attracted, is probably doomed to rapid extermination. My observations of the bird in that portion of the Pampas where it is most abundant date back some years, to a time when the inhabitants were few and mainly of Spanish race-never the destroyers of bird-life. The conditions had become extremely favourable to this species. It is partially aquatic in its habits, and in desert places is usually found in marshes, wading in the shallow water, and occasionally swimming to feed on the seeds and succulent leaves of water-loving plants. After the old giant grasses of the Pampas had been eaten up by the cattle, and the sweet grasses of Europe had taken their place, the Screamers took kindly to that new food, preferring the clovers, and seemed as terrestrial in 
their feeding habits as Upland Geese. Their food was abundant, and they were never persecuted by the natives. 'l'heir tlesh is very dark, coarsegrained, but good to eat, with a flavour resembling that of the Wild Duck; and there is a great deal of meat on a bird with a body larger than that of a Swan. Yet no person ever thought of killing or eating the Chaja, and the birds were permitted to iucrease to a marvellous extent. It was a common thing a few years ago in the dry season to see them congregated in thousands, and so little afraid of man were they, that I have often ridden through large scattered flocks without making the birds take wing. A curious thing about the Screamer is that it pairs for life, and yet is one of the most social of birds. But if a large flock is closely looked at, the birds are invariably seen methodically ranged in pairs. Another curious thing is that, notwithstanding the formidable weapons they pussess-each wing armed with two large spurs - they are extremely pacific in temper. I have never been able to detect even the slightest approach to a quarrel among them; yet it is hard to believe that they do not fight sometimes, since weapons of offence are usually found correlated with the disposition to use them. Captive birds, however, can be made to fight; and I have known Guachos take them for the pleasure of witnessing their battles. They are very easily tamed, and in that state seem to show greater dncility and intelligence than any of our domestic birds, and become so attached to their home that it is quite safe to allow them to tly about at will. They associate, but do not quarrel, with the poultry. They are quick to distinguish strangers from the people of the house, showing considerable suspicion of them, and sometimes raising a loud alarm at a stranger's approach. 'Tuwards dogs and cats they are often unfriendly; and when breeding it is dangerous for a strange person to approach the nest, as they will sometimes attack him with the greatest fury.

"The Screamer is a very heavy bird, and rises from the ground laboriously, the wings, as in the case of the Swan, making a lond noise. Nevertheless, it loves soaring, and will rise in an immense spiral circle until it wholly disappears from sight in the zenith, even in the brightest weather; and considering its great bulk and dark colour, the height it ultimately attains must be very great. ()n sunny windless days, especially in winter and spring, they often spend hours at a time in these sublime aerial exercises, slowly floating round and round in vast circles, and singing at intervals. How so heavy and comparatively short-winged a bird can sustain itself for such long periods in the thin upper air to which it rises has not yet been explained. The voice is very powerful. When disturbed, or when tlie nest is approached, both birds utter at intervals a loud alarm-cry, resembling in sound the anger-cry of the Peacock, but twice as loud. At other times its voice is exercised in a kind of singing performance, in which male and female join, and which produces the effect of harmony. The male begins, the female takes up her part, and then with marvellous strength and spirit they pour forth a torrent of strangely-contrasted sounds-some bassoon-like in their depth and volume, some like drum-beats, and others long, clear, and ringing. It is the loudest animal sound of the Pampas, and its jubilant martial character strongly affects the mind in that silent, melancholy wilderness. The Screamer sings all the vear round at all hours, both on the ground and when soaring; when in pairs, the two birds invariably sing together, and when in flocks they sing in concert. At night they are heard about nine o'clnck in the evening, and again just before dawn. It is not unusual, however, to hear thein singing at other hours. The nest is a large 
fabric placed among the low rushes and water-lilies, and is soraetimes seen floating on the water, away from its moorings. The eggs are five, pointed at one end, pure white, and in size like the eggs of the domestic Goose. The young are clothed in yellow down like Goslings, and follow the parents about from the date of liatching."

Mr. Lydekker, when in Argentina, found the Screamer nesting on a lagoon, and saw the parent birds swimming about amongst the Ducks. On his approach they fled to the banks, but soon returned to the water. They had evidently young birds on the lagoon. This aquatic feature in the Screamers is of the highest interest, as confirming the anserine affinities which their anatomy demonstrates.

These well-known birds are easily recognised by their external characters, their semi-flattened bills, shortish legs, and fully-webbed

The Geese and Ducks.-Suborder lluseres. feet distinguishing them from the Screamers and Flamingoes, while, like the latter birds, they have uncinated processes to the ribs. Count Salvadori, who has recently monographed the sub-order Auseres in the "Catalogue" of the Birds in the British Museum, divides it into no less than eleven sub-families belonging to the single family Anatidce. 'To these we can only refer in passing.

The Swans are suclı well-known birds that very little description of them is necessary. Among the Duck tribe they are easily recognisable by their abnormally developed neck, which equals, or even exceeds,

The Swans.- the body of the bird in length. There is no lobe to the Sub-family

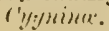
hind toe, a feature which allies the Swans to the Geese, but separates them from the majority of the Ducks. There are three genera of Swans, viz., Cygnus, containing the Swans with which we are most familiar; Chenopis, the Black Swan of Australia, with ornamental scapulars ind inmer secondaries; and Coscoroba, the Chilian Swan, which has feathered lubes, and is as much a froose in appearance as it is a Swan in reality.

The Mute Swan is the familiar species which swims about on our rivers and lakes. In most parts of the British Islands the Swinn may be regarded

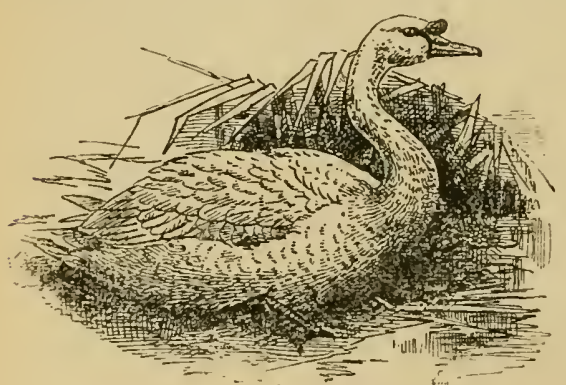

Fig. 50.-Tur Murs Swas (Cygnus olor). as a semi domesticated bird, but in many places on the Continent it is an absolutely wild species. It is to this Swan that the Polish Swan (Cygnus immutabilis), with its white cygnets, nust be referred, as Count Salvadori, and all the best of recent observers, consider it to be only a domestic variety of the Mute Swan. Other wellknown species of Cygnus are the Whooper (C. musicu.) and Bewick's Swan (C. bevicki), the latter bird nesting in Arctic Europe, where it makes a large nest composed entirely of moss. It visits us in some numbers during tho winter months. Thece British species of Swans are distinguished by the size and the colour of their 
bills. Australia has ono species, the Black Swan (Chenopis atrata), and finally we have the Coscoroba Swan (Coscorobre candidu) which is found from Chili and Patagonia to Argentina and Uruguay. Of this species Mr. W. H. Hudson writes:- "In their habits, language, and flight they differ much from the Black-necked Swan, and the country people call them Ganso (Goose), probably on account of their Goose-like habit of sometimes feeding away from the water, or because their flesh has the flavour of IVild Goose. As a rule, they go in small parties of fivo or six individuals, but sometimes flocks numbering two or three hundred are seen in the cold season. Their migrations are very irregular, and sometimes they are exceedingly abundant in a certain district one year and absent from it tho next. When disturbed they utter a loud, musical, trumpeting cry in three notes, the last with a falling inflection; and, their wings being much longer proportionately than in the black-necked species, they rise with greater ease, and have a much freer and an almost soundless flight."

The Semipalmated Goose (Anserances semipalmata) is the sole representative of a distinct sub-family Anseranatiuce, with the toes only half-webbed, and the hind toe very long, and on a level with the other toes. It is an inhabitant of Australia and Tasmania, and is still plentiful in some districts, though it has disappeared from many places where it once was numerous. Gould says that, in Northern Australia "it occurs in such countless multitudes that it forms one of the chief articles of food of the aborigines, and was of the utmost value to Leichardt and his party during their adrenturous journey from Moreton Bay to Port Essington, as shown in numerous parts of his interesting account of the expedition. So dense are the flocks that occur in the northern parts of the country, that the natives are able to procure numbers of them by spearing," and, says Leichardt, "it scemed that they only spear them when flying, and always crouch down when they see a flight of them approaching ; the Geese, however, know their enemies so well that they immediately turn when they see a native rise and put his spear into his throwing-stick; some of my companions-asserted that they had seen them hit their object at the almost incredible distance of $200 \mathrm{yds}$."-an assertion which Gould says he could readily believe, from what he has himself witnessed. This Goose has a very remarkable trachea, nearly 5 in. in length, and mostly lying outside the pectoral muscle under the skin.

The next sub-family of the (ieese consists of the Spur-winged Geese (subfamily Plectropterinu), and several allied forms. They have fully webbed fiet, a very long hind toe, and long tail-feathers. The true Spur-winged Geese (Plectropterus) have the lores naked and caruncles on the furehead and base of the bill, while on the wing they carry a furmidable spur, from which feature they derive their popular name. There are four species of Spurwinged Geese, all confined to Africa, admitted by Count Salvadori, the best authority on the Anseres, but even he is obliged to allow that there may really exist but a single species after all.

Only one other genus with bare lores and caruncles on the face is known, and this is the genus Cairina, with the single species $C$. moschata, the Muscovy Duck of Tropical America. Another prominent form of the Plectropterince is the Knobbed Goose (Sarcidiomis), of which there are two species, S. melanonota of India and Africa, and S. cannuculata of Southern Brazil and Argentina.

We remember seeing the "Comb Duck," as Indian naturalists call the Indian Sarcidiornis, on one occasion during our journey through the 
North-West Provinces, and that was at Futtehpur Sikri, near Agra, where a male was perched on the lofty entrance gateway. The testimony of Mr. A. U. Hume and other Indian naturalists is to the effect that the "Comb Duck" breeds principally in trees, and the late Mr. A. Anderson states that the eggs are generally to be found in holes of old desiduous trees, but he has also found the birds frequenting old ruined forts. He says:- " $F$ was present at the capture of a female Nukta on her nest, which yielded the extraordinary number of forty eggs. Of course it is just possible, though highly improbable, that this may have been the joint produce of two birds; but the emaciated condition of the one captured, coupled with the fact that one egg was an abnormally small one, and evidently her last effort, does not favour the supposition. The tree eelected was an ancient banyall (Ficus indicus), which overlooked a large sheet of water several miles round. The nest-hole was at an elevation of some $20 \mathrm{ft}$., $3 \mathrm{ft}$. deep and $2 \mathrm{in}$ circumference." One of the genera of the Plectropterinu is a very interesting form, viz., the Pink-headed Duck (Rhodonessu curyophyllacea). The appearance of a delicate pink head in such a family as the Anutide is one of the most curious phenomena in the whole class of birds. Its range is confincd to Behar and Bengal, to the north of the Ganges and west of the Bralımapootra, whence it ranges north to Nepal, east to Burma, and south to Madras.

Some of the most interesting of the present sub-family are the Dwarf Geese (Nettopus) or "Cotton-Teal," as they are generally called. They are little Geese of about the size of a Bantam fowl, only found in the tropics of the Old World, in Africa, India, and China, and thence stuth to Australia. The Indian species, $\boldsymbol{N}$. coromandeliamus, nests generally in holes of trees, but sometimes it is said to make "a semi-floating nest on the water, among the rushes or lotus-leaves, of weeds, grass, etc., all together, filled up several inches above the water-line." The late Mr. A. Anderson observes :- "I once had the opportunity of watching a pair in the act of selecting their habitation. They invariably flew into the tree together; and while the female used to enter the hole, to recunnoitre as it were, the male sat on a bough watching for her exit. No sooner did she make her appearance than they both flew away together, giving utterance to a peculiar cackling sound, which has been pronounced to be like the words 'Fix bayonets.' Their visits used to be repeated at intervals of every fifteen or twenty minutes. The Drake never went into the hole; and I am therefore inclined to believe that he does not lend his aid in the performance of the duties of incubation." One nest taken by Mr. Spry at Bredaon in August contained twelve eggs. It was in a hole at no great height, but it, was $3 \frac{1}{2} \mathrm{ft}$. deep, and only large enough to admit of ingress and egress; the contents had to be removed by means of an iron spoon, something like a soup-ladle with an extra long handle.

The Summer Duck ( $E x \cdot$ sponsus) of North America, and the beautiful Mandarin Duck ( $E x$ galericulata) of China compose the genus $\mathscr{E x}$, which is the last of the Plectropterince.

The genus Cereopsis is the sole representative of this sub-family, and is distinguisher by its shorter hind toe and shorter tail-feathers. The bill is high at the base, and there is no metallic wing-speculum.

The Cereopsis

Geese. - Subfamily rimpopsina. The chief peculiarity of the Cereopsis Goose is the possession of a cere at the base of the bill, which character separates it from the true Geese. It is an inhabitant of Australia, and is often seen in captivity ; and it has been known to breed in our Zoological Gardens. As Mr. Gould says, however, it 
is by no means a desirable addition to the farmyard, for it is so pugnacious that it not only drives all other birds before it, but readily attacks pigs, dogs. or any other animal that may approach it, and often inflicts serere wounds with its hard and sharp bill.

Remains of an extinct Goose (Cncmion wis culcitrans) have been discovered in New Zealand, and Count Salvadori has placed it in the vicinity of Cereopsis. It was a larger bird than the latter, and was apparently flightless, as thero is no keel to the sternum.

The characters of this sub-family are almost exactly the same as those given for the sub-family Cereopsince, excepting that there is no cere. There are at least six well-marked genera, of which the most beautiful are perhaps the Snow Geese (Chen), though some of the Brent Geese are also landsome birds. The true Geese (Anser) are found in all the northern parts of

The True Geese.Sub-family Inservine. the Old and New Worlds, breeding in the high north, and migrating south in winter, often in vast numbers. The Grey Geese (Anser) are nearly all of them British, the best-known being the Grey Lig-Gocse (A. Anser), the White-fronted Goose (A. albifrons), the Bean Goose (A. fubalis), and the Pink-footed Goose (A. brachyrhynchus). All the true Grese have the serrations or saw-like edges of the upper mandible visible from the outside, and the cutting edge of the mandible is sinuated, whereas in the Brent Geese (Branta) the cutting edge is straight, and the serrations are not visible from the outside.

These are, like the True Geese, also birds of the Arctic portior s of the U]d and New Worlds, where they breed in large numbers; and, as they

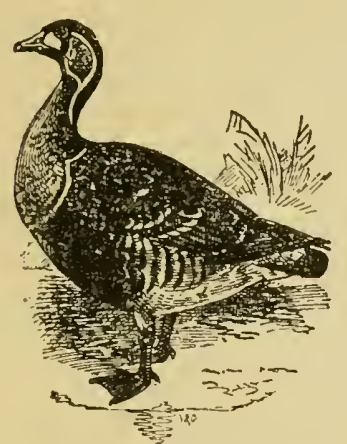

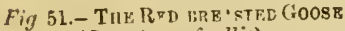
(Branta ruficollis). moult their quills before coming south, they are trapped The BrentGeese.by the natives in numbers. Genus Branta. Mr. Trevor-Battye describes the capture of more than three thousand Brent Geese on the island of Kolguev, the birds being driven by the Samoyeds in boats towards the shore, where a large circle of net is prepared for them, and the birds are thus trapped and killed.

One of the handsomest of the Geese, and, indeed, of all water-fowl, is the Red-breasted Goose (Branta ruficolitis), which breeds in Siber ia, winters in great numbers on the Caspian Sea, and has occasionally come over to Fngland. It is remarkable for having been drawn on their monuments by the ancient Egyptians, and even at the present epoch it seems to be met witl sometimes in Egypt.

Count Salvadori's next sub-family is the Chenonettine, containing the Magellanic Geese and their allies, the Bluewinged Geese (Cyranocheri) and the Maned Goose (Chenonetta).

In this group of Geese the hind toe is narrowly lobed and the bill is rather short and Goose-like, as opposed to the somewhat flat and broad bill of the Ducks which form the next sub-family Anatine. The UTland Geese(Cloephagre)

The Upland Geese. - Sub-family rlienometting. are all inhahitants of South America, where they range from Pcru, Bolivia, and Southern Brazil to Chili, Patagoniz, ond the Tain iand 
Islands: Mr. Hudson describes $C$. inomata, the Barred Upland Goose, as migrating north wards along the eastern coast of Argentina in April and May. "Their great camping-grounds," he writes, "are the valleys of the rivers Negro and Colorado, where they are often so numerous as to denude the low grounds of the tender winter clovers and grasses, and to cause serious loss to the sheep-breeders. They also visit the cultirated fields to devour the young wheat, and are intelligent enough to distinguish between a real human enemy and the ragged men of straw, miscalled scarecrows, set up by the farmers to frighten them. While committing their depredations they are exceedingly wary and difficult to shoot; but at night, when they congregate by the waterside, they give the sportsman a better chance. They are social birds, always going in large Hocks, and are very loquacious, the female having a deep, hanking note, while the male responds with a clear whistling, like that of the Sanderling etherialised."

No less than nineteen genera are admitted by Count Salvadori as belonging to this sub-family. Among them are the Tree-Ducks (Dendrocygna), the Sheld-ducks (Tadoma and Casarca), tho Wild Ducks The True Ducks, - (Anas), the Wigeons (Mareca), the Teai (Nettion and Sub-family Anatina. Querquedula), the Pin-tails (Dafila) and the Shovelers (Spatulla), besides many less-known forms of Duck. The ways of the Ducks are all very similar, and there is not much to say in detail about their habits, beyond the fact that some are frequenters of inland waters, while others are more maritime in their haunts.

The Sheld-ducks are very handsome birds, of varied plumage, and with a metallic patch or speculum in the wings. This is a character which is found in most of the Ducks, and many species are determined by the colour of the wing-speculum. Another curious feature of the Ducks is that, after the young are hatched, the males put off their bright plumage and assume a dull-coloured brown dress like that of the hen birds. This plumage is very difficult to determine, as the male birds during the moult are practically helpless, and have no quills to fly with, so that they retire into privacy, and very few specimens are procured at this stage of a Duck's existence. I am unable to say from direct observation whether this hen.like summer plumage.

which only lasts a few weeks, is assumed

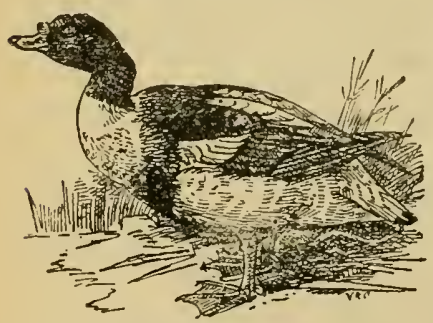

Fig. 52.-Thв Common Sueld-dick (Tadorna tadorna). by all Ducks; but I have reason to suspect that there are few species which do not possess such a stage.

The beautiful Sheld-duck is a bur. rower, sometines having its nest as far as $5 \mathrm{ft}$. from the mouth of the hole, while it has been known to penetrate as far as $12 \mathrm{ft}$. into the earth. These holes are often burrowed by the birds themselves, but quite as frequently a rabbit-burrow is made use of. The Sheld-duck often builds upon cliffs at such a height that it is evident the parent bird must carry the young ones down to the water, as must be the case also with the Common Mallard when it builds its nest in a tree, as it often does.

Of these Ducks there are four sub-families, all with the hind toe 
broadly lobed. The Scoters (Fuligulina) have the bill more or less depressed and the tail-ferthers not stiffened. A large number of genera is represented in this sub-family, which includes such forms as the Pochards (Nyroca), the Scaups (Fuligula), the Steamer Ducks (Tachyeres), the Golden-Eyes

The Diving Ducks. (Clangula), the Long-tailed Ducks (Harelda), the Harle-

quins (Cusmonetta), the Scoters (Wdemia), and the Eiders (Somateria), and their allies. They are mostly sea-ducks, and some of them, like the Harlequin Duck and Steller's Eider (Heniconetta stelleri) are very handsome birds. The stiff-tailed Diving Ducks (sub-family Erismaturince) differ fron the Fuligulince in their narrow tail-feathers, which are much stiffened. Only four genera are admitted. Thalassiornis, Nomonyx, Erismatura, and Bizinia. The latter is a curious Australian form, with a pendant lobe on the chin, and twenty-four tail-featlers.

In these birds the tail is long and stiffened, and the general look of the birds is very much like that of the Mergansers, but they have no serrations on the edges of the mandibles. They are found only in the Andes from Ecuador to Chili, frequenting the torrents of the high mountains, and being

The Torrent-

Ducks-Sub-family Merganettince. very difficult of observation.

In this last sub-family we find only the Smew (Mergus albellus) and the Mergansers (Lophodytes and Merganse ${ }^{\circ}$ ). In the latter birds the tooth-like serrations are very different from those of any other of the Ducks, being strongly inclined backwards at the tips. These are not, however, real teeth, though they have the appearance of so being, but are merely serrations along the edge of the mandible, so that in the skeleton there is no appearance of any indentation on the bone of the bill. Thus they are very different birds from the extinct Hesperomis, which had real teeth, though they are inter. esting as being the nearest approach which we can show at the present day to the toothed birds of ancient times.

Seven species of the genus Merganser are known, and they are found in the Palsarctic and Nearctic regions, but are absent in the Ethiopian and the greater part of the Indian Region. One species is isolated in the Auckland Islands, viz., $M$. arestralis, and another in South-Eastern Brazil, M. brasilianus. The Red-breasted

The Mergansers.Sub-family Heryunce.

Merganser is smaller than the Goosander (M.merganser), and nests in Scotland and Ireland. Like the other Mergansers it is an expert diver, and it feeds principally on fish. On this account they are somewhat persecuted.

These birds, often called the Steganopodes, have the hind toe or hallux united to the second toe by a web, so that all four toes are webbed. All the Pelecanoid birds have the palate bridged or "desmognatlous," and there are no basipterygoid processes in the palate. There are five sub-orders, viz., 
the Tropic-Birds (Phathoutes), the Gamnets (Sille), the Cormorants and Darters (Phalacrocoraces), the Pelecans (Pelccuit), and the Frigate-Birds (H'regati). As their name implies, the Tropic-Birds are The Pelicans and inhabitants of the tropics. They are often an interesttheir Allies, Order

Pelecaniformes. ing feature of a sea-voyage, as they fly, high in the air, round and round the steamer, with a beating flight, as if everything depended on the haste they made. The osteological and anatomical characters which distinguish them from the other Pelican-like birds are many, but their external form sufficiently distinguishes them, their lengthened tail being especially remarkable. The bill is nearly straight, and not hooked as in the allied forms, neither is there any perceptible pouch. One of the best accounts of the habits of the TropicBirds is that given by Mr. W. E. D. Scott on $P$. Havirostris, as observed by him in Jamaica. He writes:- "Of fifreen specimens procured on the 27th of February five were shot, eight were taken in a cave which opened by a small mouth from the cliff, and two were

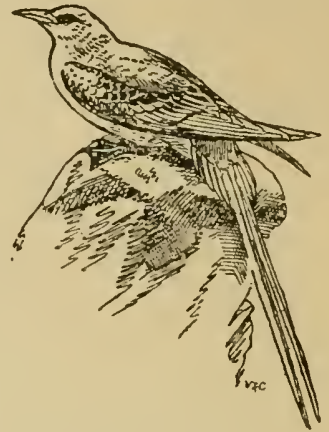

Fig. 54. -The YelLOW-BILled TROPIC-BIRD (Phceton flavirostris). secured in holes in the cliff. The cave where the birds were found had a very small entrance, about large enough for a man to crawl into, in the face of the cliff. This was approachable only in the calmest weather, in a boat. The entrance led at once into a spacious chamber of irregular shape. Going directly back from the mouth the cavern was some $60 \mathrm{ft}$. deep. It was at its widest point some 70 or $80 \mathrm{ft}$., and oval in shape as a whole. The bottom was covered with coarse sand and gravel, and boulders of varying size, evidently having fallen from above, were scattered thickly over this floor, except at the extreme back of the cavern furthest from the sea. The height of the roof or ceiling, which was of an uneven, rough surface, was about $25 \mathrm{ft}$, and many bats were hanging wherever the projections or inequalities afforded them opportunity. Toward the back of this chamber five birds were secured, each one sitting on a single egg. The place chosen for the nesting site - for this is all it can be termed-was in all these cases where two boulders on the gravelly floor lay close together, just leaving room on the ground for the birds to crawl between them. Two birds were obtained in like situations that had not laid, and may have been simply resting. The females were, in every case, the birds that were sitting on the eggs, and it was quite evident, upon dissection, that the single egr forms the complement in these cases. The birds taken from the holes in the cliff, and also those taken in this cave, were very tame, and were captured readily without attempting to escape. Later on the same day a bird was found, with a single egg laid at the bottom of one of the holes in the face of the cliff.

"In breeding the birds seem eminently gregarious, and the colonies at different points often reach an aggregate of at least fifty pairs. At sea, far out of sight of land, the birds are much more solitary in their habits, single hirds being frequently met with, and it has been rare in my exnerience to meet with more than four individuals together in such locationg." 
The limnets are distributed over the seas of the greater part of the world, and are easily recognisabie both from their internal and external characters.

Like the Tropic-Birds, they have a nearly

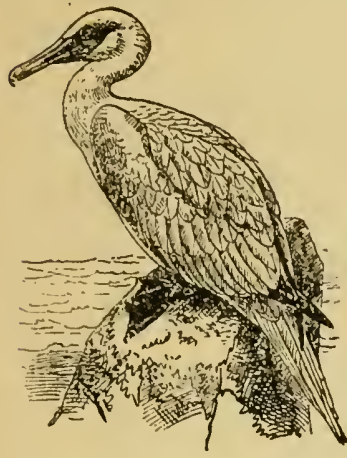

Fig, 5j. - Thr Coyson Ganset

(Dysporus bassanus). straight bill without any hook in it, and there is a small and scarcely perceptible pouch, though mucl of the face and throat is bare.

During the breeding season the Gannets leave their fishing grounds to a great extent, and our own species resorts to certain rocky places on our coast, of which Ailsa Craig and the Bass Rock are the best known, and there builds a rough nest of sticks and

The Gannets.Sub-order siule. seaweed, and lays a single chalky-white egg. This chalky egg is a peculiarity of nearly every member of the Pelican-like birds, and in the Gannets and Cormorants it is a distinct feature. On scrubbing the egg, however, with a brush, the chalky surface can be removed, and the egg appears of a delicate blue, like that of a Heron. The flight of a Gannet is very fine, and the birds are capable of covering great distances in a very short space of time, while it is certain that during the nesting season the parent birds have to go far afield to their fishing grounds to procure food for the young. Only one egg is laid, and the young birds are at first naked, and of a slaty. black colour. They then become covered with a thick coating of white down, and afterwards attain their first full plumage, which is greyish-brown with white spots, but it is believed that five moults are required before the birds attain their full white plumage.

Although agreeing in osteological characters with the preceding groups, the Cormorants and Darters have certain evident peculiarities which separate them from the Gannets and TropicBirds. The bill is more raptorial, and is furnished with a hook at the end, and the tail-feathers are more stiffened

The Cormorants.Sub-order Phalacrocoraces. than in these birds. This is especially the case with the Darters. There is, however, no perceptible pouch externally.

In the British Islands we have two representatives of the sub-order, the Common Cormorant (Phalacrocomex carbo) and the Shag (P.graculus). The former is the larger bird of the two, and has fourteen tail-feathers; while the Shag is smaller and greener, and has only twelve tail-feathers. In this way the young birds of the two species, which are brown, can always be clistinguished. Cormorants are found nearly everywhere on the face of the globe, and are particularly numerous in New Zealand and the adjacent islands.

Cormorants are great fish-eaters, and they are consequently excellent swimmers and divers. They often nest on trees in inland places, but as a rule their nest is placed on the rocks adjoining the sea. The young are hatched perfectly naked, and are ugly little black morsels, like the nestlings of the Gannet; but they are afterwards covered with dense down of a sootybrown colour, and their first full plumage is brown, with a white undersurface. In the breeding plumage the old birds generally don a crest, and 
our Conmo: Cormnrant has white filamentous plumes distributed over the Ltad and neck, as well as an ornamental white patch just above the thighs.

The way in which Cormorants and Shags feed

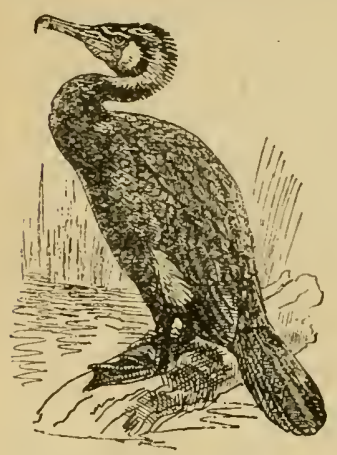

Fig. ¿́f - THe Comox Corsoraxt (Phalacrocorax carbo). their young is very curious, and is well described by Sir Walter Buller. Writing of the Pied Shag of New Zealand ( $P$. varius), he says :-

"We found the Shags in great force, and it was most interesting to watch the operations of both old and young birds. There were 80 or 100 nests, many of which were vacant owing to the lateness of our visit, the breeding having conmenced in October. The nests are large, round structures, composed, as already mentioned, of dry sticks and twigs and other lonse materials, bound together by ineans of a peculiar kind of Kelp, for which the Shags may be obserred diving in the sea, sometimes in four fathoms of water. They have a somewhat compact appearance, and are usually placed in a thick fork among the branches or between two limbs of a tree lying close together. In each of those still tenanted there were two fully-fledged young birds, and these youthful Shags kept up a constant 'squirling' noise, accompanied by a perpetual swaying of the head from side to side in an impatient sort of way. The old bird comes up from the sea with her gullet full of small fish, and takes up her station on a branch adjoining to or overlooking the nest. The young birds, after craning their necks almost to dislocation, quit their nest and mount up alongside the parent, when the peculiar feeding operation commences. The mother bends down her head in a loving way, opens wide her mandibles, and the young Shag, with an impatient guttural note, thrusts his head right down the parental throat and draws forth from the pouch, after much fumbling about, the first instalment of his dinner. No sooner has he swallowed this than he begins to coax for more, caressing the mother's throat and neck with his bill in a very amusing fashion. The old bird waits till she has recovered the discomfort of the last feed, then opens her mouth again, and the action is repeated, first by one young Shag, then by the other. When the pouch is emptied, the mother spreads her ample wings and goes off for a fresh supply of auas, whilst her offspring shuffle themselves back again into their nests to await her return. But this feeding process and the squirling cries which herald it are going on at the same time all over the camp, and as a consequence there is a perfect din of voices. In the midst of these may be heird deep guttural cries; but these are probably the occasional scoldings of the old birds to repress the inconsiderate eagerness of their young ones, for during the operation of feeding there is a good deal of apparent squabbling among the young fraternity for the first attention, accompanied by a vigorous fluttering and flapping of the wings. In one of the nests, where the young birds were not sufficiently advanced to leave it, I observed that the occupants, during the intervals when their parents were absent, kept up an incessant flapping of their wings and swaying of their long necks, first to one side, then to the other, with a never-ceasing cry as if in great bodily distress."

Although at first sight bearing considerable resemblance to the Cormorants: 
the Darters present many striking differences. They are often called "Snake-Birds," as they are able to submerge their bodies and swim along with only their snake-like heads and necks protruding above the water. Cormorants, it may be remarked, are said to be able to do the same. Then

The Darters.-

Family I'lotide. the Darters have a "link" in the neck, which the Curmorants have not; and this "kink" is arranged in a sort of set spring-like manner, so that when the bird spears a fish, its neck goes off with a jerk, and the fish is transfixed by its bill in a second. We were much interested in watching a Darter and a Cormorant in the "Fish. House" at the Zoological Garlens, and it was curious to see the way in which these two birds differed in their mode of catching fish. The Darter, when let out of his cage, plunged into the water and swam about for a little time, then he sank his body below the surface, keeping his head and neck above it, but, perceiving some tish swimming at the bottom of the tank, it simply sank below the water and then went for them with a few rapid strokes. No fish had a clance. The Darter simply let the spring on his neck go, and unerringly speared his victim as with a lance. It was curious to notice that, whereas the Cormorant often swallowed his fish under water, the Darter invariably brought them to the surface, shook them off his bill, and then swallowed them.

The Darters are tropical birds, being found in America, Africa, India, and Australia, and one species penetrates the Paliearctic region; for the

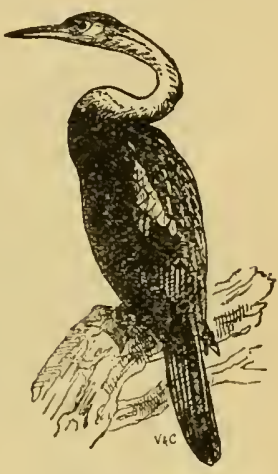

Fiq. 57. -THE DARTER (Plotus ankinga).

African Darter (Plotus levaillanti) breeds on the Lake of Antioch, where Canon Tristram found the nests. The bird, he says, merely seems to tread ciown a tuft of coarse grass or rushes, or press down the centre of a little bush. A curious liabit of the Darter, and likewise of the Cormorants, is to sit motionless in the sum with extended wings, as if the bird were "hanging itself out to dry." A captured Heron or Bittern is an awkward customer to carry home, if not dead, for the bird will reserve all its strength for a final effort to lance its bill at the eye of its captor, as I once had occasion to experience when carrying home a young Heron, which did its best to make a cleadly thrust at my face. So with the Darter and its formidable bill, for Mr. Thomas Ayres writes that a wounded African Darter ( $P$. levaillunti) made a sudden dart at his eye, and it was only by the merest instinct of self-preservation that he put up his hand to receive the thrust. The upper mandible pierced with great force the bone of his thumb, and the hill, being serrated, siuck among the muscles, and he had a hard job to pull it out.

It is not necessary to enumerate the characters, osteological and otherwise, which distinguish Pelicans, because their external appearance is so peculiar that they are easily recognisable birds. The bulky body, the long bill, hooked at the end and having an enormous gular pouch, are sufticient external

The Pelicans.Sub-order Pelecan. characters to distinguish the Pelicans, so that we need not wiste many words on them. In ancient times they were even more widely distributed, and lived in England, like the Flamingoes to which we 
have alluded above (p. 288). They are birds which are found in the temperate and tropical portions of both hemispheres, and in America the Knob-billed Pelican ( $P$. enythrorhynchus) has a remarkable bony excrescence on the upper mandible, which is put on during the breeding season, and afterwards

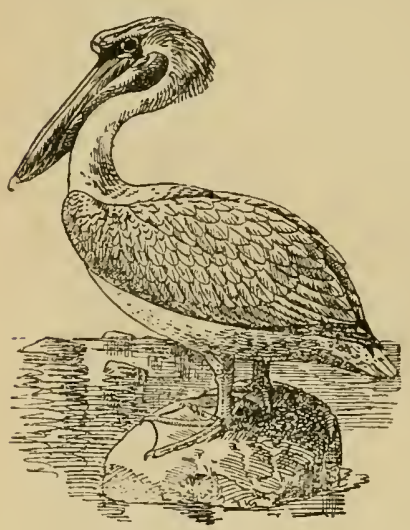

Fig. 5S.-Titr Roseate Peiticax

(Pelecunus onocivotalus).

falls off. Nearly every species assumes a patch of yellow or brown colour on the chest during the nesting season, at which time, too, a crest is generally donned.

On the habits of the Roseate Pelican in the delta of the Danube the following note lias been published by Messrs. Sintenis :-

"The islands where they breed are more or less composed of reed-fragments, often without any fresh vegetation, often also bordered by green rushes and other high plants. The aspect of the large white eggs shining through the green all round is very charming when seen from the middle of the lake; but when closely inspected, the places look very dirty and slovenly. The smell was bearable, the process of fermentation and putrefaction being generally over-a sign that the birds had not laid since the 7 th instant. Generally there were two eggs in a nest; but there were also plenty of single ones. Nearly half as many eggs as were lying on the islands were floating on the surrounding water. The latter keeps sending up air-bubbles, by which it is kept in constant commotion, no doubt caused by the substances putrefying at the bottom. The eggs were in all stages of hatching; but in most of them the young birds were fully developed, so that we had a trouble to find a number which could yet be blown. The eggs which our chasseur had taken on the 7th were, on the average, far less advanced; and it does not seem to us at all improbable that the heat of the sun may have had some influence upon the abandoned eggs, at least to a certain extent."

Of the breeding of the spotted-billed Pelican in Burma (P. manillensis), Mr. Eugene Oates gives a very interesting account:- "The whole forest consisted of very large trees, but a portion-about one in twenty - was made up of wood-oil trees, gigantic fellows $150 \mathrm{ft}$. high and more, and with a smooth, branchless trunk of 80 to $100 \mathrm{ft}$. These are the trees selected by the Pelicans. I was out one day till 3 P. m., continually moving, and must have walked at least twenty miles in various directions, but never from first to last was I out of sight of either a Pelican's or Adjutant's nest. From what I saw, and from what the Burmans told me, I compute the breeding-place if these birds to extend over an area about twenty miles long and tive broad.

"With regard to the Pelicans, I noticed that no tree contained less than three nests, and seldom more than fifteen. Some birds select the upper branches, placing their nests on the nearly horizontal branches of the tree, not far from the trunk. In all cases the nests on one hranch touch each other, and when these nests are on a horizontal branch they looked like an enormous string of beads. 
"Judying from the size of the bird, I should say the nest is about $2 \mathrm{ft}$. in diameter, and, when in a fork, to be $18 \mathrm{in.deep.} \mathrm{Others} \mathrm{on} \mathrm{flat}$ branches are shallower. They are composed entirely of twigz and small branches, and I could detect no lining in those nests which were thrown down to mie.

"The eggs are invariably three in number, and on the 11th November all I took were either fresh or only slightly incubated. The female bird sits very closely, and frequently I found that the bird would not fly off her eggs till I tired a gun. It was a most ludicrous sight to see the sitting birds stretch neck and head out of the nest to have a look at us, as often happened.

"Notwithstanding the millions of birds which breed in this forest, a most wonderful silence prevails. The Pelican seems to be perfectly nute, and the Adjutants only bellow at intervals. The only sound which is consequently heard-and after a time even this sound passes unnoticed-is a sort of Eolian harp caused by the movement of the wings of innumerable birds high in air."

In certain particulars the Frigate-Birds, of which there are only two, are closely allied to the Pelicans. Like the latter birds, they have the clavicle anchylosed to the sternum, and other osteological characters in common, while they also have a large gular pouch. Besides this, they are remarkable for their hooked and almost raptorial bill, ancl their habits

The Frigate-

Birds.--Sub-order Freguti. partake of those of the Birds of Prey to a great extent.

The thight of the Frigate-Birds is wonderful, and can be sustained for an extraordinary length of time; while the birds have a complete arrangement of air-cells beneath the skin which they are able to inflate at will. Mr. Palmer, who collected birds for the Hon. Walter Rothschild in Laysan and the adjacent islets, has given some interesting notes on the habits of the Frigate-Birds. In his diary of 20 th June he writes: - "While walking in Laysan I turned some of the Frigate-Birds which had young off their nests. Scarcely had I pushed one off when another Frigate-Bird would rush up, seize the young one, fly off, and eat it. Sometimes the parent bird would give chase, but it always ended in one or the

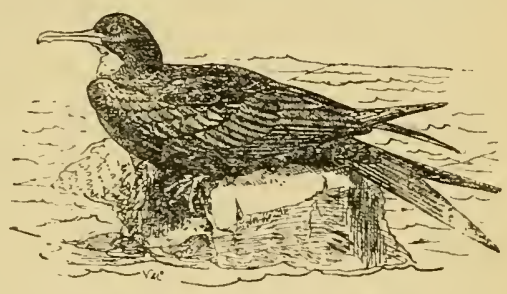

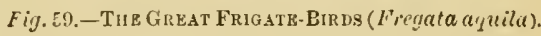
other eating the young bird. I could scarcely believe my own eyes, so I tried several; but they would even take young birds nut of the nest which were almost fully feathered." Again from Liasinsky Island he writes :"The Frigate-Birds hare their nests on the scrub round the lake. It is very interesting to watch them getting their food. In the daytime they soar about all over the island, and every now and then one of them picks up a young Tern. Then a number of others chase him, and keep taking the prey one from the other till at last it is eaten or drops to the ground. But they generally make for the sea with their prey, as it is easier for them to pick up on the sea than on land. When soaring they hardly seem to move a wing, and sometimes I have seen them cleaning and picking their feathers as they floated alorg in the air. In the evening, just before sunset, they hover close round the island, waiting for the Petrels and other birds to come 
home with food, when they give chase, and do not leave the unfortunate bird until it has disgorged some, if not all, of its food. I have seen a Petrel when thus chased drop on the water from sheer exhaustion; bat even then the Frigate-Bird would not leave it till it had disgorged."

These very aberrant kinds of Birds of Prey are strictly American, being represented in both North and South America by tho Turkey Vultures, and

The Turkey

Vultures.-0rder

Cuthertidifurmes. in.the Andes by the Condors. They differ so much from ordinary Accipitrine birds in their anatomy and osteology that they are now by common consent kept sejarate from the latter, and some ornithologists have even gone so far as to suggest that they are more nearly allied to the Storks, and even to the Hornbills. Although not true Birds of Prey, I think that there can be no doubt that they find their nearest allies in the Vultures of the Old World, which they much resemble in their habits. They have, however, a very peculiar nostril, the septum of which is perforated, so that it can be seen through. The hind toe is small, but is raised above the level of the other toes, and it is connected with the flexor perforans digitomu tendon.

The great Condor of the Andes is the largest and most striking of the Turkey Vultures, but the best-known are the smaller kinds such as the Cathartes aura of North America. In Captain Bendire's work on the Lifehistories of North American Birds, we find the following notes on the habits of the species from Dr. IV. L. Ralph :- "In Florida they are abundant and appear to decrease but little in numbers. When not molested they become very tame, and in many of the Southern cities and villages they can be seen walking around the streets or roosting on the house-tops with as little concern as domestic animals.

"Althuagh they eat carrion, these birds prefer fresh meat, and the reason of their eating it when decayed is that they cannot kill game themselves and their bills are not strong enough to tear the tough skin of many animals until it becomes soft from decomposition. I have often had Ducks and other game, which I had hung in trees to keep from carnivorous animals, eaten by them. When they find a dead animal they will not leave it until all but the bones and other hard parts have been consumed, and if it be a large one, or if it have a tough skin, they will often remain near it for days, roosting by night in the trees near by. After they have eaten-and sometimes they will gorge themselves until the food will run off their mouths when they move-. they will, if they are not too full to fly, roost in the nearest trees until thei. meal is partly digested, and then commence eating again. Many times I have seen these birds in company with the Black Vulture floating down a stream on a clead alligator, cow, or other large animal, crowded so closely together that they could hardly keep their balance, and followed by a number on the wing. I have never seen them fight very much when feeding, but they will scold and peck at one another, and sometimes two birds will get hold of the same piece of meat and pull against each other until it breaks, or until the weaker one has to give it up."

In this order are included the Secretary Birds, the

The Birds of

Prey.-Order

Accipitriformes. $\checkmark$ ultures, Hawks, and Ospreys. The characters of the Secretary Birds are detailed below, and their peculiarities emphasised, but the Ospreys (Pandiones) form a wellcharacterised intermediate group betwcen the Vulture
pitres), and the Owls (Striges), possessing certain festures

and Hawks (Accipitres), and the Owls (Striges), possessing certain festures 
which are characteristic of the latter, cspecially in the proportions of tho skeleton.

That these are Birds of Prey there can bo littlo doubt, but they are decicledly aberrant, and were separated from the rest of the Accipilies by Professor Huxley. They have abnormally long legs, and an equally abnormal tail, with the centre featlers much elongated, while from behind the head rises the crest of pointed feathers, from which the bird gets its name of

The Secretary

Bird s.-Sub-order Serpenturii. "Secretary," on account of some fancied resenblance to a secretary, who is supposed to carry quill pens belind his ear. There aro other peculiar anatomical and osteological features which separate the Secretary from the other Raptorial birds. Several ornithologists, anongst them myself, lave perceived certain characteristics in the Seriama (autea, p. 277) which suggest an affinity witl the Secretary; and, if the Seriama is admitted to be a kind of Crane, it is also certain that it possesses certain Accipitrine characters which are difficult to account for. The external appearance of the two birds is not unlike, and there is one very curious habit which they possess in conmon, viz., the way in which they attack their prey, by striking it with rapid beats of their long legs, both of which are brought down with terrific force, until the object is beatell to a pulp. Another character which those birds possess in common, is the fact that both the outer and inner toe are connected by a web, which is one of the features of the Caracaras, to which, in my opinion, the Secretary is distantly related.

Serpenturius is an African genus, and the single species is therefore strictly Ethiopian, but in ancient times the Secretary lived in Central Europe, as its remains, like those of the African Touracous, have been found in France. The Secretary is a pugnacious bird, so that frequently serious fights tak $\theta$ place between two males for the possession of a female, and the bony knob which they carry on the carpal joint of the wing is doubtless an offensive weapon. When attacking a Cubra, the Secretary defends itself by holding its wing in front of it as a shield, and strikes the snake down by vigorous blows of its feet. On account of its usefulness in destroying venomous snakes it is protected in all parts of Africa, and as many as three large snakes have been taken from the stomach of one of these birds, besides lizards and tortoises, and a quantity of grasshoppers and other insects ; while it will frequently kill a large snake by carrying it high in the air and dropping it to the gruund. The eggs are two, rarely three, in number, and white.

These are the true Raptorial or Accipitrine Birds of authors. They may be divided into two great families, the Vultures (Vulturidce) and the Hawks (Falconidce). The Vultures are mostly carrion-eaters, and are found

The Birds of Prey.-Sub-order -tecipitres. in the tropical portions of the Old World, the so called "Vultures" of the New World having been already separated off as the 
Cathartidiformes (antea, p. 304). Although so different from their American allies, the habits of the Old World Vultures are very similar. They have a bare head and neck, scantily clothed with down or plumes; but these parts are never fully clothed with feathers as in the true Birds of Prey.

The genera of the Vulturidce are six in number, viz., the Black Vultures (Vullur), the Griffons (Gyps and Pseudogyps), the Eared Vultures (Otogyps), the White-headed Vultures (Lophogyps), and the Scavenger Vultures (Neophron).

The Black Vulture is the only representative of the genus $V$ ultur. It is found in the Mediterranean countries, whence it ranges through Central Asia to the Himalayas, and even to China. It is a large bird, nearly $4 \mathrm{ft}$. in length, and is entirely black or dark brown, with a pad of thick, velvety down on the crown and a ruff of brown down on the neck. It is more solitary in its habits than the Griffons; and in Spain, according to Colonel Irby, the species breeds in trees, and not in colonies, laying only one egg about the beginning of April. It acts the part of a King Vulture towards the Griffons, and drives the latter away from any carcase which they may be feeding upon.

Four, or perhaps five, species of Griffons are known, the most familiar being the Gyps fulvus of Southern Europe. Colonel The Griffon Irby gives an interesting
Vultures.-Genus account of the species in Gyps. Spain. It is very plentiful near Gibraltar, and nests in colonies, not exceeding thirty-five pairs, in holes, or rather in caves in the perpendicular crags or "lajas" which are found in many of the Sierras. The eggs, according to Captain

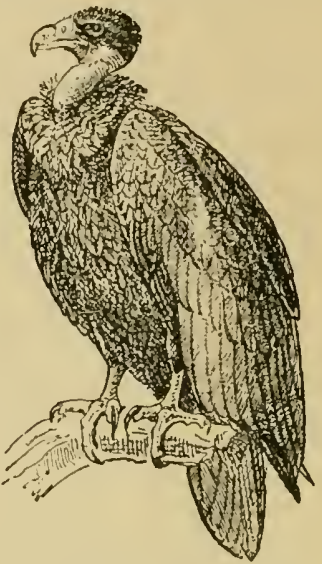

Fig. 61.-Tin Black Vututre (Vultur monachus).

Willoughby Verner, are white when fresh laid, but soon bccome stained and often covered with mud and blood. He says:- "Anyone who has seen a party of Griffons on damp soil, churning up the ground with their feet around a carcase, can easily understand the eggs becoming soiled." Colonel Irby observes:- "How the numbers which inhabit Audalucia get sufficient to eat is a puzzle to me. They must be able to fast for some days, or else travel immense distances for their food, as in the winter and spring it is unusual to see dead animals about; but in the hot parching months vast quantities of cattle die of thirst and want of pasture. A bull fight is a sort of harvest to Vultures, which flock in great numbers to revel on the carcases of the unfortunate horses that have been so cruelly killed."

Of the Scavenger Vultures there are four species, the best-known being the Egyptian Vulture (Neophron percnopterus). The members of this genus are smaller than the generality of Vultures, and have a long

The Scavenger

Vultures.-

Genus Neophron.

Africa two brown species, $N$. pileatus and $N$. monachus, occur. curved bill with a longitudinal nostril. The Egyptian Vulture is an inhabitant of the Mediterranean countries and Africa. In India it is replaced by a nearly allied form with a yellow bill, known as $N$. ginginianus. In 
The Egyptian Scavenger Vulture is a more than ordinarily foul feecler, even for one of its kind, and frequents human habitations, where it devours all kinds of offal and excrement, but it will at cther times devour lizards, snakes, and small rodents, as wcll as worms, insects, and even fruit. According to the late C. J. Ander'sson, it is said to devour ostricl egrgs, by carrying a stone up into the air and dropping it upon them. The nest is generally placed on cliffs, but sometimes on trees.

Of the True Hawks there are five sub-families, the Caracaras (Polyborince), the Long-legged Hawks (Accipitrince), the Buzzards (Buteonince), the Eagles (Ayrilime), and the Falcons (Falconime).

Of the Caracaras there are but two genera, Polyborus and Ibycter. They are distinguished from the other Hawks by llaving the outer and imner toe comected to the middle one by a membrane or web. In all the other subfamilies there is a web only between the base of the outer and middle toes. Polyborus has but two species, $P$. tharus, of South America, which is found from the Straits of Magellan to Amazonia, and $P$. cherizuy, which occurs from Ecuador and Guiana, through Central America, into the Southern United States.

Mr. W. H. Hudson has given a long and interesting account of the habits of the "Carancho," as the Polyborus is called in Argentina. It is too long to be given in its entirety, but we cannot refrain from making a few extracts:- "The Caranchos pair for life, and may therefore be called social birds. They also often live and hunt in families of the parents and young birds until the following spring, and at all times several inclividuals

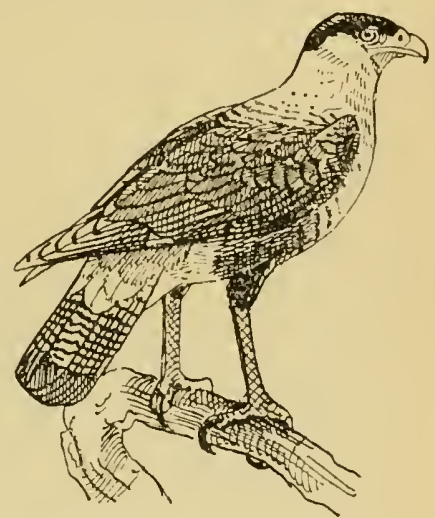

Fig. 62.-Tie Brazilian Caracara (Polyborus tharus). will readily combine to attack their prey, but they never live or move about in flocks. Each couple has its own lome or resting-place, which they will continue to use for an indefinitc time, roosting on the same branch and occupying the same nest year after year; while at all times the two birds are seen constantly together, and seem very much attached. Azara relates that he once saw a male pounce down on a frog, and, carrying it to a tree, call his mate to him and make her a present of it. It was not a very magnificent present, but the action seems to show that the bird possesses some commendable qualities which are seldom seen in the Raptorial family. Without doubt it is a carrion-eater, but only, I believe, when it cannot get fresh provisions; for, when famished, it will eat anything rather than stud.y its dignity and suffer hunger like the nobler Eagle. I have frequently seen one or two or three of them together on the ground, under a column of winged ants, eagerly feasting on the falling insects. To eat putrid meat it must be very hungry indeed. It is, lowever, amazingly fond of freshly-killed flesh ; and, when a cow is slaughtered at an estancia-house, the Carancho quickly appears on the scene to claim his share, and, catching up the first thing he can lift, he carries it off before the dogs can deprive him of it. When he has risen to a height of five or six yards in the air he drops the meat from 
his beak, and dexterously catches it in his claws without pausing or swerving in his flight. It is singular that the bird seems quite incapable of lifting anything from the ground with the claws, the beak being invariably used, even when the prey is an animal which it might seem dangerous to lift in this way. I once saw one of these birds swoop down on a rat from a distance of about $40 \mathrm{ft}$., and rise with its struggling and squealing prey to a height of $20 \mathrm{ft}$., then drop it from its beak and gracefully catch it in its talons. Yet, when it pursues and overtakes a bird in the air, it invariably uses the claws in the same way as other Hawks. This I have frequently observed, and I give the two following anecdotes to show that even birds, which one would imagine to be quite safe from the Carancho, are on some occasions attacked by it. In the tirst case, the bird attariked was the Spur-winged Lapwing, the irreconcilable enemy of the Carancho and its bold and persistent persecutor. The very sight of this Hawk rouses the Lapwings to a frenzy of excitement, and springing aloft, they histen to meet it in mid-air, screaning loudly and continuing to harry it until it leares their ground, after which they return, and, ranged in triplets, perform their triumphal dances, accompanied with loud drumning notes. But if their hated foe alights on the ground, or on some elevation near them, they hover about him, and first one, then another, rushes down with the greatest violence, and gliding near him, turns the bend of its wing so that the spur appears almost to graze his head. While one bird is descending, others are rising upwards to renew their charges; and this persecution continues until they hive driven him away, or become exlaausted with their fruitless effur ts. The Carancho, however, takes little notice of his tormentors; only when the Plover comes very close, evidently bent on piercing his skull with its sharp weapon, he quickly dodges his head, after which he resumes his indifferent demeanour until the rush of the succeeding bird takes place.

"While out riding one day a Carancho flew past me attended by about thirty Lapwings, combined to hunt him from their ground, for it was near the breeding season, when their jealous irascible temper is most excited. All at once, just as a Lapwing swept close by and then passed on before it, the Hawk quickened its flight in the most wonderful manner and was seen in hot pursuit of its tormentor. The angry hectoring cries of the Lapwings instantly changed to piercing screams of terror, which, in a very short time, brought a crowd numbering between two and three hundred birds to the rescue. Now, I thought, the hunted bird will escape, for it twisted and turned rapidly about, trying to lose itself amongst its fellows, all hovering in a compact cloud about it and screaming their loudest. But the Carancho was not to be shaken off; he was never more than a yard behind his quarry, and I was near enough to distinguish the piteous screams of the chased Lapwing amidst all the tumult, as of a bird already captive. At the end of about a minute it was seized in the Carancho's talons, and, still violently screaming, borne away. The cloud of Lapwings followed for some distance, but presently they all returned to the fatal spot where the contest had taken place; and for an hour afterwards they continued soaring about in separate bodies, screaming all the time with an unusual note in

The Long-Legged

Hawks. - Subfamily tecipitrince. their voices as of fear or grief, and holding excited conclaves on the ground, to all appearance as greatly disturbed in their minds as an equal number of lighly emotional human beings wou!d be in the event of a similar disaster overtaking them." 
Only the outer and middle toes are united by a membrane in this subfamily, but the legs are very long, the thigh (tibio-tursus) and the leg (tarso-metatarsus) being nearly as long as one another. The birds included in this group are the Gymmogenes, Harriers, Gos-Hawks, and Sparrow-Hawks.

These curious crested Hawks are Ethiopian, one species being found in tropical Africa and another in Madagascar. They are grey birds with a well-developed crest, and a bare face of a light yellow colour. The structure of the leg is peculiar, for the tibio-tarsil joint is flexible, and the bird has the power of putting its leg out of joint, as it were, and placing the tarsus at a backward angle, instead of forwards, as in ordinary Birds

The Gymnogenes. - Genus l'oly. borordes. of Prey. The Neotropical genus Geranospizias is also said to possess the same faculty. In the Gymnogene this power of twisting its leg about, as on a picot, is said by observers to bo of use to the lird in drawing out frogs from the marsh holes. Its food appears to consist chiefly of lizards and frogs, and also of insects; and Mr. Ayrcs says that in Natal it frequents lands on which the grass has been recently burnt, stalking over the ground like a Bustard.

The Harriers are long-legged birds, differing from the Sparrow-Hawks and Gos-Hawks in having the hinder aspect of the tarsus reticulate and in having an oval nostril. They have also a ruff round the face similar to that of the Owis, and on this account they have often been considered to be a connecting link be-

The Harriers.Genus Circus. tween the Hawks and the Owls. This character, however, $i$; of secondary importance compared with the development of their long legs, which, in our opinion, allies them to the Sparrow-Hawks. Some sixteen species of the Harriers are known, and they inhabit the temperate and tropical portions of both hemispheres. They do not range into the arctic regions, and those which breed in northern localities migrate south in winter, often in large numbers. The habits of all the Harriers are very much the same in different countries. The nest is built on the ground, and the eggs are white, with occasionally a few brown markings; they appear bluish inside when held up to the light. They are not birds of bold and rapid flight like the Sparrow-Hawks or Eagles, but are great robbers of other birds' eggs and young, feeding also on smill mammials, reptiles, fish, and insects. Mr. Seebohm speaks of the Marsh Harrier (Circus ceruginosus) as being "usually seen passing slowly orer its swampy haunts a few feet from the earth, quartering the ground much as a well-trained dog searching for game. Its flight is somewhat slow and laboured, performed with measured beats of the wings, raried by gliding motions as it surveys the ground below. It wiil beat over its hunting-ground, returning backwards and forwards, as if diligently searching every spot likely to contain its prey. Now and then it is seen to drop somewhat slowly to the earth to secure a frog or a mole, which it will either eat at once or convey to some distance."

Uf Montagu's Harrier (Circus pygargus) Colonel Irby records the finding of a regular colony near Lixus, in Morocco. With his telescope he could see the sitting hen birds dotted about the marsh. The North American HenHarrier (Circus hudsonius) has similar habits to those of the European species, but is not such an egg-destroying bird, and is looked upon as a beneficial Hawk, as it devours great quantities of meadow-mice and ground. squirrels, as well as noxious insects, such as locusts and destructive groundcrickets. The flight of this Harrier is described as graceful, and at certain. 
times the males perform aerial evolutions. The male never assists the female in the duties of incubation, but diligently supplies his mate with food. Mr. John Clark informed Captain Bendire that he has seen the female riso from the nest to welcome the male with shrill cries when he camo in sight, and then take the prey from his talons and fly back with it to the nest.

Intermediate between the Harriers and the Gos-Hawks comes the genus Micrastur, containing the Harrier-Hawks of Tropical America. These aro birds which have the stout build of a Gos-Hawl combined with the facial ruff of the Harriers, and, as in the last-named genus of birds, the tarsus is reticulated behind. Then follow several genera of Gos-Hawks, such as Geranospizias of Tropical America, Urotriorchis of Africa, and Erythrocnema, again a New World form, so closely allied to the Chanting Gos-Hawks of Africa (Melicrax) that the two genera are scarcely distinguishable.

Two species of this genus are known, one, $E$. unicincta, inhabiting South America from Brazil to Chili, and the other, $E$, harrisi, being found in Central America, north to the Southern United States.

The Red-thighed

Gos-Hawks.Genus

Erythrocneme.

Little has been recorded of the habits of the Red-thighed Gos-Hawks, but Captain Bendire says that they appear to be lazy and sluggish birds, with a slow and not graceful flight. They build in low trees, and the nest is a poorly constructed affair, so that on one occasion Captain Bendire declares that he could see the eggs through the bottom of the nest.

These birds are confined to the Ethiopian Region, and they are called "Chanting" Gos-Hawks on account of their supposed

The Chanting Gos-Hawks.Genus Melerar.

South Africa. utterance of a song. Le Vaillant is the principal authority for this statement, but like many other records of this traveller's, it is open to doubt; and Mr. Layard sags that he never heard anything of the sort in

The preceding genera possess a bony tubercle in their nostrils, but the true Gos-Hawks (Astur) have not this peculiarity. On the contrary, they have an oval nostril with no tubercle. They are remarkable for their stout and heavy bill, accompanied by stout legs and short toes. They are of all sizes, some of them being as big as a Buzzard, while others are scarcely larger than a Thrush.

The Common Gos- Hawk is a bird of the woods and forests, where it builds a nest of great size, which it lines with roots and moss, but does not use green leaves as many birds of prey do. The great size of the

The Common

Gos-Hawk.Astur palumbarius. nest is probably due to the additions made by the birds from year to year. The eggs are pale greenish white, and are only very rarely marked with faint brown spots. The Gos-Hawk is a most useful bird to the falconer, as it is an adept at taking rabbits, but it belongs to the group of short-winged Hawks and cannot fly down its prey like an Eagle or a Falcon. Seebohm observes:- "In spite of his comparatively short wings, he is a bird of very powerful flight, and of undaunted courage. He disdains to eat carrion, and will scarcely stoop to catch $n$ sitting bird. He hunts on the wing, and nothing is safo from his attacks, from a sparrow to a grouse, or from a mouse to a young roe. In summer he confines himself principally to the woods and the open places in their immediate neighbourhood; but late in autumn and winter lie extends the range of his hunting-grounds, pursuing partridges and hares, and 
making raids on the pigeons belonging to the farmers, and sometims snatching the game from under the very nose of the sportsman."

The Gos-Hawks are about forty in number, and many of them, though small, are of beautiful plumage, such as the Fijian Astur torquates and its allies, which are pale grey birds with a rufous collar round their necks and vinous coloured breasts. This group inhabits the Australian region, more especially the Moluccas, and the Papaan Islands. Another group is that of the Indian Shikra (Astur badius), which has allied species in Burma, Africa, and South-Eastern Europe. They are all small birds with prettily barred breasts. One of the most interesting, however, is the White Gos-Hawk of Australia, a pure white species, which looks like an albino. Astur rotce hollandice, as it is called, is confined to the Australian continent, with a representative species, $A$. leucosomus, in New Guinea.

This is also a numerously represented genus of Hawks; the difference between the Sparrow-FIawks and the Gos-Hawks consisting principally in the smaller bills and longer toes of the former birds. Like the Gos-Hawks, the members of the genus Accipiter are found over the greater part of the world, and both small and large species are met with. They are generally

The Sparrow-

Hawks,-Genus Accipiter. of slight build, but use their short wings with great dexterity, doubling in their flight in the most rapid marner, and snatching their prey with a sudden plunge, seldom attempting to seize it in the open.

In our English Sparrow-Hawk the female is a much larger bird than tho male, and is much the more powerful bird of the two, though nothing can well exceed the spirit and dash of the little male Sparrow-Hawk. The chief food of the species consists of small birds, but it takes Blackbirds, Partridges, and, according to $\mathbf{M r}$. Seebohm, even Wood-Pigeons. It is a very determined marauder on the Pheasant coops, and catches a number of young birds of all sorts, feeding its own young on these. The nest is somewhat large, and, unlike that of most of the smaller Birds of Prey, which generally appropriate the nest of some other bird, the Sparrow-Hawk builds its own nest. The eggs of the species

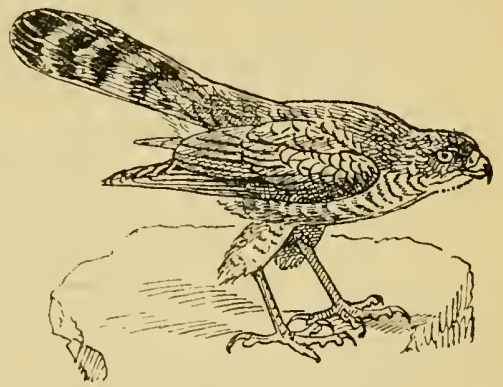

Fig. (3.-Tha Female Sparrow-Hawh (Accipiter nisus). of Accipiter are invariably more handsome than those of the Gos-Hawks, and some of the eggs of our own species are beautifully marbled with reddish brown.

The largest of tho Sparrow-Hawks is the Pied Sparrow-Hawk of Africa, which is nearly $2 \mathrm{ft}$. in length.

With this sub-family we commence the description of the shorter legged Hawks, wherein the tibio-tarsus is always longer than the tarso-metatarsus. The first of the three sub-families is that of the Buteonince or Buzzards. And here we find a character which runs through them all, and is rery

The Buzzards:Sub-family Butconina. constant, viz., that the hinder aspect of the tarsus is scaled, and not reticulated. This wo believe to be the principal character 
istic of the Buzzalds, which on the one hand are allied to the Gos-Hawks, and on the other to the Eagles, the difference between the latter and the Buzzards being by no means strongly marked.

At the head of the Buteonince we find the genus Erythrotriorchis, or Rufous Buzzard-Hawks, of which there are two species, cone, E. radiatus, found in Australia, and the other, $E$. dorice, inhabiting New Guinea. They are very rare birds, and but little has been recorded concerning their habits.

Of the succeeding genera, Buteogallus and Tachytriorchis, also very little is known. They are Neotropical forms; but $T$. abbreviatus and $T$. albicaudatus occur in the Southern United States, and some good accounts of their nesting have been published by Captain Bendire in his excellent work on the "Life. Histories of North American IBirds." The latter species visits Southern Texas during the summer, and migrates south in winter, visiting South America as far as Argentina in companies. In the winter Mr. W. H. Hudson has known them to become so reduced in flesh that, after every cold rain or serere frost, numbers would be found dead under the trees where they roosted, and in that way most of them perished before the return of spring. Captain B. F. Goss found the species breeding, abundantly near Corpus Christi, in Texas, in the spring of 1882 . His note to Captain Bendire is as follows:- "I found the favourite breeding-places of tho White-tailed Hawk to be a strip of open busliy land, lying between the thick line of timber and chaparral along the coast and the open prairie. Any bush rising a little above the surrounding level seemed a suitable nesting site, and no attempt was made to conceal the nest. In most places it was very prominent, and could be seen for a long distance. I examined fifteen, and they were all placed in low bushes, generally not higher than $6 \mathrm{ft}$. In a few cases I had to stand upon the waggon to reach them. They were composed of sticks, dry weeds, and grasses, a coarse, dry grass entering largely into the composition of most of them. They wero poorly constructed, but moderately lollowed, and usually lined with a few green twigs or leaves. Taken as a whole, the nests looked ragged in outline and slovenly in finish. About one nest in four contained three eggs; the rest but two. These Hawks are wary, and difficult of approach at all times. They would leave their nests as soon as we came in sight, sometimes when still haif a mile away, and generally they kept entirely out of sight. An occasional pair sailed high over our heads, uttering a faint cry while we were at their nest. Only a single one came within reach of our guns." Botl of the genera Heterospi:ias and Tachytriorchis differ from the typical Buzzards in their shorter tails, the wings reaching beyond the tip of the latter.

The genus Buteo contains about twenty species, of which our Furopean Common Buzzard (Buteo buteo) is the type. They are almost identical in their mode of life one with another, and mostly resemble The True Buzzards. small Eagles in their habits. They are, as a rule, useful -Genus Butco. birds, as they feed upon rats and mice, insects, and small reptiles, which they pounce upon from a sitting position; hence they do not often capture birds, as they do not take their prey on the wing. The nest of the Common Buzzard is a somewhat large structure, built in a tree, and is flat at the top and lined with fresh green leaves. The egga are three or four in number, white, or bluish white in colour, the markings being blotches or streaks of a rich brown colour, which are often absent.

Of the utility of the Buzzards to the farmer and agriculturist very good proof is given in Dr. A. K. Fisher's work on the "Hawks and 0 mls of the 
Tnited States in relation to Agriculcure," where tables of the food found in the stomaclis of the Buzzards are given, from which it appears that large numbers of small mammals and insects, especially locusts, are devoured by these Birds of Prey, and that very few small birds are captured by them, though the larger kinds of Buzzards will occasionally take a Duck or a Partridge.

In the Buteonince are also contained some other forms of Buzzards, such as the genera Asturina and Urubitinga, the habits of which call for little special notice here, though some of the latter are very handsome birds of nearly pure white plumage. They are neotropical in habitat, as are also the Harpies, with which the Buzzards conclude. It is generally the fashion to speak of the Harpies as Eagles, instead of Buzzards, but the way in which the hinder aspect of the tarsus is plated, instead of being reticulated, is sufficient to show that these great birds aro really members of the sub-fanily Buteonince.

There are three genera of Harpies - Marpyhaliaetus, with one species, $H$. coronatus, a grey bird found in Soutl America; Morphnus, also with a single species, $M$. grianensis, found in Amzonia and Guiana as far west as Panama; and Throscetus, with the true Harpy, T. harpyia, as its type, a species found over the greater part of Southern and Central America as far north as Mexico. The Harpy is

The Harpy

(Thrasatus

harpyia).

one of the most splendid, as it is the most powerful, of all the Birds of Prey. Like the other Harpies it possesses a very long crest, which it usually keeps raised, adding to its fierce appearance. It is said to kill calves and animals of far greater bulk than itself, and Dr. Felix (Iswald says that "in the Oaxaca district in Mexico, the 'Lobo volante,' or 'Winged Wolf,' attacks and kills heary old turkey-cocks, young fawns, sloths, full-grown foxes and badgers, midille-sized pigs, and even the black Sapajou monkey (Ateles paniscus). The nest is built in the highest forest-trees, especially the Adansonia and the Pims balsamifera. The more inaccessible rocks of the foot-hills are also commonly chosen for a breeding place, and it is not easy to distinguish the compactly-built eyrie on the highest branches of a wild fig tree from the dark-coloured clusters of the Mexican mistletos (Viscum mubrum) which are seen in the same tree-tops. The process of incubation is generally finished by the middle of March, if not sooner, and from that time to the end of June the rapacity of the old birds is the terror of the tropical fauna, for their hunting expeditions, which later in the year are restricted to the early morning hours, now occupy them the larger part of the day."

In this sub-family the tibio-tarsus is much longer than the tarsometatarsus, as it was in the Buteonine, but in all the Eagles the hinder aspect of the tarsus is reticulated, not plated. The bill is festooned but not toothed, as it is in the Falcons, which follow later. There are two genera with wedge-shaped tails, Gypaetus and Uroaetus. In the former genus is found the species generally called the Bearded "Vulture,"

The Eagles.-

Sub-family Aquiline. on account of the tuft of bristly feathers which is grown on its chin. The Bearded Ergle (Gypaetus barbatus) extends from Southern Europe throughout Central Asia to the Himalayas, but has become very rare, if, indeed, not wholly extinct, in Switzerland, where it was once a well-known bird. The Lremmergeier, as it is also called, is still found in some of the otlier mountain ranges of Southern Europe, and in the 
Himalayas it is by no means uncommon. I have myself more than once seen one of these magnificent birds flying over within $30 \mathrm{yds}$. of my head, and turning his head down from side to side, taking stock of everything below him. His pale yellow eye, which is surrounded by a red ring, and his bearded chin were plainly seen. The flight of a Lremmergeier is grand in the extreme. The bird, however, has many of the habits of a Scavenger Vulture, and resembles Neophron in some of its ways, though it does not seem to be such a foul feeder. The species has been known to follow camps, and it is not infrequently to be met with in the neighbourhood of villages in the north-western IImalayas and Tibet. Not only in the Mediterranean countries, but in the Himalayas also, the bird is known as the "bone-breaker," and it undoubtedly has the curious habit of devouring bones. Von T'schudi says that five bullock's ribs 2 in. thick and from 6 to 9 in. long, a lump of hair, and the leg of a young goat, from the knee to the foot, were found in the stomach of one of these Bearded Eagles, while in another the large hip-bone of a cow, the skin and fore-quarters of a chamois, many smaller bones, etc., were discovered. It is also said to drive the chamois and goats over the precipices, and devour the bodies when they have fallen below. The weak feet and claws of the Lemmergeier are vulturine, and not like those of True Eagles, and it is certain that the bird could not capture any large prey with its talons. Its method of breaking the bones which it delights in, is to take them up in the air to a great height and then let them drop on a rock, and it was doubtless in this way that Eschylus was killed more than 2000 years ago, an "Eagle," i.e., a Liemmergeier, having dropped a Tortoise on his bald head, mistaking the latter for a rock. "Marrow bones," says Mr. Hudleston, "are the dainties the Lxmmergeier loves the best; and when the other Vultures have picked the flesh off any animal, he comes in at the end of the feast and swallows the bones, or breaks them and swallows the pieces, if he cannot get the marrow out otherwise. I once saw a mature bird of this species which had eviclently swallowed a bone, or something uncommonly indigestible, close to the abattoir at Athens. He was in a very uncomfortable attitude, and appeared to be leaning on his long tail for support." A second species of Liemmergeier (Gypaetus ossifragus) is found in the mountains of North-Eastern Africa.

iVe now come to the true Eagles (Aquila) of which our Golden Fagle is the type, while the Bearded Eagles are connected with the typical Eagles by means of the Wedge-tailed Eagle of Australia ( $U_{r}$.onetus audax), a bird which has the aspect of a true Eagle, but has at the same time the wedge-shaped tail of a Lemmergeier.

In this genus occur some of the best-known Birds of Prey, such as the Golden Eagle (Aquila chrysaetus), the Imperial Eagle (A. heliaca), the

Tawny Eagle (A. rapax), and the Spotted Fagle $(A$.

The True Eagles.- maculata). When on the wing it cannot be denied that the

Genus Aquila. Eagles are birds of magnificent appearance, and I have seen nothing grander in my experience of bird-life than a pair of Eagles circling above the Himalayas and screaming in protest against an approaching storm, as it made its way up the valley. Oa the other hand, in many ways Eagles are little more than large Buzzards, and a great deal of unnecessary romance has been shed around them. Of the Imperial Eagle, Mr. A. O. Hume writes that he considers it no better than a great hulking Kite. In India, he says, it is an ignoble feeder, and he has generally found the birds gorged with carrion. After a good meal, they 
will sit stupidly on a tree, or any little mud piilar, and permit you to walk within thirty yards of them, but, before feeding, they are aomewhat wary, and can by no means always be secured, even when seen sitting. On more than one occasion he found desert rats (Gerbillus erythrums) in their crops, and he once shot one of a pair, which were busy on the line of rails at Etawah, devouring a Bandicoot rat (Mus bardicota), which some passing train had cut in two. Occasionally, but rarely, they had eaten snails and other birds. Once he shot a male, which was dancing about on the ground in such an astounding fashion that he lilled it to see what the matter was. The bird proved to have been choking, and it had swallowed a whole dry shin-bone and foot of an antelope. The bone, apparently, could not be got down altogether, and in trying to void it, the sharp points of the hoof had stuck into the back of the palate.

There are many other kinds of Eagles, such as the Buzzard-Eagles (Archibuteo), and the members of the genus Eutolmaetus, of which Bonelli's Eagle ( $E$. fasciatus) is the type, and the Booted Eagle of Southern Europe (E. pennatus) is another well-known member of the genus. Lophotriorchis is another remarkable form, with a well-developed crest. It has one species, $L$. Fieneri, found in India and the Malay Archipelago, while the only other species occurs in the mountains of Colombia in Sonth America, a very interesting fact in geographical distribution. One of the most curious of Eagles is the Birds'-nesting Eagle (Ncopus malaiensis) of India and the Malayan countries and islands. It is a black bird, with powerful talons which are nearly straight. It spends its time hunting for eggs and nestlings, and is continually on the wing, like a Kite. "It subsists," says Colonel Legge, " as far as can be observed, entirely by birds'-nesting, and is not content with the eggs and young birds, which its keen sight espies among the branches of the forest trees, but even seizes the nest in its talons, decamps with it, and often examines the contents as it sails lazily along." Part of a bird's nest has been found in this Eagle's stomach.

The Crested Eagles (Spiwctetus) of the Indian Region and the Black Eagle of Africa (Lophoctetus occipitalis) complete the list of feathered-legged Eagles. All the rest belong to the bare-legged section which have the tibio-tarsus unfeathered. To this section belong the Sea-Eagles and their allies, tho Serpent-Eagles. Of the latter there are many species in Africa and in the Indian Region, the best-known being the members of the genus Circactus and Spilornis. Of the former we have one species in Southern Europe, Circatnes gallicus, but the true Serpent-Eagles (Spiloinis) are inhabitants of India. The amount of good which they do may be calculated by the statement of Mr. A. O. Hume, who has shot numbers of these birds, that he found fifty little serpents in the stomach of one individual, and on another occasion he knew of a Cobra, $2 \frac{1}{2} \mathrm{ft}$. in length, being taken out of a Serpent-Eagle's stomach. Butrastur is another oriental genus, and the Bateleur-Eagles (Helotarsus) are confined to Africa. The true Sea-Eagles (IIaliaetus) are nearly world-wide in distribution, but they are absent in South America. In Europe and North America we have the White-tailed Eagle (Haliaetus albicilla) and the Bald Eagle (H. leucocephalus), the latter remarkable for its pure white head. The Ethiopian region contains a beautiful species, $H$. vocifer, and one of the most widely distributed Birds of Prey in Australia and the Eust is H. levcogaster, the white-bellied Sea-Eagle.

From the Sea-Eagles we pass to the Kites, which are also members of the sub-family Aquilince. At first sight they would seem to have no connection 
with Eagles, but they are connected with the latter birds through the Brahminy Kites (Haliastur). These birds inhabit India and Burna, and extend through the Malay Archipelago to Australia. The Brahminy Kite of India (Haliastur indus) makes a nest in a tree very much like that of a Kite, and lays a white egg, mottled with dots and hieroglyphics of reddish-brown.

From the genus Hraliastur is an easy transition through the African Swallow-tailed Fite (Nauclerus rigcouri) and the American Swallow-tailed Kite (Elanoides furcatus) to the typical Kites (Milvus). The Swallow-tailed Kite of America is a lovely and most graceful bird, tho back and tail being black, and the head and underparts pure white. It nests in the Southern United States, and winters in Brazil. Florida is one of its breeding grounds, and the following account of its habits is given by Dr. William L. Ralph in Captain Bendire's "Life-History of North American Birds." He writes :"Excepting, perhaps, the Turkey Vulture, i think that this bird is the most graceful of any when on the wing. It has the same easy floating motion, but at times it flies very rapidly and turns very quickly, which is something I have never seen the former bird do. Their motions are very 'Swallow'like, and this, with their forked tail, makes them look like gigantic BarnSwallows; and like the Chimney-Swifts they have a habit of travelling together in small companies, usually consisting of three individua!s, especially when they first return from the South. During the breeding season flocks, consisting of from two to three to ten or twelve birds, but oftener of three, may be seen following one another around, frequently uttering their calls and circling in and out among the tree-tops so fast as to make one dizzy to look at them. Except during this season one seldom sees one of these birds unless it is flying, and I have often wondered if they did not at times sleep while on the wing. At least I know that they usually, if not always, eat while flying, for I have many times seen one sailing leisurely along, occasionally bending its head to tear a piece from a small snake that it held in its talons, and I have never seen one alight to eat its food, like other Birds of Prey."

There are many other forms of KKite, such as the Hooked-billed Kites (Rostirumus), the Black-shouldered Kites (Elamus), and other small genera, but the best known are, of course, the true Kites of the genus Milvis. In the towns and rillages of tropical countries of the Old World these birds are nearly always in evidence, flying about with a continuous squenking cry. The Common Kite is nearly extinct in England, but there are many places on the Continent where it is still plentiful; and Mr. Seebohm gives the following account of its habits :- "In the manner of taking its prey the Kite very much resembles the Buzzards, and even the Harriers. It is by no means a bold and powerful bird, for a clucking hen has been known to put it to flight, and the fiery little Sparrow-Hawk mobs it with impunity. The Kite takes its food upon the ground, and usually catches young or weakly birds or mammals, and also does not even refuse to make a mcal on carrion. Like all rapacious birds, the Kite appears to have some favourite spot which serres as a dining-table or larder, where the food brought to feed its hungry young is also plucked and otherwise prepared for them. The nest in the breeding season is also a well-stocked larder, far more food being conveyed thither than is really consumed. In these places may be seen the remains of Grouse, Plovers, and young Curlews and Wild Ducks. In addition to this food the Kite also takes young hares and rabhits, mice and rats, frogs, lizards, more rarely snakes, and the larger coleoptercus insects 
-creatures that are taken without much exertion or power. In former days, when the Kite was more abundant in these islands than it is now, it was said to be a great enemy to the poultry, young chickens forming a favourite object of its pursuit. At the present day, however, the Kite need cause the poultry-keeper no alarm. Its haunt now, where but a remnant of its former numbers find a last retreat, is in the wildest districts of Seotland, or Wales, where the Red Grouse is probably its favourite fare. How the Kite manages to take so large and strong a bird as a cock Red Grouse is surprising; and it is most probably only the young and weakly ones that fall victims to its swoop. Mr. Booth also suggrests that the Peregrine ofttimes unwittingly finds the Kite a meal, and puts a bird in its way that would never be secured unless weakly or wounded. As is well known, that bold, rapacious Falcon oftell strikes a bird for mere sport, and will leave it where it lies; and there, no doubt, it is sometimes found by the less active Kite and conveyed away. The note of the Kite may be compared to a wild plaintive seream or 'mew,' and is but rarely heard, save in the breeding season. Unmusical as its cry may be, still it appears to be full of wild harmony with the rugged scenery of its haunts, imbues them with life, and, when heard as the bird is flying far overhead, lends a charm to districts where other bird life is wanting."

The Kites which most approach the Falcons are the Perns or Honey. Kites. These have a peculiarly soft plumage, unmistakable to the touch of a practised ornithologist; and this is shared by many of the Falcons, showing that it is practically impossible to draw distinctive characters between the subfamilies of Accipitrine birds. Thus the Buzzards merge into the Eagles, and thenee through the Sea-Eagles and the Brahminy Kites we reach the true Kites, and from them the Perns, which are half Falcons, and thence the transition is easy to the true Falcons. So it may be aftirmed that there is scarcely any order of birds in which the natural connection of the families, sub-families, and genera are better maintained and exemplified than in the Accipitriformes.

Some of the most curious of the Perns, and, one may say, of all Birds of Prey, are the Black Perns (Maehorhamphus). They are nocturnal birds, c)ming forth in the twilight to feed on bats and small swifts. One species, M. underssont, is Ethiopian, being found in Tropical Africa and Madagascar; while the second species, $\boldsymbol{M}$. alcinus, inhabits Southern Burma, the Malayan Peninsula, Borneo, and extends to New Guinea.

These birds are generdly called Honey-"Buzzards," but it is certainly wrong to think of them as Buzzards. Their habits, their outward form, and, above all, their curious soft plumage, all point to their affinities with the Kites. There are three species of Honey-Kite, Pernis apivorus of Europe, $P$. ptilonorhynchus of Tropical Asia, and P. celebensis of Celebes.

The Falcons differ from the Kites, which immediately precede them, and from the other Birds of Prey in having a toothed or notched bill. In some of the genera there is a distinct double tooth, as in the Cuckoo-Falcons $(B a \approx a)$. These are very interesting Hawks on account of their geographical distribution. 'They are all birds of the forest districts, one species being The HoneyKites, - Genus Pernis. found in West Africa, another in Natal, a third in Madagascar, and thence eastwards the species are distributed through the Indian Region and the Moluccas to the Bismarck Archipelago and North- 
Hastern Australia. These birds get their name of Cuckoo-Falcons from their large Cuckoolike yellow eyes and the barred plumage of the lower surface of the body, which is like that of a Cuckoo.

In Central and South America the Cuckoo-Falcons are represented by the Double-toothed Falcons (Hurpugus), and in the same parts of the Neotropical region occur the Grey Kite-Falcons (Ictini( ), one of which, I. mississipiensis, ranges into the Southern United States. All these genera which we have recently mentioned belong to the borderland between the Kites and the Falcons. They have the characteristics of the latter birds, united to Kitelike plumage and habits, and they further differ from the true Falcons in having an oval nostril, with no central tubercle, whereas the latter birds have a rounded nostril with a central tubercle. The habits of the Mississippi Kite-Falcon have been well described in the works of Captain Bendire and Dr. A. K. Fisher. The latter writes :- "The food of this species, like that of the Swallow-tailed Irite, consist of insects, such as the laryer beetles, grasshoppers, and locusts, lizards, small sllakes, and frogs. It never has been known to molest birds or mammals, except to drive the larger species away from the vicinity of its nest. Three specimens which Wilson examined at Natchez, Miss., contained the remains of beetles; and he saw them flying about the trees feeding on cicadas. Dr. Coues mentions one shot at Bluffton, S.C., whose stomach was crammed with the same insects, together with a few Katydids. It is wonderful at what a distance its keen eyes can detect a comparatively small insect. Mr. E. W. Nelson says:-'I saw them repeatedly dart with unerring aim upon some luckless grasshoppers from an elevation of at least 100 yards.' (Bull. Essex Inst., Vol. IX., 1877, p. 58.) As regards the economic value of this Kite much the same statement may be made as of the previous species. It does little or no damage, but much good. Soon after arriving in its summer home it begins to remodel its old nest or the deserted nest of some other bird, and more rarely, when these are not available, it builds a new one. The remodelling consists in patching up the sides with a few sticks and adding a sparse lining of Spanish moss or green leaves. The nest is usually situated in the tops of the tallest trees, among the smaller branches, where it is well concealed by the foliage. The full complement of eggs, usually two or three in number, is deposited by the middle of May, though in some cases it must be much earlier, for the writer once secured a young bird in southern Louisiana at the end of May which had already acquired nearly the adult plumage. This Kite is not at all shy, and may be secured easily as it sits on some tall stub; in fact, Col. N. S. Goss tells of shooting a pair from the same tree, as the second one did not. move at the report of the gun, but looked down with surprise on its fallen companion. It is said to be morose and irritable in captivity. and very difficult to tame. A specimen which the writer once wounded was the very picture of rage, as with flashing eyes and erect crest it threw itself on its back and prepared to repel the aggressor with its talons. This species is fully as gregarious as any of the other Kites, and oftentimes may be seen in flocks of twenty or more circling over a favourite hunting ground. It is observed most frequently around the borcler of woods in the vicinity of water, and is particularly fond of half-cleared ground where dead trees still stand, these being used for perches. Its flight is as varied and graceful as that of the Swallow-tailed Kite, is long protracted, and the birds often ascend to so great a height as to be barely visible. While soaring high in the air its flight simulates that of the turkey-buzzard very 
closely, and as the two birds are often seen together the Kite looks like a miniature of the other."

A curious little genus of true Falcons is Micronievax, the members of which are little larger than sparrows. 'I'hey inhabit the Indian region, especially the Indo-MIalayan islands. An allied genus, Poliohiever, is found in the Burmese Provinces and in the desert regions of Africa, and the two species known present this unique peculiarity among the true Falcons, that the sexes

The Falconets.Genus Jucrohicraz. differ remarkably in colour, the males being grey, while the females have a maroon-coloured beak. One of the chief characteristics of the Falcons is that the males and females are alike in colour, but the latter differ markedly in their superior size.

The true Falcons ( $F$ ulco) are typified in our Peregrine Falcon ( $F$. peregriuns), and various races of this type are distributed over the Old and New Wurlds, whilst the Lammer ( $F$. feldeggii), and the Juggur Falcon are well-known representatives of the same type.

These birds are really gigantic Kestrels, the form and habit of the birds being those of the true Falcons, while the formation of the font is that of a Kestrel, the outer and inner toe being about equal in length, whereas in the genus Falco the outer toe is much longer than the inner one. Hence the latter birds with

The Noble Falcons. -Genus Hierofiatio. their powerful foot are the Falcons par excellence. It is the Peregrine and its allies which are the chosen bird of the falconer, while the noble Falcons are not thought much of by them.

As I have said before, the members of the genus Hierofalco ought to be considered as gigantic Kestrels. They have the same proportions of the toes, but they are very much larger than any Kestrel. They are principally inliabitants of the Arctic regions, the Greenland Jer-Falcon being, like the Snowy Owl and other inhabitants of the snow-clad regions of the high north, almost entirely white, like their snowy surroundings. Thus the Greenland Jer-Falcon is an inhabitant of Labrador and Greenland, occasional stragglers, mostly young birds, finding their way to Great Britain and various countries of Europe. The Iceland Jer-Falcon (Hierofalco islandus) inhabits Iceland, and also occasionally wanders to parts of the European Continent, while in Southem Greenland its place is taken by Holboell's JerFalcon ( $H$. holboelli). In Scandinavia, and thence across Siberia to North America, occurs the Norwegian Jer-Falcon (H. gyrfalco). Two other species complete the genus-one the Saker Jer-Falcon ( $H$. saker) inhabiting South-Eastern Europe and Central Asia to North-IVestern India, while Henderson's Jer-Falcon ( $H$. hendersoni) is found in Thibet. The plumage of these last two species is rufous, rather than grey or white, and they look like large Kestrels.

Besides the Peregrine Falcon, we find in the genus Fulco a large assemblage of smaller Falcons, such as the Hobbv (F. subbuteo) and its 
allies, the Merlin ( $F$. cesulun) and kindred species, the Lanner ( $F$. feldeggii) and several other Falcons ptculiar to the tropical portions of the Old and New Worlds.

The Kestrels differ from the true Falcons in having the outer toe short, and about equal to the inner toe in length. They are birds of small size, and are chiefly insectivorous, many of them catching

The Kestrels,-

Genus C'erchneis. their prey on the wing, and devouring it as they fly. They catch a large number of field mice, and are everywhere a real friend to the agriculturist. In Dr. Fisher's report on the American Kestrel and its food, it is interesting to observe that in tho stomachs of a large series (320) examined, few remains of birds were found, but a considerable number of mice. The chief food of the species was, lowever, grasshoppers, locusts, and caterpillars.

The Ospreys, or Fishing Hawks, as they are often called, hold an intermediate position between the Hawks and the Owls. The skeletun very closely approaches that of the latter birds, and the The 0spreys,- Ospreys have another character in common with the Sub-order Pandiones. Owls, viz., that the outer toe is reversible, and can be turned backwards or forwards at will.' The soles of the feet are likewise furnished with spicules, thus enabling the bird, with its toes distributed nearly at right angles and its spiked soles, to seize and drag from the water the large fish on which it preys.

The Osprey is now a very rare bird in Great Britain, and is only found in certain parts of Scotland, where it is protected, though a few stragglers, mostly young birds, are shot in other parts of the United Kingdom from time to time. The Osprey is a cosmopolitan species, and is found nearly over the whole of the world, the birds from the Australian region being slightly smaller than those from Europe or North America. The nest of the Osprey is an enormous structure, and is placed on a tree, or on a ruined building. The eggs are among the handsomest of those of Birds of Prey.

In addition to the reversible toe alluded to above, a character which they share with the The 0wls.- distinguished by their soft Ospreys, the $\mathrm{O}$ ws are further sub-order Striges. plumage, and by the absence of a cere or waxlike skin at the base of the bill, which is seen in almost all the true Accipitres. Owls have also a facial disk, which is surrounded by a ring of short, crisp feathers reaching from below the chin, and

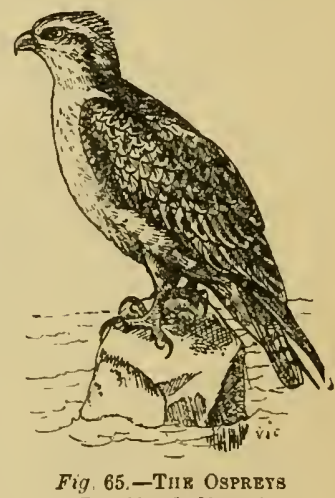

Fig 65.-THR OSPRETs (Pandion haliotus). extending above the eye to the base of the bill. The nostrils are a?so generally hidden by bristles, and the eyes are directed

The Horned and

Wood-0wls.Family Bubonide. forwards instead of sideways.

The sub-order Striges contains but two familiesBubonidce, comprising the Owls generally, and the BarnOwls (Strigidce). In these birds the hind margin of the sternum or breast-ione has two distinct clefts, and the furcula or " merry. 
thought" bone is free, and not united to the keel of the sternum. There is also no serration or pectination of the claw on the middle toe, such as is seen in the Barn-Owls.

In the Bubonude there are two sub-families-the Horned-Owls (Bubonince) and the Wood-Owls (Symina). In the former the facial disk is not so dis. tinct, and fails in intensity above the eye, whereas in the Syrniince or Wood$\mathrm{Ow}$ ls this disk is fully dereloped, and extends as far above the eye as it does below it. In the Horned-Owls, again, the ear-conch, always a striking feature in the sub-order, is smaller than the diameter of the eye itself, and is not shut in by an opercular fold. In the Wood-Owls the ear-conch is very large, exceeding the diameter of the eye, and is shut in by a very distinct opercular fold.

It is interesting to notice that we find in the Owls a group of fishing species, which remind us of the Ospreys. Like the latter birds, these Owls have spicules on their feet, and they have likewise bare tarsi, which is doubtless a convenience to the birds in The Fishing-0wls. lieu of their plunging their soft downy plumaged legs into the water ; though it must not be forgotten that some of the feathered-legged species, such as the Tawny-Owl (Syrnium aluco), and the Barn-Owl (Strix flammea), do not hesitate to catch fish on occasion. Tho members of the genus Ketupa are found in India, China, and the Malayan Peninsula and Islands. They have feathered tufts or horms on their head, and are represented in Africa by the genus Scotopelia, which has three species very similar to those of Ketupa, but without the feathered tufts on the head. Mr. Hume says that the Brown Fish-Owl of India (K. ceylonensis) feeds on birds and small Mammals, and it is also known to eat crustacea. They build a large nest on the cleft of a rock, or on a bruad shelf of a eliff, or in the hole of a tree, while sometimes they repair a nest of Pallas's Sea Eagle (Haliuetus leucoryphus), and appropriate it.

Pel's Fishing- $\mathrm{Owl}$ is a very handsome bird, discovered by Governor Pel on the Dutch Gold Coast in West Africa. He saw it sitting on a bough overhanging the Rio Boutry which he was traversing in his boat. Afterwards it was re-discovered in the Gambia, and an amusing account of this "fetish" bird is given by Culonel U'Connor, who had one alive :-"During seven

Pel's Fishing-0w1 (Scotopclia pell). years' exploration of IVestern Africa, I only met with one specimen of the Owl 'Nero.' He was brought as a chicken, full of pen-feathers, or rather down, of a delicate straw-colour, and very thick, from a lagoon in the Bawa country. No native would admit "Nero" as a visitor; and when the bird was installed in Government House, the servants and the head people came in a body to remonstrate, asserting "he was a "Gumbi Owl," a "Fettish"!!! and would destroy and kill whatever object he looked on.' The chief groom (an old soldier, who had charge of the poultry) insisted that every cock and hen would go dead. Strangely enough, an epidemic broke out, and carried off fifty to sixty head of fowls; and each day the groom placed the defunct birds on the steps of Government House to meet the eye of Mrs. O'Connor, seeming to exult in the mortality amongst the feathered tribe. "You see wid your own eye, Missus, dat debil jumbi bird, he go kill all de fowls: Governor tink he hab long head, but he no takey owl: suppose you put him in de stable, he see Nelly' (Mrs. O'Connor's favourite mare), 'de horse he go tumble down dead." Death at last ceased to reign amongst the poultry population, and Nero 
became my principal pet. He ranged over the Piazza, perching on the branch of a tree; he was fed regularly by the orderly on roasted fish, but he often came to the dimner-table and flew down for scraps of meat or breadand-butter, which he took gently from myself or Mrs. O'Connor, permitting us to rub his head, crest, neck, and back, scemingly enjoying the caressing. But he would snatch meat or bones from the cat or dog, and when the eagle was introduced into his company, he beat him in a most unmerciful manner away from his peculiar and original portion of the Piazza-the eagle being one of the fiercest and most pugnacious of African birds, brought from the upper parts of the Sabia River near 'Wallie,' and, when in vigour, able to carry away a kid or small lamb. Nero luxuriated in a tub of water, frequently washing himself and perching himself on the rim until dry. $\mathrm{He}$ was wont to go out to the garden or fields, where instantly an immense commotion arose among all the birds; the larger ones flew round the owl, keeping a very civil distance-the smaller birds flew away; but Nero treated both alike with sovereign contempt; he would return of his own accord to the roosting-place in the Piazza, and when put out and confined for some days, rejeoted all food, and pined until restored to his perch. With me he was as tame as any canary, and after an absence of two months recognised my voice when I went to his cage, at Oatlands (Devon), appearing much pleased by my taking him out for a walk on the grass. Mrany natives from the interior told me they had not seen such a bird before; but they considered him unlucky."

These are some of the largest of all the Owls, and they are found in nearly every part of the globe except Australi.t. The Eagle-Owl of Europe (Bubo bubo) is a magnificent species, with very large car-tufts, The Eagle-0wls. - and is such a powerful bird that it even kills fawns, as Genus $B u b o$. well as rabbits and hares, and is very destructive tc game. It is an inhabitant of the forests of Europe, nesting in a tree, though in some places it has been known to nest on the ledge of a cliff. The eggs, like those of all $\mathrm{Owls}$, are pure white.

The Eagle-Owl of North America (Bubo virginianus), according to Dr. A. K. Fisher, devours a good quantity of poultry, but feeds chiefly on rats, mics, and other rodents, with an occasional beetle or other insect.

These are little birds, seldom exceeding the size of a Thrush, and having the appearnce of diminutive Eagle-Owls. Like the latter they have a strongly mottled plumage and conspicuous ear-tuits.

The Tufted-0wls. They are found in nearly every part of the world, -Genus Scops. excepting in the extreme south of America and in Australia and the Pacific Islands. The species of Europe (Scops scops) is distributed over the greater part of the continent below the line of the Baltic, and is a migratory bird: it occasionally visits Great Britain.

This large Owl is of the size of the Eagle- 0 wls, and like them it has eartufts, though these are very small, and are often difficult to trace. It is distinguished by its snowy-white plumage, and is an

The Snowy-0wl. - inhabitant of the Arctic regions, both in the Old and New Nyctea nyetea.

Worlds, keeping above the limit of forest-growth and never nesting in the latter districts. It is a day-flying 0 wl, and feeds principally on mice and lemmings, but in winter, when this food fails it, the Snowy-Owl will eatch grouse, hares, ducks, and it has even been known to capture fish. It makes its nest on the ground on the tundra, 
or on a ledgo of a bauk, and it lays six or eight white eggs. Sometimes as many as $t \geq n$ are found in a nest, and they are generally laid at intervals, so that young of all sizes are to be met with, and there can be no doubt that the warmth of the downy young, which are first hatched, contributes to the hatehing of the eggs laid later on.

From its long tail and short wings, as well as from its barred undersurface, this Owl bears considerable resemblance to a Hawk, whence its popular name. The soft plumagre and the noiseless flight, however, distinguish it as an $\mathrm{O}$ w at once. It is a diurnal bird in its habits, like the Snowy-Owl, and is often seen sitting on the top of a tree on the lookout for its prey.

The Hawk-0w!

(Surma ulula).

It is also a very courageous bird, and will often attack anyone who attempts to rob its nest. The latter is placed in a tree, either in a cavity or in old nests among the branches. The eggs are white, and vary in number from four to eight. As with the Snowy-Owl, they are laid at intervals, and aru found in various stages of incubation.

In the Old World are found the group of Little Owls (Carine) and the Brown Hawk-Owls (Ninox), and these are replaced in America by the curious Burrowing-Owls. These little birds associate with the prairie-dogs, and their eggs have been found at a distance of $10 \mathrm{ft}$. from the mouth of the burrow, which is seluom made by the birds themselves. It has often been recounted how the Owls and the prairie-dogs live in harmony together, and, as Professor Elliot Coues says, "the case is further complicated by the introduction of the rattlesnakes." And no little pure bosh is in type respecting the harmonious and confidential relations imagined to subsist between the trio, which, like the "happy family" of Barnum, lead Utopian existences. He disposes of the myth as follows:"First, as to the reptiles, it may be observed that they are, like other rattlesnakes, dangerous, venomous creatures. They have no business in the burrows, and are after no good when they do enter. They wriggle into the holes partly because there is no other place for them to crawl into on the bare, flat plain, and partly in search of $O$ wl's eggs, owlets, and puppies to eat. Next, the $\mathrm{Owls}$ are simply attracted to the villages of the prairie-dogs as the most convenient places for shelter and nidification, where they find eligible, ready-made burrows, and are spared the trouble of digging for themselves. Conmunity of interest makes them gregarious to an extent unusual among rapacious birds, while the exigencies of life in the plains casts their lot with the rodents. That the Owls live at ease in the settlements and on familiar terms with their four-footed neighbours is an undoubted fact, but that they inlabit the game burrows, or have any intimate domestic relations, is quite another thing. It is no proof that the quadrupeds and the birds live together that they are so often seen to scuttle at each other's heels into the same hole when alarmed, for in such case the two simply seek the nearest shelter independently of each other. The probability is that young

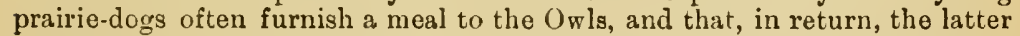
are often robbed of their eggs; while certainly the young of both and the Ow''s eggs are eaten by the snakes." The principal food of the Burrowing$\mathrm{OW}_{\mathrm{W}}$ consists of insects, and they devour large numbers of locusts and grasshoppers, though the birds also eat a great many rodents; and at times a great quantity of food has been found stored up in their burrows.

Thiese little $O$ wls are scarcely bigger than Sparrows, and none of them 
exceeds a Thrush in size. They are widely distributed in both the eastern and western hemispheres, but are absent in Australia and The 0wlets.- the Austro-Malayan and Pacific Islands. They have a Genus Glaucidium. very rounded wing, and a swollen cere like the Littlo Owls (Carine) and the other members of the Bubonince we have just been considering. Their food consists mostly of insects, and the flight of Glaucidium brodiei of the Himalayas, which is the only species I have seen alive, was very swift, and the bird appeared to be perfectly at home in daylight. The European species is the Pigmy Uwlet (Glaucidium pygmceum), and in North America, where more than one form occurs, we learn that one of the species, G. qnome, an inhabitant of the Western States as far south as the highlands of Mexico, is not only an insect-feeder, but also devours small birds and rodents, as well as lizards. It is diurnal in its habits like the little species which I saw in the Himalayas, and, like others of its kind, breeds in old Woodpecker's holes.

We have already alluded to the characters of the ear-conch and the operculum which separate the members of the sub-family Symince from those of the Bubonince. Three genera are recognised in

The Eared- and Wood-0wls - Subthe Symiunce, viz., the Horned-Owls (Asio), the Voodfamily syminime.

\section{Owls (Symium), and the Downy-Owls (Nyctala).}

The Horned, or Eared, Owls, as they are generally called, are found nearly all over the world, and our Shorteared $\mathrm{Owl}$ (Asio accipitrinus) is one of the most cosmopolitan of all birds, nesting in the north and migrating south in winter. It is one of the most useful of all the Owls, and on the occasions when Voles The Horned-0wls. have proved such a plague to agriculturists, the Short-Genus Asio. eared Owls have appeared in the stricken districts, and have devoured numbers of the mischievous rodents. It also follows the hordes of lemmings and preys upon them. It is a dayflying bird, and nests on the ground, often in small colonies. The Longeared $\mathrm{Owl}$ (Asio otus), on the contrary, is a forest-loving bird, and comes out chiefly in the gloaming and at night, when it catches ?arge numbers of mice and other small rodents. Several pairs are often found in the same neighbourhood, and in America the species has been recorded as nesting in company, the nest being generally the deserted one of a hawk or crow of some sort, with a slight lining added. It very rarely nests, like so many of the other $\mathrm{Owls}$, in hollow trees.

The Wood-Owls differ from the Horned-Owls in having no ear-tufts of feathers on the head, and in having much less of a cere than the last-named birds. The typical species is the Wood-Owl or Tawny-

The Wood-0wis. -

Genus Syrmum.
Owl of Europe (Syrnium alueco), which is entirely a woodland bird, nesting in holes of trees, in which it also passes the greater part of the day. At night it is more lively, and its hooting note is often heard throughout the night. Although generally nesting in the hollow of a tree, this $\mathrm{Owl}$ has been known to annex a WoodPigeon's nest or a squirrel's "drey," or the deserted nests of a Crow or Magpie, while a rabbit's burrow has also been known to be occupied by the Tawny-Owl. The eggs are three or four in number and are white.

Of the Downy-Owls ( Nyctala), the best known species is Tengmalm's Owl (N. tengmalmi), an inhabitant of Northern Europe and North Amcrica, and in the latter country a second species, $N$. acadica, occurs. 
These birds differ from the Bubonide in having a pectinated claw to the middle toe. The hinder margin of the sternum or breast-

The White 0wIs. bone is without notches, and the furcula or "merry-Family Straule. thought" bone is joined to the keel of the sternum. There is but one genus in the family, viz., Strix, of which our own Barn-Owl or White Owl is the type.

The present species is nearly world-wide in its distribution, but does not occur very far to the north. The Barn-Owl appears to follow man and his civilisation, doubtless from the fact that where farms are settled, rats and mice will follow. The number of mice which a Barn-Owl will consume is really wonderful, shrews and voles being also taken in great numbers; and Watertor tells us that a mouse is brought to the nest every twelve or fifteen minutes, while we ourselves have found more than forty field-mice, freshly caught, in the nest of one of these Owls. They will also catch bats in small numbers, and occasionally birds form part of their diet, but the principal food of the Owl consists of small rodents; and it may confidently be said that the Barn-Owl is one of the farmer's best friends. Dr. A. K. Fisher, in his report on the "Hawks and Owls of the United States in relation to Agricul. ture," says that he scarcely found anything but mice in the stomachs of thirty-nine Barn-Owls he examined. Four birds had been captured, as well as locusts and other insects, but the staple food

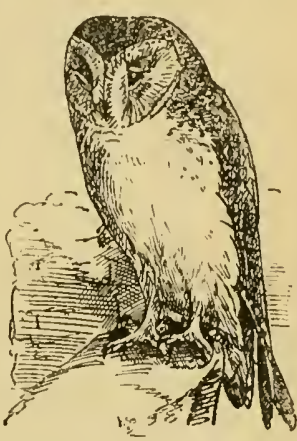

Fig. 66.-THE Barn-OwL (Strix flammea). was mice and rats. Besides the Barn.Owls, which have a mottled plumage, there aro a couple of brown-backed species, known as Grass-Owls. One inhabits Africa, and bears the name of Strix capensis, while in India and the Malay countries to Australia and the Pacific Islands, a second species ( $S$. candida) occurs. Both these birds have longer legs than the Barn-Owl, and live in the open grassy country.

We are shortly coming to the Picarian birds-the Trogons, the King-fishers, and such-like forms. Between them and the birds which wo have hitherto passed in review there would seem to be but little connection, and at first sight none but the Parrots afford a connecting link. They have been placed in all sorts of different positions in the schemes which

The Parrots.Order

Psittrevformes. have been propounded for the classification of birds, and they have been recently pushed to the end of the series by a well-known anatomist, because he did not know where olse to place them. There was reason in making them the head of all the birc.., as was done by Blyth and Bonaparte, on acconnt of their superior in ${ }^{+}$ligence, for the same reason that the monkeys were placed at the head of the Mammalia, and there was also sense in associating them with the climbing birds on account of their zygodactyle foot, with two toes directed forwards and two backwards. They have, however, certain characteristic: which isolate them from the majority of birds, and it requires a lius co cideration to determine their position in the natural system. Nowhere does their place appear better in a linear arrangement of birds than after the Accipitres and Striges, leading on to the Picarice. Like the laiter birds they nest in holes, and lay white eggs, but so 
do most of the $\mathrm{Owls}$. The Parrots liave a cere which is äistinctiy au Accipitrine character, and the $O$ wls have semi-zycodactyle foot, not very different in outward appearance from that of the Parrots. Indeed, it was one of the most curious of my experiences to see a Little $\mathrm{Owl}$ (Carine noctua) catch a black beetle and eat it. It held the beetle between its toes, exactly like a Parrot takes its food, and munched it up, holding its foot like a hand to take the insect to its mouth.

In the Parrots the palate is bridged or "desmognathous," and the upper mandible is movable and loosely articulated to the skull, while the plantar tendons are like those of the Game-Birds. The nestlings of Parrots are decidedly curious, and differ from those of $\mathrm{O}$ wls, and also of Picarian birds. They are covered with a dense coating of clown of a dusky colour, but appear to be completely naked when first hatched. The feathers are encased in sheaths, like those of Picarian birds, and these sheaths last for a considerable time, being thrown off only when the feather itself is nearly perfect, so that the young bird, from being covered with bristly spines, becomes all at once fully fectiscred.

Count Salvadori, who has monographed the Parrots in the twentieth volume of the British Museum "Catalogue of Birds," divides them into six families, the Kaka Parrots (Nestoridce), the Lories (Loriidce), the Lorikeets (Cyclopsittacidce), the Cockintoos (Cacatuidee), the true Parrots (Psittacidce), and the Owl-Parrots (Stringopidce).

In this family the tongue is fringed, and the culmen of the bill is grooved along the middle. The species are now confined to New Zealand; but Nestor productus and $N$. norfolcensis, from Philip Island The Kaka and Norfolk Island respectively, though now extinct, show Parrots. - Family that the genus extended, in former times at least, as far as Nestoridoe. the above-mentioned localities. The Nestors are forestloving birds, and the following are Sir W. Buller's notes on the habits of the Kaka:- "This is one of our highly characteristic forms, and is met with, more or less, in every part of the country. Far away in the depths of the forest, where the trees are clad with rich mosses, cryptograms, and lycopods to their very tops, where, as if to hide the mouldering decay of Nature, huge masses of green vines and creoping plants cover the aged trunks and bind the bush together-where tho sunlight. struggling through leafy tops, discloses liere and there a feathery tassel of Asplenium flaccidum hanging from the branches or a clump of the sculet-flowered mistletoe-there the Kaka is at home, and may be seen twisting and turning among the sprays, hopping Cockatoo-fashion along a branch, then climbing higher with graceful agility ; resting for a moment to whistle for his mate and, when he has joined him, expressing his pleasure in a sharp chuckling note, like tho striking together of two quartz pebbles; then, as if suspecting some treachery below, he suddenly takes wing with loud cries of ' $K$ aka,' and glides smoothly through the leafy maze, closely followed by his spouse. On a rear view the brilliant plumage under the wings is very conspicuous when the bird is flying; but when the bird is climbing or hopping, in the manner habitual to it, the wings are kept closed. Then on the outskirts of the forest you meet with him again-more generally in the early morning - hunting diligently for his insect food, or regaling himself on ripe berries of various kinds in the thick underwood; and towards evening three or more of them may be seen in company, flying high above the forest level; then alighting on the withered, naked top of some lofty 
kahikata or kauri tree-always perching on the highest points-resting a few moments, and taking wing again till they are fairly out of sight. In the early watches of the night, too, especially during the breeding season, and just before the break of dawn, its peculiar cry betrajs its wakeful restlessness."

The same author writes of the Kea Parrot (Nestor notabilis):- "When hunting for food in its wild mountain home, it may bo seen perched for a few moments on a jutting rock; then, descending to the ground to hunt for grubs and insects, or to gather the ripening seeds from certain Alpine plants, it disappears for a time and then mounts to the summit of another rock, just as I have seen the Common Raven doing in the higher parts of the Bernese Alps. On the level ground their mode of locomotion is similar to that of the Kaka, consisting of a hopping rather than a walking movement. Like that bird also, they are semi-nocturnal, exhibiting much activity after dusk and in the early dawn. The cry of the Kea, as generally heard in the early morning, has been aptly compared to the mewing of a cat; but it likewise utters a whistle, a chuckle, and a suppressed scream, scarcely distinguishable from the notes of it noisy congener. But the most interesting feature in the history of this bird is the extraordinary manner in which, under the changed conditions of the country, it has developed a carnivorous habit-manifesting it, in the first instance, by a fondness for fresh sheep-skins and other station offal, and then, as its education progressed, attacking the living sheep for the purpose of tearing and devouring the kiduey-fat, and inflicting injuries that generally prove fatal. This habit, confined at first to only a few of the more enterprising birds, soon became general, and it is a common thing now for whole parties of them to combine in this novel hunt after lire mutton! So destructive, indeed, have they become on some of the sheep-runs, that the aid of Parliament has been invoked to abate the nuisance by offering a subsidy to Kea-hunters. Before the full development of the raptorial habit described above, the penchant for raw flesh exhibited by this Parrot in its wild state was very remarkable. Those that frequented the sheep stations soon manifested a distaste for all other food and lived almost exclusively on flesh. They took possession of sheep's heads that were thrown out from the slaughter-shed, and picked them perfectly clean, leaving nothing but the bones. An eye-witness thus described this operation:- "Perching itself on the sheep's head, or other offal, the bird proceeds to tear off the skin and flesh, devouring it piecemeal, after the mamer of a Hawk, or at other times holding the object down with one foot, and with the other grasping the portion it was eating, after the ordinary fashion of Parrots."

In these Parrots the tongue is furnished with a kind of brush: and the culmen is smooth and not grooved along the middle. The Lories are birds of brilliant plumage, and since Count Salvadori's review of the family in the "Catalogue of Birds," Professor St. George Mivart has published a monograph of the Loridice, beautifully illustrated by Keulemans. Following

The Lories. Family Lornde. Salvadori's arrangement, Professor Mivart recognises fourteen genera of Lories, which are strongly represented in the Moluccan sub-region, and extend west to Celebes, and eastwards to the Australian and Pacific sub. regions. Although many of the Lories are well known as cage-birds, and the species are well represented in most museums, it is extraordinary that so little information is forthcoming as to their habits. Of several genera, 
such as Chalcopsittacus, Eos, and others, scarcely anything is known, and we have only been able to gather the following scanty notes from Professur Mivart's "Monograph" to give us some idea of the habits of the Loviidce. Of Eos rubilinosa, from the Caroline Is'ands, Dr. Otto Finsch obserres:"This Parrakeet makes itself known by its con'inued no:se, uttered both on the wing and when resting in the foliage of high trees. It is not at all a shy bird, approaching fearlessly the neighbourhood of houses and plundering the fruit trees, notwithstanding all the means taken to destroy them. They keep mostly in pairs, or in small companies of from three to five; and often, when I had shot one of a flock, the remainder would come down to their dying comrade and share the same fate."

Of the Green-tailed Lory of the Solomon Islands (Lorius chlorocercus), an account is given, by Mr. James Marler, of a pair of young birds:- "For a long time we apprehended that they would starve rather than go to the ground for their food; so I hit on the device of hanging it the wire swinging loose in the cage. To this they instantly resorted, holding it steady with one foot, and tearing it with their bills. They hang and feed in any position, holding sometimes by one foot and twisting round in every direction. Often in their play, or battles, they would simultaneously grasp claws and struggle to upset each other." In the Pacific we find the genus Vinia confined to the Navigator's Islands and the Friendly and Fanning groups. Dr. Streets gives an account of the way in which Kuhl's Lory (Vinice kuhli) is taken on Washington Island:- "When the islander wishes to take the Lories alive, he provides himself with two pieces of bamboo, each about a yard long. On the end of one he perches a tame bird, and from the extremity of the other suspends a short running nonse made of cocsa-nut fibres. The decoy bird. as it is carried about among the cocoa-nut trees, utters a harsh, rasping sound, and the wild birds fly down from the trees and alight alongside it on the bamboo-stick, when, by means of the other stick, they are skilfully noosed. When caged aboard ship, they exhibited as pretty a picture of love as one can imagine. They sat billing and smoothing each other's featbers for hours, and as night came on, two would get together, and sleep with their heads twrned towards each other. They lived in confinement but a very short time, and bore it badly. At times, even while we stood watching their lively antics, one would tumble off its perch and die, apparently in convulsions." The most numerously represented genus of the Loriidce is Trichoglossus, which is distributed over the greater part of the Australian Region, and the Papuan sub-region also presents us with a group of small pointed-tailed Lories, such as Hypocharmosyna and Orcopsittacus, some of which are not much larger than a sparrow.

Count Salvadori's next family, the Cyclopsittacidee, contains only two genera, Neopisttacres and Cyclopsittacus, from Papuasia and the Molucca I lands, as well as Australia. The bill is deeper than in the other two families noticed above, and the size of the birds is small.

In this family the under mandible has a series of ridges producing a file-like surface. They embrace at once the largest and the smallest of the Parrots, among the former being the Cockatoos, of which the Great

The Cockatoos... Family Creatrido. Blick Cockatoo (Microglossus aterrimus) is an immenseiy powerful bird, while the members of the genus Nasiterna do not possess the bulk of a sparrow. The White Cockatoos ale generally seen in this country in a state of captivity, but they form an interesting feature of wild Australian bird-life, as may be seen froin 
the following note given by Gould:- "The crops and stomachs of those killed were very muscular, and contained seeds, grain, native bread (a species of fungus), small tuberous and bulbois roots, and in most instances large stones. As may be readily imagined, this bird is not regarded with favour by the agriculturist, in whose fields of newly-sown grain and ripening maize it commits the greatest devastation; it is consequently hunted and shot down wherever it is found, a circumstance which tends much to lessen its numbers. It evinces a decided preference for the open plains and cleared lands, rather than for the dense brushes near the coast; and, except when feeding or reposing on the trees after a repast, the presence of a flock, which sometimes amounts to thousands, is certain to be indicated by their screaming notes, the discordance of which may be easily conceived by those who have heard the peculiarly loud, piercing, grating scream of the bird in captivity, always remembering the immense increase of din occasioned by the large number of birds emitting their harsh notes at the same moment; still, I considered this annoyance amply compensated for by their sprightly actions and the life their snowy forms imparted to the dense and never-varying green of the Australian forest-a feeling participated in by Sir Thomas Mitchell, who says, 'amidst the umbrageous foliage, forming dense masses of shade, the White Cockatoos sported like spirits of light.' 'The situations chosen for the purpose of nidification vary with the nature of the locality the bird inhabits; the eggs are usually deposited in the holes of trees, but they are also placed in fissures in rocks wherever they may present a convenient site; the crevices of the white cliff's bordering the Murray in South Australia, are annually resorted to for this purpose by thousands of this bird, and are said to be completely honeycombed by them. The eggs are two in number, of a pure white and rather pointed at the smaller end."

This family comprises the majority of the species of the order Psittaci. formes. They differ principally from the Cacatuidce in having the orbital ring generally incomplete, while the head is not crested as in the Cockatoos and their allies. These are small distinctions, and, as Count Salvadori has pointed out, the two families above named can scarcely be separated. In

The True

Parrots.-Family Psittacide. the family Psittacidce are comprised all the Macaws (Ara), the Conures (Conurus), the Antazons (Chrysotis), the Long-tailed Parrakeets (Palcoornis, Platycercus, etc.), as well as the true Parrots (Psittacus).

Numerous other genera, including the Love-Birds (Psittucula, Agapornis, etc.), likewise belong to this section, and one of the most curious of all is the genus Nasiterna. It consists of some little birds, less than a sparrow in size, inhabiting New Guinea and the neighbouring groups of islands. Their small size renders them difficult of observation, and little has been recorded of their habits. Baron von Rosenberg found the Pigmy Parrot of Mafoor Island in Geelvink Bay ( $N$. maforensis) nesting in holes of trees, the eggs being white, and not larger than those of the Bottle-Tit of Europe. Of the Pigmy Parrot of New Guinea (N. pygmeea) Dr. Meyer writes:- "I got this bird only near the foot of the Arfak Mountains, in New Guinea, where, at Andai, I procured specimens in the middle of the day. There this lovely little Parrot was sleeping on the lower branches of the trees, and could be whipped off with a stick. This is also the case with other Parrots which are allied to the Cacatua group. I may mention Cyclopsitta lumuata, from the Philippine Islands, the individuals of which species sleep in the middle of the hot tropical day in rows under the shade of the foliage, when one after 
another can be shot down without the survivors attempting to fly away. It may be imagined how soundly they sleep when the noise of the shot does not disturb thein; and it is the same with Nasiterna. At other times of the day it is difficult to procure, as it lives in the high trees, where its small sizc and green plumage form a sufficient protection."

Space does not permit of a full discussion of the habits and ways of all the Parrots, which are, after all, rery similar ; but, as the Grey Parrot is a typical representative of the family Psittacido, I

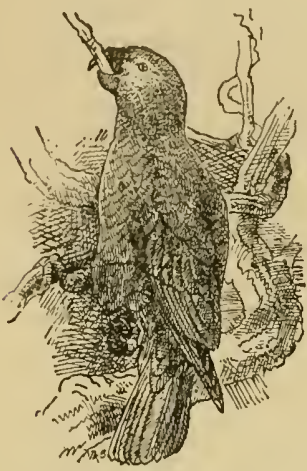

Fig. 67, -THE GREY PARROT (Psi.tacus erithacus). grive a few extracts from the account published by MIr. J. G. Keulemans, who studied the habits of the species in Prince's Island, in the Bight of Benin. In this West African island the Grey Parrot is very common, and does a great deal of mischief to the maize fields. The birds resort in great numbers to certain parts of the forest to roost. Although he ultimately discovered the nesting-place of the Parrots, it was not easy to find the actual nests, though the cries of the birds convinced him that hundreds were concealed in the dense foliage around him. His servant at last found a nest, but as darkness was coming on fast, the tree was marked for operations on the following morning. " "While thus occupied," says Mr. Keulemans, "troops of Parrots approached from different sides and settled among the trees. As for ourselves, we found capital shelter under a clump of bushes, where we concealed ourselves, and thence we observed the doings of the Parrots around us. Some were climbing and hanging on branches, others flying and scampering through the foliage. We saw them perching close to each other, and afterwards tive or six settled just above our shelter. Numbers came from all sides, and the chattering which we had previously heard at the distance was by this time close to us. There was a noise of whistling, screaming, quarrelling, and the breaking of dead branches. We saw them pass before us and settle on the trees. At this time we must have been surrounded by hundreds of Parrots. Being now almost dark, and having to pass the night in the open air, it was time to take steps to make our sojourn in the forest as comfortable as possible. A fire being the first necessity, we left our shelter in order to gather some of the dead palm-leaves that lay about. As we emerged from our corert the Parrots perceived us, and in a moment the whole place was ringing with their deafening screams. The fire was soon made, and, burning up quickly, it cast a cheerful light and warmth around the spot, rendering our bivouac more agreeable; and the Parrots, attracted by the unusual sight, kept ffying orer and around the place thus illuminated. An hour afterwards, quiet being restored, we proceeded to get our supper, consisting of roasted bananas. This being finished, we dried some moss to serve for a bed, and retired; but the night was so cold, and the inosquitos kept stinging my face so pertinaciously, that it was impossible to sleep, so I got up and roasted some more bananas, smoked a jipe, and then felt quitc ready to go in pursuit of the birds. As it wanted 
some three hours to daylight, I occupied myself in preparing lime sticks and making snares. On the appearance of the first streak of dawn, we proceeded to the tree where a nest was suspected to be. My black man, being a capital climber, went up to the hole, and looking in found two young Parrots, which he carefully tied up in a pocket liandkerchief and lowered down to me; the little things seemed to be about a fortnight old, and readily took some banana I offered them. The old birds were sbsent, probably seeking food; at least, we did not see them. The two young ones we fastened with string to the trunk of the tree, and placed some lime sticks round about them. In this way we caught one of the parent birds, the securing of which was a matter of some difficulty, owing to the resistance it made. We put the freshly caught old bird in a linen bag, and fastened it beside the young ones. In a few minutes our captive began to turn round and round, at the same time screaming vociferously; this quickly attracted the attention of the Parrots in the neighbourhood, which came near, gazing with astonishment at the bag which contrined their mysteriously hidden comrade. One, more bold than the rest, flew down and settled on a limed stick, but its struggles wero so violent that it succeeded in getting away. I then took my gun and slot two individuals, the others immediately taking flight."

The last genera of the Psittacide are the Ground Parrots (Peaporns ancl Geopsittacus) of Australia, and these lead us to the remarkable Kakapo or Owl-Parrot of New Zealand. This is a large bird, of The 0wl-Parrot. - green, moss-like plumage, which is remarkable for having Stringops - fully developed wings, but which, like other Now habroptilus.

Zealand birds, is incapable of flight. This is shown by the sternum of the bird, which has become so reduced that a keel no longer exists, and the bird can no longer fly. Of the habits of this curious Parrot, Sir Walter Buller, the historian of New Zealand birds, writes as follows:- "During the day it remains hid in holes under the roots of trees or rocks, or, very rarely, perched on the boughs of trees with a very dense, thick foliage. At these times it appears stupid from its profound sleep, and if disturbed or taken from its hole, immediately runs and tries to hide itself again, delighting, if practicable, to cover itself in a heap of soft, rlry grass. About sunset it becomes lively and animated, and playfully issues forth from its retreat, and feeds on grass, weeds, vegetables, fruits, seeds, and roots. When eating grass it rather grazes than feeds, nibbling the grass in the manner of a rabbit or wombat. It sometimes climbs trees, but generally remains upon the ground, and only uses its short wings for the purpose of aiding its progress when running, balancing itself when on a tree, or in making a short descent, half jump, half flight, from a higher to a lower bough. When feeding, if pleased with its food, it makes a continued grunting noise. It is a greedy bird, and choice in its food, showing an evident relish for anything of which it is fond. It cries repeatedly during the night, with a noise not very unlike that of the Kaka (Nestor meridionalis), but not so loud. The Kakapo is a very clever and intelligent bird; in fact, singularly so ; it contracts a strong affection for those who are kind to it, shows its affection by climbing about and rubbing itself against its friend, and is eminently a social and playful bird. Indeed, were it not for its dirty habits it would make a far better pet than other bird with which I am acquainted, for its manner of showing its attachment by playfulness and fondling is more like that of a dog than a bird. It builds in holes under trees and rocks, and lays two or three white eggs, about the size of a pullet's, in the month of 
February, and the young birds are found in March. At present (1884) the bird is known only to exist in the Middle Island of New Zsaland, on the West Coast, between Chalky Harbour and Jackson's Bay, and in the Northern Island, about the sources of the Waganui, and in part of the Taupo countries. It was, within the recollection of the old people, abundant in every part of New Zealand ; and they say it has been exterminated by the cats introduced by the Europeans, which are now found wild and in great numbers in every part of the country. They say also that the large rat introduced from Europe has done its part in the work of destruction. The natives assert that, when the breeding season is over, the Kakapo lives in societies of five or six in the same hole, that it is a provident bird, and lays up in the fine season a store of fern roots for the bad weather."

This large order contains a number of sub-orders, which will be treated of below in detail. They aro very different in outward form from each other as well as in habits and in structure, but they have one

The Picarian

Birds.-Order

Coraciiformes.

striking character in common, which separates them from the Perching birds or Passeriformes, and that is the arrangement of the deep plantar tendons of the foot. In the Picarian birds the hallux or hind toe is connected with the flexor perforans digitomem and not with the flexor longus hallucis. In all other birds an exactly opposite arrangement takes place.

These curious birds cannot be reckoned to be Nightjars, although they have the outward appearance of being members of the latter group. Their habits are crepuscular like those of the Caprimulgida, but there

The 0il-Birds.-

Sub-order

Steatornithes. are many characters which show that they are not true Nightjars, but constitute a sub-order apart. They lay white eggs, which no Nightjar ever does, the sternum has two notches on its hinder margin, and there are other osteological features which distinguish the Oil-Bird.

The colour of this singular species is reddish brown inclining to chestnut, with small triangular white spots on the head and neck, and cross-barrings of blackish on most of the upper parts, and white spots on the median wingcoverts; the under surface is pale chestnut, suffused with greyish.

The Oil-Bird (Steatornis gariepensis), or Guacharo, as it is usually called, is an inhabitant of South America, from Guiana to Venezuela and Co ombia, and thence south to Ecuador and Peru. The best account of the habits of this curious bird is that given by Mr. Jean Stolzmann, the celebrated explorer of Northern Peru. He states that the Guacharo passes "the whole lay in the caves, hiding itself in the inaccessible ledges, and if startled by a cry or by a shot they make for the roof of the cave, uttering piercing cries. A promiscuous discharge among the flying birds is usually attended with no result, as it is impossible to take aim in the darkness, and out of sixty shots which he fired in the Ninabamba grotto, the result was only eleven birds. After they become tired they return to their holes, one by one, and it is afterwards impossible to make them budge by any noise whatever. Scarcely has twilight 
set in, and while still the west is lit up by the setting sun, the Guacharos come out of their caves and fly over the forests at a considerable height, their movements being very much like those of Nightjars, but they never utter any note. They feed later on in the darkness on the fruits of Nectandra trees, and those fruits they seize while in full flight." The stones of the fruit are afterwards rejected, and Dr. Bevan Rake found large quantities of such stones on the floor of the caves in Trinidad, which he visited in order to procure some nests and young birds. The eggs are two in number, as a rule, but three and even four have been found; as before recorded, they are white. The nest is a round pile, about a foot in height, and a little more in diameter, looking like a mass of grey clay in the forn of a cheese, and when the young are about a fortnight old, they become very fat, so much so that the birds appear as if entirely hidden under a thick layer of yellow grease. It is from this peculiar development of its young that the Guacharo gets its name of "Oil-Bird." The Indians are in the labit of visiting the caves at the time when the young are sufficiently grown, and of killing the latter by humdreds, melting down the fat into earthern jars, and this fat is known by the name of guacharo-butter. Stolzmann says that the rote of the Guacharo is very disagreeable, being a loud cri-cri-coori?

These th:ck-headed birds, with their soft owl-like plumage, might well pass for relations of the Striges, and, like the latter birds, they are strictly nocturnal in their habits. They are oriental in liabitat, being found only in the Indian and Australion regions. The palate is desmognathous or bridged, and the absence of any pectination or comb-like process on the claw of the middle :oe, shows that they are not very closely allied to

The Frog-Mouths. - Sub-order. Podargi. the Nightjars, notwithstanding their external resemblance. The Podargi contain but one family, with two sub-families, Podargince and Aigothelince. In the first-named powder-down patches are present, and the nostrils are linear and hidden by bristles, while in the AEgothclince there are no powder-downs, and the nostrils are open and exposed.

The sub-family Podargince contains but two genera, Podargus and Batrachostomus.

The Frog-mouths are birds of mottled plumage, the genus Podargus being confined to Australia and the Papuan Islands. Of the habits of the Tawnyshouldered Frog-mouth (Podargus strigoides), Gould gives the following account:-_" Like the rest of the genus, this species is strictly nocturnal, sleeping throughout the day on the dead branch of a tree, in an upright position across, and never parallel to, the branch, which it so nearly resembles as scarcely to be distinguishable from it. I have occasionally seen it beneath the thick foliage of the Casuarince, and $I$ have been informed that it sometimes shelters itself in the hollow trunks of the Eucalypti, but I

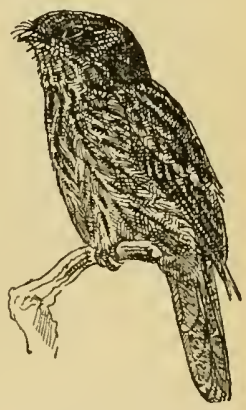

Fig. 69. - THE TAWNX. shozldered Frog-Moutu (Podargus strigoades). never could detect one in such a situation. I mostly found them in pairs, perched near each other on the branches of the gums, in situations not at all sheltered from the beams of the mid-day sun. So lethargic are its 
slumbers that it is almost impossible to arouse it, and I have frequently shot one without disturbing its mate sitting close by; it may also be knocked off by sticks or stones, and sometimes is even taken with the hand. When aroused, it flies lazily off with heavy flapping wings to a neighbouring tree, and again resumes its slumbers until the approach of evening, when it becomes as animated and active as it had been previously dull and stupid. The stomach of one I dissected induced me to believe that it does not usually capture its prey while on the wing, or subsist upon nocturnal insects alone, but that it is in the habit of creeping among the branches in search of such as are in a state of repose. The power it possesses of shifting the position of the outer toe backwards, as circumstances require, is a very singular feature, and may also tend to assist it in its progress among the branches. A bird I shot at Yarrundi, in the middle of the night, had the stomach filled with fresh-captured mantis and locusts (Phasmicice and Cicade), which seldom move at night, and the latter of which are generally resting against upright holes of the trees. In other specimens I found the remains of small coleoptera, intermingled with the fibres of the roots of what appeared to be a parasitic plant, such as would be found in decayed and hollow trees. The whole contour of the bird shows that it is not formed for extensive flight or for perforning those rapid evolutions that are necessary for the capture of its prey in the air, the wing being short and concave in comparison with those of the true aerial Nightjars, and particularly with the Australian form to which I have given the name Eurostopodus. Of its mode of nidification I can speak with confidence, having seen many pairs breeding during my rambles in the woods. It makes a slightly-constructed flat nest of sticks carelessly interwoven together, and placed at the fork of a horizontal branch of sufficient size to ensure its safety; the trees most frequently are the Eucalypti, but I have occasionally seen the nest on an apple-tree (Angophora) or a swamp-oak (Casuarina). In every instance one of the birds was sitting on the eggs and the other perched on a neighbouring bough, both invariably asleep; that the male participates in the duty of incubation I ascertained by having shot a bird on the nest, which, on dissection, proved to be a male. The eggs are generally two in number, of a beautiful inmaculate white. The night-call of this species is a loud hoarse noise, consisting of two distinct sounds which cannot be correctly described."

The Frog-mouths of the genus Batrachostomus are smaller birds, as a rule, than the Podargi, and inhabit the Indo-Malayan region. Some, like the Eared Frog-mouth of the Malay Peninsula, have long ear-tufts, and many of them have the mouth beset with long bristly hairs. The Owlet-Nightjars (Egotheles) are the sole representatives of the sub-family Agothelince. T'hey inliabit Australia and the Papuan Islands and the Moluccas. Gould describes the Australian species as being somewhat Owl-like in their carriage and in the way in which they turn their head round. They live in the holes of trees, and come out at night in pursuit of insects, flying in a straight line, and not turning and twisting about like Nightjars. They differ from the latter birds, also, in their method of sitting across, and not lengthwise, on a branch.

These curious birds form a kind of connecting link between the Rollers and the Frog-mouths, but they really constitutc one of those peculiar forms in which Madagascar abounds. The bill is something like that of a Roller, but the base is hidden by recurved plumes, while the nostril is linear, and 
is placed in the middle of the upper mandible, a quite peculiar pusitivin for that of a Picarian bird. The fourth toe is jartly reversible, a character peculiar to the Climbing Birds. The aflinity with the Frog-mouths is remote, but is shown by the possession of powder-down patches. The sexes differ in

The Kiroumbos.-Sub-Order Leptosomati. plumage, the male being glossy green above ard grey below, while the female is rufous above, with a black head, and bars on the sides of the head and back of the neck, the under-surface being fawn colour. Like tho Rollers, the Kriroumbo has a habit of playing in the air, ascending to a great height, and then descending in a curve nearly to the tops of the trees by almost closing its wings, at the same time uttering a whistle so liko that of an eagle, that Sir Edward Newton says he was some time before he could satisfy himself that the note was that of the Kiroumbo.

In these beautiful birds we find a single family, only known from the Old World, but there almost universally distributed. The palate is "desmognathous," or bridged, and the soles of the feet are flat, the toes being united together for nearly their entire length. In Madagascar three forms of Ground-Rollers

The Rollers. Sub-order Coracive. occur, constituting the sub-family Brachypterceciince, and remarkable for their long legs. Little is known of their habits; but the Pitta-like Ground-Roller (Atelomis pittoides) is known to frequent the ground, and only to pereh on the lowest branches of the trees. They liave a direct and straight flight, and jerk their tails in a curious way whenever they alight on a braneh.

The true Rollers, of which the Common Roller (Coracias garrulus) is the type, consist of two genera, Coracias and Eurystomus, forming the subfamily Coraciunce. These are birds of bright colours, and are more arboreal in liabit than the Masearene Rollers of the sub-family Brachypteraciince. Not being ground-runners, we find the metatarsus much shorter in Coracias than in the lastmentioned birds. The Rollers build in holes of trees, laying white eggs, but not making much nest, the latter consisting of a few roots, straws, or feathers. Both sexes incubate, and during the breedingseason the male ascends to a considerable height in the air, and then descends to where the nest is situated by a series of somersaults and jerks, uttering a harsh

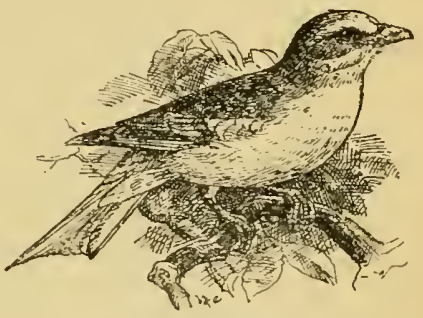

Fig. 70.-The Common-Roller (Coracixs garrulus). note, which Naumann describes as "räh-rähäh-rräh-rrì," etc., changing to "rock" as the bird throws a somersault.

The genus Coracias has a longish bill, not unlike that of a crow, and nearly all the species have bright greenish-blue on the wings and tail, which colour is very conspicuous when the birds are flying. They are found in Europe, thence to Central Asia, throughout Africa, India, and the Burmese provinces, reappearing in Celebes, where one species, $C$. temmincki, occurs.

The Broad-billed Rollers (Eurystomus) occur in Africa, India, Australia, and one species, $E$. culonyx, actually goes to Eastern Siberia during the nesting season. 
The Kingfishers agree with the Rollers in most of their anatomical characters, having a desmognathous, or "bridged," palate, and the hallux connected witl the flexor perforans digitorum

The Kingfishers, Sub-order

Halcyones.

cealed in the hole of a tree or bank, no nest being made. Dacelonince. The former contain the "fishers," and the latter the omnivorous feeders, whose food consists of crustacea, insects, reptiles, etc.

In these birds the bill is long and slender, much compressed, and with an evident keel along the culmen. There are five genera comprised in this subfamily, of which the genus Alcedo, which contains our

The Fish-Eating Kingfishers. - subfamily Alcedinune.
Common Kingtisher, is the type. There are, however, two long-tailed genera of fish-eating species, the Pied and Green Kingfishers (Ceryle) and the Stork-billed Kingfishers (Pelargopsis), which have the tail longer than the wing. The three other genera, Alcedo, Corythomis, and Alcyone, have short tails, in no case as long as the wings.

The Stork-billed Kingfishers (Pelargopsis) are large birds with long red or black bills, and they are inhabitants of the Indian and Indo-Malayan subregions. They are mainly piscivorous, but Mr. Stuart Baker records that in Cachar he has known the species of the country ( $P$. burmanica), to devour lizards and other small reptiles, while he once saw one attack a nest of young Mynas in a hole of a tree, and drag one of them out and swallow it.

The genus Ceryle is remarkable among the Kingfishers for the difference in the markings of the sexes, the male in some species having a double pectoral band, whilst in others the contrary is the case, and the

The Pied Kingfishers-

Genus Ceryle. males or the females have a band, while the opposite sex has none at all. The Pied Kingfishers are inhabitants of Africa, India, China, and Japan, and the best-known species is Ceryle rudis of Africa, over the whole of which continent it is distributed, while it ranges east as far as the Persian Gulf. The colour above is black, varied with white, and the under-surface is white, with two black bands across the chest in the male, and a single band in the female. It is a familiar bird to travellers in the Nile Valley, as it hovers above the water like a Kestrel, and falls on its prey witl a stoop like that of the latter bird. In India and China it is replaced by the Indian Pied Kingfisher (Ceryle varia), which has no black spots on the white base of the tail. In the Himalayas and the mountains of China, as far as those of the southern island of Japan, the Pied Kingfishers are represented by Ceryle lugubris, a large species with the hovering habits of $O$. rudis, and equally a fish-eater. In Africa there are also some large species of Ceryle, with grey backs, and in America a similar section of the genus is met with, of which the Ringed Kingfisher (Ceryle torquata), and the Belted Kingfisher ( $C$. alcyon), are wellknown representatives. The latter species has a pectoral band of grey in the male, while the female has an additional band of rufous. In the rest of the. South American species of Ceryle the back is greel, and in this section occurs one of the smallest of all Kingfishers, C. superciliosa, which is only 5 inches in length.

The genus Alcedo is found over the greater part of the Old World, and eleven species are known, of which Africa claims three, Europe and 
Northern Asia one, and the remaining seven are Indian aud Malayan. Our Common Kingfisher (A. ispida), is the brightest of our indigenous birds, and forms the most beautiful ornament of our rivers and lakes. It is $; !$ inches in length, with a chestnut under-surface and a brilliant cobalt-blue back, which shows vividly when the birci flies. It nests in holes, mostly in banks of sandy soil, where the tunnel is hollowed by the birds themselves, or in holes of trees, sometimes at a considerable distance from water.

In Africa and Madagascar occur the Crested Kingfishers (Corythomis), small birds with a long drooping crest, and in A ustralia and the Moluccas, the three-toed Fingfishers (Alcyone), which have the shape and fishcatching labits of our own A. ispida, but are of a dull purple colour, and have only three toes instead of four, the hind-toe being absent.

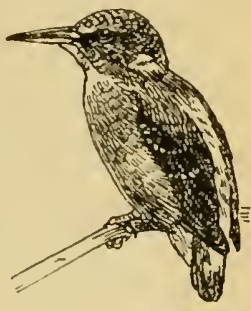

Fig. 71. Thr Cosmos LINGFISUER (Alcedo ispida).

In this sub-family the bill is shorter and wider, the tail generally long, and the food of the species consists less of tisli than of insects, small crustacea, reptiles, and even small rodents.

The first genus is Ceyx, a small form of Kingfisher which frequents forests rather than streams. The members of this genus have a wider and less compressed bill than those of Alcyone, but like the latter genus they have only three toes. They are found in India and the Malayas sub-region, being very abundant in the Philippines and extending to the Moluccas. They are mostly bright-coloured birds, some being of a

The Insectivorous Kingfi hers.Sub-tamily Intcelonina. beautiful red all over, whilst others hare a blue back and resemble species of the genus Alcedo. In Africa they are represented by a genus of tiny lingfichers (Ispidina) which are also insect-eaters, as are also the allied generi Ceycopsis of Celehes and Myioceyx of Western Africa.

From these small forms we pass to the Reptili-

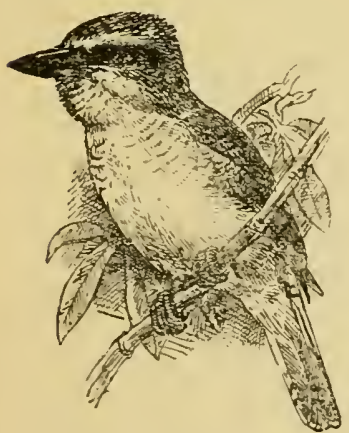

Fig. T2.-THe Latghisa lixg. FISHER

(Dacelo gigas). vorous Kingfishers, the Crested Kingfishers of Malacca and Borneo (Carcineutes), the Hookbilled Kingfisher (Melidora), and Shoe-billed Kingfisher (Clytoceyx) of New Guiana, and the Laughing Jackasses of Australia (Lacelo). Of the common Laughing Kingfisher, the "Jackass" of the Australian colonists, we have the following accomt of MIr. Gould's :- "In its disposition it is by no means shy, and when any objects are presented to its notice, such as a party traversing the bush or pitching their tent in the vicinity of its retreat, it becomes very prying and inquisitive, often perching on the dead branch of some neighbouring tree, and watching with curiosity the kindling of the fire and the preparation of the meal; its presence, however, is seldom detected until it emits its extraordinary gurgling, laughing note, which generally calls forth some exclamation according with the temper of the hearer, such as 'There is our old 
friend the Laughing Jackass,' or an epithet of a less friendly character. So remarkable are the sounds emitted by the bird that they have been noted by nearly every writer on New South Wales and its productions. Mr. Caley states that its "loud noise, somewhat like laughing, may be heard at a considerable distance, from which circumstance, and its uncouth appearance, it probably received the extraordinary appellation given to it by the settlers on their first arrival in the colony.' Captain Sturt says, "Its cry, which resembles a chorus of wild spirits, is apt to startle the traveller who may be in jeopardy, as if laughing and mocking at his misfortune;' and Mr. Bennett, in his 'Wanderings,' says, 'Its peculiar gurgling laugh, commencing in a low, and gradually rising to a high and loud tone, is often heard in all parts of the colony, the deafening noise being poured forth while the bird remsins perched upon a neighbouring tree; it rises with the dawn, when the woods re-echo with its gurgling laugh; at sunset it is again heard; and as that glorious orb sinks in the west, a last "good-night" is given in its peculiar tones to all within hearing.' It frequents every variety of situation - the luxuriant brushes along the coast, the more thinly-timbered forest, the belts of trees studding the parched plains, and the brushes of the higher ranges being alike favoured with its presence; over all these localities it is rather thinly dispersed, being nowhere very numerous. Its food, which is of a mixed character, consists exclusively of animal substances; reptiles, insects, and crabs, however, appear to be its favourite diet; it devours lizards with avidity, and it is not an unfrequent sight to see it bearing off a snake in its bill to be eaten at leisure; it also preys upon small mammalia. I recollect shooting a Great Brown Kingfisher in South Australia in order to secure a fine rat I saw hanging from its bill, and which proved to be a rare species. The Dacelo gigas breeds during the months of August and September, generally selects a hole in a large gumtree for the purpose, and deposits its beautiful pearl-white egg, which are one inch and nine lines long by one inch and five lines broad, on the decomposed wood at the bottom. When the young are hatched, it defends its breeding-place with great courage and daring, darting down upon any intruder who may attempt to ascend the tree."

The large genus Halcyon contains more than fifty species, which are found over Africa, India, and China, to Japan, and thence south to Australia, and over the greater number of the Pacific Islands. They are mostly insecteaters, and are often found far away from water. The last genus of the Kingfishers is Tanysiptera, which includes some elegant birds with only ten tail-feathers, the niddle ones being produced beyond the others, and generally ending in a spatula or racket. These are birds of the Moluccas and the Papuan Islands, one species, T. sylvia, being found in the Cape York Peninsula of North-Eastern Australia. On the habits of this species a short notice has been published by the late John Macgillivray, the original discoverer of the species:- "This pretty Tanysiptera is rather plentiful in the neighbourhood of Cape York, where it frequents the dense bruskes, and is especially fond of resorting to the small sunny openings in the woods, attracted probably by the greater abundance of insect food found in such places than elsewhere. I never saw it on the ground, and usually was first made aware of its presence by the glancing of its bright colours as it darted past with a rapid, arrow-like flight, and disappeared in an instant among the dense foliage. Its cry, which may be represented by whee-whee-uhee and 
wheet-uheet-ucheet, is usually uttered while the bird is perched on a bare, transverse branch or woody, rope-like elimber, which it uses as a look-out station, and whence it makes short dashes at any passing insect or small lizard, generally returning to the same spot. It is a shy, suspicious bird, and one well calculated to try the patience of the shooter, who may follow it in a small brush for an hour without getting a shot, unless he has as keen an eye as the native to whom I was indebted for first pointing it out to me. According to the natives, who know it by the name of 'Quatăwur,' it lays three white eggs in a hole dug by itself in one of the large ant-hills of red clay which form so remarkible a feature in the neighbourhood, some of them being as much as $10 \mathrm{ft}$. in height, with numerous buttresses and pinnacles. I believe that the bird also inhabits New Guinea; for at Redscar Bay, on the south-east side of that great island, in Long. $146^{\circ} 50^{\prime} \mathrm{F}$, a head, strung upon a necklace, was procured from the natives." We now know that the New Guinea bird is distinct, and is T. sulvedoriance.

The Hornbills are remarkable birds, not only on account of their form, but from the singular habit which every one of the species affects, so far as we know, of imprisoning the femalo while she is engaged in incubating. The Hornbills vary immensely in size, from the great Rhinoceros Hornbill (Bucerus rhinoceros), which is nearly $4 \mathrm{ft}$. long, to the tiny Lophocerus harllaubi which

The Hornbills.Sub-order Buccrotes. is only just over a foot in length. The Ground-Hornbills (Bucorix) are natives of Africa, where they are generally distributed in the Ethiopian region. They are thozoughly terrestrial birds, of black plumage, with a little red or blue decoration on the bill, or the bare portion of the throat. Walking about on the ground, they have the apnearance of black 'Turkeys, and are considered "omen "-birds among the Kaftirs. They will devour almost any food, and eat numbers of beetles, worms, small rodents, etc., and they also kill large snakes, against which they generally advance in company, holding their wings before them like a shield.

The Great Hornbil! (Dichocernsbicornis) is a native of the Western Ghauts of India and the Himalayas, and thence through the Burmese Provinces to the Malayan Peninsula to the mountains of Sumatra.

The Pied Hornbills (Authrococerus) are found in India and the Burmese Provinces to Cochin China, and south to the Malayan Peninsula to the Sunda Islands. These birds are generally found in family parties, consisting of five or six individuals. They inhabit well-wooded countries and furests, especially near rivers, where they have been known to feed on fish. Their chief food, however, consists of fruits and berries.

The habits of the Hornbills seem to be alike in their method of nidification, but in some species the act of enclosing the female is performed by the male, whereas in some instanees the female assists in her own imprisonment. Some explanation for this curious custom may be found in the circunstance that when the female has laid her egg in the hollow

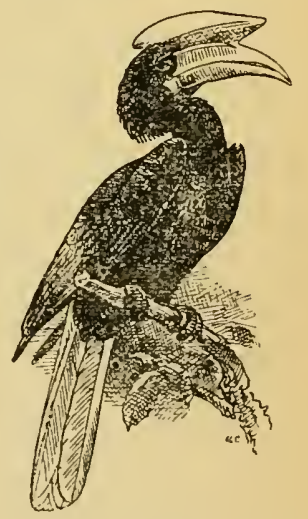

Fig. 73. - The Malabar Pied HORNBILL

(Anthracıcerus coronatus). tree, she cominences to moult, and would therefore be entirely defenceless 
and at the mercy of her enenies, if she were not fenced in, and in the closing of the fortress she herself assists. A narrow opening is left, through which the male is able to supply her with food.

At first sight there would appear to be little connection between the Hornbills and the Hoopoes, but in our brief account of the Bucerotes we were unable to illustrate all the smaller generd such as

The Hoopoes.- Lophocerus, Ocycerus, etc., which are much more like the sub-order I'pupce. Crusted Hoopoes than the larger forms of Hurnbills.

Like the latter birds, the Hoopoes have the fore-part of the sternum perforated, so as to receive the feet of the metacoracjids. There are two families of $U_{p u p c e}$ the true Hoopoes (Upupidee), and the Wood-Hoopoes (Irrisoride). The former are sandy-colouied birds, with a large crest and a square tail. The latter are black with a metallic blue or bronze gloss, and a long graduated tail.

'The Honpoe is an inhabitant of temperate Europe and Asia, being represented in certain portions of the Indian I'eninsula and the Burnese

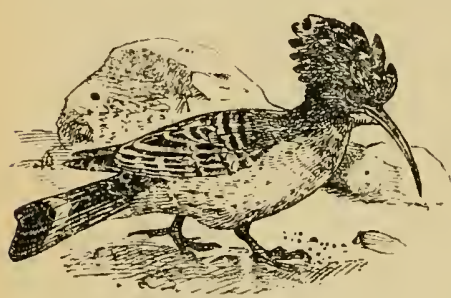

Fig. 74. -Tí Conson Hooros (Upupa epups). provinces by the Indian Hoopoe $(U$. indice). Two other species are found in Africa ouly, and one is peculiar to Madagascar. The IIoopoe nests in a hole, generally in a tree, and the female and young birds are fed by the male. 'The nest is often made of very filthy materials, but the joung do not seem to suffer, and liave the same delicate, soft plumage as the adults, which they resemble even to the possession of the crest. In North-Western India I saw the Hoopoes in suall Hocks in the open fields, and in such places they are great devourers of grubs and insects. They usually keep their crests depressed, but raise them when alarmed or excited. The note resembles the syllable hoop, uttered two or three times; and the late Consul Swinhoe states that from his observations in China, the bird produces its note by puffing out the sides of the neck and hammering on the ground at the production of each note, thus exhausting the air at the end of the series of three notes, which make up its song. 'The egors, four to seven in number, when fresh laid, are pale greenish-blue, but fade to a dull olive or yellowish-brown.

The Bee eaters are birds of bright plumage, and, as a rule, of slender form, with long tails. They resemble the King fishers and Hornbills in the form of the feet, the toes bcing juined together, the fourth

The Bee-Eaters. toe being united to the third toe as far as the last joint, sub-order. and the second toe being united to the middle one for the Ifesopes. basal joint onls. The palate is "bridged" or desmognathous, and the breast-bone has four notches in its hind margin, while the episternal process is perforated to receive the feet of the metacoracoids. The Bee-eaters are found in the temperate and tropical portions of the Old Wurld.

In Africa we find the Swallow-tailed Bee-eaters (I)icrocercus), and the Square-tailed Bee-eaters (Melittophugus), while Merops, which has the central tail-feathers elnngated, has seventeen species, which are found in Africa, India, China, the Malayail Archipelagn, and Australia, one species, 
M. "piaster, visiting Southern Europe every summer, extending even to Central Asia and Kashmir. The bird generally tummels a lole into the bank of some river, and the white eggrs are deposited in a chamber at some distance, sometimes of several feet from the opening. Oceasionally the birds have been linown to bore downwards through the sandy soil, and Mr. E. L. Layard records one instance which cimse under his own observation in Cape Colony, where the ground was " perforated with numberless holes, into which the bircls were diving and scrambling like so many lits." He found the species lrreeding on the Berg river in September and October, so that the bee-eater may be considered une of the few species which are known with certainty to nest in their winter quarters. In certain parts of Spain the bee-eater comunits great havoc amoug the bees as they fly

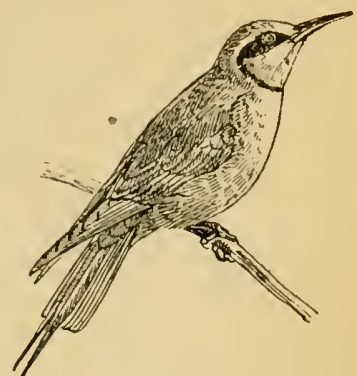

Fiy. 75. - ТUE ('WMMUN BEE-EATER (Mesopes apiuster). out of the hives, and the birr is, in consequence, detested by the peasants.

In the Indian and Malayan sub-regions occur the bearled bee-eaters, yemarkable for an ornamental tuft of plumes on the chest. One species, Meroponom forsteni, with the central tail-fenthers produced, is confined to the island of Celebes; while the genus Nyctiornis, which has a square tail, is represented by two species, $N$. athertomi, of the Himalayas, with a hlue throat, and N. cmictu, of the Malayan Peninsula, with a scallet throat. These birds are of stunter build than the rest of the bee-eaters, and are believer to nest in holes of trees.

The motnots are exelusively neo-tropical in liabitat, and contain but a single family, the Monotile. They represent to a great extent the Mero-

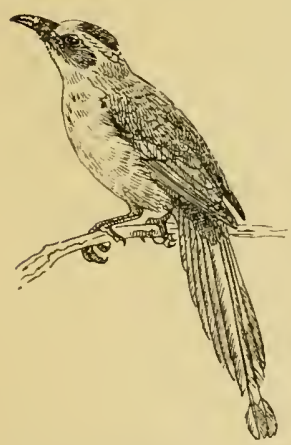

Fig. 76,-LEssox's Motsot (Momotus lpsisuri). pirlep of the Old Worth. The pialate is desmogmathous or "bridged," The Motmots.-. the sternum has four posterior notelies, and the hind-toe or halSub-order lux is always present, and is conIlomoti. neeted with the flexor perforuns diyitorm tendon. Sieven generin are recognised, Urospatha, PrioniHynchus, Eumomotu, Momotus, Bar!yphthengus, Asprithr, and Hylomenes, the last being d warf motmots, and akin to the todies (Todi).

One of the chief featmes of the motmots is the long tail, Hylomanes being the only genus with a short tail. In most of the true motmots the central tail-feathers are elougated, and generally encl in a racket, which is preceded by a bare shaft. This racket is produced by the bird itself, as it nibbles off the web of the feather with its bill, which has a serrated or saw-like edge to the mandibles. Instances have been recorded of motmots, probably young and inexperienced birds, imbued with the instinct that they liave to trim certain of their tail-feather's, bnt, as the latter grow at first all of the same length, not knowing on which rectrices to commence action. Comserquently they begin to niblole feathers to right and left, until the 
development of the two central tail-feathers beyond the rest teaches the birds that these are the two specially designed by nature to carry the "racket"!

The motmots are green birds, generally with a black patch on the crown, which is surrounded by blue; the under-side is paler, and generally of a fawn-coloured shade. They nest in holes, often tunnelling to a distance of six feet, and the eggs are laid in a rounded chamber at the end of the tunnel, as is the case with the kingfishers and bee-eaters of the Old IVorld. With the kingfishers, however, there is no nest beyond the remains of the fish-bones which are cast up by the parent hirds, whereas in the nest-hole of the motmots a few dry twigs are sometimes present. The nesting-place, according to Mr. Zeledon, is a foul-smelling habitation, in which the young remain till they are able to fly pretty well. It should be noted that young birds have the edges of the mandibles yuite smooth, and without any serrations.

The todies are also represented by a single neo-tropical fanily, the Torlide", which is peculiar to the West Indian sub-region. Only four species are known, and these are from the islands

The Todies.- of Jamaical, Cuba, San Domingo, and

sub-order Porto Rico. The long, flattened bill, Tocli. with its evident rictal bristles, suggests that of an exaggerated flycatcher, and in many of its habits a tody resembles a flycatcher, though it will at times seareh for its food like a warbler. The todies have a desmognathous palate, showing their true aftinity to the motmots and kingfishers, and they nest in holes in banks excavated by the little lirds

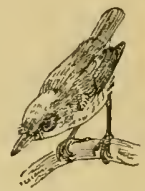

Fig. T7, - ТНE TAMAI' ToDr (Todus virirlis). themselves, though they appear likewise to avail themselves of holes and depressions already made. The eggs, like those of other picarian birds, are glossy white, and are laid on a bed of earth in a chamber at the end of the tumnel.

This is a very interesting group of birds, of which we have one representative in England, the common nightjar, or "goatsucker," as it is often foolishly called, Caprimulgus europous. In the Caprimulgi The Nightjars. - we meet with both agithognathous forms, such as CapriSub-order melgres and the allied genera, and schizognathous forms, Caprimulgi. such as Chordeiles of the New World. The presence of two types of palatine characters in one family raises grave doubts as to the value of this formation of the palate, which has been so much insisted upon by osteologists. There are eighteen genera of the sub-family Celprimulyine, and they all have the middle toe furnished with a kind of comb. They possess no powder-down patches.

Our common nightjar (Caprimulyus enroprens) is crepuscular in its habits, a bird of the twilight. During the day it rests, and only flies when suddenly disturbed ; but, as dlusk comes on, it comes forth in pursuit of insects, and is often to be seen flying by the light of the moon, soaring above with a siling flight, and occasionally producing a "clacking" noise by flapping its wings together above its head. The singular jarring noise which the creature makes seems to be its love-song, and in a heathy comntry, which is the usual habitat of the goatsucker, this "churring" utterance is heard as twilight connnences, and even far into the night.

From their mottled and soft plumage, the goatsuckers have been generally 
associated with the owls, but there is no real affinity between these motlicatching birds and the rapacious birds of the night. Their nocturnal habits are really the only character which they have in common. The young goatsuckers difler fiom those of other picarian birds in the fact that they are not hatched naked, but are covered with down, though they are not able to provide for themselves like most of the downy nestlings of other birds. The eggs, also, are not white, but are clouble-spotted, an unusual feature in picarian birds. No caprimulgine bird makes a nest, the eggs being laid upon the barle gromud.

Africa possesses two curious genera of nightjars, which, in the breedingseason at least, carry ornamental plumes. These aro Macrodipteryx longilennis of West Africa, and Cosmetornis wrillarins of Southeastern Africa. In the former genus, the ninth primary"puill is enormonsly elongated, and ends in a "racket." In c'osmetornis, the serenth and eight primaries are elongated, the ninth enormonsly, so as to produce a train when the bird is flying. Round Lake Nyassa and on the Zambesi,

The Leona Nightjar (Macrodipteryx longipennis). this bird is a well-known object as it flies over the water in the evening. I have received the following note from Miss Alice IVerner, who was connected with the Blantyre Mission. Having read some notes of mine on Cosmetomis pulblished elsewhere, whe comments on them as follows:---

"I have frequently seen the bird - at Blantyre, in Angoniland (i.e. on the Ntumbi plain, about thirty miles west of the Upper Shiré), and in the neighbourhood of Mount Milanje. The Manganja call it 'lumbe,' the Angoni 'gumbe.' I see that Sir John Kirk says that it was only from October to January that the singular prolongation of the wing feathers was observed.

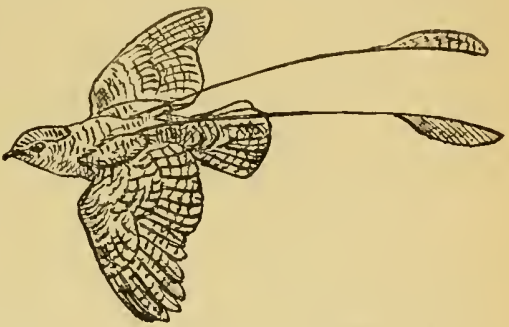

Fig. 78.-Leona Goatsucker (Macrodipteryx longipennis).

"By a note in my diary, I find that I saw one at Blantyre on September 25th. I had seen another previously to this-perhaps a fortnight before, but, unluckily, I did not make a note of it, and cannot remember the datecertuinly it was before the 25th of September, and I distinctly remember the long wing feathers on both oceasions. Seeing the bird outlined in black against the sky (just after sumset, when the light was not quite gone) I took it for a huge and grotesquely-shaped bat with an exaggerated, claw-like, prolongation at the end of the wing. I have never seen them in flocks-only singly, or, at most, one rising shortly after the other, so that they might have been a pair. While I was at Mr. John Moir's plantation of Lauderdale (at Mount Milanje) last November, one of the natives brought up to the house three young 'Lumbi' which had been found (I think) in a hollow tree. They were about the size of newly-hatched chickens, and nearly fledged-they could not fly, but raised their wings (which were of immense length in proportion to their bodies) straight above their heads, and ran along the floor very (quickly. We triel to feel them on chopped egg, soaked bread and flies, but could not keep them alive more tham a day or two. 
"I see you give no description of the feathers, but your figure gives the impression that the long wing-feathers are white, or, at least, distinctly lightcoloured. I would not be positive, but am almost sure, that in a specimen shot by Mr. E. Laidlaw Thomson at Lauderdale (which was the only one I ever had the opportunity of examining closely), these feathers were mottled black and brown like the rest of the plumage. I remember seeing two, if not three, in the bush near the Chinunka River, along the road to Fort Anderson.

"The first time I ever came across them was in Angoniland, passing through the bush in the dark. I could not see them distinctly, and at first from their noiseless flight took them to be bats, and was rather puzzled when assured that they were not bats (melemi) but birds. As far as I can remember, they always flew out of trees or hushes, and never from the ground."

In these South-American nightjars there is no pectimation of the middle claw, but powder-down patches are present on the sides of the body and on

The Mottled

Nightjars.

- Sub-family

Nyctibiinse. the breast. In this character they show an aftinity to the Podargi, and like the latter birds they lay their egg on an exposed branch or stump of a tree, as is proved by the interesting notes of Dr. Goeldi on Nyctibins jumaicensis. He observed the nesting habits of this species in the province of Rio de Janeiro, and writes as follows:-

"During certain months the smaller $N$. jamuicensis, called 'Uratío' by the natives, like all the species of the group, is heard at Colonia Alpina almost every night. Its 'pu-hu-hu' slowly pronounced, but with much encrgy, is a constant nocturmal sound, quite enough to frighten a timid wanderer in the solitary forest-patches. On the other hand, I was oftell astonished at the resemblance of the voice of the large greyish $N$. groundis to the mewing of a cat. In November, 1895 , during moonlight nights, I had occasion to hear it at Amapá regularly. The bird called continuously in the adjacent 'sirinbal' (the inundated and impassable avicenna-forests) which borders in a most. characteristic manner the lower course of the coast-rivers of Guiana. At Colonia Alpina (Rio de Janeiro) we got so well acquainted with $N$. jumaicensis: that the cry of the bird in the neighbourhood on moonlight nights was the regular signal for us to take up our guns and go forth on our nocturnal hunting-trips. The bird is easily deceived by imitating its voice. Supposing the call to be that of a rival, it leaves some inaccessible and invisible standpoint in the interior of the forest, and is drawn nearer to a post on some isolated dry gigantic tree, which, being in better light, offers more chance of a successful shot. Even here, however, its wonderful protectire colour, its singular manner of perching in the direction of the axis of the branch and appearing like a mere protuberance of it, while it retains a motionless position for a quarter of an hour or more, render it very difficult to discern, excejt to very practised eyes. My cousin, Andreas Goeldi, after long experience, is a perfect Nyctibius hunter. Notwithstanding our familiarity with the habits of the species of Nyctibins, for three years we were never lucky enongh to discorer its breeding-place, though we made all possible efforts. Before I left Colonia Alpina I strongly recommended the continuation of these efforts to my cousin, and likewise as regards Hydropsalis. At length, some months after my arrival on the Amazons, I received the agreeable news,-the discovery of an authentic nest of $N$. jomaicensis. My cousin's letter was accompanied by detailed notes and photographs, and when, in August, 1895, I made a joumey lack to Rio de Janeiro, I had, on a short visit to Colonia Alpina, the oppor- 
unity of seeing the locilities and stulying the fats, which were as follows: -On the 24 th November; 1894 , the son of one of our neighbonrs and colonists brought to us a dear male Nyctibins jamaicensis and it fresh egge, telling us that he had shot the 'Uratáo' standing upright on the top' of a stump. After having killed the bird he climbed up the stump and found, as he had supposed, that the bird had its breeding-place there. In a slight depression on the top he fomnd the egg, which he cirefully brought to my cousin, together with the bird itself. My cousin immediately went to the spot pointed out by the boy, and inquired minutely into every detail.

"The locality is on a sloping hill on the left side of a brook, tributary of the Rio Alpina, which rums through a valley parallel to that of the centre of the colomy. In 1891 and 1892 one of our colonists, now dead, had a maize flantation there, but since that time the ground has become what in Blaril is called 'eapocira,' i.e. a hill corered with shruls and small trees of about 2 inches in lieight. Along the declivity of the right side of the brook, at a clistance of about 30 metres from the latter, is a jath of communicition between the different colonial lots of the valley and the forest-slopes on both sides. The stump in guestion is abont 20 metres distant from the brook, surrounded by shrubs and easily visible from the path on the other side, and was evidently put there three years ago by the former colonist. The nenrest human residences are distant from tive to six minutes only.

"The stump, still partly covered with its original hark, lias a leight of $1 \cdot 8$ mictres above the level of the ground. Its diameter at top is 9.5 centimetres. The top has in the centre a small depression, eaused by decomposition, amel scarcely presents sutfieient room for a rather large egg. There was no trace of a softer substratum or nest material.

"The egg measures 41.5 millimètres in the longitudinal axis, and $30 \%$ millimetres in the transverse axis. Its general colour is white. On the blunt pole, however, are some very delicate pale violet spots, and regularly distributed over the whole surface, are some large ones of brownish-rufous colour resembling drops of dried blood. Neither the former nor the litter markings can be efficed by washing with spirit; they belong properly to the egg, which is of a very elegint shape."

The swifts are some of the most rapid in flight of all the birds in the world. "Greased lightning" is a term often applied by naturalists in the East to the flight of some of the speeies, notably the spine-tailed swifts of the genus Chatmu. Like some of the goatsuckels alluded to above, the palate of the swifts is agithognathous, but here the resemblance between the swifts and the Passeriformes ends. Of errurse, the most swift-like of the perching birds are the swallows, and until reeent years these birds were classiticd together, because they were long-winged, of swift flight, and had the same habit of hawking insects on the wing. In reality, however, the swallows are hicrly modified flycatchers, and lave little in common with the Cinpseli, which are more nearly related to the humming-birds of America (Trochili). Like most picarian birds, the swifts have ten tail-feathers, while the swallows have twelve. The latter have two notclies in the posterior ench of the sternum, while there are no notehes in that of the swifts, which further have a very high keel, indicating that they are birds of extremely developed powers of flight. The proportions of the wing-homes are likewise rery different in the two groups, being directly opposite to each other, for, whereas in the swifts 
the humerus is very short, the forearm longer, and the manus extremely long, in the swallows the relative proportions are exactly the contrary.

Mr. Ernst Hartert, the latest exponent of the Cypseli, divides the single family which the sub-order contains, the Cypselide, into three sub-families, Cypseline or true swifts, Chaturiure ur spine-tailed swifts, and erested swifts (Macropterygime). From the recent researches of Mr. F. A. Lueas, it seems that the last-named birds are very distinet from the true swifts, and probably constitute a distinct family, their singular mode of nidification, ri the placing of their egg in a diminutive nest on a branch or a stump, being very similar to that observed in the frogmouths (Podargi) and the Nyctibiince (antec, p. 344). Mr. Hartert characterises the sub-fanily Cypselince, which contains the true swifts, by the form of their toes, the onter and middle toes having only three phalanges, while the metatarsus is distinctly feathered. In one species, the pied swift of Central Ameriea (Aeronautes melanoleucus), the toes are also covered with plumes. The genus Microme, of which our eommon swift ( $M$. apus) is the type, has all the toes directed forward, but in the jalm swifts (Tachomis and Claudia) the toes are arranged in pair's.

The common swift is migratory, like most of the family, arriving in Europe early in May, and being one of the first of our summer birds to disappear to its winter quarters in Africa. The mode of flight in a swift is more like that

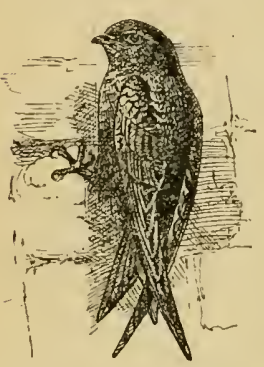

Fig. 79.-THE Common SwIFT (Micropus apus). of a bat than that of a birrl, especially in the gloaming, when the swifts chase each other at an incredible speed, uttering shrill sereams. The rapidity of their flight far exceeds that of any swallow. About sixteen species of the grenus Micropms are known.

The sub-family Clueturiure consists of the spinetailed swifts and the edible swiftlets. In these birds the toes are normal, and the metatarsus is not feathered. The spine-tailed swifts (Chatura) are found in both hemispheres, and have the shafts of the tail.feathers produced into a point or spine. Some of them are birds of considerable size. the needletailed swift (Chetura condacuta), which has occasionally been seen in England, measuring nenrly a foot in length to the end of its long wings, which in this group of swifts always protrude beyond the tail.

It nests in Siberia, and migrates to Australia in the winter.

'The swifts of the genus Collocalia are tiny birds, which inhabit the Indian and Anstralian regions. Some fourteen speeies are known. The birds build in caves, aftixing, to the walls of the limestone, cup-shaped

The Edible

Swiftlets.Genus

Collocalia. nests, which are formed principally of the bird's own saliva, though in some species there is some moss mixed up in the nests, while others are almost entirely made of moss. These "moss" nests, however, are of $n$ o commercial value, while the pure white nests are sold for making soup to the Chinese.

The tree-swifts are beautiful birds, often ormamented with a large crest or with long white whiskers. They have the metatarsus bare, and it is shorter than the middle toe, whereas in the Chaturime the tarsus is as long as the middle toe, or even longer, and there are two formuna in the hinder margin of the sternum, whereas in the other sub-families of swifts there are no such notches. There is but a single genus, Mueropteryx, with five species, 
and the most singular feature about the tree-swifts is their mode of nesting. Nearly twenty year's agro, Sir Hugl Low's native collector brought to him in Labuan a tree-swift's nest, which he said he had found lying under the bird's body when he slot it. The nest was of abrut The Tree Swifts. the size of half-a-erown, and contained one white egg, which had been broken in the fall. From what we know now of the nesting of the genus Macropteryx, it is eviclent that in - Sub-family

Macroptery. the above instance the shot must have carried away the top gine. of the stump on which the nest had been placed, as Mr. Hume has presented to the British Museum a sinilar nest obtained by Mr. K. Thompson, who found one in India. Mr. Hume says :- "The stem to which the nest was attached is about 0.8 inch in diameter ; against the sirle of this the nest is glued, so that the upper margin of the nest is on an level with the upper surface of the branch. The nest itself is laalf of a rather deep sancer, 175 inches in diameter, and about $0 \cdot 6$ inch in clepth internally. The nest is entirely composed of thin thakes of bark, cemented together by the bird's saliva, and is about an eighth of an inch in thickness." Only one white egg seems to be laid.

The humming-birts are exclusively a New World group. The species described up to the present time are nearly 500 in number, and among them are found some of the tiniest birds in the world, some of them not being larger than a bumble-bee. The bulk of the species are from South and Central America, a few only reaching $t$ o the southern United States, and only a small number migrating north in summer to Canada, and even as far as Alaska.

The Humming.

Birds.Sub-order Trochili.

The plumage of the humming birds is usually of a brilliantly metallic nature, and they are admitted to be some of the most beautiful and interesting of all birds. Their elassification is extremely difficult, for the character's blend from one genus into another, until it is almost impossible to say where the series should begin and where it should end. So much so is this the case, that Mr. Osbert Salvin, when he wrote the sixteenth volume of the British Museum "Catalogue of Birds," was for'ced, for want of more definite characters, to divide the humming-birds into three sections, those with a welldefined saw-like edge near the margin of the tip of the upper mandible, those with this serration faintly marked, and those without any serration at all.

It is impossible in the space at our disposal to pass in review all the genera and species of humming-birds, for they are of every size, shape, and variety of metallic plunage. The largest of all is the giant humming-bird (Patagonce yigas), from the Andes of Ecuador to Chili. This bird measures abont $8 \frac{1}{2}$ inches in length, whereas some of the smallest species, such as Culy/gte helence of Cuba, and Chretocercus bombus of Ecuador, only measure 21 inches.

The tongue in this order of birds is very peculiar, and its structure is only equallesh by that of the woodpeckers (Pici) and sun-birls (Nectariniid('). The structure is thus described by Sir William Flower in the "Bird-Gallery" of the British Museum :- "The tongue is slender, and very long and extensile. As in the woodpeckers, the two branches of the hyoid bone which support its base, eurve, when the tongue is dlawn within the bill, upwards around the back of the skull, and then forward over the top of the head. Instead of the tongue being, as in the woodpeekers, solid and ending in a barbed horny point, it is hollow, and divided at the free end into two slender branches, each of which hears a thin membranous fringe on its outer margin."

The wings of the humming-birds are strong, and the primaries are ten in 
number, while the secondaries are only six. The first primary-quill is sometimes attenuated (Athis, Agleactis, etc.), while in some grenera, such as Compylopterus, the shafts of the primaries are broad and stiffened. The tail

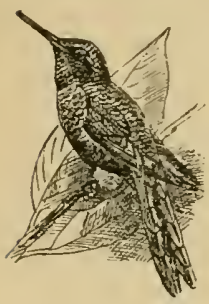

Fil. s0.-1 is of various shapes, sometimes square, sonetimes rounded, (1), as in the grenus Phrethormis, graduated, with the two central rectrices elongated and pointed. Many genela liave forked tails, with the outer tail-fonther elongated, espeeially in the male. The racket-tailed humning-lirds hive a forked tail, with the outer rectrix ending in a spatule $\mathrm{Or}^{\circ}$ racket. In some genera, like the shear-tails (Thomustrur) or the stars (Chrtocemus), all the tail-feathers are pointed ancl spine-like, and in the king humming-birds (Toparre, the central feathers are elongated and curved, crossing each other at the same time. 'The most remarkalle, however, of all the humming-bircts, as regards its tail, is Lotdigesir mivebilis from the Upper Amazons. In the female and young male, ten rectrices are present as usual, but in the alult male there are only four, a rery small pair in the middle, and an elongated pair (m the outside, which cross each other" and eud in a "hoss" or "lacket." Some of the upper tail-eorerts are so lenerthened that they appenr to be part of the tail. The thight of hmmming-binds is more like that of a hawk-moth than that of an actual bircl, for the little creatures hovel in front of a Hower, suspended, as it were. in the air, with theil wings vibrating so rapidly as to appear simply like a film. Their food consists of the tiniest insects, and in the case of the sword-bill hummer (Docimustes ensifrus) the hill is elongated to an enornums proportion, so that the bird is able to probe long tubular Howers for its foocl. The nest of the humming-birds is always beautiful, and is generally composed of the clown of plants, felted, and covered with spider's' webs or soft lichens. It is generally round, but is occasionally purse-shaped, and is placed on a branch or at the end of a leaf. The egos are white, and two in number.

The colies form a separate sub-order, which contains but a single grenus. Colins, with nine species, all peculiar to Africa. 'J here are only ten tailfeathers, and the hind-tos is

The Colies.- comnected with the fleror jersub-order Colii. forms digitomm tendon. The bill is something like that of a finch, and the bircis have a slight crest. The palate is bridgred or desmognathous, and the sternum has four notches on the posterior margin. The position of the colies in the class Ares has been much debated, and it seems to us that their place in the natural system must always be open to some comment, but they must be placed somewhere near the trogoms and the touracues.

The colies have curious feet, all the four toes being dirceted forward, the first one being perhap's reversible ; the bircts use their feet for climbing, and they hang in peculiar positions. They make an open nest, of grass and twigs, lined intermally with soft grass, placed in a fork of in tree, and the egross are white. 
The trugons are all birds of bright phumage, even the hens having brilliant colours in many of the species. They are often called Heterorlactyli on account of their peculiar feet, which constitute the ehief structural feature of the order. The palate is sclizognathous The Trogons. or slit, and the second toe is turned backwards. The front order Trogones. plantar tenclon (flexor perforents digitormm) is split into two, and leads to the two front toes, while the hind plantar (flcxorlongos hallucis) is agrain split, and leads to the two hind toes. The plumage of the trogons is of the softest description, and the skin is so thin that we have often heard travellers say that it has no more substanee than tissue-paper, and every one admits that trogons are the most difficult birds in the world to prepare.

At the present day the order is distributed over Africa, a great part of India and the Malayan sub-region, but they are most numerous in Central and Sonthern America. In ancient times they oeeurred in Franee, as fossil remains have been found there along with those of touracoes and secretary-birds.

One of the most splendid of birds is the long-trained trogon or quezal, which has been arlopted by the republic of Guatemala as its national emblem, and figures on the postage stamps of that comntry. It has a tail of eight inches in length, but the upper tail-coverts are enormously developed, the central ones extending into a train four times as long as the actual tail itself. The quezal is found in Guatemala and Costa Rica, but is not so plentiful as formerly; it is entirely a bird of the forests, and has a rapid Hight. Mr. Stolzmann noticed the Peruvian quezal clinging to the trunks of trees like a woodpecker.

The American trogons (Troyon) are ehiefly fruit-eaters, like the African species of Hapalolerma. They are entirely forest bircis, and are said to be rather stupid, not even flying away at the report of a gun, so that a whole party may be shot down one after the other. They are generally seen in pairs, but occasionally assemble in small flocks. The note is variously described as being harsh, or clucking, as well as soft and low. Of the Peruvian species, Trogon caligatus, Mr. Stolzmamn gives the note as "cou-cou-coucon-co-co-co-co," the second half being uttered in a lower tone than the first. The Indian trogons (Harpactes) are more insect-feeders than their American allies. The eggs of trogons are white or pale-buff (that of the quezal being said to be greenish-blue), three or four in number, and deposited on the dry wood in the hole of a tree.

Two sub-orders are represented in this order, riz. the cuckoos (Cuculi) and the touracoes

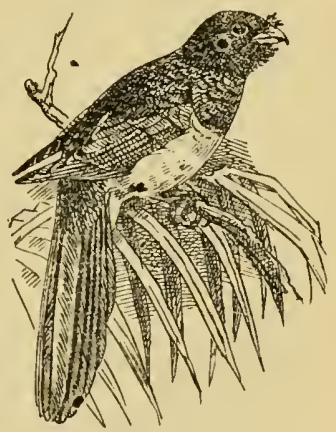

Fiy. S2.-The LaRge-TaIted Trocon (Trogon mucrurus). (Musophugi), the former being a cosmopolitan group, and the latter being contined to Africa, though there is evidence that in aneient times touracoes inhabited Europe, as fossil remains of these birds have been found in France. The cuckoos and the touracoes have the following characters in common, which differentiate the Coccyges from all other orders of hirds. The first and fourth toe are turned backwards, and the second and

The Cuckoo-

like Birds. -

Order

Coccyges. thiri forwards, the hallux being always developed, and served by the flexor 
longus hallucis tendon, and not by the flexor perforans digitorum. The palate is "bridged" or desmognathous. In the cuckoos the oil-gland is nude, and the feet thoroughly zygodactyle, with two toes directed forwards and two backwards, whereas in the Musophayidee or touracoes the fourth toe is not so completely turned backwards as in the Cuculicle, and the foot is therefore termed semi-zygodactyle.

The C'uculidee are divided by Captain Shelley into six sub-families, of which the first contains the true cuckoos or Cuculince. In these birds the tail is composed of ten feathers, the upper tail-coverts are not unduly prolonged, the wing is long and pointed, showing that most of the species are migrants, therein differing from the wing in the bush-cuckoos, which has a rounded and concave wing, indicating that they are not birds of strong fliglit.

In this sub-family are found the crested cuckoos (Coccystes), the typical cuckoos (Cruculus), the hawk-cuckoos (Hierucoccyx), the golden cuckoos (Chrysococcyx), the American cuckoos (Coccyzus), the koels (Eudynamis), the channel-bills (Scythrops), and several other genera. In the genus Coccystes we find the first instance of the curious parasitic nature of the cuckoos, but in the case of the great spotted cuckon (Coccystes glandarius) there is not the same remarkable variation in the colour of the egg that we find in the common cuckoo (Cuculus canomes). On the contrary, the egg of $C$. glandarins is very crow-like, and it is deposited in the nests of crows and magpies. The Indian crested cuckoo (C. jucobinus) lays blue eggs, and places them in the nests of birds which also lay blue eggs, such as babbling-thrushes, etc.

Ten species of true cuckoo are known, and the type of the genus Cuculus is our common cuckoo (Cuculus canomus). The genus is distributed over the whole of the Old World, excepting in the Pacific

The True Islands.

Cuckoos. - In a concise work like the present there is not space to Genus Cuculus. give in detail the habits of a bird like the cuckoo, whose life-history would require a volume to itself. It will be, however, known to most of my readers that the female cuckoo makes no nest of its own, but deposits its egg in the nest of some other bird, and leaves to the latter the task of hatching the eggs and bringing up the young cuckoo. The latter, while still blind and naked, ejects the other little occupants of the nest, and receives thereafter the undivided attention of the foster-parents.

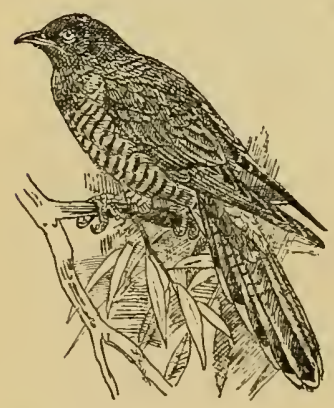

Fig. 83.-The Common Cuckoo (Cuculus canorus).
The latter are of many kinds, flycatchers, warblers, finches, etc., preference, however, being given to the warblers and pipits and other insectivorous birds. In the Western Palrearctic region alone the egg of $C$. canomis has been found in nests of 120 different species, and another curious fact in connection with the economy of the species is that the cuckoo's egg is remarkably small for the size of the bird, and is, in many cases, almost an exact copy of the egg of the foster-parent. Each female cuckoo is believed to lay the same type of egg during its life, so that a bird which lays blue eggs, to be inserted in the nest of a blueegged species like the redstart or pied flycatcher, always lays blue eggs. The cuckoo ranges all over Europe and Northern Asia, and winters "n Africa, India, and Austrialia. 
Many genera of the Cuculine have a good deal of metallic colour about them, and the golden cuckoos of Africa and India, with their emerald-green and purple plumage, are aninong the most beautiful of all birds. In America, the black-billed cuckoo (Coccysus erythrophthalmus) and the yellow-billed cuckoo (C. americanus) build their own nests, and are most affectionate parents.

In the Centropoline, the hind-claw is straight, and like that of a lark. There is but one genus, Centroprs, which is distributed over the Ethiopian, Indian, and Australian regions, and no less than thirty-two species are known. They have a hooting note, like "whoot- The Lark-heeled whoot," and on the Gold Coast the species is known as the "Scotchman." In India, Mr. Hume says that $C$. sinensis follows up the hooting note by "knrook-kwrook-kmookCuckoos. Sub-family kinook," after an interval of a few seconds. It makes a Centropodince. nest in thick thorny bushes or trees, about six inches in height and twelve inches across, composed of grass or twigs, and in the form of an oblate spheroid; it is too small for the size of the bird, so that the tail of the latter is generally seen sticking out.

The bush cuckoos have a rounderl and concave wing like the lark-heels, but want the spur-like claw of the latter birds. In this sub-family are found the rain-cuckoos (Sumothera, Hyetornis, Piaya, etc.) of America, the steel-blue cuckoos (Ceuthmochares) of Africa, the bush-cuckoos (Phcenicophres, Rhinococcyx, etc.) of the Indian region, and the comas of Madagascar. The members of this sub-family build their own nests and lay white eggs. They are mostly bush-haunting birds and thread their way through the jungle and the trees with great facility.

The most round-winged of the bush-cuckous are the members of the genus Neomorphus, which represents the sub-family Neomorphince. Only three other genera are contained in the latter, Carpococeyx, with the pheasantcuckoo of Borneo (C. rudicitus), and the road-runners (Geococeyx and Morococeys) of the New World. The species of Neomorphus are all neo-tropical, being found in the southern countries of Central America and the tropical portions of South America. Five species are known, all of which are very rare, and nothing has been recorded of their habits.

The Diplopterince, which constitute the fifth sub-family of cuckoos, are entirely American and are remarkable for the extreme length of their upper tail-corerts, and the sixth sub-family, the Crotophugince, is also American. In the latter there are only eight tail-feathers, instead of ten, and some of the Savana cuckoos (Crotophagra) have very curious habits, several females apparently laying in the same nest, so that sometimes as many as twenty eggs have been found in one nest. The egg, too, is very peculiar in the Crotophagince, as it appears at first sight to be blue covered with white scratchings and marblings, but the true colour of the egg is white, and the blue is only an orerlying colour, which gets rubbed and scratched off through contact with the lining of the nest.

In appearance these birds are very different from cuckoos, and their semizygodactyle foot has alleady been alluded to (p. 350). They are forest-birds, confined to Africa, where nearly thirty species have been described. In ancient times they appear to have inhabited France, as fossil remains have been discovered in that comntry. Some of the species are crested

The Touracoes.Family Musopharjide. 
and of a dull coloration, but the majority are brilliantly plumaged birds, and are generally called "Lowries" by the colonists of South Africa.

In the true touracoes (Turacus) the nostrils are hidden by bristles; in all the other genera they are exposed. In the genus Musophaga, of which $M$. rossce, from Angola and the Congo basin, is an example, there is not conly an ornamental frontal slield of red, but the primary quills are of a deep crimson, as they are in all the members of the genus Turacus. From the wing-feathers of these birds has been extracted a kind of copper called turacine. The nest of the touracoes is in open one, made of sticks, and the egg is white.

In all the Scansores the foot is typ,ically zygodactyle, the first and fourth toes being turned backwards, the second and third

The climbing forwards, and the arrangement of Birds.-Order the plantar tendons is as curious. Scansores. The flexor perforans digitorum tendon leads to the third digit only, while the flexor longus hallucis first sends a tendon to the other plantar tendon, and a second to the fourth digit, after which (if the hallux be present) it splits into two tendons, one leading to the hallux,

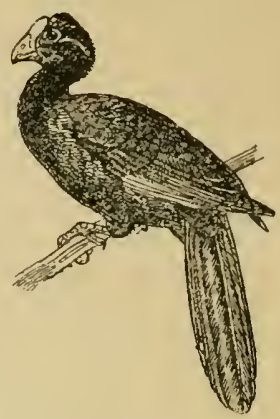

Fig. 84.-LADY Runi TOURACOE (Musophaga rossu). the other to the second digit.

Of the three sub-orders of the Scansores the toucans are exclusively neotropical. They are very plentifully represented in Central and South America, and are remarkable for their long, generally parti-

The Toucans. Sub-order Rhamphasticles. coloured bill, and for their curious feathery tongue. The palate is desmognathous or "bridged," and the vomer truncated.

The toucans are about sixty in number, and are contained in five genera, Rhamphastos, Andigena, Pteroglossus, Seleniderc, and Aulacorhamplues. The long bill, which at first sight appears so clumsy and awkward, is really a very light structure, full of empty cellules, and the colours of the bill are usually those of the adjoining bare skin of the face. The birds inhabit the forests and feed on fruit, and are often found in company. Though they have a scansorial foot, they do not climb like woodpecker's, but proceed by great hops, like the hornbills, from branch to branch.

The barbets are small birds with zygodactyle feet, which are found in the neo-tropical, Ethiopian and Indian regions, but do not extend The Barbets. - into the Australian region, nor are Sub-order Capitones. they found in the temperate regions of the Northern Zone of either hemisphere. Some have a bridged palate, but others have the palate rgithognathous or passerine. The vomer is bifid, the oil-gland tufted,

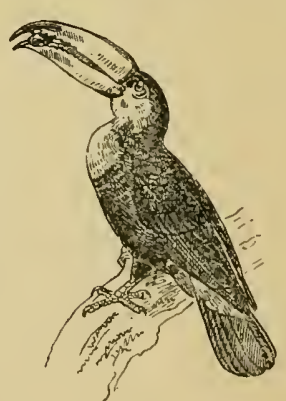

Fig. 85.-The Toco Toucan (Ramphastos toco). and there are other internal characters which separate them from the rest of 
the climbing birds. They feed chiefly on fruit, but many species are insectivornus, and their curious monotonous notes have gained for them the

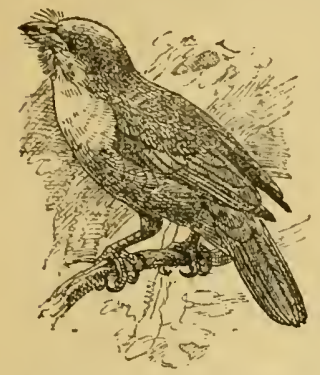

Fig. 86.-THE GOLDEN-GREEN BARBET (Capito aurovirens). names of "Tinker or Coppersmitl," the little Indian species (Xantholama hemacephala) nodding its head sideways as it utters its metallic call. Like woodpeckers they bore a hole in a tree, and lay their eggs, which are white, on the chips of woor. Of the Peruvian species of Cupito, Stolzmann says that he has found them in small parties on high trees, feeding on fruits in company with toucans, chatterer's, and other birds.

The honey-guides have an interesting distribution over the earth's surface. They are mostly confined to Africa, but one species occurs in the Himalayas, and another in the mountains of Malacea and Borneo. The palate is agithognathous, and the bill is not unlike that of a finch. The colouring of the birds is

\section{The Honey-} Guides.Sub-order Indicatores. generally sombre, though some African species have white lower backs and the Indian honey-guide (I. xunthonotus) has a yellow back: The name of "honey-guide" is derived from the fact that several of the African species will lead men to a bee's nest, sitting on the trees and uttering a piping note. If followed, they will fly on

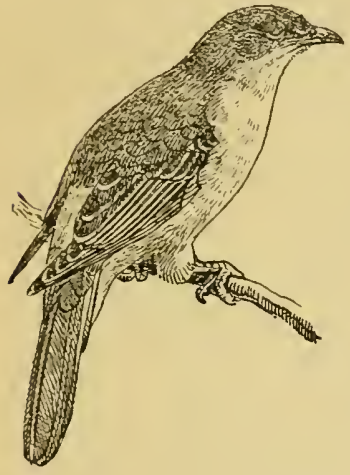

Fig. 87.-The Great Honer. Guide (Indicator). in advance a little way, and, as a rule, the bird is rewarded with a little piece of the comb, from which it extracts the grubs. The food of all the species, as far as is known, consists of hymenoptera.

The Piciformes resemble the Scansores in having the plantar tendons peculiar in their arrangement as already described by Seebohm. The flexor perfor- The Woodpeckerans digitorum leads to the third digit only. The flexor longus like Birds.Order hallucis first sends a tendon to Piciformes. the cother plantar, then a second to the fourth digit, after which (if the hallux be present) it splits into two tendons, one leading to the hallux, the other to the second digit.

In the woodpeckers the palate is peculiar, and has been termed "saurognathous" by the late Professor W. Kitchen Parker, the vomer being slender, pointed, and split, the lateral halves separate. The bill is formed for the hammering of trees, which these birds are famous for, and is, in the majority of woodpeckers, strong and

The

Woodpeckers. sub-order Pici. chisel-shaped, though weaker and more curved in the groundfeeding species. The tongue is very peculiar, for here we meet with a similar arrangement to that noticed in the humming-birds (cuter, p. 347). The tongue is long and worm-like, and is capable of being protruded to an enormous length by means of the hyoid bones, the cornua of which extend backwards 
over the skull. The tongue is furnished with a pointed, horny, barbed tip. This arrangement, so far as is known, obtains in all woodpeckers excepting Sphyropicus and Xcnopicus.

The late Mr. Edward Hargitt divided the family Picide, at which he laboured unceasingly for fourteen ycars, into three sub-fimilies, woodpeckers (Picince), piculets (Picumninke), and wrynecks (Iymgince). The latter birds have a soft and mottled plumage like that of a nightjar. They have a long tail, the feathers of which are soft and not pointed like those of the woodpeckers. Three species are resident in Africa, but our common wryneck (I. torquilla) is a migrant to Europe and Northern Asia, wintering in Africa, India, and Southern China.

The piculets are tiny little birds without the stiffened tail of the woodpecker, but otherwise resembling them in the form of the bill and the bristles around the nostrils. In the neo-tropical region the piculets

The Piculets.-

Sub-family

Picuminine. are represented by the genus Picrmmus with thirty-five species, and Nesoctites with a single species, their place being taken in Africa by the genus Vcrearxia with one species, $V$. africana, and in the Himalayas and throughout the IndoMalayan region by the genus Sasia, which has only three tues. Both the last-named genera have a bare orbital patch romd the eye.

Of the habits of the species of Picumuns very little has been recorded, but Stolzmann says that in Peru he has seen them on the borriers of the rivers, tapping the small branches of the trees, and running along the horizontal limbs, sometimes above the branch, sometimes below.

All the true woodpeckers have the tail spiny, with the shafts of the tailfeathers stiffened. They may be divided into two groups, the featherednecked section and the narrow-mecked section. In the first

The True Wood- section are found the ground woodpeckers (Gcocolaptes), the peckers.-

Sub-family Picince. yellow-winged woodpeckers (Colaptes), and all such forms as the green woodpeckers (Gccimus) and their allies, the pied woodpeckers (Dendrocopus), the three-toed woodpecker's (Picoides), and, in fact, the bulk of the sub-family. The narrow-necked woodpeckers are principally tropical, but they inhabit both the Old and the New Worlds, being, however, much more plentiful in the former, and they are represented in Europe by the great black woodpecker (Picus martins).

The distribution of the woodpeckers is interesting from the following fact, that they are universally distributed over North and South America, the whole of Africa, Europe and Asia, until we approach "Wallace's Line" in the Moluccas, and there we find that a few species extend beyond the limits of the Indo-Malayan sub-region, into Flores and Celebes. In fact, the woodpeckers coincide in distribution with the monkeys, and do not extend beyond the last-naned island.

In habits they are singularly alike, excavating holes in trees, which they drill with the utmost precision and with such accuracy that the hole appears as if it had been made by the most skilled of carpenters. No

Woodpeckers. nest is made, and the white eggs are deposited on the chips of wood at the end of the hole, which is often of considerable depth. The note of our green woodpecker, or yaffle, is a resounding laugh, while the pied woodpeckers call to each other by a series of taps on the slender boughs of the tallest trees, their ordinary note being harsh and unmusical. 
In interesting genus of the seetion of narrow-neeked woolpeekers is seen in Thriponux, which is found in the Indian region, and extends through the

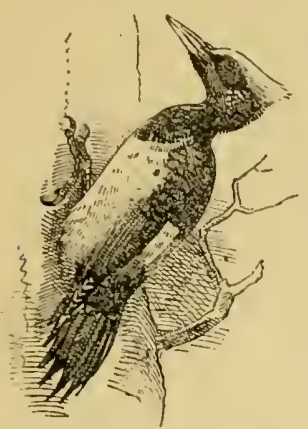

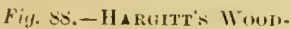
PECKEL: (Thriphute hargitti). Indo-Malayan sub-region and the Burmese provinces to the Philippines on the one hand, and to south India and the Andanan islands on the otler. 'Then the genus, of which Hargitt's woulpecker is une of the most typical species (fig. 88), reappears in Corea and the Japanese islands of 'l'su-shima, thus proving that in the Eastern Hemispliere the same introcluction of tropical forms mexpectedly oecurs in the paliearetic area as it does in the Western Hemispliere.

The puff-bivds are neotropical, and are only found in Central and South Ameriea. 'They differ from the woodpeckers in liaving a rude oil-gland and in the possession of eiecr, and their pterylogriphy is different. The palate is bridged

The Puff-Birds. -Sub-order Buccones. or desmognathous, and a vomer is present. The feet are rygodaetyle, and the flexor perforans aligitornm tendon leads to the third digrit only, the other plantar tendon serving the three other toes, as in the woodpeeker's. Tho bill is stout and eurved, and in the grems Bucco is hooked at the end, the base being well furnished with rietal bristles. The plumage of the puft-birds is mostly of a sombre chanacter.

Forty-three species of puff-bind are known, divided by Dr. Sclater into seven genera, Bucon with twenty species, Malucoptilu with seven, Micromomacha with one, Nonmule with tive, Mulecoptila with

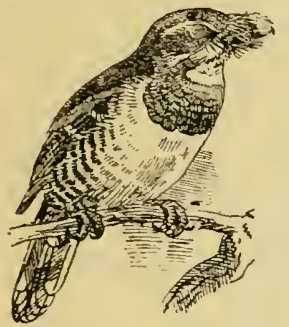

Fiy. S9. -THE GREATER

Pied PUFF-BiRD

(Bucco mecrorhynchus). one, Monacher with seven, and Chelidoptera with two. The accounts of the habits of these birds represent them to be sluggrish and apathetic; they inhabit the forests and feed (u inseets, after which they Hy from their perch, apparently in a mammer similar to that of a bee-eater or a tyeatcher. Very few notes have been published on their habits or nesting, but the egrs are believed to be white, and deposited in the holes of hollow trees.

The jacamar's are a small family of neo-tropical birds, mostly of metallic plumage, resembling the puff-birds in much of their internal structure and their zygodactyle feet. The bill, however, is not heavy, as in the latter birds, but is long, slender and pointed, and they

\section{The Jacamars. \\ -Family \\ Calbulidir.} usually liave a lonig and pointed tail.

'The jacamars feed on insects, which they dart after from a perch, like a Hyeatcher. Jacamerops aurea is said to be easually met with as solitary individuals or in pairs, preferring trees on the banks of streans to more open places in the forest. Here they wateh for passing insects, which they cateh on the wing, and return to their position. They often remain almost motionless for loours without stirring a feather. The jacamars are said to tunnel a small hole in a bank and to lay white and nearly round egrss. Of the blackchecked jacamar (Gulbulu meluroggeniu) more has been published about the 
habits, and we learn from Messrs. Salvin and (todman in their "Biologia"

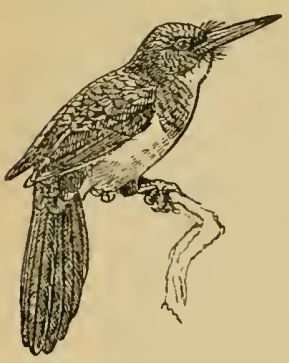

Fig. 90.-Тне WнитеBELLIED JACAYAR

(iralbula leuroga stra.) that it is a solitary bird, frequenting deep ravines overhung with trees; it has a quick, darting flight, utters no cry, and feeds on insects. Mr. Richmond says that, on the Escondido River in Nicaragua, he noticed the bird jerking its tail like a kingfisher, and he describes the cry as piercing, and resembling the syllables "keé-u," with the first syllable very shrill and strongly accentuated.

Before commencing the account of the true perching birds or Passeriformes, there remain two orders which have generally been placed with the latter, but which, in our opinion, should be kept distinct. These are the hroad-bills (Eurylcemi) and the lyrebirds (IIenur(e).

The broad-bills are only found in the Himalayan region in India, whence they extend through the Burmese provinces to the Malayin peninsula and islands to Bormen and the Philippines. They have a passerine or regithognathous palate, but The Broad-Bills. the structure of the deep plantar tendons is strikingly different -order from those of the typical passerine foot, as the flexor lougus hul-

Eurylemi. lucis tendon sends out a strong band or "rincrlum" to join the tendon of the flexor profundus digitornm. The trachea is also peculiar, and the sternum has no forked manubrial process. In the first subfamily of the Eurylemider. Dr. Sclater places but one genus, Culyptomeu, which is distinguished by the frontal plumes covering the nostrils. It contains but three species, which are, however, the finest of the broatd-bills. Their principal colour is emerald-green, varied with velvety black, and $C$. whitchendi from Kina balu Mountain in Northern Borneo, is the largest of the family, meatsuring nearly a foot in length. It builds a good-sized nest, according to Mr. John Whitehein, who discovered this splentid species, which it "suspends from the end of a slender bough about fifty feet from the ground. The wutside is composed of fresh green moss bound over the buugh, and worked into the sides, ending in a long streamer, which assists in assimilating the nest to the long dripping strcamers of mess and

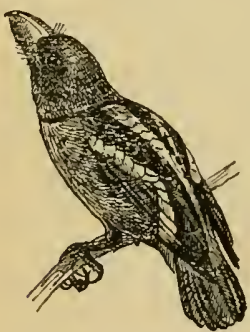

Fig. 91.-HoRsField's BROADEILL

(Eurylemus javanicus). lichens which hang from every bough in this continual rainy season. The inside of the nest is very solid, lined with dry bamboo-leaves above and below, forming a well-sheltered pocket. The egrgs are glossy creamy-white." A second species of Chlyptomem, 1 : hosii, a green bird with a blue breast, has been discovered in the mountains of Savawak by Mr. Charles Hose, while the small species, C. viridis, is found everywher'c in the low country throughout the Malayan peninsula and islands.

Of the Eurylcemine, which have bare nostrils, there are six genera, Pscrisomits with one species, Serilophus with two, Sarcopharops with two, Eurylcemus with two, Corydon with one, and Cymborhynchus with two. Psarisomus dalhousice of the Eastern Himalayas and the hills of Assam and Burma is a very handsome bird, being green, witl a black head and a blue patch on the erown. Another fine species is Hors: 
field's broadbill (E. jaranicus), which is found in Java and the Malayan islands and peninsula as far north as Tenasserim. The food of the broadbills appenrs to consist of insects, but occasionally of small reptiles. They are inhabitants of the forests, and are said to be sluggish and somewhat stupid birds. The nests are suspended from the boughs of trees, and are of a purselike shape, being composed of fibre and grass. Unlike the eggs of Cillyptomena, those of the true broadbills are spotted with black or brownish-red on at cream-coloured ground.

The lyre-hirds liave always been considered aberrant passerine birds, but they camnot in any way, according to our icleas, be associated with the Pessiviformes, on account of their curious nesting-liabits and downy nestling. In addition to this, the lyre-birds have other anatomical features, which separate them from the true perching birds, and we believe that our separation of the Arenure as a clistinct order will be followed by future systematists, as the young lyre-bird looks more like the nestling of a petrel than that of any other bird, aurl such a nestling plumage is mknown in any species of pisserine bird, the yomg of which are mostly hateled maked. The arlult lyic-bird is a very remarkable creatmre. It has legs like those of a megaporle, and altugether looks more like a (iame-lird than anything else, but it must he looker upon, we think, as a kind of gigantic wren, thongh in effect it is, like so many of the Australasian birrls, a form by itself. We have heard it suggested that the lyre-birds are allied to the birds of paradise, but the only warranty for such a proposition is that the plumage of the tail in Memere is fantastic, as is the decorative plunage of the birds of paradise. Three species of Menuru are known, all peculiar to the continent of Australia. They are very shy birds, inhabiting the brush comntry, and living solitary or in pairs. The food consists of insects, chiefly beetles and centipedes, uccasionally varied with snails. Their strong feet give them the power of making enormous leaps, and Gould states that they will jump from the ground to a bough ten feet above it. The nest of the lyre-bird is domed like that of a wren; it is of large size, formerl of sticks, and lined with feathers, and it has

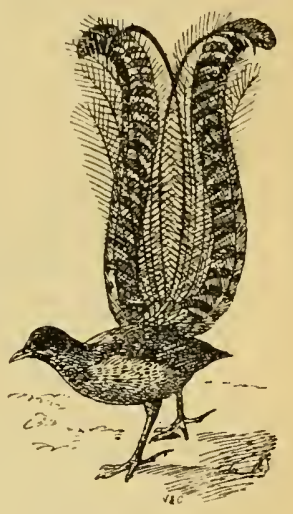

Fiq. 9?.-THe LVIE bIR, (Ment. "superlur). a kind of outer rough corering, composed of sticks, moss, and leaves. Only one egg is laid, of a purplish-grey colour, spotted and blotehed with purplish brown.

The principal character which distinguishes the Pusseres or perching-birds is the form of the palate, which is iegithognathous or passerine, with the vomer truncated in front. The hind toe is always present, and is comnected with the flexor longus hallucis tendon and not with the flexor perfoncuss digitorrm. The bulk of the Pusseriformes belong to the division Acromyodi, in which the intrinsic muscles of the syrinx are fixed to the ends of the

The Perching. Birds.-Order Passeriformes. bronchial semi-rings. Muclu discussion has taken place between ornithologists as to which is the highest form of birl, and many are inclined to think that preference should be given to the thrushes and warblers, on account of 
their powers of song, just as the monkeys are placed at the head of the Manmalia on account of their man-like aspect; but in vur opinion, the crows (Corvilte) are at the head of the Presseriformes, being, with the exception of their rant of song, the most perfectly rleveloped of birds. The wing of a crow exhibits in its fullest perfection the power of flight, every wing-covert and quill being shown in the most complete development. The same is seen in the feet of a crow, where all the scales on the tarsi and toes are more strongly indicated than in any other passerine bird.

The colour of the crows is black or decidedly sombre, as a rule, only relieved by brighter plumage in the case of the magpies (Picu), jays (Gurvlus), and the beautiful blue jays of America (Cyano-

The Crows. - corcer, X(nutherru), etc. All these forms belong to the true

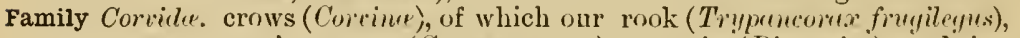
carrion crow (Corone corme), magpie (Pirel picie), and jay (Girulus glendurins) are typical examples. They all have the nostrils placed high in the mandible, whereas the choughs (sub-family F'regiliurr) have the nostril placed low in the mandible, nearer to its lower margin than to its upper one. In the Fregilinu we find four genera: Gruculns, with our own red-billed chough (G. grreculus), Pyrhocorex, with its single species, $P$. pyrrhocor $a x$, the Alpine chough, and Corcorax, with a single A ustralian species, the white-winged chough ( $(!$ melnemhemphurs). The most interesting of this

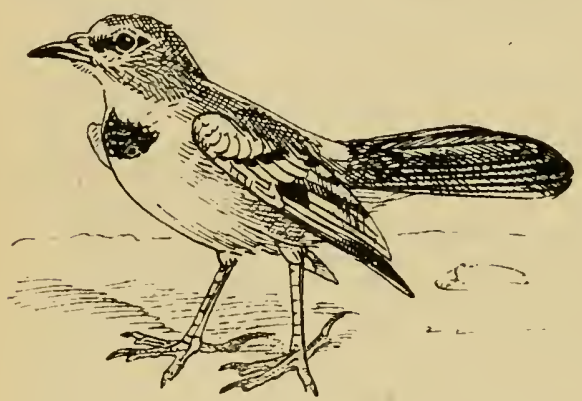

Fig. 93.-Paxders Denert-('houtin Poloces panderi). group of birts, lowever, are the ilesert-choughs (Podcres). Of these there are four species, all confined to the desert regions of Central Asia from Bucliara to Turkestan and Thibet. They are sandy-coloured bircls, like most deserthaunting creatures, bnt with brighter heads and wings: $P$. muderi from Buchara was the first species of the genus to be described, but nothing has been recorded of its habits. $P$. hemlersoni from Yarkand is better known, and Dr. Hender'son says that they always kept in pairs, and moved about from one sand-hill to another, seemingly searching for insects in the sand. The stomachs, however, were filled with grim, picked out of the horse-dung in the road. The eggs of $P$. panderi are like those of crows, but one species, P. humilis, lays white egros.

The crows are all ambulatores or walkers, but there is no proof that the birds of paradise progress by walking steps, when on the ground. On the contrary, the Parmliseidre are entirely forest birds. They

The Birds of

Paradise. -

Family

Paradiseidle. differ from the true crows in the structure of the feet, the outer toe being longer than the inner one but shorter than the middle one. Their fantastic plumage is their chief characteristic, lout the nest and eggs are corvine, and the paraclise birds are really nothing but gaudy-coloured crows. 
They include the rifle-birds (Ptilorhis), and other sickle-billed forms like the twelve-wired birds of paradise (Scleucides) ant the superb birds of paradise (Epimachus). In all the sickle-billed species, composing the sub-family Epimachince, the bill is long and eurved, and exceeds the tarsus in length. In Ptilorh is the plumage is relvety black, with a metallic head and a metallic green shield on the breast. The nest of Queen Victoria's ritle-bird ( $P$. vic' tori( $\left.{ }^{\prime}\right)$ is described as a loosely constructed structure of dead leaves and green branchlets, the egrss being of a Hesh-colour, with streaks and spots of reddish-brown. The rifle-birds are found in Australia and New Guinea.

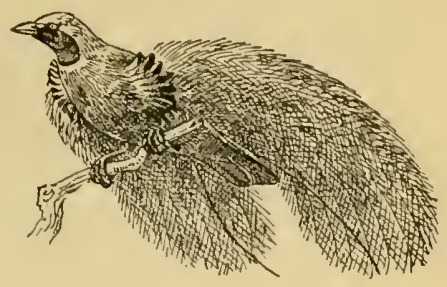

Fi!̨. 94.-The Red-pluma Bird of P.iradise (Puradisca raggiana).

The Papuan Islands and the Moluccas are also the home of the true birls of paradise, which compose the sub-family Puradiseince, which have a stouter hill, with the culmen not so long as the tarsus. Some eighteen genera are to be found in this sub-fimily, ineluding not only the true paradise-birds, but many others of varied form and decorated plumage. They inhabit the forest country at different altitudes, and in some localities, such as the Aru Islands, they are very abundant, the insensate fashion of decorating laclies' hats with the plumes of these lovely birds having, wonderful to relate, not yet succeded in exterminating them. They feed chiefly on fruit.

The bower birds are undoubtedly elosely allied to the birds of paradise, and it is difticult to say where one family ends and the other begins. Such forms as the golden bird of paradise (Xunthomelus unreus) have been placed with the Purculiseide, but this genus and TheBower Birds. its allies are probably bower-builders, and it is certain that some of the allied forms, like Prionodura nevtoniume and Amblyomis inometr, undoubtedly construct large

-Family

Ptilororpyit. chidle. bowers.

The satin bower-bird of Australia (Ptilonorhynchus holosericeus) builds an arched bower of sticks, decorated with snail-shells, bleached bones of small mammals, and the bright feathers of parakeets. But one of the most extraordinary of all these fantastic bowers is that erected by the gardener bird of North-IVestern New Guinea. Dr. Beccari, who discovered the bower of this species in the Arfak Mountains, describes it as follows:- "The Amblyomis selects a flat even place round the trumk of a small tree, which is as thick and as high as a walking-stick of middle size. It begins by constructing at the base of the tree a kind of cone, chiefly of moss, of the size of a man's hand. The trunk of the tree becomes the central pillar, and the whole building is supported by it. On the top of the central pillar twigs are then methodically placed in a radiating manner, resting on the ground, leaving an aperture for the entrance. Thus is obtained a conical and very regular hut. When the work is completed, many other branches are placed transversely in various ways, to make the whole quite firm and imperneable. A circular gallery is left between the walls and the central cone. The whole is nearly three feet in diameter. All the stems used by the Amblyornis are the thin stems of an orchid (Dendrobium), an epiphyte 
forming large tufts on the mossy branches of great trees, easily bent like straw, and generally about twenty inehes long. The stalks had the leaves, which are small and straight, still fresle and living on them-which leads me to conclude that this plant was seleeted by the bird to prevent rotting and mould in the building, since it keeps alive for a long time, as is so often the case with epiphytieal orchids. Before the cottage there is a meadow of moss. This is brought to the spot and kept free from grass, stones, or anything which would offend the eye. On this green turf, flowers and fruit of a pretty colour are placed so as to form an elegant little garden. The greater part of the decoration is collected round the entrance to the nest; and it would appear that the husband offers there his daily gifts to his wife. The objects are very various, but always of a vivid colour."

The starlings are a widely distributed group, peculiar to the Old World. Our common starling (Stumus vulgaris) is an exceedingly plentiful bird in England, where it stays all the year, receiving an additional

The Starlings. host of migrants in the autumn and winter. Like the -Family crows, the starlings are walking, not hopping, birds like Sturnidce. sparrows and finches. They differ from the crows, however, in having a streaked nestling, and they have no rictal bristles. Besides the members of the genus Stumus, which contains the true starlings of Europe and Asia, and of which our own starling is the representative, the family embraces many allied

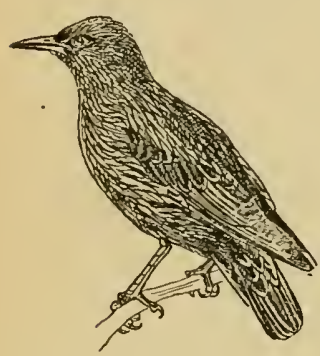

Fig. 95.-The Common StaR. LiNG (Sturnus vulgaris). genera, ehiefly Asiatie, such as the field-starlings and mynas (Sturnice and Temenuchus), and the rose-coloured pastor (Pustor roseus). The latter is an extraordinary bird, on account of its niditication. It appears in certain distriets of SouthEastern Europe in vast swarms, hurriedly rears its young, and departs again with such rapidity that its absence has hardly been noticed from its winter quarters. The starlings have the first primary very short, and have on that account been assoeiated with the swallows and wagtails, but with these families they have nothing to do. Their eggs are always bluish or white, and the nest is a rough structure, plaeed in a hole of a tree or wall. The starlings are principally insect-feeders, and they do an immense anount of good to the agrieulturist, though it must be admitted that at certain times they commit some depredation among the fruit.

This family is for the most part Indian and Moluccan, but there are several African and Australian forms. It contains the wattled grakles (Enlabes) of the Indian region, the glossy starlings of The Tree star. Africa (Lamprocolius), and the genus Calormis of the Indian lings.-Family and Australian regions. These birds are arboreal in Eulabetide. their habits, and differ from the true starlings in having distinct rietal bristles, and in laying spotted eggs. In Madagascar the Eulabetidce are represented by the genus Euryceros, a chestnut bird with a huge bill of a blue colour. Only one speeies, $E$. prevosti, is known.

The Dicruride are black crow-like flycatchers, inhabiting Afriea, India, 
and China, south throughout the Malayan Archipelago to Australia. They sit on exposed branches of trees,

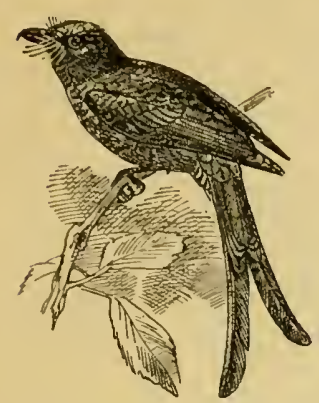

Fig. 96.-The Black Droxio (Buchunga atre). whence they fly out and capture insects. Their nest is a cradle suspended between the fork of a

The Drongos. -Family Dicruride. branch, and the eggs are whitish, with red markings. In nearly all the species the tail is very plainly forked, especially in Buchaneya, and in some genera, such as the Himalayan Chibiu, the outer feathers are curved upwards. Some of the drongos, such as Dissemurus and Bhriugu, have the outer tail-feathers greatly prolonged, and ending in a racket.

The orioles are an Old IVorld family of birds, the plumage being of a bright yellow or orange colour, though some of the Molucean and Australian forms, such as Mimeta, are dingy enough in colour, and resemble honey-suckers (Mcliphugider). The orioles build a nest like the drongos, a cup-slaped cratle between the fork of a branch.

The Orioles.--
Family
Oriolide.

The golden oriole winters in Afriea, and comes to Suthem and Central Europe in the spring. It not only visits tle British Islands

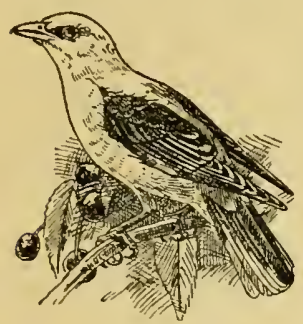

Fig. 97.--The Golden Orrole (Oriolus galbula). pretty frequently, but has certainly bred there. The note of all the orioles is very rich and flutelike, and their habits are arboreal, their food consisting of insects and fruit. The young birds are streaked below, showing an affinity to the starlings; and the eggs are white, with black spots.

These birds are usually called orioles by American naturalists, chiefly on account of their black and yellow eolour, which recalls the plumage of the crioles of the Old The Hang-Nests. World. They are, however, structurally distinct, and differ in their habits. The family contains many

-Family well-known genera, such as the bobolink (Delichonyx orysitora) and the cow - birds (Molothrus), those curious parasitic creatures of which Mr. WV. H. Hudson gives such an interesting account in the "A rgentine Ornithology." He gives cletails of the way in which the Argentine cow-bird (M. bonariensis) victimises many other small birds by placing its egggs in their nests; and he also tells us that when the young cow-bird is hatched, the other occupants of the nest soon disappear, though whether this massacre is the result of interference on the part of the old birds, or is the work of the nestling cow-bird itself, as with our common euckoo, his not yet been proved.

Another well-known member of the family is the red-winged hangnest (Agelcens phanicens), popularly known amongst us as the redwinged starling, and the meadow starlings (Stumellu) also belong to the family.

The true hang-nests or troupials of the genus Icterns are widely spread over the New World. The chief element in their coloration is a bright yellow 
or orange, but they differ from the orioles of the Old World, with which they are often confused, by having only nine primaries. Nearly 140 species of Icteride are known, and some specics of the genus Cassidix appear, from the recent observations of Mr. A. Schulz, to be parasitic on each other, for Dr. Kuschel of Breslau informs us that Cussidix on!rinoms deposits its eggs in the nest of ('. persicus. The meadow-larks (Sturnellı) are ground birds, as their name implies.

Intermediate between the liang-nests and the finches come the weaver-birds. Although they resemble the finches in their food and in

The WeaverBirds.-Family Plocrider. many of their habits, they mostly build domed and langing nests like the $I^{\prime}$ terider.

Weavers are found in all parts of Tropical Africa and Madagascar, as well as in India and Burma, as far south as the Malayan Peninsula. The weaver-finches, which are an integral portion of the family Ploceide, consist of the wax-bills, such as Estrildu, Lagonostictu, Prephila, etc., are found in the Australian

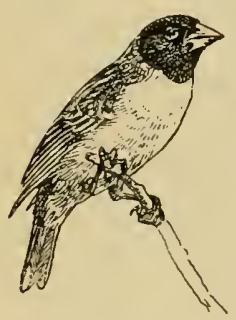

Fi! 99. - T'HE BLAr'k. HFAIEI, WEAVER-BIRD (Hyplanturnis melunoerphulus). region, as well as all over Tropical Africa and throughout the Indian region. The weaver-birds build a substantial nest, purse-like in sluape, often with a long stocking-like entrance. Is the nests are grenerally suspended from the ends of palm-branches, or from trees which overhang the water, it is supposed that this stcoking-like appendage is added to the nest to prevent the attacks of monkeys or suakes, both of which are encmies of the young weaver-birds. The weavers have no pretensions to singing powers, and can only keep up an incessant chattering, which does duty for a song. When kept in captivity, and supplied with dried grass for weaving, a baya weaver (Ploceus lu(y) will make a nest in a cage, and the industry of the birds is simply remarkable. The eggs of weaverbircls vary to a great extent, being pure white, or bluish or greenish, with deeper markings of the same colours.

Thesc are brilliautly-coloured birds of the Now World, resembling finches

The Tanagers. Family

Tanagridie. in appearance, but distinguished by liaving a notch in the upler mandible. They are very numerous in the nootropical region, and several species visit North Anierica in summer.

'These curious little birds are allied to the Thuagridu, but have nevertheless

The American

Creepers.-

Family

Cierebida. the habits of the creepers, and their creeper-like eggs, white with red spots, point to an alliance with the tree-creepers (Certhiida). The principal genera of the family are Cesthiola and Crevebr, the latter containing the well-known bluecreeper (Corebu cyuneu). 
From these families which lie on the borderland of the finches, we pass to the family Fringillide. The latter family is one of the largest in the whole series of the Pusseriformes. It is almost universal in its distribution, and comprises three sub-families: the grosbeaks (Coccothmustinu), the true finches (Fringillime), and

The Finches.Family Fringillicler. the buntings (Emberinime).

In these hirds, of which our common haw finch (Cocothrustes cocothrunstes) is the type, the hill is large and swollen, and the nasal boues are produced backwards beyond the front line of the bony orbit. There are no less than twenty-three genera of grosbeaks, and they are represented in nearly every quarter of the globe. The northern forms are coccothrustes in the Old WVorld, and Corcothranstine. Ligurinus, of which our common grecnfineh (Liguriuus chloris) is the type. In North Amerien Herlymeles is the prevailing form, while in the Himalayas we have Mycerobus and Pyenorhomphus. The smaller. grosbeaks are principally neo-tropical, and are represented by the genera śpermophilu, and in the Galapagos Islands by Geospiare and Cremerh!nchus. The cardinal grosbeaks (C'rdimulis) are inhabitants of the Southern Enited States as far as British Honduras in Central Amerien, and speeies of the genus are also found in Venezuela and Trinidar.

This family embraces all the best known of the finclies. The type may be said to be our eommon eliaftinch (Fringilla culebs), but all the linnets, siskins, goldfinches, and other familiar birds are part and pareel of this sub-family. The bill is less massive than in the grosheaks, and the upper mandible is not produced backwarts

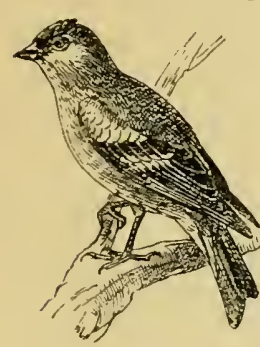

Fig. 100,-Tиғ: Снан. Fixe'h (Frimeilla caltbs).

beyond the front line of the orbit;

The Finches.-Sub-family

Fringilinu. otherwise the angle of the genys is much the same as in the grosbeaks.

The finclies constitute a very numerous sul)-family, and many benutiful birds are embraced within its limits. Besicies our own European forms mentioned above, there are many interesting tropical genera, such as the rose-finches (Carpoducus), which are found in North America, as well as in Northern Europe and Asia, being especially abundant in the Hinulayas. The sparrows all belong to this group of finches, as well as the eanaries, which are principally Afriean, and the saffion-finclies (Siyculis) of South Ameriea, the bullfinches (P!minla) aud the erossbills (Loxire).

In the buntings there is grenerally a gap between tlie two mandibles, and the angle of the lower mandible is much more acute than in the finches and grosbeaks. The buntings are grain and insect-eating birds, often of bright colours, and distributed over the greater jart of the globe, excepting the Australian and Polynesian regions. In most of the buntings, as with the finches, there is a complete winter plumage, and the summer dress is Emberisinue. gained, not by a thorongh inoult, but by a shedding of the edges of the winter feather's, so that the underlying pattern eomes into prominence. One of the best examples of this phenomenon is the snow-bunting (Plectrophenax nicalis), which arrives in England in the winter in a rufescent dress. The summer plumage is graclually assuned by the shedding of the pale edges to the feathers; the black tips to the primary coverts disaplear by abrasion, and the 
white bases of the primaries extend by degrees, as the rufous colour of the upper parts is gradually shed,

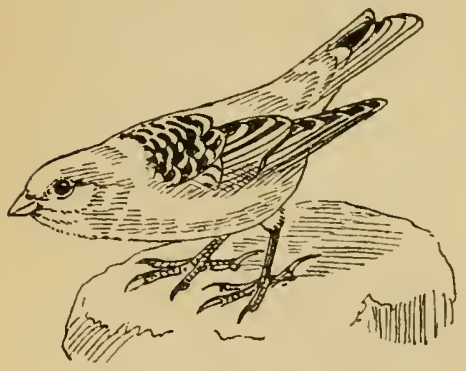

Fig. 101.-The Snow-Buntina (Mectrophenat nivulis). allowing the underlying black and white plumage to predominate, so that the summer dress of the snow-bunting is pure black and white.

Besides the genus Emberiza, which contains our yellow-hammer (E.citrinella), cirl-bunting $(E$. cirlus), and ortolan (E. hortuluma), the buntings likewise embrace the com-bunting (Miliaria miliaria), the Laplind bunting (Culcarius lapponicus), and a large number of American genera ( $/$ onotrichia, Poospiza, Junco, Spizella, Ammodronus, Melospiza, Hamophila, Pipilo, Spize, Psendochloris, Phry!gilus, Prioriviu, etc.).

Larks are chiefly denizens of the Old World, though North America claims a number of species of horned-larks (Otocory/s), which represent a circumpolar

The Larks. - in Northern Europe and Northern Asia, as well as in North

Family America. In America the holned larks are more numerous,

Alaudide. and even extend into Colombia in South America. The Alutdide are distinguished from all other passerine birds by the scutellations on the hinder side of the tarsi (plunta tarsi). They are especially numerous in Africa, and also in the plains of India, the dominant genus Mirufire extending to the Malayan Islands and even to Australia. The sky-larks, of which our own familiar species, Aluudu arensis, is the best known representative, are chiefly paliearctic, though similar species occur in the Indian region. The larks are, without exception, ground-builders, and the eggs are generally dark brown, or whitish, with brown mottlings and speckles. Some twenty genera are known, among which are the desert larks (Certhilutuda), remarkable for their long curved bill, the calandra larks (Melonocomplic), the short-toed larks (Culundrelli), the crested

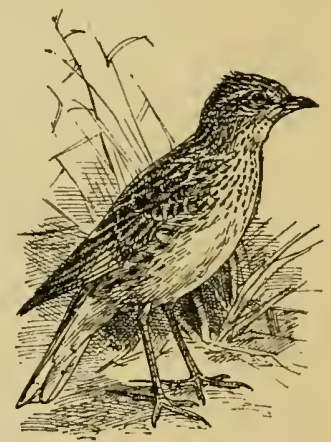

Fig. 102. -TIIE SKYLARK (Alundu arrensis). larks (Galeritu), the wood-larks (Lullutu), and the finch-larks (Pyyihulaudu).

Like the larks, the wagtails and pipits are "ambulatores," or walking birds. They do not hop like sparrows and finches. They resemble the

The Wagtails and Pipits.-

Family

Motacillicle. larks in one peculiarity, $r i z$. the extreme elongation of the inner secondaries, which are as long as the primary quills. The Motacillida have not the planta tarsi scutellated as in the larks, and they have only nine primaries, the first one being alsent. In many of the larks, however, the bastarclprinary is present, hut is so tiny as almost to defy detection. 
The pipits are generally birds of sombre brown coloration, more like that of the larks. They build their nests on the ground, generally under some sheltered portion of a bank. The true pipits (Anthus) are thirty-five in number, and are found in almost every part of the world. The common mearlow pipit (Anthus purcensis) is one well-known speeies, and the tree-pipit (A. triciulis) is another. The eggs of these two pipits are much more riehly coloured than those of wagtails, and are often of a pinkish-red or purplish colour, with darker spots and blotehes. The brightest of the pipits are the members of the Afriean genera Mucromyx and Timetothylacus, the species of Macromyx laving

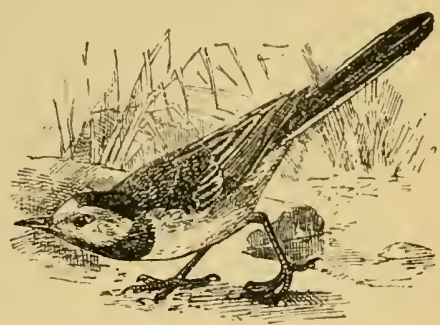

Fig. 103.-The Pien Wagtal (Motucilla letuluris). yellow breasts, while one species, MT. cmelie, has a beautiful pink breast.

The wagtails are divisible into two sections, the "water" wagtails and the "field" wagtails, the latter being less frequenters of the river banks than of the inland pastures. The most thoroughly river-haunting speeies in our own islands is the grey wagtail (Motucille melenope), while the pied wagtail (M. Tugubris) is a typical "water"-wagtail, just as Ray's wagtail (M. cumpest ris) is a typical "field"-wagtail. All these little birds, as well as the pipits, feed on inseets, which they catch on the wing or on the ground, and they all have a graceful mode of ruming and walking, keeping up the whole time a constant up-and-down waving of the tail.

The Muiotiltide embrace a number of small warblers, entircly confined to the American region, where they fultil the same functions as our own warblers (Sylviid 1 ) of the Eastem Hemisphere, feeding on insects. They differ, however, from the sylciider in laving nine primaries, nor is there any proof that the Mniotiltide have a double moult, in antumn and again in spring, like the warbler's of the Old World. The principal genera of the

\section{The American Warblers.- Family Miniotiltide.} Mniotiltide are Dendrece and Pavela, both of which are

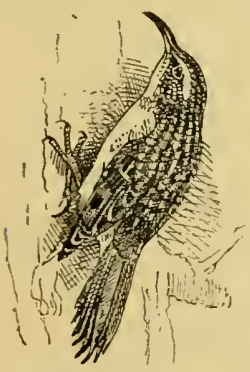

Fig. 104.-The TreE. Creeper

(Certhin familiaris). also denizens of South America. Some genera, like Mniotilta, appear to have an affinity with the creepers, while the genera Basileutemes, Setophaga, M!riodioctes, ete., have well-developed rictal bristles, and are like flyeatchers in their external appearance.

A typical creeper is easily distinguished from the other passerine birds by its stiffened tail-feathers, which resemble those of a woodpecker, and are of the same use to the birds in supporting themselves during their climb up an upright trunk. Unlike the woodpeckers, which only ascend the trunk, the tree-creepers often move along a bough horizontally. They have a long and curved bill, different from the conieal bill of the tits, which they resemble in nesting habits and in the colour of the eggs, which 
are white, with rufous or reddish-lrown spots. The grenus Certhiu contains about ten species, of which our tree-creeper (Cecthir fomili(ris) is the typical one, but members of the grenus are found throughout Europe and Northern Asia, as well as in the Himalayan mountains. They occur also throughout North Americal and extend into Central America.

Just as in the climbing birds like woodpeekers, there are stifftailed species and soft-tailed speeies, so we tind in the ereepers the spinytailed Certhir, and some soft-tailed genera like bulpomis of India and Afriea, Climecteris of Australia and New Guinea, and the crimsonwinged ereeper (Tichodroma mururiu), a species which inhabits the mountainous regions from China to the Himalayas, and from Turkestan to the Alps and the Pyrenees. It is a beantiful little bird of a delicate grey colour; in this it resembles a nuthateh, but the bill is curved like that of a creeper. Like a nut-hatch, it has white spots on the outer tail-feathers, but lias the wing-coverts crimson.

The homey-suckers are one of those curious Australasian families which stand apart by themselves, and for which it is difticult to estiThe mate the eorrect relationship. Gould Honey-Suckers. wrote in 1865 a very excellent note -Family on these birds, the habits of which Meliphargidr". he liad studied himself in nature: — "The honey-eaters are unquestionably the most peculiar and striking feature in Aus-

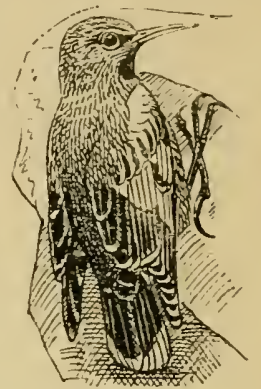

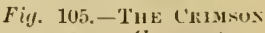
WINtiEU CrEEPER (Tichodroma muraria). tralian ornithology. They are, in fact, to the farmer what the Eucalypti, Banlisia, and Melalence are to the flora of Australia. The economy of these birds is so strictly aldapted to those trees that the one appears essential to the other; for what can be more plain than that the brush-like tongue is especially formed for gathering the honey from the flowercups of the Eucalynti, or that their diminutive stomachs are especially formed fur this kind of food, and the peculiar insects which form a portion of it." The brush-tongue is the chief eharacter of the honey-suckers, which are very numerous in Australia and New Guinea, and extends into the Moluccas and Polynesia.

The sum-birds are very similar in outward aspect to the neo-tropical humming-bircls (Trochili, antea, p. 347). They are richly decorated in metallic colours, but instead of hovering in front of

The Sun-Birds. Howers, suspended in the air with a vibrating flight, -Family they are more like tits in their ways; at least, so we

Nectariniide. gathered from watehing a little troup of Cimmyris cesiutied in a garden at Delhi, where they crept about through the bushes, uttering a little tit-like chirp, and picking off small insects from the leaves.

The Malachite sun-bird (Nectarinia famosa) is one of the largest of the Nectariniide, and is found in Southern Africa. Most of the species of sunbirds have square tails, but $N$. famose and a few other African species have the central tail-featliers elongated. The sun-birds have an extensile tongue similar to that of the humming-linds and woodpeckers, 
and Mr. Eugene Oates has shown that the bill is serrated for the terminal third of both mandibles. They build pensile-like nests, made of fine

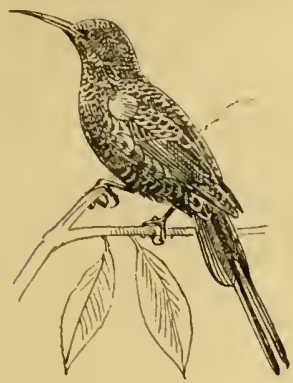

Fig. 106.-THE MALACHITH SUN-Bisu

(Necturinia famosa) grass or rootlets, and generally with a kind of hood, made of fine grass, alove the entrance. The nest is usually attached to the end of a branch, but is sometimes found on the uncler-side of a broad leaf, such as that of a plantain.

The flower-peckers are small birds, allied to the sum-birds, but differing in their shorter bills, both mandibles being serrated along their cutting-edges. Their plumage is mostly brilliant, and they are Flower-peckers. found in the Indian and Maliyan regions and throughout the MolucFamily cas, New Guinea and Australia.

Diceirle.

Their food consists of insects and small berries, and they are remarkable for the beauty of their nests, which are purse-like, made of the cotton from plants, fine griss and regetable-down, the nests heing suspended from the end of a twig, often at a great height from the ground. The two principal genera of the flower-peckers are Jicrum and Prionechilus.

The white-eyes are found in Africa, the Mascarene islands, throughout India and Ceylon, to the Burmese provinces, China and Japan, and again throughout the whole of the Maliugan region to Australia and Polynesia. They are nearly all birds of the same The White-eyes. pattern of coloration, green or yellowish - green above, mostly with a yellow forehead, sometimes with a black one, while the majority of species are yellow below, or white with -Family

Zosteropider. yellow throats. The name of "white-eye" is given to the Zosteropidr, on account of a white ring of feathers which encircles the eye, and not because the eye itself is white. They feed upon small insects, which they seek for among the trees; and Mr. Oates says that the Indian species are generally seen in flocks, and utter a constant twitter as they search for food. The nest is cup-shaped, very neatly and delicately made of vegetable fibres or fine grass, moss or wool. The eggs are blue, and two or three in number.

The tits are a numerous family, most strongly represented in the northern parts of the Old and New Worlds, reaching in the latter to Central America, and in the former occurring throughout Europe, Africa, and Asia, but being absent from the Australian region. They have stout and conical bills, and have the nostrils covered with bristles, and strongly scutellated tarsi, which have

The Tits. -

Family

Parirler. suggested to some ornithologists their affinity to the crows (Coville). There is, however, in our opinion, no relationship between these families, for the nesting habits of the two are entirely different, and the character of the eggs suggests no possible connection. The tits are all suall birds, assembling in flocks and family parties in winter, when they associate with creepers, nut-hatches, and other small birds, in traversing the woods in search of insect food. The genera of tits are not many, and they are mostly represented in the avi-famla of Europe. Thus Pams contains our great tit $(P$. major) and blue tit ( $P$. corvuleus), Pacile, the marsh tit (P. prlustris) and 
its allies, Lophophanes, our crested tit (L. cristutus), and Egithclus, our longtailed tit (AE. vagans). Nearly all of these build

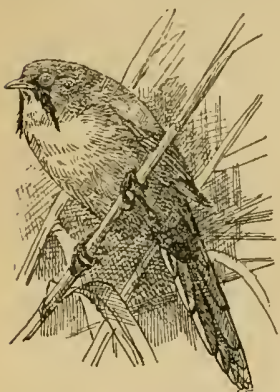

Fig. 107.-THE BEARDED REEDLING.

(Calamoplitus biarmicus). rough nests in holes of walls or of trees, and lay white eggrs spotted with rufous, from five to ten in number. The long-tailed or bottle tit, on the other hand, lays white eggs, seldom witl any spots, in an oval nest eomposed of moss, covered with lichens and lined with feathers. It is one of the most beautiful of all known nests, and is suspended in i tree or bush, generally at no great height from the ground.

The bearded reedling (Pannrus biarmicus) is often ealled the bearded tit, but it is not a true tit, being a marsh-haunting bird, building a eup-shaped nest at the base of a bunel of reeds. The eggs are white, with reddish dots and streaks. It oecurs still in the Norfolk broads in England, and extends throughout Europe to Central Asia in suitable localities. There is more difference in the colour of the sexes in the genus Prmurns than there is in the tits. The males and females are alike in colour in the latter birds, whereas in the reedling the male is a handsome birch, with a grey head and a black moustache, while the female is quite a plain coloured bird.

The nut-hatches are principally paliearetic and nearctic in their range. No species is found in South America, Africa (south of the Sahara), or in the Australian region. They are mostly grey-coloured birds, The Nut-Hatches. with conspienous white spots near the end of the tail-feather's. -Family In those parts of the world where true nut-hatches do not Sittide. occur, their places are taken by birds of similar appearance and habits, though of brighter eoloration. Thus, in the

Himalayas south to the Burmese provinces and the Malayan sub-region oecur's the genus Dendrositta, represented far away in Madagascar by Hypositta, and in Australia and New Guinea by Sitella.

The true nut-hatches (Sitta), of which our common nut-hatch is the type, are birds with the appearance of a small woodpeeker, and they climb up trees with the same facility, using their wedge-shaped bill to prize off pieces of bark to feed on the insects which their prowess discover's. They have, however, soft-plumaged tails, not spiny tails like the woorpeckers and creepers, but they run along boughs exactly as these birds do, with the exception that nut-liatches often run down a trunk, which the other birds above-mentioned do not do.

The gold-crests form a little family of northern birds, intermediate between the tits and warblers, catching tiny insects like both of

The Gold-Crests. these, but differing from them in

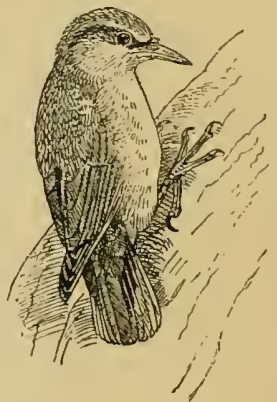

Fig. 108.-Тне Сомуом Nut-Hatch (Sittu cesia).

-Family

Regulider. their structure and mode of nidification. They are very tiny creatures, our common gold-erest (Regrelus regulus) being the smallest of our native birds. Gold-crests are 
found only in the northern parts of the Old and New Worlds, our own $R$. regulus and the fire-erest (lí. ignicapillus) being paliearctic, with a smaller race in the Himalityis ( $R$. himalayensis), and distmet forms in Mateira ( $R$. maderensis), the Canaries (li. leneriffu), and tho Azoris (R. armensis), while North Awerica lias the ruliy-erest (R. calenduler).

Although such a small bud, the exumuon goli-crest is a regular migrant to Fuglamd across tlie Nutl Sia, and imetimes miglathous have takell place which have lisst.d from eighty to ninety days. 'The nest which the bind builds is slung dike a hammock under the brinth of a yew-tree or a fir : it is macle of muss, and is generally well concealed, and linted with featl.trs. the eggs being from tive to eight in number, of a creamy white colour, with a dinker ring round the lirger end.

The shrikes are one of the most cosmopolitan families of birds, for, with the exception of South America, where they are absent, they are everywhere distributed. The true shrikes (Lanius), of which the great grey shrike ( $L$. excubitur) is the type, are elietly northern The shrikes or bircls, but are distributed also over Africa, India, and the Butcher-Birds.Indo-Chinese sub-region, but in the Malayan, Australian, Family Laniülce. and Ocennic sub-regions they are represented chiefly by the

genus Puchycephalu. 'The red-backed shrike (Lanius collyrio) and the wondchat (L. seriator) are two of the commonest of the European species, and the former visits Great Britain in the summer. The members of this family have gained their mame of "butcher bircls" from their habit of impaling their fool ou sharp thorns in the hedges near their nests, mice, frogs, grasshoppers, beetles, and other insects being of ten found in the "larders" of these birds.

The swallow-shrikes or wnod-swallows constitute a small assemblage of birds, oontaining the genus Artamus, of the Indian and Australian regions, with seventeen species, and Pseudochelidon of Wost Africa, with one species, $P$. eurystomina. The swallow-shrikes are grey or brown birds, with a pointed blue bill and very long wings, and Gould says that no one who has seen them in life ean fail to notice how clostly they resemble the swallows in the

The SwallowShrikes.Family Artamidee. actions and general mode of life. The nest of $A$. sordidus is placed in the fork of a branch, or on the side of a

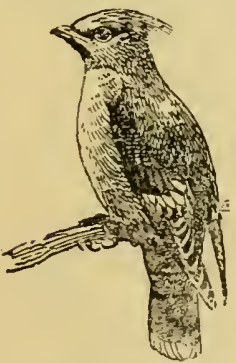

Fig. 109. - THE WAXWING

(A mpelis garrulus). tree, and is mole of flne twigs neatly lined with fibrous routs. The eggs are white, spotted with unber brown.

'The waxwings are a nine-prinaried family, chiefly morthern in their habitat, and possessing tropical genera only in North and Central America. where tlie crested chatturers (Ploriuopepla and Pliloyonys) recur.

The warwing (Ampelis qaroulus) is

The Chatterers. -Family

- impelicla. foundin Nrorth Americiand in Northern Europe and Asia. and occasionally risits Great Britain, occurring at irregular intervals in some numbers. It gains its name from the wax-like tips which are developed on the secondary quills in the adult bird. These are also found in the American cedar-bird (Ampelis cedronum), but in the Japanese waxwing ( $A$. japonicus) the secondaries and tail are tipped with crimson. The nest of A. gamulus 
is a large and conipact structure, made of twigs and moss, and lined with feathers, the eggs being stonc-grey, spotted with black or blackish-brown.

The Vireonide comstitute a small family of about sixty birds, peculiar to the New World. They are mostly of a green eolour, and in many respects resemble warblers, especially in the fact that the young birds scarcely differ from the adults, whereas in the The Greenlets. shrikes, to which the greenlets are undoubtedly also allied, the young are cross-barred. The species of the genus Vireo Family build a pendent nest covered with lichens and mosses, and Jirconide. they lay white eggs, speckled with red.

The warblers were, until recent years, considered to be a part of the family. of thrushes; but in 1881, they were separated by the late Henry Seebohm on characters which have been admitted to be of cleep-seated

The Warblers. - importance, viz., that the warblers had a double moult, one Family in spring and one in autumn, and the young were plainSylivide. colonred and resembled the adults, whereas the thrushes i: have only an autumnal moult, and liave spotted young, differing from the plumage of the adult.

The warblers are denizens of the Old World, and are everywhere distributed. Unfortunately we have not space to deseribe the many forms of Sylriidce, which include some of the finest songsters in the world, such as the nightingale (Daulias luscinia), the blackcap (Sylvia atricopilla), and other familiar summer migrants, such as the willow warbler (Phylloscopus trochilus), the ehiffeliaff $(P$. minor), etc. In the Sylizidce are also placed reed warblers, like our own species (Acrocephalus streperus), and sedge warblers (A. phragmitis); as well as all the grass-warblers (Cisticola, Prinia, and Sutorici). Some of the latter group build very interesting nests, as they take a couple of leaves and sew the edges together, so as to form a purse, in which they build their nest, which is made of fine grass, cotton down, and luair. The eggs are three or four in number, white or bluish-green, boldly marked with brownish-red. The warblers are insectivorous birds, though most of them, at certain times, feed on small fruits and berries. In autumn many of them migrate for very long distances.

As explained above, the thrushes have only one moult in the year, and that in the antumn, and they have the young birds thickly

The Thrushes. - spotted and different from the

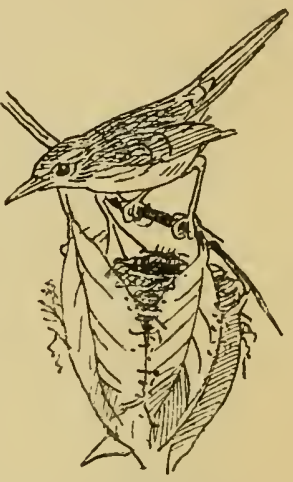

Fig. 11).-THF, INDIAN TaILoR BIRD (Satoria satori, $\iota$ ).

\section{Family}

Turdider. adults. Thus in the family Turdider are placed the robin (Evythacus rulecula) and its allies the blue-throats (Cyanecula) and redstarts (Puticilla), as well as the chats (Saxicola), and numbers of tropical genera, such as the chat-thrushes (Cossumha) of Afriea, the shimas (Cittocincla), and the dhayal birds (Copsychus) of India.

The thrushes may be roughly divided into three groups: the groundthrushes (Oreocicla and Geocichla), the true thrushes (Tuidus), and the blackbirds (Merula).

One of the largest and handsomest of the ground-thrushes is White's thrush 
(Ureocirlu ariu), a species which comes from its lome in Siberia to risit Western Europe and the British Islands occasionally,

All the thrushes are insectivorous birds, but feed also on worms and smiall molluses, while in the nutumm and winter their food consists principally of berries. Most of the northeru species are migratory, such as the fieldiare (Tudus pilaris), and the redwing ( 1 . iliucus), which come to us from Seandinavia in the winter, while even uur song-thrush ( $T$, musicus) is to a great extent a miglint.

In the blackbirds (Merula), the sexes are different in colour, the female being always of a duller plumage than in the male, as is eviclenced by our common blackbird ( $M$. merula). The ground-thrushes are distiugnished by a patch of white under the wing. There is scarcely any part of the world from which thrushes are absent.

The dippers, or water ouzels, are aquatic wrens.

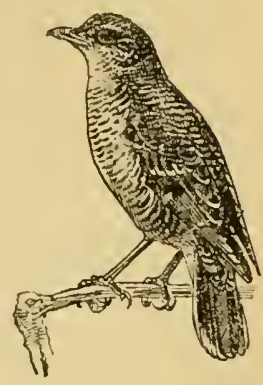

Fiy. 111.-WHITE's

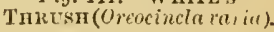
'They are generally associated with the thrushes, but they lave the front of the tarsus without any scutellæe, and only covered with a plain tarsal envelope. Like the wrens, they have no rictal bristles, and they build a round nest of moss under the shelter of a stone or the root of a tree, and lay white eggs.

The Dippers.-

Family

Cinclide.

The name of dipper is not attached to this bird because it dips under the water, but on account of the curious bobbing notion which the bird contimully keeps up. Every time that it bobs its head, it flirts its wings and slightly erects its tail. The bird is ranked as "vermin" "ly" ignorant people, who suppose that it devours the ova of trout, but it is generally allowed that the evidence of this crime on the part of the bird is open to doubt, and its food consists of caddis-worms, water-beetles, anct small molluses. The tlight of the dipper is extremely rapid, and resembles that of a kingfisher. It flies with rapid beats of the wings above the surface of the water, and will disappear suddenly beneatl the stream. but more often it settles on a rock and

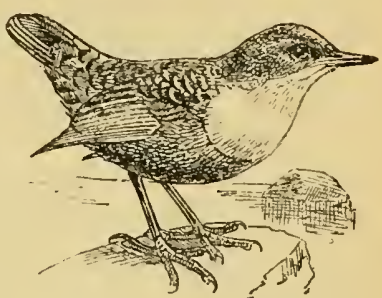

Fig. 112. -The Common DIPper (Cinclus aquaticus). deliberateiy walks into the water, searching for its food amoug the stones at the botton of the river.

Of the dippers about a dozen species are known, inhabitants of the mountain-streams of the northern parts of both hemispheres, extending to the Himalayas and China; while in the New World the genus is found in the highlands of Central America, and throughout the Andes of Colombia Eeuador, and Peru.

The Troglodytide embrace a 11 mmber of small birds such as our common wren (Anorthure troglodytes), which are spread over the greater part of the globe, being very abundant in the New ivorld, but absent in the Australian and Ethiopian regions. They have no rictal bristles, and build domed nests. Many

The Wrens.Family Troglodytidee. of them lave a remarkable power of song. 
The mocking-birds sore an American family, of which Mimus polyglottus and the cat-bird (Galcoscoptes

The carolinensis) are prominent exMocking-Birds. amples. The Mimidec are found --Family

Mimidee. throughont temperate North America, Central America, the West Indian islands, and the Ereater part of South America, even to Clili, Patagonia, and the Galapagos Islands. - Their powers of song and mimicry are proverbial.

The Timelide are short-winged, non-migratory birds, with the liabits of thrushes and the rictal bristles of flycatchers. The Babblers. - They are mostly ground birds, Family many of then, like Crateropus, Timeliidce. proceeding through the buslies in flocks, while others, like Ptilo.

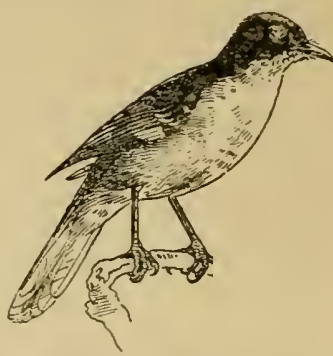

Fiy. 113.-The Muchrsg-Bird (Mimus polyglottus). cichla are clothed in dense plumage, resembling the Formicaridie of South America. The characters and limits of this large Old World family are still imperfectly understood.

The bulbuls are another family peculiar to the Old World, thrush-like in character, but differing from the thrushes in their short tarsi, and stronger rictal bristles. They are birds of quiet habits, but pussess a

The Bulbuls. - sweet song. The Pycnonotide are found all over Africa, Family and one species is an inhabitant of Algeria and Morocco.

Pycnonotilce. They are strongly represented throughout the Indian region, and extend into the entire Malayan regien.

The chief character which distinguishes this Old World family of birds The is the spiny character of the rump-feathers. They are Cuckoo-Shrikes. found throughont the Ethiopian, Indian, and Australian re-Family gions, and constitute a link between the flycatchers and the Campophagido. shrikes.

The flycatcher's are mostly broad-billed, insect-catching birds, with abundant rictal bristles, entirely confined to the Old World, over the whole of which they are distributed. They

The Flycatchers. have spotted young like the thrushes, -Family

Mruseicapidce. and on this accomnt it is often very difficult to determine whether some of the genera should be referred to the 'Turdicle or the Mnscicapidie.

Our common flycatcher (Muscicapa grisola) is a late summer migrint to England, and arrives from Africa in May. The list-mamed continent is also the home of a number of resident species of the gernus Muscicapa, which is also well represented in the Indian and Chinese regions by species similar to $M$. grisola. The nest of the latter species is often placerl in a crevice of birk on a tree and decorated with lichens and spiders' webs, which help to conceal it. The eggs are greenishwhite or stone-colour, with reddish-brown spots. The

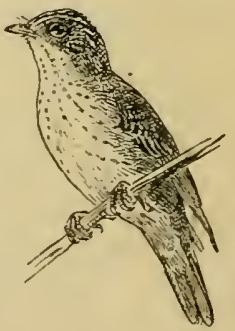

Fig.114.-Tнe Coмmon Flycatcher (IIuscicapa grisolu). jied flycatcher (Ficedule atricupille) represents another section of the Muscicupidce, and lays blue egrs, the nest being in the hole of a tree. The fars. 
tatled tijcatchers (lihipiduru) of Indiu and Ausiratia build a cup-shaped nest on in bough; and besides these few forms there are many others which we lave not space to enumerate, such as the jaradise Hycatchers (Terpsiphone) of Africa and Tndia, remarkable for their Jong tails, which form a kind of streamer.

The swallows, so often associated with the swifts, because of their similar manner of flight and mode of living, are now recoguised by all ornitholugists as bing true Passeres. They have, how-

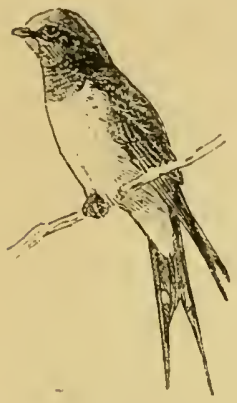

Fig. 115.-THE COMMON SWALLOW (Hirundo rustica). ever, i different arrangement of the The Swallows.fcather-tracts to the rest of the perching birds, in having the spinal tract Family forked on the back. Swallows are found all over the world, and in summer penetrate very fal. north, our conmon swallow (Hirundo rusticu) haviner been seen near Spitsbergen, and wintering as far south as the Cape Colony and the Indian Peninsula. In America the cliff-swallow (Petrochelidon pmmhomote and the purple martin (Prognif merpurea) also perform migratims almost equal in extent to those of the American barnswallow (Himendo enythrogaster), which is the comnterpart of our $H$. rustice. Many of the swallows build in barns and outhouses or in holes of trees, and make rough nests of mud and straw, lined with feathers, but some, like the house-martins (Chelidon) build their mud nests under the eaves of houses, and lay white eggs. The nest of our house-martin (Chelidon ubica) is an instance of this method, and in this genus the eggs are white, not spotted as in the case of the true swallows. The bank-martins (Cotile) also lay white eggs, which are deposited at the end of a tunnel excavated by the birds themselves.

All the birds continined in this section of the passeriformes have the intrinsic museles of the syrinx fixed to the middle of the bronchial semi-rings. The first sub-division of the Mesomyodi have the lower end of the trachea not modified, the syrinx as in the oscines, but with a lesser number of singing-muscles. This sub-division is called the Acromyode. There are eight acromyodian

Section Mesomyodi. families, of which mention is made below, and they are distinguished by the different scutellation of the tarsi. In the first division occur the Tyicumide, Oxyrhamphide, and Pipride; in these the tarsus is what is called "exaspidean." In the second division, where the tarsus is "pycnaspidean," are the Cotingide and Phytotomide. In the third is the family Philepittida, with a "taxaspidean" tarsus; and lastly, the fourth division, with an "ochreate" tarsus, containing the Pittide" and Ceniscide. The last threc families inhabit the Old IVorld, but all the others belong to the New IVorld.

In the tyrants the "exaspidean" form of tarsus prevails, i.e., the scutellation of the fore part of the tarsus is contimued over the whole outer side of it, and includes also the hinder aspect or the planta trisi. The family is divided by Dr. P. L. Sclater into four subfimilies, the Taniopterince, Ptatyhumchine, Elrmiince, and Tyramina. The tyrants number nore than 400 species, a certain portion of which are miguatory, breeding in North America. and wandering to Central and South Aneriea in winter. Iy far 
the greater majority of species are neotropical in habitat. They are inseetfeeders, and resemble our flycatchers in habits, so much so that they are commonly known as "flycatchers" in America.

In the Tyranidee and Oxyihumphide the toes are nearly free, according to Dr. Sclater, as in the Oscines or ordinary passerine birds. They differ from the member's of the foregoing fanily in laving a straight The Sharp-Bills. and pointed bill, instead of the tlattened and hooked bill of -Family the Tyramidre. As Mr. Salvin well observes, the position Oxyrhamphide. of the genus Oxyrhamphas is obscur'e, and it may turn out, when its anatomy is known, that it is not alled to the tyrants at all. In the male bird, according to MIr. Salvin, "the barbs of the central portion of the outer web of the outermost primary have their extrenities destitute of barbules, and these hare points turned rather abruptly backwards and slightly inwards, the margin of the wing thus forming a strongly serrate edge. In the fentale the outer web of this feather is normal." Nothing lias been recorded of the halits of the species of Oryihomphus, which are three in number.

The Pipride differ from the two foregoing families in laving the toes united at the base. They are mostly brightly-coloured birds, abont seventy in number, strictly neotropical in habitat, and dwelling in The Manakins.- the forests. A curious habit of one of the manakins, ChiroxiFamily phin lineries, of Central America, is recorded by Mr. Nutting.

Pipridu. Instead of fighting for the female, as is the case with most birds, this manakin dances himself into her farour. Mr. Nutting once saw two males clancing upon a bare twig about four fect from the ground. The two birds were about a foot and a lalf apart, and were alternately jumping about two feet into the air, and alighting exactly upon the spot whence they jumped. They kept time as regularly as clock-work, one bird jumping up the instant that the other bird alighted, each bird accompanying himself to the tume of tolédo, tolédo, tolédo, sounding the syllable "to" as he croucherl to spring, "le" while in the air, and "dn" as he alighted.

In the Cotingide the tarsus is "pycnaspidean," with the scales of the hinder aspect of the tarsus (plantu tursi) separate, small in size, and generally arranged without any order. The

The American bill is elongated, conpressed, and Chatterers. - not serrated." Six sub-families are Family recognised by Dr. Sclater, and all Cotingidre the species are neotropical. They comprise very varied forms, but the most striking are the cocks-of-the-rock (liripicola) and the bell-birds ('hasmoihmechus).

The plant-cutters are only four in number, and are found in Western South America from Peru to Chili, thence to the Argentine

The Plant- Republic and Northern Patagonia. Cutters. - Family There is only one genus, Phytotoma,

Phytotomide. which agrees with the Cotingider, as regirds the scaling of the tarsus, but is distinguished by its short, conical, and serrited bill.

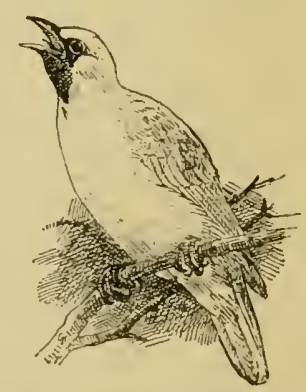

Fig. 116.-The Belt-BHow (chasmorhynchus niteus).

In the following small family the tarsus is "taxaspiclean," with the spaces on 
the soles of the tarsus close together, rectangular, and arranged in regular series. The Philepittide are ground birds, found only in Madagascar. Two species are known, ono black, the other olive above, yellow below, but both having a bluish tleshy carbuncle above the eye.

The $P$ ittide differ from all the families we have been recently

The Wattled

Ant-Thrushes.-

Family

Philepittidae. considering in havingthe tarsus "ocreate," or covered with an entire scale. With the exception of one species, l'itta an-

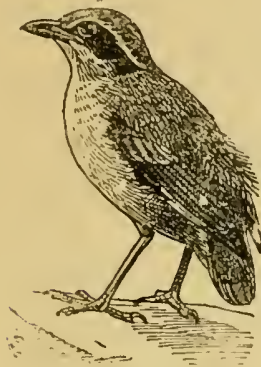

Fig. 117. - The PeRPLE PitTa

(Pitta granatina). golensis, which inhabits llest Africa, the whole of the family are denizens of

The Pittas.the tropical regions of the Tudian and

Family Pittide. Australian regions. The pittas are birds of bright coloration, inhabitants of the forests, and in many cases migratory. The Burmese genus Authocincle has long superciliary tufts, which are absent in the other genera.

The Xeniscide agree with the Pittide in the scaling of the tarsus, but have only ten tail-feathers, whereas the pittas have twelve. Three genera are known of these tiny wren-like birds, vis. Acanthidositta, Traversia, and Xenicus, all from the New Zealand subregion.

The arrangement of the voice-organs in the Tracheophonce is exactly opposite to that of the Oscines or ordinary passeres, and the lower end of the trachea is specially modified in order to form an organ of voice, and the bronchi are not involved in the arrange- Tracheophonce. ment at all.

The four families composing the Tracheophonce are all neotropical, the Dendrocolaptidce and Formicriville having only one pair of notehes in the

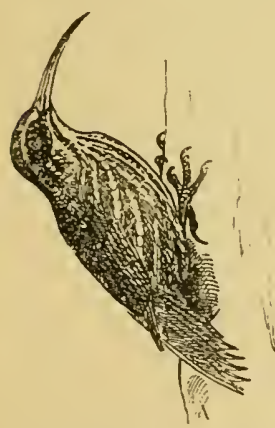

Fig. 118.-BrideE' WoONHEWER (Drymornis briclgesi). hinder margin of the sternum, while the Conopophagide and Pteroptochidee have two pairs of posterior notches.

The wond-hewers are about three

\section{The}

Wood-Hewers, Family Den. drocolaptide. hundred in number, and are contained in six sub-families, three of which, the Fur. nariince (oven-birds), Synullaxince, and Philydorna have soft-plumaged tails, while the other four, consisting of the true wood-hewers and their allies, have spiny tails. The species we lave figmed comes from North and West Algentina, is somewhat gregarious, and Mr. Barrows says that its habits are somewhat like those of a woodpecker, but it spends much of its time on the.ground searching for insects.

These are forest birds, inhabiting Central and South America, and numbering about 300 species. Mr. Osbert Salrin divides the family into two groups; those which" fre- The Ant-Birds. quent the trees and bushes and have. short tarsi, and those whose habits are terrestrial, and feed on insects on the Family uround. The hatits of the Formicariele are not very welj 
linown, but they appear to make their nests in trees and bushes, somo of them being pensile, and suspended in a forked branch near the extremity of a buingh. The eggs, according to Mr. Salvin, vary greatly, from rich darkgreenish blue to a mottled manogany colour, and many are purs white, or are whito witil few or meny spots. Although commonly known as "ant"-birds, whence also their scientific name, it is now believ d that the Formicariidoe do not eat ants, but only feed on the insects driven up by the swarms of foraging-ants (Echiton).

The Conopophagidce consist of a couple of genera, with eleven species, found in South America, from Columbia to South-Eastern Brazil and Isolivia. They bear a general resemblance to the Formicariude, but have four posterior notches in tlie sterıum.

The tapacolas, or Pteroptochido, are a family of small wren-like birds, occurring in the Andes of Ecuator and Colombia, but more pilentifully representerl in Chili and Patagonia.

In the Atrichiidce the sternum is single-notehed, and they hare a rudimentary furcula or " merry-thought." The wings are su small that the power of flight must be very limited, mul the planta tarsi is scaled The Scrub-Birds. like that of a lark. Only two species are known, both from

-Family Australia. Of the noisy scrub-bird (Atrichia clamosa), whom

Atrichiidae. Gilbert discovered in Western Australia, Gould says that it is a very difficult bird to find among the tangled beds of dwarf-ferns and dense thickets, and is only detected by its peculiar' and noisy note, 


\title{
SUB-KINGDOM I.-VERTEBRATA.
}

\section{CLASS III.-REPTILIA.}

\author{
By R. LyiekKel, B.A., F.R.S., T.P.G.S., de.
}

Fros both mammals and birds, reptiles are broadly distinguished by the coldness of their blood, which has a temperature but little, if at all, raised ibove that of the surrounding air. Probably to the popular mind this is the most obvious distinction of rentiles; and, in the ordintry accentation of the term, it does serve to differentiate the group from all other vertebrates except fishes-with which these creatures are not likely to be confounded. But it must be remembered that the popular and scientific conceptions of what constitutes a reptile are totally distinct. Under that title the ordinary observer includes frogs, salamanders, and newts ; and, in fact, all terrestrial, cold-blooded vertebrates. From certain structural peculiarities the naturalist, on the other hand, separates the creatures just namerl from reptiles, and inchudes under that title only crocodiles, tortoises, turtles, lizards and snakes, with a number of extinct forms with which we are not concerned in this volume.

Although some reptiles, such as lizards, agree very closely with the eggliying mammals (Nonotremata) in the structure of the bones forming the shoulder-girdle, while this resemblance is still more markedly displayed by certain extinct members of the reptilian class, yet the relationships of moder'n reptiles are decidedly closer with birds. Both groups, for instance, agree in that the young are not nourished with milk; while as rogards structure there are sereral points in which they are identical, and at the same time differ from mammals. Notably, each branch of the lower jaw in birds and reptiles is composed of several distinct bones; and the whole jaw is jointed on each side to the skull by means of a separate ossification known as the quadrate-bone. In both groups the ankle-joint is situated between the two horizontal rows of bones constituting the tarsus; although in lirds, as well as in some extinct reptiles, these bones are welded respectively with the long bones of the leg and of the metatarsus. A further distinction is the articulation of the skull to the first vertebra by means of a single knob-like condyle, instead of by the two condyles characterising mammals.

Such are some of the features common to birds and reptiles, as distinct from mammals. From birds, reptiles are broadly distinguished by the absence of feathers, the protective structures developed in the outer layer of the skin taking the furm either of overlapping lorny. scales, or of large shield-like plates united hy their edges. As alrealy said, reptiles are further distinguished by their cold blood; but this is obviously a feature of much less importance, for even among mammals the Monotremata have the temperature of the blood perceptibly lower than is the case with the higher members of the class. An important difference is, however, found in the wreat blood-vessel, or aorta, by which the blood passes from the licart to the bndy ; since, whereas in birrls this is single and bends over the left branch of 
the windpipe, in reptiles it is cluuble, and passes over both branches of tle latter. Then, again, no reptiles are known in which the number of digits in the fore-limb is reduced to three; while in no case are the two collarbones fused together to form the forcula, or merrythought, which constitutes sucl a striking feature in the skeleton of a bircl. Uther minor differences might be pointed out, but the foregoing are amply sufficient to distinguish a bird from a reptile. In common with the egs-laying mimmals, both groups produce their young from eggs; but in certain reptiles the young are retained so long witlin the body of the parent that they are born alive into the world.

From the lower vertebrates, that is to say frogs, salamanders, newts, and fishes, reptiles differ in that they are never provided with gills at any period of life, and when first hatched are similar in general form and structure to the adult, or, in otlier words, do not undergo a metamorphosis.

Whereas birds are remarkably alike in general appearance and internal structure, reptiles present, great diversity in these respects, and the distinction between the various orders of the latter are much mnre strongly marked than is the case with those of the former. If extinct types be taken into account, these diversities are still more strongly accentuated, and there are certain fossil forms which walked on their hind legs alone, while others were capable of flying in the same manner as a bird. For this reason the presence or absence of the power of flight is not given as one of the distinctions between birds and reptiles.

Geologically, reptiles are much oldel: than either mammils or birds, and consequently a large number of their orders are extinct, while one is represented only by a solitary survivor. The existing orders are as follows :-

I. Crocodria (Crocodiles, Alligator's, and Garials).

II. Chelonia (Tortoises and Turtles).

III. Squamata (Lizards, Chamzeleons, and Snakes).

IV. Rhynchocephalia (New Zealand Tuatera.)

In consequence of their greater antiquity, and the numerous migrations which they have undergone during early periods of the earth's history, reptiles do not agree with mammals in iespect to their geographical distributinn; so that the realms and regions into which the earth is divided from the evidence of the present and past distribution of mammals do not hold good for reptiles. Some of the leading features in the distribution of the orders and sub-orders of the present cliss are mentioned in the sequel.

\section{ORDER I.-CROCODJLTA.}

\section{Croconiles, Alugators, and Garials.}

Nobody can mistake a crocodile or alligator, or even their long-snouter allies, the garials, for any other reptile ; and consequently, although they are nearly allied to certain extinct formis, there is no necessity here for giving an elaborate and detailed definition of the order. Great lumbering brutes, lying like logs in the water, but waking into sudden and unexpected activity directly living prey comes within their reach, crocodiles and alligators are specially characterised by the rows of large shield-like horny plates covering the back and parts of the neck, and in some cases also the under surfice of 
the body. These shields, which to not overlap, but join one another by their edyes, are often marked on the back by more or less distinctly developed longitudinal ridges, and, at least on the back, are underlain in the cleep linyer of the skin by solid bony plates. In the case of the ridged shields, the underlying plates are similarly ridged; and in every instance the plates are marked by a peculiar honey-comb-like sculpture. A somewhat similar sculpture, although talking more the form of irregular branching ridges.and grooves, is likewise developed on the outer surface of the bones of the head; ind in this respect the skull of every living member of the order cliffers from that of any other existing reptile. All crocodilians-as the members of the order may be collectively designated-are huge ungainly reptiles, with large flat heads, depressed and lizard-like bodies, slort limbs, and long, compressed, and powerful tails, bearing on the upper surface a crest of homy lobes, which is double in the basal half of that alpendage. The toes, which are five in number in the fore-limbs, but are reduced to four in the hincler pair, aro more or less completely mited by webs to form efficient packlles for swimming; and on each font the three toes on the inner side are furnished with strong and sharp claws. In the huge, ugly head, the apertures of the ears can be closed by means of movable licls, so as to prevent the ingress of water; and the nostrils open at the very tip of the muzzle-whether this be short or broad, as in the alligators, or long and narrow, as in the garials. The vast and cavern-like mouth is armed with a formidable scries of sharp, conical teeth, some of which are cnlarged into tusks, while all are implanted in separate sockets, and form a single row on the summit of each jaw. To keep this terrible armament in repair, the teeth are being consequently shed and renewed, the new ones coming up beneath the hollow bases of the old ones and gradually pushing them out. Sometimes three or four teeth may be seen, one beneath the other, packed together like a nest of thimbles.

If the dried skull of one of these reptiles be examined, it will be found that the whole of the palate is formed by a solid roof of bone, and also that the quadrate-bone is tirmly and immovably wedged in between the adjacent elements of the skull. Later on, we shall see that this type of structure differs rery markedly from that which obtains among the lizards, and thus forms a most essential feature in the definition of the order. A more detailed examination of the skulls of all existing crocodiles will also show that the posterior, or internal, nostrils open on the palate right at the hinder end of the skull, close to where it joins the backbone. And it is by means of this arrargement that these reptiles are enabled to hold and drown their prey in their open mouths beneath the smiface of the water without any danger of being suffocated themselves. This is effected by means of the production of the upper extremity of the windpipe well into the month, where it enters the internal nostrils, and thus forms a closed tube from the external nostrils to the lungs.

Another peculiarity in the structure of a crocodile which has much effect on its movements, is to be found in the vertebre of the short neck. From the development of long processes on the sides of this portion of the backbone, a crocodile is totally unable to turn its head. Consequently, if a man be attacked on land by one of these monsters, he has but to await its rusl, and then leap suddenly aside, when his aggressor will continue its course mitil able to turn its whole bocly,

Members of the order are found in all the warmer regions of the glole, but are happily absent from European livers. They frequent alike rivers, 
marshes, and poids; and, although never found far removed from water. will at times travel long distances on land. In periods of drought, some of them, at least, bury themselves deep in the mud, where they remain in a semi-lorpid condition until awakened by returning moisture. They are the most thoroughly carnivorous of all reptiles; and their huge size and powerful teeth render them capable of seizing and lilling almost all kinds of living prey. Animals enming to drink are seized by the nose, and pulled under water, to be ruthlessly drowned in the manner alrendy indicated.

All erocodilians lay eggs, which are furnished with a liard white shell, and eomparable in size to those of a goose. In number they usually vary from one to three score. They are buried by the female parent in the warm sand, where in due course they liatch. It appears, however, that in some instanees, at least, the female opens the pit when the young are ready to bur'st their prison, being attracted by the cries uttered by the little crocodiles while still within the sliell. The young ones are introduced to the water by the mother.

Although all living erocodilians are included in the single family Crocoditide, they are divided into several genera, some of which have a more or less limited geographical distribution, while other's have a very Caimans extensive range. Of those with a restricted range, the first (Caiman). we have to notice are the caimans (Caiman) of Tropical America. Caimans are broad and short-snouted crocodilians, with a bony armour developed on the under, as well as the upper, surface of the body. In the skull, the nasal bones only extend as far forwards as the hinder aperture of the external nostrils; and, as a rule, both the first and fourth lower teeth, which are enlarged and tusk-like, are received into pits in the upper jaw, so as to be concealed when the mouth is elosed. The upper teeth bite on the outer side of the lower ones; and the two branches of the lower jaw liave but a very short union in the middle line at their front extremity. A peculiarity of the genus is to be found in the eircumstance that the bony plates on the back are articulated together. There are several species of eaiman, one of which ranges as far south as the La Plata River. Theiv true home is, however, the tropies, and in the Orinoco and Amazon they occur in thousands. In Brazil they are known as jaeares, and one species from that country measures from eigliteen to twenty feet in length. In capturing these ferocious and bloodthirsty monsters, the native Brazilians display great daring.

The alligatn's are so closely allied to the caimans that they can only be distinguished by anatomical features. The most easily detected distinction is to be found in the skull, in which the nasal bones extend

Alligators (Alligatcr). right across the aperture of the external nostrils, instead of stopping short at their hinder border. The bony plates on the back differ by the absence of any articulation between them ; while those on the lower surface are either very thin or wanting. Of the two well-known species, the Clinese illigator ( $A$. sinensis) is a comparatively small furm, approximating to the caimans in the retention of thin bony plates on the under surface, and having the front toes free. In the gigantic Nortl American alligator (A.mississippiensis), on the other hand, there are no plates beneatls the body, and the front toes are webbed; while there are also differences in the number of plates on the neck and back, as well as in the number of teetl, which aid in distinguishing between the two linisls. The habits of alligators are rery similar to those of other members of 
the order; but the female buries her eggs - which may roach a hundred in number-among leaves and other decaying vegetable matter, in order to hasten the process of hatching; and during the pairing-season the males spend much of their time on land. The Chinese species feeds largely upon tish.

The typical or true crocodiles are readily distinguished from both the foregoing genera by the circumstance that the upper teeth interlock with the lower ones, and likewise by the fourth lower tooth generally biting into a notel in the upper jaw. In the skull the nasil True Crocodiles bones extend only as far forwards as the linder marg.n of

(Crocodilus). the usostrils ; and whereas there are from seventeen to nineteon upper teeth, in the lower jaw the number is constantly fifteen. In all, the under surface of the body is devoid of bony plates. Crocodiles are represcuted by abuut eleven species, which are distributed over the south of Asia, Africa, Madagascar, the north of Australia, and Tropical America, and it is not a little remarkable that one of these (Crocodilus porosus) extends from India to Queensland, being also found in some of the islands of Polynesia, such as the Solomons and Fiji. This wide distrihution is, however, ruadily explained by this species being largely estuarine in its liabits, and taking readily to salt water, whereas all the others are fresh-water reptiles. Great difference $\omega b$ tains in the form of the skull in the various representatives of the gemus, the Oriental magar (C. palustris) having a short and broad alligator-like snout, whereas in the sharpnosed crocodile (C. americanus) of Central America, the muzzle is comparatively long, narrow, and pointed. Even in this species, how-

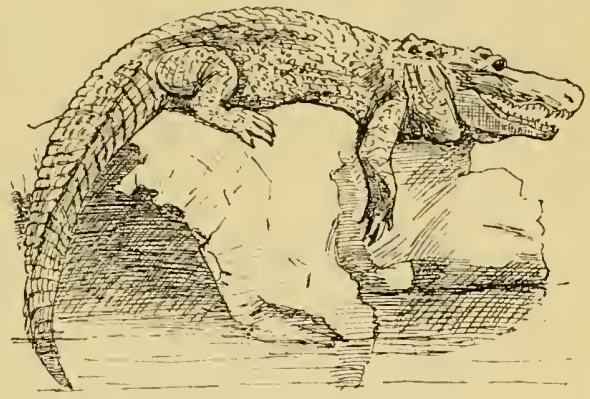

Fig. 1.-Nolth American Alligator (1. mississip. piensis). ever, the short front union between the two branches of the lower jaw is retained. In its still more elongated snout, the West African long-nosed crocodile (C. catapleractus) forms a connecting link between the more typical species and the under-mentioned garials. The species longest known is the Esyptian crocodile ( $C$, niloticus), which is one of those with a snout of medium prop: rtions.

As a rulk, the favourite haunts of crocodiles are sandbanks in rivers, where they lie basking for hours in the full sun, frequently with their ponderous jaws widely gaping. They appear to live for a great number of years--duringth: whole of which they cuntinue to grow-and often frequent the same spot for long periods of time. The ir ferucity is ton well knuwn to need men. tion; and many incautious bathers have lost their lives through these hideous reptiles, On the Hugli it is stated that women coming down to the river's edge to dlaw water hive occasionally been seized and dragrged under while stooping down on the nuarge. Although specimens are now seldom recorded of more than twelve or thirteen feet in length, there is good evidence that formerly the Inclian magar grew to at least eighteen feet. 
A small short-snouted species (Ostculcmus tetruspis) from Sierra Leone lias been referred to a genus by itself, on account of the nasal bones extencling right across the aperture of the nostrils. Although agreeing Stumpy in this respect with the alligators, in all other features this
Crocodile species is a true crucodile. (Osteolumus). Two members of the order differ from all the foregoing in having the edges of the very long and slender muzzle nearly straight, instead of more or less distinctly festooned, and likewise by the cilcumstance that the nasal bones stop considerably short of the hinder border of the external nostrils. A further marked differ-

Garials exce is to be found in the great length of the bony union be(Khynchosuchus tween the two branches of the lower jaw, which extends at ind Garialis). least as far back as the fifteenth tooth. The teeth theniselves are also much more slender than in the preceding genera, the fish-eating habits of the garials rendering a more powerful type of elentition unnecessary. Of these two species, Schlegel's garial (Fhymchosuchus schlegcli) inhabits the Maliy peninsula and Borneo, and has the snout of medim elongation and slenderness. Its claim to generic distinction is due to the circumstance that the nasal bones extend forwards on the upper surface of the smout to reach the premaxillae or anterior jawbones. It has twenty or twenty-one upper, and eighteen or nincteen lower, teeth; and its length varies fron twelve to fourteen feet.

On the other hand, the true garial (Guriulis gangetica), which inhabits tlis Ganges, Bramapntra, Indus, and Mahanadi, together with a river in Arakan,

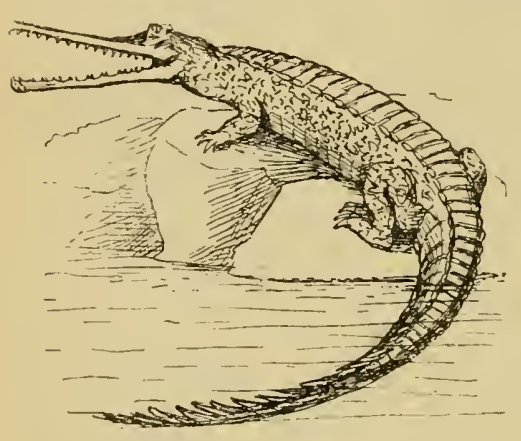

Fig. 2. Trete Garial (Guriulis gangelica). is distinguished by the much greater length and slenderness of the snout, in which the liasal bones stup short of the premaxillke, so that the maxillat, or linder upper jawbones come into contact witl one another on the upper surface of the suout between the other two pairs of bones. The almost uniformly sized teeth are very numerous, varying from 27 to 29 in the upper, and from 25 to 26 in the lower jar. Sone of the lorrer ones bite into pits in the upper jaw, whereas sume of the former are so received in the other species. All the toes are fully webbed. In the adult the general colour is dark olive on the head and back. 'The male garial may be distinguished by the development of the expanded extrenity of the muzzle into a kind of hump, in the centre of which are situated the nostrils. Tire garial grows to a length of about twenty feet, and feeds entirely on fish. For the capture of its funy prey, the numerous slender, sharply pointed, and sonewhat curved teeth are admirably suited; and the lighly developed swimning powers of this species are also correlated with the nature of its food. The female deposits her eggs in the sand of the river-banks, these being grenerally laid in two distinct layers, one above the otler. When the foung first make their appearance in the world, they have the snont propor- 
tionately much longer than in the adult; but, owing to the more rapid growth of the body, this becomes gradually sliorter. Young garials have the hody and tail ormamented with a number of oblique dark binds on a lighter fround. Although the garial is commonly looked upon with suspicion, it cloes not appear that it ever attacks man or the larger mammals.

\section{ORDER II,-CHEIONIA.}

Tolitolses axn TUUtLes.

The rresence of a bony shell, in a mor'e or less fully developed state-some. times enelosing the whole body in a solid case, and in other eases redueed to a kind of dish-cover on the back-is the grand distinguishing feature of the tortoises and turtles, whicl eollectively constitute the seeond great order of reptiles. Indeed, so far as their bony framework is eoncerned, these strange creatures may almost be described is reptiles turned inside out. For the ribs, which are generally united with bony plates in the skin to form the upper shell, or carapace, are actually plaeed outside both the blade-bones and the liaunch-bones; while, when a shell is cleveloped on the under surface of the body, its front portion is formed by the equivalents of the eollar-bones.

The presence, in some form or other, of such a shell serves at onee to distinguish the Chelonians from all other living reptiles. In ordinary tortoises and turtles the upper shell is firmly welded to the backbone; but the under shell, or plastron, which may or may not be joined by its edges to the sides of the carapace, is generally free from the intermal skeleton. Externally the shell is corered by a number of longitudinal rows of horny shields, which can be stripped off' without much trouble, and then reveal the underlying bony plates. Unfortunately for the ordinary student of natural history, the form and mode of arrangement of these hidden bony plates are of the utmost importanee in the classifieation of many of these reptiles. And as they are not shown in figures taken from specimens in the ordinary condition, he must either refer to special works on the subject, or must visit a good museum. Both the superficial horny shields and the underlying bony plates have recerved special names; and as some acquaintance with their general mode of arrangement is absulutely essential to the study of these reptiles, a brief referenes to the subject must be made in this place.

Taking any ordinary Chelonian, such as the common Greek tortoise of our gardens, we find the following general arrangement obtaining in the horny shields. Along the middle of the upper shell runs a single series of fire large symunetrical shields known as the vertebrals. On each side these aro flanked by a series of still larger slields, usually also five in number, termed the costals. The edges of the upper shell are formed by a numerous series of much smaller marginal shields, whieh in those forms with a complete shell overlap the middle of the sides, and thus come on to the plastron. At the middle of the frout elge of the earapace there is very generally a small unpaired shield known as the nuchal; while the term caudal is applied to the corresponding single or double shicld at the opposite end of the shell. On the under surface, or plastron, we find six pairs of large shields, respectively named, from front to back, the gular, humeral, pectoral, abdominal, femoral. 
and anal shields; while in some eases an mpaired intergular is interposed between the two gulars. Certain small shields on the borders of the slits for the fore and hind limbs need not be further referred to.

If wo now str p off tho horny shields, we saiall find that the underlying bony plates conform to a great extent with the arrangement of the furmer, although juesenting curtain well-marked differunces. In the midule line of the upper shell runs a single series of small many-angled plates termed the neurals, all attached below to the back-bone. A larger un ittached nuehal plate in front, and one or two simiarly detached pygals belind, cunplete this median umpaired series. The sides of the carapace are formed by the eight pairs of costal plates, which are tirmly welded to the underlying ribs; while its borders are composed of the malyinal plates, which resemble the corresponding horny shields in being angulited, and some of which join the plastron, when the latter is fully developel. Exelusive of these marginals, the lower shell or plastron generally consists of one unpair $d$ and four pirired elements. The front pair, corresponding to the collar-bones of other vertebrates, are the epiplastrils, behind or between which is the single entoplastral. Then follow the hyoplastrals, hypoplastrals, and xiphiplastrals ; the latter forming the hinder extremity of the lower shell, and being frequently more or less deeply notched in the middle line. In addition to these elements, a few tortoises have a pair of mesoplastral boues interealated between the liyo- and hypoplastrals, thus bringing up the total number of bones in the lower shell to eleven.

Scarcely less peenliar than their shells are the jaws of the Chelonia, which are invariably cased in horny sheatlis, with sharp eutting edges, like the beaks of birds, and show no vestiges of teeth at any period of life, Generally the heal is relatively short and wide ; but there is a considerable amount of diversity in this respect, as there is in regard to the structure of the skull. In all cases, however, the quadrate-bone is firmly fixed between the adjacent bones of the skull, to which its relations are somewhat different from those obtaining in the Croeodilia. There are many other peculiarities connected with the bony framework of these reptiles; but those mentioned are amply sufticient to distinguish them from all other groups.

The order is divided into three sub-orders, respeetively known as tho Cryptodira, Pleurodira, and Trionyehoidea ; and these divisions are important, not only on account of indicating structural differences, but also on distributional grounds. 'J hus, whereas the first group attains its maximum development in the countries to the north of the Equator, the second group is now entirely restricted to the Southern Hemisphere, and is the only one repre. sented in Australia. No members of the order are found in New Zealind; and the third group is unknown in both Australia and South America, as indeed it i.s in Europe, although this is probably dne to temperature.

Great diferences are observab!e in the morle of life of the different menbers of t'e rorler, the typical tortoises being almost or quite exelusirely terrestrial, the soft tortoises fresh-water, and the turtles marine. All are, however, foul of water, and even the most exclusively terrestrial species aro fond of an oecasional bath. MI:my of the so-cilled terrapins may lie regarded as amp!hibious creatures, spending much of their time in the water, but often dwelling for a considerable period on dry land. Between the land tortoises and the ordinary fresh-water terrapins there is not much difference in the structure of the feet; but in the turtles these are modified into paddles, indipted solely for swimming, and forming poor organs of progression on 
land. Even these purely marine forms are, however, in the habit of coming on shore for the purpose of depositing their eggs. It is important to remember that in ordinary language the term turtle is often applied to many of the fresh-water forms, although it is preferable to restrict it to the marine species. Whereas all the other members of the order lay hard-shelled eggs, those of the turtles are soft-shelled. In the matter of diet, Chelonians present as much diversity as in their other habits, some kinds being ex. clusively carnivorous, while others feed on vegetable substances.

\section{Sub-Order I.-Cryptodira.}

The members of this group are primarily characterised by their power of withdrawing the head within the margins of the shell by an S-like bending of the neck in a vertical plane; but as the same feature is to be found in the third group of the order, supplenental characteristics are necessary to define the present sub-order. With the exeeption of the abnormal leathery turtle, the shell of all tho forms-no matter what be its degree of development-is furmished with a complete set of marginal bones, some of which are articulated to the extremities of the ribs, Aecordingly, the Cryptodira may be defined as Chelonians which retract the head by means of a vertical S-like flexure of the neck, and either possess a complete set of marginal bones attaehed to the ribs, or have the limbs converted into flippers. These are, however, by no means the sole distinctive features of the group. An importint structural peculiarity is to be found in the circmmstance that none of the bones of the pelvic girdle have any attachment to the lower shell or plastron. Then, again, as a general rule, the latter bears only six pairs of horny shields, an intergular shield being but very rarely developed, If the dried skull be examined, it will be found that the ring of bone surrounding the aperture of the ear-technically termed the tympanic ring-is interupted by a distinct notch in its hinder border ; while the quadrate-bone articulates with the hinder end of the lower jaw by means of a convex knob or eondyle, received into a pit in the latter.

With the exception of the soft tortoises, this group includes all the land and fresh-water Chelonians of the Northern Hemisphere, as well as the marine turtles and the leathery turtle. It is, however, by no means wanting in the Southern Hemisphere, as there are numerous forms-both of terrestrial and fresh-water habits-in Africa and South America, although none are known from Australasia. There are such a large number of genera-to say nothing of species-included in this group, that limitations of space permit of referenee only to some of the more important types.

This extensive family group is probably best known in the shape of the common Grecian tortoise and European pond-tortoise, both of which are commonly exhibited for sale in Loncton shops, although neither are native demizens of the British Islands. In this family are also included the giant tortoises of the Mascarene and Galapagos Islands. There are no marine forms; but while some are terrestrial, others are more or less amphibions, spending a large portion of their lives in fresh water. With-

Land-Tortoises and Terrapins. -Family Testudinide. out going into abstruse and wearisome anatomical details, it is by no means easy to give a concise definition of the family. It may be observed, howerer, that while the head is capable of complete retraction within the margin of 
the shell, the limbs are never converted into paddles, and the shell itself is never heart-shaped. Both the upper and lower halves of the shell are well doveloped; and they may be connected together at the sides either by flattened surfaces, or they may give off minute interlocking processes, so as to be united by what are termed sutures. In no instance is there an intergular shield on the front of the plastron. Certain features connected with the bones of the carapace and internal skeleton by which this family is distinguished from those that follow may be best mentioned under the heading of the latter. Geographically the Testudinida-like the typical genus Testudo -have a range equivalent to that of the sub-order, of which they form by far the largest family. As regards diet, they are as diverse as in other habits, some feeding exclusively on vegetable substances, while others are carnivorous. It is not an uncommon belief that the Greek tortoise-which is mainly a vegetarian - will live upon black beetles; and I have known an instance where one of these reptiles was installed in a kitchen-vice a hedgehog deceased-to prey upon these troublesome insects, with results sadly to the disappointment of the purchaser.

The typical representatives of the family are the land-tortoises of the genus Testudo, most of which, like the common Grecian species, are comparatively small creatures, although some of those from the Mascarene and Galapagos Islands have a shell measuring considerably over a yard in length, and are capable of trutting off gaily with a load of three full-grown men on their capacious backs. In a work like the present the reader must not expect to find all the characters by which the tortoises of this genus are distinguished from their kin. In all cases the stout club-like limbs are adapted for walking on land, and are covered with horny scales or tubercles, while the unwebbed toes terminate in strong claw-like nails. The tail is always short. In a shell from which the superficial shields have been stripped, it will be seen that the neural bones are wide and short, with a quadrangular one generally alternating with an octagonal, although sometimes most are hexagonal. Of the costal bones, one is wide above and narrow below, and the next the reverse of this. As already said, these tortoises have a distribution practically coextensive with that of the family to which they belong; and all are herbivorous. In South and South-Eastern Europe the genus is represented by the well-known Grecian tortoise ( $T$. greeca), and also by the nearly-allied margined tortoise (T. marginata), which appears to be confined to Greece,

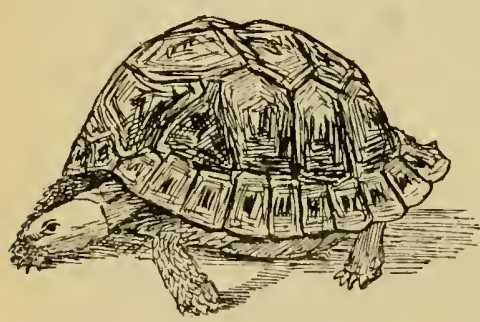

Fig. 3.-Grecian Tortorse

(Testudo greca). and is distinguished by the absence of an enlarged tubercle on the thigh. Certain Indian and South African species, such as $T$. elegans and T. geometrica, are distinguished by the extreme convexity of the shell, which is beautifully painted either with narrow yellow lines radiating on a dark ground from the cen tre of each of the shields, or with similar black lines on a light ground. Giant tortoises formerly existed in Aldabra Island, to the northwest of Madagascar; the Mascarenes (Reunion, Rodriquez, and Mauritius); and the Galapagos group, of the Pacific coast of South America. From the second. group they have, however, been exterminated, and have been greatly reduced in numbers in the others, where they formerly lived in thousands. 
and formed a valuable food supply for the crews of ships. Some of these tortoises are remarkable for the extreme tenuity and relatively small size of the shell, which is but little stouter than leather, and can be easily pierced with a knife. This is very notably the case with $T$. ephippium of the Galapagos Islands, fine examples of which are now preserved in the British Museum. Some of these monsters measure over four feet along the curve of the shell, and have been known to yield close upon four hundred pounds weight of excellent meat. In the Galapagos Islands these tortoises make regulin. tracks to their drinking-places in the hills, and feed chiefly upon the succulent stems of the cacti, so common there. During the breeding season, the males, accorcling to Darwin's well-known account, utter a loud roar, audible at a great distance. The ordinary tortoises of South Europe, Algeria, and Egypt, frequent dry sandy localities, where they have full opportunity of basking in the rays of the sun. In Europe, at least, they hibernate durings the cold season, by burying themselves deep in the earth, reappearing with the returning warmth of spring. In addition to their normal vegetable food, these tortoises are not averse to an occasional snail or insect. Four peculiar tortoises from South Africa are referred to the distinct genus Homopus, on account of the fore part of the palate lacking the distinct mediai ridge, characteristic of all the species of Testudo. Moreover, the neural bones of the carapace are never alternately quadrangular and octagonal, but always irregularly hexagonal, with the shorter of the two lateral surfaces at the hincl end. The typical $H$. areulatus has but four toes on the front foot, whereas in another species there are five.

The three species of linged tortoises from Tropical Afrien, forming the genus Cinixys, are easily and broadly distinguished by the presence of a ligamentous hinge across the hinder third of the carapace, by means of which the posterior opening of the shell can be completely closed. These tortoises are small reptiles, not exceeding some nine inches in length; and in habits the majority are amphibious, thus comnecting the land tortoises with the terrapins. Madagascar is the scle habitat of a single peculiar tortoise (Pyxis arachnoides), distinguished by having the front part of the plastron articulated to the remainder by a transverse hinge. In this species, therefore, the front aperture of the shell is capable of being closed at the will of its owner.

Coming to the terrapins, we find that these are distinguished from the foregoing by the toes being either webbed, or having rudiments of such webbing, as well as by the presence of three (instead of two) joints in the middle toe of botl the front and hind-foot. In the fore-foot the netacarpal bones are also much longer and more slender than in the preceding group. Foremost among these come three small Oriental genera, respeetively known as Geoëmyda, Nicora, and Cyclemys, all of which cliffer from those which follow by having the shorter lateral surface of the hexagonal neural bones of the carapace placed at the hinder end-a feature in which they agree with Homopus. Of these forms it will suffice to mention that the species of Cyclemys differ from the others in having the hinder half of the plastron movably articulated by means of a transierse bony linge, in consequence of which they are commonly spoken of as hinged terrapins.

In all the other members of the family, the hexagonal neural bones of the carapace have the shorter of the two lateral surfaces on each side situated in front. It is unfortunate that this important characteristic is hidden from view by the superficial bony shields-unless in the rare instances where they are sufficiently transparent to allow of the underlying bones being seen 
through them--but so it is, and the student must make the best of it. If wo were making aninials ourselves, we should doubtless give the members of each gemus a characteristic mark by which they could be recognised at a glance. Foremost in this group are the true box-tortoises (Cistumlo) of North America, which agree with ('yclemus in having a transierse hinge across the plastron, the posterior moiety of which consequently forms a movable flap, capable of closing the hinder aperture of the shell. As special features of the genus, may be noted the hooked beak, the smooth skin covering the top of the head, the imperfect webling of the toes, and the extreme shortness of the tril. These

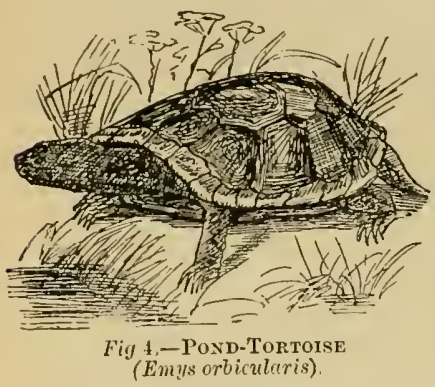
tortoises have a vaulted carapace, and, as is usual in such cases, are mainly terrestrial in their habits. From this gemus the depressed form of the shell serves at once to distinguish the European pondtortoise (Emys orbicularis), which, with in allied North American species, alone represents the genus. There is no hook to the beak; the upper and lower shells are umited only by ligament, and the hinder part of the plastron is movably articulated by a transverse hinge. The European species not only inhabits South and South-Eastern Europe, but ranges into Persia and Algeria. Its shell, which grows to a little over seven inches in length, is prettily speckled on the upper surface with golden flecks on a blackish ground. The pond-tortoise is a carnivorous species, living upon small fish, worms, and insects, and inhabiting both ruming and stagnant waters, in which it swins and dives witl great facility, It is an interesting and easily-kept denizen of an aquarium.

Of the remaining genera of the Testudivide, a very brief mention must suffice. The terrapins of the genus Clemmys form a somewhat important. group, ranging over South Europe, North-Western Africa, and North America. In common with the four following genera, Clemmys is characterised by the absence of a median ridge on the front portion of the palate of the skull; and all the species are camivorous in their nabits. As in all the remaining genera of the family, the upper and lower shells are firmly united by suture, and there is no bony hinge in the plastron. The two species of the Oriental genus Bellir may be distinguished by the stronger vertical buttresses connecting the plastron with the carapace, and the small horny shields covering the hinder part of the head ; the tues being completely webbed. The more or less decided balloon-shape of the anterier vertebral shields of the carapace is likewise a noteworthy feature of these small terrapins. Another allied Oriental gemus is typified by Damonia hamultoni, the shell of which is conspicuous for its yellow markings on a black ground, and the three longitudinal ridges traversing the carapace. The North American terrapins of the genus Malacoclemmys are also nearly allied, and have the whole head covered with a smooth skin. One species frequents brackish water; and it is members of this genus that afferd the dish so well known to epicures in the United States under the name of terrapin.

The other members of the family are mainly vegetarian in their diet, and differ from the foregoing by the front portion of the broad palate bearing one 
or two longicudinal riclges, To this group belong the exclusively American terrapins of the genus Chrysemys, some of which range as far south as Brazil and Uruguay. Burma and Bengal are the respective habitats of two allied terrupins constituting the genus Morenia, distinguished by certain features in the conformation of the skull; while the single representative of Ocadic is Chinese. The four other genera, all the members of which are known as batagurs, are contined to the Oriental countries, and include the largest fresh-water members of the whole family, the shell of one of them measuring as much as twenty inches in length. The batagurs, which are divided into the genera Cuchuga, Culluym, Bhitrgur, and IIarlella, are specially characterised by the excessive development of the vertical bony buttresses connecting the carapace with the plasiron, which project as walls into the interior of the shell in such a manner as to divide it into three imperfect compartments. The diflerent genera are chiefly distinguished by the contour of the vertebial horny shields of the carapace; the fourth shield in one genus narrowing anteriorly almost to a point in a mamer quite unknown in any other members of the order. The batagurs have shells of extraordinary strength and solidity; and the larger species are almost exclusively aquatic, and very numerous in the rivers of India and Burma. In spite of their herbirorous habits, they are said to be dangerous to bathers; and it is certain that a snap from their powerful jaws would cause a very serious wound.

A strange-looking aquatic tortoise (Platystcrmem megalocephalum) froms the countries lying between Eurmir and the south of China demands special notice as being the sole representative of a family. Externally, its most conspicuous features are the enormous size of the head; the hooked beak; the extreme flatness of the shell, which looks as if it had 110 room to contain the internal organs of the creature; the great length of the scaly tapering tail; and the rather long and powerfully-clawed legs. The skull differs from that of the Testulinide in having the whole of its hinder portion covered over by a bony roof; and most of the vertebre of the long tail articulate with one another by means of a cup behind and a ball in front, instead of in the reverse manner. These afford ample grounds for referring this tortoise to a family apart. The whole length of the shell is only about six inches. Of the habits of this remarkable reptile naturalists are ignorant.

The mud-terrapins (Cinostemum), of which there are eleven species, all inhabitants of America to the north of the Equator, alone represent a thirct family, easily distingnished from all other Chelonia by the absence of the unpaired entoplastral bone of the plastron, Mud-Terrapins. thus reducing the number of elements in the lower shell -Family Cinofrom nine to eight. The shell is depressed, with its two portions firmly united; and the plastron has its two exsternidue. tremities movable, and its gular shields either united or absent. The tail is very short ; and the webbed toes, save the fifth hind one, terminate in strong claws. In habits, these terrapins resemble ordinary fresh-water species.

Three smill genera of terrapins from Central America, respectively named Dermatemys, Strumotypus, and Ctandius, form the fourth family. Together with the Cinosternidce, these differ from the Testudinide in that each of the two lateral angles of the nuchal bone of the carapace gives off a long bouy stay projecting backwards Family Derco underlie the marginal bones. The skull is of ordinary from ; the p?astron has the usual nine bones, and the tail is short. As in 
the Cinosternidie and Chelydriace, an additional series of small hormy shields is interposed between the marginal shields and those of the plastron. Whereas in the single representative of the genus first mentioned, the plastron is fully developed, in the other two genera it is cruciform, and connected on each sicle with the upper shell only by a very narrow briclge.

Far better known than the members of the last family are the large Chelonians commonly termed snappers and alligator-terrapins, all of which are now eonfined to the northern portion of America, one

snappers and species ranging as far south as Guatemala and Ecuador. In Alligator- their relatively large head and long scaly tails, these terraTerrapins. - pins resemble the Platystemide. They differ, lowever, in Family the presence of long, rib-like processes, running backwards Chelycride. from the nuchal bone of the carapace to underlie the marginals, and likewise by the imperfect bony roof to the lateral regrions of the hinder part of the skull. The vertebre of the tail have, on the other hand, the same structure, the articular cup being on the hinder surface in the majority. The small, cross-shaped plastron is but very loosely attached to the upper shell; and it is not till a late period of life that the shell becomes fully ossified, large spaces long remaining in both the upper and lower halves. The long tail bears on its upper surface a crest, and all the toes, except the fifth hind one, arc clawed. The front borcler of the carapace is notched in orcler to

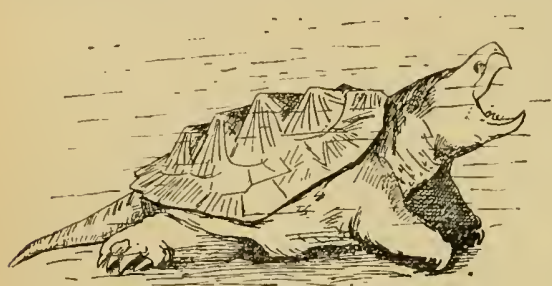

Fiy 5.-TEMMINCK's SNAPPER (Macroclcmmys tcmmincki). receive the ponderous head, which camnot be withdrawn into the shell. The largest nember of the family is 'Temmincl's snapper (Macroclemmys temmincki), which is generally to be seen in the reptile-house at the "Zoo," and ranges from Missouri to Florida. The very large head has the eyes lateral; and the tail is not so long as in the members of the second genus. In some specimens the shell measures twenty-four inches in length. The two species of alligator-terrapins, or snapping turtles (Chelydra), have the eyes clirected upwards, and the tail exceeding the shell in length. The members of hoth genera are common denizens of the fresh-waters of the United States, where they are found in rivers, swamps, and ponds. In habits they are very active, lushing on their prey with extraordinary speed, and feedings entirely on animal food. The extraordinary power of their jaws (of which the upper one is hooked) renders their bites very severe ; and bathers should always keep a good look-out to see that none of these reptiles are in their vicinity before venturing on a plumge. In captivity they are dull and sluggish creatures. Several females lay their eggs in the same spot.

The excellence of the flesh of one species, and the commercial value of the tortoise-shell yielded by a second, render the turtles a family of special importance and interest. From all the families yet menThe Turtles. - tioned the turtles are easily distinguished by the modification Family of their limbs into oar-like flippers, adapted solely for swimChelonide. ming, and also by the heart-shaped for'm of the shell. There are never more than two claws un each limb, the head cannot 
be completely retracted within the shell, and the tail is very short. The whole of the hinder region of the skull is covered by a bony roof. There is no bony union between the upper and lower shells; and in the carapace numcrous unossified spaces remain for a long time, if not permanently. Except during tho breeding season, when the females resort to shelving sandy shores for the jurpose of laying their eggs, turtles are inhabitants of the open sea, where in calm weather they may at times be seen floating placidly on the surface. When on shore, they shuffle along in an awkward manner; and if turned on their backs are utterly helpless. Their eggs, unlike those of other Chelonians, have soft shells. Like most denizens of the open sea, the three common species of turtles have an almost world-wide distribution. Of these, the green turtle (Chelone mylas) is the one whose flesh is used for culinary purposes. Nearly allied is the haw ksbill (C. imbricatc), distinguished at all ages by the strongly hooked beak, and also by the circumstance that, for a considerable portion of life the horny shields of the shell overlap one another like the slates in a roof, instead of meeting at the edges. It is this species alone that yields the tortoise-shell of commerce.

More distinct is the loggerhead (Thalassochelys caretta), in which the head is of proportionately greater size, and there are five, instead of four, pair's of horny costal shields on the carapace. The loggerhead is the largest of the threc. It is somewhat remarkable that whereas the green turtle is an

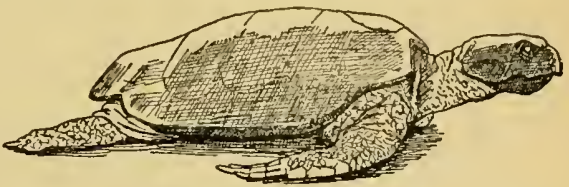

Fit. 6.-LogGerheAD TokTOSSE (Thalassochelys carctia).

herbivorous animal, feeding chiefly upon sea-weeds, both the hawksbill and the loggerhead are carnivorous; the food of the latter consisting largely of cuttle-fish.

During the egging-season turtles come ashore in immense numbers, the Seychelles and Bahamas being two of their favourite resorts. While the females are busily engaged in the occupation of laying, and of covering up their eggs in the sand, the males generally pass the time by quarrelling among themselves. Moonlight nights are those usually chosen for resorting to the coast; and these, of course, are most favourable to the turtle-catchers, whose object is to intercept their victims before they can scuttle back to the sea. Not only are the eggs largely used as an article of food, but they also yield an excellent oil. Tortoise-shell, when heated, has the peculiar property of welding like iron, so that plates of almost any size can be obtained by uniting a number of shields. It can also be pressed into moulds, and beautiful amber-like necklaces and other ornamental articles are manufactured from the scraps and fragments.

Although the huge leathery turtle (Dermochelys coriacen)- the giant of the tribe-is a marine species with flippers for limbs, yet it differs so markedly from the other turtles in the structure of its shell and the conformation of its skull, that it unquestionably represents a separate family by itself. Indeed, as regards its shell, not only does the luth (as this species is sometimes called) differ from other turtles, but likewise from all other living Chelonia. In place of the carapace being formed by a series of large regularly-shaped bones, some of which are firnly attached to the backbone and ribs, and all 
invested with separate horny shields, in the leathery turtle it is composed of a vast number c'. minute irregular ossifications, fitting together like mosaic, and having no sort of connection with the internal skeleton, while its investiture takes the form of a continuous leathery skin. Seven bold longitudinal

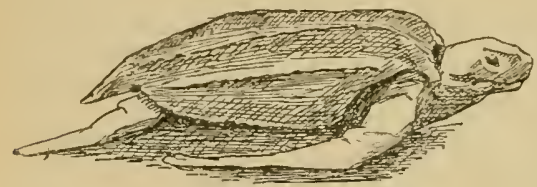

Fig. T.-Leatilery Turthe. (Dermochelys coriucea). ridges traverse the upper shell from end to end; and there are five similar rickes on the under shell, which is less fully developed. Clinws are totally wanting on the flip'pers, of which the front pair greatly exceed the hinder in length. Although the structural peculiarities of the skull are of the highest importance in determining the systematic position of the creature, they need not be further alluded to in this place. In length this turtie frequently exceeds six feet. The leathery turtle, which is now rapidly diminishing in numbers, is an inhabitant of the warmer oceans, one of its favourite laaunts being the Tortugas Islands off the Florida coast. It is known to be carnivorous, and its habits are probably very similar to those of the true turtles. Commercially this species is of no value, its Hesh having a strong and highly unjleasant taste of musk.

\section{Sub-Order II-Pleurodiva.}

The members of the second sub-ordinal group of the Chelonia are best distinguished externally by the mode in which they withdraw the head and neck into the shell. In place of the S-like movement characterising the preceding group, these tortoises always bend the neck to one side in a horizontal plane, so that instead of occupying the middle of the front aperture of the shell, the head when retracted lies more or less on one or the other side, according to the relative length of the neck. This very obvious characteristic is, however, by no means the sole claim of the group to distinction. If the dried skull be examined, it will be found that the bony ring surrounding the aperture of the ear is entire instead of being notched behind, and also that the lower surface of the quadrate-bone is hollowed in order to receire a knob on the articulating portion of the lower jaw. In all cases the upper and lower shells are fully ossified and closely joined; and both have a firm union with the bones of the pelvis. When horny shields are present at all, there is invariably an intergular between or behind the two gulars. The Pleurodira are now restricted to the Southern Hemisphere, and are the only tortoises in. habiting Australia and Papua.

The first family of the sub-order is represented by eight generic types, all of which are restricted to South America and Australasiit. As distinctive features of the family, may be mentioned the presence of

Family only nine bones in the lower shell, the incapacity of comChelyila. pletely retracting the neck within the margin of the carapace, and the absence of the so-called temporal bony arch on the sides of the skull. The typical member of the family is the grotesque matamata (Chelys fimbriata) of the Guianas and North Brazil, a species easily recognised by its flattened triangular head, the peculiar tuft-like tilaments on the sides of the broarl and long neck, and the great bosses formed by the 
shiclds of the carapace, which is serrated on its margins. In length the shell of the matamata reaches fifteen inches. In habits this tortoise is a frush-water and chiefly carnivorous animal; and it is probable that the tufts on the neck are for the purpose of attracting its prey within easy reach of its jaws. In addition to its other chiracteristies, the matamata has a proboscis to the suout, lut this is wanting in the other Solt ly American long-necked members of the fimily, which form the geuns IIydromedusi. These tortoises also lifter in the comparative smoothness of the shell, and in having only four claws to each foot. The remaining three South American

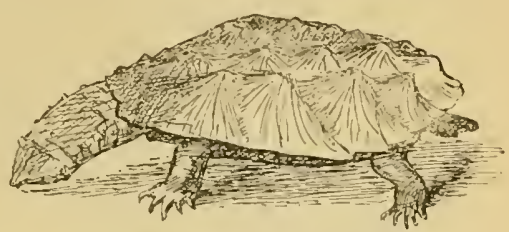

Fig. S.--Matrata (Chelys fimbriuta). genera, namely Mydraspis, Rhinemys, and Platemys, have the neck propor. tionately shorter. Three generic types of the family are met with in Australia and Papua, one of which (C'hclodinu) has the neck rery long, while in the other two (Eiseya and Emydura) it is relatively shorter.

The largest membor of the whole sub-order is the great fresh-water tortoisc of the Amazons (Podocnemis exprnsa), whose shell often measures two-and-ahalf feet in length. Together with its allies, this species belongs to the second fanily of the sub-order, characterised by the presence of a pair of mesoplastrals between the hyoand hypoplastral bones, the total number of elements in the

Family

Pelomedusida. lower shell thus being brought up to eleren. The neck can be fully withdrawn into the shell, and the skull has a lateral bony arch. The genus Podocnemis affords a remarkable example of discontinuous geographical distribution, six of the species being inhabitants of South America, whereas the seventh is found in the distant island of Madagascar. In this genus the hinder part of the skull is completely roofed over by bone; but this is not the case in the other two genelia

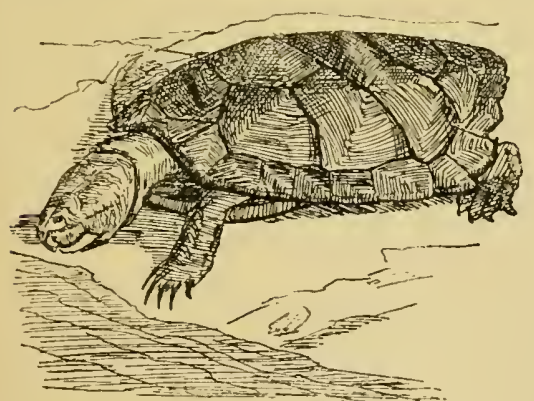

Fig. 9.-Amazonian Fresh.Water Tortoise (Podocnemis expansa). of the family. Of these, Pelomedusa, which has only a single species, inhabiting both Madagascar and Africa, resembles Podocremis in that the two mosoplastral bones only show themselves on the sides of the lower shell, and are thus widely separate in the middle line. On the other hand, in Sternothcerus the same two bones are as fully developed as the other elements of the plastron, in the median line of which they come into contact with one another. The whole of the species of this genus are African, but one extends its range into Madagascar. The great Amazonian species of Podocnemis is of considerable value to the uatives of some parts of tropical America, on account of its eggs, which are collected in vast quantities, mainly for the sake of the oil they yield. 
A fresh-water turtle from one of the Papuan rivers described under the name of Curettochelys, resembles the true marine turtles in having the limbs modified into flippers, although displaying all the other char-

Family acteristics of the present sub-order. Only two claws occur Carettochelyidte. on each tlipper; and the shell is remarkable for having a continuous leathery skin in place of the usual horny shields. There are certain other structural features in this little-known and rare Chelonian by which it differs from its allies.

\section{Sub-Order III.-Trionychide.}

The third and last sub-order of the Chelonia includes only the soit tortoises, represented by six genera, all of which are comprised in the single family Trionychidce. All these tortoises have very long necks, which can be completely withdrawn within the margins of the shell by an S-like flexure in tho same manner as in the Cryptodira. The jaws are hidden by the fleshy lips, and the muzzle is prolonged into a short proboscis. The feet are fully webbed, and only the three outermost toes are furnished with claws-a peculiarity from which the scientific name of the group is derived. None of these features are, however, of sufticient importance to justify the separation of the group as a distinct sub-order; but the shell is very peculiar. In place of the usual horny shields, both the upper and lower shells are invested with a thin, continuous leathery skin, through which can be seen and felt the raised sculpture ornamenting the surface of the underlying bones. Marginal bones, if developed at all, are restricted to the hinder border of the upper shell, and elsewhere the margins of this shell are continued into a wide, soft expansion of skin, so that the shell itself only occupies the region of the back. There is no attachment between the upper and lower shells, and the latter is only very imperfectly ossified. A greenish olive ground-colour, upon which are yellow or orange spots, is the general type of coloration, the spots being replaced by streaks on the under surface of the head. At the present day the soft tortoises are restricterl to the fresh waters of the warmer regions of North America, Asia, and Africa. In habits, these very peculiar Chelonians are purely aquatic, and al though the majority are confined to fresh waters, some frequent estuaries. They are all carnivorous ; and, being extremely bold and tierce, are highly dangerous to bathers. All are mainly nocturnal, and when basking oll a mud-bank, or on shore, for the purpose of laying their eggs, extend their long necks after any sudden surprise in a peculiarly cautious and stealthy manner. The spherical eggs are buried in the mud by the female as soon as laid.

The typical, and at the same time the widest spread, genus is Trionyx, which has a geographical distribution as extensive as that of the family, and is the only one found in America, fiftcen distinct species being known. In this genus, the sculpture on the surface of the shell usually takes the form of irregular wavy ridges; while in the lower shell the hyoplastral and hypoplastral bones of each side are separate. A distinctive feature is the want of a fold of skin on the hinder part of the plastron, which in some of the allied forms conceals the hind-leg. The head is relatively short and broad, with the eyes situated far back. The shell and leathery disc of some of the members of this genus not unfrequently measure as much as a couple of feet in length, and the species are arranged in groups according to the number of bones entering into the composition of the upper shell, and the absence or presence 
of a longitudinal ricige on the palatal surface of the fore part of the lower jaw. Nearly allied to Trionyx are the general I'elochelys and Chitra, each represented by a single species from the Oriental countries. In the formerwhich extends from India to the Malayan Islands - the eyes liave a more forward position than in the type genus, this feature being still more marked in the gigantie Indian Chitre, where they are situated close up to the snout, the whole skull being very long and narrow. The foregoing genera constitute a sub-family by themselves; and a second group of equivalent value is formed by the other three genera. The two essential characteristics of the second group are to be found in the presence of a skinny flap beneath the under shell-behind which the hind-foot can be

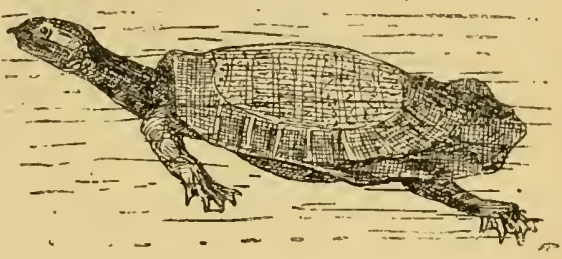

Fig. 10.-A Soft Tortolse. withdrawn-and the complete union of the hyoplastral and hypoplastral elements of the lower shell. Externally the shell is distinguished by the pustular form of the seulpture. Of the three types of the sub-family, the Indian Emyda is specially distinguished by possessing a series of marginal bones round the hinder portion of the carapace. There are but three species, and in the largest of these the shell loes not grow to more than about ten inches in length. Of the two African grenera, the one known as Cycloderma has a complete series of neural bones running down the middle of the carapace; whereas, in the nearly related Cyclanorbis the series is incomplete, so that some of the costal bones of opposite sides come into contact with one another in the middle line.

It may be added that in the absence of any connection between the bones of the pelvis and the lower shell, as well as in the mode of articulation between the upper and lower jaws, and the notch in the ring round the aperture of the ear, the soft-tortoises resemble the Cryptodira. In certain forms and certain structural features of the skull they are, however, more like the Pleurodira.

\section{ORDER III. -SQUAMATA.}

\section{SCALED Reptiles.}

By far the largest of all the four orders of existing reptiles is the one including the lizards, chamæleons, and snakes; each of those groups forming a sub-order by itself. And here it may be remarked how unimportant is the external form of reptiles in regard to their zoological affinities. The New Kealand tuatera, for instance, which externally is like a lizard, has nothing whatever to do with the Squamata, but forms an order by itself; whereas ordinary lizards and serpents are comprised in one and the same order. Moreover, the blindworms, which in external appearance are like snakes, form a portion of the sub-order typified by the lizards. A general, but by no means invariable, feature of the Squamati is the covering of overlapping horny scales on the 
head, budy, and limbs; but more important and constant struetural peculiarities are to be found in the internal skeleton. Of the highest import is the fact that in all the members of the present order the quadrate-bone is movably jointed to the other elements of the skull, from which its lower extremity projects. Secondly, there is no bony rod ruming forwards from the outer side of the lower extremity of this bone to join the upper jitw; such a rod being always developed in the Crocodilia. The palate, again, has a much more open structure than in either the Crocodilia or the Chelonia ;not that there is any difficulty in distinguishing between a lizard or a snake and a tortoise or turtle. If we turn to the backbone, equally well-marked points of difference present themselves between the Squamata on the one hand and the Crocodilia on the other. In the former group the ribs of the chest have single upper extremities, or heads, which are articulated to facets, on the sides of what are termed the bodies of the vertebre-that is to say, the solid cylindrical part underlying the arch through which passes the nerve-cord. On the other hand, in the Crocodilia the majority of the ribs have two heads; and those in the region of the back are articulated to a long horizontal transverse projection arising from the sides of the arch of each vertebre. In the majority of the order the bodies of the vertebre are movably united by means of ball-and-soeket joints : the ball being situated behind and the socket in front. Neither in lizards or in serpents are the teeth ever implanted in the jaws by means of distinct sockets. In all cases the teeth are firmly welded to the substance of the jaw itself; but whereas in some forms they are affixed to the summits of the jaws, in others they are attached to the sides of the same. To the former mode of attacliment, the name acrolont is applied, whereas the latter is termed plevrodont. Although the foregoing features are amply sufticient to distinguish the Sruamata from the Crocodilia, it may be added that when the shoulder-girdle is fully developed, there is a breast-bone, a pair of collar-bones, and an unpaired median element, with the form of the letter $T$, known as the interclavirle.

\section{Sub-Order I.-Lacertilia.}

\section{Lizaris.}

Since it has been already mentioned that the blind-worm belongs to the present sub-order, it will be obvious that the presence of limbs will not suftice to distinguish between the lizards and the serpents, although the majority of the former are four-limbed creatures, and none of the latter have four fully developed and functional legs. In the limbless snake-like lizards the tongue camnot, however, be withdrawn into a basal sheath, as it is in serpents; and whereas the former are generally fumished with eyelids or external openings to the ears, both these are invariably wanting in the latter. The examination of the skeleton will also show that whereas in all lizards the two branches of the lower jaw are joined by bone where they meet at the chin, in the serpents such union is ligamentons; and it should further be observed that the limbless lizards always retain vestiges of the shoulder-girdle. As important points of distinction between the lizards and the chameleons, it must be mentioned that such of the former as retain limbs have well-developed collarbones, and that the tongue is flattened and not dilatable.

At the present day somewhere about seventeen hundred different species of lizards are known; these forming no less than twenty distinct families, 
mostly including a large number of genera. Hence it will be obvious that only some of the leading types can be even alluded to in this volume. Although lizards arc found everywhere save the polar regions, the group attains its maximum development-both as regards bodily size and the number of forms-in the tropical and sub-tropical zones. They inhabit both dry and moist situations, although the majority prefer the former. Most are terrestrial, but many are arboreal, while a few are aquatic, one species at least venturing into the open sea. The so-called flying lizard can take long leaps in the air by the aid of a parachute-like expansion of skin supported by the elongated ribs; and an Austrulian species is stated to walk on its hiudlimbs like a bird. Sucker-like pads enable the geckos to climb vertical panes of glass like flies; and some of the arborcal species resemble the American monkeys in having the tail endowed with prehensile power. Whereas the majority lay eggs, \& few bring forth their young into the world alive. In spite of the popular dread attaching to the blind-worm, no lizards, with the exception of the few species belonging to the American family Helodermatide, are poisonous. A few members of the order are regetable-feeders, but the great majority live on animal food, especially insects and other in vertebrates. The facility with which many lizards part with a considerable portion of the tail when handled is a faniliar fact; but it is perhaps less wcll-known that the missing fragment can be speedily reproduced. As regards geographical distribution, the Lacertilia are widely difterent from the Chelonia. Thus, whereas Australasian lizarcls are unlike those of Sonth America, between the lizards of Australia and those of India there is a most marked resemblance, while the Indian forms differ decidedly from those of Africa.

The peculiar cry of some of its Asiatic members has given rise to the name by which the first family of the Lacertilia is both familiarly and scientifically known. From nearly all other members of the sub-order geckos are distinguished by the fact that the bodies of their Geckos.-Family vertebrie are cupped at both ends, instead of articulating by a ball and socket, while most of them have sucking discs on the extremities of the five-toed feet. In form they are depressed, and in coloration dull, and whereas the head is covered with bony granules or small scales, the body is generally invested with granules above and with overlapping scales beneath. In no case are the scales underlain by plates of bone. There are no movable eyelids, and the opening of the ear, and generally also the pupil of the eye, is in the form of a vertical slit. The tongue, which is short and devoid of a sheath at the base, may be either smooth or covered with shaggy prominences. The small teeth are attached to the jaws in the pleurodont manner, and in many cases the tail is more or less distinctly prehensile, although in some instances it is rudimental. Most numerous in the Oriental and Australasian countries, the geckos range over all the warmer parts of the world, and present a considerable number of generic modifications. Among these the genus Ptyodactylus is familiar to travelkers in Palestine in the form of the little lobe-footed gecko. In common with its immediate kindred, this species has the toes expanded into circular lobes, upon the under surface of which are two rows of plates. Hemidactylus, as represented by the little Turkish gecko, is an allied genus, ranging over all the warmer parts of the world except Australasia, with dilated toes terminating in compressed claws, of which the tips are free. Very aberrant is the single and considerably larger species of the Oriental genus Ptychosoum, in which the skin of the flanks forms a large expansion, while there is also a fringe of 
lubes rumning along the two sides of the tail, and likewise on the hinder borders of the legs. The toes also are completely comnected by web-like dilations, the first in each limb being clawless. A peculiarly marked type of coloration further aids in the recognition of this species. The countries bordering the Mediterranean are the chief habitat of another genus known as Tarentola, of which the common wall-gecko is the most familiar representative, all the species having the toes moderately dilated, but only the third and fourth clawed. The genus ranges as far south as the west coast of Africa, and is likewise represented by a species from the West Indian Islands. Whereas a large number of geckos frequent trees, walls, or buildings, some are found in open sandy districts, and these latter naturally have feet of ordinary

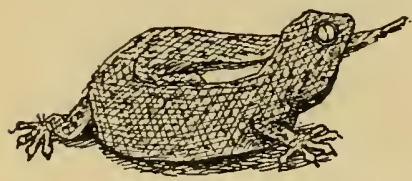

Fig. 11.-FrixaEd Gecko (Ptychozoum). type, as adhesive discs would be useless. In countries where these lizards abound, almost every house is tenanted by at least a pair. When undisturbed, such denizens will scamper orer the walls with the greatest spced in search of flies, uttering now and then their shrill cries. It is, doubtless, owing to these vocal power's that geckos are so dreaded by the uneducated in all parts of the rorld-an analagous instance of the inspiration of a similar dread being afforded by the death-watch insects.

A second family of geckos (Eublepharidce), of which there are only three genera, differ from the foregoing in being furnished with eyelids, and also in having cup-and-ball joints to the backbone.

The third family of the sub-order includes the three species of the Malagasy genus Uroplates, and is termed the Uroplatidce. While resembling the true geckos in the doubly-cupped vertebræ, as well as in many

scale-footed other structural features, these lizards agree with the followLizards. - ing nine families in that the inner ends of the collar-bones Family lack the loop-shaped expansion characteristic of the geckos. Pygopodidce, The next fimily is that of the scale-footed lizards, or Pygopodide, which are confined to Australia, and appear to present a considerable resemblance to the Geckonidce, with which they agree in the general conformation of the skull. All these lizards have assumed a snakelike form of body, with the complete loss of all external vestiges of the front limbs, although the hinder pair are represented by two large, flap-like scaly expansions, without any sign of division into toes externally. 'The commonest species grows to a length of about twenty inches, and is coppery-grey in colour, sometimes having three or five rows of blackish spots or streaks.

A very large proportion of the lizards of the eastern and southern countries of the Eastern Hemisphere pertain to the very extensive and important family of the Agumidue, - a family which includes at least a conple

Family of hundred species ranged under thirty distinct generic Agamide. groups. These lizards have a tongue of the same type as that of the geckos, no dilation of the inner extremities of the collar-bones, and no bony plates beneath the overlapping scales with which the head and body are invested ; but they differ from all the foregoing groups in their acrodont dentition. The eyes, which are relatively smaller than in the geckos, are furnished with movable eyelids, and have circular pupils. Small scales cover the crown of the head, and the scales on the lower 
aspect of the body are likewise not enlarged. Many of the species develop large ornamental crests or pouches, either in both sexes or in the male alone. These lizards generally have a long tail, which is not brittle; and they always possess well-developed fore-limbs, which, with one exception, are five-toed. As a rule, the tceth are unequal in size, those at the corners of the jaws being developed into tusks. As in other lizards, the arboreal species have com. pressed bodies, while in those that dwell on the ground the trunk is more or less depressed. Although, as already said, aganoids are widely spread in the old World, they attain their maximum development in the Oriental countries, only three generic groups inhabiting Africa. Perhaps the most remarkable members of the family are the flying lizards (Draco) of the Oriental countries, in which the hinder ribs are expanded to support a kind of parachute-like expansion of the skin of the flanks. These folds can be closed in a

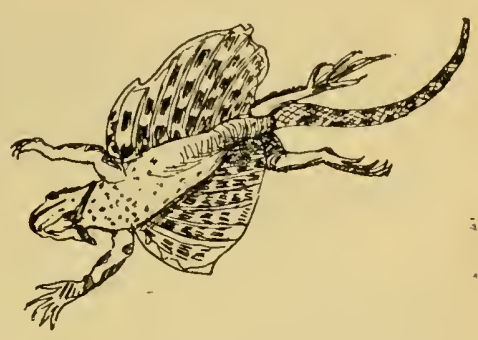

Fig. 12.-Fliting Lizard (Draco volans) fan-like manner, and there are other expansions on the throat. The entire body is much depressed, and the tail is very long and tapering. The coloration of the upper surface of the body is metallic, with dark spots and bands, the parachute of the common species being bright orange with black markings. These lizards live high up on the trees, and pass from bough to bough by taking fying leaps with the support of the parachute. At times the expansions of skin on the throat are erected. The Oriental region is likewise the home of the beautiful tree-lizards of the genus Calotes, which are also thoroughly arboreal, although unable to take flying leaps. They have the drum of the ear visible externally, a crest running down the neck and back, the large keeled scales on the back of equal size, a long, whip-like tail, and no distinct fold of skin on the throat. Many of them have the power of rapidly changing their brilliant colours, and some measure as much as sixteen inches in length. More curious are the arboreal hormed lizards (Ceratophora) of Ceylon, easily recognised by the presence of a horn on the nose of the males, and oometimes also in the females. There is no crest on the neck, and the drum of the ear is concealed. Next on our list are the numerous species of the typical genus Agama, which range from SouthEastern Europe over South-Eastern Asia, although absent from the greater part of India and Ceylon. These lizards are terrestrial in their habits, and accordingly differ from all the foregoing, with the exception of the flyinglizard, in having the body markedly depressed. They have the drum of the ear exposed, large thickened scales in front of the vent in the males, a fold of skin across the throat, and a pit on each side of the same part, while if the back is furnished with a crest, this is of small size. Jn parts of Asia these lizards are some of the most common representatives of their tribe, and niay be seen in nundreds basking in the sun.

Many of the genera of lizards are far from easy to distinguish from one another, but there is no difficulty in recognising the extraordinary Australian frilled lizard (Chlamydosaumes kingi), which has the throat surrounded by a large frill-like expansion of skin extending on to the sides of the neck. 
This lorg-tailed lizard, which grows to a length of over thirty inches, is an inhabitant of open sandy deserts, and is peculiar in that it habitually walks on its hind-legs alone. It does not, however, hop, but walks with a bold, swinging gait. Probably the frill is given to the creature for the purpose of terrifying its enernies, as when alarmed this lizard sits up on its hindlimbs, exponds the frill to its fullest extent, and shows its teeth; its appear-

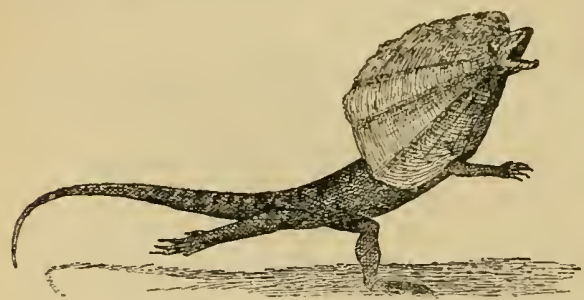

Fig. 13.-Frilled Lizard (Chlamydosaurus kingi). ance is then distinctly alarming, although the creature is perfectly harmless to large animals. From the preceding forms this lizard and a number of allied genera differ by having pores on the under surfaco of the body near the vent, or on the thighs, or in both of these situations. A closely related species is the sail-tailed lizard (Lophurus amborniensis) of the Malayan and Philippine Islands, in which the upper surface of the basal portion of the tail carries a huge vertical crest, while the nape and back are ormamented with a ridge of enlarged scales. This lizard, which has a compressed body, and an olivegreen ground-colour with irregular black markings, is an inhabitant of wooded districts near water, and if frightened, immediately plunges into the latter element. It is a vegetable feeder, and its flesh is stated to be tender ancl well-Havoured.

The tail is an important part in distinguishing many of the lizards of this family, and its characters form an easy means of recognising the thornytailed lizards of Northern Africa and Sonth-Western Asia, which constitute the genus Uromustix. Whereas the body is smoothly scaled, the whole of the rather short tail is invested with a series of rings of large scales each armed with a thorn-like spine. They have very short and rounded heads; the drum of the ear is visible, and there are pores in front of the vent as well as on the thighs. A feature in which these lizards differ. fiom all those noticed above is the large size of the front teeth, which in the adult are separated from those on each side of the jaws by a gap. Thorny lizards are abundant in the sandy plains of Arabia, Persia, and the Punjab, where they live in burrows. Probably the thorny tail is a means of defence, as if one of these lizards can but get its head and body well within its retreat, it seems to be pretty safe from attack. The writer once tried to drag one from its hole by seizing hold of the projecting tail, but the appendage gave way, learing

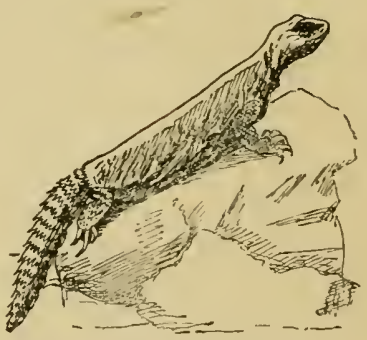

Fig. 11.-ThornT-Tatied Lizard (Uromastizi), the creature secure from further harm. Their food is entircly of a vegetalle nature; and the Arabs-by whom these lizards are frequently kopt in captivity-are very partial to thcir flesh. Tho last momber of the family that can be noticed is the moloch lizard (Moloch horridus) of South and West Australin, a creature which looks more like some monster in a pantonime 
thim a living animal. Measuring about eight inches in length, and liaving a depressed toad-like body and rather short tail, the moloch is covered all over above with large conical spines, which attain their greatest development immediately over the eyes and on the forepart of the back. It frequents sandy districts, is slow in its novements, and may be frequently seen abroad in the full sunlight. 'That its spiny arnour render's it perfectly safe from all ordinary attacks, may be considered perfectly certain ; and it is clear that the ereature's motto is defence and not defiance, as it is perfectly harmless. It has the power of slowly changing its colour to a certain extent in accordance with its surroundings; and its chief nutriment is formed by ants, although it will also eat vegetible substunces. Thorny devil or spiny lizard is the mame given to this reptile by the colunists.

The name iguma is one of those terms constantly misapplied in popular zoology, and it is very frequently given to the monitor's of India any Australia. As a matter of fict, most of the members of the great iguana tribe are confined to the New WTorld, where they take the place of the Old World Agamide, which are wanting. There are, however, a few outlying iguanas in the Old Worle, two gencra being found in Miadagascar, while a

The Iguana

Tribe.-Family

Iguaniclet. third occurs in the Friendly lslands and Fiji. In many points of their organisation the Igumide are clusely related to the Agrmide; but a ready means of distinetion between the two groms is afforded by the dentition. Whereas the latter hive the dentition of the acrodont type, in the former it is pleurolont; and a furtler difierence is to be found in the nearly uniform size and form of all the teeth in the iguanas. Very frequently the tecth liave lancetshaped crowns, with serrated elges; but in some rare instances they are dividel into three distinct cusps. Iguanas - of which there are fifty different generic modifications-present a curious parallelisun to the Agamidce in their structure and habits, doubtless due to the fact that they have to fill all the situations in the New Wrorld occupied by the different members of the latter in the Eastern Henisphere. Whereas, however, there is no flying iguana, this group contains a marine type, which has no representative among the ullied family. Nearly all the American forms are inhabitants of the warmer. regions of the New World ; most are insect-eaters, a few are vegetarians.

The beautiful iguanas of the American genus Anolis may be regarded as the western analogues of the Oriental tree-lizards. These are long-tailed arboreal species, with a pyramidal head, moderately long neck, a slender body of variable form, elongated hind-limbs, and large feet with toes of unequal length, in which the middle joints are expanded, and the claws long and elevated. The throat is ornamented with an appendage, which is generally brightly coloured in the males; but there is no crest on the back and neck. The teeth are distinctly three-lobed. More than a hundred different kinds of these lizards are known to seience, many of which take up their residence in human dwellings, where they luunt for their insect prey, quite undisturbed by the proximity of the owners. Like their Oriental representatives in the Agamidce, they have the power of changing the colour of their skin even more rapidly and decisively than the chamaleons. As the species of $A$ uolis represent Calotes in the Old Worlel family, so the basilisks (Basiliscus) simulate the sail-tailed lizard of the Malayan Islands. The American forms have, however, gone one better than their Old World prototype, for whereas in the latter the sail-like membranous cxpansion is confined to the upper surface of the tail, in the males of the former a similar vertical 
expansion of skin runs from the nape of the neck to the loins, where it is separated by a short interval from the one on the tail. In the back the crest is supported by the elongation of the spines of the back-bone; and in some eases the expansion on the tail is strengthened in a similar manner. The mules have in addition a helmet-like elevation on the hinder part of the head. Basilisks are tree-dwelling reptiles, nearly always found in the neighbourhood of water. They generally repose on a bough overhanging some pool or river; and when frightened, immediately throw themselves into the water, in which the males swim with facility by the aid of the erested tail, which aets is a rudder. How the female manages to get along without the crest is not stated.

From a group so extensive as that of the iguanas it is difficult to select the forms best deserving of special notice. There is, however, no doubt that two curious lizards from the Galapagos Islands demand lecognition here. Each of these is the sole representative of a genus by itself; but whereas one (Amblyrhynchus cristutus) lives to a great extent in the sea and feeds on seaweed, the other (Conolophus subcristatus) is a terrestrial ereature subsisting on a more ordinary vegetable diet. Having pores on the thighs, and the

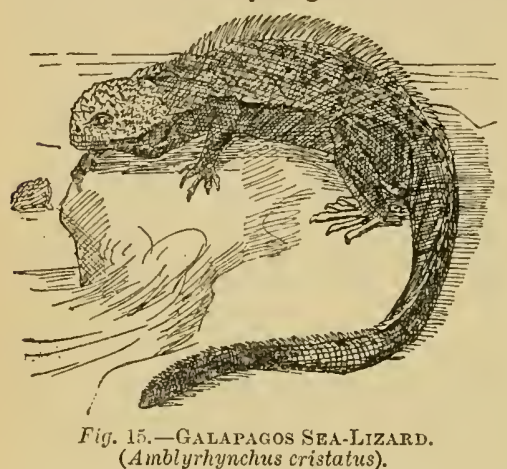

(Ainblyrhynchus cristatus). fourth toe of the hind-foot longer than the third, these lizards are specially distinguished by the circumstance that both the front and literal teeth are three-cusped. The narine species, which measures over fifty inches in length, and is considerably the larger of the two, takes its seientific name from the extreme shortness and bluntness of the head; both the body and tail being markedly compressed, and the toes furnished with incipient webs. The upper surface of the head is ornamented with a number of conical bosses ; and a strong serrated erest runs from the nape of the neck to the tip of the tail. The habits of these remarkable lizards have been well described by Darwin. He states that these reptiles are seldom found farther inland than a few yards distance from the shore; and that when in the water they swim strongly and ensily with a serpentine movement by the aid of the powerful tail alone. On the volcanie rocks forming the coasts of their native islands these lizards are met with in large droves, which from time to time proceed to sea in search of food. In spite, however, of this fondness for the sea, they never take to the water when attacked as a means of escape. The smaller terrestrial species is easily distinguished by the eylindrical form of the tail and the absence of any trace of webbing on the toes. The head, too, is somewhat longer, and the clorsal crest fully developed only in the region of the neck. In weight, they scale from ten to fifteen pounds. On the central islands of the Galapagos group these lizards are, or were, found in such numbers that there is sometimes a difficulty in discovering a space of any size free from them. They live in burrows, and in the daytime love to lie basking in the sun for hours at a streteh in a dull, listless manner. Evell when disturbed, they are slow to get out of the way ; and in 
all thein movements they are very unlike ordinary lizards. Nearly allied to the Galapagos forms are the two species of the typical genus Igrana, which are restrieted to Tropical America and the West Indies. From the former they are distinguished by the simple, conical front teeth; the lateral teeth being serrated. They have the body long and compressed, the quadrangular' and large head covered above with enlarged slields, and the long tail invested with unifom and keeled seales. The neck, back, and upper surfaree of the tail are ornamented with a continuous spiny erest, and there is an appendage on the throat which is incapable of dilation. These iguanas are essentially arboreal lizards, living in forests in the neighbourhood of water, and frequently descending at night to the ground to feed. They readily take to water, in which they swim with facility; and although their diet is mainly of a vegetable mature, they will freely eat insects and other invertebrates. The common species measures as much as four and a half fect in length. By the natives of the countries they frequent, iguanas are highly esteemed, and they are regularly limnted in some distriets for food. 'Their eggs are also much sought after for the same purpose. Nearly allied is the ring-tailed iguana (Cychura crinata) of the West Indies, in which the crowns of the lateral teeth are tricuspid, and the throat is furnished with a pouch, the back and tail being strongly crested.

As the Agumidce possess a spine-clad type in the form of the moloch lizard, so a similar type occurs in the present family. These creatures are generally called horned lizards, althongh in the States they are known by the title of Californian toad. The genus to which they belong (Plrynosuma) includes about a dozen species, which liave a geographical range extending over tho United States and Mexico. From all other members of the family they aro at once distinguished by the mumerous spines studding the skin of the body, head, and tail; while they are further characterised by their short, rounded head, general toad-like form of borly, and aboreviated tail. About five inches is the ordinary length of these lizards. As regards habits, these lizards are inliabitants of sandy districts, where they prey upon beetles and such other insects as they are able to capture. Some of them are among the few member's of the Ifuanide which give birth to their young in a living condition. This peculiarity, compled with their remarkable external appearance, would be sufficient to give these lizards a claim to distinetion above their fellows. But they have another peculiarity. They spit blvod; and this not from their mouth, but from their eyes. Ineredible as this statement may appear, it is attested by several trustworthy observers. When handled, they have been known to squirt a jet of blood to a distance of more than a foot from one eye, and soon after to emit a similar stream from the other. And this not only onee, but several times. Doubtless this most remarkable action is for defensive purposes; and American observers would do good service if they would describe in detail the mode in which the operation is performed.

A peeuliar lizard from Mexico is the representative not only of the genus Xenosaurus, but likewise of the family Xenosauridre. Passing this by as being worthy only of the attention of specialists, we come to the girdled lizards, of which there are four genera from Afriea south of the Sahara, and the island of Madagascar. To a great extent the group is intermediate between the

Girdled Lizards, - Family

Zonuride. preceding family of the Igranida and the following one of the Anguidce. From the former it is distinguished by the hinder lateral regions of the skull being roofed over by (dermal) ossifications in the skin, and likewise by the 
interclavicle being cruciform instead of $\mathbf{T}$-shaped ; while, from the latter, it is differentiated by the conformation of the tonguc-which, as in the Iguauide, is not civisible into an interior and posterior portion-as well as by the hollow bases of the teeth, and by the structure of the bony plates, which in one genus underlie the scales. All have a fold of skin covered with small scales along the sides of the body, by which the upper surface is defined from the lower. The head is invested with large and regular shields; but the back may be covered either with shield-like scales, which are frequently provided with keels, and are arranged in regular transverse zones, or with granules. As in the Ignanide, the teeth are pleurodont, and the bases of those in use are hollowed out by the tips of their successors, which rise vertically from beneath. In the three genera Zomuns, Psendocordylus, and Platysamus, both pairs of limbs are well developed, but in Chamesama, the general form is snake-like, the fore-limbs being absent, and the hind ones rudinentary, while the tail is remarkable for its excessive relative length. The only Tilalagiasy form is a species of the genus first named.

Although in several groups of the sub-order the limbs have more or less completely clisappeared, in no case is the assumption of a scrpent-like form more strongly marked than in the family typically represented

Snare-like by the common British blind-worm. It is to this family, Lizards.- accordingly, that the name of snake-like lizards is most Famiiy applicable. While all these lizards resemble the members Angnidue. of the preceding family in having the hinder lateral regions of the skull roofed by bony plates developed in the deep layer of the skin, they differ in the structure of the teeth. It is true that the teeth arc often attached in the pleurodont manner, but instead of having the base hollow, this is solid, the new teeth coming up between two of the old ones, instead of beneath the crown of the one immediately above. Whereas in must of the genera the teeth are either tubercular or in the form of short cones firmly attached to the sides of the jaws, in the blind-worms they are

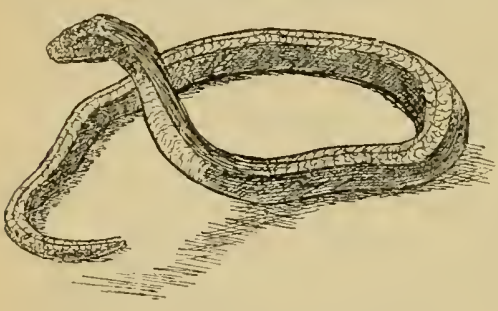

Fig. 16.-Blixd.Torm (Anguis fragilis). long, slender, highly curved, and very loosely fastened to the bone. In these respects the blind-worms come very close to the snakes, and also to the poisonous lizards of the family Helodermatide. And it is not a little renarkable that traces of a groove have been detected along the front surfaces of the teeth of the blind-worms which appear to correspond to the poison-grooves of those of the family in question. It seems, therefore, as if the popular dread of the blind-worm was in. stinctive, and that the creature is either descended from poisonous ancestors, or would be poisonous if it could. All the members of the family have bony plates developed in the deep layer of the skin beneath the scales, these plates, when viewed under the microscope, displaying a system of canals. Very peculiar is the tongue, which is divided into a large thick hinder portion, thickly covered with shaggy papille, and a small thin emarginate front moiety, of which the covering takes the form of small, scale-like papillie. This front portion is extensile, and also capable of more or less full retraction into a 
sheath formed by a transverse fold at the front of the hinder portion. A further resemblance to snakes is to be found in the circumstance that these lizards cast their skins in a single piece. As regards the limbs, great variety is presented by the seven genera included in the family, somo having the feet fully developed, and terminating in five toes, whereas in others all external traces of limbs have disappeared. It is noteworthy that all the limbed forms are American, and that Central Ameriea and the West Indiun Islands are the head-quarters of the gromp. Beyond the New World, two species are found in Europe and Nortl Africa, while a third inhabits Burma and the Himalaya. Of the seven genera, Gerromotus and Ophisumus are peculiar in having a lateral fold on the body; the former, which is exclusively American, having two pairs of fire-toed limbs, while the latter has, at most, external representatives of the hinder pair. This genus includes the wellknown scheltopusik $(O$. apus) of South and Eastern Europe, as well as one Oriental, and other Amcrican types. Of those withont folds, the genera. Diploglossus, Sutresic, and Punoplus are American and four-limbed, differing from one another in the number of the toes, which vary from one or two to five on eacli foot. Ophiodes is likewise American, but has only external rudiments of the hind-limbs. Lastly we have Anguis, represented solely by the familiar blind-worn of Europe, Western Asia, and North Africa, which lacks all vestiges of limbs extermally, and has the lateral teeth large and fanglike. This species is also peculiar in giving birth to living young, all the other members of the family laying eggs in the ordinary manner. All the Angricle live on animal food, the

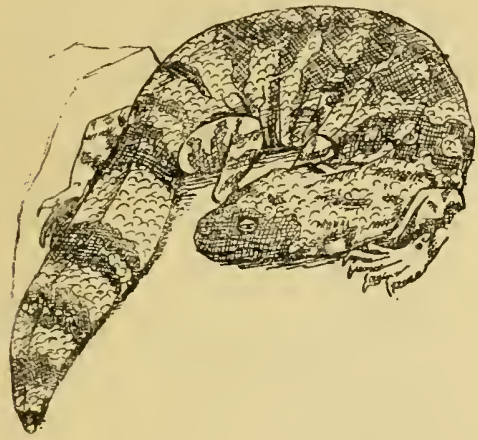

Fig. 17.-Potsosots LizARn (Heloderma). larger kinds killing and eating small mammals, birds, and reptiles, whereas the smaller species confine themselves to worms, insects, slugs, and such like. As a rule they are strictly terrestrial, although some species of Gerrhonotus will climb up low bushes.

The family Amiellide, as containing only a single Californian genus with two species, may

be passed ovel with- Poisonous out notice, and we Lizards.-Family accordingly proceed Heloclematide. to the family Helodermatide, which also comprises only two species, and ranges from Central America to New Mexico and Arizona. In common with many of the poisonous snakes, these lizards are distinguished by their brilliant coloration, one kir, having an orange or yellow ground-colour, with an irregular net-work of dark markings on, the head and body, and dark rings round the tail. These lizards possess a tongue and teeth of the same general type as in the blindworm, but have the upper surface covered with transverse rows of small granular tubercles, the uuder-parts being invested with squared scales. From those of the blind-worm the teeth differ by having grooves on the front and back surfaces for the transmission of the poisonous fluid, and there are certain structural differences in the skull. Both species are included in the genus Heloderma, and the one from Arizona is rather the larror of the two, its 
total length being about twenty inches. Both have the head broad and dopressed, the body rounded and thick, the tail moderately long and cylindrical, and the limbs relatively small, with the third and fourth toes the longest. The poisonous lizartis are sluggish and nocturnal, inhabiting sandy districts, with the soil of which their coloration is in admirable harmony. They are most commonly seen abroad in the rainy season, and are carnivorous in their diet. Small mammals are speedily killed by their bite, which is stated occasionally to have fital effects on human beings.

A third family of the sub-order with only a single genus, is that of the monitors; the range of the numerous species extending from the Caspian through Southern Asia to Australasia, and likewise

Monitors.Famlly

Varanille. embracing all Africa, as well as the Pacific Islands. They are all of large size, one measuring between six and seven feet in length. As comprared with the preceding fimmilies, their essential characteristic is to be found in the snake-like structure of the tongue, which is long, deeply forked at the tip, extensile, and capable of being withdrawn into a sheath at the base. They all have welldeveloped, five-toed limbs, a long and often compressed tail, swall scales on the head, and the drum of the ear exposed. Owing to the presence of marginal rows of granules, the scales on the back do not overlap, and in no case is there a median longitudinal crest in this region. The different species of $V$ arunus may be arranged in four groups, the distinctive features of which need not be noticed here. They are generally found in the neighbourhood of water, and one Indian species frequents

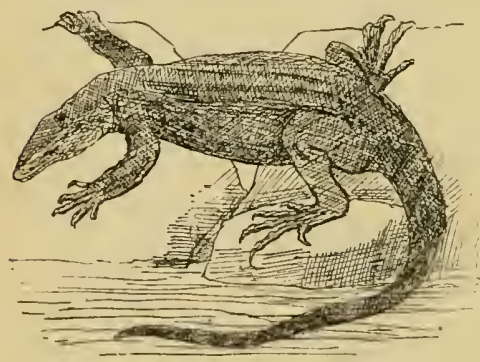

Fig. 18.-A Monitor (Faranus). the coast, and will at times enter. the sea. In habits, they are purely carnivorous ; and, with the possible exception of the Papuan species, they are also terrestrial. They are among the most active of the lizard tribe, and although generally hammless and avoiding attack, it would appear from the following account that, when driven to bay, they will turn on their aggressors. Of the Nile monitor (V. niloticus), Dr. Abel Smith writes that "it is usually met with in rocky precipices, or in low stony hills, and, when surprised, seeks concealment in the chinks of the former or in the irregular cavities of the latter, and when any projections exist upon the surface of the rocks or' stones, it clasps them so firmly with its toes, that it becomes a task of no small difficulty to dislodge it, even though it can be easily reached. Under such circumstances, the strength of no one man is able to withdraw a fullgrown individual, and I have seen two persons required to pull a specimen out of a position it had attained, even with the assistance of a rope fixed in front of its hind-logs. The moment it was dislodged it flew with fury at its enemies, who by flight only saved themselves from being bitten. After it was killed it was discovered that the points of all the nails had been broken previously, or at the moment it lost its hold. It feeds upon frogs, crabs, and small ruadrupeds; and, from its partiality to the two former, it is often found among rocks near to springs or running streams, whicb fact having 
been observed by the natives, has led them to regard it as sacred, and not to be injured without danger of drought." All lay eggs, and many, if not all the species, feed largely upon the eggs of birds.

A much larger assemblage is that of the greaved lizards of the New World, which there occupy the position held in the Old World by the allied family of the Lacertide. From all the preceding forms, the Teiidce and following families are broadly distinguished by the circumstance that their cleft and often spear-like tongues are covered either with overlapping scale-like papillæ, or are marked by oblique folds. Then, again, in place of the small scales of

\section{Greaved Liz. ards.-Family Teiida.} the $V$ aranida, the head is invested with large symmetrically arranged shields ; and in the skelcton the inner extremities of the collar-bones are expanded, and not unfrequently assume a looped form. The Teide - of which there are five-and-thinty genera, and more than a hundred species-have the headshields free from the bones of the skull, no bony plates underlying the scales, and no bony roof to the hinder lateral regions of the skull, while the scale? are arranged in transverse rows. The teeth are very variable in form and structure, but are always solid at the base, owing to the circumstance that their successors come up alongside. The teeth in the front of the jaws are always conical; but both these and the lateral series may be attached either on the acrodont or pleurodont plan. Distinct eyelids are generally present; the drum of the ear is always visible externally; and the tongue is in most cases covered with overlapping scales, and may be eapable of retraction within a basal sheath. Although most of these lizards have five-toed limbs, in certain cases each foot has but four toes, while in other instanees the limbs are represented only by stumps, and even all external traces of the hinder pair nuay disappear. The numerous representatives of this important family have their headquarters in equatorial America, although some forms may be met with throughout the warmer portions of that continent. Like the monitors, they are active in their habits, and feed upon animal substances; but they may be found in all sorts of situations, some living in holes in dry sandy districts, while others prefer the dense herbage of moist localities. The number of genera is far too great to admit of even mention in this place. It will accordingly suffice to take as our representative of the family tlie large and handsome species commonly known as the tegu (Tupinumbis tequexin), which is a common and widely-spread species, ranging from the Guianas in the North to Uruguay in the South. Measuring about three feet in length, this lizard has a bold and striking bearing, owing to the elevation of the fore-quarters. Its general colour is some shade of olive above, ornamented with blotehes and bars of black, and indistinct longitudinal rows of light spots. It is met with in great numbers among the virgin forests of Amazonia, where, with its forked tongue in rapid motion, it may be seen either sitting quietly upon a branch, or running

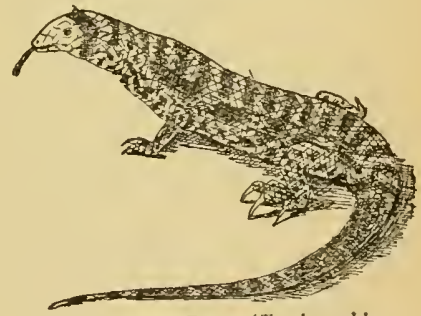

Fig. 19.-THE TEGU (Tupinambis tequexin). rapidly over the ground. As is the case with some of the other members of the family, its flesh is esteemerl as food by the natives.

As already mentioned, certain members of the preceding family have lost 
all extemal traces of the hinder pair of limbs, and as such species possess burrowing habits, they may be regarded as forming a conFamily necting limk between the Teidec and the degraded AmphisAmphisbenidee. bonide. The latter, which take their name from the fact that most of them are able to advance with equal ease in either a forward or a backward direction, may, indeed, in all probibility, be considered as derivatives from the ancestral stock of the former, which have little by little accustomed themselves to a subterranean mode of life, till the majority have acquired an almost completely worm-like form and habit. One American species, alone representing the genus Chirotes, still, however, retains minute though well-developed fore-limbs, which are placed close up to the head, and followed by the long worm-like body. And to the zoologist this form is of the highest importance, as indicating that all the other members of the family trace their origin to fully-limbed ancestors. With the exception of this solitary species, the amphisbenas are all limbless, worm-like creatures, in which even the bones of the pelvis and shoulder-grirdle are reduced to the condition of rudiments. In all, the ears are wanting, the functionless eyes are buried deep down in the skin, and the minute mouth is often situated on the lower aspect of the head. The tail is always short; and the few and large teeth, as in the preceding family, may be either acrodont or pleurodont. Indeed, it is chiefly by certain degraded features of the skull that the Amphisucenidie are distinguished from the Teiide; and as such differences are obviously produced by adaptation to their environment, the amphisbenas are but little removed from their nearest allies. Not the least interesting feature in comnection with these strange creatures is their peculiar geographical distribution-a distribution which can only be understood by taking extinct forns into consideration.

Of the existing types, the true home is Iropical America, although two species-one representing Chirotes-are found above the northern tropic ; but a considerable number of species are inhabitants of Africa, and a few occur in the Mediterranean countries. Most remarkable is the circumstance that the extensive and typical yemus Amphisbcence has representatives botli in Tropical America and Africa south of the Saliara. 'This, however', is but one out of many instances showing a community between the faunas of South Africa and South America. The family is clivicled into two groups, according to the mode of attachment of the teeth. In the first group, or' Prosphyodontes, which includes Chivotes, Amphisbanr, and six uther genera, the teeth are welded to the imer edges of the jaws; whereas in the second group, or Emphyodontes, which is represented by Trogonophis. Pachyealmus, and Agamodon, they are affixed to the edges of the same. Regarding the mode of life of the amphisbrenas, MI. G. A. Boulenger writes as follows :"All the members of this family are burrowers, and many live in ants' nests. They bore narrow galleries in the earth, in which they are able to progress backwards as well as forwards. On the ground they progress in a straight line, by slight rertical undulations, not by lateral movements, as in other. limbless reptiles. The tail of many species appears to be more or less prehensile. The food of these lizards consists of small insects and worms. Little has been published on their labits, and all that is known about their node of propagation is that Anops lingi is oviparous, and deposits its eggs in the nests of ants." It may be added that the Amphisbcenidce are peculiar among vertebrates in having the right lung rudimental or absent, whereas the left is elongated. In other snake-like lizards. and in snakes, it is the right lung that is functional. 
'The typieal family of the sub-order is exclusively an Ohl World ome, and is spreal over the three great eontinents, although unknown in the island of Makligasear and likewise in the Australasian countries. From their New World cousins the 'Tciide, these lizards may be reaclily distimguished by the circminstance that a eomvlete roof of bones cleveloped in the deep layer of the skin covers the hinder lateril regions of the skull, and also by the fact that the shields of the head are attached to the bones of the skitl. They further (lifler-and thereby resemble the Amphisbenide -in having the two anterior ulper jaw-bones, or premaxille, immovably united in front. In none are the limbs aborted; and in all eases the feet terminate in five eomplete toes. The general form is too well known to repuire mention; and it is in these lizards that the long tail breaks off so readily at or near the miclle. The teeth have hollowed hases, and are attaehed to the jaws in the pleurodont manner' ; and the tongue has the form of an arrow-head. Distinct eyelids, which can generally be elosed, are developed; and the drum of the ear is visible from the outside. In none of these lizards are bony plates developed in the skin beneath the scales; and while the scales of the back may either overlap one another or have their edges in contact, those on the under surface of the body are arranged in tramsverse and longitudinal series, and are usually superior in size to those above. The family, which includes seventeen generic types and somewhere about a hundrel species, attains its maximum development in Africa, being but poorly represented in the Oriental countries. While several species are met with in the south of Europe, two only are found in Britain, where, with the blind-worm, they are the sole representatives of the sub-order Lacertilia. All are fond of sumy localities, where their brisk movements and beautiful metallic tints render them attractive to all who do not possess an instinctive dislike to everything in the shape of a reptile. Flies, beetles, and slugs form their chief food; and as in the eolder pints of Europe and Asia, these are not to be seen alnoad in winter, lizards are perforce compelled to follow suit and jass the dull winter months in a state of torjor, either buried beneath the ground, or safely ensconced in clefts and cramies. Although one speeies proluces its youmg alive, the rest lay eggs.

Both the British speeies belong to the typical genus Lacerta; and of these the smaller is the viviparous lizard ( $L$. vivipart), which grows to a length of seven inches, and takes its name from the aforesaid peculiarity in its domestic arrangements. The second is the sand-lizari ( $L$, agilis), which may measure between eight and ten inches in length, and langes as far north as Sweden and Nolway. More beautiful and considerably larger than either of the foregoing is the green lizard ( $L$. vividis), ranging from Southern Europe through the Mediterranean comtries to Persia. The northern limits are Germany, where this lizard never reaches the dimensions it attains in more favoured climes. Yet another South European species is the pearly lizard ( $L$. ocellata), easily recognised by the presence of a row of large blue spots on each side of the body, the general colour of the upper-parts being in some cases green, with dots or a network of black, but in others dark olive with yellowish markings. This species is larger than any of the foregoing, sometimes measuring as much as twenty-three inches in length. It would be im. possible in the space available to give the names and characteristics of all the seventeen genera included in the family. It may, however, be mentioned that in Southern Europe there occur three lizards belonging to a closely allied senus known as Algiroidcs, differing from Lacerta by the larger size of the 
scales on the back. Another South European genus, also extending into the north of Africa, is Pscmmodromus, the members of which differ from both the genera above-nentioncd by the slight development or complete absence of a collar or gorget round the throat.

A small neatly-made lizard, commonly known as the skink (Scincus officinalis), which inhabits the Sahara desert and the countries bordering the Red Sea, is the type of the last large and important family of the

Slrink Tribe. Lacertilia. It should, however, be mentioned that the -Family small African family of the Germosauridce includes tive Scincida. genera, which, to a certain extent, serve to connect the Lacertidce with the Scincide. They have, for instance, the scales of the body underlain by bony plates of peculiar internal structure, as is the case with the latter family, whereas in the union of the two premaxillary bones and the presence of pores on the thighs, they are like the former. The presence of such bony plates beneath the scales, the distinctness of the two premaxille, and the invariable absence of pores on the limbs, are characters amply sufficient to differentiate the Scincidce from the Lacertidce. There are twenty-five genera included in the family under consideration, in one of which (Lygosoma) no less than one hundred and fifty-nine distinct species are recognised by zoologists. With such a number of different forms, it is not surprising to find that the family is cosmopolitan. Its head-quarters are, however, the Australasian and Oriental countries, together witl the islands of the Pacific and Africa. Skinks are essentially terrestrial lizards, all loving dry sandy cleserts, where many burrow in the soil ; and it is probably largely due to such habits that the lower eyelid is furnished with a transparent window in the centre, so that the eye can be used when protected by its covering. A peculiar feature of the family is to be found in the circumstance that the young are almost invariably born in a living condition. Whereas, in all cases the limbs are relatively short, in certain instances one, and in others both pairs are wanting. Mauy of the above-mentioned features clearly indicate that they are a highly specialised group. Since the number of young produced at in birth may be as low as two, and does not seem to exceed half a score, the rate of increase of these lizards is comparatively slow.

The common skink (Ncincu officinalis)which is a smooth-scaled, parti-coloured lizard of about eight inches in length, owes its scientificname to the circumstance

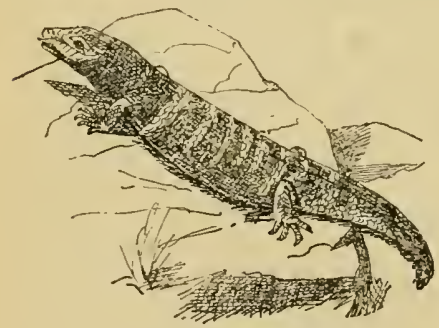

Fig. 20.-Common SkIN K (Scincus officinalis). that its flesh was formerly employed in European medicine, as it still is in the East. It is a creature common enoligh in Syria and Palestine, where it burrows in the sandy soil. Its flesh is stated by European travellers to be by no means unpalatable if properly cooked. The most extraordinary-looking member of the entire family is the Australian stumptailed lizard \$Trachyscumus rugosus), which is covered with large rough browny scales, underlain by thick bony plates, in such a manner as to give it the appearance of an extremelyelongated pinecone. The short and broad head is triangular in form; the limbs are very short, the front and hind pair beingr widely separated from each other; and the tail is reduced to a very short, wide, rouncled stump. In its habits the lizard is slow 
and lethargic, as if existence werc somiewhat of a bore, and although its chief food is of an animal nature, it is stated also to consume vegetable substances.

Certain worm-like burrowing skinks from the tropical and sub-tropical regions of the globe are degraded types, regarded as constituting two families by themselves. In both these families-the Anelytropide and the llibamide -the degradation shows itself not only in the loss of limbs, but likewise in the simplification of the skull, which has lost all its lateral arches; while the eyes are buried beneath the skin, and the ears have no external opening. In the first family-which contains the Mexican genus Auelytropsis and the African Feylinia and Typhlosaumis - the bony plates beneath the skin are retained, but the two premaxille have coalesced into a single bone. On the other hand, in the Dibumide the premaxille remain distinct, but the bony plates in the skin have disappeared. This second family is represented only by the genus Dibcmus, of which one species ranges from the Moluccas through Celebes to New Guinea, while the second is restricted to the Nicobar Islands.

\section{Sub-Oreler II.-Rhiptoglossa.}

\section{Chimalemons.}

In their slow and deliberate movoments, as well as by their peculiar revolving eyes and generally grotesque appearance, chamaleons suggest the idea that they do not properly belong to the present order of things, but are survivors from some ancient epoch in the earth's history, when strange and uncouth monsters were to the fore. Nevertheless, we have no evidence that such is really the case, since such fossil chamaleons as are known belonir to a comparatively late era, and the extreme specialisation of these strange creatures is, perhaps, rather in favour of their modern origin. Although in popular language chameleons come under the designation of lizards, they are structurally so different from the Lacertilia that there can be no hesitation in regarding them as the representatives of a distinct sub-order. Apart from the peculiarities of their external appearance, they are broadly distinguished from lizards by the conformation of the tongue. Anyone who has seen a tame chamzleon harpoon a fly at a distance of half a dozen inches from its lips, will not readily forget the appearance of the long extensile, worm-like organ which is shot ont from the mouth with the speed of an arrow, to be withdrawn immediately after with the hapless victim adhering to its viscid and club-shaped tip. The feet, too, are as unique in their way as is the tongue, some of the toos turning in one direction and the remainder in the other, so as to form a grasping organ of unrivalled power. Whereas in the front feet three toes go to form the inner half of the grasping organ, and two to the outer, in the hind-limbs this arrangement is reversed. The large revolving and prominent eye is in the form of an egg, with most of the exposed portion invested by a thick continuous lid of a granular texture, in the centre of which is the minute perforation for the pupil. Each eye can be moved independently of its fellow; and these movements serve to heighten the general grotesqueness of the creature's appearance. Owing to the frequent development of three tall backwardly-projecting ridges on the hinder part of the skull, the head often assumes a casquc-like form ; and the small triangular and compressed teeth are aftixed to the jaws in the acrodont manner. In all the species the body is so much compressed as to be much deeper than 
wide, while, owing to the great relative length of the lanky limbs, it is raised high above the ground. The long tapering tail is as good a grasping organ as that of an American monkey. Externally, the whole surface is covered with granules, or small tubercles, so that, properly speaking, chamreleons do not come under the title of Squamata. In their skeleton, chamæleons differ from all lizards with fully-developed limbs by the complete loss of their collar-bones.

Chamrleons are all so closely related to one another that a single familythe Chamceleontide-suffices for the group. Moreover, with the exception of

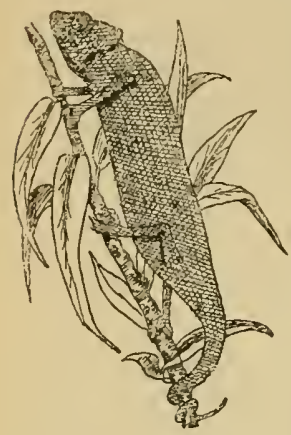

Fig. 21.-A Ch.MMeleon. threc Malagasy species forming the genus Broolesiu, and two others from Africa, which are separated as Rampholeon, all the forms may be included in the typical genus Chameleon, of which forty-four specitic representatives are recognised. As regards their greographieal distribution, chamæleons are chiefly characteristic of Afriea south of the Sahara and Madigasear; but the common Chamaleon vilgaris is an inhabitant of many of the Eastern Mediterranean countries, and is also found in Andalusia and Algeria. India and Ceylon likewise possess a representative of the same genus, while South Arabia is the home of a third, and Socotra of a fourth. Great difference exists in the bodily size of the various members of the family; the smallest being a species of Brookesirt measuring less than three inches in length, while many of the larger kinds grow to considerably more than a foot.

Chamelcons are essentially arboreal animals, mostly living in trees or bushes abundantly clothed with leaves, and in localities where moisture is plentiful. Although these reptiles have long been celebrated for their power of changing the colour of their skins, yet it appears that the phenomenon is by no means so strongly marked in this group as it is among certain lizards. Still there is considerable change ; and whereas most chamæleons are generally of an apple-green eolour in daylight, it is stated that during the night the tint of the skin fades to a greyish-white. If during the daytime a chamæleon passes from a leaf to a bough, its skin soon assimilates to the sombre Ine of the latter ; and if scized in the hand the change is even more rapid. In spite of the partiality of nearly all the species for dense tropical or sub-tropical vegetation, a few have betaken themselves to spots in desert districts where they find herbage enough for their needs. All are insectivorous, their favourite food being flies; and the rapidity with which one of these insects is seized by the tonyne forms a strange contrast to the otherwise sluggish and delibcrate movements of these reptiles.

Sub-Oreler III.-Ophidia.

\section{SNAKES.}

The leading structural features by which snakes are distinguished from the limbless lizards laving been already given under the lieading of the sub-order Lacertilia, these need not be recapitulated, and attention may accordingly be directed to some of the other characteristics of the former group. Everybody is aware that snakes are scaly reptiles, crawling on the ground without the 
aid of limbs; but it is probably less widely known that eertain members of the group retain vestiges of the hind-legs in the shape of two spur-like projections from the body in the neighbourhood of the vent. Aud in such forms, if the skeleton be examined, it will be found that there are remnants of the bony framework of the pelvis and upper part of the hind-limbs. All these ficts elearly show that snakes trace their deseent from reptiles endowed with four complete limbs. Under the heading of the Lacertilia it has been mentioned that the two branches of the lower jaw of a smake are united at the chin by a ligament, so as to be capable of wide separation from one another; and in many members of the group the eapacity of the mouth can be further augmented by a similar arrangement in the upper jaw, the bones of both the jaws themselves, and likewise those of the palate, being movably joined togethei. This arrangement permits these reptiles to devour a prey of considerably linger size th in the normal calibre of their mouth and throat. In place of movable eyelids, suakes have a continuous transparent shin stretcherl wer the eyes, which is periodically cast with the slough; and in ino case is there any external opening to the ears. A peculiar feature in a serpent is the enormous number of vertebrie contained in the backbone, not less remarkable being the number of pairs of ribs. In fact, from the head to a long way down the tail, each joint of the backbone carries a pair of these appendages, which increase gradually in length from the head to the fore-part of the trumk, and thence as gradually diminish to the tail. There being no vestiges of collar-bones or breast-bone, each rib terminates below in a free point.

fn order to give extra flexibility, and at the same time strength, to this exceedingly elongated backbone, the vertebre of serpents are provided with extra articulations, a wedge-like projection from one fitting in to a correspouling hollow in the next. Such additional articulations are, however, by $n$ means confined to snakes, but also occur in some lizards, notably the monitors. In ordinary land rertebrates the ribs are largely connected with the function of breathing ; but in snakes-in addition to supporting the walls of the trunk, and thus keeping open the eavity of the chest-their chief function is in progression, so that these reptiles may really be described as rib-walkers. On the under surface of the body the majority of snakes have a series of large transverse horny shields, which are much wider than long, and in the trunk-region extend right across the lower surface ; these shields, it may be remarked, being absent in the limbless lizards. In the tail the enlarged shields not unfrequently form a double longitudinal series. Eich of the complete transverse shields corresponds to the termination of a pair of ribs. By holding on to the inequalities of the surface they are traversing by the free edges of the shields - which project backwards-and then by drawing closer together the ribs of one side of the body, and afterwards those of the other, a smake produees the well-known lateral undulations of its body. By straightening out the front part of the body when a firm hold is obtained, and then drawing after it the hinder portion, progression is effected. On a smooth surface movement is impossible, and no snake ever produces vertical undulations of its body. All snakes have a prehensile forked tongue, capable of retraction within a basal sheath, and during their waking hours kept in constant movement. Usually the head of a snake, both above and below, is investad with a number of large and symmetrically-arranged polished horny shields, to each of which a distinctive name is given. Internally, snakes are remarkable for the great elongation of the lungs, or rather lung, since. as a rule, only the one on the right sicle is functional. 
As regards their biting organs, harmless snakes generally have two rows of teeth in the upper, and a single row in the lower jaw, such teeth being slender, sharp, and comparatively short. In some, however, either one or two pairs of teeth of the outer upper series may be larger than the rest, and provided with a groove, or completely tubular, such a type probably always inclicating more or less developed noxions properties. In some of the most deadly members of the sub-order, the arrangements for the injection of the poison are of a more complicated nature. Here the short maxillary bones are capable of being moved so as to become at right angles to the bones of the rest of the palate, while each carries a large channelled tusk, which, at the moment of biting, assumes an erect position. Through this pair of tusks, or fangs, the poison is conveyed from the secreting glands, which are placed below and behind the eyes. In some kinds these glands are short, those of the cobra being of the size of an almond ; but in others they extend far down the body. Regarding the mode of operation, an Australian writer observes that "the curious structure of the fang makes it almost certain that the poison shall be injected under the skin. The opening of the groove is not at the very tip, where it would be liable to get plugged up with skin or flesh, and so prevent the passage of the poison, but a little way up from and in front of t $l_{j}$ is, so that the shar p point goes in first, and makes a little hole into whicl the poison flows. In fact the poison fang is the model of the medical injecting syringe, and is exactly adapted to its purpose. The secretion of the gland varies in different snakes in quantity and in quality. It is a clear viscid fluid, which can retain its deadly properties for long, and does not even lose them when dissolved in water or alcohol. Sir J. Fayrer, the great authority on Indian snakes, found that the blood of an animal killed by snake poison was itself poisonous, and he transmitted the venom through a series of three animals with fatal results."

It was long supposed that hammless and noxious serpents were broadly distinguished from one another by definite external characters, but this is now known to be incorrect; and it is only by an examination of the teeth that it can be determined whether or no any particular serpent is hurtful. The clestruction of human life by snake-bite in India is something appalling, as may be gleaned by a recent return of the Indian Government. It is there stated that, whereas in 1892 the deaths caused by snake-bite in the lower provinces of Bengal were 9,510 , in 1893 the number rose to 10,797 . Thourh the deaths in Bengal, as might be supposed from its larger area, exceeded those in the other provinces, there was apparently nothing permanent in the rise, as the number fell to 9,856 in 1894. The declease of mortality during 1894 is ascribed in Bengal and Assam to the low flood-levels, the snakes not having been dislodged from their usual haunts, as happens when the water is high. In Assam the mortality is the lowest recorded in the last ten years. The loss of life from snake-bite was highest, in proportion to the population, in Bengal, Ajmir, the North-Western Provinces, and Oudh and the Central Provinces. If all the provinces be taken together, one person was killed in this manner among every 10,267 of the population in 1894 , as compared with one in every 10,424 in 1893. The apparent increase in Assam is ascribed to more accurate reporting. In the Central Prorinces the same explanation has been offered for a continuous increase; but the statistics in general are viewed with distrust. The number of venomous snakes reported to have been destroyed, and the rewards granted on this account shown in the retum, fell respectively from 117,120 to 102,210 , and from Rs.12,607 to Rs. 10,150 . 
Anything that can check this frightful mortality must be welcomed; and, after the trial of many so-called remedies, it appears that a real antidote is the blood-serum of animals which have been previously immunised to snakepoison or in that of venomous serrents themselves. Regarding the former method, Dr. J. G. M'Pherson writes that its discoverer-Professor Fraser of Edinburgh-first proved that there is a certain amount of toleration for suake-poison in animals. "Having ascertained the minimum close requircd to cause the death of an animal, he started below that amount and gradually increased the dose after intervals of ten days. By this process of gradual increases in the dose of the snake-poison, he found the animal receiving is much at one time as fifty times the amount of the minimum lethal dose without it causing any perceptible bad effects. In fact, its general health seemed to improve, as he had the animals weighed once and sometimes twice every day; and all the time he was administering the venom there was a stendy increase in weight. In the meantime Professor Fraser has not carried his experiments of quantity further than fifty times the minimum lethal dose at one time ; but still, when he had got to that point, the animal was receiving in a single dose, without being affected, enough to kill fifty animals of the same size and weight. One of the animals which he had treated by this gradually increasing (quantity had, in two months, received enough poison to kill three hundred and seventy fresh animals of equal size and weight, supposing that each just got the minimum lethal dose. He then described a second series of experiments in which he used the blood-serum of these animals which had been inmunised as an antidote for the venom. He mixed an equal part of this blood-serum and venom together, and injected the mix. ture into a fresh animal. This produced no effect, the serum counteracting the action of the poison. Next he injected some of the immunised bloodserum, which he has named antirenine, into a fresh animal, and then some venom afterwards, but the serum hindered any action of the venom. Then he took another fresh animal and injected the venom, waiting till symptoms of poisoning were manifest; at once he injected his antivenine, and put a stop to any further progress of the poisoning. The same results took place after nuany experiments. All this points to the conclusion that this antivenine, or blood-serum, in an animal that has been able to stand with impunity fifty lethal doses at a time by the inereasing dose process is really an antidote to the poison of snakes." Subsequent experiments have shown, as was not unanticipated, that the blood-serum of venomous snakes is likewise an ant: dote to their own poison.

Nearly all snakes feed upon the bodies of mimals that they have killed themselves, the few exceptions to this rule subsisting on eggs. Owing to the extensile structure of the mouth and jaws, already mentioned, as well as to the separation of the lower evds of the ribs, and the power of extension existing in the stomach, snakes can devour animals of larger circumference than the ordinary girth of their own bodies. Both absolutely and proportionately the largest animals are swallowed by the pythons and boas; and as these snakes kill their prey by encircling it in the folds of their bodies, and thus crushing it to death, the carcase is rendered soft and plastic, and thus more easily swallowed than would otherwise be the case. Occasionally these serpents will swallow members of their own species, as happened not long agc in the menagerie of the Zoological Society of London. In this instance, two large boas oceupied the same compartment in the reptile-house, the one measuring nine and the other eight feet in length. One right the two wero 
seen all safe at closing time, but when the house was opened next morning, " only onc boa was found in the eage; the other had disappeared. Though the survivor was only a foot longer than the other smake, there was no reason to doubt that it had completely swallowed its companion. It was so distended that the scales were almost separated, and it was unable either to coil itself or to move. There is every reason to believe that in accomplishing this almost incredible feat the suake acted by mistake, and that it deroured its companion by what deserves to be called an accident. The larger boa was ferl with a pigeon before the house was closed for the night. It swallowed the bird, and the other boa was then given a pigeon, which it had begun to swallow when the snakes were left for the night. It is believed that the larger suake then caught hold of the part of the pigeon which projected fron the other's mouth, and gradually enveloped not only the bird, but the head of the other snake. Once begun, the swallowing process would go on almost mechanically. As the swallowed snake was only one foot less in length than the swallower, and of nearly equal bulk, weighing about fifty pounds, the gastric juices must have dissolved the portion which first entered the snake's stomach before the remainder was drawn into the jaws. Though still rather lethargic, the surviving boa is not injured by its meal. It coils itself up with. out difficulty, and its scales have the beautiful iridescent bloom peculiar to the skin of snakes when in perfect health." Within about a fortnight the camnibal had completely recovered its usual condition. The majority of snakes swallow their prey while still living, as may be often witnessed when a common English water-snake seizes an unfortunate frog. Vipers and cobras, on the other hand, first kill their prey by the injection of renom. But few meals suffice for a snake, in spite of the circumstance that these reptiles digest their food with great rapiclity.

In their gemeral mode of life serpents show much variation, some living in saudy deserts, others haunting swampy localities, while yet others spend a large portion of their time in fresh water. Some, again, are mainly arboreal, and the member's of one group are marine, and may be met with swimmins, in the open sea far away from land. 'The aquatic snakes-both fresh-water' and marine-as well as vipers, give birth to living young; whereas the others lay soft-shelled eggs. Generally these are left to hatch by themselves, aided sometimes by such heat as may be produced by the decomposition of the heaps of leaves and other vegetable substances in which they are not infrequently deposited; but pythons actually brood their eggs. It might be thought that incubation by a cold-blooded creature would not aid development; but it is a renarkable fact that at such seasons the temperature of the blood of these snakes is raised slightly above the normal.

Serpents attain their maximum development, both as regards numbers and size, in the steamy tropical and sub-tropical zones; and it is here also that the most venomous forms are met with. Even in such localities there is, however, great variation in the relative proportions of noxious and innocuous kinds; and in the large proportion of the former the Oriental countries bear an evil reputation, as they also do in respect to the abundance of snakes in general. Next to these countries comes Tropical America in point of numbers; whereas Africa has only about half as many suakes as inhabit the Indian and Malayan countries. The African serpents are, as a whole, unlike those of Madagascar; while the latter show a considerable resemblance to Soutli American types. The Australian snake-fauna is allied to that of India and the Malayan countries, as is well exemplified by the occurrence in both of 
pythons. In temperate regions suakes become gradually less common as we proceed north in the one hemispliere and south in the other; but, with the exception of New Zealand and the polar regions, the group may be considered to enjoy practically a world-wide range. Nine families of snakes are recognised by zoologists ; and these include a very large number of genera, and probably more than fifteen hundred distinct species. With such a vast assemblage, it is of course impracticable in our limited space to do more than notice the leading and most important types. And even treating the group in this manner, there is considerable difticulty in giving the student a proper idea of the subject, on account of the close structural similarity between many of the families. To understand snakes thoroughly requires an intimate acquaintance with a mass of structural details, and the acquisition of a host of technical terms; and these can only be acquired by a patient practical study of the group.

At the head of the sub-order are now placed the two comparatively unimportant families of blind-snakes, which differ from all the rest in lacking teeth in either the upper or the lower jaw. In form, these snakes are cylindrical and worm-like, with relatively short heads and tails; while in habits they likewise resemble worms, passing most of their lives in tunnels driven by themselves beneath the surface of the ground. Here they

Blind-Snakes. Families

Typhlopida and Glauconiida. subsist by feeding upon such insects or their larvæe as they happen to encounter, ants being apparently a very favourite dish. Dull, rainy weather will occasionally tempt them above ground. Living in such subterranean haunts, the large inferior transverse shields of ordinary serpents would be useless, and we accordingly find the bodies of the blind-snakes covered all round with scales of equal size, although there are some large shields on the fore part of the head, beneath a pair of which are buried the rudimental and useless eyes. Unlike most of their kindred, these snakes cannot expand their jaws; and the small aperture of the mouth is placed on the under side of the head. That these snakes are nearly related to limbed reptiles is proved by the retention in the skeleton of more or less distinct vestiges of the pelvis. An important feature in the structure of the bony palate, which need not be considered in cletail here, suffices to distinguish them from all the other members of the sub-order, to which it seems likely that they have no close relationship. Indeed it is quite probable that whereas the blind-snakes are descended from one group of lizard-like reptiles, all other ophidians may trace their origin to a second. In the first of the two families into which the blind-snakes are divided, it is the lower jaw which has lost its teeth, and the pelvis is represented by a single pair of boncs. The family, which includes three distinct genera, with about a hundred species, ranges over all the warmer countries; one species of the large typical genus Typhlops occurring in Southern and Eastern Europe. On the other hand, in the Glauconiidce it is the upper jaw that has no teeth, while two pairs of bones remain to represent the pelvis. The family includes only the genus Glauconia, of which there are nearly thirty species ranging over Africa, the south-west of Asia, and America.

Of far more importance than the last is the great family of boas and pythons, which include the largest of all living snakes, and are characterised by their habit of killing their prey by crushing it in the folds of their bodies. Like the blind-snakes, these huge serpents retain external vestiges of the lind-limbs, and likewise internal traces of the pelvis ; but as they differ con- 
siderably from the former in the conformation of the bony palate of the skull, it is most probable that they have a totally distinct origin. Since they agree in this respect with the other seven more specialised Boa Tribe.- families included in the sub-order, it is not improbable that Family Boidee. these snakes are the survivors of the ancestral stock from which all the latter have originated. The jaws, too, are unlike those of the blind-snakes in that both are armed with a complete series of teeth. The restiges of the lind-limbs usually take the form of a pair of spurs in the neighhourhood of the vent. The other distinctive features of the family are mainly connected with the structure of the skull; and as the only other snakes with vestiges of limbs are the small Ilysiidue, which are not likely to be confounded with the members of the present family, it will be superfluous to allude further to these peculiarities. The family, which ranges over all the warmer regions of buth hemispheres, is divided into the two subfamilies of the pythons or rock-snakes (Pythonime), and the boa-constrictors and sand-snakes (Boince). All the species included in the former are restricted to the Old World ; but whereas the typical boas are solely American and Malagasy, some other members of the second group are widely distributed in the Eastern Hemisphere. The first sub-family is particularly characterised by the presence of an additional pair of bones--the supraorbitals-in the roof of the skull, which enter into the composition of the margins of the eyesockets. The members of the genus Python are all large serpents, having teeth in the premaxillary or front upper jaw-bones, and a double series of shields on the lower surface of the tail, the latter being distinctly prehensile. Still more important is the presence of pits in two of the shields on each side of the fore part of the head; while other distinctive features are to be found in the characters of the teeth, as well as in the vertical slit formed by the pupil of the eye. There are nine different species of pythons recognised by zoologists; and these range over Africa and the Oriental countries, together with Australia and New Guinea. Fifteen and even twenty feet is by no means an uncommon length for the larger kinds, such as the Indian $P$. molurus; and occasionally specimens grow to between twenty and thirty feet.

A python, after having suffocated its victim by enveloping it in the coils of its body, proceeds to swallow it by seizing it by the liead and gradually diawing it down. Greatly exaggerated notions are prevalent as to the size of the animals which can be swallowed by pythons and boas; and the stories of whole buffaloes and large deer are obviously unworthy of credence. Indeed, it seems probable that even a full-grown sheep is too large for the capacity of the leave of eren the biggest of the tribe; and a sheep of half the full size would seem to be about the limit. In habits, pythons are chiefly nocturnal, and they are partial to damp forest districts where water is easy of access. In such situations they not unfrequently take up their residence in the roofs of houses when made of straw or other vegretable substances; and a well-known account of the discovery of such an unwelcome intruder into his temporary abode is narrated by Mr. Wallace. Perhajs the most peculiar circumstance in the life-history of these serpents is the incubation of the eggs. These, which comprise a large number, are arranged in a pyramidal heap, round which the parent coils her body; this posture being in some instances maintained for nearly two months. Regarding the appetite of a python (miscalled a boa) formerly in his possession, Captain Heyland writes as fullows :- "The animal was brought to me early in Jannary, and did not taste food from that time until the July follow- 
ing. During this period he generally drank a quart of water daily, The man who brought hin stated that he had been seen to eat a hog-deer the day before he was taken. One evening early in July, hearing a noise, I went out, and discorered that the siake had left his harbour under the boards of a stable where he generally lay, and having entered a small shed in which some fowls were rousting, had swept eleven from the perch, and destroyed them by pressing them between his fulds. Then taking them one by one head foremost into his mouth, swallowed the whole down in twenty minutes. The lirgest animal that he ate while in my possession was a calf, which he lilled and gorged in two hour's and twenty minutes. He never attacked dogs, eats, or pigs. Of these last, indeed, he seemed to be in dread, for whenever one was presented to him, he retired to a corner and coiled limself iij with his head undermost. If fed with animals not larger than a duck, he ate readily every day, but after the meal of a goat refused food far a month." In Alstralia the genus is represented by $P$. spilotis, of which one variety is cummonly termed the diamond-snake, the other the carpet-snake.

An Australian writer observes that " of our two pythons or rock-snakes, one, the diamond-snake, does not occur farther south than New South Wales, whilst the carpet-suake has a wider range, cxtending from Queens. lind to even as far as Southern Victoria. These pythons may reach the length of sixteen feet, but a more usual length is eight feet to ten feet. The diamond-snake has a yellow spot in the centre of each of its black scales, whilst the carpet-snake has a series of lighter patches with dark centres along each side, producing a fancied resemblince to the pattern of a carpet. They are really nocturnal animals, feecling on birds and small mammals, whilst in turn the blacks will eat their flesh with avidity." Kirefit thus deseribes the way in which they seeure their prey:- "Coiled on the branch of a tree, the reptile moves only the head and part of the borly, advancing and retreating, in fact measuring its distance, with its head and neck bent into the form of a horizontal S. When pretty sure of its aim, the snake darts forward with open jaws, fastens upon its victim, and in an instant brings it witlin a loop formed by a portion of the body, which gradually tightens till the prey is suffocated. In this position the snake will remain for twenty minutes or half an hour, holding the body of the animal tightly. It then gradually uncoils, and, if inclined to feed, begins the process of swallowing with the head." In Africa the best lnown representative of the genus is Python scbu, commonly termed the Natal rock-snake in the southem parts of that continent. Nearly allied to the pythons are the genera Laxocemus, Nardore, and Liasis; the first including a single small species from Mexico, the second one inhabiting New Ireland, while the third has several representatives ranging from Timor to New Guinea and Northern Australia. All these resemble the true pythons in having the premaxillet toothed, but in the Papuan Chroudropython, as well as in the North Australian Aspidites and the West African Culeburia, those bones carry no teeth.

The absence of premaxillary teeth is likewise characteristic of the members of the sub-family Boince, which are, however, specially distinguished by the want of the aforesaid supraoccipital bone in the skull. All have teetl on the palate, and likewise most of the shields on the lower surface of the tail arranged in a single series; but in these respects they resemble some of the three genera last mentioned. Most of the boa tribe have the head well marked off from the neck, and the tail with a certain mount of prehensile power. Foremost anong these are the tree-boas of the genus Epicretes, in all 
of which the teeth in the fore part of the jaws are superior in size to those behind, while the head is covered with shields, the scales on the body are smooth, and there are, at most, but shallow pits in the so-called labial shields of the muzzle. All the members of the genus are inhabitants of Tropical America, the largest not exceeding seven feet in length. The presence of deep pits in the labial shields serves to distinguish the species of the nearly allied genus Corallus, of which four are from Tropical America, while the fifth is found in Madagascar. Four other snakes from the Moluccas, New Guinea, and Oceania, constitute the genus Enygrus, which differs from both the preceding in having ridges on the scales of the body. These boas do not appear to molest human beings, but the case is different with the anaconda (Eunectes murinus) of Tropical America, which grows to thirty feet or more in length.

In common with three other genera from the same countries, two of which are respectively represented by a single species, while the third includes several, the anaconda differs from all the foregoing in that the front teeth are not greatly enlarged, the whole series gradually diminishing in height from before backwards. Among the distinctive generic characters of the anaconda may be noticed the small size of the scales. Its general colour is olive or greyisli-brown on the upper surface, upon which are one or two rows of large, dark, transversely-elongated blotches, and one or two of eyelike spots on the sides. The anaconda is essentially a water-snake, and in those parts of its habitat which are subject to a long period of drought, it buries itself in the dried river mud till the return of moister conditions. In the anaconda one of the pairs of shields on the head, technically known as nasals, come into contact with one another in the middle line behind the muzzle, but in the nearly-allied snakes forming the genus Boa a median line of small scales separates all the nasal shields. Of the seven species of true boas, five are from the warmer parts of Central and South America, whereas the other two are met with in far distant Madagascar. The common boa-con-

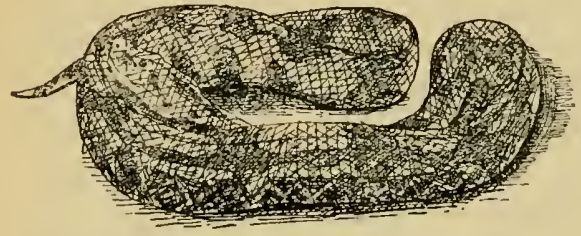

Fig. 22.-Bo.l Constrictor. strictor (Boa constrictor) has a wide geographical range, being found from Venezeula to the inland districts of the Upper Argentine. Although marvellous stories are current as to the rapacity of this species - whose maximum length is about a dozen feet -it appears, that its usual food consists of the smaller mammals, while even eggst are sometines swallowed. It will, however, occasionally attack and kill deer or peccaries. All its victims are destroyed by the crushing effect of the compression of the encircling folds of the body. A snake from a small island near. Mauritius, forming the genus Casarea, differs from the true boas in having distinct keels on its scales, as well as in the greater relative length of the tail.

The only other members of the family that can be noticed are the sandsnakes $\left(E_{r} y, x\right)$ of South-Eastern Europe, Asin, and North and East Africa, which differ from the boas in the want of any distinct line of demarcation between the head and neck. These snakes derive their name from frequenting open sandy districts, where they frequently enter the burrows of small mammals and lizards for the purpose of preying on their rightful occupants. 
Two small and comparatively unimportant families of the sub-order claim a few lines. 'The first of these, which includes but three genera, with a total of tive species, is that of the Jysiidce, all the members of which resemble the pythons and boas in the retention of cylinder-snakes external vestiges of the hind pair of limbs, but differ in the and Shield-Tails. conformation of the sliull. The typical form is the coral cylinder-snake (Ilysia scytale), a sniall species from the npyer jurt of the valley of the Amizon and the Guianas, the others -Families Ilysiidce and Uropeltidce. being the various species of Cylindrophis from South-Eastern Asia, and the one representative of the nearly-allied Anomalochilus, which is Sumatran. The Uropeltide, which, in common with all the remaining snakes, have lost all external traces of limbs, form an allied,family agreeing with both the preceding in the structure of the lower jaw, and taking their name from the peculiar conformation of the tail. Although in one genus it has a conting of keeled seales, in all the rest this appendage terminates in a bare roughened disc, and is thus quite unlike that of all other snakes. In all cases the tail is very short, the bouly is cylindrical, and there is no distinct neek, while both the month and the eyes are relatively small. These snakes, which are all of small size, and frequently brightly and handsomely coloured, are found only in the mountains of India proper and Ceylon, where they generally spend their time in tunnels channelled at a considerable depth below the surface, although in rainy weather they frequently skulk beneath stones and wood, and sometimes even venture out among grass and other lierbage. In addition to the typieal Uropeltis, they include six generic types, the total number of species recognised in 1893 being forty-one, of which only one pertains to the type genus. It may be added that a snake from SouthEastern Asia known as Xenopeltis unicolor is regarded as representing by itself the family of the Xenopeltida, the reason for this reference being that in the structure of the skull it exhibits distinct indications of relationship with the Boidce, although agreeing with the next family in the number of bones entering into the composition of the lower jaw.

Together with the aforesaid Xenopeltis, the snakes included in the two great and important families of the Colubridce and $V$ iperide are broadly differentiated from the Boide and their allies by having one bone less in each lateral brimch of the lower jaw, the missing bone being termed the coronoid. It is unfortunate that this important distinetive feature is not visible in the living animal ; but so it is, and the student must make the best of it. As already said, none of these suakes retain external vestiges of limbs. The colubrine tribe is an extremely large group, embracing as it dues many more snakes than any of the other families into which the sub-order is divided. All are characterised by the circumstance that the maxille of the upper jaw are horizontal, and incapable of movement. Whereas, however, some, such as the cummon water-snakes, are perfectly haimless-exeept to the small creatures upon which they prey-others, like the sea-snakes and cobras, are among the most deadly of all serpents. In such a vast assemblage it is im. possible to do more than notice some of the leading types.

As an example of the first of the three great sections into which it has been found advisable to divide the family, we may take the water-snakes of the genus Tropidonotus, of which the common British ringed-snake ( $T$. natrix) is the most familiar representative. From the fact that all the teeth are completely solid throughout, showing no traces of either an external groove or a deeper 
channel, the section to which this genus belongs is technically known as the Aglypha. And this fact alone is sufficient to indicate that all the members of the section are innocuous. It will be superfluous to point out all the characteristics by which the water-snakes differ from their immediate alliesmore especially as many of these are deep-seated, and require a considerable amount of anatomical knowledge for their proper apprehension. It may be mentioned, however, that teeth are present throughout both the upper and lower jaws, and that those in the hinder part of the upper series exceed in size those near the muzzle, while all those in the lower jaw have approxim. ately the same climensions. The relatively large eye has a circular pupil, the scales are arranged in regular series running lengthwise, and between the openings of the nostrils are placed a pair of internasal shields.

Of water-snakes there are forty or fifty species; and the range of the genus embraces the greater portion of the glolse, with the exccption of South America and Anstralia south of the tropic. The species are, howerer, less numerous in Africa than in the other countries of the Old World. All are fond of water, in which they swim well, and their favourite haunts are damp situations where access to a river or pond is easy. They live on frogs and other small animals, which are seized in the mouth and swallowed as rapiclly as possible, without being killed by crushing in the folds of the body. In aldition to the ringed snake, several other species of the genus inhabit Europe. Another familiar European species is the smooth snake (Coronella lcevis), which belongs to a rather large genus. The so-called fierce snakes (Zcmenis) are also well represented on the Continent, among such being the dark green snake ( $Z$. gemonensis) and the horseshoe-snalie ( $Z$. hippocrepis). To the same genus belongs the well-known Indian rat-snake ( $Z$. mucosus). Although many or all of the foregoing will at times ascend trees in search of their prey, the section includes others which are truly arboreal, and in coloration resemble the foliage among which they dwell. Such are the American woodsnakes of the genus Herpetodiyas, and their Old iVorld cousins included in the genera Dendrophis and Dendrelaphis. In all these, the eyes are proportionally much larger than in the water-snakes, and the borly is more or less strongly compressed. Some are remarkable for being able to change the colour of their skin to harmonise with their surromaings after the mamner of the clismeleons and certain lizards. Far more interesting than any other member of the family is the small South African egro-eating snalie (Dusypeltis strobre). It may well be asked how a snake, with its long pointed teeth, manages to seize and swallow the eggs of bircls without losing their savoury contents. And if the egg-eating suake had the ordinary dental armature, it would doubtless find this a very difticult task. But special armangements have been made to suit its particular diet. Whereas teeth are wanting in the fore part of the jaws, the upper surface of the throat is provided with a long series of tooth-like organs formed by the elongation of the lower spines of the joints of the backbone, which project through the membranes jnto the throat. Taking an egs into the nearly tootliless mouth, the snake gradually passes it downwards into the throat, where it is split by the pressure of the mill-like teeth, and its contents safely swallowed. Although this snake is a very small creature, it will at a pinch cram a hen's egg into its mouth, when it looks somewhat like a football with a tail to it. How it manages to force such a huge object into its throat, and still more, how it cracks it when once there, we are not told.

The second section into which the family Culubride is divided takes its 
name of Opistloglypha from the circmustance that either one or sereral pairs of teeth in the hincter part of tho upper jaw are traversed by a longitudinal groove for the purpose of conveying poison from the secreting gland. Whereas all are more or less noxious, many are deadly. In habits and form many of these curiously simulate the members of the first section of the family. The : roup is but poorly represented in Europe, but among tho Cuntinentil species is the so-called cat-snake (Turbophis vicux), forming a genus by itself. This snake belongs to a sub-family of the section - the Dipsadomorphince-in which the nostrils are always situated on the sides of the muzzle. It frequently grow's to a yard or so in length, and is grey or brownish-yellow in general colour, with various dark snots and blotches, and a chestmut patch on the licad-shields. It is fond of warm sumny spots anong rocks, where it feeds chiefly on lizards, which it kills by the injection of poison. The typical repre. scntatives of the sub-family are the arboreal snakes of the genus Dipscdomonihws which are widely spread through the warmc regions of the Old World, where they have precisely the same morle of life as the arboreal forms included in the section $A$ glypha. In colour they incline to black and brown, while in lenglh they may exceed a comple of yards. Many of them, at least, are purely nocturnal snakes, and whereas some feed on birds, others prey almost or quite exclusively on the smaller kincis of mammals. Occasionally they descend from their leafy haunts to wander on the ground. Of similar habits are the Inchun whip)-snakes (Dryophis), in which the somewhat compressed bodly and lail are remarkable for their extreme length and slenderness. This habit of boly enables these snakes to curl their tail tightly round a bough, whence they strike to a long distance at any passing prey. Here, too, belongs the Tropical American and West Indian genus Plizlodiyas, which includes a considerable number of arboreal species, characterised by the green tone of their coloration. This genus is also represented in Madagascar. The number and arrangement of the tecth form important features in the distinc. tion of these genera of tree-snakes. In the present section the place of the water-snakes among the section Aglywha is taken by the fresh-water snakes of the genera Hommlopsis and C'cutoria, which range from India to New Guinea and the North of Australia. These snakes, few of which grow to more than a yard in length, are far more aquatic in their habits than the species of Tropidonotus, and but seldon leave the water at all ; and some of them eren descend rivers to entel the sea. Their food consists of fish and other aquatic creatures; and they give birth

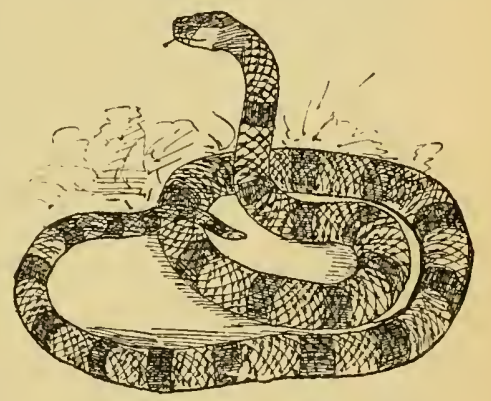

Fig. 23.-THE CORAL-SxAKE (Elaps corallinus). to living young while in the water. A considerable number lie in wait for their prey by anchoring themselves to roots or sumken branches by means of the prehensile tail.

Iı snakes, beauty and venom frequently go together, and an excellent instance of this association is afforded by the coral-snake (Elaps corallinus) of South America and the West Indies. Together with the remaining members of the colmbrine family here noticed, the coral-snake belongs to the section 
Proteroglypha. The essential feature of that section is to be found in the circumstance that it is the front, instead of the hinder, upper maxillary teeth that are grooved for the transmission of the poisonous secretion. Needless to say, all are venomous - some highly so. The genus in which the coral-snake is included comprises many other species, of which the majority inhabit the warmer parts of America, although a few are found in Southern Africa. They typify a sub-family (Elapince) in which the tail has a cylindrical form, and all the nembers of which live either on the ground or in trees. The coral-snake, which grows to rather more than a couple of feet in length, is easily recognised by its brilliant coloration, the whole body and tail being divided into a number of segments of cinnabar-red, separated by shorter segments of black, with indistinct borders of greenish - white. The coral-snake, which frequents wooded districts, is a strictly terrestrial species, feeding upon other reptiles and insects. Nearly allied are the resplendent adders (Cullophis) of the warmer parts of Asia, distinguished by the presence of a groove traversing the whole front surface of the upper fangs, and likewise by the scales forming thirteen rows. These slender snakes are generally found in rocky districts.

The dreaded crait (Bungarnes cceruleus), and its relative the banded adder, or raj-samp (B. fasciatus), are well-known Indian representatives of a genus whose geographical range extends from India and Ceylon to the south of China. From Callophis, in which all the teeth behind the fangs are channelled, this genus differ's in that from one to three of the same teeth are solid throughout; a connecting link being formed by the genus Hemibungarus, in which there is one unperforated tooth in the hinder portion of each side of the upper jaw. Although the banded adder is larger than the crait, it cloes

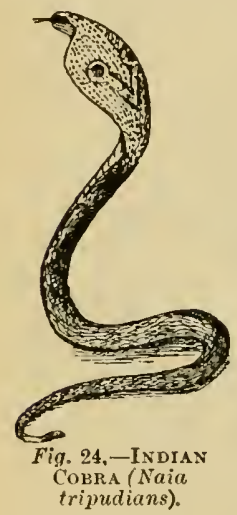
not appear to be so fatal to human life in India as the latter, owing to the circumstance that it mainly keeps to the open country. The crait, on the other hand, is one of the snakes most commonly met with in human dwellings, where it is fond of hiding in all kinds of unsuspected places. In colour, the crait is very dark brown above, marked with narrow rings, bars, or streaks of white.

Whereas the crait and its immediate allies have the head passing imperceptibly into the neck, and lack the power of inflating the latter, the cobras (Naia) possess a distinctly defined neck, the lower part of which can be dilated at will; while they further differ by the equality in the size of the scales of the back with those of other parts. Cobras are represented by half a score of species, some of which are Oriental, while the others are African; the best known being the Egyptian asp ( $N$. haie) and the common Indian cobra ( $N$. tripudians). The latter is familiar as being the species commonly exhibited by Indian snakecharmers, and as it has been described in so many popular works, while newspapers are always giving accounts of its ravages, nothing in the way of description need be given in this place. Ordinarily this species does not exceed six feet in length; but Capt. F. Hawkins writes in the Asiun newspaper of August 5th, 1892, that in Sangor a specimen was killed measuring seven feet three inches. The giant cobra ( $N$. bungarus) of the Oriental countries is, however, a considerably larger species. Mr. P. A. Bulkley, writing from Burma, observes that "it may interest your readers to know 
that about ten years ago, while shooting in the jungle, I came upon a fino specimen of the sulke in question over $12 \frac{1}{2}$ feet long, and, after an exciting chase, succeeded in capturing it alive and uninjured. I kept it in captivity for some montlus at Castle Ruck in a large case, giving an occasional exercise in the spare room of my bungalow, and eventually took it to Eugland for the reptile-house at the Zoological Gardens. At Brindisi I lad to leave the snake to complete its journey by steamer to London, and upon opening its case on arrivil at the Zwo, it was, unfortunately, found to be dead. The body, however, was in good preservation, and may be seen in a large case of alcohol in the reptile-room of the Natural History Museum at South Kensington." Although there are no cobras in Australia, that country is the home of an equally deitlly serpent known as the deatl-adder (Pseudechis porphyriaca). In this snake the cylindrical body is extremely long and slender, the head is but imperfectly defined from the neck, and the scales are smooth. The species which grows to as much as seven feet in length, is commonly known in its native comtry as the black snake.

The last group of the present section of the Co? $u b$ ride is that of the seasnakes, which form the sub-family Hydrophiine. They differ from the Elcipince by the compressed and oar-like form of the tail, and also by the scales on the under surface being either nearly similar to those on the upper parts, or if enlarged into shields, by their being much smaller than in ordinary terrestrial snakes. As their name implies, the sea-snakes are peculiar in the sub-order for their marine habits. Most of them, indeed, pass the whole of their time in the open sea, where they produco their young alive without the intervention of eggs ; but there are certain species which are partly terrestrial, and serve to commect the more typical representatives of the sub-family with the crait and its allies. Sea-snakes are

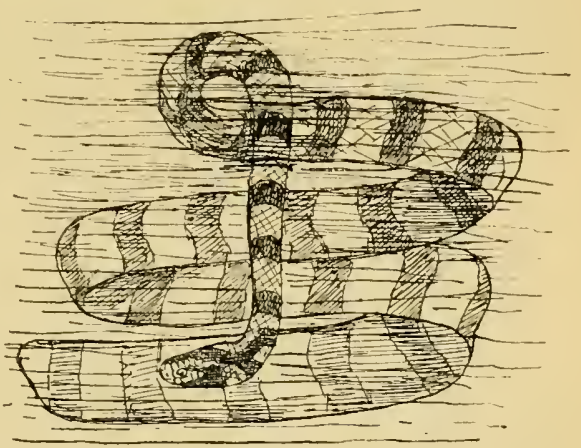
most abundant in the tropical portions of the Wester'n Pacific and the Indian Ocean, although a few enjoy a much more extensive range. They are all highly venomous, and most are handsomely and brilliantly tinted, the coloration being always variegated. They feed on fish and other marine creatures, and frequently associate in companies of considerable size. When cast on shore by the waves, the majority are utterly helpless, lying where they are thrown until they die. Unlike other members of the sub-order, sea-snakes change their skins piecemeal instead of entire; the renovation taking place very frequently. They also differ from ordinary snakes in the shortness of the tongue; and while at sea only the extreme tips of this organ are thrust out through a couple of small notches from the closed mouth. The three speeies constituting the genus Platurus are those which serve to connect the rest with the crait group, and are distinguished by having the under surface of the body and tail covered 
with transversely elongated shields, while the upper surface is invested with smooth overlapping scales. One of the most common kinds, which grows to a length of about three feet, is met with from the Bay of Bengil to Oceania. These snakes can crawl witl ease on land, and specimens have been from time to time met with at considerable distinces inland. In addition to certain features commected with the nostrils, the more typical members of the subfamily -which are arranged under several scpiaite genera-differ from the preceling in having the under surface scaled like the back, although in somo forms more or less distinct vestiges exist of the enlarged shields. These genera are to a great extent distinguishec from one another by the character: of the teeth, the most important among them being Hydrus, Hydrom his, and Distire. Emerson Temnent writes that "sea-snakes are found on all thu: coasts of Ceylon. I have sailed through large shoals of them in the Gulf of Manaar, close to the pearl-banks of Aripo. The fishermen of Calpentyu, on the west, live in perpetual fear of them, and believe their bite to be fatal. In the course of an attempt which was made to [] ]ace a lighthouse on the great rocks of the south.east coast, known by seamen as the Bassess or Baxos, the workmen who first landed found the portion of the surface lialle to be covered ly the tides honeycombed and hollowed into deep holes filled with water, in which were abundance of fishes and some molhuscs. Some of these cavities also contained sea-snales from four to fire feet long, which were described as having the head hooded like the cobra de capello, and of a light grcy colour sliglitly speckled. They coiled themselves like serpents on lind, and darted at poles thrust in among them. The Singhalese who accompanied the party said that they not only bit venomously, but crushed the limbs of any intruder in their coils."

A small group of suakes, the members of which are externally very similar to those of the sub-fanily Dipsadmorplince in the Culubride, are considered to form a fanily by themselves. From the Dipsadomorphina they

Blunt-Heads. - are distinguished externally by the absence of a groove on the Family chin. They resemble the Colubride in having the maxilla fixed Amblycepha. in a horizontal position, but differ both from that family ancl lide. from the Viperide by the shortness of those bones in the hinder part of the palate known as the pterygoids, which do not extend sufficiently far back to reach either the hinder ends of the lower jaw or the quadrate bone. Both jaws are provided with teeth, all of which are solid, so that these snakes are non venomous. The slisht expansibility of the month indicites; that they prey upon small animals, while the relatively large dimensions of the eye, in which the pupil is vertical, proclaim rocturnal habits. Five genera of these snakes are known, two, namely, Amblycephalus and Haplopeltura, being confined to the Oriental countries, whereas Dipsas, Pseudopareus, and Leptognathus are from Tropical America.

The last family of snakes is a large one, and includes the vipers, pit-vipers, puff-adders, and rattle-snakes; all being highly venomous. The essential distinctive feature of the Viperide is to be found in the fact

The Viper Tribe. that the short maxilla of the upper jaw are armed witl a -Family

Viperide. pair of large perforated fangs, and can be ereeted so as to beeome situated at right angles to the plane of the hinder portion of the palate. Obviously, this gires to the fangs the most favourable position for inflicting severe wounds. In the viperine snakes the head is always more or less flattened, and is frequently triangular in shape; while the body is plump and thick, and the tail abbreviated. In 
aceordanee with their chiefly nocturnal habits, the eye has its pupil in the form of a vertical slit. Only a few vipers climb, and none are aquatic ; while, so far as present information goes, all give birtl to their young in a fully developed state without laying eggs. In almost all countries popular report declares that the females of many spccies receive their young into their mouth when alarmed, whenee they apparently pass down the throat; and although many attempts have been made to discredit such statements, it is ditficult to believe that they have not some foundation of truth.

Of the two sul)-families into which these suakes are divided by zoologists, the typical vipers, or Viperince, are confined to the Eastern Hemisphere, and are characterised by the absence of pits or depressions in the pair of head. shields known as the loreals. The common British viper (Vipera berits) is the most familiar representative of the typical genus, all the members of which have two longitudinal series of shields on the under surface of the tail, while the scales on the body are keeled and arranged in from nimeteen to thirty-one straight longitudinal rows, and the upper surface of the head is invested either with relatively small shields or with scales. There are about twenty different kinds of true vipers, and these are distributed over the greater part of the Old World, although there are none in Australasia or Madagascar, and only one in India. The common viper enjoys a very wide geographical distribution, extending from the Arctic Circle to Spain and Portugal, and from the latter country eastwards to Siberia. It not unfrequently grows to ten inches in length, and, like its kindred, is partial to warm sandy heaths. The sand-viper ( $V$. ammodytes) of Southern and Eastern Europe is remarkable for having a flexible horn-like and scaly appendage surmomnting the tip of the muzzle, the use of which has not yet been explained. To the genus Bitis belongs the dreaded African puff-adder ( $B$. rerictans), in which the head is broader and more distinctly triangular than in any of its kindred. As this noxious selpent has a habit of lying with only its head exposed, it is frequently not noticed by men and animals until too late; and it is consequently responsible for many deaths. Even large mammals are said to succumb very speedily to the loite of this loatlsome monster. The name of puffadder is derived from the habit possessed by this snake of blowing itself out with air when excited.

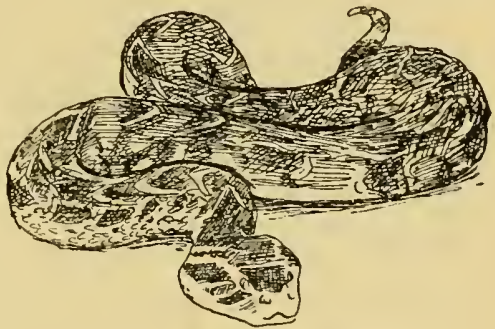

Fig. 26.-PUFF-ADDER (Bitis arietans). Nearly allied to the true vipers are the homed ripers of the genus Cerctstes, so named from the presence of a pair of scaly holns situated above the eyes of the males, and in some species in the females also. The scales, too, are arranged in oblique instead of straight series. Both species of the genus are inhabitants of those parts of Northern Africa lying to the eastward of Morocco, but one is also found in Arabia. They grow to about a couple of feet in length, and assimilate remarkably in coloration to the sandy deserts they frequent. They may be often seen so deeply buried in the sand that only the head and a portion of the neck project above the surface. Another nearly allied genus is that of the saw-vipers, or Echis; these snakes being distinguished from the last by the absence of 
horns un the head, and by the shiclds on the luwer surface of the tail forming a single instead of a double series. This genus is likewise represented by two desert-haunting species, but one of these has a much wider geographical range than either of the horned vipers, extending from Northern Africa to India, whereas the second is restricted to Palestine and Arabia. Whereas the puff-adder produces a prolonged liissing sound by the expulsion of the air which has been drawn in to blow out the body, the Indian saw-viper gives rise to a somewhat similar sound in a totally different mamner. In this species the keels on the seales of the sides of the body are clistinctly ser'ated; and by rubbing the folds of the body together the contact of these saw-like keels gives rise to a kind of grating, or even lissing noise. This snake is a very fierce species, often attacking without provocation; and a large percentage of the deaths from snake-bite in India may be attributed to this species and to the equally deadly Russell's viper (Vipera russelli).

The second sub-family, or Crotalince, the members of which may be col. lectively termed pit-vipers, are typitied by the well-known rattle-snakes of the New World, although several other genera belonging to the same sub. family are found in various parts of Asia. There are, however, 10 representatives of this group in Africa, where, on the other hand, the typical vipers, or $V$ iperince, attain their maximum degree of development. The distinctive feature of the pit-vipers, and the one from which they take their name, is the presence of a pair of deep pits in the fore front of the head, situated between the eyes and the nostrils in the so-called loreal shields. Doubtless these pits have some special function in the economy of these reptiles, but what this may be naturalists do not seem to have hitherto discovered. The peculiar jointed horny appendage to the tail known as the rattle gives to the snakes
of the typical genus Crotalns their

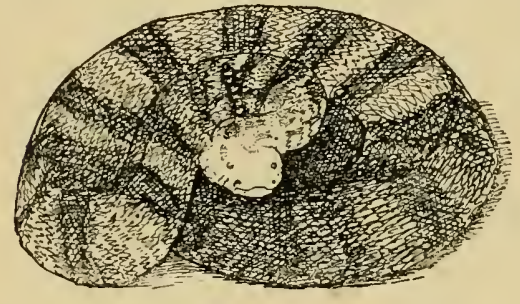

Fig. 27.-A Rattle-SNake (Crotalus). distinctive name, and at the same time scrves to distinguish them at a glance from all the other members of the sub-order. This rattle increases in size by the intercalation of new joints between its terminal button and the scaly portion of the tail, young specimens having only the button. The longer a rattle-snake lives, the more joints it has to its rattle ; and formerly specimens with as many as twenty rings were by no means uncommon, although at the present day, owing to the war of extermination waged against these noxious reptiles, such are very rare. Very diverse views have been entertained as to the precise use of the rattle to its owner, and since the question is by no means even yet decided, it need not be discussed in this place. All rattle-snakes are characterised by the unusually large size of their venom-glands, and they are consequently among the most deadly of serpents. Most of the eleven representatives of the genus are. North American, although one species extends to South Anerica. In their general habits they are very similar to vipers, frequenting dry sandy districts; but in parts of North America rattle-snakes frequently take up their abode in the warrens of the prairie-marmot, where they prey on the young of the rightful owners. In the colder parts of their habitat, these snakes become torpid during the 
winter months; and in certain rocky districts they were formerly wunt to assemble in enormous numbers, passing the winter huddled up together in caves, where they kept one another warn. At the approach of the cold season, thousands of these snakes might be seen travelling from all points of the compass to their own special cave; and marvellous stories lave been told of attacks made upon these haunts when the hapless reptiles were sleeping in fancied security. It is somewhat eurious that rattle-snakes lack the power of hissing; and it is highly probable that this disability has some connection with the presence of the rattle. Nearly allied to the rattle-snakes is the equally deadly bushmaster (Lachesis mutus) of tropical South America, which has a spine in place of a rattle at the tip of the tail, while the lower surface of the latter bears a number of spiny scales. There is often a wellmarked keel rumning down the middle of the back, of which there is no trace in the typical genus. This snake is one of the few serpents which do not flee at the presence of man, always standing its ground and endeavouring to inflict a blow. Since it frequently grows to ten feet and over, and its bite is rapidly fatal even to large mammals, it is one of the most dangerous of its tribe, and were it more conmon than it actually is, fatalities would be very numerous. By Mr. Boulenger the serpents formerly designated Trigonocephalus and Trimeresaumus are now included in Lachesis. These differ from the typical forms in having the whole of the top of the head covered with small scales, instead of large scales. Some species are arboreal, and have the tail prehensile; some of these inhabiting Tropical America, and others South-Eastem Asia. Whereas the species from the latter area have two rows of shields beneath the tail, those from the former have only a single row. Among the American forms with a non-prehensile tail, one of the most formidable is the jararaca ( $L$. lanceolatus).

The so-called halys vipers, forming the genus Ancistrodon, have representatives alike in the northern half of the American Continent and Asia, while one kind is found in the Ural Mountains. Although none have a rattle, in some kinds there is a small spine at the tip of the tail, which appears to be a vestige of that organ. Of the Transatlantic species, one of the most dreaded, and at the same time one of the handsomest, is the so-called copper-head ( $A$. contortrix). It takes its name from the metallic coppery hue of the upper surface of the body ; this ground-colour being ormamented with a number of brown bands with darker edges. The copper-head, which frequents damp situations, has a wide geographical distribution. It is one of the species furnished with a spine-like horny appendage to the tail ; and differs from some of its kindred in having a single instead of a double series of shields on the under surface of the tail.

\section{ORDER IV.-RHYNCHOCEPHALIA.}

If we were to trust solely to external features a lizard-like reptile inhabiting certain small islands to the north-eastward of New Zealand, and locally known as the tuatera, would almost certainly be included in the order Squamata. When, however, the internal structure of this creature is examined, differences so important are observable that there can be no question of its 
total distinctness from that order. Accordingly, the tuatera, which is tech. nically known as Sphenodon punctatus, not only represents by itself the family Sphenodontida, but also a distinct order. This, however, is only true at the present day, for in last epochs of the earth's history there flourished a number of reptiles evidently bolonging to the sume ordinal group, severai of which lived in Britain. T'he tuatera, which grows to a length of about twenty inches, is characterised by the presence of a ridge of spines extending from the back of the head to the base of the tail, and represented on the latter by a less distinct crest. Superiorly, the body is covered

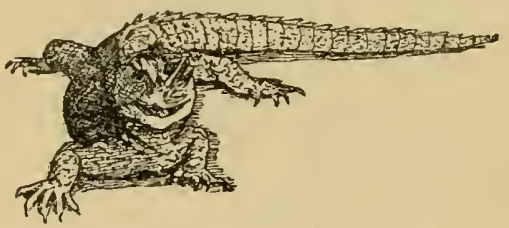

Fig. 28. -Tvatera (Sphenodon punctatus). with a mixture of small tubercles and granular scales; but the lower aspect is invested with somewhat quadrangular large scales forning regular transverse bands. The toes, which are five in number on each foot, are partially webbed, and terminate in elaws. In the eyc the pupil takes the form of a rertical slit, and there is nu external opening to the ear. None of these feitures are, however, sufficient to distinguish the tuatera from the lizards ; and to understand the distinetion the skull must be examined. In the description of the Squamata it was stated that in all the members of that order the quadrate-bone is loosely connected with the other bones of the palate, and there is no bony arch connecting the former with tho maxilla. On the other hand, in the tuatera the quadrate is firmly and immovally wedged in between the other bones, and is conneeted with the upper jaw by the aforesaid arch. There are likewise important differenees in the structure of the bony palate, which is of a more primitive type than that of tho lizards. Indeed, in many respects the skull is more like that of a crocodile, or even a tortoise, than that of a lizard. The teeth, too, are very peculiar. In the front of the jaws are a pair of chisel-like teeth, giving the form of a beak to this part of the skull: while the sides of the upper jaw and palate bear a double row of elosely approximated teeth separated by a groove, and in that groove are received the single row of lower teeth, which are attached to the jaw in the acrodont mamner. Although there are many peculiar features in this strange reptile, it will suffice to mention that within the skin of the hinder part of the under surface of the body are a number of abdominal ribs, forming a structure which corresponds anatomically with the plastron of a tortoise.

Although now becoming scarce, tuateras were formerly abundant in their native islands, where they might be seen in parties basking in the sun within easy reach of the sea. In captivity, where they flourish well, tuateras eat freely of meal-worms and other inseets, but it is probable that regetable substances form a part of their diet. Perhaps the most remarkable feature about this reptile is the vestige of an unpaired median eye situated deep down among the tissues of the head, and now totally functionless. Doubtless, however, in its ancestors this eye was functional, so that the original form may have been a veritable cyclops. 


\title{
SUB-KINGDOM I.-VERTEBRATA.
}

\section{CLASS IV.-AMPHIBIA.}

\author{
BY R. LYDEKKER, B.A., F.R.S., T.P.G.S., d.
}

Is popular natural history nearly every cold-blooded verebrate that breathes atmospheric air by means of lungs is conmonly spoken of as a reptile, whether it crawls or creeps on the ground like a lizard, a frog, or a snake, or swims in the water like a newt; and if we take their adult condition alone into consideration, there is a good deal to be said in favour of regarding frogs and salamanders as reptiles, since they agree in many of their essential characters with the creatures to which the naturalist restricts that term. 'The case is, however, very materially altered when the developmental history of frogs and salamanders is taken into consideration. As every one knows, these creatures-with a few exceptions-commence their active existence after leaving the egg in the form of a tadpole. And as a tadpole is an aquatic creature, breathing the air dissolved in water by means of gills, and being provided with a fish-like tail, it is obvious that we have here a very important clistinction from reptiles, which, at the commencement of life, are mere miniatures of the adult. It may be said, indeed, that frogs and salamanders commence life as fishes, but turn into reptiles when they become adult, and the existence of this remarkable change or metamorphosis serves to differentiate these creatures from reptiles as a distinct class, for which the name Amphibia is now usually adopted, although the alternative term Batrachia is also extant. It is true that in certain cases no such metanorphosis exists, the egg dereloping at once into a perfect air-breathing frog, while in some other instances the gills of the larval state are retained througlout life. In the former of these instances it is, however, evident that the larval stage has bcen suppressed owing to the exigencies of abnormal conditions in the life-history of the particular species. In the latter case, either the creature has now ceased to develop in to the air-breathing adult form, or it has never advanced beyond the larval stage at any period of its history.

Amphibians, then, may be detined as cold-blooded vertebrates usually furnished with external gills at the commencement of life, but before becoming adult passing through a metamorphosis-during which the gills are exchanged for lungs; - and such of them as possess limbs having these structurally similar to those of reptiles. This change from a fish-like tro a reptile-like animal is one of the most marvellous plienomena to be met with anong vertebrates, and it is not a little remarkable that while everybody has the opportunity of witnessing this transformation each year of their lives, so many still refuse to believe in the evolution of animal life in general.

The metamorphosis is, however, by no means the sole feature by which amphibians are distinguished from reptiles. There are many structural peculiarities by which the adults of the former differ from the latter, although these are, unfortunately, deep-seated, and not externally apparent. Com- 
paring the skull of a reptile with that of an amphibian, it will be found that whereas the former has a single knob-like prominence, or condyle, by means of which it is movably articulated to the first joint of the backbone, in the latter there are two such condyles. The einbryo, too, of amphibians has a less complex type of enveloping structures, lacking the membranes respectively termed the allantois and the annion.

Bearing in mind these important points of distinction, the student will readily see the propriety of separating the Amphibia as a class apart from the Reptilia. In the adult condition, the members of the present class show great differences of external form. The frogs and toads, for instance, are tailless, four-limbed creatures, in which the hind-legs exceed the front pair more or less markedly in length. On the other hand, the salamanders and newts, although likewise furnished with two pairs of limbs, have a long tail, and thus present a lizard-like form. In the newts, the tail, and sometimes also the back, is furnished with a longitudinal vertical fin, somewhat like that of a fish, although differing from the latter in the absence of any bony supports. Other forms have the body eel-like, and the limbs-of which the hinder pair may be wanting-small and rudimental; while in some of these, like the olm, the external tuft-like gills are permanently retained. In yet another group, the whole form is worm-like, without any external vestiges of limbs.

In spite, however, of this great variation in external form, all the existing members of the class present the common feature of having the head, body, limbs, and tail covered with a soft skin, although in a few scales are buried beneath its surface. The outer skin, or epidermis, which is from time to time cast in a single piece, is always transparent, and the colour is consequently situated in the deeper layer. Various shades of black, brown, red, and yellow, are the predominant colours of amphibians, and these are very generally arranged in large irregular blotches, or in streaks; but more rarely blues and greens are present. Peculiar glands, which may be either distributed over the whole surface, or confined to the region of the neck, secrete a milky fluid of a poisonous nature, which is poured out under the influence of rage or excitement. Ancl that this secretion serves as a means of defence, will be evident to all who have watched a dog seize a toad. When this secretion reaches its highest development, the apertures of the glands open in the form of warty protuberances on the skin, as is the case in all toads and many salamanders. There are many peculiarities connected with the anatomy of the skeleton and soft internal parts of the Amphibia, but it will suffice to mention two. Unlike that of all the higher vertebrates, the tongue, when present, is attached to the front extremity of the lower jaw, so that it is protruded by being turned right over as if on a hinge; and when in repose its tip is directed down the throat. It is always of a thick and fleshy nature, and thus quite unlike the same organ in snakes and lizards. The second peculiarity is connected with the skeleton, in which the ribs are either completely wanting, or represented merely by small rudiments affixed to the extremities of the long horizontal transverse processes of the joints of the backbone. This lack of functional ribs prevents amphibians from breathing in the same manner as the higher vertebrates, in which the cavity of the chest is alternately expanded and contracted by the movements of the ribs; and they are, in consequence, compelled to take in air in large gulps by a swallowing action. In the presence of a large, thin, flattened bone, lying on the under surface of the hinder part of the skull, and known as the para- 
sphenoid, amphibians differ from the existing forms of the higher vertebrates, and thereby approximate to fishes. In certain extinct reptiles, this bono appears, lowever, to be well developed, so that its importance in classification is less than has been supposed.

To describe in detail the developmental history of amphibians would re. quire nearly as much space as is allotted in this volume to the entire class; and it is possible to grive only the merest outline. Premising that all the members of the class lay eggs, and that in certain special cases some of the stages of development are abbreviated, the ordinary life-Ihistory of an amphibian is as follows. The eggs are generally deposited by the female in fresh water and are usually of small size and enveloped in a litge jelly-like mass, among which the yoiks are conspicuous as dark balls. When these eggs are ripe for liatching, the larve burst their investing membrames to make their appearance in the world as free-swimming tish-like creatures, provided with a long laterally compressed tail, but deroid of limbs or external gills. They still retain a portion of the yolk, which serves for a short time as nourishment. Soon a couple of pairs of foather-like gills make their appearance on the sides of the neck, and give the creature somewhat the look of bearing two prirs of fins. Although in those forms which permanently retain the tail these external gills persist for a considerable period, or even throughout life, in those of which the adults are tailless they soon disappear, and are replaced by internal gills comparable to those of tishes. These external gills are enclused in a special gill-chamber, from which the water that has been taken in through the mouth is clischarged through a single tube or a pair of tubes; the aperture of the latter being generally single, and situated either on the left side of the body or on its lower surface. With the sprouting of the external gills, tle tail rapidly increases in relative size, and soon forms the greater portion of the creature. About this time small bucl-like processes indicate the appearance of the limbs, the hinder pair first showing in the frogs and toads, but the front pair being the earlier in the tailed forms. In the earlier stages the jaws are furnished with horny teeth, but later with a kind of beak composed of the same substance. At this time the tadpole subsists on vegetable substances, and, consequently, has a long and much convoluted intestine. It, of course, breathes the air dissolved in the water in which it lives in the same numner as a fish, and has a two-chambered tish-like heart. In the tadpole stage the large tail has no backbone; and in the frogs and toads this appendage, after the limbs are well developed, is gradually absorbed, and finally disappears entirely. In the permanently tailed forms, on the other hand, this appendage develops vertebræ in its internal axis, when it becomes similar to the tail of a land reptile. About this time the jaws lose their homy beak, and develop teeth, and the intestine becomes shortened. Equally remarkable changes are at the same time taking place in the respiratory and circulatory organs. From the oesophagus a bag-like projection grows out, which, subseqquently, divides into two, and eventually forms lungs, which little by little come into use, until the creature is able to breathe both in air and in water. Finally, the gills wither, and the adult frog or salamander appears as an air-breathing, insectivorous or carnivorous reptile-like creature, which has been dereloped from the fishlike tadpole. During the development of the lungs the heart has changed from a two-chambered to a three-cliambered organ; so that even in this respect the adult amphibian is indistinguishable from a reptile. In nost calses, when all these changes have been completed, the animal emerges from 
the water to pass a considerable portion of its time on land, although nearly always returning to its original element for the purpose of breeding. It has been said that the externial gills usually form two pairs, but it should be added that, in some instances, these are increased to three, while in one case they are reduced to a solitary pair.

As regards their mode of life, amphibians are especially characterised by their partiality for moisture, some passing the whole of their time in the water, while none are found in absolutely desert districts. 'To their soft sensitive skins moisture is, indeed, an absolute necessity; and it seems that they imbibe such moisture as they require through the skin. In countries where one season of the year is especially dry, terrestrial amphibians are consequently compelled to undergo a period of more or less complete torpor. To a certain extent this is the case even in Britain, where a sudden shower after a dry spell brings out numerous frogs and toads at the commencement of evening in gardens where not one had been visible previously. In some parts of Argentina the effect of a shower after a drought is much more startling. There a garden may appear for weeks or months absolutely devoid of amphibian life, but after a single shower it will appear literally alive with huge frogs and toads of various kinds. Probably all the terrestrial amphibians are essentially nocturnal creatures, and, indeed, their skins soon become parched and withered by exposure to sunlight. Few objects are more pitiable than a belated frog or toad attempting to cross a dusty high-road in the full glare of the summer sun. Cloudy or wet days will, however, generally tempt these creatures from their hiding-places. Although the tailed forms are entirely or mainly silent creatures, frogs and toads during the breeding season utter their well-known croaking cries, and in moist tropical and subtropical countrios life is rendered at times almost unbearable by their nocturnal choruses. In the breeding season frogs and toads become exceedingly bold, and they may be seen sitting within a few feet of the spectator, alternately dilating and contracting their capacious throats, as they give vent to their discordant cries. In order to make their sounds more intense, the males of many kinds are furnished with large sacs projecting on either side of the throat, which can be dilated till they resemble miniature balloons. Mast members of the class subsist chiefly or entirely on insects and other small invertebrates, but some of the aquatic kinds consume fish, and some of the larger toads and frogs will readily attack not only other reptiles, but even the smaller birds and mammals. 'Thus a newspaper correspondent, writing from Nagpur, in India, observes that in the garden adjoining his house was a small pond, which was the home of a huge kind of frog. One afternoon he heard a myna making a great noise, and screaming as though it had been caught by some creature, so he went down the garden to ascertain what was the matter, and was just in time to see the bird disappearing down a big frog's throat. There were only a few feathers left, and the bird had been swallowed feathers and all. Now the common myna is quite as large as our English starling, and the frog certainly looked as though he had dined, so he was left in peace to enjoy his meal. On another occasion a big rat appeared in the house, and was being chased by himself and servants from room to room, when it dashed through a disused bathroom. A large frog which happened to be there made, a most determined rush, but missed the rat, which disappeared down the waste water-pipe.

In conformity with their fondness for warmth and moisture, amphibians are most abundant in the tropical and sub-tropical portions of the globe, 
gradually diminishing, both in size and numbers, in the temperate zones, and being unknown in the polar regions, as incleed they are in deserts. Although members of the class are found in all regions except those named, the orders are by no means evenly distributed. In the Northern Hemispliere, for instance, salamanders and newts are abundant, and the burrowing forms, known as cacilians, are wanting; whereas in the Sonthern Hemisphere ciecilians oceur, but salamanders and newts are totally unknown. Among the frogs and toads certain families are confined to particular areas, but it is remarkable that there are indications of distinct relationship hetween certain groups respectively restricterl to South America and Africa south of the Sahara.

\section{ORDER I.-ECAUDATA.}

\section{Frogs axi Tonls.}

The frogs and toads constitute one Order, all the members of which are easily recognised when adult by the short and often plump form of the body, the total absence of a tail, and the presence of four fully-developed limbs, the hind pair being generally much longer than the flont ones. Even more striking features are displayed by the skeletor. Instead of continuing to the end of the body, the backbone proper' stops short about the middle of the back, and never comprises more than eight vertebrie. Beyond this it is continued as a long, tapering, unjointed rod. To tho extremities of the horizontal transverse processes of the last, or sacral vertebra, are articulated the anterior ends of the greatly elongated ilia of the pelvis, these bones rumning as far backwards as the hinder end of the aforesaid rod, where they bear the sockets for the articulation of the uppermost bone of the hind-legs. By this very peculiar, and indeed unique arrangement, the setting-on of the hind-limbs is carried far behind the sacrum. The radius and ulna in the fore-limb, and the tibia and fibula in the hind-limb, are respectively united to form a single bone, and the elongation of the hind-legs is produced by the lengthening of those bones in the ankle-joint known as the astragalus and calcaneum, so as to form a pair of parallel long bones. Like all other living members of the class in which both limbs are fully developed, frogs and toads have four front and five lind-toes. In the tadpole stage-which is accasionally suppressedthe hind-limbs bud before any trace of the front pair is visible. Usually this stage of existence is passed entirely in the water, but there are some very peculiar forms in which the young are produced in the moist foliage of leaves. On land the adults of the tailless batrachians progress either by taking long leaps from the hind-legs or by dragging forwards first one and then the other of these, and thus pushing the body along. In swimming, the hind-legs are alone employed for propulsion, the front pair being pressed close to the chest. The total number of species of the tailless amphibians probably does not fall far short of a thousand, and representatives of the group are found in all countries suitable to the existence of amphibian life. Curiously snough, the largest forms are found in some of the islands of the Pacific. Whereas the majority are torrostrial, a considerable number have adopted an arboreal life. The group is clivided into twelve families, of which the two last differ from all the rest in the absence of the tongue. Unfortunately, the characters by which the 
first ten of these families are divided into two larger groups are taken from the skeleton, and are consequenfly somewhat difticult to explain to reader's not specially versed in anatomy.

\section{Sub-Order I.-Firmistemiu.}

The five families constituting this subordinal group are characterised as follows:-The tongue is present, and the large plate-like bones on the chest termed the metacoracoids are united together by a large median cartilage, attached to their free inner margins.

In tlie family typified by the eommon British frog teeth are dereloped in tile upper jaw, and the horizontal transverse processes of the sacral vertebra have, at most, only a slight teminal expansion, and are fleTypical Frogs. - quently cylindrical throughout. The frogs of this family Family Ranielu. display remarkable diversity in the form of the tips of the terminal bones of the toes, which may be either rounded, jointed, forked, T-shaped, or, more rarely, claw-like. The family-which includes a lorge number of genera and a host of speeies-has a wide geo-

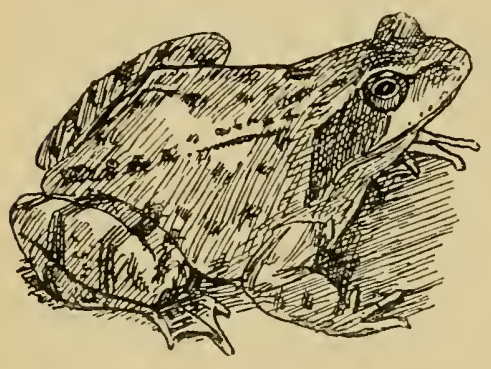

Fig. 1.-Cosmox Froa (îana temporaria). graphical distribution. With the exeeption of a species of the typieal genus from the extreme north of Australia, and another belonging to the gemus Conifer from New Guinca, there ale no members of the family in Australasia. South America, too, is puorly ofi, having, in addition to certain species be. longing to the typical genus fince, only tive genera, and about a duzen species. Moreorer, since none of these latter range farther' south than Ecuador and Colombia, while Ricuce does not apparently extend soutlward of Amazonia, the more southern parts of that continent are characterised by the total absence of the present family. In a group so extensive, it is difficult to select genera for special notice, although the typical Rana must of course be mentioned. In the numerous frogs of this genus the tongue is free and more or less deeply notched at the tip, the pupil of the eye forms a horizontal slit, and the toes of the fore-feet are free, whereas those of the hind-feet are more or less fully webbed. By putting the finger into the mouth of any frog of this genus, it will be readily felt that teeth are present on the vomers, occupying the middle region of the palate. Whereas in some forms the tips of the toes are simple, in others they are dilated. The genus has a distribution nearly coextensive with that of the family, one species being found in the extrenie north of Australia, although there is nome from Papua. There are several species of the gemus inlabiting Eurvpe, such dis the common frog $(R$. temporaria), the edible frog ( $R$. esculenta), the arrile frog $(R$. agilis), the sjpansh frog $(R$. iberica), and Litaste's frog $(R$. latastei). Of these, the only one indigenous to Britain is the common frog, in which the lind feet are incompletely webbed, and the n.tes are unprovided with the dilatable throat-sacs cliaricterising those of the edible species. Although the latter- of which 
there are two varieties, differing from one another in culour-i, properly a native of the Continent, it lias been introduced into the fens of Cambridge and Norfolk, where it seems to llourish. It lias a very extensive geographical lange, being fomnd as fir' south as North-Western Africa, and as far east as Japan, Althongh the species is the only one eaten in Europe, other members of the sub-order are sent to table in distant lands, and the writer has partaken of a dish of frogs in Argentinia which belonged to a totally different family. The great relative length of the lind-legs and generally slender form of the body serves to distinguish the agile frog; while the fourth and fifth of the species mentioned above differ from the rest by their spotted bellics. All these frogs are comparatively small creatures, which are greatly exceeded in size by species from more distant lands.

Among these, the bull-frog $(R$. catesbyana) of Eastern North America occupies in intermediate position in this respect; the largest member of the whole genus being the Solomon Island frog $(R, g m p m y i)$, which grows to nime inches in length, exclusive of the limbs. T'he habits of the common frog are too fimiliar to need description; and it is probable that, like this species, all the members of the genus take to the water at the time of breeding. Some are, horrever, more aquatic than others; and there are also certain frogs of this genus which are partially arboreal in their labits, while others have taken to burrowing in the ground. The climbing species lave the tips of the toes expanded into discs, but smaller expansions may be juresent in the aquatic kinds. An Indian species ( $R$. breviceps) makes burrows in the ground to a depth of aljout eighteen inches. Onitting mention of most of the other numerous genera of this extensive family, attention must be concentrated on the curions flyingfrogs constituting the genus Rhacophorus. These frogs-of which there are more than forty species from the Oriental countries and the island of Madagascar-have the tips of both pairs of feet expanded into large discs, and very generally the front pair are is fully webbed as the hinder, although in some kinds the webs of the former are less fully developed. The eyes

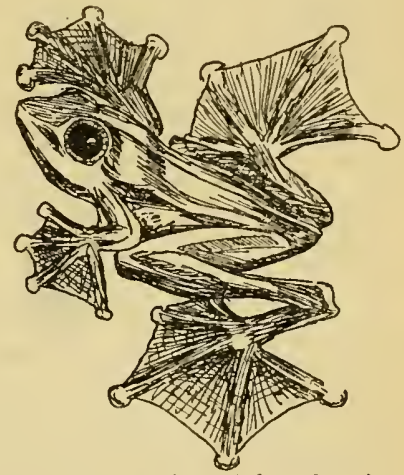

Fig :- Furisa Frog (Rhecephorus).

are remarkable for their fulness and brilliancy; and the general hue of the skin is bright green. Some species, are, however, stated to have tlie power of changing their hue to harmonise with their surroundings. In the skeleton of many of the species the tips of the terminal joints of the toes are in the form of the letter $Y$. Except during the breeding season, when they doubtless take to the water, these frogs are arboreal in their liabits. They derive their name of flying frogs from a statement to the effect that one species at least has been observed to take a long flying leap from a tree, apparently supported by the large webs between the toes. Although it does not appear that such a feat has ever been witnessed by a European observer, it is almost incredible that the sole use of these huge webs is for swimming, more especially since these frogs pass but a comparatively small portion of their existence 
in water. One member of a Tropical American genus of this family-namely Phyllobates trinitalis, of Trinidad and Venezuela-is remarkable on account of its curious nursing habits. The tadpoles are provided with sucking-dises on the mouth, by means of which they attach themselves to the back of their female parent, and are thus carried about in safety. As many as from twelve to eighteen tadpoles may sometimes be found thus clinging to one frog. A similar mode of attachment occurs in one species of the under-mentioned genus Dendrobates, but in this case this mode of locomotion seems to be resorted to only when the ponds in which the individuals have bred dry up.

In addition to the members of the genus Rhacophorus, there are many other frogs which have taken to an arboreal life, and so much do these resemblo one another in external appearance that it is pro-

Family bable any non-scientific observer would regard all of them Dendrobatida. as being very closely allied. Not so that dreadful personage the anatonist, who tells us that while the members of one family conform in the structure of the bones of the chest to the sub-order now under consideration, all those of another family to be mentioned later have a totally different conformation of this region. Accepting this distinction, we must regard the Tropical American tree-frogs of the genus Dendrobates, and those belonging to the nearly allied Malagasy genus Mantella, as forming a family by themselves. From the frogs of the family Ranide the Dendrobatidee are distinguished by the absence of teeth both in the upper jaw and un the bones of the palate. In both genera the toes are unwebbed, and terminate in small adhesive discs, but whereas in Mantella the tongue is notched at the tip, in Dendrobates it is entire. One species of the latter genus (D. tinctorius) is remarkable for the brilliancy and variability of its coloration; while it is further noticeable as being less arboreal than its congeners, generally frequenting low herbage or ground strewn with dead leaves, As already mentioned, another species carries its tadpoles clinging to its back from pool to pool in seasons of drought.

Another nearly allied famity of frogs is distinguished from the last by the expansion of the extremities of the horizontal transverse processes of the sacral vertebra; both

Family groups agreeing in the Engystomatida. absence of teeth in the upper jaw. These frogs present great variation in the structure of the bones and cartilages forming the chest; the typical genus Engystoma, together with Cacopils and several others, showing the absence of the bones known as precoracoidsa feature rare in the sub-order. This family may be regarded as essentially a southern one, its geographical range embracing Africa, Madagascar, the Malayan Peninsula and Islands, India,

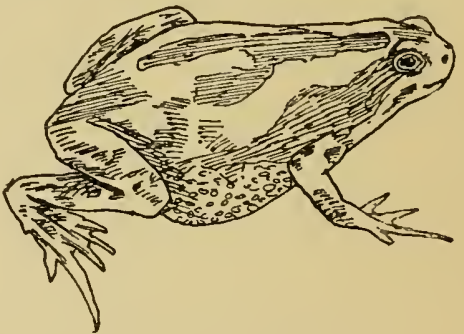

Fig. 3.-Cacopus systema. the south of China, New Guinea, and South and Central America. Two species of the typical genus extend, however, into North America as far as Mexico and Carolina. Nearly a score of genera are included in the family. Among thesc, a considerable number are characteriscd by the extremely small relative width of the opening of the mouth; and it is probable 
that all these subsist more or less exclusively on ants and termites. A large proportion of these frogs are nocturnal in their habits, and these may be recognised by the rertical pupil of the eye. Although many have discs at the tips of the toes, none of these are tree-haunting species. A considerable number of members of the family are, however, burrowers ; and in these the hind-limbs are unusually powerful, and are also specially protected by horny sheathings. Others, again, pass a large portion of their time in the water. It would be profitless to give in this place the distinctive characteristics of all th genera included in this extensive family; and attention may accordingly be confined to a few which are noteworthy on account of some peculiarity in the habits of their representatives. Foremost among these is the Chilian Darwin's frog (Khinoderma darrini), in which the female has transferred the task of carrying and tending the eggs and young to her partner. Whereas there is nothing remarkable about the structure of the female of this frog, the male has a capacious pouch underlying the whole of the lower surface of the body, which communicates with the exterior by means of a pair of apertures opening into the mouth on each side of the tongue. As soon as his partner has deposited her eggs, the male frog takes them in his front paws and transfers them to his mouth, whence they pass into the great nursing pouch, where they remain in perfect security till hatched into young frogs, which make their way into the world by the same passages. The tadpoles never develop gills, and this frog is the sole member of its genus. Equally noteworthy are the African frogs constituting the genus Breviceps. These species, which take their name from the small size and shortness of the head, would almost seem to have given rise to the fable of the ox and the frog, since they hav e the singular habit of pufting out the body till the head and limbs are nearly buried, and the creature looks almost like a ball. What may be the object of this curious habit does not appear to have been ascertained.

This family of frogs includes eight genera, all of which are confined to tho island of Madagascar, with the single exception of the one species constituting the genus Calluella, which inhabits Burma and Tenasserim. The essential distinctive features of the frogs of this family are the presence of teeth in the upper jaw, coupled with the expansion of the extremities of the transverse pro-

Family

Dyscophidce. cesses of the sacral vertebra, the latter feature serving to distinguish them from the members of the family Ranide, in which there is no such expansion. These frogs are very closely allied indeed to those of the preceding family, and as their chief interest lies in their peculiar geographical distribution, they need no further notice on this occasion.

A large frog from the Solomon Islands technically known as Ceratobatrachus guentheri, and easily recognised by the extremely sharp point formed by the tip of the nose, is regarded as forming a family by itself. From all the members of the sub-order under consideration, this frog differs by having both the upper Ceratobrachidce. and the lower jaw armed with a full series of teeth; and it is further characterised by the absence of expansion of the extremi. 
ties of the transverse processes of the sacral vertebra. It is an uglylooking creature at best, the lurge triangular head bearing ridges, and the printed nose being surmounted with a lunse flal) of skin, and similar flaps covering the cyus. The mouth, too, is of enormous capacity, and thus adds to the generally repulsive appearance of this frog. 'Ihe sharp-nosed frog is evidently a lighly specialised species, since it lays rery large eggs, from whicl young frogs emerge in a highly developed condition, the tadpole stage being compressed and passed in the eggs. MIr. Guppy writes that "during the descent from one of the peaks of Faröe Island, 1 stopped at a stream some 400 feet above the sea, where my native boys collected from the inoist crevices of the rocks close to tho water a number of transparent, gelatinous balls, rather smaller than a marble. Each of these balls contained a young frog absut a third of an inch in length. On my rupturing the ball, the tiny frog tuok a marvellous leap into existence, and disappeared before I could catch it."

\section{Sub-Order II.-Arifera.}

The remaining families of the order in which the tongue is present constitute a second subordinal group, differing from the first by the conformation of the bones and curtilages of the chest. Instead of the two metacoracoid bones being connected together in the middle line by a single cartilage attached to their free inn $3 r$ edges, each of the metacoracoids is expanded on the same side into a plate of cartilage, one of which overlaps the other.

Having the above-mentioner type of chest-structure, the large and important family of the Leptodactylidce-the Cystignathide of many authors-are spread over Central and South America and Australia. In all of

Family them only the upper jaw is furnished with teeth, and the Leptodactylida. extremities of the horizontal transverse processes of the sacral vertebra are either eylindrical, or only slightly expanded. In both these respects these frogs resemble the Ranidie, so that they may be regarded as holding the same relative position in the present sub-order as is occupied by the latter in the Firmisternia. More than a score of genera and a very large number of species are included in the family, and it may be noted that whereas in the majority of the Australian genera the pupil of the eye is vertical, this is but seldom the case in the American forms. The family may be divided into three gloups, in the first of which the breast-bone terminates below in a rod-like process. To this group belongs the typical genus Leptodactylus, of which all the numerous species are American. These frogs, in which the pupil is horizontal, are much like the Ranide in external appearance, but the hind-toes are not webbed. They are peculiar in that during the breeding season the fore-limb becomes much swollen, and in the skeleton the humerus bears a conspicnous bony ridge. All these frogs possess a very powerful voice, and in parts of the Argentine their croaking is a dreadful nuisance. Many of them burrow holes in the ground for their eggs. As an example of the second group, in which there is no bony rod to the breast-bone, and the hind-toes are nearly or completely free, we may take a West Indian species (IIylndes martinicensis) belonging to a large American genus, all the species of which are arborcal. This particular kind has the peculiar habit of laying its large eggs singly in the axils of leaves, where a few drops of water may flom time to time collect after a shower. From these eggs the young frogs emerge with only a small remmant of the tail, which is 
Somn absurbed; ani it al'pear's that during development no gills are produced, but that the tail, which is jichly supjlied with blood-ressels, acts as a breathing urgan. A third American genus is Ceratophrys, which includes the well-linown horned-frogs of Brazil and Algentina, and belongs to a group in which there is no bony rod to the breast-bone, and the hind-toes are more or less fully webbed. The Brazilim $C$. boiei is a luge creature, growing to as much as cight inches in length, and furnished with a pair of large horn-like outgruwths on the upper eyelids. In the Argentine esquerzo ( $C$. or. nata) these processes are less developed, and the whole size is less. Like its kindred, furnished with an enormous mouth, this species is beautifully mottled with green, olive, and gold, and in this respect is really a handsome creature, although its shape is hideous. All the larger kinds are very fierce in disposition, and carnivorous in their lubits, killing and eating small mammals, birds, reptiles, and other member's of their own order. They are much dreaded by the natives of the districts they inhabit, who tell wonderful stories as to their flying at men, and even at the noses of horses and cattle. Their bite is stated to produce rery extensive swellings. When attacking a large animal, they utter a cry more like a bark than anything else; but their ordinary note is bell-like. I once brought several

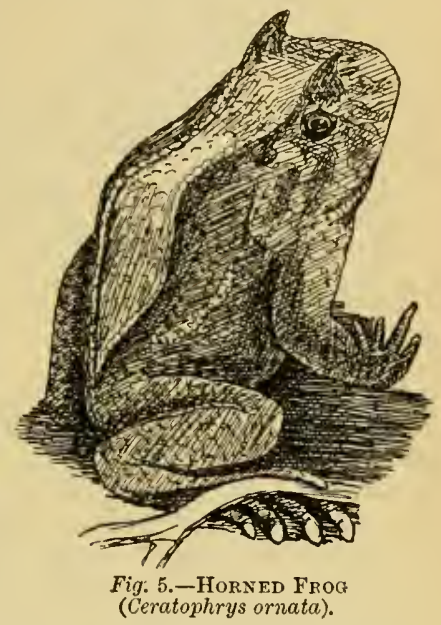
of these frogs in a box to Buenos Aires by rail, and during the journey the guard and some of the passengers were comsiderably alamed by the noisos proceed. ing from the cage, many of them wondering what kind of noisome beasts were therein enclosed.

Nearly allied to the preceding are the two South American genera Dendrophrymiscus and Butrohophrymus, forming a small family differing from the Leptodactylide merely hy the absence of teeth in the upper jaw, and thus serving to connect them with the next group. Family Dendro.

Of far more importance is the almost cosmopolitan and large toad family, in which teeth are absent in both jaws, while the extremities of the transverse processes of the sacral vertebra are expanded. 'That the family is closely allied to the Leptodaetylidee is indicated by the approximation of two of its gemera to two of the latter. Thus the Australian Pseudophryne resembles Criniu of the same country, while Engystomops is like Paludieola, both these latter being South American. Again two other pheryniscidee. genera exhibit resemblances to the Engystomatida. Most of the members of the family are crawling creatures, but the Javan Nectes is completely aquatic in its habits, and the members of the Oriental and African gemus Neetophryme appear to be arboreal. The nembers of Rhinophrymus-which is one of the two genera approximating to the Engystomatidu-feed on ants. Whereas in some forms the extremities of the terminal bones of the toes are simple, in others, such as Nectophryne, they are shaped like the letter ' $\Gamma$. Our remarks must be restricted to the typical genus bufo, of which there are 
a very large number of species distributed over the greater part of the world, with the exception of Oceania, Australasia, and Madagascar. In this genus the pupil of the eye forms a horizontal slit, the tip of the tongue is not notched, the tocs of the fore-feet are free, but the hinder ones are partially webbed. Occasionally the ends of the toes are expanded into small discs; the head may bear bony ridges, and in many cases the skin is covered with warts, which under excitement secrete a milky acrid fluid. Two species are

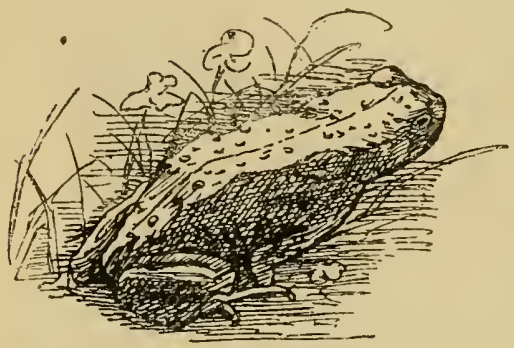

Fig. 6.-Natterjack Toad (Bufo calamita). met with in Britain, namely the common toad (B. vulguris), and the natterjack (B. colamita); the latter being very local in our islands, and easily recognised by the whitish or yellow streak on the middle of the back. Although not found in Britain, a third European species is the handsome green toad (B. viridis), which also ranges into the north of Africa and Asia. The males differ fron those of the common species in possessing a vocal sac beneath the throat.

Although many of the tree-frogs belonging to this family are very similar externally to the Dendrobatide, they agree with the toads in the conformation of the skeleton of the chest. From the Bufonidoe they Family Hylidce. may be readily distinguished by the possession of upper teeth ; while a still nore distinctive peculiarity is to be found in the claw-shaped terminal joints of the toes. The frogs of this family, which are mostly arboreal in their habits, and are ranged under a considerable number of generic divisions, attain their maximum development in America (especially its tropical regions) and Australasia, but also occur in Europe and Northern Asia, while a single representative of the typical genus Hyla is found in India. The genus just named includes more than a liundred and fifty species, and has a distribution coëxtensive with that of the family. Whereas the European $H$. arborea is a tiny little ereature, some of the Brazilian species measure as much as three inches in length. These frogs have the tips of the toes expanded into discs, and the hind-feet more or less fully webbed. In the eye the pupil is horizontal ; and the hinder end of the tongue may be either adherent or partially free. The males of the European species, and likewise those of some other kinds, have a huge vocal sac on the throat.

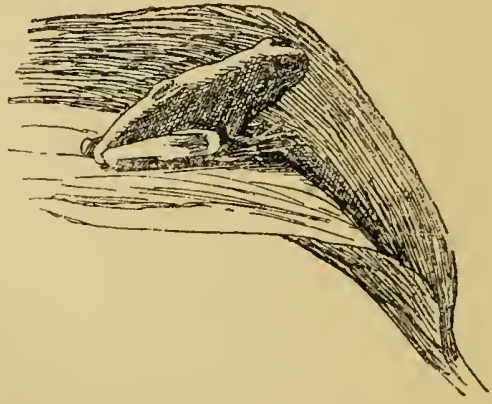

Fig. 7.-European Tref-Frog (IIyla arborea).

In order to assimilate them to their surroundings, tree-frogs are of a brilliant green colour. Except during the breeding season-when they descend tem- 
porarily to the water-they pass their whole time in trees or shrubs, and are enabled to absorb the moisture from leaves by means of special glands on the skin of the under surface of the body. Some of the species inhabiting the hottest parts of Brazil construct basinshaped nests of mud in pouds for the protection of the eggs, this task falling entirely to the share of the female. As an example of a non-arboreal species, the North American grasshopper-frog (Acris gryllus) may be mentioned. This species, which is the sole member of its genus, and is very closely allied to IIyla, spends its time among herbage in moist situations. More remarkable are the pouched frogs (Nototrema), with several species from Central and Western Tropical America, and one from Pernambuco. These frogs are also closely allied to $H_{y l a}$, but the females have a large pouch in the skin of the back, with its aperture near the linder end of the body. In this pouch the eggs-to the number of about tifteen--are deposited by the male, and there they develop into tad-

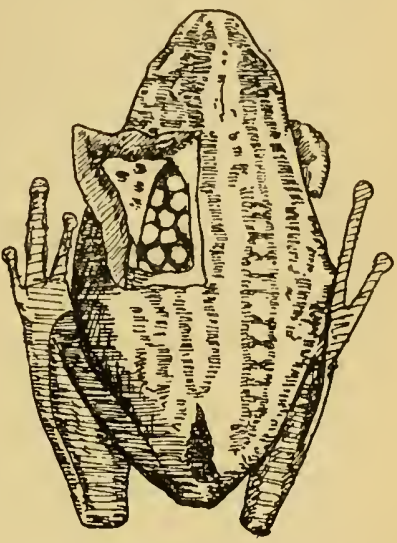

Fig. 8.-Povched Frow (Nototrema.) poles. The gills of the tadpoles are protected by a special bell-like organ : and the young do not leave the chamber until they have assumed the adult form.

A small number of genera' constiture a family distinguished from the Hylidce by the much greater expansion of the extremities of the horizontal transverse processes

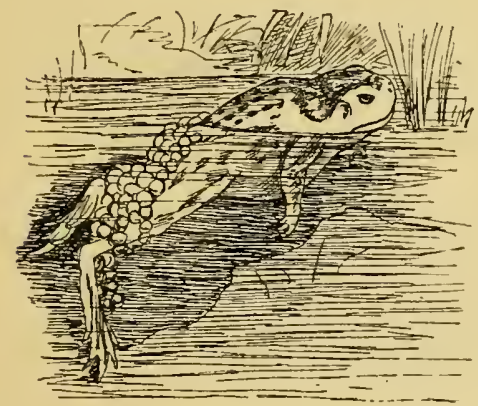

Fig. 9.-Midwife Frog (Alytes). of the sacral vertebra, and also by the

Family Pelobatidce. simple terminations of the end joint of the toes. The genera have a small geographical range, but the family occurs in North America, Europe, the Oriental countries and Papua. In the country first named it is represented by several species of Scaphiopus, nearly allied to which are the two Central and South Europcan species of Pelobates. The members of both these groups are burrowing frogs, with the hind-toes largely webbed, and in their movements they are somewhat intermediate between the true frogs and
forms are laid in long strings, which the toads. The eggs of the European forms are laid in long strings, which
are twined by the males round the stems of aquatic plants. Another European species (Pelodytes punctatus), together with the other genera of the family, differs from the foregoing in the mode by which the rod forming the hinder termination of the back-bone is articulated with the last vertebra. 
The sixth family of the present sub-order includes four genera, with a very small number of species, and is confined to the northern half of the Eastem Hemisphere and New Zealand. These frogs, which Family have teeth in tlie upjer jaw, and the extremities of the transDiscoglosside. verse processes of the sacral vertebra expanded, are specially distinguished by the rotention of rudimental ribs. To this family belong the painted frog (Discoglossus pictus) from the south of Europe and Algeria, and the fire-bellied frog (Bombinator igneus) of Europe and Asia, the latter having a triangular pupil to the eye, an adherent tongue, and no drum to the ear. The under-parts are mottled with orange or yellow, and the croak is very loud. The two European species of midwife-frogs (Alytes) are so named from the circumstance that the male takes the chains of eggs laid by the female and winds them round his hind-legs. After remaining concealed in a hole till the eggs are mature, he enters the water, when the tadpoles burst their shells.

These two small Tropical American families differ from all the other mem-

Families Hemi. phractidoe and Amphignathodontida. bers of the sub-order in possessing teeth in both jaws, the first of the two having the extremities of the liorizontal transverse processes of the sacral vertebra cylindrical, whereas in the second they are expanded.

\section{Sub-Order III.-Aglossa.}

The two genera and families by which alone this sub-order is represented differ from both the other subordinal groups in the complete absence of the tongue.

The three African species of spur-toed frogs (Xenopus) are sufficiently distinguished by possessing teeth in the upper jaw and the presence of spurlike nails on three

Family of the toes of the Xenopodida. hind - feet, which are fully webbed. Their tadpoles, which are born of large size, and without external gills, are furnished with a pair of barbels to the upper jaw.

The well-known Surinam watertoad, or pipa (Pipa americance), of the Guianas and

Family Brazil, is the only Pipida. member of this family, which is characterised by both jaws being toothless. Externally, the pipa may be recognised by its short and triangular head, which is furnished

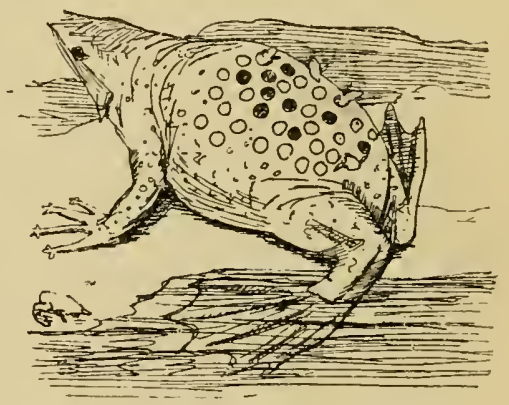

Fig. 10.-SURINAM Water-TOad (Pipa americana). with a large flap of skin at each corner of the mouth, and has very minute eyes. The four front toes are quite free, and terminate in expanded star-like tips, but a large web unites all the five toes of the hind-foot. In any state the creature is ugly, but when the female is carrying her nursery about with her she is repulsive. Soon after they are laid, the eggs are taken up by the male 
and pressed, one by one, into the cells in the thickened skin of his partner's back, where they grow till they fit elosely to the hexigonal form of their cells, each of which is elosed above by a kind of trap-door. After some eightytwo day's the eggs reach their full development and produee, not tadpoles, but perfect little toads. The reison of this is that tadpoles, which require to breathe the air dissolved in water by means of their external gills, could not exist in the eells, and, conserpently, this stage of the development is passed through very rapidly within the egg. When ready to come forth, the young toads, which are usually f:on sixty to seventy in number, although there may sometimes be more thin a liundred, burst "pen the lids of their eells, and, after strutehing forth their liend or a limb, nalie their appearance. When free from her charge, the mother rubs off wliat remains of the cells against any convenient stone or plant-stem, and comes out in a new skin. After breeding, these trids hecome much flattened, and pass the whole of their time in water.

URDER II.-CAUDATA.

\section{TEWTS AXI SALAMANERS.}

THE ortinary British newts and the black-and-yellow salamander of the Continent are familiar representatives of an order of amplibians broadly listinguished from the frogs and toads by the yermanent retention of the tail. In the skeleton they aiffer by the more normal strueture of the bones of the limbs, in which there is no elongation of any of thuse in the ankle joint, while the ulna and fibulit are respectively distinct from the radius and tibia. The more typical representatives of the order are lizard-like in external forn, having a comparatively short body and two pairs of well-develuped limbs. There are, however, certain aberrant types in which the body becomes more or less elongated in form, with a diminution in the size of the limbs, and in some instances the disappearance of the hinder pair. From the permanent retention of the tail, it is obvious that even in the more typical forms the metamorphosis is a much less marked feature among these amphibians than it is in the frogs and toads. And in certain instances there is no metamorphosis at all-the external gills persisting throughout life. In another case we have the peeuliar condition that whereas certain individuals may retain their gills permanently, and breed while in this condition, other individuals of the same species lose their gills, and develop into the proper adult terrestrial form before breeding. It is thus evident that these amphibians are in a state of unstable equilibrium as regards their transformation; and it nlay be a question whether those kinds with permanent gills are not realiy larve, which for some reason have ceased to develcp into the proper adult form.

Numerically, the tailed amphilians form a small group, containing probably less than one hundred and fifty species, arranged under four families. They are ehiefly confined to the Northern Hemisphere-where they attain their maximum development in North America-and are umrepresented in Australasia, the intra-tropical districts of South America and Afriea south of the Sahara. The true newts arc, however, ehiefly an Old World group. The Oriental region is very poorly furnished with these amphibians, liaving only 
three species altogether. Of these, one is an axolotl from Siam, belonging to the American genus Amblystoma, while the other two constitute the genus Tylotriton, one inhalbiting the Liu Kiu Islands, and the other the castern part of the Himalaya and Yumman. All the tailed amphibians are noctumal creatures, the great majority of which pass some portion of their time in water, while others are permanently aquatic. Such as develop lungs and lose their gills lhave to rise periodically to the surface of the water in order to breathe. Their tenacity of life forms a striking feature in the physiology of these creatures ; species inhabiting tropical regions, subject to periodical droughts, becoming torpid at such seasons, while those from colder regions hibernate. Even envelopment in ice is not always sufficient to destroy life. The same low organisation is indicated by their power of reproducing the tail and limbs. Whereas the majority of species have large and well-develi ped eyes, a few which inhabit underground waters have lost the power of sight, and have the rudimental eyes deeply buried beneath the skin. The aquatic species swim chiefly or entirely by means of a tail, and thus differ markedly from the frogs, in which the hind-limbs alone are employcd. Most of the terrestrial forms are slow-moving ereatures, although a few clart about with the rapidity of lizards. Certain members of the order ale peeuliar in producing living young, the tadpoles being in some cases retained within the body of the female until considerably developed.

The greater number of the members of the order sre included in the fanily typified by the common yellow and black salamander, although the genera may be arranged in four sub-families. As a family,

Family the Salamandricle are distinguished by undergoing a full Salamandrida. metamorphosis, with the consequent loss of the gills in the adult condition, as well as by the presence of teeth in both jaws, of eyelids, and of maxillary bones. In the typical sub-fanily Salcmendrince, the teeth on the palate are arranged in the form of a pair of posteriorly diverging rows, such rows being situated on the inner margins of two long processes ruming backwards from the palatine bones. No teeth are developed on the bone forming the hinder part of the imicr surface of the skutll, and known as the parasplienoid;

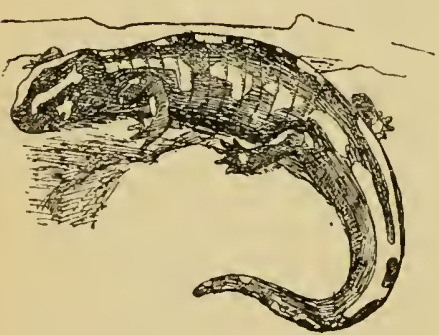

Fig. 11.-Common SAlaMaNdER (Sall. mandre maculosa). and in the backbone the bodies of the vertebra have a cup at the hinder end, and a ball in front. The common black and yellow salamander (Salamandra maculdisa) is the best-known representative of the typical genus of the subfamily, which includes two other species, and is confined to Central and Soutliern Europe, Algeria, and Syria. From the newts, the typical salamanders may be clistinguished by the following features. In form the tail is cylindrical and tapering; there are five toes to cach of the hind-feet; the two rows of the teeth on the palate are curved; and the tongue, which is of rather large sizc, and nearly oval in form, is free at the sides, and to a certain extent behind. The black ground-colour, marked with a double row of longitudinal yellow blotches on the head and back, and similar markings on the upper surface of the tail and limbs, sußiciently distinguish the silamander from the other 
members of the same genus. This species is a somewhat solitary and sluggish creature, spending most of the year on land, but resorting to the water during the spring, when breeding takes place. Usually the young are bor'n alive, but oceasionally eggs are laid, when they almost immediately hateh.

A large number of tadpoles come into the world at once, and these, in the ordinary mode of development, have already lost their grills. Formerly, highly poisonous properties were attributed to this salamander-as they, doubtless, still are among the uneducated peasantry of various parts of Europe, - and the creature was believed to be capable of being cast into a furnace without suffering harm. Beyond secreting an acrid fluid, it is, however, perfeetly harmless. The ramge of this speeies includes a considerable part of Europe, as well as Syria and Algeria. Nearly allied is the somewhat smaller black salamander (S. utra) of the Alps. Although many eggs may be found in the body of the female, it appears that only a pair of tadpoles are produced, these being nourished by the egrgs which never develop. While within the body of the parent, these tadpoles have very long external gills, which are shed previous to birth. Many years ago some tadpoles in the gilled condition were taken frum the parent and placed in water. Almost immediately the large gills were cast off, and their place taken by much smaller ones, which remained for a long period. As remarked by Professor Mivart, "the eurious and noteworthy point in this experiment is the fact that, after the criginal gills (which were unadapted for free external life (have perished, new and suitable gills become developed, and this not in a struggle for existence against rivals, but directly and spontaneously from the innate nature of the animal." The third and last species is S. cancasica, from the Caucasus, which differs from the other two in that the tail is shorter than the head and body. Its colour is black, with rows of roundish yellow spots on the back. It may be remarked here that in both the spotted species the young are uniformly dark-coloured, the yellow markings being only gradually acquired. Hence the ornamentation may be regarded as a lately acquired feature. On the other hand, where-as in the lion and deer-skin-markings occur only on the young, such omamentation is very ancient, and tending to disappear. The Spanish salamander (Chioglossa lusiturica) differs by the tongue being fixed on a protrusile pedicle.

From the true salamanders, the newts (Molge) are distinguished by the laterally compressed form of the powerful tail, as well as by their permanently aquatie mode of life. Many of the speeies, too, are furnished with an upright longitudinal fin on the back, such fin generally attaining a special development during the breeding season in the males. Newts range orer the three great continents of the Nurthem Hemisphere, although they are unknown to the south of the Himalaya, and are much more abundant in the Old World than in the New. They are the only members of the order inhabiting Britain,

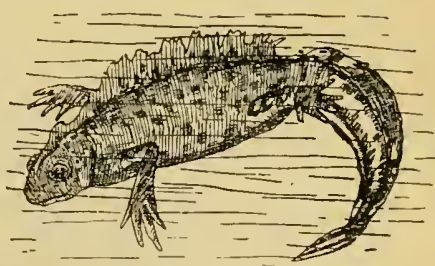

Fig. 12.-Crested Newt (Molge cristata). where the common species in many districts is to be met with in every pond. The liandsomest and largest of the British species is the crested newt (II. cristati), which belongs to a group characterised by the presenee of a fin-like crest on the back of the males, and in some cases of the females also, where, 
however, it is always considerably lower. In the males of the crested newt the crest is scalloped; and in both sexes the under surface of the body is orange with black marblings. When in full breeding-dress, a male of this species is indeed a beautifully-coloured creature. In size it grows to five inches or rather more. From Sweden southwards, this newt is spread over the greater part of Europe, with the exception of Italy. It is distinguished from all other members of the genus by a peculiarity in the structure of the skull. Far more abundant in this country is the much sulallcr common newt (M. vulgaris), in which the crest of the male is likewise festconed, while the hind-toes of the same sex are lobed during the breeding season, the under surface of the body being yellowish, with large black spots in the male, and sniall dots in the female. In the latter, the back carries either a simple crest or a mere ridge. It is only in the breeding-season that the crest of the male assumes its full development; and at this time the tail-fin is also festooned.

With the exception of Western Europe, this species is widely distributed on the Continent, and also ranges into $A$ sia. The last and smallest of the British rejresentatives of the genus is the webbed newt (M. palmutu), which, in addition to a peculiarity in the structure of the skull, is distinguished by the hind-toes of the male being fully webbed during the breeding-season. The crest of the male is straight; and that of the ftmale either very small, or represented by a ridge. The lower surface of the body is more or less nearly uniformly coloured, although there is a narrow streak of orange in the middle line.

Several species found in the sunth of Europe have no crest in either sex. The habits of newts are so familiar to all who have lived in the country, that but little need be said on the subject. During the brceding-season, all are inhabitants of the water; but later on many of them forsake that elcment for a longer or shorter period, and become terrestrial. While scme hiber. nate in holes or beneath stones, others retire to tlie mud at the bottom of ponds. The eggs are generally deposited on the stems of aquatic plants; and when the tadpoles first make their appearance, they have small, simple gills, behind which are a pair of small projections, representing the future forelimbs. In the course of time the gills become branched, the fore-limbs slow their four toes, and the hind-legs make their appearance. Soon after, the gills begin to shrink, and finally disappear, while lungs are developed, and the limbs acquire their full adult proportions, when the creature ceases to be a tadpole, and becomes a newt. It lias been already mentioned that the tadpoles of the frogs and toads differ from those of the newts and salamanders in that the hind-limbs make their appearance before the front pair. The reason for this remarkable difference is doubtless to be found in the circumstance that in the former group the hind-linbs are proportionately much larger than in the latter, and consequently require a longer period for growth. From both the foregoing genera the Italian spectacled salamander (Salamandrina perspicillate) is at once distinguished by having only four toes to each of the hind-feet, the number of toes being consequently the same in both pairs of limbs. It is a small species, varying between three and four inches in length, with a slightly compressed and lieeled tail, and a rough warty skin. The under surface of the tail and of the hinder end of the body is of a brilliant carmine red. This salamander inhabits moist, rocky districts, where its rapid movements render it liable to be mistaken for a lizard. True to its amphibian nature, it resorts, however, to the water in spring for breeding purposes. The warty salamander. Tylotriton rermicosus, of the Eastern Himalayi and Yumm, together with the allied T. andersoni of the Liu-Kiu 
Islands, constitute a genus confined to the Oriental region, and differing from all those nentioned above in the conformation of the skull, in which the pterygoid boines extend forwarch to touch the maxillie, instead of being separated from them by an interval. These salamanders have five hind-toes, and the tail strongly conpressed. They are inhabitants of mountain districts. Nearly allied is the single species of Pachytriton, from South Kiansi, China, in which the tail is cylinchical at the root, although compressed near. the tip.

In the second sub-family - Amblystomatince - of the Salemandivide the teeth on the palate for'm either it transwerse or posteriorly converging series, and are attached to the hinder margin of the posterior portion of the vomers, insteal of to processes of the palatine bones. The vertebre, too, differ from those of the first group in that both terminal faces of their boclies are slightly cupped ; this being a lower tyje of structure than the ball-andsucket articulation. The type of this group is the creature known in Mexieo as the axolotl, which is the permanent larval form of a salamander from the United States described as Amblystomu tigrium. It was lomg thought that these two forms were totally distinct animals; but the iclentity of the two was conclusively proved by some Mexican axolotls kept many year's ago in Paris. One of these layed eggs, which in due course developed into axolotls, but these latter ultimately assumed the form of the adult salamander. The most curious fact about the matter was that wher'eas the axolotls bred freely, nowe of the adult salamanders could be induced to propagate their kind. There are several species of the genus inlabiting Nortl America, ancl a sungle outlying form in the mountairs of Siam. With the single exception of the Mexican race of Amblystoma

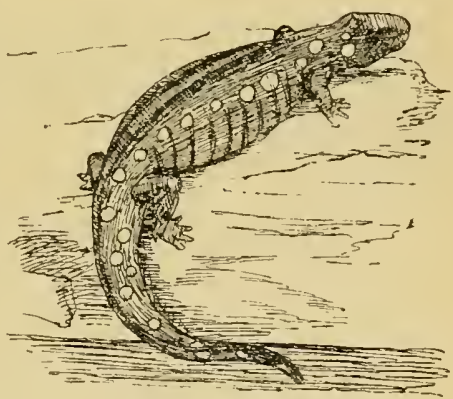

Fig. 13. - Adult Axuloth

(Amblystomu tigrinum).

tigninum, all these appear to pass from the tadpole to the salamander stage in the usual manner. The reason of the Mexican race retaining the larval stage appears to be that the country is very arid, and unfit for amphibian life. Consequently the axolotls remain permanently in the large lake by which the city of Mexico is surrounded. In this larval conclition they have a long compressed tail, with a crest aljore and below, which is continued as a ridge on the back; and on the sides of the neck are abundant bushy external gills. The limiss are rather small, and the general hue of the skin is mottled olive. On the other hand, the adult-which is normally developed in the United States-is an ordinary-looking salamander, with a relatively large head, good-sized limbs, and a sub-cylindrical tail; the colour of the skim being blackish or brown, with numerous yellow spots. As special. clialacteristics of the genus Amblystoma, it may be mentioned that the teeth on the palatines are arranged either in nearly a straight line or in an angle without any wide gilp in the middle, and that the tongue bears a series of landiating pleats. Very closely allied is the genus Linguctupsus. A specimen of $L$. com alcetus has been taken in Arkansis from a hot spring. Of the other 
genera included in the sub-family now under consideration, Ranidens from the north-eastem provinces of China and the east of Siberia, Batruchyperus from Tibet, and Iicamptodon from California, constitute a group characterised by the teeth on the palate forming a pair of arches, separated from one another in the middle line, and with the convexity forwards. The second of these genera differs from the otlier two in that the hind-feet are four-toed. A third group is formed by the Japanese Onychodactylus, in which the palatal teeth form a double arch, without any medium gap, while the claws are black. In the last group, represented by the Japanese and Chinese Hynolius, and Salamandrella of Eastern Siberia and Kamschatka, the palatal teeth converge backwards in a somewhat V-shaped figure ; the first genus having five hind. toes, and the secund only four.

The other two sub-families are small. In the first, or Plethodontince, the parasphenoid bone differs from that of the two preceding sub-families in bearing teeth; the vertebra being of the same type as in the Amblystomatina. Of the genera included, Autodax (Anaides), Plethodon, and Butrachoseps form a North American group characterised by the tongue being attached along the medium line as far as its front margin; the first genus having very few teeth in the jaws, while in the second the hind-toes are five in number, and in the third only four. The second group, which is likewise North American, although its flrst genus ranges into Central America and the West Indies, includes Spelerpes and Manculus, and differs from the last in that the tongue is attached only by a pedicle from the middle of the lower surface, so that all its edges are free.

The fourth and last sub-family, Desmognathince, is also North American, and while agreeing with the third in having teeth on the parasphenoid, differs in that the bodies of the vertebre are cupped behind and convex in front. In the typical genus Desmognathus the tongue is attached all along the middle line, whereas in Thorius it has a central pedicle, and is thus mushroom-like. Haptoglossa, from Costa Rica, is nearly allied to the latter, but differs in that the tongue is adherent in front. Of more interest is the single species of Typhlotriton, which inhabits a cave in Missouri, and is totally blind, the rudimental eyes being buried beneath the continuous skin of the head.

Although very small, the second family of the tailed amphibians is noteworthy on account of containing the largest members of the entire order. Most of the few species are North American, but the giant Family salamander is an inhabitant of Japan and China. In their Amphiunidue. general structural characters the members of this family agree with the Salamandrido, from which they are sharply differentiated by the absence of eyelids. All of them have the bodies of the vertebræ cupped at both ends, and in all the body is much elongated, and the relatively small front and hind-limbs widely sundered from one another. These features are clearly indicative of a closer relationship with fishes than obtains in the case of the true salamanders and newts. The same aftinities are indicated by the aquatic habits of these creatures, and likewise by the permanent retention of internal gills; and, owing to the presence of the latter, respiration can be effected without the necessity of coming to the surface, at any rate for a considerable time. It is interesting to note that remains of a fossil species belonging to the same genus as the giant salamander occur in the Tertiary rocks of the Continent, from which it may be inferred that the family has migrated westward. The giant salamander (Megalobretraclus maximus) is a huge sluggish creature, frequently growing to as much as a yard in length. 
and occasionally considerably more. With its flat, oval head, depressed body, warty skin, short, splay-toed limbs, and lighly compressed tail, its appearance is by 110 means prepossessing, and when lying almost motionless in a tank of slimy green water in the reptile-house in the London Koological Gardens, the attention it attraets from the general public is probaluly but slight. Nevertheless it is one of the most interesting of living animals, and our notions of zoological aflinities would be much less clear thin they are had this salamander and its allies become extinct. Extermally this salamander is rlistinguished by having four toes in front and three behind, and likewise by the absence of gill-openings on the sides of the neck. Jnternally it will be found that there are two arches for the support of the gills on eacl side. If the mouth be opened, it will be seen that its floor is completely covered by the elosely adherent tongue, and also that the teeth on the palate form a series rumning parallel to those on the elge of the upper jaw, these teetl being situated on the vomers. These salamanders, which, as already said, are common to Japan and Cinina, inhabit elear momtain streams, where they feed on such ayuatic creatures as they are able to eapture ; in captivity, at loast, they ale known to be eannibals, but this depraved taste was pl' bably developed owing to latek of a sufficiency of otlier fuod. In autumm the female lays a number of small eggs; but the eally stages of development are unknown, although it is probable that at first the young tadpoles are provided with external gills. The much smaller

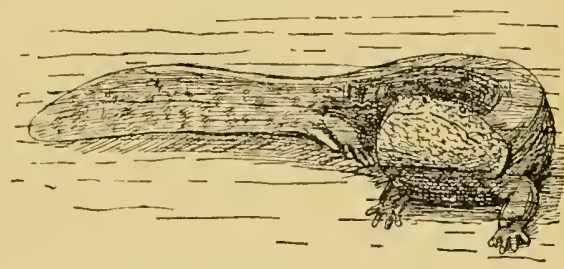

Pig. 14.-Ciant SalaMander

(Mejalobatrachus maximus).

Mississippi salamander, or hell-bender (Cryptobranchus lateralis), is distinguished by the retention of a gill-opening on one or both sides of the neck, and the free front cdge of the tongue, as well as by the presence of four pairs of arches for the support of the internal gills. Less than twenty inches seems to be the maximum size of this salamander. Geographically the range of the species extends from the Mississippi basin and the streams of the Louisianian district to North Carolina.

Very different in appearance and strueture from both the preceding is the species representing the genus Amphimma, which has a somewhat more ex. tended range than the hell-bender, since it is found in Soutl Carolina. It is an exceedingly elongated eel-like creature, with very minute limbs, of which the front pair are situated close to the head, while the hinder ones are placed vely far back at the commencement of the tail, which is much shorter than the body. It is a rather curious circumstance that whereas in some examples each foot is furnished with three toes, in other's the number is redueed to two; but in organs which are either about to disappear, or are in the course of development, similar variations are by no means of unfrequent oceurrence. In the nature of its food this creature is very similar to the Mississijppi salamander; but whereas the latter oceasionally leaves the water for a stroll on the bank, it does not appear that the former ever quits its native element. The female Amphume deposits a string of egros resembling a rosary, round which she subsequently eoils herself, after arranging the string in a mass. 
According to the system of classitication now favoured by zoologists, the tailed amphibians constitute a series regularly descending in their grade of organisation; and witl the present family we reach a group

Family in which the external gills of the young are permanently

Proteide. retained, while there are two pairs of rudimental limbs. An additional peculiarity is to be found in the absence of the maxilla in the scull. As in the preceding family, the bodies of the vertebra have cupped terminal faces, and eyelids are wanting. The typical member of the family is the famous olm ( $P$,oteus) from the subteriaiean waters of Carniola, Carintlia, and Dalmatia. No better description of this creature is extant than one by Sir Humplny Dary, which runs as follows:- "At tirst sight you might suppose this

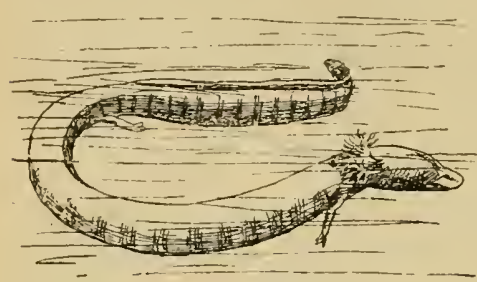

Fig. 15.-0ix (Proteus anguineus). creature to be a lizird, but it has the motions of a fish. Its head and the lower part of its body and its tail hear a strong resemblance to thuse of an eel; but it has no fins; and its eurious bronchial organs are not like the gills of fishes, they form $n$ singular vascular structure, almost like a crest round the tlinoat, which may be removed without oceasioning the death of the animal, which is likewise furnished with lungs. With this double apparatus for supplying air to the blood, it can live either below or above the surface of the water. Its fore-feet resemble hands, but they have only three claws or fingers, and are too feeble to be of use in grasping or supporting the weiglit of the animal. The hinder feet have only two claws or toes, and in the larger specimens are found so imperfect as to be almost obliterated. It has small points in place of eyes, as if to preserve the analogy of nature. It is of a fleshy whiteness and transparency in its natural state, but when exposed to light, its skin gradually becomes darker, and it last gains an olive tint. Its nasal organs appear large; and it is abundantly furnished with teeth, from which it may be concluded that it is an animal of prey; yet in its confined state it has never been known to eat, and it has been kept alive for many years by occissionally changing the water in which it was kept." From the olm the North American genus Necturus is at once distinguished by the possession of well-developed eyes, and likewise by the presence of four toes to each foot. In form, too, it is more lizarl-like, the body lacking the cel-like elongation characteristic of the olm, while the limbs are less rudimental. There are two species of the genus, one of which is not uncommon in the rice-fields of the Southern United States. Although both breathe almost entirely by means of their plume-like external gills, it is stated that they will occasionally venture on land, when the lungs of course become the respiratory organs. In sinking a well recently in Texas, a third generic representative of the family was discovered at a depth of 180 feet in a subterranean stream. This form is related both to Protens and Necturus, and has been named Typhlomolge rathbuni. It is characteirised by the great length and slenderness of its limbs, and the broad, 'tlattened, and squared muzzle.

The last family of the tailed amphibians is confined to North America, where it is represented by Siren lacertina of the South-Eastern United 
States and I'seudabranchus striutus of Georgia. Both these lowly creatures have long eel-like bodies, external gills, and a small pair of front.legs. The hind-legs are,

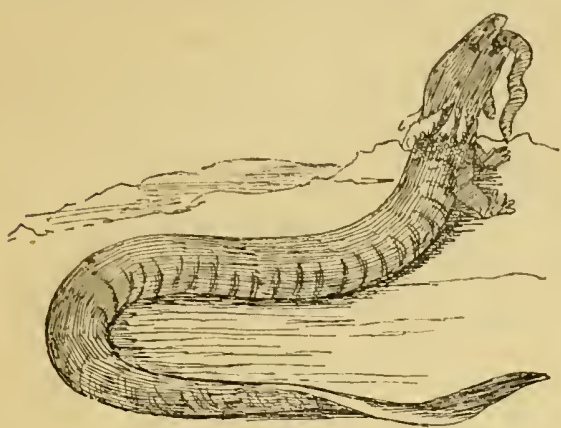

Fig. 16. -Two-Legged Salamander (Siren lacertina). however, totally wanting, and

Family Sirenida. there are no teeth in the margins of the jaws. In the species first namedwhich mily measure nearly twenty inches in length-there are three pairs of gill-openings on the sides of the neck, and each of the fore-feet is furnished with four toes. From this genus Pseudobranchus is distinguished by the presence of only a single pair of gill-apertures, and the reduction of the front toes to three. These salamanders frequent damp situations and pools, and occasionally ascend the aerial roots or stems of trees. They are carnivorous in their habits, and are able to breathe either by their gills or their lungs. During the colder months of the year they hibernate.

\section{ORDER III.-APODA.}

\section{Cacilians.}

THE third and last order of Amphibia is represented by the blind, burrowing creatures commonly known as crecilians. In appearance they are so worm-like that by the non-scientific observer they might readily be mistaken for Invertebrates. In the adult state they show no trace of limbs; but budlike remmants of hind-legs have been detected in the embryos of Ichthyophis qlutinosus. This clearly shows that they are a degraded form, but whether they are descended-as has heen considered the case-from the tailed amphibians may, perhaps, be doulstful, seeing that they differ from that group in an important feature comnected with their reproduction. They have either a rudinental tail or none at all, and they are further characterised by certain structural peculiarities in the osteology of the skull. The eyes are generally deeply buried beneath the skin, or placed beneath the bones of the skull, and in certain members of the group overlapping scales are concealed deep down in the skin. The head is provided with a tentacle, which may be capable of protrusion and retraction. Creciliaus present a very remarkable geographical distribution, being restricted to South and Central America (with the IVest Indies), Africa south of the Sahara, the Seychelles, and the Oriental countries. Their absence from Madagascar, coupled with their existence in the Seychelles, is a rery noteworthy circumstance, and seems to indicate a connection between those islands and either Africa or India after Madagascar was insulated. The adults burrow in moist earth, 
like worms, where they lay large egrgs, from which, in duc course, are developed tadpoles furnished, at least before birtl, with gills. Soon after hatching, the tadpoles take to the water, where they appear to remain until they assume the adult condition.

All the members of the order are so similar in structure that they are included in a single family group. The first genus, Ichthyol his, includes two

Family

Caciliide. species, ranging from India to the Malayan Islands; but whereas one (I. glutinosus) is also found in Ceylori, the secoud ( $I$. monuchrous) is unknown there. In these species overlapping fisli-like seales are embedded in the skin, the eyes are distinguishable, the lower jaw is furmished with a double series of teeth, and the tentacle, which is capable of protrusion, is situated near the upper lip betwcen the eye and thc nostril. The first-named species grows to a length of about fifteen inches, but has a diameter of only half an inch. Writing of this sprecies in Ceylon, the late Sir J. Emerson Tennent wrote as

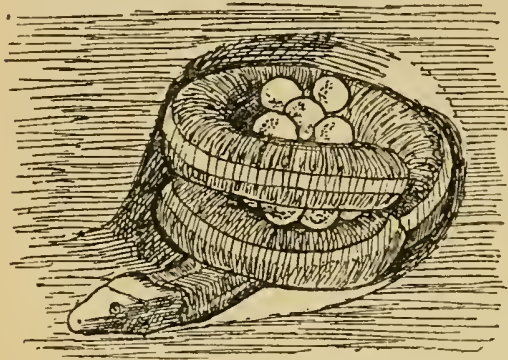

Fig. 17.-A Cecilian Broodixg its Eggs (Ichthyophis glutinosus). follows:-"The rocky jungle, bordering the higher cotiee estates, provicles a safe retreat for a very singular animal, first introduced to the notice of European naturalists by Limneus, who gave it the name Cecilia glutinosre, to indicate two peculiarities manifest to the ordinary olserver, an apparent defect of vision, from the eyes being so small, and cmbedded as to be scarcely distinguishable, and the power of secreting from minute poles in the skin a riscous fluid, resembling that of snails, eels, and some salamanders. Specimens are rare in Europe, owing to the readiness with which it decomposes, breaking down into a flaky mass in the spirits in which it is attempted to preserve it. The creature is about the length and thickness of an ordinary round desk-ruler, a little flattened before and rounded behind. It is brownish, with a pale stripe along either side. The skin is furrowed into 350 circular folds, in which are embedded minute scales. The head is tolerably distinct, with a domble row of fine curved teeth for seizing the insects and worms on which it is supposed to feed." More recent observations-especially those of Dr. Sarasin-have largely increased our knowledge of the mode of life of these strange and interesting creatures, which are generally found in soft mud. As already mentioned, rudiments of hind-limbs have been detected in the embryos. The large globular eggs are laid in a burrow near water, and are brooded by the female, who coils her body round the mass. The tadpoles are not hatched until after the loss of their external gills, and when they take to the water they breathe through a pair of gill-ojenings on the sides of the neck. These tadpoles have a rery fishlike head, in which the eyes are much more distinct than in the adult, while they have also a well-dlefined and highly-compressed tail, furmished below and above with a fin, after the manner of a flog's tadpole. A nearly-allied Ori. ental genus is Epicrinops, witl a single species. From Ichthyophis tho zenus Uraotyphlus is readily distinguished by the tentacle being situated 
below the nostril. The genus is represented by two species from Southern India, a West African form which has been referred to it having been shown to belong to Geotrypetes. In the foregoing genera the tentacle has a conical form, but in the typical genus Crecilia, which is confined to Tropical South America, it becomes flap-like, with a horse-shoe shaped groove at the base, its situation being below the nostril. On the other hand, in the nearly-allied II!pogeophis, the same organ is placed below the nostril. This genus is specially interesting on account of its geographical distribution, having two species from Africa, and two from the Seychelles. A West African species formerly included in the same genus is now distinguished as Geotrypetes petersi. Still more remarkable is the distribution of the genus Dermophis, which has several species from 'Tropical Anerica, one from West Africa, and another from the eastern side of the latter continent. From the preceding kinds this genus is distinguished by the globular form of the tentacle, which is surrounded by a circular groove, and situated below and in front of the eye.

In addition to the presence of scales in the skin, all the preceding genera are characteriscul by the eyes being either distinct or buried only in the skin. From these, Gymnopis and IIerpele differ in that the same organs have sunk so deep as to be actually beneath the bones of the skull. In the former genus, which is confined to Tropical America, the globular tentacle is surrounded by a circular groove, and placed close to the muzzle, whereas in the latter-which is West African-it is nearer the nostril.

In the remaining genera of the family, the skin is devoid of scales. Of these, Gegenophis, as represented by a single Indian species, is remarkable on account of its extremely restricted range, being apparently recorded only from the Peria peak, in the Wynad district, at an elevation of about five thousand feet. Eren there it is stated to be of rare occurrence. Unlike most of its kind, it lives mnder stones. As a genus, this caecilian is characterised by the eyes being beneath the bones of the skull, and by the tentacle being globular, and surrounded by a circular groove. From this genus, Siphonops, with three species inhabiting Tropical South America, differs by the distinct eyes, and the flap-like tentacle, which has a horse-shoe shaped groove at the base, and is placed much nearer to the eye than to the nostril. The allied genus Typhlonectes, from the same regions, may be distinguished by the tentacle, which is of similar shape, being nearer to the nostril than to the eye, as also by the compression of the hinder end of the body. Lastly, we have the South American Chthonerpetum, which differs from all the other scaleless forms in the arrangement of some of the bones of the skull. It has a flap: like tentacle, situated mid-way between the eye and the nostril. One species of this genus is found in the neighbourhood of Buenos Ayres, and is thus more southern than any other American member of the family. 


\title{
SUB-KINGDOM I.-VERTEBRATA.
}

\section{CLASS V.-PISCES.}

\author{
By R. LynekKer, B.A., F.R.S., V.P.G.S., \&e.
}

Is the preceding section it has been shown that the tadpoles of the Amphibia make a very close approximation in structure - and to a certain extent also in form-to fishes. The resemblance, however, stops suddenly short in regard to the structure of the limbs. In all amphibians the limbs resemble those of the higher vertebrates in being composed of a definite number of segments, and terminating in distinct digits, which are normally five in number. On the other hand, although in fishes there are distinct segments in the upper portion of the limbs, these do not correspond exactly with those of the ligher animals, and there are no structures corresponding with fingers and toes. The limbs are, in fact, fins, and terminate either in a fringe of rays, or, more rarely, in a jointed cartilaginous rod, bordered on one or both sicles with a smaller number of somewhat similar rays. In some fishes, it is true, limbs are wanting; but then this is also the case among the higher vertebrates, and does not impair the classificatory value of these appendages. Another important clistinction from amphibians is to be found in the circumstance that the median fins of fishes - which are always present in some form or other-have rays similar to those of the paired fins. Accordingly, in a popular way, fishes may be defined as aquatic, cold-blonded, back-boned animals, breatling the air in water by gills (sometimes supplemented by lungs), and furnished with paired nostrils, paired and median fins, the former of which (when present) differ essentially from the limbs of higher animals. This definition will suffice to distinguish the elass Pisces from all the preceding classes. but as it fails to differentiate the group from the lampreys (now regarded as a class apart), it must be added that all Pisees have a functional lower jaw.

Whether the earliest ancestors of fishes nere as purely aquatic in their habits as their descenclants is a question somewhat difficult to answer, although the reply should probably he in the aftirmative. Anyway, it is certain that we have at present no indications of a direct transition between fislies and the elasses immediately above and immediately helow them, so that they stind out as one of the best defined of all groups ; and there is very considerable uncertainty whether the paired fins of fishes can be regarded as the ancestral type from which the limbs of higher animals were evolved. In spite of certain minor variations-as exemplified by the difference in shape hetween an eel and a flat fish-all the members of the class are characterised by the adaptation of their bodily form to an aquatic life, a feature in which they resemble whales and porpoises among mammals. As is well observed by Dr. Bashford Dean, this adaptation to aquatic existence "has stamped them in a common mould, and has prescribed the laws which direct and limit 
their evolution ; it has compressed their head, trunk, and tail into a spindlelike form; it has given them an easy and rapid motion, enabling them to cleave the water like a rounded wedge. It has made their mode of movement one of undulation, causing the sides of the fish to contract rhythmically, thrusting the animal forward." Very beautiful indeed are the lines of a typical swift-swimming fish, such as the common mackelel; and in a front view the sectional ontline will be found to form a perfect ellipse, from which projeet the fins as thin vertical or oblique ridges.

Interesting and important as is the structure of fishes in general, our remarks on this subject must be the briefest. Here it is important to mention that the ordinary bony fish of the present day, such as a mackerel or a roach, are very specialised forms, and afford but little idea of the general or primitive structural type of the class, a shark or a lumg-fish heing far preferable in this respect. Among the special organs of many, although by no means all fishes, is the air-blidkler, which has the power of altering the specific gravity of the body to accord with that of the surrounding water. Frequently this bladder is comnected by means of a duct with the oesophagus, and in the lung-fishes it assumes the characters of a lung. Of the external corerings of fishes, the most characteristic are the scales, although these are wanting in some gromps and in certain members of others. The ordinary over-lapping scales are classified as cyeloid or ctenoid, according as to whether the free margin is entire or pectinate. When they are coated with a highly polished enamol-like structure, and at the same time are more or less leetangular in form, they are telmed ganoid. The lateral line found on the sides of many fishes is formed of scales, modified partly for the purpose of supplying mucus. Tho terminal portions of the fins-namely, the fin-raysare likewise structures furmed in the skin; and these rays are articulated below with the interspinal bones in the bony fishes, and with the radial cartilages in the sharks and rays. The paired fins comprise the pectoral and pelvic; and tho median or unpaired, the dorsal, caudal, and anal. When the pelvic pair are situated in advance of the peetorals, they are said to be jugular in position; when in the same line, thoracic; and when far back, abdominal. Of the internal structure of the paired fins, such observations as are necessary may be cleferred till the different groups are treated of ; but it may be mentioned that when the rays of the candal fin surround the hinder extremity of the bick-bone symmetrically, the tail-fin is said to be diphycercal. When, on the other hand, the upper lobe is greatly developed at the expense of the lower, while the rays are unsymmetrically, as in the sharks, it is termed heterocercal. More specialised than either of the foregoing is the so-called lomocercal or completely forkerl tail, in which, although the back-bone terminates in an abbreviated unsymmetrical manner, the arrangement of the rays is symmetrical. Whereas in some fishes the untochord persists in its original form, in others it is partially surrounded by rudimental vertebral arehes, and in the higher forms is completely replaced by bony vertebra. Much the same may be said with regird to the primitive eartilaginous skull, which is retained in its original form in the sharks, but is completely bony in the higher fishes, in which, in addition to bones developed from cartilage, a number of investing so-called dermal bones likewise arise. Dermal bones, too, are developed in the pectoral girdle of the latter group. Very important in the skull of the bony fishes is the gill-eover or opereulum, which when fully developed comprises the bones respectively known as the pre-, sub-, and interopercular, and the opercular proper. The gill-membrane aids the 
operculum in closing the gill-carity in the higher fishes, and in this may be developed the so-called branchiostegal rays. In the membrane joining the two branches of the lower jaw may be certain large jugular plates. The teeth of fishes need not engage our attention further than to notice that they may be developed not only in the jaws and. on the bones of the palate, but likewise also on the tongue and the pharyngeal kones of the throat. The soft internal parts must likewise be passed over almost without notice, although it may be mentioned that whereas the heart generally comprises only two chambers, in the lung-fishes it is furnished with three. The false gills, or remnants of a former gill situated in front of the permanent pair, and represented in the adult by a plexus of blond-vessels, are likewise too important not to be named. Then, again, there are the spiracles of the sharks, which are situated on the head, and are the openings of canals leading into the pharynx, and representing the first visceral clefts of the embryo. It is likewise important to notice that certain fishes, such as the bichir of the Nile and some of the lung-fishes, develop during the earlier stages of their existence pectinate external gills, and thus serve to connect the class with the larval forms of the Amphibia. As regards reproduction, it must suffice to say that whereas most fishes lay eggs-it may be of very small size, when they are collectively known as roe, or comparatively large-in certain kinds these are retained within the body of the parent till hatched. The interesting subject of distribution-both in depth and in horizontal extent-must be passed over without mention.

Excluding lampreys and lancelets, which are here assigned to distinct classes, very different views have been entertained even by modern systematists as to the proper classification of fishes. By Dr. Gïnther the following scheme for the existing forms was followed cren as late as 1880, ri: :-

\section{Sub-class I. PAL玉Ichthyes.}

Order i. ChONDROPTERYGiI.

Section 1. Plagiostomata._Sharks and Rays.

Order ii. Gavoidei.

2. Holocephala. -Chimæroids.

Section 1. Dipnoi.-Lung-fishes.

, 2. Chondrostei.-Sturgeons.

, 3. Polypteroidei.-Bichir.

", 4. Lepidnsteoidei._Bony Pike.

", 5. Amioidei-Bow-fin.

Sub-class II. Teleostei.-Bony Fishes.

Order i. ACANThopterygit.

"ii. Acanthopterygi Pharyggograthi.

", iii. Anacanthini.

", iv. Physostomi.

", v. LOPHOBRANCHII.

, vi. Plectognathi.

The defects in this classification, are the wide separation of the Ganoidei from the Teleostei, which, through the intervention of extinct forms, pass completely into one another, and the association of the Chimæroids with the Sharks and Rays to form a single subordinal group.

A far better scheme is the one just published by. Dr. Bashford Dean, which is is follows - 
Sub-class I. Eeasmobrancuit.-Sharks and Rays.

"II. Holocephal.-Chim:eroids.

, III. DipNoI-Lung-fishes.

" IV. Teleostomi.-Ganoids and Eony Fishes.

Order i. Crossopteriar.-Fringe-finned Group.

,, ii. Actinopteryair-Fin-fimned Group.

Section 1. Chondrostei.-Ganoids.

"2. Teleocephali.-Bony Fishes.

Even this system has, however, certain disadvantages, and the following arrangement appears preferable. This is as follows, viz. :-

Sub-class I. Dipxor.-Lung-fishes.

II. Holocephali. - Chimeroids.

,, III. T'eleostoni.-Bony Fishes and Ganoids.

Order i. Actinopteryair.-Fan-fimned Group.

:. ii. Crossopterygil.-Fringe-finned Group.

Sub-class IV. Elasmodranchil.-Sharks and Rays.

With these preliminary remarlis, we may procecd to a brief systematic review of the various gromps of the class. It must, however, be remembered that the number of existing fishes is so vast that it is quite impossible to notice even all the family types, while of the genera only a small percentage are selected for mention. It must also be born in mind that the true relationships of the sub-classes cannot be properly graspect unless the fussil forms are also studied.

\section{SUB-CLASS I.-DIPNOI.}

\section{IJUNG-Fishes.}

Like the next, the present group is now represented by a very suall number of species, and as it was abundant in earlier epochs, it is evidently one that is on the wane. Whereas in many respects the lung-fishes approximate to the amphibians, in others they show affinity to the earlier sharks; and it has been suggested that they ought to form a class intermediate between Amphibia and Pisces. Regarding them, however, morely as a subclass of the latter, they agree with the Chimæroids in the essential feature that there is no movable separate suspending arrangement for the lower jaw ; and from this peculiarity the name of Autostylica has been suggested for the two sub-classes in question. In the existing members of the group, which form the order Sirenoidei, the body is thick and spindle-shaped, its covering consisting of large overlapping horn-like scales, and the tail forming a diphycercal fin. In form, the head approximates to that of amphibians, as it does in its slimy integument. The paired fins are of the fringed type, their skeleton consisting typically of a jointed cartilaginous rod, fringed on both sides with divergent rays. In the skull the original cartilaginous cranium is roofed over with dermal membrane-bones, and the nostrils have posterior apertures opening into the back of the mouth to form true posterior nostrils, the latter 
feature distinguishing these fishes from all other members of the class. . The small and compressed gills open externally by a single aperture which is protected by an operculum, from beneath which may protrude stunted and rudimental external gills. The

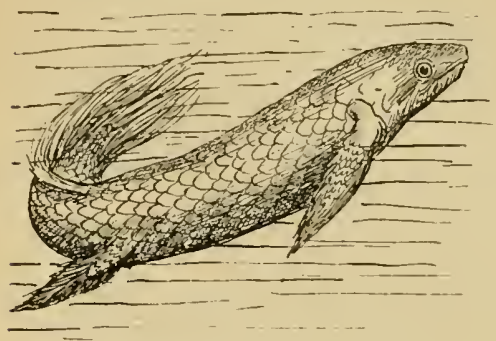

Fig. 1.-Australian Lung-Fish. nerves supplying the eyes, where they cross one another, have an interlacing of their tibres, and the sh rt digestive tract exhibits the sh trk-like feature of a spiral ralve in the membrane of the intestine. Not only is the elongated and, sacculated air-bladder provided with a duct, but it acts in all respects as a lung, with which indeed it is in every sense comparable. The backbone is mainly notochordal, true vertebræ being developed only in the cauclal region. The dentition is of a very peculiar type, and consists of a few very large and strongly-ridged plates, most of which are paired, and divided by a distinct median line.

Lung-fishes are now represented only by three species, belonging to as many distinct genera, but all included in the single family Lfpidosirenidce. Of these, the least specialised is the Australian lung-fish (Ceratodus), which in the form of its paired fins retains more of the primitive type than does either of the other two. The scales are very large, and the paired fins are broad and lobate, consisting of a central sealed portion bordered by a fringe. Marginai teeth are wanting in the jaws; but the palate contains a pair of large dental plates behind, and a couple of smaller chisel-like teeth in front, the lower jaw having a single pair of large plates. Long before it was known to science, the Australian lung-fish was familiar to the settlers on the banks of the two great rivers of Queensland, on account of the excellent quality of its salmon-coloured flesh; - whence the name of Burnett salmon commonly applied to it. The fish, which grows to a couple of yards in length, lives among mud and leaves, and rises at times to the surface to bresthe. Its food consists of both vergetable and animal substances; and the large eggs are deposited singly. In the two remaining forms-one of which (Lepidosiren) inhabits the rivers of Tropical South America, and the other (Protopterus) those of Africa-the body is more eellike, the limbs are reduced to whiplike filaments, and the anterior teeth are situated in the margins of the jaws. In many parts of the country the African lung-fish during the dry season envelops itself in a kind

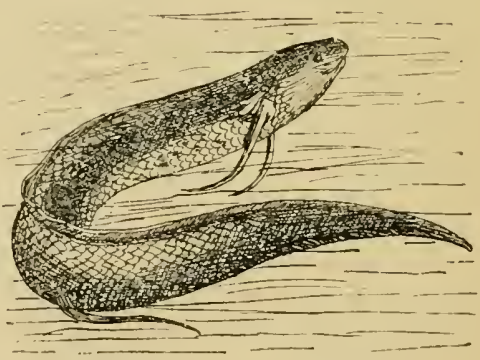

Fig.2-AFrican Lung-Fish. of shell or cocoon of mud, and in this state it can be dug up and exported, reviving when placed in warm water. Di. Dean observes that "lung-fishes 
have unquestionably many struetures which may have been derived from the more generalised eonditions of the sharks; and as a group they may not unreasonably be looked upon as deseended from the primitive elasmobranchian stem."

\section{SUB-CLASS II.-HOLOCEPHALI.}

\section{Chinlekolus.}

THE group typically represented by the spook-fish or ehimera is, as already mentioned, now a small and waning one, which agrees with the last in the structure of the skull. In spite of their many marked resemblances to the sharks, the writer last quoted is of opinion that they cannot be elosely associated with that group. This external resemblanee to the Elasmobranchii, coupled with the total absence of membrane-bones from the cartilaginous skull, at once serves to differentiate the chimaras from the lung-fishes ; from which they also differ by the absence of true posterior nostrils, although there are nasal passages. Further differences are to be found in the form and strueture of the paired fins, and the absence of an air-bladder. The optie nerves and intestine are similar to those of the lung-tishes and sharks; and the accessory reproductive organs of the males, known as claspers, are found elsewhere only in the latter group. Unlike the lung-fishes, the skin is generally naked, and when (as in the young) hard structures are developed therein, these agree with teeth, whereas such plates as are found in the lung-fishes are bony. Although the paired fins are not very unlike those of modern sharks, consisting of an abbreviated base and numerous rays arranged in a fan-like manner, their clermal margins are very large, and terminate in a sharp point. A large spine protects the front of the first dorsal fin, which is capable of being folded so as to lie in a groove in the back. The gill-arches are closely packed, and open by one aperture on each side, which is slit-like, and protected with a dermal fold containing an operculum of cartilage. The teeth are in the form of large plates closely aftixed to the jaws, and are

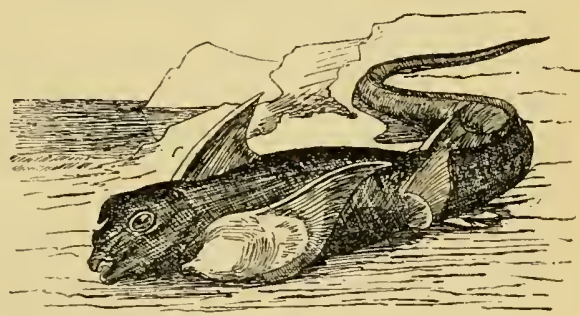

Fig. 3. - Common Chimdra. thickly studded with roughened grinding facets termed tritors. In the cartilaginous skeleton the axis of the back-bone remains notochordal, its sheath lacking distinct vertebre, but being strengthened in the fore-part of the column by rings of cartilage. A lateral line is present on the sides of the body, and the tail gradually tapers away, to terminate in a diphycercal fin. Like sharks, chimeroids deposit large eggs, which are completely separate from one another.

Existing chimæroids are classed under three genera, all included in the family Chinceride. The first of these is Harriotta, which comprises two deep 
sea forins, one from the Atlantic and the other from Japanese waters. It appears to be the most shark-like type, and is characterised by the long slender beak, and the abserice of an appendage on the forehead of the males. From the small size of the claspers in the same sex, it has been inferred that the eggs are fertilised after extrusion. The second genus, Callorhynchus, is represented by the bottle-nosed chimera of the Southern Seas, and, together with the next, has an erectile spine on the forehead of the males. In form it is very shark-like, with the tail inclined upwards and without a fin on its upper surface ; the muzzle being of moderate length, with a cartilaginous proninence terminating in a flap of skin. Chimcerc, of which there are three species, is less shark-like than the other two, with the extremely abbreviate muzzle devoid of any appendage, and the whip-like tail forming a continua-1 tion of the longitudinal axis of the body, and finned for some distance both above and below. These fishes appear to be rare and local, and are generally taken in fairly deep water. Little is known of their life-history, but inmature examples have been captured at great depths. Although some writers have considered the chimeroids as degenerate types allied to the Dipnoi, Dr. Bashford Dean is of opinion that they are more nearly related to the primitive sharks. If this should prore to be well founded, the antostylic type of skull must have been independently acquired in the Dipnoi and Holocephali, and camnot, consequently, be of much classificatory value.

\section{SUB-CLASS III.-TELEOSTOMI.}

\section{Bony Fishes and Gayoids.}

THE passage between the modern bony fishes and the ancient ganoids having been discovered to be complete, there is no possibility of assigning these two nominal groups to distinct sub-classes, or even orders, and. accordingly, all the fishes which come under the designation either of Dipnoi, Holocephali, or Elasmobranchii, are now classed as Teleostomi. Indeed, the terms bony fishes and ganoids, as Dr. Bashford Dean well remarks, can only be used in a popular and convenient sense-the latter to denote the oldfashioned type, with its rectangular ganoid scales and cartilaginous internal skeleton, and the former to designate the modem type, with its rounded horny scales and fully calcified skeleton. The group is a very vast one, including by far the great majority of existing forms, and a host of extinct ones; and the range of variation is so great that a concise definition is by no means easy. All the members of the sub-class are, however, broadly distinguished both from Dipnoi and Holocephali by the existence in the skull of a movable apparatus for the suspension of the lower jaw, this type of skull structure being known as the hyostylic. In the internal skeleton, calcification exists to a greater or lesser degree, and membrane-bones are al ways present on the jaws. Moreover, the membrane-bones of the pectoral girdle, like the scapula and the various clavicular bones, form a chain connected with the posterior region of the skull. Very important is the close crowding of the gill-arches, and their complete protection by a fully-developed operculum. The external skeleton, when present, consists either of rounded horn-like scales, or of quadrangular bony plates. All the living forms deposit a vast 
number of minute eggs, crowded together into a mass. Whereas in the higher types the optic nerves simply. cross one another, and there is no spiral valve to the intestine, in the ganoids the latter is present, and the fibres of the optic nerves interlace where they meet, to form what is known as a chiasma by the complete fusion of the two nerves. Very generally an airbladder is present, and the less specialised bony fishes and all the ganoids are provided with a duct to the gullet. In the higher types the rays of the fins are entirely of dermal origin, their cartilaginous supports being abbreviated and enclosed within the body. In addition to the features already noticed, the ganoids have a larger number of gill-arches, a spiracle, an arterial cone furmished with many valves to the heart, a cellular air-bladder, and several shark-like features in other organs.

\section{ORDER I.-ACTINOPTEIYGII.}

\section{SUB-ORDER I.-ACANTHOPTERYGI.}

The first great orler of the sub-class includes what may be termed the Fan-finned Teleostomes, in which the fins are entirely supported by dermal rays, the primitive cartilaginous supports being greatly reduced and enclosed in the body-wall. A single paired series of transversely elongated rays-to which an unpaired anterior element may be added-are developed in the branchiostegal membrane between the two branches of the lower jaw. The caudal fin is variable. The spiny-finned fishes, forming the sub-order Acanthopterygii, together with the six following sub-orders, 1 are collectively distinguished by the supporting bony elements of the dorsal and anal fins being equal in number to the dermal rays, and by the tail being generally of the homocercal or abbreviate-heterocercal type, although occasionally diplycercal. In the Acanthopterygii and four following sub-orders the skeleton is fully ossified, the optic nerves simply cross, and there is no spiral valve to the intestine. In common with the three following sub-orders, they have generally no duct to the air-bladder, the two parietal bones of the skull separated by the supra-occipital, and the pelvic fins usually jugular or thoracic. The chief distinction of the Actinopterygii themselves is that usually some of the rays of the dorsal and anal fins are not articulated, and form spines.

In this section the lower pharyngeal bonez are generally distinet, and the scales ctenoid; while the preopercular bone is not connected by a bony stay with the orbit, the spinous dorsal is large, and the pelvic fins are thoracic, and usually furnished with five branched rays, Section 1. Percialthough sometimes with only four. Certain other features formes. - Family connected with the skeleton are too complex to be noticed here. The Centrarchidce form a comparatively small family, containing ten gener:i, and typified by the single species of Centrarchus, from the fresh waters of the United States; one of their distinctive characters being the presence of three or more spines in the anal fin. In habits these fishes are carnivorous; and many of them resemble the stickle-backs in building nests.

1 The following are the sub-orders of the Actinopterygii-viz, (1) Acanthopterygii, (2) Lopho. branchii, (3) Plectognathi, (4) Anacanthini, (5) Physostomi, (6) Etheospoudyli, (7) Protospondyli, (8) Chondrostei, 
Of far more general interest are the twelve genera constituting the family Percide, in all of which there are never more than two spines in the anal fin, while there are two pairs of external nostrils. Like their

Family nearest allies, the perches generally have a complete lateral Percide. $\quad l i n e$, no scales on the median fins or karbels to the mouth, and the teeth conical. Six to eight pairs of branchiostegal rays are present, as well as four pairs of gills, the last of which is followed by a shit ; and the rilyed portion of the dorsal fin does not much exceed the anal

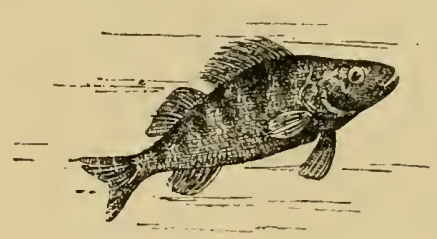

Fig. 4.-Comsos PERch. in length. Although Lucioperca (Stizostedion) and Percurinu enter salt water, the fanily is essentially a fresh-water type, its members being spread over North America, Western Asia, and Europe. Among the generic types of the family are the true perches (Percrt), with a distribution equivalent to that of the family; the aforesaid Lucioperca, or pike-perches, with a similar range; the three small species of the Danulian genus Aspro; Percorina, with two species from the neighbourhood of the Sea of Azov and the Black Sea ; and the ruffes (Aceinut), of which the three representatives are restricted to Europe and Asia.

Nearly allied to the last is the family of Serrunidce, or sea-perches, distinguished by the development of an internal lamina from the second suborbital bone supporting the globe of the eye, the number of

\section{Family}

Serranidue. spines in the anal fin being variable. In this extensive family the genus Centrogenys is noteworthy, on account of the union of the lower pharyngeal bones. It would be tedious to mention the distinctive characters of even the commoner and best known genera, and only a few will be referred to at all. As an example of the group of the sub-family Serranince, with two dorsal fins, we may take the Suuth American Percichthys, which is one of the few fresh-water types. In this and four other allied genera the tongue is smooth, but in the bass, Morone, which have likewise two dorsals, that organ is covered with patches of teeth. Whereas some bass are marine, others are fresh-water in habitat. They all have nine dorsal and (like the other members of the sub-fanily) three anal spines. Among the group with a single dorsal fin, especial interest attaches to the widely-spread sea-perches of the gemus Serrcmes, on account of the vast number of species and the large bodily size to which some of them attain. Although the tongue is edentulous, teeth are developed on the palate, and large tusks occur at intervals among the small teeth in the margins of the jaws. Centropristes is an allied genus. In another group of the same sub-family Mr. Boulenger includes the genera Plesiops and Trachinops, which were formerly referred to the Nandidar. In these the lateral line is double, consisting of an upper portion, which disappears posteriorly, and a lower running along the middle of the side of the tail. Whereas the first genus is from the coral-reefs of the Indo-Pacific, the second is Australian, buth being marine. To another sub-family-Centropomincedistinguished by the extension of the lateral line on to the caudal fin, belong the two species of Lrites, one of which is Nilatic, while the other is Oriental and Australian. The Oriental species grows to a length of 


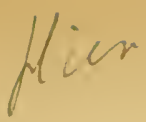

three to as many as tifteen. All ate comparatively small tishes, and whereas the majority are inhabitants of fresh waters, a few are marine. What they lack in size, they make 11 for in tierceness, stickle-backs being perfect demons for fighting among themselves, while they are terribly destructive to the spawn and fry of larger and better tishes. They have, however, the redecming yuality of taking most excellent care of their own eggs and young, for the reception of which the male builds a nest, which he guarts with vigilance, mul, if necessary, with his life. Not only is this nest-building habit found in the fresh-water speeies, but it is likewise common to the sea stickle-back of the British cousts, which selects for its site of operations shallow brackish water, where sea-weeds are abundant. Alnong many anecdotes relating to the voracity and pugnacity of stickle-backs, we select one from the pen of Mr. J. Stark. On one occasion this gentleman placed in the water inhabited by a stickle-back a number of leeches. Thereupou the fish "darted round the tumbler with lively motions till it found a leech detached and in a proper. situation for being seized. When the leech was very small, say about lialf an inch in length, it was often swallowed at unce, before it reached the bottom of the vessel; but when a larger one, about, an inch or an inch and a half in length in its expanded state, was put in, and had fastened itself by its mouth to the glass, the efforts of the stickle-back to seize aud tear it from its lold were incessant, and never failed to succeed. It darted at the loose extremity, or, when both ends were fastened, at the curve in its middle, seized it in its month, rose to near the surface, and after i hearty shake (such as a dug would give a rat), let it drop). The leeel, which evidently wished to avoid its enemy upon its release, again fastened itself by its mouth to the glass; lut again and again the attack was repeated, till the poor leech became exliausted, and ceased to attempt to hold itself by its clise. The stickle-back then seized it by the hend in a proper position for swallowing, and after a few gulps the leech disappeared. 'The flattened leech being of an oval form, and having a hard skin, was not attacked, unless when very young and small; and leeches of the other species, when pretty well grown, or larger tham himself when expanded, were killed in the mamner above mentioned, but not swallowed. In come of his attempts to seize a leech, the stickle-back having got it by the tail, the amimal eurled back, and tixed his dise upon his snout. The efforts of the stickle-back to rid himself of this encumbrance were amusing. He let go his hold of the leech, which then hung over his mouth, and darting at the sides and bottom of the glass with all his strength, endeavoured to rub off this tantalising morsel. This lasted for nearly a minute, when at last he got rid of the leech by rubbing his back upon the bottom of the vessel. 'The leech, perfectly aware of the company he was in, no sooner loosed his hold than he attempted to wriggle away from his deyourer; but before he had reached mid-way up the tumbler, the stickle-back had turned, and finished the contest by swallowing him up."

The second family of the section, which comprises the flute-mouths (Aulostomu, Auliscops, and Fistulariu), is readily characterised by the pro. duction of the muzzle into a long Hute-like tube, at the extremity of which is situated the small mouth; and, likewise, by the pelvic fins, which may be either thoracic or Aulostomatidu. abdominal, comprising six (rarely five) soft rays and no spine.

When they are abdominal they have no commection with the polvis, which is always attached to the peetoral girdle. Whereas in some forms the bodywhich is always much clongated - is completely naked, in others minute scales 
are developed. The first donsal-fin may either be wanting or compused of a few feeble isolated spines. The backbone contains a rery large number of joints, and presents the peculiarity that many of those at the front end are united together to form a solid tube. The flute-mouths are confined to the warmer temperate and tropical seas. In spite of their large dinnensions - their length being frequently as much as from four to six feet-they can only be regarded as highly developed stickle-backs.

We now come to the first of three sectional groups, each of which is represented only by one family. The first section is characteriserl by the presence of two dorsal fins, of which the spinous is very short, whereas

Section Centris- the soft one-like the anal--is of moderate length. Of more ciformes. - importance is the fact that the pelvic fins are truly abFamily dominal, and have no sort of connection with the pectoral Centriscidee. girile. These fish constitute the two genera ('utriscus and Amplisile; one species of the former being popularly known as the bellows-fish or trumpeter-fish. They are small, short-bodied fishes, with a tubular mouth similar to that of the Aulustomatide; and as their powers of swimming are of the very feeblest, they are often carried by currents far out to sea, although their proper haunts are the shallows.

Although the members of this section and family are likewise of small size, they differ from the last in the more normal conformation of their mouths and bodies. Having no spiny dorsal-fin, these fishes are Section Gobioe- easily recognised by the possession of a sucker on the lower sociformes. - surface of the body, placed between the pelvic fius, which

Family are nearly jugular in position. Both the soft dorsal and

Crobioesocidre. anal fins are situated on the caudal region of the borly, and are of small or medium extent. There are numerous genera of sucker-fishes, such as the West Indian and South American frobioesox, the European Lepulogaster, and the New /sealand Diplocrepis; the latter being distinguished by the presence of incisor-like teeth in the front of the jaws. The group attains its maximum development in the temperate seas; all its representatives being marine and littoral.

The so-called serpent-heads (Chomuce and $\theta_{p}$ hivcephulus) are inhabitants of the fresh waters of Africa and the Oriental countries, although more abundant in the latter than in the former area. They are lougSection Channi- bodied, flat-headed fishes, fond of grovelling in the mud, formes.-Family and often leaving their native element to travel some distance Ophiocephalidie. on land, where they progress by the aid of their pectoral fins.

In these fish the head and body are corered with scales of

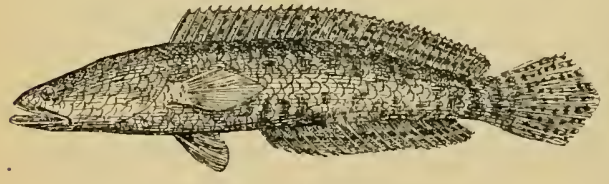

Fig. 15. - SERPENT.HEAD. moderate size, and the fins are without spines, the single dorsal, which is similar to the anal, being low and elongated, and the pelvic pair, if present, thoracic in position, and comprising six soft rays. The most characteristic feature in the structure of the serpent-heads is,

- however, the presence of a supplemental cavity on each side of the head above the gill-chamber; and it is probable that this aids in keeping the gills moist while the fish are on land. One yard is no uncommon length 
for tishos of this group. Daring seasons of drought the serpent-heads bury thenselves in mud; and when living in muddy waters they are in the habit of coming from time to time to the surface to gulp down a mouthful of air.

The fimous elimbingr-perch (Auclus scumdens) of the Oriental region, which has given rise to somany stories, true and false, is the type of a small soction chanacterised by the possession of an aceessory breathing-organ situated in a cavity on each side of the Seation Labyrin. heal above the gill-elimmber. In both families of the thici.--Family

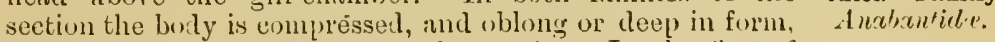
with the investing scales of moderate size. In the first of the two fimilies spines ale present in the dorsal and ant fins, although their number is variable; while the lateral line is either interrupted or altog sther absent, and the aperture of the gills is small. Like those of the next family, these fishes are inhabitants of fresh $" \mathrm{l}^{\circ}$ brackish waters, and are able to exist for a consiclerable time out of water, where they brethe by means of the special organ. There are several genera, such as Awh's (climbing-perch), Polyucanthus, Ospluromenus (grumini), and Bettu, all of which are contined to the Oriental region and Tropicul and South Africa. The Malayan gurami is a deep-bodied tish marked with vertical stripes, and with one of the rays of the pelvie tins greatly elongated. On account of the excellent quality of its Hesh, it has been introduced into several districts in India, where it thrives well. The climbing-pereh is a less deep and more uniformly eoloured fish, with no elongation of the pelvie rays, and a taller dorsal fin. During dry seasons it will bury itself in the mud, but more frefuently appears to migrate to pourls which are eapable of withstanding the diought. On lind it travels by using its pectoral tins as legs, fixing these on the further sicle of such objects as are capable of afforching a sufticient fulcrum. One instance at least is on record of these fishes having been taken high up on a pilm trec. The reader may well wonder as to the object of such an ascent, but it appears the fish make for the moisture often to be foumd in the hollows of such trees. The Oriental genus Polyaconthus is best known by the domesticated and beautifully coloured Chinese paradise-fish, which, from long eultivation has altered considerably from the original parent form. Another nember of the family which has long been domesticated is the Siamese fighting-fish (Bette preguex). In common with the Malays, the Siamese are inveterate gamblers, and in this instance they stake their money on the fighting endurance of their favourite fish. The fish themselves are by no means loth to afford their misters as much sport as possible, and whereas when alone their colours are dull, directly an opponent is seen, the whole body assumes a brilliant metillic lustre. Even a mirror is stated to be sufticient to arouse the pugnacious propensities of these fish, which will then clart forwards agrainst their own image.

The second family of the section is represented by the small frosh-water Malayan fish known as the pike-head (Luciocephelus pulcher), and sufficiently distinguished from the preeeding family by the presence of a complete lateral line, the protruded jaws, and the general pike-like form of the head and body. The tail is rounded, the dorsal fin is single, and, like the anal, devoirl of

Family rencio. cephrelicle. spines; the pelvic fins comprise one spine and five lays, and the eyes are large.

The fishes of this and the next section arc amply eharacterised by their 
elougated and ribant-like bolily form. This conformation gives them much the alpearance of sea-suakes; and although they are ordinSection Lophoti- arily inhabitants of deep water, they are sometimes driven fcrmes.-Family to the surfice. On such occasions it is highly probalole that Lophoticle. they axe responsible for some of the alleged appearances of the "sea-serpent." Moreover, when cast on shore, they are extremely likely to be mistakem, by persons macquainted with zoology, for that mysterions monster; and not many years ago a telegram in the papers announced the discovery in Australia of a dead sea-serpent, which subsequently turned out to be a gigantic stranded rilond tish. Here it may be well to remark that the writer by no means defuses to believe in the possibility of the existence of "sea-serpents," but at present contents himself with considering that the evidence is not yet suffieiently convineing. To return to the Lophotiformes, this section, in addition to the riband-like body, is characterised by the vent being situated near the hinder extremity of the latter, and closely followed by the anal fin ; the dorsal fin ruming along almost the entire length of the body, and eommencing in an enomnous backwardly-curved spine, which arises frem an elevated crest on the summit of

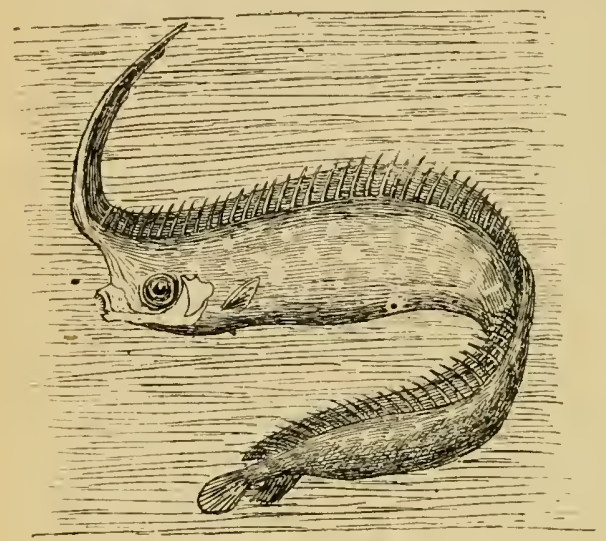

Fig. 16.-UNICORN FJAH. the short head. To the presence of this spine, or lom, the one representative of the settion and family ( $L o-$ photes cepelicums) owes its jupular name of unieorntish. Rhinoceros-fish would, lowwerer, be a better title. The miemm-fish grows to a lengtl of between five and six feet, and has been taken at comsirlerable depths in widely distant parts of the ocean. That it is indeed at fitirly deep-seat monster is apparent from its large eyes ; but this feature indicates that it is not an inhabitant of the deepest abysses, where ordinary visual or' gans would be of mo use. Ithough we can never hope to acquire such knowledge, it would be matter of extreme interest to discover the use of the enormous horn of this strange fish.

The riband-fishes differ from the Loghotiele: by two eliarneters eonnected with the fins. In the first place, the anal is alosent; and in the second, the caudal fin is either rudimental, or is so placed as not to form Section Tænil- a direct continuation of the longitulinal axis of the body, formes.-Family being then directed upwards in a fan-like mamner. Very Trachypteride. generally, however, this caudal appendage is lost in full. grown specimens. Young riband-tishes are so totally unlike their parents that no one would dream they belonged to the same group. Dr. Giintler observes that such young fish, of from two to four inclies in lengtl, "are not rarely met with near the smface. They possess the most 
extraordinary development of tin-rays observed in the whole class of fishes, some of them being several times longer than the body, and provided with lappet-like dilatations. There is no doulst that tishes with such delicate appendages are bred and live in depths where the water is absolutely quiet, as a sojou'n in the disturbed water of the surface would deprive them at once of organs which must be of some ntility for their own preservation." Ribandfishes are classed under three genera, respectively known by the names of Reyulecrs, Sty?ophomes, and Truchypterus. Of these, the first includes the largest known species; Banks' ribund-tish (R. bunksi), which is occasionally cist on the shores of England, where it is known-most inappropriately-as the "king of the herrings," exceeding a score of feet in length. In place of the horn of the unicorn-fish, this ribind-fish has a crest of eurving spines on the crown of the head, which recalls the feathery crest of a cockatuo. In this genus the pelvic tins, which are placed almost immediately behind the extremely short pectoral pair, are recluced to long tapering tilaments, without rays; the caudal fin being rudimental or absent. On the other hand, in the rare Stylophories, the pelvic fins are totally absent, and the caudal forms. a very long appendage like a whip-lash. In the tylical T'reh!pterus, however, the pelvic pair of fins still retain their r:ays. The best known member of this genus is the morthern one commonly known as the deal-fish, which is not unfrequently cast ashore after gales on the mainland and islands of the north of Brituin.

An aberrmt group of the sub-order is formed by the long-borlied deep-sea fishes, commonly known as thorn-backs, all of which may be included in the single grenns Notacanthus. In these fishes the dorsal fin has no soft portion, and is composed of a great number of low tooth-like spines, separated firm one another by comparatively long intervals, and extending over nearly the whole length of the back, the long anal being of somewhat similar structure. The muzzle is produced some distance in advance

Sestion Notacanthiformes. Family Note conthicler. of the suout. The pector'al and pelvic fins are widely separated from one annther, so that the latter are truly abdominal in position; lut in spite of this the caudal region extends a long distance behind the polvics, the tail terminating in a sharp point, without a distinct tin.

The menibers of the last sectional group of the great sub-order Acanthopterygii are distinguished from nearly all the forms hitherto mentioned by the coalescence in the median line of the lower jharyngeal bones. On this aceourit the group has been regarded as of subordinal ralue, although it seems preferable that it should rank only as a section. That it is a specialised group is indicated, not only by the union of the pharyngeals, but also by the loss of the air-bladder. The group includes four fimilies, of which the first is represented by the coral-tishes, forming the genera Luscyllus, Heliristes, Pomacentrus, etc. Most of these are inhabitants of the tropical seas, where, as their name implies, they frequent coral reefs. In form and coloriation, as well as in habits, they are very similar to the Chutodontidue (p. 4ti5), many of them liaving alternate dark and light bands on the body. The absence of scales on the fins in the present, family serves, however, to distinguish them at a glance from the nembers of the other group. In these fishes the body is deep and compressed; the scales are of the ctenoid or eomb-like type; the lateral line is either interrupted, or stops short of the candal fin ; and false gills are developed in the head. The number of species 
is very large. In habits these fish are carnivorous, some of them being provided with powerful incisor teetl, for the purpose of feeding on eoral.

More familiar than the last is the extensive and inportant family of the wrasses, or thick-lipped fishes, in which the scales lave smouth margins (cycloid), and the pouting lips are often greatly thickened. Family Lalwide. As in the preceding family, the clorsal fin is single, with the spiny portion at least as well developed as the rayed, which is similar to the anal ; and the pelvie pair are thoracic in position, and comprise five rays and a single spine. Whereas in some of the wrasses the body

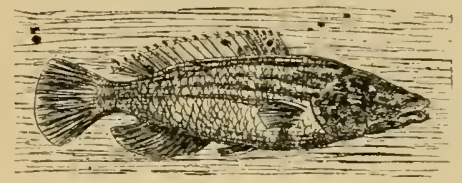

Fig. 17.-STRIPED WRAsse. is deep, in others it is of a more elongated shape. Wrasses are coast fishes, mostly of carnivorous habits, which attain their maximum development in the tropical and temperate seas. Although their palates are unarmed, their jaws are provided with a number of powerful teeth adnirably suited for erushing the shell-fish on which these fishes ehiefly subsist. Sea-anemones or corals afford, however, a preferable diet to some of the species, while a few are strict regetarians. Wrasses are divided into a number of genera, which may be arranged in larger groups in correspondence with the conformation of the front teeth. In the typieal Lulurux, of which the headquarters is the Mediterranean, the jaw-teeth are conical and arminged in a single series. The two British forms are the ballan ( $L$. muculutus) and the striped wrasse ( $L$. mixtus), of which the latter exhibits great sexual differences in colnration. The gold simny represents in Britain a genus (C'reuilalmus.) differing from the true wrasses in having the elge of the preopereular bone serrated at all ages, instead of only in the young.

Passing by many other types, brief reference must be made to the parrotwrasses (Scrums), deriving their name from the confluence of the anterior teeth to form a cutting beak. One species is common in the

Family Mediterranean, where it was well known to the ancients. Diatrematide. The viviparous wrasses (Ditremu and Heterocurpus) are noteworthy on account of their peculiar reproduetion, and are accordingly referred to as a family by themselves. These fishes, which do not ittain to a large size, are very characteristic of the temperate portions of the North Pacific, where the majority of the species are contined to the American sicle, althongh a few oceur on the Asiatic.

The last group of the Acanthopterygii is the somewhat important fimily of the chromids, which have a very remarkable geographical distribution. From the other members of the group with the lower Family pharyngal bones united, they are distinguished by being Chromididce. exclusively fresh-water in their habitat. Although none if the genera inhabiting the Eastern Hemisphere are common to the Western, these fish inhabit the river's of 'Tropieal Africa, Madagasear, Syria, Palestine, and Tropieal America, while a single genus is found in India. From the other members of the present group, the chromids may be distinguished by the absence of false gills. In appearance they are not very unlike wrasses, having a single clorsal fin, of which the anterior portion is spiny, the seales generally ctenoid, and the lateral line more or less markedly interrupted. In regard to diet, they display considerable variation, some 
forms being entirely carnivorous, whereas others are as distinetly vegetablo feeders. Most are relatively small fishes, although the balti of the Nile, whieh belongs to Chromis, grows to twenty inehes. Of the genera, Etroplus is Indian, Chromis and Hemichromis are African and Syrian, and Peretroplus Malagisy.

\section{SUB-ORDER II. - LOPHOBRANCHII.}

This and the following sub-order include a small number of peculiar fishes which may probably be regarded as highly specialised offshoots from the primitive stock of the Acanthopterygii, neither of them having a duct to the air-bladder. The Lophobranchii take their name from the form of the gills, which consist of smatl rounded tufts arising from the gill-arches; the gillapertures being small, and the operculum or gill-cover eomprising only a single platc-like bone. All these tishes have the body enelosed in a many. jointed shield of bone, and the mouth is produced into a toothless tube. Another peculiarity is to be found in the exceedingly feeble development of the museles.

The first family of the sub-order is formed solely by the nembers of the genus silenostomu, which are few in number and small in size, and inhabit the Indian Ocean. These fishes have the fins well dereloped, $n$ soft rays to the first dorsal, wide gill-apertures, and the muzzle greatly elongated. The body is much conpressed and the tail very short; the soft dorsal and anal fins

\section{Family Soleno-} stomatide. arising opposite one another from elevations of the hincler part of the body, while the pelvic pair, which are seven-rayed, are sitnated below the first dorsal, and in the female are united to the chest by their outer edges to form at receptacle for the eggs. None of these fishes have an air-bladder.

The seeond family of the group is represented by the pipe-fishes (Syngnathus, Siphonostomu, ete.), and the still more bizarre sea-horses (Hippocempus and Phyllopter?/x), the latter clitfering from the former in having the tail prehensile, and employing it as an anchor. These fishes are distinguished from the first family by the aperture of the gill-chamber being reduced to a very minute opening

\section{Family Syngnathidce.} at the hinder upper angle of the operculum, and by the loss of the first dorsal and pelvie fins. In certain eases some of the other fins are likewise aborted. The pipe-fishes have the body exceedingly elongated, whereas in the sea-horses it is shorter and deeper, while spiny leaf-like proeesses arise from the ridges on the head and back. Many of these fish have special structural modifications for the purpose of protecting the eggs, as is also the case with some of the Solenostonatide. Thus, the females of Solenostoma are provided on the lower surface of the body with a roomy pouch, formed by the adherenee of the pelvic fins to the skin of the abdomen. The immer walls of this pouch are fumished with long filaments, which aicl in keeping the egg in position; and it is probable that after the fry are hatched they are retained for some time by attachment to the walls of the chamber. In the

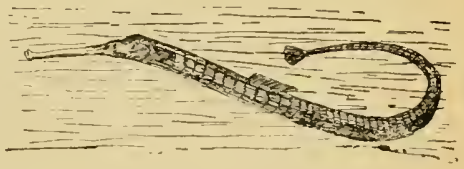

Fig. 18.-PIPE-FisH. typieal pipe-fishes (Symmathus) the care of the family falls to the share of the miles, which are provided with a long pouch on the under surfatce of the tail, 
furmed by a fold of skin arising on oach sicle, and the two meeting in the middle line. The mamner in which the eggs are conveyed into this jouch appear's to be unknown, but when once there they are completely enclosed by the junction of the edges of the two folds of skin, and thus remain till they are hatched into minute eel-like pipe-fish, which soon make their way into the water by bursting open the folds of the pouch. In the sea-horses the development is earried one stage further, the nursing-ponch being closed a'ong the middle line, so as to communicate with the exterior only by means of a small aperture at the anterior end, through which the eggs are hy some means or other introduced, and by which in clue course the young make their escape. Certain pipe-fishes (Doryichthys) differ from the ordinary forms in that the males have the pouch placed beneath the abdomen instead of under' the tail; and it is remarkable that in some allied genera (Nerophis) the eggs are simply attached to the lower surface of the abdomen of the male without the development of any pouch.

Both the Solenostomatide and Syngnathide are feelle swimmers; they generally frequent coasts well protected by sea-weed, to which the speeies jovided with prehensile tails attach themselves by means of that useful appendage. In swimming, they generally maintain themselves in a more or lass nearly vertical position. Writing of the sea-horse, Dr. Bashford Dean says that, "in spite of its many structural oddities, its genetic kinship with t'ie stickle-backs camnot be doubted. Yet to have attained its jresent form, its evolution must have carried it along a widely divergent path. It may, in the first place, have fused the lines of its metameral scales, dividing oft the surface of its elongate body in sharp-edged rectangles, whose corners have become produced into spines. At this state of evolution its appearance might well be represented by that of the kindred pipe-fish. To secure more perfect anchorage in its algous feeding-ground, its body-terminal must now have discarded its fin-membranes and become prehensile, probably the most remarkable adaptation in the entire class of fishes, sinco it causes metameral organs to change the plane in which they function from a horizontal to it rertical one."

STB-ORDER III. PLECTOGNATHI.

The spine-clad globe-fishes, of which dried specimens are so frequently exhibited in old curiosity shops, may be taken as a familiar example of this small sub-order, which, like the last, includes highly modified and specialised forms. All these fislies have a narrow mouth, and some of the bones of the upper jaw fuscd together, while in some of them the jaws are produced into a beak-like form. They have but few segments in the back-bone, and whereas the bones of the head are fully hardened, those of the rest of the skeleton are comparatively soft. In form, the gills are pectinate; the gillapertures being very small, and placed in adrance of the pectoral pair of fins. If the pelvic fins persist they are reduced to mere spines; the spinous dorsal, too, is more or less rudimental, although the soft dorsal is generally well developed and situated far back, immediately over the anal. Very rarious is the covering of the body, the skin in some forms being naked, while in others it is dotted orer with long spines; in others the whole head and body is invested in a complete cuirass of true bone, while in others there are roughened scales. All, however, agree in the absence of a duct to the air-bladder. 
The first family of the Pleetogathi is represented by the file-fishes (Bulistes, etc.) and the strange coffer-fishes (Ostracium). In these fishes there are a few separate teeth in the jaws, and traees of the spinous dorsil and pelvic fins usuilly persist. In form, the body may be either compressed or angulated, and the muzzle is rather elongated; the skin being either spiny or rough, or replaced by a bony armour. Their chief habitat is the tropieal oceans, although some range into cooler'seas. The Oriental genus Trincauthus belongs to a sub-family characterised by the presenee of roughened seale-like plates on the skin, and the retention of from four to six spines in the first dorsal fin. On the other hand, Bulistes is included in a sub-family in which there are never more than three spines

Family Balistide. in the fin last mentioned; while the pelvie fins are absent, or indicated only by a swelling on the lower surface of the body ; the compressed body being clothed with seale-like plates eapable of being moved, or with a roughened skin. There are several genera in this group, and the flesh of certain kinds is poisonous. Bulistes itself, which is furnished with powerful eutting teeth in the front of the jaws, browses upon living coral, or eats through the shells of molluses in order to get at the animal within. The angulated bony carnpace-composed of hexagonal plates joined together like mosaie-sutticiently distinguishes the coffer-fishes (Ustracium), which constitute a sub-fanily by themselves.

The seeond family inclucles the globe-fishes and their near allies the sunfishes, in both of which the bones of the jaws are welch together so as to form a eutting parrot-like beak of great power. The teeth are modified into large dental plates tightly adherent to the juws, and consisting structurally of a number of very thin parallel lamine, arranged like the leaves in a book. These

Family

Dioulontirle. tishes are mostly inhabitants of the hotter seas, although a few have taken to a fresh-water existence. The one Oriental species of Trionlon alone represents the first sub-family, and has the skin of the lower surface dilated into a large, intlatible sae; the dental plate of the upper-jaw being divided in the middle,

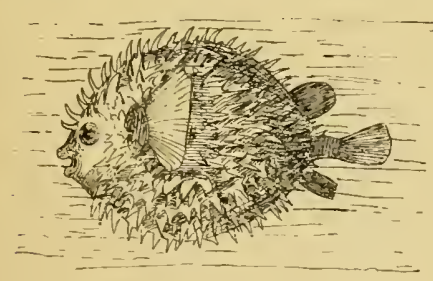

Fig. 20.-GILUBE-FISH. while that of the lower is single. Spiny bony plates, which do not overlap, clothe the body, and the tail-fin is forked. The globe-fishes (I)iodon, Tetrodon, ete.) form the seeond subfamily, and have the more or less shortened and rounded body covered with spines, while there is a distinct tail and eaudal fin, and the distensible throat ean be inflated with air. The clifferent generi are ehiefly distinguished from one another by the conformation of the dental plates, and the size and distribution of the spines. D1. Giunther writes, that " these fishes have the power of inflating their body by filling their distensible resophagus with air, and thus assume a more or less globular form. The skin is then streteled to its utmost extent, and the spines protrude and form in more or less formidalle defensive armour, is in in 
hedgehog ; thereforc they are frequently called sea-hedgehogs. However, it is probable that the spines

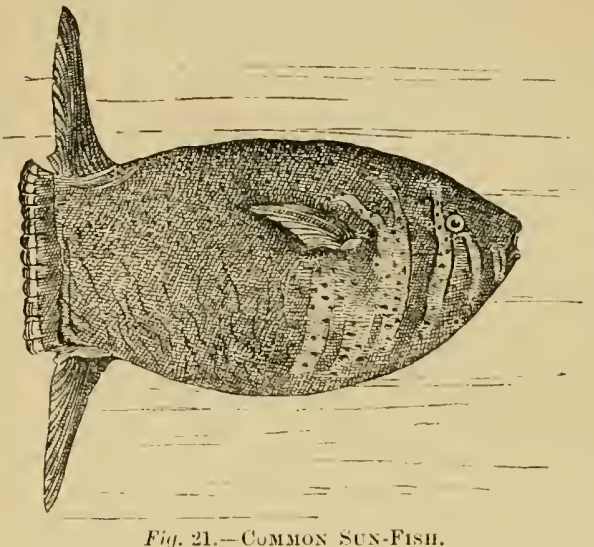
are a protection not only when the fish is on the surface and able to take in air, but also when it is under water." The third sub-family of the Diodontida. includes wnly the two species of suntish, Oithagoriscus, specimens of which at times grow to as much as seven foet in lengtl. Having the body excessively compressed and deep, with in very tall dorsal and anal fin placed one above the other at the hinder end, the sunfishes are especially characterised by the short, deep, and trumcated tail, of which the fin is confluent above witl the base of the dorsil, and

below with that of the anal. There is no dilatable sac beneath the skin, which may be either rough or smoothly tesselated; and externally the pelvic tins and internally the air-bladider are absent. Sun-fish are pelagic forms, generally swimming in a vertical position near the surface of the water. Both kinds seem to feed chiefly on shell-fish.

\section{SUB-ORDER IV. - ANACANTHINI.}

The members of this comparatively small, althongl highly important sub-order are distinguished from the Acanthopterygii by the pelvic and median fins being, as a general rule, devoid of spines and composed of soft jointed rays. When present at all, the pelvic fins are invariahly either throacic or jugular in position ; and in those forms furnished with an air bladder, this has no commmnication with the cesophagus.

The first four fanilies of the sub-order form a section known as the Gildoidei, and are characterised by the normal and symmetrical form of the head and borly. The family of the Lycodidu includes several Family generin of blenny-like tish characterised by the union of all Lycodide. the median fins, and by the pelvics, when present, being small, jugular, and artieulated to the pectoral arcls. Most of these fishes are inhabitants of the seas in the neighbourhood of the two poles. Passing by the family with the bare mention that Lycodes and Gymuctis are two of the best-known genera, we turn to the much more important cod family. In these the caudal tin is generally distinct from the others, but when it is united therewith, the first clorsal is divided, so Family Gadidee. that thiree dorsals are produced. Generally the pelvic fins - which are jugular-are well developed, but in those instances where they are filamentary, the first dorsal is double. There may be either a single or a double anal. As regards their internal inatomy, it will suffice to sity that the cords generally have an air-bladder; while as their 
extermal form is so familiar, it will not be necessary to say more than that the scales are smiall and the lateril line distinct. Cod are for the most part inhabitants of comparatively shallow seas of the cooler portions of the Northern Hemisphere, although there are some widely distributed deep-sea forms, and a very few live in fresh water. All the members of the family are edible; and as they are particularly suitable for salting, their value as a food-supply is very great, although the taste and quality of their flesh is firr inferior to that of many other fish. In the typical genus Gadus are included the greater number of the larger and mole valuible species, such is the coml-

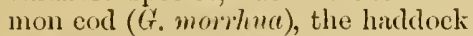
(G. wylefinus), the whiting (G. merlamgris), the pollack (Cr. pollachins), and the coal-fish (G. vivens). In all of these there are three dorsal and two inil fins; and whereas teeth are developed on the vomerine bones of the palate, the pallatines are toothless. Most, althongh not all,

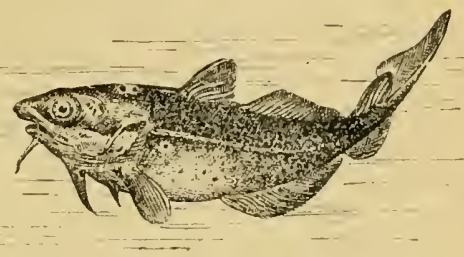

Fig. 22.--Commox Com. have a barbel on the chin. In the allied group of the hakes (Merlnceirs) this barbel is wanting, while the number of dorsal tins is reduced to two, and there is but a single anal; the pelvic tins being strong, and broal at the base, and teeth being present alike in the jaws and on the vomer. The large fresh-water cod known as the burbot (Lota Melyaris) is found both in Europe and in North Americil, and has the same number of fins as the hakes, but the boly is longer, the hear flatter, and the chin beals a barbel. Nearly allied are the marine lings (Mclca), distingnished by having several large teeth on the vomer and in the lower jaw. In the rocklings (Motelle) the first dorsal fin merely forms a fringe, partly concealed in a groove; and there are barbels-varying in number with the species-to both jaws. Some members of this genus are remarkable on accomnt of their sonthern habitat, being found in the seas of New Zealind and the Cape.

Althougl most familiarly known by the sand-eels, the chief interest in the fimily Ophidida centres round the blind cave-fish from the caves of Cuba. In none of the tribe are the pelvic tins fully developed, and in some they are wanting; while there is no distinct first dorsal or first anal, and the caudal fin is in most cases not distinct from the other median fins. The two small fresh-

Family

Ophidiulle. water fishes constituting the genus Lucifuga are sufticiently distinguished by the absence of eyes; but they have a near ally in the marine Brotula, which possesses fully developed visnal urgans. There are, however, blind deep-sea types, such as Typhlouns. All these retain pelvic fins, which are jugular in position; but in the typical Ophidimm these are replaced by long filaments. Very interesting are the somewhat eel-like small parasitic fishes constituting the genera Encheliophis and Fierrsfer, which frequent the breathing-chambers of seit-eucumbers, the interior of bivalve molluses, and other safe positions in living animals. They have no pelvic fins, and the vent is situated quite close up to the throat. On the other hand, in the sand-lamnces, or sind-eels (Ammodytes), while pelvic fins are absent, the position of the vent is nomal. These fish-which love to bury themselves in the sind-have elongated lodies, on which the low dorsal tin extends from a little distance behind the heal to the tail, while the anal occupies almost all the hinder half of the lower surfice. 
Of comparatively little importance is the small marine family typified by the gemus Mrcmurs. Their ehief character is that the body terminates behind in an elongated, tapering, compressed tail, without Family an expanded caudal fin, and is coated with scales, which may Macruridie. be either striated, keeled, or spined. Some of the numerous species measure as much as a yard in length.

The last family of the sub-order is that of the Hat-fishes, which forms a section to itself, known as the Plemronectoidei, and characterised by the unsymmetrical conformation of the head and anterior portion

Family of the body in the adult. This strange moditication renders Pleuronectoidu. the flat-fishes quite distinct from all other members of the elass, and by bringing the two eyes to one side of the bodyit may be the right or it may be the left-enables them to rest with the other sicle on the bottom of the stal. Generally, too, they swim in this position, although it is believed that some of the less modified types swim, at least at times, in the normal manner. In this type of fish we have, as Dr. Basliford Dean remarks, "a singular instance of envirommental evolution, the flattener boly adapting itself both in shape and colour to its bottom-living. Its entire side-not the ventral region, as in the rays-is flattened to the lottom. The mpaired fins now become of especial value; they increase in size, and their undulatory movements enable the fish to swim rapidly yet retain its onesided position; ventral fins beeme useless and degenerate. The further adaptations of the flat-fish include its pigmentation only on the upper on' light-exposed side, in this giving one of the most remarkable cases of adaptation known among rertebrates." Among the rather numerous genera constituting this family, the one in which the ataptation is least developed is Psettules, represonted by a species whose distribution extends from China to the west coast of Africa. In this fish the dorsal fin, which in the other types commenees at, or in front of the eye, begins on the neck; the eyes being either on the left or the right side. The two species of halibut (Hippoylosiss) mark one step in advance, the dorsal fin stating above the eye, although the jaws are still of nearly equal development on looth sides. More specialised is the gemus Rhombus, which includes the turbot, brill, and mary-sole. Here the dorsal fin commenees on the snout, and the eyes are situated on the left sille of the lorly; the scales being either minute or wanting. All these fishes have teeth on the vomerine bomes of the palate, but since the so-

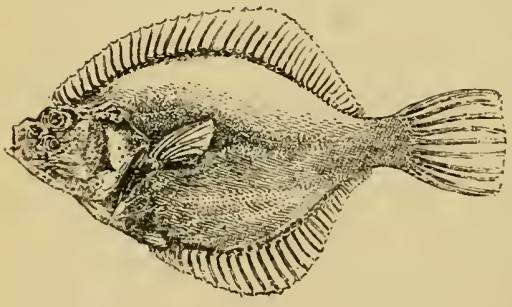

Fig. 23.- THe Flulinder. ealled top-knot of the Mecliterranean and the Chammel has an edentulous romer, it is referred to a genus apart, under the name of Phryorhombus. Omitting nention of a number of other less fimiliar genera, brief reference must be made to Plenronectes, so well known in the shape of the flounder and the plaice. In these fish the dorsal fin starts above the eye, and the marow mouth is very musymmetrical, having its teeth much morederelojed on the blind than wn the enlomred side. There are mo teeth in the pralate, and the eyes are generally on the right side, scales being small or wanting. Lastly, the soles (Solece) 
are right-eyed fishes, with the upper eye smmewhat in front of the lower one, and the naliow mouth twisted round to the left side; the dorsal fin, which is distinct from the caudal, starting ou the snout.

\section{SUB-ORlEL V. PHYSOSTOMI.}

\section{Sectim A.-Apodes.}

The hony tishes forming the present group are broakly distinguished from all the foregoing by the possession of a cluct to the air-bladder when present; sich dlut opening either into the cesopliagus or the stomach. To this leading and all-important internal feature of the gromp it may be added, that externally all these fishes have the pelvic fins situated far behind the pectoral pair, whence they are described as alokminal in position. If the skull be exanined, it will be foumd that, as a general rule, the parietal bones meet in the mildle line. The rays supporting the fins are mostly soft, although the first in the peetoral pair and dorsal are spiny. Most of these features are primitive-a duct to the air-bladder being found in the succeeding sulb-orders of the Teleostomi, which are elearly low types-and it may accordingly be inferred that the Physostomi are inferior in their oromisation to the groups in which the air-bladeler is umprovided with a duct. The seetion named alove includes three fumilies of eel-like fishes, but as the features by which this section differs from those that follow are deep-seated and would require is considerable amount of technical language for their adequate explanation, they cannot be described on this occasion.

The Murenide are all eharacterised by their snake-like bodily form, but as this form is common to the other two families included in the section, other features have to be relied on for the definition of the group.

Unfortunitely, many of these features can only be observed The Eel-Tribe.- liy an exanination of the skeleton or internal soft parts. Externally eels are elaracterised hy the absence of the pelvic

Family Murnenirler. pair of tims, and in some forms the peetorals are likewise wanting. If the dorsal and anal tins are developed, these either form with the tail a contimuous fringe, or are merely sejarated by the projecting extremity of the latter. The skin is either bare, or contains minute rudimental scales. The baekward position of the vent is likewise a chalacteristic feature of the family. More important is the strueture of the upper jaw, of which the fornt portion of the margin is formed by the premaxille, while the sides are constituted by the maxillie, which are well provided with teeth. Equally important is the eircumstance that posteriorly the skull has no commection with the peecoral arch, which is attrcherl solely to the vertebrie of the neck. Of the soft parts, it will suffice to state that there are no ducts to the reproductive organs. Whereas some members of the family are exclusively marine, others pass a eonsiderable portion of their existence in fresh waters. Among the former are the brightly-coloured and frequently gigantic species constituting the genus Murcem, some of which grow to fully eight feet in length. They have no paired fins, although the median ones are well developed ; and save for the presence of the latter, are exeeedingly like large snakes. In all the skin is naked, and in many the teeth are very large and powerful. A peenliar feature is the presence of two pairs of external nostrils, of which the foremost are tubular, while the hinder pair are also of a sinilar type in certain 
species. There are many representatives of the genus from tropieal and temperate seas, some of which aseend tidal rivers. All are highly prestaceous. The so-ealled grass-eels (Leptocephulus) are larval forms of the members of the present family. Although oecasionally brought by eurlents to the surface, they live at great depths in the sea. Before turning into the alult form they undergo a distinet metamorphosis. Nearly allied are the five representatives of the genus Gymnommornu, which inhabit the Paeifie and Indian Oceans, and have the median fins represented by mere rudiments near the extremity of the tail. From both these genera the true eels (Anunilla) may be easily distingruished by the retention of the pectoral fins, which are placed elose to the hearl, and have the narrow gill-openings just behind their roots. The two juws are approxinately equal in length; the skin contains a number of rindimental seales; and the teeth are small and arranged in the form of bands. Eels ne so faniliar to all that they need no further deseription. Before companies were so eareful in filtering their water as at present, eels would, not unfrequently, enter the service-pipes, where they would remain until the passage became completely choked, owing to their inerease in size. Eels oceur in the fresh waters of all parts of the world where the temperature is not permamently below the freezing point. Reams of paper have been spoilt in discussing their breeding-habits, which long remained a mystery. It is, however, now aseertained that eels breed only in the sea, and that the reproductive process seems to be fatal to their existenee; such individuals as are confined to fresh water being sterile. In autumn such adults as are enibled to find a passage make their way to the ocean, whence they never return; while in springr the elvers, or young eels, ascend the rivers, frecuently in enormons number's. On such migrations searcely any obstacles will stay their art-

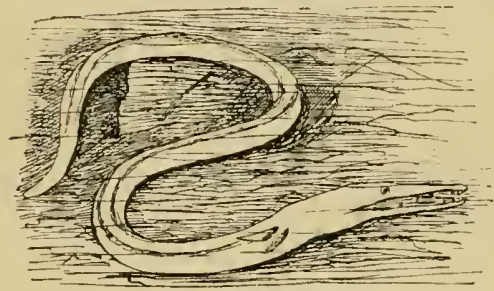

Fij. 24.-SERPENT-EEL. vanee, and they have even been known to eiremurent a hariver hy leaving the water and making a detomr orer moist melis or mashy ground. Thus St. John writes thist in a Scotel river when the elver's "came to a fall that they could not possibly ascend, they wriggled ont of the water, and gliding along the rock, elose to the edge where the stome was constantly wet from the splashing and spury of the fall, they made their way up till they got above the difticulty, and then again slipping into the water, continued their course." Writing of eel-migrations in the Thames, Jesse observes that this takes place in May. "The young eels are about two inches in length, and they make their ajp) roach in one regular and undeviating eolum of about five inehes in breadth, and as thick together as it is possible for them to be. As the procession generally lists two or three days, and as they appear to move at the rate of nearly two miles and a half an hour, some idea may be formed of their enormous number." The largest eels vecur in Oeemia, where examples measuring as much as ten feet in length liave been recorder. From the true eels the marine species inclurled in the genus Conyer differ by the total want of scales, as well as by the latgrel mouth, the presence of an outer series of cutting teeth in the jaws, and the more forward extension of the dorsal fin. It least four species of eonger are known, mong which $C_{\text {. culyuris is almost }}$ 
cosmopolitan in distribution. Congers ale fomml at moderate depths an rocky bottoms, and are extremely voracions, taking at night almost any kind of bait. Eight feet is not an meommon lemerth for one of these eels. Thare are also

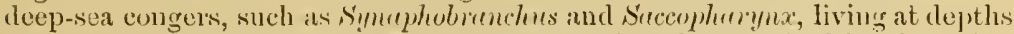
down to two thousand fathoms; the former being characterised hy the mion of the rill-openings to form in median slit on the under surface of the fore-part of the bolly, and the latter hy the soft and spongy texture of the flesh of the body. An allied group is formed by the numerous tropical species of () phichth!s, in which the nostrils are situated in the lips, and the extremity of the tail is free and finless.

'There are many other generie represuntatives of the Mmanirla. lut we pass on to bricfly notice the small family of the sigmmonchider, which talies its name from the gill-olyenings forming a transverse slit on the lower surfice. In these euls the nuediun fins ane wanting, and the paired fins mulimental, while the mangin of the

Family

Siymbranchider. upper jaw is formed sulely by the juemaxillie. The airl,adder, too, is wanting ; hut duets are josent to the reproductive organs. Must of the nembers of the family are fresh-witter forms from Tropical America and Asia, but the Tasmanian and Australian gemus Chilohumchus is marine. The Indian Amphipmous - in which the gills are much reduced-is reminkable for the possession of an adrlitional breathing-orgam in the form of a lung-like sae on each side of the loody close behind the head.

The third ind last family of the section is represented ly certain fleslwater eels from Tropical America, which are armanged in tive genera. From the Muruidur these ecls may be distinguished by the absence or rudimental condition of the dorsal fin, the great cloncration of the anal, and the greneral alssence of the caural, fin, the tail terminating in a point, and being as fragile as

\section{Family}

ciymoticle. that of the blind-worm. The vent is placed close to the throat, the reproductive orgaus have ducts, and the pectoral girdle is commected with the skull. The chief interest of this family is concentr"ated on the electric eel (Gymmotus electricus), from the fresh-water's of the Guianas and Brazil. which attains a length of six feet, and is plovider with electric organs very similar in structure to those of the electric lay described in the sequel, and capable of inflicting equally powerful shocks. Most books on natural history coly from Humboldt a wonderful account of the capture of these eels by means of horses driven into the water's they frequent, but there is omly too much reasom to believe that the whole story is a pure fiction, although not

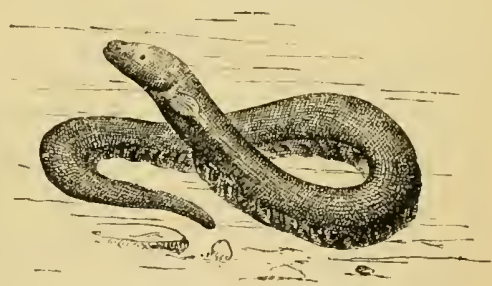

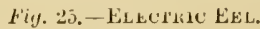
an intentional one, on the part of the illustrious traveller. It is ligh time that it should be forgotten. 


\section{Siection B.-Nemutagnerithi.}

The second section of the Physostomi includes only the cat-fishes or sheathtishes, typitiod by the huge wels (Silums glanis) of the larger rivers of Easter'm Europe, which is the sole European representative Cat-fishes. - of this immense family. A pirt from the structural features Family distinctive of the section, the eat-fishes are characterised by Siluridur. the skin of the body being vither naked, or protected by bony plates of variable size, seales being invariahly wanting. In all, the nouth is provided with barbels, or feelers, frequently of great length, and it is from the presence of these highly sensitive organs that the lame of eat-fish is due. Many of them have the hones of the hinder region of the skull ornamented with a rough tubercular sculpture, and there is frequently a linge shield, similarly seulptured, covering the upper surfice of the neck and shoulders. Often, too, the front of the dorsal fin is armed with it lomg, powerful, and sometimes poisonous, spinc, which in some forms ean be raised or depressed by the aid of a kind of trigger-like arrangement connected with the spines of the vertebr'e of the neck. Very often there is a fatty dorisal fin, and there is also a rayed clorsal. In the sliull the margin of the up)er jaw is mainly formed by the premaxille ; lut a more important character is to be found in the absence from the gill-cover of the bone technically known as the subopercular. The air-bladder, which may be bony, is very generally present, and is then connected with the internal ear by means of minute bones. Cat-fishes are ugly creatures, with large ungainly hearls. small eyes, and the aforesaid long barbels. Some, like the Oriental Bugarins !reelli, grow to a length of a couple of yards, and have huge ugly mouths, "pening nearly the full width of the head. In habits they are sluggish, and dwell for the most prart on the bottom of muddy rivers, lakes, or ponds, where their barbels probably play a large part in enabling them to find their way about. They are remarkably tenacions of life, and the writer once found it absolutely impossible to kill some of these fish, caught while he was yuarantined on board ship in the Rio de la Platir. All these fishes should be handled with extreme caution, as the spines of miny of them are eapable of inflicting extremely dangerous wounds. 'Their flesh, although eatable, is of poor quality. In the rivers and lakes of India and other Oriental comtries, eat-fish are extremely abundant, as they also are in those of South Americi, where the shores of every little pond is strewn with their skulls. 'They aplent to inhabit ponds or lakes liable to be dried up in seasons of unusuil drought, and at such times they doubtless are enabled to survive by burying themselves deep down in the mud. Although the majority are fresh-water tishes, some will enter salt water temporarily, while others are permanent residents there. For the most part they keep near the coasts, but from the circumstance that one species is eommon to the rivers of India and some of the Malayan countries, it would seem that certain kinds oecasionally traverse a considerable extent of sea. In certain forms, like the members of the genus Arius, the males are in the habit of taking charge of the nursery arrangements, by earrying the eggs about with them in their mouths. Since the family comprises considerably more than a hundred distinet genera, it is obviously impossible to give any adequate necount in a work of the present nature. It is sub-divided into several seetions, in the first of which the dorsal and anal fins vecupy the greater part of the length of the body, the 
African and Asiatic genus Clurias being an example of this section. To the second section belongs the typicul Silurus, of which there are five species, from the temperate regions of Asia and Eastern Europe. Here the rayed portion of the dorsal fin is much redueed in length, and, if present at all, contined to the hinder region of the back, while the fatty dorsal is also small or wanting. Unt the other hand, the anal is long, oceupying nearly the whole of the cuudal region. The thind gromp is small, and of little importance; but the fourth is a very large one, and includes the Nilotic Baymes (represented by the bagad), the South American Pimcloelus, the widely

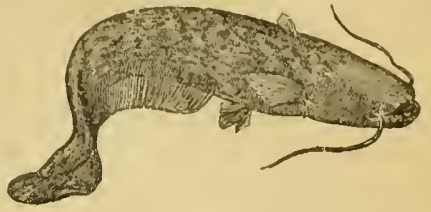

Fiø. 26. -THE WELS spread Arius, the gigantic Asiatic Bugurius, and a host of others. In this group the short-rayed dorsal does not include more than a dozen rays, and is placed far back on the body; the fatty dorsal is present, although often snall; and the anal is much shorter than the caudal portion of the backbone. If barbels are present on the nose, they belong to the hinder of the two pair's of nostrils. Passing over the fifth group, and likewise omitting mention of the seventh and eighth, attention may be directed to the sixth, on account of its including a number of South and Central American forms in which the body is invested in a more or less complete armour, formed of large plates of bone. As examples, may be mentioned the short and deep-bodied Cullichthys, and the long and slender Lorictive and Hypoptopoma, all three of which are abundantly represented in the Amazons.

\section{Section C:-Plectispondyli.}

The third section of the Physostomi is an important one, as containing the large family of the carps, together with two other family groups. In both the Nematognathi and Plectispondyli the first four vertebre in the neck are specially moditied and united into a single mass; but the subopercular bone, which, as already mentioned, is wanting in the gill-cover of the former seetion, is present in that of the latter.

Although the numerous members of the large fresh-water family of the carps come under the designation of "coarse-fish," yet, owing to its cheapness, their flesh affords an important article of food among certain races and classes, while many of the species afford sport to those anglers who do not aspire to the highest grade of their pastime. All the carps have naked heads and toothless sucking mouths; such teeth as they may possess being confined to the pharyngeal bones of the throat. Usually the body is covered with scales, but if these are wanting the skin is naked. Some kinds are provided with false gills of a glandular type ; and the air-bladder, when present, is large, and may be divided either longitudinally or transversely into two portions. When longitudinally divided, it has a bony capsule. In no carps, is there a fatty dorsal fin; but the mouth often bears short barbels. Carp are unknown both in Central and South America and Australasia, but are elsewhere almost universally distributed. Their distribution is thus coëxtensive with the Arctogreic realn, as defined in the introductory part of the section on 
mammals. Unlike the eat-fish, the carps prefer clear water; and while the majority subsist on a mixed diet, some prefer animal substances ; some others confine themselves more or less exclusively to food of a regetable nature. Although the family approaches the Siluride in point of numbers, the importance of its members claim for it a somewhat fuller notice.

The typical sub-family Cypridina is characterised by the air-bladder being divided by a transverse constriction into two elmmbers, and not invested in a bouy capsule. With the exception of the Oriental genus Homalopterusin which they are increased to three, and the air-bladder is wanting-the number of pairs of barbels does not exceed two, but one or both of these may be absent. Of the various genera of this sub-family, the typical Cyprinus includes a small number of species from the fresh waters of temperate Asia and Europe, the common Cyprinis errpio having been originally introduced to the latter continent from

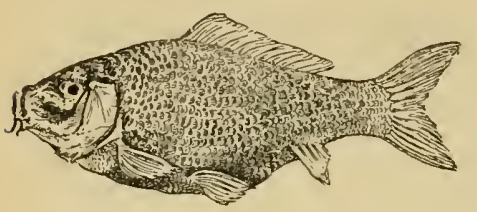

Fig. 27.-Common CARP. the former. In common with certain other genera, C?prinus generally has the short anal fin provided with five or six blanching rays; but it is specially characterised by the lateral line occupying the middle of each side of the tail, and by the dorsal fin having its front edge placed immediately above the pelvic pair, and including one serrated bony, and more than nime branching rays. The blunted muzzle carries two pairs of barbels; and the teeth form a complete triple series, the outermost of which are adapted for crushing. From this genus, Curussius, which includes the crucian carp of Europe and the gold-fish of China and Japan, differs by the absence of barbels. Nearly allied is the very large Old World gemus Bublus, typified by the common European barbel, but also well known in the person of the huge mahasir (B. tor'), which affords such excellent sport with rod-and-line from Kashmir to Ceylom. The members of this gemus have the mouth arched, and are provided with false gills; the barlsels may be either four, two, or none, and the scales are very variable in size, while the form of the body is often less deep than in Cyminus. Of the mahasir, or mahseer, General Macintyre writes, that "on the back its hue is a dark olive-green, shaded off-on the sides of a well-conditioned fish--into a golden orange, which merges into pale pink and silvery-white below. It has rather large toothless jaws, lined with a very tough membrame, so it requires to be struck pretty hard to be properly hooked. When I say struck, I mean that after the fish has hooked itself, as it will do by its own weight, a good pull without a jerk is necessary to drive home the barb into its leathern jaws. Owing to this toughness of mouth, a mahasir when fixed is seldom lost unless it breaks the tackle. This a hig fish will often do in its first plunge, when it sometimes has a way of lashing its tail over the line. That crisis being safely over, if your tackle is trustworthy, landing your fish is usually only a matter of time and patience. Its strong teeth are set far back in its gullet, and the stoutest tackle has a poor chance if it gorges your lure beyond them. It camnot be easily clipped, as its large round scales are so hard that the sharpest gaff will glance off them. When rumning a mahasir after it has been finely hooked, I have never known it leap from the water, and I think it rarely does so, but its long and rapid rushes quite equal, if they do not surpass, those of any salmon of a similar size, As regrards its 
weight, I am well within the mark when I state that the mahasiv reaches nearly, if not youte, $100 \mathrm{lbs}$. The largest mahasir I ever heard of as having been taken with a trolling bait was 93 lbs, and with fly, and that tmmed the seale at 62 lls. But such monsters as these ane very seldom landed with the rod."

Nearly allied are the two species of gudgeons, emstituting the genus Gobio, which differ from the carps in that the pharymgeal, or throat-teetl, are alranger in one or two series instead of forming three rows. In these f:miliar tish the whole of the body is invested with scales of moderate size, and the montl, which is inferior in position, has the bones on its mpper margin protrusile, and there are two barbels. Guclgeom are found on the pebbly beds of elear streams, where they feed on minute aquatic animals.

'The numerous kinds of so-called white fish, such as the dace, loich, and chub, belong to the genus Lenciscus, and, in common with certain other gencra, diffir from the foregoing types in the confornation of the anal fin, which is either of moderate length or short, includes from eight to eleren branching rays, and does not extend so far forwards as the line of the limeler erlge of the dorsal. In the preceding forms the same fin usually has only five or six branched lays. The white fish have no barbels, neither is there a cutting elge to their jaws; while the throat-teeth are arranged in one or two rows, and the dorsil tin is short, and without a bony ray. White fish are found throughont the fresh waters of the cooler portions of the Northem Hemisphere, but their species are nonre numerous in Europe and Asia than in America, Their form and habits are sufticiently familiar to all. Nearly allied to the white fish is the golden-colnured tench, which represents a gremus (Tima) distinguished by the presence of a jair of barlyels to the month, the slight extent to which the tail is notehed, and the minute size of the scales. In this fish the lateral line is complete, and runs nearly in the middle of each sicle of the tail, as it does in such of the white fish as have it fully leveloper. Certain allied fishes from the Old World, eonstituting the genus Chomdiostum, may be reeogniserl by the sharp eutting edge of the lower jaw, which is sheathed in horn. None of these fishes are British, as is also the case with the so-called bitterlings (Rholens), of which there are four species. The breans (Abrumis) bring us, however, to another genus with an English representative. In this and certain other genera of the earp tribe, the anal fin is considerably elongated, and some portion at least of the lower border of the abdomen is emmpresserl to such an extent as to form a sharp keel-like edgre. In the bream the short and spineless dorsal fin is situated over the space between the pelvics and anal, the scales are of moderate size, and the lateral line runs somewhat below the middle line of the tail. As in the white fish, the bones of the upper jaw are capable of protrusion, and some members of the genus present the remarkable peculiarity of being " underhung," that is to say, they have the lower jaw somewhat longer than the upper. Passing over several allied species, mention must be made of the beantiful pearly little fish known as bleak (Albumus), of which there are a considerable number of species inhabiting the fresh waters of Europe and Western Asia. In addition to the silvery listre from which they take their name, these little fishes are specially characterised by the slender form of their gill-rakers, which are placed close together ; the body being rather slender, the lateral line rumning somewhat below the middle of the tail, and the lower jaw somewhat exceeding the upper in length. Formerly the scales of the bleak were employed for making artiticial perrls, the pearly matter being washed off, and after. 
wards deposited in the inner side of thin glass balls, of which the small aperture was finally elosed with wax. An account of this manufacture will be found in a small work on British fishes by Frank Buckland. On account of the almost vertical position of the eleft of its up-turned mouth, mention nust be made of the sichel of Eastem Europe, which forms a genus (Pelecus) sufficiently distinguished by this one characteristic.

The rare and local British fish known as the spiny loach (Cobitis treniu) is the typical member of the second sub-family (Cobitinu) of the car ${ }^{\prime}$ tribe ; $A$ group which includes several other genera of lonches, all confined to the fresll waters of Europe and Asia. In all the member's of this sub-family the air-bladder is enclosed, either completely or partly, in a bony capsule, and none possess false gills. The body, too, never has the deep form characteristic of the carps, and in some gromps is much elungated. Barbels, varying in number from six to twelve, ne always present, and the mouth is inferior in position, with Heshy lips. Whereas the pelvie pair may be wanting, the median fins nre devoid of spines, the number of rays in the dorsal being variable, but those of the mal always few. The tail-tin is romoled, and the scales, if present, are small, and buried in the mueus of the skin. One grenus from the Oriental comtries is peculiar in possessing scales on the top and sicles of the head. The spiny loaches, of which there are at least three species, take their name from the presence of a pair of forked spines below the eyes; such spines being capable of erection at the will of their owners. In the large genus $\Lambda$ emachilus, which includes the common loach $(N$. buber tulus) of every English strean, the spines below the eyes are wanting, and the upler jaw alone is furnished with barbels, of which there are three pars. The thind Europenu genus, Mistmerums, inclurles the giant loach of Europe, and three cother species; its distributional area inclublug Europe and Asia nortl of the Himalaya. In this genns there are either five or six pairs of barbels, two of which arise from the lower jaw. Many other genera are fonnd in the Oriental comntries, and it is noteworthy that whereas the Eurojean forms ale imliabitants of clear roming waters, these latter dwoll in tauks, where they bury themselves in the mud at the bottom. All, how. ever, agree in that their forl is composed exclusively of mimal substances.

In the fiesh waters of Tropical A frica the place of the loaches is taken by the two species of the gemus Kueria, which form a family by themselves, distinguished from the Cyprivide by the absence of throat, Family or pharyngeal teeth, the simple, unclivided form of the air'Kneriide. bladder, and the absence of barbels.

Of far more importance than the last is the very extensive family of fresh-water fishes commonly known as characinoid fishes, but which might perhaps be termed the southern carps. Their distribution is indeed largely complementary to that of the Cyminide, since

Family they are confined to Central and South America, and Africa

Erythrinilue. south of the Sahara; carps being absent from the former comntries, although present in the latter. This peculiar geographical distribution is one anong many instances of the close aftinity existing between the fammas of these two areas. The explanation of the absence of the Cyprinide from South America may possibly be that the characinoids entered Africa at the time when that country was in communication with Soutl America, whereas the carps did not come in till that communication was severed. If that be so, the Cymrinide must have come into Africa at the same time as many of the large mammals, such as 
hippopotani, griraffes, rhinoceroses, elephants, and antelones. From the Cyprinide the present family is broadly distinguished by eertain peeuliarities in the structure of the skull, and hy the number of upper phiryngeal bones being one or four, in place of two. 'The margin of the upper jaw is ilso different, in that it is formed in front by the premaxillie, and by the maxillae at the sides, instead of entirely by the former hones. Barbels, too, are wanting ; but whereas the head is as devoid of scales as in the Cimprinida, the jaws may he either smooth or furnished with powerful teeth. In such an extensive family, it is but little use referring to genera by name, when their distinctive features eannot be described. It may be mentioned, however, that the African and the American genera are distinct from one another, and that the typical Erythriums is from Ameriea. Two genera-of which Hydrocyon is African, and Cymorlom Tropical America-are, however, noteworthy on accomit of the large size and predaceons habits of some of their representatives. Two species of the former genus are abundant in the Nile, where they grow to about four feet in length, and are respectively known by the Egyptians by the names of Kelb-el-bulir and Kelb-el-moyeh.

\section{Section D.-Heplopomi.}

In this fourth section of the Physostomi the first four vertebre of the backbone are distinct from one another, and unmodified ; the supranecipital bone of the skull extends forwarks to separate the two parietals, and the full number of bones is developed in the gill-covers, or operculum. The phiryngeal bones, too, are Cyprinorlontide. separate, and in the upper jaw are three or four in number, and directed forwards. The first family of the section is that of the Cyprinudontida, which includes a considerable number of genera of small fishes ranging over America, Africa, Asia, and the south of Europe, and inhabiting alike salt, brackish, and fresh water. With a mouth devoid of barbels, these fish are easily reeognised by the scales extending on to the head, as well as by the absence of a fatty dorsal fin, and the backward position of the rayed dorsal. As in the carps, the margin of the upper jaw is formed entirely by the premaxillary bones. The third upper pharyngeal bone is enlarged, and teeth are present, not only on the pharyngeals, but likewise in the margins of the jaws. Whereas some cyprinodonts feed on living animals, others seek their food in mud. The males, which are much inferior in size to their partners, include some of the smallest of all living fishes; and most species produce their young in a living condition. In a family so extensive, it is difficult to select genera for special mention. The typieal Cyprinodon has a very wide distribution, and is represented by seven species from the countries bordering the Mediterranean. Some of its members are remarkable for inhabiting springs or pools almost saturated with salt, while others are found in springs of very high temperature. Perhips the most noteworthy forms are the speeies of the genus Ambleps from 'Tropical Ameriea, in which the eyes are divided by a horizontal line into an upper and a lower half. The convexity of the lens differs in these two halves, the upper half being suited to vision in air, and the lower in water. This enables the fish to see perfectly in both media when swimming near the surface of the water, with one lialf of the eye below, and the other above, the surface. A good account of the habits of these eurious fishes has been 
recently published in the Field newspaper. It may be mentioned that, according to an American writer, the name of the family should be changed from Cyprinulontide to Pecilivilu.

Nearly allied to the last are two genera of small North American fishes, in one of which (Amblyopsis) the eyes are wanting, while in the second (Chologuster) they are very minute. The one is represented lyy the

Family Amityopsicle. well-known blind tish from caves and other subterranean waters, while the single species of the latter is found in the rice-fields of the Southern States, although very rare. Chologuster has no pelvic fins, but these may or may not be present in Amllyopsis; as is also the case with C!lminodon. The blind fish, which grows to a length of about five inches, is quite colourless, and when the dark waters of their habitat are artificially illuminated these fishes liave a weird and ghostly alpearance.

Of the other two families of the section, the first is an unimportant one, represented by one species of the single genus Umbra from Austria and Hungary, and a second from the United States. Small in Families size, these fish are very similar to the Cyprinodontide, from Umbridre and which they may be distinguished by the lateral margin of Esocille. the upper jaw being formed by the maxillae. Although likewise represented only by a single genus $\left(E_{s}(x)\right.$, , the pikes are a much more important and better-known family, the common Enropean species ( $E$. lwrins) being well known to all. Pike are inhabitants of the fresh

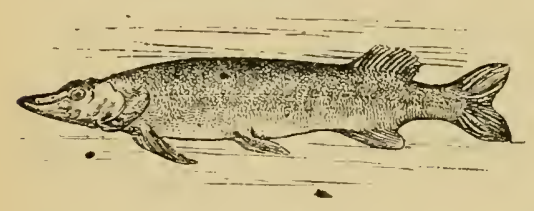

Fiy. 28.-Commox PIKe. water's of North America, Temperate Asia, and Europe, but are more numerously represented in the Western than in the Eastern Hemisphere, six species being exclusively American, whereas the common pike ranges over all three continents. In these fishes the margin of the upper jaw is formed in the sime manner as that of the umbrers; but the absence of scales on the head serves to distinguish them from all other member's of the section. Their elongated, "pike"-like form, their large size, and their voracious habits, are familiar features of the family; but it may be added that there are mo barbels to the mouth, while there is no fatty fin, and the dorsal occupies the position of the fatty fin of the Sulmonidre. Summarising some of the accounts which have been given of the voracity anc fierceness of the pike, the editor of this volume writes as follows:- "It has been known to attack a man when its retreat has been cut off, to bite the legs of hathers, and to snap at the finger's of persons cooling their hands in the water ; and when pressed with humger, to fight an otter for the pussession of a cillp. Its strength and endurance have often been demomstrated in the destruction of strong tackle, and in its power to survive-without apparent inconvenience-with hooks and wires mingling with its anatomy. Calptain Brown gives an instance of a pike being caught which had a strong piece of twisted wire projecting from its side. It was in excellent condition, and on being opened, discovered in its stomach a double eel-look, much corroded, and attached to the protruding wire. Another pike, when caught in the River Ouse, was fommd in possession of a watch with a black ribbon and seals attached--property which, it was afterwards discovered, had belonged to a 
gentleman's servant who had been drowned. The pike has often been caught witl portions of tackle broken from the line in former engagements hanging from its mouth. Its rapacity is extraordinary. Eight hundred gudgeon are said to have been eonsumed in three weeks by eight pike of not more than five pounds weight each."

\section{Section E.-Scipluphori.}

The next family of the Physostomi comprises a few fishes from Tropical Africa which appear to have no very near relations, and are consequently regarded as forming in seetional group by themselves. The chief eharacters of the section are derived from the bones of the skull, in which the parietals are separate alike from one amother, and from the suprabocipital; while the pterotic

\section{Family Mormyrida.} bones, which are situated on the onter sides of the parietals, are large, fumnelshaped, and contain a eavity elosed by a lid. The full series of bones are developed in the gill-cover, and in the back-bone the four first joints are sepalate and unmodified. Ais a family, the Mormyride are ebaracterised by the naked heid, the want of loarbels, the slit-like opening of the gills, the simple air-bladder, and the absence of a fatty fin on the back. The front portion of the margin of the upper jaw is constituted hy the premaxille, which are united toggether; but the sides are formed by the maxilla. All these fishes are dwellers in fresh water. The typieal genus is Mormyrus, from which some writers distinguish certain species under the name of Mormyrops, other members of the family being included in Gymumchus, which is characterised by the eomplete disappearance of the pelvic, anal, and eaudal fins, the tail terninating in a point. Many of the species of Mormyrits have the nuzzle more or less elongated ind beak-like, but $\boldsymbol{M}$. petersi has the extremity of the lower jaw produced into a large, ennical, fleshy appendage of great relative length. (iymuarehus-of whieh there is only one species-is, on the other hand, a large eel-like fish, growing to a length of a couple of yarts.

\section{Sertion F.--Isospondyli.}

The sixth and last section of the Physostomi is the largest and most important of all, including - in addition to many other groups - the families of the herrings and salmon, whose numerous representatives are so highly vilued as food.

These fishes are the most generalised of all the Physostomi, and consequently make the nearest approach to the under-mentioned gamoids. In all of them the two parietal bones are separate, and the so-called symplestic bone, which is wanting in the preceling family, is here present. As in the latter, the anterior segments of the rertebral column are of the simple, ummodified type; but

\section{Family}

Notopteridce.

both the upper and the lower pharyngeal bones are separate. The first representative of the section is the genus Notopterns, which constitutes a family by itself, and inclucles several species from the Oriental countries and West Africa. None of these fishes have a fatty clorsal fin or barbels, but many of them possess in short and tall dorsal fin, situated far back on the body, 
and standing up in such a conspicuous manner as to give rise to the name of "feather-back." A better character is, however, to be found in the backward continuation of the anal fin to form a fringe surrounding the tail. There are many other structural peculiarities in these fresh-water fishes, but it will suffice to mention that the air-bladder is divided into a number of compartments, and furmished at each end with a pair of prolongations, so that it presents some resemblance to a shark's egg in form. More important, on accumt of their peculiar geographical distribution, are the small Family fresh-water fishes from the Sonthern Henisphere, forming Galaxiidu. the genus Galaxias, and typifying a family by themselves. They have the base of the skull single, the pterotic bones solid, and the tail forked or romnded, while there are neither scales, barbels, or a fatty fin, the dorsal being situated dircetly over the anal fin. The eggs of the female are discharged into the cavity of the abdomen, as in the last fanily, from which these fishes differ by the simple structure of the airbladder. The typical Galuxias has long been known from the extremity of South America, Australia, and New Zealand (where, from their spotted coloration, they were formerly known as trout), but it is only recently that a species has been recorded from the Cape. The New Zealand Neochumnaof which the known specimens have been found buried in mud far away from water-differs by the latck of the pelvic fins.

This family is notewortly on account of its containing the largest freshwater bony fish, the huge Arapaima gigas of the Guianas and Brazil, which attains a length of fully fifteen feet, and a weight of four

Family Iundred pounds. As a family, the arapaimas are distin-

Osteoglossidue. guished from the Galaxiidce by generally possessing three, instead of two, upper pharyngeal bones. The body of these fishes is invested with unusually large scales, marked with a kind of mosaiclike sculpture, but the head is devoid of scales, and protected by large roughened, ossified plates. WVide openings of the mucus canal

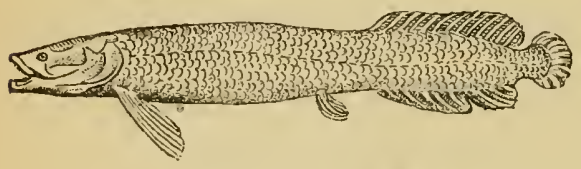

Fig. 29.-ARAPAIMA. constitute the lateral line, and the long dorsal fin is placed immediately over the analto which it is almost similar -very far back on the body. Indeed, so far back are these fins, that they sometimes coalesce with the candal. The openings of the gills are wicle, and both the premaxilla and maxillae enter into the formation of the margin of the upper jaw ; but there are no false gills. Whereas some forms have the air-blidder simple, in others it is composed of cells. Allusion having been already made to Arapaima, we pass on to the typical Osteoglossum, of which there is me species from South America, and a second from Bomeo and Sumatra, while the other two are inhabitants of Australia. A pair of barbels to the lower jaw, and the obliquity of the cleft of the month, are sufficient to distinguish these large fishes from Arapaima. The flesh is of excellent quality. The last genus, Heterotis, is African, and differs from the other two in having only two upper pharyngeal bones-thereby resembling the Galcxiidc-and its air-bladder is cellular. The one species is conmon to the Nile and the livers of West Africi.

A fresh-water fish from North America known as the moon-eye (Hyndon 
tergissus), and a small fish (Pantoulon bucholsi) remarkably like a cyprinodont, from West Africa, severally represent two fimilies. From the foregoing families of the section, these two groups are distinguished by the under-mentioned characters. The Hyodontide and pterotic bones are of normal conformation; there are four Pantodonticle. separate upper pharyngeal bones, of which the third and largest is direeted forwards; and the base of the skull is double. All these features are common to the remaining families of the section. In the $H_{y / 0}$ dontide the two parietal bones are united together, and the bony structure supporting the tail-fin is preceded by two true caulal rertebre. Whereas in the moon-eye the tail is deeply forked, in Puntodon it terminates in a point. A long slender fish from the seas of Australia, Japan, and South Africa, known as the beaked salmon (Gonorlyynchus grequi), likewise constitutes a separate family, distinguished Gonorhynchide. from the last two by the presenee of barbels to the mouth, and the absenee of true eaudal vertebre. The beaked salmon varies from a foot to a foot and a half in length, and is often found in sandy bays. Its flesh is eaten.

The three families now to be mentioned inclucle marine fishes, of which the majority are deep-sea or pelagic in their habitat, while many are remarkalole for the development of special phosphorescent organs, by the aid of which they find their way in the dark ocean abysses. From the preeding family, the Scopelicte are distingnished hy the absence of barbels, and of spines on the seales (when Sternoptychider, the latter are developed), and the presence of a small and stomiaticlir. fatty fin posterior to the dorsal. Whereas some forms are scaled, others are naked; but all are characterised by the wide gill-openiug, the possession of false gills, the absence of an air-bladder, and the formation of the margin of the upper jaw by the premaxille alone. A peculiarity of these fishes is the extreme shortness of the intestine. The typical genus Scopelus includes fishes of normal form, with rows of phosphorescent spots on the lower side of the body ; but in Ipnops the whole hody is exceedingly long and slender, and the upper surfice of the flattened head oceupied by a large luminous organ. Other genera are Sumrus, Puralepis, Plagyodus (in which the body is naked, and the jaws are armed with large tusks), and Gymnoscopelus, in which scales are likewise wanting. Of the other two families it will be umneeessary to give all the eharacters, but it may be mentioned that in the Stemoptychidce the fatty fin is either very small or rudimental, while there are no barbels, and the body may be either naked or covered with thin deciduous scales, while the maxiliae enter into the nuargin of the upper jaw. On the lower parts, light-organs are developed. One of the best-known forms is the somewhat elongated Photichthys, from which the allied Chauliodus differs by the large size of its teeth. On the other hand, the typical Sternopt yx has the body deep and compressed, and the tail short. The Stomictider differ by the presence of a long barbel attacherl to the hyoid bone, which depends from the lower jaw, the fatty fin being often totally wanting. Astronesthes, which is one of the genera with a small fatty fin, has a large head, and jaws armed with powerful teetl. Stomias and Echiostoma both lack the fatty fin, but whereas the former has the body covered with minute scales, in the latter the skin is naked, and the small pectoral fins have some of their rays prolonged into thread-like filaments. At times the deep-sea fishes of the present group are met with floating in a helpless inert condition (n) the surface of the ocean; but they are generally omly obtained hy 
dredging. Wheu brought to the surface, owing to the sudden diminution of pressure, their eyes start out of the sockets, the scales stand ereet, and the tlesh is loose and fragile, so that the preservation of specimens is frequently al matter of considerable difficulty.

These two unimportant families, severally represented by a single type, may be distinguished from the preceding members of the Isospondyli by the cireumstance that the supraoccipital bone of the skull exFamilies Chiro- tends forwards so as to separate the two parietals from one centridre and another. And in this feature they agree with the members Bathythrissicla. of the following families of the seetion, exeept for a few aberrant types of two. The first family is represented by the doral) (Thirocentrms domb), of the Malayan and Red Seas, and is distinguished by the possession of but one caudal vertebra. The dorab is a large elongated fish, with a deeply-forked tail, no fatty fin, an up-turned muzzle, powerful teeth, and a sharply-keeled and serrated under surface. In length it is stated to grow to as much as twelve feet. Very different is the deep-sea Brethythrissa dorstlis of Japan, in which the body is deep and oblong, with the under surface rounded, the head naked and without barbels, and the clorsal fin so much elongated as to occupy nearly the whole length of the back, a fatty fin being wanting. This fish forms an exception to the generality of the members of the sub-order in lacking an air-bladder.

The fanniliar "recl-herring," in its natural condition, is the type of a family of mostly marine and littoral fishes whose importance as a food-supply can

Herrings. - scarcely be overrated. Limits of space, unfortunitely, Family allow of only a very inalequate notice of the group. Dr. Clupeide. Giunther writes "that the family of herringss is probably unsurpasised by any other in the number of individuals, although others comprise a much greater variety of species. The herrings are principally coast fishes, or at least do not go far from the shore; nome belong to the cleep-sea fauna, searcely any have pelagic habits, but many enter or live in fresh-waters communicating with the sea. They are spreal over all the temperate and tropical zones." With the exception of one genus, agreeing with the Chirocentide in the structure of the skull and presence of a single caudial vertebra, the Clupeider are specially chisacterised by the want of a fatty fin, and the general presence of small plates of bone on the lower surfice of the body, which is usually sharp and often serrated. The head is devoid of barbels, and usually also of seales, but the body is always fully scaled, although the lateral line is generally wanting. The margin of the upper jaw is formed in pirt by the premaxillie, and in part by the maxillie; each of the latter bones consisting of three distinct elements. Usually the gill-openings are complete, and the

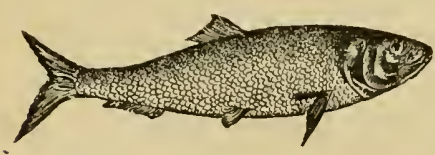

Fig. 30,-THE HERRIsi. operculum comprises the full number of elements. The rays of the short dorsal fin are few and weak, although those of the anal may be numerous. The airbladder is comparatively single, and nost members of the family are fur. nished with false gills. In the typical gemus Chupere the two jaws are sub-erpual in length, the eyes have fatty lids, and the body is compressed, with the abdomen serrated inferiorly as far forwards as the chest. The cleft of the mouth is of moderate width, and if teeth are present at all, they are rudi- 
mental and deciduous. The anal fin is of moderate length, with less than thirty rays, the dorsal fin is placed above the pelvic pair, and the catudal is deeply forked. Amrong orer half a humdred species, we may name the common herring (C'.hurengus), the spratt ((!. spruttres), the alliceshad (C. alosu), the shad (C'. funtu), the Anerican mosshimker (C. meuladen), and the pilchard or sardine (C! pilchurdus). Herrings, as is well known, are gregarious and carnivorons fishes, going about in huge shoals, the presence of which is often inclicated not only by the appearance of the surface of the water, but by the Hocks of sca-birds which lover overhead in search of prey. The shoals appear to approach the coasts solely for the purpose of spawning, after which they retire to deeper water. Anstralia is the home of certain fresh-water herrings forming the genus Diplomystus, and eharacterised by having plates of bone behind the head similar in character to those on the under surface. Another and larger genus (Enymulis) is typified by the Mediterranean anchovy, and is characterised by the prolongation of the nearly conical snout beyond the tip of the lower jaw, and by the eyes being covered with a continuous skin. The Mediterranean species, either preserved whole, or made into a paste, affords the piruant anchovy of commerce. The only other type that can be nentioned here is Elops, which ispeculiar in that the parietal bones of the skull are in contact, and also for the possession of two caudal rertebre. 'Phere are two species from the warmer seas, in both of which the space between the two branches of the lower jaw is protected by a thin plate of bone, while the lower surface of the boly is rounded and smouth.

Tery brief notice must suftice for two small and umimportant families now generally placed between the closely allied groups of the herings and salmon. The Aleprephlalider resemble Elops, and thus the Solmonidie,

in having two caulal rertebre, but differ from the former, Families Alepoand thereby agree with most of the latter, in that the two cephalinle. and parietal bones of the skull are separated by the supra-Haplochitonidu. occipital. 'They lack, however', the fatty fin of the latter, and

barbels are wanting to the head, which is likewise devoid of scales, as is sometimes also the body. Both parirs of jaw-bones enter into the formation of the margin of the upper jaw, and the stomach lacks the blind appendage, or cecum, characterising that of the herrings. In the typical genus Alepocephulus the body is corered with thin seales, but in Xenodermidhthys these are replaced by fine nodules. Two other genera are known. The tront-like fish from the rivers of Chili and the soutlem extremity of South America and the Falklands known as Haplochiton, together with the allied Australian genus Prototioctes, represent the second of the two families now under consideration; the first of these resembling a scaleless trout, whereas in the second the body is sealed and the jaws are armed with minute teeth. These fish differ from the families last noticed in possessing a small fatty fin. In this respect they resemble the Sulmonidre, from which they may be distinguished by the fact that the maxilla do not enter into the formation of the margin of the upper jaw.

From the other allied families the Sulmonide may be distinguislied by the possession of a small fatty fin between the dorsal and the tail, compleal witl the ciremistance that the margin of the upper jaw is formed in front by the premaxillie and at the sirles by the maxillie. Salmon Tribe. The inferion aspect of the body is romded; and whereas the skin of the head is invariahly naked, the body is generally Family clothed with scrles. The Sulmomide are in the main re- 
stricted to the cooler portions of the Northern Hemisphere, although one genus is found in the fresh waters of New Zealand. Whereas some kinds spend the whole of their time in fresh water lakes or rivers, other's descend periodically to the sen-or, as it is perhaps more correct to say, ascend rivers from the sea for the purpose of spawning. Certain kinds are, however, permanently marine, most of these being deep-water fishes, although the menbers of two genera are pelagic. On account of the large size of many of the species, coupled with the superlatively excellent quality of their flesh, the Solmonide are commercially one of the must valuable families of fishes. It appear's that the "salmon-colom" characterising the flesh of some of the species is due to the pigment derived from the crustacenns on which they feed ; the action of the gastric juice turning such pigment red in the same minner as boiling. Volmmes have been written on the life-history of the Sulmonidre, and the question as to the number of species of fresh-water tront and charr; and many pages of this work would be necessary to give even a full outline of the subjeet. As it is, little more than a bare mention of the leading genera and species can be attempted. It should, however, be mentioned that whereas the adults are usually silvery, or spotted with black and red, the immature fish pass throngh a stage-the "parr" - when they are marked by clark transverse bars. In certain fresh-water kinds these immature markings may, however, be retained individually dming the whole of life. There are also sexual or seasomal differences in the adult fish; as

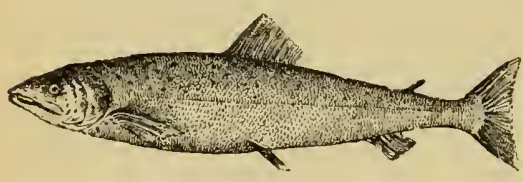

Fig. 31,- THE SALMON. exemplified by the hooked lower jaw of the male salmon in the spawning season. The genus Sulmo, which includes the common salmon (S. salmo), and the various species or varieties of trout and charr, has the dorsal fin situated nearly or immediately above the pelvic pair, the scales small, and well-clevelopecl teeth in the jaws, and likewise on the vomerine and palatine bones and tongne; while the and fin never ineludes more than fourteen linys, and the intestine is furnished with a large number of small blind appendages or caeer. Moreover, the mouth is so deeply cleft, that its opening extends at least as far back as the eye. Southwards, the range of this large genus does not extend beyond the Atlas and Hindu Kush in the Eastem Hemisphere, or the rivers flowing into the head of the Gulf of California in the Western. In the various kinds of true salmon and trout the whole length of the bone known as the vomer carries teeth during some period of life. On the other hand, in the mostly smaller and more brilliantlyenloured charr the vomerine teeth are restrieted to the heal of that bone. The largest memler of the charr group is the Damubian bucho (S. hucho), which rivals the salmon in size. The nigratory species, whieh periodically ascend the rivers of North America and Asia flowing into the Pacific in ineredible nmmbers, form the genus Onchorhynchus, distinguished by the possession of more than fourteen rays in the mal fin. A third genus (Osmerus) contains the three species of smelt, and is to some extent intermediate between Salmo and Onchorhyuchus on the one hand, and Coregonus on the other. They are, however, peeuliar, on accumt of the small size and number of the execal appendages to the intestine, while their eggs are relatively small. As examples of the large and mostly fresh-water genus Corr- 
ymus, may be mentioned the rendace (C. vendesins), the pollan (C. pollen), and the powan (C.clnpeoides), all of which are British. Like smelts, these fish have small eggs ; but then they have a great number of blind appendinges to the intestine, and if any teeth remain in the adult, they are usually restricted to the tongue, while even in the young state these organs are minute. The cleft of the mouth is always much less deep thin in the sulmo, while the forking of the tail is more strongly marked. In common with the grayling, these tishes differ from the other members of the family in that the two parietal bones meet together for a short distance in the middle line in idvance of the supraceipital. The genus extends over a eonsiderable portion of Northem Europe, Asia, and America ; and its very numerous members are for the most part permanent inhabitants of fresh water. The grayling (The!mullus), which have a geographical distribution very similar to that of ('oregmus, differ from that genus by the taller and longer dorsal fin, in which the number of rays varies from thirteen to twenty-three. The mouth, too, has a smaller eleft; while the blind appendages of the intestine are much less numerous, and teeth are present in the jaws, and on the palatines and the heal of the romer, although wanting from the tongue. Although ranging from Lapland to Venice, and from England to Russia, the grayling is a rery loeal fish, which is unknown in Ireland; and it appear's that only under eertain conditions will it thrive and multiply in a river. A writer in Lond mul Wuter for 1868 remarks, that "there is one singular peeuliarity about the grayling that distinguishes it from all other speeies of sulmonider, and that is its remarkable odour. It resembles more thin anything else the smell of a freshly-cut cucumber ; by this eriterion it may be inmediately detected. fome anthorities assert that the smell of this fish resembles thyme, but I camot endorse this, or perceive the slightest aftinity."

A small family is represented hy the North American fresh-water Fecopsis grettete and the allied Columbia trensmontame, which, although possessing the structural features of the Salmomidor, assinilate in the nature of the scales and the bones of the mouth to the perch Percopsidx. tribe.

\section{SUI-ORDER VI.- TTHEOSPONIYLI.}

'This and the next subordinal group of the Actinopterygii are now respectively represented only by a single Nonth American genus, although both were abundant during earlier epochs of the earth's histrry. To understand fully their relationship to other fishes it is essential to take the extinct forms into consideration, but as this is inpossible here, their general structural features cin be only very slightly touched upon. The present sub-order is now

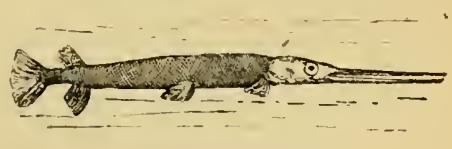

Fig. 32.-Boxy PIKE. represented only by the three species of bony pike (Lepidostens) from the fresh waters of North Ameriea, which typify the family Lepidosteidce. These fishes, some of which measure fully six feet in length, have the head covered with bony plates, and the whole body invested with a coat of hard, shining, quadrangular seales, which articulate together by means of a peg and socket. The long head is depressed, with the jaws well-armed with teeth; and the body is elongated, with the anal and dorsal fins-which have no spines-placed near the tail, and the latter of the so-ealled abbreviate 
heternecreal type. In the skeleton, the rerteln"e are unique monong living fishes in that the articular surfaces of their bockies form a eir) behind and it loall in front. The air-bladder has a duet, and the nerves suplying the eyes where they meet one another in the midlle line give off interlacing filnes, and there are remmants of a spinal valve in the lining membiane of the intestine. Bony pike, which are abundant in many of the North American rivers, are very analogous in their habits to true pike, feeding upon other fishes.

\section{SL'B-ORDER VII. - PROTOSPONDYLI.}

The single existing family (Amiirlu) of this once abundant suborelinal group is now represented by the bow-fin (Amia-calia) of the fresh waters of the United States. This fish, while agreoing with the bony pike in the eonformation of the optie nerves smplying the eyes, (liffers in the fuller (levelop)ment of the spiral valve in the intestine, and in the simpler form of the bodies of the vertehrie, which are disc-like. Although the seales are coated with ganoin, they cliffer from those of the bony pike in being thin, rounded,

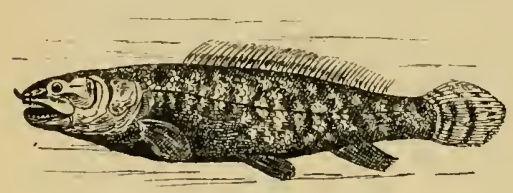

Fig. $33-130 w-F+x$. and deeply over-lapping. A peculiar feature of the bow-fin, and the one from which it takes its vernacular name, is the great length of the dorsal fin, which oecupies more than half the entire length of the back, and pusteriorly is separated only by a noteh from the tail-fin ; the latter being of the abbreviate heterocercal type. The bow-tin grows to a length of about a eouple of feet, and is a earuivorous hish, exeeelingly abundant in some of the North Amerien lakes. It feeds not mly on other fishes, but likewise on various invertehrate animals, and can exist for a eonsiderable time ont of water. Its favomite launts nre the dense masses of floating regetation fringing the North. American lakes, anong which it lays cluring the month of May a lost of minute eggss.

\section{SUB-OLDER VIII. - CHONDROSTEI-STURIEONS.}

The title of royal fish bestowed on the common sturgeon would seem to indicate that it has some special elaim to superiority orer the other members of the finny tribe. This, however, is not the ease, the title being due to the eircumstance that all such fish, accorling to an act of Edward II. which appear's to be still in force, belong of right to the erown. The enactment runs that "the king shall have wreek of the sea throughout the reahm, whales, and great sturgeons, taken in the sea or elsewhere in the realm, except in certain places privileged by the king." From all the other subordinal groups of the Teleostomi, the sturgeons and their extinet allies are broadly distinguished by the greater relative number of the dermal rays in the dor'sal and anal fins, which exeed the bony or eartilaginous elements pertaining to the true skeleton by whieh they are supported, instead of these two elements being numerically equal. As regards the optie nerves and the lining membrane of the intestine, the sturgeons resemble the preceding sub-order. All the member's of the sub-order lawe a persistent notochord and a eartilaginous skeleton, but the tail may be of either the heteroeercal or the diphycerca 
ype. It might he thought that the bony shielis investing the head, and the longitudinal rows of pominent lony tubereles or plates frepuently present on the otherwise entirely naked skin, would form a distinetive feature of the groul). As a matter of fact this is not so, seeing that a number of extinct fishes now classed with the stmrgons have a complete coat of gamoid scales. Sitill, however, as distinctive of the existing forms-with which alone we are concerned here-the presence of these shields or plates, or both, eompled with the alosence of scales (sive in one fanily on part of the tail) are very distinctive. Existiug sturgeons nay be classitied in two families, in both of which the tail is lieterocercal.

The first of these is represented only by two genera, each with a single species, and its distinctive features are to be found in the presence of minute teeth in the jaws throughout, life, as well as of a median series of unpaired bony shields in the armour of the head, and likewise by the slin-sire for a few minute stellate ossifications-locing maked all over the boly, although there may be

a few scales on the upper lube of the tail. The typical Polyodon folins, from the Mississippi basin, is a comparatively small fish, apparently not exceeding about six feet in length, characterised by the upper jaw terminating in an enormous shovel-like beak, furnished with soft thin margins, and expal to fully one quarter the entire length of the fish. Tastly larger is Psephurus gladius from some of the great Chinese rivers, which grows to something appronching twenty fect, and has a much more slencler beak. Both these fishes have minute eyes, and appear to grovel in the mud in the river bottom in search of their fuod. The occurence of two such closely allied forms in the rivels of North America and China is paralleled by the instance of the Amerien and Chinese alligators, and likewise the two kinds of grant sillamander (Mcyrlobutirechus and Criptobrenchrs), all these examples indicating the close aftinity between the fauma of North America and that of NorthEasteln Asir.

The members of the second family of the grom] differ from the Polyertomtide by the disajpearance of the teeth in the adult, and likewise lyy the bare skin of the body being traversed by five longitudinal lows of large elevated buny plates. The median series of shields is also wanting on the head, and the under surface of the muzzle is provided with two pairs of flexible barbels, of

Family itcipenserider. which there is no trace in the first family. All the members of the family are restricted to the temperate parts of the Northern Hemisphere, and all are largely fresh water in their habits, some being exclusively so, although others ascend the larger rivers unly for the purpose of spawning, after which they retur'n to the ocean. Whereas the typical members of the family belong to the genus Acipenser, certain fresh-water kinds from the basin of the Mississippi and Central Asia form a genus apart, under

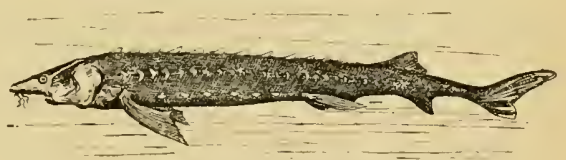

Fig. 34.-COMMON Sturgeos. the nime of Scrplirhmichus, one of their rlistinctive features being the production of the muzzle into a shovel-like beak vely similar to that of Psephurus. Uf the typical genus, the largest species is the huso (Acipenser huso) of the Russian rivers and inland seas, which occasionally attains the enomous 
length of four-and-twenty feet. The smallest is the sterlet (A. ruthrenus), whose length is unly about three feet, while the common species (A. sturio) is intermediate between the other two. The sterlet claims pre-eminence on account of the excellent quality of its flesh, while the roe of all the larger species affords caviare, and the air-bladder isinglass. Frank Buckland writes that "sturgeons seek their fuod chiefly anong the mud at the bottom of rivers, and their head is admirably andapted for the purpose. The elongated snout, protected by broad plates, ploughs up the mud as a hog does the ground; and it is probably from this habit they got the name of sturgeons, from the German, stören (which means to rake up, poke, or stir). A little way behind the point of the snout, and on the under side, is placed a series of worm-like tentacles, or feelers, the office of which is to examine the objects turned up by the snout; and in rear of these comes the sucker-like mouth, ready to receive what is thus provided." In reference to the last sentence, it may be suggested that the use of the tentacles may be to attract other fishes within range of the mouth.

\section{Orier II.-Crossopteritit.}

FRINGE-FINNED GANOIDS.

Africa is a country where several ancient types of animal life that have disappeared from other regions of the globe still linger on, and a remarkable instance of this survival is afforded by two fishes from the fresh waters of that continent. One of these is the bichir (Polypterus bichir) of the Nile and its tributaries, as well as the rivers of the west coast, and the other the reed-fish (Culumoichthys culuburicus) of the fresh waters of Old Calabar on the west coast. In the structure of their fins, and likewise in the hard quadrangular ganoid scales with which the body is covered, these strange tishes resenble a host of ancient types which were widely spread orar the fresh waters of the ylobe during the Palieozoic epoch. Their essential difference from all other living rejresentatives of the sub-class Teleostomi is, however, to be found in the structure of the tins, seeing that scales of a similar nature are met with in the bony pike already described. In all these tishes the pectoral and pelvic fins consist internally of a jointed longitudinal axis, from which proceed a larger or smaller number of divergent rays belonging to the dermal system. On the under surface of the lower jaw there is at least one pair of jugular plates occupying the space left between its two branches. The nerves supplying the eyes when meeting one another in the middle line give off' interlacing fibres, and another primitive feature is the presence of a spiral valve in the lining membrane of the intestine. The air-bladder is provicled with a duct, this being probahly likewise a primitive character. Both the lising members of the order are included in the family Polypteride, which is characterised by the replacement of the

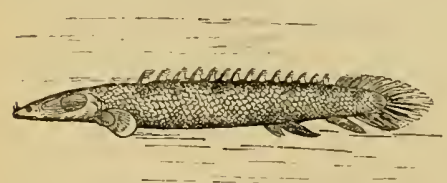

Fig. 35. -THE Bichir. primitive notochord by bony vertebrie, as well as by certain features of the skeleton which need not be noticed here. The tail is very short, and terminates in a cliphycercal fin; and the dorsal fin is peculiar in being split up into a number of finlets, severally supported by a spine in front, such finlets varying in the type genus from eight to eighteen in number. 
The anal fins are situated rery far back on the elongated body, so as to be separated by only a short distance from the candal. It is only in the pectoral fins that the lobate structure is visible externally, each of these consisting of a central scaled portion, surrounded on the free mirgins by a fringe of rays. The bichir, which grows to a length of four feet, is characterised by the moderate elongation of the body, and the presence of well-deroloped pelvic fins. These last are wanting in the much smaller reed-fish, which takes its name from the excessive attennation of the body. Information is much wanting as to the life-history of these tishes, although it is known that they lay small exrgs. If we may judge from the malogy of the Australimu lung-tish, which has a similar type of fins, it is, however, mobable that they are comparatively slow and sluggish in their movements, and live on, if not in, the mud at the river bottoms. In the late larval state, Polyptems, at any rate, develops a large extermal gill on each side, projecting backwards from the gill-opening. In addition to the fringing clorsill fin, the tubular nasal openings may be noticed as peculiar characters of the existing forms. It may be added that some authorities like Dr. Steindachner recognise more than a single species of bichir, one of them being named Poly/terws leprodei.

\section{STB-CLASS IV.-ELASHOBRANCHII.}

\section{SHaRks and RaYs.}

TuE drealed sharks are the types of a fairly large sub-class of fishes, which also includes the smaller but very similar dog-fishes, as well as the more aberrant saw-fishes, and the skates and rays. The latter are, indeed, so mulike sharks in general appenrance, that it is probable their aftinities to the latter are not generally recognised. Nevertheless, the two groups agree in all essential structural features, and are evidently very nearly allied. Perhaps the most characteristic feature of the sub-class, and the one from which it derives its title of Elasmobranchii, is the conformation of the gills and their inertures. Everybody knows the five rertical slits on each side of the neck of a $\operatorname{dog}$-fish. These are the apertures leading into the gill-chambers; and in the latter the gills themselves are attached by their margins to the skin. It will not fail to be noticed that in this type of structure there is nothing comparable to the gill-cover or operculum of the bony fishes and their allies. Still there is a rery important point of comnection between the Elasmobranchii and the Teleostomi ; this being a feature whereby these two subclasses are broadly distinguished from the Dipnoi and Holocephali. To explain this peculiarity in detail requires the use of a number of technical terms; and it must suftice to state that it is connected with the mamer in which the suspending apparatus of the lower jaw is attached to the skull; the attachment in this case being movable, whereas in the other two subclasses it is immovably tixed. It has been said above that the number of gill-slits in a dog-fish is five, and this number is very characteristic of the order generally. Still, however, there are a few exceptions, and the number of slits may be increased to six or even seven on each side of the neck. 
Although the strueture of the breathing apparatus alone is sufticient to distinguish the Elasmobranchii from all other fishes, it is advisable to glanee at some of the other leading structural features of their organisation. And here it may be mentioned that we allude only to the living forms, and that some extinct groups do not agree in all respeets with the eharacteristics of the sub-class as defined from the former alone. From the typical bony tishes, the Elasmobranehii are distinguished internally by the eartilaginous nature of the skeleton; such hardening as takes place in this framework being due to the deposition of calcareous matter in the cartilage, and not to the replacement of the latter by bone. In eonsequenee of this want of development of bony struetures, the primitive eartilaginous skull persists throughout life; and the functional jaws are bars of eartilage, which do not correspond with the bony jaws of higher ereatures. Teeth of the ordinary structure are developed on these spurious jaws; and sueh hard struetures as exist in the skin likewise partake of the nature of teeth, and are, therefore, very distinct from bone. Of this kind are the fine granules found in the skin of sharks, and the larger pustules, cones, knobs, or spines oceurring on that of many kinds of rays, where they are often arranged in a number of isolated prominent ridges on different parts of the back. From this remarkable absence of bone in the group, the name of boneless tishes would not be an inappropriate name for the sharks and rays. Owing to the number of minute tooth-like structures embedded in its surface, shark-skin forms an admirable polisher; and as it also affords a firm hand-hold, it is likewise used for eovering sword-hilts.

In their internal strueture the Elasmobranchii show a decidedly primitive type, in that where the two nerves supplying the eyes meet, there the fibres interlace to form a ehiasma. The formation of a spiral valve by the lining membrane of the intestine also seems to be a primitive feature. In no member of the group is an air-bladkler ever developed. Unlike ordinary tishes, sharks lay a small number of eggs, each of which is of large size, and is entirely separate from the other. Generally these eggs are invested in a hard, horny envelope, which is of an oblong shape, and furnished at each angle with a curling tendril, by means of which they become moored to the stems of sea-weeds or other submarine objeets, where they remain till the young come forth. The empty envelopes are frequently to be found thrown up on the beach, and are commonly known as sea-purses. In eertain species the eggs are, however, retained within the body of the female parent until hatehed, so that the young are born alive. While within the shell, young sharks and rays are provided with external gills, and thus resemble tadpoles, but these gills are always lost before birth. 'The upper surfaee of the head in many members of the group is furnished with the organs known as spilateles.

As regards the internal skeleton of the fins of the Elasmobranchii, it will suffice for our present purpose to state that the supporting cartilages are arranged somewhat in the form of a fan made up of flattened divergent rays, at the base of which are eertain other short cartilages. To the homologies of these latter it is unnecessary to refer in this work. In a few living sharks powerful spines-whose structure is also comparable to that of teeth-form the front portion of the dorsal tins, such spines being loosely inserted in the flesh, without any basal comnection with the vertebre. The pelvic fins are situated a long distanee behind the peetoral pair; and in the males the supporting axis of each of the former is developed, as in the Chimaroids, into a 
long conical elasper. The tail-fin is of the heterocereal type, with its upper lobe-which is traversed by the extremity of the back-bone-greatly dereloped at the expense of the lower one. As all are aware who have ever seen a shmk turn over on its back to seize its prey, in most members of the elass the month is situated on the lower aspect of the head, some considerable distance behind the tip of the muzzle. And a cruel mouth it is in the ease of ordinary sharks, where it is lined with row after row of sharp triangular teeth, of which the outermost stand upright in readiness for inmediate use, whereas those of the innermost rows are recumbent, and not destined to see active service until those near the margins lave been worn out and shed. Some sharks, like the Port Jackson species, have, however, the mouth placed in the ordinary position at the extremity of the muzzle, while the teetl-except a few at the front of the jaws-have low flattened, crowns, and form a milllike pavement adapted to grinding the shells of molluses and erabs. Rays, too, have pavement-like teeth of a still more markedly crushing type, although in the males of certain kinds the individual dentienles are eusped.

Sharks include the most predaceous and most dreaded of all fishes, and many of the rays are likewise formidable monsters, which have the power of inflicting terrible wounds by means of the poisonous spines arming the whiplike tail. Bodily size is, however, by no means a criterion of offensive power among the members of the sub-clisss, since the largest of all sharks, namely, the basking-sharks, are hammless species, whose terminal mouths are armed only with feeble teeth, and whose food consists chiefly of vatrious invertebrate animals. Skates and rays, which are bottom-hamting creatures, likewise feed on invertebrates, their grinding teeth being specially adapted for crushing shells. Althongh many kinds aseend tidal rivers for considerable distances, while a few have become adapted-probably owing to physical alterations on the earth's surface-to a fresh-water mode of life, the Elasmobranchii in general are marine fishes. Although, as alreally stated, the rays are found on the sea-bottom, while some sharks are met with at great depths, the majority of the latter group are essentially pelagic creatures, pursuing their prey at or near the surface of the open sea. The abumlance of food to be met with in the neighbourhood of frequented harbours renders these fishes generally more numerous in such localities than elsewhere.

\section{Order I.-Selachil.}

\section{SLE-ORDER I. - ASTEROSPONDIII.}

As all the existing members of the sub-class are placed in a single ordinal group, it will be umnecessary to enter into the consideration of the features by which that orler is distinguished from the extinct groups now included among the Elasmobranchii. It will accordingly suffice to point out the distinctive features of the sub-order Asterospondlyli, which includes the greater number of the sharks. The group takes its name from the structure of the bodies of the vertebre, which in section show a star-like arrangement of the calcareous plates forming their internal support, such radiating plates being considerably more numerous than the circular ones running parallel to the outer surface. The members of this sub-order are characterised exter- 
nally by the long and nearly cylindrical body, the powerful rudder-like titil, the presence of an anal fin, the moderate dimensions of the pectorals, and the small size or alssence of the spiracle. In consequence of the divergence of the two branches of the jaws, the teeth form oblinue rows, and at least the teeth in the front of the jaws are sharp-pointed, their general form being a much tlattened cone, with or without lateral cusps at the bitse.

In the family typified by the formidable blue shark there are no spines to the fins; the first dorsal fin is placed immediately over the space separating the pelvics from the pectorals, the teeth have hollow crowns, Family and are generally sharp-pointed, the mouth is inferior, the Carchariule. skin is of the shagreen type, and the eyes are fumished with a nictitating membrane, which fulfils the function of an eyelicl. The linits of onr space forlsid giving the distinctive features of the various genera included in this family. The blue shark (Curchurias glancus)

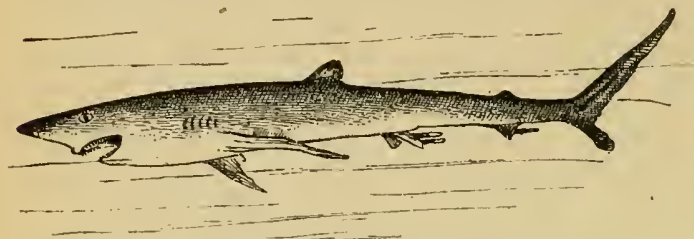

Fig. 3t. -BLUE S̈HAK. is the most familiar representative of the type genus, while the strange-looking hammer-headed sharks form another genus (Sphyrne), distinguished from all other tish by the peculiar flattening and lateral expansion of the muzzle into a pair of projecting lobes, each bearing an eye at its apex. These sharks grow to a length of about fifteen feet, and are fairly abundant in the warmer seas. The genus Guleus, in which the head is of normal form, includes small sharks, represented in British waters by the tope (G. cunis). Other small British sharks known as hounds (Mustelus) differ exterually by the more blunted form of the muzzle. Unlike the species of Carcherias, these sharks hamnt the bottom of shallow seas, where they feed on shell-fish, crabs, etc. They produce living young. Stories of the ferocity of the various kinds of large carnivorous sharks are so numerous that it is difticult to make a selection. The following aneclote by the well-known writer, Mrs. Bowdich, is, however, of special interest, as illustrating the indifference to the near presence of these terrible monsters which seems to become habitual to the natives of many of the warmer coasts. "Sharks abounded at Cape Coast," writes this lady, "and one day, as I stood at a window commanding a view of the sea, I saw some of the inhabitants of the town bathing, and the sharks hastening to seize upon them-they being visible from always swimming with part of their dorsal in out of water. I sent to warn the men of their danger, and all came ashore except one, who laughed at the caution of his companions. A huge shark was rapidly approaching, and I sent my servant again, and this time armed with half a bottle of rum to bribe the man to save himself. It was too late. 'The mur. derous creature had seized him, and the water around was dyed with his blood. A canoe was despatched to bring him ashore, but a wave threw him on to the beach, and it was found that the shark had taken the thigh-bone completely out of the socket. The man, of course, expired in a few minutes. Accidents were often happening, and always fatil, and yet the negroes, who 
seldom think beyond the present moment, conld not be dissumled from bathing. A man walking in the sea up to his knces was dragged awaly by one almost before my eyes."

From the Curehuriilu the members of the allied fimily Lamnide differ by the solid crowns of the fully developed teeth as well as by the absence of it nietitating membrane to protect the eye. The typical representative of the family is the well-known porbeagle (Lammu cormubicre), a species widely spread in the seas of

Family Lammide. the Northern Hemisphere, where it feeds on fishes, which are bolterl whole. It seldon grows to more than about ten feet in length, and is believed to produce its young alive. Far larger is the gigantic Curcluredon rondeletii, whieh may attain the enormous length of forty feet, and is in truth the giant of the carnivorous sharks. It has huge, flattened, triangular teeth of great depth ; but as teeth of similar type, although of mueh larger dimensions, are met with in various superficial deposits, as they are also in some of the ocean abysses, it is evident that the living speeies is only an unworthy representative of its aneestor's. It is, however, quite large enough, and we may be thankful that its still more gigantic predecessors have disalppeared from the scene. Much smaller, and with a different type of teeth, me the two species of the allied genus Odontrspris. Next comes the thresher or fox-shark (Alopecius milpes), a species growing to a length of about fifteen feet, and easily reeognised by the excessive development of the upper lobe of the tail, which forms more thim half the total length of the ereature. It has feeble teeth, and feeds on mackerel and other fish, which it drives together by striking the surface of the water with its tail, whence the name of thresher. Sailors state that threshers also harass whales by jumping up in the air, and dealing them somding "whacks" with their tails in their descent. But this nituralists, who are for the most part an incredulous raee, stontly refuse to believe. However, we think that, as in the case of adder's swallowing their young, popular observation is more likely to be in the right than conclusions drawn from the study of museum specinens. To the same family belongs the gigantic basking-shark (Cetorlinus maximus) of the North Atlantic, commonly met with off the west coust of Irelind, and attiining a length of fully thirty feet. This shark, which has very minute teeth, is characterised, among other features, by the small size of the anal and second dorsal fins, and the large dimensions of its gill-shits. It is a somewhat sociahle species, fluating motionless on the surface of the sca in calm sunny weather. On account of the large quantity of excelient oil yielded by its liver, it is a regular oljject of pursuit.

Another species (Rhinodon t!mpicus), commonly known by the same vernuevlar name as the last, forms a family by itself, being distinguished from all the foregoing members of the order by the terminal position of the mouth, which is of huge size, and somewhat reminds ns of an open square-topped bag. The eyes are extremely minute, the teeth feeble, and the whole budy much depressed, with the first dorsal tin relatively small, and placed behind the highest point of the back, nealy above the pelvic pair. Still smaller is the second dorsal, which is situated near the tail, just over the anal. ln spite of its huge dimensions, fifty feet or more, this shark is a perfectly harmless creature. It probably feeds on small fishes and varions invertebrate animals. It appears to be confined to the Indo-Pacific seas, where it is common in the neighbourhood of the Seychelles. 
The dog-bishes and allied members of this family differ from the foregroing sliarks with the mouth terminal by the backward position of the second dorsal fin which oecupies a position immediately over, or

Family s'cyl- behind the line of the pelvic pair. The teeth, of which liidr. several series are generally in use, are of small size, the eye lacks the nictitating membrane, and spiracles are present on the head. The dog-tishes, of which there are two species from British waters, form the genus Scyllium; most of the species having their skins elegantly spotted. Much larger is the Indian zelora-shark (Steyostomu), growing to some fifteen feet in length, and taking its name from its zebra or tigel-like eoloration. Mention must also be made of the sharks of the genus Cirssorhinms, from Japan and Austialia, not only on aceount of the eircumstance that they are deep-water forms, but likewise from the presence of leaf-like ontgrowths of the skin of the sides of the head; suel appendages being probably for the purpose of attracting prey within reach of the jaws.

The Port Jackson shark, togrether with three allied species, form the genus Cestracion (or more properly, (estracium ${ }^{1}$ ), which now alone comstitutes a family easily recognised by the peculiar character of the - Family dentition, and likewise by the presence of a spine in the Cestraciide. front portion of each domsal fin. Whereas in the forepart of both jaws the numernus lows of teeth are shal'p and cusper, wn the sides and hinder legion they for'm a parement-like strueture, ar'ranged in oblique rows; the teeth in some of these rows being much larger than

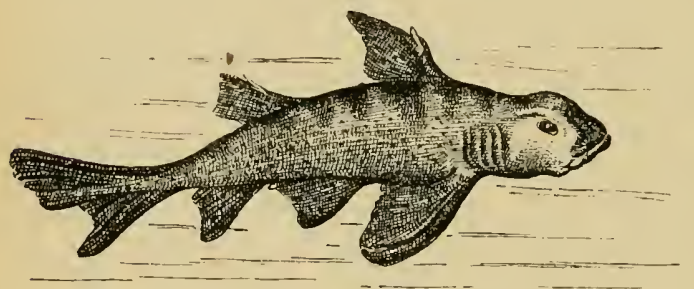

Fiy. 37.,-POKT JACKson SHARK. in the others. The mouth is situated at the extremity of the muzzle, and the eye is unprovided with a nictitating membrane. Thesesharks, which do not grow to more than abont five feet in length, are widely distributed in thewarmer seas. Although we are still very ignol"ant is to their life-history, it is known that their food is principally composed of shell-tish, and also that their eggs are minlike those of other members of the order, their enveloping membranes being twisted into the form of a serew.

The two genera of sharks eonstituting this small sub-family stand aprart from the other members of the sub-order in regatd to the manner in whieh the jaws are artienlated to the cranium, while externally Family they are realily distinguished ly the mumber of gill-clefts Notidanidu. being increased from the normal five to either six or seven, and also by the single dorsal tin. There is no spine to the latter, and the teeth are eusped, and form several series. The typical genus Notidums includes four species, chinacterised by the simple gill-slits and the complicated structure of the teeth, which consist of an elongated base

1 The name of the family is commonly given as c'ctraciontidu, but it should be as written here. 
cinying a large number of eusps, these latter gradually diminishing in height from one end of the tooth to the other. 'The notochord remains in its original condition throughont the greater' jart of the backbone. 'These sliarks, which may grow to aloout fifteen feet in length, are to be found in most of the wammer seas. In the second gronus, Chlumydoseluche, which is represented only by a single species from the Japanese seas, the six gill-slits lave frill-like expansions of skin on their margins, the teeth are of simpler structure, and the body is so long and slender as to be almost eel-like.

\section{SUB-ORDER II. -TECTOSPONUTLI.}

In this sub-order-which includes the spiny dog-fishes, siw-fishes, and the rays - the vertebre, when fully developed, have their calcareous plates so aranged that in crosis-section the circular ones predominate orer those that radiate from the centre to the circunference. None of the members have an mal fin, but the spiracles are large. In the rays the body is characterised by its extreme depression, and the pectoral tins are developed into huge flaps bordering its sides.

While agreeing with the other members of the sub-orler in the structure of the vertebra, the species forming the family spinucide are externally like sharks. The gill-clefts are small and lateral in position, the spinaeles are situated behind the eyes, and there are two dorsil fins, which. maly be furnished in front with spines. In addition to the typical genus spinax, the family includes the

spiny dog-tishes (Aconthias), taking their name from the presence of spines to the dorsal fins, and likewise the Greenland shark (Lomrorgus). Whereas the spoiny dog-fishes do not exceed about four feet in length, the latter species grows to as much as tifteen, and has no spines to the hos of the back. It has a peculiarly tuberculated skin; and whereas the upper tecth are small, those of the lower jaw are taller, and have their tips bent to one side. Nearly allied is the spiny shark (Echinorhimms) of the Atlantic and Mediterinanean, in which the upper and lower teeth are alike.

The monk- or angel-' sh (Squatiure velyuris) is the sole member of a family which serves to comnect the last with the true lays. This ugly fish has a depressed skate-like hody, but a nearly terminal nouth, and the pectoral bns not connected at thein bases with the head. The conical teeth are sharply pointed, the gill-slits are lateral, the skin is tuberculated, and the dorsal hus, which have no

Family Squatinide. spines, are placed on the tail. The monk-tish reaches a leugth of fully five feet, and is found in nearly all seas.

The production of the extremity of the upper jaw into a long, flattened bouy process, armed on each side with sharp quadrangular teeth set in sockets, selves at once to distinguish the saw-tishes from all their kindred. They form two genera-Pristiophoms and Pristis-each of which is regarded as representing a family by itself, although such a division certainly seems somewhat

Families Pristiophoride" and Pristidu. superfluous. The member's of the first genus are relatively small tishes from the seas of Australia and Japan, characterised, among other features, by the lateral situation of the gill-slits, and the possession of a pair of tentacles arising from the middle of the jaw, and projecting far beyond the 
teeth. In the second genus, of which various member's range through all the warmer seas, the gill-slits are placed on the inferior aspect, and there are no tentacles to the saw. Siw-fishes of this genus grow to twenty feet or more in length, when their offensive weapon may measure as much as a couple of yards. They are some of the most terrible and cruel members of the whole order, using their formidable saw for the purpose of ripping

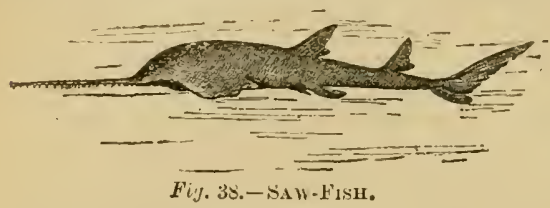
open the hodies of their victims by a lateral stroke, and then feeding greedily on the intestines and torn thesh. Even bathers in fresh waters are by no means exempt from their attacks, as these fishes frequently ascend large rivers to a considerable distance.

The genera of beaked rays constituting this family differ from all the preceding groups by the much greater develropment of their pectoral fius, which extend forwards to join the head, the portion of the head Family and body thus surrounded by fins being technically termed Rhinobatide. the disc. In these and the other rays referred to below, the dorsal fins are shifted backwards to the more or less whiplike tail, and the gill-slits are placed inferiorly, as is generally the mouth. The Rhinobatide are specially distinguished from their kindred by the moderate development of the pectoral fins, of which the portion furmished with cartilaginous lays does not extend forwards to the beak; and the long; tail, which is marked on the sides by a fold of skin, earries two large dorsal fins. In addition to the typical genus Ihinobatis, which includes a considerable number of' species from all the warmer oceans, the present family con1prises the Australian Trigonorhina and the two species of Iihynchobutis, from the hottest regions of the Indian Ocean. The list-named is remarkable for' the beantiful structure of its teeth, which form a compact pavement, with a prominent ridge in the middle line of one jaw fitting into a corresponding depression in that of the other, and also having undulations at the sides. From six to eight feet is a common length for these rays. Like the skates and rays of the following families, the members of these genera are somewhat sluggish fishes, living near the bottom in water of moderate depth, and flapping lazily along when in movenent by the aid of their huge pectoral fins, the tail acting merely as a rudcler. When at rest, the colour of the upper surface of a ray's back is so like the sand ox mud on which the ereature rests that it often requires a practised eye to detect its presence. The ridges of tubercles found on the backs of some species probably increase the resen. blance by simulating lines of small stones on the sand. The food of rays consists of shell-fish and various crustaceans, whose hard shells are instantaneously ground up by the powerful mill-like jaws. In seizing their prey, these fish throw themselves right above it, so as to be able readily to convey it to the mouth, which is situated on the lower surface of the head some considerable distance behind the muzzle.

The second family of rays includes the genera Picia, Psommobutis, and Platyrtina, in all of which the disc is very broad, with its rayed portion extending as far forwards as the muzzle, while the tail is Family Raiidu. marked on each side by a fold. Very generally the skin is roughened by tubercles, which may terminate in spines. To 
the typieal genus belongs the common thornback skate of the British seas, in which the two sexes are distinguished by the strueture of the teeth, those of the female forming a comparatively smooth pavement, whereas those of the mile-althongh still arranged in the same mamer-are cusped. In other species of the same genus sexual differences display themselves in other parts of the body. Skates of this genus are more abundant in northern than in tropical seas, and some of them range considerably farther north than any other members of the group. The flesh of all is largely used as food.

The presence of an electric organ,

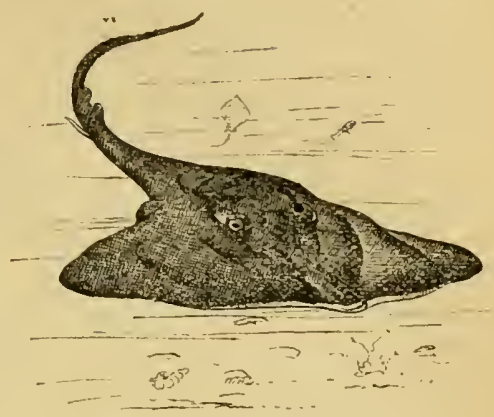

Fig. 39.-THORNBACK SKATE. composed of vertical prisms, between the head and the pectoral fins, serves to differentiate the numerous kinds of electric rays from the other representatives of the group. The body of these fishes forms a broad, smooth dise, eovered with a naked skin; the tail has a longitudinal fold on each side and a caudiul fin, and

\section{Family \\ Torpeclinieler.} there is generally a rayed dorsal fin. The rertical prisms of the electric urgan are divided by a number of horizontal partitions into separate cells, each filled with it translucent substance somewhat resembling jelly in appearance. The currents produced by this singular structure are precisely similar to those from a galvanic battery; and in fishes of moderate dimensions are sufticiently powerful to disable even human beings. The typical genus Torpeto includes half a dozen species from the Indian and Atlantic Oceans, some of which are also abundant in the Rediterranean, while one occasionally wanders to the southern shores of Britain. From the warmer seas there are also sereral other genera belonging to this family, such as Astrape, Diseopyge, Hypmus, Nureine, and Temeru, severally distinguished by the conformation and position of the fins.

The largest and most hideous of all the skates are the so-called eagle-rays, several of which are popularly known as devil-fish. In the five genera included in this family the pectoral fins obtain an enormous development, in consequence of which the dise becomes greatly widened. Along the sides of the head the pectoral fins are, howerer, interrupted ; their anterior extremities forming small tinlets on the muzzle, known as cephalic fins. In sone of the genera these cephalic fins are modified to form a pair of hom-like structures projecting forwards on each side of the muzzle, the function of which is to assist in capturing and conreying to the mouth the prey. In all, the tail forms a long, tapering, whip-like organ. When the mouth is armed with teeth, these take the form of a pavement, which in the typical genus Myliobretis is perfectly smooth, and composed of a number of oblong and hexagonal plates, fitted closely together at their edges, and with their grinding surface like polished ivory. Sereral wilely-spread speeies are included in the typical genus, two of which are visitors to the British cuists. Most of them have a harbed spine to the tail, and with this, when caught, they lash out 
violently, and thus inflict severe wounds. In eomparison with the electrie rays - in which the width of the dise seldom exceeds from two to three feetthese fishes are giants, their length being at times as much as fifteen feet. The tropical deril-fishes forming the genera Dicerobutis and Cephulopterce are, however, still more gigantie, some examples measuring uearly twenty feet across the dise, and weighing considerably more than a thousand pounds. In Dicerobutis the truncated muzzle is arned with a formidable pair of horms, the mouth is inferior, and has both its jaws furnished with teeth. On the other hand, in Cephalopterce, the position of the mouth is terminal, and there are teeth only in the lower jaw. Of these ungainly monsters, Mr. S. Ward, in a letter quoted by Dr. Percival Wright, describes his experiences in the Seyehelles as follows:- "Coming home, we passed elose to an enormons diable-de-mer floating quietly about. We changed from the pirogue to the whale-boat, whieh I had scientifically fitted up for the grosses poissons, and went alongside of him, driving a regular whale-harpoon right through his body. The way he towed the whaler was beantiful, but we would not give him an inch of line, and he liad to succumb to a rather protracted laneing. His size will give you an iclea of his strength in the water-forty-two feet in circumference. We got him awash on tlie beach, but the united strength of ten men could not get him an inch farther, so we were obliged to leave him there. By this time the sharks will not have left much of him; they have not had such a meal for a long time. The fishermen say that, when alive, the sharks do not molest the iliuble-le-mer; whose offensive weapons consist of their enormous flexible sides (one ean hardly eall them tins) with whieh they can beat almost any shark to death. As a rule, when harpooned, they endeavour, like other rays, to bury themselves in the sand, and if they succeed in doing this, no line can ever haul them out of it--their flat bodies act on the prineiple of an enormous sucker. Another curious fact about them is that when harpooned, they swim sideways, edge-on, in order to avoid exposing too broad a surface to the enemy. They never do this unless harpooned." Other genera are Aëtobutis and Rhinopteru, both distinguished by the dentition and the position and form of the fins. Whereas the former of these has but a single species, the latter possesses several.

The last existing representatives of the Elasmobranchii are the formidable and dreaded sting-rays, which are typified by the genus Tringon, but also include Pterophuter, Urogymmus, and Urolophris. In species Family the typieal genus is very numerons, some of these having a Trygonile. very wide geographical range. They are mostly tropical, and attain their maximum development in the Atlantic Ucean and the Indian seas. It is remarkable that certain species inhabiting the eastern districts of Tropical America have become accustomed to a freshwater existence, and are now restricted to eertain inland lakes. All these fishes are distinguished by the excessive development of the fore-part of the pectoral fins, which are so extended as to encirele the muzzle, and thus complete the dise. The whip-like tail is distinetly marked off from the body, and generally bears a poisonous serrated spine; and in many kinds the median fins-which are never large-are replaced by similar spines. These armed rays are some of the most dangerous of all fishes. 


\title{
SUB-KINGDOM I.-VERTEBRATA.
}

\author{
CLASS VI.-CICLOSTOMATA.
}

BY R. LYDEKKER, B.A., F.R.S., V.P.G.S., de.

\section{LAMPREYS AND HAG-FISHES.}

As indicated by the name hag-fishes, which is popularly applied to the members of one of the two fanilies, the animals now to be considered are commonly reganded as tishes. Popular natural history and scientific zonlogy take, however, very different estimates of the mutual relationships of organised beings; and zoologists are now pretty well agreed that, although they were formerly admitted within its limits, lampreys and hag-tishes have $n o$ real claim to be included in the class Pisces. Conserfuently, they are now regarded as forming a elass by themselves-the Cyclostomatil. This class includes the last grotup of animals now termed true Vertebrata; the lincelets, which were likewise fornerly regitrcled as fishes, being now considered as the highest of the Protochordati or semi-Vertebrates. The essential features by which the members of the lamprey group are broadly distinguished from the higher classses of the Vertebrates are the eomplete absence of jaws, the single -instead of double-aperture of the nostrils, and the rasping tongue. Round-moutlis-the English equivalent of Cyclostonata-is it name which well expresses the first of these three distinctive features; but, in allusion to the second characteristic, the alternative name of Monorhina has likewise been proposed for the elass. Whicherer name may be selected, there ein be no doubt as to the right of the lamprey group to eonstitute a class by itself. Hatd we these living forms alome to deal with, there would be no need to sub-divide the class into groups of higher rank than families. It happens, however, that there are certain extinct, somewhat fish-like creatures, which there is eonsiderable reason for regarding as more or less distantly related to the modem limpreys. Consequently, it is necessary to make the latter into a sulb-class by themselves; and for this sub-class the name of Marsipobranchii has been selected. This name refers to the circmmstance that in the lampreys and liag-fishes the gills form a series of ponches on the sides of the neck, on which they usually open by round apertures coincident in number with the pouches. Either six or seven is the number of pairs of gill-ponches, in which there are no supporting gill-arches. The suckingmouth, which occupies the extremity of the muzzle, is of circular. form, with its more or less lip-like margin sustained by a system of internal eartilages. The skin of the body is soft, and unprovided with scales; but the upper and lower surfaces of its hinder half hear well-developed fins in the middle line, which are supported by vertical rays of cartilage. Paired fins-corresponding to those of fishes and representing the limbs of the higher Vertebratesare, however, conspicuous by their absence; this lack of limbs forming, indeed, a characteristic of the class rather than a feature of the sub-class. Internally, a lamprey lacks all traces of ribs. and the vertebral eolumn is either represented by the primitive notochord alone, or hy that structure surrounded by a series of calcareous rings. In reality, therefore, a lamprey 
has only the very remotest claim to be called a vertebrate animal; but since some of the sharks are in a very similar predicament as regards the differentiation of their backbones, this deficiency can scarcely be regarded as a bar to the title. The heart of a limprey is decidedly of a lower type than that of a tish, since it lacks the chamber at the front end technically designated the bulbus arteriosus. The digestive tract is peculiar in being quite simple and straight; and the orgaus of reproduction discharge their products directly into the general cavity of the body. The function of teeth is discharged by a variable number of horny plates or cuspss.

As a family, the lampreys are distinguished from the hag-fishes by undergoing a metamorphosis, and by the nostril terninating behind as a blind sac without perforating the palate. In the adult form rasping

Lampreys. - horny teeth cover the tongue, and teeth of similar structure Family Petromyzide. are present above and below the mouth, as well as in the surrounding adhesive disc, while the aperture of the nostril is situated near the middle of the head, and there are welldeveloped eyes. The gill-pouches are seven in number, and each opens by a separate aperture on the side of the neck; but internally those of each side lave only a single opening into the pharynx, their ducts uniting to form one tube. On the other hand, the larve, which were long regarded as distinct creatures, under the name of Ammocretes, have an uncivided median fin, and toothless mouth. All the members of this family lay very small eggs, and the lining membrane of the intestine forms a spiral valve. The true lampreys, or those inclurled in the genus Petromyjum, appear to be four in number, and have a wide range in the Northern Hemisphere, one extending as far south as the west coast of Africa. In this genus the hinder of the two fins on the back is continuous with the tail-fin; the rasp-like teeth on the tongue are serrated ; and on the upper side of the mouth there is either a transverse liorny ridge bearing one two-ensped, or two separate teeth situated close together. The largest form is the sea lamprey ( $P$. murimm $)$, which is not unfrequently as much as three feet.in length, whereas the common river lamprey ( $P$. fluciutile) does not reach a comple of feet. Lampreys live chiefly or entirely on the flesh of fishes, to whose bodies they attach themselves by their adhesive discs, and then rasp off the flesh with their horny dental organs. All aseend rivers for the purpose of breeding, and the larva of some kinds remain in fresh water until they develop into the adult form. At the breeding season some lampreys ascend the rivers of the Northern Henisphere in vast shoals. They deposit their eggs in furrows excavated in the river bottom. Another genus (Morducira) is represented by a species found in localities as remote from one another as the coasts of Tasmania and Chili, and differs in that the teeth above the month are arranged in two three-cusped groups. In the allier genns Geotriu, of which one species is found in South Australia, and the second in Chili, the hinder fin on the back is distinet from the tail-fin. The last genus is the little-known Exomegar, from the Argentine coast.

In this family the nostril is extended backwards to perforate the palate. and its front apcrture is placed close to the muzzle. Two pairs of harbels decorate the sides of the muzzle, the mouth has no lip-like

Hag-Fishes. Family Myxinide. structure, a single tooth occupies the middle of the palate, and the teeth on the tongue are arranged in a double comblike series. Each gill-pouch opens lyy a duct of its own into the pharynx, and the external apertures of the pouches are 
situated a considerible distance behind the head, instead of close to it. The eggs differ from those of the lampreys by their relatively large size, as well as loy having a horny coating furnished with tendrils for the purpose of attichment to submerged objects. The young are hateherl in a fullydeveloped state, and undergo no metamorphosis. In the members of the typical genus Myxine there is only one gill-aperture on each side of the body, but this gives rise to six ducts leading to the gill-pouches. On the other hand, in the genus Bdellostoma ench of the six or more gill-pouches communicates directly with the exterior by a separate aperture. Whereas the members of the first genus have a wide gengraphieal range, the two representatives of the second appear to be contined to the coasts of the South Pacific. All are exclusively marine, and they have been taken at great depths. They are blind, and to a large extent parasitic, so that they may be regarded as degraded types; and they have the labit of secreting a vast quantity of stiff slime. Like the lampreys, they feed on the flesh of fishes, the various members of the eod tribe being their especial favourites. They do not, however, content themselves by hanging on to the surface of the body, for which the structure of the mouth is less suited, but actually bore their way into the flesh of their unwilling hosts. 


\title{
SUB-KINGDOM I.-VERTEBRATA.
}

\author{
CLASS VII.-PROTOCHORDA.
}

By W. Garstang, M.A., F.Z.S.

\section{SUB-CLASS I.-CEPHALOCHORDA.}

Tнғ group Cephalochorda contains a number of small marine animals which resemble tishes in many respects, but are much more lowly organised than even the simplest of the finny tribe. They breathe like fishes by taking water into their mouths and passing it out through a series of slit-like holes in the sides of their throats (gill-slits). The number of these gill-slits is much greater than in fishes, frequently amounting to more than a hundred. A supporting rod, the notochord, the forerumer of the lackbone of higher forms, extends along the baek of the animal from head to tail, and the tubular nervous system lies above it. There are no true side-fins, but a pair of ridges along the under side of the body of the young animal possibly represents them. In the very young animal the gill-slits open directly to the outside, but at an early period the fin-like ridges, which have just been mentioned, elose over the slits and unite with one another on the under side of the body, leaving merely a small hole or water-pore for the outflow of the water. These little animals are capable of extremely rapid movements, wriggling their lancet-shaped bodies from side to side after the manner of an eel. They have no jaws, and depend for their food upon the microseopic plants and other organisms contained in the stream of water constantly passing throngh their mouths. This current of water is set up by the action of innumerable fine whip-like lashes which beset the sides of the gill-slits, and by their united action drive the water outwards into the surrounding watereavity, and so to the exterior through the water-pore. New water is constantly streaming into the mouth to take the place of the water driven out, and the food-particles it eontains are incessantly extracted from it by means of the slimy coating of the walls of the throat, to which they adbere. Another set of microscopic lashes then drives the entangled food-partieles down the proper ehannel to the animal's stomach, where they are digested in the ordinary way.

The lancelet (Amplioxus lunccolutus) is the only representative of the group in the Mediterranean and North Atlantic seas. It is a semi-transparent little ereature, from one to two inches in length, eompressed from side to side, pointed at both ends, provided with a circle of small stiff tentacles round the mouth, and with a distinet tail-fin behind. It lives in shallow water, in beds of loose sand, into whieh it burrows with lightning-like rapidity. It lies

Fig. 1.-The LanCelet (Amphineus lanceolatus).

obliquely on its back in its sancly bed, its head and mouth alone protrnding 526 
above the surface. These habits clearly provide the reason why the delicate gill-slit region of the body should be protected from injury and enclosed within a special chanber, formerl by the union of a pair of fin-like ridges.

Other representatives of the group, closely resembling the European lancelet, are found in shallow seas all over the world. A peculiar type (Asymmetron lucuyumum), which possesses a slender backward prolongation of its tail, is found in the Bahamas, where it may be taken swimming freely at the surface of the sea at night, or in the day-time buried in the coral sand.

\section{SUB-CLASS II.-UROCHORDA OR TUNICATA.}

ThIs group of exclusively mine animals is closely related to the Cephalochorda, althongh its various representatives are very unlike Amphioxus in their final shape and appearance. They agree with Amphioxus, however, in having similir organs for breathing and feeding, and in having a similar tubuliur nervous system and supporting rod along the back of the body. Unlike Amphioxus, however, the primitive backbone or notochord of 'Tunicata is confined to the hinder part of the body, which is in the form of a wellmarked tail like that of a tadpole. The body also possesses the power of producing a gelatinous envelope or tunic called the test, which clothes the animal either loosely as in Appendicularians, or closely as in all others. The group consists of two principal sections, which may be called the Tailed and Tailless Tumicata.

The members of the first section (Appendicularians) are free-swimming, and retain their tails with the nerve-cort and notochord during their whole

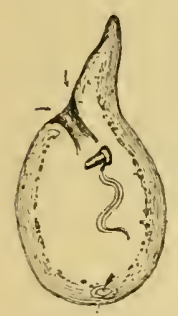

Fig. 2.-Ax A PPENDICULARIAN (Oikopleura). In its house. career. They are very small and inconspicuous creatures, the body being about the size of a small pin's head, and the tail less than a quarter of an inch in length, and the whole animal is of glass-like transparency. The tunic is thin, and forms a delicate "house" in which the Appendieularian swims about, and from which it can escape when attacked by its enemies. These creatures can often be caught at the surface of the sea round our coasts by the use of a fine muslin net.

The members of the second section, the Tailless Tunicata, are tailed only in their early stages. After a brief free-swimming career they lose their tails, like the tadpoles of the common frog, and grow up into soft back-boneless animals of a quite different appearance. Some of these tailless forms retain, or regain, their free-swimming habits, and usually acquire a barrel-like shape and

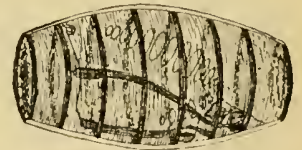

Fig. 3.-Doliolum Tritonis. a number of hoop-like muscle bands, by the contractions of which they drive themselves through the water (Salps), or they may form definite colonies and float idly about at the mercy of the waves (Pyrosoma). The majority of the Tailless Tunicata, however, become permanently attached to rocks, stones, and sea-weeds on the sea-bottom, and are especially abundant between tide- 
marks round our shores. They are known as Ascidians or sea-squirts, and they may be either solitary or colonial. The solitary forms are sac-shaped, leathery creatures fastened at the base, and posscssing a mouth at the opposite

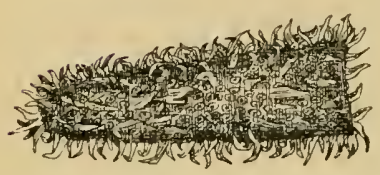

Fig. 4.-PYRosoma.

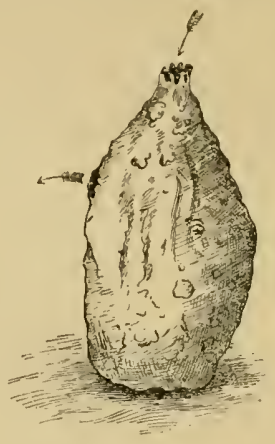

Fig. 5.-Common Sed Squint (Ascidielle (cspers(t).

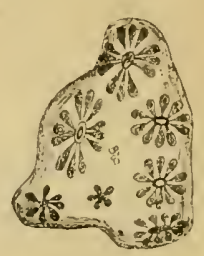

Fig. 6.-Botryllus

end. There is also another opening by which the water from the gillslits is passed out of the body. The colonial forms are smaller in size, and are united togcther into irregular or star-shaped clusters usually brightly coloured.

\section{CLASS VIII.-HERMICHORDA ON ENTEROPNEUSTA.}

THE commonest representative of this group is the remarkable Balanoglossus, an animal which combines the creeping mud-burrowing habits of a worm with some of the organs especially characteristic of vertebrata. The body is divided into three parts, a flexible

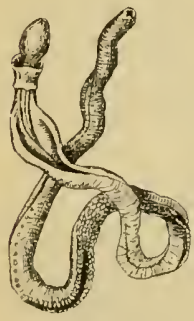

Fig. 7.-BALANoGLOSSUS SARNIENSIS. tongue-like proboscis in front of the mouth, a raised collar behind it, and a long cylindrical hind-region, the sides of which are perforated by numerous inconspicuous gill-slits. In the back of the collar of Bulanoglossis a short tubular nerve-cord is found like that of vertebrata. In its young condition Balunoglossus is a small transparent creature, about one-tenth of an inch in length, remarkably similar to the free-swimming larval form of starfishes and sea-cucumbers.

Bulunoylossus has only once been taken

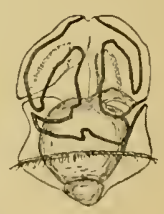

on the coast of the British Isles, but is Fig. 8.-Tornaria. not uncommon on the shores of the Channel Islands and other parts of the world. Bulanioglossus sumiensis, found in the Channel Islands, varies from one to three feet in lengtl, and is difficult to obtain in a perfect condition, owing to its softness and fragility. The young form, Tomaria, may be found in the autumn months free-swinming at the surface of the sea off the southern shores of Great Britain. 


\title{
SUB-KINGDON II.-ARTHROPODA.
}

\author{
CRUSTACEA, INSECTA, ¿C.
}

By W. F. Kınвy, F.L.S., F.E.S., \&c:

The Aithropodre (otherwise called Articulute or Amulosa) include an enormous number of animals with an external skeleton, or, at least, a thickened integument to which the muscles are attached; and a body divided into segments, and furnished with jointed organs for locomotion, etc. Many of them undergo a metamorphosis, passing through several dissinilar stages before reaching the perfect state in which they become sexually mature, and capable of reproducing their kind. The sexes are generally distinct. They breathe by trachea, or by gills, and the nerrous system consists of a series of ganglia, of which the largest, situated in the head, are considered to correspond to the brain. The bluod is usually white.

The following clisses may be grouped under this lieading :-

I. Crustacea (Crabs, Lobsters, Shrimps, etc.).

II. Arachniba (Spiders, Scorpions and Mites).

iII. Mrkiofod (Centipedes and Millepedes).

Classes of Arthroroda.

\section{Protracheata.}

V. Insecta (Insects).

The characters of these classes are noticed in their places, and to enumerate them here would be repetition. It must not be forgotten that all organic beings show complicated affinities all round, and that no linear arrangement can possibly be natural, and, therefore, we can only follow what appears to be a fairly natural sequence, always remembering that by laying stress on some characters we are necessarily ignoring others of perhaps equal or greater importance; and sometimes widely separating creatures which, when looked at from a slightly different point of view, are seen to be closely allied.

Space at disposal necessarily limits this article to a brief sketch of a vast subject ; but care has been taken to preserve a certain proportion in allotting the space to the different sections of which it is composed, and the information given, though far from exhaustive, will be found to be useful and instructive. The selection made is that of the most important and interesting groups into which these animals have been divided. These are dealt with in the order given above, and are illustrated by numerous original drawings reproduced in most cases life size. 


\section{CLASS I.-CRUSTACEA.}

THe Crustrect may be considered as the marine representatives of the Insects; for although a few insects are marine, and some Crustacee are found on land "1. in fresh water, yet an overwhelning preponderance of the ('instuceu are exelusively marine. In the perfect state they are covered with a hard jointed shell. Sometimes the heal is mited with the thorax, as in the class Arachmich, but it is more often sejarated. Heing water animals, Larval Forms of or living with few exceptions in damp places on land, they

Crustacea. breathe with gills. They have generally two eyes, two pairs of antenne, three pairs of jaws, three pairs of fort-jaws, the two outer pairs of which often serve the purpose of legs, and five pairs of legs. Most of the species undergo a preculiar metamorphosis, like that of the Barnacles, which has led to the latter

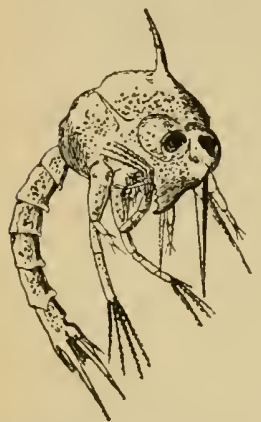

Fig. 1.-Zoea-Larva of SPIDER-Crab (Maia Sruincedo). Magnified. being now classed as retrograde Crustucer. These larral forms are generally cilled Narplins, or Zoeu, these names having been given to them when they were tirst discovered, and were supposed to be perfect urganisms. They have large eyes, and curious bifid appendages terminating in long bristles, and utilised as swimming feet. The Nanplins-form (compare Fig. 5) shown by many Crustecea on emerging from the egg, is oval, with a single eye, and it gradually acquires three pairs of limbs. In the Copepode and Ostracorle it passes gradually into the perfeet state by suecessive moults; but in the Siphomostoma it undergoes a retrograde metamorphosis, lusing the eyes, and limbs, as locomotive organs. This form of larva is seldom met with among the Decapoda. The Zueu-form of larra has seven pairs of jointed appendages, of which the foot-jaws are very large; and two large eyes. (See Fig. 1.) When the Zoer was first discovered, it was thought to be a cleature of the greatest rarity and interest, and it is amusing to read in the old books of the capture of single specimens of a Zoea at intervals of years, in clistant parts of the globe. Now they are known to be simply the larval forms of many of our commonest Crustecee. Similar unexpected discoveries perhaps still exist, in the ease of other. as yet unsuspected, inhabitants of our globe.

C'rustacea are carnivorous or omnirorous, and some of the smaller kinds are parasitic. Some Crustacen are of very small size, while others are the largest of known Arthropode. Their average size is considerably above that of insects. There are probably no species which can be considered actually injurious to man; but many are of considerable economic importance. Crabs, shrimps, lobsters, prawns, and crayfish are the only Arthropode which form staple articles of diet among civilised nations at the present day, though there is no reason why locusts and large wood-feeding grubs

Edible Arthropoda.

by the Romans. and caterpillars should not be eaten. Locusts have always been relished in the East; and the Cossus, which was probably the larva of some large beetle, was considered a dainty ans. Huwever, with the exception of cheese-maggrots and cheesenites, both of which are probibly less wholesome than the inseets just 
mentioned, Europenns turn from insects, etc., with disgust, while eating crabs and shrimps without hesitation. Food is more a matter of fashion than of anything else, after all.

A most ingenious theory has lately been proponnded by $\mathbf{M}_{1}$. H. M. Bernard, in his work on the Apodide. He considers the C'motucen to have originated from the Anuelida, and that the earliest ('mostucen were simply Alueliclu with the head bent down moler the body; but this is a matter on which only specialists are entitled to express an opinion. Nevertheless, we mal begin the crustacen with the Entomostrace, as the group nearest ipproaching to the Anuelielu. We may add that the I'ycuogonida, which we have included with the Arach mide, have been placed hy some authors in the cirstuce, while others have regarded them as forming a distinct cliss of Arthropoulu by themselves.

\section{SUB-CLASS I.-ENTOMOSTRACA.}

Tuis large section is only retained as a matter of convenience to inclucle the smaller Cinstuce, many of which exhibit forms which have little resemblance to the more typieal Crustace. It includes most of the parasitic species. The cimipediu are sometimes treated as an additional order of Eutvarostrace.

\section{Order I.-Phyllopolis.}

The Phyllopulu have received their name from their leaf-like swimming legs, of which there are four pairs, or more. Sometimes more or less of the animal is covered by a bivalve shell, somewhat as in the Ostiacoda, or by a

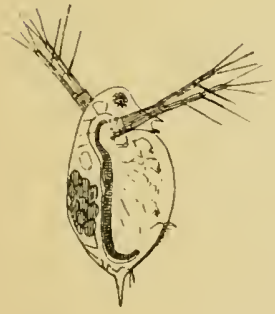

Fig. 2.-WATER.FLEA (Itephuin pulter). Magnified.

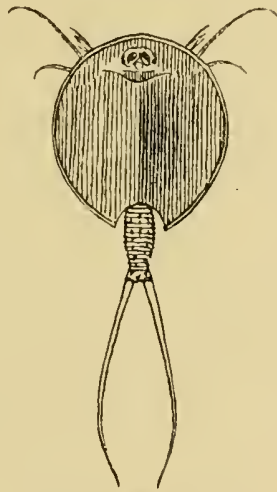

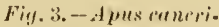
firmis. Nat. size.

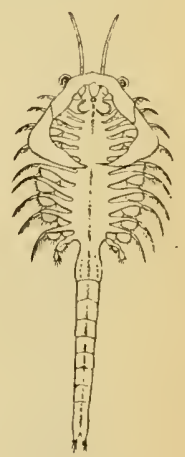

Fi. 4. - BRINE SHRIMLP (1)trmin suline) Magnified.

solid carapace; in other cases this is wanting. Some are manine, while otlrers inhabit fresh water. They have usually two eyes, which, howerer', are some. times contiguous. Three families of this order mat be briefly noticed. The 
Diphluider, or water-fleas are small Cristaceu which abound in fresh water. They are of a compressed oval form, and are partly covered hy a thin, transparent bivalve shell. The first prair of antemne is small, but the second very lange, bifid at the extremity, and set with long hairs, which serve as the prineipal orgaus of locomotion. The eyes are fused into one large one, near which is often another small one. They have from four to six pairs of swimming legs. They are very farourite objects with microscopists, being abundant, and admitting of easy observation. In the Apodide the body is covered with a shiekl-shaped carapace, and there are two contiguous eyes, and from 30 to 40 pitirs of gill-feet. Apus cancriformis, Schrift., is a brownish yellow species, alout two inches long, which is found in ponds. The large, oval carapace covers all but the last few segments of the body, whieh ends in a that double tail, on each side of which a long bristly appendage is visible. This family is of interest as having formed the subject of Mr. Bernarl's memoir, alrendy alluded to, in which he comnects the Annelidl, with the Trilubites through the Apodide. The Branchipodider lave no shell, but a strongly-segmented body, stalked eyes, and a long tapering tail, encling in a flat pair of flattened appendages set with bristles. The most interesting species of this family is the brine shrimp, Artemire salime (Limn.), which is of a pink colour, and alout half an inch long. It is more shrimp-like in appearance than any other species of Entomostraca which we have mentioned, and is only found in brine pits, appearing to prefer the most concentrated brinc.

\section{()RDER II.-Ostracond.}

In the ()stremlat the budy is not segmented, and is entirely enrered by a bean-shaped bivalve shell. There are four antemie set witl bristles, and one (11 both pairs are used for swinming aud grasping. There are five paris of other appendages, of which the first, seeond, often the thind, and sometimes even the fourth, serve the purpose of jaws, and only the last paic or pair's perform the oftice of legs.

\section{ORWER III.- COPELODA.}

In this order there are ten swimming-legs at most, generally bifid, and set with hairs and bristles. One or two sessile eyes

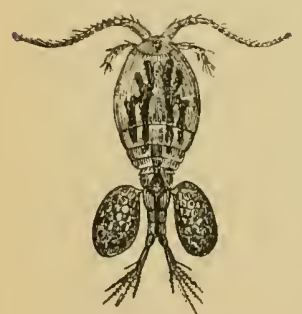

Fig. 5.-Cyorol's Quatits. cornis. Magnitied. are present, and the mouth is fumished with leaflike gills. The large eye possessed by some of the species led to their being placed in a genus ('yclops by Miiller. They commence life in the Nanplins-form, to which the full-grown animal still exhibits a strong resemblance. Some species are free, and other's parasitic ; as, for instance, those belonging to the family Notodelphyide, which live within the branchial cavity of Ascilia. A few species like these are marine, but the majority of the Cyclopicle live in fresh water, onc species, Canthocamptus alpestris (Vogt), being found in the glacier waters of the Aar in Switmerland, at an elevation of 8,500 feet. The family dignlide inclucles some species which are parasitic on the earp, and which are known as "carp lice." 


\section{Oriner IV. - Cirriptenia.}

By recent authors the Ciripedire have been treated as a section of the Crustucer, from which, however, they differ so much when adult, that they were formerly regarded as a separate cliss. In their perfeet state they are fixed immovably by their heads to a rock, or some other object submerged in the sea, and are without antennie, eyes, or any means of loconotion. Their bodies are enclosed more or less completely in a eileareous shell, formed of several parts, which led to the earlier naturalists regarding them as $M$ ollusen, and their shells were ealled Multivalves by collector's, in opposition to Univalves and Bivalves. In the larval stages they are provided with antennie, eyes, and swimming-feet, the last of which become modified into short, jointed, cirrhated appenclages, of which there are usually six pairs, and which are usel to cupture prey. They are

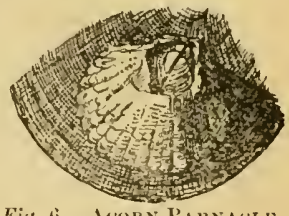

Fig. 1) - ACORE BARNAILE (Bulumus bulanoide's).

Nat. size. generilly hermophrodite. All the species are marine. A peculiar interest attaches to these animals, owing to their having formed a special object of study with Charles Darwin, who published an elaborate

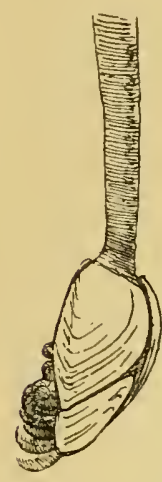

Fig. フ. -Goose

BARNACLE (Lepes amati. ferut). $\frac{1}{2}$ Nat. size. monograph upon them in 1851 and 1854 . There are several sub-divisions of the Cirripedia, many of which live parasitically on various Crustucea, Mollusca, or on other Cimiperliu. The only two families which we shall notice here are the Buldenidie and the Lepadiste.

The Balunide or acorn barnacles attach themselves to the rocks, often between tide-marks, after the mamner of a limpet; but they can always be distinguished from true Mollusecu by their multi- Acorn Barnacles valve shells. The Lepartida, on the other hand, fix themselves by a fleshy stalk to any

(Balanidie). suitable object, from which they hang. Some of the larger marine animals are often chosen by them; and they frequently attach themselves in great numbers to the bottoms of wooden ships, which require to be periodically freed from such appendages. There was a curious belief in

Goose Barnacles (Lepadidet). the Middle Ages that the bird known as the barnacle goose was born from hanging barnacles, and a common barnacle was named Lepres aratifcre by Limneus on this account. Old traditions of this description, when investigated without prejudice, almost always prove to contain some germ of truth; but it is clifticult to imagine in what curious error the story of the bamacle gonse could have originated.

\section{SUB-CLASS II-MALACOSTRACA.}

The Mraluchostrece, which inclucte all the higher Girstures, are normally composed of 20 segments; 13 segments, each bearing a pair of jointed ap- 
pendages, composing the head and thorax; 6 abdominal segments, also frequently bearing jointed appendages; and a tail-piece. They have two antemae, and two or four eyes. They differ very much in shape and appearance, but include nearly all the rinstrece which fill moler ordinary observation.

\section{Order I.-Arthrostraca.}

The Avthrostrace are small or moderate-sized Cinstrcea, with two compound eyes, which are not stalked. There are two pairs of anteme, three pairs of jaws, and one pair of foot-jaws attached to the head. The thorax usually consists of seven segments (rarely less), each bearing a pair of legs. The abdomen likewise generally consists of six segments bearing legs, and a terminal segment, but is sometines much modified and aborted.

The Aithrostirce are divided into two sub-orders, and these igain into numerous families.

\section{Sub-Order I.-Isopoda.}

In the Isopota the head is distinctly separated from the thorax. The body is broad, and somewhat arched, and there are usually 7 thoracic segments bearing legs; but the abdomen is short and often imperfectly developed, bearing lamellated gill-feet. In some fami-

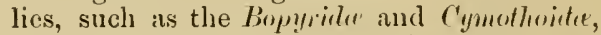

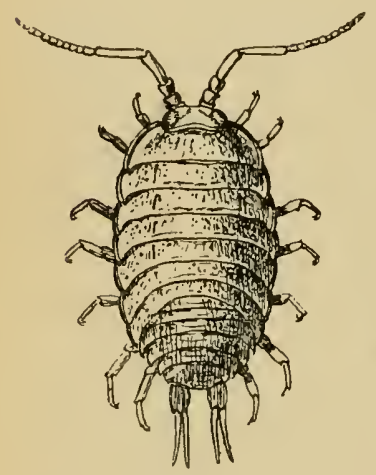

Fig. 8.-LYuiA OCEANICA. Nat. size. which are parasitic on other ('instuceu, or on fishes, the legs are armed with claws. But the most familiar family of the $I$ sopurle is the Oniscida, which inclurtes the creatures known as "wood-lice," "sows" or "sow-bugs." They are short, broad, brown scaly creatures, with conspicuous antennse, and a body arched above, and flattish below. Some are able to roll themselves up into a ball. They are about half an inch or less in length, and are found in clamp, dark places among moss, moler the loose bark of trees, $o r$ in cellar's. One large species, over an inch in length, Ly!pin oceanicu (Limn.), is marine, and is met with rumning over rocks between tide marks. As I have already mentioned elsewhere, a specimen which was found running along a towrope in Dublin Harbour during the Colorado Beetle scare some year's ago, was secured and amnounced in the papers as the dreaded Colorado Beetle just landing from Anerica !

Sub-Order II.-Amplipoalu.

In the Ampliprola, the liead and the first thoracic segment are fused together, and the body is laterally compressed, and strongly arched. There are 
always seven pairs of legs, and the abdomen and its appendages are also well developed in some families, the hinder segments bearing long legs adapted for leaping. 'This deseription applies best to the foummeriele, one or two of which, that live in fresh water, grow to the length of half an inch. The greater part of the Amphipolu, however, are marine, and differ considerably in size, shine, and habits. Some swim freely in the water, and others burrow into woodwork. Many are in the habit of attrehing themselves to various marine animals; and one family, Letrmoliprodide, in which the abdomen is rudimentary, is truly parasitie. One curious genus, Cyomus (Lamarek), which is parasitic on whales, has strong hooked appendages at both ends of the budy; and the species are known as WhaleLice. We have figured ('. arelis (Runssel).

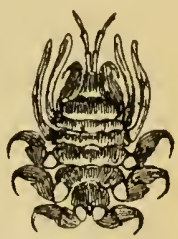

Fiy. 9. -

WHALE-Lot'SE ('yentris ormlis). Nat. size.

\section{Order II.-Thoracostraca.}

The present order agrees with the last in the number of segments, but is distinguished from it by having more or fewer of the thoracic segments mited with the head by a common shell, or earapace, and there are usually two eompound stalked eyes. We find no true parasites in this gronp, thongh some of them seek the society of other animals for the sake of food and shelter, as in the case of the small crab which takes up its residence in the shell of the Pinmu.

\section{Sub-Oider I.-Cumacer.}

Tncludes small marine species, with sessile eyes, and a long, slender ahilomen.

Sulb-Order II.-Stomutopoda.

This order is now restricted to the single family Simillicle, which are marine ('mustucen resembling large prawns, three inches or more in length, with the

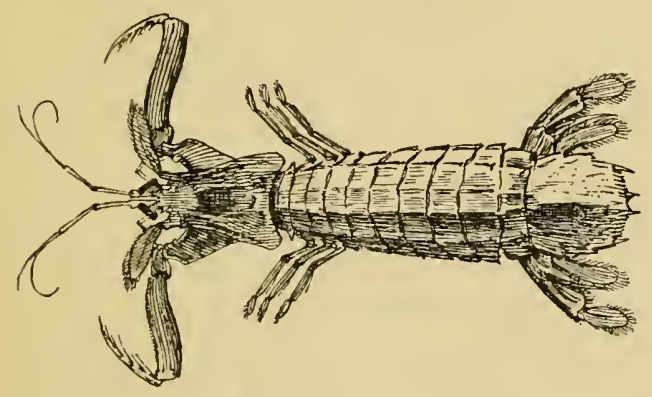

Fi!f. 10. - SQuilla MANTik. cephalothorax slender, ir large tail-fin, and the second pair of foot-jaws developed into an enormous claw, which has led to one of the common speeies being callerl Squilla mantis (Rondel), on account of the shape and attitude of its legs very closely resembling the predaceous legs of the Mrentide among the Oithopterm. This species swims strongly, and is eaten in Italy, where it attains a length of six inches; in the British sens it does not exceed $4 \frac{1}{2}$ inches in length, 


\section{Sub-Order III--Sehiropoda.}

These are slender shrimp-like Cnustacect, with a large soft shield covering the cephalothorax, and even part of the abdomen. The legs and gill-feet are bitid, and similarly formed. They swim in large shoals in the open sea, and are among the numerous surface-aninals which form the food of whales.

\section{Order III. -Decapoda.}

This extensive order is the most important among the Cinstacer. The species which it includes have a hard calcareous shield, which generally covers the head and thoracic segments, as well as more or less of the abdomen. Under this shield lie the gills. There are two faceted stalked eyes, between which frequently projects a strong spine. They have usually three pairs of jaws, three pairs of thoracic gill-feet, and five pairs of walking legs, from which they derive their name. They may be divided into three sub-orders - the Mucrum, or lobsters, prawns, and shrimps ; the Anomeru, or hermit crabs ; and the Brechyure, or erabs.

\section{Sub-Order I.-Maciwa.}

In the Macrura the abdomen is largely developed, and the first five (or more rarely, four) segments bear walking legs. There is a large flattened triple fin at the extrenity of the abdomen, formed by the terminal segment, and a leaf-like appendage attached on each side to the one preceding.

The Crangonidu are moderate-sized Crustacen with semi-transparent bodies, a thin horny carapace, the outer antenne with a large moveable scale at the base, and sometimes a very strong ridged spine between the eyes. The first three pairs of legs are generally chelate (pincer-like). The

\section{Shrimps and} Prawns. species generally live in shoals in shallow water, near the shore, where they are captured by waders in specially-constructed nets. Most of the species are marine, such as the shrimps and prawns; some are found in fresh water lakes and rivers; and one or two blind species in eaves. Some species, in which the skeleton is universally soft, inhabit the large shells of the Pinna.

The Astacide are large hard-shelled species, with a small scale at the base of the outer antennie. The first pair of legs is developed into great claws. The gills are numerous; sometimes there are as many as 20 pairs. They inhabit the sea, where they live in clefts among the rocks; and other species are found in lakes and rivers, where they live in holes in the banks. The two representative species of this family are the lobster and Lobsters. the river crayfish. Some years ago a detailed monograph on the crayfish was published by the late Prof. Huxley, to which those who wish to study the anatomy of a Crustacean can easily refer.

The crayfish forms a very important article of diet in Eastern Europe, and is recorded in the Esthonian ballads to have formed the principal article of food of their mythieal hero, the Kalevi poeg, when he retired to a

Crayfish. hermitage on the banks of a river, after a clisastrous war. He used a tall fir-tree torn up by the roots, as an angle, and haited it with the body of a dead mare. (See my "Hero of Esthonia," i., p. 140.) 
In the Palimurida, or Spiny Lobsters, the outer pair of antemnit are much thickened at the basc, but are clestitute of a scale. The legs are short and all end in simple claws; the abdomen is broad. These animals resemble lobsters in si\%e and appenrance, but the shell is very hard and spiny. 'They are numcrous in the

Spiny Lobsters. Mediterranean, but are not common in the colder seas of Northern Europe.

\section{Sub-Order II.-Anomuru.}

This section is often included with the Macrum, but may conveniently be trented separately. The abdomen is more or less reduced ; it is soft, and its appendinges are rudimentary ; the hinder legs are also frequently much reduced. The front pair of legs is armed with strong pincers, and the outer antemut are long. 'The animals generally burrow in the sand, or live in the shells of molluses. They are more abmulant in warm countries than in cold.

The following are the two most interesting families :-

In the Birgide the abdomen is haid above, and pouch-shaped at the extremity. The cephalothorax is broad, and angulated in front. The type of this family, Birgne latro (Herbst), is a very large Crustacean, measuring over two feet in length; it is of a blue colour. It Robber Crabs. is common in the Eastern Archipelago. It is amphibious, and is said to climb trees in search of cocon-1nuts, which it is strong enough to clenude of the husk, when it contrives to force in the eye-hole, and to extract the contents with its pincers.

The Pu!mide, or Hermit Crabs, have a very soft abdomen, and take up their abode in empty univalve shells. Several common species inhabit our shores, and may often be seen ensconced in whelk-shells, etc., into which they retreat as far as possible on the least appearance of danger. In Tropical countries they grow to a much

Hermit Crabs. litrger size ; and some of them are land-animals, and inhabit land-shells, such as Helix and Bulimens.

\section{Sub-Order III.-Brachyma.}

This section includes the Crabs proper, in which the cephalothorax is short and broad; and the short abdomen, which has usually no tail-fin, and is narrow in the male and broad in the female, is curved under the cephaluthorax. In the males there are one or two pairs of abiominal feet, and in the females five.

The Porcellanider are represented in Englind by one or tivo species, the commonest of which is the Porcelain Crab), Poreellana platycheles (Tennant), a polished Hattened crab, of a reddish brown eulour, with very large broad

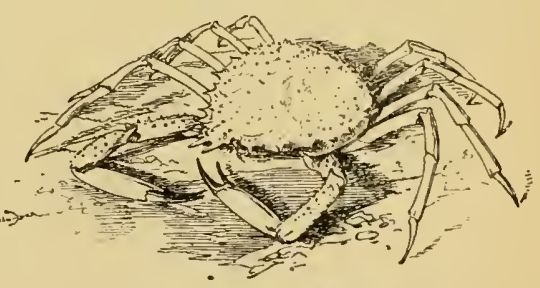

Fiy. 11.-Spider Crae (Maia $S_{1} u$ inado). claws. It is nearly round, and aboul two inches in length ; and is common under stones near low-water mark. 
The Spider Crab, Muic Syminrerlo (Limm.), is the representative of another family. (See Fiy. 11.) It is a large oval crab sometimes measuring 8 inches in length and 6 inches in breadth. It is covered and margined with strong sharp spines, two of which project in front. It is an active sea-scavenger, and most of our readers will renımber the amusing account in "Glaucus" of "Maia Squinado, Esq.," sitting at the buttom of the boat, twiddling his feelers. It ereeps, but does not swinl. The young form of the larva is represented on an earlier page (Fig. 1.) There are a great many other erabs, buth British and foreign, differing very mueh in size, shape, and liabits. Some are smoctl, others rough, spiny, or hairy. Some are round, others oval. Many small erabs and some larger ones are common running orer the sand, or among seaweed, or in roek-pools between tide-marks ; others, like the large Edible Crab, Curcer prgmus (Linn.), are imhabitants of deep water, and some are gool swimmers.

Among foreign crabs we may mention the genus Pinotheres (Latr.), which lives in pairs, in large shells, such as Pimm, from which they derive their name.

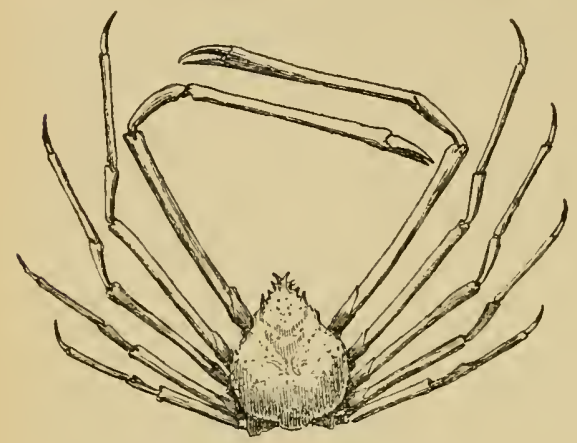

Fi!) 12.-CiREAT TAPANESE C'RAB. (Macrocheire Kïmpfevi).

The land crabs of tropical countries are large erabs which live almost entirely on laud. They burrow in the ground, and are able to run with extraordinary swiftness. One genus, with very large claws, has been ealled Gelusimus (laughable) from the ridieulous appearance whieh it presents when clusing along brandishing its great claws, only one of which is fully developed, wer its body.

One of the largest known Crustucer in expanse is Mraciochpir, Kimiferi (De Haan), a Japanese erab, not very remotely allied to the Spider Crabs, which has a compact, slightly oval body ratlier less than a foot long, but with enomously long, tlough comparatively slender legs, four or five feet in length. Two fine specimens may be seen in the public Insect Room at the Natural History Museum, South Kensington, where Crustacea are exhibited as well as Insects.

\section{SUB-CLASS III.-GIGANTOSTRACA.}

\section{Order Xiphonura. - King-Crabs.}

In the king-erabs, Limulus (Miiller), the upper part of the body is eovered by two great liorny shields, the first covering the eephalothorax and curved backwards at a sharp angle on each side, and the second smaller, covering the abdomen, and set with several strong, sharp projections on the sides, 
pointing obliquely backwards. Heyoud this is a sliarp horny spine not jointerl, and at least as long as the rest of the body. 'The antemma, jaws, and gill-feet all resemble legs, and all terminate in pineers except the last pair. Two compound and two simple eyes are present. The lers are

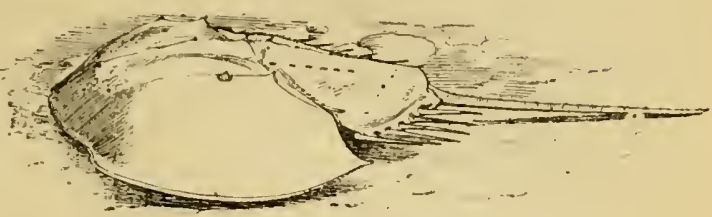

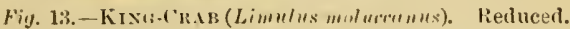
short, and are entirely cuvered by the shields. The few living species known are found in the East and West Indies, and on the Eist coast of Nortl America, living in shallow water, or ruming over and burowing in the sand. The species tigured, Limmlus moluccums. (Clusius), has larger spines than the others. 'The Limulic sometimes attain a length of two of three feet. They are the last survivors of il great group of Crustaceans, now only imperfectly known by their fossil remains. Three other orders, now wholly extinet, are referred to the Ginantestrace: the Merostomata, the Hcmiaspiela and the Tribuitu. Some authors have recently proposed to regard Limmlus as nore nearly allied to the Arachnidu thin to the Constucen; but its external resemblance to the latter is certainly far more obvious.

\section{SUB-CLASS IY.-PYCNOGONIDA.}

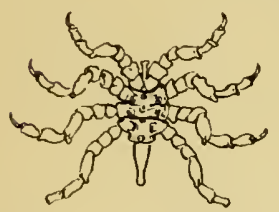

Fig. 14.-P!cnumonum lilorile. Miiller. Nat. size.

These are sluggish animals, found among seaweeds on the sea-shore, and somewhat intermediate between Ameluirlu and Cinstrece. The front of the body consists of four well-marked segments, the first of which is formed of three fused togrether, each bearing a pair of long, jointed legs, and the abdomen is very small. They are provided with a long suctorial proboscis. In their young state, they are parasitic on Hydractiniar, and are provided with three additional pairs of limbs, which wis slort or wanting in the adults.

\section{CIASS II.-ARACHNIDA (SI'IDERS, SCORPIONS, $A N D$ MITES).}

THI rather extensive group of animals is generally recognisable by a few salient characters. 'The head and thorax, instead of being separated, as in insects, are usually fused together into a single mass, called the cephalothorax; there are two pairs of jaws, one pair of which are sometimes regarded as modified antennat; from two to twelve simple eyes, variously ar'ruged in ditterent species ; and ustially eight pairs of legs, all situated wn 
the cephalothorax. The abdomen is without limbs, and is most frequently separated from the cephilothorax. The sexes are distinct, except in the Tredigicele. Most of the animals comprising this class are carnivorous; but among the mites, many feed on vegetable, as well as on animal substances; and some species are parasitic, and often subcutaneous, giving rise to, or accompanying various diseases, such as iteh, mange, Plica Polonica, dysentery, etc., in man and beast. The Aruchnida may be classed in three main divisions.

\section{Order I.-Scorpionidea (Scorpions).}

The scorpions are well known by their curved foot-jaws, cleft at the end like the claws of a crab, which they mueh resemble; and their long jointed tail ending in a sharp and venomous sting. They are generally of a blaek or yellow colour, and differ very mueh in shape and size, sone being small and slenter, ind not more thim a comple of inches in

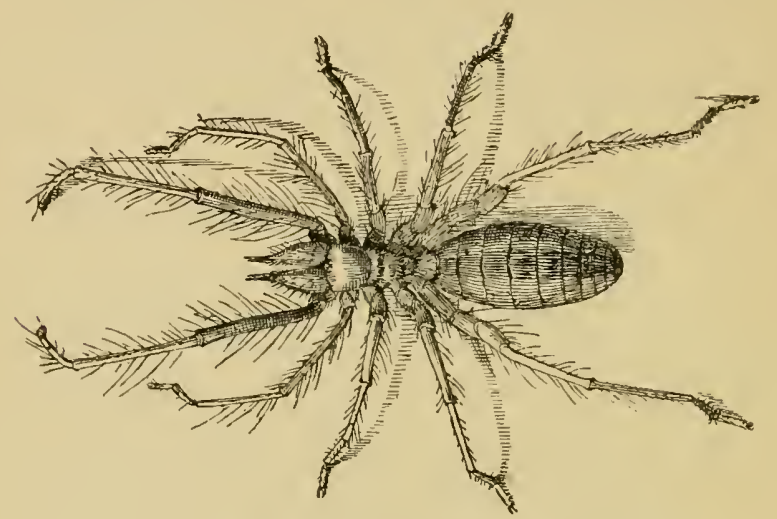

Fi!!. 15.-Galeodes ARibs, Koch. $\frac{1}{2}$ Nat. size.

length; and others being much shorter and thicker in proportion, and attaining to i length of 8 or 9 inches. They are not British, though several small speeies are met with in the Sonth of Europe. They are found under stones, under the bark of trees, in holes in walls, etc., and are only active at night. The effects of the sting differ very much in different species, irrespective of size, as it appears. That of many species is probably not very much more severe than the sting of the wisp; but that of others is liable to cause great pain and suffering, and sometimes death. Scorpions are viviparons, and the young are earried about by the mother on her back for some time after birth. There is an old story, which has been recently revived, that when a scorpion is surrounded by a ring of fire, it will sting itself to deatl ; and the same result is said to ensue if a drop of irritating Huid, such as whisky, is allowed to fall on its baek. 
ORDER IT.-SOLUUHW.K.

These are large animals, resembling spiders, but with the head and thorax separaterl, and the abdumen segmented; the legs are very hairy. They are not numerons in species, and are chiefly found in warm countries. They inhabit satndy places, and although frequently ealled sol ifumu, the majority of the species are most active by day. One species is (ruleodes (1)umpoides (Pallas), which is common on the Lower Volga; it is about two inehes long, and is much dreaded on aecount of its very painful bite. They hide themselves in the sind and among plants, from whence they rush upon their prey. They will sometimes lill lizards and birds, but their eommonest food appears to be grasshoppers. They are sometimes very troublesome to camels by their bite. The North African speeies, which we have figured, G. arebs (Koeh)-(Fiig. 15) -is one of the largest known; it is of a yelluwish colour.

\section{Order III. -Pseudoscorpionidea (Book-Scorpiosis)}

These are small, but not microscopic, animals, with the abdomen united to the eephalothorax, but distinctly jointed, and with very long eurving foot-jaws, eleft at the end. They resemble very small tril-less scorpions, and are freruently found among old books and papers, where they feed on mites and other small ereatures. They ine often seen elinging to the legs of Hies, but rather, perhaps, as a conrenient means of transport from place to place, than with the intention of preying on the flies themselves. The number of speeies is not very large ; the typical genus is Chelifer (Latr.).

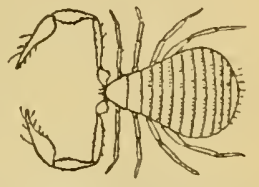

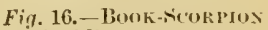
(Chiridium museormm, Leach). Magnified.

\section{Orher IV.-Pehpulpi (False Scolploss).}

These are large tropical creatures, an inch or more in length, resembling spiders, but with in jointed abdomen, large pincers like a scorpion, long hairy legs, of which the first pair are much longer and slenderer than the others, and no tail, or else a short one, not terminating in a sting. They are much dreaded by the natives of the comntries in which they are found, but whether their claws are venomons does not seen to have been positively ascertained.

The typical genus is Phr?mus (Latr.).

\section{Orner V.-Phalanghida (Hahiest-inen).}

These are small spider-like animals, with enurmously long slender legs. The abdomen is segmented, there are 110 spinning glands, and the maxillary palpi end in a single claw, while the mandibles are jointed. They breathe liy trachere. They feed on Athides and other small inseets by night. (See Fig. 17). 


\section{Order VI. -Araneida (Spiders).}

THe Araneida, or Spiders, are a very extensive group, with the usually unjointed abdomen well separated from the cephalothorax ; strong mandibles ; spinning glands; and breathing with lungs and tracheae $\mathrm{cr}$ with tracheie alone. There is a variable number of eyes. They have been divided into many families differing much in habits. They are very ferocious, and will often kill and eat each other, but are much exposed to the attacks of birds and camivorous insects, many sancl-wasps provisioning their nests chiefly

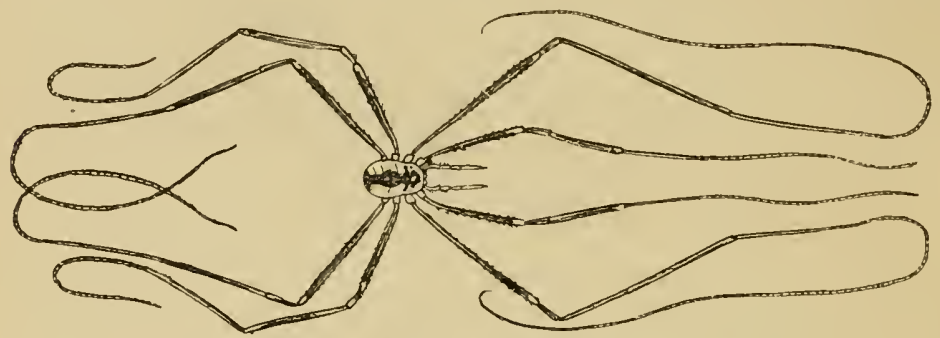

Fig 17.-Harvest Mas (Livbunum religiosum simon). Nat. size.

with spiders. As they camnot be domesticated, owing to their cannibalistic propensities, their silk cumnot be collected in sufticient quantities for comnereial purposes; but spider's web has been recomuended as a useful application to stop bleeding. There are many kinds of spiders in various comntries the bite of which is said to be dangerous to man.

\section{Family J.-Theraphosin t:}

This family is distinguished from all the remaining spider's by the possession of four lungs and only four spinnerets (except in At!/mus, etc., which have six); the remaining spiders having only two lungs (or two lumgs and sometimes two trachere also) and six spimerets. These characters are sometimes used to separate the spiders into two main sections, the Tetropmemmones, including only the Therrphosider (formerly called M!ngulider), and the Liprenmones, including the remaining spiders.

The Therrphosidu are further remarkable for their large size, very hairy legs and bodies, and hard polished poison-fangrs. Some of the larger species attain a length of from two to four inches, and spin a dense white web, in which birds as large as finches are sometimes entangled. This was first recorded by Madame Merian two centuries ago. It was

Bird-catching spiders. "Naturalist on the Amazons," i. pp. 160-162 ; and by other observers. Bates further adds that the liairs of these large spider's are excessively irritating to the skin ; and lastly, "Some Mygales are of immense size. One day 1 saw the children belongring to an Indian family who collected for me, with one of these monster's secured by a cord round 
its waist, by which they were leading it about the house as they would a dog." The amount of valuable scientific and general information collected by Bates during his eleven years of travel on the Amazons was very extensive, and it is much to be regretted that though part was published in his book, and in varions essays shortly after his return to England, a great dea] must have died with him.

The Therophoside also include smaller spiders, which construet nests in the ground provided with a round trap.door, which fits down over it in such a

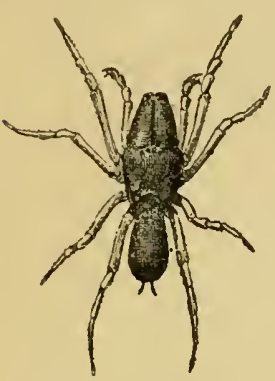

Fiy. 1s.-(Atyyus sulzeri.)

Twice nat. size. mamer as to completely close and eonceal it. Trapd(x)r spiders are plentiful in many parts of the world, including South France; but our only British representative of the fanily, Atymes sulweri (Latr.), constructs a tubular gallery in the ground, abont lalf an inch in diameter, in which the female deposits her eggs, but which is not elosed with a trapcloor. The spicler itself is about laalf an inch in length.

Turning now to the remaining spiders, it will, perhaps, be sufticient to illustrate them by noticing a few of the more interesting and representative groups and species.

The Salticidr', ar hunting-spiders do not construet a web, except as a resting-place at night or when moulting their skins, and as an eggsac, but eapture their prey by leaping on it, comnecting themselves, however, with the spot they have quitted by chawing out a thread behind them as they leap. The cephalothorax is arched, and they have eight eyes. Their legs are lather short and stont. Several species, both British and foreign, resemble ants, a resemblance which is probably protective to themselves rather than designed to mask their approach from their prey.

The Lycoside, or wolf-spiders are similar in some of their brabits to the last family, but generally pursue their prey by rumning, not by leaping. Their eephalothorax is arched, but narrowed in front. They have eiglit eyes arranged in three or four transverse rows, and their less are long and hairy. The egg-pouch of the female is carried about with her attached to the end of her body till the young hatch, when they chimb on her back. Some species carry their egg-sac in their mandibles.

To this family belongs the famous spider Lyerose trrentulu (Limneus), the bite of which was supposed in Italy to produce a fit of melancholia, that eould only be cured by the tume known as the Tarentella. The nests of some of these spiciers are hardly less curious than those of the trap-door spiclers; that of a North American species, Lycosa crenicola (Scudder), tigured in Comstock's "Mamual for thc Study of Insects," p. 41, makes a structure resembling a high bird's-nest, ol' small turret, over the entrance to the tube. Some of the Lycosille frequent water, and are able to pursue their prey on or in it; and Dolomedes fimbrictus (Clerek) actually constructs a small raft on which it sails about.

The Thomisider, ot crab-spiders, have small eyes arranged in two rows, and long sprawling legrs, like those of a crab. Their colours are usually protective, being grey or brown in the ease of tree frequenting species, and green or yellow in the ease of those which conceal themselves in flowers. 
The Uloboridce are an unimportant family in England; but Comstock quotes from Dr. Wilder the following curious account of the use of the triangular web of Hyptiotes curatus (Hentz), a conmon species in the United States:-"Its web is most often found stretched between the twigs of a dead bianch of pine or spruce. At first sight this web appears like the fragnent of an orb web, but a little study will show that it is complete. . . . It consists of four plain lines corresponding to the radiating lines of an orb web, and a series of double cross lines. . . From the points where the radiating lines meet, it strong line extends to one of the supporting twigs. Near this twig the spicler rests, pulling the web tight so that there is some lonse line between its legs. When an insect becomes entangled in one of the cross lines, the spider suddenly lets go the loose line, so that the whole web sjorings forward, and the insect is entangled in other threarls. The spicler then draws the web tight, and snaps it again. This nay be repeated several times before the spider groes out upon the web after its prey."

The Epeivide, or garden-spiclers, are large and handsome spider's, with a rounded abdomen, and moderately long hairy legs, the first pair longest. They have eight eyes irregularly arranged in two row's. Garden-spiders. They spin circular webs, and await their prey either near the centre of their web, or in a place of concenlment close by. The comnonest species, Epeiru diudema (Clerck), is nearly an inch long, and has a green ablomen marked with white or yellow spots in the form of a cross. One Nortl American species, Aryiope riparia (Walckenaer), is recorcied to make a large egg-sac, in which the young pass the winter; only those emerging from it in spring which have not heen devoured by their fellows in the interval. Other species have the same curious cannibal halbit.

The Gustrucunthide are a very curious family of exotic spiders, with hard, lominy, angular bodies, and sometimes with a long curved spine projecting on each side at the extremity of the abdomen. They are often of very varied colours. Many writers include

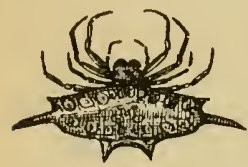

Fig. 19.-(Gustrecenthet formicata.) Nat. size. them in the Epciridu. The species tigured is Gastruconthe fornicate (Fabr.). It is reddish (probably yellow when alive), with the head, thorax, and some round spots on the abrlomen, blackish; and it inhabits Ceylon, Java, and Australia.

To the Agelenide, a large family in which the eyes are arranged in two curved transverse rows, belong our common house-spiders, which are too well-known to need description, and which spin their cobwebs wherever they are left for a day or two undisturbed. Another very interesting species is the waterspider, Aryyronetu (tquatica (Limn.), which dives beneath fresh water, enclosed in a shining bubble of air entangled in the hairs of its body, and constructs a silken subaqueous dome, which it fills with air like a diving-bell, in which it waits for prey, hibermates, and deposits its egg-cocoons.

To the allied fanily Theridiidce belong several large and handsomelycoloured spiders found in Southern Europe, New Zealand, and elsewhere, which are much dreaded on account of their poisonous bite. 


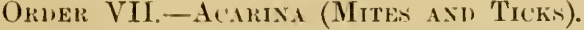

This large order includes a great variety of ereatures. Most of them are very minute, and many are ahmost mieroscopic. The eephalouborix and abdomen are fused together, the body forming a sompact, rounded, or oval mass ; the sexes are separate, and sometimes very differenu in appearance ; the mouth is formed for biting or sucking, and there are nearly always eight legs in the perfect state, but often six only in the carlier stages. The Phytopti have usuilly only four. Many of the species are more or less bristly. Some feerl on plants, and others on clecaying animal and regetable substances. A considerable number are parasitic.

The Bullider are mites of a bright red colour, with a long snout, and long palpi, which are grenerally elbowed, and have the appearance of antemre. Some are found among moss, and others on the sea-shore; while others, again, are parasitic on various insects. The number of eyes varies, and in some cave-frequenting species, the eyes are olsolete.

The Gamusicle are a family of mites, many of which are parasitic on inseets, and others on warm-blooded animals. They are without eyes, the mandibles are pincer-like, and the legs are hairy, and fumished with two claws. The first or second pair of legs are frequently much thicker than the others; and the immature mites have only six legs. The species of Crumusus (Latr.) infest different

Insect-Mites

(Giamasidle). kinds of insects, especially the black dung-bectles belonging to the genus (reotrupes (Fabr.), and its allies; and they are also numerous on humble-bees. They may often be found rumning over these insects; but there are other mites infesting beetles which are attaehed to their host hy a thread; these belong to the genus Uropoda (Latr.). Other mites of this family attack warmblooded animals, and are very mumerous among poultry and eaged birds, and sometimes become troublesome to man by transference.

The Hrelacaridre are a small fimily of mites, living habitmally under the sea, having either a stiff, or a more or less rigid, cuirassed skin, and with their legs springing from the inner margin of the body. They are found among sea-weeds in lock-pools, or are brought up, sometimes in large numbers, by the dredge. The body is oval, the snout more or less produced, and the palpi rather long.

The next family we have to consider is that of the Hydruchuide, or freshwater mites. These are round, or, more rarely, oval, and are generally smooth and velvety, and of a red, black and red, or purple colour. Most of them have only six legs when immature. They have a hook at the extremity of the palpi, and are in the habit of attaching themselves to various water- (Hyclrachnidie). animals.

The Ixodide, or ticks, are among the largest and most troublesome of the whole group. They are usually of an oval form, and have a tough skin, and a mouth fitted for sucking. Some are provided with eyes, and others are blind. They live on grass and herbage, and the usual habit of the female is to attach herself to any warm-blooded animal, pieree the skin, and suck the blood

Ticks

(Ixolide). till she is gorged, when she falls off. They are sometimes very troublesome in summer and autumn, even in England; but in hot comtries they are often a terrible pest, especially in the Southern States of America, and in some parts of South America, where they are particularly troublesome to cattle. 
In Brazil they are said to have been introduced. This has been doubted; but it is not unlikely that a particularly troublesome speeies may be carried from one eountry to another, or introdueed into districts in which it was previously unknown. For a tropieal country, Jamaica is remarkably free from noxious creatures; and it is only of late years that ticks have multiplied in the island to such an extent as to make it highly unpleasant to venture among the herbage at all. This is attributed to the introduction of the mongoose, which was imported to destroy rats, and which is said to have earried the ticks over the whole island. The largest known tieks, which sometimes attain a length of nearly an inch, are those which are found oecasionally upon the tortoise. Argus persicus (Fisel..) was said by traveller's to produce fatal injuries by its attacks, and to abound so mueh in some parts of Persia as to lead to the abandonment of whole villages; but these reports are now believed to have been much exaggerated.

The Oribatidce are dark-coloured, hard, shiny mites, found among moss and vegetable refuse; but when they are older, they feed on various small inseets. The front of the body is often produeed into a broad, triangular shape, and, as in many other mites, the palpi are frequently so liargely developed as to resemble antennie in appearance.

The Plyptoptidce, or gall mites, are an extremely large group, coneerning which much has been written of late years. They are very long, mieroscopie mites, usually with only four legs visible at the anterior end

Gall-Mites (Phytoptide). of the body. They produce small galls on the leaves of various plants, sometimes conical, as on the lime trees, and sometimes rounded, as on the vine. These galls may be distinguished from insect-galls by having a small opening at the base.

The Surcopticle, or iteh-mites, are a family of parasites which, not eontent with sucking blood, burrow under the skin of warm-blooded animals, causing, by their irritation, diseases known as the iteh or mange.

Itch-Mites Various species have also been observed on patients suffering (Sarcoptidee). from Polish Plait (Plicu polonica), and whether they actually cause this disease or not, they doubtless aggravate it. The itch-mites are round, with short, bristly legs, and most mammals seem to be more or less subject to their attacks. In birds, they frequently attack the feet. They are nost active at night, and the

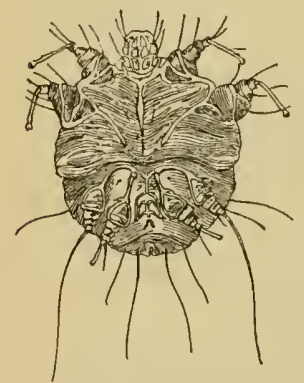

Fig. 20.-ITCII-MITE (Sarcoptes scabiei). Undersurface of male. Magnified. Two other families of parasitic mites may be briefly mentioner. troublesome itching they eause is consequently worst then. There are two prineipal forms of the disease in man, one eommon in most parts of the world, eaused by Sarcoptes scabici (Latr.), while the other, S. scabiei-cristose (Murray), which is far worse, is almost enfined to Nortlieru Europe. The itch has often been a great pest during the hardships of a eampaign, and the survivors of Sir John Moore's force, in the Peninsular. War, were greatly affeeted by it. Before the eause was diseovered, it was regarded as a most formidable disease, and $\mathbf{D r}$. Russell informs us that in the last century it was more dreaded at Aleppo than the plague itself. But in reeent years, the use of sulphur baths has proved to be an easy and efficacious method of getting rid

Two other families of parasitic mites may be briefly mentionerl. These 
are Myolied, small, wal mites, not unlike lice in shape, which infest mice and other small mammals, and bircls; and lhemorlicidre, the few species of which are long, tapering, microsenpic mites, infesting the lair-follicles of man and other animals. In min, the common Demodex folliculorum (Simon) often occurs on the face, where its presence is indicated externilly by a black speck; but as it is a parasite of very small size and stationary habits, its presence does not cause anything like the same amnoyance as that of Sarcoptes scabiei.

The Trombiclicke are a family of brown, or bright scarlet mites, which are in the habit of attaching themselves to insects, to which they cling so tightly that they may often be seen in numbers attiched to Museum specimens. They attack flies, sawtlies, and other insects, but are most conspicuous when attached to the wings of dragonflies in more or less symmetrical rows. Some very large species, measuring nearly half an inch in length, are often found pinned in miscellameous collections of insects, etc., from Africa and the East Indies.

The T'etcmychidu are allied to the last family, but are plant-feeders. The two best known species are that great pest in hothouses, the "Red Spider" (Tetrungchus teluives, Limn.), which, however, is not a spicler, but a mite; and the harvest bug ( $T$. antrmmalis, Shaw), which burrows into the skin, causing great inconvenience; while in the case of allied tropical species, sup-

"Red Spiders"

(Tetranychus). purition and ulceration may result in extreme cases. However, most of the species of this family are harmless, living on plants, or under stones, and not attacking animals.

The last family we have to notice, the Tyroglyphide, includes several of the most typical mites, such as the cheese-mites and the sugar-mite. 'Tyroylyphus siro (Lim.), the commonest of the former, abounds in cheese, causing a kind of dry rot; and the dust from such Cheese-Mites,etc. a cheese, when placed under the microscope, generally proves (Tyroglyphidur). to be full of mites. They are harmless when swallowed, nor du they attack the shin. Other mites, belonging to the genus Cheyletıs (Latr.), with large claw-like palpi, feed on cheese-mites, etc. Very small mites, belonging to the genus Tyroylyphns, are among the most destructive pests in collections of insects. The sugar-mite ( $T$. srcchuri, Cameron), abounds in unrefined sugar, and is sometimes the cause of a complaint known as "grocer's itch." Now, however, almost all sugar brought into the market is more or" less refined, and no longer liable to the attacks of mites. Most of the Tyroglyphide are harmless, some feeding on ciried vegetable or animal substances, while others are carnivorous, feeding on insects; and others, again, are, or may accidentally become, parasitic. Cases of dysentery have sometimes been attributed to the presence in the intestines of mites belonging to this family, which had been accidentally swallowed.

\section{Order VIIT.-TARdigraja.}

These are small mites found among moss and seaweed. The cephalcthorax and abdomen are fused together; the body is broad, with four indistinct rings on the body. The sexes are not separate. The position of this group is still doubtful. 


\section{Oriner IX. - LiNGitatulida.}

These are worm-like parasites, with jointed bodies and separate sexes. They are curiously intermediate between parasitic worms and $A$ rthropola, but they are now referred to the $A$ rachuide as an aberrant group. In their embryo state, they have two pairs of short, two-jointed legs, with two strong claws, and two hooks at the mouth. In their sexually mature condition, they have four hooks at the mouth, but no legs. They are met with in the encysted laval conditions in the lungs and liver of the horse, dog, wolf, hare, and rabbit, as well as in suakes, erocodiles, and tish; and occasionally in man. In their mature form, they inhabit the frontal sinuses of the hare, rabbit, and horse.

\section{CLASS III.-MYRIOPODA (CENTIPEDES AND MILLEPEDES).}

THIs is the most worm-like elass of the sub-kingdom Anmose in the perfect state of the animals included under it. The head is well differentiated from the lest of the body, and is provided witl one pair of antenne, and three (uore rarely, two) pais of jaws. The

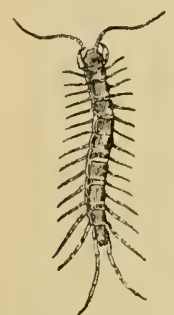

Fill. 21.-(Litllwbitis foryicutus.) Nat. size. thorax and abdomen are not differentiated, except into segments. They undergo a reversed and very imperfect metamorphosis compared to that of insects, for whereas insects begin with a worm-like body, sometimes provided with as many as twenty-two legs, and end with only six, the M!rriopodu sometinues begin with only six legs, and eontinue to increase both in number of joints and number of legs, till they have reached their fuli growth, in which they are generally long and worm-like. Hence they are called Myriaprode or Myriopodse (either form of the word being equally eorrect); and they are sub-divided into two principal orders, the Chilopod, which are generally called centipedes or hundred-feet; and the Chilognuthe, which are generally called millepedes or thousand-feet.

\section{Örder Chilopoda (Centipedes).}

The centipedes are carnivorous, and are provided with perforated fontjaws, connected with a poison-gland. The budy and jaws are generally rather flattened, and there is never more than a single pair of legs on each segment. 'The head is divided into two regions, provided with two pairs of maxille, behind which spring the great foot-jaws.

The sontigerider are distinguished from the other families of Chilopoda by having the two pairs of mandibles united, and by the long autenne, legs, and abdominal appendages, which has led to the common South European speciess being ealled scutigerre rerrueoides (Pall.), from its fancied resemblance to a spider. It is about m inch long, the antenne being at least as long as the budy, and the last pair of legs twice as long; the other legs are compara- 
tively short in front, lut increase rapilly in length till they are mealy as long as the body. The gropontions of the limbs, etc., however, viry considerably in different species; the legs are very brittle. 'These centipodes feed on insects, and are very active. Most of them are inhabitants of warm climates (the family is umrepresented in England), and the colour is usually greenish when alive, but is liable to change rapidly after death. They hare only sixteen joints, and are provider with compound eyes insteal of ocelli.

The Lithobiide are represented in Britain by Lithobius forficatus (Limn.), which has two clusters of ocelli, fifteen pairs of legs, increasing in length hindwards, and long antemne, with more than forry joints. It is a repulsive-looking, reddish-brown creature about an inch long, with a comparatively broad body. It is very active in its movements, and feeds chiefly on worms; and is often unearthed by digging in garden-monld or in a dumg-heap. (Fig. 21.)

The scolopeulvidu generally have four simple eyes on both sides, antenne with about twenty joints, and usually twentyonc pairs of legs. The boly is often very broad and thattened. The family is represented in Soutl Eurupe, and the species are often of consiclerable size, sometimes measuring more than a foot in length. Their bite is as painful and dangerous as that of a scorpion, though they are sometimes used as an article of food by the matives of the countries where they are mumerous. They are generally of a brown or reddish colour, or banded with green and yellow. In Britain we have only one small blind yellowish species of the family, Civytops hortensis (Leach), which is harmless.

The Goophilid, are very long slender centipedes, with fourteen-jointed antemne, neither compound eyes nor ocelli, and from thirty-one to one hundred and serenty-three legbearing segments, each provider with a pair of rather short legs. They are nocturnal creatures, of a whitish or yellowish colour, and are remarkable for emitting a pile phosphorescence which has led to their being called electric centipedes. 'They are found in Britain as well ats in warmer countries.

\section{Order Chilogratha (Millepenes).}

The millepedes are distinguished from the centipedes by their feeding chiefly on vegetable matter's; and, comsequently, they have imperforate foot-jaws, and are not venomous. Their bodies are generally convex above, and more or less Hattened beneath; and while the first three segments behind the head, corresponding to the thorix in insects, bear only one pair of legs each, the remaining segments bear two pairs. The head of the millepede is composed of a single segment only. They vary much in size; and dead specimens become extremely brittle, the segments separating at the least touch.

The Poly:oniide' are semi-cylindrical creatures, with small heads, and from 30 to $100 \mathrm{or}^{\mathrm{m}}$ more joints, and cajable of rolling themselves up spirally. The mouth-parts are moditied into a sucking proboscis. The best known species, l'olyzonimm geimanicmm (Brandt), is about two-tifths of an inch long. 
The most familiar representatives of the millepedes in European countries are perhaps the Julidrt. They have a large head, and a long, cylindrical body

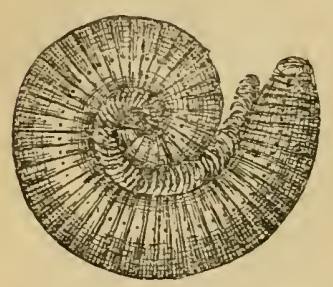

Fig. 33.-MiLlePede (Firostreptus piyrocepilituts, Koch.). composed of upwards of 30 segments, which ean be rolled up spirally. They are either eyeless, wr furnished with aggregations of ocelli. They are called snake-millepedes, and are very injurious in fields and gardens, feeding on roots and tubers, like wireworms. Our species are of small size, measuring from half an inch to nearly two inches in length, and are mostly of a dull bluish-black or lead colour. In tropical countries, some species grow to the length of a foot rir more; and they are described as creeping about the branches of the trees in the damp African forests. Unlike the centipedes, the millepedes are very sluggish ereatures, and move very slowly, notwithstanding their numerous legs. The species tigured, śpirostreptus pyrocephalus (Koch), inhabits South Afriea. It is black, with a bright red head, and is about four inches long.

The Polydesmidr much resemble the Julidu in habits, but are more Hattened, and the three single pairs of legs are placed on the second, fourth, and fifth segments, insteind of on the second, third, and fourth. They are very hard, but very brittle. The British speeies are small; but sonue of the foreign ones attain to a considerable size. They are composed of about 20 segments. Some species belonging to this family have been met with in the great eaves of Moravia and Carinthia. All are blind.

The Polyxenile are very small, whitish milleperles, not exceeding one-third of an inch in length in the largest species, and composed of only 9 or 10 segments. The head is well-marked, and they are provided with two clusters of ocelli. They are found under fallen leaves.

The Glomeride are composed of from 10 to 13 segments above, but each segment composed of four divisions below, an arrangement which enables the animal to roll itself up like a ball. They are short and broad, and much resemble wood-lice in shape, size, and appearance.

\section{CLASS IV.-PROTRACHEATA.}

THIs class includes the single family Peripatide, the typical genus being Periputus (Guilding). The few known species resemble caterpillars in appearance; but have two rather long antennz, and soft, eylindrical bodies, indistinetly divicled into from 13 to 40 segments, each bearing a pair of imperfectlyjointed feet, armed with two small claws. They are viviparous, and are found under leaves and among rotten wool. The body is capable of great extension and retraction. When first discovered, they were supposed to be Molluser, but were afterwards found to have more resemblance to the M!rimude. There is a well-developed tratheal system, upening by inconspicuous stignata placed irregularly over the hudy. The kuown species are 
found in South Africa, and in various parts of the West Indies and South America, as well as in Australia and New Kealand. Periputus inliformis (Guilding), from the Island of St. Vincent, is about two inches long. (See Fiy. 24).

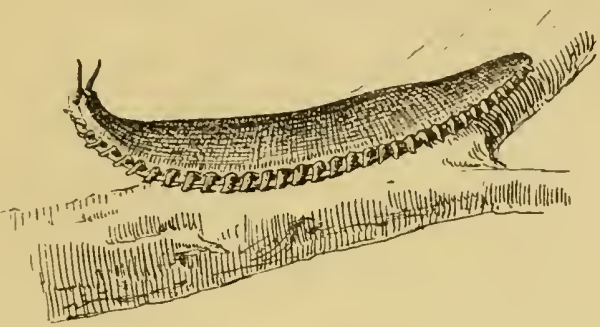

Fig. 24.-Peripatu; iuliformis (Guild.).

\section{CLASS V.-INSECTA.}

IxsEcts are by far the most numerous class of animals which inhabit the globe at the present time. The actual number of species on our lists cannot be much less than 300,000 ; and many thousands of new species are described every year. In this country alone we have between 12,000 and 13,000 species, although our famna is exceedingly poor, not only as compared with that of tropical countries, but even in comparison to that of Continental Europe. Only a few families and orders of insects are at all adequately known at present, and those only as existing in the best explored countries. The late Professor

\section{Number of Species of Insects.} Riley estimated the probable number of existing species of insects at possibly ten millions; and such estimates are generally far below the mark. The alternative estimate of two millions, which is put forward by some entomologists, seems to me to be ridiculously low, when we consider that the world has been so badly explored that we are not yet acquainted with a dozen species of Phasmide, or stick-insects, from Madagascar, an island which has been visited by many collectors, while the Phasmida are not a group of small and obscure insects, but one which includes many very handsome and conspicunus species, and to which belong the largest of all known insects.

To take another illustration, Mr. E. Ernest Green is now working at a monograph of the Coccide, or scale-insects, of Ceylon. Very few species were previously known from that island, and he will probably be easily able to multiply them at least by ten.

Nevertheless, insects, like the plants on which they feed, are bccoming 
rapidly exterminated in nearly all parts of the world by eultivation, clearing of forests, clrainage, etc.; and there is good reason to beExtermination of lieve that a large proportion of the insects now existing will species. become extinct before they ever find a place in our museums at all. The extermination of small animals proceeds puri yussu, with that of larger ones; but is rarely noticed, as their existence is, for the most part, unknown and unsuspected.

Insects generally pass through four stages, ealled egg, larra, pupa, and imago. In some orders, the pupa is inactive, and the insect is then said to have a perfect metamorphosis. In other orders, the pupa Metamorphoses only differs from the larva by possessing wing-cases, and of Insects. continues to feed as before. Then the metamorphoses are said to be inecmplete. The egg is laid by the parent insect on or near the appropriate food of its progeny, which, in insects with perfeet metamolphoses, is nearly always very different from that of the perfect insect. The larva is frequently called a grub, maggot, or eaterpillar, and is generally more or less worm-like. It may be legless, or may possess several pairs of legs, as well as the six pair's analogous to those of the perfuct insect. In insects with imperfect metamorphoses, the larva and pupa much resemble the perfect insect; and their food is frequently nearly similar. When insects reach their final stage, they generally acquire wings, and become cupable of perpetuating their species. 'There are, however, numerous insects which never acquire wings ; and in other cases the wings are undeveloped in one sex, generally the female.

In the perfect state, an insect consists of a number of rings, called segments, or somites, agglutinated into three masses, called the hear, thorax, and abdomen, which ean generally be well distinguished. Head of Imago. The head is considered to consist of a number of somites, just as the skull of vertebrate animals is thought to consist of a number of modified vertebra. The head contains several of the most important organs of the senses, such as the compound facetted eyes on each side of the head; the antenne, two long jointed organs, often feathered, or knobbed at the extremity, which are generally inserted in front between the eyes; the ocelli, stemmata, or simple eyes, of which there may be one, two, or three, on the crown of the head; and the mouth, which is either furnished with mandibles for biting, or a proboscis for sucking. There are also two pairs of jointed organs projecting in front of the mouth, called labial and maxillary palpi ; but one or otler pair is frequently wanting.

The three segments behind the head are called the thorax. Each of these bears one pair of legs beneath, and the second and third pairs bear the wings at the sides; for most inseets have four wings and six legs Thorax. in the perfect state. The legs are composed of several parts, ealled the coxa, or hips ; the trochanters, or hinge-joints; the femora, or thighs; the tibize, or shanks; and the tarsi, or feet. The tarsus is composed of five or fewer joints, known as the joints of the tarsi. The abdomen is composed normally of nine segnents, exelusive of some smaller ones at the extremity in comnection with the appendages of the generative system; but there are often fewer visible. Insects breathe by trachere, tubes which open by spiracles on the sides of the body. Many inseets are fumished with stridulating organs in the abdomen, while others stridulate by means of various struetures on their legs and wings; and in some insects the organs of hearing are situated on the legs. 
The wings of inseets are funished with a ramifying system of tubes, ealled nervures. When the insect emerges from the pupa its wings are small and limp); but first fluid and then air is pumperl through these tubes, and the wing quiekly grows to its proper size and dries. These nervures differ much in arrangenent in difler-

Wings. ent insects, and are very useful in elissification. The front of the wing is called the costil, the part nearest to the body the base, the part opposite to the body the hind margin or outer margin, and the part opposite the costa the inner margin. The extremity of the costa is ealled the tip, and that of the inner margin the hinder, or in the hind-wings the anal, angle. But these divisions sloade impereeptibly into cach other in insects with rounded wings. Between the bases of the fore-wings we sometimes find a triangular plate called the scutellum. The hind-wings ine often smaller, rounder, ind of a different consisteney to the fore-wings, but when the fore-wings play the part of wingcases, under which the hind-wings are folded, the latter are often much larger. Many inseets possess the power of leaping, in which ease the hind legs are often very long, or the coxie and femora are much thiekened.

Inseets are divided into several large orders, of which the following are he princijal ones:-

I. Coleoptera (Beetles). - Insects with mandibles; fole-wings (called elytra) horny or leathery; wings membranous, folded and doubled beneath them.

II. (IRTHOPTERA (Grasshoppors, ete.). - Insects with mandibles ; fore-wings (called tegmima) leathery; hind-wings folded fin-like beneath them.

III. Nevroptera (Dragonflies, ete.).--Insects with mandibles (sometimes very imperfectly developed; wings with many nervures; membranous and naked, or clothed with hairs.

IV. Hyuexoptera (Bees, Wasps, Ants, ete.).-Insects with mandibles, and often a proboscis; wings membranous, rather small, with few nervures; the fore and hind-wings often connceted together by a series of little hooks.

V. Lepidoptera (Butterflies and Moths). - Inseets with it sucking proboscis, and membranous wings clothed with scales.

VI. Hemptera (Bugs and Froghoppers).--Inseets with a sucking firoboscis, fore-wings leathery or membranous (or membranous only at the tips); hindwings membranous.

VII. Diptera (Flies).- Insects with a sucking proboscis, and only we pair of membranous wings.

The first four orders are sometimes called Insectu Mundibulutu, and the three last Insecta Honstellatu.

Fuller eharacters for these orders will be given in their plices. There are also some groups of insects (chiefly apterous) which will not fit very well into any of these orders, and which will be notieed separately.

\section{Order Coleortera (Beetress).}

The Coleoptern are physically anong the most highly organiser insects, although they eamnot enmpare with the Hymenoplem in intellectual development. They are distinguished by having four wings, the first pair of 
which, called elytra, are of a horny or leathery consistency, and when elosed, form covers for the true wings, which are membranous, and are folded beneatl them like a fan, but with the end doubled back. They undergo a perfect metamorphosis, the pupa being what is called necromorplous, or corpse-like, because, although inactive, it is not enclosed in a single tight-fitting integument, like that of a butterfly or moth, but is furnished with separate though immovable sheaths for the anteuna, legs, etc. The mouth of the perfect insect is mandibulate, or furnished with strong jaws or mandibles.

Beetles are very numerous. We are probably at present acquainted with at least 150,000 species; and although they have been more carefully collected than most other orders of insects, there are, doubtless,

Number of Species. enormous numbers which yet remain to be discovered. In Britain we liave in round numbers about 3,000 species. They feed on all kinds of animal and vegetable substances on land, in the water, and on the seashore; but very few are parasitic on other insects. They vary in size from an almost invisible speck to six inches in length, or with expanded legs and antennie much more. Many of the plant-feeding beetles, as the wire-worms, the chafers, the Colorado potatobeetle, the turnip-fly, etc., are extremely destructive to our crops; but the carnivorous beetles, such as the gromud-beetles, the tortoise-bectles, the lady-birds, etc., are very useful in destroying other injurious insects; and the grubs of some of the large wood-feering beetles are esteemed a great delicacy in some countries ; indeed, it is far more probable that the Cossus of the Romans was the larva of some linge Lamellicorn or Longicorn beetle than that it was the repulsive foul-smelling larva of the goat-moth, although Limné applied the name to the latter insect.

In the classification of beetles, the structure of the antenna, wing-cases and legs is of primary importance. The neuration of the wings, which is important in some orders of insects, is not mucl used in

classification. Coleoptera. It should, perhaps, be noted that the wings are sometimes wanting, when the elytra are sumetimes free, and sometimes soldered together at the middle line where they meet, which is called the suture. Sometimes both wings and elytra are absent, either in both sexes, or in the female only, as in that of the glow-worm. In some beetles there is a triangular space, let in, as it were, between the bases of the elytra; this is called the scutellum. In some families the anal appenclages are useful in elassification, while in others the structure of these parts is so uniform that it is not wortl noting in this connection. Ridges on the body or elytra are called carine, and circular pits (very conspicuous and numerous in some species) are called punctures.

The first large group of the beetles is that of the Geodephega, or carnivorous ground-beetles, which are divided into two main families, the Cicindelide, or tiger-beetles, and the Carabidie, or ground-beetles proper. They are hardshelled oval beetles, with long slender legs and antenna, and five-jointed tarsi on all the legs.

The tiger-beetles have a small moveable hook at the end of the maxillae, large heads, with rery prominent eyes and strong jaws, and very long and slender legs and antenuse. The front tibire are not notched Tiger-Beetles. on the inner side. We have but one British genus, of which the green tiger-beetle, Cicinclele compestris (Limu.), is the commonest species. It is found in sandy places, where its larva eonstructs a 
pitfall for other insects, very much resembling that formed by an ant-lion. The perfect insect is bright green, with white markings, and coppery logs and under-surfice. It feeds on other insects, and runs and thies in the sun with great activity. Some of the foreign species are very handsome. Some grenera frequent trees. We have figured a large green Chinese species, C. Chinensis (Limn.), with black and white markings.

In the Curduide the legs and antenne are less slender, the front tibie being sometimes flattened, and often furnished with a conspicuous notch on each side, and the heat is smaller and eyes less prominent; the maxillee have no moveable hook at the tip. They are much more nocturnal in their habits than the tiger-beetles, though many species may be met with by day. The species of the typical gentis Cumbus. (Lim.) are rather large beetles, many of them measuring an inch or more in length. The elytrit are well developed, and moreable, but the wings are absent. They are long beetles, of a black or bronzy

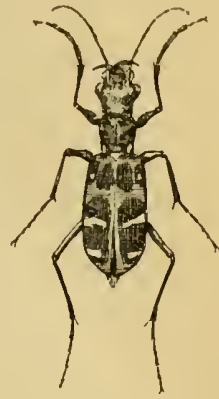

Fï. 25.-THE:LBEETLE (Cirindelt (Wivensis, Linn.). colour, and some species are benutifully metallic. One of the most conspicuous of these is the golden-green Carubus auratus (Limn.), a common garden insect abroad, but rare in England, though it is not unfrequently imported with vegetables. Some of the smaller species of this group-genus liembilium, (Latr.), etc.

Ground-Beetles. -are found in marshy places, though they are not quite aquatic in their habits. We have figured Zabrins yibbus, a blackish insect half an ineh long, with red legs and antenne ; which, contrary to the usual habit of the family, is destructive to growing com, attacking the ears at night. The Bombardier beetles, belonging to the genus Brachimus (Weber), are reddish beetles, about one-third of an inch long, with blueblack elytra, much broader than the thorax. They lurk under stones, and when alarmed, discharge an acid fluid which volatilises into smoke with a slight explosion.

Among the foreign Carabidie the most remarkable is the fiddler beetle Mormolyce phyllodes (Hagenbach), a reddish-brown

Fig. 26.- beetle, about two inches in length, with very broad elytra. The Zarrus firbers. shape of the beetle is really something like that of a fiddle. It is a native of Java.

The nest group, the Hydratephem, or water-beetles, have the two front pairs of legs near together, and the hinder pair more widely separated, and widened, flattened, and fringed with hair, so as to form a pair of oars. They are divided into two main fanilies, the Dytiscide and the Gyrinide. The species of Dytiscus (Limn.) are large smooth or furrowed olire-brown beetles,

Carnivorous Water-Beetles. an inch in length, and nearly half as broad. Their larve are long white grubs, with very strong jaws, and both the larve and the beetles are very voracious, destroying great numbers of water-animals, and are even very destructive to fish fry. The beetles quit the water at night and fly alout, returning to the water for the day. Sometimes they will dash themselves ugainst i pane of glass, mistaking it for water. There are numerous smaller species of this fanily, more arriegated in their colours; but the Gyrinida, of which there are only a few species in England, are more likely to attract 
attention by their habit of spinnmg round in circles on the surface of the water, which has given them the name of whirligig bectles. They are blueblack beetles, about one-third of an inch long, with reddish legs and antennie. They have four eyes (each eye being divided in two, an upper and a lower one), and it has been suggested that the upper eyes are intended for use in the air, and the lower ones for use below the surface of the water. The front legs are long and slender, but the two hinder pairs, as well as the antenne, are very short and stout.

The Birchelytirn are a very extensive family of beetles, distinguished by the very short square-cut elytra, which do not nearly reach to the extremity of the abromen, but which cover the amplo wings, which are folded beneath them. They are often called "Rove-Beetles," owing to

Rove-Beetles. some of the larger species, such as Ocyllms olens (Limn.) being found ruming about in search of dung or carrion. The beetle to which we have referred is a black, foul. smelling beetle with strong jaws, whieh lifts up its heal and tail when molested, and is known in many parts of the country by the name of the "Devil's Coach-Horse" In

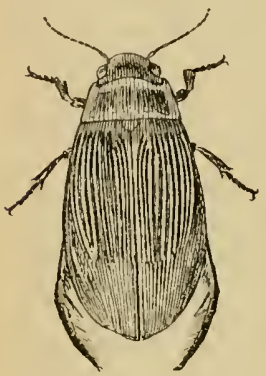

Fig. 27.-In!tisisus muryinalis.

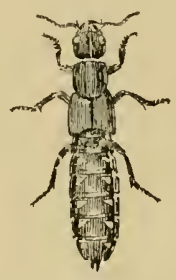

Fiig. $28 .-$

strimplimus crisurels.

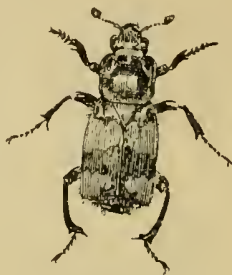

Fig. 29.Neringheruses iespilln.

Ireland it is regarded as a diabolical creature, which it is a meritorious action to kill. We have figured Striphylivurs cusurens (Cederh.), a black species with red legs and tegmina, and the thorix and segments of the abdomen partly bordered with silky yellow or golden pubescence. Most of the species of Brockelytra are much smaller than eicher of those just mentioned. Their habits are very varied. Many species may be found among moss or flowers, and others again live in ants' nests.

The next group, the Necrophaga or Claricomir, is tolerably numerous in species, though less so than the last, and is chiefly distinguished by the conspicuous knobs at the end of the antennae. MI ost of the species feed in decaying animal or vegetable substinces (carrion, fungi, etc), and some of those belonging to the genera Dermestes (Linn.), Anthemes (Geoffi.), and their allies, are very destruetive to hams, dried skins, etc. Dermestes lurdurins (Linn.) -the "Bacon Beetle")--is black, banded with grey, and spotted with black ; it is about a third of an inch long. The beetle and its hainy larva are too familiar objects to mamy housekeepers.

The burying beetles, which belong to this section, are larger inscets, lialf 
an incl or more in length, and are black, with orange-red bands on the elytra. They are renarkable for their habit of interring the budies of small animals, such as mice or birds, which they may finci lying about, by scooping out the earth underneath, dragging and Burying-Beetles. stamping them down, and covering them up. The females are buried with the carcase, on which they deposit their egors, and then make their way back to the surface. We have figured Necrophorns respillo (Linn.), one of the commonest species.

'There is a cromp of beetles allied to, and sometimes included in, the Necrophaya, called, from their aquatic habits, the I'hillyglinla. 'The largest species, Hydrous picens (I.imu.), is a shining black beetle, longer, narrower, and unre convex than the speeies of D!ytixus, from whieh its short-clubled antemne and much

\section{Great \\ Water-Beetle.} longer hind legs will at once distinguish it. It is sometimes ealled the great water-beetle.

The Lamellicories or chafers form a very interesting and important gromp of beetles, but are not very numerous in Europe. They are distinguished ly the structure of their antemne, which are short, and furnished at the extremity with a series of flat plates, which spread out like a fim. 'They feed on plants or dung, and

Chafers. some species are very destructive. They are stout, round, or oblong beetles of considerable size. Many of the species are black, but others exhibit much variety of colom: There are many large species among them, and they are frequently furnished with great horms, largest in the miles, and often assuming rely strange shapes, on different parts of the head and thorax.

The dung-beetles or Sormbride (a name sometimes applied to all the Lromellicornes) are generally black and shining, though sometimes inclining to greenish or purple, especially beneath. They have strongly toothed and thattened legs for digging. Some species, like the Egyptian sacred beetle, form pellets

\section{Dung-Beetles.} of dung which they roll to a suitable place,

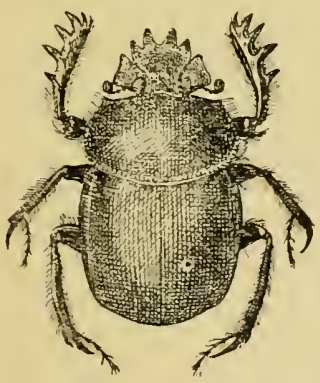

Fig. 30.-The Egyptian

SACRED BeETLE (Scuralueus sacer, Linn.). and in this deposit their eggs. This insect, Scoraluess sacer (Limn.), is eommon throughout the Meditermean region, and is black, with a broad Hat head, with a vertical spine in the middle, and strongly dentated on the front eurve. There are it number of species of more or less similar appearance and habits, several of which are represented on Egyptian monmments.

Our common black dung-beetles belong to the genus Geotripes (Fabr)., and have a much smaller liead than the sacred beetles. They fly in a straight line in the evening, as in the time of Shakespeare, who speaks of the "shardhorn beetle with his drowsy hum." They are frequently much infested with mites. The smaller dung-beetles of the genus Aphodims. (Illiger) are more numerous in species, and more ralious in colour. They resemble very small cock-chafers in appearance, and may of ten be seen thying about dung in the sunsline.

The Melolonthidre include the true coek-chafers, Our species, Melolonthe 
mlyaris and hippocesteni (Fabr.) are about an inch long, and are reddishbrown abuve, and black beneath, more or less clothed with

Cock-Chafers. whitish pubescence; the abdomen ends in a blunt projection. They are very destructive insects. The larva, which is ealled the white grub, lives in the ground for three years, feeding on the ronts of plants; and the beetle feeds on the leaves of trees. A similar but smaller species, Rhinotrogens solstitialis (Linn.), is common in many places, flying round trees in the evening.

The Dynastide include the largest and most strangely-shaped of the Lamelliconices, but they are not British, though one or two speeies are found in the sonth of Europe. The larve feed, like those of the stag-beetles, in the wood of trees. The largest species are found in South Ameriea, the males

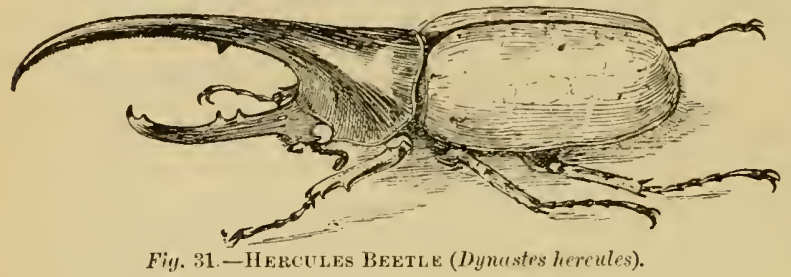

of the $\mathrm{Her}$ culles beetle, Jyynastes her:cules (Linn.), and one or two other species, having a huge horn, nearly as long as the rest of the body, project-

ing from the front of the thorix, and curving downwards to meet a similar horn which projects from the front of the head, and eurves upwards. It is black, with greenish-grey elytra, and is represented of half the natural size in the acempanying illustration.

To the Cetomiide belong the great Goliath beetles of Afriea, probably the bulkiest, but not the largest of all beetles. They are black, brown, or reddish, with longitudinal white bands on the thorax. Our Rose-Chafers. most faniliar representative of this family is the rose-chafer, Cetoniu anratu (Linn.), the beantiful, round, green, whitespotted beetle which we so of ten find nestling in roses and other fluwers.

The stag-beetle, Lucanus cerrus (Linn.), is the typical representative of the important family of the Lncanidee. It is black, with reddish-brown elytri, and the large males are often two inches long, having very

Stag-Beetles. large branching mandibles; in the females the mandibles are comparatively small. The mandibles of the male of this and other speeies of Lucanide vary very much in size and in development, but conform to certain reeognised patterns, commeneing with small males in which the mandibles are searcely more developed than in the female, and proceeding to the largest males, in which the mandibles are very large and bramehed. However, our common stag-beetle never attains the great development of mandibles which is noticed in some allied East Indian species. As already mentioned, the larve feed in the wood of trees.

The Servicomes are another group of plant-feeding beetles, comprising (besides others) the two important fimilies of Buprestide and Elateridu. These are long and narrow beetles with hard integuments, and generally with more or less pectinated antenne. The Buprestidu have no power of leaping, but many of the foreign species are remarkable for their brilliant goldengreen colour; and as they often measure nearly two inches in length they form very conspicuous objects in collections of foreign insects. The British 
species are not remarkable, lut the larva of the next fimily, the Eluteride, or click-beetles, are too well known to all click-Beetlesand acriculturists as wire-Worms. The beetles are often found wire-Worms. in corn, flowers, etc.; they are about half an inch long, and of various subdued colours. The hinder angles of the thorax are rather pointed, and on the under-surface there is a strong spine pointing backwards

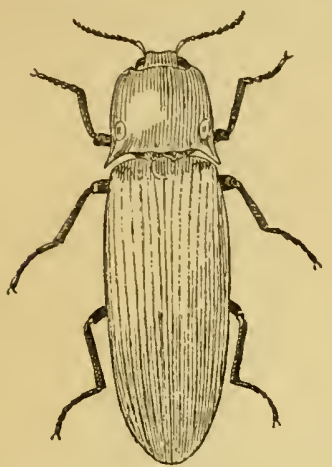

Fig. 32.-The Fire-Fuy (Pyropheru; noctilueus, Linn). and tixed in a groove. If the insect is placed on its back it bends its body, and uses this apparatus to enable it to leap up with a cliching somd.

Some of the larger foreign species of Elutcrilu rival the Buprestide in size; but thomgh sometimes green, rarely exhibit the siune brilliant metallic colouring. However, some of the linger.

Fire-Flies. species are luminous, the species of Pyrophomes, (Ill.), being the well-known tire-flies of Mexico and the West Indies. Some of these emit two different-coloured lights from different parts of their body. Their body-coloms are not conspicuous; the species figured, P!rophorus noctilucus (Limn.), is brown.

The Mulccodermi are another group, in which the form is generally long and narrow, the integuments unusually soft, the elytra being leathery rather than horny, and the thorax often rounded above. They are active insects, and of carnivorous habits. The most interesting beetles of this section are the glow-worms, in which the females are apterous. In our common yellowish grreen glow-worm, Lampyris noctiluca (Limn.), both sexes of which

\section{Glow-Worms.} are here figured, the female, which is apterous, is most luminous ; and is frequently noticed shining like a spark on a grassy bank or under a hedge. An allied species is common on the Continent, and may be seen flying about in the evening like little sparks; but the Italian fire-fly, which is also a Lampyris, and which is not found north of the Alys, is far more brilliant.

In almost all the beetles, which we have hitherto been considering, the tarsi are five-jointed on all the legs; but we now come to the large group of Heteromer, in which the two front pairs of legs hare five-jointed tarsi, but there are only five joints to the hind tarsi. An-

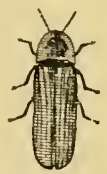

Fig. 33. (Lamp!ris nortiluer, Linn.). other peculiarity of this group is that the antenne are generally moniliform ; that is, consisting of a series of rounded joints looking like a string of beads. They are generally of a black colom, and many of the species have much resemblance to the Curabida, from which either of the characters mentioned will at once distinguish them.

The Heteromera, though rather numerous, meed not detain us very long, but we may mention three or four of the more interesting species. The cellar-beetles, which belong to the genus Blaps, are hard, wingless beetles nearly an inch long, with the body ending in a point, and of the colour of an mpolished boot. Black

Cellar-Beetles. as they are, they are not the "black-beetles" of our housekeepers, this 
scientific term being reserved for the reddish-lnown cockronches, which do not agree with either the arljective or the noun.

Another beetle common in houses is Tenebrio molitor. Limn.), a narrow, dark brown beetle about half an inch in length, which is better known in its linval state as the meal-worm. Ont of doors the oil-beetles, of the Meal-Worms and genus Meloe (Lim.), are fimiliar objects, and eam hardly be oil-Beetles. mistaken for anything else. They are large, soft, sluggish, blue-black beetles, with short, soft, and perfectly useless elytra, and are foumd elinging to blades of grass. Their transformations are extremely remarkable, for they pass their early stages in bees' nests, and undergo two or three transformations into larva and pupe before assmming the perfect state, which even then is sufticiently incomplete, as they never develop wings, except in the rudimentary form above described.

The blister-beetle, Contharis resicatoria (Linn.), is too well-known to need description. It is found in the south of England, but is too rare with us to be of any commercial value; the chief supply comes from

Blister-Beetles. Southern Europe. An ash tree loaded with these beautiful metallic green beetles is a splendid sight in the sumshine. Mylubris (Fabr.) is a rather large genus of Heteromera, the species of which are used for blistering purposes in some countries, but it is not represented in Britain. They are black beetles, with yellow or tawny sinots and bands.

The Rhynchophora, or weevils, are a very large group of beetles, which may easily be distinguished by the apparently four-jointed tarsi on all the legs ; by their very hard integmments, and by the struc-

Weevils. ture of their head and antemne. The head is produced into a long snout, towards the end of which the short, angulated, and generally clubbed antemna project on ench side. Must of our British speeies are of small size; but among the foreign beetles we find the large and beatiful metallic green diamond-beetles, and Diamond. the palm-weevil of the West Indies, a large Beetles. reddish-hown beetle an inch and a half long, the wood-feeding grub of which is considered a great delicacy. The nut-weevil, Bulanimus mom (Linn.), is a small brown beetle, with the elytra varied with grey. It is about $\frac{2}{3}$ of an inch in length, and is represented somewhat above natural size in the accompanying wood-cut. It exhibits the peculiar structure of the rostrum and antenne very typically. The Scolytidu have the head less prolonged

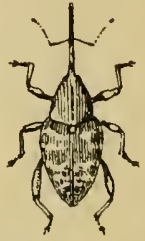

Fiy. 35.-THE: NUT-IVEEVIL (Bulanimus mucum, Linn.). than usual among the weevils, and are extremely destructive to trees, eating galleries through the wood in all directions.

The Lomgicornes, or long-horned beetles, are an extensive gromp, with ap)parently four-jointed tarsi, long slender antennie, of ten as long and sometimes many times longer than the body; not clubbed at the ex-

Long-Horned tremity, but with a long and thick basal joint. The eyes are Beetles. generally more or less constricted in the middle, at least on one side, and are sometimes completely divided, as in the Gyminidu. They are generally insects of large size with long bodies, and their larva feed in the wood of trees. They are very numerous in warm climates; but most of our British species are either of small size, or are scarce. ()thers, which are not considered indigenous, are frequently imported into England with timber. One of the commonest and most beantiful of our 
larger species is the musk-bectle tromin moschetr (Limn.), which is eommon in most parts of the country, and is often found resting on the trunks of willows, in which the larve feed, in the daytime. It exhales a strong but agreeable orlomr, eontrary to the hathit of most other beetles, many of which discharge an extremely offensive liquid when touched. It is of a bright green colour, and often exceeds an inch in length.

This species belongs to the Cemmluyidre, the typical farnily of the Lungicornes; but the largest and bulkiest species belong to the Priomida, which

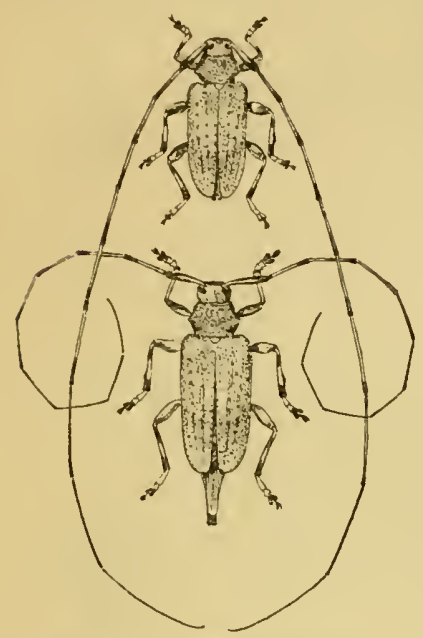

Figs. 36, 37.-Aernthreinus adilis, Linn. are brown or reddish-brown bectles frequently three inches long. Our single native species, Prionms corirerins (Linn.), is rather scarce. It is aljout the length of the musk-beetle, but much stouter, and of a brown colour. We have figured both sexes of Acunthorinus aditis (Linn.), which lias longer antenne in the male than any other British species. It is rather scarce with us, being found chiefly at Rannoch, in Scotland, in the pine forests. It is reddish-brown with grey pubescence, and four yellowish spots on the thorax. It belongs to the family of the Lamiide, which is distinguished by the large head, and almost vertical face.

The last group of the beetles with apparently four joints to the tarsi is that of the Phytophargu, or plant-feeding beetles $p a r$ excellence. They are round or oval jeetles, of small or' moder-

Plant-Feeding Beetles.

ate size, and of varions colours, many being of a brilliant green. The antenne are grenerally rather short, and not elbowed, or set on a rostrum, and this alone will generally distinguish them from the beetles of the two preceding groups.

This group includes several very injurious species, among others the Colorado potato-beetle, and the turnip-beetles. The Colorado Potatobeetle, Leptinoturs decemlineata (Say), is a native of the IVestern States of America. It is about half an inch long, and of a yellowish colour, with eighteen black spots on the thorax, and ten black stripes on the wing-cases; the larva is

red, spotted with b]ack. Onr figure is somewhat above natural size. Some years ago this bectle began to spread eastwards from its haunts in the Roeky Mountains, where it used to feed on a wild species of potato; and to attack the cultivated plant. It soon spread over the whole of the United States, and there is no efficient way of arresting its ravages but by the free use of "Paris Green," a dangerous compound of arsenic. Great fears were expressed lest it should spread to Europe, and special measures were taken by all the principal Govermments to guard against its invasion. Nevertheless, in addition to a few isolated instances of its occurrence in various countries, a whole colony was dis-

\section{Colorado \\ Potato-Beetle.}

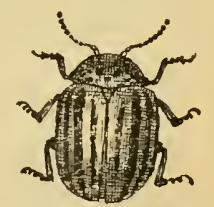

Fiq. 38.-Colorado BeEthe (Leptinotarsu decemlineata, Say). 
covered many miles from the sea-coast in some potato fields at Mülheim-onRhine, nearly opposite Cologne. The tields were at once ploughed up, drenched with petroleum and burned over; and the pest was fortunately stamped out. The scare has now subsided, but it is all the more necessary for us to be prepared to take equally prompt and encrsetic measures if the Colorado beetle should happen to make its appearance among us, as is always possible enough, perhaps at some out-of-the-way place where it is least expected.

Among the largest and most conspicums of the foreign species of this group are the species of the genus Sagru (Fabr.), which are found in the East Indies and Africa. They are lomg, smooth Turnip-Beetles, beetles, of a brilliant green colour, sometimes varied with coppery red, or purple, and the hind femora are of very large size, being constructed for leaping. These beetles are an incl long, but the destructive turnip-beetles, belonging to the genus Phyllotretr (Latr.), have also thickened hind femora, and skip aloont like fleas. They are oval, and less than a fuarter of an inch in length. The elytra are bronzy black, and marked with a yellow stripe. They are often called "Turnip Flies," but turnip fleabeetles would be a more appropriate term. Our figure of Phyllotreta nemomim (Linn.) is somewhat above natural size.

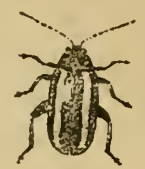

Fig. 39., -Phyl. lotreta nemorum.

The last of the great group of beetles are the Pseudotrimera, which are small species, distinguished by having only three visible joints to the tarsi. The hest known of these are the lady-birds (Coccinellidce).

Lady-Birds. of which there are a considerable number in England. They are small round beetles, and the elytra are mostly red with black spots, or black with red or yellow spots. The head and thorax are black with white markings. They are very useful insects, for they are carnivorous, and destroy large numbers of A phides, or plant-lice.

We have figured the typical form of one of the commonest species, Coccinella bipnenctuta (Linn.), slightly maguified. It is very variable, and the elytra are sometimes almost black, instead of being red, with a black spot on each, as in our figure.

Other families of this group are the Trichopterygide, the smallest of all beetles, and if we except some of the egg-parasites among the $H$ ymenoptera, almost the smallest insects known. They are little black beetles, with long, slender, clubbed antennee, and are found among dtcaying vegetal)le refuse.

Other species belnnging to the Psendotvimere are found in fungi, and others, again, inhabit ants' nests, where, it has been suggested, they may be preserved as pets.

\section{Order Orthoptera (Crickets, Locusts, etc.).}

The Order Orthoptera, or straight-winged insects, includes the earwigs, cockroaches, crickets, grasshoppers, locusts, etc. These are all insects with strong jaws, instead of a proboscis, and differ from the other mandihulate orders by the fore-wings (which are called in Orthoptera not elytra. but tegmina) being generally of a different consistency to the other's throughout, 
and leathery, rather than horny, as in the Coleopterm. 'They also difter from the Coleoptera in the hind-wings being folded lengthwise, and not doubled back at the tips, except in the earwigs and cockroaches, which some authors consider to form two separate orders, distinct from the Orthoptere.

In the Orthoptera the metamorphosis is ineomplete, there being no inactive pupit-state. The larva resembles the perfect insect, except in size, and in the alosence of wings. During the period which elitpses betwcen the list two moults, the inseet possesses short wing- Metamorphoses. cases which enclose the undeveloped wings, and this stage is considered to correspond to the pupa-state of insects with complete metamorphoses. The inseet is, however, as active and voracious as in the larva state, and is frequently temed a "nymph" by those who restrict the term " pupa" to insects with complete metamorphoses. In the perfect insect the antenma mre usually slender, with well-marked joints, and are sometimes of great length.

The bulk of the Orthopteru are plant-feeding inseets, but the Muntidu, ur praying inseets, are carnivorous, and the earwigs and cockroaches will eat lecaying animal as well as regetable substanees. This order contains no parasitic insects, and searcely any which are directly harmful to man, but the economic injury occasionally caused by locusts in many countries probably far exceeds that due to the ravages of all other insects put together. These insects are generally voracious in all their stages after leaving the egg.

The Orthopterc are one of the least numerous orders of inseets in species, though most abundant in individuals, and are very poorly represented in cold countries. In England we have only about sixty species, inchuding casual visitors, and introrluced species.

The Forficulide, or earwigs, much resemble the Stchliglivider among the coleoptera, and were actually included in the Colcopteru by Linneus. Their" tegmina are very short, and the large transparent wings are folded beneath them, so as to be quite invisible when closed, except the projeeting tips of the opaque part of the costa, which are of about the same colour and consistency as

Earwigs (Forficulider). the tegmina. At the end of the body there is always a peculiar appendage like a forceps, which is mole developed in the male than in the female, and which is said to be used for folding and unfolding the wings. Many species however, are apterous, and others, though provided witl ample wings, are never seen to fly, though they may possibly use them only in the darkness of night; others, however (chiefly small species) tly about by day. They are fond of coneealing themselves in any sort of crevice, and some flowers, such as dahlias and sunflowers, are greatly infested by them. They have sometimes been known to creep into the human ear, and there is no doubt that their popular name has originated in this manner. They are generally dull reduishbrown, unattractive-looking inseets, though one or two East Indian species are of a rich purple. They measure from half an inch to rather over an inch in length; the antenne are generally of moderate lengtl, and the legs are short. We

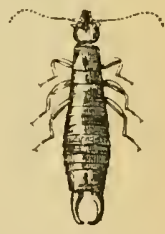

Fig. 41.-EAR WIt: (Anisolabis. maritima). have fignred a brown apterous species, which has been introduced into most parts of the world, and is oceasionally found in England.

The Blrttidr, or cockroaches, mre another.very isolated group. These are 
oval insects, generally more or less flat, with a rounc or oval thorax, umler which the small head is often quite hicklen. The antemie

Cockroaches are slender, ancl moderntely long, and the legrs are

(Blattille). very spiny. Many species are apterous, at least in the females ; but the majority are winged, the wing-cases being of a parchment-like consistency, and generally more or less overlapping; the wings are transparent. They are noctumal insects, feeding chietly on decaying vegetable matter ; but many are carnivorous, our domestic species being particularly fond of bed-lougs. The eggs are deposited in a capsule, and the female may often be seen rumning about with the copsule projecting from her body. They are nearly always of dull colours, such as grey, reddish-brown, or black. Three species commonly infest unr houses, all of which appear to have been imported insects, like most of our household pests. The first and smallest of these is Phyllodromin germanicu (Limn.), a pale brown, winged insect, about half an inch long. It is sometimes found in bakeries. The female is said to open the egg-case to allow of the escape of the young. In America, where it is much commoner than with us, it is ealled the croton bug, and is said to frequent the neighbourhood of water-pipes. Our common cockroach, Bluttu oricntalis (Limn.), a redelishbrown insect, with fully dereloped wings in the male, but only rudimentary wings in the female, is gonerilly called "the black beetle," though it is neither black nor a beetle. An-

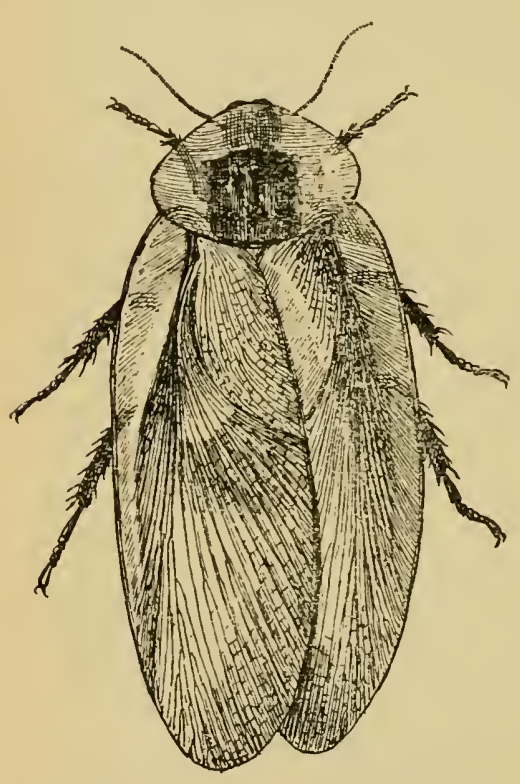

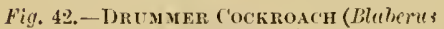
giyanteus, Linn.).

in Mexico and South America. other species, Periplanetu rmericumu (Fabr.), which is winged in both sexes, is redder; the thorax is yellowish-grey, with a large black mark in the centre; it expands nearly two inches across the wings, ind is not uncommon in warehouses. Cockroaches of various species abound on board ship ; and it)art from one or two small indigenous species (found not in houses, but in woods and fields), many others, hesides those which we have mentioned, mily he met with in the docks, and elsewhere, some of which may perhaps succeed in establishing themselves in this country. Even specimens belonging to the genus Blaberus (Serville), which includes the great broadwinged species called "drummers" in the West Indies, have been met with occasionally. These are yellowish-grey, with a large black mark on the middle of the thorax, ind measure at least three inches across the wings; but the largest of all the cockroaches belong to the genus Megaloblatta (Dohrn), found They have longer and narrower wings in 
proportion than blaberns, measuring fully six inches in expanse, and are of a dark reddish-brown colour.

Tho late Mr. H. N. Museley, in his "Notes of a Naturalist on the Challenger" (p). 592, 593), gives the following amusing aceount of the eockroaches on board shıp :- "The first coekroaches apparently came on board at St. Vincent, Cape Verdes, for a linge one of these insects was eanght by one of the lieutemants on his

Cockroaches on bed soon after we left that port. Cockroaches soon became the Challenyer.

plentiful on buarl, and showed themselves whenever the ship was in a wam elimate. A speeial hannt of a swarm of them was hehind the books in the chemical laboratory, from which Mr. Buehaman in vain attenupted to evict them. At one period of the voyage, a number of these insects established themselves in my eabin, and devonred parts of my bouts, nil,bling off all the margins of leather projecting beyond the seams on the upper lenther. One huge winged evekroach baftled me in iny attempts to get rid of him for a long time. I could not diseover his retreat. At night he eame out and rested on my book-shelf at the foot of my bed, swaying his antennie to and fro, and watehing me elosely. If I reached out my hand from bed to get a stick, or raised my book to throw it at him, he dropped at once on the deck, and was forthwith out of harm's way. He bothered me much, becaluse, when my light was out, he had a familiar liabit of eomine to sip the moisture from my faee and lips, which was clecidedly umpleasant, and awoke me often fiom a dome. I believe it was with this object that he watehed me before I went to sleep. 1 often had a shot at him with is book or other missile as he sat on the book-shelf; but he always dodged and eseaped. His quickness and agility astonished me. At last I triumphed, by adopting the advice of Captain Maclean, and

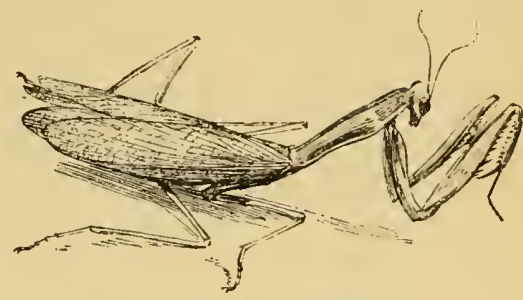

Fig. 43.-Mantis migiost. shooting him with a pellet of paper from my air-gum, a mole of attack for which he was evidently unprepared; lut I was taken to task for diseliarging the air-gun in my cabin, beeause it made a noise just like the sharp erack of a spar when broken by the foree of the breeze, and ereated some exeitement on the mper deck, where the sound was plainly heard."

Tuming now to the more typical Oithopteru, we commence with the Muntidu. or praying insects, which are not British, though one or two speeies are common in Southern Europe. They are generally green, yellow, or brown (very larely blue), with ample wings, which are generally transparent; the tegmina are likewise hroud, and are opaque, at least along the costit. They are usually

Praying Insects (II Iantider). insects with long slender bodies and slender legs; the front pair of legs, however, is large and strong, and the lower surface of the tibia is furnished with a row of very strong eurved spines, which elose against the femora, which are also sometimes denticulated or knobbed. They are carnivorous and very predatory insects, and usmally sit with the forepart of the body and the fore-legs ratised on the wateh for prey. This position las caused then to be looked upon with superstitious reverence; and it was salid that if 
children had lost their way they had ouly to ask a Mantis, which would immediately extend one of its front legs in the desired direction. Some idea of their real propensities, however, may be gathered from the following anecdote: A male and female Mantis were once observed courting, when the female suddenly chopped off the head of her mate and deroured it. This incident was followed by their mion, after which the female devoured the body of her unfortumate partner. But it should be mentioned that in most insects (subject, however, to exceptions) the female is much langer and, as at rule, less brightly coloured than the male. Wre have figured a green European species of Mantis. (Fiø. 43.)

The Phrsmide are another group of Oothoptere, which are wholly umrepresented in England. though in few small species belonging to the typical genus Phasmu (Illiger) are found on the northem shores of

Stick Insects

(Phasmide). the Mediterranean. These are apterous insects, about two or three inches long, and with shont antemme, though the generic name is frequently misalplied to it South American genus with long antemne, and large, brightly-coloured wings. The Phresminler, in stick insects, have long slender legs and bodies, and are exclnsirely regetalle feerlers. Although the legs are spiny in many species, they are not raptorial, as in the Mantide. A great number of species are apteroms, and of a brown or yellowish colour, perfectly resembling pieces of dead stick in appearance. The largest insect known is a species from Borneo, Phrygartistric seritipes (Gray), the female of which measures more than a foot in length. Other apterous species, ahout nine inches long, and half an incli broad, are flattened rather than rounded, and are of in green colour. perfectly resembling shoots of bamboo. In the winged Phasmide the tegmina are alway's very short, and frequently scale-like; but the wings are often very ample, and are thickened along the costal area, which really answers the purpose of tegmina in protecting the delicate fan-like wings. Many of the Australian Phasmida measure six or seren inches in exfanse, and are most beautiful insects, with large pink, blue, or green wings. 'There is a smallel. green species in the Pacitic Jslands, Lopmphus. cocopharges (Newp.), about five inches long, which is extremely destructive to the cocomut trees. It has odd little rudimentary red wings not more than an inch long; and shares with other species of Phasmide the habit of ejecting a disagreeable Hluid when alarmed. This particular insect is said to be able to shoot it a distance of five feet, and the fluid is so acrid that it is liable to cause blindness if it reaches the eyes.

The next fimily, the Gryllide, or crickets, ayrees with the remaining groups in having the hind femora much thickened, and adapted for leaping. The antemne are long and slender. the tegmina rest flat on

Crickets

('inyllieler). the back, and are frecunently eurved downwards at the sides, but are never rouf-like, and the head is linge and vertical, with prominent eyes. The legs ate generally strongly spined, 
and the oripositor of the female is short and straight. In the male the tegminis are differently formed from the female, exhibiting a bare space corered by strong veins, which are roughened benoath like a file, so as to produce a ehirping sound when the tegminit are rubbed over one another. The females are mute, as in most other Orthopterous insects.

We have three conspicuous kinds of erickets in this country, of which the best known is the pale brown house-ericket, Gryllus domesticus (Linn.). It is very similin in its habits to the cockrnach, but is a much less disgusting insect, both in appearance, and heciuse it does not possess the foul odour of the cockroach. It is, however, il destructive insect, and is very fond of moisture; and this is the reasson why it sometimes eats holes in wet clothes left hinging at the fire to dry during the night; though 1 have sometimes heard that "it was out of spite against the maid, who was in the habit of killing them." Many persons have a superstitious dislike to injure crickets; and I lately heard of an attack of toothache being attributed to the murder of a ericket. The field-cricket, Acheta campestris (ILimn.), is rather lirger and stouter than the house-cricket, and is of a nearly blitck colour, exeept the tegmina, which are brown. It is a very destructive inseet, feeding on the roots of plants; but has become exterminated by cultivation, and is now very rare in England, though it and severil other elosely-allied species are abundant in most parts of the world. The mole-cricket, Curtilla yryllotalpa (Limn.), is a brown inseet two inches long, which represents a small section of erickets in which the front legs are very broad and tlat, resembling those of a mole, and are used for burrowing in a similar manner. It does much mischief by destroy-

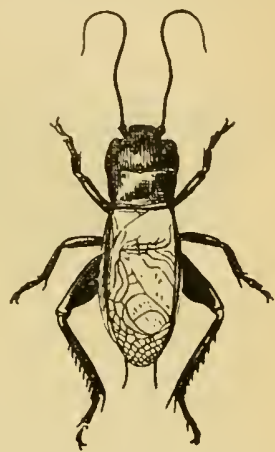

Fig. 15.-FIELD-CRICEET (Acheta campestris). ing the roots of plants, and is a common insect, though seldom seen above ground.

The Phasgonuride, or long-horned grasshoppers, are a large group divided into numerous sub-families, which resemble the crickets in many respects, having large heads which frequently slope inwards and downwards, and long or rery long antenne. The tegmina, however, are generally roof-like, and the colour is most frequently green, though sometimes brown. The ovi- (Phasgonurida.) positor of the female is long, compressed, and curved upwards at the end. The legs are generally less strongly spined than in the crickets. The typical species of this family is known as the Great Green Grasshopper, and is not uneommon in the south of England, where it can easily be recognised by its large size (three inches or more in expanse of wing), bright green colour, very long antennæ, and in the female its long oripositor. Some of the North American species of this fimily are called "Katydids," their chirping having been read into the words, "Katy did, Katy did, Katy didn't, she did, she didn't," and so on.

Some insects belonging to foreign sub-families of this group are of very large size, measuring six or eight inches in expanse; and some are remarkable for their broad flattened thorax, or for their disproportionately long hind legs. Others, which are found in the deserts of Africa, are bulky apterous insects, on the large fore-legs of which the curious auditory organs 
which many Orthopterous insects possess in this odd situation are rery conspicuous, opening either in a large oral depression, or in a mere slit.

The last family of the Orthoptera, the Locustida, which comprises the true locusts and grasshopper's, may be distinguished at once by the short antenne.

The ovipositor is inconspicuous, and the lind legs are long

Locusts and and slender, the hind tibie being generally furnished with a Grasshoppers double row of spines abore. Our common grasshopjers leap (Locustider). rather than fly, but the locusts, some of which risit us occasionally, thougl they probably never breed here, are very strong on the wing. The body and tegmina are generally brown, but the wings are often red, blue or green. The most destructive species in Asia and Afriea are about five or six inches in expanse; but the largest South American locusts measure nearly a foot across

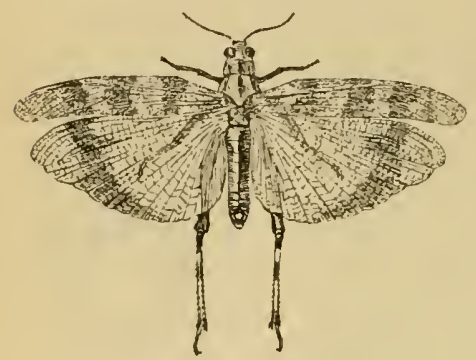

Fig. 46.-BLUE-WiNgen GrasshopPer (Edipoda ccerulescens). the tegmina. In some of the earlier sub-families, the antenne are very broad and flattened, but in the more typical species they are cylindrical. These chiefly inhabit the warmer parts of Asia and Africa. Destructive locusts are not always large; for instance, those which ravage Cyprus and the United States are small species, not expanding more than a couple of inches across the wings. Species of about the same size, with blue and red wings, are common on the Continent, in pine forests, and rineyards, etc.; and the blue-winged grasshopper, Edipoda camlescens (Limn.), is said to be sometimes found in England.

Locusts are equally destructive in all their stages after quitting the egg, $\mathrm{f}\left(\mathrm{r}^{\circ}\right.$ the young locusts can leap, though not fly, and they advance across the country in vast hordes in this manner, before they acquire their wings, and they have no quiescent pupa stage. No one cain form any conception of the meaning of an invasion of locusts who has not actually seen one; and at present, schemes are in progress for checking their ravages in Natal by the use of specially constructed guns and mortars, in addition to other means. In America and Australia the term "locust" is frequently but improperly applied to the Cicididce, which belong to quite a different order of insects.

\section{Order Neuroptera (Lace-winged Ixsects).}

Linneus applied the term Nenropter, or Nerve-wings, to an Order including a number of conspicuous insects of rather large size. They have strong jaws, four wings, similar in texture, and generally covered with a notwork of very numerous ncrvures; incomplete metamorphoses, and carnirorous habits.

Several very discordant grons are included under the tern Nenroptern;

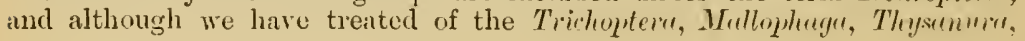


and Collembolu separately, many groups lesides these are regarderl by some iuthoirs as forming clistinet orders.

Although the size and importance of the dragonflies indicate them as the true types of the Limnean Newroptera, yet they have sometimes been united with the Orthopterc under the absurd term Pseudo-neuroptera. But the dissimilarity of their wings is quite suftieient to preclude their being clissed in the same order as the

Dragonflies

(Odonata). Orthoptere; while if they were, the name Oithoptere would liave to be abolished, being of post-Limnean date, and its contents transferred to the Nentroptere. The diangonflies ire frequently called Odonutu.

They are grenerally slender-bodied insects, with long, moderately broad wings, and a large heald, the greater part of which, however, is oetupied by the two linge compound eyes. Their wings are generally culourless, but in some species are very brightly coloured, in Metamorphoses. whole, or in part, with irideseent purple, blue, green, or scarlet. The commonest pattem, where any exists, and which reappears in several distinct families, is a broad purplish-brown band across the middle of both pairs of wings. They are predaceons insects in all their stages. The larva and pupa are brown, and live in fresh water; the pupie can be distinguished by their conspicuous wing-eases. When the pupa is matured, it leaves the water, climbing up a reed, or some other convenient support, and then splits down the back, to allow of the emergence of the perfect insect.

The neuration in some of these insects is often very complieated, the network forming many thousands of cells in each wing in some species, while other's exhibit comparatively few nervures. They are divided into several families and sub-families, of which we will notice two or three. In the Libellulide, the triangular (or more rarely, quadrilateral) space near the base of the wing, from

\section{Family}

Libellulide". which several of the principal longitudinal nervures of the wings start, is differently shaped in the fore and hind wings, and the eyes are eontignous,

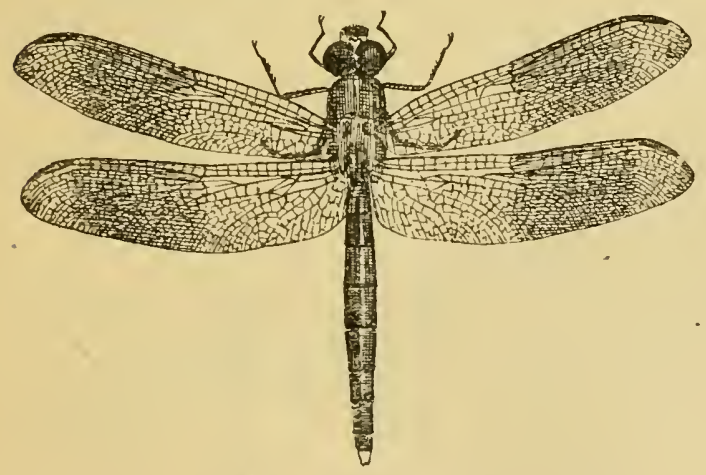

Fig. 47.-Distgoxfux (Trithem is umbrata). Nat. size. but rarely united by a long suture. This family takes in the greater part of the moderate-sized dragonflies with rather stout bodies, the commonest of which, Libellula depressu. (Limu.), which may often be seen flying over water, has transparent wings three inches in expranse, and a flattened and rather short and broad body, which is blue in the male, and yellow in the female. We have figured a common South Aneriean species of this fanily, Trithemis nmbrete, (Lim.). The Gompleidn resembles the Libellulicle, but the eyes are distinctly 
separated. The Exichide, which perhaps attract more notice than any other. dragontlies, measure three or four inches in length, and also Family across the wings, and have a long narrow triangle, crossed Eschnidre. by several nervures, on each wing, shaped nearly alike on all the wings, and very large eyes, which are contiguous, being only separated hy a small suture on the top of the head. The wings are trinsparent, tinged with brown in one species; and the bodies are elegantly marked with blue, green, and yellow, on a brown or black ground ; but these colours generally fade in a sliort time after deatl.

The Ayrionider have slender bodies, small and inconspicuous triangles on the wings, and wide hearls, with the eyes far atpart; in fact their heads are something like those of the hammer-headed shark on a small

Family scale. Some of the larger European species, measuring upA frionile". wards of two inches across, have beantifully colomed wings, and frequently blue or green bodies. Two species are comnom in England, one with purplish wings, and the other with a purplish band, resembling our figure 47 , but with a longer and more slender body. Some of the foreign species are far more brilliantly coloured, the common Indian Nenrobasis chinensis (Linn.) having bright green or blue hind wings. Several of the American species of Hetrinu (De Selys), and allied genera, are transparent, with a bright scarlet patch at the base of the wings, which are otherwise transparent. Our two British species of Agrion, already mentioned, are fond of flying over ponds or slowly-flowing streams. These coloured species belong to the family Agrionina, and have more cross-nervures on the costa before the middle of the wing than the other sub-family Canagrionina, in which there are only two. The latter sub-family includes a considerable variety of species, all slender, but among them are the largest and the smallest dragonflies known. The largest are Soutl American species, six or seven inches in length and expanse, with long transparent wings, tipped with black or yellow; the smallest are the little slender-bodied, transparent-winged drigonflies which are so abundant among reeds and rushes. The type of this sub-family is Concgion puella (Linn.), which has a loug body prettily marked with blue and black. It measures rather more than an inch in length, and in the expanse of its transparent wings.

In all the true dragonflies the antenne are very short, filiform, and inconspicuous, and are generally only three-jointed; but in the Planipeniu $\begin{array}{cl}\text { Ant-Lions } & \text { we meet with insects } \\ \text { (Myrmeleonirle). } & \text { areoften of consider- } \\ \text { able length, and fre- }\end{array}$ quently clubbed. Theant-lions, which belong to the family Myrmeleovide, much resemble dragonflies by their. long, narrow, and generally transparent wings, but their bodies are much shorter, the neuration of the wings is dissimilar, and the antemne are short and clubbed. The ant-lions are not British, though several species are found in Southern Euroje; their

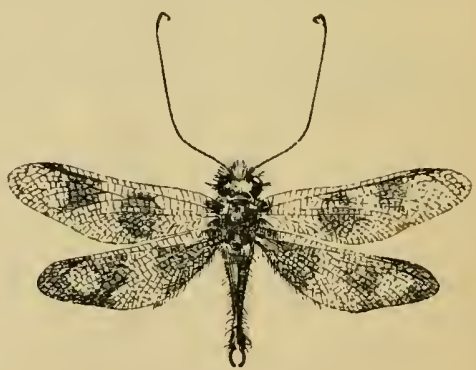

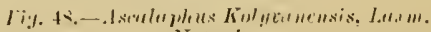
Nat. size. larve have strong jaws, and lible thenselves at the bottom of pitfalls, 
which they dig in sandy soil, to entretp the ants and other insects on which they feer. The Asculnplicler are another family not represented in Britain, but which has also several representatives in Southern Europre. It is distinguished by its very long, clubhed antemuse. In the typical gemus Ascrlephus (Fabr.),

Family A secelaphider. the wings are black and yellow, and broaler and shorter than in the Mymelomide; lont in many of the allied tropical genera, the wings are longer, narrower, and mostly transparent. I third allied family, the Nommiterifle, not British, and not extending so fal south as the other's, beins enntinerl in Enrope to the shores of the Mediteranein, has rather short and slender antemue, broarl, wral, black and yellow fore-wings, and very long and narrow lind-wings, looking, when the insect is held head upwards,

Family

Nemopterilue. almost like a jair of stilts. The fore-wings measure about an inch and a half in expanse, but the curinus narrow hind-wings are nearly two inches long. 'The most interesting British species of Plunipemuin belong to the Chrysopirlw, or lace-winged flies, which halve bright green hodies, long slender antemue, golden eyos, and transjatrent, delicately reticulated wings, rarely exceeding an inch in expanse. Their larve are very useful in gardens by

Lace-winged Flies

(Chry:sopidw). destroying the Aphiles, or plant-lice.

The Elhemerille, which are generally called May-Hies, or Day-Hies, Hy over streams in summer. They have long, slender antemma, slender bodies,

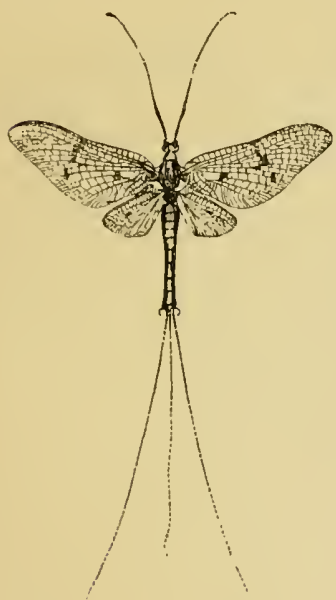

Fig. 49.--MAY Fu (Elhemera vulgata, Linn.). ending in two or three long filaments, broad fore-wings, about an inch and a half in expanse, and very small, or ${ }^{\text {m }}$ undeveloped

May-Flies

(Ephemerida). hind-wings. Their larve are aquatic, and take several months to arrive at maturity; but the perfect insects live a very short time. They are insects of dull colours, brown, greenish, dull grey, or whitish; and on the Continent there are several white species which emerge from the water after sunset, and perish before sunrise. In the evening they swarm in at the open windows of waterside houses to the lights in great numbers. In the morning the ground near the rivers where they breed is covered with their dead bodies, lying in heaps.

The Perlider is another family of brown Neuroptera, with well-developed hind-wings, large heads, and two long filaments at the end of the body. Their larva likewise are aquatic.

The Termitide, or white ants,

Stone Flies (Perlide). are fortmuately not British, and it is to be hoped that they will never succeed in getting a footing in this country. The males and

females have long and rather narrow wings, and short, stout boules; the workers are wingless, and have very large heads, and powerful jaws. They are very similar to ants in their habits, and shme the light, always living either in

White Ants

(Teimetirlw). 
large nests, or forming galleries in wood, which they eat away from the inside.

Some of the remaining families of Neuropterc eontain very small species. Among the Psocide, some are winged, and other's are apterous. The species most often seen is Atropos mlsatorin, a small white apterous

Family Pxocidre. insect, which is frequently met with in neglected collections of insects, and is often called it mite. It is active, and sufficiently linrge to be seen rumning about. It has been stated on grood atuthority to produce a ticking somend, lut this appear's almost impossible in the case of so small and soft il creature.

The Thripuile are rery small insects, which are sometimes placed in a distinct order, muler the name of Thysunoptera. They have Family rather long narrow wings, with very Thripide. long fringes, and sometimes cause much injury to plants, especially in greenhouses, where the most tronblesome species

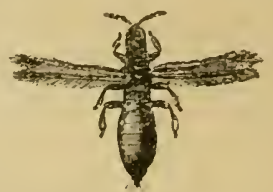

Fig. 50. Thrips arrelium. Magnified. have received the name of the "black fly." Tohacco smoke is recommended for their destruction. 'The species figured, Thrips cerealimm (Hal.), infests the ears of wheat.

\section{Orinek Trichoptera.}

The Trichoptera, or hairy-winged insects, include the Caddis Flies, which were formerly placed with the Neuroptera, from which they differ in many important particulars. The insects have four wings, similar Caddis Flies in texture. The mouth parts are imperfectly developed, the (Trichoptercu). antemne and legs are long and slender, and the latter spined, and the metamorphoses are complete, and aquatic. 'The Trichoptera, especially some of the smaller species, have much resemblance to some of the Pyrulide and Tineide anong the Lepidoptera, in shape, neuration, and in

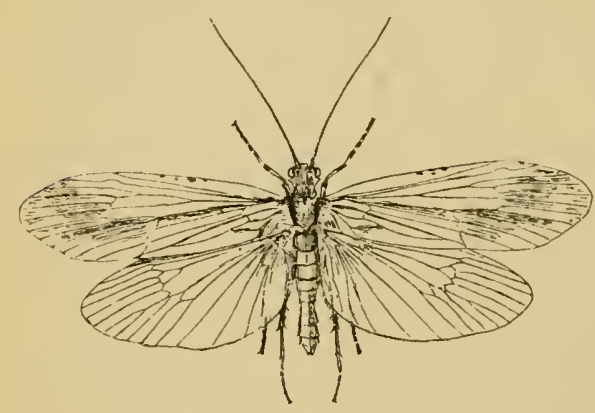

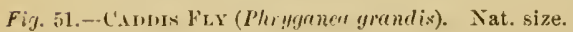
the structure of their legs and anteme, but the wings are clothed with hair instead of scales. The pupre are necromorphous, as in the Coleopter: and Hymenoptera.

The Caddis Flies are rery dull-coloured insects, of small or moderate size. They are nearly always of a brown, grey or buff colour, and very few, even among the foreigu species, are varied with white, purplish, or yellow. The largest British species, Phrigane a grandis, (Limn.) measures ibout an inch int it half across the wings.

Sonte of the smaller species have very long antemie, several times as long as the burly. 'These insects are chicfly reminkille for' the habits of the larvac. 
The enduis worms, as they are called, live in ponds and ditehes, and make themselves cases of stick, or small stones and shells, bomnd together, and lined with silk, and in these they live, and undergo their metamorphoses.

\section{Hingless Trsects, allied to Nemoptere.}

There are three gromps of wingless insects, which are sometimes elassed with the Nemontera, and ale sometimes treated separately. They are as follows :-

The Mallophaga are placed by some authors with the Anoplura, or true liee, as an aberrant family of Hemiptera, but others place them with the Neur. optera, and others again treat them as a distinct oreler. They much resemble the lice, but differ from them in possessing well-developerl mandibles. They have large thattened bodies, large leads, and rather short legs. They

Bird Lice ( $\mathrm{Kal}$ lopharg(t). infest different species of birds, feeding on the soft part of the feathers near the yuills. Most of them are of rather small size; the largest, which are nearly half an incl in length, infest the eagles, vultures, and allatrosses.

The Thysanura and Collembola are two small orders or sub-orders of wingless inseets, whieh have long, jointed antennse, and six legs, but undergo no metamorphoses. The Thysanura have an apparatus

spring Tails for leaping at the end of the body, and are frequently ealled (Thysanure). sporing tails. The best known, however, is the silver fish, Lepisma saceharina (Limn.), a

Silver Fish. silvery-grey inseet, about half an inelh long, often found in crevices in dark eorners in louses, where it darts about with great activity when disturbed.

\section{Oriner Hyuexoptera (Bees, Wasps, Ants, etc.).}

In this Order we find insects with four wings, which are generally long and narvow, and frequently elothed with short hairs, only visible uncler the mieroscope. The fore and hind wings are often linked to. gether by a row of sull links, which has suggested the name of the order. The veins of the wings are never very numerous, nor is the nemation eomplieated. In many families, however, the females and sometimes both sexes are wingless, and in others there is a race of imperfectly developed females, ealled neuters or workers, which are frequently wingless. The ovipositor of the female is modified either into a sting, or into a boring apparatus, which, in the latter ease, is sometimes of great length. There are usually three ocelli, or simple eyes on the vertex in addition to the two large lateral compound eyes. The metamorphoses are complete, and the pupa is inactive, and necromorphous, as in Coleoptera, the limbs being encased in separate inmovable sheaths. The pupa is usually enelosed in a eocoon.

The Hymenoptera include a large number of insects, which, thongh very diversified in form and habits, have still such a strong fanily likeness that they camnot easily be mistaken for inseets of any other order. Some are vegetable-feeders, like the saw-flies, the larva of which so much resemble eaterpillars that they liave been not inaptly termed "false eaterpillars" ; the larve of the wond-wasps burrow in the wond of trees; the gall-flies form 
excrescences called galls on various plants, especially on the rak and rose, though many of the smaller species are parasitic; the groujs

Habits. generally classed together roughly as ichneumons, though they really include several very distinct families, are parasitic on other insects; the hurrowing and solitary wasps are carnivorous, the social wasjs and the ants are ommivorous, and the bees feed on the pollen and honey of thowers.

The ants, bees, and wasps, and the termites, or white ants, which greatly resemble them, but which belong to the order Neuroptera, far surjass all other animals in intelligence, and are the only creatures known to scientific men which have developed any phases of social life and civilisation at all resembling our own, and this is especially true of the ants.

The Hymenoptera are probably the most numerous of all insects in number of species, for although only 36,000 species have yet been described, a much smaller number than either the Coleoptera or Lepidoptera, yct

Number of we have considerably more than 3,000 species in England, a Species. greater number than is known of any other order, and fully half of these belong to the parasitic groups, which only one or two entomologists have taken the trouble to study at all, and many of which are of very small size, some, indeed, being the most minute of all known insects, and there is no reason to doubt their being proportionately as numerous in other countries as in our own.

The Hymenoptera are divided into two principal sections : the Terebrantia, or Boring Hymenoptera, in which the ovipositor is modified into a boring Boring Hymen. aparas; and the Aculeata, or Stinging Hymenoptera, in Boring Hymen- which it is modified into a sting. In the Terebrantia the optera trochanter, or small hinge-joint which separates the coxa, or (Terebrantia). hip, from the femur, or thigh, is generally double, while in the Aculeuta it is generally single; but this is not an invariable character.

The first division of the Terebrantia consists of the Serrifere, including the families Tenthredinide and Siricide, or saw-flies and wood-wasps.

The Tenthredinide are divided into several sub-families, in some of which the antenne are short, and strongly clubbed at the end, like those of a butterfly. The commonest of these species in England is

Saw-Flies Trichiosoma lucomum (Linn.), which is a blackish hairy (Tenthredinid(e). insect, measuring mather more than an inch in expanse, with transparent wings bordered with brown. The twentytwo-legged larva feeds on hawthorn, and constructs a very solid buown egg-shaped cocoon. It belongs to the sub-family Cimbicince. Another very interesting sub-family is that of the Pergince, which are found in Australia, and have short, club-shaped antennæ; the species are mostly black and yellow, and smaller than Trichiosoma, though some of them are greenish, and about the same size. Their black larve have only six true legs, no prolegs being developed, and they feed gregariously ou gum-trees Habits of Perga. (Eucalyptus). In some species, the female is said to tend the young larva after they are hatcherl, an unusual habit, except in the

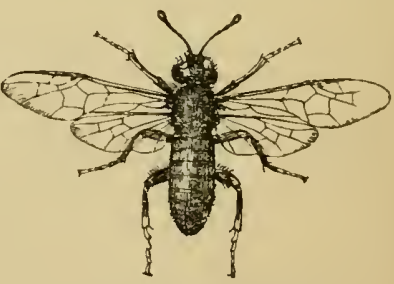

Fig. 52.-SAw-FLy (Trichiosoma lucorum). Nat. size.

case of social insects. The number of joints of the antenne varies in the 
Tenthredinilu, but is most frepuently nine, espeeially in the more typieal sull-families, in which the joints itre long, cylindrical, and well-marked. In one sub-family, however, the short, thick Antenna of Sawantemne are composed of only three well-separated joints ; the scape, a short joint, and a long terminal one composed of Flies. several fused together. Sometimes this third joint is bifid, each antemua being thus double ncarly to the base.

Our fruit-trees often suffer sercrely from the attacks of the larve of rarious siw-flies. Those best known to ordinary observers are probably the small greenish or yellowish black-clotted larve which frequently strip our gouseberry and currant bushes of all their leaves, and which develop into small black and yellow four-winged flies about half-an-inch in expanse, belonging to various species

Saw-Flies injurious to fruit trees. of thegreat geuus Nemutu (Panzer.). But these bushes are liable to the attacks of the larve of siw-flies belonging to other sub-families than the Nematime, and also by the larve of various Lepidoptera and other inscets.

The Siricide, or wood-wasps, burrow in the larva state in timber, with which they are frequently imported into this country. The commonest and most

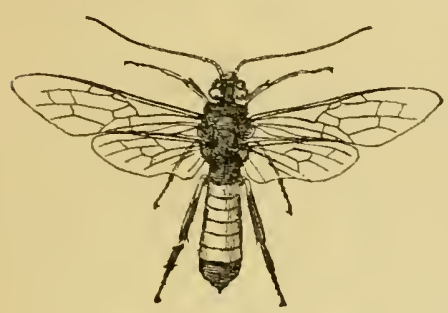

Fig. 53.-Sirex gigus. Male. Nat. size. conspicuous species is Sirex aigus (Limn.), a very formidable-looking inseet, the large females of

Wood-Wasps

(Sivicide). which sometimes measure nearly two inches across the wings, thongh many specimens are much smaller; for woodfeerling inseets, as a rule, vary very much, both in size, and in the length of time which they require to reach maturity. It is black and yellow, and the female las a stout ovipositor projecting behind the body for about one-third of its length. The abdomen of the male, on the other hand, terminates in a rectangle. These insects will sometimes emerge from planks of deal ur pine, which have been built into the floors or fittings of a house, and make a loud buzzing, which has sometimes led to their beingmistaken for hornets, but they are really quite harmless.

The Giullicolee, or gallflies, are far better known by the galls which grow upon the leaf or stalk in which they have deposited their cogs than by the flies themselves, which are generally small shining black (1) reddish insects, with long antenna and transparent wings, with the very

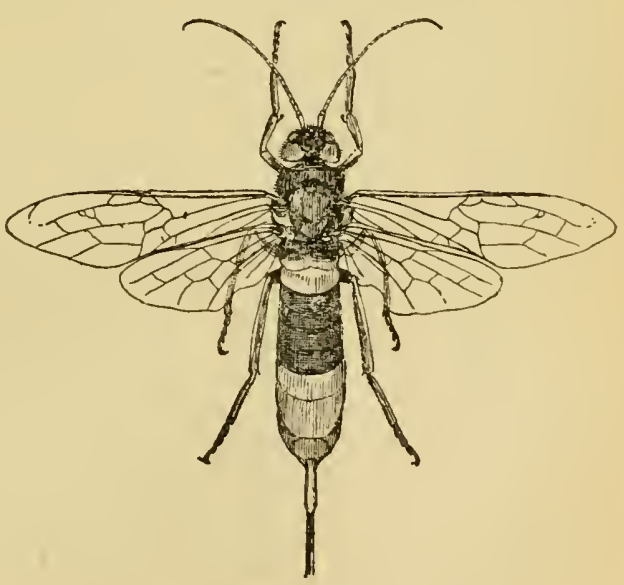

Fig. 54.--Sirer gigas. Female. Nat. size. 
few nerrures visible on the fore-wings froming one large cell near the centre. The abdomen is short, slightly compressed, and much elevated. A common British species is figured. It is hardly necessary to l'cmind

Gall-Flies

(crallirolee). wur readers that the principal ingredient in ink is obtained

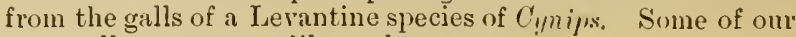
own galls are not unlike a eherry, or other fruit ; and there are foreign galls which are much lirger and more tempting in appearance; some of these are called "A Apples of Sodom."

Many of the gall-flies appear at different seasons of the year in two different forms, onc in which the sexes aje separate, while the other consists exclusively of females, or rather of individuals capable of self-reproduction. Sometimes one form is winged, and the other apterous and subterranean. It is needless to say that until their habits were discovered, the two broods were regarded as belonging not only to different

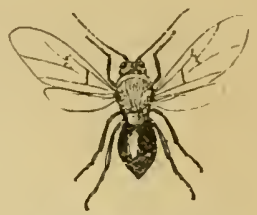

Fig. $\overline{\text { ). }}$-GALL-FLY (Cynips loollari, Hart.). ilightly magnified. species, but to distinet genera. Another noteworthy circumstance relative to galls is their extreme liability to attacks of parasites. You may collect a very large quantity of some kinds of galls, and breed humGall-Parasites. dreds of specimens of different species of insects from them, and yet never obtain a specinen of the original gall-maker; all will be parasites, and not a few will be a small parasitic species of Cymipida.

The Entomophrau, or truly parasitic groups of Hymenoptera, include the

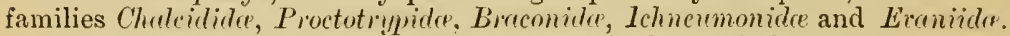

The female usually pierces the body of the caterpillars, or

Parasitic other victims which she atticks, with her ovipositor, and Hymenoptera lorlges an egg in each womd. In other eases, the eggs are (Entomophaga). deposited on the eggs or larve of their victims. Eggs thus attacked never hatch; but ichneumoned larve generally attain their full growth, and then die, when the larvie of the parasite, which have been feeding on it all the time, often emerge from it, and form their own cucoons round the dead body of the caterpillar. In other cases, the larva assumes the pupa-state, and the parasites pupate within it, emerging from the pupa-skin instead of the butterfly.

The Chalcidida are a very extensive family, divided into many sub-families. The antenne are generally 13 -jointed, consisting of a long basal joint and a series of short ones. The females

Family are generally provided with a long Chalcidicle. or short ovipositor, which, in the gemus Lencospis (Fabr.), is eurved over the back. These are among the largest species of the family, and thongh not British, several species are found in Southern Europe. They are black, with yellow markings, and resemble small wasps, but may at ouce be distinguished from them by the very rudimentary and incomplete neuration of the wings. Iencospis and several other genera among the larger Chalcidide

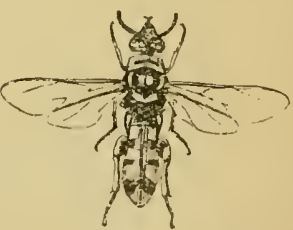

Fig. 56.-Leucospis grandis. Nat. size. have very thick hind femora, toothed on the muder-surfice.

The genus Crllimome (Spin.), to which many species which are parasitic in galls, belong, are considerably sualler, rarely measuring more than about 
half an inch across the wings. They are, however, by no means inconspicuous insects, being of a bright metallic green, or eupreous; and the fenale has a long straight ovipositur.

The pupe of the Chalcididce are naked, but those of the next family, the Proctotrypider, are enclosed in cocoons. The body, which is usually stout in

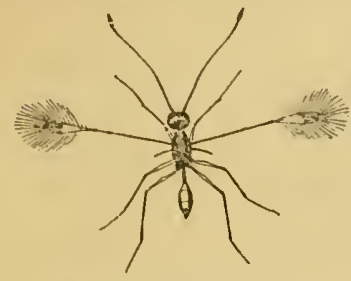

Fi(f. 57.-FAtry FLY (Mymar mulchellus, Curt.) Magnified. the Chalcidide, is slender in the Proctotrypide, and the wings are almost destitute of any trace of nemation. Most of

Family Proctotrypidre. them are egg-parasites, and some are among the smallest of known insects, being barely visible even to the most practised eye, except as a mere speck on a window-pane. The smallest of all belong to the sub-family Mymarince, and Mr. F. Enock, who has paid special attention to them, calls them "fairy flies." They have very narrow oval or battledore-shaped wings, fringed round with long hairs ; and one or two of them are acpuatic in their habits, probably attacking the eggs of some water-insect.

The Breconide and Ichnermonidre include the greater part of the remain. ing parasitic Hymenoptera. The neuration, though still not very complicated, extends over the greater part of the forewings ; and the antenne are generally long and slender. In the Bretconicke there is one small joint beyond the scape of the antenne, but in the Ichneumonide there are always two.

\section{Family \\ Braconide.} In the Ichnermonide we often find an open space towards the middle of the forewings, in which the principal nervures of the wing centre; this is called the areolet. In some genera of these two

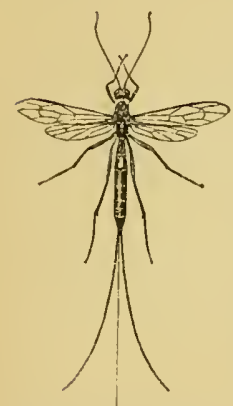

Fig. 58-I'HNEUMON Fry (Rhysse persua. soria). $\frac{1}{2}$ Nat. size. families, the ovipositor is concealed; but in some of the larger Ichnentmonicle

Family Ichneumonida. belonging to the sub-family Pimplime, the ovipositor, which is usually composed of three separate filaments, is of great length, being intended to reach the larve of wood-boring insects. Rhyssce persuccsoric (Linn.), which attacks the larva of Sirex gigas in its wooden galleries, is black with yellow markings, and is one of the largest of the British Ichnevmonida, measuring nearly two inches across the wings, and nearly three inches from the head to the extremity of the ovipositor, which is nearly twice as long as the rest of the body. But in some of the allied foreign species, the ovipositor is much longer, not measuring less than six or eight inches in length.

The Eaniino are a small family of parasitic insects, remarkable for their peculiar forms. The abdomen is attached to the upper part of the metathorax, which gives the whole insect a very peculiar appearance. The species of the genus Ercuic (Fabr.) are parasitic on the egg-capsules of cockroaches, and are found all over the world, though for some reason or other they are extremely rare in England. They are small black insects, measuring about three-quarters of
Family

Evaniide. 
an inch across the expanded transparent wings, with a rery small petiolated abdomen, so smill that it hardly appears to belong to the inseet; and long sprawling legs, with very long black or red hind femora, nuch longer and thicker than the abdomen of the insect. Another genus of this family, Pelecinus (Latr.), is of a very different size and shape, but is not less remarkable. The speeies are black and shining, and measure an inch and a half across the rather long wings. The whole insect, howerer, is three inclies in length, on account of the great length of the joints of the abdomen, which looks like a telescope, except that the joints are of equal thickness. Such is the female. The male, which is very rarely seen, is much smaller, and has the abdomen rery differently formed; it is slender at the base, and gradually thickened into an oval club at the end. Here we see that instead of the ovipositor being lengthened in the female, the whole abdomen has been inordinately lengthened instead. This genus is not British, but is eommon in North America, and other parts of the world.

We now come to the important section of the Hymenoptera Aculeata, which are not only more familiar

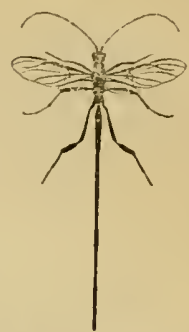

Fig. 59.-1'pecinus potiturator, Linn. Reduced.

\section{Stinging Hymen- optera}

(Aculeata). insects thin the Tcrebicantiu, but have been much more studied by entomologists, though not to anything like the same extent as the two favourite orders of colernitera and Lepidopterr.

The first section, the Tubulifera, includes only one family, the Chrysidida, or ruby-tailed wasps, which hold an intermediate place between the two great seetions of the Hymenoptera, being armed with a rudi-

Ruby-Tails (Chrysidide). mentary sting. They are small insects, generally expanding less than an inch aeross the transparent wings. 'Their bodies are very hard, and very strongly punetured, and when alarmed, they double their bodies together, and sometimes roll themselves

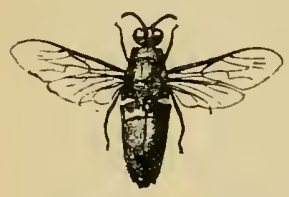

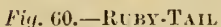
(Stitbum anethystinum). Nat. size. up into a ball. Most of the species are of a brilliant metallie green (more rarely blue), with the abdomen, which is more or less smooth, at least towards the tip, often purple or fiery-red towards the end. The abdomen is nsually composed of only three or four segments visible above, and is more or less retractile under the first, which is usually very mueh longer than the others ; the last dorsal segment terminates in a row of strong teeth, varying in size, form, and number aecording to the species. The larve are parasitic in the nests of other Hymenoptera. We have figured Stilbum amethystimm (Fabr.), a large speeies found in Asia and Afriea, which is sometimes blue and sometimes green.

The flrst section of the true Hymenoptera Aculeata is that of the Heterogymu, or ants. They are social inseets, and consist of limited numbers of winged males and females, and of numerous wingless and imper-

Ants (Heteroyyna). fectly developed females, ealled workers, or neuters. In all Hymenoptera the female is the predominant sex, but this is pre-eminently the case in the social species. When the ants swarm, the males and females fy away and pair, after which the great bulk of them perish. The females sher their wings, 
and those which are sufticiently fortumate to return to a nest of their own species, beenme the future mothers of the community, and devote all their. energies to egg-laying. The wings of ants are rather long and large, and the two prineipal nervues zenerally eross obliquely about the midlle of the forewings, and beyond this, a large, elosed eell is formed in some genera. Ants are divided into three prineipal families. The Fomicide bite, but rle not sting, and have only one note on the petiole of the abdomen. In the Pomerida, the node is formed by the first segment of the abdomen, which is frequently nearly as large as the other's, but is emmletely detached from them ; and in the My/micillm there are two small nodes forming the petiole (If the abdomen. Both these last families sting as well as bite. The most familiar eximples of the first and last families are the wool ant, Formion infu (Limn.), a large, smonth, reddish ant, which forms large momd-nests in woods; the much smaller red ants of the genus Myrmicr (Latr.), which infest our gardens : and the minute yellow houseant, which is so troublesome and difficult to get rid of wherever it effects a lorlgment. Our Britisl representatives of the Ponerilu, or "wicked ones," ire small and insignificant; but to this family belong some of the largest known ants, such as the great black Dinupmeru !mundis (Guér.) of Brazil, which measures upwards of an inch in length. In some of the larrer species of $M$ ! / micide, belonging

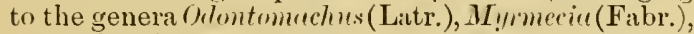
etc., the jaws are rery long, and armed with formidable teeth. We have figured a large red and black Australian ant, Myrmerive fimficutu (Fabr.).

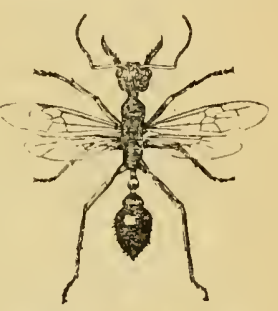

Fig. (11.-A T $($ Myrmecin firficutu). Nat. size.

We have no space here to diseuss the habits of ants, but those of our readers who are interested in their wars, slave-raids, argriculture, cattle and pets, will find ample information in the works of Huber, Kirby and Spence, Moggridge, Lubbuck, M`Cook, and otluers.

The Fossores, or sand wasps, are a large group of insects consisting of winged males, and winged or ipterous females, which are solitary in their habits, and generally dig loles in the ground, which they fill with insects or spiders which they have paralysed but not killed with their sting, and which remain as a store of fresh provision for the larve of the wasps. The wings of the

Sand Wasps

(Fossores). burrowing wasps are not folded longitudinally when at rest; the abdomen is often petiolated; the legs are usually very spiny or hairy, and the prothorax is transverse, the sides not being arched backwards to the base of the wings, as in the true wasps. We notice here some of the principal families only.

The Mutillicle have winged males, and very hairy apterous females, and are sometimes improperly called "solitary ants." They are very numerous in the warner parts of the world, and we have two or three species in Britain, though they are not very common. The Thymnide are another family with apterous, but nearly naked females: they are almost confined to Australia and

\section{Families of}

Fossore. South America. In both the above families the legs are very liairy. The Pompilil, have long spiny legs, and the abdomen is shortly petiolated. Among them we find the largest Hymenopterous insects known, some of 
Which measure upwards of three inches across the wings. Some of the species of Mymmimiu (Smith) arc conspicunus by their beantiful green or purple iridescent wings.

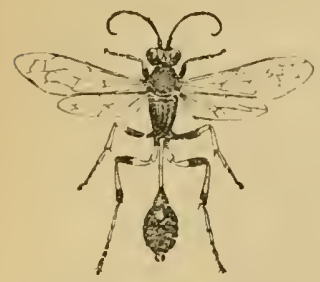

Fig. (6.). - KANบ WAXP

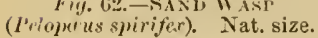
The last family we can notice is the sylhegiche, which are remarkable for the long petiolated abdomen, and for the hrilliant metallic green of some of the Indian and African species of Chlorion (Litr.), etc. In these, however, the wings are generally transpirent, or are at most only bordered with lnown. Peloperes spivifex (Linn.) is a black and yellow species, common in the warmer parts of the Old World.

The Diploptera, or true wasps, may be clistingruished by the fore-rings being longitudinally folded in repose, and by the prothorax being arched backwarks to the hase of the wings. The species are solitary or social; and the former generally construet small

Wasps nests or cells, which they provision with insects. The social

(lliploptera). Wasps, helonging to the typical genus Vespa, are too well known to need deseription; they construct large nests in the ground or in trees, lut their habits are less interesting than those of the ants and bees. The nest is, however, always commenced by one queen, which

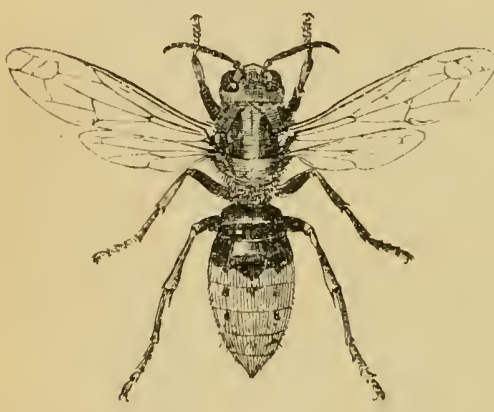

Fiy. 63.-Hohnet (Iesput crebro). Nat. size. has survired the winter; and its extension is afterwards carried (m by her progeny. The loulk of the inhabitants consist of neuters, thougli males and females are also prodneed; the latter assist the motles in enrrying on the work of the nest, for, unlike bees, more than one perfect female is allowed to live in a wasp's nest at the same time. At the end of the season, the whole community dies oft, except a few queens, which perpetuate the brood next year ; and hence every was] destroyed in spring means the clestruction of a possible 11est. We have six species of Vespe in England, all very similar, excejt the hornet, which is twice as large as the other's, but lives in smaller eommunities. It is much scarcer, too, and rarely stines except under provocition. The largest known species of $V$ exper are found in India, China, and Japan.

The last family of the Hymenoptera is that of the Anthophila, or bees. They are generally short, hairy insects, though some genera are almost naked, such as the curious wasp-like parasitic bees of the Bees genus Nomada (Fabr.), which are mostly black and red, in (Anthophila). various proportions, with yellow markings.

Many of the solitary bees of the large gemus Audrenu (Fal,r.) appear in spring, sometimes as early as . Jamury or February, and malie nests in the ground. Some are very peeuliar in their habits, such a 
the leaf-eutter bees, Metychile (Latr.), and the earpenter bees, Myluropu (Latr.), which are common abroad, but are not known in England, and have deep violet-colomed wings; while there are other bees which form their nests in old walls. The humble-bees, Bombus (Filbr.), make their nests in the gromud,

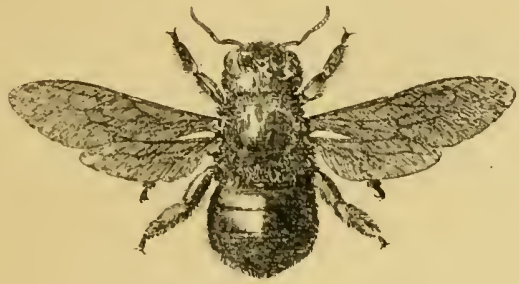

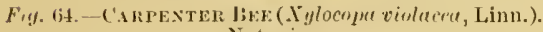
Nat. sizt.

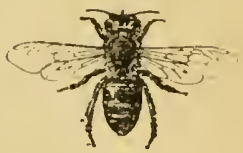

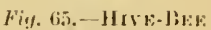
(.tpis melliticu) Nat. size.

ind live in small communities, consisting, like the hive bee, of males, females and worker's, all winged.

Apis mellifica (Linn.), the hive-bee, eloses our list of the Hymenoptera. The genus Apis oceupies a rather isolated position among the bees, and may be recognised at once by the very long narrow costal cell, which extends almost to the tip of the fore-wings. The speeies of Apis are not numerous; but apart from the eommon hive-bee, ten or twelve others are met with in different parts of the world.

\section{Order Lepinoptera (Butterfles axd MLths).}

The Lepidoptera, or seale-winged insects, have four wings, elothed with scales, which look like tine powder, and ensily rub off, but which exhibit a great variety of form under the mieroseope. The eolour of the inseets is due partly to pigment, and partly to refraction from the edges of the seales, whieh sometimes prodnees the characteristics. most brilliant iridescent changes, as in some of the blue Morphos of 'T'ropical America, and in the widely-dispersed grenus Aputure (Fabr.), to which our own Puple Emperor belongs. The antenne are long and manyjointed, and one pair of palpi, at least, is more or less conspieuous. There is also a long probuscis for imbibing the neetar of flowers, or moisture from trees or the ground. In some of the hawk moths this is of immense length, nearly reaching a foot in the largest South American speeies; but in some groups of moths, as in many of those classed under the heading of Bombyces, it is often so slightly developed as to be practically obsolete.

In Lepidoptera the metamorphoses are complete, the inseets passing throngh four stiges. The female lays her eggs on a plant suitable for the nourish. ment of her brood. These are laid singly or in clusters, and ale frequently covered with a kind of cement, or else with down from the body of the mother. They are of various

Eggs. shapes and sizes, and are often ribbed or fluted.

From the eggs emerge the larva, or caterpillars, which are usually provided 
with sixteen legs : six horny legs, corresponding to the true legs of the perfect insect; eight Heshy legs, called prolegs ; and a terminal

Larva, or Caterpillar. pair, called claspers. In the larve of the Geometride, and in the early stages of those of many other moths, the first three pairs of prolegs are obsolete, and the larvit arch the back at every movement, and are then called "loopers." Caterpillars are very voracious, and generally moult, not only their skins, but the linirs of part of the internal respiratory and digestive apparatus as well, more than wnce before arriving at tlieir full growtl.

The next stage is that of the pupa or chrysalis, which is almost motionless, being encased in a tight-fitting integument, on the upper half of which the outlines of the perfect insect may be observed. These are

Pupa, or

Chrysalis. not, however, enclosed in separate sheaths, except in the case of some hawk-moths, which have the proboscis enclosed in a sheath which is detached from the main body of the pupa. The pupa takes no nourishment, and it is either attaehed by threads to a leaf, ${ }^{1}$ etc, as in the case of most butterflies, or enclosed in a cocoon, formed of silk in those species in which it is constructed on or above the sround, and of agglutinated enth in most instances in which it is subterranean. In clue time the perfect buttertly or moth quits the pupa-case; its wings, which are at first soft and limp, soon expand to their full size; the limbs of the insect dry in the sun and air, and it flies away to join its eomrades, and to reproduce its kind. Most species, on emerging from the chrysalis, discharge a fluid, which in former times, when they liapjened to be particularly numerous, and when everything unusual was attributed to miraculous causes, sometimes gave rise to the notion that a rain of blood liad fallen.

Entomolugists in England have generally agreed to call the first few f:milies of Iepidoptera buttertlies, and the remainder motlis; but there is no such distinction on the Continent, where they are Rhopalocera, or grenerally called by words colresponding to day-buttertlies Butterflies, and night-butterflies. Butterflies are broad-winged insects, often aclorned with loright colours, and with comparatively slender bodies. The antemme are almost invariably thickened into a knob at the extremity, a peculiarity which is not very common in other insects, though we meet with it in some saw-flies, flies, the ant-lions, and other allied families of Nenroptera, and in many beetles, etc. Hence the buttertlies are often ealled Rhopmlocer, or club-horns. They fly by day, and seldom, unless disturbed, at dusk or at night, though some 'Tropical genera are twilight-Hiers, or frequent the deep gloom of thick forests. Moths, on the other hand, have. the antennie of various shapes, sometimes thickened in the middle, or hefore the end, but almost never clubbed at the extremity, and generally thieadlike or comb-like. Most motlis tly at niglit, or, at least, not before rlusk, though a few are day-fliers, and may be seen frequenting flowers, anoms butterflies. Many of them liave stout bodies, and are of dủl or subdued colours. Buttertlies often rest with the wings raised over the back, an attiturle rarely assumed by moths. The latter, however, more frequently rest with all their wings spread out flat, while in the stout-bodied moths the fore-wings often more or less cover the hind-wings when at rest, and are sometimes

'In the $N$ mmplatirlu the pupa is suspented freely by the tail: in the other families of hutterflies (except in the Hesperiflle) it is generally attacherl by the tail, am hy a girth roumil the borly as well. 
sloped roof-like, the hind-wings frepuently folding together like a fan, whieh is never the case in buttertlies.

Moths are much more numerous in proportion than buttertlies, especially in temperate climates. Tropical America produces more than half of all the known buttertlies; in the tropics of the Old World they are mucl less numerous. England is poor in butterflies, producing only 60 or 70 species out of the 300 European species,

Moths. as against 2,000 British moths. The richest countries in Europe for butterHies are those lying round the central ranges from the Pyrenees to the lalkans; but the numbers rapidly diminish, both north and south. Sweden produces about twice as many species of butterflies as Britain ; but Andalusia is not richer than Sweden, and North Africu is much poorer. Nevertheless, both butterflies and moths are to be met with (though, of course, their number is but few), not only in Lapland, but everywhere in Greenland where any vegretation will grow. Iceland, though producing many moths, is the only important comntry in which it is believed that no buttertlies are to lo met with.

In the wings of buttertlies, the front edge is called the costa, the outer edge the hind margin, the hinder edge (which, in the lind-wings, is parallel to the abdomen) the inner margin, and the side nearest to the body of the insect the base. The nervures of the wings are useful in classification. The principal nervures which rum from the base are the costal, subcostal, median, subunedian, and internal nervures. The norvures which do not start from the base are called nervules. A wide space, which extends from the base towards the middle of the wing, between the subcustal and median nervures, is called the discoidal cell. The subcostal nervure divides into two branches on the liundwings, and generally into from three to five on the fore-wings; and the median nervure always divides into three. These branches are either called branches of the subcostal and median respectively, or subcostal and median nervules. The discoidal cell is closed at the extremity by short nervules, called discocellular nervules; and from the end of the cell one or two nervules (called cliscoidal nervules) run to the extremity of the wing. In some butterflies one of the discocellular nervules is absent or imperfectly formed, leaving the wing open from the base to the hind margin. In such a case the discoidal cell is said to be open; but otherwise it is called closecl. 'The internal nervure is absent in some families of butterflies.

'The first family of buttertlies, the $N y$ mphalider, includes about half the entire number of species, and may be lnown by the first pair of legs being always more or less imperfect, especially in the males. The pupa, when attached to anything (for in exceptional cases imong the sutyrince it is placed on the ground), is suspended freely by the tail. The larve are cylindrical, and are generally

Family

Nymphalidice. furnished with bristles, spines, or long filaments, or are naked, with a bifid tail. Sometimes they have horny projections on the head.

The Nymphulide are divided into several sub-families. The Danaince are chietly an Old World group, and the best-known species is Limnas chrysippus (Linn.), a tawny butterfly, about three or four inches across the wings, with an oblique white bar across the tip of the forewings, and a curved row of small black spots on the middle of the hind-wings. It is common throughout Africa and Southern Asia, and extends into South-Eastern Europe. Another section of this family is represented hy the East Indian genus Euploa (Fabr.), and 
its allies. Many of these are butterflies of a rich velvety black or browns with bluish-white spots towards the extremity of the long, broad, rounded wings, and also in the midale. They are often flushed with rich purple. The Danaine are butterflies with very tough integuments, and exhale an odour which is supposed to render them distasteful to birds.

Iany other butterflies and moths resemble them externally, and are believed to share in their immunity from persecution. This phenomenon is called "mimicry," and is exhibited in the greatest per-

Mimicry in fection by Limuas chrysippus, the pattern and coloul's of

Butterflies. which are more or less accurately reproduced in at least a dozen butterflies and moths, belonging to different families; but in several instances in the female only, the male exhibiting the normally and frequently very different colouring of its proper geuus. The larve of the Drincince are usually provided with several pairs of long fleshy filaments, and feed on Aristolochice.

Of the remaining sub-families, several are entirely exotic, and two, the Ithomiince and Helicmince, are American butterflies with long rounded wings and slenderbodies, which have sometim es been compared to dragon-

sub-Families flies. They are butterflies generally measuring from two to

Ithomiince and four inches across the wiugs, which are often black, with red or

Heliconine. yellow markings, or yellow with black markings. The typical species of the Ithomiinu, however, often have transparent wings, with only brown borders, and a brown hand at the end of the discoidal cell.

The Acreince are another long-ringed sub-family of butterflies, chiefly found in Africa and America. The African and the few Eastern species are generally red or tawny, with black spots, and sometimes

Sub-Family Acreince.

markings on a dark ground, especially on the hind-wings.

Two more sub-families of large butterflies are chiefly South American. These are the Morpline and Brassolince.

Sub-Families The typical species of MorMorphince and pho (Fabr.) measure from Brassolince. three to eight inches across the wings, and many of them are of a brilliant azure blue; others are black, with a broad blue band through the wings; while others, including some of the largest and longest-winged species, are brown or orange. These are all American; but there is a greater variety of genera, though much smaller, and more varied in colour, in the East Indies. On the under-surface they are always marked with large eye-spots, as in the Satyrina. The Brassolince are large brown or tawny butterflies (rarely dull blue), which are entirely confined to Tropical America. They have generally ono large cye-spot on the under-side of the wings, and traces of one or two more; 
and, like some of the Tropical Sutyrine, they are twilight-fliers, although true buttertlies. The acempanying figure represents the under-surface of the wings of Cilligo tencer (Linn.), a conmon South American species belonging to the sub-family Brissolince. The expanded wings of this butterfly mensure five or six inches from tip to tip.

The two remaining sub-fimilies, the Sutyrince and the Nymplualince, contain miny of our commonest and most familiar British butterflies. The Satyrince are brown or tawny buttertlies, such as the meadow brown, of moderate or 1"ather small size, and are nearly always adorned with eye-spots, at least on the under-surface of the wings. The wings are rounded, and there is usually at least one eye-spot towards the tip of the fore-wings, and two or three towatds the borders of the hindwings.

The typical Nimphaline may be known from the foregoing sub-families, except the Morphince, by the open wing-cells, and often by the more or less dentated wings. This is a very large group of large or moderate-sized butterflies, and includes the tortoise-shells, peacock, red admiral, fritillaries, purple emperor, and white admiral, among our British buttertlies, which are described

\section{Sub-Family} Salyrince. in full in every book on the subject.

We have figured Kallima inchehis (Boisduval), a butterfly found in North India, which is remarkable for its resemblance to a deal leaf. It measures three inches across the wings, which are dull blue above, with a broad orange band with a transparent spot in the midclle, on the fore-

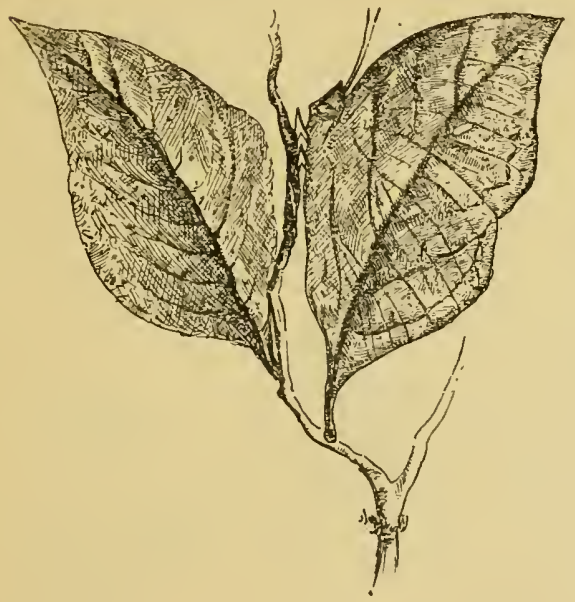

Fig. 67.-Dead-Leaf Butterfly (hallima inachis). Reduced. wings. The under-surface is brown, with a dark line running from the tip of the forewings to the end of the lobe on the hind-wings. This line represents the midrib of the leaf, and the butterfly is shaped and lined and mottled in such a mamner as to increase the deception. There is a case of such butterflies mounted, with leaves, in the hall of the Natural History Museum at South Kensington; and the butterflies and leaves can harlly be distinguished from one another. Our figure shows a butterfly on one side of a twig, and a leaf on the other.

The Lemonicile. are a large family of small, brightly-coloured butterflies, which are most numer-

Family

Lemoniivlir.

ous in South America, and least so in Europe and Africil.

The fomales have perfect legs, but the fore-legs of the male are imperfectly 
develuperl. The only European species is Nemestres lncine (Limn.), the Duke of Burgundy Fritillary, a brown buttertiy ahout an inch in expause, with rows of tawny spents on the wings.

The Libythcide, which some entomologists consider to be a sub-family of the Lemoniidar, are distinguished by their very long palpi (nuch longer than in any other butter-

Family Hies, except one ol

Libytheide. two Nymphuliner). and by their lowown, dentated, tawny-spotted wings, which gives them a superficial resemblance to some small species allied to $V$ anessu. The only Eurolyean species is here figured.

The Lyceniele are a large family of small or moderate-sized butterflies, liffering little strucFamily turally from the Le-

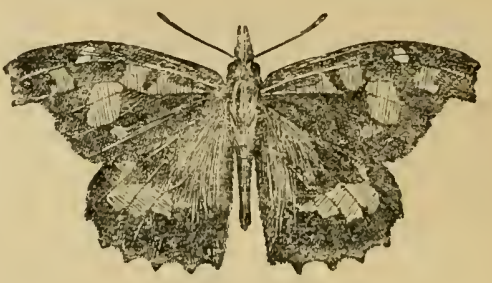

Fiy. 68. - Libythen celtis. Nat. size.

Lyconide. moniide. They are;

however, more of an Old World group, although many are found in America, too. Our species are known as hairstreaks, blues, and coppers. The hairstreaks are brown or blue butterflies, with white lines on the under-side of the wings, and a short tail. The green hairstreak, however, C'alluphrys rubi (limn.), is tailless, and the under-side of the wings is green. There are a large number of brown or blue species allied to the hairstreaks in Tropical America, some

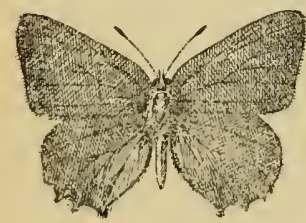

Fiy. 69.-(iRENA HiIRSTRFAK (Callophriys muli). Tat. size. measuring as moln as two inches across the wings. The blues, which belong to the renus Polyommatus and its allies, are small butterflies, usually without tails, and gemerally with rows of ocellated spots on the muler-side of the wings. Towards the hindmargins we often find a row of red spots above or below. The females of the blues are often brown, and in some species of the gromp both sexes are brown. They generally measure a little more than an inch in expanse. One species, Lumpides buticns (Linn.) has a short tail and a streaked muder-sirle; but in England it is only occasionally net with on the sonth coast. The coppers are a very handsome gromp of butterflies, distinguished by the brilliant coppery red of many of the species, several of which formerly inhabited England; but they are all now believed to be extinct with us except the small copper, an insect with the coppery wings bordered and spotted with blinek. Some of the other species are shot with purple.

The Pievider are a large group of middle-sized butterflies, most of which are white or yellow. All the legs are fully developed in both Family sexes; and they can most readily be Pitrile. distinguished from the next family by

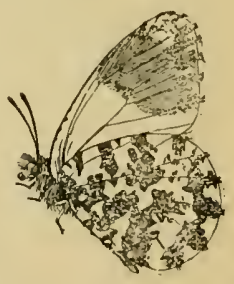

Fig. 70.-Oranah 'Tir' (Euhlor cordamines). Nat. size. possessing an internal nervure to the: 
hind-wings, Th the l'ieride belong om sinden whites, clomeled yellows, rrange tip, ancl brinstone louttertlies, etc. 'The largest huttertlies of this family are the great East Indian orange tips of the genus /lubmomir, Hiilmet. 'liey measme tive a six inches across the wings, which are much shonter and hroader in proportion than in our common orange tip, Euchlore curlumines (Limn.), which is one of the prettiest and most admired of our vernal insects.

The Equitider, or swallow-tails, are a family of very liandsome butterflies, many of which possess the long tails to the hind-wings from whenee they derive their English name. Our only British speeies is the well-known swallowtail butterfly Eques muchaon(Limn.), it present almost confined, with us, to the fen districts of Norfolk, though formerly much more ibundant. It is black and yellow, with a large red spot on the lower part of the hind-wingss, aml measures about four inches in expanse. 'The green caterpilliur, with blisck spots and bands, and a retractile fork on the neek, feeds (in fennel, carrot, and other unbelliferous plants. We luve figured an allied species, Enresal xamur(Esper.), distinguished by the

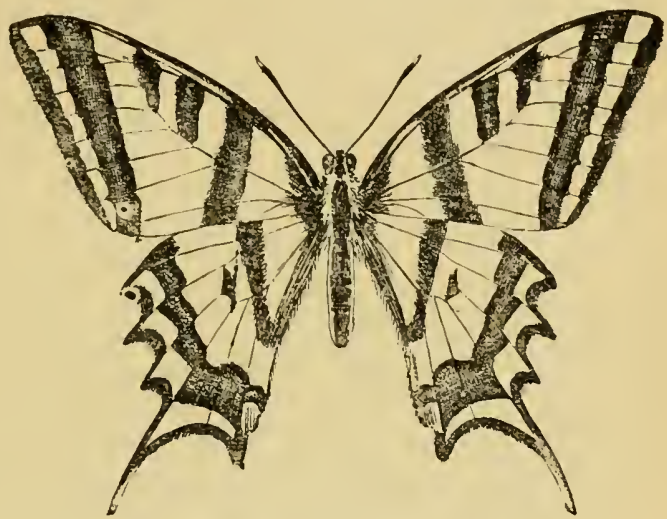

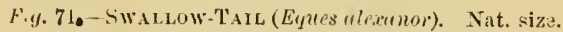
continuous black band near the base of the wings, which is found in the mountains of South Europe. To this family belong the great bird-winged buttertlies, Oinithopterc (Boisd.), oi the East Indies and the Eastem Arehipelago. They share, with the Morphine, the distinetion of being among the latrest butterflies in the world, measuring from three to nine or ten inches in expanse; but usually about six or seren. They are long-winged butterHies, with black fore-wings and yellow hind-wings : or with large green, blue, or orange longitudinal bands on the dark fore-wings, and the hind-wings mostly of the colour of the bands. The larvie are covered with rather long and thick Heshy spines, but have al ways the retractile fork on the neck, which is one of the inost characteristic marks of the Equiticle. Another interesting genus is Parmassins (Latr.). These are satiny-white butterflies, slightly transparent towards the edges, with black spots, and generally also round red spots, more or less centred with white, on the hind-wings, at least. They are mountain butterflies, and are most numerous in Central Asia; though three species inhabit the Swiss Alps, the commonest being Parmassins apolls (Limm.), which must be well known to everyone who has ever colleeted butterflies in Switzerland. These might easily be mistaken for Pierirle, but that the immer margin of the hind-wings is not gutter-shaped, as it generally is in the l'ieridlr, and the internal nervure, which is very conspicuons in the l'ieviulu. is wholly absent in all the Emitidu. 
The last family of butterflies, the Hesperiid", has six perfect legs in both sexes, but differs very much from any of the preeeding groups. The head is broad, the antenuie are set widely apart, and are

\section{Family}

Hesperiulue

(Skippers). generally hooked at the tips, the body is rather stout, and the flight is short and jerky. Our species have somewhat triangular fore-wings, and rounded hind-wings, and are brown and tawny ; black, tesselated with square white spots; or brown, with dull greyish and rather indistinct spots. The IIesperiide are very numerous in South Americil, but less so in the Old World. They are mostly of small size, the largest being a dull blue West African species, Thopalocrmptu iphis (Dru.), which measmes about four inches across the wings. They form a transition to the moths ; many species sit with the wings expanded, instead of raising them over their backs; and they often make a rough sort of cocom in a leaf. The Grizzled Skipper, Hesperia malcu (Linn.), here figured is a small black and white butterfly not uncommon in England.

The Heterocera, or moths, are clivided into a great number of families, which are loosely classed together under various headings ; but the classification of moths is still in an unsatisfactory state, and though

Heterocera, or many groups of families, large and small, are perfectly Moths. natural, others are ill-defined and unsatisfactory. The old group Sphingles is now quite given up, including, as it did, three totally distinct sections, the hawk-moths, clear-wings, and burnets. The Bomlyces include a number of very discordant fimilies, for which no definite collective characters can be found, snch is the tigers, footmen, eggars, emperor moths, swifts, ete. The Noctue, or night-flying moths proper, are more compact, though even here there is a dificulty in determining whether many genera belong to this group, or to the Bombyces. The Geometro are a compact group, and so to some extent are the remaining gromps. We will now eonsider the moths more in detail.

Of the families classed under Sphinges and Bombyces, most of the species have short, stont, and often tufted bodies, large wings, and peetinated, or sometimes fusiform antennie. The larvie have sixteen legs, and generally spin cocoons, thongh some pupate in the grounc. Many beautiful day-flying moths belong here, some of which were formerly classed as butterflies. Among these are the bright green black-striped Uraniilce of Sonth America, three inches in expanse, with long tails on the hind-wings like swallow-

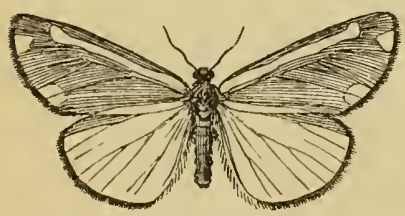

Fig. 73.-Cinnabar Moth (Hipustita jacoluta). Nat. size. tail buttertlies. More familiar to us are the burnets (Zyganide), moths with long fore-wings about an inch and a half across, with long pubeseent bodies, and blackish bronzy fore-wings, with five or six crimson spots, and red hind-wings. They are found in meadows, flying hearily from flower to flower in the daytime. The tiger moths (Airtiirl' ) are larger, and very brightly colsured moths, ind more noctumal in their habits as a rule. The commonest, Hypercompe cetic (Limn), has brown fore- 
wings, with interlacing white markings, and red hindwings with large bluish black spots. Its caterpillar, which is often called the woolly bear, is common in gardens, and is covered with long reddish-brown hair, partly tipped with white. It feeds on all sorts of low plants, and when disturbed, rolls itself up into a ball, and drops among the herbage. Hred specimens of the moth are peculinrly liable to vary, some of the specimens being yuite black; but those reared in a state of uature are much less variable.

'The Liprovide are another' family of stout-bodied Bumbyces. Many of the species are white, like the gold-tail and brown-tail moths, which are common oil hedges, and receive their names from the tuft of wool at the end of the body, which the female uses to cover her egoss. They measure rather more than an inch across the wings, and the larvie are gregarious, and are often very lestructive.

Some of the families of moths clissed as Bombyces have slender bodies and long wings. The Lithosider are a group well represented in Europe. They generally have oblong greyish fore-wings, with a yellowish streak on the costa, and slate-coloured hind-wings; they measure ibout an inch and a half in cxpanse, and their larvie feed on lichens. The cimmabar moth, Hipocrite jacoluee (Linu.), is more brightly coloured, being black and red, like the burnet moths, though the antemne and the pattern of the wings are quite different. It is not rare in Britain. The South American family Dioptidu inchdes larger moths, with more rounded wings, and nore varied in them colours. Some of them are partially transparent; and many, excent in their simple or slightly pectinated antennie, resemble butterflies of the sub-family Ithomiiner.

The Cyllopodidr! me austher south American family of rather small moths, rarely measuring more than an inch and a half across the wings, which are remarkable for their strongly contrasted black and yellow colour.

'The Psychidr" are a fimily of small grey or, more freruently, smoky-black moths, remarkable for their thick, hairy bodies, and strongly-pectinated antemnic. They rarcly reach an inch in expanse, and are found Hying among long grass in the daytine. The larvie construct a case of bits of vegetable matter, in the same way as the larvie of the caddis-flies, and the females are wingless, and in sone instances, legless also, in which latter case they never quit the dwelling which they have inhabited as larvie and pupie. The species

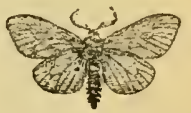

Fig. 7t.-Chalie rurve. Nat. size. figured, Chalic furve (Borkhausen), is rather scarce in England.

Among the largest moths are the Satumielce, to which our emperor moth, Saturiu peronire-minor (Linn.), belongs. The emperor moth measures two and a half to three inches across the wings, which are light hrown, varied with orange in the male, and of a soft grey in the female; in the middle of each wing is a large round eyc-spot. The green, red-spotted larva feeds on heath, and makes a flask-like cocoon.

All the moths of this fanily have stout and often short bodies, pectinated antenne, and ample wings, with a more or less developed eye-spot or transparent mark in the middle of each. Some are green or brown, with long tails on the hind-wings ; but the largest of all, the Indian Atlas Moth, which sometimes measures a foot in expanse, has tawny brown fore-wings, with festuoned black and white lines, between which is a large talc-like spot on each wing, of very irregular shape. 
Most of the silk-producing moths of any eommereial value belong either to the Saturiedr or the Bombycida. The common mulbery silk-worn moth, Bombyx moi i (Liun.), the type of the Bombyces, is ton well kuown to need deseription liere.

The Lasiocrmpider are stont-bodied moths with strongly pectinated antemne, and hairy caterpillars. They are generally of a brown or yellowish

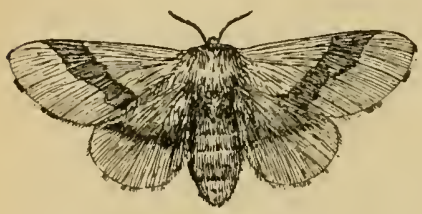

Fig. 75. - LAC'K EX МотH (Clisiocampa neustria). Nat. size. colour, and the wings are sometimes dentated, but never tailed. It includes the rak-eggar, drinker moth, lappet, lackey moth, and wther familiar British species. The lackey moth, r'lisiocommu verstric (Limn.), is remarkable for tle habit of the female in laying her egors in a ring round a slender twig. All the larve of this family are very hairy.

Three families of Bomly!ces are remarkable for their lirvie feeding in the trunks of trees, or on the roots of grasses; as well as for the abnormal neuration of the perfect insects. The gont-moth, Trypauns cossus (Limm.), belonging to the family Zeniseider, is a broad-winged greyish-brown coarsely-scaled moth, in which the discoidal cell of the wings is divided by additional nervures, which are obsolete in must Lepidoptera. Its dark red, foul-snelling, naked larva is very destructive to old willows, and takes three years to arrive at maturity.

The Castnida are a South American group of stout-bodied moths, with rather short and broad wings, measuring from two to six or seven inclies in

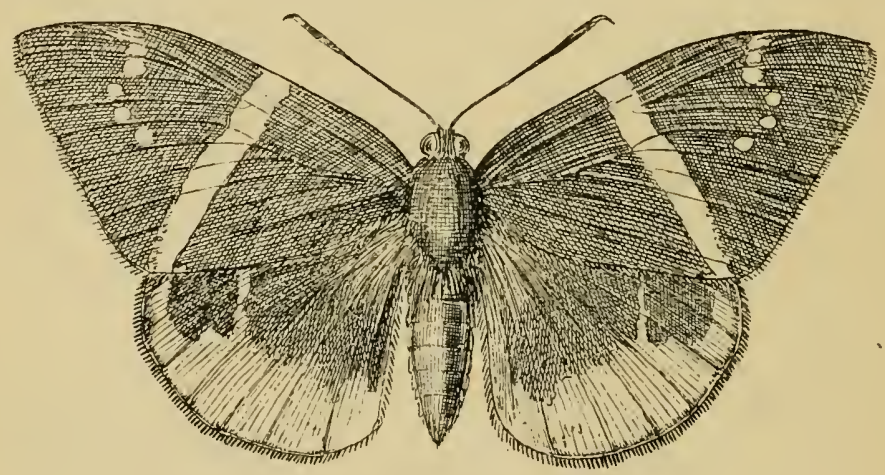

Fig. 76.-Custriu sylhax.

expause. The antemnie are very thick, and rather tapering at the ends. They are brightly-coloured insects, and fly by day. They somewliat resemble large Hesperide, and were classed as butterflies by all the older writers. The cells of their wings are sub-divided, as in the Zeuceridr, and hence we notice them now, though their natural position is neas the beginning of the moths. The species figured, Festuire s!lphrex (Fabl.), is black, with white markings on the fore-wings and a red border to the hind-wings. 
Our swift moths (Iepiclide) have rather long wings and very short antemae. They exhibit many remarkable peculiarities; the wings are separated at the base, the connecting link between them being not by a bristle, as in many moths, but by a long lobe. The fore and hind-wings have similar neuration, and the hind-legs of the males are more or less aborted in some of the species. The ghost moth, Hepialnes lı!muli (Limn.), is common in every meadow, where the male, which is white on the upper-side of the wings, and brown below, thies at dusk with a peculiar hovering motion. The female has yellow fore-wings blotched with red, and the hind-wings and undersurface are brown. The

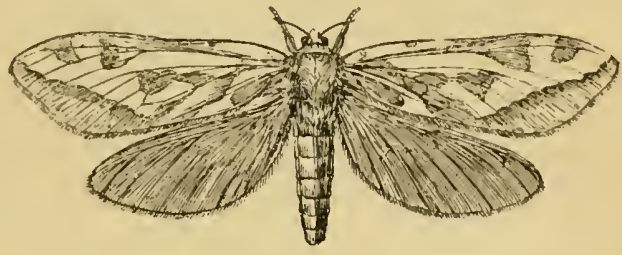

Fiy. 7T.-Gнost Мотн (female) (Ilepialus humuli). Nat. size.

European swifts feed on the ruots of plants, but there are some splendid green Australian species, measuring four or five inches across the wings, the lirva of which feed on the wood of trees. Owing to the musual neuration and mode of connection of the wings in the Hepialicle, Professor Comstock has recently proposed to associate this family with the Micropterygidre, a family which used to be placed among the Tinere, and to treat them as forming a primary division (in fact, a sub-order) of the order Lepidoptera. In this innovation he has since been followed by other anthor's.

The Nocture are a large group of stout-bodied moths. To it belong many of the moths which we see Hying over flowers, or about a candle in the evening. Most of our species measure from one to two inches in expanse, and

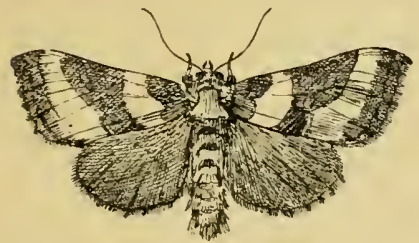

Fiy. 78.-Bursished Brass Morm (I'lusia chrysitis). Nat, size. many are of dull colours. Some have inetallic spots, or letter-like markings, like the burnished brass moth, Plusiu chrysitis (Limn.), which has large bronzygreen markings on its brown fore-wings; or the violet-grey gamma moth, Plusia yamma (Linm.), a very common day-flying species, with a white mark resembling the Greek letter $\gamma$ on each of its fore-wings. Others are brown, with black streaks and dashes on the wings, like the heart-anddart moth, Agrotis exclamatimis (Limn.). The larve of the dart moths are often very destructive, as they live just below the surface of the ground, where they eat through the roots of plants. There are many closely-allied species, and the Americans call them "cutworms."

If we toss about a heap of hay, or disturb the leaves of a strawberry-bed, we are very likely to start a specimen of one of the common yellow underwing moths, Triphena (Hübn.), which, after a short headlong flight, will scttle again, and soon disappear. In these moths the fore-wings are hrown, and comparatively long and narrow, and the hind-wings are very broad, and of a bright yellow, with a blick border. In tropical countries other yellow underwinged buttertlies are found, Ophidcres (Boisd.), measuring three inches 
across the wings. They are remarkable for having the proboseis modified into a kind of boring instrument, with which they pierce the skin of oranges, and suck out the contents.

IVe now come to the Geometrre, or land-measurers, which may always be distinguished (if the transformations are known) by the larva only possessing ten legs, the tirst three pairs of prolegs being obsolete.

Geometræ. When they walk they fix themselves by the last pair of prolegs and the claspers, stretch out their bodies, fix themselves firmly by their true legs, and then draw up the four hinder legs, and repeat the process. Thus, the body of the caterpillar is arched into a loop at every step, and these caterpillars are often called "loopers" on that account. This performance, though it takes a long time to describe, is nevertheless comparatively rapid, and the larve are able to make as good progress as other caterpillars with the full complement of legs. These curious larvie often fix themselves, as described, by the claspers and hind pair of prolegs, and stretch their bodies straight ont, when they look for all the world like little bits of green or dried twigs.

Most of these moths have slender bodies and broad wings. They are frequently adorned with bright colours, and the fore and hind-wings are, more or less similar in markings; some species, however, have short, thick, hairy bodies, and resemble Bomblces, except in their larve. In several brown species, which appear during the

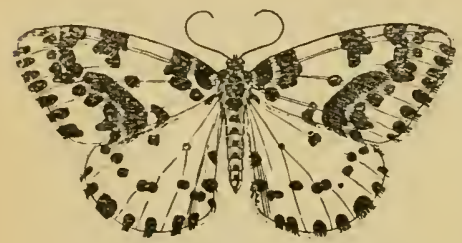

Fig. 79.-Micipie Мотн (Abrexces grossulariata). Nat. size. winter, the females have only rudimentary wings. One of the commonest of the Geometre is the magpie moth, Abraxas grossuluriatre (Limn.), which is found among gooseberry and currant bushes, on the leaves of which the larvie feed. It measures an inch and a half across the wings, which are white, with black and yellowish spots.

The next group of moths, the Prirales, have long slender legs and antemne, slender bodies, and large wings, the fore-wings being generally triangular, and the hind-wings rounded, They are of rather small size, rarely much exceeding an inch in expanse, and are often white, grey or yellow. Two of the best known species, the small magpie, Botys urticata (Linn.), which is white, marked with large black spots; and the mother-of-pearl, $B$. rerticulis (Linn.), are common among nettles. Some of the smaller white and brown species are found among reeds, the larve feeding on water plants; other small species of this family, which frequent hill-sides and mountains, are black, with

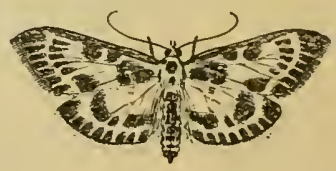

Fig. 80.-Siall Magipie Motu (Botys urticate). Nat. size. or without white lines or spots; or are beautifully marked with purple and gold.

The foregoing butterflies and moths mostly include species of comparatively large size, and are therefore often called Macro-Lepidoptera. The succeecling families mostly include small moths. The first group of these is the Crambi, which were frequently included in the Pyrales by the older entomologists. They are sinall moths, grenerally not much exceeding an inch in expanse, 
with long narrow fore-wings, and broad hind-wings. sentatives of this group are the grass moths, belonging to the genus Crambus (Fabr.), which have long 1alpi, like a snout, ycllowish white-streaked forewings, and broad brown hind-wings. In some species, as in $C$. ericellus (Hiibner), this white streak is vely conspicuous. In walking through long grass, we often disturb these moths, which fly a short distance and then settle again on a stalk, head The best known repredownwards, with their wings folded round them in almost a tubular form.

The Tortrices, or bell moths, generally have broad, short fore-wings, cut off straight at the ends, and rounded hind-wings. They sit with their fore-wings flat, meeting over their backs, and covering the hind-wings, and in this position somewhat resemble a bell in shape, whence their popular name. There are about 300 British species of this group, some of which are very destructive. One of the best known and most easily

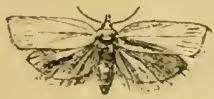

Fig. S2. -

GrenN OAK Tortrix (Tortrix viridana). Nat. size. recognised is the green oak tortrix, Tortrix viridance (Linn.), which has green fore-wings with a yellow costa, and brown hind-wings. If an oak-branch is struck or shaken, we may often see a whole shower of these couspicuous little green moths come fluttering down. They measure rather less than an inch in expanse. The larre are also green, with a brown head; they live between rolled-up leaves of the oak, and if alarmed, drop themselves a little way down by a thread, and climb back as soon as the danger appears to be over.

Other Tortices feed, in the larva state, in flower-heads, and others, again, in fruits. Different species of the genus Carpocapsa (Treitschke) feed in acorns, beech-nuts, plums, etc.; but perhaps the most injurious of all is the codling moth, $C$. pomonelle (Limn.), the pink larva of which feeds in apples and pears. The moth is grey, with darker lines, and some coppery markings towards the tip. It measures about three-quarters of an inch in expanse. It has been introcluced into all parts of the world, and is everywhere as destructive as in England.

The Tinece are a very large group of small moths, numbering in Britain alone upwards of 600 species. Vely few exceed an inch in expanse, and the greater number are much smaller. They are divided into a great number of families, which differ very much in structure and habits, but they may generally be easily recognised by their small size and long narrow wings, with very long fringes. Some of them feed in cases or galleries, like many species of Tinere (Limn.), to which genus the true clothes-moths, the corn-moth, and other highly destructive insects belong. Others feed on fungi, like Tinea ful vimitrella (Sodoff'sky), a purplish-brown moth with white spots, which is a woodland insect, and not found in houses. Some have very long antennæ, like the beautiful delicate bronzy moths of the genus Adela (Latr.), which we tind flying about bushes in spring. The small ermine moths of the genus Hyponomente (Latr.) are white or lead-coloured moths, with rows of black spots on the fore-wings; and their larve web over and devour our liedges and apple-trees, for they are gregarious, and often very destructive. 
Many entomologists regard the Hyponomeutidce as more elosely allied to the Bombyces than to the Tinece. Many Tinere mine the leaves of grasses, and this habit is characteristic of the Eluchistidce. Others, like the Nepticulidee, a family which includes the smallest moths known, make long galleries or mines, as they are called, between the membranes of a leaf. These may often be found on leaves of bramble, nut, etc. ; but such mines are not itlways due to the larve of Timere; for this habit is shared by other insects. Thus there is a very common mine on holly leaves which is produced hy the larva of a two-winged fly. Some larva which feed in a similar manner produce a blotch on the leaf, and not a mine. One of the commonest of these blotches is that formed by the larva of the beautiful delicate little Gracilaria syringella (Linn.) on the leares of the lilac.

The Pterophoride, or plume moths, are now considered by most authors to be allied to the Pyrules. They are very delicate insects, with long, slender bodies and legs, and long wings, measuring an

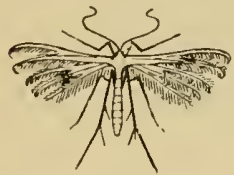

Fig. 84.-White Plume Moth (Pterophorus pentaclactylus). inch or less in expanse, and cleft almost to the base into separate feathers, two on the fore-wings, and three on the hind-wings. The largest, commonest, and most conspicuous among them is the white plume moth, Pterophorus pentudactylus (Linn.). Its larva foeds on Convolvulus, and it may often be seen floating about weedy places, strawberry beds, ete., looking like a snow-flake. Strawberry beds are a favourite resort of many inseets, probably for purposes of eoneealment.

The last family of moths, the Alucitide, which forms an isolated group, is represented in England by the twenty-plume moth, Alucite hexedrectylu (Linn.). Its larva feeds in the buds of the honeysuckle. The moth is grey, with broad wings about twothirds of an inch in expanse, and it is often noticed on windows, walls, etc., sitting with its wings spread out flat, and looking like one of the smaller Geometre. But on a closer inspection we find that each wing is split up into six separate feathers, which distinguishes it at once from any other moth found in this country.

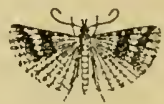

Fig. 85.-

TWENTY-PluMe MIOTH (Alucita hexadactylie). Nat. size.

\section{Order Hemiptera (Bugs and Frog-Hoppers).}

This is a somewhat extensive order of insects, with four wings, of which the front pair, or tegmina, are usually of a stouter consistency than the hindwings. They are dirided into two main sections. In the first, the Hemiptera Heteroptera, or true bugs, the tips of the tegmina are usually transparent, and veined; but in the Hemiptera the fore-wings are nearly of the same consistency throughout. In many large groups of Hemiptera, however, the fore-wings are transparent and veined, like the hind-wings; but all the insects belonging to both sections of the order may be known by their strong sucking proboseis, and the absence of mandibles. The metamorphoses are incomplete. 


\section{Sub-Order Heteriptera.}

\section{Bugs.}

The word bug is derived from the Arabic, and has nothing etymologically to do with bogy, with which it is popularly associated. It suggests an ngly, foulsmelling, wingless insect, which sucks blord, hicles itself in crevices, and shmis the light. In America, however, the word has come to be extended to insects in general. Entomologically it is applied to the insects belonging to the suborder Heteroptera, only some of which suck blood, the

Sub-order

Heteroptera

(Bugs). greater number feeding on the juices of plints; and these are as beautiful and varied in form and colour as the beetles; or more so, in proportion to their numbers, and they are mostly diurnal insects. These insects may easily be recognised, not only by the characters mentioned above, but by the peculiar structure of the antemne, which, though generally of considerable length, are composed of a very few long and well-separated joints-generally four or five.

The scutellvidre, or shield-bugs, are those which most resemble beetles, and would be easily mistaken for them at first sight. But the hard convex wingcovering is not formed by wing-cases meeting on their inner edges, as in beetles, but consists of an inordinate development of the appendage to the thorax called the scutellum, under which not only the wings, but the tegmina also, which in such cases differ little in consistency from the wings, are completely hidden. These bugs are not numerous in Europe, but in tropical countries they are often as large as a cockchafer, and of brilliant colours. Callidea perplexa (Hope), here figured, is a common East Indian species, of a brilliant green or purple, with black spots.

In the family Pentatomide, the body is still short, broad, and bulky in many of the species, but the scutellum, though still of considerable size, is a long structure, differ-

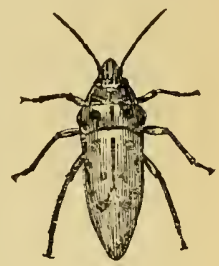

Fig. 86.-SHIELD-Bug (Cullidea perplexa).

Nat. size. ing in shape, separating more or less of the basal portion of the tegmina, when the wings are closed. Beyond its extremity, the membranous portion of the over-lapping tegmina is generally visible. Several brown or grass-green species belonging to this family are not uncommon in England. In many species, especially foreign ones, the front of the thorax expands into a kind of spine or horn on each side, often of consiclerable length.

Some species of Pentutomidce are carnivorous as well as herbivorous, and will attack caterpillars and other soft insects, and suck out their juices. Acenthosoma griseum (Linn.), which Fig. 87.-Acen. is common in England on birch, is an oval insect, about a thosoma grisenm. third of an inch long. The thorax is angulated in front, and the colour is reddish-ochreous or greenish, finely punctured with black; at the base of the scutellum is a black patch. Like some of the earwigs and Australian sawflies, the female of this species has been observed to watch over her newly-hatched young like a hen, and it is said that, as in the case of the crocodiles, and some other animals, her vigilance is chiefly required to guard them against the attacks of the male. 
The species of this family are more numerous in America than in England, and they are called "stink-bugs" in the former country, on account of the offensive odour which many of them emit.

There are a great variety of other flower-frequenting bugs belonging to various families, but the European species are mostly of small size, though often prettily coloured. The scutellum is generally much

Plant-Bugs. $\quad$ smaller than in the Pentatomirle, and the bocly is more oval ; the legs and antenne are often long and slender, remarkably so in some species; and occasionally the antenna are clubbed. In some of the large foreign species belonging to the family Harpactoricle, the thorax is often curved forwards on each side, and toothed in front, while the antennse and tibiæ are often lobate, and the hind-femora much thickened and dentated.

Among the carnivorous land-bugs, two families are specially notable. One of these is the Cimicidre, the type of which, and, indeed, of the whole suborder Heteroptera, is the common bed-bug, to which we have The Bed-Bug. already allucled. It is of a reddish-brown colour, broad, flattened, with very slight rudiments of wings (which are said occasionally to become fully developed in hot climates), and measures less than a quarter of an inch in length when full grown; but the larval forms, which are, of course, nuch smaller, are equally fond of blood, though they must be capable of subsisting on other food, as they have been known to multiply in empty houses. Very similar species are found attacking pigeons, fowls, and bats. This insect has always been common throughout Africa and Southern Europe, but was scarcely known in England till it was introduced in numbers with foreign timber after the Fire of London. (See my "TextBook of Entomology," p. 204.) It has many enemies, including the cockroach and the wheel-bug; and I have been informed that in the poor parts of London, fleas and bugs do not generally exist in equal numbers in the same house, and that, as a rule, it is the cleaner houses which are most infested by bugs. Can it be that fleas will attack bugs? I an not aware that this has been previously observed or surmised ; but, as fleas are known to attack caterpillars, it does not seem by any means impossible.

The Reduviide, or wheel-bugs, are a family of rather large bugs, with a large head, contracted behind into a neck, prominent eyes, two ocelli, rather short antenne, and a curved proboscis or rostrum. The type of the family is the masked-bug, Reduvius personatus (Linn.), the larva

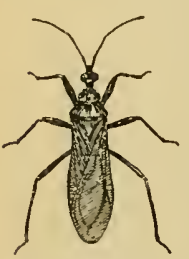

Fig. 88. MASKEDBue (Reirurius personatus).

Nat. size. and pupa of which cover themselves with particles of dust, apparently in order to creep upon their insect prey unnoticed. This species is not uncommon in outhouses, and is a blackish or dark brown insect, two-thirds of an inch long, and very hairy, especially on the head, antenna, and legs. There is a whitish line on the membrane-suture of the tegmina. This species is rarely found in houses ; but, as already mentioned, it preys on the bed-bug, as well as on flies, etc. Its own bite is said to be as painful as the sting of the bee, which may well be the case, considering its comparatively large size ; but it does not appear to attack man or the higher animals habitually. There are, however, other and much larger species of the same family that are great pests to both man and beast in the Southern States of America, Chili, and other parts of the world.

Many bugs, including several of this family, are usually apterous, but 
acquire wings occasionally ; while in some species, two forms are habitually met with, in one of which the wings are more or less rudimentary, while in the other they are fully developed.

Hitherto we have been discussing land-bugs, but several families of the Heteroptera are aquatic, and among them we find the largest species of the sub-order.

The first family includes the Hydrometride, the watermeasurers, which are long, narrow, black insects, often with fine silvery pubescence. They have very long middle and hind-legs, and the front-legs are clirected forward. Here, too, we meet with both winged and apterous adult inclividuals of the same species. They measure from one to three-quarters of an inch in length, and are found running rapidly on the surface of the water, and feeding on small insects. They can also dive when alarmed. One genus of this fanily, Halobates (Esch.), is found running on the surface of the open ocean in various regions of the tropics.

The Nepilce, or water-scorpions, have an oval and rather flattened body, terminating in a breathing tube of nearly half its length, and the front pair of legs have thickened femora, and project forwards in such a mamer as to suggest the pincers of a scorpion. Our British Water-scorpion. species, Nepa cinerea (Limn.) is a brown insect, nearly an inch long exclusire of the spiracular tube, and is found in muddy, stagnant pools.

Piencetru linearis (Linn.) is an insect allied to the last, and belonging to the family Ranatride. It is, however, very long and narrow, and of a lighter yellowish-brown colonr. The middle and hind-legs are very long and slender, and the front pair are much longer and less thickened than in Nepa. It measures nearly three inches in length, of which the abdominal breathingtube occupies nearly half. It is not a very common insect in England, and creeps about at the bottom of stagnant water.

The largest Heteroptera belong to the family Belostomatide, which is not British, though common in most of the warmer parts of the world. They are oval insects, with the legs flattener, especially the front femora. The insects sometimes measure four and a half inches in length, and six inches or more in expanse of wing. They are of a yellowish-brown colour. In the evening they leave the water, and fly about. This is a common habit with many water-insects, which enables them to migrate from one place to another, if the ponds in which they live dry up. In America, where one or two species are common, they are sometimes attracted in large numbers by the electric light. They feed on small fish, frogs, etc., as well as on water-insects.

The water boatmen (Notonectidce) are represented in England by one or two yellowish species, about half an inch long, with flattened hind-legs fringed with hairs, and which stand out from the body in the position of oars. They are used in a similar manner, for the insects Water-Boatmen. Hoat on their backs, and row themselves about with them. Zuithue aurentiaca (Leidy) is a light brown North American species.

Among the remaining water-bugs are the Corixide, which are not unlike the Notonectidce, but are smaller, much broader in proportion, especially the head, and more obtuse behind. They are brown or black, glossy, with yellowish strie above.

A friend once showed me an absurd error with respect to the term waterboatmen, which is frequently applied to different species of water-bugs. It .occurred in connection with the habits of some South American birds, in an ornithological work, the name of which I have forgotten, and ran 
something like this :- "They feed on the eggs which the fishermen lay on the banks of the streams, in clusters of six lines long

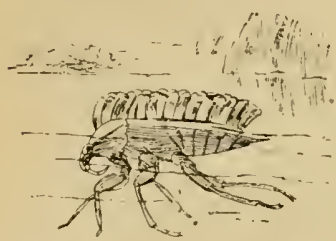

Fig. 89.-WATER-Bug (Zaitha aurantiace), WITH EGGs. Nat. size.

instcad of the breech-loader. by three broad." If I remember right, the passage was translated from the French, and I have little doubt that in the original some expression was used equivalent to "water-boatinen." It reminds one of another story which I read in the translation of a Russian book of travels, in which an elcphant was described as seizing an object with his tail, instead of his trunk. I have also heard of a translation of a German book, in which a naturalist on shipboard, who wanted to shoot a bird, was described as taking down the back-shutters,

\section{Sub-Order Homoptera (Froci-Hoppers, Plant-Lice, etc.).}

A great number of insects are classed under this sub-order, which we have already briefly defined. They do not emit any foul odour like the Heteroptera ; their antenne are generally very short ; and they are sub-order exclusively plant-feeders. Some of them supply us with Homoptera. $\quad$ iseful products, such as shell-lac and cochineal, while others are among the most injurious insects which infest oul gardens and greenhouses.

The Homoptera are divided into several very distinct families, of which the first is the Ciccudide. They are large, wedge-shaped insects, with a broad head, large eyes, a pointed body, with a short ovipositor in Family the female, and broad wings, which are generally, but not Cicadida. always, transparent. When at rest, the wings are folded roof-like over the body, and generally extend considerably beyond the abdomen. They are difficult insects to classify, as the most tangible characters available for the purpose are to be found in the drums of the males. These organs are found on each side of the abdomen, and are visible above in some genera, while in others they are covered by a flap. On the under-surface they are always covered by two flaps, called the opercula, which are sometimes very short, small, and rounded, and in others are very large, and extend nearly to the end of the abdomen. In the Australian genus Thopha, amongst the opercula are extended over the sides of the abdomen, as well as beneath. InPTibicinc (Latr.), there are no covers at all on the upper. surface of the abdomen; and in Zammara (Amyot), the rims of the npenings are slightly raised, giving them something of a pitcher shape. It has been proposed to divide thelcicadide into two sub-families, according to whether the drums are open or closed above ; but I find, not only that the upper abdominal covers differ very much in completeness or absence, but that many genera, otherwise closely allied, run in pairs, one with closed, and one with open tympana.

The sounds made by these insects have always made them celebrated, and they are among the noisiest denizens of the tropical forests. They are, however, difficult to capture, as they are not easily seen, and their flight, when disturbed, is rery sudden and rapid. This is chiefly a tropical family, and the largest known species, P'mponice imperutoriu (Westwood), which inhabits 
the Malay Islands, measures nearly eight inches in expanse. Several species are found in Southern Europe, and their song was greatly admired by the Freeks. In Northern Europe they are scarce, and we have but one small species in England, which is very far from common, and is almost confined to the New Forest, though it has once been met with near Haslemere. This species is Giclampsalte montana (Scop.), and measures rather less than two inches in expanse. It is brown, with reddish markings on the thorax; and the principal wing nervures towards the base, and the incisions of the abdomen are of the same colour. It belongs to a very extensive genus of rather small species, in which the basal cell of the tegmina is long and narrow, and emits one bifurcating

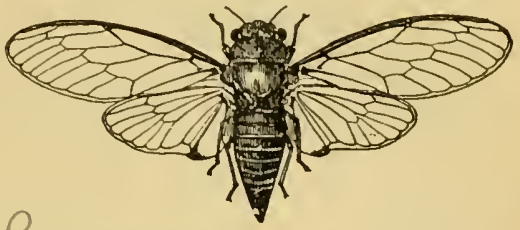

Fig.90.-Melampsalta montana. Nat. size. longitudinal nervure from its extremity, instead of two separate ones. This genus is represented by numerous, but usually comparatively small, species, in most parts of the world, and is especially numerous in Australia ; and it is at present the only genus of Cicudide which is known to occur in New Kealand.

The Cicadide vary from the general character of the Homoptera in the tegmina and wings being of uniform consistency, though the tegmina are al ways larger, and have a more elaborate neuration. They are insects with imperfect netamorphoses, and in countries where they are common, the empty pupa-skin may often be seen attached to trees by its strong claws, with a large hole in the back, through which the insect has emerged.

The Fulgoridue are an extensive and varied family, differing from the Cicadidce in many particulars. There are only two ocelli, instead of three; the tegmina and wings are opaque, and generally differ considerably in consistency; the antenne are inserted on the sides of the head and below the eyes ; and the larve, and in nrany cases the perfect insects, are frequently covered with

\section{Family Fulgoriclo. - Lantern Flies.} a white waxy exudation, which we seldom observe in the Cicadidce, and then only to a trifling extent. This family is divided into several sub-families, of which we will mention some of the most interesting.

The Fulgorine, or true lantern and candle-flies, are exotic insects of rather large size, and are remarkable for having the front of the head produced into a long horn or excrescence, differing considerably in size and shape. The largest species is the lanteru-fly of South America, Fulgora laternaria (Limu.), which often measures more than four inches in expanse. It is of a greenish-yellow colour, with a large eyelike spot on the hind-wings; the head is produced into a great hollow appendage,

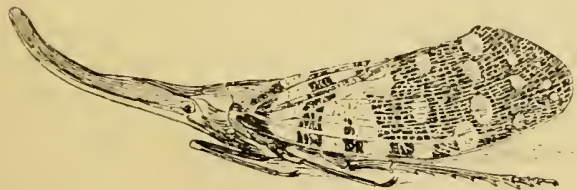

Fig. 91.-Cande-Fly (Hotinus candelarius). Nat. size. slightly bent downwards, and then continued forward. The candle-flies of the East Indies, Hotinus candelarius (Limn., etc.), are also large insects, measuring two or three inches in expanse. In the species we have mentioned, the tegmina are black and green, spotted 
with yellow, and the hind-wings are yellow, bordered with brown. There is a long and somewhat recurved hurn on the head. Other species of this family are varied with blue or red, and the horns are of different colours and shapes ; yellow or green, and pointed; dentated; white, with a red knob at the $\mathrm{cx}$ tremity; rather short, and trifid at the end, ctc. Most of the species are East Indian or South American; a few are African.

The Lystrince are also tropical species of considerable size and bright colours, but the excrescence on the head is absent. They are chiefly, but not exclusirely, South American.

$\checkmark$ The Flatince are another extensive tropical group, in which the tegmina are bordered more or less broadly with a row of oblique or transverse nervures. They generally measure from one to two inches in expanse. The tegmina

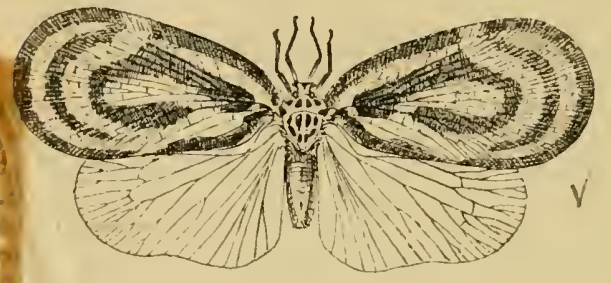

Fig. 92,-Flata circulatd. Nat. size. are frequently green, sometimes prettily spotted with red, and are oval or angulated at the tips, and not much longer than the wings, which are generally light brown, grey, or white, and sub-hyaline. The species figured, OFlata circulate (Guérin), is pale grey, with black markings. It is a native of Java.

Most of the Europcan Fulgoridee are small insects. The

- Delphacince, which measure about one-sixth of an inch in length, have comparatively long anteune, with the joints much thickened, and the last ending in a bristle. The hind-legs are very long, and strongly spined at the end of the tibire; they are generally of a yellow colour. The head is broad, and the face more or less keeled. They are gemerally found on grass in damp places, and many species are dimorphic, exhibiting both winged and subapterous forms.

The Derbince are a small exotic sub-family, with very short, oval bodies, comparatively long antennæ, unarmed legs, and long narrow wings, an inch in expanse, and shaped more like those of a Tipula or a Pterophorus than those of gther homopterous insects.

In the Cercopida, the antenme are placed between the eyes, just under the vertex; the scutellum is rather small, and the hind tibire are usually armed with from one to three spines, and a crown of stronger ones at their extremity.

This family includes the true fror-hoppers, the most conspicuous species of which is Triecphora vulnerata (Illiger), which is not unlike a small beetle in appearance. It is black, and measures about three-quarters of an inch across the long, oval, horny tegmina, which are black, with bright red markings; the wings are subliyaline. It is not uncommon in England. Aphrophore alni (Fall.) is about the same size, but is dull yellow, with brown markings on the elytra, which are broader than in Triecphora vulnerata, and more pointed at the tips; the hind-wings are also broader and more rounded than in the latter insect. Its soft yellow larva is very common on grass, etc., and is always surrounded by a

C Fig. 93.-Tricephor'a iulneratu. Nat. size.

mass of froth, called popularly "cuckoo-spit." 
The $J_{\text {cssidce differ from the }}$ Cercopidee in the hind tibize having a row of spines below. They are small yellowish insects, most of which are placed by Mr. G. B. Buckton, in his "Monograph Family Jasside. of the British Cicade," under the genus Deltocephalus (Burm.).

The Membracidce are remarkable for the thorax being produced into a long horn or spine, which is frequently recurved over the abdomen. The genus Centrotus (Fibr.), represented in England by $C$. cornutus (Limn.), is very numerous in species, which are generally of a black or brown colour, with paler wings and tegmina, the sides of the thorax projecting to a more or less sharp point, and a long spine, broad at the base, and narrowing behind, projecting from the thorax over the back. They are insects of small size, rarely reaching a quarter of an inch in length. Among the foreign species, the forms of the horn in this family are frequently very remarkable. In one genus, Umbonin (Burm.), the species are yellow, streaked with red, and the whole insect is shaped exactly like the thorn of a rose tree. These are found in Tropical America. Respecting the North American species, Prof. Comstock remarks, "In some cases the prothorax is elevated above the head, so that it looks like a peaked nightcap ; in other's it is shaped like a T'am-o'-Shanter'; and sometimes it has horns, one on each side, which have given one species the name of the buffalo tree-hopper." In others, again, the horn of the prothorax is nearly vertical, larger than the whole of the rest of the insect, and recurved and bifid at the extremity, and in some species from Tropical America, belonging to the genus Bocydinm (Latr.), the horn separates into a number of little bails, each of which again throws off a small spine.

The remaining families of Homoptera which we have to notice are all plant-feeding insects of small size, in which the proboscis appears to issue from between the front-legs, if present at all. The antennie, when present, are usually long and slender, and the tarsi are one or two-jointed.

The Psyllidce are short, broad insects, which have been compared to minute Cicadas. The hind legs are thickened, and the antennie terminate in two bristles. They leap about on plants, and many of the species produce galls. They resenble the Aphidoe in discharging a sweet fluid, which attracts ants, and their larvet are covered with a white cottony exudation. They are provided with three ocelli. The wings are transparent.

The Aphidida, which are often called plant-lice, smother-flies, or blight, have slender legs, not fitted for leaping; the antennae are long and slender, not terminating in a double bristle; the ocelli are absent, and the wings are transparent. There is a most curious alternation of broods in these insects, some forms being winged, and with separate sexes, and others winged or apterous, and capable of producing their kind for an inclefinite

Family

Psyllidice. number of generations before a sexual brood is again developed. Some produce galls, but the greater part feed on the leaves of trees. Sometimes one generation will live on one tree, and the next migrate to another, a future generation returning to the original food-plant. In fact, the anomalies of these insects are endless, and it would require volumes to epitomise even the comparatively little which has already been discovered with reference to their 
habits and transformations. They are small insects, but some are capable, like the Phylloxera of the vine, of ruining or crippling a vast industry over a considerable portion of the world. They exude a sweet liquid known as honey-dew, of which ants are extremely fond ; and to ants they bear the relation of milch-kine, and are frequently protected and tended by them accordingly. In some cases the ants are even said to superintend the breeding of the various broods.

The Aleyrodidce are a small family, of which the perfect insects resemble very small moths, covered with a whitish powder. One or two species are very destructive to cabbages and tomatoes.

The Coccidre, or scale-insects, differ much from all other insects. The male has no rostrum, and only two wings, but possesses anal setie, and the wingless, short-legged female settles herself

Family permanently down on a leaf or twig,

Coccide. - and forms a scale-like covering for

Scale-Insects. her own egrgs. Some of these furnish useful products, such as cochineal, but others are highly injurious. One species, Iceryu purchesis (Maskell), caused great clamage in California; but by the advice of the late Prof. C. V. Riley, an Australian lady-bird, Novines cardinalis (Muls.), was introduced into the country, and has since been effectual in keeping the ravages of the Icerye within bounds. Many of the Coccidce, especially the larval forms, are covered either with a white cottony substance or with large plates of white wax, which in some cases has a con-inercial value.

\section{Order Axoplura.}

The true lice, which are wingless insects, parasitic on mammals, and furnished with a sucking proboscis, are sometimes regarded as a sub-order of Hemiptera. Three species at least infest man in European countries, and, besides the discomfort and annoyance which they occasion, are either the cause of, or accompany various diseases. They multiply very rapidly, but can usually be destroyed or kept away by ordinary attention to cleanliness. In warm countries, or, indeed, in any community where cleanliness is neglected, they are universally prevalent. There has been much controversy as to whether the lice infesting different races of mankind are to be regarded as distinct species, or only as slight varieties. Even the two species of lice which infest the head and elothes respectively, Pediculus capitis (Linn.), and $P$. restimenti (Nitsel), although certainly distinct, are so much alike that they can hardly be distinguished from each other. The third species, the crab louse, Pthirius inguinalis (Leech), belongs to a distinct genus, and is much smaller, broader, and shorter than the others.

\section{Orher Diptera (Flies).}

The Diptera, or Flies, differ from other insects in possessing only two wings 
throughout the whole of the Order, the hind-wings being represented only by two knobbed appendages like drumsticks, which are known as halteres or poisers. They are furnished with a proboscis, with which they imbibe their food, which consists, in the characteristics. perfect state, of liquid substanees only. They undergo a complete metamorphosis, their larve being footless maggots, which pass the pupa state in a barrel-shaped integument formed of the dried skin of the larva. In the larval state, many species live in water, some in the ground, others on plants, sometimes forming galls, while others feed on carrion, dung, etc.; and others, again, are parasitic on various animals, neither vertebrate nor invertebrate animals being secure from their attacks. They probably form one of the largest orders of insects, but have been so little studied that only 28,000 species were described up to 1892 , of which between 2,000 and 3,000 inhabit the British Islands. The Flies are divided into two principal sections, and the Aphaniptera, or fleas, are now usually regarded as forming a third main seetion of Diptera rather than a separate order.

The body is not generally very hairy, and the wings are usually destitute of hair or scales, generally transparent, and with very few nervures, most of which are longitudinal. 'The Aphaniptera have the barest rudiments of wings, while some genera of Diptera are provided with small additional lobes at the base of the wings, which are usually called alulie.

\section{Diptera Nemocera (Gnats axd Crane-Flies).}

The insects belonging to this group are generally slender-bodied flies, with the antemne long, or of moderate length, and composed of six joints and upwards. The palpi have from three to six joints. They frequently undergo their metamolphoses in the water or in the ground; and none of the species of this section are parasitic, or even caruivorous, in the larval stage, though the females of certain families will suck blood in their perfect state.

The Cecidomyiidce, or gall-gnats, with which we will commence our notice of the Nemocera, are very small, gnat-like insects, with long moniliform or cylindrical antenne, often set

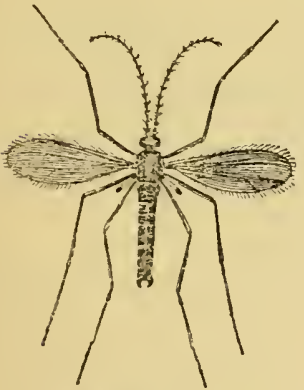

Fï. 96.-IIESSIAN-Fir (cécidumyiu dests uetor). Magnified. with whorls of hairs, and comparatively broad, iridescent wings, with from two to five longitudinal nervures only, and these frequently

Family Cecidomyiide. -Gall-Gnats. not all clearly defined. Their bodies are clothed with long hairs. The larve are very various in their habits, many of them causing galls on various trees and plants, especially willows, while others live in bulbs, fungi, rotten wood, under bark, or in fir-cones. One or two species are at times very lestructive to wheat, especially the wheat-midge and the Hessian-fly, Diplosis tritici (Kiri.), and Cecidomyia destructor (Say.). The latter has only lately been recognised as a British species. It attacks the stems of the wheat, which crack and bend over, and this appearance furnishes the easiest and lnust reliable evidence of the presence of the pest among the wheat. Its ravages are, however, much checked by the attacks of various small parasites belonging to the Hymenopterous family Chalcidide. 
Besides the true gnats or mosquitoes (Culicidce), some of the species belonging to several other families of this section of Diptera are extremely troublesome, the females sucking the blood of men and

Gnats and animals. These are the sand-flies (Simuliidce), and also the Sand-Flies. Chironomidce and Psychodidce. The larve of all these families, except the Psychodida, live in water. The Culicidce and Chironomidce have more or less plumose antennie in the males, which may often be seen on our windows. The transformations of the common gnat are very curious, and have often been described. The female gnat lays her eggs in a compact, boat-shaped mass, which floats on the surface of the water. The larva swims head downwards, having a respiratory tube at the hinder extremity of the body, through which it breathes. The pupa is of a different form, and swims head upwards, the upper end of the body, which is much thickened, being now provided with respiratory organs. When it has arrived at maturity, the skin of the upper end of the pupa splits, and the gnat gradually disengages itself, steps out on the surface of the water, and flies away. The Simuliide have short, broad wings, comparatively short and stout antennie, and spotted legs, in which the first joint of the tarsi is as long as the remaining joints. The larvie and pupre live in water, where they form small cases, which they attach to grass-stems, weeds, stones, etc. Our British species are harmless, or nearly so; but in many countries, as in the Banat of Hungary, for example, they form a terrible pest. The Psychodidu, the last of this group of blood-sucking families which we sliall notice, resemb]e small moths, and sit on the underside of leaves, or rmuctively over them. The principal blood-sucking species in this family is Phlebotomus prepatasii(Scopoli), which inhabits the south-east of Europe. It is a small, hairy, yellowish-brownfly.

Next to the gnats and gnat-like Hies, the most fanilini insects belonging to the Nemocera are the Tipulide, which are generally called crane-flies, or daddy longlegs. These are flies

Family with long, narrow, transparent

Tipulidie. - or mottled wings, expanding

crane-Flies. from one to two inches; a long pointed smout, on each side of which are moderately long antennie ; and a long slender body, generally greyish-brown, but sometimes banded with yellow, and terminating, in the female, in a short lorny point. They have very long slender legs, which break off at the least touch. They are easily disturbed when we are walking through the meadows, when they flit a few feet, and settle again with their wings extended. They frequently fly into rooms at night, being easily attracted by a light. Their grubs live in the ground, and feed on the roots of grass, frequently causing whole tields to wither and tum brown, as if parched up with drought. The smaller insects of this rathor extensive family resemble gnats in size and general appearance, and some of them appear during the winter months. The species figured, Pachyrhina

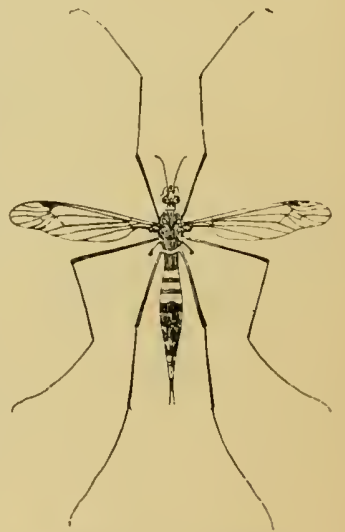

Fig. 97.-CRANE-Fù

(Puchyrhina crocato). Nat. size. rocetu (Limn.), is a rather liandsome black and yellow insect, and is found in woods. 


\section{Dimtera Braritrorera (Flies).}

The flies of this section are generally stouter than those of the last, and may be distinguished from them by their very short antenure, which generally consist only of three joints (never more than six), and often terminate in a long bristle ; the palpi, too, consist of one or two joints only.

The Stratiomyicle are a family of small or moderate-sized flies of sluggisl labits, which are often to be met with on Howers. Some are rather pretty black or black and yellow flies, often with spines on the scutellum. Many of their larva live in water

Family or mud.

The Tubrnide, or gad-flies, are large flies with stout bodies and a very strong proboscis. They vary in length from an inch downwards, and

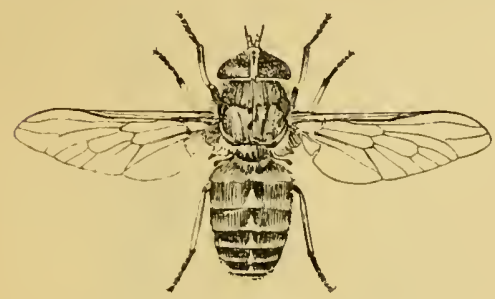

Fig. 9.,-GAD.FEY (Tubunus bnimus). Nat. size. are frequently very troublesome in the woods and fields, by sucking the blood of Family Tabanide. men and animals.

Gad-Flies.

Some are of a plain brown colour, but others are rather pretty, being clothed with golden hair, while others are banded or marked with reddishyellow. The larve are harmless, living in damp situations, among fallen leaves, etc.; and, as usual, it is only the female flies which suck blood. We have been spoaking here chiefly of the genus Tabonus (Linn.), the largest British species of which, T. bovimus (Linn.), is here tigured; but there are several other equally troublesome genera of this family, such as Chrysops, with its variegated wings and beautiful large golden-green eyes; and Hrematopoda (MLigen), which

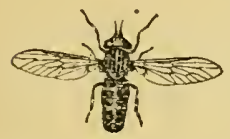

Fig. 99.-Hematopota. pluvialis. Nat. size. contains dull-coloured species, with longer and slenderer bodies than Tabamus and its allies. The species of $H_{1 \ell-}$ matopota are particularly troublesome in the neighbourhood of woods, especially in rainy weather, one of the Linnean species being actually named plucialis (rainy).

The next family of interest is that of the Asilide, which are large flies, often measuring an inch or more in length, which feed, in the perfect state, on other insects. They have long and narrow wings, and long bodies, but their comparatively short and thick legs render it impossible for the most careless observer to mistake them for Tipulide. A handsome black

\section{Family}

Asilidre.-

Robber-Flies. and yellow species, Asilus crebroniformis (Limn.), is not rare. So far as is known, the larve feed on vegetable substances, either under the surface of the ground, or in the wood of trees; but the transformations of most of the species of this family still remain to be discovered. Most flies which are either carnivorous or blood-suckers in their perfect state are vegetable-feeders in their early stages; but some of the exotic family Midcidce, the perfect insects of which are carnivorous, also feed on insects in the larva state, while the larve of others live in rotten wood. In the 
latter case, howerer, it is possible that they feed on other insects which live in the wood, and not on the wood

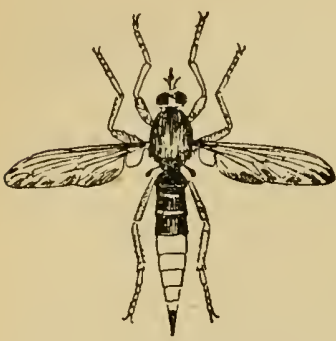

Fig. 100.-Asilus crabroniformis. Nat. size. itself.

The species of the family Empide much resemble the Asilide in habits, but are smaller, and frequent words rather than open places. They will, however, feed on vegetable as well as animal substances, and their larve live in loose earth.

The Bombyliidre, or bee-like flies, are another interesting family. They are moderate-sized hairy flies, much resembling bees, but with a long straight proboscis, with which they suck the honey of flowers. The larve are parasitic on the earlier stages of other insects.

The Syrphidce are a large family of handsomely - coloured flies of moderate size, which are remarkable for their curious hovering and darting flight. Many of the species resemble wasps and bees; and their larvæe live on decaying animal or vegctable substances, and frequently in foul water. The most interesting species of this family is Eristalis tenax (Linn.), a blackish fly, more or less clothed with tawny hair, and rather more than half an inch long. Its larva is often found in foul water, and is called the rat-tailed grub, from a long respiratory appendage at the end of the body. This species appear's to have given rise to the widespread belief that bees might be reared from dead

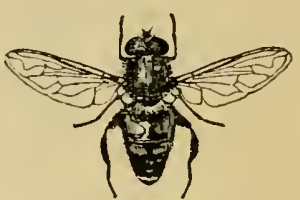

Fig. 101.-Fristalis tenax. Nat. size. carcases, as we find recorded in the story of Sampson ; in the "Georgics" of Virgil, and in many other old writings. Wasp-like flies of sinilar habits have also given rise to the idea that wasps or hornets were, or might be, bred from the carcases of horses.

The Estride, or bot-flies, are chiefly remarkable for being parasitic in mammalia. Recent statistics have shown that the amount of damage caused by the following species to cattle in England alone is quite Family Fstrida. astounding. Hypoderma bovis (Linn.) is a black hairy fly, -Bot-Flies. varied with whitish and yellowish, which attacks oxen; it is about half an inch in length. The flies themselves are very rarely seen, unless when reared. Other species of this family live in the nasal fosse of sheep and deer; in the stomach of the horse; and in various other situations. They have sometimes been known to attack man, especially in warm countries; but whether any species of this family habitually attacks man is doubtful. Hypodermic dipterous parasites which infest man belong, as a rule, to some section of the immense family Muscidce, which we have now to consider.

The Muscidle include nearly half the known Diptera, and have nearly all more or less resemblance to the common house-fly, which is the type of the whole order. The antemne are always three-jointed, with Family the third joint compressed, and bearing a bristle on the Muscide. back, which is often plumose. The proboscis is always present, and is usually membranous, rarely horny; the palpi 
are unjointed, and the abdomen has from four to seven joints, and is generally soft. The larvie are footless maggots, and are either parasitie, or live on decaying animal and vegetable substances. The Muscide are divided into two main seetions: the Muscide Calyptere, in which the appendages ealled alule, or winglets, are present; and the Muscide Acalyptere, in which they are absent or rudimentary. (The alule must not be confounded with the halteres, or poiser's, which are drumstick or battledore-shaped organs, which are consiclered to correspond to the hind pair of wings in four-winged insects.) Each of these two sections is divided into several large sub-families, the more interesting of which we will now proceed to consider.

The Tuchinince are a sub-family remarkable for the very bristly abclomen of most of the speeies. The larvie are parasitic on various species of Lepidoptera, and the flies, which are rather numer-

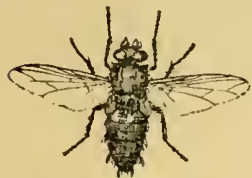

Fig. 102.-Tachina, sp. Twice nat, size. ous in genera and speeies, are frequently found on the flowers of wild carrot, and other Umbelliferce. A species of this sub-family has been reared from a nest of the gregarious larve of a West African moth of the genus Anaphe, and is here figurecl.

The typical sub-family of the Muscince includes a large number of our most familiar flies; and among them the true house-fly, Mrusca domestica (Linn.), which is blackish, more or less varied with grey, and with the base of the abdomen reddish ; it is about one-third of an inch long. The various organs of this insect: the compound facetted eyes, the proboseis, and the peculiarly complieated foot, all form interesting microscopic objects, and have often been described and figured in books on natural history. It is now believed that the pads of the foot do not support the insects when walking on a ceiling or window-pane by performing the office of suckers, but that they exude a viscid fluid which enables the insects to adhere to a smooth surface. The larva of Musca domestica live in dung, or in any sort of animal or vegetable refuse ; and owing to the much greater cleanliness of our houses and enclosures, to what was the case formerly, flies are not nearly so numerous and troublesome as was the case even thirty or forty years ago. They do not bite or sting, but there is a greyer fly, Stomoxys calcitrans (Limn.), which eomes into houses in wet weather, and bites sharply. Its pupre have been found in horse-dung, in which the larva very probably feeds. But any flies ean convey the infection of diseases which ean be communicated in this manner, even those which do not bite; and ophthalmia is frequently thus eonmunicated in Egypt; and the bite of flies that have been feeding on putrid substances is still more dangerous. The mosquitoes in the East Indies are even said to eonvey the germs of a small blood-parasite from one person to another in this manner. At the best, therefore, flies are undesirable visitors in our houses; but they are not allowed to inerease indefinitely, but are linble to various natural eheeks. They are frequently seen in autumn plastered to the windows by a white fungus, which has spread over and round them till it has killed them. They are also frequently seen with the eurious little creatures called false scorpions (belonging to the Arachnide family Cheliferidce) elinging to their legs. These resemble microscopie seorpions without the tail, but it is doubtful if they are really injurious to the flies, which, it has been suggested, they may use as winged steeds to carry them to fresh fielcls and pastures new. 
The house-fly is most common in summer and autumn, but there are other flies very similar to it in size and colour, belonging to the sub-family Anthomyince, which are common in houses earlier in the year, and are commonly called house-flies. It is perhaps hardly necessary to say that although many genera and species of flies are common in houses, either habitually or casually, none of them ever grow after assuming the perfect state ; and it wonld, consequently, be an absurd error to suppose that the small flies are the young of the large ones, even though individuals of the same species may vary a little in size within narrow limits.

Other larger flies are common in our houses, with brown bodies and blue or purple abdomens. They are generally called blue-bottle flies, and their grubs feed on meat, or carrion. A smaller and prettier species, the greenbottle, Lucilia cersar (Limn.), is more frequently observed out of doors. Linneus is reported to have said that the progeny of three blow-flies could devour the carcass of an ox as quickly as a lion could. The Tse-tse Hy, Glossina morsitans (Westwood), which destroys horses and cattle in South Africa, is another species of this sub-fanily; it is about the size of a bee.

\section{Muscide ACALyptere.}

This is another large section, divided into several sub-families, mostly of small size. Some of them feed on dung, like the conspicuous yellow fly, Scatophaga stercoraria (Linn.); others, as the sub-families, Ortalina, Tripetince, and Agromyzince, feed on plants; some in the heads of flowers, and others mining the leaves of trees, like the Tinee anong the moths. Most of the flies of this section are small and slender, and many have very prettily variegaterl wings. The best known species is perhaps Piophila casei (Limn.), a rather slender, black, hairy fly, the larva of which feed on cheese or bacon. It belongs to the sub-family Piophitine.

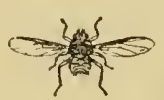

Fig. 103.-Swallow Fuy (Ornithomyia avicularia, Linn.). Nat, size.

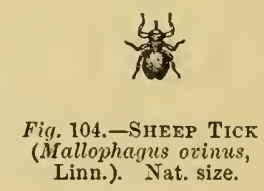

Fig. 104.-SHEEP TICK

Linn.). Nat. size.

\section{Diptera Homaloptera.}

This section contains only two families, the Hippoboscidce and Nycteribiide, which include a few species with a rather horny integument, and very hairy, sprawling legs. They are parasitic on various mammals and birds; and some of the species, such as the sheep tick, Melophagus orinus (Linn.), are apterous. 


\section{Diptera Aphaniptera.}

This section includes the fleas, which are tou well known to need description. The species are not well-defined, and it is not clear how far those which are found on different animals are really distinct. They are all remarkable for their great powe1s of leaping; and they possess the merest rudiments of wings. 'They sometimes form colonies on the ground, especially in warm countries, and have been observed to attaek catelpillars, so that their food is not confined to the blood of mammals or birds. They are probably quite as ready to attack any soft-bodied animal which comes in their way. I have already suggested (anteà, p. 596) that it is possible that they may even attack the common bed-bug, and exterminate it in houses where they are sufticiently numerous. In Ameriea it is said that the common house-flea is the dogflea, the liuman flea being much less common. 


\title{
SUB-KINGDOM III.--MOLLUSCA.
}

\section{SNAILS, ETC.}

\author{
By B. B. Woonward, F.L.S., F.G.S., Etc.
}

THE sub-kingdom Mollusca includes such well-known creatures as the whelk, the oyster, the garden snail, and the octopus. It may be roughly cliaracterised as comprising soft-bodied animals that are usually possessed of a hard shell into which they can withdraw for protection. The forms of its different members are as varied as the different conditions of life to which they have become adapted; for some live in the open sea, others hide in its depths; some live in rivers or swift-flowing streams and even torrents, or abide in still lakes and ponds; others, again, are adapted for life on dry land, and, though mostly lovers of moist, shady spots, will some of them rejoice in sun-baked rocks, or live in arid spots where vegetation is scanty. Indeed, save for the frozen polar regions and snow-capped mountain summits, or desert wastes-such as the Sahara-there is no spot on the surface of the globe, nor, unless it be certain of the extreme depths, any point on the sea bottom, without its representative mollusc. But it is in the tropical regions and oceans that they most abound. Their mode of life is as varied as their habitat: some are strong swimmers, others only float in the water; some crawl on land or under water, others burrow in the mud or sand, or even into hard rocks, whilst a few live in the tissues of other animals; others, again, attach themselves to different objects more or less permanently; this is especially the case with the shore drvellers, who have to withstand the action of currents, the sweep to and fro of the tides, or the violence of storm-tossed waters. Their food, too, differs, some being carnivorous and even cannibals, others strict vegetarians, whilst many prefer a mixed diet. Those that burrow, or are attached, generally feed on microscopic organisms, which they obtain from the mud or the water; whilst the parasites, as all the world over, dine at the expense of their hosts.

Owing to the great variations in form, and even in structure, which conformity to these widely different requirements of life has brought about, it is impossible to draw up any satisfactory definition of a mollusc which shall be fairly applicable to even the majority of the larger groups. Nevertheless, certain characters they do possess more or less in common. The shell, though not universally present, is on the whole, perhaps, the most conspicuous feature, although not the most important part of the animal. They have also a well-developed muscular system, of which that portion pertaining to the foot, or organ of locomotion, is the most prominent. There is a distinct nervous system; a heart and circulatory system with its associated organs of respiration; an alimentary system, or 
set of organs for preparing and digesting the food; an excretory system ; and reproductive organs.

The shell in the majority of Mollusca consists of a single more or less coiled tube (as in the whelk and snail), and hence they are termed univalves; in the oyster and other bivalves the shell is in two pieces; whilst in the coat-of-nail shells, chitons, there are eight little overlapping shelly plates. The shell is composed mainly of carbonate of lime, with the admixture of an organic substance known as conchiolin, which is very similar to chitin, the horny material forming the hard parts of insects. It is generally divisible into layers exhibiting differences of structure. The outermost, called the periostracum, largely and often entirely consists of conchiolin ; it varies greatly in appearance, being sometimes smooth and shiny, at others rough and coarse, frequently it is fibrous. In many forms it readily rubs off, in others it is firmly united to the true shell beneath. The term epidermis, which has been misapplied to this layer, should be reserved exclusively for the outermost layer of the skin of the animal itself. Of the shell proper the main layer is usually either porcellaneous or crystalline in structure, and in certain cases, such as Pinna, it is prismatic. The innermost layer is frequently pearly (nacreous), and in some, like the fresh-water mussels or the pearl oyster, it is the thickest of all. The iridescent play of colours, for which mother-of-pearl is noted, results not so much from any fine microscopic sculpturing of the surface as from the breaking up and refraction of the light that falls on them by the extremely thin films of which the pearly layer is built up. Yet another quality of slelly matter is that which is deposited when a damage in the shell lias to be made good, or an unoccupied space requires to be filled up. Very similar, too, is the calcareous material of which the trap-door (operculum) closing the mouth of some shells is forned. These different layers of shelly matter are secreted by a series of special cells near the margin (collar) of the tough muscular skin (mantle) that envelops the greater portion of the animal's body, the outermost layer by the cells nearest the margin, the next one by those further in, and so on. The shell, therefore, increases in size by the addition of fresh material to its free edges, the whole being subscquently thickened and strengthened by further deposits on the inner surface. The successive additions along the growing edge generally leave ridges or marks parallel with it, that are known as lines of grouth. The deposition of shell does not go on continuously; every now and again there comes a period of rest, and these rest-periods are frequently indicated by the occurrence of a stronger ridge or mark. The different details of sculpturing on the surfaces of the shell, striæ, ribs, spines, etc., are all the products of corresponding irregularities on the margin of the mantle, and were, when first formed, situated on the growing edge. Pearls result from the coating over with nacre of any irritating object that may have got between the mantle of a pearl-producing mollusc and its shell-a fact taken advantage of by the ingenious Chinese who introduce small metal images. More often, perhapsand certainly it is the case with the finer examples-they result from a diseased condition of the cells that secrete the nacre.

The muscular foot, which is generally an organ of locomotion, takes various forms in the different groups of Mollusca: the univalves (snails and whelks) creep along by its means; the bivalves employ it to burrow with; in the cuttle-fish it is drawn out into the arms; in other Mollusca it is transformed into fins to swim with; whilst in some, like the oyster, it has ceased to be 
employed, and has degenerated into a mere rudiment. Most of the muscles of the body are concerned with the extension or retraction of the different organs of the body, and do not here need special enumeration.

The nervous systen of Mollusca accuires peculiar importance in that it is the last feature to be influenced by the modifications of the organism, and hence is of extreme value in tracing relationships of the parts. Its principal elements comprise a series of paired nerve centres or ganglia; of these one pair, the cerebral ganglia, lying above the oesophagus, sends off nerves to (innervates) the head, eyes, and the special organs of sense; another pair, the pedal ganglin, situated below the oesophagus, innervates the foot; whilst the pleural ganglia, lying one on each side just above the pedal ganglia, form the third pair. These several ganglia are united by nerve cords, so that the whole usually forms a ring or collar round the throat. A nerve cord runs, also, from each pleural ganglion back into the visceral mass, innervating the viscera and various organs: these two ultimately joining form what is known as the viscercl commissure. Sometimes these two cords cross over each to the opposite side of the body before uniting, and the loop becomes a figure of 8 . Various sense organs are present in the Mollusca. Many of these are situated on the integument, and are probably, like the tentacles, organs of touch. Eyes are found in most forms, sometimes very perfect organs, as in the cuttle-fish; in snails generally they are less well-developed, and placed near the base of the horns, or on the summit of a special pair: the bivalves being headless, have usually no eyes; when visual organs are present they occur in some part of the margin of the mantle and are numerous. In the case of one or two molluscs, eyes are developed over the back. From their discrimination of certain food, some Mollusca appear to be capable of tasting, and they certainly can smell. The seat of the olfactory sense is believed to vary, and sometimes to reside in a tentacle, at others to be traced to a special organ called an osphradium, which in marine snails is situated close to the gills and resembles them somewhat in appearance. That molluses can hear is inferred, rather than known, from the presence of otocysts, small cavities filled with fluid in which grains of shelly material float. These otocysts are situated close to the pedal ganulia and supplied by nerves from the cephalic ganglia.

The most important feature in connectiun with the digestive system of Mollusca is the armature of the mouth, and consists of a horny jaw or jaws, and the radula, as it is called. Both, however, are wanting in the bivalves and in a few other isolated forms.

The cuttle-fish have a pair of jaws, upper and under; the common snails and limpets, a single upper jaw ; but the majority of the univalve Mollusca have a pair of jaws, right and left. The radula is characteristic of the Mollusca. It consists first of a ribbon-like horny, or chitinous, transparent, yellowish membrane lying on the floor of the mouth, and passing over two cartilages, to which it is attached by special muscles. On the surface of this membrane are set a series of minute, recurved teeth, also formed of very dense, hard chitine. In a few instances there is but a single row of teeth, one behind the other; usually there are several, sometimes a great many, side by side, and row upon row, each tooth r'veating the form of the corresponding one in the row immediately in front of it. Only those teeth near the front are in use, the muscles attached to the basal membrane pulling that portion of the radula backwards and forwards over the cartilages, so that the teeth act very much after the manner of a chain-saw, and rasp off portions of the food. 
The cartilages, too, which are attached by one end to the floor of the mouth, can be worked backwards and forwards by spccial muscles, and so bring the teeth into plity. The action of the tongue thus formed can be well seen in a common pond snail, as it slowly crawls up the glass-side of an aquarium, clearing off the microscopic plant-growths as it goes. Of course the teeth in front scon wear away and drop off, so that further and further portions of the radula have to be brought into use as required. The portion of the radula held in reserve for this purpose is stowed away in a kind of pocket (the radula sac), situated at the back of the mouth and immediately under the nesophagus. At the extreme end of this radula sac a special set of cells, in the substance of its wall, are engaged in forming fresh teeth, so that a constant supply is being manufactured ready to be moved forward in place of the worn-out ones. When the reserve supply needed is very great the radula is of great length, and the radula sac, correspondingly long, has to be stowed away amongst the other organs of the body. This is especially the case in the limpet and tho periwinkle, which last has proportionately the longest known radula of any mollusc. As a rule, in each transverse row of teeth there is a symmetrical central one called the median or rachidian tooth; on either side of this the teeth are unsymmetrical, and their shape changes as they are traced outwards from the centre, but eacl one pairs exactly with the corresponding tooth on the opposite side of the median one. Generally the first few near the median more or less resemble each other, and are succeeded rather abruptly by smaller ones, so that the whole radula appears divided into three longitudinal tracts. The middle tract is then termed the rachis and the teeth on it the mcdian and admedian, whilst the outer tracts are styled pleurce and their teeth uncini. Sometimes between the admedian and the uncini there is a conspicuous tooth differing from either, which may be termed the lateral or capituliform tooth. Theshapes and patterns of these teeth (Fig. 1) and their arrangement are so characteristic in the different genera as to form valuable aids to classification, though, since they are apt to vary in the young and adult state of the same individual, they do not furnish an unerring clue to the identity of species. A formula has been invented for expressing the number of teeth in each transverse row thus :-

$1 \cdot 1 \cdot 1$ signifies that there is a median, with a single lateral on either side $; 2 \cdot 1 \cdot 1 \cdot 1 \cdot 2$ has in
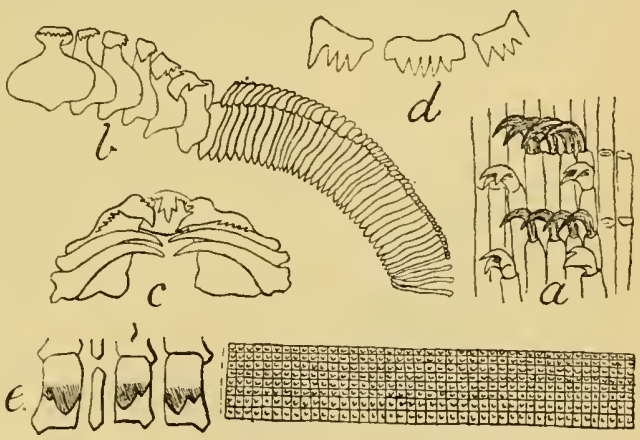

Fig. 1.-RADULE.

A, Docoglossa (Patella vu'gata).

B, Rhipıdoglossa (Trochus cinerarius)

C, Tænioglossa (Cyprcea Europara).

D, Rhachiglossa (Buccinum undatum) - Wheik.

E, Achatina fulica.

addition 2 uncini on either side. When the uncini are very numerous the sign $\infty$ (= infinity), or, better still, $x$ is employed, thus $\infty \cdot 1 \cdot 4 \cdot 1 \cdot 4 \cdot 1 \cdot \infty$, 
or $x \cdot 1 \cdot 4 \cdot 1 \cdot 4 \cdot 1^{\circ} x$, is the formula for certain kinds. Further allusion to these will be niade when treating of the different groups.

All the Mollusca have a circulatory system, with a heart as the central organ, which propels the blood through the body. The heart lies in a cavity, known as the pericardium, and receives from auricles, usually two in number and lying one on each side of it, the blood that has been aerated in the gills. This blood is driven by the heart through a series of arteries, whence it passes in most Mollusca through a series of cavities amongst and between the various organs and muscles of the body; hence it finds its way back, for the most part through reins, to the gills, but some passes direct to the heart without aeration and thence circulates again. The blood is often colourless, or is slightly bluish, from the presence of an albuminoid (hemocyanin) con. taining copper ; sometimes it is red, and contains the same colouring matter (hcemoglobin) as the blood of vertebrates.

The gills have been so largely employed in classifying Mollusca that it is impossible to omit a brief description of their mail features. The simple or primitive form of gill has been aptly compared to a plume, in tlat, like an ostrich feather, it consists of a main axis or shaft, from which, at short intervals, filaments are
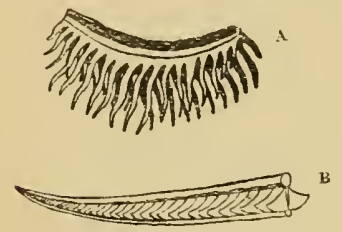

Fig. 2-Diagray Illustratixg THE TWO TYPES OF GiLL STRECTURE.

A, Pectinibral ciate.

B, Foliobranchiate.

In the Foliobranchiate, and in the more complicated forms of gill, the vessels conveying the blood to and from the gill have their positions with relation to the axis considerably modified.

A pair of organs called nephridia, which play the part of kidneys and free the blood frcm impurities on its way to the gills, lie in the region of the heart; they open into the pericardium on the one liand, and communicate on the other with the exterior.

In the majority of Mollusca the sexes are distinct, but in the land snails, the sea slugs, and their allies, the sexes are united in each individual. Most Mollusca are oviparous; that is to say, lay eggs. In a few instances the young are brought forth alive, the eggs being hatched within the body of the parent; whilst in numerous other cases, notably the bivalves, the eggs are retained within the parent shell till hatched. The land snails lay separate eggs, which have each a tough outer layer or case, or even a regular shell like a bird's egg. There is one West African snail whose egg is as large as that of a pigeon, and has nearly as thick a shell. The fresh water and marine snails deposit their eggs generally in clusters, adhering together either in a mass, or spread out in a ribbon. Sometimes each egg is enclosed in a tough albuminous capsule, as in the case of the whelk and the cuttle-fish. 
The early stages in the development of the young Mollusca are the same as in all other animals. The original single coll splits up into many ceils, till it looks like a mulberry. These cells next arrange themselves in a single layer, so as to form a hollow ball; one side then becomes folded in, so that a double layer of cells results, enclosing a cavity which ultimately becomes the digestive tube; other cells arisc between the two layers, that subsequently form the various organs and the muscles of the young animal. Meantime there arises a swimming organ, which is peculiar to the young mollusc; this is called the velum. It begins as a ridge, fringed with fine hairs (cilia), encircling that part of the head of the cmbryo which lies in front of the mouth, and it finally expands into a sort of disc, which is drawn out into lobes or into fingers. This is known as the veliger stage, and is further marked by the formation of the young shell and the first appearance of the foot. The young shell is always a simple coil, even in those forms which, when adult, have a straight shell, or discard their shell altogether. As the ycung snail grows up the velum disappears.

The inolluscan sub-kingdom is divided into five classes :-

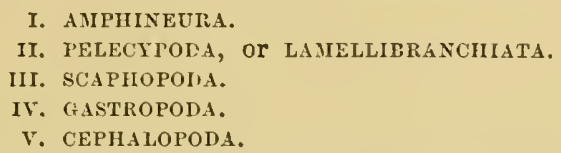

Formerly the sea-butterflies PTERopoda were considered to form a class by themselves: they are now, however, known to be only very greatly modified forms of Gastropodi.

\section{CLASS I.-AMPHINEURA.}

The Amphineura are in many respects the most primitive of all the Mollusca. They are literally symmetrical; that is to say, if the body were divided down the middle from liead to tail, structures found on one side of the body would be seen to be repeated on the other.

The elementary canal is iiot bent, the hinder end opening at the opposite extrenity of the elongate body to the mouth. The nervous system consists of two lateral and two ventral nerve trunks, which start from the cerebral ganglia and are connected together at intervals by numerous transverse nerve cords. The class is divided into two orders :-PoLyPLAcOPHORA and APLACOPHORA.

\section{Order I.-Polyplacothora.}

The Coat-of-Mail Shells, or Chitons(Fig. 2), aro readily distinguished by being alone amongst the Mollusca in possessing a shelly corering of many pieces called the lorica. There are eight plates or valves in all on the back of the animal, fitting one over the other like the tiles on a roof. Generally the lorica is surrounded by a leathery girdle, so called, which helps to unite the several plates, and which, though sometimes naked, is usually studded with scales or beset with spines.

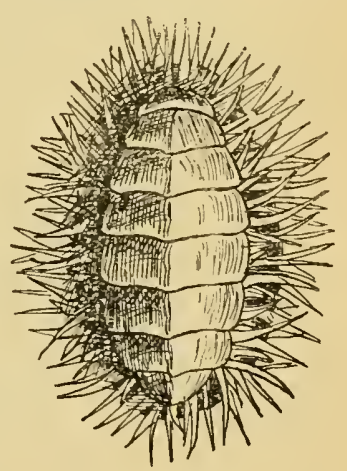

Fig. 3.

A Cunton. 
In some forms the animal is very long in the body and the shelly plates are placed at intervals. The animals, which are regetable feeders, may be found clinging, like limpcts, to the under surfaces of roeks and stones at low tide, and when cletached will coil up much after the fashion of the well-known wood-louse. 'The muscular foot extends the whole length of the under surface of the body; the end of the snout is just visible; there are no tentacles. A row of small gills is seen along each side of the body under the edge of the mantle. A remarkable feature in the shell of many chitons calls for specisl mention. The outer chitinous layer of the valves is perforated for the passage of sense organs, which, in the family Chitonidæ, are in part converted into eyes.

The Polyplacophora are divided into families as follows, according to details of sculpturing, etc., of the valves:-LEPIDOPLEURIDE, Ischnochitonide, Mopalinde, Acanthochitide, Cryptoplacidz, Chitonide.

\section{Order II.--Aplacophora, or Solenogastra.}

The Aplacophora, which are carnivorous, are so modified that they scarcely resemble molluscs at all. The body is worm-like and there is no trace of shell, but the much thickened outer skin contains

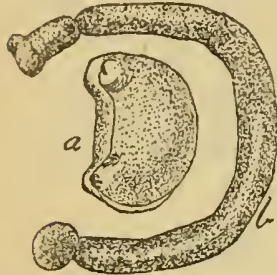

Fig. 4.

$\alpha$, Neomenia. b. Chetoderma. shelly spicules, which probably represent the spines and scales of the Polyplacophora. The foot is extremely reduced, or altogether wanting. The gills are in a chamber at the latter end of the body, into which chamber also the excretory orifices open. Their blood is red. Two suborders are distinguished :-

Sub-order 1.-Neomenina, in which the foot is reduced to a ridge sunk in a groove along the ventral side of the body.

The radula is of the usual many-toothed order, or wanting. There are four families:-NEOMIENIIDE, Proneonenimde, Dondersidde, and Paranenitde.

Sub-order 2.-Chetoderifatina, represented by a single genus Chcetoderma, in which the body is extremely long and cylindrical ; the foot is wanting, its position being merely indicated by a groove ; whilst the radula is represented by a single tooth.

\section{CLASS II.-PELECYPODA, OR LAMELLIBRANCHIATA.}

The principal characteristic of this class is the division of the shell into two halves, the valves, which lie on either side, right and left, of the animal: hence the class at one time received the name of Bivalvia. These valves are usually connected by an elastic, chitinous ligament, and are further kept in place, when the shell is closed, by a series of interlocking teeth that project from their margins. The shell is closed by powerful adductor muscles, but opens spontaneously, when the muscles relax, by the action of the ligament. Each valve is a hollow, irreguldr cone, the apex of which, termed the beak or umbo, is the point at which growth began, and is in fact formed by the valve of the young shell. In very good specimens, when the umbones are not worn or eroded, the two valves that were formed by the animal ere it 
issued from the egg can be seen crowning the umbones; they generally differ in shape and marking from the portion subsequently formed and are called the prodissoconch.

The umbo is gencrally curved more or less to one side, and usually points towards the head, or anterior end, when the shell is said to be prosogyre, in contradistinction to thoso in which the umbones are straight, orthogyre, or are directed backwards, opisthogyre. More often than not the two valves are of equal size and shape, and the shell is equivelvc, as in the cockle; sometimes, however, as in the oyster, one valve is smaller than the other, and the shell is inequivalve. The bivalves are all more or less inequilateral; that is to say, if a line be drawn from the umbo to the ventral margin of the vaive the portion on one side of that line, usually the front one, will be found to be smaller than that on the other. When the shell is shut it is said to be ciose, if the valves fit accurately; and to gape, if openings be left. The ligament is made up of two elements: an external horny, non-elastic layer, or ligament proper, and an inner, fibrous layer, the resilium, which imparts elasticity to the whole. The latter is sometimes separated from the outer layer and situated in a pit, resilifer, in the margin of the shell, or even borne on a process projecting into the interior. This resilium was formerly known under the misleading name of cartilage. The margin of the shell, on which the ligament and the teeth that lie close to it are situated, is termed the linge line: it is sometimes expanded inwards and forms a sort of platform, the hinge plate, on which the teeth are placed. The central teeth, under the umbo, are termed cardinal, those on each side lateral teeth: frequently some one or other of these, and sometimes all, are wanting. The mode of origin of these teeth is a matter of extreme interest and importance, but is too special a subject to be followed out here. On the interior of the shell in each valve are impressed markings or scars, which indicate the points of attachment of the muscles. Firstly,

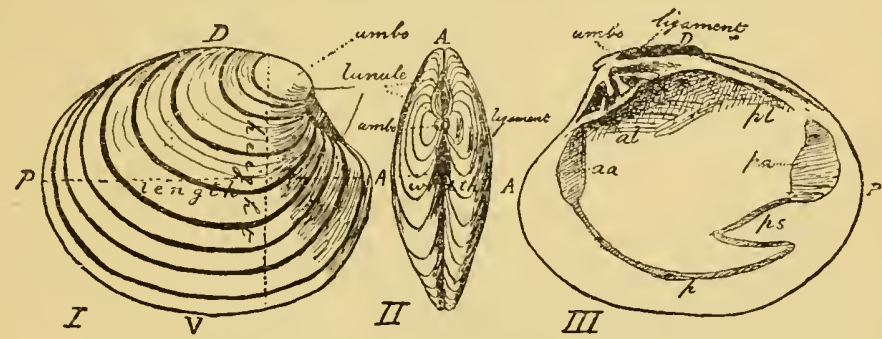

Fig. 5. -Topography of a Bivalve Shell.

I Exterior of right valve. Interior of right valve.
III. Intew of both valves.

A: Anterior or front. $P_{s}$ Posterior or hinder end. D, Dersal area or back. V, Ventral area or under margin. $c$, Car'inal teeth. al, Antelior lateral teeth. $p l$, Posterior lateral teeth. $a a$, Scar cf anterior adductor muscle. $p a$, Scar of posterior adductor muscle. $p$, Pallial line. $p s_{3}$ Pallial sinus.

there are in the majority of shells-e.g., the fresh water mussel-two $\operatorname{larc} \theta$ impressions in each valve, one near the front, the other near the hinder, margin; these are the scars of the adductor muscles that close the shell. In 
some forms, like the oyster, only one such, the hinder one, remains. Bivalves with two adductor scars in each valve are termed Dimyaria, the others Monomyaria. The reduction and disappearance of the anterior adductor may be accounted for by the more rapid growth of the latter half of the body, which thus tends to bring the two muscles and the hinge into line, when the anterior adductor, being less and less required, is proportionately reduced and ultimately disappears. In Pinnce the hinge is reduced to the lowest limit instead. Running from one adductor scar to the otluer in the Dimyaria, and at a short distance from the ventral margin of the shell, is a shallow groove, the pallial line, which marks the attachment of the muscular mantle. In a large group of the bivalves this line, instead of running in a continuous curve, makes, shortly before it reacles the lindei scar, a sharp bend back towards the centre of the valve, forming a bay or sinus called the pallial simus. Its presence indicates that the animal had retractile breathing tubes or siphons, and to these further allusion will bo made later ou. Other small scars of lesser importance are generally present. The terms employed in designating the different parts will best be gathered from the accompanying diagrams (Fig. 5).

No bivalve mollusc possesses a head, and hence the term Acephala, or its equivalent Lipocephala, has sometimes been applied to the class. The aninal is enclosed between the two lobes of the thin mantle, one lying on either side of it immediately under the shell. These lobes are attached along the back and reach out to the margin of the valves. In the more primitive forms the mantle margins are quite simple, and open from the front round the ventral edge to the back; but many different modifications take place in the higher forms. Instead of the margins being simple, there may be folds,
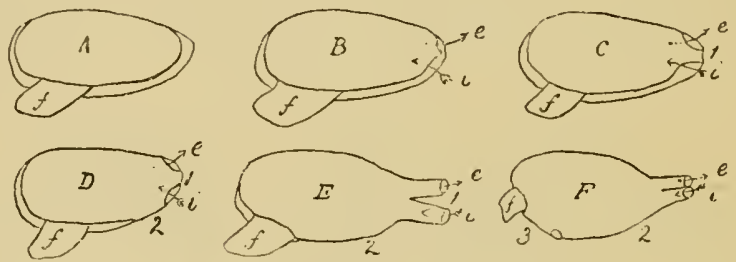

Fig. 6.-Diagram to Illestrate this Different Fords of Maxtle OpeniNa axd tit Formation of tIIE Siphos.

A, Jautle open all round.

B, Mantle margins appled to each other except at $e$ (exhalent aperture) and $i$ (iahalent apertur 3 ) and where $f$ (the foot) protrudes.

$\mathrm{C}_{\text {s }}$ Mantle margins grown together at 1 .

D, Mantle margins grown together at 1 and 2.

$\mathrm{E}$, Mantle margins prolonged into siphons, $e$ ard $i$ (as before), united at 1 and 2.

F, Siphons united, also mantle margins at 2 and 3.

thickenings, protuberances, tentacles, various glands, and even eyes. Nor are the margins al ways free; indeed, in extreme cases, they are united nearly the whole way round. There are various stages (Fig. 6): counting the open one as the first, in the second the currents of water, instead of being drawn in all the way round, the edges of the mantle are kept close together except where the foot protrudes and at two points at the hinder end, one of which $(i)$ serves to admit the fresh water to the gills and food to the mouth, and is called the 
inhaient aperture, whilst the other (e) allows the fouled water to escape and is termed the cuhalent aperture. In the next stage the edges of the mantle are united permanently at the point between these two openings, and in the fourth at a second point below the inhalent aperture. In the fifth stage the margins of these apertures have grown out into tubes (siphons), and the remaining portions of the mantle margins have united all round, except where the fout is protruded. Finally, the two siphons become united externally. In these cases there is frequently a fourth small aperture left in the ventral margin. The siphons, the ends of which are frequently fringed, can bo wholly or partly withdrawn; and it is to make room for them within the shell that the pallial attachment is set further back at that point, giving rise to the pallial sinus already spoken of. The proportionate length of the siphons forms a rough index to the burrowing habits of the animal, since the longer the siphons and the more complete the union of the mantle margins, the deeper the mollusc can burrow into the mud or silt and still inhale clear water from above.

The gills lie underneath the mantle, one on either side, in the space between the latter and the body of the animal. In strueture these organs vary progressively from a very simple to an extremely complicated form, and since their features have been made the basis whereby this difficult group is classified, it is necessary briefly to describe them. In the more primitive bivalves the gill is of the fuliobranch type (see ante, p. 614); but in the higher Pelecypods they are filibranch, only the filiments of each of the two rows, instead of running separate, have an arrangement whereby they interlock and form a continuous membrane, like the web of a feather. The mechanism by which this is brought about is extremely simple. At regular intervals on either side of each filiment are little patches of stiff hairs which interlock with the corresponding ones on the two neighbouring filiments, just as two brushes can be inade to do; these are known as the ciliated junctions (Fig. $7 \mathrm{E}$ ). Moreover, the two membranes lamelle thus arising do not simply depend from the axis, but their edges are folded upwards-that of the outer one outwards, that of the inner, inwards, making a $\mathrm{W}$ in section as shown at B, Fig. 7 .
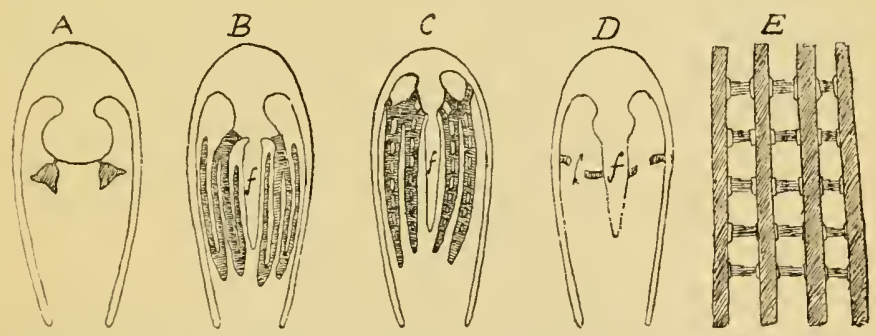

Fig. 7.-Diagram Illugtratixg Succesgive Develophext of Pelecypod Gills. C, Eulamellibranch, A, Protobranch (or Foliobranch). B, Filibranch.

E, Diagram of Ciliated Junctions.

A further complication of structure ensues when junctions, called interlamellar junctions, are formed between the dependent part of each filament and its reflected portion. In a more advanced stage still both the ciliatcd 
and the interlamellar junctions become solid connections, so that the whole structure presents a spongy appearance, whilst the reflected ends of the filaments, uniting with the walls of the mantle and foot, subdivide the pallial chamber (C, Fig. 7). One further development remains to be mentioned, in which the gills have become converted into a sort of party wall. The following diagrammatic drawings will make these various stages more clear (Fig. 7).

The muscular foot is a prominent feature in most bivalves, lying in the middle line towards the front of the body. It is actuated by special muscles, and is principally of service in forcing a way for the creature into the sand or mud; in a few it is a creeping organ; whilst the cockles, by its means, take extraordinary leaps. In some forms it is greatly reduced, or altogether wanting. Towards the back of the foot is situated the apparatus for spinning the horny threads by which many bivalves anchor themselves to stones, seaweed, etc. The common mussel is a faniliar example; and the bunch of threads is known as the byssus. The animal generally has the power of rejecting its byssus at any time and spinning a fresh one.

The mouth is situated a little behind and beneath the front adductor muscle; it is unarmed, neither jaw nor radula being present. It is flanked on either side by a pair of twin, triangular lobes, the labial palps, which are in a line with, and in front of, the gills. Their function apparently is to collect, and possibly to taste, the food before it passes into the mouth. A short osophagus leads to the stomach at the base of the foot, whence the intestine, mure or less coiled, leads off, and, after passing through the pericardium, terminates beneath the hinder adductor muscle, at the base of the exhalent siphon.

The heart, in addition to the ventricle, which frequently encircles the alimentary canal, has usually two auricles. The nervous system is sym. metrical, and consists typically of three pairs of ganglia :-The cerebropleural, resulting from the fusion of the cerebral and pleural ganglia, lying above the oesophagus; the pedal ganglia, which are situated in the foot, near its base; and the visceral ganglia, placed close to the posterior adductor muscle. These ginglia are connected by nerve cords, and supply nerve fibres to the various organs. The remaining anatomical features call for no comment here.

The classification of the Pelecypoda is a most difficult and vexed question ; but that founded on the structure of the gills, as explained above, will be employed here. The five orders thus crcated are :-

\footnotetext{
I. PROTOBRANCHIATA.

II. FILIBRANCHIATA.

III. PSEUDOLAMELLIBRANCHIATA.

IV. EULAMELLIERANCHIATA.

V. SEPTIERANCHIATA.
}

\section{Order I.-Protobranchiata}

Contrins the most primitive forms of Pelecypoda. The gills are foliobranchiate in type, and the mantle margins generally open. The foot has a creeping disc on its ventral surface.

Two families are included in this order-the Nuculide and the SolenoMYIDE. To the former belong the little nutshells ( $N u c u l a)$, small triangular shells of a plain brown exterior and pearly interior, provided with a series of fine transverse teeth in the hinge, calling to mind a comb, with the re. 
silium borne in a small triangular pit in the middle. The umbones are directed backwards. Their close allies, Leda and Yoldia, are elongate, and have fewer and moro prominent teeth, and a more prominent ligament pit. The family is one of the oldest known, dating back to the earliest geological times, and its modern representatives are found in all seas.

The SolenomyID E comprise a single genus Solenomya, and are remarkable for being without teeth in the hinge, and in having the periostracum greatly prolonged beyond the margin of the valves. The typical species, $S$. togatu, is found in the Mediterranean. The genus also occurs on the east coast of North America, the Antilles, Patagonia, New Zealand, and Australia.

\section{Order II.-Filibranchiata.}

In this order the gill filaments are dependent and reflexed with ciliar, but no interlamellar junctions. The animal generally spins a strong byssus. Four sub-orders are distinguished :-

Sub-order 1.-Anomacex, whose typical genus Anomia is well-known by the common $A$. ephippium, found on our shores. The shell is very variable in shape, but the right valve is generally the flatter of the two, since it is moulded to the surface of the object the animal is attached to. The strong byssus, by which it holds on consists of a shelly "plug," instead of a bundle of threads, and passes through a notch in the right valve near the umbo. When quite young the notch is in the ventral margin of the valves, as in the next grcup, but the shell subsequently grows round it. 'There are no teeth in the hinge; only a single adductor muscle, the posterior one, is present in the adult; and the heart projecting into the pallial cavity lies almost without the body. The Saddle oyster, Placuna sella, also belongs to this group.

Sub-order 2.-Arcaces, of which the Noah's Arkshells are the type (Fig. 8), have hinge-teeth like Nucula; but the ligament is external, extends forward in ad vance of the umbones, and spreads over the wide space between the two beaks, frequently obtaining additional hold by grooves in the shell. In Arca there is often a strong and sometimes shelly byssus, which passes through an opening in the rentral margin of the shell. The two adductors are nearly equal in size. The mantle margins are entirely open. The genera Pectunculus and Limopsis hare much rounder shells; the teeth are far fewer, and less comb-like than in Arca.

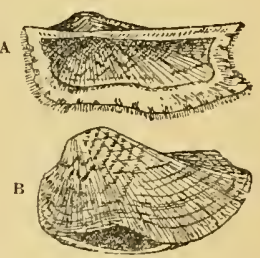

Fig. 8.

A, ARCA NOE.

B, ARCA ZEBRA.

All three genera are represented on our coasts, and have a wide distribution; whilst Arca dates back to almost the earliest geological times.

Sub-order 3.-Trigoniacea, represented by a single family, Trigonidde, having one genus Trigonia. This genus, now confined to the Australian seas, was in geological times very widely distributed. The living species are beautiful pearly shells, roughly triangular in shape and externally ribbed, after the manner of a cockle-shell. The right valve bears two cardinal teeth, the left four. These teeth are transversely grooved. There is no byssus.

Sub-order 4.-MYTILACEA is so well known through its representatives the common marine mussel, Mytilus edulis, and the Horse-mussel, Modiale 
modiolus, as to need no further description. The genus Mytilus is worldwide in its distribution: Modiola is chiefly tropical.

The genus r.renella is interesting on account of its hinge margin, which is crenulated belind the ligament. Lithodomas, the Date-shell, so called from its resemblance in external shape to a date-stone, is an interesting example of adaptation to habitat. It perforates corals and the hardest rocks, forming for itself a long, narrow burrow into which it exactly fits.

The fresh-water genus Dreissensia, introduced into this country from the Baltic on timber, may be placed here rather than with the fresh-water mussels, despite certain of its anatomical features, till its true aftinities shall have beell determined.

\section{Order III.-Pseudolamellibranchiata.}

In this division, to which the oyster belongs, the mantle is entirely open; the foot is but little developed, and the gill filaments are reflected and joined by interlamellar connections. The order is further subdivided into Aviculacia, Ostreacea, Pectinacea.

Sub-order 1.-The A viculacea, or swallow shells,

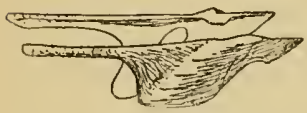

Fig. 9.-Atrcula hirindo. are so called from the fancied resemblance presented by representative forms, when the two valves are spread open, to a flying bird (Fig. 9).

They are extremely pearly shells, indeed the pearl oyster of commerce is a conspicuous example, the nacreous layer being the thickest; the middle layer of the shell is prismatic and consequently brittle; the periostracum is very thin. In shape they are inequivalve; the linge is long and straight, witl few and obscure teeth, or none at all, and the hinge line is usually produced on either side of the umbones, forming expansions, technically known as ears.

The ligament is external, and placed in a groove or grooves. The posterior adductor is very large; the anterior, situated close to the umbo, is small, or sometimes wanting; the pallial liue is represented by a chain of small isolated scars. They spin a strong byssus, which issues through a notch in the right valve beneath the front ear. 'I'hey dwell in temperate or tropical seas, and in point of geological time are found right back to almost the earliest fossiliferous rocks. The principal genera are Avicula, Meleagrina (the pearl oyster), Malleus (the hammer-headed oyster), Perna, in which the ligament is crumpled into numerous folds, occupying transverse grooves in the thick linge, and the common Pinna.

Sub-order 2.-The OstreaceA, of which theoyster(Ostrer) is the type, present some points of great interest other than gastronomic. The mantle nargin is double and finely fringed, forming the so-called "beard." The foot is reduced to a rudiment, and there is no byssus. The anterior adductor in the adult is entirely wanting; but in the embryo, that, as in all bivalves, is the first of the two adductors to be formed, the posterior developing later and persisting, whilst the former disappears. The stage in which both are present has not yet been seen in the European oyster. Traces of teeth are sometimes to be observed. Oysters are world-wide in their distribution, if Arctic seas be omitted.

Sub-order 3.-Tho Pectinacea are best known by the scallop (Pecten), of 
which there are numerous species, many of them most beautifully coloured and marked. As in the oyster, the mantle margins are double and fringed, but in addition, there is a row of conspicuous round black cyes. Most of the pectens spin a byssus when young, and some do habitually; whilst many not only remain free but move about, progressing through the water by rapidly opening and closing their valves. With few exceptions the Pecten shells are ornamented with radiating ribs. The genus Lima resembles pecten, but is more clongate and not so equilateral.

The thorny oyster (Spondylus) is ornamented, as its popular name suggests, with spines and other shelly prominences. The Spundyli attach themselves to various objects, sometimes slightly by a few spines, sometimes by the whole surface of a valve. Two curved teeth in each valve so interlock with corresponding sockets in the other that it is impossible to separate them without damage. The big Water Spondylus in its growth leaves cavities in the shell substance which retain sea water.

\section{Oruer IV.-Eulanellibranchitata.}

In this order is included the great majority of the bivalves. The gills have complete interfilamentary and interlamellar junctions. Both adductors, with few exceptions, are present. The hinge teeth are few and strong.

The following seven sub-orders may conveniently be distinguished:- SUBmytilacea, Tellinacea, Veneracea, Cardiacea, Myacea, Pholadacea, Anatinacea.

Sub-order 1.-Submytilacea. The Submytilacea are generally devoid of siphons, and hence the pallial impression is simple. They are more nearly related to the Mytilacea than to the Pseudolamellibranchiata just described: indeed the Dreissensiide and the fossi: Modiolopside are by some included in the Mytilacea, and the Unionidie and Ftheriide placed close to them.

The Uxionide include, amongst others, the fresh-water mussels familiar to all. The young, as soon as they leave the parent shell, attach themselves; to passing fish, and, becoming buried in the skin, pass a short period of their lives as parasites. This stage of the young mussel, till its true nature was ascertained, was called Glochidium.

The Etheridde include AEtheria, the fresh-water oyster of the Nile, that has a rem.rkable cellular shell, the layers on the inside looking like blisters. The corresponding South American form, Mulleria, has only a single (posterior) adductor, and looks yet more like an oyster.

The CrRenide, another fresh-water family, are represented in the British Isles by the genera Cyclas and Pisiclium. Formerly there was a third genus, Corbicula, which spread all over Europe and Siberia, but is now confined to warmer climes.

The Cyrenidie have equivalve, subtriangular shells with brown periostracum. The hinge has two or three cardinals, and laterial teeth are present, which in Corbicula are striated; the ligament is external. The siphons are short.

Amongst the marine forms belonging to this group are the CARDITIDF, stout, equivalved, heart-shaped shells, generally with radiating ribs like the Cockles, and having a strong hinge with one or two oblique cardinal teeth and one or two laterals; the ligament is external. One member of the family, Cardita concamerata, is remarkable for the curious egg-pouch, formed by an infold of the ventral margin of the mantle and shell. The Carditidx are 
principally inhabitants of southern waters, but are represented in the Mediterranean.

The Astartid.玉, on the other hand, are northern forms. Their shells are rather flattened, subtriangular, or ovoid in outline, marked with concentric ribs, and covered with a thick brown periostracum. There is a strong hinge with two or three cardinal teeth in each valve ; the ligament is external.

The Crassatellides, another family of southern range, have a much longer shell, generally subtriangular and concentrically ribbed; there is a distinct lunule; the hinge is furnished.with two or three cardinals in each valve; the resilium is lodged in a pit between the teeth.

The ARCTICIDE are best known by the Arctica [=Cyprina] Islandica of our own northern shores. It has a strong, fairly globose shell, with prominent umbones, covered with a rough brown periostracum; there is no lunule. The ligament is external; the hinge teeth well developed, and, like those of the Veneracea, there are two cardinal teeth, two posterial laterals, and two feeble anterior laterals in each valve. Another genus, Libitina, is found in the Red Sea and Indian Ocean; it is an oblong shell with very long, straight, posterior teeth. Another member of the group is Coralliophaga, which, in external form, closely resembles Lithodomus, already alluded to under Mytilacea.

The IsOCARDIIDE, or heart-cockles, which were formerly associated with the preceding, have very globose shells, and very prominent, widely separated, spiral umbones. The ligament which follows the umbones in their growth is split in front and curved out on either side.

A contrast to the foregoing is offered by most of the Lucinide, which have very round, but rather depressed, and generally white shells, with small umbones. The teeth, when well developed, comprise two cardinal and one lateral in each valve; the ligament is internal and very large. There is generally, in addition to the usual muscular scars on the interior, the mark of a muscular attachment running obliquely right across the valres. The foot is long and cylindrical. The UNGULINIDE, with a single genus Ungulina, arc closely allied.

The three remaining families, Keldyellide, Erycinide, and GaleonIIDX are small shells, which have the common characteristic of a foot adapted for creeping; many of them when thus crawling spread the valves wide open. The mantle is generally more or less reflected over the shell, and in Ephippodonta and Clamydoconcha it completely and permanently envelopes the valves.

Sub-order 2.-Teldinacea. These have very long siphons, which are not united; the pallial sinus is correspondingly deep; the foot is large and flattened.

In the type family TeLLinidx, or sunset shells, the shell is generally very elongate, sometimes smooth and polished, sometimes marked with concentric ribs, and oblique and gaping behind. There are two cardinal and two lateral teeth, one anterior and one posterior, in each valve; the ligament is external. The Tellinidæ are world-wide in their distribution, but the finer specimens come from tropical seas.

The ScrobICULARIIDE are Telline in which the ligament is internal ; they love the mud of estuaries to dwell in, and obtain their food from it.

The Psammobinde resemble the Tellinidre both in shell and animal. The former, however, is more equivalve, less twisted, and gapes more widely 
behind. The hinge plate is broader and there are no lateral teeth. As their name indicates, they aro sand $d$ wellers. A few occur on the British coasts, but the finer examples come from the Pacific and Indian Oceans.

The DovacIDis, or wedge shells, are very inequilateral, the front portion being much longer than the truncated hinder part. The exterior is usually smooth, the umbones are directed backwards, and the margins of the valves are usually very finely crenulated, whilst the pallial sinus is deep. There are two or three cardinals and two laterals, one auterior and one posterior, in each valve.

The TaxchedIID have very similar shells to the Donacidx.

The Mactrine are a large and widely distributed family dwelling in sand. The shell is equiralve and somewhat triaugular; commonly smooth and white, with a trace of periostracum. The hinge is usually marked by the conspicuous interual resilium lodged in a deep pit; but in some furms the whole ligament is external. The hinge-plate is well developed; the teeth vary somewhat, typically there is a $\Lambda$-sliaped cardinal tooth in each valve in front of the resilifer, and single anterior and posterior lateral teeth in the right valve fitting into double ones in the right one.

The CARDILIDDE are very similar in their shell to the preceding, and are probably closely allied to them, but their anatcny is still unknown.

The MEsodesuatide resemble the Mactridae in their anatomy, but the siphons are not united, the shell usually is more like that of Donex with umbones directed backwards.

Sub-order 3-Veneracka. These hare usually short siphons, and therefore a moderate pallial sinus. The shells of the principal family, VENERID E, are remarkable for the elegance of their forms and colours. Their texture is very hard and procellaneous, the exterior is frequently smooth and highly polished, sometimes ornamented with V-shaped lines of colour,sometimes with concentric grooves, whilst a few have projecting plates or spines (Fig. 10). The margins are closed, and often crenulate. The siphons are more or less united. The ligament is external, and there is a wellmarked lunule; the hinge is strong, and con-

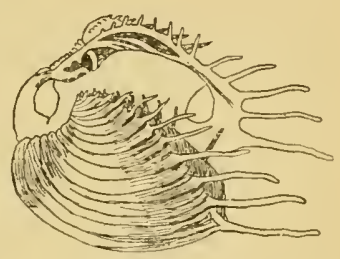

Fig. 10.-CITHeREA DIONE. sists of three well-developed cardinal teeth in each valve, two out of the three appearing double; the laterals are variable.

The PETRICOLIDE, which occupy burrows in limestone, are very elongate; in their shape and external markings they closely resemble the well-known rock-borer Pholas, though they are readily distinguished by the possession of three cardinal teeth in each valve.

The GLAUCONYIDE, which are fresh, or brackish-water forms, have very long siphons, and live buried in the mud of estuaries in India, China, and the Eastern Archipelago. The shell is shaped like Mya.

Sub-order 4.-Cardiacea comprises the cockles and their allies. The shell is heart-shaped, with an internal ligament, and there are one or two cardinals in each valve; whilst the right valve usually carries two anterior and two posterior laterals, which receive the corresponding single teeth of the 
left valve. The siphons are short and deeply fringed; the foot very lnng and slender.

The cockles; CARDID.E, live buried in sand or sandy mud, and in some species with a prickly shell the size and number of the spines is dependent on the nature of the sea bottom, the spines being fewest in those which bury in the firmest silt. The shells of the genus Hemicardium are the most peculiar in shape of almost any bivalve, for they are much shorter than wide or thick.

The "giant clam" (Tridacna), and the bear's-paw (Hippopues), so commonly used to make shell-baskets, form the family TRIDACNid.e. In these no anterior adductor is present in the adult, nor are there any siphons. The shell is ormamented with radiating ribs, and the margins are deeply indented. The hinge has a single cardinal in each valve, and two posterior laterals in the right, one in the left valve. Trilucna is the largest bivalve known, either recent or fossil, $T$. gigas attaining $2 \mathrm{ft}$. in length. It lives in coral reefs moored by its huge byssus, which issues through the large notch in the valves in front of the umbones. The animal is most gaudily coloured, rivalling the corals amongst which it, dwells. Large dull pearls are sometimes found in it. Hippopus, on the other hand, has a close-fitting shell, through it spins a small byssus. It, too, is a reef-dweller.

The CHAIIDE, which resemble oysters in external appearance, and in being attached, are inequivalve, with sub-spiral umbones and external ligament. The shell is rough, and generally ornamented with frills, or flit shelly projections. Sometimes one valve is attached, sometimes the other; the hinge teeth consist of two cardinals in the attached, and one in the free valre, with traces of laterals. They inhabit tropical seas.

Sub-order 5.-MYACEA. The shells of this group gape mare or less widely, and never completely enclose the animal. The muntle margins are united, except where passage is given for the foot, and at the siphons, which are long and more or less united. The hinge is degenerate. The typical family, Myide, includes the common $M$ ya or "gaper"' of our coasts. The animal is difficult to obtain owing to its liabit of burrowing a foot down in the mud. Its siphons are encased in an extension of the horny periostracum, and are never completely withdrawn into the shell. The hinge is peculiar : from the left valve at the umbo a spoon-sliaped process projects that carries the resilium, the corresponding attachment in the right valve being underneath the umbo, the hinge plate being folded quite back. Traces of the cardinal teeth are sometimes visible.

In the Solevine, or razor-shells, the shell is usually very elongate and open at either end. The ligament is external, the linge teeth are small, usually two or three in each valve. The foot is long and cylindrical; the siphons short, and mostly united. The family is world-wide in its distribution. The common Solen of the English shores is known to all. The razor-fish live deeply bedded in sand or mud, into which they force themselves by mexns of their powerful foot. By some the Solenida are placed as a sepurate group nearer the Tellinidæ.

The SAXICAVID.玉 resemble the Myidre, but the gills extend into the cavity of the inhalent siphon. The genus Glycimeris also resembles $M y a$ in its habitat; but the members of the typical genus Saxicava bore into luard stone, and are generally found in colonies, honeycombing the rocks with burrows sometimes $6 \mathrm{in}$. in depth, nor do they saruple to drill through 
their neighbours should they lie in their path. They are anchored in their crypts by a byssus. The shell is elongate and when young has two teeth in each valve; these disappear in the adult. It is one of the most widely distributed of all bivalves, and varies a great deal in shape.

The GAstrocH.ExID. the anterior adductor sear is smaller than the posterior; the pallial sinus is deep; the gills are as in Saxicava; the siplions naked and united. 'The ligament is external ; sometimes a single carainal tooth is present. Some members of the family line their burrows with a shelly tube, to which, however, they are in no way attaclied.

Sub-order 6.-Pholadacea. In this are included the Pholas, or piddock, known to every sea-side visitant, the ship-worm, and their allies. The Pholadidie have white, brittle shells, roughened like a file on the outside; they are generally elongate and gape at both ends widely; but in one genus, Jouanettic, the two valves form an almost spherical shell, with one small aperture. There is no hinge properly speaking, or ligament, the hinge plate being bent back over the umbo and the anterior adductor muscle carried with it so that it lies without the shell. It is by the action of this muscle that the valves are opened, the posterior adductor serving to close them. The little curved, shelly process that arises from beneath the umbo in each valve and projects into the interior serves the purpose of muscular attachment. The animals, which are phosphorescent, have long, united siphons; the mintle margins are united, except in front, where the large foot, that fills up the opening in the shell, protrudes. The adult animal has additional shelly plates on the back on either side of the umbones. The common Pholas of our shores bores into rocks, the burlows lying parallel to one another; but some species bore into floating wood across the grain.

The TerEdINIDE, or ship-worms, have two very small valves widely gaping at both ends, that are borme at the extreme anterior end of the long cylindrical animal. The greater portion of the creatures' length (ordinarily they are a foot long, and sometimes two and a half feet) is taken up by the gills and the fleshy siphons. These last are united to within a short distance of their extremities. At the point where they separate two little shelly pallets, or styles, are found. The true ship-worms bore into timber with the grain, and become so abundant where they once settle that they soon honeycomb and destroy the stoutest balks. Their burrows are lined with shell and sometimes show cross partitioning. One species bores into cocoa-nuts and other woody fruits floating in tropical seas. The tube of the giant Teredo is often a yard long and two in diameter: it burrows in sand and in the roots of mangroves.

Sub-order 7.-ANatiNaCEA. In the gills of this group the outer lamella on each side is directed upwards instead of downwards, and its free edge is not reflected. The margins of the mantle are largely united. The shell is usually thin, and pearly within, frequently strengthened at the umbo by a buttress. The hinge rarely has any teeth; the ligament is generally internal, and more or less divided by a shelly portion or ossicle. The principal families are:-Pandoride, Chanostreide, Verticondidd, Lyonsidd Anatinide, Pholadonrid.e, and Clavigellid.e. The Pandorida are represented in British seas by Pandora, in which the right valve is flat, 
whilst the left is convex; the shell is also very inequilateral. There are two diverging resilium grooves at the hinge. It lives buried in sand.

The single species Chamostrea albida, found off the coast of New South Wales, constitutes the family Chamostreide. It has a thick, pearly shell ; the right valve, by which it is attached, is deep and strongly keeled; the left valve is flat, with a conical tooth in front of the resilifer; the ossicle is extremely large.

The VERTICORDIIDE and LyonsIIDE are deep-water forms not often met with.

The ANativide have extremely thin shells, sometimes granular on the surface, and gaping behind. The genus Thracia is British.

The Pholadomyide, represented to-day by a single species, Pholadomya candida, in the West Indies, was formerly an abundant group. The shell is oblong and equivalve, gapes behind, and is ornamented with obscure radiating ribs. The ligament is internal, and there is one tooth in each valve.

The CLAVIGELLIDE are in some respects the most interesting members of the group. One genus, Clavigella, bores into rocks, the left valve becomes attached to the wall of the burrow, the right remaining free; the passage to the exterior, occupied by the siphons, has a shelly lining, which projects freely on the exterior and terminates in two or more frills.

The other principal genus Brechites $[=$ Aspergillum $]$, known as the watering-pot shell, burrows in sand, lining the burrow witl a shelly tube, into the wall of which the valves of the young shell are built. The free end of the tube is also frilled. The adductor muscles not being required are aborted. When the animal is full grown the botton of the trabe is closed with the familiar perforated plate, secreted by the fringed foot. It occurs only in the tropical seas.

\section{Order V.--Septibranchitata}

Contains two families-POROMYIDE and CUSPIDARIIDE-principally interesting on account of the modification of the gills to form a transverse septem as already described (ante, p. 620). The Poromyines are rounded shells with a single tooth in each valve. The siphons are fringed. The Cuspidariddes are represented in British waters. The shell is beaked belind, and the valves are closed except at the end of the beak through which the fringed siphons protrude. There are no teeth in the hinge.

\section{CLASS III.-SCAPHOPODA, OR SOLENOCONCHA.}

The Elephant's-tooth shells belong to a small but very distinct class of low organisation. The sliell is long, slightly curved, and tapers almost to a point, resembling in external appearance a miniature elephant's tusk. It is, of course, quite hollow, and there is an opening at each end ; the one at the small end is generally notched on the ventral, i.e., the convex side. Sometimes the shell is finely striated lengthwise. The animal is symmetrical. The margins of the mantle are united beneath, forming a long tube open at either end; a barrel-shaped prominence or snout represents the head, and the mouth at its extremity is surrounded by leaf.like tentacles.

The formula of the radula is $1 \cdot 1 \cdot 1 \cdot 1 \cdot 1$. The alimentary canal is doubled on itself, and terminates about the middle of the ventral side, opening into the mantle cavity, which latter has its efferent opening at the apex of the shell. There are no gills properly so called, but their function 
is probably taken by a double row of retractile filaments, each terminating in a knob-like thickening, that encircle the base of the snout. The heart is quite rudimentary. The foot lies under the swout, and is a long, cylindrical body directed forwards and terminating in three lobes. The nervous system
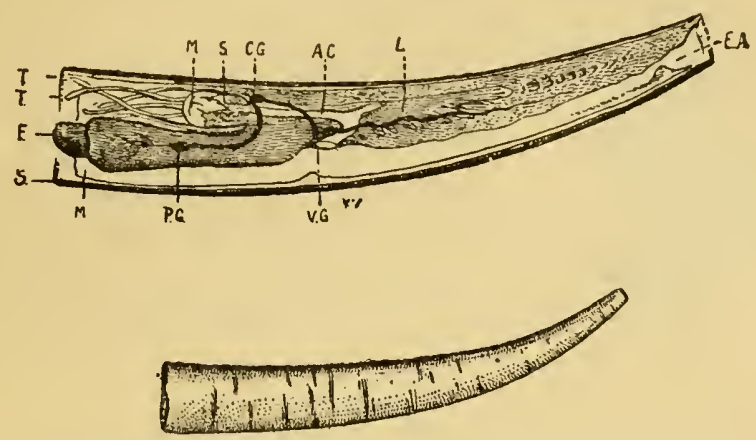

Fig. 11.-Dentalium Shell and Diagram or Anatomt.
AC, Ailmentary canal.
CC, Cephalic ganglia.
EA, Efferent aperture.
F, Foot.
L, Liver.
Ii, Bouth.
$M^{\prime}$, Mantle.
$\mathrm{PG}$, Pedal ganglis.

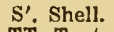
TT, Tentacles.
S, Snout
VG, Visceral ganglia.

is simple and resembles in general arrangement that of the Pelecypoda already described (p. 620), except that the cerebral and pleural ganglia are not fused. The Scaphopoda live in mud, and feed on the small organisms they find in it.

\section{CLASS IV.-GASTROPODA.}

In this class are included mollusca like the snail, whelk, etc., that have a distinct head, and, along the underside of the body, a muscular foot on which they crcep; whilst the visceral mass situated above is sometimes naked, but more often covered with a shell, composed of a single piece.

The organs of the body are asymmetrical, i.e., those on one side of the body are not matched by corresponding ones on the other.

The shell is essentially a longer or shorter hollow cone. In some, such as the limpet, it is a simple cone, but in by far the greater number it is an elongated cone, coiled round and round spirally, each coil forming a whorl, the last being the body-whorl. Nearly all spiral shells are dextral; that is to say, when placed with the mouth uppermost, and the apex directed away from the observer, the mouth lies to the right hand of the axis of the shell. Some are wound in the opposite direction, and are sinistral. Reversed varieties of shells normally dextral, or sinistral, are met with.

The axis or columella of the shell is sometimes hollow or umbilicated (the hollow itself being called the umbilicus), sometimes the whorls are closely coiled, and solid pillar of shell results. The apex or extreme top of the shell generally differs in markings and other features from the rest, and offers important characters. This mucleus or protoconsh is the portion formed in the egg, hence it is also known as the embryonic shell. 
The spiral channel formed by the junction of the whorls is termed -the suture. A spiral line traced along the whorls midway between the sutures would mark the periphery.

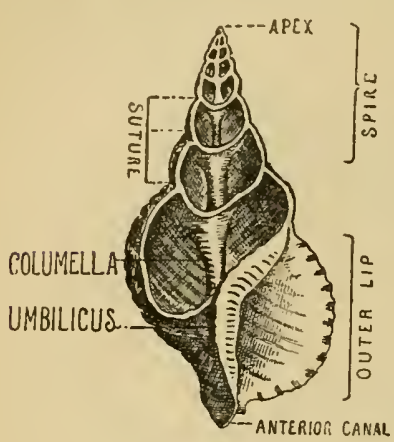

Fig. 12.-TOPOGRAPHY OF A GASTROPOD SHaLL.

The mouth or aperture has sometimes quite a circular margin (peristome) when it is said to be continuous; more often it is interrupted, the side next the columella being bounded by the inner wall of the body-whorl only, when the exterior fortion is known as the outer lip or labrum, and the other side as the inner, columella lip or labium. There is frequently a notch in the margin of the aperture near the junction of the outer lip with the body-whorl, and another where it joins the anterior end of the columella: these are respectively termed the posterior and anterior cancl, and give passage to the siphons of the animal (Fig. 12).

The labrum is thin and sharp in most immature shells, and in some adult forms; but more frequently it is either thickened, or curved outwards (reflected), or curled inwards (inflected), or expanded, or fringed with spines. When these thickenings or expansions occur periodically during the growth of the shell they forn conspicuous transverse markings on the whorl termed varices.

The exterior of the shell is also more frequently than not ornamented with either spiral lines or ridges running in the direction of growth, or with transverse markings coinciding with the "lines of growth," or with both.

Many Gastropods, like the periwinkle, close the aperture of the shell when they retire with a horny, or shelly trap-door, the operculum. It is developed in the embryo within the egg, and to its inner surface are attached strong muscles that hold it firmly in place, The following figures (Fig. 13) give some idea of the principal forms.
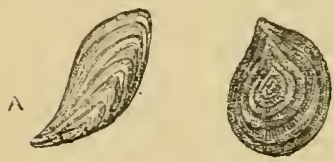

B

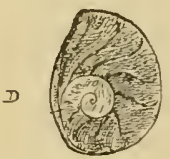

(1)

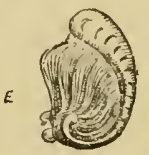

Fig. 13.-PRinctpal Foris of Opkrcula.

A, Unguiculate or claw-shaped. B. Concentric.

C. Mrulti:piral. D, Pancispiral. E, Articulate.
The head of the animal bears either a single pair or two pairs of tentacles, beneath which, quite in front, the mouth is situated. Of the armature of the mouth mention has already been made (ante, p. 612-14).

The visceral mass is externally covered by the mantle, which is in one piece. Towards the front, and a little to the right side, there is, under the edge of the mantle, a cavity in which are placed the gills or gill, whilst into it also the excretory duct and the terninal end of the digestive tract open. The mantle margin is sonetimes 
prolonged in front of this carity into a respiratory siphon : a posterior exhalent siphon is likewise present in certain forms.

Originally, in all probability, the animal, like the Amphineura, had a straight alimentary canal, terminating behind with a gill on either side of the opening; but, through the operation of causes which need not here be discussed, the alimentary canal first became arched, then its hinder portion was tucked-under, so to speak, whilst subsequently the visceral mass became twisted, the hinder portion, with the gills, being forced round by the right side to the front, so that in its final stage what had been the left gill is, in the typical gastropod of to-day, now on the right side, whilst the right one has passed over the neck to the left side. This last, however, is wanting in the majority of Gastropoda.

In the process of this torsion the visceral nerve-loop became twisted into a figure of 8 , and, though in one great group the body is again untwisted, traces of its former contortion can still be traced in the nerve loop.

The Gastropoda are divided first into two sub-classes : A, Streptoneura, in which the visceral nerve-loop forms a figure of 8 ; and $\mathrm{B}$, Euthyneura, in which the loop is not thus twisted.

\section{SUB-CLASS A.-STREPTONEURA.}

To this section the name Prosobranchiata has also been applied, since the gills are in advance of the heart. There is only a single pair of tentacles, the eyes being situated on prominences near their bases. The sexes are usually distinct.

They are further sub-divided, according to the structure of their gills, into Scutibranchiata and Pectinibranchiata.

\section{Order I.-Scutibranchiata}

(Sometimes called Diotocardia because the heart has two auricles) comprises the Limpets, Keyliole Limpets, Orners, and Top-Shells.

For convenience they are further sub-divided, according to the arrangement of the teeth on the radula, into Docoglossa and Rhipidoglossa.

Sub-order 1. - The Docog LossA, or limpets, are characterised by their simple conical shell without airy operculum. The animals adhere by the suckerlike foot to rocks between tide-marks. There are three families:-The ACA addition a series of leaflets arising from the mantle in a circle between it and the foot, that also serve for the purpose of respiration, and are known as pallial gills. The PATELLID $\mathrm{s}$, to which the common limpet belongs, have a circlet of pallial gills, but nearly all trace of the ordinary gill has disappeared. The LEPETIDE, going a step further, have neither ordinary nor pallial gills, nor have they any eyes.

Sub-order 2.-RinpIDogLossA. The radula of this group is very distinctive. The teeth are numerous and weak, the large number of uncini being especially remarkable.

The Fissurellid. the shell that communicates with the pallial chamber, where the two gills are. In Emarginula the "keghole" takes the form of a notch in the edge of the shell. 
The Pleurotonrd., or slit-shells, have conical, spiral shells with a notch in the outer lip at the periphery. The typical genus Pleurotoma is one

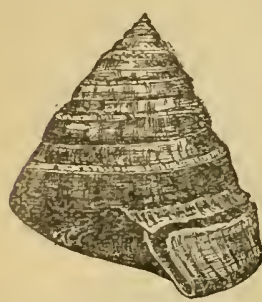

Fig. 14.-PLEUROTOMARIA Adaxisoniana. of the rarest of living sea-shells (only a few specimens have ever beel dredged), but they include one very fine example measuring over 6 in. in height (Fig. 14). There are two gills and the mantle is slit in front. The shell is pearly within, and there is an operculum.

The HALIOTID E, or ormers, have an ear-shaped, flat, spiral, pearly shell, with a row of perforations, a very wide aperture, and no operculum. The animal has two gills, of which the right one (left in position) is the smaller.

In the families next succeeding the mantle is entire, there is no slit or perforation in the shell, and only one gill remains, the (originally) left one.

The Trochide have spiral shells of conical form, and very largely composed of nacre; they are frequently usea for necklaces after the non-pearly outer coat has been removed. Some of the smaller examples are common on our coasts, but the finer and more handsomely coloured ones all come from tropical seas. The operculum is circular, horny, and spiral.

The Stonatide are for the most part pearly shells with a minute spire and large aperture; the operculun is like that of the Trochida.

The DelPHiNULIDAs are flat-topped, spiral shells, having few whorls; the umbilicus is wide and the angles of the whorls rough or spiny; the interior is pearly. They occur in tropical seas.

The Cyclostrematine are small, sometimes minute, nearly discoidal shells, with cross-ribbing on the whorls. They are not pearly within.

The TURBINID E include large and very pearly shells, much used as ornaments. They have a moderate number of rounded whorls, sometimes very richly coloured. The operculum is calcareous, and sometimes very thick and heavy, with the outer surface frequently beautifully sculptured or coloured: one kind, called cat's-eyes, has been used for necklaces. The Turbinide are trof ical forms.

The Neritopside have solid shells much resembling Natica in shape. There is only une living species known.

The NERITID 2 have solid and rather globular shells of not many whorls and very short spire, or none at all; the columellar lip is crenulate or toothed, and the shelly operculum is articulated. The genus Neritince occurs both in the sea and in fresh water.

The TITISCANIID are shell-less: one species only is known, which comes from the Pacific.

The Prosproptinide, HeltCINide, and Hydrocenide are terrestrial nembers of the sub-order, in which the gill is absent and the gill cavity transformed into a pulmonary chamber, as in the snail. The shell is more or less globular, and mostly of a yellow tint. All three are tropical families, and occur, the first two in the New World, the last in the Old.

\section{Order jI.-Pectinibranchiata}

(Sometimes termed Monotocarcia, the heart having only one auricle).

In this order, which includes the majority of the marine Gatrofods, ouly one gill remains, the (originally) left one. The greater number, 
moreover, are monopectinate; that is to say, the gill has only one row of filaments.

The Pectinibranchiata are further divided into sub-orders according to the characters of the radula.

Sub-order 1.-Granogrossa. Under this are grouped some more or less parasitic Mollusca which have no radula. The arrangement is artificial but convenient. Two families are distinguished, both of universal distribution:-Eulinide and Pyranidelidid. The former are mostly high-spired, very glossy; small white shells, with slightly bent axis ; at times furnished with an operculum. Some species are found crawling in the stomachs of sea-cucumbers (Holothuria), others affix themselves to the exterior of tho same creatures by means of the long proboscis, which is thrust through the skin of the host. The genus Stylifer has a glassy, globular shell, and lives amongst the spines of Echinoderms or buried in the skin of star-fish. The Pyramidellidæ form the preceding family by the occurrence of plaits or folds on the columellar, and by the fact that the protoconch is sinistral, whilst the rest of the shell is dextral and the axis of the former inclined at a considerable angle to that of the latter.

Sub-order 2.-Pтenoglossa. Two families are associated, probably provisionally, under this sub-order, having but one feature in common, viz., the radula contains a great number of similar teeth in each row, the largest being at the outer edges.

The IANTHINIDE, or purple sea-snails, float about in mid-ocean. Their violet shells are thin and translucent; the animal has a distinct snout; the eyes are generally wanting. Two plume-like gills are present. At certain seasons a membranous float or raft, full of air cells, is secreted by the animals, the egg-sacs are attached beneath, and when the whole is complete it is cast adrift. They seem to be gregarious, and stray parties brought by the Gulf Stream are frequently stranded on our western shores.

The Scalaridde, or wentle-traps, are high-spired shells, with the whorls often only united by the prominent varices that occur at regular intervals and impart to the shell its most characteristic feature. The aperture is circular, the operculum horny and spiral. The animal has a retractile snout. The Scalariide are curnivorous snails and widely distributed. Four species aro British.

Sub-order 3.-Tenioslossa. To this the greater part of the Pectinibranchiata belongs. The radula usually has the formula $2 \cdot 1 \cdot 1 \cdot 1 \cdot 2$. The various families may be conveniently taken in the following order, but the position in the group of the first two is still undecided.

The SolariID.E, calied "stair-case shells," from the appearance of the whorls as seen within the open umbilicus of Solarium, comprise forms having, for the most part, depressed shells $\Gamma^{i}$ th wide and deep umbilicus. The opercula vary in the different genera.

The HomalogrRIDE include one genus-Homalogyra-which has a very small, flat, coiled shell with circular operculum. The animal has no tentacles, and the eyes are not on stalks; the front of the foot is lobed and covered with fine hairs.

The NATICIDE have, for the most part, very stout, globular shells in which the umbilicus is sometimes open, sometimes more or less completely filled 
up with a shelly deposit termed the callus. The operculum is either horny or shelly. The animal of Natica is blind and has an extension of the forepart of the foot that projects over its head when the animal is crawling; extensions of the side of the fuot also partially envelop the shell. The Naticas prey on bivalves, boring a small hole right through the shell. Several species are British.

The LAIIELIARIID $\mathrm{E}$ have a delicate shell over which the mantle is reflected to a greater or less degree. The aperture is very large and rounded, and there is no operculum.

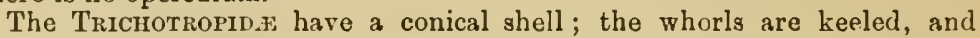
the periostracum, where it covers these, is fringed with hairs. They are northern forms and come from moderately deep water. The operculum is short and claw-shaped.

The NA RiCID $\approx$ have shells shaped like $N$ atica, but covered with a velvety periostracum, whilst the shell itself is marked with spiral and transverse ridgea, forming a kind of network sculpturing. The operculum is thin and horny.

The majority of the XENOPHORID.F may be recognised at once by their

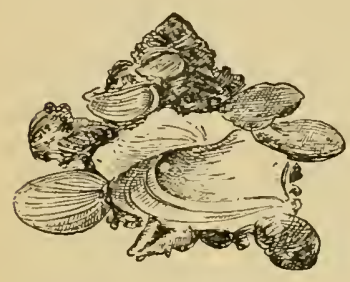

Fig. 15. - Xexopuora. curious habit of building into their own shells those or parts of others, stones, corals, or whatever may happen to be lying on the sea-bottom where they dwell (Fig. 15).

The shell in the CAPULIDE is limpet-like. In Capulus, the cap-of-liberty shells, it has is little curly apex; whilst in the eup-and-saucer limpets (Crucibulum, etc.) there is an internal shelly projection which serves for muscular attachments.

The HipPonicid.玉 hare also limpet-like shells, but the mouth is closed by an aceurately-fitting shelly plate attached to some fixed object. This plate is sccreted by a kind of second mantle that envelopes the under surface of the animal and represents the foot, of which there is none properly so-called. A great horse-shoe-shaped muscle holds the shell to its base.

The four next families are all dwellers on the land, and in place of the gill, which is not developed, the pallial cavity is converted into a lung, as in the common snail. The animals have a distinct snout.

The Truncaterlide and ARICUlid: are diminutive forms with cylindrical, many-whorled shells having a blunt apex, and closed with a spiral operculum.

The Cyclostonatid 2 have spiral shells, sometimes top-shaped, sometimes globose, closed by a spiral opereulum. One species of Cyciostoma is found on our chalk downs.

The CYCLOPHORID.E vary much in the shape of their shells, some having high spires, whilst others have none at all. The mouth is always circular, and closed with a tightly-fitting operculum, in which the nucleus is generally central. To enable the creature to breathe, when fast shut in its shell, there is often either a notch in the peristome or an aperture a short distance from the margin, that is occasionally prolonged into a tube. A few examples occur in Southern Europe, but the majority are found in the tropical regions of the Old World.

The succeding five families are all fresh or brackish-water forms. 


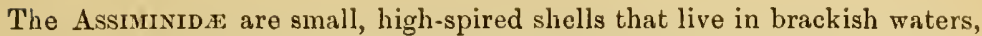
near the mouths of large rivers through Europe, Asia, and in the Antilles. One species is still to be found in ditches beside the mouth of the Thames, but is rapidly becoming extinct.

The AnPULLARIID $\mathrm{E}$ dwell in tropical lakes and rivers. They have globular shells, with greenish periostracum, and closed with a horny or shelly concentric operculum. In some species the shell is sinistral. The animal of Ampullaria has a double respiratory chamber-one portion for breathing air, the other for respiring water.

The VALVATIDE, in which there is but a single genus Valvata, are restricted apparently to the northern hemisphere. Two species occur in Britain. The shell is flat, or moderately spired, and furnished with a manywhorled operculum fitting the circular mouth.

The VIVIPARID \pm have two common British representatives, known as the banded water-snails. The shell is high-spired with rounded whorls, the mouth is oval, and the operculum horny.

The right tentacle of the males is shorter than the left, and has a deformed look. The eggs are usually hatched within the parent. Tho family is confined to the northern hemisphere, except in Africa, where it extends to the head-waters of the Nile.

The Paludestrinid es are miniature editions, so to speak, of the preceding : but the tentacles are not modified. The operculum is calcarcous in Bythinia. They are world-wide in their distribution, and there are several British representatives.

The RissoIID无 are minute marine shells, very similar to the preceding; they are abundant everywhere. The LITIOPID $\approx$ and JEFFREYSIID closely allied to the Rissoiidre.

The Litrorinid.E, or Periwinkles, both the common one with its round, banded shell and short, sharp spire, and the yellow one without any spire, are too well known to need description. Some of the species have spiral ridges on the shell. Pagodus has a conical shell with tubercles or spines. The operculum in this family is horny and spiral.

The FosSARID五 are closely allied and very similar to the Littorinidz.

The Melanifd and Pleuroceride have as a rule very high-spired shells covered with a brown periostracum; the mouth is simple, and the spiral operculum oval. The whorls are sometimes smooth, sometimes ornamented with spiral ridges and lines of tubercles, or a row of spines near the suture. They are exclusively fresh-water forms.

The CACIDE, sole genus Cacum, are strange little curved shells without any markings. The young shell is coiled, but the creature, as it grows, breaks off successive portions and blocks up the end with a shelly plate, so that the whole shell is never found in the adult. It has a horny, spiral, circular operculum. Two species occur in Britain.

The TURRITELLID A, or screw-shells, have long, slender, pointed shells of a great many whorls, more or less keeled, or ornamented with spiral ridges ; the aperture is small, the lip simple, and the operculum horny, manywhorled, and covered with short hairs. The family lias a world-wide distribution. One species of Turritella is British.

The VERIETIOA, when young, often have a neatly-wound spiral shell like Turritella, but in the more mature and the adult state this straggles off into an irregular circular tube much resembling those of certain marine worms. The shells are attached to each other in masses or to other objects. The foot 
of the animal is plug-like and quite useless for crawling. In the genus Tenagodes the tubular shell is fissured for almost its whole length.

The Cerithins e have long shells like the Turritellidæ, but the mouth is not so round and is interrupted by the anterior and posterior canals, the former of which is usually bent to the left. The operculum is horny. The whorls are generally sculptured, or ornamented with ribs, tubercles, or spines. They occur in all parts of the world and dwell in the shallow waters of coasts and estuaries, some even advancing up the rivers into fresh waters. There are three British species.

The wing-shells, Strombide, Aporrhaidz, and Struthiolaridde, are noted for their strong shells, with very short spire and widely expanded outer lip, which is often drawn out into curved spines. The fountain-shell, Strombus gigas, of the West Indies, the scorpion-shells, Pterocera, and the pelican's-foot shell, Aporrhais, are familiar examples. The operculum, which is rudimentary in all, is horny and claw-shaped : in the Strombidre its outer edge is serrate.

In the CrPRAIDE, or cowries, the outer lip of the adult shell is curled inwards, blocking still further the already narrow aperture, which is, moreover, edged with numerous fine teeth, whilst the short spire is almost, if not quite, concealed. The young shell, on the other hand, has a distinct spire and thin, sharp lip. The mantle when the animal is crawling is greatly extended, enveloping the shell, which thus acquires that beautiful polished surface for which the cowries are noted.

The DoLIID $=$ are, for the most part, large, thin, and rather globose shells, the fragile whorls of which are strengthened by their walls being corrugated. In Pirula the shell is stouter, and furnished with a long anterior canal. There is no operculum. They are denizens of tropical seas.

The CASsidid 2 , or helmet-shells, resemble the preceding, to which they are closely allied, and with which they are found. Their shells, however, have the margin of the outer lip inflected, cr thickened and crenulated, and they furthermore possess a fan-shaped, horny operculum. The under-layers of the shell in Strombues, Cyproea, and Cassis being of a different colour to the upper ones, these shells lend themselves especially to the art of the cameo engraver : the best results are generally those obtained from the Cassis rufa of West Africa.

The LотоRIID ere best typified by the great triton-shell (Fig. 12), which the sea-gods in mythical pictures are represented blowing. It is a fine large shell, with slender pointed spire and numerous varices, resulting from the formation of periodic mouths. The aperture is large and oval, whilst both inner and outer lip are denticulate. The periostracum in this family is usually stout and fibrous : the operculum is horny and claw-shaped.

The most highly specialised of all the Tænioglossa are certain pelagic forms formerly placed in a separ-

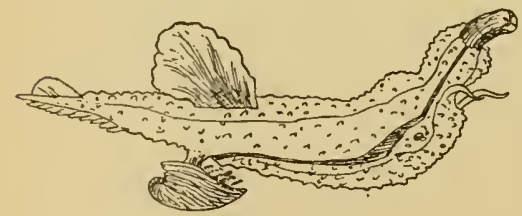

Fig. 16.-CARIXARIA ate group, and called Heteropoda or Nucleobranchiata. The animals are remarkable for their transparency, all the various organs being perfectly visible even through the shell. They swim upside down in the water, the flattened foot acting as a fin. Two families are distinguished :- 
The Atcantides have convolute shells, which in Atlanta is flat, and furnished with a single remarkably deep keel at the periphery, and in Oxygyrus is globose, and provided with many small keels.

The Pterotrach eid.z, as a rule, have neither mantle, shell, nor tentacles; in Carinariu (Fig. 16), however, there is a cap-shaped, transparent, glassy shell covering the small visceral mass. The animals are carnivorous.

To the Trenioglossa, also, in all probability, belong the families Clroristid $s$, ADEORBIDE, SEgUeNzIID.E, and OOCORYTHIDE.

Sub-order 4.-RACHIG LOSSA, Mollusea with long retrac tile proboscis. The formula for the radula is $1 \cdot 1 \cdot 1$; the laterals, however, are often wanting.

The Muricine are a numerous family, chiefly familiar by the many examples of the spiny species of Murea that adorn some people's houses. Their shells have moderate spires and generally a large body-whorl ; the mouth is furnished with both anterior and posterior canals, the former often being of great length, and a horny operculum. They are usually more or less spirally ribbed, whilst Murex has numerous strong rarices frequently ornamented with spines of great length, which, in the Venus' Comb (Fig. 17), extend the whole length of the anterior canal. The dog-periwinkle, Purpura lapillus, so common on our coasts, belongs to

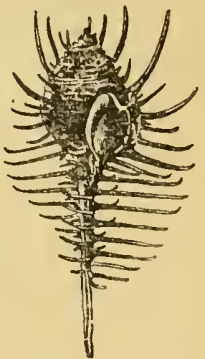

Fig. 17.

MUREX TENUI-SPINA. this family.

The Coralliophiline live amongst masses of coral; Magilus, indeed, becomes buried in them, and forms a tubular shell to keep pace with the coral as it grows. The young Magilus, before it becomes fixed, and the other members of the family resemble Purpura, both in shell and animal, but have no radula.

The COLUMBELLID\& are small fusiform shells resembling Strombus in shape ; but the lip, instead of being expanded, is thickened and dentate within ; the aperture is narrow and the anterior canal short.

The NASSIDE, or dog-whelks, have a shell like the common whelk, only smaller; the outer lip is thickened and dentate; the columella lip is thickened with a callus; the operculum is horny; the wide, thin foot of the animal is divided behind into two tails. Nassa reticulata is very common on our coasts.

To the Buccinid E belong the common whelk and its allies. The siphon is rather long and allows the animal to burrow in the mud in search of the bivalves on which it feeds, boring a neat little hole in their shells and rasping out its victin with the radula in its long, retractile proboscis. The foot is large and thin; the operculum horny and oval; a scanty, rough periostracum is found on fresh specimens, but soon rubs off.

The TURBINELLIDE have generally pear-shaped, solid shells, usually with shelly plaits or folds on the columella ; the anterior canal is fairly long. They are for the most part tropical forms. To this family belongs the largest known Gastropod, Semifusus proboscidiferus, which attains $2 \mathrm{ft}$. in length. It comes from Australia.

The Fasciolaridd a have elongate fusiform shells; the spire is generally high and pointed and the anterior canal long. The columella bears several shelly plaits or folds; the lip is simple, and the horny operculum bluntly claw-shaped. The whorls are frequently ornamented with tubercles arranged 
spirally, and with spiral strix. The members of this family, also, chiefly inhabit southern seas.

The Mrruide are more cylindrical shells than the preceding, with more or less acute spire and narrow aperture, without operculum; the columella bears several folds, of which the hindermost, i.e., the one furthest from the well-marked anterior canal, is the largest. The Mitride are tropical shells, the best-known examples being, perhaps, Mitra episcopalis, which is white, with squarish, red spots arranged in rows.

The Volutide include some of the finest of the tropical shells. The animal has a long foot and a wide, flat head; the shell varies, being spindleshaped in some, and greatly swollen in others; in all, however, the aperture is large, the outer lip slightly turned out, the margin simple, notched for the siphon at the anterior end next the columella, which ends in a point, and bears several folds. The protoconch is set obliquely.

The Marginellide have oval, or sub-conoidal, shells that are shining and polished, without operculum.

The HARPID include but a single genus, Harpa, to the shell of which the periodic mouths impart its characteristic lirate appearance. The spire is short, the aperture wide, lip simple, with anterior siphonal notch; there are no folds on the columella, nor is there any operculum. The Harps are found in tropical seas, and so, too, are olives, which come next.

The Orivine, or olives and rice-shells, in point of polished surface and in colour-markings, are equal to the cowries. They are more or less cylindrical, with a short spire and long, narrow mouth; the columella is callous, and bears several plaits towards the anterior extremity; an operculum is sometimes present.

Sub-order 5.-Toxoglossa. The radula normally has the formula $1 \cdot 0 \cdot 1$, and the teeth are large.

The Cancellarim.玉 include but one genus, Cancellaria, so named from the cancellate, or cross-marked sculpturing of the shell, which is oval, or turreted, with anterior siohonal notch; the columella is strongly plicate; the operculum is wanting.

The Plfurotomid-x include a great number of spindle-shaped shells, most of which bear a characteristic notch in the outer lip, and a marked anterior canal; the columella is smooth; the operculum is not always developed.

The CONID.E are too universally known to require description, their conical shells, with long, narrow apertures, are only approached in form in one or two exceptional instances by members of other families. The operculum, when present, is very small, and almost rudimentary. Perhaps the most remarkable feature about the animal lies in its radula, the teeth of which are proportionately large, are barbed, and perforated by a duct leading to a poison gland. This character has not been obserred in any other group. The cones are essentially tropical inhabitants. The varied markings of their shells are completely concealed during the lifetime of the occupant by the tough periostracum in which they are enveloped.

The Terebrid.e, or auger shells, are extremely long and slender, with many whorls, which are sometimes smooth but often ribbed; the mouth is oblique, with simple, thin lips and large anterior notch; the columella is without folds. The horny operculum is bluntly claw-shaped. The sole genus, Terebra, is entirely confined to tropical seas. 


\section{SUB-CLASS B.-EUTHYNEURA.}

Gastropoda, in which the visceral nerve-loop, with one exception, is not twisted into $a$ figure of 8 , and in which the nerve ganglia are brought closer together around the eesophagus. The $t w i s t$ in the visceral mass is not so great as in the preceding sub-class, and the pallial cavity with its accoinpanying organs lies on the right side of the body. The head generally bears two pairs of tentacles ; the radula is usually composed of rows of uniform teeth on either side of a central one ; and the sexes are united in each individual.

The Euthyneura are divisible into two orders-Opisthobrancliata and Pulmonata.

\section{Order I.-Opisthobranchiata.}

In this group the lieart is placed in front of the gills. The order is sub. divided into Tectibranchiata and Nudibranchiata.

Sub-order 1. Tretibranchiata. The animal possesses a shell usually more or less completely concealed by the folds of the mantle and skin. For convenience this sub-order is further divided into three groups-Bulloidea, Aplysioidea, and Pleurobranchoidea.

\section{A.-Bulloinea.}

The Bulloidea have a well-developed shell, external or internal (Fig. 18 A-C); the head is generally devoid of tentacles, and the skin of the upper purt is produced into a broad disc. In many the stomach is armed with shelly plates for crushing the shells of their prey.

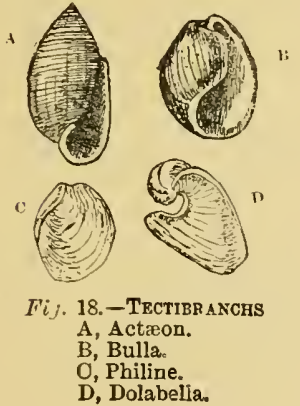

The genus necting link ovate, spired shell, with pointed apex and a narrow aperture that widens out in front. The horny operculum is elliptical in shave, 
In the genus Tornatina the shell is cylindrical, the apex of the short spire being sinistral; in Volvulella the spire is no longer raised, the shell being convolute, i.e., wound on itself like a measuring tape; in Bulla and Bullinella [ = Cylichna] it is involute, i.e., the spire is sunk, leaving an aperture, whilst the columella is less pronounced; in Scaphander the latter has disappeared and the shell is without any central axis, the whole interior being visible from the front; in Philine this is carried still further, the shell, which is internal, being widely open-unrolled, as it were.

To the Bulloidea is now referred that section of the old class Pteropoda, or sea-butterflies, in which the animal retains its shell in the adult state.

The chief peculiarity of the Pteropoda lies in the conversion of the foot into a pair of wing-like fius. Their shells vary greatly in shape, whilst their general appearance will best be understood from the foregoing figures (Fig. 19).

The following families are referred to the Bulloidea:-Actaenidre, Tornatinidæ, Scaphandridæ, Bullidæe, Aplustridæ, Ringiculidæ, Gastropteridæ, Philinidæ, Doridiidæ, Runcinidæ, Oxynoidæ, Limaciniclæ, C5mbulidæe, Cavolinidæ.

\section{B.-Aplysioidea.}

In the Aplysioidea the shell is either very greatly reduced or wanting altogether; the head carries two pairs of tentacles.

The APLYsIIDE, or sea-hares, have large boaies of greenish or olive-green hue, with a pair of lappet-like extensions of the foot folded over the back ; the shell, concealed beneath the mantle-folds, is thin, covered with a horny periostracum, triangular in shape, and flexible when first remored srom the animal (Fig. $18 \mathrm{D}$ ).

The shell-less sea-butterflios are now placed with this group, which includes the following families:-Aplysiidæ, Pneumonodermatidic, Clionopsidæ, Clionidæ, Notobranchæidæ, and Eurybiidæ.

\section{C. - Pleurobranchoidea.}

The Pleurobranchoidea have two pairs of tentacles, no lappet-like extensions of the foot, and no gill cavity, the gill occupying a narrow space between the mantle and the foot.

In the Pleurobranchides, the thin flexible shell which is covered by the mantle is large, oblong, and nearly flat, with the nucleus at the hinder margin. In Umbrella, the sole genus in the family UMBRELLID s, the external shell is a flat, circular disc, with the nucleus nearly in the centre.
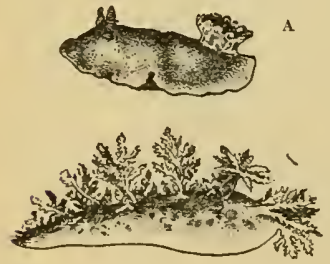

Fig. 20.-NudiBRaICHs.

A, Doris. B, Dendronotus.

Sub-order 2.-Nudibranchiata. The sea. slugs are shell-less in the adult state, but possess when still in the egg both shell and operculum. There are no true gills; their place is taken by certain tentacle-like organs that sometimes are placed in a cluster near the end of the body (Fig. $20 \mathrm{~A}$ ), and sometimes ranged in rows down the back (Fig. 20 B). These "branchial leaflets," "dorsal appendages," or "cerata," as they are variously styled, frequently bear a striking resemblance both in form and colour to some other marine object, such as a cluster of zoophytes or small sea-weeds, etc. The radula is very variable, sometimes there are many teeth in each 
transverse row, sometimes the whole radula consists of a row of single teetl, one behind the other. In one group, the Elysioidea, the wornout teeth as they drop off are saved up in a little pouch in front of the mouth.

The Nudibranchiata are divided into Elysioidea, Tritonioidea, Eolidioidea and Doridoidea.

Though they occur on every sea-coast they are not forms often met with by the ordinary student, and hence will not be discussed in further detail.

\section{Order II.-Puluoxata.}

In this order are included the vast majority of the land Mollusca (both snails and slugs) and of the fresh-water snails, besides three genera, representing a like number of families, of marine Gastropods. In all, the gills have entirely disappeared, and the pallial cavity has been converted into a breathing organ. The free edge of the mantle has been united to the skin of the neck and back, leaving only a small contractile aperture, whilst on the roof of the chamber thus formed respiration is effected by means of a branching net-work of blocd-vessels that surround and lead to the heart, which lies with its auricle to the front. In the marine forms sea water is admitted into this cavity, in the others air is drawn in and then expelled. With one exception no operculum is present in the adult.

The Pulmonata are divided into-BasomмaторноRA, or those in which the eyes are placed at the base of the tentacles, aud Stylommatophora, in which the eyes are borne on the ends of tentacles.

Sub-order 1.-Basomatophora. These have one pair of tentacles, which are not retractile, and the eyes are placed at their bases. All have an external shell, and, in the egg, an operculum, which is subsequently lost, except in Amphibola.

The AURICULID.E greatly resemble the Actreonidæ-from which in all probability they have descended-in the sliape of their shells as well as in certain points in their anatomy. The shell is oval in outline, with a promineut spire and large body-whorl, whilst the aperture is long, narrow behind, and widening out in front. There are two or three strong folds on the columella; the margin of the outer lip is thickened and often more or less toothed on its inner side. They especially frcquent salt marshes and damp spots within reach of the waves. The smallest British land-shell, Carychium minimum, is, however, found inland everywhere in damp spots at the roots of grass.

The OTINIDAs are closely related; their sliells are auriform. They occur between tide-marks, and one species is British.

The АлгнгвоціD are represented by a single genus, Amphibola, which has a globular, spiral sliell, with an uneven surface, looking as if it had shrivelled. The operculum is horny and sub-spiral. They live by the margins of the sea in the Indian Ucean, Australia, New Zealand, and the Pacitic Islands.

The SIPHONARID \& have limpet-like shells, only distinguishable from those of the true Patellida by the slight, cliannel-like depression on the interior that marks the position of the opening into the respiratory chamber. Like the limpets they are fuund clinging to rocks at low water, but do not occur in the colder seas.

The CHILINID a are fresh-water forms that occur in Scuth America. The 
single genus Chilinia has a globose shell with wide aperture, a thickened columella with one or two strong folds; the exterior is ornamented with zigzag lines and spots of colour.

The LIMINIDE include our commonest pond-snails, Limncea and Planorbis, as well as the little fresh-water limpet, Ancylus, with a few other allied genera. A characteristic feature of their shells is that their surface looks as if it had been beaten with a hammer.

The Limnæidæe are amongst the most widely distributed of Mollusca, being found from arctic to tropical climes, whilst Limnce can even live in hot springs where the water attains a temperature of $104^{\circ} \mathrm{F}$. The shells of Limncea vary from very high to very short spired forms, but all have a very large body-whorl. The genus Planorbis, or the flat-coil shells, are really sinistral forms. Ancylus is found clinging to stones in swift-flowing streams.

The PHyside are sinistral forns, and lave very thin, globular, horncoloured, and glossy little shells.

Sub-order 2.-Stylommatophora. The Stylommatophora have, as a rule, two pairs of tentacles, which can be withdrawn into the body by a process of inversion, and carry their eyes on the summits of the upper pair. They are all terrestrial forms and have an external spiral shell, except the slugs, in which it is reduced to an internal shelly plate, or is wanting altogether. The slugs do not constitute a group by themselves, but belong to different families.

The land-snails occur in all climes and at all altitudes where life is possible, and include innumerable forms which have been variously divided into a great number of families and sections; the following, how. ever, may be taken as constituting the principal groups :-

The ONCHIDIDE are slug-like animals, entirely devoid of any shell, that live close down to the margin of the sea. Only one pair of retractile tentacles, bearing the eyes, is present. Certain species are also furnished with eyes on the back. There is a British representative found locally on the coasts of Cornwall and Devon. The VAGINULIDE are shell-less slugs, unrepresented in Europe. Only
one genus, Vaginula, is distinguished.

The ATHORACOPHORID.E, with a single genus, Athoracophorus, have a small, flat, internal, shelly plate. The lower pair of tentacles is wanting. They are found in New Zealand, New Caledonia, and the New Hebrides.

The SUCCINEIDE include snails, in some of which the shell is external, whilst in others it is internal. The lower pair of tentacles is either little developed or wanting. The type genus Succinea, or the amber-snails, are world-wide in their distribution, and have pretty little delicate, ambercoloured, glossy, spiral shells. Two or three species are British. Hyalimax is one of the slug-like members of the family found in the Mascareigne
and Nicobar Islands.

The ACHATINELLID marked, and very variable little high-spired shells, that are sometimes dextral and sometimes sinistral.

The AcHatinide include at the same time some of the largest and of the smallest land-snails. The type genus Achatina is confined to Africa and its islands, although one species has been introduced into the Botanical Gardens in India. It has a high-spired shell, usually with a large body- 
whorl. The largest species attains $7 \mathrm{in}$. in length, and lays an egg as large as a pigeon's, with a calcareous shell. Stenogyra has a very long and narrow, many-whorled, glossy shell; some species are nearly an inch in length. Cocillianella is very small and lives underground. It is, as its name implies, blind. One species occurs in England.

The PuPID often strongly striated and frequently sinistral.

The genus Pupa, the clirysalis-shells, is represented in Britain, as also is Clausilia, in which the shell is very long and sinistral. The latter is remarkable for possessing a curious little valve, the clausium, which is attached within the shell by a spiral elastic stalk to the columella, and closes automatically behind the animal when it retires (Fig. 21).

The CrLINDrellide, which are confined to America and the West Indies, have exceedingly long, many-whorled shells, with circular aperture : the last whorl often stands out from the rest.

The Bulimulide occur in America, Southern Asia, and Polynesia. With the exception of the slug-like genus Peltella, they have external high-spired shells.

The Ortualicid.z are an American family, whose single genus Orthalicus has a shell in external shape resembling that

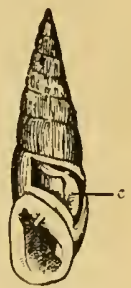

Fig. 21.-

Cuausilia, showing clausium (c)in position. of Bulimulus.

The HELICID E comprise an enormous number of forms:-High-spired shells as in the genus Bulimus, which is confined to South America and the West Indies; or as in the gaudily-painted shells of the Philippine genus Helicostyla and our own Cochlicella; shells with short spire or no spire at all, as in the big genus Helix, of which the garden snail is an example.

The family THYropHorellide has been created to receive one small species, Thyrophorella Thomensis (Fig. 22), from the Island of St. Thomas, Gulf of Guinea.

The unique feature about the shell, which is a flat, spiral one, consists in the prolongation of the upper half of the peristome beyond the aperture and the formation of a hinge allowing this projection to close over the mouth and thus act like an operculum when the animal retires.

The Arionid 2 are slugs whose shell is represented by a few calcareous grains beneath the mantle. The big black slug
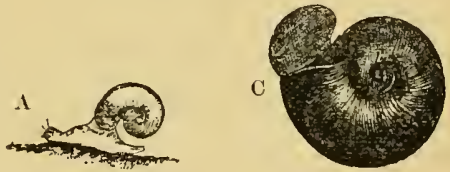

B

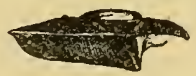

Fig. 22.-THYROPHORELLA,

A, The animal crawling. B, The shell seen edgewise, C, Do. seen from beneath. Arion ater is a type.

The Philonycides are shell-less slugs found in North and Central America, Eastern Asia, and Java.

The ENDODONTID 2 have flatly-coiled shells, generally ribbed and marked with little red patches. The common little Pyramidula rotrindata is a British example.

The Limacida are slugs with small, internal, shelly plate. The majority of the British slugs belong to this group.

The Zonitides have external shells, often very thin and shining. The 
peristome is sharp. The cellar-snail, Vitrea cellaria, is one of several British examples.

The Testacellid a and Selenitide are the most highly specialised of the Stylommatophora and are almost all voracious carnivores. Testacella looks like a slug with a tiny shell at the end of its tail. It is a worm-eater and follows its prey in their burrows, hence it is seldom seen though fairly abundant in England. Other members of the group have shells of varying sizes and shapes.

\section{CLASS V.-CEPHALOPODA.}

TuE Cephalopoda include not only the most highly organised Mollusca, but also the largest of them all, some forms, it is calculated, exceeding $50 \mathrm{ft}$. in total length. The pearly nautilus has an external shell, the cuttle-fish and its near allies have internal shells, whilst the octopus has none at all.

The Cephalopoda are symmetrical animals, the two halres of the body correspending in structure. The visceral mass is large and often elongated. The head, on either side of which there is a large and well-developed eye, is more or less distinct, and is surrounded by the foot, which has in fact grown around the head and has developed, or keen drawn out into, eight or ten long processes called arms.

In the majority of living forms these arms are furnished with rows of suckers or hooks. The upper part of the back of the foot has grown out into two fleshy lobes, the free, outer edges of which can be applied to each other so as to form a tube, known as the funnel, or siphon, that con municates with the mantle-cavity. Sometimes the $\epsilon$ dges of these lobes have grown together and form a complete tube. The bell-shaped mantle which envelopes the body is extremely tough and nuscular.

The mantle-cavity is on the under side towards the back of the bcdy, and the water for respiration is taken in at its open end and then discharged through the siphon. By the forcible expulsion of water in this way these animals can dart backwards through the water with great rapidity.

The mouth is placed in the centre of the arms; it is furnished with two jaws which resemble a parrot's beak and which are moved by powerful muscles. The radula is sniall in proportion to the animal, and has but few teeth in each row; the alimentary canal runs in an almost straight line from the mouth to the stomach near the further end of the bcdy, thence the intestine leads forwards and downwards and terminates in the mantle-cavity. Just at the same point the ink-bag also opens into the mantle-cavity. By discharging the ink or sepia-pigment contained in this gland, and thus clouding the water, the animal is enabled to cover its retreat from an eneny. On either side of the median line, within the pallial-cavity also, are the gills, either two or four in number and foliobranchiate in type. The heart has a corresponding number of auricles and a ventricle, whilst the blocd is largely confined to veins and arteries, so that nearly the whole of the blood returning from the body passes through the gills. The nervous syst $\mathrm{cm}$ is highly concentrated, whilst the ganglia around the osophagus are fused together into a ring of nervous tissue. This nerve-collar in Nautitus is partly, and in the other Cephalopoda completely, enclosed by a cartilage called the cephalic cartilage. There are other cartilages present, except in Nautilus, in different parts of the body, that serre as points of attachment for the larger muscles.

The faculty which Cephalopods possess of changing their colour is one of 
considerable interest. Scattered over the surface of the body, and just beneatl the outer lajer of the skin, are a number of pignent cells called chromatophores, and it is by the contraction and expansion of these, which are partly under the control of the aninal, that the changes of colour are effected.

The class is divided into two orders, according to the number of gills present, riz.:-Tetrabranchiata and Dibranchiata.

\section{Order I. - Tetrabranchiata}

Is represented at the present day by a single genus Nautilus; but in past times there wcre-many other very strange forms whose shells were either uncoiled or curved or quite straight.

The shell of Nautilus is entirely external and coiled forwards over the animal's back; the aperture of the shell of the male is proportionately wider than that of the females.

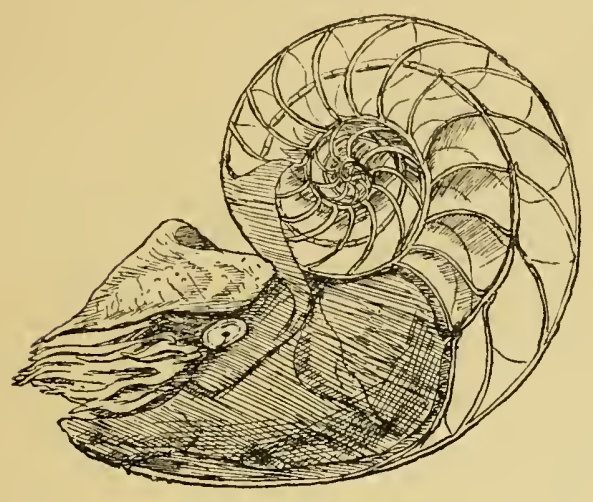

Fig. 23.-NAUTILUE. Its outer layer is porcellaneous, the inner nacreous. Inside, when neatly cut in half, it is seen to be divided off by a number of shelly partitions into a series of chambers (Fig. 23). The reason for these lies in the fact that the animal does not occupy the hinder part, which it shuts off each time that growth compels it to construct a wider and more commodious portion in front. The first chamber of all, or protoconch, being horny, is never preserved in the Nautiloidea. Rumning right through these chambers to the last one is a small tube, the walls of which are pervious and lined with a black horny layer. It is occupied by a backward extension of the mantle called the siphuncle. What the function of this siphuncle may be is still unknown, nor is it yet ascertained for certain whether the untenanted chambers are filled with gas or water, though the latter appears more probable.

The animal of Nautilus is rare, and differs conspicuously from other Cephalopods in that it has no long arms furnished with suckers; the mouth is, instead, surrounded by numerous suckerless tentacles which can be retracted into special sheaths. The margins of the lobes which form the funnel are not united. There is no ink-bag. The gills are four in number.

The eye is remarkable for being of the simplest description : it consists of a cup-shaped depression lined by the retina and covered with an outer layer of the skin, save for one small aperture in the centre. The sea-water fills the cavity when the animal is alive, and the whole apparatus must work on the principle of a pin-hole camera.

Four species of Nautilus are known-from the Gulf of Persia, the Indian Ocean, the China Sea, and the Pacific Ocean. 
To the Tetrabranchiata probably also belongs the fossil group Ammonea, in which the shell was external and of various shapes, but retained the protoconch.

\section{Order II. - Dibranchiata}

Characterised by the possession of a single pair of gills. The funnel is complete. The eye is highly developed, having both lens and cornea. The shell, when present, is internal.

Sub-order 1.-Decapoda. The members of this sub-order have ten arms. Eight of these, often shorter than the body, are tapering and armed with rows of suckers. Each sucker, or ocetabulum, is on a short stalk or pedicle, and strengthened by a horny rim which is frequently toothed. The horny rim is sometimes replaced by a hook which is retractile like the claw of a cat. The other two arms, called the "prehensile tentacles" or "tentacular arms," placed one on either side, are longer than the rest and cylindrical in form, with expanded ends armed with suckers, or with hooks. Just beneath the expanded tips there is sometimes an arrangement of suckers enabling the two to lock together and act in concert. These arms are retractile, and in the cuttle-fish can be withdrawn into special pouches.

The shell is concealed beneath the mantle on the side of the body opposite to the pallial cavity. It is generally more or less rudimentary, but is most developed in the cuttle-fish (Sepia) in which the "cuttle-bone" or "sepion" occupies the whole length and nearly the width of the body. In another form, Loligo, the shell is reduced to a horny "pen" or "gladius." Spirula

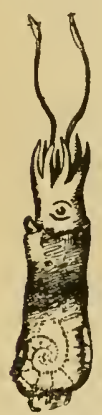

Fig. 24. SPIRULA.

The position of the shell is indicated as if seen through the skin. (Fig. 24), however, has a spirally-coiled chambered shell in which the whorls are widely separated. This shell lies in the hinder extremity of the body, and, in the few specimens of the animal that have been obtained, is not completely concealed by the mantle, though whether this is the natural state or due to injury is not yet clearly ascertained. It is thus strikingly different from the shells of other living Decapoda; the gap between them is, however, supplied in fossil forms. In some of these, the Belemnites, the apex of the shell is enclosed in a calcareous sheath called the guard, or by quarrymen "thunderbolts." The shell of Spirula is common enough and frequently cast up on our shores, but the animal is an inliabitant of deep water and rarely obtained. The other members of the group frequent tho open sea, and often have lateral expansions of the mantle that act as fins.

The Decapoda are divided into two sections:-OrgorsIDA, in which the sea-water has access to the space between the cornea and lens of the eye, and Mropsids, in which the cornea is entire and water is not admitted.

The following are the principal families:- A, OrgopsidAFamilies-Thysanoteuthidx, Onmastrephidre, Onychoteuthidx, Gonatidæ, Chiroteuthidæ, Cranchiadæ, Spirulidæ, and the fossil Decapods with "guarded" shells. B, Mropsida-Families-Sepiolidæ, Sepiadariidæ, Idiosepiidæ, Sepiidæ, and Loliginidæ.

Sub-order 2.-OCTOPODA. The members of this sub-order liave short baglike bodies without tentacular arms, only the cight tapering ones, which are 
always longer than the body, and the suckers of which have no horny rings. In many the arms are connected by a web, the umbrella, which may exist only at their base or extend almost to their tips, as in Cirroteuthis; it is probably of assistance in swimming.

There is no shell except in the famous "Paper-Nautilus" (Argonauta), and then it is not a true slell but a secondary one. This is carried by the females only, and is formed after the

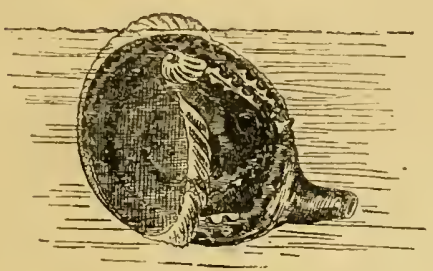

Fig. 25. - ArgonadT. animal is hatched. It consists of a thin, white, perfectly open shell, which is slightly coiled towards the back; its corrugated walls are formed of three layers-the outer ones prismatic, the inner fibrous. The animal nestles in the boat-like shell, which is in nowise attached to the body, and holds it in place with the two front arms. The ends of these arms are curved round and sustain thin membranes, vela, which cover the exterior of the shell on either side (Fig. 25). Whether the mantle takes part in the secretion of this shell, or whether it is wholly formed by the "vela," is not yet quite clear; its function, however, is probably less to protect the animal than to serve as a receptacle for the eggs.

The following families are included in the Octopoda:--Cirroteuthidæ, Amphitretidæ, Argonautidæ, Tremoctopodidæ, Allopsidx, and Octopodidæ. 


\section{SUB-KINGDOM IV.-BRACHIOPODA.}

\section{IAAMPSHELLS, ETC.}

By F. A. Bather, M.A., F.G.S., Etc.

The Brachiopoda are marine animals which, like some Mollusca, form cxterual shells; but they
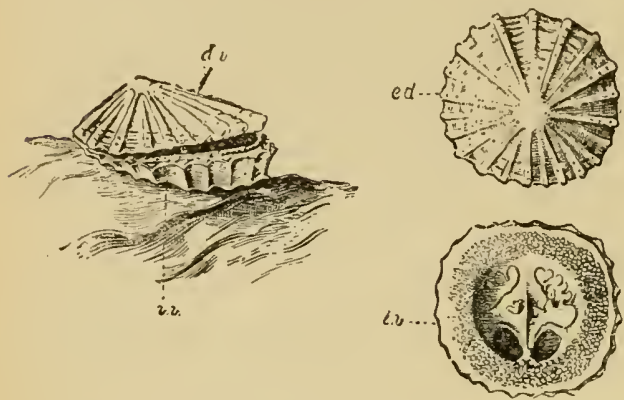

Fig. 1.-A Srssile Brachiofod (Crania); attachad to a piece of oyster-shell; $d . x$., dorsal valve; $v . v$, ventral valve; e.d., exterior of dorsal valve; i.v., interior of ventral valve. Twice natural size. valve to the rock (e.g., Crania, Fig. 1), or, as is more usual, by means of a in many points.

The shell consists of two valves, which lie on the back and front of the animal, not on its sides as in bivalve Molluscr. Each ralve is symmetrical in itself, which is very rarely the case in Mollusca; but one valve is nearly always larger than the other. By this larger valve the adult animal is usually attached to rocks or other objects, eithor by the cliffer from the Mollusca

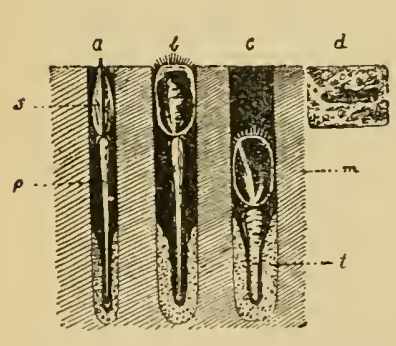

Fig. 2.-A Pedunculate BrachioPOD (Lingula). The animal lives in the mud $(m$.$) in a tube, the$ bottom of which is lined with cemented sand-grains $(t$.$) . The$ shell $(s$.$) is attached to this by a$ peduncle $(p$.$) , which can con-$ tract. $a$. and $b$, the peduncle outstretched; c., the peduncle contracted; $d$. , the opening of the tube from above. Creatly reduced.
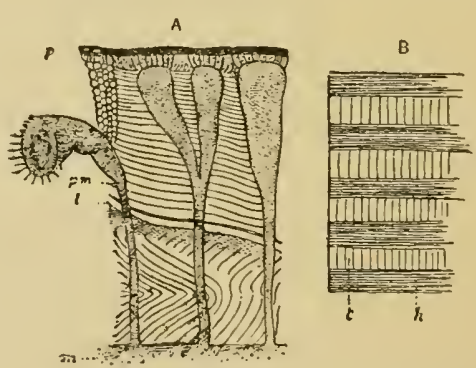

Iig. 3.- Shell structure of $A$, a calcareous shelled Brachiopod, $I$, a horny shelled; $m_{\text {., }}$ mantle, which sends proces es ( $\left.p . m.\right)$ through the prisms of carbonate of lime that make up most of the shell; $p$., outer imperforate layes ; $l$, line of growth $; h$., lorny layers; c., calcareous layers with vertical canals, Greatly magnified. 
iong muscular stalk, cillerl the peeluncle (Fig. 2). This larger valve is therefore often called the "peduncle valve"; by English writers it is called the "ventral valve," although in the natural position of stalked forms it is always the uppermost. The smaller valve is called the "brachial " or " dorsal" valve. In microscopic structure, also, the shell differs from that of the Mollusca (Fig. 3). The two valves may be united by a hinge at the hinder, or umbonal end (Articulata, Fig. 4), or they may not (INARticulata, Fig. 5).

The shell-valres are lined by two mantle-folds, or extensions of the bodywalls, which contain prolongations of the body-cavity; and in them the generative products are formed. The free margins of the mantle-folds are beset with bristles (setie, shown at $b$. in Fig. 2). IIuscles pass across the body of the animal from one valve to the other; they serve to open and to close the valves, and to move them sideways. The imprints of these muscles on the she!l are important in the study of fossil brachiopods (Fig. 5).
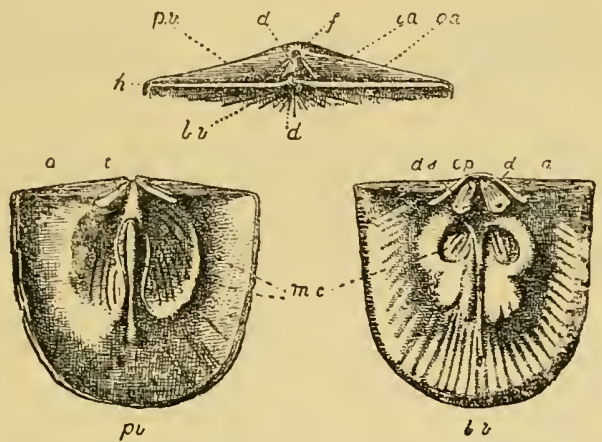

Fig. 4.-A MrxaEd BRAchionon (Rafineaquina alternata). The upper figure shows the hinge from outside; the lower figures show the inside of the valves. p.v., peduncular or ventral valve; $b . v$. , brachial or dorsal valve; $h$., hinge-line; $d$. , deltidium; $f_{.}$, foramen ; $a_{.}$, area; $i . a$. and $0 . a_{.}$, its inner and outer portions; $t$, tooth; d.s., socket in which tooth works; c.p., car. dinal process; m.c., muscle scars. Two-thirds natural size.

The riseera (Fig. 6) lie near the hinder umbonal part of the shell, and the mouth is directed towards the fore-part or opening of the shell. Around the mouth is a somewhat horseshoe-shaped disc, bearing ciliated tentacles, and called the lophophore (tuft-bearer). It is often produced into two processes or "arms," which fill the fore-part and sides of the shell-eavity, and are often spirally coiled. From these "arms" is derived the name "Brachiopoda" (Bpaxiwy, an arm, and rôv;, a foot); they are often supported by a calcareous skeleton, the shape of which is of great importance in classifying fossil forms. The movement of the cilia of the lophophore serves to drive to the mouth currents of water containing foodparticles. A lophophore is also found in the Bryozoa, and in a few other sessile marine animals (Phoronis, Rhabdopleura, Cephalodiscus). The mouth 
leads to a slightly-coiled intestine, which may have an anus (Thetexter.tia), or may not (CLISTENTERATA).

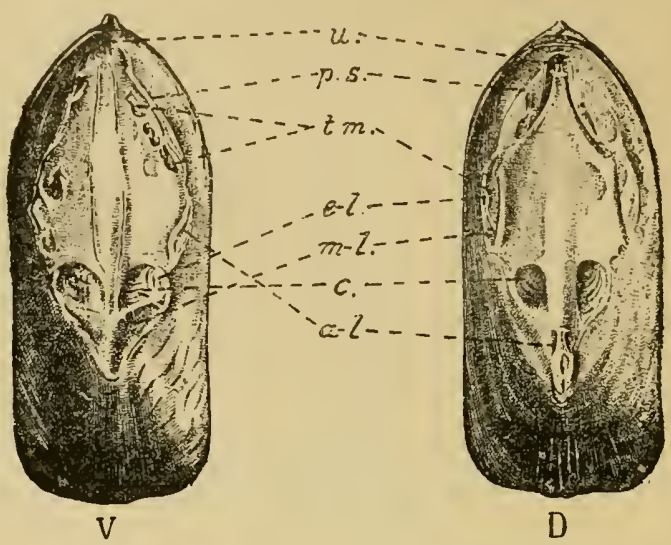

Fig. 5:-A Nox.HrNGED BRACHIOPOD (Lingula anatina). In. terior of ventral $\left(V_{\circ}\right)$ and dorsal $\left(D_{.}\right)$valves, showing muscle scars, named as follows: $u$., umbonal; p.s., parietal; t.m., transmedian ; $e_{0} . l_{.}$, externo-lateral ; m.-l., medio-lateral ; $c_{\text {., }}$ central; $\dot{\alpha}_{.} \cdot l_{.}$, antero-lateral. Natural size.

The Brachiopoda possess a system of blood-vessels, with a contractile heart, a distinct nervous system, and a pair of excretory organs (nephridia), which

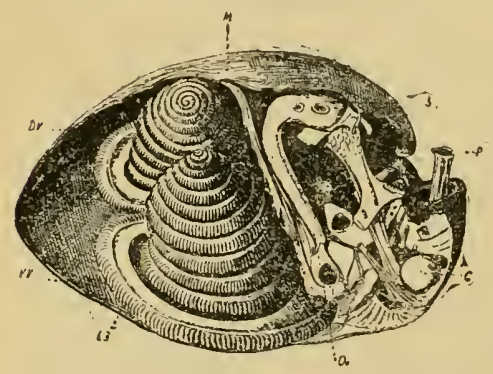

Fig. 6. - Internal organs of a Brachiopor (Rhynchonclla psittacea). p., peduncle; $D . V$, dorsal valve, and $V . V$., ventral valve, of the shell, which are broken away on one side, exposing-L., lophophore; $M I$., median partition; $\mathrm{Oe}$, oesorhagus, leading from a mouth between the coils of the lophophore to the stomach, $S$,; $C$., the coecum, or blind end of the gut, which has no anus. serve also for the transmission of the generative products. The sexes are usually separate, but Lingula is hermaphrodite.

The Brachiopoda are found in seas all over the world, and usually at depths of less than 100 fathoms, but they have been dredged at a depth of 2,900 fathoms. A few (e.g., Linunla, Fig. 2) bury them. selves in mud; but most attach themselves to rocks. They occur in great numbers wherever found. Their shells, which are easily preserved, abound in strata of all ages, so that a knowledge of them is of great assistance to tho geologist.

The simplest form of Brachiopor known occurs in the Lower Cambrian rocks of America, and is callecl Patering (Fig. 7). Its valves are oval in outline, with one side truncated by a straight hinge-line. Concentric. 
lines of growth rum parallel to the curved margin of the shell, and up to the hinge-line, whence we see that at all stages of its growth the shell was of the same shape. A very large number of the genera of the Brachiopods pass through a stage in early youth in whieh both valves, or, more generally, the dorsal valve alone, are of the same shape as the adult Paterinca. But during growth, changes in the shape of the valves

Fig. 7.-ТпЕ AพCESTOR OF THE BrachIopodA (Paterina). Enlarged.

take place, chiefly produced by the enclosure of the peduncle in the walls of the ventral valve, and by the formation of a definite hinge. In the simple types of Brachiopoda, such as Paterisua and Lingula (Fig. 5), the peduncle passes ont freely between both of the valres; such forms are known as Atremata.

Next, the peduncle-opening is restricted to the ventral valve, where it lies in a slit, which may become transformed into a round opening by growth of shell substance, a stage that is still seen in the modern Discinc and Discinisca (Fig. 8). Such forms are known as Neotreniata. The two orders. Atremata and Neotremata, are equivalent to the old order, Inarticulate or Tretenterata.

In the next order, the Protrenata, the peduncle lies at the apex of a tramgular fissure (delthyrium). This is partially closed in early life by a single shelly plate (pseudo-deltidium), as in Clitambonites (Fig. 9). This plate is secreted by the peduncle and posterior part of the body itself, and lies towards the apex of the delthyrium. In the adult, the pseudo-delthyrium becomes fused to the ventral valve, and often decreases in size.

The last order is the Telotremata, in which the delthyrium becomes closed by the development of a pair of shelly plates (deltidial plates). These are

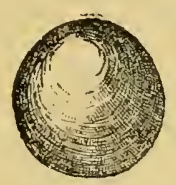

D.

Fig. S.-Discinised. D., dorsal, and $V$., ventral, valre; $\vec{F}$., peciuncle slit. Natural size.

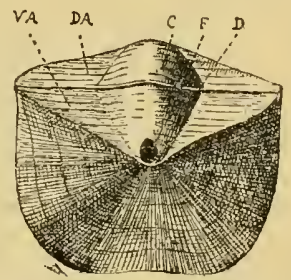

Fig. 9.-Clitambonites ddscendens. $F$., foramen for peduncle ; $D_{\text {., deltidium }}$ of ventral valve; $C$, , deltidium of dorsal valve (chilidium); V.A. anil $D . A$., areas of veutral and dorsal valves. N'atural size.

secreted by the edges of the mantle, and may fuse, either in the adult o: from their earliest appearance, to form a single plate (delticlium). (See Fig.10.) Some of the earliest forms of this order are the Phynchonellide, which occur early in palæozoic times. Subsequently, we find two main branches of the order, in which the lophophore is borne either by simple loops of shelly substance (e.g., Terebruinta and Magellania), or by coiled spires (e.y., Spirifer and Atrypa) respectively (Fig. 11). The two orders Protiemata and Telotremata together correspond to the old order, Articulatc on' Clisterterala. 
The Brachiopodi, which were formerly very numerous, both in genera, species, and individuals, are now represented by a little over a hundred species, distributed among some fifteen or sixteen genera.
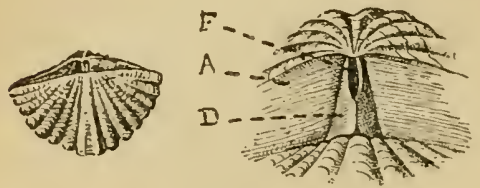

Fig. 10.-Spirifer sulcatus. A specimen, natural size, and an enlargement of the middle part of the linge-area (A.) of the ventral valve, showing the delthyrium almost closed by two deltidial plates $(D$.$) , so that only a small$ foramen $(F$.) remains.

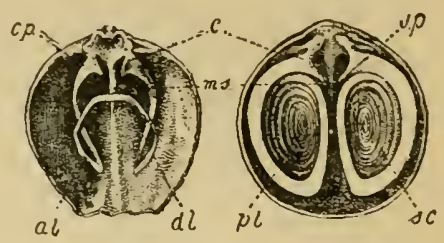

m

Fig. 11.-Lophophore supports in Magel. lania (m.) and Atrypa (a.). m.s., median septum; c., crurn; c.p., crural processes; i.p., jugal processes; d.l., descendiog lamella; $a . l .$. ascending lamella; $2 . l .$, primary lamella; s.c., spiral coils.

The Braehiopoda have often been grouped tngether with the other forms that have a lophophore (Bryozoa, ete.) under the name Molluscoidea (mol. lusc-like). But, while they certainly are not related to the Mollusca, it is very doubtful how far they are allied to these other forms. It is therefore safer to keep them as a separate group of the animal kingdom. 


\title{
SUB-KINGDOM V.-ECHINODERMA.
}

\author{
STAR-FISH, ETC. \\ By F. A. Bather, M.A., F.G.S., Etc.
}

THIs is one of the main groups of the animal kingdom, and the anmals contained in it, such as the star-fish (Figs. 1, 2), brittle-stars (Figs. 5, 6), sea-urchins (Figs. 7, 8), feather-stars (Figs. 13, 15), and sea-cucumbers (Figs. $9-12$ ), are well marked off from all other animals by certain well-defined characters. The first is the feature that has suggested the name of the group, namely, the deposition in the lower layers of the integument of a crystalline deposit of carbonate of lime. This may be in the form of minute spicules (Fig. 11, s), of separate plates, or of larger plates and ossicles closely joined together into a more or less rigid test (Figs. 7 and 13). In all cases it is characterised by its trellis - work structure, and by the ease with which it may be

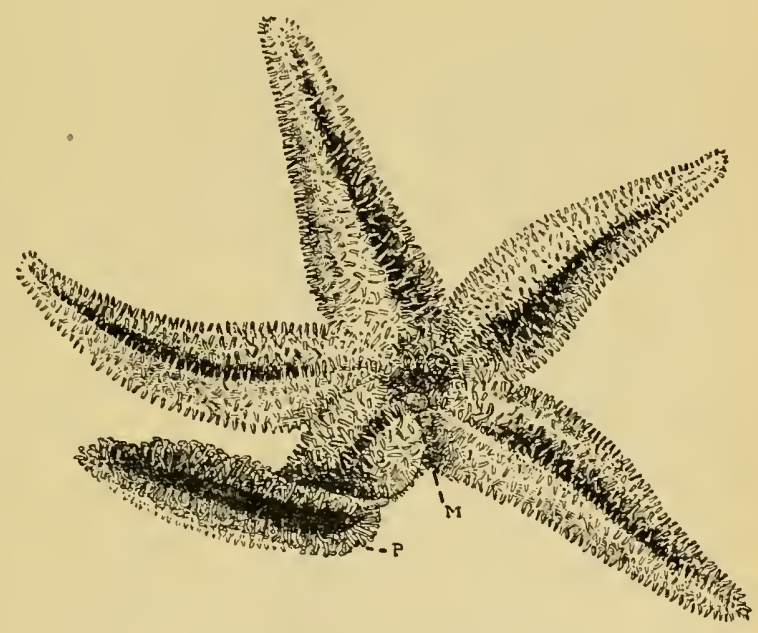

Fig. 1.-A Star-FISH (Asterias rubens) Frosi UpPeR SUgFack. Two thirds natural eize.

split in certain definite directions. Such deposition of carbonate of lime may also take place among the internal organs of the animal.

The second feature is the radiate structure so obvious in the ordinary star-fish (Fig. 1). The number of rays is generally five, and the external and internal organs of the animal are variously affected in the various classes of echinoderms by this five-rayed symmetry. The Echinoderma resemble the Mollusca, the Arthropoda, the Vertebrata, and many other groups, in possessing a separate gut, shut off from the rest of the body-cavity, as well 
as a system of branched tubes which convey blood through the body; and in these respects they differ from the jelly-fish, with which their radiate symmetry has often caused them to be allied.

A system of tubes conveying water from the exterior throughout the body, and serving as a hydraulic systern, is characteristic of the echinoderms. On the under side of the rays in a living star-fish may be seen a number of small cylindrical processes which wave about gently like trees in a wind (Fig. 1, P). They lie in each ray along two rows with a clear space between, as trees on either side of an avenue; hence the whole band of them in each ray is called an ambulacrum (garden-walk). In the sea-urchin similar rows of the tube-like processes are seen passing from the summit down to the base, dividing the test into five equal portions. In the star-fish and sea-urchin these processes end in sucker-like discs. The tubular process can be extended to a considerable length and its disc attached to some neighbouring object. The contraction of the process then draws the animal along; hence in these animals the processes are called tube-feet. Similar processes occurring in the brittle-stars and crinoids have no suckers at the end, and serve only for purposes of respiration and not for locomotion. The processes in general may therefore be called podia. Their movements are caused by the squeezing of water into them from the internal water-vessels ; for each podium is like an indiarubber tube, closed at one end, passing through the test to join with one main tube which runs along under the ambulacrum in a radial direction (Fig. 3, W), and before it joins this radial canal, each podium gives off a small swelling likewise filled with fluid, so that when this swelling, or ámpulla (Fig. 3, Amp.), is contracted, all the fluid is squeezed up into the podium, and pushes it out like the finger of a glove when one blows into it. All the radial canals meet in a ring-canal surrounding the mouth, and this is connected with the outside water by a canal that passes right across the body-cavity to the other side of the animal, where it opens to the exterior through a sieve-like plate called the madreporite (Fig. 1, M). The walls of this canal are often hardened by limy deposits, whence it is known as the stone-canal. Some such system of water-canals occurs in all echinoderms, but in the sea. cucumbers the madreporite that should connect it with the exterior is sunk inward, and hangs in the fluid of the general body-cavity. Direct communication with the exterior is perhaps not so necessary with these animals since their flexible muscular walls enable them to drive the fluid of the bodycavity in any desired direction.

There are three main systems of nerves found in echinoderms, one supplying the skin, the podia, and the gut, and consisting of a nerve-ring round the mouth, with radial nerves passing. from it beneath the ambulacra; the second, with a similar arrangement, but placed deeper, and supplying the internal muscles of the body wall ; the third, which is best seen in crinoids, starts from the other side of the body, opposite to the mouth, and supplies the muscles that work the arms and stems.

In the star-fish the generative glands are orange-coloured tubes somewhat branched and knotty, which pass down the sides of the rays and communicate with the exterior at the angles between the rays (Fig. 2, G); they have a similar position in the sea-urchins; in crinoids they extend right down the arms, at the extremities of which the generative products are produced. In the sea-cucumber, however, there is but a single much-branched generative gland. 
The echinoderms now living are divided into five classes-Asteroidea, star. fish ; Ophiuroidea, brittle-stars; Echinoidea, sea-urchins; Crinoidea, sealilies, feather-stars; and Holothuroidea, sea-cucumbers. 'There are two extinct classes - first, the Cystidea, which are closely allied to the ancestors of all echinoderms; and second, the Blastoidea, which are perhaps nothing more than an offshoot from the crinoids. In the star-fish and brittle-star the mouth (see Fig. 6) is in the centre of the under side of the body, directed towards the sea-floor; while the anus (Fig. 2, As), when it exists, is on the other side and directed upwards. In a regular sea-urchin (Fig. 7) the mouth and anus are in a similar position, but in the irregular sea-urchins (Fig. 8) the body has become somewhat elliptical in shape and the mouth has moved a little forward; while the anus has moved down from the top of the body to its lower surface, so that both mouth aud anus lie on the under surface at either end of the long axis. In a lolothurian (Fig. 9) the body is cucumbershaped, with the mouth at one end and the anus at the other, and the aninial usully crawls along on one side of its body. In the crinoids both mouth and anus are on the upper surface of the body, the mouth usually in the centre (Fig. 15, M) and the anus (Fig. 15, As) a little on one side, and both are directed upwards; while the opposite or under side of the body is prolonged into a stem (Figs. 13, 14) by which the animal is generally attached to the sea-floor or some other object.

Echinoderms cannot live on land, since they require water to work their hydraulic apparatus, neither can they live in fresh water, where they would not find enough lime-salts from which to build their skeletons: in the sea, however, they have a universal distribution. Hence their calcareous remains have often been preserved as fossils, and are found in the rocks from the earliest period in which animals are known to have existed. Echinoderms nove litt'e from place to place during adult life ; many of them, however, have rather larger powers of locomotion in the lar-

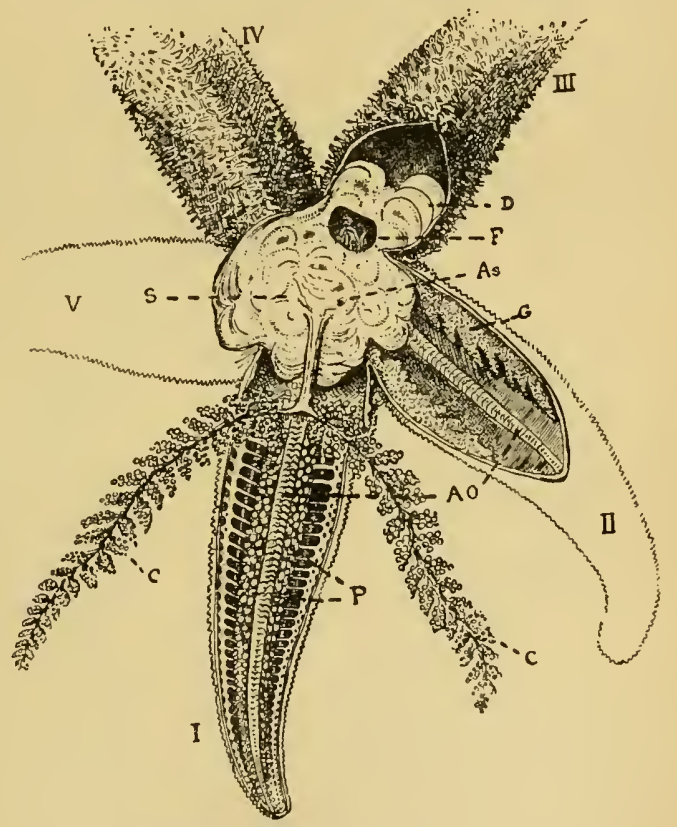

Fig. 2.-Dissection of Common Cross-pisil (Asterias rubens Two-thirds natural size. val stage, and the free-swimming larvae are occasionally carried to considerablc distances by ocean currents. 


\section{Asteroinea (Star-fish).}

The common cross-fish, Asterias rubens, is perhaps the commonest example of an echinoderm, known to all visitors to the sea-side. Fig. 1 shows it from the upper surface, one of the arms being slightly turned over so as to show the ambulacral groores with the tube-feet $(\mathrm{P})$ on either side. Towards the middle of the body, at the junction of two of the rays, is seen the madreporite (M). These two rays are known as the bivium, while the other three rays form the trivium. A line drawn between the two rays of the bivium, through the madreporite and down the central ray of the trivium, would divide the star-fish into two equal and symmetrical portions. In Fig. 2 the same animal is shown, also from the upper surface, but partly dissected. In the ray marked IV. the rough spiny skin has been left on, while it has been removed over the middle of the bcdy from portions of rays II. and III., and from the whole of the upper surface of the ray marked I. In the middle is secn the stomach (S), which cends into the rays the pouch-like extensions (D). At $F$ part of the roof of the stomach has been removed to show the folded arrangement of its walls. Near the centre is the anus (As). From the stomach there pass down in the rays blind, much-tranched outgrowths (C), known as pyloric caeca, which lave been dissected out in the ray marked I. Underneath these, on either side of each ray, are the generative glands $(G)$, which are seen in ray II. In rays I. and II. the central line of plates (Ao) separating the ray is exposed. On either side of these there are shown in ray I. the little swellings or ampullae (P) at the inner ends of the tube-feet.

Fig. 3 is a diagram showing the arm of a star-fish in section. Here the same organs may be seen, namely, the pyloric caeca $(\mathrm{PC})$, the blind processes from the stomach, the generative glands $(G)$, which open to the exterior

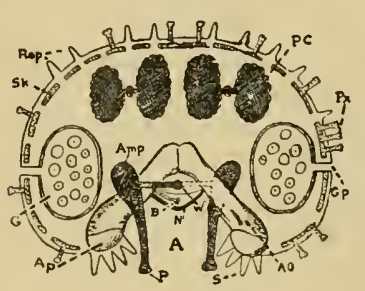

Fig. 3.-Diagramatic Cross Shction of StAR-FISU ARM. Natural size.

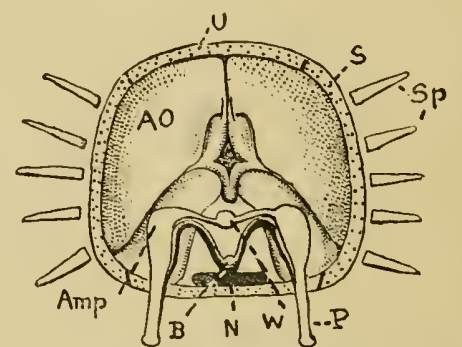

Fig. 4.-Diagramatic Cross Secticn of OpHiÚ.1D AR3. Much enlarged.

1hrough a pore (GP) which is situated near the junction of two adjacent riys, and the ampullae (Amp), from which the tube-feet (P) pass through the ambulacral ossicles $(\mathrm{AO})$. In the groove $(\mathrm{A})$ on the under side of the arm, formed by the ambulacral ossicles and lying between the tube-feet, there are shown the following structures : close to the surface, the radial nerve $(N)$; below this, the radial blood-vessel $(B)$; and below this again, the radial watervessel (IV). All of these give off side branches, those from the latter going to the ampullae. The arm is encased in an external skeleton of irregular limestone plates (SK); some of these support spines (S), and others support 
curious kinds of spines with branched heads, known as paxillae (Px). Between the plates there pass out thin-walled processes (Rsp), which serve for respiration by bringing the fluid of the bcdy-cavity into the proximity of the outer water. Besides the paxillae, there occur on the outer surface of a star-fish, as well as on that of a sea-urchin, small pincer-like organs called pedicellariae. These resemble little pincers supported at the end of a morable stalk, and they have probably been evolved from the smaller spines that corer the test of these animals. They move with extreme rapidity, and catch hold of any minute object that is brought into contact with their inner surfaces. They are variously supposed to hold small particles of food, to clean the test of dirt, and to catch hold of fronds of sea-weed for the steady. ing of the animal; while the fact that in the sea-urchin they are sometimes provided with poison-glands seems to show that they serve also as weapons of offencc. At the extremity of each arm is a single tube-foot, with no

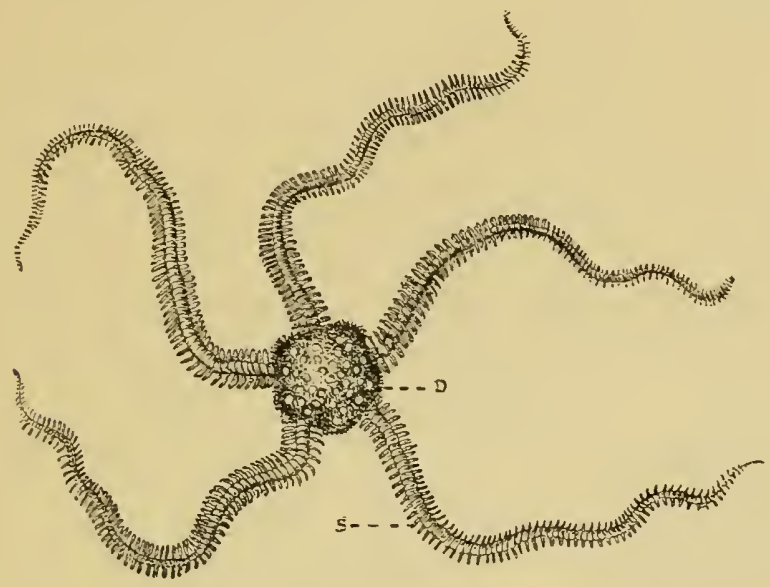

Fig. ป.-A Thathesiat (Ophitpholis aculeata), Two thirds natural size.

sucker at the end : this is always stretched straight out, and is known as the unpaired tentacle. Immediately above it is a small eye coloured with red pigment, and protected by small tentacles.

Star-fish are sluggish animals, rarely moving of themselves, and staying for days in the same position. They can, however, travel at a fair pace when disturbed. When turned over on their backs, they are able to right themselves, but some of them, which have very stiff skeletons, take much longer over the process than those that are able to twist their arms about in acrobat fashion. They are, like most echinoderns, a sociable class, living usually in swarms. Some species of shallow-water forms have been observed to pair during the breeding sfason. They are voracious animals, eating all kinds of fond, and taking plenty at a time. The stomach can, in most cases, be extruded through the mouth, and can enfold such articles of food as an oyster; star-fish are, in fact, dangerous enemies to oysters, and also attack 
the bait of fishermen, whence they are regarded by that class with a looly horror, and the cross-fish sometimes is called by them "Devil's fingers." To their credit it must be said that they serre as the scarengers of the sea, and that they make excellent manure.

\section{Ophiuroidea (Brittle-stars).}

The brittle-stars and sand-stars, which may often be found hiding under the rocks, or in the sea-weed, or in pools at low tide, resemble the ordinary starfish in having five distinct arms. These, however, as shown in Fig. 5 , are long and serpent-like, and are attached to a relatively small body or disc (D, in Fig. 5). There are other differences, as may be seen by a comparison of the section shown in Fig. 4 with that of the starfish in Fig. 3. Here it is seen that the digestive and generative systems do not extend to the arms but are confined to the body. The arms are cylindrical and have no groove on the under side, such as exists in star-fish, but they have little openings through which the tube-feet $P$ pass. In this class, however, it is the arms that are used for locomotion and not the tube-feet, so that the latter liave no terminal suckers. The greater part of each arm is formed by a central axis of successive calcareous ossicles not unlike the vertebræe of a backbone. Each arm-ossicle (AO) is composed of two parts-one on either side and united in the middle line. The successive ossicles are connected by pairs of straight, muscular bundles, and articulate with one another by tenon-and-mortise joints, according to whose degree of development the arms vary in their power of coiling. The arm-ossicles are encased in the tough outer skin of the arm, in which are developed plates (U, upper, and $\mathrm{S}$, side-arm-plates in Fig. 4). Spines (Sp) are borne by these plates, and these are clearly shown in Fig. $5(\mathrm{~S})$; they aid the animal in locomotion. The integument of

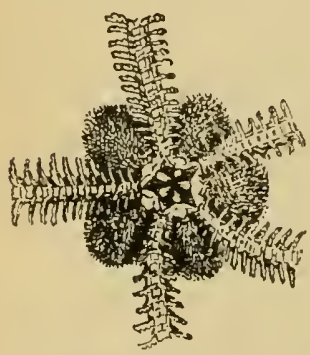

Fig. 6. - UNDER SURPACB OF OPHIURID BODY (Ophiopholis aculeata). Natural size. the disc, as shown in Figs. 5 and 6 , also bears small plates which are often covered with minute spines. Returning to the section of the arm, we see on its under side between the tube-feet, the nerve, blood-vessel, and water-vessel, which give off branches just as in the star-fish, the difference being that they are here enclosed by the integument of the arm. The mouth is shown in Fig. 6 on the under surface of the disc. Around the mouth are a number of short, flat processes, the mouth papillæ, which serve as strainers. Inside the mouth are seen the five tooth-plates.

Ophiuroids are found in all seas, usually occurring in quantities. They are most abundant in the rock-pools of the tropics. They gather their food to them by sweeping their arms over the sea-bottom, and thus conveying any suitable substances to the mouth. Figs. 5 and 6 represent a daisy brittle-star, Ophiopholis aculeata, which occurs all round the British coast. The colloquial name is due to the resemblance to a daisy caused by the intermingling of spines and plates on the surface of the disc. The popular name, brittle-star, applied to the ophiurnids is due to their fragile nature and their habit, so distressing to the collector, of breaking themselves into small portions when touched. 
Echinoidea (Sea-urchins).

The sea-urchins are the best known and most numerous of echinoderms. They are divided into two groups-regular and irregular sea-urchins. Fig. 7 shows the test of a regular sea-urchin, Cidaris papillata, which is called the Piper from the supposed resemblance of its spines to the drones of a bagpipe. In the figure most of the larger spines have been removed, but three or four have been left on (S). Several of the plates of the test are seen to bear a rounded tubercle (T), and it is to these that the large spines are attached by a balland-socket joint, which is surrounded by muscles that can move the spines in any direction. The bases of the large spines are protected by smallerspines $\left(\mathrm{s}^{1}\right)$ - -see figure - which are similarly attached to smaller tubercles. The spine-bearing tubercles do not cover the whole test, but are disposed chiefly in five broad zones, interambulacra (IA), which extend from one pole to the other. Alternating with these are the narrower ambulacra (A). In these can be seen the holes through which the tube-feet pass. At the summit of the test, where these zones converge, is a star-shaped space covered with membrane, and in the middle of this is the anus. Regularly placed round this, at the summit of the interambulacral zones, are five conspicuous plates, each pierced by a

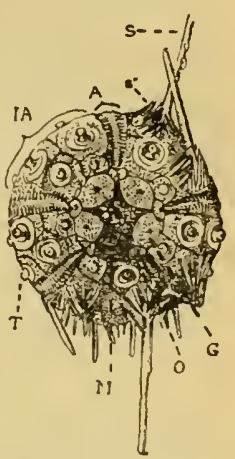

Fig. 7.-A REgULAR SEA - URCHIN (Cidaris papillata). One-half natural size. hole $(G)$, which is the duct of the underlying generative gland. One of the plates (M) is also pierced by a number of small water-pores, and is the madreporite. Outside these five plates, and alternating with them, are five other plates, each at the top of an ambulacrum, and each pierced by the unpaired tentacles which terminate the water-canals, and represent the unpaired tentacles near the eye at the end of the star-fish arms. These plates, marked $\mathrm{O}$, are therefore called oculars; in a few cases they do actually bear eyes. The mouth is at the other pole of the body, and is therefore not shown in the figure. It is surrounded by an elaborate arrangement of teeth, found in all regular urchins, and compared by Aristotle to a lantern. The gut, which passes from the mouth, coils round inside the test. Such a sea-urchin as Cidaris, or the common egg-urchin, Echimus, shows most clearly the five-rayed symmetry that has been impressed upon the echinoderms. In the irregular sea-urchins, however, one of which, Echinocardium cordatum, is shown in Fig. 8, the animal has become elongated along one of the axes so as to have a superficial two-sided symmetry. This is connected with constant movement in one direction, and such modification is found among those urchins that live on muddy bottoms, and especially in those from considerable depths. Not only is the test elongated, but the mouth moves forward to the

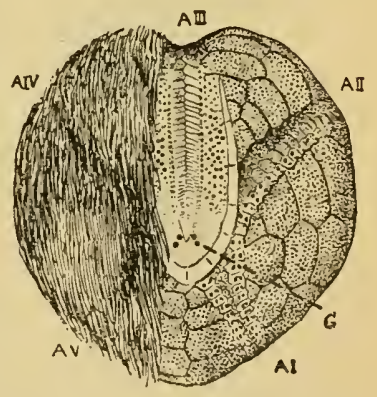

Fig. 8. - Irafgclar SEA-t'rchin (Echinocardium cordatum). Two. thirds ratural size. 
front margin, while the anus mores downwards to the hinder margin, and eventually comes to lie on the under side of the test. These heart-urchins, as they move along through the sand and mud, scoop it up into their mouths, and pass it through the gut, extracting from it on its passage such nutriment as the minute organisms in it can afford. Urchins of this type have short delicate spines, as shown on the left side of Fig. 8. They move almost entirely by stretching out their long tube-feet. It is, perhaps, the lair-like spines that have caused the urchin here figured to be popularly known as Mermaid's head, Child's head urchin, and Hair sea-egg.

The sea-urchins, like the star-fish, have pedicellariz. In the regular urchin locomotion is chiefly effected by means of the spines, which are used like crutches; they can also be used like chop-sticks for prebension. The spines also serre as organs of protection, but their efficacy varies much in different forms. In Diadema setosum the spines reach a length of $10 \mathrm{in}$., and are so fine that one is pricked by them before one can see them. A few urchins, such as Asthenosoma urens, have poison-glands attached to their spines. On the other hand, the large spines of the Piper appear to be very small protection against its natural enemies, fish and star-fish; it is only the small spines that have any defensive value, and they are placed for this purpose near the main openings and organs of the body. Some sea-urchins cover themselves with dead shells, sea-weed, and similar objects, which they hold on by their tube-feet and so move about unobserved. Other sea-urchins do not move about but live in holes in the rocks, which in some cases they can be proved to have bored for themselves. The sea-urchins here figured have a rigid test; but there are others in which the plates are not so closely joined together, and the test is flexible. Fossil examples of such leathery urchins

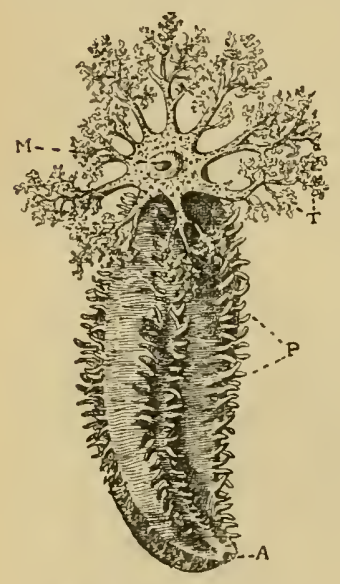

Fig. 9.-A SeA-CUCEMBrR

(Cucumaria planci). Natural size. have long been known from the Chalk, but were not found in the living state before the dredging expedition of the Porcupine. The regular seaurchins breathe by ten thin-walled extensions of the body-cavity which are protruded around the mouth. In the irregular urchins some of the tube-feet are modified for respiration.

Sea-urchins live on both animal and vegetable food, and even on one another. They themselves are often eaten by fish, and some are thought delicacies by man. The ovaries, when in the spring they are full of eggs, are said to equal the best fish-roe.

\section{Holothurolnea (Sea-cucumbers).}

A typical example of the sea-cucumber, Cucumaria planci, is represented in Fig. 9. The body, as already said, is elongated, with a mouth (M) at one end, and an anus (A) at the other. Around the mouth is a fringe of branched tentacles connected with the water-vascular ring. Two of these tentacles, those in the direction of the letter $\mathbf{M}$, are shorter than the others. Five rows of tube-

feet pass from the mouth to the anus, and under them lie radially-disposed nerves and muscles. In no holothurian, however, does the radial arrange- 
ment affect any portion of the digestive or generative systems. In most other echinoderms, it will be remembered, a canal passes from the watervascular ring, and opens to the exterior by a madreporite. In a few holothurians of primitive structure this is similarly the case, but in Cucumaria, as in most, the connection with the exterior is lost, and the canal with its madreporite hangs down into the body-cavity. The skin is leathery, and contains a comparatively small amount of calcareous matter. What there is occurs usually in small spicules, which assume very definite shapes, such as anchors in Symapta, or wheels in Chiridota. Such spicules are represented

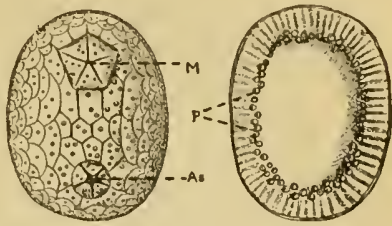

Fig. 10.-Plated Ifolotuurian (Psolus diomediae). 3-2 natural size. in Fig. 11 ( $\mathrm{S}^{1}$ and $\mathrm{S}^{2}$ ). In such forms as Psolus, however (Fig. 10), the spicules increase in size so as to form a plated integument; there may also often be a ring of calcareous

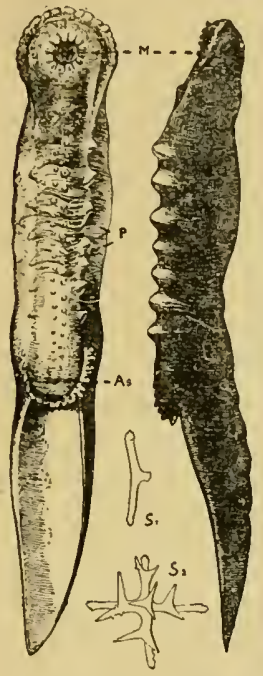

Fig. 11. - DERP.SFA HoLO. TIILRIAN (Psychropotes raripes). Two - ninths natural size. plates round the gullet and round the snus (M and As in Fig. 10). The tentacles of Cucumaria and some other forms are used like a net to intercept floating organisms in the surrounding water. Many holothurians take a good deal of sand into the gut and the intestines; those that live near coral reefs generally contain fragments of coral. They usually attach themselves by their tube-feet to rocks or seaweed, and wave the tentacles around. The foodladen tentacles are thrust one after the other into the circular mouth. Some curious modifications of form have taken place among the Holothuroidea. In Psolus the animal has become flattened, and the tube-feet restricted to three out of the five ambulacra, and by these three the animal creeps about or holds itself fixed to the rock. The species shown in Fig. 10 is one of those that were dredged by the U.S. steamer $A l$ batross, and occurs near the Cocos Islands at a depth of 66 fathoms, adhering to the rocks like a limpet. It represents a highly specialised form of the genus.

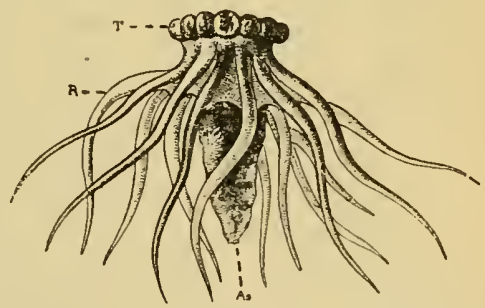

Fig. 12.-A Free-Swimmixg Holctherian (Pelugothuria natatrix). Ose-half natural size.

The tube-feet (P) are seen on its under side, forming a somewhat irregular ring. The curious form, Psychropotes raripes, shown in Fig. 11, is one of the deep-sea forms known as Elasipoda. It also was dredged by the Albatross, and comes from a depth of 1,573 fathoms, south of Cape Sin Francisco. The left-hand figure shors the under side of it, with the mouth 
(II) at the anterior end, and the anus (As) at the posterior. The row of tube-feet passes down the middle of the under surface, between the mouth and anus. On either side of these tube-feet, and well seen in the side-view, is a row of podgy stumps, by which the animal moves as a centipede moves by its legs. Rehind the anus a part of the body is prolonged into a flat tail. These animals live on the ooze of the abyssal ocean, gorging themselves therewith. Some of the holothurians that live in the sand of the deep sea, by constantly keeping both mouth and anus above the surface of the mud, have had their bodies curved in U-fashion, and in one genus the two openings have come to lie close together at the top of a thick stalk, so that one may compare the animal to a conjuror's bottle with a divided mouth. A yet stranger modification of the holothurian type is the beautiful Pelagothuria, represented in Fig. 12; this lives in the East Pacific on the surface of the ocean. It has no calcareous spicules, and the longitudinal muscles are mostly changed into a jelly tissue. Around the mouth is a circlet of short tentacles $(\mathrm{T})$; and from these radiate thirteen to sixteen long feelers (R), the bases of which are united by a web forming a disc, by which the aninal swims in much the same way as a floating jellyfish. The rest of the body, with the

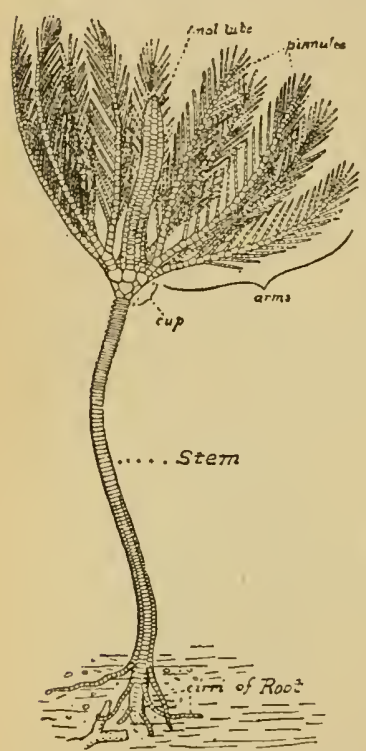

Fig. 13.-RESTORATION OF A FOSSIL Crinoid FroM THE WeNLOCK LINGsroNe (Botryocrinus decadactylis). Two-thirds natural size. anus (As) at the end of it, hangs vertically downwards. In life the semi-transparent body is tinged a purplish red.

Holothurians are of interest to men, especially Chinamen, as furnishing a food known as Trepang, which ranks with edible birds' nests among the delicacies of the celestial table. The fishing for this takes place in the East Indies and along the Barrier Reef of Australia. Only those species that have few calcareous spicules are of value for this purpose, while others are rejected because, when caught, they get rid of all their insides.

\section{Crinoidea (Sea-lilies).}

The echinoderms that we have hitherto discussed have all availed themselres, to a greater or less extent, of their power of free locomotion. The crinoids, on the other hand, together with the extinct blastoids and some of the cystids, are for the most part attached, either during youth or for the whole of their existence, to the sea-floor by means of a jointed stem (Fig. 13). The body of the crinoid, which is relatively small, is placed on the top of this stem, and from it there extend long arms which are usually branched and often provided with yet smaller branches regularly arranged along them, and called pinnules. Each of the pinnules, or each of the finer divisions of the arms, is provided on the upper side with a groove, carpeted by the minute rapidly waving processes known as cilia. These constantly drive a stream of water down the groove towards the main arm, which is provided with a similar groove. The water itself passes down the arms towards the body, and is then carried down fire similar groores, one leading from 
each arm to the mouth, which is placed at or near the centre of the upper surface of the body. The stream of water, containing numerous animalculae and food particles, passes through the mouth into the gut, which is coiled round the inside of the body, and passes out again at the anal opening. This latter is often raised on a small eminence or papilla (Fig. 15, As). In some forms, especially in some extinct genera, this papilla was extended into a long tube, so that the excrement was carried far away from the food-grooves of the arms (Fig. 13). Ranged along the sides of the food-grooves are the tube-feet, which, however, are not provided with suckers, but probably serve as respiratory processes. The small size of the body is perhaps to be accounted for by the fact that the generative glands do not develop within the body, but extend along the arms underneath the food-groove into the pinnules. Here the generative products become ripe and swell up the pinnules, from which they ultimately burst. The calcareous case that encloses the organs of the body is known as the calyx; it may be regarded as composed of a cup supported like a wine-glass on a stem, from the edges of which cup the arms originate; while it is covered by a lid in which are the openings for the mouth and anus. The licl is pierced by pores which put the water-vascular system in connection with the exterior. These may either be dispersed over the surface of the lid, or, as in other echinoderms, collected in one plate-the madreporite. This plate, when it exists, lies between the mouth and the anus. In the crinoids now living the cup is composed of only two or three circlets of plates, with no more plates than five in each circlet, and in many cases the two lower circlets are hardly to be distinguished. In some ancient crinoids, however, the organs of the body take up much more room, and to accommodate them the cup had an increase in size. This was effected, not by the plates becoming larger, but by the lid being, as it were, raised up the arms, so that the lower plates of the arms were included in the walls of the cup. At the same time, further plates were intercalated between the arms and their branches, binding them all into a plated integument, which looked like a tesselated pavement.

The stem is perhaps the most interesting part of the crinoid anatomy. All echinoderms, and many other animals, including, oddly enough, some which are generally reckoned by zoologists among the ancestors of the Vertebrata, have in their youngest stages a small process or lobe extending in front of the mouth, by which lobe they are accustomed to attach themselves as though by a sucker. In many cases the attachment lasts but a short period; but in the crinoids, at all events, it persists for some time, and the lobe becomes extended, while rings of calcareous substances are deposited in its integument. The increase of these rings in number and in size gradually produces a stem or column formed of superposed ossicles, perforated by a canal which is an extension of the original body-cavity. In the crinoids this canal contains extensions of bloodvessels and also of a sheath of nervous substance surrounding the blood-vessels. These extensions pass from a central five-chambered organ placed at the bottom of the cup, just at its junction with the stem. From this strands of the same nervous substance also pass in criss-cross fashion through all the plates of the cup, and finally join 
together and pass up the ossicles of the arms. These are motor nerves, and the central organ controls the movements of the arms, the stem, and all appendages of the crinoid.

Although crinoids are typically fixed by this stem, and although the ancestors, at least, of all crinoids have been fixed by such a stem, still there are some, both living and extinct, in which the stem has entirely or almost entirely disappeared, leaving the crinoid with powers of free locomotion. There are some four or fire living genera in which this has taken place; the most familiar instance is the rosy feather-star of our own seas, shown in Fig. 15. In its younger stages, however (see Fig. 14), the animal is provided with a stem. From this it ultimately breaks off, retaining but a few of the ossicles. These ossicles become fused together, and form a thick knob at the base of the cup. From this knob, which is called tha centrodorsal, there pass small branches called cirri (C, Fig. $15)$; by these cirri the animal can hold on to stones or other objects at the bottom of the sea, so that, although able to move at will, it can sare itself from being swept away by storms or currents. Fig. 15 slows one of these creatures in the act of crawling away from the stone to which it was attached. The arm towards the spectator is stretched out and slightly curved back, the pinnules at its extremity being bent right back like the barbs of a fish-hook. By these it will hook on to the rough surface of the sea-floor, and the arms will then bend and the animal be dragged along.

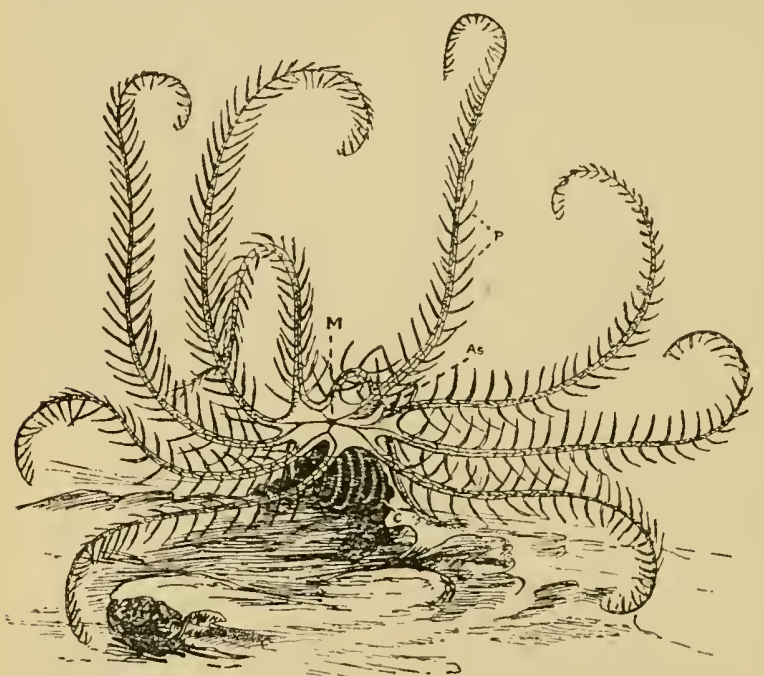

Fig. 15. -A Ftather-STar CRawlina (Antedon rosacea). Natural size. At the same time the opposite arms are bent downwards and their pinnules are pushed in the opposite direction. This shortening of the stem and power of locomotion has heen a gradual development. The Pentacrini, which are among the commonest of living stalked crinoids, have their stem beset at intervals with whorls of cirri. The joints of the stem just below each whorl are not muscular, but brittle, so that the crinoid

can easily break its stem at those joints, and after moving away a short space, can again affix itself by the whorl of cirri remaining at the hruken end. In this way Pentacrini have been found attached to telegraph orbles but a short time after they had been laid down. 


\section{SUB-KINGDOM VI.--BRYOZOA \\ [OR POLYZOA].}

\section{OSS ANIMAIS.}

By R. KIRKPATRICK.

If the sea-weeds and shells cast up on the sea-shore be carefuliy examined, some of these objects will probably be found orergrown by encrustations and patches, which, viewed through a lens, resemble fine lacework or tracery of varying pattern. Probably, also, some of the supposed sea-weeds themselves will, on closer inspection, prove to be wholly different from plants, and to

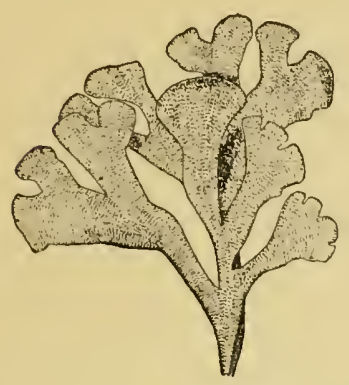

Fig. 1,-Flestra Foliacra.

be, in fact, Bryozoa. One of the commonest of these plant-like animals is the Sea Mat or Broadleaved Hornwrack (Fllustra foliacea), (Fig. 1), found all round the shores of Great Britain, growing in shallow water, attached to shells and rocks. It is often found in abun. dance amongst the seaweeds cast up on shore, especially after a gale.

The Sea Mat forms thin brown strap-shaped or fanshaped fronds, expanding upwards from a flat, narrow stem to a height of four to six inches, and branching in one plane. A very fine reticulate pattern is visible on both surfaces. Under a low magnifying power this appearance (Fig. 2) is seen to be due to the raised margins of oblong boxes arranged in longitudinal rows; two spines rise from the margin on each side of the rounded and expanded upper end, and frequently a fifth spine between and above the lateral pairs. The front of each box is corered with a roof of membrane. On examining a fresh leaflet in sea-water, crowns of very slender tentacles will be seen to be extruded through the upper ends of the front of the boxes, a thin, horny, semi-circular lid being pushed up during the process; on the slightest alarm the ten-

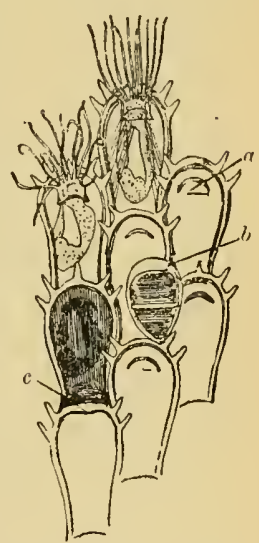

Fig. 2,-FLUETRA (magrifitd), showing polypicies. $a$, Horisy lid. $b$, Aricularium. c, Egg capsule. tacles are rapidly withdrawn. It is also possible to see a bent tube beneath the membranous roof. Each lox or cell (Fig. 2) is the home of a polypide, which has formed the cell. The tentacles of the polypide arise in a circle from a platform, in the centre of which is an orifice, the mouth. 
The circle of tentacles surmounts a conical proboscis, which, together with the tentacles, can be completely withdrawn into a sheath cavity, over which there falls a horny lid. The proboscis is merely a part of the cell wall, which always remains flexible and capable of being rolled in or out. The horny lid is a specialised fold of the wall, and is characteristic of the order of Bryozoa (Chilostomata, lip-mouthed) to which Flustra belongs. A glove-finger, with a hole in the top, surrounded by a crown of bristles to represent the mouth and tentacles, will convey an idea of the arrangement of the tentacular sheath; when the top is rolled in, a fold or lid must be supposed to fall over the cavity thus formed. The tentacles are hollow, and each is provided with a double row of cilia, by whose motion currents are set up, which converge to the

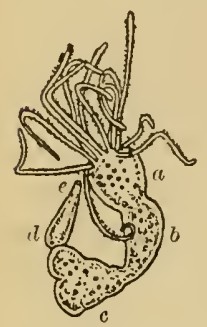

Fig. 3,-FLUSTRA. Polspide removed from cell.

a, Pharynx.

$b$ Gullet.

c Stomach.

$d$, Intestices.

e, Vent mouth. This opening leads into a pharynx and gullet (Fig. 3), and the latter opens into the stomach, which forms the bend of the bent tube; the stomach is continued into the intestine, which opens to the exterior outside the circle of tentacles. The U-shaped intestinal tract is suspended in the cavity of the cell, and is separated from the walls by a space filled with fluid and continued up into the interior of the tentacles; the latter organs thus hare a respiratory function, since the peri-visceral fluid is brought into close proximity to the sea-water. Further, the tentacles are sensory organs capable of perceiving tactile and, perhaps, other sensations. A nerve ganglion is situated at the upper end of the cell between the pharynx and intestine. In the walls of each cell are round sieve-like areas, through which the inner linings of adjacent cells become continuous, so that an organic and, perhaps, nervous continuity exists between all the cells of a colony.

Passing down from the stomach to the base of the cell is a cord, in which the eggs and male cells are formed. The fertilised eggs pass up to a hemispherical brood-chamber, which forms a hood orer the top of scme of the cells, and there develop into embryos, which swim away from the parent. The embryos are minute, nearly spherical, bodies, flattened at each pole, and with a broad zone of cilia round the equator. At one pole is the mouth and intestine, and at the other a flattened disk, wherewith the $6 \mathrm{mbryo}$, after a short free life, fixes itself, and gives 1 ise to the frst rolypide; the latter produces buds which develop, and in their turn prcduce other buds, with the result that a colony is formed.

Scattered over the surface of the frond, and interpolated among the ordinary cells, are small oval shallow cells with large thick lids; here the polypide has degenerated, and a muscular apparatus for opening and shutting the lid alone remains. The purpose served by the se modified cells is the retention of prey, and probably the motion of the lid also serves to frighten away undesirable intruders. In some species of Bryozoa these metamorphosed cells have an extraordinary resemblance to birds' beaks, and hence were named "avicularia" (avicula, a bird's beak), this name being applied to all such cases of metamorphosis, whatever the shape of the modified cell may be.

In all Bryozoa we find an approximately $U$-shaped intestinal tract contained in a sack or box. The mouth is either surrounded by a circular or horse. shos shaped crown of tentacles, or the area surrounding the mouth is drawn out into processes provided with tentacles, and the vent opening is on about 
the same level as the mouth opening. Further, all Bryozoa fexcepting the doubtful Phoronis) produce buds, which (excepting in Loxosoma) remain connected so as to form colonies. The colonies vary greatly in their composition, texture, and outward appearance. They may be stony, horny, and flexibls; gelatinous, fleshy, or like leather or paper. They may form crusts and patches, hard or flexiblo leaves, busliy or shrubby growths, stony nodules, branches or plates, shapeless fleshy masses, etc. In all, we have as the unit the polypide in its cell. Often the same species occurs as a crust, or in plates of single or double lamelle, the identity being revealed by the characters of the individual cells composing the colony. A few typical and interesting species will now be briefly referred to.

The Birds' Head Coralline (Bugula turbinata, Figs. 4, 5) forms brownish horny tufts about two inches in height; the branches, which are arranged spirally round the stem, are very slender. The

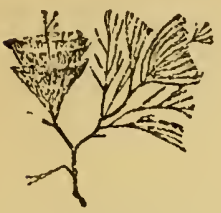

Fig. 4.-Evatua TurBINATA. cells are boat-shaped, and expand at the upper end. The upper three-fourths of the front surface is mem. branous, the rest of the cell being composed of hard, horny material. At the upper part of the membranous area is the lid, which is pushed up when the tentacles are extruded. The animal owes its popular name to the remarkable avicularia which arise from the edges of the cells; these organs consist of a short stalk, a curved head and beak, and a horny mandible. The " head" is filled with powerful muscles, which keep the mandible continually snapping, the whole presenting a ludicrous resemblance to a bird's beak (Fig. 5).

In the Creeping Coralline (Scrupocellaric reptans) a further modification of the cell is seen. At the back of each ordinary cell is a very minute tubular cell known as a vibraculum (bristle cell), with a cleft at the top in which a long fine bristle is hinged. Sometimes the bristles are all kept moving together like oars, or, again, individual bristles may sweep round the front of the cells to clear away debris or frighten trespassers. The cell and its contained polypide are here reduced to a tubular cell and muscular apparatus, while the lid of the ordinary cell has become lengthened out and changed into a bristle.

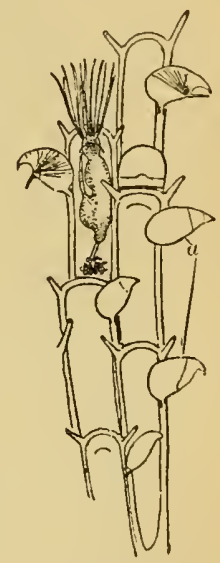

Fig. 5.-BugLLA (magnificd). $\alpha$, Avicularia.

Bryozoa are perhaps most commonly met with in the form of crusts and patches on stones, shells, and sea-weeds. The Lepralia of Pallas (Lepralia pallasiana (Figs. 6, 7) forms circular reddish-white or vitreous patches on shells, etc. The cells are

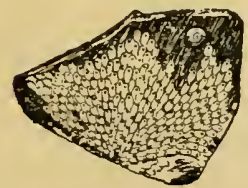

Fig. 6.-LERRALIA PAL. LASIANA (encrusting \& shell). arranged in radiating lines, each cell being a stony box with a punctured pattern on the front surface. At the outer end of the front surface is a square aperture, surrounded by an elevated rim and closed by a horny lid. One of the cells in the figure shows a lid partly pushed up by the tentacles of the polypide in the interior.

All the species hitherto referred to belong to the order Chilostomata (lip-mouthed), which is characterised by 
the presence of the horny lid covering the tentacle sheath. A second order, the Cyclostomata (circular-mouthed), commonly form white circular or fanshaped stony crusts, plates, or branches, the component cells being tubular, and without horny lids. The tubes are frequently arranged in single or double rows. In a third order, the Ctenostomata (comb-mouthed), the colonies are horny or fleshy, never stony. When the tentacles are extruded, a comb-like circle of fine bristles is seen arising from the proboscis near the base of the tentacles; when the tentacles are retracted the bristles form a kind of operculum. The gelatinous Alcyonidium, so called from its resemblance to the zoophyte Alcyonium ("dead men's fingers"), forms fleshy nasses or long cylindrical branches. The polyps, which are embedded near the surface, extrude their tentacles when undisturbed. The Nit Coralline (Amathia lendigera) forms little dark brown bushy tufts, the

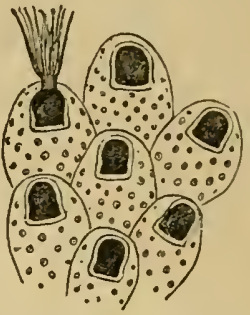

Fig. 7.-Leprala PaL. LASIANA (magnified). cells being arranged on the branches in double rows of small horny cylinders like I'an's-pipes.

The three orders above mentioned are included in one group, the

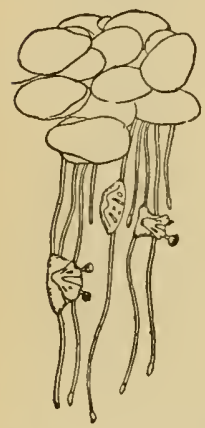

Fig. 8.-LOFIIOPUS CRYsTALLINES ON DCCK. W'EED. Infundibulata (infundibulum, a funnel), in which the tentacles form a funnel-like circle round the mouth. The rest of the Bryozoa are included under the group Lophopoda (crest foot), in which the tentacles are arranged in a horse-shoe shaped zone round the mouth. Nearly all the fresh-water Bryozoa belong to this group. Lophopus crystallinus (Figs. 8,9) is found in the form of little jelly-like blobs on the stems of Duck-weed (Fig. 8). The polypides can be seen as yellowish red streaks in the interior of a blob; when the horse-shoe plumes of tantacles are expanded the animal presents a beautiful appearance. Lophopus and other fresh-water Bryozoa commonly propagate themselves by means of peculiar internal buds, termed "statoblasts" (Fig. 10), which arise in the cord passing from the stomach to the base of the cell.

In Lophopus each statoblast is a flat, elliptical, seed-like body about ${ }_{70}$ in. in diameter, pointed at each end, and with a dark-brown oval centre surrounded by a broad band with a reticulate pattern. In the autumn the central part opens like a watch, and a young polypide half emerges and forms the nucleus of a colony. The remarkable Cristatella mucedo forms pale-green worm-like colonies averaging about an inch in length and one-sixth of an inch in breadth; the animal

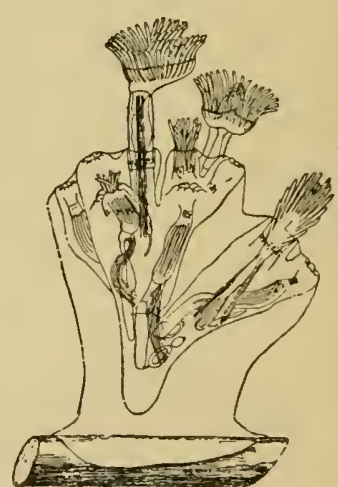

Fig. 0.-Lophorts (nagnificd) creeps about on the stems of rater weeds. The polypides are arranged in 
three concentric series on the upper convex surface, the lower flat surface, on which the colony moves along, being devoid of polyps. The statoblasts are provided with a double circle of long slender spines, ending in recurved hooks. Alcyonella fungusc is a species commonly found in streams and ponds in the form of brown clumps and nodules on tloating timber, stems, sticks, etc.

In the Pedicellinidie, which are mostly marine, tho polypides are stalked, the stalks arising from a creeping stolon; the tentacles, which form an almost complete circle round the mouth, are not capable of being retracted into a sheath. In the aberrant genus, Rhabdopleurc, the platform round the mouth is drawn out into two long tentacle-bearing arms. In Cephalodiscus, dredged up in the Straits of Magellan by the Challenger, the oral platform is drawn out into twelve processes-six on each side, armed with plumes of tentacles; the colony, which resembles a branching, spiny, gelatinous sea-weed, is permeated by canals along which the polypides can wander freely. In most of the Lophopoda a lobe projects over the mouth; the presence or absence of this character was made use of by Allman for the purpose of classifying Bryozoa into two groups -Phylactoliemata (guarded throat) and Gymnoliemata (unprotected throat).

The Bryozoa are found in the Palaeozoic rocks, and occur in great abundance in the Chalk, the Cyclostomatous group prevailing in the earlier formations. A classitication is here

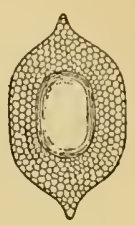

Fig. 10. -

StATOBLAST OF LOPHOPL'S (magnified). appended for reference :-

Sub-class I.-Infundibulata - with a circle of tentacles. a, Chilostomatawith a horny lid shutting down over the tentacle sheath (Flustra, Bugula, Lepralia, etc.). b, Cyclostomata-all calcareous; without a horny lid; without avicularia (Crisia, Tubulipora). $c$, Ctenostomatawith a circle of bristles forming a kind of operculum; never calcareous (Amathia, Alcyonidium, etc.).

Sub-class II.-Lophopoda-with horse-shoe shaped plume of tentacles or arm-like processes bearing tentacles (Alcyonella, Pedicellina, etc.).

[Note.-The name Polyzoa is often used by English zoologists in place of Bryozoa, but the latter term, definitely employed as a class name by Ehrenberg in 1834, apparently has greater claims to acceptance. Bibliography - Johnston's "British Zoophytes ;" Hincks' "British Marine Polyzoa;" Allman's "Fresh-water Polyzoa;" "Encyclopæedia Britannica," Polyzoa (Lankester). 


\section{SUB-KINGDOM VII.-VERMES.}

\section{THE WORMS.}

BI R. I. Pocock.

To give a concise diagnosis of the Vermes is a matter of no small difficulty, for the different classes that are discussed in this chapter are merely grouped together for the sake of convenience, since they present few features in common to justify their association, apart, that is, from the negative fact that they do not possess the characters by which the rest of the sub-kingdoms may be recognised. From the Echinoderms (star-fish, sea-urchins, etc.) and Coolenterates (corals, jelly-fish), for example, they may be distinguished by being bi-laterally and not radially symmetrical; bi-laterally symmetrical animals being those in which the right and left halves of the body are alike. From the Arthropoda (insects, spiders, etc.) they may be recognised by the absence of jointed limbs and of limbs modified to act as jaws; from the Chordata (Vertebrates and Ascidians) by the absence of the cartilaginous dorsal chord (notochord) and of slits in the walls of the gullet; and from the Mollusca (srails, cuttle-fish, mussels) by the absence of the gland for producing the shell, and of the muscular foot, which subserves locomotion. In addition, however, to these negative features, it may be said that the body is soft, usually long, and often jointed; the alimentary canal, when present, usually traverses it from end to end; but in the lowest forms it has no posterior outlet, and in some of the parasitic species has entirely disappeared. In the simpler types the nervous system consists of two chords, one running along each side of the body, and uniting in the head to form the brain, which is placed just above the gullet. But in the higher groups these chords are united throughout their length, and form a double chain, traversing the body from end to end beneath the alimentary canal. In the higher forms, again, there is a highly developed circulatory system, consisting of longitudinal and transverse vessels, but no such organs have been observed in the less highly organised types. Very characteristic, too, of all the classes are the excretory vessels, consisting of tubes that open to the exterior, and at their inner end communicate with the body cavity.

A bond of union, however, between some of the classes, which in the adult stages are very dissimilar, may perhaps be sought in the similarity that is observable in their larval forms. For example, in the groups known as Polychreta, Gephyrea, Nemertinea, and Turbellaria, in addition to some others of less importance and extent, the young is an active larva furnished with cilia, or vibratile hairs, arranged in one or more definite belts around the body, by the movement of which it is enabled to swim freely through the water. These groups would thus seem to have at least a common startingpoint in development, from which they have diverged in different directions. 
But too much stress must not be laid upon this circumstance, seeing that other marine groups of invertebrated animals, like the Mollusca and Hemichordata, may also be developed from ciliated larva not very different in structure from those that are met with in the Vermes.

The Vermes may be divided into the following six classes :-1. Annelidi (earthworms, leeches, etc.); 2. Gephyrea ; 3. Nematohelminthes (threadworms); 4 . Rotifera (wheel-animalcules); 5 . Nemertinea; 6 . Platyhelminthes (flat-worms).

\section{THE RINGED WORMS.}

\section{Class Annelida.}

To this class belong those highly specialised worms whose organisation has been briefly referred to above. The body consists of a series of rings or segments, each of which is substantially similar to the one behind and the one in front of it. The alimentary canal traverses the body from end to end, and beneath it lies the nerve-chord, consisting of a double thread united in each segment to form a ganglion or swelling, and connected in front with the brain, one of the threads passing on each side of the osophagus. Each segment, too, typically contains a pair of excretory tubes or nephridia, and the circulatory system consists of longitudinal vessels, connected by transverse branches. The most highly organised members of this class, namely, the Chretopoda, are structurally not very far removed from the Arthropoda (crustaceans, insects, centipedes, etc.). The chief distinctions between the two groups are, however, three in number. In all the Arthropods, except Peripatus, the legs are jointed, and at least one pair of them has become modified to act as jaws. But in the Chretopoda, although there may be distinct leg-like processes, these are never jointed, and the jaws, when present, are merely horny teeth developed in the mouth. Again, in the Arthropods the walls of the heart, or dorsal blood-vessel, are perforated by slits, by means of which the blood makes its way back to that organ, whereas no such slits are present in the corresponding blood-vessels in the Annelids. The Annelida are divisible into the Chæтородa and Hirudinea.

The Bristle-Footed Worirs-Sub-Class Chatopoda.-At the head of the Vermes stand the species known as the Bristle-Footed Wornis or Chætopoda, which in many details of their organisation approach the Arthropoda. For example, in the typical members of the class the body consists of a series of approximately similar segments, each of which is furnished at the sides with two rows of bristles, and very often with limblike prominences, known as a parapodia. There is a distinct head, bearing above the mouth, a prostomium or kind of enlarged upper lip, and often furnished in addition with one or more pairs of tentacles. The alimentary canal traverses the body from end to end; and beneath it lies the double nerve chord, which is in front connected with the brain, placed in the head above the mouth.

Leaving aside for the moment some of the less important types, the Chrtopoda may be said to fall into two orders, known as the Polychata and the OLIGoch жta.

The Polychæta have a conspicuous head, usually bearing feelers and gills, and the segments of the body are furnished at the sides with limb-like processes, usually supplied with a rich armature of bristles. 
Nearly all the species are marine, and many of them are of considerable size and great beauty. According to structure and mode of life, they are divided into two sub-orders-(1) the Sedentaria or Tubicola and (2) the

\section{Errantia.}

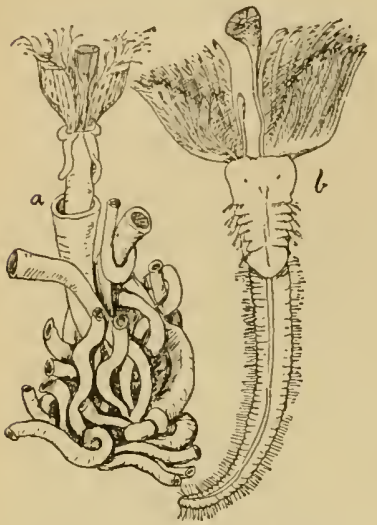

Fig. 1.-TUBE.MAKING AxNeLid (Serpula contortuplicala).

$a$, Group of tubes with norm proirudirg.

$b$, Worm remcied from tube.

The typical membars of the Sedentaria live in tubes of sand, mud, or pieces of shell glued together by the slimy secretion of their skins, or composed of a dense, shelly, chalk-like substance. The worm known as Terebella constructs a dwelling-place of the former kind, gathering together the particles by means of long flexible tentacles placed on its head; while tubes of cement are built by such forms as Serpula and Spirorbis. Tho latter is the maker of those tubes so much resembling a snail-shell, which are common on our coasts ; while Serpula makes the long, sinuous, serpent-like tubes which may be often found in interlacing clusters encrusting stones and shells of various kinds. When undisturbed these worms may be seen protruding from their tubes and waving in the water their gills and tentacles, which are affixed to the head, but upon the slightest alarm they shoot back like a flash out of harm's way, and remain securely concealed within their homes until the danger is overpast. To render it-

self still safer within its retreat, the worm called Serpula has one of its tentacles transformed into a veritable stopper, which exactly fits the mouth of the tube and completely closes it up when the worm has withdrawn itself.

Although differing from the Serpula and Terebella, and approaching the Errant Polychrta in many characters, the conmon Sand-worm or Lug-worm (Arenicola marina), so much sought for on our coasts as bait, also belongs to the group of Sedentaria. In this species the gills are represented by plumes situated on the middle segments of the body. At low water on the sandy shores of northern Europe the Lug-worm may be found at times in great quantities, the position of its burrows being easily detected by the little heaps of sand that accumulate at the entrance. For, like the Earth-worm, the Lug-worm swallows large quantities of sand, in order to extract for its nourishment any organic matter it may contain; and it ccmes to the suiface to unburden its body of the sand that has passed through it.

To the section Errantia belong the most highly-organised species of the class. They lead a free predatory life, wandering hither and thither in search of food, which consists almost exclusively of animals more defenceless 
than themselves. For this purpose they are fitted with organs of locomotion in the furm of prominent limb-like, bristle-bearing, processes (parapodia); the conspicuous head is supplied with tentacles of various kinds, and generally with ejes, while the gullet, which is protrusible, is armed with horny teeth. Many of these worms are of large size and are composed of a long series of segments, a species, for example, named Linnice gigantea, is said to have over 400 of them, and to be upwards of four feet in length. But one of the commonest furms upon our coast, known as the Sea mouse (Aphrodite aculeata), is a very different looking animal, with a short, broad, nore or less oval body, convex above and that below, like that of a Slug. Its sides are ormamented with the most beautifully iridescent hairs, and with barbed retractile spines, which serve as a protection against carnivorous fish or other enemies.

An interesting feature connected with some of these Bristle-worms, is that their method of development takics place by means of what is called an alternation of generations. In Autolytus, one of the Syllidie, for example, the worm that is hatched from the egg and grows to maturity is a neuter, and is consequently quite incapable of reproducing its kind in the ordinary way. But the difficulty is over-

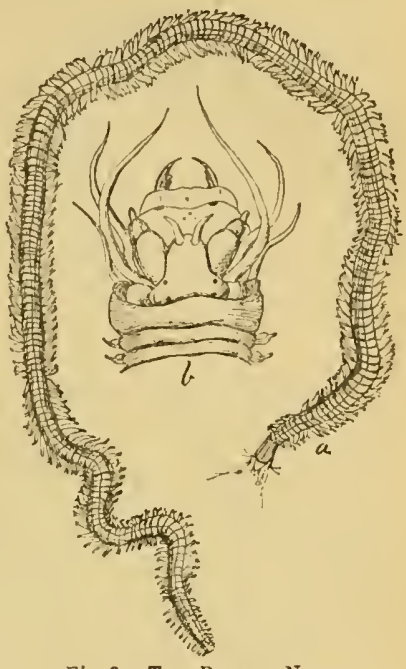

Fig, 3.-The Pearly Nereis (Nere is margaritacen).

$a$, Entire worm.

$b$, Head with jaws, fcelers, and eyes.

come by the formation of a new worm, the hinder end of the old one breaking off and turning either into a male or a female. In some cases more than one individual is product at a time by this process of division, so that before they sever thenselves from the parent stock a regular chain of worms is forn.ed. In another nember of this family, namely, the Branched Syllis (Syllis ramosa), which lives in certain sponges, new individuals are produced as lateral branches, as well as one behind the other. Very exceptionally in the Polychieta the young are born alive. In the majority of cases the eggs giverise to a free swimming larva, the Trochophore or Trochosphere, characterised by the presence of one or more belts of long vibratile cilia encircling the body. According to the number and disposition of these belts the larra have beell named; those that possess several of them being known, for example, as Pulytrochous. Sometimes there is but one belt, which may bo in the middle of the body (Mesotrochons), or in front of the mouth (Monotrochous), while not infrequently the Monotrochous larva has a second belt surrounding its posterior end, when it is known as Telotrochous. Sometimes, again, there is no definite belt (Atrochons), the larva being uniformly covered with short cilia, bearing, in addition, a special tuft of them at the front end of the body. Somewhat sinilar larro are found in other groups of Termes, and are of special interest, as showing possible relationship between them and the Annelida.

The second order of Bristle-footed worms is named Oligochata, on account 
of the relatively poor development of the armature of bristles as compared with the Polychata. In otler respects they are less highly organised, as is shown by the absence of tentacles and gills and teeth, and by the fact that the sexes are united in one individual. The best-known members of this order are the familiar earth-worms, belonging to the families Lumbricidce, etc. Most people are probably of opinion that but one species of this animal occurs in Great Britain; but, as a matter of fact, there are about twenty belonging to three distinct genera. Another popular belief connected with them is, that if a couple of specimens be cut in two, and the head end of one be applied to the tail end of the other, the two parts will grow together and form a complete individual. In fact, the curious swelling which may be observed in the fore part of the body of a full-grown worm is often regarded as the point of union of two such separate pieces. As a matter of fact, this swelling, called the clitellum or cingulum, is an organ used in the formation of the cocoons in which the eggs are laid.

Although occasionally seen on the surface of the ground during the daytime, Earth-worms are for the most part strictly nocturnal and subterranean, burrowing into the soil in all directions, and devouring any animal or vegetable refuse it may contain. In connection with food they swallow large quantities of earth, and when this has passed through their bodies, it is voided at the surface of the ground, forning the so-called vegetable mould. During spells of dry weather they bury themselves deep in the earth in search of moisture, without which life is an impossibility; and in the winter months they descend to the lower lajers of the soil so as to be out of reach of the frost. These animals are subjected to ruthless persecution at the hands of farmers and gardeners on account of their propensity for pulling shoots of young corn and blades of grass beneath

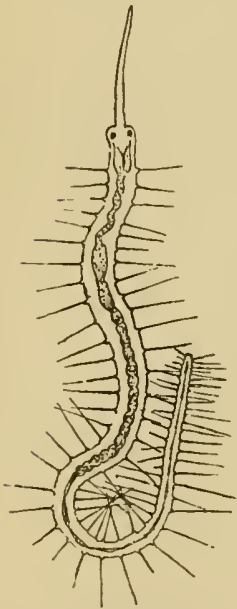

Fij. 4.-SxotTED NA:s

(Jais proboscidea). the surface. But it is doubtful if the harm done in this respect is not more than counteracted by the benefit that plants derive from the ceaseless tunnelling of the soil, the loosening of its particles, and the porterage of the lower layers to the surface, to be deposited as castings. In fact, so extensively is this work carried on by earth worms, that $\mathrm{Mr}$. Darwin has compared their action to that of a plough, and adds that it is doubtful whether many other animals have played so important a part in the history of the world. Earth-worms are found in all parts of the world in spots suitable for their existence, and in some countries they reach an enormous length as compared with the common species with which we are familiar. In South Africa, for instance, there is a species called Microchceta $R a p p i$, which attains a length of about five feet. It is, however, by no means frequently seen, rarely appearing on the surface, and then only after heavy rains.

Other worms, however, besides the earth-worms, belong to the Oligochreta. Many representatives of this group lire in fresh water streams and ditches, as well as in the sea. For example, the common Tubifi $x$ rivulorum, a long, slender, reddish worm, may be found in quantities in the muddy bottom of ponds, where it constructs long tubular burrows. When undisturbed it has the peculiar 
habit of projecting the hinder part of its body from its burrow and waving it incessantly in the water. But one of the best known of these aquatic worms is the species called Nais proboscidea, which has long hair-like bristles jutting out from the sides of its body, and a proboscis-like feeler projecting from the forepart of its head. This worm may be regarded as more highly organised than the earth-worm, as is indicated by the presence of a couple of eyes upon its head. Like some of the Polychieta, too, it possesses the power of reproducing by fission. Between two of the segments in the posterior half of the body a mass of tissue appears, and from the front part of this a new tail is formed for the original piece bearing the head, while from its hinder part a new head develops for the part that was primarily the tail-end of the parent form. It not infrequently hapuens that several new worms start almost contemporaneously in this way one behind the other, and before the severance between them is effected, they appear as a chain of individuals, exactly as described above in the case of Autolytus, one of the Polychata.

In addition to the Polychreta and Oligochreta a third group, called Archiannelida, is now referred to the Chretopoda, in spite of the fact that the integument bears no bristles, and the only external signs of segmentation are shallow grooves in the skin and serially arranged rows of cilia (fine hairs). The head is furnished with tentacles, but there are no parapodia. This group, lying in some respects midway between the Chretopoda and the Flatworms of the sub-class Turbellaria, contains several marine forms, of which the best known are Protodrilus and Polygordius. The young of the Archiannelida are developed from Trochophore larra of the type known as Telotrochous (see p. 673).

Usually now regarded as aberrant members of the class Chxtopoda are the remarkable species belonging to the genus $M y \sim o s t c m a$, of the family Myzostomida. These degraded creatures live parasitically upon the Sealilies (Crinoidea), their preserce giving rise to tumours or various irregularities of growth. The body is oval and flattened and unsegmented, and its margins are produced into a number of short, prehensile filaments; while on the lower surface near the edge are four pairs of suckers, and on the imner side of these five pairs of conical, foot-like processes, each of which is provided with a pair of retractile bristles. But in spite of the anomalous structure of the adult, these parasites are developed from free-swimming larvie furnished with ciliated bands, and calling to mind the Trochophore of the Annelida.

The Leeches-Sub-Class Hirudinea. - The Leeches, or Hirudinea (Latin, hivudo, a leech), sometimes called the Discophora (disc-bearers), on account of the suckers with which they are furnished, are not unlike earth-worms in general appearance, and also in many points of structure. The integument is divided by shallow transverse grooves into a multitude of rings, a varying number of which (five to three) correspond to each true segment of the body. There are no bristles nor organs of locomotion in the form of parapodia, movement from one spot to another being effected by means of swinming or by crawling, with the aid of the suckers, after the manner of the "looper" caterpillars. There is always a large sucker situated at the hinder end of the body, and usually a second at the opposite extrenity, with the mouth placed in its centre.

The Leeches are divisible into two families-the Gnathobdellide, or jaw. 
bearing species, and the Khynchoudellidu, or proboscis-bearing species. Of the Gnathobdellide, the medicinal leech (Hirudo medicinalis) is a well-known example. This animal is usually of a blackish colour, and ornamented witl longitudinal bands of yellow spots. It is somewhat scarce in England, and in the days when blood-letting was extensively practised by doctors the demand for it was met by the importation of large quantities from the Continent, where it is not only more abundant than with us, but was artificially cultivated on a large scale in especially-constructed tanks. The power of these animals to pierce the skin and draw blood, upon which their value as blood-letters depends, is due to the presence in the mouth of three semi-circular jaws, each of which is studded with a series of minute horny teeth. By means of a set of powerful muscles these jaws are capable of being worked backwards and forwards after the manner of a saw, while by aid of the sucker, the mouth is kept closely applied to the wounded spot and the blood is drawn into the worm's stomach. This is a capacious sac, consisting of no fewer than eleven pairs of pouches, capable of considerable distention, and occupying the greater part of the space between the walls of the body. When the leech has pumped itself full of blood, but not before, it relaxes its hold; and it has been aftirmed that the amount thus imbibed will be sufficient for a whole year.

In a natural state these leeches are found in ponds, marshes, or sluggish brooks with a bottom of mud or clay. Out of water they cannot live for any length of time, since they speedily succumb to

Fig. 5. - Mifdichial LeEch

(Hirudo medicinalis) the drying effects of the atmosphere. During the day, especially if the weather be rarm and bright, they may be seen swimming about with liveliness, but in cold or dark days and at night-time they lose their activity, and remain curled up with head and tail closely applied. In the autumn they bury themselves deep in the mud. Their food consists of the blood of fishes or aquatic amphibians, or of terrestrial vertebrates, that visit their haunts to bathe or drink. Like earth-worms, leeches are hermaphrodite, and after pairing in the spring they creep up the banks of the pond or ditch above the surface of the water and dig burrows in the soft damp soil, and in these, like the earth-worms again, they construct for the reception of their eggs elliptical cocoons, formed of a secretion from certain skin-glands, which afterwards hardens. Externally, the cocoons are covered with a layer of spongy material, while the inside is filled with albumen, in which the small eggs, usually about twenty in number, are embedded. When the eggs are hatched, the young float in the albumen, and obtain their nourishment from it. Upon quitting the cocoon after several weeks' residence therein, the young leeches resemble their parents in form, though they are not dark-coloured. Growth, howerer, is a slow process, maturity not being reached until five years have passed, and life enduring, under favourable conditions, for about twenty years.

A far commoner species in England than the medicinal leech is the so-called Horse-leech (Aulostomum gulo), which may be distinguished from the former by the absence of the bands of yellow spots, the skin being of a uniform 
greenish-black, and by the fact that its jaws are furnished with fewer and blunter teeth. This differenco of dentition is evidently correlated with the difference in the feeding habits of the two animals, the food of tho Horseleech, in spite of its name, consisting of such soft-bodied creatures as earthworms and snails.

It must not be supposed, however, that all leeches are inhabitants of fresh water. In many countries, indeed, especially in the tropics, land leeches are abundant, as many a traveller knows to his cost. They inhabit jungle and forest land, where the vegetation in the wet season is saturated with moisture; but in the dry season they entirely disappear, presumably burying themselves deep in the earth. According to the accounts of those who have had practical experience of them, these animals are a terrible plague. Gifted with the power of perceiving the presence of prey at some distance, they hasten towards it in crowds from all quarters, or collect in the lierbage bordering the forest paths, with head extended, ready to seize hold of any passing man or beast. To protect themselves from their attacks, Europeans are compelled to wear leather or closely-woven cloth gaiters, tied tightly round the knee, while the natives rub their bare legs with oil or lemon juice.

The leeches of the second family (the Rhynchobdellida) differ from those belonging to the Gnathobdellidie, that have been hitherto discussed, in having the front of the body furnished with a protrusible proboscis at the end of which the mouth is situated. To this family belongs the fresh water leech Clepsine. This animal is yellow, grey, or whitish in colour, occurs on the leaves of plants or on the lower side of stones, and feeds apparently upon water-snails and the young of fresh water mussels. The eggs, in number about 200, are not embedded in albumen as is the case in the medicinal leech, but are of larger size and contain their own food-yolk. They are laid in flattish cocoons which are attached to some stone or water-plant, and the leech curls itself round the cocoon to protect it. More.

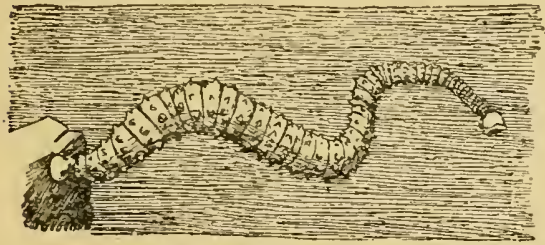

Fig. 6. - WARTY SKATE-LEECH (Pontobdella muricata). over, when the young are hatched, the mother still con. tinues to look after them, carry. ing them about with her attached to the lower surface of the body. Also belonging to this family is the Warty Sea-leech (Pontobdella muricata) which is common on our coasts, and may be readily recognised by its greenish grey colour, cylindrical body, and tough knobby integument. It is found mostly on fishes of the skate tribe, and hence is sometimes called the skate-sucker.

\section{THE GEPHYREAN WORMS.}

\section{Class Gephyrea.}

The worms of this class are all marine, and although more or less cylindrical in shape, show scarcely any traces of segmentation. The front of the body is furnished with a large proboscis, and the integument is covered with warts. 
The species fall into two well-marked orders known as the Cinatilera and the Achreta. The Chretifera, or bristle-bearing Gephyrea, show strong indications of aftinity with the Chrotopoda, and are by some authors considered to belong to that class. In the young the body is partially segmented, and in the adult is furnished below witl a pair of hooked bristles. The alinentary canal terminates at the hinder end of the body, and the proboscis, which is ciliated and often of enormous length as compared with the size of the animal, appears to be nothing but an enlargement of the prostomium or region in front of the mouth, the latter being situated at its base. The best-known members of the group are Bonellia, Echiurus, and Thalcessema. They are to

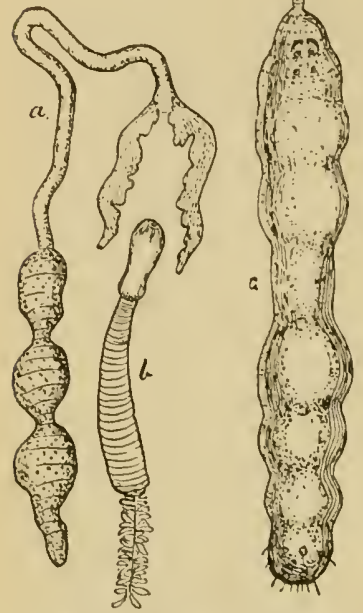

Fig. 7.-Gepuyrean Worms.

a, Bonellia viridis ( $x$ ith proboscis distended).

$b$ Priapulus caudatus.

c, Echiurus. be found at the bottom of the sea or beneath stones in pools, and appear to be gifted with but little activity.

The Achreta have no bristles, as their name indicates; there is no sign of segmentation at any period of life; the alimentary canal is twisted upon itself, and terminates in thic front half of the body; and the proboscis carries the mouth at its tip, and can be rctracted inside the body by muscles specially set apart for the purpose. In some of these worms -- in those, for example, known as Sipunculus, Phascolosoma, and Phymosomathe tip of the proboscis is furnished with a circlet of tentacles surrounding the mouth. These animals live on the sea-bottom in deserted univalve shells, closing up the mouth of the shell with sand grains cemented together with slime, but leaving an aperture just large enough to allow the extensiblc proboscis to be thrust in and out with ease. A British representative of this group is Sipunculus bernhardus. A still more curious form is Priapulus, found in deep water in the North Atlantic. This worm burrows in the sand, and is furnished with a stout probocis armed with horny teeth, but without the circlet of tentacles observable in Sipunculus.

In both groups of the Gephyrea occur ciliated larval forms which present a close resemblance to the Trochophore of the Polychreta.

\section{THE THREA D.W ORMS.}

\section{Class Nematohelminthes.}

As implied by their name, the worms of this class are mostly long, slender, and more or less thread-like. The body is usually pointed at both ends, and it presents at most but slight external indications of segmentation, and none of that serial repotition of internal organs which is so characteristic of the highly organised Annelida. The skin, moreover, instead of being furnished with bristles or the delicate hairs known as cilia, is protected by a smooth and relatively tough cuticle. In all the typical members there is a distinct 
alimentary canal traversing tho body nearly from end to end, and there is an excretory system, consisting of tubes lying lengthwise, which ccmmunicate with each other in the fore pat of the body and open upon its lower surface by a single pore. Tho sexes are generally distinct.

Although a large majority of the species of this class are parasitic, spending the whole or part of their lives within the bodies of othcr animals, a few, nevertheless, are to be found on plaits, on fresh water or damp eaith, or even in the sea. But amongst the parasitic forms we meet with species that are free during a part of their existence; that is to say, either during the immature stages of life or after maturity is attained. Such species as these thus show an interesting gradation in habit between those kinds that are wholly independent and those that live permanently in other organisms.

One of the best known of the free living species is the Vinegar or Paste. eel (Anguillula aceti), which feeds upon the minute fungi fcund growing in these substances. Allied fornis, known as Leptoder a and Pelodera, occur in water or damp earth; but, unless supplied with plenty of nitrogenous food in the form of decaying antmal or vegetable matter, they remain in the larval stage, a supply of food of this nature being necessary for the attainment of maturity.

Before passing to the most interesting members of this class, namely, those that are parasitic in animals, and especially in mankind, brief reference may be made to a couple of species which infest plants and are of considerable econonic importance on account of the damage done by their agency to corn crops and vegetables of the turnip kind. Adult examples of the Wheat-eel (Tylenchus tritici) attack developing ears of wheat, converting them into a kind of gall. Here the young are hatched, ultimately reaching the ground by the falling of the grain. They are then set free in the moist earth, and wander hither and thither in search of the young shoots of growing corn. If successful in their quest they ascend the stalks, and, finally reaching the summit, take up their abode in the blossom of the wheat; and, nourishing themselres upon it, arrive at maturity and then produce new generations. The second vegetable pest to be noticed is the Turnip Thread-worm (Heteroderc schachti), which gives rise to swellings on the roots of the sweet turnip or sugar-beet. These swellings are caused by the expansion of the female worm into a spherical body owing to the quantity of nourishment she absorbs. Here the eggs are laid, and after being retained for a time in a special brood-pouch, pass to the outer world, and undergo the first stages of their development. Subsequently the females bore their way into the turnip roots by means of a special instrument with which the throat is fitted fur the purpose.

Passing now to the species that live parasitically in other animals, we find the simplest life-history in such kinds as Ascaris lumbricoides and Oxyuris vermicularis, known to medical men respectively as the "round-worm " and the "thread-worm," and occurring not infrequently in the liuman intestine, especially during childhood. The eggs of these worms are discharged from tho alimentary canal of their host, and make their way back again through the mouth in connection with food or impure water. In addition to mankind, species of thread-worms allied to those just mentioned infest the intestines of horses, pigs, dogs, cats, and a variety of other animals.

In addition, however, to the alimentary canal, other organs of man are liable to the attacks of various Thread-worns. The Guinea or Medina-worm (Dracuiculus medinensis), for example, reaches maturity in the subcutaneous. 
tissue of man in the tropicsl countries of the Old World, measuring, when adult, many inches in length. It is usually extracted by being carefully wound round a small roller, an operation which often occupies several days. owing to the precautions that are taken not to fracture the animal. But if allowed to remain benesth the skin, the worm cficcts its escape to the outer world through the abscess to which its presence gives rise. 'Then the joung with which the females are laden make their way into fresh water streans or lakes, and falling in with minute water-fleas of the family Cyclopidæ, bore their way into the interior of these crustaceans, which are smallowed by mankind in connection with drinking-water; and so, by means of an intermediate host, the young Guinea-worms are introduced into their final place of abode. A similar transference of parasitic worms from one host to another is of common occurrence in this, as in ether, groups of entozoic rermes, and we meet with it again in another thread-worm (Filaria sanguinis-hominis) which, in various parts of the Old World, infests the blood system of man, giving rise, by the stoppage of the circulation in the small ressels, to the disease known as elephantiasis. In this case the embryos are sucked from the vascular system by mosquitoes or other suctorial diptera, and so become scattered abroad, making their way in all probability back again into the human body along with drinking water.

To the genera Gordius and Mermis belong the horse-hair worms, so named on account of their length, slenderness, and colour, which recall the form of a long hair from a horse's mane or tail. In Gordius, which is found in fresh water streams and ponds, the alimentary canal is functionless and the mouth closed. The eggs, deposited in clusters

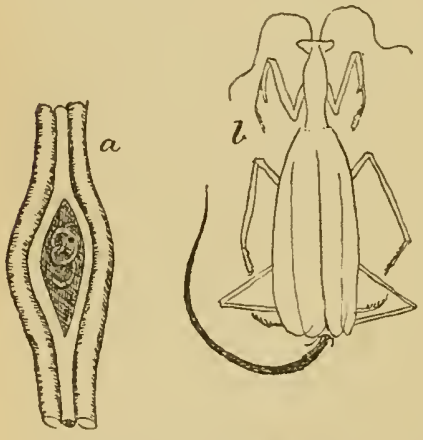

Fig. 8.-THREAD-TORMS,

a, Trichinosis-worm (Trichina spiralio) encysted in muscle.

$b$, Horse-hair worm (Gırdius) escaping from an insect (Muntis).

abode in abode in the bodies of caterpillars or other insects, whence, after a prolonged residence, they escape again to the ground, become mature, and lay their eggs.

The descriptions that have hitherto been given of the life-histories of the parasitic thread-worms deal with species which lead a free existence, at all events during a part of life. But the last of the species that we have 
space to notice is of special interest, not only on account of its being one of the most dangerous of parasitic worms to mankind, but also becauso it spends the whole of its existence within the bodies of two hosts, carrying the parasitic habit to a greater extreme than is met with elsowliero in the group. This is the worn called Trichine spiralis, which gives rise to the dreaded disease trichinosis. In the adult or sexually maturo stage this worm lires in the intestine of various carnivorous mammals, man being amongst tise number. But the minute young, which are born alive, instead of making their way to the outer world in connection with excrementitious matter, bore through the wall of their host's alimentary canal and entering the blood-stream are carried by the circulation to various parts of the body, ultimately coming to a standstill in the muscles. Here the little creatures begin to grow and form for themselves a protective capsule or cyst between the fibres of the muscular tissue. Neat infested with these encysted worms is said to be "trichinised" (Fig. $8, \alpha$ ). In this state the Trichinæ remain without attaining maturity until the meat in which they have taken up their abode is eaten by another animal, whereupon the action of the digestive juices of the new host, dissolving away the muscular fibres and the capsule, set free the worms, which in their new surroundings quickly become adult, and each female gives birth to thousands of new individuals. Man as a rule contracts "trichinosis" through eating "trichinised" pork in an underdone state. But, happily, since the discovery of the source of infection some fifty years ago, and the introduction of stringent laws against the sale of unhealthy pork, the disease has become far less common than in former times.

Usually classified with the thread-worms, though differing from them in the absence of mouth and alimentary canal, and in other anatomical details, are the parasitic-worms, known as Echinorhynchus, belonging to the group Acanthocephali. These two names-the former meaning "spiny-beaked" and the latter "thorny-headed" - refer to the presence on the worm's head of a retractile proboscis, armed with rows of backwardly directed hooks. The various species of Echinorhynchus are internal parasites, the mature stages being found in vertebrata of different kinds, and the immature stages in certain invertebrated animals. For example, a species known as Echinorhyn:hus gigas, which infests the alimentary canal of the pig, passes the earlier part of its life in the intestine of the larve of various kinds of chafers, such as the cock-chafer (Melolontha vulgaris) or the rose-chafer (Cetonia aurata). The migration from the one host to the other is effected in the following manner:-The enbryos of the worm, invested in a protective membrane, after passing out of the pig's alimentary canal in connection with excrementitious matter, are devoured by the beetle-larve along with their food. In the stomach of the new host the investing membrane becomes dissolved, and the worm; thereby set free, bores into the intestinal walls of the larre. These in turn are rooted up and swallowed by the pigs, and the young a, Echinorhynchus gigas. Echinorhynchi thus become transferred again into the $b$, sagitta bipunctata. 
alimentary canal of the animal from which they set out. The migrations of other species is substantially similar to that of $E$. gigas. For instance, $E$. polymorphus lives as a mature animal in the intestine of ducks or other water-fowl, while in the inmature stage it occurs in the little fresh-water crustacean (Gammarus pulex). This amphipod $(G$. pulex) is also, in conjunction with the fresh-water wood-louse (Asellus aqueticus), the intermediate host of two other species, $E$. angustatus and $E$. xroteus, which, when mature, infest the alimentary canal of fresh-water fish. Instances of the occurrence of worms of this group in mankind have been recolded, but, happily, such cases are rare.

Although, probably, more nearly related to the Thread-worms than to any other group in the animal kingdom, the Arrow-worm (Sagitta) presents so many peculiarities of organisation that its true systematic position is still a matter of doubt, and it forms the sole type of an order known as Chætognatha. This name, meaning "bristle-jawed," is given to it in allusion to the fact that the head is armed with a number of strong, movable, horny spikes which act as jaws. 'T he body is long, slender, and unsegmented, with a rounded, blunt head, bearing eyes, and a narrow-pointed tail; but the tip of the tail and the sides of the body in its hinder half are furnished with torizontallyprojecting fins (Fig. 9, b).

The Arrow-worms, so called from their arrow-like shape, are not parasitic like the Thread-worms, but are to be found swimming in numbers on the surface of the ocean in all parts of the world.

\section{THE WHEEL-ANIMALCULES.}

\section{Class Rotifera.}

The Rotifera, or "Wheel-animalcules," as they were formerly called, on account of the appearance in the water of a rapidly rotating wheel, to which the movement of the circlet of hairs on their heads gives rise, aro all small, aquatic animals, varying in length from $\frac{1}{8}$ to $\frac{1}{500}$ of an inch, and found universally in marine and fresh water, but most abundantly in stagnant pools.

The front end of the body is usually broader than the opposite extremity,

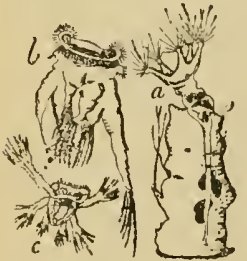

Fig. 10.-WInet-ANiMaLCULES.

a, Floccularia coronetta.

$b$, Fedalion mirum.

c, Hcxarthra polyptera (aiter Iludson). and is shaped like a disc, the trochal disc, which is fringed with long vibratile hairs or cilia. By means of the currents of water set up by the movement of these cilia, particles of food are swept into the mouth, a wide aperture placed in the middle or at the sides of the trochal disc. The mouth passes into the stomach, which is supplied with a complicated armature of teeth, and by means of these the food is crushed and divided. In the females the alimentary canal passes right through the body, but in the males, strange to say, it has ceased to be functional, and is reduced to a solid chord-like organ. Apart from the cilia of the trochal disc, the integument of the body is smooth, and the only signs of segmentation that it presents are a few weak wrinkles. The tail-end, or the foot, as it is called, varies considerably in structure according to the habits of the species. In some forms that are 
fixed (Floscularia), it ends in an adhesive disc or cup, and is not wrinkled nor retractile; but in most of the free-living species the foot is retractile within the body and terminates in a couple of nippers which serve to anchor the body in place. In other forms (Pedalion and Hexarthra), the body is provided with pairs of limb-like processes, ending in a fan-shaped tuft of cilia. These two are free-living forms, skipping through the water by means of their limbs and swimming by means of the ciliary wreath.

The habitat of the " Wheel-animalcules" is tolerably varied. They may bo found in ditches, gutters, ponds, and streams; sometimes attached to stems and laves of plants; sometimes creeping upon them; sometimes roving through the water. Some species, again, are parasitic. A species, for instance, named Drilophaga bucephala, holds by means of its jaws to a waterworm, Lumbriculus, and sucks the animal it clings to. Again, Callidina parasitica is always found adhering to the limbs of the fresh-water shrimp (Gammarus pulex), and merely creeps about the body of its lost. And lastly, the genus named Albertia furnishes an instance of internal parasitisn, its species, vermiculus, being found living in earth-worms and slugs.

The true position of the Wheel-animalcules amongst the Vermes is one of some doubt. But it is important to notice the resemblances that exist between them with their wreath of cilia and the Trochophore larva of the Polychætous Annelids.

\section{NEMERTINE WORMS.}

\section{Class Nemertinea.}

Although the members of this division are but little known to the ordinary public, many of them, so far as length is concerned, are the most striking of all Vermes. There is, however, a most astonishing difference in size between various species, for while some of those belonging to the genus Lineus may attain a length of several yards, the species of other genera are comparatively of quite insignificant dimensions. In other respects, however, there is a close similarity between the various members of the class, the structural characteristics of which may be briefly summarised as follows :The body is not segmented, and its integument is covered externally with cilia. At the front end a head-region may be distinguished by the presence of eyes and of a pair of ciliated pits, which are probably sense organs of some kind. On the lower side of the head opens the mouth, and this leads into a spacious alimentary canal which traverses the body from end to end. But in addition to the mouth, the head is also furnished with a second aperture, from which a retractile proboscis can be shot forth. This proboscis is one of the most characteristic features of the Nemertines. When retracted it rests in a special sheath lying along the back, above the alimentary canal, and reaching sometimes to the hinder end of the body. In this state the proboscis has been compared to the finger of a glove that has been turned outside in within the part that covers the hand, the latter representing the sheath ; but when protiuded, the organ is comfarable to the finger of the glove in its normal situation. This type of proboscis is of not uncommon occurrence in the Vermes, and from its method of protrusion and retraction is often called an "introvert." The nervous system consists of a pair of chords, one running along each side of the body and uniting at its fore end with the brain, which lies above the alimentary canal and beneath the 
proboscis-sheath-or rather round the pruboscis-sheath like a ring, for the right and left halves of the brain are joined together by a transverse band which passes above this sheath. The only other orgnns that need be noticed are the paired nephridia or excretory organs situated in the front part of the body and the thin blood-ressels, sometimes containing red blood, which lie just above and at the sides of the alimentary canal and unite at the anterior and posterior ends of the bedy.

In most Nemertines the sexes are distinct, and, as a rule, the young are produced from eggs that are deposited by the mother either singly or in gelatinous clusters; some forms, however, such as Monopora vivipara retain the eggs until the development is far advanced and the young are born alive.

In many species again, as in Lineus,

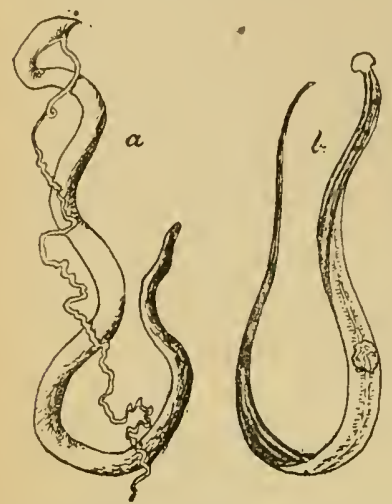

Fig. 11.

$a$, NEMERTINE WorM.-Linetcs marinus (with proboscis protruded).

$b$, Land Planarian (Bipalium keuense). the joung goes through a striking metamorphosis, the egg giving rise to a freeswimming ciliated larva known as the pilidium and consisting of an upper bell-shaped part, from the lower rim of which spring a pair of lobes. Within this larra the young Nemertine is gradually formed, and when sufficiently advanced to lead an independent life it breaks free from its pilidium-caso and deserts it. In other cases the development is less com. plicated, conditions in different species having been observed, which lead from the complete metamorphosis by means of the pilidium to the direct development of such species as Tetrastsmma and Malacobdella.

The class is usually divided into two orders, the Enopla and the Anopla, the difference between the two consisting in the presence of stylets on the proboscis in the former and their absence in the latter. To the Anopla belong such genera as Polia and Lineus, and to the Enopla or Hoplonemertinea, Malacobdella, Tetrastemma, and Geonemertes.

All Nemertines appear to be carnivorous, feeding upon annelids or other soft-bodied living organisms. The great majority of the species are marine, occurring for the most part amongst sea-weeds and coral rocks, in shallow water; a genus, however, called Pelagonemertes is found in the open sea. Of the marine forms Malacobdella, which was originally regarded as nearly allied to the Leeches, lives parasitically upon bivalved Mollusca of the genera Myce, Venus, and Cypridina. The genus Tetrastemma is interesting for the reason that some of its species are marine, some fresh water, and some terrestrial, one fresh-water species having been found in England, another (T. aquarum-dulcium) in North America; the two known land species being from Rodriguez $(T$. rodericanum) and the Bermudas ( $T$. agricola). The rest of the land species are furnished by the genus Geonemertes, which has a representative $(G$. australierisis) in Australia, another in New Zealand $(G$. novce-zelandice), a third in the Pelew Islands ( $G$. palaensis), and a fifth, which has probably been introduced, in Germany; all these land spccies are found in damp spots beneath logs, stones, etc. 


\section{FLAT-IVORMS.}

\section{Class Platyhelinnthes.}

Many of the worms of this division have been greatly modified by a parasitic life, have lost all trace of the mouth and alimentary canal, and in the case c $f$ the Tape-worms have acquired a rich segmentation of the body, which, as will be explained, is subservient to the process of reproduction; but the forms that lead a free existence, and may be looked upon as the primitive members of the elass, approach the Nemertines in many points of structure, though, on the whole, they are much less highly organised, there being no distinct vascular system, no dorsal proboscis and sheath, and the alinentary canal, when present, lias no posterior outlet.

The Plaxarian Worms-Sub-Class Turbellaria.-To this sub-class belong the free-living flat-worms alluded to above. The flattish unsegniented body is either short and broad or long and slender, and, as in the Nemertines, its integument is covered with cilia. The mouth, which varies much in position, being sometines placed at the front end of the body aud sometimes in the middle of its lower surface, leads into a muscular pharynx, and this usually passes into a spacious digestive tract, upon the structure of which the classification of the group is based. In the first section, named RHa BDocess , for example, the alimentary canal consists of a single undivided pouch. In the DExDROcELA, on the other hand, the stomach is branched, being divided into three (T'ricladida), or a very large number of branches (Polycladida), while in the section known as Acces there is no true intestine, the alimentary canal being merely represented by the mouth and the muscular pharynx or gullet which immediately follows it. In some cases, as represented in our figure of Bipalium kevense, one of the land Planarians, the pharynx is capable of protrusion through the aperture of the mouth, and of acting as a sucker. The nervous system is well developed, and consists of a bilobed mass or ganglion placed in the head, and from this a pair of widely-separated chords pass backwards to tho hinder end of the body, and others go to supply the head and eyes, of which there are sometimes many, though more usually only one or two pairs. Sometimes, too, ears of a simple kind are found.

The habitat of Planarian worms is tolerably varied, some species being found in the sea, others in fresh water, and others, again, on the land. Most of them are free living. A few, however, have taken to a parasitic life, two of the Rhabdocola, named Graffila and Anoplodium, occurring respectively upon Mollusea of the snail-kind and upon Sea-cucumbers, while Bdellura, a Trielad Dendrocol, lives on the king-crab. All the members of the Polyelad Dendrocols are marine, and in this group we meet with a metamorphosis in the development, the young Planarian, known as Miiller's larva, being furnished with eight ciliated processes arranged round the middle of its body. Thus equipped it leads a free life, circling about in the water. In other members of the elass the development takes place without the intervention of active larval forms. Usually the method of reproduction offers nothing worthy of special comment; but one of the Rhabdoccels, known as Microstoma, presents an alternation of generation such as has been deseribed in the case of some Annelids (e.g., Nereis). The hinder portion of the body becomes divided by a partition from the front portion; 
each part then again divides into two, the process being repeated until there may be as many as eight, sixteen, or thirty-two divisions. Each division acquires a mouth, and when each is sexually mature, the chain breaks up into a number of separate individuals, which lay eggs, these ultimately giving rise to sexless individuals, which can only reproduce by fission.

Many Planarians are elegantly coloured, presenting either a tolerably uniform rivid tint, or considerable diversity of pattern. Two species, namely, Vortex viridis and Convoluta schultiii, the former belonging to the RilABDOCGLA and the latter to the ACELA, are noteworthy in this connection as being coloured with chlorophyll, the material which imparts to plants their characteristic green tint, and which enables them under the influence of sunlight to break up carbonic acid gas into its constituent chemical elements, oxygen and carbon. Both of these Planarians are of small size, measuring less than half an inch in length. Many other kinds are, however, much larger than this, one of the terrestrial species, Geoplana australis, from New Zealand, being upwards of a foot long.

The acquatic forms swim by means of the undulatory movement of the body, aided by the sweeping action of the nultitude of cilia which clothe the integument. The terrestrial forms progress in the same manner, preserving their moisture by the copious secretion of slime. Avoiding the light and living under stones and logs of wood during the daytime, they venture forth at night from their dark humid haunts, and crawl about with the sensitive head raised and gently swayed from side to side to feel the way. Their food consists of earth-worms and defenceless insects, the soft parts of which are imbibed by means of the gullet, the prey being securely held the while by the slimy cuils of the Planarian. The figure of the Planarian (Bipalium kewense) on page 684, represents one of these terrestrial leech-like species, which is recognisable by the peculiar shape of its head. It was first obtained in Kew Gardens, and has been introduced into many parts of the world in connection with imported exotic plants.

The Tape-Worms-Sub-Crass Cestoda.-Almost all the members of this class live, when mature, as parasites in the alimentary canal of carnivorous vertebrated animals; but during the younger stages they occur in different parts of the body of animals of many kinds, including ticks, fresh-water shrimps, molluscs, and water-worms, as well as fish, rabbits, pigs, etc. Unless, in fact, the worm is able to change its host it is quite unable to reach the adult state. The truth of this is well illustrated in the case of onc of the commonest of mankind's Tape-worms, known as Trenia solium, which may be selected as a convenient type to illustrate the life-history and the structure of the other members of the class.

Upwards of three yards in length, this worm floats in the intestinal juices, inaintaining a firm hold of the inner wall of the gut by means of its minute pin-sized head, which is furnished for the purpose with a circlet of five hooks and four strong suckers. Immediately belind the head comes a narrow part, called the neck, which is unjointed and only about half an inch long. This is continuous with the rest of the body, which gradually expands into the characteristic tape-like form, and becomes divided into a vast number of segments. At first imperfectly defined, these segments become longer and longer and more and more distinct as they pass from the neck to the posterior end, the last ones alone being what is called "ripe" and ready to break off from the parent stock. The worm is furnished with a well-developed muscular 
system, consisting of fibres that run lengthwise throughout the body, and of others that pass from wall to wall of the segments. It also possesses a
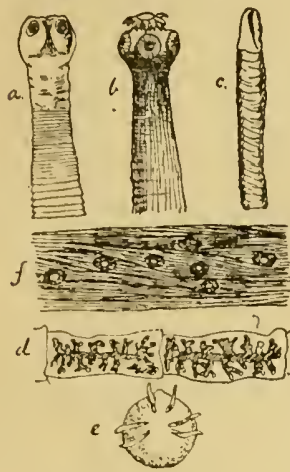

Fig. 12. -TAPE-TORHS.

$a$, Hexd of Trenia saginata.

b, llead of Trenia solium.

c, Hexd of Buthriocephalus la'us.

d, Ripe Segments of Tarict s)lium

e, Hooked Embryo of Tania solıum.

$f$, Measly Pork infested with Cysticercus.

nervous and excretory system, the former represented by a ganglion in the head, whence a pair of nerves run backwards along each side of the segments to the end of the body. The excretory organs consist of a circular canal lodged in the head, from which spring four branches, one corresponding to each sucker; two of these traverse the sides of the body, and, becoming united in the last segment, open by a common aperture on its hinder edge. They are also put into communication with each other in each segment by means of a transverse canal, which runs along its posterior border. Of mouth and alimentary canal there is no vestige, the animal gaining its nutriment by absorbing the fluids in which it floats.

A Tape-worm is unable to propagate its kind within the host in which it is lodged. But each segment contains a complete set of organs mecessary for the purpose, and when it is ripe and breaks off in the manner mentioned above, it is found to be charged with eggs. Such a segment, called a proglottis, makes its way to the exterior, and, bursting, sets free the eggs, which are thus disseminated. Sooner or later some of them, in connection with food or water, are swallowed by a pig. Each egg is then hatched and gives rise to the young known as the proscolex, a minute organism provided with three pairs of hooks (Fig. 12,e). By means of its armature, the proscolex bores it way through the coats of the pig's alimentary canal and enters its blood-vessels. It is then carried by the blood stream to some such organ as the brain, lung, muscles, etc., where it ultimately becomes lodged. Then growth sats in in earnest, the proscolex loses its looks, and, enlarging, becomes converted into a bladder. Pork thus infested is technically called measly (Fig. 12, $f$ ). At one point of the bladder a deep depression arises, and at the bottom of this the hooks and suckers of the tape-worm liead are developed; the depression is then pushed outwards until it becomes a process, carrying at the tip the head which is thus formed outside in. But beyond this stage, known as the Cysticercus or Bladder-uorm, the parasite cannot pass without again changing its host. This is effected when the meat of an infested pig is eaten in an uncooked state by a human being, whereby the Cysticercus is introduced into the alimentary canal, the bladder is digested, and the head or Scolex, attaching itself to the wall of the intestine, starts growing in length, until it assumes the adult form and breaks up into proglotides.

Anotlier tape-worm, common in man, and presenting the same cycle of development as Tania solium, with the exception that oxen are the intermediate hosts, is Tcenix saginata, which is larger than the one just described, and may be at once recognised from it by the absence of the circlet of looks on the head (Fig. 12, $a$ ).

A third species that infests mankind, but is of more frequent occurrence 
in Central Europe than in England, is the cleft-headed or Broad Tape-worm (Bothriocephalus latus), which is said to attain a length of $30 \mathrm{ft}$. The head has neither hooks nor protuberant suckers, but is furnished on each side with a deep groove (Fig. 12, c). The intermediate hosts of these rorms and of their allies, which live in water-birds, are fresh-water fish of various kinds, and an interesting fact connected with their development is the ability of the larve to live for a while an independent life, swimning about in water by means of a set of vibratile hairs or cilia with which they are furnished.

It nust not, however, be supposed that man is only infested witl these parasites in their sexual stage. There is a kind, called Tania echinococcus, found in dogs, which scatter the eggs broadcast with their dung; and these, if swallowed by man in connection with water or unwashed salad, are con. verted into embryos, which ultimately, making their way to the liver, give rise to cysts of large size, and often cause the death of the patient.

Fluke - Wormis-Sud - Class Trematoda. - The Flat-worms belonging to this section are characterised by having smooth (not ciliated), more or less leaf-like, shortish, unsegmented bodies, provided with two or more suckers; by means of which they adhere parasitically to the hosts they infest. According to the number of the suckers, these worms are divided into two sections, the Polystomece and the Distomece. The Polystomere have two suckers in the fore part of the body, and one large one or several smaller ones at the hinder end; not infrequently, too, they are armed with hooks for clinging. This rich equipment of organs for adhesion is explained by the fact that these creatures live mostly as external parasites upon various kinds of fish, and are thus constantly exposed to the danger of being washed from their moorings by the water. Their development also takes place directly and without any such curious metamorphoses as obtain in many of the entoparasitic

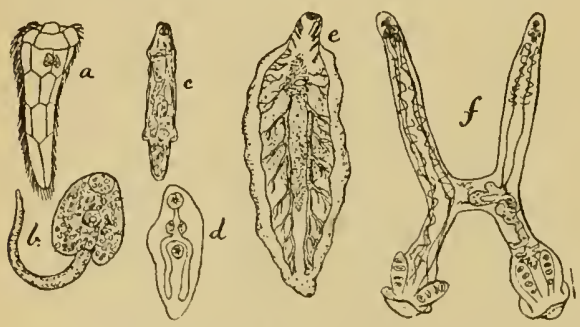

Fig. 13. worms. The following species may be cited as examples of this order:-Cyclatella anneli. dicola found upon annelidan worms ; 'Trochopus tubiporus on the Gurnet; and Aspidogaster conchicola, which lives in the pericardial cavity of the fresh-water mussel. Perhaps the most remarkable form of all is the one known as Diplozoon parcedoxum, the double-worm, which frequents the gills of minnow, gudgeon, etc. The young of this worm is ciliated and leads a free swimming life. It is fur-

$\alpha$, Free swimming lirva; $b$, cercaria larva; $c$, redia larva; $d$, young fluke; $e$, adult fluke ; $f$, Diplozoon paradoxum.

nished with two eye-spots and with a small ventral sucker and a dorsal papilla. In this stage it is known as the Diporpa. After a time the Diporpce settle down upon the gills of their host, and two of them approaching each other unite, the one seizing the papilla of the other with its sucker, then with a dexterous twist the second similarly gets hold of the papilla of the first, and, growing together, the two become inseparably united (Fig. 13, $f$ ). 
The Distomeit, as their name, meaning two-mouthed, implics, are providcd with only two suckers, and have no clinging hooks; for, being internal parasites, they have no such special need of instruments for maintaining a secure hold as the more highly organised species of the previous group. Their development, too, is often complicated by the most extraordinary metamorphoses, and is accompanied by migrations from one host to another.

$\Lambda$ well-known example of this section is the Liver-fluke (Distoma hepaticum), which lives parasitically in the liver of herbivorous mammalia-such as sheep. The worm is less than an inch long, and is broad and flat, wider in front than behind, and bearing on its front end a conical projection supporting the mouth, which is lodged in the centre of a sucker. The second sucker is situated on the ventral surface a short distance behind the first. The eggs of the Fluke enter the intestines of the sheep through the bile ducts, and are thence discharged with the droppings. Thereupon they hatch; but the embryo perishes, unless by chance it is carricd or washed into some fresh-water pond or stream. If favoured by fortune in this particular, it swims actively about by means of its long cilia in search of the particular host in which it is forced for a while to sojourn. This host is the water-snail known as Limneus truncatulus. Into the soft tissues of this nollusc the young Fluke bores its way, and after losing its cilia becomes converted into an oval sac known as the sporocyst. Within this fresh individuals, known as licdice, are developed, the liedice being short cylindrical little worms, furnished, like the parent form, with nıouth, gullet, and stomach. After making their way to the snails' liver, the Redice in turn take up the process of development, and give rise to individuals as different from themselves as they are from the ciliated embryo. These new forms, known as Cercarice, somewliat resemble a tadpole in shape, ccnsisting of a flattish, heart-shaped body, furnished with two suckers, a mouth, a forked alimentary canal, and produced behind into a long vibratile tail. These make their escape from the body of the snail, and, after swimming about for a time, settle upon some plant, and envelop themselves in a coating or cyst. In times of flood this takes place upon the grass blades of some overflowcd meadow, and in this case there is a chance that the organism will be devoured by a grazing sheep, and will become lodged in the bile ducts of its new host, where the development into the adult Fluke will be completed (see Fig. 13, a-e).

To be regarded in all probability as degenerate Flat-worms are the minute organisms belonging to the Dicyemidce and Orthonectide, which live as parasites, the former in the branchial veins of cuttle-fish and the latter upon Planarian and Nemertine worms and on sand-stars. They are ciliated vermiform creatures, without trace of body cavity or alimentary canal, the chief peculiarity of their organisation consisting in the fact that the solid body consists of a central mass, composed in the Dicyemidre of one large nucleated cell, and in the Orthonectidre of a cluster of cells, surrounded externally by a single layer of ectoderm cells. 


\section{SUB-KINGDOM VIII. \\ TH L C O E L E N T E R A T A.}

SPONGES, COPALS, ETC.

By Henry M. Bersard, M.A., F.L.S., Etc., and Matilda Bersard.

The Coelenterata are to be distinguished from all the animals hitherto described by the fact that the alimentary canal no longer runs througl the toody as a free tube suspended to its walls and surrounded by the body cavity. Animals in which such a closed alimentary canal is found are known as the Coelomata, on account of the spaces between the canal and the body wall. In contradistinction, the Coeleuterata or loollow-bodied aninals are called the Acoelomata, because the digestive sac fills up the whole body without leaving any spaces between the digestive layer and the body wall. The body is, in fact, a more or less simple sac into which the mouth opens.

The Coelenterata, while thus distinguished from all animals higher than themselves, are nevertheless associated with them owing to the multicellular composition of the body. As Metazoa, or many-celled animals, they differ from all lower animals or Protozoa, whose bodies are unicellular.

The Coelenterata may be divided into two groups-(1) the Sponges, and (2) the Cnidaria.

\section{I.-The Sponges.}

The Sponges, which are also known as the Porifera, on account of the pores that perforate their walls, are usually considered to be Coelenterates of a very simple kind, although many naturalists place then in a group by themselves.

The Sponges have been the subject of frequent discussion among naturalists from the time of Aristotle down to the present day. Aristotle was of opinion that they were animals, because they appeared to shrink when torn from the rocks, and thus seemed to show signs of sensation, but their real nature was altogether misunderstood by most of the earlier naturalists, some considering them to be plants, others congealed foam of the sea. Lamarck, even, imagined the apertures on the surface of a Sponge to be the mouths of cells occupied by small polyps something like the Coral polyps, which, however, could never be discovered in their homes. Peysonnel, on the other hand, considered a large worm which often lives in Sponges to be their "sole fabricant, the rest being mere nidus or excretion." About one hundred and fifty years ago the secret of Sponge life was revealed when the fact that water is drawn into the Sponge and expelled by it was established, but the various ways in which the currents of water pass through the body, and their relation to the life of the Sponge, were not accurately investigated until about seventy ycars ago, and are, indeed, still to a certain cxtcnt jroblematical. 
In the Sponge we have the very simplest type of Metazoan or multicellular animal. The component cells of the body, which, in the higher Metazoa, lose much of their individuality, functioning in masses (as tissues or organs) for the good of the whole complex organism rather than as individuals for their own benefit, are comparatively little modified in the body of the Sponge, still acting individually almost more than collectively.

The body wall of a Sponge consists of two layers. The outer layer is of a gelatinous nature, and contains (1) cells which, like some of the unicellular animals such as the Amoeba (Fig.1,p. 714), can change their shape, throwing out processes in various directions; and (2) needle-like bodies, callcd spicules, which are formed by cells and give firmness to the wall and support the

Constitution of the Sponge Body.

apertures on its surface. The inner laver primarily consists of cells closely resembling another form of unicellular organisms, the collared Flagellata (Fig. 6, C, p. 718). Each of the collar cells in this lager is provided with the whip-like appendage which characterises the Flagellata, so that the whole inner surface of the wall of the simplest Sponge is lined with fine, waving whips. The presence of these "whip cells" at one time led naturalists to consider the Sponges as mere aggregates of unicellular animals.

The very simplest type of Sponge, such as the one depicted in Fig. 1, is a simple sac, generally more or less cylindrical, and attached by its narrowed base to a rock or some other surface. This sac, which opens above by a wide, circular orifice, the oscule, consists of an outer and an inner layer such as have just been described.

The water necessary to the life of the Sponge does not enter in at the oscule, which must not be considered as a mouth, but through multitudes of much smaller apertures or pores that perforate the wall. Within the cavity of the sac the collar cells of the lining layer draw in from the water, which enters at the pores and streams out at the oscule, small particles of nourishment, and for this reason this space has been called the "gastral cavity." All indigestible matter, together with the water containing it, is ejected through the oscule. The whips with which the collar cells are provided keep the water in constant motion, and help to draw it in through the pores and to eject it through the oscule.

Other Sponges are less simple in structure, complexity being brought about by the thickening of the walls of the sac and by new arrangements of the whip cells.

In a rather more complicated type of Sponge, the wall is bulged out in the form of numbers of small radiating tubes. The wall of each of these tubes is perforated by pores through which the water is drawn by the action of the whip cells, and is passed on into the central cavity with which all the tubes communicate. It is finally ejected through the oscule, which has here the same position as in the simpler type of Sponge. In this second type of Sponge the collar cells line the tubes only, the central cavity being lined with flat cells.

In still more complicated types of Sponges with very thick walls an elaborate canal system arises, leading the water through the thick walls to the central cavity. The collar cells here no longer line either the central cavity or the canals, but form the lining of a great number of round 
chambers which may be called "whip chambers." The water, entering through the pores on the outer surface, passes through canals into these spherical chambers, the whips of the lining cells keeping it in movement and sending it on through

The Canal System. other canals, which unite with those from other whip chambers to form large channels that finally open into the central cavity. When such a sponge is cut across and highly magnified we see, as in the diagram Fig. 2, an elaborate and repeatedly branched system of canals. The whip chambers unite the ramifications, which come from the outer surface (the incurrent canals), with those that lead to large trunks opening into the gastral cavity (the excurrent canals).

The above descriptions apply only to what may be regarded as single sponge individuals ;

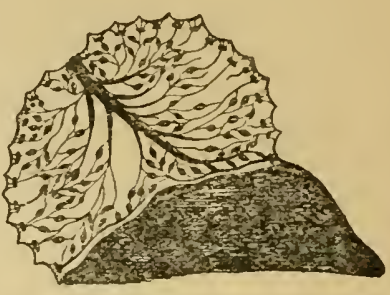

Fig. 2.-Diagram of thik CaNaL Systey of A SPONGE. but, by repeated budding, individual sponges may, in some cases, form colonies in which the individuals are no longer separately recognisable. This budding process giving rise to colonies is, however, not the Development of a only method of reproduction. In a Sponge whose lifesponge.

history has been fully worked out, the process is as follows :-Eggs are produced at certain parts of the bodywall which, when fertilised, divide up and give rise to small oval embryos covered with cilia. These are either solid or are provided with a small central cavity. They escape from the parent through the oscule, and swim about for a short time, varying from a few hours to a day or two. During this time they change their shape, and spicules derelop in their walls. When such an embryo attaches itself and becomes a sponge, the whip cells which clothed the outer surface and rowed the tiny creature about, come, in various ways, to line the interior and set up currents of water which bring in the necessary food.

Although the canal system is so essential to the life of the Sponges, and is so typically developed in the different kinds, its various modifications are apparently of little use in classification. Those who have

\section{Classification of} Sponges. made Sponges a special study prefer to group them according to the structure of the hard parts which support the outer layer of the body. These hard parts are either spicules or fibres, and are very rarely absent.

In the Calcareous Sponges, the skeleton consists of separate spicules of carbonate of lime. In the Siliceous Sponges, flinty spicules are found, which either remain separate or become united together to form networks or other supporting structures. There are, further, Sponges with skeletons composed of horny fibres, and besides the spicules or fibres secreted by the Sponge itself, foreign objeets are sometimes appropriated to assist in the formation of the skeleton.

The spicules found in Sponges assume a vast variety of shapes, a few of which are given in Fig. 3. Some are like fine needles pointed at both ends, others have several rays, the number of these determining the classification of the Siliceous Sponges into those with six or four-rayed or uniaxial spicules. Other spicules, again, terminate either at one end or both in anchor-like 
projections, or else resemble thorny sticks; others end in lokes instead of points. The spicules either lie embedderl separately in the Spongo tissue, giring it firmmess, or unite in many different ways, forming rosette-like or plate-like structures or else delicate supporting frameworks. Several kinds of spicules may bo found in the same Sponge. Besides strengthening the body, they also protect it, as is evident from their position. Spicules of the anchor type are frequently found projecting from the outer surface, especially round the oscules and pores, and, in some Sponges, spicules stand out like thorns all over the surface of the gastral cavity.

Tho exceedingly fine and brittle nature of Sponge spicules causes them to penetrate any soft object that comes in contact with them. If some Sponges are handled carelessly, a burning irrita. tion is set up by the fine points, which pierce and break off in the skin. One Sponge has on this account received the significant name of Agelas

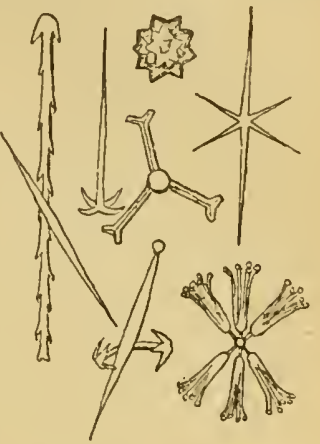

Fig. 3-Spoxar Spiculrs. noli tangere. This peculiarity no doubt efficiently protects Sponges from many enemies which might prey upon them.

In size, Sponges vary greatly ; some are minute objects only to be distinctly seen under the microscope, others form enormous masses several feet high.

By far the greater number of Sponges live in the sea; a few species of fresh-water Sponges, however, occur in our own rivers, lakes, and ponds, and many others are found in various parts of the globe.

A considerable number of marine Sponges are to be found in our own coasts, but these are less attractive in appearance than some of the tropical

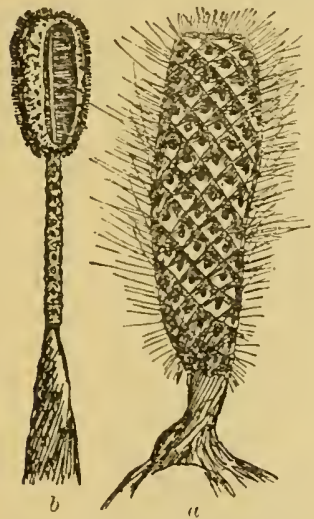

Fig. 4.-SIX-RATED STONOES (Hexactinel lida).

a, Venus's Flower Basket (Euplectelln)

b, The Glass-Rope Sponge (Byalonema).
Sponges, especially those with elegant framework, produced by combinations of six-rayed spicules. The skeletons of the Venus's Flower Basket (Fig. 4, A), the Licework Sponge, and Bird's-Nest Sponge are familiar objects in museums. Below the beautiful framework of the Sponge itself, a tangle of very fine threads resembling spun glass is to be seell. These are modified spicules, and by their means the Sponges anchor themselves in the mud. The Glass-Rope Sponge (Fig. 4, B) derives its name from the rope-like appearance of the anchoring threads, which are slightly twisted.

Among the more massive Sponges is the Neptune's Cup, which may stand several feet high.

The most familiar of all Sponges, the Bath Sponge, has a skeleton of horny fibres. In a living condition, it forms large dark, often almost black masses, The Bath Sponge the surface of which is raised up (Euspongin offici. into numberless conical promin- nalis). ences and broken through by. large oscules; each oscule is surrounded by an 
iris-like membrane; fine pores are to be found opening on the surface between the conical prominences. Canal systems with whip chambers run through the entire mass, all the cavities and canals being lined with flat cells, while the collar cells are restricted to the whip chambers. The tissue through which the canal systems run receives firmness from the presence of the horny fibres, which are specially plentiful along the clief canals and round the oscules.

The Bath Sponge, like most of the other massive Sponges, may be regarded as a colony, each individual of which consists of a cavity opening through an oscule and of the canal system which finally leads into that eavity. Such colonies arise by budding; the reproduction of the colony is, however, effected by means of eggs which grow into free-swimming larvæ.

The Bath Sponge flourishes on the coasts of the eastern half of the Mediterranean, in the West Indics, the Bahamas, and Florida. The sponges are fished for either with harpoons or nets, or are obtained by means of divers, and are carefully prepared for the market. Large Sponges are also artificially produced, from small pieces which, under favourable conditions, grow to a marketable size in the space of about seven years.

\section{II.-The Cridaria.}

The Cnidaria, which form the other great division of the Coelenterata, derive their name from the peculiar stinging cells with which they are provided. They have been divided into:-(1) The Hydrozoa, or water animals, to which all the Zoophytes or plant-like animals, and some of the Jelly-fish belong. (2) The Scyphozoa, which include most of the larger Jelly - fish, the Sea-anemones, and the Corals. (3) The Ctenophora or Combbearers.

A short account of one of the simplest and most easily accessible of the Hydrozoa will serve to give some idea of the essential features of the Cnidarian body. The Hydra is a small fresh-water Hydrozoan very common in ponds and The Hydrozoa. aquaria. As it is from $\frac{1}{4}$ to $\frac{1}{2}$ an inch in length, it can easily be seen with the naked eye hanging from the under surface of some water plant or other submerged object, to which it has attached itself by a very simple kind of sucker at the lower end of the body. The free end terminates in a mouth at the tip of a prominence which is surrounded by a ring of long tentacles. Both the body and the tentacles are exceedingly contractile, so that while the whole animal, when retracted, appears like a gelatinous ball crowned with bud-like knobs, when fully extended its body is slender and the tentacles thread-like.

The walls of the simple tube-like body

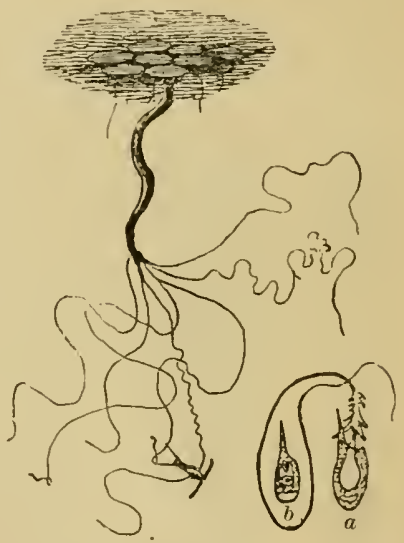

Fig. 5.

The Fresh-water Polip ( $B y d r a)$. Stinging Cell (Nematocysts), much magnified.

$a$, The vesicle with thread discharged.

$b$, The vesicle containing coiled thread.

of the Hydra consist of two layers of cells-an outer layer in contact with the 
surrounding medium, and an inner layer lining the tube-lihe interior or stomach cavity. Separating these cell layers there is a very thin intermediate or supporting (non-cellular) layer. This supporting layer by itself might be thought of as a kind of framework cxactly corresponding with the shape of tho body, for it penetrates even to the tips of the tentacles, which arise as outpushings of the body wall, and are therefore themselves tube-like. In this intermediate layer are found all the processes of the cellular layers which function as nerves and muscles. At the mouth, the outer and inner cell layers pass into one another ; this is an important point, because, as we shall presently see, the arrangement of the layers at the mouth forms one of the chief distinctions between the Hydrozoa and the Scyphozoa.

The cells of the outer layer of the IIydra body are chiefly remarkable for their stinging apparatus. The stinging cells contain minute resicles (Fig. 5), many of them measuring not more than $\frac{1}{1500}$ of an inch, in which are coiled up stinging threads, which are very valuable weapons of attack and defence. Each of these stinging cells is provided with a minute projection, the cnidocil, and it appears that, when this is touched, the resicle shoots out its long, coiled, barbed thread so rapidly that, delicate as it is, it is able to penetrate the body of any creature rash enough to approach too near. The poisonous effect of these weapons is shown by the fact that any small animal thus attacked appears to be paralysed; the victim speedily ceases struggling to escape, and is drawn in by the tentacles to the mouth. It is said that each tentacle of a Hydra is prorided with many thousands of such weapons, which are being constantly produced afresh, new cells taking the place of those which have been discharged.

The cells constituting the inner lining of the body are provided with fine hairs or whips, and are capable of changing their shape, and of sending out processes into the cavity of the body; they are therefore called amoeboid cells. The simple crustacean or other prey which, caught and paralysed by the stinging tentacles, has been pushed through the mouth into the cavity of the body, is digested by the cells of this lining layer. Whatever cannot be assimilated is thrown out again at the mouth, the muscles of the body wall and the current of watcr kept up by the whips in the cavity assisting in this process.

The Hydra often reproduces itself by means of buds which grow out from the parent body, and when fully equipped for independent life, break off and attach themselves near the parent. But, at certain seasons, a large globular body forms at some part of the surface of the fully-grown Hydra. This represents an egg, and, when fertilised, separates from the parent and develops into a new Hydra.

The Hydra and its allies have a wonderful power of repairing injuries which the body may suffer. Almost any part of the body, if cut off, is able to reproduce the rest. Some naturalists have amused themselves by produc. ing monstrous growths possessed of a large number of heads, and others have tried the experiment of turning the sac-like body inside out, and have even asser ted that the Hydra is able to carry on its life activities in such a condition. It has, however, been proved that, under such circumstances, the IHydra either manages to regain its normal state or else dies.

In this account of the Hydra, which is also known as the Fresh-water polyp, in contradistinction to other marine polyps, such as the Sea-anemones, the Corals, and the Zoophytes, we have noticed some of the essential points in the structure of the Cnidarian body. Among these are the sac-Jike nature 
of the body, the digestion of food by the walls of the body cavity, the capture of prey, and defence against enemies, by means of the formidable stinging threads.

The Hydra we hare described is not an entirely stationary animal ; it can detach its disc and creep along by using alternately its tentacles and its disc, and Hydroid Colonies
-Zoophytes. sonetimes even casts its body loose, using the expanded disc as a float and the tentacles for swinming. Most other Hydroids, howerer, unite to form stationary colonies, the young, which bud from each successive generation, remaining attached like branches, or by means of rootlets, to the original parent animal. Such colonies are often found encrusting empty shells, which they sometimes entirely cover with branched growths. One of them is represented in Fig. 6. Some of the members of this colony (A, A) bear a great resemblance to the Hydra, having the same tube-like body, surrounded at the free end by a crown of tentacles. But a large colony of such highly contractile creatures as the Hydra clustered together would be unmanageable, so, in these cases, their trunks are generally enveloped in a more or less stiff covering, which protects and supports the colony. The free ends of the individuals, with the mouths and tentacles, however, protruding from the open ends of the envelopes, contract and expand freely.

In the branched Hydroid figured, two important points are to be noticed. First, the gastral cavities of all the members of the colony are in communication with each other,

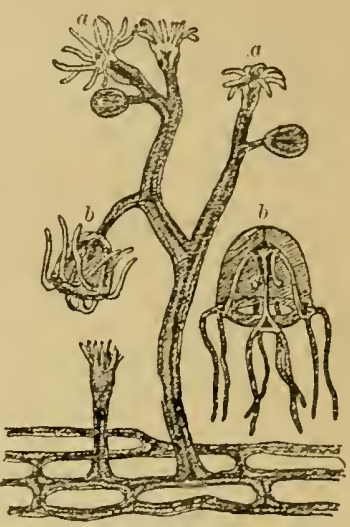

Fig. 6-A Hroroid Coloxy (Bougain. villea ramosa).

$a$, Hydra Jike individuals.

$b$, Medusoid individuals.

so that, when one of them captures fond, the superfluous nutritive fluid produced can be passed on to the other members through the communicating canals that run along the trunk and stems. Secondly, while most of the members of a colony are Hydra-like, and help to feed the whole, others (Fig. 6, B) are quite unlike the Hydra, differing both in the shape of the body and in the character of the tentacles. These, which are called Medusoid individuals on account of their resemblance to Medusæ or Jelly-fish, are the members in which the reproductive elements are produced. In some cases the medusoid buds remain attached to the colony, and send forth ciliated larve, which swim away and settle later to start fresh colonies; but, in the colony depicted, the medusoid individuals break loose, swim about freely, often greatly increasing in size, and after a time give rise to young forms which attach themselves as Hydroids.

Here, then, we have a most interesting phenomenon.- These colonies of Hydroids are stationary like trees or bushes, and, as in the case of trees or bushes, it would be a disadvantage to them if their young grew up too close around them; they would crowd each other to death. In the vegetable kingdom there are many beautiful arrangements for securing the scattering of the seed, but surely none more beautiful than the method adopted by some of the Hyroids. The individuals selected to bear the young change their 
shapes, break off and swin away as minute Jelly fish (Fig. 6, B), dispersing their young as they go.

Before giving any further account of these reproductive individuals, we must describe the Hydroid colonies a little more closely. They frequently resemble delicately branching trees or bushes, fine moss, or feathers, or sometimes form crusts over stones-hence the name of Zoophytes or animalplants. Such growths are very common on our coasts, and are still popularly considered, on account of their plant-like appearance, to be sea-weeds ; this deceptire appearance being heightened by the fact that the very minute polyps forning the colony are, in many cases, when contracted, entirely hidden within the protectire framework. This common protective covering is sometimes of a horny nature and transparent, sometimes hard and chalky, and, round the bodies of the individuals of the colony, may take the form of cups into which the soft polyps can withdraw. The Campanularians received their name from their bell-shaped, protective cups. In the Sea-firs or Sertularia, the cups project from each side of the stalk; in the Plumularians, from only one side. In other forms, again, there are no protective cups. The Oaten straw coralline (Tubularia) resembles a number of closely-packed straws, from the ends of which the beautiful little crimson-tentacled polyps project,

Besides these colonies which invest themselves with hard, tubular coverings, there are others in which the chalky parts become so greatly developed as to form massive skeletons so like those of Corals that they were long classed as such. These Hydrocorallia are often found in coral reefs, and would be taken, by the uninitiated, for true coral. In one family, the skeleton

The
Hydrocorallia. of which exactly resembles that of a branched, pink coral, the similarity is even carried out in the structure of the polyp. This family has receivcd the name of the Stylasteridæ, because of the central style or column which seems to imitate the columella of the true coral.

Another family of the Hydrocorallia, the Millepora, affords an interesting example of the division of the life-work of a colony among its different members. We have already described colonies in which the feeding was undertaken by some of the members and the reproduction by others, but here we have a more remarkable distinction between the different members. If we examine a mass of skeleton of a Millepore, the minute apertures on its surface are often seen to be arranged in groups, one larger, central aperture being surrounded by a number of smaller ones. When the surface of such a skeleton is alive with polyps, the central tube is inhabited by a polyp shorter and thicker than its neighbours, with a mouth and a few knob-like tentacles (Fig. 7 , A). From the smaller tubes, long slender polyps project, not provided with mouths, but only with tentacles (Fig. 7, B). The outer slender polyps keep up

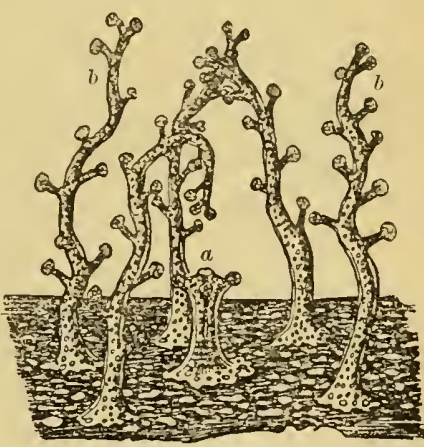

Fig, 7.-MTLLerord. $a$, Gastric individual. $b$, Tentaculate individua!

a constant waving motion, bending from time to time orer the central polsp. 
With their tentacles, no doubt amply provided with stinging threads, they catch the food which, being themselves unable to eat, they pass on to the mouth of the central polyp. Within the body of this central polyp the food is digested, but not for itself alone, as the products of digestion, flowing along the many canals of the colony, feed all its members. There are no freeswimming Medusæ connected with these Hydrocorallia.

We return now to the reproductive individuals, which, in many Hydroid colonies, carry and distribute the eggs (Fig, 6, B). These, when seen swimming about independently, are so like the larger JellyHydromedusæ. fish belonging to the Scyphozoa that they were long mistaken for them. The general plan of the body, indeed, is rery similar and is worth describing, especially in order to show what changes are necessary in the ordinary Hydra-like body to produce a swimming bell.

In all Medusæ the general shape of the body is due to the great thickening of the middle supporting layer in the body wall, which we described in connection with the Hydra. Instead of a long bcdy like that of the Hydra, $\mathrm{l}$ unning like a tube from the mouth to the bottom of the gastric sac, we have one flattened out like an umbrella, the upper part of the umbrella corresponding with the former closed end of the tube, while the mouth is at tho tip of a short stalk or handle to the umbrella. The transformation of the Hydra into the Medusoid can be imagined by supposing the mouth prominence between the tentacles to be pushed down into the body, which expands laterally, till the whole forms a bowl with the oral prominence rising up in its base; the tentacles take up positions on the rim of the bowl. The stomach lies partly in the mouth stalk or manubrium (handle) and partly in the body of the umbrella. Here it sometimes forms a cavity, and a number of canals run from it radially out, like spokes, to the edge of the umbrella, there to meet a canal which runs round the margin. When food is taken into the stomach the nutritive fluid derired from it passes through the radial canals to the circumferential canal and nourishes the whole body. The number of these radial canals in the Hydromedusæ is usually small (two, four, or eight), and these are little if at all branched. The margin of the body is fringed with tentacles, and carries the so-called "marginal bodies," some of which are minute bags (lithocjsts) containing bodies called otoliths, whose function is usually said to be auditory, but is more probably that of regulating the position of the animal in the water. Other brilliantly coloured bodies, again, have been named "eje-spots." The Hydromedusa were formerly distinguished from the Jelly-fish proper as "naked-eyed "Medusæ, because in them these "eyes" are exposed, whereas in the other Jelly-fish, or "covered-eyed" Medusæ, they are protected by a hood-like lappet of gelatinous tissue. Simple tactile organs are also found along the margin of the Hydromedusæ, round which a double nerve ring runs.

Another characteristic of the $\mathrm{H}_{5}$ dromeduse is the velum (veil), a thin, muscular membrane which hangs down from the margin of the umbrella, slanting inward toward the manubrium.

The swimming movements of these animals also deserve notice. The lower concave surface of the "umbrella" is supplied with a very thin layer of contractile tissue or muscle, by the contraction of which the umbrella is partially closcd. This action, performed suddenly, drives the water out from under the umbrella and propels the Medusa along.

The eggs. in the Hydromedusæ, form along the radial canals, or on the 
inner walls of the manubrium, and give rise to ciliated larve whicl pass through the cavity of the umbrella into the open water, become attached, and, by budding, produce new Hydroid colonies. Such colonies again produce Medusoids, and so on. This process is a simple case of what is called alternation of generations. The Hydroid form has been called in German the "nursing" generation, as it does not itself produce the young, but brings to perfection the individuals which, when free, become the reproductive generation.

Although most Hyclromedusie are the products of a $\mathrm{Hydroid}$ colony, and their eggs develop again into such colonies, there are others which develop direct from forms in every respect like themselves, i.e., the young ones no longer pass through any attacled Hydroid stagc. On the other hand, there are Hydroid colonies which never develop free medusoid forms to secure the dispersal of their progeny.

Leaving the fixed Hydroid colonies and their free swimming members, we come to the one remaining group of the Hydrozoa, the Siphonophora, which consists of large Hydroid colonies, no longer attached, but floating freely about. These are very complicated creatures in which the Hydroid and Medusoid type of

The Siphonophora. body is so curiously changed as to be scarcely recognisable, and in which also division of labour has reached an extreme point.

The Siphonophora are exceedingly striking and beautiful objects, only to be seen in tropical seas, where they delight the traveller by their exquisite shapes and brilliant colouring.

The colonies are not branched, but the many members are arranged round a central stalk. The cavities of all the members communicate as in the Zoophytes. The uppermost individual is turned into a kind of air-blaclder for floating the colony, and then come a number of individuals turned into swimming-bells which drive the whole colony through the water. Beneath these locomotory individuals come nutritive individuals, which are often little more than stomach-tubes, reproductive individuals, frequently in clusters, and protective individuals, arranged in such a way as to overlap the nutritive and reproductive members of the colony. There are, further, tentacular individuals which are usually long filaments (sometimes called fishing lines). These are richly provided with stinging batteries, their function being to capture food for the colony and to defend it from its enemies.

In the simpler forms of Siphonophora the stalk is long, and the members of the colony project from it at intervals. Sometimes several pairs of swimming bells follow each other for a short way down the stalk, in other cases a single pair lieads the colony. In other forms the stalk is much shortened, and a central air-bladder is surrounded by medusa-like swimming bells, the other members of the colony being crowded together beneath these. One of the best-known Siphonophora is the Portuguese Man-of-War, illustrated in Fig. 8. This is one of the most specialised

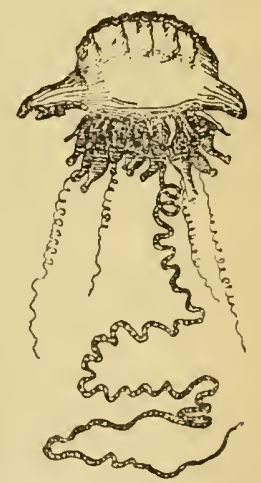

Fig. 8.-The Portugress, IIAN-OF-WAR (Physalia),

forms. The large, crested, and exquisitely coloured air-bladder alone appears above the wares. This air-bladder secretes its own gas, and has 
an aperture through which some of its contents can be forced out. The feeding, reproductive, and other members cluster beneath the float, and several immensely long filaments, supplied with multitudes of stinging batteries, trail down into the water. The stinging powers of this Cnidarian are so great that adrenturous people who have tried to capture a large specimen have narrowly escaped with their lives.

Turning now to the second great dirision of the Cniclaria, the Scyphozoa, we find that an important change has taken place in the simple sac or tube-

like body. A tube has grown inward from the mouth

The Scyphozoa. into the body, forming a passage to the stomach (a simple kind of wophagus); this, being an ingrowth from outside, is always lined with the outer layer of tho body wall. All the Scyphozoa-i.e., the Jelly-fish proper, the Anemones, and the Corals-are distinguished by the presence of this asophagus from the Hydrozoa above described.

In the Hydrozoa we had single stationary polyps, stationary colonies, medusoid individuals which have broken loose from stationary colonies, and medusæ which no lunger belong to any stationary form. In the Scyphozoa, also, we have single stationary polyps, colonies of polyps, and free-swimming medusæ. Taking the last of these forms, the Scypho-

The medusæ, first, we find not only that they are far larger

Scyphomedusæ. and more important than are the Hydromedusæ, but that the thickening of the middle gelatinous layer of their body is even greater than in the Hydromedusæ. The gelatinous tissue is a mere network of connective tissue, the interstices of which are filled witl water, which far exceeds in volume all the delicate body tissues of the animal. This is well illustrated by the fact that a Jelly-fish weighing 34 lbs., and measuring $7 \mathrm{ft}$. in diameter without its tentacles, when left to dry in the sun, in a few days lost 199 of its original weight. It has also been stated that, when a large Jelly-fish is placed in the sun on blotting paper, nothing but the out. line of its form has been found after a few hours have passed.

These Scyphomedusæ differ from the Hydromedusæ in sereral ways. The margin of the umbrella is generally lobed, and there is no true velum; the mouth at the tip of the manubrium is often squarc.

An English Jelly. The cavity of the body is more complicated than in the

Fish (Anvelia Hydromedusw, being divided up in various ways, and aurita).

the radial canals are often richly branched. To the Scyphomcdusi belong, not only many lovely tropical forms, but those commonly seen floating in our own waters. In the commonest of these last (Aurelic aurita) the margin forms eight slightly marked off lobes and is fringed with very fine tentacles. The square mouth is edged with four long arms, which hang down into the water and catch prey. At the eight notches between the lobes are small sensory bodies which are protected in the way characteristic of the "covered eyed" Medusæ (as the Scyphozoa were formerly called). Four large coloured patches, which are very marked on the upper surface of the umbrella, represent the reproductive masses, beneath which the under surface of the umbrella is hollowed out into four pits. The water needed for aerating the tissues is thus brought into closer proximity to the reproductive elements.

A curious modification of the ordinary form is found in the Rhizostoma or Root-footed Jelly-fish. The corners of the square mouth at the tip of the 
manubrium are prolonged into long oral arms. The edges of each of these fold together so as to form tubes. The mouth then closes and suckers are developed along the inner surfaces of the tubes, through which alone nourishment reaches the stomach. Very large prey, such as fish, is often captured by these Jelly-fish, and held fast by the oral arms while the nourishment is sucked out of it.

In many of these Jelly-fish, reproduction takes place by means of eggs which develop in the reproductive chambers. Theso eggs usually develop into Medusa, but, in the liargo family of the Discophore, to which our own Jelly-fish belong, the larva which results from the egg is a small spherical body covered with cilia, and never grows into a Medusa direct. It attaches itself to a rock or sea-weed (Fig. 9, 1), develops tentacles, and lengthens out. Constrictions then begin to appear round its body: the first just below tho tentacles, and others successively further down. The edges formed by the constrictions become lobed, and the little creature, usually not more than an inch

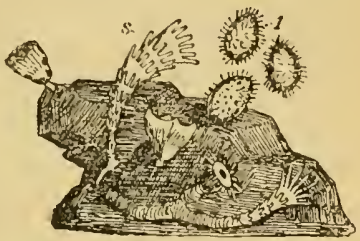

Fig. 9.-Strobilation.

1, Larra. $S$, Strobila. long, soon has the appearance of a series of saucers with lubed margins piled one upon another, but increasing in size upward (Fig. 9, S). After a time the whole structure breaks up, each detached disc developing later into a Medusa, often of gigantic size. This curious process of a sexual multiplication is known as strobilation, each series of developing young boing a strobila, which is the Greek for fir-cone.

There is only one permanently attached form among these Medusie. This is the Lucernaria, a rery beautiful flower-like unimal often found adhering to sea-weed.

The Anthozoa or flower-like animals, which form the next group of the Scyphozoa, include the stationary Sea-anemones and the Corals, the living bodies of both of which are built on essentially the same plan. The body of the Sea-anemone, however, always remains soft, while that of the Coral proper develops a hard

The Anthozoa.

skeleton. For this reason the Sea-anemones have been called the Fleshy Corals, while one large division of the Corals is called the Stony Corals, on account of their stony skeletons. The Sea-anemones always remain single, while the Corals comprise both single and colonial forms.

The Sea-anemone is a familiar object to most of us, as it is very plentiful on our rocky shores. Small, coloured, jelly-like masses are often to be seen adhering to the rocks at low tide, which, as soon as they are again covered by water on the return of the tide, expand in beautiful and brilliantly-coloured flower-like animals. Looking down upon an Anemone, the central

The Sea-anemones (Actinia).

mouth can generally be made out fringed with its tentacles. If the body were cut across a little below the level of these, we should find that it consisted of two tubes, one within the other. The inner tube is the stomach tube or oesophagus, lined with the outer skin, which, as above described, characterises all the Scyphozoa. It is united to the wall of the outer tube, which is the body wall of the Anemone, by a number of fleshy partitions, which, running right through the length of the body, divide it up into many compartments. The uppermost portion of each of these compartments runs 
up into a tentacle. These fleshy "septa" are infoldings of the inner layer of the wall of the sac-like body. They do not all arise at the same time, nor do they all project equally far into the body cavity. Only some of them run out far enough to connect the two tubes in the upper part of the body.

This dividing up of the bociy into compartments is one of the chief distinctions between the Sea-anemone polyp and the Hydra polyp. In many other respects the Sea-anemone closely resembles the Hydra. It has the same power of retracting its tentacles and reducing its whole body to a budlike shape. It captures food with its tentacles, and digests it within its body cavity, throwing out at the mouth all that it cannot assimilate. It has also a limited power of motion, not, however, like the Hydra, using its tentacles for this purpose, but gliding along on its base.

The Anemone is still richer than the Hydra in stinging cells. It has been calculated that some Anemones possess as many as $43,000,000$ of stinging cells in one tentacle, and in the whole body something like $6,450,000,000$. The stinging cells in Anemones measure from $\frac{1}{350}$ to $\frac{1}{5000}$ of an inch, the thread being often twenty times as long as the cell, and more richly supplied with barbs than are those of the Hydra. These cells, too, in the Anemone, are not merely found in the outer skin, but form in great quantities in the gastric cavity.

The outer skin of the Anemone is nut always smooth and jelly-like; it is often covered with wart-like protuberances, which sometimes secrete a sticky' fluid. Some Anemones have, further, a circle of "eyes" placed like a necklace round the body. Each of these has a lens and simple optic nerve, but the latter is not connected with any other nerves. From time to time, as the Anemone grows, it is able to cast off its outer skin, after having formed a new one beneath it ; the old skin can often be seen in a wrinkled, dead-looking condition encircling the base of the animal.

Although none of the Sea-anemones found on our own shores attain the size of some of the tropical specimens, they are very beautiful and well worthy of study. A few only can here be briefly described.

The Plumose Anemone (Fig. 10) and the Daisy Anemone are two of the English varieties of the Sagartiadæ, so-called after a tribe in the army of Xerxes, known for their practice of en-

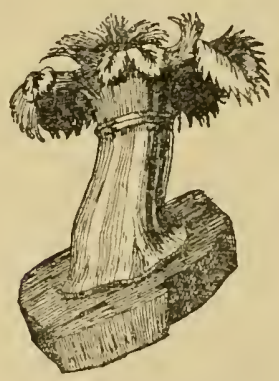

Fig. 10.-The Plumose ANrmong (Actinoloba dianthus). tangling their enemies by means of noosed ropes. All these Anemones possess, attached to the septa of the gastric cavity, tangled masses of stinging threads resembling tangles of white cotton. These they can at

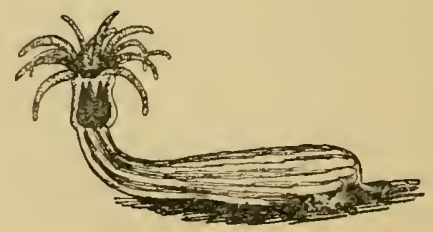

Fig. 11.-EDWARDgIA.

will shoot out of the mouth, and, in some cases, through apertures at the sides of the body, for the purpose of paralysing their enemics. In large 
sfecimens these "acontia" may, when extended straight through the mouth, measure as much as six inches.

In the Plumose Anemone, which is flesh-coloured, pale orange, or clear white, the pillar-like body is surmounted by a widely-expanded, frilled disc cdged with numberless fringe-like tentacles. When these Anemones move along on the disc small pieces are sometimes torn off and left behind. These pieces can develop into young Anemones; at other times young forms bud out from the parent.

In the Daisy Anemone the upper part of the body wall is studded with suckers, to which fragments of shell or gravel may become attached. In colour this Anemone varies greatly, almost all shades, from a delicate flesh colour to a deep chocolate or olive green, being seen in various specimens. The small tentacles are arranged in many rows, and may amount to 500. The Daisy Anemone is exceedingly prolific. Its young, which arise from fertilised eggs, are usually matured within the body cavity and thrown out at the mouth as minute but perfect Anemones. From 160 to 300 of such young are said to have been produced by a Daisy Anemone in a single day.

The Cloak Anemone is noted for being constantly found in company with the Hermit Crab, on the lip of whose borrowed shell it attaches itself. Two wing-like lobes grow out from the base of the Anemone, gradually surround the lip of the shell, meeting finally on the other side and forming the so-called "cloak." The Anemone no doubt profits by its chosen position, as it can feed on particles of the prey caught and torn up by the claws of the crab, and is borne alung by him in his wanderings, sometimes thus travelling a mile or two out to sea, and enjoying constant change of water. If the shell chosen by this strange couple is too small for the Anemone, or gets broken, it can fabricate a shelly substance which makes good all defects.

The Opelet, so called because its disc is habitually expanded, has long, emerald-green tentacles, which can coil round its prey. Large sea-weeds are often found studded with these beautiful flower-like creatures, which, in some parts of France, are appreciated as an article of food.

The Beadlet is distinguished by brilliantly coloured beadlike vesicles set near the edge of the disc. These may be stinging batteries, for these Anemones are not provided, like the Sagartiadæ, with internal stinging threads. The Beadlet, which is also called the Strawberry Anemone, is the commonest of the red Anemones found on English rocks. It is very hardy, and has been known to live as long as thirty years in The Opelet (Anthea eereus). captivity, during that time giving rise to three hundred and thirty-four young Anemones.

The Dahlia Wartlet has the surface of its body covered with small grey warts to which fragments of stone or shell adhere. 'I'his Anemone is scarcely less abundant on our shores than the Beadlet, and is very handsome, one variety having white tentacles, vividly contrasting with the crimson disc. It is particularly voracious, devouring The Beadiet (Actinia mesembry. anthemum). shore crabs, limpets, and oth(r molluscs, and eren sea-urchins and fish. 
The Cave-dwelling Anemone, though plentiful on our coasts, is very difficult to find, its colouring being wonderfully adapted

The Cave-dwelling to the sand or mud of the pools it inhabits. The black, Anemone white, and grey of the disc are arranged in delicate

(Sagartia

troglodytes).

suckers on its column. patterns, which have been compared with those on the feathers of a snipe. The purpose of concealment-is further aided by fragments of shells, etc., attached to the

In the Edwardsias (Fig. 11, p. 702) the body is much elongated, and the lower part is usually buried in the sand or mud.

The Crimson Pufflet

(Edwarlsia carnea). One of the best-known of these Anemones is the Crimson Pufflet, which often inhabits the old burrows of Molluscs in limestone rocks on the coast of South Devon, the beautiful crimson tentacles protruding from the mouth of the burrow.

On tropical shores there are many brilliantly beautiful rarieties of Seaanemones, some of which attiin a very large size. Actinia paumotensis, found on the islards of the Paumotu Archipelago, is

Tropical Anemones. described by Dana as one of the most beautiful of all Anemones. It has a disc often $14 \mathrm{in}$. in diameter, "densely covered with large tentacles tipped with bright lake, the margin undulating so as to form numerous lobes, each of which has the appearance of being a separate Actinian, and the whole resembling a beautiful bouquet." Other tropical forms have been said to resemble brilliantly-coloured carpets covering the rocks. Some of these large, tropical Anemones are used as homes by other animals, which live within the stomach cavity. A fish some $3 \mathrm{in}$. long and very vividly coloured in striking contrast to its host, and a brightly-coloured prawn are almost always found thus associated with certain large Anemones on the great Barrier Reef of Australia, as recently described by Mr. Saville Kent. These curious lodgers emerge from their refuge from time to time to swim about in the sea, but dart back again into the mouths of their hosts when pursued by enemies. It has been supposed that this association may be of advantage to the Anemone as well as to the fish and the prawn. Animals are attracted to pursue these brilliant decoys and fall victims to the voracious Anemone, while the fish and the prawn live on the crumbs which fall from the feasts of their magnificent friends and protectors.

In the Corals proper, the polyps are essentially like the Sea-anemones, but are able to form a hard, protective framework for their bodies.

The soft, fleshy body first gives off upon the rock below

The Corals. it a quantity of chalky matter from its base, and thus forms a kind of pedestal for itself, which is called the foot-plate. From this, six hard ridges rise up into the body, given off by the fleshy parts of the base; six, at least, is the number first produced, other ridges arising later in the intervals between these. From the outer edges of these plates, phlanges may grow out till they meet one another, and make a hard ring supporting the ridges. Sometimes, too, a hard column arises from the centre of the foot-plate; this is called the columella. All over these hard ridges, rings, and columns, the basal skin of the soft body of the animal fits closely. This arrangement is doubtless protective, for, on being disturbed, the whole animal, which was perhaps seen a moment before as a beautiful Anemone, with expanded tentacles, collajses 
between the projections, and nothing is seen over them but a thin shiny skin.

Fig. 12 shows us the skeletons of two solitary corals which have

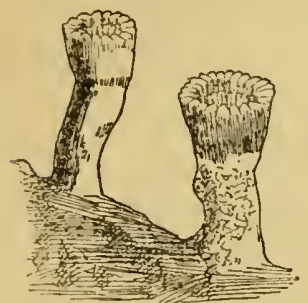

Fig. 12.-The Cup CoRaL (Caryophyllia). thus built up their pedestals to a considerable height. The greater number of coral polyps, however, do not remain solitary, but are continually producing daughter polyps, whole families together forming great colonies, each nember of which as it grows adds its own pedes. tal to the mass. All the stony corals seen in our museums are but the complicated skeletons, i.e., the combined pedestals of polyps whose soft, jelly-like bodies have perished. In the living state these hard masses were covered by the flesh of the animal colony, as a thin layer of slimy matter. The individual Sea-anemone-like animals lurked in the cavities, rising and expanding their tentacles when in search of food, but drawing them back under shelter whenever threatened or disturbed.

Corals are usually grouped according to the number of divisions, compartments, or "rays" in their bodies, each compartment, as in the Anemone, running up into the hollow axis of a tentacle.

Six-rayed polyps have six tentacles or (approximately) some multiple of six, eighteen, twenty-four, forty-eight, and even more.

Eight-rayed polyps have eight tentacles or some multiple of eight.

Most of the six-rayed polyps live in great colonies, their skeletons producing the chalky masses with which we are much more familiar than we are with the living animals. One important family of the six-rayed polyps, huwever, the Fungidæ, or Mushroom The Six-rayed corals, consists of single individuals. The median slit seen Corals (Hcxactinia). along the surface of the Mushroom coral (Fig. 13) indicates the position of the mouth, while the many jagged ridges that radiate out from it and give the whole the appearance of an inverted mushroom are the hard, stony ridges and partitions over which the body of the polyp fits. When the polyp is expanded, all this skeleton is hidden from view by the beautifully coloured

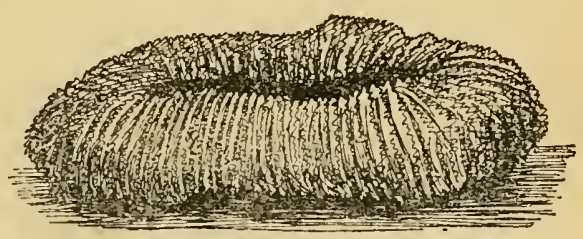

Fig. 13.-A Mushroom Corau (Fungia). soft body, the whole surface being one mass of tentacles, often of a vivid green, tipped with white. With these tentacles, each richly provided with stinging cells, the huge polyp paralyses and masters its prey, using them also as weapons of defence against enemies. When disturbed, the whole animal sinks down among the toothed ridges, which project through without actually piercing the thin skin, and may well defy any enemy to touch him. These IIushroom corals, when young, are cup-like or cylindrical like other corals, and provided with a stalk; as they grow, the sides of the cup get flatter and flatter until the whole becomes quite flat, or the bottom of the original cup rises even higher 
than the rim. The young, as a rule, bud from the urder surface of the parent, then drop off, and lie loosely on the rock or sea-buttom. A branched form is known in which young Fungia drop from the tips of branches.

This branching condition, which is exceptional in the Mushroom corals, is the rule in nearly all other corals. By division or budding of various kinds an endless variety of colonies are produced. Sometimes, as among

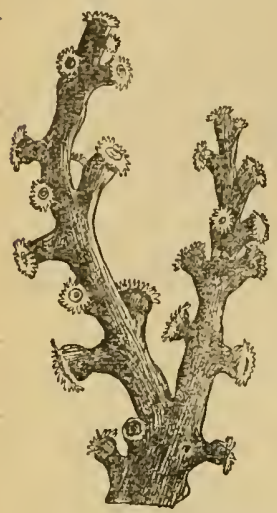

Fig. 14.-Corau Coroniks.

Dendrosoma.

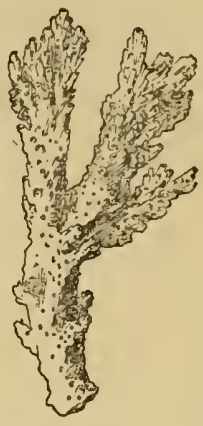

Madrepora.

the Zoophytes, the polyps build up branched frameworks, from which at intervals they protrude, like flowers from a branched stalk. The form of such colonies depends upon the intervals separating tho polyps, and the angle at which they branch out from the parent individuals. In Fig. 14, in the coral on the left, the polyps are far apart, in that on the right the budding is frequent and the polyps crowded. In this latter case the skeleton is penetrated in all directions with canals which, for a certain distance below the surface, carry food juice from polyp to polyp. The Madrepores, of which the coral to the right of Fig. 14 is an example, are amongst the most important builders of coral reefs and islands. Other coral colonies form waving plates, often beautifully frilled at the edges, the polyps usually projecting from the upper surface of the plate. The variety in form and structure of coral colonies is, indeed, almost endless.

Entirely different coral forms are produced by polyps which, instead of budding, simply divide into two or more new individuals. In Fig. 15 we

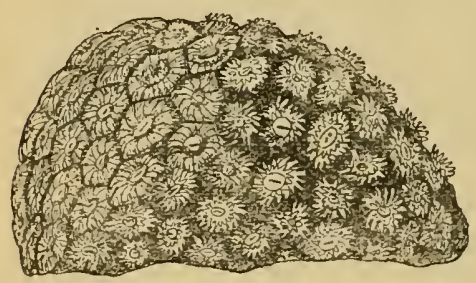

Fig. 15.-Tue Star.Coral (Astroea). have a hemispherical mass, the surface of which is thickly set with star-like polyps ; some are seen expanded, with the slit-like mouths in the centre of the disc, others are in a retracted condition. The star-like shape of the polyps in this kind of coral has obtained for it the name of star-coral. On such a mass a larger polyp is often found which has two mouths instead of one; a row of tentacles forms between the two mouths, this row then breaks up into two, and two polyps are seen on the surface where only one was before. In this case we have complete division of the individuals, for, while these outer changes have been going on, corresponding changes have been taking place below the surface, resulting in a more or less complete division of the original animal into two. In these colonies, the whole hemispherical mass, which may grow to an enormous size, is built up layer after layer, the 
living flesh of the colony never forming more than a thin layer over the surface.

The skeleton of the Brain Coral (Fig. 16), which is distinguished by the systems of ridges and furrows winding over its surface, is built up in successive layers like that of the Star Coral, but the polyps multiply in a different manner. Each long furrow denotes the former home of a large polyp, which formed a whole row of new mouths without dividing up into new individuals. Here, therefore, we have incomplete division of the individuals. This furrow was fringed by tentacles which rose above the ridges. After a certain stage of elongation of the polyp was reached, the body completed itself, as it

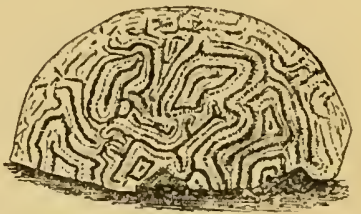

Fig. 16.-Brain Coral (Maeandrina). were, with a new row of tentacles between two of the mouths, and so a new individual was started.

While budding and division play such a large part in increasing the number of polyps forming a colony, each new colony itself is started by another method of reproduction. Eggs, which form on the internal partitions or septa of the polyp, give rise to minute larve that swim about, first within the body of the parent, and then in the open water, sometimes for as

Development of Corals. long as two months. Then they attach themselves by one end to a rock or some other surface, and begin to assume the polyp shape, tentacles and mouth developing at the free end of the body, and the hard parts form as in the parent animal. Such polyps, by budding and division, found new colonies.

All the skeletons we have as jet mentioned are more or less massive or stony, as is usually the case with the skeletons of the six-rayed polyps (hence the name stony corals), but some colonies of this division secrete horny instead of chalky skeletons. The skeletons of the Black Corals or Antipatharia form branching tufts or trees of horny substance. The surface of the branches

The Black Corals (Antipatharia). appears smooth and polished, and, in some of the larger species, resembles ebony. These corals grow to a great height as single trunks, or as treelike growths; sometimes the separate branches fuse to produce networks. In such coral skeletons there are none of the traces of the former presence of polyps such as we see on the surface of the stony corals, because the branched stem is merely the central axis of the living colony that produced it and once covered it with a soft crust. Out of this crust the individual polyps protruded at intervals. The hard, rod-like skeletons of the Black Corals are used by natives in various parts of the world for dagger handles, necklaces, or mouthpieces for pipes, on account of their toughness and susceptibility to polish.

The eight-rayed polyps differ in several ways, too technical for us to enter upon, from the six-rayed polyps. The eight tentacles of the individual polyps are toothed or feathered, and form a more imposing crown than do the simple cylindrical tentacles of the six-rayed order. The hard parts produced by The Eight-rayed them, in the majority of cases, take the form of a central Corals (Uctactinia). axis like that found in the Black Corals, but here of chalk or horn, or of 
chalk and horn alternately. The fleshy crust which covers the axis, and out of which the individual polyps protrude, is supported by chalky spicules or plates scattered through its substance (see Fig. 18). There are, however, massive forms produced by the eight-rayed polyps which have no central skeletal axis, such as the Blue Coral (Heliopora) and the Organ Pipe Coral (Fig. 17). In the latter, the polyps grow up side by side in separate tubes which result from the fusion of coloured chalky spicules. Those tubes, from which

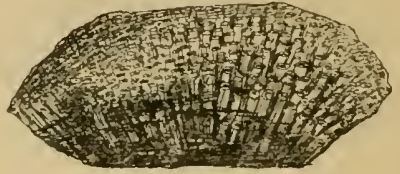

Fig. 17. Organ.Pite Coral (Tubipora musica). the coral takes its name, are, at regular intervals, joined together by platforms. It is from these platforms, where the interval between two tubes is considerable, that new buds arise to grow up alongside of the older polyps. Both the skeleton and the soft parts of this colony are of a deep crimson, the tentacles of the polyps being of an emerald green.

The coral we probably know best in its skeletal condition, the Red Coral of commerce, is also the product of one of the eight-rayed corals. Some idea of the structure of this coral in its living condition may be gained from the diagram-

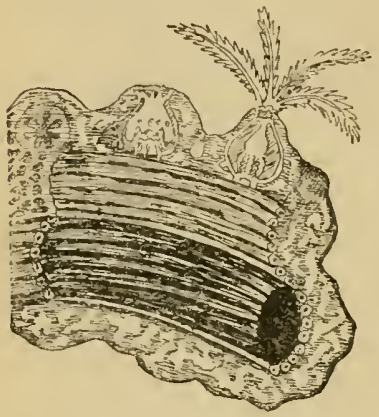

Fij. 18. -THE Red CoRal of CoM. MERCE (Corallum rubrum). atic section of it given in Fig. 18. The central hard (chalky) axis answers to the smooth red brancl with which we are familiar. This is covered by a layer of soft tubes, some of which, in the illustration, are thrown back in order to reveal the hard axis, the grooved markings on which show where the canals ran. These tubes convey the nourishing fluid through the whole colony, receiving it from the polyps and giving it off through branches connecting them with the soft crust that lies over them. Throughout this crust star or plate-like spicules are scattered, which give it some degree of firmness. Three polyps are seen in the illustration: the one to the right has its fringed tentacles extended in search of prey, the middle one is in a retracted condition, and that to the left is cut across to show the partitions in the body. The soft bodies of these polyps are pure white, and the effect of their feathered tentacles, projecting here and there from the bright red crust, is very beautiful.

These corals form tree-like growths often several feet high, and are very plentiful in the Mediterranean. Coral fisheries on an extensive scale are carried on, chiefly by Italians, off the coasts of Italy, Algiers, and Spain, the corals being dredged for with nets. The soft living crust is easily removed, and the axis, which takes a high polish, is used for ormamental purposes.

Though the two corals last described, the Organ Pipe Coral and the Red Coral of commerce, as well as a few other of the Octactinia, are rigid growths, in the majority of the eight-rayed corals, which have horny axial skeletons; the branches are not hard and stiff like those of the stony corals, but ean wave about with the motion of the water, the brightly-coloured 
living jelly that covers them often glistening with metallic lustre. Sometimes the delicate branches unite to form networks, as in the Sea-fans (Gorgonia). In other cases fine branches stand out from a central shaft, and the whole colony resembles a feather with its barbs. Fig. 19 represents one of the Sea-pens belonging to this group. The lower end of the colony does not carry any polyps, but is buried in sand or mud. This is a peculiarly beautiful object when alive, especially in the dark, as waves of pliospliorescent light sweop over the surface of the colony and make it glow witl indescribable beauty. It is these graceful and vividlycoloured corals which form the chief adornments of the coral reefs, the solid rocks of which are derived from the harder and more massive skeletons produced by the six-rayed corals.

The marvellous beauty of the banks covered with living corals in the Red Sea and elsewhere, where shallow water enables the traveller to feast his eyes on these exquisite growths, has often roused the enthusiasm of naturalists. They have been compared with fields or gardens of the choicest and most brilliantly-coloured flowers growing in the richest profusion, all the intervals between the larger growtlis being filled up with bright moss, which is itself composed of minute corals. Among the elegant flowering

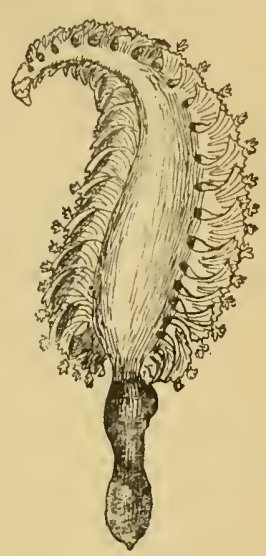

Fig. 19.-SEA-PFA (Рет̆natula). shrubs and bushes of this garden brilliantly-coloured fishes, glittering with metallic lustre, dart to and fro; Star-fishes, Sea-urchins, and Snails climb about among the branches, while transparent Crustaceans and Jelly-fish swarm in the crystal water around.

Before quitting the Corals we must briefly recall the important part they have played in Nature in helping to build up the continents which we now inhabit, a process which can still be seen going on in the great coral reefs and islands of tropical seas. With the exception of a few unimportant forms, Corals are now restricted to regions within $30^{\circ}$ on either side of the

Coral Reefs and Islands. equator, the more important reef-building forms being able to carry on their life activities only in water above a certain temperature. Even within these latitudes corals are not found everywhere. They flourish best in the Indian Ocean, the Pacific Ocean, and the Carribean Sea, where the reef-builders are at work over thousands of square miles.

A coral reef is a bank of coral rock built upon the shallow sea-bottom immediately surrounding the shores of tropical lands. Where the land is edged by a reef, as in the island of Mauritius, the ordinary beach passes into a flat irregular bank terminating at a varying distance from land, in a ridge over which the sea continually breaks. This bank, which is called a

The Fringing Reef. "fringing reef," is almost entirely made up of the skeletons of colonies of corals, with which, however, are mixed the calcareous remains of myriads of molluscs, sea-urchins and crabs, and the tubes of the tubc-dwclling worms which haunt every cranny and crevice of coral growths. At low tide broad expanses of the coral rock are to be seen just above water level, strongly contrasting with the usually steep shore of the land to which the reef forms 
a margin. At high tide, except when a retreating wave reveals a small portion of rock, the only sign of the presence of the reef is the line of breakers along its outer edge, where the shallow water suddenly passes into deep water, the outer side of the reef sloping steeply down to a great depth. Between this outer cdge and the land a shallow basin or channel arises, and here the water is usually very clear, and brilliantly-coloured corals are geen covering the rocky bottom.

From such a "fringing reef" there arises, in process of time, a "barrier reef." The channel between the edge of the reef and the shore tends to widen, the corals along its bottom not flourishing so well The Barrier Reef. as those along the outer edge. The water, too, in which they are condemned to live receives its chief additions from rivers or streams of fresh water washing down mud and aand from the land. The corals liere, indeed, cannot grow fast enough to repair the continual disintegration which is going on. The coral colonies at the edge of the reef, on the contrary, grow luxuriantly, continually raising the level of the reef and carrying it out to sea. It seems at first sight strange that corals exposed to the full fury of the breakers should thus flourish; this is no doubt due to the constant supply of food in the shape of minute organisms which 8 warm in the open sea. Even the storms which often break up the coral colonies into fragments help on the work they are doing, as the broken pieces are thrown up on the recf and fill up all interstices left in it, rendering it thus only the more solid and complete. Even the fragments broken off can give rise to new colonies if only the living polyps retracted within their stony cells have escaped undamaged, and provided also that their new position is favourable in the matter of food.

Barrier reefs are found rising up like ramparts against the waves even as much as one hundred miles from the shores where they must have originated. They thus cover vast areas of the sea-bottom. The Great Barrier Reef off the N.E. coast of Australia is $\mathbf{1 1 0 0}$ miles long, the distance from land of its outer edge being usually from 20 to 30 miles, and in places over 100 miles. Saville Kent computes the total area of this reef, built up by coral polyps, as at least 80,000 square geographical miles! Over the whole of this enormous area of coral rock, the water remains comparatively shallow, while the outer edge dips down almost suddenly into as much as 1000 fathoms. The whole surface of such a reef is covered, wherever the circumstances are favourable, with living masses of coral, while, in the large areas where the corals cannot flourish, the reef is a vast conglomerate, the sand and fine mud, swept about by the tides, filling up the interstices between the skeletons of original coral colonies.

When reefs form round small islands, the edge of the reef rising a little above the water, a coral island is produced, enclosing a lake or lagoon out of which rises the original island. Such circular reefs are Coral Islands and also found surrounding a clear lake of still water without Atolls. any island in the middle; these latter are known as "atolls." These wonderful products of the coral polyps are a very marked feature of tropical seas, to the beauty of which they greatly add. The reef encircling an island or smooth lagoon becomes raised above the level of the surrounding sea by the debris washed up upon it; as a rule, however, it does not rise more than a few feet above the surface, the sea often dasling, at the narrower parts, over into the enclosed lagoon. In other cases, it may rise 10 or $12 \mathrm{ft}$. above high tide and may be covered 
with the rich verdure of the tropics, the wind and birds having supplied it with seeds as soon as it rose above the waves. The enclosed lake is often fringed with graceful palms, and the whole island, the product of minute coral polyps, becomes a fruitful habitation for man.

These different kinds of reef formations were all traced back by Darwin to fringing reefs, and accounted for by the subsidence of the land round which these reefs originally formed. A fringing reef would gradually become a barrier reef as the land on which it stood sank, and in the same way, a reef surrounding an island would be transformed, after subsidence of the island, into a circle of coral rock enclosing a lake. As long as the highest points of the land remained above water, the lagoon would contain islands, but, when the original land had entirely sunk beneath the waves, an atoll would result. In the case of a very large island, surrounded, as New Caledonia now is, by a barrier reef, the gradual sinking of the land would lead to the formation of a complicated archipelago of islands, like that of the Maladives to the west of Ceylon, where 12,000 small islands appear to represent a huge reef which must once have surrounded a vast island long since sunk beneath the waves. Darwin's theory of subsidence has, however, recently been disputed, and cannot be considered as fully established.

The Ctenophora, which constitute the last division of the Cnidaria, are beautiful, almost transparent, marine creatures, either more or less round in form, or else flattened out in the shape of ribbons. Their relationship to the other groups is still a matter of uncertainty; they are often placed near the Hydrozoa. The animals belonging to this group move through the water, mouth downward, by means of swimming plates or "combs," from which they take the name of Ctenophora or Comb-bearers. Eight rows of these swimming plates run from pole to pole of the body, each plate consisting of a row of fine hairs or cilia connected at their bases, but capable of independent movement. The animal can, at will, more the plates either separately or collectively, and thus bring about slow locomotion in the direction opposite to the mouth, and, by the help of tentacles and other appendages, twisting and swaying movements can also take place. In the ribbon-like forms muscular contractions bring about serpentine movements.

The mouth leads into a stomach, which, again, opens into a funnel that sends off eight vessels, which run, in meridians, down the sides of the body, just below the eight rows of swimming plates. The animal is usually provided with tentacles and with long "capturing filaments" (Fig. 20). These are not armed, like the tentacles of other Cnidaria, with stinging cells, but with small knobs on coiled stalks, which are called "adhesive" cells. These are not poisonous, but simply sticky, and when shot out at

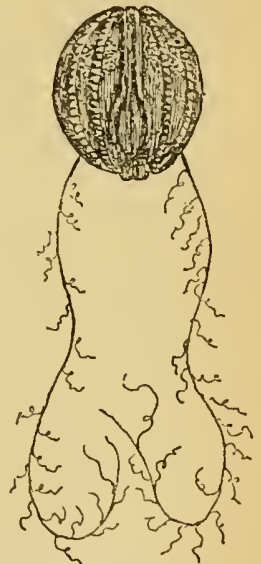

Fig. 20.-The Sea Goose. BERRY (Cydippe). prey entangle it and prevent its escape. They differ from stinging cells also in the fact that they are not finally discharged from the body, but, when the prey is mastered, can be drawn in again, and are capable of functioning any number of times. 
Another peculiarity of the Ctenophora is a sensory organ almays found at the end of the body opposite to the mouth. This somewhat resembles a small weight borne on springs, and, as it is sensitive to the-slightest oscillations of the body, seems to enable the animal to regulate its position in the water.

The Sea Gooseberry, depicted in Fig. 20, is a good example of a round Ctenophoran, the swimming plates and long capturing filaments being well developed. The best known of the ribbon-like forms is Venus's Girdle (Cestus veneris). The mouth lies at the centre of the long, transparent ribbon, which has no swimming plates, but is fringed with cilia. When alarmed, this Ctenophoran can roll up either or both ends of its body spirally, but, when undisturbed, passes through the water with a graceful, undulating motion. Its iridescent colouring makes it a peculiarly lovely object. Other Ctenophorans are barrel-shaped, or resemble Phrygian caps, and many are beautifully phosphorescent at night.

Most of the Ctenophora feed on small Crustaceans. Some, e.g., the Beroidæ, are very voracious, devouring creatures of their own kind, and often larger than themselves, as the mouth is very wide, and the body distensible. They have even been known to $s$ wallow and digest fish.

All the Ctenophora multiply by means of fertilised eggs and ciliated larvæ, which only very gradually attain the adult form. 


\section{SUB-KINGDOM IX.-THE PROTOZOA.}

\section{ANIMALCULA.}

By Henry M. Bernard, M.A., F.L.S., Etc., and Matilda Bernatid.

The Protozoa, or first animals, are distinguished from all others by the fact that they are unicellular organisms, i.e., the body of a Protozoan consists of a single cell, whereas the bodies of all other animals, or Metazoa, are built up of many cells. The one-celled Protozoan is capable of all the vital functions of feeding, moving, breathing, and reproducing itself. In the Metazoa, the greater number of the living cells of which the body is composed are stationary in relation to one another, and the vital activities of the whole have to be considered apart from the lives of the individual cells building it up. We accordingly find these cells arranged into organs and tissues, each specialised for some function necessary to the life of the whole.

The Protozoan, then, is a free-living cell essentially like the cells which, organised into great masses, build up the bodies of all other animals.

All the Protozoa are of microscopic size, and are therefore removed from ordinary observation. This is the more to be regretted since they compare favourably with other classes of animals in variety and beauty of form, and probably surpass all others in actual number of existing individuals. At least five thousarid species of these minute creatures are known, swarming, at the present day, in salt and fresh water or in other animal organisms. There are, in addition, several thousand fossil forms, the latter representing, of course, only those Protozoa of past ages which were provided with a shell or skeleton capable of preservation. Countless millions of such shells form the chief constituent of vast areas of limestone rocks all over the world's surface, and, in some more or less transformed condition, enter into the composition of a large part of the earth's crust. Vast numbers, again, are daily being deposited on the sea-bottom to form the rocks of future ages. Ninetenths of the ooze over the greater part of the North Atlantic consists of the shells of Protozoans, and one ounce of sand from the Naples shore yields no fewer than one and a half million of their shells or parts of such shells.

The very lowest of the Protozoa, that is, the very simplest of all animals, called the Monera, are mere microscopic particles of living jelly or protoplasm, in which, so far, no definite structure has been discovered.

The Monera. In all other Protozoa, however, some differentiation of the protoplasmic body has been found. Among many minute granular particles scattered about in the jelly, there is always one body (sometimes more than one) somewhat larger than the granules, and different in character from the rest. This usually rounded body is known as the nucleus. 
The lowest of the nucleated Protozoa are the Rhizopoda or root-footed animals, a name given to them on account of their manner of moving by means of root-like prolongations of the body. The The Rhizopoda. simplest of these Rhizopoda is the Amoba, which has been called the Proteus animalcule because of its constant changes of shape. These animalcules are to be found in most rain-water puddles and in ponds, and when seen under the microscope might escape observation as mere specks of clear jelly-like matter, yet the careful observer will find that each such speck is capable of moving about and feeding, and, indeed, can be proved to be living, carrying on all those functions which, taken together, we designate as life.

If a Proteus aninalcule is magnified about three or four hundred times the following important points can be noted:-(1) It is naked, i.e., it lias no

The Amoba. cuticle or shell. (2) The surface layer of protoplasm, though not forming a skin, is clear and glassy, and completely envelops the more fluid and granular inner portion of the Amceba. (3) Among these granules can be seen the nucleus and foreign particles, taken in as food, the remains of such particles, and other bodies not understood. (4) Lastly, if the

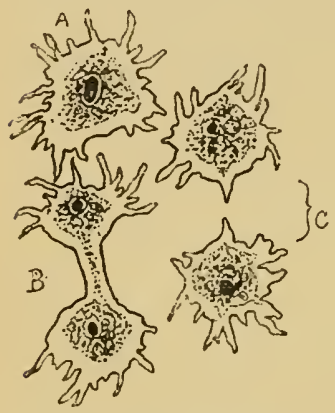

Fig. 1. $-A, B, C$.

A Proteus axtmalcule (Amoeba) in three stages. Amoba is carefully watched, a round space, like a bubble, appears, increases in size, and then instantaneously disappears, forming again at another spot. This is the contractile vesicle which is thought to collect the waste products of the body and to eject them when it contracts.

Tho Amœba is seen to change its shape slowly by protruding at certain points fingerlike or knob-like processes which are called pseudopodia or make-believe feet. Its exceedingly slow movements over the surface of plants or other submerged objects, or through the water, are all made by the extension of pseudopodia in one direction and corresponding withdrawal on another side, the whole body seeming to flow on along its pseudopodia. If, in its course, it meets with minute plant cells suitable for food, it admits them into its body at any point, retains them within it for a time, while it evidently assimilates some nourishment from them, and then flows on, the indigestible remains of its meal being left behind. The manner in which the Amoeba breathes cannot be seen, but the fact that it breathes is indisputable, for if the water in which Amobæ are kept is deprived of its free oxygen, the assimilation of which, is what is meant by breathing, the animals become rigid and lifeless.

When, in consequence of the nourishment derived from the assimilated particles, an Amoba has grown to a certain limit, its shape becomes that of a dumb-bell (Fig. 1, B), the nucleus divides into two, each end of the dumbbell containing one of the new nuclei, the connecting part narrows more and more, and finally the two ends separate completely (Fig. 1, C), and each half (or "daughter") repeats the simple life activities of the original whole (or "mother"). These terms mother and daughter at first sight appear hardly justifiable, yet we now know that all reproductive processes, even in 
the highest animals, are but specialisations of this simple dividing up of living cclls.

The Amceb has been described somewhat fully, as a simple type of the Root-footed animals. Many different kinds of Amabre have been distinguished, varying in the cliaracters of tho pseudopodia and in other respects, but they all agree in being single cells of granulisted protoplasm, containing a nucleus, and moving and feeding by means of pseudupodia.

In the group next above the Amobie, the Foraminifera, the protoplasm of the central body is no longer naked. The animal assimilates from the water in which it lives the necessary material for surrounding itself with a chitinous or shelly covering, or The Foraminifera. perhaps it utilises its own waste products for this purpese.

This shell, in some of the Foraminifera, is merely a delicate case within which the soft body lives. In others, grains of sand, or sponge spicules are obtained from without and embodied in the shell.

For the purposes of morement, the animal sends out pseudopcdia into the surrounding water through the openings in its shell. The Foraminifera liave been divided into the Perforate and the Imperforate, according as the pseudopodia protrude through small openings scattered all over the surface of the shell, or througl only one or two large openings. The shells depicted in Fig. 3 are those of Perforate Foraminifera, while in Fig. 2 we have an Imperforate form, the egg-shaped Gromia. In this latter, the protoplasm streams out at one aperture, breaks up into numberless fine threads which, here and there, rul together, forming thicker patches. The whole surface of the simple shell has also become covered with a thin layer of protoplasm. If any small plant cell or other particle suitable for food touches one of the pseudopodia, other threads flow together round it, and it is slowly drawn in towards the aperture and passed into the body. Such particles of food can often be seen, as in the illustration, within the body of a Gromia.

The shells of the Perforate Foraminifera are very varied in form. Sometimes they consist of many chambers, for the protoplasm, as it grows, has not room in the

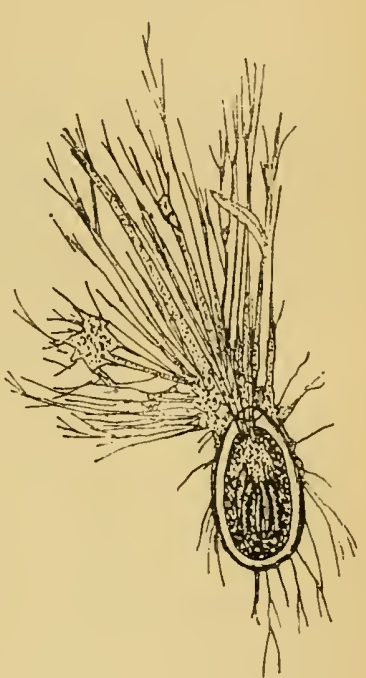

Fig. 2.-Gromis OVIFormis. one little chamber with which it at first surrounds itself, and adds another from time to time, each chamber, however, remaining in communication with the last by means of one or more minute apertures through which a thread or threads of protoplasm pass. The inner protoplasm can also stream out in all directions through the perforations in the sides of the shell.

A few of the many forms assumed by the shells of such Foraminifera are given in Fig. 3. Some are more or less flattened, like coins, and have therefore been called Nummilites (Fig.3, A); others areflask-shaped (C); others agrain closely resemble the shells of the Ammonite or the Nautilus $(B)$; in fact, 
such forms were long considered to be minute Molluscs. The shells of the Globigerina, or globe-bearers(D), help largely to build up Chalk. They are said

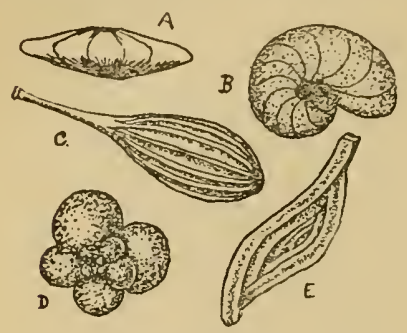

Fig. 3.-ShrLls of ForaminiferA $A$, Nummulites.

$B$, Nonionina.

$C$, Lagena.

$D$, Globigerina.

$E$, Milliola.

to constitute almost one-third of the ooze covering vast areas of the sea-bottom in the North Atlantic. Milliolite shells(E) are the chief constituent of the stone of which the houses of Paris are built. Nummilitic limestones cover an enormous area of Central and Southern Europe, North Africa, West Asia, and India. All limestones indeed abound in the shells of Foraminifera, some species being found in the Coal formations also.

The Foraminifera nearly all live in the sea, creeping along its bottom ; but some float about. Young ones are produced by the breaking up of the protoplasm into small portions, which secrete their characteristic shelly covering before leaving the body of the parent. Some young Foraminifera have very simple single shells, but others are provided from the first with a three-chambered shell.

Passing from those Protozoa whose protoplasmic processes are mere protrusions of the soft body showing no definite shape, but constantly varying, we come to others in which these body processes are highly specialised, and here again we have naked and shelled forms.

The Heliozoa, or Sun animalcules (Fig. 4), have straight, ray-like pseudopodia, which, however, are not rigid, but when brought in contact with particles of food,

The Heliozoa. can contract or bend so as to draw them in towards the body. Sometimes a minute animalcule, touching one of the rays, appears to become paralysed and to glide down the pseudopodium to its root, where a protruding part of the protoplasm can draw in it. In most of the Heliozoa the body is naked, and the contractile vesicle is very conspicuous, often growing to a very large size at the edge of the body, and bursting with such violence as to shake the whole animal. Some idea of the size of these animalcules can be gained from the fact that four hundred of them set closely side by side would

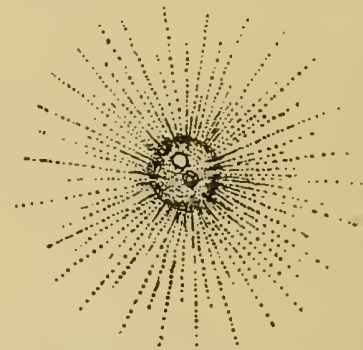

Fig. 4.-The Sun ANimalcile (Actinophrys sol). measure an inch. In spite of the formidable rays by which the Sun animalcule is surrounded, it often falls a prey to a simple Amœba, which either envelops the whole animalcule or tears out portions of its soft body.

Next in order above the Sun animalcules, and far more conplicated in appearance on account of their elaborate skeletons, are The Radiolaria, the Ray animalcules or Radiolaria. In these the soft body is not, as in the Foraminifera, enclosed in an almost continuous outer shell, but the hard matter, usually of a flinty nature, 
derived from the surrounding water, takes the form of rods or spikes which pierce the soft body, and also often form some kind of protective framework around it. Another peculiarity of the Radiolaria is that the soft body is divided into an inner portion, containing the nucleus and enclosed in a gelatinous membrane called a capsule, and an outer portion which surrounds the other and is itself enclosed in a gelatinous envelope. The inner capsule is perforated so that the inner protoplasm can pass outward, while the outer protoplasm sends out radiating threads in all directions through the numberless fine perforations of its envelope.

A vast number of exquisite forms assumed by the skeletons of the Radio. laria were found in the dredgings made by the Challenger expedition. Some of these skeletons consist only of spines radiating from the centre which, however, are often beautifully sculptured or branched; in one form the number of the spines is always twenty, and these are arranged with absolute regularity at definite angles to each other. The whole animal often has the appearance of a spiny ball (Fig. 5, A). In other cases the hard rods, which

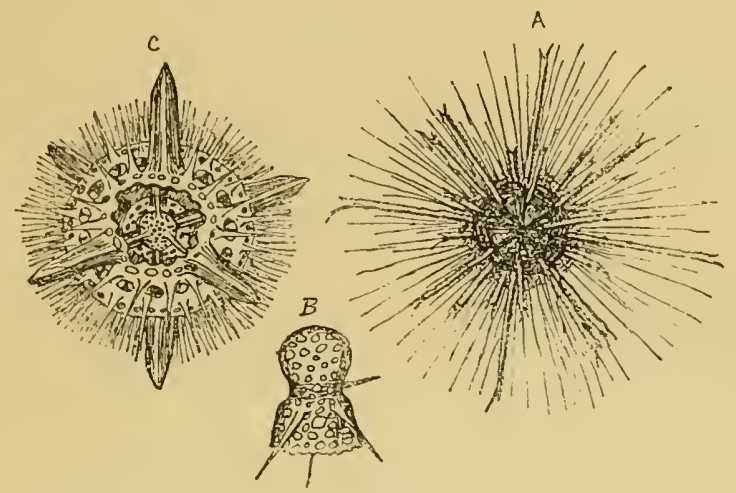

Fig. 5.-SKELETONS OF RADIOLARIA.

$C$, Actinomma. $\quad B$, Lithoinelissa. $\quad A$, Acanthometra.

form the constituent elements of all these skeletons, may be arranged so as to form a framework or network outside the protoplasm with hexagonal apertures. Such a framework may be more or less round for a time, and then a second framework may be added below the first with a wide opening at its base-the whole having the appearance of a helmet ornamented at definite points with a few of the characteristic spines that pierce the inner protoplasm (B). Sometimes a whole series of fenestrated balls is produced, one outside the other (C), recalling the elaborate carved ivory spheres of the Chinese. In the illustration, some of the outer spheres have been broken through to show the inner structure. Such successive spheres are firmly united together by means of cross rods or of the characteristic spines.

The Radiolaria are all found in salt water, but, unlike the Foraminifera, float near the surface. Their skeletons form an important element in the rocks of Sicily and Greece; and the "Barbadoes earth," which is used for polishing, is mainly composed of the flinty skeletons of Radiolarians. Although 
there is little doubt that Radiolaria abounded in the seas where the great Chalk beds were deposited, they are not found in chalk; their siliceous skeletons probably having been dissolved and re-deposited as flint.

In the next division of the Protozoa, we find animals in which the protoplasmic processes of the body are still further specialised. They no longer send out indefinite pseudopodia for creeping slowly along The Flagellata. on the surface of the ground, nor do they float free in the water, the protoplasm streaming out on all sides in fine rays. We now have only one or two processes adapted for locomotion through the water, and these are long and whip-like. These whips or "flagella," at the anterior end of the body, by their constant movement, drag it along rapidly through the water.

Some of the simplest of these Flagellata are so very like vegetable cells, that they were long excluded from the animal kingdom. It is, indeed, impossible to draw any very hard and fast line between the lowest plant and animal cells, and, as authorities are still more or less divided in opinion, such simple Flagellates may be regarded as belonging to a border land. One point in which many of the Flagellata resemble vegetable cells is colour. The Protozoa of other divisions are usually colourless and transparent, whereas many Flagellates are of a bright red, yellow, brown, or green. Some of the simplest of these animalcules (Fig. 6, A) as they dart across the microscopic field by the help of their whips, which, on account of the rapidity of their movements are for the time invisible,

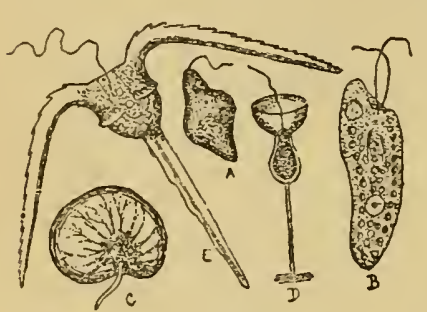

Fig. 6.--FLAGELLATA.

$A$, Euglena.

$B$, Chilomonas.

$C$, Noctiluca.

$D$, Monosiga.

$E$, Ceratium. sparkle like minute emeralds. Some of the red Flagellata, when swarming in great numbers, produce large red patches on the sea. Other forms shine with phosphorescent light, and cause the beautiful glow often seen among the breakers on a shore at night. Thirty thousand animalcules are said to be contained in one cubic inch of such phosphorescent water.

Some of the Flagellata are distinguished by a collar-shaped projection round the depression from which the whip-like appendage rises (Fig. 6, D), others by taking in food at one spot only of the body, i.e., at the base of the chief whip (C). A shelly covering is present in some forms, in which it may resemble a cuirass or may be prolonged into several sharp, horn-like processes $(\mathrm{E})$. These horny cases are often found in Chalk rocks.

The Flagellata do not always, like the creatures we have hitherto described, lead independent lives, each individual feeding, moving, etc., on its own account. They are often found grouped together in Flagellate colonies, the various individuals composing the colony Colonies. being united by a common mass of protoplasm. The manner in which such colonies arise is interesting and important, inasmuch as, from this primitive grouping of single cells to form simple colonies, complex and highly organised colonies arose, culminating in the bodies of the higher animals, which are in reality gigantic colonies of 
countless living cells arranged into organs, each with its own special function to perform for the life of the whole. Single cells multiply in several ways, the simplest being that of the Amoeba, which, creeping along the ground, parts into two daughter Amobre, each of which creeps on its separate way. In the case of free-swimming cells, like the Flagellata, separation into two might not be so easy, especially if the mechanism of locomotion is not very powerful as compared with the size of the body. In such creatures the cells, though actually dividing, need not finally separate, but may swim about in contact with one another; and, if successive generations of cells thus remain together, simple colonies arise. Several balls made up of flagellate cells are known, in which all the whips of the component cells are turned outward, and, by their movement, send the whole colony rolling along through the water. The best known of these is Volvox globator, which, on account of the bright green colour in its cells, is often claimed as a plant.

It is clear again that colonies may also arise by the dividing up of cells which are stationary. The daughter cells in this case may either grow up simply alongside of the parent, or may branch out from it. We are, however, fairly safe in assuming that all the higher animals arose from free-swimming, and not from stationary colonies, a stationary manner of life being but little conducive to progress. In Fig. 7, A, we see stationary colonies of Flagellata which, but for the stalk of attachment, somewhat resemble Volvox above mentioned. Another stationary colony is seen in the same figure (B), and is formed by the contiguous tubular sheaths of a number of flagellate cells, each provided with two whips. This colony forms folded, fan-like growths, the height of the whole structure being often not more than $\frac{7}{75}$ of an inch. Collared Flagellates also form colonies, sometimes being grouped together in flower-like bunches on stalks, as in Fig. 7, C, or

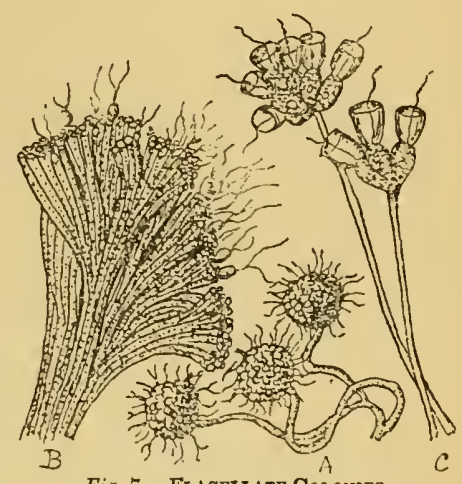

Fig. 7.-Flagellate Colonies.

$A$, Anthrop hyse.

$B$, Rhipidcdendron.

C, Codosig? floating about freely with the collar's and whips projecting from a mass of common protoplasm. A colony of this latter sort has been named Protospongia, as it seems to foreshadow the arrangement of somewhat similar collared cells found in the Sponges.

Returning, however, to the Flagellata which remain single, i.e., do not form colonies, reproduction takes place among them in several different ways. Some Flagellata simply break up into parts, like the Amceba, others detach only small pieces of their bodies, each piece developing into a new animal, a process which is called budding or gemmation; others, again, reproduce themselves by a kind of internal budding called spore-formation. The whole inside of the animal divides into a great number of ninute "spores," each of which, after resting a while, grows into an animal like the parent. The Noctiluca (Fig. 6, C), for instance, which causes the marine phosphorescence already alluded to, may pass through a resting stage when it loses its whip and looks like a mere gelatinous ball (it is then said 
to be encysted). The protoplasm seems to collect in one part of the cyst and to break up into minute nodules. These nodules, which are called spores, raise up the outer surface into prominences, and finally, when mature, pass through the wall of the cyst, develop whips of their own, and swim about freely as young individuals known as "swarm spores."

Leaving now for a moment those Protozoa, which are rising higher and ligher in the scale of organic life, we must notice a group which shows curious degeneration, the Gregarinæ. These creatures The Gregarinæ. possess neither pseudopodia nor flagella : they can only move very slowly by a kind of contraction of the protoplasm just below the outer surface, which, being somewhat different from the rest of the body, we may call the "skin." These animalcules are all parasites, lience their degradation. They have managed to get into the bodies of animals higher than themselves, and are able to draw in as food, through the whole surface of the body, the juices of their "host" without any exertion on their own part. They are very common in the bodies of all classes of animals from the worms upward, each kind of Gregarina having its own special feeding ground in some part of a higher animal. One species, for instance, is only found in the gills of a small Crustacean, another in the liver of the Rabbit, and so on. The only kind of outward appendages ever found in these creatures are hooks which enable them the better to attach themselves to their victims. The chief life activity in these, as in most other parasites, is reproduction, which takes place by spore-formation. Two or more of the worm-shaped Gregarinæ fuse together, become encysted, and, after a time, produce spores, which are released by the bursting of the cyst. Eacl spindle-shaped spore develops into an independent individual, being supplied by its immediate surroundings with appropriate nourishment.

We pass on from these degenerate creatures to the highest of the Pro. tozoa, the Infusoria, so-called on account of being found in infusions-i.e., in water in which decaying animal or vegetable matter The Infusoria. has been soaked, and in which it was at one time thought that they bred spontaneously.

In the Infusorians the protoplasm of the body shows more variety than in any other Protozoans. Not only is the outer surface of the body distinctly unlike the inner protoplasm, but it is more or less covered with very fne hairs or cilia (literally eyelashes), which promote its motion. It is sometimes provided with hooks or bristles as well, by means of which it can creep or hang on to other objects. At one definite spot there is a simple mouth, from which a depression often leads into the interior of the body. The mouth is usually encircled by cilia, which, by their rapid vibrations, keep up a kind of whirlpool, and bring particles of food within reach. As the food, which passes on into the body along the tube, is absorbed, definite streamings in certain directions can be made out in the granulated protoplasm. The indigestible portions of the food are, in some forms, ejected at a definite part of the body. The nucleus is not always round-it may be horse-shoe-shaped, or ribbon-like, or it may even resemble a string of beads. There are often several contractile vesicles.

The Infusoria are very plentiful in fresh water: they prey upon each other, and sometimes upon higher animals, such as Rotifers. Some arc parasites.

There are Ciliated Infusorians and Tentacled Infusorians. 
The Ciliated Infusorians are classed according to the arrangement of their cilia. These sometimes cover the whule surface of the body, as in the

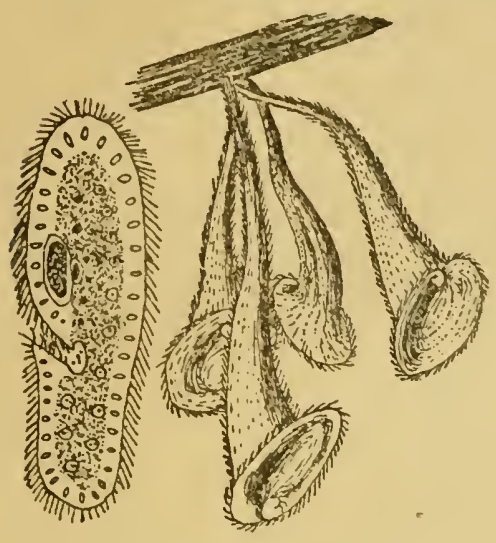

A

Fig. 8.-Ciblated Ixfusoria. $A$, Paramocium.
$B$, Stentor.

Slipper animalcule (Fig. 8, A), which is very common in pond water or in infusions of hay, and measures from $\frac{1}{96}$ to $T^{\frac{1}{2}} \overline{0}$ of an inch in length. In this Protozoan, the distinction between the outer part of the body and the inner granulated part is very clear, and the mouth and tube leading from it are very evident. In tho outer "skin" a number of small oval bodies can bo seen pointing outwards. These, which are known as trichocysts, are minute bags containing threads which can bo shot out of them and are probably used as a defence against enemies. These structures recall the stinging threads of the Coelenterates, but are still more wonderful as the products of a single cell.

In the next division of the Ciliated Infusorians, very fine cilia cover the surface of the body, while longer ones encircle the moutl. The Trumpet animalcules (Fig. 8, B), usually about $\frac{1}{20}$ of an inch in length, are found moving about freely in the water or attached, either singly or in groups, to some submerged object by the narrowed end of the body. The lower parc of the body is sometimes protected by a kind of sheath or case. The wide opening at the free end which surrounds the mouth is fringed with long and strong cilia. In order to multiply, these Trumpet animalcules divide into two, a new mouth and oral fringe forming on the parent animal before division.

The Infusorians of the next division have smooth bodies, the cilia being usually confined to the region round the mouth; in some cases, however, a second band of cilia surrounds some other part of the body. Some of the attached Infusorians of this kind surround themselves with a slippershaped case of protoplasm, which helps to protect

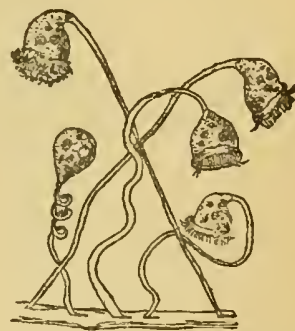

Fig. 9.-GROUP OH BRLL ANimalculks (Vorticellidac). the soft part of the body, and can, when necessary, almost entirely cover it. As a rule, however, the mouth end, with its circle of cilia, protrudes from the aperture of the case in search of food. Other forms attach themselves by stalks which are contractile, and can, by coiling up spirally, quickly withdraw the animal from any threatening danger.

The Bell animalcules, when watched under the microscope, afford a very interesting example of the complexity of life and movement which may be attained by the single cell. When the water in which they are is, for any 
reason, in a state of disturbance, the minute gelatinous balls lie hidden close to the surface of some water weed at the ends of their tightly coiled stalks, and thus easily elude observation. But if the water is at rest, the observer, through the microscope, will see them gradually emerge from their place of refuge, one individual after ancther rising into view on its slowly uncoiling stalk, the ball lengthening and assuming the sliape of a bell about $\frac{1}{300}$ of an incl in length. Long cilia, fringing a spiral membrane which can be protruded beyond the aperture of the bell, wave about in the water, and bring within reach particles of food that are swept down a groove leading to the inner protoplasm. As such a group of Bell animalcules is watched, one individual or another suddenly vanishes, being drawn down instantaneously by the contraction of its stalk, while others more gradually come into sight. These animalcules multiply by dividing lengthwise; the young form, when provided with its circle of cilia, breaks loose from the parent and swims about freely for a time before attaching itself by a stalk. Young are sometimes also produced within the parent as spores.

These beautiful creatures are often found in colonies of various shapes, some of the most delicate (Fig. 10, A) resembling the frond of a maidenhair

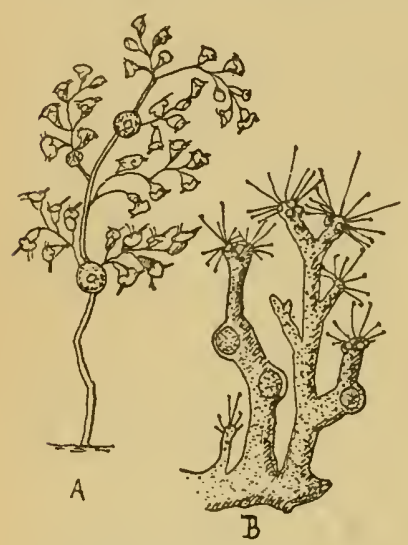

Fig. 10.-Infusoriax Colonirg. $A$, Zoothamnium. $B$, Dendrosona. fern. The stem is, in such cases, formed of protoplasm, produced by the various individuals of the colony, which are not always all alike. In the form illustrated spherical individuals without stalks are to be seen attached at the bases of the branchlets which carry the other individuals.

In the fourth division of the Ciliated Infusorians the cilia are confined to the lower surface of the body, and are sometimes changed into bristles or hooks; these forms are much less attractive in appearance than those we have just described.

We come, in the last place, to the Tentacled Infusorians which are often to be found attached to pond weeds by long, straight stalks. The soft body is usually contained in a cup-like sheath, sometimes triangular in form, and terminates at the free end in one or more projecting knobs, ornamented with groups of stiff, hollow tentacles. The animal has no mouth, but feeds by means of these tentacles, the minute discs in which they end arresting and piercing the bodies of any small animalcules that conie within reach. The soft parts of the victim are sucked up through the hollow tentacles and drawn into the body within the sheath. These stationary bodies give rise, by means of budding, to free young forms with cilia which swim about for a time, then attach themselves, lose their cilia, and develop tentacles like those of the parent form.

These Tentacled Infusorians sometimes form very complicated colonies consisting of creeping roots, from which rise trunks and branches (Fig. 10, B). Each branch and branchlet terminates in an individual with its radiating tentacles, but besides these tentacled members of the colony there are other 
spherical members, sometimes clustered together like bunches of herries, and within the protoplasm of the trunks there are capsules in which the young are produced and matured. So complicated are these beautiful colonies, in which a distinct division of labour takes place, that it is difticult to realise that they are nothing more than communities of Protozoans.

THE ENI. 



\section{N D EX}

A.

A.MD.YARKS, 155

Aaril-wolf, 6:

Abbreviatus, Tachytriorchis, $31 \cdot 2$

Abiterites, 204

Abramis, 499

Abraxas grossulariata, 592

A bu-maskul, 28.2

Acadica, Nyctala, 324

Acalyptere, Muscidae, 607

Icantlias, 519

Acanthiclositta, 375

Acanthocephali, 681

Acanthochitidie, 616

Acanthocinus adilis, 561

Acanthoclinislie, tis

Acanthometra, $7 t i$

Acanthopterygii, 463

Acanthosoma griseum, 595

Acanthuridie, 470

Acarina, 545

Accipiter, 311

Accipitres, 304

Accipitriformes, 304

Accipitrina, $30 \%$

Aecipitrinus, Asio, 324

Acephala, 613

Acerina, 404

Aceti, Anguillula, $6 \div 9$

Achatinellida, 612

Achatina, 642

Achatinida, 64:

Acheta campestris, 567

Acipenser, 511

Acipenser huso, 511

Acipenser ruthvenus, 512

Acipenser sturio, 512

Acipenseridie, 5 11

Acnraida, 181

Acorlon, 101

Acola, $\$ \$ 5$

Acoelomata, 690

Acomus, 236;

Acomys, 106

Aconamys, 111

Acorn, Barnacle, 533

Acraina. 581

Acris gryllus, 443

Acrobates, 203

Acrocephalus phragmitis, 370

Acrocephalus streperus, 370

Acromyolie, 373

Acromyodi, $35 \pi$

Acronurida, 170

Acronurus, 470

Acryllium vulturinum, 240

Actæon, 639

Actæonidie, 640

Actinia, 701

Actinia mesembry anthemum, 703
Actinia paumolensis, 701

Actinoloba diantluus, 702

Actinomma, 717

detinophrys sol, 716

Actinopterygii, 463

Aculea ta, 574-5is

Aculuata, Alirodite, 673

Aculeata, Echilna, 217

A culerta, Ophiopholis, 657

Alamsi, Colynbus, 251

Adamsia palliata, 703

Adansoni, Excalfactoria, 235

Alansoniana, Pleurotomaria, 63:

I dapis, $3:$

Addax, 154

Addax nasomaculatus, 154

Adders, The, $4 \div 4$

Adder, Bandled, 4:24

Adiler, Death, 425

Adrer, Putf, 427

Adder, Resplendent, $4: 24$

Adela, 593

Aleorbidx, 637

Adjutants, 27

Arscendens, Clitambonites, 651

Adustus, Canis, $66^{\circ}$

Edilis, Acanthocinus, 561

Egagrus, Capra, 159

Agialitis, 270

Egithalus, 368

Egithalus vagans, 368

Eglefinus, Gadus, 491

Egotheles, 334

Egothelinæ, 333

Agyprymnus rufescens, 197

Eluropus melanoleucus, 75

Elurus fulgens, $75-76$

Anea, Carpophaga, 243

Eolidioidea, 641

Epyceros, 152

Epyornis, 220

Epyornithiformes, 221

Xepypodius, 227

Eronautes melanoleucus, 346

Eruginosus, Circus, 309

Esalon, Falco, 3:0

. Eschnida, 570

Etheospondyli, 463,509

Etheria, 623

Etheriida, 623

F.thiopica, Ibis, 258

Aëthiopicus, Phacocharus, 131

Etobatis, $52 \%$

Ex galericulata, 294

Ex sponsa, 294

Aftinis, Cervus, 143

African darter, 301

African elephant, 123

African flring squirrel, 89

African giraffe, 147

African lung-fish, 460
African swallow-tailed kite, 316

Africin will ass, 129

Africana, Verreauxia, $35 t$

Africanus, Elephas, 12:3

Africanus, Sus, 134

Agami heron, 283

Agamia agami, :s:?

A gamidie, 398

Agamodon, 40s

A gapornis, 32!

Agedastes, 23:)

Agelaus phounicens, 361

Agelas noli tangere, 693

Agelenilia, 544

A gile frog, 436

Agile wallaby, 194

Agilis, Lacerta, 40!)

Agilis, Marropus, 194

A gilis, Pana, 436

Agleact is, 348

Aglossa, 444

Aglypha, 42.2

Agonus, 476

Agrestis, Microtus, 103

Agricola, 103

Agricola, Tetrastemma, 6\$1

Agrion, 570

Agrionidie, 570

Agronyzine, 608

Agrotis exclamationis, 591

Agutis. $s$

Agutis family, The, 115

Ajaja, $286^{\circ}$

A jaja, A jaja, 286

Alactaga, 110

Alactaga decumana, 110

Alaurla arvensis, 36

Alaudida, 364

Alba, Chionis, 265

Alba, Gygis, 262

Albatros, The, 257

Albatros, Cautious, 250

Albatros, Culminated, 255

Albatros, True, 258

Albatros, II andering, 258

Albellus, Mergus, 297

Albertia, 683

Albertis:, Gymnophaps, 244

Albicaudatus, Tachytriorchis, 312

Albicilla, Halisetus, 315

Albicollis, Rbynchops, 26:2

Albicore, 473

Albida, Chamostra, 628

Albifrons, Anser, 295

Albifrons, Bubalis, 150

Albinucha, Poecilogale, 81

Albipennis, Tachybaptes, 253

Albofuscus, Nycticejus, 39

Alburnus, 499

Alca torda, 260

Alcerlinina, 336 
Alcedo, 336

Alcedo ispida, 337

Alces machlis, 145

Alchata, Pteroclesrus, 241

Alcinus, Maehorhampluus, 317 Alcce, 259

Alcyon, Ceryle, 336

Alcyone, 336

Alcyonella fungosa, 669

Alcyonidium, 6 (is

Alector, Crox, 229

Alectoroporles, 220

Alectrinas, 243

Alectrænas nitidissina, 243

Alepocephalirlie, 507

Alexanor, Eques, 5st

A leyrodes proletella, 602

Aleyrodidæ, 602

Alfredi, Cervus, 143

Alfurus, Babirusa, 134

Algiroirles, 409

Alle, Mergulus, 263

Alleni, Neotona, 10:3

Allicesliad, The, 507

Alligators, 350

Alligator, Chinese, 380

Alligator mississippiensis, 380

Alligator, North American, 350

Alligator sinensis, 380

Alligator-terrapins, 390

Allopsida, $6 \pm 7$

Alni, Aphropliora, 600

Alopecias vulpes, 517

Alosa, Clupea, 507

Alouatta, 23

Alouatta nigxa, 24

Alouatta seniculus, 23

Alpestris, Canthocamptus, 532

Alpestris, Otocorys, 364

Alpine chongl, 358

Alpine marmot, 93

Alpinus, Canis, 68

Alternata, Rafinesquina, 649

Alucita hexadactyla, 594

Alucitidia, 594

Aluco, Syrnium, 321

Alueco, Syrnium, 32t

Alytes, 413

Anathia lendigera, 663

Ansazonian dolphin, lis

Amazonian fresh-water tortoise, 393

Amazons, 329

Amber-snails, 642

Amblyceplialidie, 4:6

Amblyceplialus, 426

Amblyopsidæ, 502

Amblyopsis, 502

Amblyornis inornata, 359

Amblyrlynclius cristatus, 102

Amblystoma, 446

Amblystoma tigrinum, 449

Amblystomatinse, 449

Amboynensis, Lophurus, 400

Amelia, Macronyx, 365

American barlgers, 79

American barn swallow, 3is

American beaver, 99

Americal bison, 163

American black bear, 75

American bluejays, 358
Antericau boat-bill, $2 \$ 3$

American cedar-bird, 369

American chatterers, 374

American creepers, Tlie, 362

American cuckoo, 350

American deer, 146

American golden plover, 2\%0

American racoons, 75

American swa!low-tailed kite, 316

American trogons, 349

American warblers, The, 365

American wood-snakes, 422

American wood-stork, 281

Americana, Antilocapra, 119

Americana, Mustela, 80

Americana, Periplaneta, $56 t$

Americana, Pipa, 444

Americana Phea, 22:

Americanus, Bos, 163

Americanus, Coccyzus, 351

Americanus, Crocodilus, 3si

Americanus, Ursus, 75

Amethystinum, Ktilbum, 57s

Anlierstia, Chrysolopluus, 238

A mia-calva, 510

Amicta nyctiornis, 341

Amiide, 510

Ammocretes, 524

Ammorlorcas clarkei, 153

Ammodronus, 364

Ammodytes, 491

Ammodytes, Vipera, 49

Ammon, Ovis, 160

Aminonea, $6+6$

Ammoperdix, 233

Ammoperdix bonhami, 23:3

Anmoperdix lueyi, 233

Amceba, 691, 714

A nupeliciz, 369

Ampelis certrorum, 369

Ampelis garrulus, 369

Ampelis japonicus, 369

Amphibia, 431

Amphibius, Hippopotamus, 131

Amphibius, Microtus, 103

Amphibola, 641

Amplibolidæe, 641

Amphignathodonticlw, 4 t4

Amphineura, 615

Amphioxus, 526

Amphioxus lanceolatus, 526

Amphipuous, 495

Amphipoda, 554

Amplisbrenidæ, $40 \mathrm{~s}$

Anmpisile, 482

Amphitretida, $64 \overline{7}$

Anphiuna, 451

Ampliunidie, 450

Ampullariidie, 635

Anabantida, 483

Anabas scandens, 483

Anableps, 501

Anacanthini, 490

A naconda, 420

Anaides, 450

Anaphe, 607

Anarhynclius. 27i

A narrhichas, 478

Anas, 296

Anastomus, 280

Inaticla, $: 292$
Anatifera, Lepas, 533

Anatina, Lingula, 650

Anatinacea, 623-627

Anatinidæ, 628

Anatinus, Ornithorhyuchus, 215

Ancestor of Brachiopoda, 651

Ancistrodon, 42 ?

Ancistrodon contortrix, 429

Ancylochilus, 269

Ancylus, 642

Andersoni, Tylotritom, 415

Anderssoni, Maehcerhamphus, 317

Andigena, 35\%

Andina, liecurvirostra, 2\%0

Andinus, Phenicoparrus, 290

Andrena, 580

Anelytropidz, 411

Anemones, 700

Anemone, Cave-dwelling, 701

Allemone, Cloak, 703

Anemone, Daisy, $70: 2$

Auemone, Plumose, 702

Anemone, Strawberry, 713

A nemones, Sea, 701

Anemones, Tropical, 704

Angasi, Tragelaphus, 15 ;

Angel fish, 519

Angler fish, 4it

Angolensis, Pitta, 375

Anguidie, 404

Anguilla, 494

Anguillula aceti, 679

Anguineus, Proteus, 45.

Anguis, 405

Anguis fragilis, 404

Angustatus, Echinorlynchus, 682

Anlinga, Plotus, 3in

Animal plants, 697

Animalculr, 713

Animalcule, Bell, 722

Animalcule, slipper, $\lceil 21$

Animalcule, Trumpet, 721

Aninalcules, sun, 716

Anisolabis maritina, 563

Anisonyx, 91

Annelid, Tube-making, 6 '.2

Anuelida, 531, 671

Annelidicola, Cyclatella, 655

Anniellidie, 405

Annulatus, Linguielapsus, 449

Annulosa, 5:29, 548

Anoa, 162

Anolis, 401

Anomalochilus, $4: 21$

A nomaluridae, 89

Anomalurus, 89

Anomalurus peli, 90

Anomalurus pusillus, on

Anomia, 621

Anomia ephippium, 621

Anomiacea, 621

Anowiura, 537

Anoplodium, 685

Anoplogaster, 468

Anoplura, 602

Anops kingi, 408

Anorthura troglodytes, $3 \pi 1$

Anser albifrons, 29,5

Anser anser, 295

Anser brachyrhynchus, 205 
Auser fabalis, 295

Anseranas semipalmata, 993

Anseranatine, 293

Inseres, 292

Anserinie, 295

Ants, 5is

Int, Australian, 579

Ant, House, 579

Ant, Red, 5i?

Ant, Wood, 579

Ant-bears, 189)

Ant-birds, The, 375

Ant-eaters, $1 \mathrm{si}$

Ant.eater, Freat, 184

Ant-eater, Lesser, 1st

Ant-eater, Two-clawel, 154

Ant-eaters, True, 18:3

Ant-lions, 570

Ant-thrushes, 37

Antaretic white seal, 86

Antaretic wolf, 64

Antarctica, Megalestris, 263

Antarcticus, Canis, $6 t$

Intechinowys laniger, 209

Intedon rosacea, 6 tis

Antelopes, The, 149

Anteloye, Bubaline, 150

Anteloje, Equine, 153

Antelope, Four-horned, 15i

Antelopes, Haruessed, 156

Anteloye, Prong-horned, 149

Antelope, Royal, 151

Antelope, sable, 15 ;

Antelope, salts', 151

Intennarias, 47.5

Inthea cereus, 703

Anthocincla, 375

Inthomyine, 60s

Inthophila, 580

Inthops ornatus, 36

Anthozoa, Tu1

Anthracocerus, 339

Anthracocerus coronatus, 339

Anthrenus, 556

Anthrophysa, 719

Anthropoidea, 11

Anthropopitbecus, 14

Anthropopithecus calvus, 15

Anthropopithecus troglodytes, 15

Anthus, 365

Inthus pratensis, 365

Anthus trivialis, 365

Intigone, 274

Antigone australasiana, $27 t$

Intilocapra, 10

Antilocapra americana, 149

Antilocapride, 149

Antilope cervicapra, 152

Antilopine, 152

Antipatharia, 707

Antisiensis, Cervus, 140

Anurosorex, 46

A patura, 581

A pe, Barbary, 22

Ape, Black, 2:2

A pes, Man-like, 11

I phanapteryx, 251

Aphaniptera, 60 :

Aphaniptera, Diptera, 609

I phanolimnas monasa, 251

Aphididee, 601
Aphodius, 557

A phrodite aculeata, $6: 3$

A plirophora alni, 600

A piaster, Merops, 341

Apis mellifica, 581

Apivorus, l'ernis, 317

Aplacophora, (i15-616

Aplustrida, 640

A plysidae, (64)

Aplysioilea, 610

A pocka, 45:3

I porles, 4!):3

Ipodille, 532

Apollo, Parnassius, is -

A porrlaiclie, $636^{\circ}$

Aporrhais, $6: 36$

Aprendicularians, 5:?

Apples of sodom, $5 \vec{i}(\mathrm{i}$

A ytenodytes longirostris, 25.5

Aptenclytes patachonica, $25 \overline{5}$

Apteryges, 2:1

Apterygiiformes, $2 \cdot 21$

Auteryx, The, $2 \cdot 24$

A ptery a a stralis, 224

A ptornis, 25:3

tpus cancriformis, 531

Apus, Micropus, $3 \frac{16}{6}$

Apus, Ophisaurus, 405

Aquarum-dulciun, Tetrastemina, 654

Ayuatic carpincho, 116

Aquatica, Argyroneta, 54

Ayuaticus, Cinclus, 37

Aquaticus Rallus, 219

Aquila chrysaetus, 314

Aquila, Fregata, 303

A (juila heliaca, 314

Iquila niaculata, 311

Aquila rapax, 314

Aquilina, 307,313

Ara, $3: 29$

Arabian camel, 136

Arabs, Galeorles, 540

Araclinida, 539

Arachmoides, Brachyteles, 25

Arachnoides, Pyxis, 337

Arani, 275

Aramides, 249

Aramides ypecalua, 250

Aramus pictus, 2:5

Aramus scolopaceus, 275

Araneida, $54^{\circ}$

Araneoides, Galeodes, $5+1$

Araneoides, Scutigera, $5+8$

Araneus, Sorex, 46

Arapaima, 504

Arapaima gigas, 504

A rborea, Hyla, 44:

Arboricola, 234

Arca Nor, 6:1

Arca Zebra, 621

Arcacea, 621

Archeopteryx, 220

Archiannelida, 675

Archibuteo, 315

Arcifera, 440

Aretic fox, 73

Arctic tern, 261

Arctica, Fratercula, 260

Arctica Islandica, 621

Areticiales 6i2t

Aretictis binturong, 59
Arcticus, colymbus, 254

Arctiidie, 588

Arctogale, 59

A retomys, 92

Arctomys aureus, 93

Arctomys bobac, 93

A retomys caurlatus, 91

Aretomys dichrous, 9.1

Aretomys himalayanus, 98

Arctomy's marmotta, 92

Arctonyx, 79

Aretus, Ursus, T5

Ardea cinerca, 2s?

Ardeiformes, $27 \mathrm{~s}$

Ardeirallus, 284

Irdetta, $2 s t$

Irrletta involucris, 204

Ardetta minuta, 284

Arenaria, 271

Arenaria interpres, 97

Arenaria melanocephala, $27: 2$

A renariina, 272

Arenicola, Lycosa, 543

Arenicola marina, 6.2

Areolatus, Homopus, 3s-

Argali, True, 160

Argas persicus, 546

Argentatus, Canis, 7

Argentatus, Larus, : 103

Argentine cow-bird, 361

Argentine peludo, 1 so

Argiope riparia, 544

Argonaut, $6+7$

Argonauticlae, $6 \pm 7$

Argulidie, 532

Argus, Argusianus, 239

Argus, Common, 239

Argus, Crested, :239

Argus, ('ray's, 239

Argus plieasant, $235+239$

Argusianus argus, 239

Argusianus bipunctatus, 239

Argusianus grayi, 239

Argyroneta aquatica, 544

Ariculide, 634

Arietans, Bitis, 127

Arion ater, 643

Arionidie, 613

A rmadillos, 1s1, 135

Armarlillo, liroat, 186

Armarlillo, Fairy pink, 158

Armatillo, Giant, $1 s 7$

Armadillo, Hairy, Ist

Armadillo, Six-banded, $1 \times 0$

Armadillos, Three-banderl, Isi

Armenian sleep, 160

Arnuxi, Berardius, 17T

Arnux's whale, 177

Aromia moscliata, 561

Arquatela, 269

Arrow worm, 682

Artamidz, 369

Artamus, 369

Artamus sorditus, 36 ?

Artenia salina, 531

Arthropoda, 5\%9

Arthropoda, Edible, $530^{\circ}$

Arthrostraca, 584

Artibeus, 41

Artibeus perspicillatus, 11

Articulata, 520, 651

Aru Lsland wallaby, 121 
Arui, 160

Arundineum, Cobus, 152

Arvensis, Alunda, 364

Arvicanthis, 105

Ascalaphidie, $5 i 1$

Ascalajhlus, 571

Ascalaphus kolyvaueusis, 570

Ascaris lumbricoides, 679

A scetta, 691

Ascidians, 532

I scilliella aspersa, 5:23

A sellus aquaticus, (\$\$2

Asiatic bittern, $2 \$ t$

Asiatic will ass, 1:9?

A siatica, Cinnyris, 366

Asilida', $60 \bar{s}$

Isilus crabroniformis, 605

A sinus, Equus, 129

Asio, 32t

Asio accipitrinus, $3: 4$

A sio otus, 321

Asp, Egyptian, 424

Ispatha, 341

Aspergillum, 6:3

Aspersa, Ascidiella, 520

Aspiclites, 419

Asuidobrancliate, 614

Aspidogaster conchicola, 688

dspro, 464

Ass, African wild, 129

iss, Asiatic wild, $1 *$ ?

Assiminida, 635

Assogue, 81

Astacider, 536

Astartidic, $62 t$

Asterias rubens, 653,656

Asteroitlea, 656

Asterospondyli, 51 is

Asthenosoma urens, 660

Astrae, 706

Astrape, 521

Istronesthes, 505

Istur, 310

Astur batluis, 311

Astur novie liollandiae, 311

Astur leucosomus, 311

Astur palumbarius, 310

Astur torquatus, 311

Isturina, 31:

Astutus, Bassariscus, 76

Asymmetron lucayanum, 5:27

Atalapha, 37

Atalaplua cinerea, 37

A teles, 25

Ateles variegatus, 2.7

Atelornis pittoirles, 335

Ater, Arion, 613

Aterrimus, Microglossus, 328

Atherina, 479

A therinida, 479

Athertoni, Nyctiornis, 341

Itherura, 11:3

A thoracophoridit, 642

A thoracophorus, 64 ?

Atlanta, 635

Atlantidia, 637

Atolls, 710

Atra, Salamandra, $44 \%$

Atre, Buchanga, 361

Atrata, Chenopis, 993

itremata, 6ij

Itricapilla, Ficedula, 3̈2
Atricapilla, Sylvia, 370

Atrichia clamosa, 376

Atrichiida, 376

Atrochous, 67:3

Atropos pulsatoria, $5 \pi \cdot 2$

Atrypa, 651

Attagides, 266

Attagis, $266^{\circ}$

Atthis, 348

Atypus, 54:2

Atypus sulzeri, $5+3$

A ucklanrlica, fiallinago, 268

Audax, Uro:etus, 314

Anks, The, 25:9

A uk, (ireat, 26i)

A uk, Little, 260)

Aulacodus, 11:

Aulacorhamphus, 352

Auliscons, 481

Aulostoma, $4 \$ 1$

Aulostomatidz, $4 \$ 1$

Aulostomum gulo. 676

Aura, Cathartes, 304

Aurantiaca, Zaitha, 59-

Aurata, Cetonia, $55 \mathrm{~s}$

Auratus, Carabus, 555

A urea, Jacamerops, 355

Aurelia aurita, 700

Aureus, Aretomys, 9:;

Aureus, Canis, 66

Aureus, Xanthomelus, 359

Auriculidie, $6+1$

Aurita, Aurelia, foo

Auritum, Crossoptilum, 236

Auritus, Plecotus, : $: 9$

Auritus, Podiceps, 253

Australasiana, Antigone, 274

Australian ant, 579

Australian brush-turkey, 227

Australian lady-bird, 602

Australian lung-fisll, 460

Australian megapode, 228

Australiensis, Geonemertes, 68t

Australis, Apteryx, 22t

Australis, balina, 172

Australis, Euporlotis, 27j

Australis, Gallinago, 26s

Australis, (teoplana, 68ti

Australis, Merganser, 207

Australis, Mycteria, 25il

Australis, Peltolyyas, $27(1$

A ustralis, Rostratula, 267

Australis, Struthio, 2.23

Autodax, 450

Autolytus, 673

Autumnalis, Tetranyclus, 547

Avahi, Woolly, 29

Avahis, 29

Avahis lanigera, 29

Avellanarius, Muscarlinus, 99

Aves, 218

Avicula, 622

Avicula lírundo, 622

A viculacia, 622

Avicularia, Ornithormyia, 608

Avocet, Chestnut-breasted, 270

Avocets, 270

Awantibo, 31

Axis, C'ervus, 143

Axis, or spotted deer, 143

Axolotl, 446

Axolutl, Ailuit, 4.19
Aye-aye, The, 31

Azarie, C'anis, 69

Azara 8 dog, 69

Azorensis, Regulus, $36 ?$

B.

Babblers, The, 37:

Babirusa, 134

Babirusa alfurus, 134

Babiun, Palvio, 2:3

Baboon, Dog-faced, 2-2

Baboon, Gelarla, $2:$

Baboon, Yellow, 2:

Bacon beetle, 556

Bactrian camel, 130

Bactrianus, ('amelus, 130

Badgers, 79

Badgers, American, 79

Badger, Common, i!

badgers, Ferret-, so

Badgers, Malayan, 70

Badgers, sand-, 79

Badia, Felis, 55

Badius, Astur, 311

Badius, Rhizomys, 107

Breticus, Lampicles, 586

Bagad, 49\%

Bagarius yarelli, 196

Baillon's crake, 251

Balana australis, 172

Baliena mysticetus, 172

Balæniceps, 2\$2

Balæniceps rex, :25?

Balanicipiticles, 252

Balrenicipitide, 2is

Balaniclæ, 171

Balenoptera, 173

Balienoptera musculus, 174

Balatnoptera rostrata, if

Balitnoptera sibbaldi, 173

Balanidie, 533

Balaninus nucum, 560

Balano, 5:S

Balanoglossus, 528

Balanoglossus sarnicnsis, $5 \cdot 2 y$

Balanoides, Balanus, 533

Balanus balanoides, 533

Bald chimpanzee, 15

Bald eagle, 315

Bald uakari, 27

Balistes, 489

Balistidæ, 489

Ballan, 456

Balti, 'The, $45 T$

Bamboo-rats, 106

Band-fishes, 477

Banded adder, 425

Banded ant-eater, 209

Banded lemming, 103

Banded mungoose, 61

Banded sea-snake, to5

Banded wallaby, 196

Babded water-snails, 63 i

Bandicoot tribe, 205

Bandicoot, Gunn's, 206

Bandicoot, Pig-footed, 206

Bandicoot-rats, 105

Bank martin, 373

Bank-vole, 10:3

Bank's ribband-fisli, $4 \$ 5$

banksi, Regalecus, 185 
Banteng, 16\%

Banting, Hos, 16i;

Barbarus, Mus, 105

Barbary ape, 2.2

Barbary llouse, 105

Barbary red-legged partridge, 232

Barbastelle, 37

Barbata, Phoca, 85

Barbatulus, Nemaclilus, F.00

Jarbatus, (iypatus, 313

Barbatus, Mullus, 465

Barbel, 4!s

Barbets, The, 352

liarbus, 498

liabus tor, 498

Bare-throated francolins, The, 233

Barn owl, 321, 325

Barnacle, Acorn, 533

Barnacle, Goose, 533

Barracula-pikes, 475

Barracuclas, 470

Bartaculias, Tlıe, 470

Barred-back pheasants, 238

Barred rail, 24 ?

Jarrier reef, The, 710

Baryphthengus, $3+1$

Basileuterus, 365

Basilisks, 401

Basiliscus, 401

Basking shark, 517

Basomuatoldora, 641

Bass, 464

Bassanus, Dysporus, -299

Bitssaricyon, 76

Bassariseus, 76

Passariscus astutus, 76

Bats, The, 33

Bat, Bechstein's, $3 \mathrm{~s}$

Bat, Chin-leaf, 41

Bat, Common, 37

Bat, Cusp-toothed fruit, , 35

Bat, Daubenton's, 34

Bat, Epauletted fruit-, 35

Bat, False vampire, 36

Bat, Flower-noserl, sit

Bat, Fox, 35

Bat, Free-tailed, 38

Bat, Fruit, 34

Bat, folden, 33

Bat, fireater horse-shoe, 36

Bat, Hare-lipped, 39

Jat, Hoary, 37

Iat, Hor'se-shoe, 36

Bat, Javelin, 41

Bat, Leaf-nosed, 36

Bat, Long-eared, 3 ;

Bat, Long-tailed, 3;

liat, Mastiff, 39

Bat, Naked, 40

Pat, Pouch-wingerl, 39

Bat, Schreiber's, 38

Bat, Sheath-tailed, 39

Bat, Short-nosed fruit-, $35 \%$

Bat, Tailed fruit-, 35

Bat, Tomb, 39

Pat, Tricolor, 38

Bat, Tube-mosed, 37

Bat, Typical, 36

Pat, Vampire, 40

Bat, White, 39
Batagurs, 38?

Bateleur Lagle, 315

Bath sponge, $69: 3$

Bathyergus maritimus, 107

Bathythrissa dorsalis, 506

Bathythrissidie, 506

Batoniys, 10.4

Batrachislie, 474

batrachopliynus, 441

Bat rachoseps, 450

Batrachostomus, 334

Batrachus, 474

Batrachyperus, 450

Bava, l'loceus, $36^{2}$

Baya weaver, $36 \%$

Baza, 317

Bdellicla, 545

Bdellostoma, 5:5

Briellura, 68.5

Bdeogale, 60

Beadlet, 'The, 703

Beakerl gurnard, 476

Beaked salmon, 505

Beaked whales, $17 \%$

Bean goose, 205

Bear 'Tribe, The, it

Bear, American black, 75

Bear, Brown, 75

Bear, Cat, 75

Bear, Crizzly, 75

Bear, Himalayan black, 75

Bear, Inclian sloth, 75

Bear, Isabelline, 75

Bear, Malayan, 75

Bear, Parti-coloured, 75

lear, Polar, 75

Bear, Sea, s:

Bear, Spectacled, 75

Bear, Syrian, 75

Bearded bee-eater, $14:$

Bearded eagle, 313

Bearderl partridge, $2: 34$

Bearled reedling, 3is

Bearded seal, s.5

Bearded tit, 368

Bearded vulture, 313

Bear's paw, 626

Beavers, The, 96

Beaver, American, 98

Bechsteini, Vespertilio, 38

Bechstein's bat, $3 s^{\circ}$

lied bug, 5.96

Beech-marten, so

Bee-eater's, 340

Bee-eater, Bearted, 341

Bee-eater, Common, 341

Bee-eater, square-tailer, 340

Bee-eater, Swallow-tailed, 340

Bee, Hive, 581

Bees, 553, 573, 580

Bees, Carpenter, 581

Bees, Humble, 581

Bees, Leaf-cutter, 581

Beetles, 55:

Beetle, Bacon, 556

Beetle, Blister, 560

Peetle, Bombardier, 55.5

Beetle, Burying, 5.7

Beetles, C'ellar, 559

Beetles, Click, 5.59

Beetle, Colorado, 561

Beetles, Diamond, 560
Beetles, Dung, 55.7

Beetle, Egyptian sacred, 557

Beetle, Fidiller, 555

Beetle, Golden-green, 555

Beetles, fround, 5.55

Beetle, Hercules, 5.58

Beetles, Long-horned, 560

Beetle, Musk, 561

Beetles, (0il, 560)

Heetles, P'lant-feeding, 561

Beetle, hove, 556

Beetles, ritag, 558

Beetles, Tiger, 5.54

Beetles, Turnip, 561

Beetles(water), Carnivorons, 5055

Beetle (water), Great, 557

Beetles, Whirligig, 556

Bell animalcule, $\tau^{2}-1$

Bell-birds, 374

Bell-moths, 593

Bellia, 3ss

Bellis sagartia, 70:3

Bellows-fish, $45^{\circ}$ ?

Belone, 479

Belostomatida, 599

Belterl kingfisher, :i30

Beluga, 179

Bembidium, 55.5

Bengal fox, 73

Bengal monkey, 22

Bengalensis, Canis, 73

Benvalensis, Felis, 5.5

Benuetti, ('ynogale, 60

Bennettianus, Dendrolagus, 19:

Bennett's civet, 60

Bennett's wallaby, 194

Berardius arnuxi, 177

Berdmorei, Hapalomy's, 104

Berdmore s rat, 10.4

Bernhardus sipunculus, fits

Beroidie, 71\%

Berus, Vipera. 427

Berychidie, 407

Berychiformes, 467

Beryx, 468

Betta, 483

Betta wugnax, $18: 3$

Bettongia, 197

Bewicki, ('ygnus, 2922

Bewick's swan, 29-?

Bharal, 160)

Bhringa, 361

Bichir, 512

Bichir polypterus, 512

Bicornis, Dichocerus, 333

Bicornis, Phinoceros, 121;

Binturong, 50

Binturong, Aretietis, 69

Bipalium kewense, 684

Bipunctata, Coccinella, 562

Bipunctata, Sagitta, 6st

Bipunctatus, Argusianus, 239

Birds, 215

Bird-catching spiders, 5.42

Bird lice, $57: 3$

Bird's hearl coralline, 667

Bird's nest sponge, 693

Birds'-nesting eagle, 315

Birds of Prey, The, 304

Birds of Paradise, 358

Birgidæ, 537

Birgus latro, 53" 
Bison, American, $16: 3$

Bison, Bos, 162

Bison, European, 162

Bitis, 427

Bitorquatus, Rhinoptilus, 273

Bitterlings, 499

Bitterns, 'l'he, 276

Bittern, Asiatic, 284

Bittern, 1)warf tiger, 284

Bittern, Little, 2s4

Bittern, Sun, The, 276

Bittern, True, 2S4

Bivalve shell, Topography of, $61 \%$

Bizarre sea-hol'ses, 487

Biziura, 297

Blaberus, 5ijt

Blaberus giganteus, 564

Black aje, 22

Black-backed jackal, 66

Black beetle, 564

Black-billed cuckoo, 3.1

Black-billed white stork, 279

Black corals, 707

Black cuseus, $2(n)$

Black drongo, 'l'he, 361

Black eagle, 315

Black-facetl nacaria, 27

Black fox, 71

Black grouse, 230

Black guillemot, 240

Black-hearled gull, 262

Black-headerl, red-legged partrirlge, $2: 32$

Black-liearled lıangnest, 362

Black-hearled weaver bircl, 36:

Blaek lowler, 24

Black perms, 317

Black rat, 105

Black rlinoceros, 126

Black saki, 27

Black salamander, 447

Black sea-bream, 466

Black-shouldered hites, 316

Black silug, 643

Black stork, 279

Black swan, 2922

Black tern, 261

Black-throated diver, 254

Black turn-stone, $2-2$

Black vultures, 306

Black water-hen, 250

Black wood-yartridge, 234

Black wood-rail, 249

Blackbirds, 370

Blackbird, Common, 37!

Blaekcap, 370

Bladder seal, 8 t

Bladder worm, 6s

Blainvillei, Mormous, 41

Blainvillei, Stenodelphis, 1 is

Blaps 559

Plarina, 46

Blastoidea, 65.5

Blatta orientalis, 504

B'attida. 563

Bleak, 199

Blennies, The, 47s

Blennidie, 478

Blenniiformes, 477

Blennius, 4is

Blesbok, 150
Hilight, 601

Blind-mouse, 106

Blind-snakes, 417

Blind-worm, 404

Blister beetle, 560

Blood-pheasants, 235

Blue bottle flies, 608

Hine coral, 708

Blue creeper, 362

Blue jays of America, 358

Blue rorquals, 173

Blue shark, 516

Blue-throats, 370

Blue tit, $36 \%$

Blue water-hen, 248

Hlue-winged geese, -995

Blue-winged grasshopyer, 568

Blues, 'T'he, 586

Bluut-heads, 426

Boa-constrictors, 418

Boa constrictor, Common, 120

Boa tribe, The, 418

Boar, Wilıl, 133

Boat-billed heron, $28 t$

Bobac, 93

Bobac, Arctomys, 93

Bobolink, 361

Bocydium, 601

Boilie, 415

Boiei, Ceratophrys, 441

Boine, 418

Bombardier beetles, 565

Bombinator igneus, 444

Bombus, 581

Pombus, C'1retocercas, 347

Bombyces, ¿ss

Bombliidre, 600

Bombyx mori, 590

Bonariensis, Molot]rus, 801

Bonasa, 231

lionellia, $67 \mathrm{~s}$

Bonellia veridis, fis

Bonelli's eagle, $31 \mathrm{j}$

Bouliami, Ammoprerlix, 2333

Bonito, $4 i 3$

Bontebok, 150

Bony fislies, 46:

Bony pike, 509

Book scorpions, 541

Boops, Megaptera, 17:3

Booterl eagle, 315

Bopyride, 534

Boring hymenoptera, 5it

Pornean Bay cat, 5 is

Bos, 161

Bos americanus, 163

Bos banting, 165

Bos bison, 16?

lios bubalis, 102

Bos caffer, 162

Bos depressicornis, 162

Bos frontalis, 164

Bos gaurus, 164

Bos grunniens, 164

Bos indicus, 165

Bos mindorensis, 162

Bos pumilus, 162

Bos taurus, 165

Boselaphus tragocamelus, 154

Bot flies, 606

Botaurus stellaris, 284

Bothriocephalus latus, 687
Botryllus, 5 gs

Bottie-nosed chimera, $4\left(i^{2}\right)$

Bottle tit, 368

Botys uricata, 532

Botys verticalis, 592

Bougainvillea ramosa, 696

Bovidie, 149

Bovinus, Tobanus, 605

Bovis, Hypoderma, 606

Bow-tin, 510

Bower-bircls, The, 359

Bower-bird, Satin, 359

liox-tortoises, 383

Boyciana, Ciconia, 2=9

Brachejytra, 556

Brachinus, 555

Brachiopod internal organs, 6,50

Brachiopod, Hinged, 649

Brachiopod, Non-hinged, 650

Brachiopod, Pedunculate, 6ts

Brachiopod, Sessile, 645

Bracliopoda, 648

Brachiopoda, Aneestor of, 651

Brachypteraciina, 335

Brachyrhyuchus, Anser, 295

Bracliy tarsomys, 102

Brachyteles arachnoides, 25

Brachyura, 537

Braconidie, $57 T$

Bradypodilate, 1S2

Brallypus, 182

Bradypus tridactylus, 183

Braliminy kites, 316

Brain Coral, 707

Brancherl syllis, 673

Branchipodidie, 532

Branick's paca, 115

Branta, 295

Branta ruficollis, 295

Brasilianus, Merganser, $99-$

lirassoline, 684

Brazilian caracara, $30^{-}$

Breams, 49!)

Brechites,

Brent geese, ut

Brevieaulata: Indris, ․ㅡㄴ

Breviceps, 439

Breviceps, Cogia, 176

Breviceps, Petaurus, 20:2

Breviceps, Rana, 437

Brevipes, Gstrelata, 25\%

Bridges' wood-hewer, 3i5

Brilgesi, Drymornis, 375

Brill, 492

Brine shrim]), 531

13ristle-footed worms, $6 \pi 1$

British eapercailzie, 230

British riuged-snake, $4: 21$

British turtle-dove, 244

British viper, 427

Brittle-star, 657

Broad armadillo, 186

Broadbills, 350

Broalbill, Horsefield's, 35t

Broad-leaved lıornwrack, (jtis

Brocket, Red, 146

Brodiei, Glaucidium, 324

Brookesia, 412

Brotula, 491

Brown bear, 75

Brown fish-owl, 321

Brown hawk-owls, 323 
Brown hymua, 62

Brown-tailed mungoose, 61

Irowni, Macropus, 194

Bruijni, Proëchidlua, 21

Bruijn's echirlna, 217

Brunii macropus, 194

Brunnea, Hy:ena, 62

Brush-tailed porcupines, 113

Brush-turkeys, 226, 227

13ryozoa, 665

liubaline antelope, 150

Bubalis, 150

Bubalis albifrons, 1.50

Bubalis, Bos, 162

Lubalis pygargus, 150

Bubo, 322

Bubo bubo, 322

Pubo virginiaus 32 ?

Bubonirlae, 321

Bubonine, 321

Bucciniclie, 637

Bucco, 355

Buccones, 355

Bucephala, Drilophaga, $6 \times 3$

lincerotes, 339

Bucerus rhinoceros, 339

Buchanga atrit, 361

Bucholzi. Pantolon, 50:

Buck, Inclian black, 45:

Puck, Prong-, 149

Rucorax, 339

Budorcas taxicolor, 157

Buffalo, Cape, 162

Buffalo. Indian, 162

[3uffon's skua, 263

Hit fo, 441

Bufo calamita, 442

Bufo viriclis, 442

Pufo vulgaris, 44:

Bufonida, 441

Bugs, 553, 594

Bug, Bed, 596

Bug, Masked, 596

Pug, Plant, 596

Bug, Shield, 595

Bug, Water, 597

ling, Wheel, 596

Rugula turbinata, 667

Bulbuls, The, 372

Bulimulidie, 643

Bulimus, 643

Bull frog, 437

Bull-heads, 475

Bullfinches, $: 03$

Bullirlae, 640

Bullinella, 610

Bulloidea. 639

Bulweri, Lobiophasis, 236

Bungarus ceruleus, 424

Bungarus fasciatus, 424

Bungarus, Naia, 424

Buntings, 363

Bunting, Cirl, 364

Bunting, Corn, 364

Bunting, Lapland, 364

Bunting, Snow, 363-364

Buprestid:e, 558

Burbot, The, 491

Burchelli, Equus, 128

Purchell's rhinoceros, 126

Burchell's zebra, 128

Burhinus grallarius, $2 \overrightarrow{7} 3$
Burnanica, Pelargopsis, 336

Burmeigteri. Chunga, 27T

Burmeisteria, 18S

Burmcister's seriama, 277

Buruets, 588

Burnett salmon, 460

Burnished biass moth, 591

Burrowing owls, The, 323

Bursarius, Geomys, 109

l'urying beetles, 557

Bush cucknos, 351

liush-dog, 74

Bush-pig, 134

Bushmaster, $4: 39$

Bustards, The, 264, 273

Bustard, Crested, 27:3

Bustard, Great, $27: 3$

Bustarl, Kori, 2:3

Bustard, Lesser, 273

liustard-quail, 241

Butastur, 315

Butcher-birals, 369

Buteo 312

Buteo buteo, 312

Buteogallus, 312

Buteonina, 307, 311

Butterties, 553, 581

Butterfly, Dead leaf, 585

Butterfly, swallow-tail, 587

Buzzards, The, 307, :11 ?

Buzzard, Common 312

Buzzard. Honey, 317

Buzzard-eagles, 315

Buzzard-hawk, Rufous, 312

Bjthinia, 635

\section{C.}

Caballus, Equus, 128

Cabalus, 249

Cabalus dieffenbachii, 249

Cabalus moulestus, 249

Cabalus sylvestris, 249

Cabul, Marmot, 94

Cacatuido, $32 \mathrm{~S}$

Caccabis chukar, 232

Caccabis magna, 23.

Caccabis melanocephala, 232

Caccabis petrosa, 232

Caccabis rufa, 232

Caccabis saxatilis, 232

Cachuga, 389

Cacomistle, 76

Cacopus, 438

Cacopus systema, 438

Caddis flies, 572

Caddis worms, 573

Creca, Talpa, 48

Cæcirlæ, 635

Cæcilians, 453

Crecilian brooding its eggs, 454

Creciliidar, 451

Crecum, 635

Canagrioninæ, 570

Canolestes, 204

Cesar, Lucilia, 608

Cæsareus, Staphylinus, 556

Cresia, Sitta, 368

Caffer, Bos, 162

Caffer cat, 55

Caffer, Perletes, 110
Caffra, Felis, 5,

Caia, Hypercompa, 588

Caimans, 380

Cairina, 293

Cairina moschata, 293

Calabarensis, Pottos, 31

Calabaria, 419

Calabaricus, Calamoichthys, 512

Calrenadinxe. 214

Calrenus, 245

Calamita, Bufo, 442

Calamoiclıtlıys calabaricus, 512

Calamophilus biarmicus, 368

C.tlandra larks, 364

Calandrella, 364

Calcareous sponges, 692

Calcarius, lapponicus, 364

Calcitrans, ('nemiornis, 295

Calcitrans, Stomoxys, 607

Calendula, Regulus, 369

Calichris, 269

Californian quail, 210

Californian toad, 403

Californiana L(iphortyx, 210

Caligat us, Trogon, 349

Caligo teucer, 584

Callagur, $3 \circ 9$

Callichtliys, 197

Callillea perplexa, 595

Callidina para-itica, 683

Cal imome, 576

Callithrix, 26

Callithrix torquata, 26

Callophasis, 238

Callophasis ellioti, 238

Callophasis humia, $23 \mathrm{~s}$

Callophis, 424

Callophrys rubi, $580 ;$

Callorhynchus, 462

Calluella, 439

Calomys, 101

Calonyx, Eurystomus, 33\%

Caloperdix, 234

Caluprymnus campestris, 197

Calornis, 360

Calotes, 394

C'alva, Uacaria, 27

Calvus, Antliropopithecus, 15

Calypte helena, 347

Calypteræ, Muscida, 607

Calyptomena, 356

Calyptomena hosii, 350

Calyptomena viridis, 356

Calyptomena whiteheadi, 3.56

Caura, Canis, 73

Camarhynchus, 363

Camel Tribe, The, 135

Camel, Arabian, 137

Camel, Bactrian, 137

Camelidæ, 135

Camelopardilis, Giraffe, 147

Camelus, 136

Camelus bactrianus, 136

Camelus dromedarius, 136

Camelus, Struthio, 223

Campanularians, 697

Campestris acheta, 567

Campestris, Caloprymnus, 197

Campestris, Cervus, 146

Campestris, Cicindela, 554

Campestris, Motacilla, 365

Campestris raphiceros, 151 
Campophagldie, 372

Canadensis, Castor, 98

Canadensis, Cervus, 143

Canadensis, Felis, 56

Canadensis, Ovis, 160

Canatian lynx, 56

Canadian porcupine, 113

Canarian fork-tailed petrel, 257

Canaries, $363^{\circ}$

Cancellaria, 638

Cancell iriidie, 638

Cancer pagurus, 538

Canchroma, 283

Canchroma cochlearia, 284

Canchroma zeledoni, 284

Cancriformis, Apus, 531

Cancrivorus, Canis, 69

Candelarius, Hotinus, 599

Candicans, Hierofalco, 319

Candidia, Coscoioba, 293

Candirla, Pholadomya, 628

Candila, Strix, 325

Candle fly, 599

Cane-rat, 112

Caniceps, Lepidolemur, 30

Canicle, 63

C'anis, 63

Canis adiustus, 60

Canis alpinus, 68

Canis antareticus, 64

('anis argentatus, $i 1$

Canis anreus, $6 j$

Canis azara, 69

Canis bengalensis, 73

Canis cama, 73

Canis cancrivorus, 69

Canis corsac, 73

Canis deccanensis, 68

('anis dingo, 66

Canis clukhunensis, 68

Canis famelicus, is

Canis ferrilatus, 73

Canis flavescens, 71

C'anis fulvus, 71

Canis, Galeus, 516

Canis japonicus. 73

Canis jubatus, 69

C'anis lagopus, $7:$ ?

Canis laniger, 6.5

Canis latrans, 66

Canis leucopus, 73

Canis lupus, 64

Canis macrotis, 73

Canis mesomelas, 66

C'anis montanus, 71

('anis niger, 65

C'nis niloticus, 71

C'anis pallipes, 64

('anis pennsylvanicus, 71

Canis primevus, 68

('anis procyonides, 69

Canis pulex (dog flea), 609

Canis rutilans, 68

Canis velox, 72

Canis virginianus, 72

Canis vulpes, 71

Canis zerda, 73

Cannabateomys, 112

Canorus, Cuculus, 350

Cantharine, 466

Cantharis vesicatoria, 560

Cantharus, 466
Canthocamptus alpestris, 532

Cantiaca, Sterna, 261

Cantoria, 423

Canus, Larus, 262

Cap.of-liberty sheils, 634

Caje buffalo, 162

Cape coly, The, 349

Cape golden mole, 50

Cape hunting-dog, 74

Cape jumping-liare, 110

Cape inoles, 50

Cape polecat. 80

Cape quail, 234

Caped pheasants, The, 238

Capensis, Coturnix, 234

Capensis, Orycteropus, 189

Capensis, Rostratula, 267

Capensis, Strix, 3:25

Capensis, Tachybaptes, 253

Capercailzies, 'i'he, 230

Capercailzie, British, 230

Capercailzie, Dusky, 231

Capitis, Pediculus, 602

Capito, 353

Capitones, 352

Capivara, $116^{\circ}$

Capivara, Hydrochorus, 89

Capra, 158

Capra agagrus, 159

Capra, Cervus, 146

Capra cylindricornis, 158

Capra falconeri, $\mathbf{1 5 9}$

Capra hisuanica, 158

Capra ibex, 158

Capra pyrenaica, 158

Capra sibirica, 159

Capreola, Pelea, 151

Capreolus, $1+6$

Caprimulgi, 3 เ?

Caprimu'gus europaeus, 342

Capuine, 158

Capromys, 112

Capuchins, 24

C'apuchin, White-throated, 24

C'apulidæe, 634

Capulus, 634

Carabidie, 5.54

Carabus, 555

Carabus auratus, 555

Caracal, 55

Caracal, Felis, 55

Caracaras, 307

Caracara, Brazilian, 307

Carancho, 307

Carangidie, $4 \pi 1$

Caranx, 471

Carassius, 499

Carbo, Phalacrocorax, 299

Carchariidae, 516

Carcharodon rondelctii, 517

Carcineutes, 337

Carcinophaga, Lobodon, 86

Cardamines, Euchloe, 586

Cardiacea. 623-625

Cardiidie, 626

Cardiliidre, 625

Cardinal grosbeaks, 363

Cardinalis, 363

Cardinalis, Novius, 602

Cardita concamerata, 623

Carditide, 623

Caretta, Thalassochelys, 391
Carettochelyidro, 394

Cariacus, 146

Cariama cristata, 277

Carinaria, 636

Carinata, Cyclura, 403

Carinatit, 225

Carinate avis, 225

Carinate birds, 225

Carine, 323

Carnea, Edwardsia, 704

Carnivora, 50

Carnivorous water-beetles, 55.5

Carolinensis, Galeoscoptes, $37: 2$

Carp, Common, 498

Carp, Crucian, 495

Carp lice, 532

Carpenter bees, 581

Carpet-snake, 419

Carpincho, 89

Carpincho, Aquatic, 116

Carpio, Cyprinus, 493

Carpocapsa. 593

Carpocapsa pomonella, 593

Carpococeyx, 351

Carpococeyx radiatus, $3 j 1$

Carpodacus, 363

Carpomys, 104

Carponycteris, 35

Carpophaga anea, 243

Carpophagina, 24?

Carrion crow, 358

Carterorlon, 113

Carunculata, Sarcidiornis, 29:) .

Carychium minimum, 641

Caryophyllacea, khodonessa, 294

Caryophyllia, 705

Casarea, 296

Casei, Piophila, 608

Cashmirianus, Cervus, $14: 3$

Caspia, Hydroprogue, 261

Caspian seal, 85

Caspian tern, 261

Caspica, Phoca, 85

C'assidida, 636

Cassidix, 362

Cassidix oryzivorus. 362

Cassidix persicus, 362

Cassis rufa, 636

('assnwaries, The, 224

Castanotis, C'hceropus, 206

Castnia syphax, 590

Castniida, 590

Castor, 96

Castor canadensis, 98

Castor fiber, 96

Castoridie, 96

Casuarii, 223

Casuariiformes, 221, 223

Cat-bear, 75

Cat-birl, 372

('at-fishes, 496

Cat-snake, 423

Cats, The. 5?

Cat, Bornean Bay, 55

Cat, Caffer, 55

Cat, Domestic, 55

Cat, Jungle, 5.5

Cat, Leopard OrientaI, 55

Cat, Marbled, 55

Cat, Tiger, 55

Cat tribe, 52 
C'at, Will, 55

Cataphractus, Crocodilus, 381

Catarihactes, Megalestris, 263

Catesbyana, Rana, 437

Cathartes aura, 304

Catliartidiformes, 304

Catheturus, 227

Catleturus lathami, 207

Catreus wallichii, 237

Catta, Lemur, 29

Cattle, Indian humped, 16 s

C'atus, Felis, 55

Cucasica, Nalamandra, 44

C'audacuta, C'hetura, 346

Caudata, 445

('audatus, Aretomys, 94

('aurlatus, l'riapulus, 678

C'audivolvulus, Cercoleptes, 76

Cautious albatros, 259

Cautus, Thalassogeron, 259

Cavatus, Hyptiotes, 544

('ave-dwelling anemone, T04

C'ave-fish, 491

(avia, 115

('avies family, The, 11 i

('aviide, 115)

('avoliniliz, $6 \pm 0$

('ebilla, 然

('ebus. 24

('ebus hypoleucus, 24

'ecidomyia destructor, 603

('ecidomyiidre, (i) :

('edar-birl, American, 369

('e lro um, Ampelis, 369

('elebensis, P'ernis, 317

('ellar-beetles, 559

Cellar-snail, 644

('ellaria, Vitrea, 644

C'eltis, Libytlısa, 586

('emas, 157

Centetes ecaudatus. 49

Centetida, 49

C'entipedes, 548

C'entipede, Electric, 549

Centrarchidx, 463

Centrachus, 463

C'entriscida, 482

('entrisciformes, 48?

('entriscus, 4S2

('entrogenys, 404

Centrolophus, 4i2

('entropelma, 253

Centropodina, 351

(entropomina, 464

('entropristes, 464

Centropus, 351

C'entropus sinensis, 351

Centrotus, 601

C'entrotus cornutus, 601

('epedianus, Laphotes, 484

Cephalocliorda, 520

C'ephalodiscus, 649

Cephalophus, 151

C'eplialopoda, 644

C'euhaloptera, 5\%2

Cephalorhynchus, 179

Cephalorty ncluus heavisidei, 179

('ephalus, Harpyio, 37

('epolida, 477

Cerambycidæ, 561

Cerastes, 427

Ceratiun, i1s
Ceratobrachidie, 439

Ceratobrachus guentheri, 439

('eratodus, 460

Ceratophora, 399

('eratophrys, 441

Ceratophrys boiei, $\mathbf{4 1 1}$

('eratophrys ormata, 441

Cercarite, (is?

Cerchneis, 320

Cercocebus, 21

Cercoleptes caudivolvulus, 76

C'ercomys, 113

Cercopithecidr, 19

Cercopithecus, 21

Cercopithecus callitrichus, 21

Cercopithecus diana, 21

Cercopithecus mona, 21

Cercopsina:, 294

Cerealium, Thrips, 572

('ereopsis geese, The, 294

Cereus, Anthea, 703

C'erithijdie, 6336

C'erivoula, 38

(erthia familiaris, 365

('erthiid:s, 362

('erthilauda, 364

Certhiola, 362

('ervicapra, 15:

('ervicapra antiloje, 152

('ervicaprina, 151

('ervidie, 140

Cervulus, 14]

Cervulus muntjac, 14을

Cervus, 142

Cervus attinis, 143

Cervus alfredi, 143

('ervus antisiensis, 146

('ervus axis, 143

Cervus campestris, 146

C'ervus canadensis, 143

Cervus caprea, 146

Cervus cashmirianus, 143

Cervus chilensis, 146

('ervus clavatus, 146

Cervus dama, 144

Cervus davidianus, 14:3

Cervus duvauceli, 143

Cervus elaphus, 143

Cervus eldi, 143

Cervus eustephanus, 143

Cervus giganteus, 144

Cervus, Lucanus, 558

Cervus macrotis, 146

Cervus maral, 143

Cervus mesopotamicus, 144

Cervus philippinus, 143

Cervus porcinus, 143

Cervus pygargus, 146

Cervus rufti, 144

Cervus rufus, 146

C'ervus schomburgki, 143

Cervus sica, 143

Cervns swinhoei, 143

Cervus thoroldi, 143

Cervus unicolor, 143

Cervus virginianus, 146

Cervus xanthopygus, 143

Ceryle, $336^{\circ}$

Ceryle alcyon, 336

Cersle lugubris, 336

Cervle rudis, 330

Ceryle superciliosa, 336
Ceryle torquata, 330

Ceryle varia, 336

Cestoda, 686

Cestoni, Nyctinomus, 40

Cestraciila, 518

Cestracion, 518

Cestraciontidie, 513

('estracium, 518 .

Cestus veneris, 712

Cetacea, 169

Cetonia aurata, $55 \mathrm{~s}$

Cetoniidle, 5.58

C'etorhinus maximus, 517

Ceycopsis, 337

Ceylonensis, Ketupa, 321

('eyx, 337

Chacma, 23

Charonycteris, 41

Charopsis, 131

('haropus castanotis, 2116

C'hatoceraus, 348

Chetocercus bombus, 34

C'hatoderma, 616

chatodermatina, 616i

Chretodon, 465

Chatodontida, $46 . i$

Chrotognatha, 68:

Chatomys, 113

Cliwtopoda, 671

('hetura, 345

Chrtura caudacuta, 346

Cheturine, 346

('hafers, 557

Chattinch, Common, 363

Chajá, 291

Chalcididæ, 576

Chalcopsittacus, 328

Chalia furva, 589

Chalinolobus, 37

Chalinolobus tuberculatus, 40

Cliamaleons, 411

Cham

Chamaleontida, 41.?

Chamasaura, 404

( hamida, 626

Chamois, 156

Chamostrea albida, 628

Chamostreida, $62 \%$

Changu, 65

Clianna, 48?

Channel-bills, 350

Channiformes, 482

Chanting gos-hawks, 310

Charadrii, 266

C'haradriidx, 266

Charadriiformes, 260

Charadriine, 270

Charadrius dominicus, 270

Charadrius pluvialis, 271

Charcharias glaucus, 516

Chasmorliynchus, 374

C'hat thrushes, 370

Chats, 370

Chatterers, The, 36 ?

Chatterer, American, 374

Cliatterer, Crested, 369

Chauliodus, 505

Chauna, 290

Chauna ehavaria, 290

Chauna cristata, 290

Chaus, Felis, 55

Chavaria, Chauna, 290 
Cheer pheasant, 237

('heese-mites, 547

Chelidon, 373

('helidon urbica, 373

Chelidoptera, 355

Chelifer, 541

Clielmon, 465

Chelodina, 393

Chelone imbricata, 391

Chelone mydas, 391

Chelonia, 383

Chelonisla, 390

('helydridx, 390

('helyidxe, 392

(helys fimbriata, 392

Chen, 295

Chenomorpha, 288

('henonetta, 295

('henonettina, 295

(henopis, 292

C'henopis atrata, 20:3

Cheriway, Polyborus, 307

C'lestnut-breastell avocet, 270

Chevrotain family, The, $\mathbf{1 3 9}$

Chevrotains, Oriental, 139

('hevrotain, West Ifrican, 139

Cheyletus, 547

Chibia, 361

Chiffchaff, 370

Chill's head urchin, 660

Chilensis, Cervus, 146

Chilensis, Hegalestris, 263

Chilian swan, 202

Chilinia, 642

C'hilinidle, (it1

Chilobranchus, 495

Chilodactylus, 467

Chilognatha, 549

Chilomonas, 718

('hilonycteris, 41

('hilopoda, $54 \mathrm{~s}$

('hilostomata, 666

Chimera, Bottle-noser, 462

Chimera, Common, 461

('himiroids, 461

('himpanzees, 14

Chimpanzee, Fald, 15

Chimpanzee, Cominon, 15

C'himarrogale, 47

Chin-leaf bats, 41

('hinchilla tribe, The, 113

Chinchilla, Cuvier's, 114

C'hineasis neurobasis, 570

Chinese alligator, 380

Chinese water-deer, 146

Chinquis, Polypectrum, 238

Chioglossa lusitanica, 447

Chionarehus minor, 265

Chionarchus crozettensis, 265

Chionides, 265

Chionis alba, 265

C'hipmunks, 91

Chirille, 478

Chiridium museorum, 541

Chiridota, 661

Chirocentridx, 506

Chirocentrus dorab, 506

Chirogale, 30

Chiromeles torquata, 40

Chiromyidx, 31

Chiromys madagascariensis, 31

Chironectes minimus, 214
Chironomldre, 604

Chiropodomys, 104

Chiroptera, 33

Chirotes, 408

Chiroteuthidæ, 646

Cliroxiphia linearis, 374

Chiru, Tibetan, 152

Chiruromys, 106

Chiton, 615

Chitonidie, 616

Chitra, 39.5

Chlamrdophorus retusa, 188

Chlamydophorus truncatus, 188

Chlamytlosaurus kingi, 399

('hloris, Ligurinus, 363

Chlorocercus, Lorius, 328

Chloron, 580

Chloropus, Gallinula, 25:2

Cholæpus, 182

Chologaster, 502

Chondrostei, 510

Chondrostoma, 499

Cluneziphius cuvieri, 177

Chordeiles, 342

Choridactylus, 467

Clsorinemus, 467

Choristide, 637

Clough, 358

Chough, Alpine, 3.58

Chough, Desert, 358

Chough, Red-billed, 35,8

Chorgh, White-winged, 358

Chromatophores, 645

Chromididæ, 456

Cliromids, 486

('hromis, $4 \$ 7$

Chrondropython, 419

Chrotomys, 100

C'lirysinas victor, 243

Chrysaetus, Aquila, 314

Chrysalis-shells, 64:3

Clirysidida, $57 \mathrm{~s}$

Chrysippus, limnas, 5s:

Chrysitis, Plusia, 591

Chrysochloride, 50

Chrysochloris, ¿0

Chry sweoccyx, 350

('hrysolophus, 23s

C'hrysolophus amherstire, 238

Chrysolophus pictus, 238

Clirysophrys, 466

Chrysopidiz, 571

('hrysops, 605

('hrysothrix, 26

Chrysotis, 329

Chthonerpetum, 455

Chukar, Caccabis, 232

Chukar partridge, 232

Chunga burmeisteri, 27\%

Cicadidie, 598

Cicindela campestris, 554

Cicindelidx, 554 .

Ciconia boyciana, 279

Ciconia, Ciconia, 278

Ciconia nigra, 279

Ciconiidis, 278

Cidaris papillata, 659

Ciliated Infusoriams, 720

Cimbicine, 574

Cimicidæ, $596^{3}$

Cinclus aquaticus, 371

Cinerea, Ardea, 282
Cinerea, Atalapha, 37

Cinerea, Nepa, 597

Cinereus, Phascolarctus, 19?

Cinixys, 357

('innabar moth, 588

Cinnyris asiatica, $360^{\circ}$

Cinosternilla, 359

Circaetus, 315

Circaetus gallicus, 315

Circulata, Flata, 600

Circus aruginosus, 309

Circus hudsonius, 309

Circus pygargus, 309

Cirl-bunting, 364

Cirlus, Euberiza, 364

Cirrhites, 467

Cirrhitichthys, $46{ }^{\prime}$

Cirrhitida, 4665

Cirripedia, 533

Cirroteuthicla, 64-

Cirroteuthis, 647

Cisticola Prinia, 370

Cistudo, 388

Citrinella, Emberiza, 364

Cittocinela, 370

Civet tribe, $50 ;$

Civet, Bennett's, 60

Civet, J)aubenton's, 57

Civet, Palm-, Small-toothed, 59

Civet, Palm-, True, 59

Civet, T'rue, 57

Civetta, Viverra, 57

Cladorhpnchus leucocephalus. 270

Clanosa, Atrichia, 376

Clamydoconcha, 624

Clangula, 297

Clarias, 497

Clarkei, Ammordorcas, 15:

Clarke's gazelle, $15: 3$

Clauilia, 346

Claudius, 389

Clausilia, 613

Clavatus, Cervus, 146

Clavicornia, $556^{\circ}$

Clavigella, 628

Clavigellidie, 62i

Claviglis, 99

Clepsine, 677

Click beetles, 559

Cliff-swallow, 373

Climbing birds, The, 352

Climbing-perch, 45.3

Clionidae, 640

C'lionopsida, 640

Clisiocampa neustria, 590

Clistenterata, 650

Clitambonites, 651

Clitambonit s adscenrlens, 651

Cloak anemone, 703

Clophaga, 295

Clcephaga inornata, 296

Clothes moths, 593

Clouded lenpard, 55

Clupea alosa, 507

Clupea finta, 51 -

Clupea harengus, $50 \pi$

Clupea menlıaden, 507

Cinpea pilchardus, 507

Clupea sprattus, 507

Clupeida, 506 
Clupeoirles, Coregonus, 509

Clytoceyx, 337

Cnemiornis calcitrans, 295

Cnidaria, 694

Coal-fisli, 491

Coati, 77

Coatis, 70

Cobitina, 500

Cobitis tienia, 500

Cobris, 'The, 424

Cobra, Giant, 424

Cobra, Indian, $42 \pm$

Cobus, 15:

Cobus arundinemm, 150

Coccidle, 60:2

Coccinella bipunctata, 502

Coccinellidis, 56.2

Coccothraustes coccothraustes, $30 i 3$

Coccothraustina, 363

Coccyges, : 4 ?

Cocrystes, 350

Coccystes glandarius, 350

C'occyzus, 350

Coccyzus americanns, 351

Coccyzus erythrophthalıus, 351

Cochlearia, Cancliroma, 284

Cochlicella, (it3

Cock-chafers, 558

Cockatoos, The, 328

Cockatoo, Great black, 328

Cockles, The, $1: 6$

Cockroaches, 564

Cockroach, Common, 564

Cockroach, Drummer, 564

Cocks-of-the-rock, $37 t$

Cocophagez, Lopaphus, 566

Cocorax, 358

Cocorax melanorhamphus, $35 \mathrm{~S}$

C'orl. The, 491

('odling moth, 593

C'odosiga, 719

Cocillianella, 643

Cielebs, Fringilla, :363

Cielenterata, 690

Ccelogenys, 9, 115

Colomata, 690

C'cenagrion puella, 570

Coreba, 362

Cerreba cyanea, 362

Corebidx, $36^{2}$

Corulea, Crossopus, 16

Corulescens, Edipoda, 505

Coruleus, Bungarus, 424

Coffer-fishes, 489

Cogia brevicejs, 176

Colaptes, 3.54

Colclicus, Phasianus, 237

Coleoptera, 55:

Colies, The, 343

Colii, 348

Colius, 345

Colius colius, $3+3$

Collembola, 573

('ollocalia, 346

Collyrio, Lanius, 369

Colobus, 21

Colorado beetle, 561

Colubrida, 421

Colubrine tribe, The, 421

Columba, 244

Columba ænas, 244
Columba livia, 244

Columbas, 212

Columbia transmontana, 509

Columbid:t, 244

Columbiformes, 242

Columbillida, 637

Coly, Cape, 345

Colymbitormes, $25 t$

Colymbus adamsi, 254

Colymbus areticus, 254

Colymbus glatcialis, 254

Colymbus septentrionalis, 254

C'ouadréja, :12

Comadréja-colorada, 213

Comb-bearers, 711

Comb-duck, 293

Comephorus, $47 \mathrm{~s}$

Comeri, Porphyriomis, 252

Common argus, 239

Common badger, 79

Common bat, 37

Common bee-eater, The, 341

Common blackbird, 371

Common bou-consti ictor, 420

Common buzzart, 312

Common carp, 498

Common chattinch, 363

Common chimera, 461

Common chimpanzee, 15

Common cockroach, 564

Common cormorant, 299

Common crane, 27.5

C'ommon cuckuo, 350

Common ripper, 371

Conmon emu, 223

Common flycatcher, 372

Common francolin, 233

Common frog, $436^{\circ}$

Common fulmar petrel, 258

Common gannet, 299

c'ommon gold-crest, $36 \mathrm{~s}$

Common gos-hawk, 310

Common greentinch, $30 ;$

C'ommon grey seals, 85

Common gull, 262

Common gurnard, 475

Common hare, 115

Common hawtinch, 363

Common heron, 232

Common herring, $50 t$

Common hippopotamus, 131

Common hoopoe. 340

Common liorse, $12 \mathrm{~S}$

Common jackal, 66

Common kingtisher, $3: 7$

Common kite, 316

Common lapwing, 871

Common lenming, 103

Common loach, 500

C'ommon lynx, 56

Common mackerel, 473

Common marmot, 92

Common mole, 48

Colamon newt, 448

Common nut hatch, 368

Common opossum, 211

Common ox, 165

Common partridge, 233

Common perch, 464

Common pewit, 271

Common phalanger, 200

Common pheasant, The, 237
Common pike, 502

Common poryoise, 179

Common pratincole, 272

Common quail, 234

Common rat, 105

Common rhea, $2 \cdot 21$

Common roe, 146

Common roller, 335

Common rorgual, 174

Common salamander, 446

Common sargus, 460

Common sea-squirt, 528

Common seal, b5

Common seriama, 277

Common sheld.duck, 296

Common shrew, 46

Common skink, 410

Common skunk, 78

Common snipe, $26 \mathrm{~s}$

Common spoon-bill, 286

Common squirrel, 91

Common starling, 360

Conmon sturgeon, 511

Common swallow, The, 373

Commion swift, 346

Common sword-fish, 469

Common ter'n, $: 61$

Comimon toad, 442

Common trumpeter, 277

Common turn-stone, 272

Common vampire, 4 ?

Common weasel, The, so

Common wolf, 64

Common wren, 371

Common wrrneck, 354

Communis, Phocena, 179

Concamerata, Cardita, 623

Conchicola, Aspidogaster, fis

Concolor, Felis, 53

Conlor, The, 3ut

Conclylura cristata, $4 \mathrm{~S}$

Conepatus mapurito, is

Conger, 494

Conger vulgaris, 494

Conicle, 638

C'onies, 124

Conilurus, 106 ;

Connochietes, 150

Conolopluus suberistatus, 402

Conopolyagida, 375

Constrictor, Boa, 420

Contortrix, Ancistrodon, 429

Contortuplicata, serpula, 672

Conurus, 329

Convoluta schultzii, 080

Coots, 252

Copepoda, 533

Copper-head, 429

Copper pheasant, 238

Coppers, The, 586

Coppersmith, 353

Copsychus, 370

Coracix, 335

Coracias, 335

Coracias garrulus, 335

Coracias temmincki, 335

Coraciine 335

Coraciiformes, 332

Coralline, Bird's head, 667

Coralline, Creeping, 667

Coralline, Nit, 668

Coralline, Oaten-straw, 697 
Corallinus, Elaps, 423

Coralliophaga, 624

Coralliophilidæ, 637

Corallum rubrum, 708

Corallus, 420

Corals, The, 090,704

Coral, Black, 707

Coral, Blue, Tos

Coral, Brain, Tu7

C'oral colonies, 706

Coral, C'up, 70.5

Coral, Development of, 707

('oral, Eight-rayed, 707

('ora], Fieshy,

Coral Islands, 709

Coral, Mushroom, 70. .

Coral, Organ.Pipe, T(Is

('oral, Red, 708

Coral reefs, 709

Coral, six-rayed, ins

('oral, Star, 7116

Coral, Stony, 701

('oral cylinder-snake, 421

('oral-fishes, 485

('oral snake. 42:3

('orbicula, 623

('ordatum, Echinocarlium, 659

('oregonus, 508

Coregonus clupeoilles, 509

Coregonus jollan, 509

('oregonus vandesius, 5690

Coriacea, Jermochelys, 391

Coriarius, Prionus, 561

Corixid $*, 597$

C'ormorants, The, 299

Cormorant, Common, 399

Corn-bunting, 364

C'orn-crake, 251

Corn motli, 593

Cornifer, 4330

C'ornubica, Lamna, 517

('ornuta, Palamedea, 290

Cornutus, Centrotis, (i)1

Coromandel courser, 273

('oromandlelianus, Nettopus, 294

C'oromandelicus, ('ursorius, 273 Coronata, Goura, 245

Coronatus, Anthracocerus, 339

('oronatus, Harpyhaliaetus, 313

('orone corone, $35 \mathrm{~s}$

('oronella levis, $\mathbf{1 2}$ :

('oronetta, Floscularia, 682

('orsac, Canis, 73

Corsac fox, $7:$

Corvida, 338

Corvine, 35

Corydon, 356

C'oryphena, 472

('oryphenas, 244

C'oryphrenidie, 472

('orythornis, 336

('oscoroba, 292

Coscoroba candida, 293

Coscoroba swan, 293

C'osnetornis, 343

Cosmonetta, 297

('ossus, Trypanns, 590

Cossypha, 370

C'osta Rica deer, 146

Cotile, 373

Cotingidæ, 373
Cottidæ, 475

Cotto-scombriformes, 470

Cotton-teal, 294

Cottus, 475

Coturnix, 234

Coturnix capensis, 234

Coturnix coturnix, 234

Coturnix japonica, 235

Coturnix nove zealandire, 235

Coursers, The, 273

Courser, Coromandel, 273

Courser, Cream-coloured, 273

Courser, True, 272

Cow-bird, Argentine, 361

Cowries, 636

Coyote, North American, 66

Cospu, 8, 111

Coypu myopotamus, 112

Crabs, The, 537

('rab, Edible, 538

Crab, Great Japanese, 538

Crab, Hermit, 5:37

Crabs, King, 538

C'rab, Porcelain, 537

Crab, Pobber, 537

Crab, Nilider, 537

Crab-eating clog, 69

Crab-eating macaque, 2-2

Crab plovers, The, 264

Crabro, Vespa, 580

Crabroniformis, Asilus, 605

Craces, 226

Crait, 424

C'rakes, The, 251

Crake, Baillon's, 251

Crake, C'orn, 251

Crake, Little, 251

Crake, Spotted, :-1

C'rake, White-winged 251

Crambi, 592

('rambus ericellus, 593

Cranchiada, 646

Cranes, The, 2\%4

Crane, Common, 275

Crane flies, 604

Crane, Sarus, $2-4$

Crangonida, 536

Crania, 648

Crassatellidie, 6:4

Crassicaudata, Villelphys, 213

Crassicornis, 'Tealia, 70.3

Crassiclens, Pseuilorca. 1 \&0

Crassipes, Linotrenia, 549

Crateromys, 101

Crateropus, $3 \% 2$

Cratogeomys, 109

Crax alector, 229

Cray-fish, 536

('ream-coloured courser, 272

Cream-colonred turtle-dlove, 245

('recinæ, 248

Creepers, The, :65

Creeper, Crimson-winged, 366

Creeper, Tree, 365

Creeping coralline, 667

Crenidens, 466

Crenilabrus, 486

Crepidatus, Stercorarins, 264

Crepitans, Psolyhia, 277

Crested argus, 239

Crested chatterer, 369

Crested cuckoo, 350
Crested curassow, 229

Crested eagles, 315

Crested guinea-fowls, 210

C'rested kingfisher, 337

Crested larks, 364

Crested newt, 447

Crested-rat, 10:

Crested screamer, 290

Crested swift, 346

Crested tit, $30 \mathrm{~s}$

Crested wood-partridges, 234

Crex crex, 245

Cricetinæ, 101

Cricetine Group, The, 101

Cricetomys, 106

Cricetus frumentarius, 101

Cricettis, 101

Crickets, The, 566

Cricket, Field, 507

('ricket, House, 567

('ricket, Hole, 567

C'rimson pufflet, 701

C'rimscn-winged creeper, 366

Crinia, 441

Crinoidea, 662

C'ristata, Cariama, 2T-

Cristata, C'launa, 290

Cristata, Condylura, 45

Cristata, Cystophora, 8.

Cristata, Guttera, 240

Cristata, Molge, $44 \bar{\imath}$

Cristatella mucedo, 608

Cristatus, Amblyrhynchus, 400

C'ristatus, Loplophanes, 3is

Cristatus, Opisthocomus, 217

('ristatus paro, 239

C'ristatus, Porlicipes, $25: 3$

Cristatus, Proteles, 62

Cristatus, sus, 134

C'rocata, Pachyrhina, 604

Crocislura, 46

Crocodiles, The, $37 \mathrm{~s}$

Crocodile, Egyptian, $3 \$ 1$

('rocodlile, Long-nosed, :381

('rocodile, Stumpy, 35 .

Crocodilia, 378

Crocodilidæe, 330

Crocodilus, 381

Crocodilus americanus, 381

('rocodilus cataphractus, $3 \$ 1$

C'rocorlilus niloticus, 381

Crocorlilus palnstris, $3 \$ 1$

('rocodilus porosus, $3>1$

Crocuta, Hyæna, 6:3

Cross-fox, 71

Crossarclius, 61

Crossarchus fasciatus, 61

Crossbills, 363

Crossopterygii, 512

Crossoptilum auritum, 230

Crossopus, 46

C'rossopus crerulea, 46

C'rossopus fodiens, 46 ;

C'rossorhinus, 518

Crotalina, 428

Croton bug, 564

Crotophaga, 351

Crotophaginie, 351

Crows, The, 358

Crow, Carrion, $35 \mathrm{~s}$

Crowned pigeon, 24i

Crowther, Ursus, 75 
Crozettensis, Chionarchus, 2605 ('rucian carp), 498

C'rucibulum, 634

Crustacea, 530

C'rustacea, Larval forms of, 330

C'rymophilus, 20 it;

Crymoplilus fulicarius $2: 6$

Cryptobranchus lateralis, 4is

Cryptodira, 3sis

('ryptoplacida', 616

Cryptoprocta ferox, 56

Cryptops hortensis, 549

Crystallinus, Laphopus, 60s

Ctenodactylus, 111

('tenomys, 111

('tenopliora, 694, 711

C'tenostomata, (icis'

I'uckoos, The, 350

I'uckoo, American, 350

('uckoo, Black-billed, B51

C'uckoo, Bush, 351

('nckoo, Comuon, 350

('uckoo, Cresterl, 350

('uckoo, frolien, 350

('uckoo, ireat-sjotted, 350

('uckoo, Hawk, 3.5)

I 'rekoo, Indian crested, 350

'uckoo, Lark-heelerl, 351

I'uckoo-like birds, The, 349

('nckoo, Pheasant, 351

('uckoo, Rain, 351

('uckoo, spottel, 350

('uckoo, sarana, 351

('uckoo, Nteel-blue, 351

('uckoo, True, 350

('uckoo, Typical, 350)

Cuckoo, Yellow-billed, 3.i1

Cuckoo-doves, 244

cuchoo-falcon, 317

('uckoo shrikes, The, 3i'

('uculi, 34 )

Cuculitie, 350

Cuculine, 350

C'uculus, 350

Cuculus canorts, 3.51

('uculus jacobinus, 350)

('ncumaria planci, 660)

culicida, 604

C'ulminated albatros, 255

C'umacea, 535

Cumingi, Negapodius, 228

('umming's megapode, 228

('uniculus, Lepus, 115

Cuniculus torquatus, 103

Cup-and-saucer limpets, 634

Cup coral, The, 705

Curassows, The, 229

Curassow, Crested, 229

Curlew, Pearl-grey, 270

Curlew, sandpiper, 269

Curlew, Stone, 273

Cursorii, 27?

Cursorius, 272

Cursorius coromandelicus, 273

C'ursoriu; gallicus, 272

Curtidre, 468

Curtiformes, 468

Curtilla gryllotalpa, 567

Curtis, $46 \mathrm{~S}^{\circ}$

curtus, 471

C'uscus, black, -300
Cuscus, spotted, 200

Cusimanses, 61

Cusp-toothed fruit-bat, 35

Cuspidariilar, 6?

Cuttle-tish, $6 \pm 6$

Cut-water, 202

Cut worms, 59)

Cuvieri, Choneziplius, 177

Cuvier's chinchilla, 11t

('uvier's wlıale, 175

('yamus ovalis, 535

Cyane, Careba, 362

('yanecula, 370

('yanochen, 29)

('yanocorax, 358

('yelanorbis, 395

('yclas, $6: 23$

Cyclatella annelidicola, 6ss]

('yclemys, 38\%

('ycloderma, 395

C'yelophoridie, 634

('yclops, 532

('yclops quadricornis, 5332

Cyclopsitta lunulata, 328

Cyclopsittacida, 3:5

Cyclopsittacus, 328

Cyclopteridie, 476

Cyclopterus, 476

Cyclostoma, 6334

Cyclostomata, 523, 669

1'yclostomatidie, 634

(yclostrematida, $6: 32$

('ycloturus didactylus, 1st

(yclura carinata, 403

Cydippe, 711

Cygmina, 29?

C'ygnus, 292

Cyguus bewicki, 2(y)

Cyguus innmitabilis, 202

Cygnus musicus, 292

Cygnus olor, 292

('yliclina, 641 )

Cylinder snakes, 421

cylindrellidie, 643

Cylindricornis, Capra, 158

Cylindrophis, 421

Cyllopodiclæ, 589

Cymborlivnchus, 356

Cymbulida, 640

Cymothoidie, 534

Cynæelurus jubatus, 56

Cynictis penicillata, 60

Cynipida, 576

Cynips, 576

Cynips, Kollari, 576

Cynocephalus, Thylacinus, 207

Cynodon, 501

(ynogale bennetti, (i)

Cynomolgus, Macacus, 22

Cynomys, 92

Cynopithecus niger, 22

Cynopterus, 35

Cyon, 67

Cypræidæ, 636

Cyprina, 624

Cyprinicla, 497

Cyprinodontida, 501

Cyprinus, 498

Cyprinus carpio, 498

Cypseli, 345

Cypselina, 316

Cyreaicle, 6:
Cysticercus, 687

('ystidlea, 655

(ystignathidie, 440

Cystophora cristata, 57

Cytherea dione, 625

Cyttida, 471

Cyttus, 471

\section{D.}

1)abchick, 25:3

Dace, 4 (y)

1)acelo gigas, $3: 3$ -

Dacelonine, 336

I)act ylomys, 11:2

Dacty lopsila, 201

Dactylopterida, 476

Dactylopterus, 476

Dahlia wartlet, 'T'he, 703

Daisy anemone, 702

Dallousia, Psarisomus, 356

Dama, Cervus, 14t

J)imaliscus, 150

Damascena, Perdix, 234

Damonia hamiltoni, 3ss'

Danaine, 583

Daphnia pulex, 531

Dark green silake, 4.2?

Darters, The, 29s, 301

1)arter, African, 301

Darwini, Rhea, 2.2:2

Darwini, Rhinoderma 439

Darwin's frog, 4:39

Darwin's rhea, 20.2

Daryprocta, 8

Dascyllus, 485

Dasypus, 186

Dasypus minutus, $186 ;$

Dasypus sexcinctus, 1\&6

Dasypus villosus, $151 ;$

Dasymys, 101

Dasypeltis scabra, $4 \cdot 2 \cdot 2$

Dasyporidie, 185

Dasyprocta, 115

Dasy proctidia, 115

Dasyure, Spotted, 303

Dasyure, spotted-tailed, 208

Dasyure tribe, 206

Dasyuridie, 206

Dasyurus, 208

Iasyurus maculatus, 203

Dasyurus viverrinus, 218

Taubentoni, Fossa, 57

Daubentoni, Vespertilio, $3 \vec{\imath}$

Daubenton's bat, 37

Daubenton's civit, 57

Daulias luscinia, 370

Daurica, Perdix, 234

Davirlianus, Cervus, 143

David's cleer, 143

Dear leaf butterfly, 555

Death-addler, 425

Decapora, 536

Decapodo, 646

Deccanensis, Canis, 68

Decemlineata, Leptinotarsa, 561

Decumana, Alactaga, 110

Decumanus, Mus, 105

Deer, Axis, 143

Deer, Chinese water, 146

Deer, Costa lica 146 
Deer, David's, 143

Deer, Eld's, 143

Deer, rallow, 144

1)eer, Hog, 14:3

Jeer, Irish, 14t

Deer, Japanese. 143

Deer, Large-eared mule, 1 I 6

Deer, Musk, $1+1$

Deer, Pampas, 146

Deer, Persian fallow, $\mathbf{1 4 4}$

Deer, P'urlu, 147

Deer, lien, 143

Veer, Roe, 146

Deer, Ruff's. I4t

Jeer, śpotted, 143

Deer, swamp, 143

Jeer, Thorold's, 14:3

Deer tribe, The, 140

Veer, Virginian, 140

Deep-sea holothurian, 661

Degu, 111

Delichonyx oryzivora, 361

Delphacinee, 600

Delphinapterus leucas, 179

Delphinide, 180

T)lphinida, 17s

Jelphinulidie, 632

Jelphinus, $18 \mathrm{~L}$

Del tocephalus, 601

Demiegretta, $28: 3$

Demodex folliculortm, 547

Demodicida, 547

Dendraca, 305

Dendragapus, 231

Dandragapus obscurus, 231

1)endrelaphis, 4.2.3

Dendrobates, $43 \mathrm{~s}$

Dendrobates tinctorius, 438

1)endrobatille, $43 \mathrm{~s}^{\circ}$

Dendroceela, 655

Dendrocolaptidx, 375

Dendrocopus, 354

Dendrocygna, $\mathbf{2 9 6}$

Dendrogale, 44

Dendrolagus, 195

Dendrolagus bennettianus, 195

Denitromys, 101

Dendromyinæ, 10

Dendroplis, 422

Dendrophrynisciıle, 441

Dendrophryniscus, 441

Dendrositta, $36 \mathrm{~s}$

Dendrosoma, $7 \cdot 2 \cdot 2$

Dentalium shell, $6: 39$

Deomys, 104

Depressa, Libellula, 569

Depressicornis, Bos, 162

Derbian screamer, 290

Derbianus, Oreophasis, 223

Derbinæ, 600

Derby's guan, 229

Dermatemys, 389

Dermestes, 556

Dermestes Jardarius, 550

Dermochelyidx, 391

Dermochelys coriacea, 391

Desert-chough, 358

Desert fox, 73

Desert larks, 361

Desmans, The, 47

Desman, Pyrenean, 4

Desman, Russian, 14
Desmodus, 41

Desmodus rufus, 41

Desmognathina, 450

Desmognatlius, 450

Destructor, Cecilomyia, 603

Development of corals, 707

Devil-fish, 521

Devil, Tasmanian, 207

Devil's coach-liorse, 556

Dharal bircls, 370

Diadlema, Ejeira, 544

liadema setosum, 660

Diamond beetles, 560

Jiamond snake, 419

Diana monkey, 21

I Hiantlus, Actinoloba, 70.2

Diatrematidie, $480^{\circ}$

Dibamicla, 411

Dibamus, 411

Uibranchiata, 645

Dicะum, 367

Dicamıtorlon, 450

Diceide, 367

Jicerobatis, 5:?

1)ichocerus bicornis, 339

Dicholouhi, 27

Dichromanassa rufa, $28: 3$

bichrous, Aretomys, :4

Dicliclurus, 3!)

Dicotyles, 9, 135

Dicotylidite, 135

Dicrocercus, 340

Dicruridæ, 361

Dicyemidie, 659

Didactylus, C'ycloturus, 1st

jidelphyidie, 9,210

Didelphys, 211

Jidelphys crassicaulata, 213

Diclelphys marsupialis, 211

Didelphys opossum, 213

Didelphys velutina, 213

Didi, $24:$

Diclunculus, 245

Didunculus strigirostris, 245

Didns, 245

Didus ineptus, 246

Dieffenlacliii, Cabalus, 249

Dimyaria, 618

l)ingo, $(66$

1)ingo, Canis, 66

Dinomys, 115

Dinoponera grandis, 579

Dinornithida, 224

Dinornithiformes, 221

Diodontida, 489

Diomedea, 258

Diomedea exulans, 258

Diomedeidre, $25 \bar{t}$

Diomedir, Psolus, 661

Dione, Cytherea, 625

Diotocardia, 631

Diphylla, 41

Diphylla ecaudata, 42

Jiplocrepis, 48?

Diploglossus, 405

Diplomesodon pulchellus, 46

Diplomystus, 507

Diploptera, 5 SO

Diplouterinæ, 351

Diplosis tritici, 603

Diplozoon pararloxum, 6S5

Dipneumones, 542
Dipnoi, 159

Dipodida, 105

Dipodomys, 109

Dipodomys phillipsi, $1(\omega)$

Diporpa, 688

Dippers, The, 371

Dipper, Common, 371

Ijiprera homaloptera, 60s

Dipsadomorphine, 42

Dipsadomorplius, 423

Dipssas, 420

Diptera, 553, 602

Diptera aplaniptera, 609

Diptera brachycera, 605

Diptera homaloptera. 60

Diptera nemocera, 6u:3

Dipus, 110

Discina, 651

Discinisca, 651

Discoglossida, $4 \frac{14}{4}$

Discoglossus pictus, 441

Discophora, (i75

Discopyge, 521

Dissenurus, 361

Dissura episcopus, 280

Distira, 426

Distrechurus pennatus, 20.2

Disto.na hepaticum, 654

Distome:e, fiss

Ditrema, 486

Divers, 'lhe, 254

Diver, Black-tlroated, 2.54

Diver, fireat northern, 25 !

Diver, Red-throated, 254

Diver, White-billed, 2.54

Diving-ducks, The, 297

Diving-duck, Stiff-tailed, 297

Diving petrel, 257

Docimastes ensiferus, 340

Jocoglossa, 631

Dodo, The, $2 \pm 6$

Dogs, The, 63

Dog, Azara's, 69

Dog, Bush, it

Dog, Crab-eating, 69

Dog, Hunting-, Cape, 73

Dog, Prairie-, 92

Dog, liacoon, 69

Dog tribe, The, $6:$

Dog-faced baboous, 22

Dog-fish, 518

Dog-fislies, Spiny, 519

Dog-flea, 609

Dog-periwinkle, 637

Dog-whelks, 637

Dolichotis, 115

Doliidæe, 630

Doliolum tritonis, $52 \cdot 7$

Dolomerles fimbriatus, 543

Dolphins, 169

Dolphin, Anazonian, 178

Dolphins, Fresl-water, 177

Dolphin, Gangetic, 177

Dolphin, Heaviside's, 179

Dolphin, Irawadi, 179

Dolphin, La Plata, 17s

Dolplin, Risso's, 180

Dolphin, Rougl-toothed, IsI

Dolphins, True, 181

Domestica, Musca, $\mathrm{CO}$

Domesticus, firyllus, 507

Dominicus, Characlrius, 270 
Donacidas, 625

Donax, $6: 5$

Dondersiidix, 616

Dorab, 506

Durab, Chirocentrus, 506

Durca kangaroos, 194

Dorcatherium, 139

Dorcatragus, 153

Dorcopsis, 194

Doria, Erythrotriorchis, 312

Doridiidre, 640

Doridoidta, $6 \notin 1$

1)ormouse-plialanger, 20 ?

l)ormouse tribe, The, 99

Dorsalis, Batlyythrissa, 506

Doryichthys, 4s

Dotterel, i70

Dotterel, True, 2:1

Double-toothed falcon, 318

Dougalli, Sterna, :61

Jouroucoulis, 26

Douroucouli, Three striped, 26

Doves, The, $24 t$

Jove, Cuckoo-: 244

Jove, Rock-, 244

Dove, Ring., 244

Dove, stock-, 24t

Dove, Turtle-, 244

Dove, Turtle-, British, : $\$ 4$

Dove, Turtle-, Cream-coloured, 245

Downy owl, 324

Draco volans, 399

Dracunculus medineusis, 679

T)ragon-tishes, $476^{\circ}$

Iragonflies, 553. 569

Dreissensidie, 623

Drilophaga bucephala, 633

Urinker moth, 590

Dromades, 264

Dromedarius, Camelus, $1: 36$

Dromea, 223

Dromece irroratus, 223

Dromee nova-hollandice, 2.23

Dromicia, 202

Dromiciops, 214

Dromornis, 224

Drongos, The, 361

Drongo, Black, 361

Drum, The, 4 is

Drummer cockroacl, 5 tit

Dryophis, 423

Dryopithecus, $1 \pm$

Drymornis bridgesi, 375

Duck-bill, 215

Duck-mole, 215

Ducks, The, 293

Duck, Comb, 293

Duck, Diving, 297

Duck, Long-tailed, 297

Duck, Mandarin, $29 \pm$

Duck, Pink-headed, 294

Duck, sheld, 296

Duck, Steamer, 297

Duck, Summer, 294

Duck, Tree, 296

Duck, True, The, 296

Duck, Wild, 296

Dugongs, 165

I)ugong halicore, $16 \%$

Duikerboks, 151 1)uke of burgundy Fritillary, $5 s 0^{\circ}$

Dulitensis rhizothera, 233

Dung beetles, 557

Dupetor, 2st

Dusky capercailzies, 231

Dusky rail, 249

Juvanceli, C'ervus, 14:3

Dwarf geese, 294

Dwarf tiger bittern, $28 t$

1)ynastes hercules, 558

l) scophilke, 439

Dysporus bassanus, 299

1) $y$ tiscictit, 555

1) ytiscus, 5.55

bytiscus marginalis, 556

E.

Eagles, The, 313

Eagle, Bald, 315

Eagle, Bateleur. 315

Eagle, Bearded, 313

Fagle, Birds'-nesting, 315

Eagle, Black, 315

Eagle, Bonelli's, 315

Wagle, Booted, 31:

Eagle, Crested, 315

Eagle, (iolden, 314

Eagle, Imperial, 31

Eagle, Sea, 315

Eagle, Serpent, 315

Eagle, spotted, 314

Eagle, Tawny, 314

Eagle, White-betlied sea, 315

Eagle, White-tailed, 315

Eagle-owls, The, 322

Eagle-rays, 5:1

Eared owls, 324

Eared pheasants, The, 230

Eared seals, 81

Eared vultures, The, 306

Eartl-worms, 674

Ear'wigs, 563

Ecaudata, 435

Ecaudata, liplylla, 42

Ecaudata, Peunula, 251

Ecaudatus, Centetes, 1!

Echeneis, 473

Echidna aculeata, 217

Echiclna, Bruiju's, 217

Echidua, Five-toed, 217

Echidnas, 216

Echidnidæ, 216

Echinocardium cordatum, 6.59

Echinococcus, Trenai, 685

Echinoderma, 65:

Echinoidea, 659

Echinomys, 11:

Echinops, 49

Echinorhinus, 519

Echinorhynchus, 681

Echinorhynchus angustatus, 682

Echinorhynchus gigas, 681

Echinorhynchus polymorphus, (ix:2

Echinorhynchus proteus, 682

Echinotlirix, 106

Echinus, 659

Echiostoma, 505

Echis, 127
Echiurus, 678

Ectopistince migratoria, 244

Edentata, 181

Edible arthropoda, 530

Edible crab, $53 \mathrm{~s}$

Edible frog, 436

Edible swiftlets, The, 346

Edouardi, (iuttera, $2 \pm 0$

Elulis, Mytilus, 621

Edwardsia, 70:

Edwardsia carnea, 704

Edwardsi, Eupoclotis, 275

Eels, 'The, 493

Eel, Electric, 495

Eel, ('lass, 494

Eel, Servent, 494

Eel, Spiny, $17 \mathrm{~s}$

Eel tribe, The, 493

Eel, True, 47s

Eel, Paste, 679

Eel, Vinegar, 679

Eel, Wheat, 67?

Effodientia, 1ss

Egg-eating snake, 42.2

Egg-laying mammals, 2.14

Egg-urcliin, 659

Egret, Little, 283

Egyptian asp, $4 \geq 4$

Egyptian crocollile, $3 s t$

Egyptian sacred beetle, 5.57

Egyptian vulture, 306

Eiclers, The, 297

Eider, steller's, 297

Eight-rayed corals, 707

Elacate, 473

Elachistida, $59 \cdot 1$

Elaeniina, 373

Eland bull, $156^{\circ}$

Elanoides furcatus, 316

Elanus, $316^{\circ}$

Elajinz, 424

Elaphodus, 141

Elaps corallinus, $4: 23$

Elasmolranchii, 513

Elateridie, 558

Eldi, C'ervus, 143

Eld's deer, 14 s

Electric centipede, 549

Electric eel, 495

Electricus, Gymnotus, 195

Elegans, Galirlia, 61

Elegans, Nectogale, 47

klegans, Testudo, $381 ;$

Elegant mungoose, 61

Elephant, African, $1: 3$

Elepliant family, The, 119

Elephant, Indian, 119

Elephant seal, si

Elephantidæ, 119

Elephant's-tooth shells, 6:28

Elephas, $11 \mathrm{~s}$

Elephas africanus, $12:$

Elephas indicus, 119

Elephus, Cervus, $14:$

Eliomys, 99

Eliurus, 102

Elk, 145

Ellioti, Callophasis, 23s

Ellobius, 104

Elops, 507

Elseya, 393

Elvers, 121 
Elysioidea, 641

Emarginula, 631

Emballonura, $3 ! 9$

Emballonuride, $3 \mathrm{~s}$

Emberiza cirlus, 364

Emberiza citrinella, 304

Emberiza hortulana, 364

Emberizina, 363

Emperor fish, 465

Emperor moth, 589

Emperor venguin, 255

Emplyyodontes, 40 s

Empicia, 600

Emu, The, 223

Emu, Conimon, 223

Emu, Spotted, $2 \cdot 23$

Emyda, 305

Emydura, 393

Emys orbicularis, 388

Encheliophis, 491

Endodontida, 643

Endrina, 29

Endynamis, 350

English puttin, 260

Engraulis, 507

Engystomatide, 438

Engystonıops, 441

Entellus, Senmopithecus, 20

Enteropneusta, 5:3

Entomophaga, 576

Entomostraca, 531

Enygrus, 4:0

Eos, 328

Eos rubiginosa, 328

Epanorthinlie, 204

Epanorthus, 204

Epauletter fruit-bats, 35

Epeira diadema, 544

Epeiride, 544

Ephemerida, 571

Ephemera vulgata, 571

Ephippium, Anomia, (i21

Ephippium, Testudo, 3st

Ephippodonta, 624

Epicrates, 419

Epicriniops, 454

Epimachine, 359

Epimachus, :359

Episcopalis, Mitra, (63s

Episcopus, Dissura, 280

Epomophorus, 35

Epops, Upupa, 340

Equatorial flying-squirrel, 90

Eques alexanor, 587

Eques macliaon, 587

Equida, 127

Equinus, Hippotragus, 153

Equiticle, 587

Equus, 127

Equus asinus, 120

Equus burclielli, 128

Equus caballus, 128

Equus grevyi, 128

Equas henionus, 129

Equus prezevalskii, 128

Equus quagga, 129

Equus zebra, 128

Erethizon, 113

Ericulus, 49

Ericulus setosus, 49

Ericulus telfairi, 49

Erinaceide, 14
Érinaceus, to

Erinaceus eurolbeus, 15

r riomys, 113

Erismatura, 297

Erismaturinæ, 297

Eristalis tenax, 606

Erithecus, Psittacus, 330

Ermine, 81

Ermine moths, 593

Erminea, Mustela, \$1

Errantia, 6i2

Erycinidae, 624

Erythacus rubecula, 370

Erythrinidæe, 500

Erythrinus, 501

Erythrocnema, 310

Erythrocnema unicincta, 310

Erytlirogaster, Ilirundo, 373

Erythromachus, 251

Erythrophthalmus, Coccyzus, 351

Erythrorhynchus, Pelecanus, 302

Erythrotriorchis, 312

Erythrotriorchis doriæ, 312

Erythrotriorchis radiatus, 312

Eryx, 420

Esacus recurvirostris, 273

Esculenta, Rana, 436

Esocidie, 502

Esox, 502

Esox lucius, 502

Estrilda, 362

Etroplus, 457

Eublepharidie, 395

Euclilue cardanines, 5 50

Euchore, Gazella, 153

Euclioretes, 110

Euriromias, 271

Eudromias morinellus, 271

Eudyptila minor, 255

Euglena, 718

Eulabes, 360

Eulabetidæ, 360

Eulamellibranchiata, 623

Eulimidæ, 633

Eulipoa, 228

Eulipoa wallacii, 228

Eumomota, 341

Eunectes murirus, 420

Eunice gigantea, 673

Eupetaurus, 95

Euplectella, 693

Eupleres goudoti, 61

Euplcea, 553

Eupodotis australis, 275

Eupodotis edwardsi, 275

Europæa, Talpa, 48

Europaus, Caprimulgus, 342

Europreus, Erinaceus, 45

Europreus, Lepus, 118

European bison, 162

European horned-lark, 364

European tree-frog, 442

Eurostopodus, 334

Eurybiidæe, 640

Euryceros, 360

Euryceros prevosti, 360

Eurylæmi, 356

Euryliemus, $356^{\circ}$

Eurylæemus javanicus, 356

Eurynorhyncluus pygmeus, 269
Eurypygat, 276

Eurypyga helias, 27t;

Eurypyga major, 276

Eurystomina, Pseudocheliclon, 369

Eurystomus, 335

Eurystomus calonyx, 335

Eusiferus, Docimastes, 345

Euspongia ofticinalis, 693

Eusteplianus, C'ervus, 143

Euthyneura, 6:39

Eutolmatus, 315

Lutolmatus fasciatus, 315

Eutolmatus pennatus, 315

Euxenura maguari, 2sit

Evania, 577

Evaniida, 576

Evotomys, 103

Excalfactoria, 2:35

Excalfactoria adansoni, 235

Exclanuationis, Agrotis, 591

Excubitor, Lanius, 360

Exocutus, 479

Exomegas, 524

Expansa, Potocnemis, 393

Exquisita, (3rtygops, 25:

Extinct birrs of Patagonia, 2is

Exulans, Diomedea, 258

Eyra, Sonth American, 55

Eyra felis, 55

\section{F.}

Fabalis, Anser, 995

Faber, Zeus, 471

Fairy fly, 577

Fairy pink armadillos, $18 \mathrm{~s}$

Falcinellus, Plegadis, 28s

Falco, 319

Falco esalon. 320

Falco felıleggii, 319

Falco peregrinus, 319

Falco subbuteo, 319

Falcon, Cuckoo, 317

Falcon, Donble-tootlied, 31s

Falcon, Juggur, 319

Falcon, Peregrine, 319

Falcon, True, 317

Falcon-kite, Grey, 318

Falconeri, Capra, 159

Falconets, The, 319

Falconide, 305

Falconinae, 307, 317

Fallow deer, 144

False vampire bats, 36

Famelicus, Canis, 73

Familiaris, Certhia, $366^{\circ}$

Famosa, Nectarinia, $366^{\circ}$

Fan-tailed flycatchers, 373

Fasciatus, Bungarus, 424

Fasciatus, (rossarclus, 61

Fasciatus, Eutolmatus, 315

Fasciatus, Lagostrophus, 196

Fasciatus, Myrmecobius, 209

Fasciolariide, 637

Feather-Star, Crawling, 664

Felleggii, Falco, 319

Felidæ, 5:

Felis, 52

Felis badia, 55

Felis bengaleusis, 5 
Felis caffra, 55

Felis canadensis, 5ti

Felis caracal, 55

Felis catus, 55

Felis chaus, 55

Felis concolor, 53

Felis eyra, 55

Felis leo, 53

Felis lynx, 56

Felis marmorata, 5.5

Felis nebulosa, $5 \dot{5}$

Felis onca, 53

Felis pardalis, 55

Felis pardina, 56

Felis pardus, $5: 3$

Felis serval, 55

Felis tigrina, 55

Felis tigris, 53

Felis uncia, 53

Fennecs, 73

Fennec, Isalande's, 74

Ferox, Cryptoprocta, 56

Ferret-badgers, so

Ferrilatus, Canis, 73

Feylinia, 411

Fiber, (astor. 96

Fiber ziberthicus, 103

Ficedula atricapilla, 372

Fiildler beetle, 555

Field cricket, 567

Fieldfare, 371

Fjeld-starling, 360

Fieli-vole, 103

Field wagtail, 365

Fierasfer, 491

Fierce snakes, 4:?2

Fighting-fish, Siamese, 483

Filaria sanguinis-lrominis, 680

File-fishes, 489

Filibranchiata, 621

Fimbriata, Chelys, 392

Fimbriatus, Dolomedes, 543

Finch-larks, 364

Finches, The, 363

Finfeet, The, 252

Finfoot, senegal, 252

Finfoot, South American, 252

Finners, 173

Finta, Clupea, 507

Fin-whale, 173

Fin.whale, Lesser. 174

Fire backed pheasant, 236

Fire-bellied frog, 444

Fire-crest, 369

Fire-flies, 559

Fire fly, Italian, 559

Firmisternia, 436

Fisl-eating kingtisher, 336

Fish-eating rats, 102

Fisl-owl, Brown, 321

Fish, Pilot, 47 !

Fish, Scabliard, 470

Fishing frog, 475

Fisling hawks, 320

Fishing ow\}, Pel's, 321

Fishing owls, 321

Fissurellidæ, 631

Fistularia, 481

Five-toed echidna, 217

Flagellata, The, 718

Flagellate Colonies, 718

Flamingoes, The, $2 \mathrm{~S} 8$
Flammea, Strix, 321

Flat-tislies, 49 ?

Flat worms, 685

Flata circulata, 600

liatina, 600

Flavescens, Canis, 71

Flavicollis, Mus, 105

Flavigula, Mustela, 80

Flavirostris, Phaton, 298

Flavirostris, Phyncho]s, 262

Flea, Water, 532

Nleas, 609

Flesh-eating mammals, 50

Flesliy corals, 701

Flies, 553, 602

Flies, Blue bottle, 608

Flies, Bot, 6006

Flies. Cadalis, 572

Flies, Crane, 604

Flies, Gail, 605

Flies, Gall, 576

Flies, Ilouse, 607

Flies, Lace-winged, 571

F'lies, Lantern, s99

Flies, May, 571

Flies, Rouber, 605

Flies. Sand, 604

Fies, Saw, 574

Flies, smother, 601

Flies, Stone, 571

Florida limpkin, 275

Floscularia coronetta, $6 \mathrm{~S} 2$

Flounder, The, 492

Hlower-nosed bat, 36

Flower-peckers, The, 367

Fluke-worms, liss

Fluminalis, Orcella, 179

Flustra foliacea, 665

Flute-mouths, 481

Fluviatibis, Tachybaptes, 253

Fluviatile, Petronyzum, 524

Fluviatilis, Sterna, 201

Fly, Candle, 599

Fly, Fairy, 577

Fly, Ichnemmon, 577

Fly, Swallow, 608

Fly, Tse-tse, 608

Flycatchers, The, 372

Flycatcher, Common, 372

Flycatcher, Fan tailed, 373

Flycateher, Paradise, 373

Flycatcher, Pied, 372

Fiying-fish, 480

Flying frog, 437

Fjying gurnard, 476

Flying lemur, 43

Flying lizard, 390

Flyin:-phalanger, 202

Fodiens, Crossopus, 46

Foina, Mustela, 80

Foliacen, Flustra, 665

Folius, Po'rodnn, 511

Folliculorum, Demodex, 547

Foraminifera, The, 715

Forficata, Myrmecia, 579

Forficatus, Lithobius, 548

Forficulidæ, 563

Fork-tailed gull, 262

Fork-tailed petrel, 257

Formica rufa, 579

Formicariida, 372

Formicida, 579
Formicata, Gastracantha, 544

Forsteni, Meroporon, 34t

Fossa, 56

Fossa laubentoni, 57

Fossaridae, $\{i 35$

Fossoles, 579

Fosteri, Ortaria, 82

Fountain shell, 636;

Four-horned antelope, 151

Four-toed mungooses, 60

Fox-like animals, 69

Fox, Arctic, 73

Fox, Common, 71

Fox, Bengal, 73

Fox, Black, 71

Fox, Corsac, 73

Fox, C'ross, 71

Fox, J)esert, 73

Fox, Japanese, $7: 3$

Fox, Kit-, 72

Fox, Long-eared, 73

Fox, Mountain, 71

Fox, Nile, 71

Fox, Kell, i1

Fox, Tibetan, 73

Fox, Virginian, 72

Fox, Yellow, 71

Fox-bats, 35

Fox-shark, 517

l'ragilis anguis, 404

Francolin, Bare-throated, 233

Francolin, Common, 283

Francolin, Hose's long.billed, 2:33

Francolin, Long-billed, 233

Francolinus francolinus, 233

Fratercula artica, 260

Free-swinming holothurian, 661

Free-tailed bats, $3 \mathrm{~s}$

Fregata aquila, 303

Fregati, 29S

Fregilinæ, 358

Fresh-water leech, $6: 7$

Fresh-water mites, 545

Fresh-water jolyp, 694

Frigate bircls, 'I he, 303

Frigate-birds, (rreat, 303

Frilled lizard, 399

Fringe-finned ganoids, 512

Finged gecko, 398

Fringilla celebs, 363

Fringillicle, 363

Fringillina, 363

Fringing reef, The, 709

Frit llaries, 585

Fritillary, Duke of Burgundy. 586

Frogs and toaris, 435

Frog, Agile, 436

Frog, l'ull, 437

Frog, Common, 436

Frog, Darwin's, 439

Frog, Edib]e, 436

Frog, Fire-bellied, 444

Frog, Flying, 43i

Frog, Grasshopjer, 443

Frog, Horned, 441

Frog, Lataste s, 436

Frog, Midwife, 443

Frog, Painted, 441

Frog, Poucher, 443 
Frog, Solomon Island, 437

Frog, Spanish, 436

Frogs, spur-toed, 444

Frog, Tree-, 442

Frogs, Typical, 436

Frog-fislies, 474

Frog-hoplpers, 594, 598

Frog.mouths, The, 333

Frontalis, Bos, 164

Frontatus. Fteno, 181

Frugilegus, Trypancorax, 358

Fruit bats, 34

Fruit pigeons, The, 242

Frumentarius, Cricetus, 101

Fulgens, filurus, 75

Fulgora laternaria, 599

Fulgoriclie, 599

Fulica, Heliornis, 25?

Fulicarius, Crymophilus, 266

Fulicidre, 243

Fuligula, 297

Fuligulıne, 297

Fuliginosa, Sterna, 262

Fuliginosus, II yracodon, 204

Fulmars, The, $25 \mathrm{~s}$

Fulmar, Petrel, 258

Fulmarina, 258

Fulmaris glacialis, 258

Fulvimitrella tinea, 593

Fulvus, ('anis, 71

Fungia, 705

Fungosa, Alevonella, 669

Furcata, Xema, 26:2

Furcatus, Elanoides, 316

Furnarina, 375

Furva, Chalia, 589

Fuscicaudatus, scaptonvx, 48

Fuscus, Larus, 263

\section{G.}

Gad-flies, 605

Gadida, 490

Gaclus aglefinus, 491

Garlus nerlangus, 491

Gadus niorrluua, 491

Gadus pollachius, 491

Gadus virens, 491

Galago, 30

Galago, Senegal, 30

Galago senegalensis, 30

Galagos, 30

Galmpagos sea-lizard, 402

Galaxias, 504

Galaxiidas, 504

Galbula melanngenaia, 355

Galbula, Oriolus, 361

Galbulidx, 355

Galeodes arabs, 540

Galeodes araneoides, 541

Galeoittes, 468

Galeommida, 624

Galeopithecide, 43

Galeovithecums rolans, 43

Galeopithecus, 43

Galeoscoptes carolinensis, 372

Galericulata, $\mathrm{Ex}, 294$

Galerita, 364

Galeus, 516

Galeus canis, 516

Galictis, 80
Galidia elegans, 61

Gall-flies, 576

is

Gall-gnats, 603

Gall-nites, 546

Fall-parasites, 576

Gallicole, 575

Gallicus, Circætus, 315

Fallicus, Cursorius, 272

Galliformes. 226

Callinago, 268

(sallinago aucklandica, 268

Gallinago australis, $26 \mathrm{~s}$

Gallinago gallinago, 268

Gallinago gigantea, 268

Gallinago imperialis, 268

Gallinago jamesoni, 268

Gallinago nujor, 268

Gallinago megala, 263

Fallinago nemoricola, $26 \mathrm{~S}$

(rallinago pusilla, 268

Gallinago stenura, 268

fallinago unclulata, 268

Gallinula chloropus, 252

Gallinula, Limnocryptes, 268

Gallinuliclæe, 248

Gallopavo, Meleagris, 240

Gallus, 238

Gamasida, 545

Gamasus, 545

Came-birds, The 220

famma moth, 591

famma, Plusia, 591

Gammaride, 585

Gammarus pulex, 682

Gangetic dolphin, 17

Gangetica, Garialis, 382

Gangetica, Platanista, 177

rannets, The, 299

Ganoids, 462

Ganso, 293

Gaper, 626

Garilen snail (Helix), 643

Garden spiders, $5+4$

Garials, 382

Garial, Scblegel's, 382

Garial, True, $35 \%$

Crarialis, 38:

Garialis gangetica, 3S:

Gariepensis, Steatornis, 332

Garpike, 479

Garrulus, 358

Garrulus ampelis, 36 ?

Garrulus, Coracias, 335

Garrulus glanclarius, 358

Garzetta, 283

Garzetta garzetta, 283

Gastracant ha fornicata, 544

Gastracanthidæ, 544

Gast rochisma, 472

Gastrochanida, 627

Gastropod Shell, Topography of, 630

Gastropoda, 629

Gastropterida, 640

Gastrosteidas, 480

Gastrosteiformes, 450

Gastrosteus, 4SO

Gaur, 164

Gaurus, Bos, 164

Gayal, 164

Gazella, 152

Gazella euchore, 153
Gazelle, Clarke's, 15.

Gazelle, Waller's, 153

Gecinus, 354

Geckos, 397

Gecko, Fringed, 398

Gecko, Turkish, 397

Gecko, Wall, 398

Geckonida, 397

Geese, The, 292

Geese, Blue-winged, 295

(ieese, Brent, 295

Geese, Grey, 295

( eese, Magellanic, 295

(Heese, snow, 295

Geeve, spur-winged, 293

Geese, The true, 295

(iegenophis, 455

Gelacla baboons, 2.)

Gelarla, Th"ropithecus, 22

Gelasimus, 538

Gemonensis, Kamenis, 42 ?

Gemsbok, 153

Gemze, 150

Genets, 58

Genetta, $5 \mathrm{~S}$

Gennaus, 236

Gentle lemur, 30

Geocichla, 370

Geocnceyx, 351

Geocolaptes, 354

Geodlephaga, 554

Geö̈myla, 357

Geoffroyensis, Inia, 17s

Geogale, 4s

Geometra, 592

Geometrica, Testudo, 3s;

Geometridre, 582

Geomyiliæ, 107

Geomys bursarius, 109

Geonemertes, 694

(ieonemertes australiensis, 6.4

Geonemertes nova-zelandia, 681

Geonemertes palæensis, 684

Geopeliinæe, 244

Geophilide, 549

Geoplana australis, 686

Geopsittacus, 331

Georgian black grouse, 230

Georychus, 10 t

Geospiza, 363

Geotria, 524

Geotrupes, 545

Geotrygoninæ, 244

Geotrypetes, 455

Fieotrypetes petersi, 455

Gephyrea, 67\%

Gephyrean worms, 67\%

Geranospizias, 309

Gerbil group, The, $\mathbf{1 0 1}$

Gerbillina, 101

Germanica, Phyllodronia, 564

Germanicum, Polyzonium, $5+9$

Gerrionotus, 405

Gerrhosauridae, 410

Ghost moth, 591

Giant armadillo, 187

Giant clam, 626

Giant cobra, 424

Giant extinct lemur, 32

Giant humming-birds, 347

Giant salamander, 450 
(iibbons, 18

Gibbon, Hainan, 19

Gibbus, Zabrus, 555

Gigantea, Eunice, 673

Gigantea, Gallinago, 268

Gigantea, Leguatia, 25:

Gigantea, Ossifraga, 258

(iigantens, Blaberus, 56 it

Giganteus, Cervus, 144

Giganteus, Macropus, 194

Gigantostraca, 538

Gigas, Arapnima, 504

(iigas, 1)acelo, 337

Gigas, Fchinorlyynchus, 681

Cigas, Patagona, 347

trigas, l'rioulon, 1si

Gigas, Klytina, 168

irigas, virex, 575

(rigas, Ntrombus, 636

Gigas, 'Tridacna, $626^{\circ}$

Gillesplie's sea-lion, 82

Aillespii, Otaria, 82

(iilt heads, 466

Ginginianus, Neopliron, 306

Girattida, 147

Giraffa camelopardalis, 147

Giraffe family, The, 147

Girdled lizards, 403

(rlacialis, Colymbus, 254

Glacialis, Fulmaris, 258

Gladiator, Orca, 180

Gladius, Psephurus, 511

Glandarius, Coecystes, 350

Glandarius, Garrulus, 358

(ilanis, Silurus, 496

ilareola, 272

Glareola pratincola, 272

Glareolus, Microtus, 103

Glass eels, 494

Glass rope sponge, 693

Glaucidium, 324

Glaucidium brodiei, 324

Glaucidium gnoma, 324

filauciclium pygmæum, 324

Glaucomyidæ, 625

Glauconia, 417

Glauconiidæ, 417

Glaucus, Carcliarias, 516

Glis, Myoxus, 99

Globator, Volvox, 719

Globe-bearers, 716

Globicera, 243

Globigerina, 716

Globiocephalus melas, 180

Glochidium, 023

flomeridie, 550

(ilossina moristans, 608

Glossophaga, 41

Glossy ibis, 253

(:lossy starling, 360

Glow-worms, 559

(ilutinosus, Ichthyophis, 453

Gilutton, 81

(ilycimeris, 626

Glyptodonts, ?

Gmelini, Ovis, 160

Gnathobdellidix, 675

Gnats, 603

Gnoma, Glaucidium, 324

Gnus, 150

Goat moth, 590

(roat, Persian wild, 159
Goat, Rocky Mountain, 15i

('oatsucker, 342

Gobies, The, 476

Gobiilite, 476

Gobiiformes, 476

Gobio, 499

Gobioesocida, 482

Gobinesociformes, 482

Trobioesox, 48:

robius, 476

Godwit, 269

Gold-crests, The, 368

Gold-crest, Common, 368

Gold-fish, 498

Gold sinny, 486

Golden bat, 38

(iolden birl of Paradise, 359

irolden cuckoo, 350

Folden eagle, 314

Golden eyes, The, 297

Folden fruit-pigeon, 243

Golden-green beetle, 555

Golden marmot, 93

Golden-moles, 50

Golden oriole, The, 361

Goldeu plover, 271

Golunda, 105

Gomphicla, 569

Gonatide, 646

Gonorhynchida, 505

Gonorhynclus greyi, 505

Goosander, 297

Goose barnacles, 533

Goose, The, 291

Goose, Bean, 295

Goose, Cereopsis, 294

Goose, Dwarf, 294

Goose, Knobbed, 293

Goose, Maned, 295

Goose, Pink-fonted, 295

Goose, Red-breasted, 295

Goose, Semipalmaterl, 298

Goose, White-fronted, 295

Gophers, 91

Goplier, Striped, 92

Goral, 157

Gordius, 680

Gorilla, 15

Gorilla, Dentition of, 6

Gorilla savagei, 15

Gorsachius, 284

Gos-liawk, Chanting, 310

Gos liawk, Common, 310

Gos hawk, Rerl-thighed, 310

Gos-hawk, White, 311

Goudoti, Eupleres, 61

Goura, 245

Goura coronata, 245

Gracilaria syringella, 594

Graculus, 358

Graculus graculus, $35 \mathrm{~s}$

Graculus, Phalacrocorax, 299

Graca, Testudo, 386

Graffila, 685

Grakles, IVattled, 360

Grallarius, Burhinus, 273

Grampus griseus, 180

Grampuses, 179

Grandis, Dinoponera, 579

Grandis, Leucospis, 576

Grandis, Nyctibius, 344

Grandis, Phryganea, 572 (iraphiurus, 99

Grass motlh, 593

(irass owls, 325

Grass warblers, 370

Grasshoplers, 568

Grasshopper, Blue-winged, 568

Grassho]pler, Long-horned, 567

Trasshopper frog, 443

(irayi, Argusianus, 2:39)

Frayling, 509

Fray's argus, 239

fireat ant-eater, 184

(ireat auk, The, 260

(ireat-billed liliea, 2:?

(Treat black cockatoo, 328

Great black wood jecker, 354

Great bustard, 273

(ireat-crested grebe, 253

Great frigate-bircl, $30 ;$

Great grey shrike, 369

freat loney-guirle, 353

Great hornbill, 339

Great Japanese crab, 538

Great mole-rat, 106

Great northern diver, 25t

Great sand-mole, 107

Great skuas, The, 263

Great snipe, 268

Great spotted cuckoo, 350

Great tinamou, 2:6

Great tit, 367

Great vampire, 41

(ireat water-beetle, 557

Treater black-backerl gull, 263

Greater horse-shoe bat, 36

Greaved lizards, 407

Grebes, The, 253

Grebe, Great-crested, 253

Grebe, Little, The, 254

Grebe, sclavonian, 253

Grecian tortoise, 386

Greek partridge, 232

Green-bottle, 608

Gireen fruit-pigeon, 24 ?

Green hairstreak, 586

Green kingfisher, 336

Green lizard, 409

Green monkey, 21

Green oak tortrix, 5.93

Green sandpiper, 269

Green-tailed lory, $3: 3$

Green tiger-beetle, 554

Green toad, 442

Green turtle, 391

Green woodpecker, 354

Greenfinch, Common, 363

Greenland jer-falcon, Tle, 319

Greenland-whale, 172

Greenland seal, $\$ 5$

Greenland sliark, 519

Greenlets, The, 370

Gregarinie, The, 720

Grevyi, Equus, 128

Grevy's zebra, 128

Cirey geese, 295

Grey kangaroo, Great, 194

Grey kite-falcon, 318

Grey lag-goose, 295

Grey mullet, 479

Grey parrot, 330

Grey phalarope, 266

Grey plover, 271 
Grey wagtail, 365

(irey-whale, 17:

Greyi, (ionorliynchus, 50:5

Griffun, 1 he, 300 :

Griseum, Acanthosoma, 59s

Griseus, Grampus, 1st

Grisola, Muscicaja, 3\%2

Grizzled skipper, 58ऽ

(irizzly bear, 75

Grenlanelica, Phoca, 85

fromia oviformis, 715

Groove-tootherl mise, 105

(iroove-tootherl squircel, 91

Groove-toothed vole, 103

Frosbeaks, $36:$

Grosbeaks, Cardinal, 363

(irossulariata, Abraxas, 592

Ground-beetles, 55.5

Ground hornbills, 339

Ground parrot, 331

Ground pigeons, 'The, 244

(iround-rollers, 33.)

Ground sloths, 183

Ground-squirrels, 91

Ground-thrushes, 370

Ground woodpeckers, 3.54

C'ruuse family, The, 229

firouse, Blark 230

Grouse, fieorgian black, 230

(irouse, Pinnated, 231

(irouse, Red, 2:30)

(irouse, Ruffed, 231

Grouse, Sand-, 241

firouse, Sand-, Pallas', 241

frouse, Sand-, T'in-tailed, $2+1$

irrouse, Willow-, 2:99

(irues, 274

firuiformes, 274

Grunniens, Bos, 104

Grus, frus, $27 \overline{0}$

Grylle, Uria, 260

Tiryllidae, 566

Gryllotalja, Curtilla, 56:

firyllus, Acris, 443

Fryllus domesticus, 567

Grypus, Halichoerus, 85

(ivacharo, 33:)

Guan, Derby's, 229

Guanaco, 13s

(iuanacus, Lama, $13 \mathrm{~s}$

liuemels, 146

(ivenons, 21

Cruentheri, Ceratobrachus, 439

(iuerezas, 21

(iugeons, 499

Guianensis, MIorplinus, 313

(ruib, 156

Cruillemot, 260

Givillemot, Black, 260

(ivinea-fowls, The, 240

Guinea fowl, Crested, 240

(iuinea-fowl, Vulturine, 240

(ruinea-pig, 115

Guinea-worm, 679

Gulls, The, 261

Gull, Black.headed, 262

(Full, Common, 262

Full, Fork-tailed, 262

Fill, r'reater black-backed, 263

Grull, Herring, 263

Gull, Hooted- 262

(irull, Lesser black·backed, 203 (iull, I,ittle, 263

Gull, Ross's, 26:2

irull, Sabine $\mathrm{s}, 26$ ?

(iull, True, 262

Giulo, Aulustonum, 676

Gulo luscus, 81

Gumbi owl, 321

(iundi, 111

Gunni, Perameles, 200

(iunn's bandicoot, 206

(iuplyyi, Rana, 437

(iurami, $4 \times 3$

Gurnard, Beaked, 476

Gurnard, common. 475

Gismard, Flying, 470

Guttata, Percopsis, 509

Guttera, 240

(iuttera cristata, 240

Guttera edouardi, 240

(iuttera pucheraui, 240

Gygis alba, 26") "

Gymnarclius, 503

Grmnelis, $49 \mathrm{~J}$

Gymno scopelus, 505

Gymnobelideus leadbeateri, 201

Gymnogenes, The, 309

Grmmoglossa, 633

Gymnomurena, 494

Grmnophays, 244

Gymnoplaps albertisi, 244

Gvmnopis, 455

firmnoticlae, 49:3

Gimnotus electricus, 495

Gymmura raftlesi, 4.5

Gypatus, $31: 3$

Crypetus barbatus, 313

(ippetus ossifragus, 314

(:5ps, 306

Gylfalco, Hierofalco, 319

(ivrinidx, 555

H.

Habroptila wallacii, 249

Habroptilus, Stringops, 331

Haddock, The, 491

Hadomys, 102

Hæmaceplia'a, Nantholæma 353

Hæmatopoda, 60.

Hæuatopodinæ, 271

Hrematolıta pluvialis, 605

Hæmatortyx, 2:34

Hæmophila, 364

Hag.fishes, $5 \pm 3$

Haie, Naia, 424

Hainan gibbon, 19

Hainan is, Hrlobates, 1

Hair sea-egg, 660

Hair-tails, The, 470

Hairstreak, Green, 58

Hairy armadillo, 186

Hairy saki, 27

Hairs-tailed inoles,

Hakes, 491

Halacarirla. 545

Haleyon, 338

Halcyones, 336

Halizetus, 315

Haliztus albicilla, 315

Halimetus leucocephalus, 315
I Haliztus leucogaster, 315

Haliatus leucoryphus, $3: 1$

Haliztus, Pandion, 320

Haliretus vocifer, 315

Ilaliastur, 316

IIaliastur indus, 316

Halibut, $49^{\circ}$

Halicherus grypus, S.j

Halicore dugong, 167

Halicorida, 165

Haliotide, 632

Hallomys, 10 \%

Halobates, 597

Halys vipers, $4: 29$

Hamiltoni, Damonia, 358

Hammer-head stork, 281

Hammer-headed oyster, 622

Hawsters, 101

Hamster, True, 101

Hang-nests, The, $\$ 61$

Hang-nest, Red-winged, 361

Hangul, 143

Hapalemur, 30

IIapalidie, 27

Hapaloderma, 349

Hapalomys berdmorei, 104

Haplocerus montanus, 1 i,

Haplocliton, $50 \%$

Haplochitonidz, 507

Haplodactylina, 460

Haplodact $y l u s, 466$

Haflognathirie, 46 it;

Haplopeltura, 426

Haplopomi, 501

Hajoloriontidae, 95

Haptoglossa, 450

Hardella, 389

Hardwickei, Ifemigale, 5s

Hardwicke's hemigale. is

Hares and rabbits, 117

Hare, Common, 118

Hare, Cape jumping, 111)

Hare, Mountain, 11s

Hare-lipped bats, 39

Hare-wallabies, 194

Hare'da, 297

Harengus, Clupea, 507

Hargitti, Thriponax, 3.55

Hargitt's woodpecker

Harlequins, The, 297

Harmless vampires, 41

Harnessed antelopes, 150

Harpa, 638

Harpactes, 349

Harpactoridæ, 596

Harpagus, $31 \mathrm{~s}$

Harpirla, 638

llarpy, 'I he, 313

Harpyhalizetus, 313

Harpyhalizetus coronatus, :31:

Harpyia, 35

Harpyia, Thrasetus, 313

Harpyio-cephalus, 37

Harriers. The, 309

Harrier, Marsh, 309

Harrier, Montagu's, 309

Harriotta, 461

Hartebeests, 150

Hartlaubi, Lopliocerus, 3:39

Harvest bug, 547

Harvest-men, 541

Harvest-mouse, 105 
Iawfinch, Coumon, 363

Hawk-cuckoos, 350

Hawks, 304, 307

Hawks, Long-legged, 308

Hawk, White-tailed, 3I2

Hawk-owl, 323

Hawk-owl, Brown, 323

Ilawksbill, 391

II azel-hens, 23I

Heart-and-dart moth, 591

Ilenrt-cockles, 62 . I

Ileavisidei, Cephalorlinnchus, 17 ?

Heaviside's dolphin, 179

Hebomoia, 587

llerlgehog tribe, $\$ 4$

Hedgehog, shrew-, Raftle's, 1.5

Hedgehog, shrew-, inaller, th

Hedgelıog-tenrees, 49

Hedymeles, 363

Ilelena, Calypte, 347

IIeliaca, Aquila, 314

Helias, Eurylyga, 276

IIeliastes, 485

Helicida, 643

Helicinille, 632

Heliconinze, 584

Helicostyla, 643

Helictis, 80

Heliopais, $25^{\circ}$

Heliopora, $70 \mathrm{~s}$

Heliornis, $25^{\circ}$

Heliornis fuiica, $25^{\circ}$

Heliornithida, 25

Heliozoa, The, $716^{\circ}$

IIelix, 643

IIell-bender, 451

Helmet-shells, 636

Heloderma, 405

Heloclermatidæ, $39 \overline{7}, 405$

Helodromas, 269

Helodromas ochropus, 269

Helogale parva, 60

IHelotarsus, 315

Helvetica, Squatarola, $2 \nmid 1$

Hemiaspida, 539

Hemibungarus, 424

Hemicardium, 6?6

Hemicentetes, 49

Hemichorda, $5 \% 8$

Hemichromis, 437

Hemidactylus, 397

Hemigale, 58

Hemigale hardwickei, 58

Hemigale, Hardiricke's, 58

Hemigale hosei, 58

Hemigalidia, 61

Hemionus, Equus, 139

Hemiphractidie, +44

Hemiporles, The, 241

Hemipodii, 226

Hemiptera, 553, 594

Hemitragns hylocrius, 159

Hemitragus jemlaicus, 159

Hen, Black water, 252

Hen, Blue water, 245

Hen, Nortl A merican harrier, 309

IIendersoni, Hierofalco, 319

Henclersoni, Porloces, 358

Ifenderson's jer-falcon, 31?

Heniconetta stelleri, $: 97$
II enioclius, 465

Hepalicum, Distoma, 689

Iepialidre, 591

Hepialus humuli, 591

Hercules beetle, 568

Hercules, I)y nastes, 5.58

Il ermit crabs, 537

IIerodias, $28: 3$

Herocliones, 252

llerons, 'I'he, '25'?

Heron, Agami, 2s:?

lleron, American, 25:3

lleron, Common, $25 \cdot 2$

IIeron, Night, $25: 3$

lleron, Purple, $2 \$$

Heron, Reef, 283

11 erpele, 455

If erpestes iclineumon, 60

Iferpestina, 60

II erpetodryas, 4:2:2

Herrings, The, 506

Herring, Common, 507

IIerring gull, 263

ITesperia malva, $588^{\circ}$

Hesperiida, 588

Ifessian fly, 603

llet:erina, 570

II eterocarpus, $456^{\circ}$

II eterocephalus, 107

Heterocera, 585

Heterodactyli, 349

Heterodera schachti, 679

Heterogeomys, 109

lleterogyna, 5is

Heteromera, 559

Heteromys, 109

Heteropoda, $636^{\circ}$

Heterolutera, 595

Heterotis, 504

Hexactinel liclae, 693

Hexactinia, 705

Hexadactyla, Alucita, 594

Hexarthra polyptera, 682

Heyi, Anmoperdix, 233

Hibernica, Nustela, 81

Hierococcyx, 350

Hieroralco, 319

Hierofalco candicans, 319

Hierofalco gyrfalco, 319

Hierolalco hendersoni, 319

Hierofalco holboelli, 319

Hierofalco islandus, 319

Hierofalco saker, 319

Himalisan black bear, 75

Himalayan ibex, 1.58

Himalayan marmot, 93

Himalayan tahr, 159

Himalayanus, Arctomys, 93

Himalayensis, Regulus, 360

Himalayensis, 'Tetraogall us, $2: 32$

Himaniopodiza, 270

Himantopus melas, 270

Hinged brachioporl, (it9)

Hiposrita jacobrea, 5ss

11 ippoboscida, $60 \mathrm{~s}$

Hippocampus, 4s7

Hippocastani, $55 \mathrm{~s}$

Hippocrepis, Zamensis, 4:2

Hippoglossus, 492

Hipponensis, Hippopotanus, 133

Hipponicidie, 6:34 llippopotamus, The, 130

Ilippopotami family, The, 130

Hippopotamidee, 130

IIippopotamus amplibius, 131

IIip)opotamus, Coinmon, 131

Hippopotamus hipponensis, $13: 3$

Hippopotamus iravaticus, 13:

Hipyopotamus lemerlei, 133

Ilippopotamus liberiensis, I3I

Iippopotanus namadicus, 13:2

IIippopotamus ulreindicus, I:-2

lippopotamus, l'igmy, 131

llippopotamus sivalensis, 13:-

Hippopotamus, siwalik, 132

Hippopus, 626

Hipposiclerus, 36

Hippotragus equinus, 153

Hippotrazus niger, 153

Hirudinea, 675

Hiruclo medicinalis, 676

Hirundinida: 373

Hirundo, Avicula, 622

Hirundo erythrogoaster, 3 ris

Hirundo rustica, 373

Hispanica, Capra, 158

Hisuldus simmorlon, 10 ?

Histiopliorus, 469

Hive-lee, 581

Hoary-bat, 37

Hoatzin, 246

Hobby, The, 319

Hoclgsoni, Ovis, 160

Hodgsoni, Pantholops, 152

Horlgsoni, Vespertilio, iss

Hodgsonite, Perdix, 234

Hollomys, 102

Hog-deer, 143

Hog, Pigmy, I:34

llog, Wart-, 134

Holacanthus, 465

Holboelli, Hierofalco, 319

Holboell's jer-falcon, 319

Holocentrum, 468

Holocephali, 461

Holochilus, 10:

Holosericeus, Ptilonorhynchus. 3.59

IJolothurian, Deep-sea, 601

Holothurian, Free-swimming, 661

IIolothurian, Plated, 661

IIolothuroidea, 660

Hollow llorned ruminants, 14y

Homalogyra, 6:3:3

Homalogyriclae, 633

llomalopsis, 4:3

Homaloj,tera, l viprera, 608

11 omalopterus, 498

Homoptera, $5.9 \mathrm{~s}$

Homopus, 387

Homojus arcolatus, 357

Honduras turkey, 240

Honey buzzards, 317

Iloney guides, The, 358

Honey-guicle, freat, 353

Honey-guide, Indian, 353

Honey-kites, 317

Honey-suckers, The, 366

Hooded gulls, 262

Hooderl seal, 87

Hooferl mammals, The, 115

llook-billed kingtisher, 337 
Hook-billed kites, 316

Hoopoes, 'The, 340

Hoopoe, Common, 340

Hoopoe, Indian, 340

Hoopoes, Wood, 340

Hoplognathide, 466

Hoployterus, 271

Hopolgnathus, 466

Hopping-fish, 477

Hornbills, The, 339

Hornbill, (rreat, 33 ?

Hornbill, Ground, 339

Hornbill, Nalabar pied, 339

Hornbills, Pied, 339

Hornbill. Rhin oceros, 339

Horned frog, 441

Horned-larks, 364

Horned-lark, Europeau, 364

Horned lizards, 399

Horned-owls, 3:1

Horned pheasants, The, 235

Horned screamer, 290

Horned vipers, 427

Hornet, 580

Horribilis, Ursus, 75

Horridus, Moloch, 400

Horse tribe, The, 127

Horse, Common, 128

Horse-hair worm, 680

Horse leech, 676

Horse mackerel, 471

Horse mussel, 621

Horse-shoe bats, 36

Horsefield's broadbill, 356

Horsesloe snake, 422

Hortensis, Cryptops, 549

Hortulana, Einberiza, 364

Hosei, II migale, 58

Hose's long-billeit francolin, 233

Hosii, Calyptomena, 356

Hotinus candelarius, 599

Hounds (Sliark), 516

Houbaropsis, 273

House-ant, 579

House cricket, 567

House flies, 607

House martin, 373

House-mouse, 105

Hova, Oryzorictes, 49

Howlers, 23

Howler, Black, 24

Howler, Red, 23

Hucho, The Danubian, 508

Hucho, Salmo, 508

Hudsonius, Circus, 309

Hulock, 18

Hulock, Hylobates, 18

Human skeleton, 3-4

Humble bees, 581

Humboldti Lagothrix, 24

Humboldt's woolly monkey, 24

Humix, Callophasis, 238

Humilis, Podoces, 358

Humming-birds, The, 347

Humming-bird, (iant, 347

Humming.bird, King, 348

Humming-bird, sword-bill, 348

Humpback whale, 173

Humuli, Hepialus, 591

Hunting-dog, Cape, 73

Hunting-leopard, 56 ;

Hunting spiders, 543
Huso, Acipenser, 511

Hutia, 112

Hyanas, 62

Hyæna, Brown, 62

Hyæna brunnea, 62

Hyrena crocuta, 63

Hyrena, Spotted, 63

Hyana striata, 62

Hyana, Striper, 62

Hyænida, 62

Hyalimax, 642

Hyalonema, 693

Hybrida, Tatusia, 187

Hydra, 694

Hydrachnidae, 545

Hydradephaga, 555

Hydraspis, 393

Hydrobates, sitomys, 101

Hydrocenida, 632

Hy drocharus, 116

Hydrocherus capivara, 89

Hydrochelidon, 261

Hy rrochelidon nigra, 'Z6I

Hydrocorallia, 697

Hydrocyon, 501

Hydroid colonies, 696

Hyllromedusæ, 698

Hydrometridie, 597

Hydromyinae, 100

Hydropliiinæ, 425

Hydroplis, 426

Hydropotes inermis, 146

Hydroprogne caspia, $26 \mathrm{~L}$

II ydrous piceus, 557

Hydrozoa, 694

Hydrus, 426

Hyla arborea, 443

Hyetornis, 351

Hylicle, 4.2

Hylobates, 18

Hylobates hainanus, 19

Hylobates bulock, 18

Hylobates leuciscus, 19

Hylobates syndactylus, 19

Hylocrius, Henitragus, 159

Hylodes martinicensis, 440

Hylomanes, 341

Hylomys suillus, 45

Hymenoptera, 553,573

Hymenoptera, Aculcata, 578

Hymenoptera, Boring, 574

Hymenoptera, Stinging, 578

Hynobius, 450

Hyodon tergissus, 504

Hyodontidæ, 505

Hyperboreus, Phalaropus, 266

Hypercompa caia, 588

Hyperoöion rostratus, 177

Hypnus, 5:1

Hypotharmosyna, 328

Hypoderma bovis, 606

Hypogeonys, 102

Hypogeopliis, 455

Hypoleucus, Cebus, 24

Hyponomeuta, 593

Hyponomeutidre, 594

Hypoptopoma, 497

Hypositta, 368

Hy potanidia, 249

Hypselornis, 2.24

IIypsiprymodon moschatus, 197
Hypsiprymnorlontinæ, $19 \mathrm{~s}$

11 yptiotes cavatus, 544

Hyraces family, The, 123

Hyracodon, 204

Hyracoron fuliginosus, 204

Hyracoidea, 123

Hyrax, 124

Hystricida, 113

Hystrix, 113

\section{I.}

Ianthinida, 633

Iberica, Rana, $\mathbf{4 3 6}$

Ibex, 158

Ibex, Capra, 158

Ibex, Himalayan, 159

Ibex, Nilgiri, 159

Ibex, Spanish, 158

Ibidida, 287

Ibidorhynchine, 270

Ibidorhynchus struthersi, 270

1bises, 287

Ibis athiopica, 288

Ibis, Cilossy, 288

Ibis, Pseudotantalus, $9 \$ 1$

Ibis, Sacred, $28 \mathrm{~s}$

Ibycter, 307

Iceland jer-falcon, 319

Icerya purchasi, 60:2

Ichneumion fly, 577

Ichneumons, 60

Ichneumon, Herpestina, 60

Iclmeumonida, 577

Ichthyomys, 10:2

Ichthyophis glutinosus, 453

Ichthyophis momochrous, 454

Icteridr, 361

Icterus, 361

Icticyon venaticus, 74

Ictinia, 318

Ictinia mississippiensis, 318

Ictonyx, 81

Ictonyx zorilla, 80

Idiosepíidæ, 616

Idiurus, 90

Ignicapillus, Regnlus, 369

I gneus, Bombinator, 444

Iguana tribe, The, 401

Iguana, Ring-tailed, 403

1 guanida, 401

Iliacus, Turdus, 371

Ilysia scytale, 421

Ily'siidas, 421

Inberbis, Strepsiceros, 154

Imbricata, Chelone, 391

Imhausi, Trilophonys, 102

Immutabilis, Cygnus, 29:-

Impennis, Plautus, 260

Imperatoria, Pomponia, 598

Imperial Eagle, 314

Imperial snipe, 268

Imperialis, Gallinago, 268

Impeyan plieasants, 235

Inachis, Kallima, 585

Inarticulata, 651

Indian atlas-moth, 589

Indian black-buck, 152

Indian buffalo, I6:2

Indian cobra, $4: 4$

Indian crested cuckoo, 350 
Indiau eleplant, 119

Indian honey-guide, 353

Indi:tn hoopoe, 340

Indian liumpel eattle, 165

Indian musk-shrew, 46

Indiun jied kingtisher, 336

Indian porjoise, 17 !)

Iudian rit-snake, $4 \cdot 2$

Indian rhinoceros, 126

Indian slikra, 311

Indian sloth bear, 75

Indian tailor bird, 370

Intian wolf, 65

Inclica, U pupa, 340)

Indicator xanthonotus, 353

Indicatores, $3 . \overline{3}$

Indicus, Bos, 165

Indicus, Elephas, 119

Indris, 29

Indris brevicaudata, 29

Indus, Haliastur, $316^{\circ}$

Ineptus, Didus, 246

Inermis, $H$ jdropotes, 146

Infundibulata, 668

Infusoria, The, 720

Infusorian colnnies, 722

Infusorians, Ciliated, 720

Infusorians, Tentacled, 720,722

Inguinalis, Pthirins, 602

Inia geoffroyensis, 178

Inoruata, A mblyornis, 359

Inornata, Clophliaga, 296

Insect-eating mammals, 4:

Insect-mites, $5+5$

Insecta, 551

Insecta haustellata, 553

Insecta mandibulata, 553

Insectivora, 42

Insectivorous kingfishers, The, 337

Insects, Lace-winged, 568

Insects, Praying, 565

Insects, Stick, 566

Insects, Wingless (Neuroptera), 573

Intercedens, Rhynchops, 262

Intermedla. Porzana, 251

Interpres, Arenaria, $2 \% 2$

Inuus macacus, 22

Involucris, Ardetta, 284

Iphis, Rliopalocampta, 588

Ipnops, 505

Iravaticus, Hippopotamus, I32

Irawadi dolphiu, 179

Irish elk, 144

Irregular sea-urchin, 659

Irrisoridæ. 340

Irritaus, Pulex (Flea), 609

Irroratus, Dromece, 223

Isabelline bear, 75

Isabellinus, Ursus, 75

Isclınochitonidæ, 616

Islandica Aretica, 624

Islandus, Hierofalco, 319

Isocardiidie, 624

Isopoda, 534

Isospondyli, 503

Isjuida, Alcedo, 337

Is]jidina, 337

Italian fire-fly, 559

Itch-mites, 546

Ithagenes, 235
Ithomiina, 584

Iuliformis, P'eripatus, 551

Ixodila, 545

Iyngina, 354

Isugina torquilla, 354

Izard, 156

\section{J.}

Jacamars, The, 355

Jacanierops aurea, 355

Jacares, 3s0

lack snipe, 268

Jackal, Black-backed, 66

Jackal, Common, 66

Jackal, side-striped, 66

Jacobaea, Hiposrita, iss

Jacobinus, Cuculus, 350

Jaguar, 53

Jamaica tody, The, 342

Jamaicensis, Nyctibus, 344

Jamesi, Phanicoparrus, 290

Jamesoni, Gallinago, 268

Jameson's snipe, 268

Japanese deer, 143

Japanese fox, 73

Japanese waxwing, 369

Japonica, Coturnix, 235

Japenicus, Ampelis, 369

Japunicus, Canis, 73

Jararaca, 429

Jassida, 601

Javan rhinoceros, 126

Javanicus, Eurylænus, 356

Javelin-bats, 41

Jays, 358

Jeffreysiicle, 635

Jelly-fish, 700

Jelly-fish, Root-footed, 700

Jemlaicus, Hemitragus, 159

Jerboa-rats, 106

Jerboa tribe, The, 109

Jerboa, Kirghiz, 110

Jer-falcon, 1-reenland, 319

Jer-falcon, Hentlerson's, 319

Jer-falcon, Holboell's, 319

Jer-falcon, Iceland, 319

Jer-falcon, Norwegian, 319

Jer-falcon, Saker, 319

John-dory, 471

Johnnie, 255

Jouanettia, 627

Jubata, Myrmecophaga, 184

Jubata, Otaria, 8:

Jubatus, Canis, 69

Jubatus, Cynelurus, 50

Jubatus, Rhinochetus, 276

Juggar falcon, 319

Julida, 550

Jumping-mice, 110

Jumping-shrews, 44

Junco, 364

Jungle-cat, 55

Jungle fow], The, 235

\section{$\mathrm{K}$.}

Kagus, The, 276

Kagu, Marlagasear, 270

Jiaka parrots, $3: 6$
Kiakayo, 331

Kalij pheasants, 'The, 236

Kallima inachis, 555

Kampfer: macrocheira, 533

Kantehaticus, 'letrao, 230

Kang iroo tribe, 192

liaugaroos, Dorca, 194

Kangaroo, (irey, 194

Kancaroo, Musk, 197

Kangaroo, Plain rat, 19\%

Kangaroos, J'rehensile-tailesl

list, 197

Kangaroos, Rat, 1!)

Kangaroo, liufous rat, 1!)

Kangaroos, Tree, 195

Liangaroo-rats, 10 ?

Kashmir stag, 143

Katydicls, 567

Kea pariot, $3: 7$

Kelb-el-bahr, 501

Kelb-el-moyeh, 501

liellyellidie, $6: 4$

Kestrels, The, 320

Ketupa, 3:2

Ketuja ceylonensis, $3: 21$

Kewense, Bipalium, $65 t$

Keyhole limpets, $6: 31$

Khannanay, 2029

Kieneri, Lophotriorchis, 31 j

Killer, 179

Killer, Lesser, 1SU

King crabs, $53 \mathrm{~s}$

Kingfishers, The, 336

Kingtisher, Belterl, 33it;

Kingfisher, Comnon, 337

Kingfisher, Crested, 337

Kingfisher, Fish-eating, 336

Kingtisher, freen, 3330

Kingfisher, Hook-billed, 337

Kingfisher, Indian-pied, 33̈t

Kingfisher, Insectivorous, 337

Kingfisher, Laughing, 337

Kingfisher, Pied, $336^{\circ}$

Kingfisher, Ringed, 336

Kingfisher, shoe-billerl, 33 T

Kingfisher, stork-billed, 330

Kingtisher, Three-toed, 337

Kjng humming-birds, $34 \mathrm{~s}$

Kingi, Anops, 405

Kingi, Chlamydosaurus, 399

King-of-the-herrings, 455

King penguin, 255

Kinkajou, 76

Kirghiz jerboa, 110

Kirghiz shrew, 46

Kiroumbos, The, 335

Kites, The, 316

Kite, African swallow-Lailed, 316

Kite, American swallow-tailed, 316

Kite, Black-slouldered, 316

Kite, Bralıminy, $316^{\circ}$

Kite, Common, 316

Kites, Honey, The, 31\%

Kite, Hooked-billed, 316

Kite-falcon, Mississippi, 31:

Kit-fox, 72

Kittiwake, 263

Kiwis, The, 224

Klipspringer, 151

lineria, 500 
Knerlidæ, 500

Í nobberl goose, 293

Knob-billed pelican, 302

Knot, The, 263

Koala, 199

Koels, The, 350

Koklass plieasant, The, 237

Kollari, Cynips, 576

Kolyvanensis ascalaphus, 570

Kudu, Lesser, 154

Kudu, Strepsiceros, $15 \cdot 1$

Findu, True, 154

Kuhli, Vinia, 398

Kuhl's Lory, $32 \mathrm{~s}$

L.

Labrax, 486

Labrax maculatus, $4 \mathrm{S6}$

Labrax mixtus, 486

Iabridre, 486

Labyrintbici, 483

Lacerta, 409

Lacerta agilis, 409

Lacerta ocellata, 409

Lacerta, Viridis, 400

Lacerta vivipara, 409

Lacertiliæ, 409

Jacertilia, 396

Lacertina, Siren, 452

Lace-winged flies, 571

Lace-winged insect $\because, 56 \mathrm{~s}$

Lace-work sponge, 693

Lachesis lanceolatus, 429

Lachesis mutus, 429

Lackey moth, 590

Lady-birds, 56:

Lady-bird, A ustralian, 602

Lady Ross Touracoe, 352

Lremargus, 519

Lremmergeier, 313

Lamodipordidæ, 535

Lævis, Coronella, 422

Lagenorhynchus, 180

Lag-goose, Grey, 295

Lagidium, 114

Lagouyidæ, 117

Lagoniys, 117

Layonosticta, 362

Lagopus, 229

Lagopus, Canis, 73

Lagojus lagopus, 229

Lagopus mutus, 230

Lagopus scoticus, 230

Lagorchestes, 194

Lagostomatide, 113

Lagostomus, 114

Lagostrophus fasciatus, 196

Lagothrix, 21

Lagothrix, humboldti, 24

Laisurus, Plataeantlomys 100

Lalande's fennec, $7 t$

Lama guanacus, $13 \mathrm{~s}^{\circ}$

I ama vicuna, 138

Lamellaritdæ, 634

Lamellibranchiata, 616

Lamellicorns, 557

Lamiidæ, 561

Lamna cornubica, 51

Lamnidæ, 517

Lampides bæticus, $586^{\circ}$
Lampreys, 528

Lamprey, River, 524

Lamprey, Sea, 5:4

Lampris, 472

Lamprocolius, 360

Lampshells, 648

Lampyris noctiluca, 559

Lancelt $\mathrm{t}$, The, 526

Lanceolatus, Amplioxus, 526

Lanceolalus, Lachesis, 429

Land planarian, 684

Land-tortoises, 385

Langurs, 20

Langur, Sacred, 20

Laniger, Antechinonys, 209

Laniger, Canis, 65

Lanigera, Avahis, 20

Laniilla, 369

Lanius, 360

Lanius collyrio, 369

Lanius excubitor, 369

Janius senator, 369

Lanner, 319

Lanteru flies, 599

Lanaphus cocophagez, 566

Lapillus, Purpura, 637

La Plata dolphin, 178

Lapland bunting, 364

Lapnet, 590

Lapponicus, Calcarius, 364

Lapradei, Polypterus, 513

Lawwing, Common, 271

Larlarius, Dermestes, 556

Large-eared mu?e-deer, 146

Large fruit-pigeons, The, 243

Large sun-bittern, 270

Large-trained trogon, 349

Isaridae, 260

Lariformes, 261

Larks. The, 364

Latk, Calandra, 364

Lark, Crested, 364

Lark, Desert, 364

Lark, Finch, 364

Lark, Horned, 364

Lark, Short-toed, 364

Lark, Sky, 364

Lark, Wood, 364

Lark-heeled cuckoos, The, 351

Larus, 26:

Larus argentalus, 263

Larus canus, 26:

Larus fuscus, 263

Larus marinus, 263

Larus, minutus, 263

Larus, rirlibundiss, 262

Larval Forms of Crustacea, 530

Larvatus, Nasalis, 19

Lasiocampille, 590

Latastei, Rana, 436

Lataste's frog, $\$ 36$

Latax lutris, 77

Lateralis, Cryptobranchus, 451

Laternaria, Fulgora, 599

Lates, 464

Lathami, Catheturus, 227

Latham's snine, 26 s

Laticaudatus, llaturus, 425

Latrans, Canis, 66;

Latro, Birgus, 537

Latus, Bothrioceplalus, 6s7

Laugling jackass, 337
Laughing kingftsher, 337

Laxocemus, $\$ 19$

Layardi, Mesoplodon, 177

Leach's netrel, $25 \%$

Leadbeateri, Gymnobelideus. 201

Leadbeater's phalanger, 201

Leaf-cutter Lees, 581

Leaf-nosed bats, 36

Leathery turtle, 391

Le la, 62I

Leeches, The, 675

Leech, Fresh water, 677

Leeeh, Horse, 676

Leech, Medicinal, 676

Leguatia gigantea, 25.2

Lemerlei, Hippopotamus, 13:3

Lemming, Bauded, $10^{\circ}$

Lemming, Common, 103

Lemoniidæe, 585

Lemmus, Myodes, 103

Lemurs, The, 29

Lemur catta, 29

Lemur, Flving, 43

Lemur, Gentle, 30

Lemur, (riant extinct, $3:$

Lemur, MLuse, 30

Lemur, Ring-tailed, 29

Lemur, Sportive, 30

Lemurs, True, 29

Lemurs, Typical, 28

Lemuridre, 28

Lemuroidea, 11

Lencorrhoa, Oceanodroma, 25\% Lendigera, Amathia, 668

Leo, Felis, 53

Leona, Nightjar, 343

Jeoninus, Macrorhinus, $8 i$

Leopards, 53

Leopard, Clouded, 55

Leoparr, Hunting, 56

Leoparl, Seal, 86

Leopard, Snow, 53

Lepadidæ, 533

Lepadogaster, 482

Lepas anatifera, 533

Lepetirke, $(i 31$

lepidolemur, 30

Lepidolemur caniceps, 30

Lepiclopleuridre, 616

Lepidoptera, 553, 581

Lepirlopus, 470

Lepillosirenida, 460

Lepidosteidæ, 509

Lepirlosteus, 509

Lepisma saceharina, 573

Leporiclae, 117

Lepialia of Pallas, 667

Lepralia, Pallasiana, 667

Leptino:arsa decemlineata, 561

Leptodact ylidæe, 440

Leptodactylus, 4.40

Jeptodera, 679

Leptognathus, $4 \geq 6$

Leptonychotes wedrlelli, si

Leptonyx, Ogmorhinus, 86

Leptoptilus, $27 \mathrm{~s}$

Ieptoscopus, 473

Leptosomati, 335

I. ерus, 117

Lepus cuniculus, IIs

Lepus europere is 
Lepus timidus, 113

Lerwa, 231

Lesser alit-eater, 184

Lesser black-backed gull, 263

Lesser bustard, 273

Lesser fin-whale, $17 \pm$

Less ' $\mathbf{r}$ killer, 180

Lesser kudu, 154

Lessoni, Momotus, 341

Lesson's Motmot, 341

Lesser shrew, 16

Lesser sperm-whale, 176

Lesser tern, 261

Lethrinus, 466

Leucas, 1)elphinapterus, 179

Lencerodea, Platalex, $2 \mathrm{~S} 6$

Leuciscus, 49!)

Leuciscus, Hylobates, 19

Leucocephalis, Cladorhynchus, 270

1.eucoceplialus, Iraliztus, 315

Leucopus, Canis, 73

Leucoryphus, llaliaetus, 321

Leucosomus, Astur, 311

Leucospis, 576

Leucospis grandis, 5,6

Levaillanti, Plotus, 301

Liasis, 419

Libelilula depressa, 569

Libellulidæe, 569

Liberiensis, Hippopotamus, 131

Libitina, 624

Libythea celtis, 586

Libytheida, 586

Lidre, Hexactinel, 693

Ligurinus, 363

Ligurinus chloris, 363

Lima, 623

Limacide, 643

Limacinidæ, 640

Jimacomys, 101

Limnaa, 612

Limnæidze, $64^{2}$

Limnas chrysippus, $5 \$ 3$

Limnocrsptes gallinula, 268

Limnopardalus, $2 \pm 9$

Limonites, 269

Limopsis, 621

Limosa, 269

Limpets, 631

Limpets, Cup-and-saucer, 634

Limpets, Keyhole, 631

Limpkins, The, 275

Limpkin, Florida, 275

Limpkin, South American, 275

Limulus, 53 s

Linulus moluccanus, 539

Linearis, Chiroxiphia, 374

Linearis, Ranatra, 597

Lineus marinus, 684

Lingualapsus, 449

Lingualapsus annulatus, 449

Linguatulida, $54 \mathrm{~s}$

Lingula, $6+8$

Lingula anatina, 650

Linotenia crassipes, 54 !)

Linsanga, 58

L,insangs, $5 \mathrm{~s}$

Liobunum religiosum, 54 르

Lion, 53

lion-tailed monker,

Iiparidie, 55 s
Liparis, 4 tit

Lipoa, 223

Lijoa ocellata, 2.s

Lipocephala, 615

Lithobiide, 54?)

Lithobius forficatus, 519

Lithocranias walleri, 153

Lithomelissa, 717

Lithosiidie, 589

Litiopiclse, 635

Litopterna, ?

Litorale, P'yenogonum, 53 ?

little auk, 260

little bittern, 284

Little crake, 251

little egret, $20 \% 3$

Little gisll, 263

Little owls, 3:3

Little skunk, is

littoriniclæ, 635

Liver-fluke, 659

Livia, Columba, 244

Livingstonianus nanotragus, 151

Lizards, 390

Lizard, Flying, 399

Lizard, Frilled, 399, 400

Lizard, Girdled, 403

Lizard, Greaved, 407

Lizard, Green, 409

Lizard, Horned, 399

Lizard, Moloch, 400

Lizard, Pearly, 409

Lizards, Poisonous, 405

Lizard, sail-tailed, 400

Lizard, sand, 409

Lizard, snake-like, 404

Lizard, spiny, 401

Lizard, Ntump-tailed, $\$ 10$

Lizard, Thorny-tailed, 400

Lizard, Tree, 399

Lizard, Viviparous, 409

Llamas, $13 \mathrm{~s}$

Loach, Common, 500

Loach, spiny, 500

Lobed pheasant, 236

Iobiophasis bulweri, 236

Lobivanelline, 271

Lobodon carcinophaga, $s 6$

Lobsters, 536

Lobster, Spinz, 537

Loculator, Tantalus, 281

Locustidæe, 568

Locusts, $56 \mathrm{~s}$

Loddigesia mirabilis, $34 \mathrm{~s}$

Loggerhead tortoise, 391

Loliginidæe, 646

Loligo, 646

Lonclieres, 112

Long-billed francolin, 233

Long-eared bats, 36

Long-eared fox, 73

Long-eared owl, 324

Long-horned beetles, 560

Long-horned grasshoppers, 567

Longicornes, 560

Lomgipernis, Macrodipteryx, 343

Longirostris, A ptenorlytes, 255

Longirostris, Rhizothera, 233

Long-legged hawks, 30 -

Long-legged petrel, 2.57
Long-legged pouched-mouse, 209

Long-legged thick-knee, 273

Long-nosed crocodile, 381

Long nosed jumping-shrews, 44

Long-nosed rat, 106

Long-snouted phalanger, 203

Long-tailed African flyingsquirrel, 90

Long-tailed bat, 39

Long-tailed ducks, The, 297

Lons-tailed marmot, 94

Long-tailed parrakeet, $3: 9^{\circ}$

Long-tailed jigeons, 244

Long-tailed skuas, 204

Long tailed tit, 368

Loopers, 59:"

Lophiida, 474

Lophiom ys, 102

Lophius piscatorius, 474

Lophoatus oecipitalis, 315

Lophobranchii, 487

Loplocerus, $3 \pm 0$

Lophocerus hartlaubi, 339

Louhodytes, 297

Lopliogy p5, 306

Lopholamus, 243

Lopholatilus, 473

Lophophanes eristatus, 368

Lophophanes, 368

Lophophorus, 235

Lophopoda, 665, 669

Lophopus, 6 is $^{\circ}$

Lophorty $x$ californiana, 240

Lophotes cepedianus, 454

Lophotida, 454

Lophotiformes, 484

Lophotis, 273

Lophotriorchis, 315

Lophotriorchis Kieneri, 315

Lophura, 236

Lophurom ys, 101

Lophurus amboynensis, 400

Loricaria, 497

Lories, The, 327

Loriidæ, 327

Loris, 31

Lorisis, 31

Lorius chlorocercus, 325

Lory, Green tilied, 328

Lory, huhl's, 328

Lota vulgaris, 491

Lotoriida, 63 ,

Louse, Whale, 535

Love-birds, 329

Lowi, Ptilocercus, $\$ 4$

Lowries, 352

Loxia, 363

Loxosoma, 667

Lucanus cervus, b5s

Lucayanum, Asymmetron,

Incifuga, 491

Incilia casar, 608

Lucina, Nemoebius, 586

Lucinide, 6:t

Luciocephalicle, 4\$3

luciocephalus pulcher, to:

Lucioperca, 464

Lacius, Esox, 502

Lucorum Trichiosoma, 5it

Lug worm, 6\%?

Lugubris, Ceryle, $3: 36$

Lugubris, Motacilla, $36 . ;$ 
Lullula, 364

Lumbricidre, 67t

Lumbricoides, Ascaris, 679

Lump-suckers, 476

Lung-fishes, 459

Lung-fish, Australian, 460

Lunulata, Cyclopsitta, $3: 9$

Lupus, Canis, 64

Luscinia, Daulias, 370

Luscus, Gulo, 81

Lusitanica, Chioglossa, 447

Luth, 391

Lutra, 76

Lutreola, Mustela, 81

Lutris Latax, 77

Lycænida, 586

Lycaon pictus, 73

Lycodes, 490

Lycodida, 490

Lycosida, 543

Lycosa arenicola, 543

Lycosa tarentula, 543

Lygia oceanica, 534

Lygosoma, 410

Lyncodon, 81

Lynx, Canzdian, 56

Lynx, Common, 56

Lynx, Felis, 56

Lynx, Spanish, 56

Lyonsiidz, 628

Lyre-birds, 357

Lyrurus, 229

Lyrurus mlokosiewiczi, 230

Lyrurus tetrix, 230

Lysiurus unicinctus, 186

Lystrinæ, 600

M.

Macacus, 21

Macacus cynomolgus, 22

Macacus inuus, 22

Macacus rhesus, 22

Macacus silenus, 2:

Macaques, 21

Macaque, Crab-eating, 22

Macaws, 329

Maccormicki, Megalestris, 263

Machaon, Eques, 587

Machlis, Alces, $\mathbf{1 4 5}$

Mackerels, The, 472

Mackerel, Common, 473

Mackerels, Horse, 471

Macrauchenia, 9

Macro, Lepidoptera-, 592

Macrocephalus, Physeter, 175

Macrocheira Kämpferi, 538

Macroclemmys tem mincki, 390

Macrodipteryx longipennis, 343

Nacrogeomys, 109

Macrolopha, Pucrasia, 237

Macronyx, 365

Macronyx amelize, 365

Macropodidæ, 192

Macropodinæe, 193

Macropteryginae, $3+6$

Macropteryx, $3 \pm 6$

Macropus, 193

Macropus agilis, 194

Macropus browni, 194

Macropus brunii, 194
Macropus giganteus, 194

Macropus walabatus, 194

Mlacropygia $24 t$

Macrorhinus leoninus, 87

Macrorhyncha, Rhea, 223

Macroscelitles, 44

Macroscelides tetradactylus, 44

Macroscelididae, 44

Macrotis, Canis, 73

Macrotis, Cervus, 146

Macrura, 536

Macrula, Sterna, 261

Macruridæ, 492

Macrurus, 492

Mactridæ, 625

Maculata, Aquila, 31

Maculatus, Dasyurus, 208

Maculatus, Labrax, $4 \mathrm{~s} 6$

Maculatus, Phalanger, 200

Maculosa, Salamandra, 446

Madagascar kagu, 276

Madagascar mungoose, 61

Madagascariensis, Chiromys, 31

Maderensis, Regulus, 369

Madoqua, 151

Madreporo, 706

Maeandrina, 707

Maehorhamphus, 317

Maehcerhamphus alcinus, 317

Maehorhamphus anderssoni, 317

Maforensis, Nasiterna, 320

Magar, Oriental, 381

Magellania, 651

Magellanic geese, 295

Magilus, 637

Maginrostris, Orthorhamplus, 273

Magna, Caccibis, 232

Magnifica, Megaloprepia, 243

Magnificent fruit-pigeon, 243

Magpies, 358

Magpie moth, 592

Maguari, Euxenura, 280

Maguari stork, 279

Maliasir, 498

Maia squinado, 530

Maimon, Papio, 23

Major, Eurypyga, 276

Major, Gallinago. 268

Major, Parus, 367

Malabar pied liornbill, 339

Malabar spiny mouse, 100

Malacanthide, 47t

Malacanthus, 474

Malaccensis, Viverra, 57

Malachite sun-bird, 360

Malacobdella, 684

Malacoclemmys, 388

Malacorlermi, 559

Malacomys, 101

Malacoptila, 355

Malacostraca, 533

Malaiensis, Neopus, 315

Malayan badger, 79

Malayan bear, 75

Malayan tapir, 121

Malayanus ursus, 75

Maleo-bird, $2 \cdot 26$

Malleus, 6*:

Mallopliaga, $5 \% 3$

Mallophagus ovinus, 608
Malva, Hesperia, 588

Mammalia, 1

Mamnalia, Dentition of, 5

Mammalia, Human Skeleton 3.4

IIammals, Distinctive features of, 2

Mammals, Egg-laying, 214

Mammals, Flesh-eating, 50

Mammals, (reographical distribution of, 7

Mammals, Insect eating, 4:2

IIammals, Pouchel, 190

Mammals that gnaw, 88

Manakins, The, $37 t$

Manatis, 165

Manatus, 167

Manculus, 450

Mandarin duck, 294

Mandril, 32

Maned goose, 295

Mangabeys, 21

Manidie, 189

Manillensis, Pelecanus, $3 v^{\prime 2}$

Manis, 19!

Man-like apes, 11

Mantella, 43s

Mantidæ, 563

Mantis religiosa, 565

Mantis, Squilla, 535

Manx shearwater, $25 \mathrm{~s}$

Mapi, 195

Marabous, 27s

Maral, Cervus, 14:

Maral, Persian, 143

Marbled cat, 55

Mareca, 296

Margaritacea, Nereis, 67-3

Margaroperdix, 2:34

Marginalis, Dytiscus, 556

Marginata, Testudo, 386

Margined tortoise, 386

Marginellicle, 638

Marina, Arenicola, 672

Marine gurnards, 475

Marine lings, 491

Marine mites, 545

Marine mussel, 621

Marinum, Petromyzum, 524

Marinus, Larus, 263

Marinus, Lineus, 684

Maritima, Anisolabis, 563

Maritimus, Batlyyergus, 107

Maritinus, Ursus, 75

Markhor, 159

Marmorata, Felis, 55

Marmosets, The, 27

Marmot, Alpine, 93

Marmot, Cabul, 94

Marmot, Common, 92

Marmot, Golden, 93

Marmot, Himalayan, 93

Marmot, Long-tailed, 94

Marmuts, Prairie, 9:2

Marmot, Red, 94

Marmots, True, 92

Marmotta, Arctomys, 9:

Marpurito, Conepatus, $7 \mathrm{~s}$

Marslı harrier, 309

Marsh tern, 261

Marsh tit, 367

Marsipobranchii, 5:3 
Marsupial mole, 210

Marsupialia, 190

Marsupialis, Didelphys, 211

Marten, Beech-, 80

Marten, North American, so

Marten, Pennant's, so

Marten, Pine, so

Marten, Sable, 80

Marten, Yellow-throated, 80

Martes, Mustela, su

Martiu, Bank, 373

Martin, House, 373

Martin, Purple, 373

Martiniceusis, Hylodes, 440

Martius, Picus, 354

Mary-sole, 49:2

Masked bug, 596

Mastacembelus, 4 is

Mastacomys, 106

Masterdons, 9

Mastiff-bats, 39

Matamata, 392

Maximus, Cetorhinus, 517

Maximus, Megalobatrachus, 450

May flies, 57 I

Mayeri, Nesanas, 244

Meadow brown, 585

Mearlow pipit, 365

Meadow-starling, 361

Meagre, The, $46 s$

Meal-worms, 560

Medicina! leech, 676

Medicinalis, Hirudo, 6,6

Melina worm, 679

Merlinensis, Hracunculus, $6 \circ 9$

Medusoid, 696

Meerkat, 61

Megacephalum, $2: 6$

Megachile, 581

Megacrex, 249

Megaderma, 36

Megala, Gallinago, $26 \mathrm{~s}$

Megaladapis, 32

Meralestris, 263

Megalestris antarctica, 263

Megalestris catarrhactes, 263

Megalestris chilensis, 263

Megalestris maccormicki, 263

Megalobatrachus maximus, 451

Megaloblatta, 564

Megalocephalum, Platyster. num, 3 s?

Megaloprepia, 243

Megaloprepia magnifica, 243

Megalotherium, 183

Megalotis, Otocyon, 74

Megapode, Australian, 228

Megapode, Cumming's, 228

Megapode, Nicobar, $2 \nexists 8$

Megapode, Ocellated, $2 \mathrm{as}$

Megapodes, True, $2 \cdot 28$

Megapodii, 2:36

Megapodius, 228

Megapodius cumingi, 2:s

Megapodius nicobariensis, 228

Megapodius tumulus, 2:2

Megaptera, 17:3

Megaptera boops, 173

Melampsalta montana, 5y9

Nelaniida, 635

Helanocephala, Arenaria, 272
Melanocephala, Caccabis, 232

Melanocephala, Uacaria, 27

Melanocetus, 475

Melanocoryplia, 364

Melanogenit, Galbula, 355

Melanoleucus, Aeronautes, 346

II elanoleucus, Eluropus, 75

Melanonota, Sarcidiornis, 293

Melanoye, Motacilla, 365

Melanoperdix nigra, 234

Melanorhamphus, Cocorax, 358

Melinura, lihynchops, 362

Melis, Himantopns, 270

Melas, Globiocephalus, 180

Meleagrina, 622

Meleagris gallopavo, 240

Meleagris ocellata, 240

Meles, 79

Meliceps, Mydaus, 79

Melidora, 337

Melierax, 310

Meliphagida, 366

Melittophagus, 340

Melleri, Rhynchogale, 61

Meller's mungoose, 61

Mellifica, A pis, 581

Mellivora, 79

Melne, 560

Melolontlia vulgaris, 557

Melolonthida, 557

Melophagus ovinus, 608

Melospiza, 36t

Melursus ursinus, 75

Membracida, 601

Menhaden, Clupea, 507

Menura superba, 357

Menura, 356

Mephitis, 77

Mephitis, Mephitica, is

Merganettinæ, 297

Mergansers, The, 297

Merganser australis, 297

Merganser brasilianus, 297

Merganser merganser, 297

Merganser, Red-breasted, 297

Nerginæ, 297

Mergulus alle, 258

Mergus albellus, 297

Meriones, 101

Merlangus, (indus, 491

Merlin, 'T'be, $3: 0$

Nerlnccius, 491

Mermaid's head, 660

Mermis, 690

Meropogon forsteni, 341

Merops, 340

IIeropes, 340

Nerostomata, 539

Nerula, 370

Merula merula, $37 \mathrm{I}$

Mesembry-anthemum, Actinia, 703

Mesites variegata, 276

Mesodesmatida, 625

Mesomelas canis, 66

Mesomyodi, 373

Mesomys, 112

Mesoplodon, It

Mesoplodon layardi, It

Mesopotamicus, Cervus, $14 t$

Mesotrochous, 67:3

Metachirus, $\because 13$
Mexican turkey, 240

Mice, (iroove tootlied, 105

II ice, Jumping, 110

Mice, Mosaic-tatiled, 106

Nice, Narrow-footed pouched, 209

Mice, Pouched, 201

Mice, Singing, 105

Mice, spiny, 106

Mice, Waltzing, 105

Mice, Wlite-footcd, IUI

Micoureus, 213

M icrastur, 310

II icrocebus, 30

Microchieta rappi, 674

Microgale, 49

Microglossus aterrimus, 328

Microhierax, 319

Micromonacha, 355

Microperdix, 234

Microphyllum, Rhinopoma, 34)

Micropterygirle, 591

Micropus, 467

Micropus apus, 346

Microstoma, 685

Microtina, 103

Microtus, 103

Microtus agrestis, 103

Microtus amphibius, 103

Microtus glareolus, 103

Micrura, Talpa, 18

Midaida, 605

Midas, 27

Midwife frog, 443

Migratoria, Ectopistima, 244

Migratory quail, "234

Miliaria miliaria, 364

Milleperles, 543

Millepora, 697

Milliolite shells, 716

Nilvus, 316

Mimeta, 361

Miınida, 372

Mimus polyglottus, 372

Mindorensis, Bos, 162

Minimum, Carychium, 641

Iinimus, Chironectes, 214

Miniopterus schreibersi, ;s

Mink, Nortl American, s1

Minor, Chionarchus, 265

Minor, Endyptila, 255

Minor, Phaniconaias, 290

Minor, Philohela, 267

Minor, Plhylloscopus, 370

Mlinuta, Ardetta, 284

Minuta. Sterna, 261

Minutus, Dasypus, 186

Minntus, Larus, 263

Minutus, MI 11 , 105

Mirabilis, Lod(ligesia, 348

Mirafra, 304

Mirum, Pedalion, 68:

Misgurnus, 500

Mississippi kite-falcon, 318

Mississippi salamander, 451

Mississippiensis, Alligator, 380

Mississippiensis, Ictinia, 318

Mitchelli, Phegornis, 267

Mites, 539, 545

Mites, Clieese, 547

Mites, Fresh-water, 545

Mites, Gall, 546 
Mites, Itch, $5 \pm 6$

Mites, Marine, 545

Mite, Sugar, $5 \pm 7$

Mithan, 164

Mitra episcopalis, 638

Mitrida, 638

Mixocebus, 30

Mixtus, Labrax, $4 \$ 6$

Mloko iewiczi, Lyrurus, 230

Mniotiltida, 365

Moas, The, 220

Mocking-birds, The, 372

Modestus, Cabalus, 249

Modiola, 6?:-

Nodiola modiolus, 621

Modiolopsidie, 023

Modiolus, Modiola, 6?1

Modoqua saltians, 151

Moles, The, 47

Mole, Cape golden, 50

Mole, Common, 45

Mole, Duck., 215

Moles, frolden, 50

Moles, Hairy-tailed $4 \mathrm{~s}$

Mole, Marsupial, 210

Mole, Musk-, 48

Mole, sand-, Great, 107

Mole, Star-nosed, is

Moles, True, 48

Moles, Web-fonted, 47

Mole, Yellow-tailed, $4 \mathrm{~s}$

Mole-cricket, 567

Mole-rats, The, 106

Mole-shrews, 46

Molge, 447

Molge cristata, 477

Molge jalmata, 44s

Molge vulgaris, 448

Molitor, Tenebrio, 560

Mollusca, 610

Moloch horridus, 400

Moloch lizard, 400

Molossus, 39

Molothrus, 361

Molothrus bonariensis, 361

Moluccanus, Limulıs, 539

Molurus, Python, 418

Molybdophanes, Struthio, 223

Momotidre, $3 \pm 1$

Momotus, $3 \neq 1$

Mometus lessoni, $3 \$$ I

Mona, Cercopitliecus, 2I

Mona monkey, 21

Monacha, $355^{\circ}$

Monachus, 5 .

Monachus, Neophron, 306

Monaclus, Pithecia, 27

Montchus, Vultur, 306

Monasa, Aphanolimnas, 351

Moneceros, Monodon, 178

Monera, The, 713

Monitors, The, 406

Monitor, Nile, 406

Monk fish, 519

Monkeys, The, I0

Mlonkey, Bengal, -...

Monkey, Diana, 21

Monkey, Green, 2I

Monkey, Lion-tailed, :2.

Monkey, Mona, 21

Ionkey, Proboscis, 19

Monkey, Squirrel, $₫ 6$
Monkeys, New World, 23

Monkeys, Old World, 19

Monkeys, Spider, 25

Monkeys, Woolly, $2 t$

Monocentris, $460^{\circ}$

Ionochrous, Ichthyophis, 454

Monodon monoceros, 17s

Monomyaria, 6is

Monopora vivipara, 684

Monorhina, 5:3

Monosiga, 713

Monotocardia, 632

Monotremata, 214

Monotrochous, 673

Montagu's Harrier, 309

Montana, Melampsalta, 594

Montana, Perdix, 234

Montanus, Canis, 71

Montanus, Haploceros, 157

Moon-eye, 504

Ioonals, The, 235

Moor-hen, 252

Moose, 145

Mopaliidre, 616

Mordacia, $52 t$

Morenia, 389

Mnri, Bombyx, 590

Morinellius eudromias, 271

Moristans, Gilossina, 608

Mormolyce phylloes, 555

Mormops, 41

Mormops blainvillei, 41

Mormy ridæ, 503

Mormyrops, 503

Mormyrus, 503

Mormyrus petersi, 503

Morococey $x, 35$ I

Iorone, 464

Norphina, 584

Morphnus, 313

Morphnus guianensis, 313

Morpho, 584

Morrlua. Gadus, 491

Morse, 84

Mosaic-tailerl mice, 106

Mosclata, Aromia, 56 I

Moschata, Cairina, 293

Moscliata, Myogale, 47

Moschata, Talpa, 48

Moschatus, Hypsiprymnodon, 197

Moschatus, Nesotragus, IjI

MIoschatus, Ovibos, 160

Moschiferus moschus, I4I

Moschus, I I I

Moschus moschiferus, I 1 I

Moschus sifanicus, 141

Mosquitoes, 604

IIoss animals, 665

Mossbanker, The, $50 \vec{\imath}$

Motacilla campestris, 365

Motacilla lugubris, 365

Motacilla melanope, 365

Motacillida, 364

Motella, 491

Motlis, 581

Moth, Atlas, 539

Joth, Burnished brass, 5UI

Moth, Cinnabar, $58 \mathrm{~s}$

Moth, Clothes, 593

Ioth, Codling, 593

Moth, Corn, 593
Motl1, Drinker 590

Moth, Emperor, 589

Motb, Ermine, 593

Moth, Hart-and dart, 59I

Moth, ( iamma, 59I

Moth, fhost, 591

Moth, lioat, 590

Moth, I'rass, 593

Moth, Lackey, 590

Moth, Magpie, 592

Moth, Mother-of-pear-1, 592

Ioth, Silk-wormı, 590

Moth, small magpie, 592

Moth, Tiger, 588

Moth, Twenty-plume, 594

Moth, White plume, 594

Moth, Yellow underwing, 5.

Moths, Bell, 593

Moths, Plume, 594

Moths, Swift, 591

Motmots, The, 34I

Motmot, Lesson's, 311

Mottled night-heron, 281

Mottled nightjars, 344

Mouflon, I 60

Mound-builders, The, $2: 6$

Mountain fox, 71

Mountain hare, 118

Mountain partrilge, 234

Mountain zebra, 1:8

Mouse tribe, The, 100

Mouse, Barbary, 105

Mouse, Blind, 106

Mouse, Harvest, I05

Mouse, House, 105

Mouse, Long-legged poucherl, 209

Mouse, Malabar spinr, 100

Mouse, Prehensile-tailed, 106

Mouse, Tree-, Pencil-tailed, I0t

Mouse, Wood, 105

Mouse-lemurs, 30

Mucedo, Ci istatella, 668

Mud-skippers, 4,T

Mul-teriapins. 359

Nugil, 479

Mugilida, $\$ 79$

Mugiliformes, 178

Mulita, 187

Mulleria, fos

Mullet, irey, 4 9

Mullide, 415

Mullus barbitus, 465

Mungoose, The, 60

Munzoose, Bandled, 61

MI ungoose, lirown-tailed, $6 I$

Mungoose, Egyptian, 60

Mungoose, Elegant, 61

Mungoose, Four-toed, 60

Iungoose, Marlagascar, 61

Mungoose, Meller's, 61

Irungoose, Pencilled, 60

Mungoose, simall African, 60

Iungoose, small-toothed, 61

Muntjacs, 141

Muntjac, ('ervulus, 14:

Murana, 493

Murænidre, 475,493

Iuraria, Tichodroma, : ibi

Ilurea, 637

Murex, 637 
Murex tenui-spina, (33) Muricata, Pontoblella, (iti

Muricidat, $6: 37$

Muriclae, 100

Mlurinae, 104

Murinus, Eunectes, 420

Mus, $10 t$

Mus harbarus, 105

Mus decumanus, 105

Mus flavicollis, 105

Mus minutus, 105

Mus musculus, 105

Mus rattus, 105

Mus svlvaticus, 10.5

Musteorum, Chirillium, $5+1$

Musca clomestica, 607

II uscarlinus avellanarius, 99

Muscicapa grisola, 372

Muscicapide, 372

Muscidie, 600

Muscirla acalyptera, $607-608$

Muscidie calypterv, 607

Musculus, Balæmoptera, $17 t$

Musculus, Mus, 105

Mushroom, Coral, 705

Musica, Tubipora, Tos

Musicus, Cygnus, 29-2

Musicus, Thudus, 371

Musimon, Oris, 160

Musk-beetle, 561

Musk-deer, 141

Musk-kangaroo, 197

Musk mole, ts

Musk-ox, 160

Musk-rat, Round-tailed, 103

Musk-rat, True, 103

IIusk-slirews, 46

Musophaga rossa, 3.52

Musophagidat, 351

Musquash, 103

Mussel, Horse, $6 \approx 1$

Mussel, Marine, $6:-1$

Mustela, so

Mustela americana, 80

Mustela erminea, $s 1$

Mustela flavigula, so

Iustela foina, $S 0$

II ustela hibernica, S1

Mustela lutreola, $\$ 1$

Mustela martes, 80

Nustela pennanti, so

IIustela putorius, sl

Mustela vison, 81

Mustela vulgaris, 81

Mustela zibellina, so

Mustelidæ, 76

II ustelus, 516

Inte swan, $29 ?$

Il uticus, Paro, 239

Mrutillida, 579

Mutus, Lachesis, 429

Iutus, Lagopus, 230

Mya, 626

Myacea, 623, 626

Ir veerobas, 363

Mvcteria australis, 230

Mycteria senegalensis, 280

Mydas, Chelone, 391

Mydaus meliceps, 79

Mygalidæe, 542

Mvgnimia, 580

Iyille, $6: 3$
Myioceyx, 337

Iriorlioctes, 36.

Mylabris, 560

Mrliobatida,, 21

Myliobatis, 5:1

Mymar pulchelhus, 5it

Mynas, 360

Myobiidie, 547

11 youles, 103

Iyorles lemmus, 100

Myogale, 47

Myogale uoschata, 47

Myogale pyrenaica, 47

Myopotamus, 111

Myopotamus, Coypu, 112

Myopsida, 646

II yoscalops, 107

Iyosorex, 46

II yoxicle, 99

Myoxus, 99

Myoxus glis, 99

Myoxus nitella, 99

Myriopola, 548

Myripristis, 468

Myrmecia, 579

Myrmecia forficata, 579

Myrmecobiñ, 209

Myrmecobius fasciatus, 209

Myrmecopliaga jibata, 184

Myrmecophagidie, 183

Myrmeleonidie, 5\%0

Myrmica, 579

Myrmicicke, 579

Mystacoceti, 171

Iystacons tuberculatus, 40

Mystromys, 101

My tilacea, 621

II tilus, $6: 2$

Mytilus edulis, 621

Nyxine, 525

Myxinida, 524

Iyxopoda urita, $3 S$

IIyzostonia, 675

Myzostomide, 675

\section{N.}

Nahura, Ovis, 160

Naia, 424

Naia bungarus, 424

Naia haie, 424

Naia tripudians, $4: 4$

Nais proboscidea, 674

Nais, snouterl, 67t

Naked bat, 40

Nakong, 156

Namadicus, Hippopotanus, 132

Nana, Rhea, 221

Nantidie, 464

Nandinia, 59

Nandu, 2.2.2

Nannosciurus, 95

Nanotragine, 151

Nanotragus livingstonianus, 151

Nanotragus moschatus, 151

Nanotragus pygnæus, 151

Napoleonis, Polyuectrum, 235

Narcine, 521

Vardoa, 419

Naricida, $63 \cdot 4$
Sarrow-footed pouched-mice, 209

Narrow-necked woolpceker. 354

Narwlial-spotter, 17s

Nasalis larvatus, 19

Naselts, 471

Nasiterna, 329

Nasiterna maforensis, $3: 9$

Nasiterna pygmoa, 329

Nasomaculatus, Adclax, I5t

Nassa reticulata, 633

Nassidie, 637

Nasua, 9, $7 u$

Natal rock-snake, $\mathbf{4 1 9}$

Natalus, 38

Natatrix, P'elagothuria, 66

Naticıda, 633

Natrix, Tropidonotus, $f: 1$

Natteijack toad, 442

Nauclerus riqcouri, 316

Naucrates, $4 \div 1$

Nauplius, 530

Nautilus, 645

Nebulosa, Felis, 55

Necroplago, 556

Necrophorus vespillo, 556

Nectarinia famosa, 366

Nectariniid:e, 360

Nectes, 441

Nectogale elegans, 47

Nectophryne, 441

Neeturus, $45^{\circ}$

Needle-tailed swift, 34

Nemachílus, 500

Neunachilins barbatulus, 500

Nematagnathi, 496

Nematohelminthes, 675

Nematu, 575

Nemeobius lucina, 586

Nemertine worms, 683

Nemertinea, 683

Nemopteridie, 5il

Nemorhadus, 157

Nemoricola, Gallinago, 268

Nemorum, Phyllotreta, 56"2

Neobalana, 17:

Neochanna, 504

Neofiber, 103

Neameniida, 616

Neomeniina, 616

Neomorphine, 351

Neomorphus, 351

Neophron, 306

Neophron ginginianus, 306

Teophron monachus, 306

Neophron percnopterus, 306

Neophron pileatus, 306

Neopsittacus, 328

Neopus malaiensis, 315

Neoscolopax rochusseni, 26 t

Neotoma, $10^{2}$

Nentoma alleni, 102

Neotramata, 651

Nepa cinerea, 597

Nepida, 597

Neptune's cup, 693

Nereis margaritacea, 673

Neritidæ, 63?

Neritina, 632

Neritopsidze, 632

Nerophis, 458 
Nertz, 81

Nesaenas, 244

Nesænas mayeri, 244

Nesiotis, Porphyriornis, 252

Nesocia, 105

Nesoctites, 3.54

Nesomys, 102

Nestor norfolcensis, 326

Nestor notabilis, 337

Nestor produetus, 32 ;

Nestoridie, 326

Nettion, 296

Nettopus, 294

Nettopus coromandelianns, 294

Neurobasis chinensis, 570

Neuroptera, 568

Neuroptera, Pseudo, 569

Neurotrichus, 47

Neustria, Clisiocampa, 590

New world monkeys, 8,23

Newts and salanaanders, 445

Newt, Common, 448

Newt, Crested, 447

Newt, Webbed, 448

Newtoniana, Prionodura, 359

Nicobar megapode, 228

Nicobar pigeon, 245

Nicobariensis, Megapodius, 228

Nicoria, 387

Niger, Canis, 65

Niger, Cynopithecus, 22

Niger, Hippotragus, 153

Nigra, Alouatta, 24

Nigra, Ciconia, 279

Nigra, Hydrochelidon, 261

Nigra, Melanoperdix, 234

Nigra, Rhynchops, 262

Night-heron, Mlottled, 284

Nightingale, 370

Night.jars, The, 342

Nightjar, Leona, 343

Nightjar, Mottled, 344

Nile fox, 71

Nile monitor, 406

Nilgai, 154

Nilgiri ibex, 159

Niloticus, Canus, 71

Niloticus, Crocodilus, ?81

Niloticus, Varanus, 406

Ninox, 323

Nit, Coralline, 668

Nitella, Myoxus, 99

Nitidissima, Alectrænas, 243

Nivalis, Plectrophenax, 363

Nivicola, Ovis, 160

Noble falcons, The, 319

Noctilio, 39

Noctiluea, 718

Noctiluca, Limpyris, 559

Noctilucus, Pyrophorus, 559

Nocture, 588

Noctula, Vesperugo, 37

Noctule, 37

Noisy scrub-bird, 376

Nomarla, 580

Nomæidæ, 472

Nomaus, 472

Nomonyx, 297

Non-hinged bracliopod, 650

Nonnula, 355

Norfolcensis, Nestor, 326

Norfolk plover, 273
North American alligator, 380

North American hen harrier, 309

North American marten, 80

North American wapiti, 143

Northern sea-cow, 168

Northern sea-lion, 82

Norwegian jer-falcon, 319

Notabilis, Nestor, 327

Notacanthicke, 485

Notacanthiformes, 485

Notacanthus, 485

Notidanidie, 518

Notiosorex, 46

Notobranchaidæe, 640

Notodel phyida, 532

Notonectidæe, 597

Notopterida, 503

Notopterus, 503

Notornis, 252

Notoryctes typhlops, 210

Notoryctide, 210

Nototrema, 443

Nova-hollandia, Astur, 311

Nove-hollandir, Dromer, 223

Nova-zealandia, Coturnix, 235

Novæ-zealandiæ, Geonemertes 684

Noveboracensis, Ortygops, 252

Novius cardinalis, 602

Nucleobranchiata, 636

Nucula, 620

Nuculidæe, 620

Nucum, Balaninus, 560

Nudibranchiata, 640

Nudibranchis, 640

Numenius, 269

Numida, 239

Nummilites, 715

Nut hatches, The, 368

Nut bateh, Common, 368

Nut-weevil, 560

Nutria, 111

Nyetala, 324

Nyctalea acadica, 324

Nyctalea tengmalmi, 324

Nyctea nyctea, 322

Nyctereutes, 69

Nycteribiidie, 608

Nycterida, 36

Nycteris, 36

Nyctibiinæ, 344

Nyetibus grandis, 344

Nyctibus jamarcensis, 344

Nycticebus, 31

Nycticejus, 37

Nycticejus albofuscus, 38

Nyetieorax, 283

Nyctieorax nyctieorax, 283

Nretinomus, 40

Nyetinomus cestoni, 40

Nyetiornis, 341

Nyctiornis amicta, 341

Nyctiornis athertoni, 341

Nyctipithecus, 26

Nyetipithecus trivirgatus, 26

Nymphalidæe, 582

Nyroca, 297
O.

Oak eggar, 590

Oaten straw coralline, 697

Obscurus, Dendragapus, 231

Obscurus, Theropithecus, 22 Ocadia, 389

Occipitalis, Lophoaetus, 315

Oceanica, Lygia, 534

Oceanitinx, 257

Oceanodroina leucorrhoa, 257

Ocellata, Lacerta, 409

Ocellata, Lipoa, 228

Ocellata, Meleagris, 240

()ellated megaporle, 228

Ocellatus, liheinhardius, 239

()celot, 55

Uchropus, Helodromas, 269

Ochthodromus, 271

Octactinia, 707

Octodon, 111

Octodont tribe, The, 110

Octodontiıæ, 110

Octopoda, 646

Octopodidx, 647

Osycerus, 340

Ocydromus, 251

Odonata, 569

Odontaspis, 517

Odontoceti, 171

Odontomachus, 579

Odontophorinæ, 231

CLdemia, 297

Qdicnemi, 273

Erlicnemus aulicnemus, 273

Edipoda cærulescens, 568

Estrelata brevipes, 257

Estrida, 606

Otficinalis euspongia, 693

Officinalis, Scincus, 410

Ogmorhinus leptonsx, 86

Oigopsida, 646

Oikopleura, 527

Oil beetles, 560

Oil birds, The, 332

Oil fish, 478

Old world monkeys, 19

Olens, Oeypus, 556

Oligochæta, 673

Olividæ, 638

Olm, 452

Olor, Cygnus, 292

Ommastrephidæ, 646

Ommatophoca rossi, 8 i

Onca, Felis, 53

Onchidiilæ, 642

Onchorhynchus, $50 \mathrm{~S}$

Oniscidae, 534

Onocrotalus, Pelecanus, 302

Onychodactylus, 450

Onychogale, 194

Onychomys, 101

Onychoteuthida, 646

Oocorythidie, 637

Opelet, The, 703

Open-billed storks, $2 S 0$

Open-bills, 278

Opercula, Principal forms of, 630

Operculum, 630

Ophichthys, 494,495

Ophilleres, 591

Ophidia, 412 
Ophidiidæ, 491

Ophidium, 491

Ophiocephalida, 482

Opliocephalus, 48 ?

Ophiodes, 405

Ophion, Ovis, 160

Ophisaurus, 405

Ophisaurus apus, 405

Ophispliolis aculeata, 657

Ophimoidea, $65 \mathrm{~s}$

Opisthobranchiata, 639

upisthocomus cristatus, 247

Opolemur, 30

Ojrossums, 211

Opossum, Common, 211

Opossun, liclelpliys, 213

Opossum quica, 213

Opossum, Thick-tailed, 213

Opossum, Velvety, 213

Ojюsinu, Water, 211

Orang-utan, 16

Orange tip, .380

Orbicularis, Emys, 388

Orca, 17!

Orca gladiator, 180

Orce la fluminalis, 179

Oreucicla, 3,0

Oreocicla varia, 371

Oreophasis derbianus, 229

Oreopithecus, 14

Oreopsittacus, $3: 8$

Oreotragus saltator, 151

Orias, 156

Oribi, South African, 151

Oribia, Scoparia, 151

Oriental chevrotains, 139

Oriental leopard cat, 55

Oriental magar, 381

Oriental shrews, 46

Orientalis, Blatta, $56 t$

Orioles, The, 361

Oriole, Golden, 361

Uriolidie, 361

Oriolus galbula, 361

Organ-pipe coral, 708

Orwers, 'The, 632

Ornata, Ceratoplirys, 441

Ornatus, Anthops, 36

Ornatus, Ursus, 75

Ornithomyia avicularia, 608

Ornithoptera, 587

Ornithorhynchidre, 215

Ornithorhynchus anatinus, 215

Ortalina, 608

Orthagoriscus, 472

Orthaliciclie, 643

Orthalicus, 643

Orthogeomys, 109

Orthonectidix, 689

Orthoptera, 562

Orthorhamphus maginrostris, 273

Ortolan, 364

Ortygops, 251

Ortygops exquisita, 252

Ortygops noveboracensis, 252

Ortyx virginianus, 240

Orycteropodidit, 189

Orycteropus capensis, 159

Oryx, 153

Oryzivora, Delichonyx, 361
Oryzivorus, Cassidix, 362

Oryzomys, 101

Oryzorictes, 49

Oryzorictes hova, 49

Oryzorictes tetradactylus, 49

Osmerus, 508

Ospliromenus, 483

Ospreys, 320

Ossifraga :igantea, 258

Ossifrayus, (iypaetus, 314

Usteoglossirliz, 504

Osteola'mus, 382

Osteolmmus tetraspis, 382

Ustracium, 4S!)

(Istrucoda, 53:

Ustrea, $6 \geqslant 22$

Ostreacea, 622

Ostrich, The, 2??

Ostrich, Somali-land, 223

Ostrich, Soutl African, 223

Otaria, 8:

Otaria fosteri, 82

(Utaria pusilla, 82

Otaria gillespii, 82

utaria jubata, 83

Otaria stelieri, 82

Otaria ursina, 82

Otariidæ, 81

Otides, 273

Otinidæ, 641

Otis, 273

Otis tarda, 273

Otocorys, 364

Otocorys alpestis, 364

Otocyon megalotis, 74

Otogyps, 306

Otomys, 101

Otters, The, 76

Otter, Sea, 77

(Otus, A sio, 324

Uunce, 53

Ovalis, Cyamus, 535

Oven-birds, 375

Ovibos moschatus, 160

Oviformis, Gromia, 715

Ovinus, Melophagus, 608

Ovis, 159

Ovis ammon, 160

Ovis canadensis, 160

Ovis gmelini, 160

Ovis hodgsoni, 160

Ovis musimon, 160

Ovis naliura, 160

Ovis nivicola, 160

Ovis opbion, 160

Ovis poli, 160

Ovis tragelaphus, 160

Ovis vignei, 160

Owls, The, 320

Owl, Barn, 325

Owl, Brown Hawk, 323

Owl, Burrowing, 323

Owl, Jlowny, 324

Owl, Eagle, 322

Owl, Grass, 325

Owl, Horned, 321

Owl, Little, 323

Owl, Long-eared, 324

Owl, Pel's Fishing, 321

Owl, Short-eared, 324

Owl, Snowy, 322

Owl, Tawny, 321
Owl, Tengmalm's, 324

Owl, Wood, 320, 324

Owls, Eared, 3:4

Owls, Fisling, 3:1

Owls, Tufted, 322

Owl-parrot, 331

Owlets, 'The, 324

owlet, Piginy, 324

Owlet-nightjar, 334

Ox, ('oinmon, 165

Ox, Musk, 161

Oxygyrus, 637

Oxyıycterus, 101

Oxynoiclae, 640

Oxyrhamphidee, 373

Oxyrhanıpus, 374

Oxyuris vermicularis. 679

Oyster-catchers, 271

Oyster, Hammer-headed, 622

Oyster, Pearl, 62:3

Oyster, Saddle, 621

Oyster, Thorny, 623

\section{P.}

Pacas, 115

Paca, Branick's, 115

Pacas family, The, 115

Pachyealmus, 408

Pachycephala, 369

Pachyrhina crocata, 604

Pachytriton, 449

Pachyuromys, 101

Pacificus, Pareudiastes, 252

Pagellus, 466

Pagodus, 635

Pagrinæ, 460

Pagrus, 466

Pagurida, 537

Pagurus, Cancer, 538

Painted frog, 444

Painted fruit-pigeon, 242

Painted pigeons, The, 243

Painted quails, 235

Painted snipes, The, 267

Pala, 152

Palæindicus, Hippopotamus, 132

Palæusis, Geonemertes, 684

Palæolodus, 290

Palamedea, 290

Palamedea cornuta, 290

Palinuridæe, 537

Pallasiana, Lepralia, 667

Pallas' sand-grouse, 241

Pallas' sea-eagle, 321

Palliata, Adamsia, 703

Pallipes, Canis, 64

Palm-civit, 59

Palm squirrel, Indian, 91

Palm swifts, 346

Palm weevil, 560

Palmarum, Sciurus, 91

Palmata, Molge, 448

Palmeri, Porzanula, 251

Palseornis, 329

Paludestrinidæe, 635

Paludicola, 103, 441

Palumbarius, Astur, 310

Palustris, Parus, 367

Pamir sheep, 160 
Panıpas.rleer, 146

Panda, The, 75,76

Panderi, Podoces, 3.58

Pandiones, 304, 320

Pandion haliztus, 320

Pandora, 627

Pandorida, 627

Pangolius, 188

Panoplus, 405

Panther, 53

Pantholops, Hodgsoni, 152

Pantodon bucholzi, 505

Pantodontida, 505

Papatasii, Phlebotomus, 604

Paper nautilus, 647

Papillata, Cidaris, 659

Papio, 10,22

Papio babuin, 23

Papio maimon, 23

Papio porcarius, 23

Pappogeomys, 1 ng

Paradise-fish, Chinese, 483

Paradise flycatchers, 373

Paradiseidæ, 358

Paradiseinæ, 359

Paradoxuni, Diplozoon, 688

Paradoxurus, 59

Paradoxus, Syrrhoptes, 241

Paralepis, 505

Parameniide, 616

Parasitic Hymenoptera, 576

Parasitica, Calliılina, 653

Parasiticus, Stercorarius, 263

Pardalis, Felis, 55

Pardina, Felis, 56

Pardus, Felis, 53

Paretroplus, 487

Pareudiastes pacifieus, 252

Paridæ, 367

Parmassius, 587

Parnassius A pollo, 587

Paro, 239

Paro cristatus, 239

Paro muticus, 239

Paroaria, 364

Parrakeet, Long-tailed, 329

Parrots, The, 325

Parrot, Grey, 330

Parrot, Ground, 331

Parrot, Kea, 327

Parrot, Owl, 331

Parrot, Sea-, 260

Parrots, Kaka, 326

Parrots, True, 329

Parrot-wrasses, 486

Parti-coloured bear, 75

Partriclges, The, 231

Partricige, Barbary red-legged, 232

Partridge, Pearded, 234

Partridge, Black-headed redlegged, 232

Partriılge, Chukar, 232

Partridge, Common, 233

Partridge, Greek, 232

Partridne, Mountain, 234

Partridge, Prjevalsky's red. legged, 232

Partridge, Rock red-legged, 232

Partridge, See-see, 233

Partridge, Toothed, 240
Partridge, The true, 234

Partridges, Snow, 231

Partridges, Tooth-billed, 231

Parula, 365

Parus, 367

Parus cieruleus, 367

Parus major, 367

Parus palustris, 367

Parva, Helogale, 60

Parva, Zapornia, 251

Parvirostris, Tetrao, 230

Pasang, 159

Passenger pigeons, The, 244

Passeriformes, 357

Paste, Eel, 679

Pastor, Rose-coloured, 360

Pastor roseus, 360

Patachonica, A ptendytes, 255

Patagona gigas, 347

Patellidæ, 631

Paterina, 650

Paumotensis, Actinia, 704

Pavoncella, 269

Pavoncella pugnax, 269

Pavonia-minor, Saturnia, 589

Pea-fowl, The, 239

Peacock butterfly, 585

Peacock pheasants, The, 238

Pearl-grey curlew, 270

Pearl oyster, $6 \geq 2$

Pearly lizarit, 409

Pearly nereis, 673

Peccaries, 9

Peccaries family, The, 135

Pecora, 140

Pecten, 62.2

Pectinacea, 62:

Pectinator, 111

Pectinitranchiata, 632

Pectintinibranchiate, 614

Pectunculus, 621

Peclalion mirum, 682

Pedetes caffer, 110

Pediculus capitis, 602

Pediculus vestimenti, $60^{\circ}$

Pedionomus, 241

Pedipalpi, 541

Perlunculate Brachiopod, 618

Pegasus, 476

Pelagica, Procellaria, 257

Pelagonemertes, 684

Pelasothuria, 662

Pelagothuria natatrix, 661

Pelargopsis, 336

Pelargopsis burmanica, 336

Pelea carreola, 151

Pelecaniformes, 208

Pelecani, 298

Pelecanoididre, 258

Pelecanus erytlirorhynchus, 302

Pelecanus manillensis, 302

Pelecanus onocrotalus, 302

Pelecinus, 57s

Pelecinus soliturator, 578

Peleenanoida, 257

Pelecus, 500

Pelecypod gills, Development of, 619

Pelecypoda, 616

Peli, Anomalurus, 90

Peli, Scotopelia, 321
Pelicans and allies, 295

Pelicans, The, 301

Pelican, Knob billed, $30^{\circ}$

Pelican, Roseate, 302

Pelican, Snotted-billed, 30:-

Pelican's foot shell, 630

Pelidua, 269

Pelobatidxe, 443

Peluchelys, 395

Pelodera, 679

Pelodytes punctatus, 443

Pelomedusidie, 39

Peloprus spirifex, 580

Pelor, 467

Pel's fishing-owl, 321

Pel's flying-squirrel, 90

Peltella, 613

P'eltohyas, 270

Peltohyas australis, 270

Peitohyatinx, $: 70$

Pe.udo argentine, 186

Pemperis, 468

Pemplieris, 471

Pencillata, Cynictis, 60

Pencilled mungoose, 60

Pencil-tailed tree-mouse, 104

Pendadactylus, Pterophorus, 594

Penguins, The, 255

Penguin, Emperor, 25.5

Penguin, King, 255

Pennanti, Mustela, 80

Pennaut's marten, 80

Pennatula, 709

Pennatus, Distæchurus, 202

Pennatus, Eutolmatus, 315

Pennula ecaudata, 251

Pentacrini, 664

Pen-tailed plialanger, 202

Pen-tailed shrew, 44

Pen-tailed tree-shrew, 202

Pentanemus, 468

Pentatomidx, 595

Peragale, "05

Perameles, 206

Perameles gunni, 206

Peramelida, 205

Peramys, 213

Perca, 464

Perearina, 464

Perch, Common, 464

Perching birds, The, 357

Percichtliys, 464

Percida, 464

Perciformes, 463

Percunpterus, Neophron, 30 f

Percopsidr, 509

Percopsis guttata, 509

Perdicinæ, 231

Perdicula, 234

Perdix, 934

Perdix damascena, 234

Perlix daurica, 234

Peldix hodgsoniæ, 234

Perdix montana, 234

Perdix perdix, 235

Perdix sifanica, 234

Peregriue falcon, 319

Peregrinus, Falco, 319

Perforate formanifera, 715

Pergine, 574

Periopthalmus, 476 
Peripatidæ, 550

Peripatus, 671

Peripatus iuliformis, 551

Periplaneta americana, 564

Perissodactyla, 124

Peristerida, 244

Peristerinæ, 244

Peristeropodes, 226

Periwinkles, 635

Perlida, 571

Pern, Black, 317

Perna, 62:

Pernis, 317

Pernis apivorus, 317

Pernis celebensis, 317

Pernis ptilonorhynchus, 317

Perodicticus, 31

Perodicticus potto, 31

Perodipus, 109

Perognatlius, 109

I'erplexa, Callidea, 595

Persian fallow-deer, 144

Persian wild goat, 159

Persian maral, 143

P'ersicus, Argas, 546

l'ersicus, Cassidix, 36?

Persicus, Phasianus, 23i

Personatus, Reduvius, 596

Perspicillata, Salamandrina, 445

Perspicillatus, Artibeus, 41

Persuasoria, Rlinssa, 57

Petauroides volans, 201

Petaurus, 20?

Petaurus breviceps, 202

Petersi, Ceotrypetes, 455

Petersi, Mormyrus, 50:3

Petrels, The, 256

Petrel, Canarian fork-tailed, 257

Petrel, Common fulmar, 258

Petrel, Diving, 257

Petrel, Fork-tailed, 25'

Petrel, Fulmar, 258

Petrel, Leach's, 257

Petrel, Long-legged, 257

Petrel, Short-legged, $25 \%$

1'etrel, Storm, 257

Petricolida, 625

Petrochelidon pyrrhonota, 373

Petrodomus, 14

Petrogale, 194

Petroinys, 111

Petromyzida, 5:4

Petromyzum, 524

Petromyzum fluviatile, 524

Petromyzum marinum, 524

Petrosa, Caccabis, 232

Pewit, lommon, 271

Pezophaps, 245

l'ezophaps solitarius, 245

Pezoporus, 331

Phabina, 244

Phacocherus athiopicus, 134

Pheeton flavirostris, 298

Phainopepla, 369

Phalacrocoraces, 299

Phalacrocorax carbo, 299

Phalacrocorax graculus, 299

Phalacrocorax varius, 300

Phalangers, The, 200

Phalanger, Common, 200

Phalanger, Dormouse, 20:?

Phalanger, Flying, 202
Phalanger, Flying, Taguan, 201

Phalanger, Leadbeater's, 201

Plialanger, Long-snouted, 203

Phalanger maculatus, 200

Phalanger, Pen-tailed, 202

Plialanger, Ring.tailed, 200

Phalanger, 'T'ribe, 198

Phalanger ursinus, 200

Phalangeridr, 193

Phalangerinæ, 199

Phalangiida, 541

Phalaropes, The, 266

Phalarope, Grey, : $66^{\circ}$

Phalarope, Red-necked, 266

Phalarope, Wilson's, $266^{\circ}$

Phalaropina, 260

Plaalaropus, 360

Phalaropus hyperborens, ?66

Pharyngognathi, 185

Pliascolarctinæe, 199

Pliascolaretus cincreus, 199

Pliascologale, 208

$P$ hascolom yidæ, 204

Phascolomys, 203

Phascolosoma, 675

Phasgonuride, 567

I'hasiani, 2?6

Phasiandie, 229

Phasianine, 235

P'hasianus colchicus, 237

Phasianus persicus, 237

Phasianus principalis, 237

Phasianus reevesi, 238

Pliasianus sœmmeringi, 238

Pliasianus scintillans, 238

Phasianus talischensis, 237

Pliasianus versicolor, 238

Phasidus, 239

Pliasmidæe, 551

P'heasants, The, 235

Pheasant, Argus, 235

Pheasant, Barred-backed, 238

Pheasant, Caped, „38

Pheasaut, Cheer, 237

Pheasant, Common, 237

Pheasant, Copper, 238

Plieasant, Cuckoo, 351

Pheasant, Fire-backed, $₫ 36$

Pheasant, Horned, 235

Pheasant, Impeyan, 235

Pheasant, Kalij, 236

Pheasant, Koklass, 237

Pheasant, Lobed, 236

Pheasant, Pucras, 236

Pheasant Reeves, 238

Pheasant, Silver, 236

Pheasants, Blood, 235

Pheasants, Eared, 236

Plieasants, Ring-necked, 237

Phegornis mitchelli, 267

Phenacomys, 103

Philander, 213

Philepittidæ, 373

Philhydrida. 557

Philinidæe, 640

Philippine rats, 101

Philippinus, Cervus, 143

Phillipsi, Dipodomys, 103

Phillotis, 101

Philodryas, $4^{3} 3$

Philohela minor, 267

Philomycidæ, 613 l'hilydorina, 375

Phleomyine, 101

Phlebotomus papratosi, 604

Phoca, 85

Ploca barbata, $\$ 5$

Phoca caspica, 85

Ploca groenlandica, 85

Phoca sibirica, 85

Phoca vitulina, 85

Phocida, 84. 85

Phocoena, 170

Phocœna communis, 179

Phocena phocoenoides, 179

Phocœnoides, Phocana, 170

Plicebetria, 258

Phoenicens, Agelæus, 361

Pliœeniconaias, 290

Phoeniconaias minor, 290

Phounicoparrus, 290

Phoenicoparrus andinus, 290

Phonicoparrus jamesi, 290

Phonicophaine, 351

Pliønicouhaes, 351

Phœnicopteriformes, 283

l'hoenicopterus, 290

Phcethornis, $34 \mathrm{~s}$

Pholadacea, 623

Pholadidre, 627

Pholadomya caudida, 628

Pholadom yidre, 6:s

Pholas, 625

Phoronis, 649

Photichthys, 505

Phoyx purpurea, 282

Pluragmitis, Acrocephalus 370

Phryganea grandis, 572

Pliryganistria serratipes, 566

Phrygilus, 364

Phrynorliombus, 492

Phrynosonia, 403

Plirynus, 541

Phylactolæmata, 669

Phyllobates trinitatis, 438

Phyllodes, Mormolyce, 555

Phyllodromia germanica, 564

Phyllonycteris, 41

Phyllopoda, 531

Phyllopteryx, 487

l'hylloscopus minor, 370

Pliylloscopus trocliilus, 370

Phyllostoma, 41

Phyllostomatidæ, 40

Phyllotreta, 562

Phyllotreta nemorum, 562

Phymosoma, 678

Physalia, 699

Physeter macrocephalus 175

Physeterida, 175

Physidæe, 642

Physodon, 176

Physostomi, 493

Phytophaga, 561

Phytopti, 515

Phytoptidæ, 546

Phytotomida, 373

Piaya, 351

Pica, 357

Pica pica, 358

Picarian birds, Tlie, 332

Picas family, The, 117

Piceus, Hydrous, 557

Pichi, 186 
Pichiago, 185

Pichiciagos, 188

Pici, 353

Piciformes, 353

Picinæ, 354

Picoides, $35 \pm$

Pictus, Aramus, 275

Pictus, I iscoglossus, 414

Pictus, Lycaon, 73

Piculets, 354

Picumninæ, 35

Picumnus, 351

Picus martius, 354

Piddocks, 'Jhe, $62 \%$

Pied flycatcher, 37.

Pied hornbill, 339

Pied kingfisher, 336

Pied shag, 300

Pied sparrow-hawk, 311

Pied swift, 346

Pied wagtail, The, 365

Pied woodpecker, 354

Pieridæ, $5 \$ 6$

Pig tribe, The, 130

Pig, Bush, 134

Pigs, True, 133

Pig-footed bandicoot, 206

Pigeons, The, 242

Pigeon, Crowned, 245

Pigeon, Fruit, 212

Pigeon, Ground, 24

Pigeon, Long-tailed, 244

Pigeon, Nicobar, 245

Pigeon, Painted, 243

Pigeon, Passenger, 214

Pigeon, Tooth-billed, 245

Pigeon, Wood, 244

Pigmy hippopotamus, 131

Pigmy hog, 134

Pigmy owlet, 324

Pigmy squirrels, 95

Pigmy whale, 17:

Pike, Bony, 509

Pike, Common, 502

Pike-head, 483

Pike-perclies, 464

Pilaris, Turdus, 371

Pilchard, 507

Pilchardus, Clupea, 507

Pileatus, Neophron, 306

Pilidium, 684

Pilot-fish, 171

Pimelodus, 497

Pimplinæ, 577

Pine-marten, 80

Pink-footed goose, 295

Pink-headed duck, 294

Pinna, 622

Pinnated grouse, 231

Pinnotheres, 538

Pin-tailed sand grouse, 241

Pin-tails, 296

Pioplilinæ, 608

Pipa aniericana, 444

Pipe fislies, 487

Piper, The, 659

Pipidæ, 444

Pipilo, 364

Pipistrelle, 37

Pipistrellus, Vesperugo, 37

Pipits, 364

Pipit, Meadow, 365
Pipit, Tree, 365

Pipridæ, 373

Pirula, 636

Piscatorius, Lophius, 474

Pisces, 456

Pisidium, 623

Pit vipers, 428

Pithechirus, 106

Pithecia, 27

Pithecia monachus, 27

Pithecia satanus, 27

Pittas, The, 375

Pitta an zolensis, 375

Pitta, 'The Purple, 375

Pittidie, 373

Pittoidles, Atelornis, 335

Placuna sella, 621

Plagiorlon, 112

Plagyodus, 505

Plain rat-kungaroo, 197

Planarian, Land, 684

Planarian worms, 655

Planci, Cucumaria, 660

Planipennia, 570

Planorbis, $6+2$

Plant bugs, 590

PJant cutters, The, 3 it

Plant-feeding beetles, 561

Plant-lice, 598, 601

Platacunthomys lasiurus, 100

Platalee, 286

Plataleæ leucerodea, 286

Platanista gangetica, 177

Platanistidre, 177

Platax, 471

Plated holothurian, 661

Platemys, 393

Platibis, 286

Platurus, 425

Platurus la ticaudatus, 425

Platycerconys, 110

Platycercus, 329

Platycheles, Porcellana, 537

Platygeomys, 109

Platyhelminthes, ES5

Platyrlina 520

Platyrhynchina, 373

Platysaurus, 404

Platysternidæ, 389

Platysternum megalocephalum, 389

Plautus impennis, 260

Plecotus, $36^{\circ}$

Plecotus auritus, 37

Plectispondyli, 497

Plectognathi, 488

Plectroplienax nivalis, 363

Plectropterinæ, 293

Plectropterus, 293

Plegadis, 288

Plegadis falcinellus, 288

Plesiops, 464

Pletliodon, 450

Plethodontina, 450

Pleurobranclioidea, 640

Pleuroceridłe, 635

Pleurodira, 39?

J'leuronectes, 492

Pleuronectidæ, 492

Pleuronectoidei, 49:?

Pleurotoma, 632

Pleurotomaria adansoniana, 632
Pleurotomidæ, 632

Ploce dæ 36 ?

Ploceus Laya, 362

Plotidæ, 301

Plotus anlin a, 301

l'lotus levaillanti, 301

Plovers, The, 264

Plover, American golden, 270

Plover, Crab, $26 \pm$

l'lover, Golden, 271

PJover, Grey, 2i]

Plover, Norfolk, 273

Plover, Spur-winged, 271

Plover, Stone, 273

Plover, True, 270

Plover, Wattled, 271

Plover, Wry-billed, 270

Plume moths, 594

Plumose anemone, 702

Plumularians, 697

Plusia clirysitis, 591

Plusia gamma, 591

Pluvialis, Charadrius, 271

Pluvialis, Hæmatopota, 605

Pneumonodermatidæ, 640

Pochards, The, 297

Pocket-gophers, The, 10 ;

Porlargi, 333

Podarginæe, 333

Podargus, 333

Podargus strigoides, 333

Podica, 252

Podica senegalensis, 25:

Podicipes auritus, 253

Podicipes cristatus, 253

Podicipedidiformes, 253

Podilymbus, 253

Podoces, 358

Podoces hendersoni, 358

Porloces humilis, 358

Podoces panderi, 358

Podocnemis expansa, 393

Puecile, $36 \%$

Paciliidæ, 502

Pacilogale albinucha, 81

Poènsis, Poiana, 58

Pophila, 362

Pogonias, 468

Poiana poènsis, 58

Poiphila casei, 608

Poisonous lizards, $\$ 05$

Polar bear, 75

Polecat, 81

Polecat, Cape, 81

Poli ovis, 160

Poliohierax, 319

Polish swan, :92

Politurator, Pelecinus, 578

Pollack, The, 491

Pollan, 509

Pollan, Coregonus, 509

Polyacanthus, 483

Polyborinze, 307

Polyboroides, 309

Polyborus, 307

l'olyborus clieriway, 307

Polyborus tharus, 307

Polyclizeta, 671

Polydesnidie, 550

Polyglottus, Mimus, 372

Polygordius, 675

[68:

Polymorphus, Echimorhynchius. 
Polynemidite, tis

Polynemiformes 16 is

Polynemus, 468

Polyodon folius, 511

Polyodontidae, 511

Polyommatus, 586

Polypectrum, 235

Poly pectrum chinquis, 238

Poly vectrum napoleonis, 235

Polyplacophora, 615

Polyptera, Hexartira, 6s?

Polypterida, 512

Polypterus, 513

I'olypterus bichir, 512

Polypterus lapraulei, 513

Polystomea, 6ss

Polytroclious, 67:3

Polyxenidre, 550

P'olyzoa, 665

Polyzoniida, 549

Polyzonium germanicum, .44)

Ponacentricle, 455

Pomacentrus, 485

Pomatorline skua, 20 t

l'omatorlinus, Stercorarins, 264

Pomonella, Carpocapsa, 593

Pompilida, 579

Pomponia imperatoria, 598

Pond-tortoise, 3s'

Poneridæ, 579

Pontobdella muricata, 67

Poospiza, 364

Porbeagle, 517

Porcarius, Papio. 23

Porcelain crab, 537

Porcellana platycheles, 33 ;

Porcellanidæ, 537

Porcinus, C'ervus, 143

Porcupine, Canadian, 113

Porcupine tribe, The, 113

Porcupine, True, 113

Porcupines, Brush tailed, 113

Porcus, Sus, 134

Porifera, 690

Poromyida, $62 \mathrm{~s}$

Porosus, Crocodilus, 381

Porphyriaca, Pseudechis, 425

Porphyrio, $2+3$

Porphyriornis comeri, 25 ?

Porphyriovnis nesiotis, 25:

Porpoises, 169

Porpoise, Comnion, 179

Porpoise, Indian, 179

Port Jackson shark, 518

Portuguese man-of-war, 699

Porzana intermedia, 251

Porzana porzana, 251

Porzana sandwichensis, 251

Porzanula ualnzeri, 251

Potamochærus, 134

Potamogale, 43

Potamogale velox, 18

Potamogalidæ, 18

Potoroina, $19 \overline{-}$

Patorus, 197

Pottos, 31

Potto, Perodicticus, 31

Potto, True, 31

Pottos calabarensis, 31

Pouched frog, $\mathbf{4 3}$

l'ouched mammals, 19 !

l'ouched-mice, $20 \mathrm{~s}$
Pouched rats, 106

Pouchell-winged bats, 39

P'owan, 509

Prairie-clogs, 92

Prairie-marmots, 92

Pratensis, Anthus, 363

Pratincola, Glareola, 27:2

I'tatincoles, The, 272

Pratineole, Commou, 2:-2

Prawns, 536

Praving insects, 565

Prehensile-tailed mouse, 106

Irehensile-tailed rat-kangaroos, 197

Prevosti, Euryceros, 360

1'rezevalskii, Equus, 1:s

Priapulus, 675

Priapulus caudatus, $67 \mathrm{~s}$

Primates, 10

Principalis, Phasianus, $23 \overrightarrow{7}$

Priodon gigas, 137

Prionidæe, 561

Prionirhynch 11s. 341

Prionochilus, 367

Prionodura newtoniaua, 35 ?

Prionurus, 171

Prionus coriarius, 561

Pristidæ, 519

Pristiophoride, 519

Pristiophorus, 519

Pristis, 519

Prjevalski's red-legged par. tridge, 232

Proboscidea, Nais, 674

Proboseidiferus, Semifuses, 3\%

Proboscis-monkey, 19

Procavia, 124

Procaviidie, 1:33

Procellaria pelagica, 257

Procellariidæ, 257

Procellariiformes, 256

Proctotrypidæ, $5 \pi 6$

Procyon, 75

Procyonidie, 75

Procronides, Canis, 69

Prodissoconch; 617

Productus, Nestor, 3:6

Prö̈chedna, 217

Proëchidna, Bruijn's, 217

Proglottis, 687

Progne purpurea, 373

Proletella, Aleyrodes, 602

Proneomeniida, 616

Prong-buck, 149

Prongbuck family, The, 149

Prong-horned antelope, 149

Propithecus, 29

Proscolex, 657

Prosobranchiata, 631

Prosogyre, 617

Prosperpinidæ, 63:2

Prosphyodontes, 408

Proteidæ, 45:

Proteleidæ, 6?

Proteles cristatus, 6:?

Protens anguinens, $\mathbf{4 5 2}$

Proteus animalcule, 714

Proteus, Echenorhynclius, (6s:)

Protobranchiata, 6:0

Protochorda, 5:6

Protodrilus, 675

Protopterus, +60
Protospondyli, 510

Prototroctes, 50 T

Protozon, The, 71:

Protracheata, 550

Protremata, 651

Psammobatis, 520

Psammobiidæe, 624:

Psammodromus, $\$ 10$

P'sarisomus, 356

P'sarisomus dalhousiæ, 356

l'sephurus gladius, 511

Psettodes, 19:

Pseudechis porplıyriaca, $\mathbf{t} 5$

Pseuilo neuroptera, 569

Pseudobranchus striatus, 453

'seudochelidon, 369

I'seudocheliclon eurystomina 369

P'seudochirus, 200

l'seutochloris, 364

Pseudochromis, 474

Pseudocordrlus, 404

'seudogyps, 30t'

I'seudolamellibranchiata, 6.3.?

l'seudoplareus, 4265

Pseudophryne, +41

'seudorea crassidens, 180

Pseudoscorpioniclea, 541

Pseudotantalus ibis, 281

Pseudotantalus leucocephalus. 281

Pseudotrimera, 56:3

l'sittacea, Rhynchonella, 650

Psittacidæ, 329

Psittaciformes, 3:5

Psittacula, 329

Psittacus erithecus, 330

Psocidiw, 572

Psolus diomediæ, 661

Psophia repitans, 277

Psychidæ, 589

Psychodida, 604

Psychropotes raripes, 661

Psyllidæ, 601

Ptarmigan, 230

P'tenoglossa, 633

Pternistes, 233

Pternistes swainsoni, 233

Pterocera, 636

Pteroclurus alchata, 241

Pteroglossus, 35:

Pterois, 467

Pteromys, 95

Pterophoridæ, 594

Pterophorus pendadactylus, 594

Pteroplatea, 52?

Pteropoda, 640

Pteropodidze, 34

Pteroptochidæ, 375

Pteropus, 35

Pterotrachæidæ, 637

Pthirins inguinalis, 60:

Ptilocercus, 20:2

Ptilocereus lowi, 44

Ptilocichla, 372

Ptilogonys, 369

Ptilonorhynchide, 359

Ptilonorliynchus holosericeus 359

Ptilonorhynchus, Pernis, 317

Ptilopodina, 242

Ptilorhis, 359 
Ptilorhis victoria, 359

Ptychozoum, 397

Ptyodactylus, $39 \%$

Pucherani, Guttera, 240

Pucras pheasant, 236

Pucrasia, 237

Pucrasia macrolopha, 237

Pudu-deer, 147

Pudua, 147

Puella, Cænagrion, 570

Puff adder, 427

Puff birds, The, 355

Puttin, English, 260

Puttinidide, 25\%

Puftinus, 257

Pugnax, Betta, 433

Pugnax, Pavoncella, 269

Pulchellus, Diplomesodon, 46

Pulchellus, Mymar, 577

Pulcher, Luciocephalus, 483

Pulex canis (dof Hec ), 609

Pulex, Daphnia, 531

Pulex, Gammarus, 68

P'ulex irritans (Hou), 609

Pulmonata, $6+1$

Pulsatoria, Atropos, 572

P'uma, 53

I'umilus, Bos, 162

Punctatus, Pelodytes, $\mathbf{4} 43$

Punctatus, Sphenodon, $\mathbf{4 3 0}$

Pupa, 643

Pupide, 643

l'urchasi, lcerya, 602

Purple emperor, 585

Purple heron, 252

Purple martin, 373

Purple sandpiper, 269

Purule sea-snails, 633

Purpura lapillus, 637

Purpurea, Phoyx, 282

Purpurea, Progne, 373

Pusilla, Gallinago, 268

Pusilla, Ortaria, \$2

Pusillus, Anomalurus, 90

Putorius, 80

Putorius, Mustela, 81

Putorius, Spilogale, $7 \mathrm{~s}$

Pycuogonida, 5:9

Pycnogonum litorale, 539

Pycnonotidx, 27.2

Pycnorhamphus, 363

Pygargus, Bubalis, 150

Pygargus, Cervus, 146

Pygargus, Circus, 309

Pygamæa, Nasiterna, 329

Pygmæum, Glaucidium, 324

Pygmæus, Eurynorhynchus, 269

Pygmaus, Nanotragus, 151

Pygmæus, Sorex, 46

Pygopodida, 398

Pygoscelis triata, 255

Pyrales, 592

Pyralidie, 572

Pyramidellidæe, 633

Pyramidula rotundata, 643

Pyrenaica, Capra, 158

Pyrenean desman, 47

Pyrocephalus, spirostreptus, 550

l'yrophorus noctilucus, 559

Pyrosoma, 52S

Pyrrhocorax, 358

Pyrrhocorax pyrrhocorax, 358
Pyrrhononta, Petrochelidon, 373

Pyrrhula, 363

Pyrrluulauda, 364

Python, 418

Python molurus, 118

Python sebæ, 419

Python spilotis, 419

Pythonina, 418

Pyxis arachnoides, 387

\section{Q.}

Quadricornis, Cyclops, $5: 32$

Quadricornis, Tetraceros, 151

Quagga, 129

Quagga, Equus, 129

Quails, The, 234

Quail, Bustard, 241

Quail, Californjan, 240

Quail, Cape, 234

Quail, Common, 234

Quail, Migratory, 234

(quail, Painted, 235

(ruail, Swamp, 235

(Yuail, Tirginian, ?t)

Queen Victoria's rifle-birds, 359

Querquedula, 296

Quezal, 349

Quica-opossum, 213

Quizos, 115

R.

Rabbit, 118

Rabbit-bandicoots, 205

Rachiglussa, 637

Racoon-dog, 69

Racoon tribe, The, 75

Racoons, American, 75

Radiatus, Carpococeyx, 351

Radiatus, Erythrotriorchis, 312

Radiolaria, 716

Raffle's shrew-hedgehog, 45

Rafflesi, Gymnura, 45

Rafinesquina alternata, 649

Ragosus, Trachysaurus, 110

Raia, 520

Raiidæe, $5: 0$

liails, The, 248

Riail, Barred, 249

Rail, Water, 249

Rail, Wood, 249

Rails, Weka, 251

Rain cuckoo, 351

Raj-samp, 424

Rallidie, 225

Ralliformes, 248

Rallus aquaticus, 249

Ramosa, syllis, 673

Ramosa, Bougainvillea, $696^{\circ}$

Rampholeon, 41:

Rana, 436

Rana agilis, 436

Rana breviceps, 437

Rana catesbyana, 437

Rana esculenta, 436

Rana guppyi, 4,

Rana jberica, 436

Rana latastei, 436

Rana temporaris, 136
Ranatra linearis, 597

Ranatricla, 597

kangifer, 145

Pangifer tarandus, $14 \Xi^{\circ}$

Ranidæ, 436

Ranidens, 450

Rapax, Aquila, 314

liaphiceros campestris, 151

Rappi, Microchreta, 6it

Raripes, Psychropotes, 661

Rasse, 5

Rats, The, 101

Rat, Bamboo-, 106

Rat, Bandicoot-, 105

Rat, Berdmore's, 104

Rat, Black, 105

Rat, Cane-, 112

Rat, Common, 105

Kat, Crested-, 102

Rat, Fish-eating, 102

Rat, Jerboa-, 106

Rat, Kangaroo, 109

Kiat, Long-nosed, 106

Rat, Mole, Great, 106

Rat, Musk-, 103

Rat, Philippine, 101

Rat, Ponched, 106

Rat, Pice, 102

Rat, saud, 107

Rat, Shrew-, 104

Rat-snake, Indian, 423

Ratels, 79

Rathbuni, Typhlomolge, $45 \mathrm{~m}$

Ratita, 2.21

Rattle suake, $4: 28$

Rattus, Mus, 105

Ray's wagtail, 365

Razor-shells, 626

Razorbill, 260

Recurvirostra andina, 270

Recurvirostris, Esacus, 273

Red admiral, 585

Red ant, 579

Red-backed shrike, 369

Red-billed chough, 358

Red-breasted goose, 295

Red brocket, 146

Red coral, 708

Red-deer, 143

Red-fox, 71

Red-grouse, 230

Ked herring, 506

Red howler, 23

Red-legged partridge, 232

Red marmot, 94

Red mullet, 155

Red-necked phalarope, 266

Red spider, 547

Red-thighed gos-hawks, 310

Red-throated diver, 254

Red uakari, 27

Red vole. 103

Red-winged hang-nest, 361

Red-winged starling, 361

Rediæ, 689

Redstarts, 370

Reduviidæ, 596

Reduvius personatus, 596

Redwing, 371

Reed-fisl, 512

Reed-warbler, 370

Reedling, Bearded, 368 
Reef-herons, 283

Reeve, 269

Reeve's pheasant, 23s

Reevesi, Phasianus, $23 \mathrm{~s}$

Kegalecus, 485

Regalecus banksi, 48.5

Regulidae, 368

Regulus azorensis, $30 \%$

Regulns calendula, 369

Regulus himalayensis, 269

Regulus ignicapillus, 36 ?

Regulus marlerensis, 36!)

Regulus regulus, $36 \mathrm{~s}$

Regulus teneriffa, 360

Rehbok, 151

Reindeer, 14,

Reinwardtanas, 241

Reitbok, South African, 152

Keligiosa, Mantis, 56.5

Religiosum, Ljobunum, 54ㄹ

Reptans, Scrupoceltaria, 667

Reutslia, 377

Resplendent adder, 424

Reticulata, Nassa, 637

Retusa, Chlamytophorus, 158

Rex, Balaniceps, 282

Rhabdocæla, 685

Rhabdopleura, 649

Rhachianectes, 172

Rhacophorous, 437

Rliamphastides, 352

Rhamphastos, 35 ?

Rhea americana, 221

Rhea, Common, 2.21

Rhe darwini, 222

Rhea, Darwin's, 222

Rhea, Great-bil]ed, 222

Rhea macrorlyncha, $2 \%$

Rhea nana, 221

Rheiformes, 2021

Rheinhardius ocellatus, 239

Rhesus macacus, ?2?

Rhinemys, 393

Phinobatidx, 520

Phinobatis, 520

Rhinoceroses, The, 125

Rhinoceros bicornis, 126

Rluinoceros, Black, 120

Rhinoceros, Bucerus, 339

Rhinoceros, Burchell's, 12(i

Phinoceros- Indian, 126

Rhinoceros, Javan, 126

Rhinoceros simus, $1 \geq 6$

Pihinoceros sondaicus, $1: 6$

Rhinoceros, S!unatran, 126

Rhinoceros sumatrensis, 126

Rhinoceros unicornis $126^{\circ}$

Khinocerotida, 125

Phinoceros-Jrornbill, 339

Rhinochetides, 276

Rhinochetus jubatus, 276

Phinococcyx, 351

Rhinoderma darwini, 439

Rlimodon typicus, 517

Rhinodontidæ, 517

Phinolophide, 36

Rhinolophus, 36

Rhinolophus ferrum-equinum, 36

Rhinophrynus, 44]

Rhinopoma microphyllum, 39

Rhimoptera, 5:?
Rhinoptilus, 273

Rhinoptilus bitorquatus, 273

Rhipidodendron, 19

Rhipidoglossa. (631

Rhipidomys, 101

Rhịiılura, 373

Rhiptoglossa, 411

Rhithrodon, 102

Flithrodontomys, $10^{3}$

R:ithrosciurus, ?1

Rhizomys, 106

Rhizomys ballius, 107

Rhizopoda, 714

Rhizostoma, 700

Rhizothera, 233

Rhizothera dulitensis, 233

Rhizothera longirostris, 233

Rhizotrogus solstitialis, 5.55

Rhodeus, 4.49

Rhodoneson caryoplayllacea, 594

Rhodostethia rosea, 262

Phombus, 492

Rhopalocera, 5\$2

Rhopalocompta iphis, $58 s$

Rhyacophilus, 269

Rhynchobatis, 520

Rhynchobilella, 4is

Rhynchobdellidie, 478,676

Rhynchocephalia, 429

Rhynchocyon, 44

Rhynchogate melleri, 61

Rhynchomys, 104

Rhynchonella psittacea 650

Rliynchomellida, 6.51

Rhynchophora, 560

Rhynchopine, 261

Rhyuchops albicollis, 262

Riynchops flavirostris, 269

Rhynchops intercedens, 262

Rhynchops inelanura, 262

Rhynchops nigra, 262

Rhynchosuchus, 38:

Rhynchosuchus schlegeli, 382

Rhynchotus rufescens, $2: 06$

Rliyssa persuasoria, 577

Rhytina, 168

Rhytina gigas, $1 \in S$

Ribhand-tishes, 48 t

Ribband-fish, Banks, 48.5

Rice-rat, 102

Rice-tenrecs, 49

Richardson's skua, 264

Ridibundus, Larus, 26?

Rifle-birds, 359

Rifle-bird, Queen Victoria's, 359

Right-whales, 172

Ring-netked pheasants, 237

Ring-tailed iguana, 403

Ring-tailed lemur, 29

Ring tailed phalanger, 200

Pinged kingfisher, 336

Ringed snake, British, 4?1

Ringed worms, 671

Ringjculidx, 640

Kipa, 2.29

Riparia, Argiope, 544

Riqcouri, Nauclerus, 316

Risorius, Turturina, 245

Rissa trillactyla, 263

Rissoiide, 635

Risso's dolphin, 180

River lamprey, 52t
River tern, 262

Rivulorum, Tubifex, 674

Roach, 499

Roari-runners, 351

Robber crabs, $53 \%$

Robber flies, 60.7

Robin, 370

Rochusseni, Neoscolojax, 268

rock-dove, 244

Rock redl-legged partril ge, $: 28$ ?

Rock-snakes, 418

Rock.snake, Natal, 419

Rock-wallabies, 194

Rocklings, The, 491

Rocky Mountain goat, 157

Rodeletii, Carcharodon, 517

Rodentia, 88

Rodericanum, Tetrastemma, $6 s 4$

Roe, Common, 146

Roe-deer, 146

Rollers, 'The, 335

Roller, Common, 33i

Roller, (tround, 335)

Rollulus, 284

Rollulus rouloul, 234

Rook, 358

Root-footed jelly-fish, 700

Rorqual, Common, 174

Rorqual, sibbald's, 173

Rorquals, Blue, 173

Rosacea, Antedon, 663

Rose-chafer, $\$ 58$

Rose-coloured pastor, 360

Rose-finches, 363

Rosea, Rhodostethia, 262

Roseate pelican, 302

Roseate tern, 261

Roseus, Pastor, 260

Rosmarus, Trichechus, 84

Rossa, Musophaga, 352

Rossi, Ommatophoca, 87

Ross's gull, 262

Ross's seal, 87

Rosthramus, 316

Rostrata, Balænoptera, 174

Rostratula, 267

Rostratula australis, $26 \%$

Rostratula capensis, 267

Rostratula semicollaris, 267

Rostratus, Hyperoödon, 17

Rostratus, Tarsipes, 203

Rosy feather-star, 664

Rosy spoon-bill, 286

Rotche, 260

Rotifera, 682

Rotundata, Pyramidula, 643

Rongh-toothed dolphin, 181

Rouloul, Rollulus, 234

Round worm, 679

Rove-beetles, 556

Royal antelope, 151

Rubecula, Erythæus, 370

Rubens, Asterias, 653

Rubi, Callophrys, 586

Rubicunda, Uacaria, 27

Rubiginosa, Eos, 328

Rubrum, Corallum, 708

Ruby-crest, 369

Ruby-tailed wasps, 5:5

Ruclis, Ceryle, 336

Rufa, Caccabis, 232 
Rufa, Cassis, 636

Rufa, Dichromanassa, 289

Rufa, Formica, 579

Rufescens, Egyprynnus, 197

Rufescens, Rhynchotus, 226

Ruff, 269

Ruffed grouse, 231

Rufies, 464

Rutti, Cervus, 144

Rutf's deer, 144

Ruficollis, Branta, 295

Rufous buzzard-hawks, 312

Rufous rat-kangaroo, 197

Rufus, Cervus, $1+6^{\circ}$

Rufus, Desmodus, 41

Runcinidse, 640

Rupicapra tragus, 156

Russelli, Vipera, 428

Russell's vijer, 428

Russian desman, 47

Rustica, Hirundo, 373

Ruthvenus, Acipenser, 512

Ruticilla, 370

Rutilans, Canis, 68

\section{S.}

Sabine's gull, 262

Sabinii, Xema, 262

Sable antelope, 153

Sable marten, 80

Sacchari, Tyroglyphus, 547

Saccopharynx, 495

Saccopteryx, 39

Naccostomus, 106

Saccopharynx, 495

Saceharina, Lepisma, $57 ?$

Sacer, Scarabreus, 557

Nacred Ibis, The, 288 .

racred langur, 20

Saddle oyster, 621

Sremmeringi, Phasianus, $23 s^{\circ}$

Saffron finches, 263

Nagartia bellis, 703

Sagartia troglodytes, 704

sagartiadæe, 702

Naginata, Trnia, 68?

Nagitta, 682

s'agitta bipunctata, 681

Sagra, 56:

Saiga, 15?

Naiga tartarica, 152

rail-tailed lizard, 400

Naker, Hierofalco, $: 19$

saker jer-falcon, 319

Sakis, 27

Siaki, Black, 27

Saki, Hairy, 27

Salamanders, The, 446

salanander, Common, $\mathbf{4 4 6}$

Nalamander, Giant, 450

Salamanter, Mississippi, 451

Salamander, Spanish, 447

Salamander, sipectacled, 448

Salamander, Two-legged, 453

salamarider, Waity, $44 \mathrm{~s}$

Nalamandra atra, 447

Salamandra caucasica, 447

Salamandra maculosa, 446

Salamandrella, 450

Salamandridse, 446

Salamandrina perspicillata, 448
Salmo hucho, 508

Salmo salmo, 508

Salmon, Beaked, 505

Salmon tribe, 'I'lie, 507

Salmonidie, $50 \%$

Saltator, Oreotragus, 151

Saltiana, Modoqua, 151;

Salticidre, 543

Salt's antelope, 151

Salvadoriana, Tauysiptera, 339

Srlvanius sus, 134

Sambar, 143

Sand-badgers, 79

sand-eels, 491

Sand-flies, 604

sand grouse, The, 241

iand-launces, 491

Sand-lizard, 400

Sand-rats, $10 \vec{r}$

Sand-smelts, 479

Sand-snakes, 418

Sand viper, 437

Sand wasps, 579

Sand worm, 6it

Sanderling, 269

sandpipers, T'le, 269

Sandpiper, Curlew, 269

Sandpiper, Green, 26 ?

Sandpiper, Purple, 269

sandpiper, Spoon-billed, 262

Sandpiper, Wood, 269

Sandwich tern, 261

Sandwichensis, P'orzana, 251

Sanguinis-hominis, Filaria, 680

Sarcidiornis, 293

Sarcidiornis carunculata, 293

Sarcidiornis melanonota, 293

Sarcophanops, 355

Sarcophilus ursinus, 207

Sarcoptes scabiei, 546

Sarcoptes scabiei-crustosa, .546

Sarcoptirla, 546

Sardine, $50 \vec{T}$

Sargina, 466

Sargus, Common, 4 lifi

Sarus crane, 274

Sasia, ?54

Sittanus, Pithecia, 27

Satin bower-bird, 359

Satoria, 370

Satoria satoria, 370

Saturata, Scolopax, 267

Saturnia pavonia-minor, 589

Saturniidæ, $5 \$ 9$

Satyrina, 585

Satyrus, Limia, 16

Sauresia, 405

Sauries, 479

Saurothera, 351

Saurure, 220

Saurus, 505

Savagei, Gori!la, 15

Savana cuckoos, 351

Saw fish, 520

Saw flies, 574

Saw viper, 427

Saxatilis, Caccabis, 232

Taxicava, 626

Saxicavidre, 626

Saxicola, 370

Scabbard fish, 470
'Scabiei, Sarcoptes, 546

Sicabru, Dasypeltis, 422

Scalariida, 633

Sca'e-footed lizards, 398

scale insects, 602

Scaled reptiles, 395

Scallop, The, 62.?

Scalops, 47

Scaly-finned fishes, 465

Scandens, Anabas, 493

Scansores, 352

Scapanus, 48

scaphandridæ, 640

Scaphiopus, 443

Scaphirhynchus, 511

Scaphopoda, 628

scapteromys, 101

scaptochirus, 43

Scaptonyx fuscicaudatus, 48

Nicarabeidæ, 557

sicarabeus sacer, 5.57

searus, 486

scatharus, 466

Scatophaga stercoraria, 608

Scaups, 'I'he, 297

Scavenger vultures. The, 30 ,

S'chachti, Heterodera, 679

Schizopoda, $b 36$

Scheltopusik, 10

Schlegeli, Rhynchosuchus, $38 \geq$

Schlegel's garial, 382

Schomburgki, Cervus, 143

Schreiber's bat, 38

Schreibersi, Miniopterus, 38

Schultzii, Convoluta, 686

Sciana, 468

Sciænidi, 468

Siciæniformes, 468

Scincus officinalis, 410

Scintillans, Phasianus, 23ऽ

Scissor-bills, 26?

Siciuropterus, 95

Siciurus, 91

Sciurus palmarum, 91

Sciurus vulgaris, 91

Sclavonian grebe, 253

icolopaceus, A ramus, 27.5

Scolopeinse, 267

Scolopax, 267

scolopax saturata, 267

S'colopendridre, 549

Ścolytide, 560

Scomber, 473

Scomberida, 472

Scombresocidre, 479

Sicombresociformes, 479

Scombresox, 479

Scoparia, Oribia, 151

Scopelida, 505

Scopelus, 505

Scopi, 278

Scops, 322

Scops scops, 322

f́copus umbretta, 281

Scorpena, 467

Scorpenidre, 467

Scorpreniformes, 467

Scorpions, 539,540

Ścorpion, Book, 541

Scorpion, False, 541

Scorpion shells, 636

Scorpionidea, 540 
Scotcliman, The, 351

Scoters, '1'he, 297

scoticus, Lagopus, 230

Scotonycteris, 35

Seotope.ia, 321

Scotopelia peli, 321

Screamers, The, 290

Scramer, Crested, 290

Screamer, lierbian, 290

Screamer, Horned, 290

Screw-shells, 635

Scriptus, 'Iritgelaphus, 156

Scrobit:u ariidie, $6 \geq 4$

Scrofa, sus, 133

Scrub-birts, 'The, 3 ; 6

Scrib-biril, Noisy, 376

Scrupocellaria reptans, 667

Si:uiritie, (91

Scurria, 631

Scutellridæ, 595

Scutib:anchiat 3,631

Scutigera araneoides, 548

Scutiveridre, 548

Seylliilie, 518

Scyllium, 518

Scyphophori, 503

Scyphomeduse, The, 700

Scypllozoa, 700

Scytale, Ilysia, 421

scytlirops, 350

Sea anemones, 701

Sea-bats, 471

Sea-bear, $s 2$

Sea-breams, 466

Sea-butterflies, 640

Sea cow, Northern, 168

Sea-cucumbers, 600

Sea-ea le, 315

Sea-eagle, Pallas, 321

sea-gonseberry, 'The, 711

Seu-hares, 640

Sea-hedgehogs, 190

sea-horse, 458

Sea-lamprey, 521

Sea-leeth, Warty, 677

Sea-lilies, 66?

Sea-lion, 81

Sea-lion, Gillespie's, 8 ?

sea-lion, Northern, $\$ 2$

Sea-lion, Southern, S2

Sea-lizarl, Galapagos, 402

Sea-mat, 665

sea-mouse, 6 rs

Sea-otter, 76

Sea-parrot, 260

Sea-pen, 709

Sea-perclies, 464

Sea-serpent, 481

Sea-slugs, 610

Sea-snakes, 425

Sea-snake, Bauded, 425

Sea-squirt, Common, 528

Sea-swallow, 261

Sea-unicorn, 17s

Sea-urchin, Irregular, 659

Sea-urchins, 659

Seals, The, 85

seal, Antarctic white, 86

Seal, Bearded, 85

Seal, Bladder, 87

Seal, Caspian, 85

Seal, Common, 85
Seal, Common grey, $\$ 5$

Seal, licplant, 87

Seal, Greenland, 85

Seal, Hooderl, 87

seal. Leomarl, $\$ 6$

Seal, Russ's, 57

Seatls, True, 55

Sicals, I he typical, 85

Seal, Werlatels, 87

Sebie, P'yth 119

Sebastes, 467

Secretary bitds, The, 305

Secretrius, Serpentarius, 305

Sed -nt tria, 672

Selge warbler, 370

Seed suipes, The, 66

See-see partrilue, 233

Segir-nziidre, 637

Selachii, 515

Selenidlera, 352

Selenitille, 144

Selencirles, 359

Sella, Placuna, 621

Selvas, $20 t$

Semicollityis, liostratula, 267

Semifus s proboscidiferus, 637

Semipalmat , Anseranas, 293

Semipa matel goose, :93

Semno sithec is, 20

+mnopithecus entellus, 20

Senator, Lanius, 3 i9

- enezal finf 1 ot, 25 2

Senegal gal ıgo, 30

Seneralen sis, r valago, 30

Senegit en-is, Mycteria, 280

Senegalensis, Podica, 252

-eniculus, Alouatta, 23

Selp a, 646

Sepiadariidæe, 646

Sepiida, 646

Sepiolid «, 646

Septentrionalis, Colymbus,

Se ptibranchiata, 628

Seriamas, The, 277

Seriama, Burmeister's, 27

Seriama, Common, 277

: ierilopluus, 356

Serotine, 37

Serotinus, Vesperugo, 37

Serows, 157

Serpens, Ophichthys, 495

Serpent eagle, 315

Serpent eel, 494

Serpent-heads, 482

Serpentarii, 305

Seruentarius secretarius, 277 , 305

Serpula, 672

Serpula contortuplicata, 672

Serranilæe, 4 (64

Serraninze, 464

Serranus, 461

Serricornes, 558

Serrifera, 574

Serval, 55

Serval, Felis, 55

sessile orachiopod, 648

Setophaga, 365

Setosum, Diadema, 660

Setosus, Ericulus, 49

Sewellels, 95

Sewellels family, The, 95
Sexcinctus, Dasypus, 186

Sha, 16)

shad, The, 507

Shag, The, 299

Sliag, Pierl, 300

Sliamas, 3:0

Shirks and rays, 513

Shark, liasking, 517

Shark, Blue, 516

Shark, Fox, 517

Shark, 1.reenland, 519

Shark, Port Juckson, 518

Shark, Spıny, 519

Shark, Zebra, 518

Sharp-bills, I'lie, 374.

Shear-t ils, 348

Shearwaters, 258

Sheathbills, The, 265

Sheath bill, Yellow-billed, 265

Sheath tailed bats, 39

Sheep, 159

Sheep, Armenian, 160

Sheep, Pamir, 160

Sheep tick, bils

Shelit ducks, 296

Shelit duck, Common, 290

Shell ibises, 230

Shell-less slugs, 642

Shell storks, 280

Sh:ehl bug, 595

Shield-tails, 421

Shikra, Indian, 311

Ship worm, 6.7

shoe-bilied kingfisher, 337

Shoe-billed storks, 278

Short-eared owl, 324

Short-legged petrel, 257

Short-nosed fruit-bats, 35

short-toed larks, 364

Shou, 145

Shavellers, 296

Shrews, 'l'he, 45

shrew, Common, $4 f$ i

Shrew, Jumping, 44

Shrew, Kirghiz, 45

Shrew, Lesser, 46

Slirew, Mole, 46

Shrew, Musk, 46

Shrew, Oriental, $40^{\circ}$

Shrew, Pen-tailed, 4 t

Shr $-w$, Swimming, 47

Shrew, Tree, 43

Shrew, Water, 46

Shrew, IVeh-footed, 47

Shrew-rat, 114

Shrikes, The, 369

Shrike, Great grey, 369

Shiike, Red-backed, 369

Shrike, Swallow, 369

Slirimps, 536

Shrimp, Brine, 531

Siamang, 19

Sibbaldi, Balænoptera, 173

Sibbald's rorqual, 173

Sibirica, Capra, 159

Sibirica, Phoca, 85

Sica, Cervus, 143

Side-striped jackal, 66

Sifakas 29

Sifanica, Perdix, 234

Sifanicus, Moschus, 141

Sigmodon hispidus, 102 
Silenus, Macacus, 22

Slliceous s]onges, 692

Silk-worm moth, 590

Siluridæ, 496

Sllurus, 497

Silurus glanis, 496

Silver fisli, 573

Silver pheasant, 236

Simia satyrus, 16

Siniidæ, II

Simuliida, 604

Simus rlinoceros, 126

Sinensis, Alligator, 380

Sinensis, Centropus, 351

Singing-mice, 105

Siphneus, 104

Siphonarijdæ, 611

siplionopliora, 699

Siphonops, 455

Siphonustoma, 487

siphuncle, 645

Sipunculus, 678

Sipunculus hernhardus, 678

Siren lacertina, 452

Sirenia, 165

Sirenidæ, 453

Sirex gigas, 575

Siro, Tyroglyphus, 547

Sitatunga, 156

Sitella, 368

Sitomys, 101

Sitomvs liydrobates, 101

Sitta, 368

Sitta, Caesia, 368

Sittiriæ, 368

Sivalensis, Hippopotamus, 132

Siwalik hippoptamus, 132

Six-banded armadillo, 186

six-rayed corals, 705

Skate, Thornback, 5:1

Skeleton of Mammals, 3

Skimmers, The, 261, 262

Skink tribe, The, 410

Skiuk, Common, 410

Skippers, 588

Skipper, Grizzled, 588

Skuas, The, 263

Skua, 260

Skua, Buffon's, 263

Skua, Great, 263

Skua, Long-tailed, 264

Skua, Pomatorhine, 264

Skua, Richardson's, 264

Skunks, 77

Skunk, Common, 78

Skunk, Little, 78

Skunk, South American, 78

Sky!ark, The, 364

Slipper animalcule, 721

Slit-shells, 632

Sloths, 181

Sloths, Ground, 183

Sloths, Three-toed, 182

Sloths, Two-tned, 182

Slugs, 641

Small magpie moth, 592

Small mungoose, 60

Small-toothed nuungoose, 61

Small-toothed palm-civets, 59

Smaller shrew-hedgehog, 45

Smelt, The, 508

Smew, The, 297
Smintlopsis, 209

Sminthus, 109

Smooth snake, 422

Smother flies, t0I

-nails, 610

Snake-birds, 301

Snakes, The, 412

Snake, Blind, 417

Snake, Carpet, 419

Snake, Cat, 423

Snake, Coral, 423

Snake, Cylinder, 421

Snake, Dark green, 422

snake, Diamond, 419

Snake, Egg-eating, 4:2

Snake, Horsesloe, 422

Snake, Rat, 422

Snake, Rattle, 48

Snake, Sand, 420

Snake, Sea, 425

Snake, Smooth, 422

Snake, Whip), 4:3

Snake, Wood, 422

Snakes, Water, $4: 21$

Snappers, 390

Snapper, Temminck's, 3

Snapping turtles, 390

Snipes, The, 267

Snipe, Common, 218

Snijue, Great, 28

Snipe, Imperial, 268

Snipe, Jack, 268

Snipe, Jameson's, 268

Snipe, Latham's, 268

Snipe, Painted, 267

Snipe, Seed, 266

Snipe, Summer, 269

Snipe, True, 268

Snipe, Wire-tailed, 268

Snipe, WVood, :68

Snoek, The, 470

Snouted nais, 674

Snow bunting, : 63

Snow cocks, The, 232

Snow geese, 295

Snow-leopard, 53

Snow partridges, The, 231

Snow plieasants, 232

Snowy owl, 3:2

Snowy tern, :62

Soft tortoises, 394

Sol, Actinophrys, 716

Solariidæe, 633

Solea, 492

Solen, 620

Solenidre, 626

Solenoconcha, 628

Solenorion, 49

Solenodontidæ, 49

Solenogastra, 616

Solenomy a, 621

Solenonya togata, 621

Solenomyidr, 620

Solenostoma, 487

Solenostomatidæ, 487

Soles, The, 492

Solifugæ, 541

Solitarius, Pezophaps, 245

Solitary ants, 579

Solium, Trenia, 686

Sulomon Island frog, 437

Solpugidæe, 541
Solstitialis, Rhizotrogus, 558

somali-land ostrich, 223

Somateria, 297

Sombre wallaby, 194

Sondaicus, Rhinoceros, 126

Song thrush, 371

Sooty albatros, 258

Sooty tern, $26 \%$

Sorlidus, Artamus, 369

Sorex, 46

Sorex araneus, 46

Sorex jygmæus, 46

Soricidæe, 45

Soriculus, 46

Sotalia, 181

South African oribi, 151

South African ostrich, 223

South African reitbok, 152

South American finfoot, 25?

South American limpkin, 27.

South American ostrich, 221

South American skunk, is

South American sun-bittern, 276

Southern sea-lion, 82

Sow bues, 534

Spalacida, 106

spalacopus, 111

Spalax typhlus, 106

Spanish frog, 436

Spanish ibex, 158

Spanish lynx, 56

Spanish salamander, 44 ;

Sparida, 466

sparrow-hawk, 311

Sparrow-hawk, Pied, 311

sparrows, The, $3 \in 3$

Spatula, 296

Spectacled bear, 75

Spectacled salamander, 445

Spectrum, Tarsius, 31

Spectrum, Vampirus, 41

Spekei, Tragelaphus, 156

Spelerpes, 450

Spernı-whale, 175

Spermophila, 363

Spermophilus, 89

Spermophilus tridecemlineatus, 9.)

Sphærodon, 466

Sphegidæ, 580

Sphenisciformes, 255

Splenodon punctatus, 430

Sphenodontidæ, 430

Sphinges, 588

Sphyræna, 479

Sphyrænidæ, 478

Sphyrna, 516

Sphyropicus, 354

Spiders, 539

Spider, Bird-catching, 54 ?

Spider, Garden, 544

Spider, Hunting, $\mathbf{5 4 3}$

Spider, Trap-door, 543

Spider, Water, 544

Spider, Wolf, 543

Spider-crab, 537

Spicler-crab. Zoea-larva of, 530

Spider-monkey, Variegated, 25

Spider-monkey, Woolly, 25

spilogale putorius, is 
sipilornis, 315

Spilotis, Python, 419

Spinacida, 519

ipinax, 519

spine-tailed swifts, 345

iviny dog-fishes, 519

Sipiny eels, 478

Siviny lizard, 401

Spiny loach, 500

Siviny lobsters, 537

Spiny-mice, 106

spiny shark, 519

Spiny stuirrels, 91

Spiralis, Trichina, 680

Spirifer, 6.51

sipirifer sulcatus, 652

Spirifex, Pelopaus, 580

ipi-orbis, 67:

sipirostreptus pyrocephalus, 550

Spirula, 646

Spirulida, 646

Spiza, 364

Spizatus, 315

spizella, 364

spondylus, 623

sponges, The, 690

sponge, Bath, 693

sponge, Birds'-nest, 693

Sponge, Glass-rope, 693

sponge, Lacework, 693

Sponge spicules, 693

sponge, System of a, 69 ?

Sponges, ('alcareous, 692

Sponges, Siliceous, 692

sponsa, Fx, 294

Spoon-bills, The, ¿s6

spoon-bill, Common, 286

Spoon-bill, Rosy, 2s6

Spoon-billed sandpiper, 269

Sporocyst, 689

Sportive lemur, 30

Spotted billed pelican, 302

Spotted crake, 251

Spotted cuscus, 200

spotted-dasynre, 208

Spotted deer, 143

Spotted eagle, 814

śpotted emu, 223

spotted Hyæna, 63

spotted-narwhal, 178

Spotted tailed dasyure, 208

Spratt, The, 507

Sprattus, Clupea, 507

Springbok, 153

Spring tails, 573

Spur-toed frogs, 444

Sipur-winged geese, The, 293

Spur-winged plover, 271

squamata, $: 95$

square-tailed bee-eaters, 340

Squatarola helvetica, 271

Squatina vulgaris, 519

squatinida, 519

squilla mantis, 535

sionillidæ, 535

Śquinado, Maia, 537

Squirrel tribe, The, 91

Squirrel, African flying, 89

squirrel, Common, 91

Squirrel, Flying woolly, 95

squirrel, Groove-toothed, 91
Squirrels, Ground, 91

Squirrel. Palm, 91

Squirrels, Pigmy, 95

Squirrels, spiny, 91

Squirrel-monkeys, 26

Stag beetles, 558

Stag, Kashnir, 143

sitag, Thian Silıan, 143

Stair-case shells, (333

Staphylinus cresareus, 550

Star-coral, 706

Star-fish, 6.53

Star-gazers, 473

Star-nosed mole, 48

Starlings, The, 360

Starling, Common, 360

Starling, Field, 360

Starling, Glossy, 360

Ntarling, Meadow, 361

Starling, Red-winged, 361

Starling, True, 360

staurotypus, $\$ 8 ?$

Steamer ducks, The, 297

Steatomys, 101

Steatornis gariepensis, 332

Steatornithes, 332

Steel-blue cuckoos, 351

Steganopodes, 297

Steganopus, 266

Stegostoma, 518

Steinbok, True, 151

Steinbok, Zanzibar, 151

Stelleri, Heniconetta, 297

Stelleri, Otaria, 82

Stelleri, Ursina, 82

Steller's eider 297

Steno frontatus, 181

Stenodelphis blainvillei, 178

Stenoderma, 41

Stenogyra, 643

Stentor, $7: 1$

Stenura, Gallinago, 268

Stercorariida, 260

Stercorarius, 264

Stercorarius crepidatus, 264

Stercorarius parasiticus, 263

Stercorarius pomatorhinus, : 64

Stercoraria, Scatophaga, 608

Stereornithes, 278

Sterlet, 512

Sterna cantiaca, 261

Sterna dongalli, 261

Sterna fluviatilis, 261

Sterna fuliginosa, $26^{\circ}$

Sterna macrura, :61

Sterna minuta, 261

Sternina, 261

Sternoptychidæ, 505

Sternoptyx, 505

Sternotharus, 393

Stick-insects, 551

Stickle-backs, 480

Stiff-tailed diving-ducks, 297

Stilbum amethystinum, 578

Stilts, The, 2,0

Sting-bull, 474

Stinging hymenoptera, 574

Stink-bugs, 596

Stint, 269

Stizostedion, 464

Stoat, 81

Stock dove, 244
Stomatida, 63?

Stomatopoda, 535

Stomias, 505

Stomiatid:e, 50.5

Ntomoxys calcitrans, 107

Stone-curlew, 273

Stone flies, $5 \% 1$

Stone plovers, The, 273

Stony corals, 701

Stork-billedl kingfisher, 336

Storks, The, 2 \% 8

Stork, Black, 279

Stork, Hammer-head, 281

Stork maguari, 270

Stork, Open-billed, 280

Stork, Shoe-billed, 282

Stork, White, 278

Stork, White-necked, 280

Storks, Wood, The, 281

Storm petrel, 257

stration yida, 605

Strawberry anemone, 703

Streaked tenrecs, 49

Streperus, Acroceplialus, 370

Strepsiceros, 154

Strepsiceros imberbis, 154

Strepsiceros kudu, 154

Streptoneura, 631

Striata, Hyana, 62

Striatus, Pseudobranchus, 453

Striges, 304

-trigidae, 320

Strigirostris, Didunculus, 245

Strigoides, Podargus, 333

Stringops habroptilus, 331

Striped goplier, 92

Striped hyæna, 62

Striped wrasse, 486

Strix candida, 325

Strix capensis, 225

Strix flammea, 321

Strobilation, 701

Stromateus, 172

Stromateidæ, 471

Strombida, 636

Strombus gigas, 636

Strurnella, 361

Struthersi, Ibidorhynchus, $2 \% 0$

Strutlio australis, 223

Strut hio camelus, 223

Struthio molybdophanes, 223

Strutliolariidæe, 636

Struthiones, 220

Struthioniformes, 221

Stuinp-tailed lizard, 410

Stumpy crocodile, 382

Sturgeons, 510

Sturgeon, Common, 511

Sturio, Acipenser, 512

Sturnia, 360

Sturuidæ, 360

Sturuus vulgaris, 360

Stylasteridae, 697

Stylifer, 633

Stylommatophora, 641-642

Stylophorus, 485

Subbuteo, Falco, 319

Suberistatus, Conolophus, 402

Submytilacea, 623

Succinea, 642

Succineirla, $64 \%$

Sucking-fisli, 473 
sugar mite, 547

Suillus hylomys, ti

Suina, 135

Sinlæe, 298

Sulcatus, Spirifer. 652

Sulphur-bottom, 174

Sulzeri, Atspus, $5+3$

Sumatran rhinoceros, 126

Sumatrensis, Rhinoceros, 126

Sunimer cluck, 294

Sumuler snipe, 269

Sun animalcules, 716

sun-birds, The, 366

sun-bird. Malachite, 360

Sun-bitterns, The, 276

sun-bittern, Large, 270

Sun-bittern, Sonth American, $2 ; 6$

Sun-fish, 490

Sunset shells, 624

Superba m?nura, 35 i

Superciliosa, Ceryle, 336

Surciata tetradactyla, 61

Surinam water-toad, 444

Surnia ulula, 323

Sus, 133

Sus africanus, 131

Sus cristatus, 134

Sus porcus, 134

Sius salvanius, 134

Sus scrofa, 133

Susliks, 91

Susu, 177

Swainsoni, Pternistes, 233

Swallows, The, 373

Swallow, American barn, 373

Swallow, Cliff, 373

Swallow, Common, 373

Swallow, Sea, 261

Swallow.fly, 608

Swallow shells, 6:2

Swallow-shrikes, The, 369

Swallow-tail butterfly, 5S

Swallow-tailed bee-eaters, 340

Swamp deer, 143

Siwamp quail, 235

Swans, the, 292

Swan, Bewick's, 292

Swan, Black, 292

Swan, Chilian, 292

Swan, Coscoroba, 293

Swan, Mute, 292

Swan, Polish. 92

Swifts, The, 345

Swift, Common, 346

Swift, Crested, 346

Swift, Needle-tailed, 346

Swift, Palm, 346

Swift, Pied, 346

Swift, Spine-tailed, 345

Swiftlets, The Edible, 346

Swift-moths, 591

Swimming-shrews, 47

Swinhoei, Cervus, 143

Sword-bill hummer, 315

sword-fish, Common, 469

Syllis ramosa, 673

Sylvaticus, Mus, 105

Sylvestris, Cabalus, 249

Sylvia atricapilla, 370

Sylvia, Tanysiptera, 338

Sylviidæ, 370
Symbranchide, 495

synallaxinæ, 375

Synapliobranchus, 49.;

Synapta, 661

Synaptomys, 103

Syndactylus hylobates, 19

-yngna hidae, 4\$7

Syngnathus, 487

Synutus, 37

Sypliax, Castnia, 590

Sypheotis, 273

Syriacus, Ursus, 75

Syrian bear, 75

Syringella, Giracilaria, 594

syrniinx, 321

Syrnium, : $: 24$

Syrnium aluen, 321

Syrphidæ, 606

Syrrlioptes pararloxus, 241

Systema, Cacopus, 438

T.

Tabanide, 605

Tachinina, 607

Tachurnis, 346

Tachybal'tes allipennis, 253

Tachybajtes capensis, 253

Tarluybaptes fluviatilis, 253

Tachy triorchis, 312

Tachstriorchis albicadautus, 312

Tuchytriorchis abbreviatus, 312

Tallorna, 296

Tadorna taciorna, 296

Tænia echinococeus, 683

Trenia, Cohitis, $5: 0$

Trenia sainata, 687

Trenia solium, 686

Treniata, Pygoscelis, 255

Tænifformes, 484

Tænioglossa, 633

Treniopterina, 373

Taguan flying-phalanger, 201

Talir, Hiinalayan, 159

Tailed fruit.bats, 35

Tailless tunicata, 527

Takin, 157

Talegallus, 226

Talischensis, Phasianus, 23i

Talpa, 48

Talpa creca, $4 \mathrm{~s}$

Talpa europæa, 48

Talpa mierura, 48

Talpa moschata, 48

Talpiria, 47

Tamahoa, 184

Tamandua tetradactyla, 184

Tanuarins, 27

Tameng, 143

Tamias, .1

Tana tupaia, 43

Tanagers, The, 362

Tanagridæe, 82

Tancrediidæ, 625

Tantalus, 278

Tantalus loculator, 281

Tanysiptera, 38

Tanysiptera salvadoriana, 339

Tanysiptera sylvia, 338

Tapacolas, 376
Tape worms, The, 686

Taphozous, 39

Tapirs family, The, 124

Tapir, Malayan, 124

Tapiridæ, 124

Tapirus inılieus, 124

Tarandus, Rangifer, 145

Tarantula, $5 \$ 3$

Tirbophis vivax, 423

Tarda, Otis, 273

Tardigraiła, 547

Tarentola 398

Tarentula, Lyensa, 543

Tarsius, 31

Tarsiidæ, 31

Tarsipedinæ 203

Tarsipes rostratus, 203

Tarsius spectrum, 31

Tartarica, Saiga, $1: 2$

Tasmanian clevil, 207

Tasnıanian wolf, 207

Tatlers, The, $2 \dot{9}$

Tatouay, 186

Tatusia hybrida, 187

Taurus, Bos, 165

Tawny eagle, 314

Tawny owl, :3:1

Tawny-shoulder frog-mouth. 333

Taxicolor, Budorcas, 157

Taxidea, 79

Te:al, 206

Tealia erassicornis, 703

'Tectibrancliata, 659

Tectospondyli, 519

Teeth of gorilla, 6

Teeth of mammalia, 5

Tegu, The, 407

Teiidæe, 40 t

Teirao, 229

Telarius, Tetranychus, 547

Teleostomi, 46?

Telfairi, Ericulus, 49

Tellinacea, 624

Tellinidæ, 624

Telmatornis, 248

'Telotrenıata, 651

Temenuchus, 360

Temera, 5:1

Temmineki, Coracias, 335

Temmincki, Macroclemmys, 390

Temminck's snapper, 390

Temporaria, Fana, 436

Tenagodes, 636

Tenax, Eristalis, 606

Tench, 499

Tenebrio molitor, 560

Teneriffr, Regulus, 369

Tengmalmi, Nyctalea, 324

Tengmalm's owl, 324

Tenrecs, The, 49

Tenrecs, Hedgehog, 49

Tenrecs, Rice, 4 ?

Tenrecs, Streaked, 49

Tentacle fish, 475

Tentacled infusorians, 722

Tenthredinidae, 574

Tenui-spina, Murex, 637

Teonoma, 10 ?

Tequexin, Tupinambis, 407

Terebra, 638 
Terebrantia, 374

Terebratula, 65 l

Terebella, 672

Terebrida, 638

Teredinidæ, 627

Tereslo, 627

Tergissus, IIyodon, 505

Termetidie, 571

Terns, The, 261

Tern, Aretic, 261

Tern, Black, 261

J'ern, Caspian, 261

Tern, Conmon, 2ti1

Tern, Lesser, 261

Tern, Marsh, 261

'Tern, River, 262

Tern, Roseate, 261

Tern, Sandwich, 261

Tern, Snowy, 262

Tern, Sooty, 262

Terpsiphone, 373

Terrapins, 385

Testacellidae, 644

Testudinidæ, 385

Testuclo, 386

Testuclo elegans, 386

Testudo ephippium, 357

Testudo geometrica, 386

Testudo graca 386

Testuilo marginata, 386

Tetrabranchiata 645

Tetraceros quadricornis, 151

Tetradactyla, Surciata, 61

Tetradactyla, Tamandua, 184

Tetradactylus macroscelides, 44

Tetradactylus, Oryzorictes, 49

Tetranychida, 547

Tetranychus autumnalis, 547

Tetranychus telarius, 547

Tetrao kamtehaticus, 30

Tetrao parvirostris, 230

Tetrao uralensis, 230

Tetrao urogallus, 230

Tetraogallus, 23*

Tetraogallus himalaşensis, 232

'Tetraonidx, $: 29$

Tetrapneumones, 54 ?

Tetraspis osteolæmus, 382

Tetrastemma, 684

Tetrastemma agricola, 684

Tetrastemma aquarum-dul. cium, 684

Tetrastemma rodericanum, 684

Tetrastes, 231

Tetrax, 273

Tetrax tetrax, 273

Tetrix, Lyrurus, 230

Tetrodon, 489

Teucer, Caligo, 584

Thalassema, 678

Thalassiornis, $\approx 97$

Thalassochelys caretta, 391

Thalassogeron cautus, 259

Thallassophryne, 474

Tharus, Polyborus, 307

Thaumastura, $: 48$

Theraphosidx, 54 .

Theridiidæ, 544

Theropithecus gelada, 22

Theropithecus obscurus, 2:

Thian shan, 159

Thian shan stag, 143
Thick-knee, 273

Thick-knee, Long-legged, ‘73

Thick-lipped fishes, 486

7 hick-tailed opossum, 213

Thinocorus, 266

Thinornis, 270

Thomensis, Tlirophorella, 643

Thomiside, 543

Thomomys, 109

Thopha, 598

Thoracostraca, 535

Thorins, 450

Thornback skate, 521

Thorn-backs, 485

Thorny devil, 401

'T'horny oyster, 623

Thorny-tailed lizard, 400

'Thoroldi, Cervus, 143

'Thorold's tleer, 14:3

Thracia, 628

Thrasatus, 313

Thrasatus harpyia, 313

Thread worms, 678

Thread-worm, Turnip, 679

'Three-banded armadillos, 187

Three-striped clouroucouli, 26

Three-toed kingfisler, 3.5

Threc-toed sloths, 182

Three-toed woodpecker, 354

Thresher, $51 \%$

Thripidæ, 572

Thriponax, 355

Tliriponax hargitti, 35.5

Tlirips cerealium, 57 ?

Thrushes, Tle, 370

Thrush, Ground, i70

Tlirush, Song, 371

Thrush, True, 370

'Thrush, White's, 370

Thrynomys, 112

Thylacine, 207

Thylacinus cynoceplialus, 207

Thymallus, 5,09

Thynnidæ, 579

Thyonus, 473

Thyrophorella thomensis, 64 ?

Thyrophorellide, 643

Thyroptera tricolor, 38

Thyrsitis, 470

Thysanoptera, $5 \% 2$

Thysanoteuthida, 640

Thysanura, 573

Tibetan chiru, 15?

Tibetan fox, 73

Tibetan yak, 164

Tibicina, 598

Tichodroma muraria, 366

Ticks, 545

Tiger, $5: 3$

Tiger-beetles, 554

Tiger-beetle, Green, 554

Tiger cat, 55

Tiger moths, 588

Tigris, Felis, 5:3

Tile.fish, 473

Timeliidæ, 372

Timidus, Lepus, 118

Tinamiformes, 225

Tinamous, The, 225

Tinamou, Great, 226

Tinca, 499

Tinctorius, Dendrobates, $\mathbf{4 3 8}$
Tinea, 591

Tinea fulvimitrella, 593

Tineidie, $57: 2$

Tinker, 353

Tipulidie, 604

Tits, The, 307

Tit, Beardedl, 368

Tit, Blue, 367

Tit, Bottle, :68

Tit, Crested, 368

Tit, Great, 367

Tit, Long-tailerl, 368

Tit, Marsh, $36 \%$

Titis, 26

Titi, White-collared, 26

Titiscaniitle, 632

Tmetothylaens, 3 tis

'Toarls, The, 441

Toad, Common, 442

Toad, Green, 4 42

Toad, Natterjack, $4+2$

Tobanus bovinus, 605

Toulida, 34:

Todies, The, 342

Todus viridis, $3+2$

T'ody, Jamaica, 34?

Togata, Solenomya, 621

Tolypeutes, 187

Tomb-bats, 39

Tooth-billed partridges, 231

Tootl-billert pigeons, The 245

Toothed partridges, The, 240

Toothed whales, 171

'Topaza, 348

Tope, 516

Tor, Barbus, 498

Torda, Alea, 260

Tornaria, 528

Tornatina, 640

Tornatinida, 640

Torpedinida, 521

Torpedo, 521

Torquata, Callithrix, 26

Torcuuata, Ceryle, 336

Torquata, Chironeles, 40

Torquatus, Astur, :311

Torquatus, Cuniculus, 103

Toryuatus, Ursus, 75

Torquilla, Iyngine, 354

Torrent ducks, The, 297

Tortoises and turtles, 383

Tortoise, Amazonian fresh. water, $39: 3$

Tortoise, frecian, ?86

Tortoise, Land, 385

Tortoise, Loggerhead, $: 91$

Tortoise, Margined, 386

Tortoise, Pond, 388

Tortoise, Soft, 394

Tortoise, True Box, 388

Tortoise-shells, 585

Tortrices, 59.3

Tortrix, Green Oak, 593

Tortrix viridana, 593

Totanina, 269

Tritanus, 269

Toucans, The, 352

Touracoe, Lady Ross, 352

Touracoes, 351

Toxodon, 9

Toxoglossa, 628

Tracheophona, 375 
Trachichthys, 468

Trachinidæ, 473

Trachinops, 461

Trachinus, 473

Trachypterida, 484

Trachypterus, 485

Trachysaurus rugosus, $\$ 10$

'Tragelaphine, 154

Tragelaphus, 156

Tragelaplius angasi, 156

Tragelaplıus, Ovis, 160

Tragelaplius seriptus, 156

Tragelaplius spekei, 156

Tragocamelus, Boselaphus, 154

Tragopan, 235

Tragulidæ, 139

Tragulus, 139

Tragus, Rupicapra, 156

Transmontana, Columbia, 509

Trap-lloor spiders, 543

Tratratratra, 33

Traversia, 375

Tree-creepers, 362

'Tree-ducks, 296

Tree-frog, European, 44.'

Tree-kangaroos, 195

Tree-lizarils, 399

'Tree-nice, The, 101

Tree-partridge, The, 234

Tree-pipit, $36 i$

'Tree-slirews, 43

Tree-starlings, The, 360

Tree-swifts, The, 347

Trematoda, 688

Tremoctopodida, 647

Treronicla, 24?

Treronina, 242

Tretenterata, 650

Trétrétrétré, 33

Triacanthus, 489

Triclsechida, 84

Tricheclıus rusmarus, 84

Trichina spiralis, 680

Trichinosis worm, 680

Trichiosoina lucorum, 5, 4

Trichiuridæe, 470

'Trichiuriformes, 470

Trichiurus, 470

Trichoglossus, $32 \mathrm{~s}$

Trichonotidæ, 478

Trichoptera, 572

Trichopterygida, 562

Trichosurus, 200

Trichosurus vulpinus, 200

'Trichotropidæe, 634

Trichys, 113

Tricolor bat, 38

Tricolor, Thyroptera, 38

Tridacna, 62 i

Tridaena gigas, 126

Tridactyla, Rissa, 263

Tridactylus, Bradypus, 183

Tridanidæ, 626

'l'rideremlineatus, Spermophilus, 92

Triecphora vulnerata, 600

Trigla, 475

Trigonia, 621

Trigoniacea, 621

Trigoniida, +21

Trigonocephalus, 429

Trigonorhina, 520.
Trilobita, 539

Trimeresaurus, $4 \geq 9$

Tringa, 269

Tringoides, 2 ค9

Trinitatis, Phyllobates, 438

Triodon, 489

Trionychida, 394

Trionyx, 394

Tripliaena, 591

Tripurians, Naia, 424

Trithemis umbrata, 569

Tritici diplosis, 603

Tritici, Tylenchus, 179

Triton-shell, 636

Tritonioidea, $6+1$

Trivialis, Anthus, 365

Trivirgatus, Nyctipithecus, 26

Trochida, 632

Trochili, 347

Trochilus, Phylloscopus, 370

Trochophore, 6i3

Trochopus tubiporus, 658

Trochosphere, 673

'Trogloriytes, Anorthura, 371

Troglodytes, Anthropopithecus, 15

Troglorlytes, Sagartia, 704

Troglody tida, 371

Trogons, The, 349

Trogon, American, 849

Trogon caligatus, 349

Trogon, Large-tailed, 349

Trogonophis, 408

Troile, U ria, 260

Tronibidiida, 547

Tropic Birls, The, 298

Tropic Birl, Yellow-billed, 298

Tropical, Anemones, 704

Tropicoperdix, 234

Tropidonotus, 421

Tropidonotus natrix, 42I

Tropterodon, 466

True albatros, 258

True ant-eaters, 183

True argali, 160

True badgers, 79

True bittern, 284

True buzzards, The, 312

True civets, 57

True coursers, 279

True cranes, The, 274

True crocodile, 381

True crows, 3.8

True cuckoo, 350

True dolphins, 181

True dotteral, 271

True ducks, The, 296

True eels, 478

True falcon, The, 317

True finches, 363

True fruit-pigeon, 242

True hamster, 101

True garial, $38 \%$

T'rue geese, 295

True grouse, The, $: 30$

True gulls, 260

True hawks, The, 307

True kudu, 154

True lemuis, 29

True marmots, 92

True megapodes, 228

True moles, 48
True mound-builders, 226

True palm-civets, 59

True parrots, The, 329

True partriclges, The, 234

True phalangers, 200

True pigeons, The, 244

True pigs, 133

True pipits, The, 365

True plovers, 270

True porcupine, 113

True potto, 31

True rails, 248

True seals, 85

True snipe, 268

True steinbok, 151

True teurec, 49

True thirushes, 370

True whales, 172

'True woodcock, 267

True wood-peckers, The, 3 in 4

Trumpet animalcule, 721

Trumpeters, The, 277

Trumpeter, Common, 275

Trumpeter fish, 467

Trumcatellida, 634

Truncatus, Chlanydophorus, 188

Trygon, 522

Trygonida, 520

Trypancorax frugilegus, 358

Trypanns cossus, 590

Trypetine, 608

Tse-tse fly, 608

Tuatera, 4:30

Tube-making annelid, 672

Tube-nosed bats, 37

Tube-nosed fruit-bats, 5

Tuberculatus, Cbalinolobus, 40

Tuberculatus mystacops, 40

Tubicola, 672

Tubifex rivulorum, 674

Tubinares, 256

Tubipora musica, 708

Tubiporus, Trochopus, 688

Tubularia, $69 \%$

Tubulifera, 578

Tuco-tucos, 111

'Tufted owls, The, 3 ??

Tunulus, Megapotius, 228

Tunicata, 5:7

Tunny, 47:3

Tupaia, 44

Tupaia tana, 13

Tupaiide, 43

T'upinambis tequexin, $40{ }^{\circ}$

Turacena, 244

Turacus, 35?

Turbellaria, 685

Turbinata, Bugula, 66 ?

Turbinellide, 637

Turbiniclae, 632

Turbot, 493

Turditlie, 370

Turclus, 370

Turdus iliacus, 371

Turdus pilaris, 371

Turdus musicus, 371

Turkey-brush, Australian, 2:T

Turkish gecko, 397

Turkey, Honduras, 240

'Turkey, Mexican, 240

Turkey vultures, The, 304 
Turn-stones, The, $27 \cdot 2$

Turn-stone, Black, 272

Turn-stone, Common, 272

Turnip-beetles, 561

Turnip flies, 562

Turnip thread-worm, 679

Turnix, 241

Turritellidre, 635

Turtle-doves, 244

'Turtles, The, 390

Turtle, Green, 391

Turtle, Leatliery, 391

Turtur, Turturina, 245

Turturæena, 244

Turturinze, 244

Turturine risortus, 245

Turturinæ turtur, 245

'T'wenty-plume motb, 594

Two-clawed ant-eater, 184

Two-legged salamander, 453

'Iwo-toed sloths, 183

Tylenchus tritici, 679

Tylopoda, 136

Tylotriton, 447

Tylotriton andersoni, 448

Tylotiiton verrucosus, $44 \mathrm{~s}$

Tympanuchus, 231

Typhlomolge rathbuni, 452

Typhlomys, 106

Typhlonectes, 455

Typhlonus, 491

Typhlopicle, 417

Typhlops, 417

Typhlops, Notoryctes, 210

Typhlosaurus, 411

Typhlotriton, 450

Typlilus, Spalax, 106

Typical bats, 30

Iypical cuckoo, 350

Typical frogs, 436

Typical seals, The, 85

Typical tree-slirews, 44

Typicus, Rhinodon, 517

Tyrannidæ, 373

Tyranninæ, 373

Tyrants, The, 373

Tyroglypluidæe, 547

Tyroglyphus sacchari, 547

Tyroglyphus siro, 547

\section{U.}

Uacaria, 27

Uacaria, Bald, 27

Uacaria, Black-faced, 2خ

Uacaria calva, 27

Uacaria melanocephala, 27

Uacaria rubicunda, 27

Uakari, Red, 27

Uakaris, 27

Uloboridæ, 544

Ulula, Surnia, 323

Umbrata, Trithemis, 5)

Umbrella, 640

Umbrellidw, 640

Umbretta, Scopus, 281

Umbridie, 502

Umbrina, 468

Umbrine, The, $46 s$

Ưmbonia, 601

Uncia, Felis, 53
Undulata, Gallinago, 268

Ungulata, 118

Ungulina, $6: 1$

Ungulinidæ, 624

Unicincta, Frythrocnema, 310

Unicinctus, Lysuirus, 186

Unicolor, Cervus, 143

Unicolor, Xenopeltis, 421

Unicorn fish, 481

Unicorn, Sea, 178

Unicornis, Rhinoceros, 126

Unionid:e, 623

Upland geese, The, 295

Upupa epops, 340

Upupa indica, 340

Upupte, 340

Upupidie, 340

Uræotyphlus, 454

Uralensis, Tetrao, 230

Uraniilæe, 588

Uranoscopus, 473

Urbica, Chelidon, 373

Urens, Asthenosoma, 660

Uria grylle, 260

Uria troile, 260

['rial, 160

Uroztus, 313

Uroztus audax, 314

Urochorda, 527

Urogallus, Tetras, 230

Urogymnus, b22

Uroloplius, 522

Uromastix, 400

Uromys, 106

Uropeltidæ, 421

Uroplates, 398

Uroplatida, 398

Uropoda, 545

Uropsilus, 47

Urospatha, 341

Urotrichus, 47

Urotriorchis, 310

Ursida, 74

Ursinus, Melursus, 75

Ursinus, Plialanger, 200

Ursinus, Sarcophilus, $20 \%$

Ursus, 75

Ursus a mericanus, 75

Ursus arctus, 75

Ursus crowther, 75

Ursus horribilis, 75

Ursus isabellinus, 75

Ursus malayanus, 75

Ursus maritimus, 75

Ursus ornatus, 75

Ursus syriacus, 75

Ursus torquaters, 75

Urticata, botys, 592

Urubitinga, 313

\section{V.}

Vagans, Egithalus, 363

Vaginula, 642

Vaginulidæ, 642

Valvata, $6: 5$

Valvatidæe, 635

Vampire-bats, 40

Vampire, Conimon, 42

Vampire, Great, 41

Vampires, Harmless, 41
Vampirus, 11

Vampirus spectrum, 11

Vandeluria, 104

V andesius, Coregonus, 509

Vanellus vanellus, 271

Varanidæ, 40ú

Varanus, 403

Varanus niloticus, 406

Varia, Ceryle, $3: 36^{\circ}$

Varia, Oreocicla, 371

Variegata, Mesites, :76

Variegated spider-monkey, 25

Variegatus, Ateles, 25

Varius, l'lalacrocorax, 300

Velox, Canis, 72

Velox potamogale, 48

Velutina, Didelphys, 213

Velvety-opossum, 213

Venaticus, Icticyon, 71

Vendace, 509

Veneracea, 623

Veneris, Cestus, 712

Venus' comb, 637

Veuus's flower basket, 693

Venus's girdle, 71:

Vermes, 670

Vermetidæ, 635

Vermicularis, Oxyuris, 679

Vermiculus, 683

Verreauxia, 354

Verreauxia africana, $\$ 54$

Verrucosus, Tylotriton, 448

Versicolar, Phasianus, 235

Vertebrata, 1

Vertebrates, Characteristics of, 1

Verticalis, Botys, 592

Verticordiidæe, 628

Vesicatoria, Cantharis, 560

Vespa, 580

Vespa crabro, 580

Vesperimus, 101

Vespertilio bechsteini, 38

Vespertilio daubentoni, 37

Vespertilio hodgsoni, 38

Vespertilio welwitschi, 38

Vespertilionida, 36

Vesperugo, 38

Vesperugo noctula, 37

Vesperugo pipiptrellus, $\Sigma 7$

Vesperugo serotinus, 37

Vespillo, Necrophorus, 55;

Vestimenti, Pediculus, 602

Victor, Chrysænas, "243

Victoriæ, Ptilorhis, 359

Vicuna, 138

Vicuña, Lama, 139

Vignei, Ovis, 160

Villosus, Dasypus, 186

Vinegar eel, 679

Vinia, 328

Vinia kuhli, 328

Violacea, Xylocopa, 581

Vipers, The, 427

Viper, British, 427

Viper, Halys, 429

Viper, Horned, 427

Viper, Pit, 428

Viper, Russell's, $4 \delta$

Viper, Sand, 427

Viper, Saw, $4: 7$

Viper tribe, The, 423

Vipera aumodytes, $4 \geq 7$ 
Vipera arietans, 427

Vipera berus, 427

Vipera russelli, 493

Viper ddæ, $426^{\circ}$

Viperinæ, 427 .

Virens, Gadus, 491

Vireo, 370

Vireonida, 370

Virginian deer, 116

Virginian fox, 72

Yirginian quail, 240

Virginianus, Bubo, 32:

Virginianus, Canis, 72

Virginianus, Cervus, 146

Virginianus, Ortyx, 240

Viridana, Tortrix, 593

Viridis, Bufo, 442

Viridis, Calyptomena, 353

Viridis, Lacerta, 409

Viridis, 'Todus, ' 4 '?

Viridis, Vortex, 686

Viscacha, 114

Vison, Mustela, SI

Vitrea cellaria, 644

Yivax, Tarbophis, 423

Viverra, 57

Viverra civetta, $5 i$

Viverra malaccensis, $5 \bar{t}$

Viverricula, $5 i$

Viverrida, 5 'j

Viverrinæ, 60

Viverrinus, Dasyurus, 208

Vivipara, Lacerta, 409

Vivipara, Mouopora, 684

Viviparidæ, 635

Viviparous lizard, 409

Viviparous wrasses, 486

Vocifer, Haliatus, 315

Volans, Draco, 399

Volans, Galdopithecums, 43

Volans, Petauroides, 201

Voles, The, 103

Vole, Bank, 103

Vole, Field, 103

Vole, Groove-toothed, 103

Vole group, The, 103

Vole, Red, 103

Vole, Water, 103

Volutida, 638

Volvox globator, 719

Volvulella, $6 \pm 0$

Vortex viridis, 686

Forticellidæ, 721

Vulgaris, Bufo, $4+2$

Vulgaris, Chamæleon, 112

Vulgaris, Conga, 494

Vulgaris, Lota, 491

Vulgaris, Melolontha, 557

Vulzaris, Molge, $\mathbf{4} 48$

Vulgaris, Mustela, 81

Vulgaris, Sciurus, 91

Vulgaris, Squatina, 519

Vulgaris, Sturnus, 360

Vulgata, Ephemera, $5 \% 1$

Vulnerata, Triecphora, 600

Vulpes, 70

Vulpes, Alopecias, 517

Vulpes, Canis, 71

Vulpinus, Trichosurus, 200

Vultur, 306

Tultur monachus, 306

rulture, Black, ioj
Vultures, Eared, 306

Vulture, Egyptian, 806

Vulture, Turkey, 304

Vulture, White-healed, 306

Vulturidæ, 305

Vulturine guinea-fowl, 210

Vulturinum, Acryllinm, 240

W.

Wagtails, The, 364

Wagtail, Field, 365

Wa atail, Grey, 365

Wagtail, Pied, 365

Wastail, Ray's, 365

Wagtail, Water, 365

W'alabatus, Macropus, 191

Wall gecko, 39s

Wallabies, The, 194

Wallabies, Hare, 194

Wallabies, Rock, 194

Wallaby, Agile, 194

Wallaby, Aru Island, 194

Wallaby, Banded, 196

Wallaby, Bennett's, 194

Wallaby, Sombre, 194

Wallacii, Eulipoa, 2:8

Wallacii, Habroptila, 249

Walleri, Lithocranias, 153

Waller's gazelle, 153

Walliehii, Catreus, 237

Walrus family, The, 84

Waltzing-mice, 105

Wandering albatros, 258

Wapiti, Nortl American, 143

Warblers, The, 370

Warbler, Grass, 370

Warbler, Reed, 370

Warbler, Sedge, 370

Warbler, Willow, 370

Wart-hog, 131

Warty salamander, $\mathbf{4 4 8}$

Warty sea-leech, 677

Wasps, 580

Wasps, Ruby-tailed, 57s

Wasps, Sand, 579

Wasps, Wood, 575

Water-animals, 694

Water-beetle, Great, 557

Water-beetles, Carnivorous, 555

Water-boatmen, 537

Water-buck, 152

Water-bugs, 597

Water-flea, 531

Water-hens, The, 25:

Water-opossunı, 211

Water-ouzels, 371

Water-rail, 249

Water-scorpion, 597

Water-shrews, 16

Water-snakes, 421

Water-spider, $5 \pm 1$

Water-toad, Surinam, 44

Water-vole, 103

Water-wagtails, 365

Wattled ant-thrushes, 375

Wattled fruit.pigeon, 243

Wattled grakles, 360

Wattled plovers, The, 2 I

Waxwing, The, 369

Waxwing, Japanese, 369
Weasles, 80

Weasel, Common, 80

Weasel tribe, The, 70

Weaver birds, The, 362

Weaver, Baya, 36:

Webbed newt, $44 \mathrm{~s}$

Web-footed moles, 47

Web-footed shrew, 47

Weddelli, Leptonychotes, 87

Weddell's seal, 87

Weevil, 560

Weevil, Nut, 560

Weevil, Paln , 560

Weka rails, 251

Wels, The, 497

Welwit=chi, Vespertilio, 3s

Wentle-traps, 633

West African chevrotains, 139

Whales, \&c., 169

Whale, Arnux 8, 177

Whale, Beaked, 177

Whale, Cuvier's, 177

Whale, Fin, 173

Whale, Greenland, 17:

Whale, Grey, 17?

Whale, Humpback, 173

Whale, Lesser sperm, 170

WIale, Pigmy, 172

Whale, Right, 172

Whale, Sperm, 175

Whale, Toothed, 175

Whale, Whalebone, $1 \overline{1} 1$

Whale, White, I79

Whalebone whales, 171

Whale-louse, 535

Wheat eel, 679

Wheat midge, 603

Wheel animalcules, 68 ?

Wheel bugs, 596

Whip snakes, 423

Whirligig beetles, $556^{\circ}$

White admiral, $5 \$ 5$

White ants, 5ī

White bats, 39

White-bellied sea-eagle, 315

White-billed diver, 254

White-collared titi, 26

White-eyes, The, 367

White-footed mice, 101

White-fronted goose, 295

White gos-hawk, 311

White-headed vultures, The, $\$ 06$

White-necked stork, 280

White owls, The, 325

White plume moth, 594

White stork, 278

White stork, Black-billed, 279

White-tailed eagle, 315

White-tailed hawk, 312

White-throated capuchin, 24

White whale, 179

White-winged chough, 358

White-winged crake, 251

Whitelseadi, Calyptomena, 350 '

White's thrush, 370

Whiting, The, 191

Whooper, 29:2

Wigeon, 296

Wild boar, 133

Wiild cat, 55

Wild ducks, 290 
Willow-grouse, 229

Willow-warbler, 370

Wilson's phalarope, 260

Wingless insects, 573

Wing-shells, $636^{\circ}$

Wire-tailet snipe, 268

Wire worm:s, 550

Wolf-like animals, 64

Wolf, Airrd, 62

Wolf, Antarctic, 64

Wolf, Common, 64

Wolf, Indian, $6 j$

Wolf, Tasmanian, 207

Wolf-fish, $47 \mathrm{~S}$

Wolf-spiders, 543

Wolverine, $>1$

Wombats, 204

Wood ant, 579

Wood.cliat, 369

Wood-hewers, The, 375

Wood-hewer, Bridge's, 375

Wood hoopoes, 340

Wood-ibises, 273

Woort larks, 361

Wood lice, 534

IVood-mouse, 105

Wood-owls, is 21

Wood-pigeon, 244

Wood rails, The, 249

Wood-rats, $10: 3$

Wood sand piper, 269

Wood-sn3kes, American, 422

Wood-suipe, 268

IVood sturks, 278

Wood stork, American, 2sl

Wood-swallows, 369

Wood wasps, 575

Woodeocks, The, $26 \mathrm{~s}$

Woodcock, True, 267

Woodpeckers, The, 353

Woodpecker, Great black, 35

Woodpecker, Green, 354

Woodpecker, Ground, 354

Woodpecker, Hargitt's, 355

Woodpecker, Narrow-necked, 354

Woodpecker, Pied, 354

Woodpecker, Three-toed, 354

Woodpecker, True, 354

Woodpecker, Yellow-winged, i54

Woodpecker-like birds, 353

Woolly arahi, 29

Woolly flying squirrel, 95

Woolly monkeys, 21

Woolly monkey, Humboldt's, 24

Woolly spider-monkey, 25

Worms, The, 670

Worm, Arrow, 68?

Worm, Bladder, 6s,
Worm, Bristled-footed, 671

Worm, Earth, 674

Worm, Fliat, 635

Worm, Fluke, $68 s$

Worm, Geplisrean, 677

Worus, Guinea, 179

Worm, Horse-hair, 680

Worm, Lag, 67\%

Worm, Meilina, 679

Worm, Nemertine, 6st

Worm, linged, 671

Worm, Round, 679

Worm, Sand, 672

Worm, 'Tape, 6S6

Worm, Thread, 67s

Worm, Trichinosis, 630

Worms, Planarian, 685

Wrasse, Parrot, 486

Wrasse, siriped, 456

Wrasses, Viviparous, $4 \$ 6$

Wrens, The, 371

IV ren, Coinmon, 371

Wry-billed plover, 270

Wrynecks, 354

Wryneck, Common, 354

X.

Xantlarpyia, 35

Xantholæina hamacepliala, 353

Canthomelus aurens, 359

Xanthonotus indicator, 353

Xanthopygus, Cervus, 143

Xanthura, 358

Nena, 62

Xema furcata, 26:3

Tema sabinii, 262

Xenicus, 375

Teniscida, 373 , 375

Xenodermichthys 507

Tenopeltida, 421

Xenopeltis unicolor, $\$ 21$

Xenophorida, 634

Xenopicus, 354

Nenopodida, 444

Nenopus, 444

Xenosaurus, 403

Yenosuride, 403

Xeromys, 100

Xerus, 91

Xiphias, 469

Xiphidiopterus, 271

Xiphiid $æ, \pm 69$

Xiphifformes, 469

Niphosura, 538

Xylocopa, 551

Xylocopa violacea, $5 \$ 1$
$\mathrm{Y}$.

Iaffle, 354

Yak, 'Tibetan, 164

Yapock, 214

Yare.li, Bagarius, 496

Yellow baboon, 3

Yellow-billed cuckoo, 351

Yellow-billed sheathbill, 265

Yellow-billed tropic bird, 295

Yellow fox, 71

Yellow liammer, 364

Yellow-tailed mole, 48

Yelluw-tliroated marten, 80

Yellow underwing moth, 591

Yellow-winged woodpecker, $35 t$

Yoldia, ti21

Ypecaha, Aramides, 250

Yjecaha wood-rail, 250

Zabrus gibbus, 555

Zaglossus, 217

Zaitha a urantiaca, 597

Zamensis, 422

Zamensis gemonensis, 42:

Zamensis hippocrepis, 42:-

Zammara, 595

Zanzibar steinbok, 151

Zapornia parva, 251

Zapus, 110

Zebra, Burchell's, 12๖

Zebra, Equus, 128

Zebra, Grevy's, 1:8

Kebra, Mountain, 128

Zebra-fish, 465

Zebra shark, 518

Zebrilus, $2 S 4$

Zeledoni, Canchroma, '2st

Zenaidinæ, 244

Zerda, Canis, 73

Zeus faber, 471

Zeuzeridz, 590

Zibellina, Mustela, so

Zibethicus, Fiber, 103

Ziphius, 175

Zoarces, 478

Zea, 530

Zoea-larva of spider-crab, 530

Zonitida, 643

Zonotrichia, 364

Zonuridæ, 403

Zonurus, 401

Zoophytes, 696

Zoothamnium, 72:2

Zorilla, Ictonyx, so

Zosteropida, 367

Zygænidæ, 5 ss

Lygogeomys, 109 


